Southern Branch of the

University of California Los Angeles

Form L 1

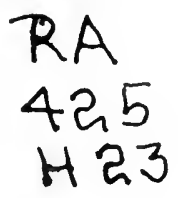




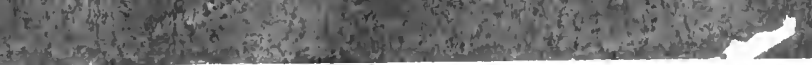

This book is DUE on the last date stamped below

JUL 26 1923

$$
\text { vinit } 2 \text { E } 1922
$$

APR I 192\%

Nov i6 1927

is:-
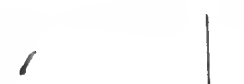
STATE RORRAL STTOOL

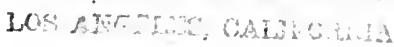





\section{A MANUAL}

OF

\section{PRACTICAL HYGIENE}

FOR

\section{STUDENTS, PHYSICIANS, AND HEALTH OFFICERS.}

BY

CHARLES HARRINGTON, M.D.,

Late Professor of Hygiene in tile Medical, School of Harvard University.

25504

FOURTII EDITION, REVISED AND ENLARGED.

BY

MARK WYMAN RICHARDSON, M.D.,

Secretary to the State Board of Health of Massachusetts.

ILLUSTRATED WITH TWELVE PLATES IN COLORS AND MONOCHROME, AND ONE HUNDRED AND TWENTY-FOUR ENGRAVINGS.

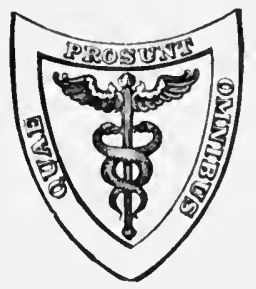

LEA \& FEBIGER,

PHILADELPHIA A ND NEW YORK. 
Entered according to Act of Congress, in the year 1911, by LEA \& FEBIGER,

In the Office of the Librarian of Congress. All rights reserved. 


\section{PREFACE TO THE FOURTH EDITIION.}

Prion to his departure for England in 1908, where he died $111-$ expectedly, Dr. Harrington had been preparing for a revision of his Hygiene, the demand for which he foresaw. He had then largely completed the chapters on Milk and Disinfection. His manuscript, as well as the remainder of the volume, have been brought to date by the present writer. Dr. Harrington's work had won its way to an enviable position in the literature of one of the most important branches of human knowledge. No effort has been spared to maintain its usefulness as an authoritative guide for all classes of readers interested in hygiene and sanitation.

It is a pleasure to the writer to extend his thanks to those who have been of service to him in getting out this new edition, and especially to Mr. H. W. Clark, chemist in charge at the Lawrence Experiment Station, for his assistance in revising the section on Sewage Disposal.

144 State House, Boston,

M. W. R.

1911. 
Digitized by the Internet Archive in 2007 with funding from Microsoft Corporation 


\section{CONTENTS.}

\section{CHAPTER I.}

Section 1. General Considerations...................

The nutritive value of foods, 17. Amount of food neeessary, 18. Composition of foods, 19. Proteids, 19. Fats, 22. Carbohydrates, 22. Organic acids, 24. Inorganic salts, 24.

Section 2. Animal Foods: Meats, Fish, Eggs, and Meat Products..... Meats, 25. Digestibility, 25. Flavor, 25. Texture, 26. Effects of cooking, 26. Characteristies of good meat, 27. Comparative digestibility of meats, 28. Composition of meats, 28. Beef, 29. Pork, 30. Veal, 31. Mutton, 31. Lamb, 31. Poultry, 32. Horse meat, 32. Meat preparations, 33. Sausages, 33. Fish, 35. Digestibility, 36. Keeping qualities, 36. Composition, 38. Meat and fish and parasitic diseases, 38. Transmission of disease by meat, fish, and vegetables, 44 . Tuberculosis, 46. Relation between human and bovine tuberculosis, 50 . Typhoid fever and cholera, 58. Poisoning by meat and fish, 64. Due to substanees normally present in the living organism, 64. Due to bacterial produets in meats and fish, 65. Signs pointing to an epidemic, 68. Onset and course of symptoms, 68. Nature symptoms, 69. Post-mortem appearances, 69. Character of meats which eause poisoning, 70. Cases illustrative of poisoning by fish and meat, 72. Poisoning by mussels, 72 . Poisoning by herrings, 73. Poisoning by salmon, 74. Poisoning by pike, 75. Poisoning by oysters, 75. Poisoning by veal, 76. Poisoning by pork, 78. Poisoning by beef, 84 . Poisoning by horse meat, 86 . Poisoning by sausages, 87. Poisoning by kid meat, 89. Meat inspeetion and slaughtering, 89. Eggs, 91. Lard, 94. United States standards, 94.

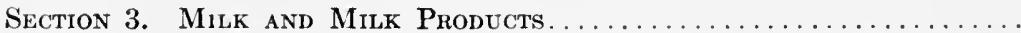

United States standard, 95. Composition of milk, 96. Fat, 97. Milksugar, 98. Proteids, 99. Mineral matter, 99. Specific gravity of milk, 99. Reaction, 99. Appearance, 99. Taste, 100. Koumiss and kefir, 101. Colostrum, 102. Consistence of milk, 102. Ferments of milk, 103. Trypsin or galactose, 104. Pepsin, 104. Diastase or amylase, 104. Lipase, 104. Salol-splitting ferment, 105. Oxydases, 105. Reductases, 105. Bacteria in milk, 105. Laetie ferments, 106. Peptonizing ferments, 107. Butyrie ferments, 107. Number of bacteria in milk, 107. Preservation of milk, 114. Cold, 114. Heat, pasteurization, and sterilization, 114. Objections to heat, 115. Chemicals, 118. Boric acid and borax, 118. 
Formaldehyde, 118. Adulteration of milk, 122. Cream, 124. United States standard, 124. Condensed milk, 124. Milk as a factor in the spread of disease, 125. Poisonous milk, 125. Milk from diseased cows, 127. Milk contaminaterl from without with organisms related to human diseases, 136. Analysis of milk, 146. Determination of specific gravity, 147. Determination of fat, 148. Determination of total solids, 151. Determination of milk-sugar, 152. Determination of ash, 153. Determination of proteids, 153, Detection of alded water, 154. Coloring matters, 158. Detection of preservatives, 160. Methods of distinguishing between raw and cooked milk, 162. Detection of gelatin in cream, 163. Detection of sucrate of lime in crean, 164. Butter, 164. United States standard, 164. Butter as a carrier of discase, 167. Analysis of butter, 169. Determination of the nature of the fat, 169. Cheese, 173. Composition, 175. Adulteration of cheese, 175. Analysis of cheese, 176. Cheese as a cause of poisoning, 175.

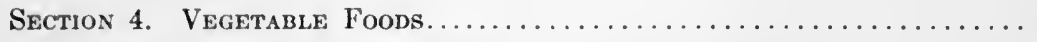

Farinaceous seeds, 178. Cereals, 178. Wheat, 178. Composition of wheat, 179. Wheat flour, 179. Preparations of wheat flour, 180. Bread, 180. Composition of wheat bread, 183. Adulteration of flour, 184. Bleaching of flour, 185. Rye, 185. Barley, 186. Oats, 186. Corn, 187. Rice, 189. Buckwheat, 189. Legumes, 190. Peas, 191. Beans, 191. Lentils, 192. Farinaceous preparations, 193. Sago, 193. Tapioca, 193. Arrowroot, 193. Fatty seeds, 193. Almonds, 194. Cocoanuts, 194. IValnuts, 194. Peanuts, 194. Chestnuts, 194. Vegetable fats, 195. Olive oil, 195. United States standard, 195. Cotton-seed oil, 196. Tubers and roots, 196. Potatoes, 196. Sweet potatoes, 199. Artichokes, 199. Roots, 199. Herbaceous articles, 200. Fruit, products used as vegetables, 201. Fruits, 201. Apples, 201. Pears, 202. Peaches, 202. Apricots, 202. Plums, 202. Cherries, 202. Oranges, 202. Grapes, 203. Melons, 203. Bananas, 204. Figs, 204. Berries, 204. Edible fungi, 205. Mushrooms, 205. Saccharine preparations, 206. Cane-sugar, 205. Maple sugar, 206. Glucose, dextrose, 206. Molasses, 207. Honey, 208. Confectionery, 209. Jellies and jam, 210.

\section{Section 5. Beverages. .}

Stimulant beverages containing alkaloids, 210. Tea, 210. Adulteration of tea, 212. Coffee, 213. Cocon, 215. Milk chocolate, 217. Fermented alcoholic beverages, 217. Beer, 217. Process of manufacture of beer, 219 . Substitutes for barley malt, 220. Substitutes for hops, 221. Physical properties and chemical composition of beer, 222. Adulteration of beer, 222. Analysis of beer, 223. Determination of beer, 223. Table showing percentage of alcohol by weight and by volume, 224. Analysis of beer, 229 . Determination of methyl alcohol, 229. Determination of extract, 232. Detection of preservatives, 233. Salicylic acid, 233. Fluorides, 233. Method of IJefelmann and Mann, 233. Brand's method, 233. Other determinations, 233. Total acidity, 233. Fixed and volatile acidity, 233. Ash, 234. Wines, 234. Classification of wines, 235. Composition of wines, 236. Adulteration of wines, 236. Analysis of wines, 238. Determination of alcohol, 238. Detection of coal-tar colors, 239. Detection of preservatives, salicylic acid, 240. Formaldehyde, 240. Sulphites, 240. Cider, 240. Perry, 241. Distilled alcoholic beverages, 241. Brandy, 242. Whiskey, 243. Rum, 245. Gin, 245. Liqueurs, 245. 
Vinegar, 246. Cider vinegar, 247. United States standard, 247. Wine vinegar, 247. Malt vinegar, 247. Sugar vinegar, 247. Glucose vinegar, 248. Molasses vinegar, 248. Adulterations of vinegar, 248. Examination of vinegar, 248. Acidity, 248. Lemon-juice and lime-juice, 249. Adulteration, 249. Salt, 249. Mustard, 250. Pepper, 250. Cloves, 250. Cinnamon and cassia, 251. Allspice, ginger, nutmeg, mace, Cayenne pepper, 251. Baking powders, 252.

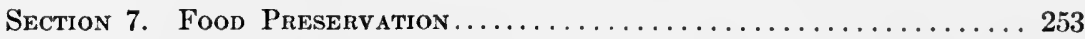

Cold, 254. Drying, 254. Salting, 254. Smoking, 254. Canrring, 254. Chemical treatment, 256. Boric acid and borax, 258. Salicylic acid, 261. Sulphites, 262. Formaldehyde, 262. Hydrogen peroxide, 263. Sodium fluoride, 264. Sodium bicarbonate, 264.

Section 8. Contamination of Foods by Metals................ 264

Copper, 264. Lead, 266. Zinc, 267. Nickel, 267. Tin, 267. Metallic Contamination from kitchen utensils, 267.

\section{CHAPTER II.}

AIR .

Oxygen, 269. Nitrogen, 271. Argon, 272. Hydrogen, 272. Carbon dioxide, 272. Ozone, 274. Ammonia, 275. Nitrogen acids, 275. Aqueous vapor, 276. Dust and micro-organisms, 278. Carbon monoxide, etc., 280. "Sewer gas," 282. Organic matters, 286. Effects of vitiated air, 286. The air as a carrier of infection, 290. Influence of fog, 297. Examination of air, 297. Determination of aqueous vapor, 298. Direct determination of moisture by weighing, 298. Determination of relative humidity by the wet and dry thermometer bulbs, 299. Glashier's table, 300. Table of tensions, 301. Determination of carbon dioxide, 303. Solutions required, 303. Process of analysis, 304. Corrections, 307. Example of method of reckoning $\mathrm{CO}, 309$. Determination of $\mathrm{CO}$ by Wolpert's method, 309 . Determination by Fitz's method, 310. Determination of carbon monoxide, 311. Determination of ozone, 312. Determination of dust, 313. Bacteriological examination, 314 .

\section{CHAPTER III.}

THE SOIL

Constituents of the soil, 318. Physical properties of soils, 319. Permeability of soils, 320 . Capacity for water and water-retaining capacity, 324. Soil temperature, 326. Changes in the character of soils due to chemical and biological agencies, 328. Soil-air, 329. Soil water, 332. Sources of soil-water, 335 . Loss of moisture by evaporation, 335 . Influence of vegetation on soil moisture, 336 . Other effect of vegetation upon the soil, 337. Pollution of the soil, 338. Bacteria of the soil, 340. Soil and disease, 342. Soil dampness and discase in general, 342. Soil and pulmonary tuberculosis, 343. Typhoid fever, 343 . Cholera, 346. Bubonic plague, 346. Diphtheria, 347. Malaria, 348. Yellow fever, 348. 
Tetanus and malignant edema, 348. Anthrax, 349. Uneinariasis, 350. Goitre, 353. Epidenie diarrhea, 354. Examination of soils, 354. Permeability to air, 356 . Permeability to water, 357. Water capacity, 359. Capillarity, 359. Moisture, 359. Organic and volatile matters, 360. Determination of $\mathrm{CO}$ in soil-air, 360. Bacteriological examination of soil, 362 .

\section{CHAPTER IV.}

WATER.

Rain, 363. Surface waters, 364. Ground-waters, 365. Physical and chemical characteristics of water, 367. Appearance, 368. Reaction, 369. Odor, 369. Taste, 371. Substances found normally in water, 371. Gases, 371. Carbon dioxide, 372. Organic matter, 372. Albuminoid ammonia, 375. Nitrates and nitrites, 375. Mineral matters, 377. Hardness, 378. Bacteria in water, 379 . Water supplies, 382. Stored rain, 382. Surface waters, 384. Ground-waters, 385 . Driven wells, 387 . Bored wells, 388 . Drainage area of wells, 391. Pollution of wells, 391. Filter galleries, 393. Classification of waters from the sanitary standpoint, 394 . Purification of water, 396. Oxidation, 396. Dilution, 397. Sedimentation, 397. Bacterial action, 397. Vegetation, 397. Methods of purification, 398. Boiling and distillation, 404. Filtration, 404. Domestic filters, 404. Filtration of public supplies, 406. Mechanical filtration, 412. Destruction of Alga, 412. Removal of hardness, 413. Removal of iron, 414. Action of water on lead and other metals, 414. Action on iron, 418. Action on zinc, 418. Action on tin, 419. Water and disease, 420. Disorders connected with mineral matter, 421. Disorders connected with organie pollution, 423. Typhoid infeetion of water supplies, 425. Influence of introduction of public water supplies on typhoid rates, 426. Examples of typhoid-fever epidemies and of limited outbreaks traced to infected water, 429. Epidemic at Lausanne, Switzerland, 429. The Plymouth, Pa., epidemic, 430. Outbreak at Uvernet, 431. Epidemic at Ashland, Wisconsin, 431. Epidemic at Luneberg, 432. Epidemic at Zehdenick, 433, etc. Asiatic cholera, 436. The propagation of cholera in India, 438. Parasites and drinking-water, 438. Parasites and drinking-water, 441. Ice, 443. Chemical examination of water, 444. Colleetion of samples, 444. Determination of free ammonia and albuminoid ammonia, 445. Solutions required, 445. Apparatus required, 446. Nesslerizing tubes, 447. Determination, 447. Precautions, 448. Permanent ammonia, standards, 449. Determination of other nitrogen compounds, 450. Determination of nitrogen as nitrates, 450. Permanent nitrate standards, 451 . Determination of nitrogen as nitrates, 451. Determination of chlorine, 452. Determination of residue, 453. Determination of hardness, 453. Solutions required, 453. Determination of "oxygen required," 454. Solutions required, 454. Determination of color, 455. Determination of odor, 455. Determination of reaction, 455. Determination of turbidity, 456. Detection and determination of lead, 456. Detection of zine, 458 . Detection of tin, 459. Detection and determination of iron, 459. Inferences as to character of water from the results of sanitary chemical analysis, 459. Bacteriologieal examination of water, 462. Collection of samples, 463. Planting the samples, 463. Quantitative determination, 464. Qualitative determination, 46i. Comparative value of ehemical and bacteriological analysis of drinking-water, 467. 


\section{CHAPTER V.}

Section 1. General Considerations.

Aspect, 470. Construction and arrangement, 470. Care of habitations, 471. Schools, 471. School furniture, 472. Chairs, 472. Desks, 472. Blackboards, 473.

Section 2. Ventilation and Heating

Amount of space required for good ventilation, 475. Natural forces in ventilation, 476. Diffusion and gravity, 476. Perflation and aśpiration, 479. Natural ventilation, 481. Inlets and outlets, 482. Mechanical ventilation, 485. Artificial heating in its relation to ventilation, 485. Radiation, 486. Conduction, 486. Convection, 486. Methods of warming, 487. Open fires, 487. Stoves, 487. Furnaces, 489. Hot-water pipes, 489. Steam pipes, 489. Regulation of temperature, 490. Necessity of providing moisture, 491. Filtration of air, 493. Determination of rates of ventilation, 493 .

Section 3. Lighting.

Natural lighting, 495. Artificial lighting, 497. Luminosity of flame, 497.

Gas burners, 498. Varieties of illuminating gas, 499. Coal gas, 499. Water-gas, 499. Acetylene gas, 500. Impurities given off in lighting, 501. Gas pipes, 501. Fixtures, 502. Electric lighting, 502.

Section 4. Plumbing

The soil-pipe and main drains, 504. Waste pipes, 509. Traps, 510. Loss of seal, 516. Non-siphoning traps, 518. Water-closets, 520. The pan closet, 523. The plunger or plug eloset, 524. Hopper eloset, 525. Open wash-out closets, 525. Siphon closets, 526. Flushing apparatus, 528. Water-closet connections, 529. Urinals, 530. Wash-basins, 530. Bathtubs, 532. Sinks, 534. Honse-maids' sinks, 535. Laundry tubs, 535. House service tanks, 535. Service pipes, 536. Testing plumbing, 537.

\section{CHAPTER VI.}

DISPOSAI, OF SEWAGE

Methols of sewage disposal, 540. Discharge into the sea, 541. The pail system, 541. Sedimentation and chemical precipitation, 542. Sewage irrigation, 544. Influence of sewage irrigation on health, 545. The Waring system of irrigation, 547. Sewage filtration, 548. Contact filtration, 550. Trickling filters, 551. The Cameron septic tank, 554. Septic tanks for the digestion of sludge only, 554 .

\section{CHAPTER VII.}

DISPOSAL OF GARBAGE.

Reduction, 559.

\section{CHAPTER VIII.}

DISINFECTANTS AND DISINFECTION

Physical agents, 560. Light, 560. Heat, 563. Steam, 565. Boiling water, 568. Cold, 569. Chemical agents, 571. Non-metallic elements 
and their compounds, 572. Oxygen, 572. Ozone, 573. Hydrogen peroxide, 574. Chlorine, 574. "Chloride of lime," bleaching powder, chlorinatel line, 575. Sodium hypochlorite solution, 577. Hypochlorous acid, 577. Iodine, 577. Bromine, 577. Sulphur dioxide, 577. Sodium carbonate, 579. Sodium earbonate or washing-soda, 579. Lime, quicklime, 5S0. Metallic salts, 581. Ferrous sulphate, 581. Ferric sulphate, 581. Ferric chloride, 581. Zine chloride, 581. Aluminum chloride, 581. Potassium permanganate, 582. Copper sulphate, 582. Mercuric chloride or corrosive sublimate, 582. Mereuric cyanide, 584. Sublamin, 584. Silver conpounds, 584. Sodium aurate, 585. Mineral acids, 585. Carbolic acid and cresol preparations, 586. Cresols, 587. Liquor cresolis compositus, 585. Creolin, 589. Lysol, 589. Bacillol, 590. Saprol, 590. Solveol, 590. Sulfonaphthol, 590. Alcohol, 591. Essential oils, 593. Soaps, 594. Medieated soaps, 596. Lysoform, 598. Paralysol, 598. Metakaline, 598. Formaldehyde, 598. Methods of use and apparatus, 599. Germicidal properties, 606. Conditions favoring aetion, 607. Toxicity, 607. Amount necessary for room disinfection, 608. Disadvantages, 608. Technic of room disinfection, 609. Other applications of formaldehyde, 609. Prevention of dissemination of infectious material; practical disinfection, 609. Disinfeetion of feees, 610. Urine, 610. Sputum, 611. Discharges from mouth, ete., 611. Eating utensils, ete., 611. Bed-linen and clothing, 611. Hands, 611. Air, 612. Room disinfection, 612. Disinfection of books, 616. Disinfection of water-elosets, 616.

\section{CHAPTER IX.}

MILITARY HYGIENE.

The recruit, 619. Examination of the recruit, 625. Chest capacity, 626. Grounds for rejection, 626. The hygiene of the soldier, 627. Personal cleanliness, 627. Contentment and cheerfulness, 627. Clothing of the soldier, 628. Wool, 628. Cotton and linen, 628. Shoddy, 629. Color, 629. Military dress coats, 629. Trousers, 629. Gaiters and leggings, 629. Head covering, 630. Stockings, 630. Boots, 630. Underelothing, 631. Abdominal bands, 632. Water-proof blankets, 632. The soldier's exercise and work, 633. Marching, 633. Care of the feet on the mareh, 638. Care of other parts, 639. The soldier's food: "rations," 639. Garrison ration, 640. Field ration, 641. 'Travel ration, 641. Alcohol in the ration, 643. Preparation of food, 644. Is the United States ration suited to the tropies? 645. Posts and camps, 649. Sites, 651. Barracks, 652. Tents, 653. Huts, 656. Sewerage, 657. Sinks and latrines, 658. Inspections, 659. Sanitary police, 660. The diseases of the soldier, 665 . Typhoid ferer, 667. Dysentery, malaria, 668. Measles, 669. Diarrheal diseases in general, 669. Sunstroke, 669. Venereal diseases, 670.

\section{CHAPTER X.}

NAVAL AND MARINE HYGIENE.

Naval reeruits, 671. The naval ration, 672. Water supply, 675. The sailor's sleeping quarters, 676. The diseases of sailors, 677. Ventilation of vessels, 677. General hygiene of ships, 679 .

CHAPTER XI.

TROPICAL HYGIENE

The soldier and the civilian in the tropies, 681. Residence, 683. Habits 
of life, 683. The use of alcohol in the tropies, 685. Clothing, 687. Carc of the person, 688. Tropical diseases, 688.

\section{CHAPTER XII.}

THE RELATION OF INSECTS TO HUMAN DISEASES

Flies, 691. Fleas, 694. Bedbugs, 695. Arachnids, 696. Ticks, 696. Body louse, 696. Mosquitocs, 696. Mosquitoes and malaria, 697. The malarial parasite, 700. Preventive measures, 706. Mosquitoes and yellow fever, 707. The yellow fever mosquito, 709. Preventive measures, 711. Mosquitoes and filarial discase, 712. Mosquitoes and dengue, 714.

\section{CHAPTER XIII.}

HYGIENE OF OCCUPATION.

Classification of occupations, 721. Occupations involving exposure to air vitiated by respiration, 723. Occupations involving exposure to irritating and poisonous gases and fumes, 723. Irritating gases and fumes, 724 . Poisonous gases and fumes, 725. Occupation involving exposure to poisonous and irritating dusts, 729. Poisonous dusts, 729. Irritating dusts, 732. Occupations involving exposure to infective matter in dust, 735. Occupations involving the inhalation of offensive gases and vapors, 736. Oceupations involving exposure to extreme of heat, 737. Oecupations involving exposure to dampness, 737. Oceupations involving exposure to abnormal atmospheric pressure, 737. Occupations involving constrained attitude, 738. Occupations involving sedentary life, 739. Prophylaxis in general, 739. Employment of women and ehildren, 740 .

\section{CHAPTER XIV.}

VITAL STATISTICS.

The census, 743. Estimated population, 745. Inerease of population, 746. Population constitution, 746. Registrar's returns, 747. Marriage rates, 748. Birth-rates, 749. Death-rates, 751. Influence of sex, 751. Influence of age, 751. Influence of race, 752. Other influences, 753. Influence of density, 753. Weekly death-rates, etc., 754. Zymotic deathrate, 754. Infantile death-rate, 754. Death-rates of children, 756. High and low death-rates, 756. Correction of death-rate, 757. Classifieation of eause of death, 758. Registration of sickness, 758. Duration of life, 759. Probable duration of life, 759. Mean duration of life, 759. Expectation of life, or mean after-life-time, 760. I iffe tables, 760.

\section{CHAPTER XV.}

PERSONAL HYGIENE. . . . . . . . . . . . . . . . . 762

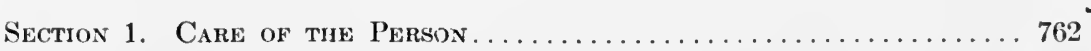

Section 2. Regulation of the Diet.................... 704

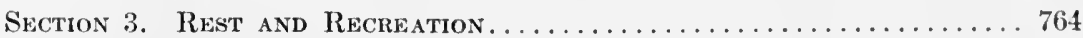

Section 4. Piysical Exercise......................... 765

Effects of active exercise, 765. Circulation and respiration, 765. Skin, 766. Nervous system, 766. Digestive apparatus, 767. Kidneys, 767. Effect of exercise on weight, 767. Amount of exercise required, 768. Kind of exercise, 769. Golf, 769. Wheeling, 770. Tennis, cte., 770. Rowing, 770. 
Section 5. Clothing.

Color, 770. Texture, 770. Heat conductivity, 771. Hygroseopieity, 771.

Materials, 771. Wool, 772. Silk, 773. Cotton, 774. Linen, 775. Rubber, leather, 776. Fur, 776. Felt, 776. Adulteration of clothing, 776. Chemical analysis, 777. Microscopical examination, 777. Poisonous dyes, 777. Selection of elothing, 778.

\section{CHAPTER XVI.}

INFECTION, SUSCEPTIBILITY, IMMUNITY.

Exciting eauses of disease, 780. Channels of infection, 780. Infection and contagion, 781. Susceptibility, 781. Ehrlich's theory, 783. Toxins and antitoxins, 783. Bacteriolysis, 788. Hemolysis, 789. Complements, 793. Immune bodies, 795. Agglutinins, 796. Wassermann's reaction for syphilis, 800. Metschnikofr's theory, 801. Opsonins, 802. Practieal applications of the results of studies in immunity, 802. Diphtheria, 804 . Tetanus, 805. Hay-fever, 805. Dysentery, 806. Typhoid fever, 807 . Asiatic cholera, S08. Bubonic plague, 809. Antistreptococeus serums, 811. Tubereulosis, 811. Cerebrospinal meningitis, 812 .

\section{CHAPTER XVII.}

\section{CHAPTER XVIII.}

QUARANTINE.

Quarantine law of 1893,822 . Interstate quarantine, 826. State quarantine, 826. Sanitary cordon, 828. Municipal quarantine, 828. Camps of detention, 829 .

\section{CHAP'TER XIX.}

DISPOSAL OF THE DEAD. .

Earth burial, 830. Sites for cemeteries, 832. Cremation, 832. History of modern cremation, 834 . 


\title{
PRACTICAL HYGIENE.
}

\author{
25304 \\ C H A P T E R I.
}

FOODS.

\section{Section 1. GENERAL CONSIDERATIONS.}

Foons may be said to include everything taken into the system capable of being utilized directly or indirectly to build up normal structure, repair waste, or produce energy in any form, but in the common acceptation of the term they inchde only those substances which ean be oxidized in the system, thus excluding water and air, withont which the funetions of the body can not be performed. Diet is a mixture of food materials of various kinds habitually taken in such quantity as is needed to maintain or improve the condition of the system.

\section{The Nutritive Value of Foods.}

The potential energy of food is measured by the amount of heat which can be obtained by its eomplete eombustion, and is expressed in units of heat or calories. The amount of energy required to raise the temperature of 1 kilogram of water $1^{\circ} \mathrm{C}$. is known as a large calorie; that required to raise the temperature of 1 gram to the same extent is known as a small calorie; thus, 1 large calorie equals 1000 small ealories. When the term is used without qualification, large calories are understood. These heat units correspond to 425.5 units of work; that is to say, the same amount of encrgy required to raise the temperature of the given weight of water $1^{\circ} \mathrm{C}$. is suffieient to raise 425.5 times the weight one meter. The amount of work done is expressed in kilogram-meters.

The heat unit of the English system is the amount of energy required to raise the temperature of a pound of water $1^{\circ} \mathrm{F}$., and its mechamical equivalent is 772 units of work; that is to say, the same amomnt of energy will raise 772 pounds one foot. According to the English methorl, work done is expressed in foot tons rather than in foot pounds.

The ealorimetric values of different food materials express also their 
plyysiological values as nutriment. Rubner ${ }^{1}$ determined the calorimetric value of the proximate prineiples as follows:

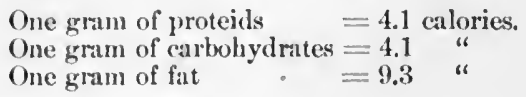

In the system, the carbohydrates and fats are burned completely to carbonic acid and water, but the proteids leave a residue of urea ineapable of still further oxidation. It is estimated that the physiological value of the proteids averages only about 75 per cent. of their calorimetrie value.

The calorimetrie value of different foods of the several elasses is not to be understood as being exactly the same. Thus, two kinds of sugar or two kinds of fat, or two kinds of proteid have not exactly the same calorimetric values, and the figures above given are to be understood only as fair averages. Rubner ${ }^{2}$ has determined by actual experimentation the relative calorimetric values of eertain food materials, and has shown that 100 grams of fat are equivalent to 225 of syntonin, or 232 of starch, or 234 of eane sugar, or 243 of muscle fiber, or 256 of grape sugar. In other words, these several amounts of food material are isodynamic.

\section{Amount of Food Necessary.}

For the maintenance of a proper degree of health and strength, the individual must ingest an amount of food sufficient to meet the daily loss of nitrogen and carbon. This must necessarily vary according to cireumstanees, and hence no rule ean be laid down to fit all cases. 'The best that can be done is to make eertain general rules based on the amount of work performed, for the greater the amount of work done, the greater the amount of food required to meet the necessary consumption of fuel and to repair the tissues. When performing heavy labor, the naturally inereased desire for food is shown particularly in the direetion of fats, and secondarily of proteids.

For many years Voit's estimate, that a man of 154 to 165 pounds, working at moderately lard labor 9 or 10 hours a day, requires 118 grams of proteid, 56 of fat, and 500 of carbohydrates, the whole yielding 3054.6 ealories, has been generally accepted as correct. Recently, however, Chittenden ${ }^{3}$ has demonstrated conclusively by experiments extending over many months, the subjects being men engaged in intellectual pursuits, soldiers, and athletes in training, that half the stated amomit of proteids is ample for the real physiological needs of the body under ordinary eonditions of life, and that a fuel value of 3000 ealories is not necessiry, the diminution in the proteid intake requiring no additional amount of non-nitrogenous substances.

Knowing the eomposition of a given article of food, the proteid, fat, and carbohydrate value of a given weight can easily be determined; and thus one can construct standard dietaries for the various eonditions

${ }^{1}$ Lehrbuch der Hygiene, Icipsic, 1900, p. 438.

${ }^{3}$ Physiological Economy in Nutrition, New York, 1904.

${ }^{2}$ Ibidem, p. 430. 
of bare subsistence, rest, and performance of various amounts of daily labor. Up to the present time it has been customary to preseribe the constituents of the standard diets in the following proportions: For each part of proteids, two-thirds of a part of fat, three and one-sixth parts of carbohydrates, and one-fourth of a part of mineral matter, the proportion of 1 part of nitrogen to 15 of carbon being maintained as nearly as possible. In view, however, of Chittenden's results, these proportions should be changed, not only on aceount of the fact that an excess of proteids is a burden to the system, but also for economical administration, sinee the nitrogenous foods are, as a elass, by far the most expensive.

In any dietary, nutritive value must not be the sole consideration, for taste and variety are highly important and the palate must be flattered.

\section{Composition of Foods.}

The constituents of food materials are partly organic and partly inorganic. The organic constituents include proteids, fats, carbohy olrates, and organic aeids; the inorganic include water and mineral salts.

Proteids.-The proteids are the most important constituents of both animal and vegetable foods, and their presenee is necessary for the carrying on of all the phenomena of life. They are very complex colloid substances composed of carbon, oxygen, hydrogen, nitrogen, and sulphur, possessing common properties and connected in very close genetic relationship. They are divided into animal proteids and vegetable proteids, but between the members of the one elass and those of the other there are no important chemical differences, and they are about equal in nutritive value. Some of the vegetable proteids are not colloills, for aceording to Schmiedeberg, Weyl, Masehka, and others, they are found in crystalline form in the tissues of certain plants, and notably in the bean, pea, lentil, and various nuts.

Proteids when completely split up by acids yield as end products ammonia, nitrogen, organie bases, and amido acids. Ther are never completely absent from animal and vegetable tissues, but their amount in different substances is very widely variable, some foods being very rich in them, while in others they exist only in traces.

Ingested in great excess of the needs of the system, they are likely to eause general disturbance, diarrhoa and albuminuria, whilc a diet from which they are practically exeluded will eause rapid loss of strength, anemia, great prostration, and greatly diminished resistance to invasion by specifie diseases, especially tubereulosis and pneumonia.

The animal proteids are more rapidly digested than the vegetal,le proteids, some of which are largely wasted through imperfect digention. The proteids, whatever their source, yield in the main the same produets of digestion, and consequently may replace each other in the diet.

The most reent and most satisfactory elassification of proteids is 
that made by a combined committee of the American Society of Biological Chemists and the American Physiological Society. ${ }^{1}$

The recommentations are as follows :

First: The word proteid should he abandoned.

Seeond: 'The word protein should designate that group of substanees which consists, so fir ats at present is known, essentially of combinations of a-amino acids and their derivatives, $c . g$., a-amino-aectic acid or glyeocoll, a-amino-propionic aeid or alanine; phenyl-a-amino propionic acid or phenylalanine, guanidine-amino-valerianic aeid or arginine, ete., and are, therefore, essentially polypeptides.

Thirl: 'That the following terms be used to designate the various groups of proteins:

\section{The Simple Proteins.}

Protein substances which yield only a-amino acids or their derivatives on hydrolysis.

Although no means are at present available whereby the chemical individuality of any protein ean be established, a number of simple proteins have been isolated from animal and vegetable tissues which have been so well characterized by constancy of ultimate eomposition and uniformity of physical properties that they may be treated as chemieal individuals until further knowledge makes it possible to characterize them more definitely.

The various groups of simple proteins may be designated as follows:

(a) Albumins. Simple proteins soluble in pure water and coagulable by heat.

(b) Globulins. Simple proteins insoluble in pure water, but soluble in neutral solutions of salts of strong bases with strong acids."

(c) Glutelins. Simple proteins insoluble in all neutral solvents, but readily soluble in very dilute acids and alkalies. ${ }^{3}$

(d) Aleohol-soluble proteins. Simple proteins soluble in relatively strong alcohol (70 to 80 per cent.), but insoluble in water, absolute alcohol, and other neutral solvents. ${ }^{4}$

(e) Albuminoids. Simple proteins which possess essentially the same chemical strueture as the other proteins, but are characterized by great insolubility in all nentral solvents. ${ }^{5}$

$(f)$ Histones. Soluble in water and insoluble in very dilute ammonia and, in the absence of ammonium salts, insoluble even in an excess of ammoni: ; yield precipitates with solutions of other proteins,

1 American Journal of Pluysiology, 21, 1908, p. xxvii.

2 The precipitation limits with ammonium sulphate should not be made a basis for distinguishing the albumins from the globulins.

3 Such substances occur in abundance in the seeds of cereals, and, doubtless, represent a well-rlefined natural group of simple proteins.

4 The sub-classes defined $(a, b, c, d)$ are exemplified by proteins obtained from both plants and animals. The use of appropriate prefixes will suffice to indicate the origin of the enmpounds, e. \%., ovogrobulin, myoalbumin, ete.

5 These form the prineipal organic constituents of the skeletal structure of animals, and also their external covering and its aplendages. This definition does not provide for gelatin, which is, however, an artificial derivative of collagen. 
and a coagulum on heating which is easily soluble in very dilute acids. On hydrolysis they yield a large number of amino-aeids anong whieh the basic ones predominate.

(g) Protamines. Simpler polypeptides than the proteins included in the preceding groups. They are soluble in water, uneoagulable by heat, have the property of precipitating aqueous solutions of other proteins, possess strong basic propertics, and form stable salts with strong mineral acids. They yield comparatively few amino-aeids, among which the basic amino-acids greatly predominate.

\section{Conjugated Proteins.}

Substances which eontain the protein moleenle united to some other molecule or molecules otherwise than as a salt.

(a) Nueleoproteins. Compounds of one or more protein molecules with nucleic aeid.

(b) Glycoproteins. Compounds of the protein molecule with a substance or substances containing a carbohydrate group other than a nucleic aeid.

(c) Phosphorproteins. Compounds of the protein molecule with some, as yet undefined, phosphorus-containing substance other than a nneleic acid or lecithins. ${ }^{1}$

(d) Hremoglobins. Compounds of the protein molecnle with hematin or some similar substance.

(e) Lecithoproteins. Compounds of the protein molecule with lecithins (lecithans, phosphatides).

\section{Derived Proteins.}

1. Primary Protein Derivatives. Derivatives of the protein molecule apparently formed throngh hydrolytic changes which involve only slight alterations of the protein molecule.

(a) Proteins. Insoluble products which apparently result from the incipient action of water, very dilute acids, or enzymes.

(b) Metaproteins. Produets of the further action of acids and alkalies whereby the molecule is so far altered as to form protuets soluble in very weak aeids and alkalies, but insoluble in neutral fluids.

This group will thus inelude the familiar "aeil proteins" and "alkali proteins," not the salts of proteins with acids.

(c) Coagulated proteins. Insoluble products will result from (1) the action of heat on their solutions or $(2)$ the action of aleohols on the protein.

2. Secondary Protein Derivatives. ${ }^{2}$ Produets of the further hydrolytie cleavage of the protein moleeule.

(a) Proteoses. Soluble in water, uncongulated hy heat, and preeipitated by saturating their solutions: with ammonium or zine sulphate. ${ }^{3}$

1 The accumulated chemical evidence distinctly points to the propriety of classifying the phosphoproteins as conjugated componds, $i$. e., they are possibly esters of some phosphoric acid or acids and protein.

${ }^{2}$ The term secondary hydrolytic derivatives is used because the formation of the prinary derivatives usually preceles the formation of these seendary deriratires.

${ }^{3}$ As thus defined, this term does not strictly eover all the protein derivatives eommonly called proteoses, e. g., heteroproteose anl dyproteose. 
(b) Peptones. Soluble in water, uncoagulated by heat, but not precipituted by siturating their solutions with ammonium sulphate.

(c) leptides. Definitely characterized combinations of two or more amino-acids, the carboxyl gromp of one being united with the amino gromp of the other with the elimination of a molecule of water. ${ }^{2}$

The albumins are not preeipitated by alkaline carbonates, common silt, or dilute acids, but they are coagulated by being heated to $65^{\circ}-$ $73^{\circ} \mathrm{C}$. Casein, legumin, conglutin, syntonin, and albuminates, on the contrary, are not coagulable by heat, but are precipitated by common salt, sodium acetate, and trisodium phosphate. The albumoses are widely distributed throughont the vegetable kingdom, and are found larrely in the cereals. In the animal kingdom, they are intermediate prodnets of the action of pepsin on ordinary proteids, becoming eventually converted to peptones. The collagens are very rich in nitrogen, but have an inferior nutritive value. Gelatin, for instance, contains 17-18 per eent., while the albumins contain but 16 .

Fats. - The fats are compounds of the triatomic alcohol, glycerin, with fatty acids, mainly stearic, palmitic, and oleic. 'These several compounds are known as stearin, palmitin, and olein. 'The two first mentioned are solids at usual temperatures, while olein is a liquid. Most fats are combinations of two or all of these substances, and some, as, for example, butter, contain additional glycerides in small amount. Stearin and palmitin being solids, and olein liquid, the consistency of a fat is dependent upon the proportions in which these substances are present. Stearin is a component of most animal fats, but never is found in regetable fats. The chief constituent of animal fats is palmitin, and this occurs also in nearly all vegetable fats. Olein exists in both. Butyrin, caprin, caproin, and caprylin are glycerides of volatile fatty acids present in the fat of milk.

Fats consist of carbon, hydrogen, and oxygen, and contain no nitrogen. The hydrogen and oxygen are not present in the proportions in which they exist in water and in carbohydrates, the oxygen being deficient.

As taken in food, fats are chiefly in the form of neutral substances, but more or less free fatty acid is always present, and in some foods which have been kept for a time, particularly in well-ripened eheese, fatty acids may be present in a free state in quite large proportion.

The fats play an important part in the maintenance of animal heat and mechanical energy. When hard labor is being performed, an excess of fat is instinctively taken.

Carbohydrates.-The earbohydrates include the starches, sugars, and cellulose.

The Starches, though presenting very different appearanees under the microscope according to source, are of equal value as foods, and have the same composition. Stareh is insoluble in water, but, heated

1 In this group the kyrines may be included. For the present we believe that it will be helpful to retain this term as defined, reserving the expression peptide for the simpler compounds of definite strueture, sueh as dipeptides, ete.

${ }^{2}$ The peptones are undoubtedly peptides or mixtures of peptides, the latter term being at present used to designate those of definite strueture. 
with it to $72^{\circ} \mathrm{C}$, the cells swell and burst, and produce a sort of mucilage. Heated with dilute mineral acids, it is converted into dextrose. Subjected to the action of liastase, it is converted into maltose.

Starch is found almost exchnsively in vegetable cells. It forms the chief part of the seeds of the cereals and of the dried residue of certain other vegetable products, such as potatoes. A form of starch known as animal stareh or glycogen is found in the liver and muscles, and also in some of the mollusea. Dextrin is an artificial product formed from stareh by the action of ferments or of dilute acids and heat.

The sugars are of vegetable and animal origin, and include the following :

1. Sucrose, cane sugar. A disaccharid. From sugar cane, sorghum, sugar maple, sugar beet, and some other vegetable sources. Insoluble in strong alcohol, does not reluee eopper; not directly fermentable. Boiled with dilute acids, is converted to invert sugar, a mixture of dextrose and lævulose.

2. Dextrose, glucose, grape sugar. A monosaccharid. Found in many fruits and flowers. Formed from cane sugar, maltose, starch, and dextrin by boiling with dilute acids. In the presence of decomposing proteids, splits into two molecules of lactic acid. Fermented with yeast, splits into alcohol and carbonic acid.

3. Maltose, malt sugar. A disacebarid. ('Two molecules of dextrose.) Formed from starch by the action of diastase.

4. Lævulose, fruit sugar. A monosaccharicl. Found in honey and varions fruits. Rotates the ray of polarized light to the left. Does not form erystals. Isomeric with dextrose.

5. Lactose, milk sugar. A disaceharid. (Dextrose and galactose.) Found only in milk. Behaves like dextrose.

6. Galactose. A monosacharid. Formed from lactose by boiling with dilute mineral acids.

7. Inosite, musele sugar, phaseomannite. Found in certain animal tissues, as the heart's muscle, and in certain plants, ats peas, beans, and grapes. Has no rotatory power, does not reduce eopper, and is not fermentable. It eontains the benzene ring, and hence is not a tme sugar. In the presence of decomposing proteids, it is converted into lactic and butyrie acids.

Cellulose.-Cellulose, while of value as a food for herbivora, has no nutritive value for man. It is converted to dextrose by boiling with dilute sulphurie acid.

Pectin.-Pectin is a substance unt uncommonly classified as a carbohydrate. It is composed of carbon, hydrogen, and oxygen, but its precise composition is unknown.' It is found in valrions Heshy fruits and in roots, and is believed to be formed from peetose by the action of vegetable acids. It is known also as vegetable jelly.

Pectose.-Pectose is an insoluble substance found in unripe fruits and roots: an earlier stage of peetin.

The carbohydrates play an inportant part in the maintenance of heat and the production of force. They lessen the need of fat and form fatty tissue. Excessive ingertion interferes with the metamor- 
phosis of nitrogenous tissue, causes deposition of fat in excess, and is likely to produce digestive disturbances. Deprivation for a time can be borne, provided the system receives sufficient fatty food, but not otherwise.

Organic Acids.-The organic acids exist in foods either in the free state or in combination as salts. In the system they are converted to carbonates, which exercise a most important influence in controlling the alkalinity of the blool and other fluids. Deprivation lads to a peenliar disturbance of the system resulting in senrvy. They include malic, acetic, lactic, oxalic, citric, and tartaric acids. Malic acid is a constituent of apples, pears, and some other fruits. Acetic acid is the essential element of vinegar. Oxalic acid is found in considerable amounts in spinach, tomatoes, strawberries, sorrel, and rhubarb. Lactic acid is present in fresh meats and in milk. The two most important acids are citric and tartaric. The former is found in oranges, lemons, limes, and other fruits; the latter largely in grapes.

Not all vegetables contain these acids, and, therefore, not all have antiscorbutic properties. Potatocs, cabbage, and roots are very efficient in this respect, while peas and beans are notable examples to the contrary.

Inorganic Salts.-The important inorganic salts taken into the system with food include sodium and potassium chlorides, sodium, potassium, magnesium and calcium phosphates, and compounds of iron. The sulphates are of minor importance and are ingested in only snall amounts. The sulphur essential to growth is taken into the system in combination in the proteids. The chlorides keep the globulins of the blood and other fluids of the body in solution, and are the source of the hydrochloric acid of the gastric juice. The phosphates are very essential to the growth of bone and to the nervous system, and iron is needed for the hromoglobin of the blood. Deficiency of calcium and magnesimm salts leads to rickets and other abnormal conditions.

\section{Section 2. ANIMAL FOODS : MEATS, FISH, EGGS, AND MEAT PRODUCTS.}

The foods of animal origin used by man include the flesh and various organs of the herbivora and swine, domestic and wild fowl, egge, fish and shellfish, milk and milk products. The flesh of all carnivorons animals except fish is unpalatable, and, therefore, undesirable as food, though under stress of circumstances it may be borne. Thus, during the sicge of Paris, about 5,000 eats and 1,200 dogs are said to have been eaten when the food supply had become so meagre that anything in the form of flesh was acceptable. In Germany, according to a communication of Consul-General Guenther to the State Department at Washington, under date of May 26, 1900, the statistical year-book shows that, on account of the high price of other meats, not only horses, but also dogs are much used as food. At Breslau, Chemnitz, Dresden, Leipzig, Zwickau, and other places, dogs are slaughtered extensively for this purpose and regularly inspected. 
Pirl ${ }^{2}$ reports that in Saxony during 1894, 295 ; in 1895, 388 ; in 1896,399 ; and in 1897, 474 dogs were slaughtered and inspected. In Dessau, between 1893 and 1898, the number averaged 251 yearly, and inspection showed that one in 202 was triehinous. According to Tempel," of 289 killed at Chemnitz during 1897, 1.391 per cent., and of 147 killed during the first half of the year 1898, 2.04 per cent. were found to be trichinous. The meat is eaten chiefly in the roasted state, but also, in many parts of Saxony, raw, but highly seasoned. The same animals are commonly eaten by the Chinese, and the Canada lynx and the skunk are rated as delicacies by the North American Indians.

\section{MEATS.}

The value of meat as food depends upon the presence of proteids, fat, and mineral salts. The nitrogenous extractive matters (creatin, etc.), sometimes called "meat bases," formed by cleavage of the proteids, give flavor, but have little value as foods. The carbohydrates play but an insignificant part, being present thiefly as musele sugar and to only a very small extent. All meat, however lean, contains fat, some of which is visible and some indistinguishable from the muscle fibres by which it is surrounded. The visible fat varies widely in anount. Very fat beef may contain considerably more than a quarter of its weight of visible fat, and fat pork meat more than a half, while chicken and veal contain comparatively little.

The content of water varies very widely and in general may be said to be governed by the richness in fat, for, while the proteids are fairly constant in amount, the remainder is almost wholly water and fat, and the greater the amount of the one, the less the amount of the other. The less fat a meat contains, the less, therefore, its relative nutritive value.

Digestibility.- While the amount of nutriment contained in meats chiefly determines their food value, the latter is to no inconsiderable extent dependent upon the ability of the alimentary tract to digest and absorb them. Gastrie digestion is by no means to be accepted as a measure of the true digestibility of a food, and the same is true of the results of artificial laboratory experiments; henee many of the aceepted statements bearing on this subjeet, based upon the oft-quoted experiments on Alexis St. Martin and upon test-tube observations, may be wholly disregarded.

Raw meat is digested more easily, but less completely, than that which has undergone the process of cooking, and roasted moat is more eompletely digested than that which has heen boiled. Fat meats, as beef and mutton, and especially pork, require more time for digestion than those whieh, like ehicken and veal, contain but little fat. In general, it may be sairl that meats are assimilated more casily than vegetable foods.

Flavor.-The flavor of meats depends largely upon the nature and

I Zeitschrift für Fleisch- und Milchhygiene, X., No. 1.

2 Ibidem, IX., No. 1. 
amounts of nitrogenous extractives which they contain, and is greatly modified by the eondition of the animal when killed, its age, sex, and the character of its food. 'The high flavor of birds and game is due to the riehness in extractives, while in the case of meats defieient in these substances, as, for example, mutton and pork, the flavor is due largely to their contained fats. Most meats are improved in flavor by being kept for a time, during which, additional flavors, due to decomposition produets similar to the extractives, are developed. The meat of young animals is flavored less highly than that of adults, and that of females than that of males, though in the case of the goose this condition is reversed, and in that of swine no difference is observable.

Asexualization by spalying or astration produces a fatter, more tender, and better flavored meat. Thus, the flesh of oxen is far preferable to that of bulls or eows, and that of capons and poulards to that of coeks and hens.

Texture. - Whether a given meat is tongh or tender depends upon the character of the walls of the musele tubes and upon the amount of connective tissue present. The tube walls are thin and delicate, and the connective tissue is small in amount in the young and well-fed, but as the animal becomes older or is made to work, the tubes thicken and become hard, the connective tissue increases in amount, the fat may diminish, and the result is a eoarser flesh. Very young animals have a very watery, gelatinous, and flavorless flesh.

The texture of meat undergoes very considerable change after slaughter. When freshly slanghtered, it is tender and juiey, but as rigor mortis supervenes, it becomes hardened and tough. The stage of rigor is suceeeded by the first stage of decomposition, during which lactic acid is formed. This acts upon the eonnective tissue and eatuses softening and tenderness, and as the process of decomposition proceeds within proper limits, inerease of flavor is developed.

Effects of Cooking.-When meat is cooked, the comective tissue is softened, the bundles of fibrillae are loosened from each other, the albumin is coagulated, flavor's are improved and new ones developed, parasites and micro-organisms are destroyed, and the whole mass is rendered more acceptable to the eye and palate. In the process of roasting or broiling, considerable shrinkage due to loss of water occurs. The heat to which the meat is subjected should be sufficiently intense to produce speedy coagulation of the exterior and prevent the meat juices from becoming dried up. In order that the surface shall not be burned, the meat must be basted from time to time with hot melted fat, which forms a protective coating. 'The heat employed should be less intense with large joints than with small ones, sinee before the heat can penetrate well into the interior, the outer parts will become burned.

In boiling, the temperature of the water into which the meat is immersed varies according to the object sought. If a rich broth is desired, the meat is placed in cold water, which then is heated gradually. During the heating process, the soluble albumins together with a portion of the salts and the extractives are dissolved out. When the tem- 
perature reaches $134^{\circ} \mathrm{F}$, the albumin begins to coagulate, and above $160^{\circ}$, the connective tissue is changed to gelatin and dissolved. The solution of certain of the constituents is assisted by the small amounts of lactic acid formed.

If, on the other hand, it is desired to have the juices and flavors retained within the mass, the meat chould be plunged into boiling water, which quickly coagulates the albumins at the surface and causes thereby the formation of a protective coating. After this is formed, the temperature should be lowered to about $180^{\circ} \mathrm{F}$., for otherwise the neat becomes tough, even to the center. The shrinkage in meat that has been properly boiled amounts to from 20 to 40 per cent. of its weight.

In frying, the meat is dropped into very hot fat, as lard or vegetable oil, which causes speedy coagulation of the surfice, such as is brought about in the process of boiling, whereby all the flavors and juices are retained. It is essential that the fat be very hot, since otherwise it will penetrate the tissues and cause the meat to become greasy and unpalatable.

In stewing, the meat is cut into small pices and placed in cold water, which then is heated slowly to about $180^{\circ} \mathrm{F}$., at which temperature the whole is kept for several hours. If heated above $180^{\circ}$, the meat becomes tough, stringy, unpalatable, and of diminished digestibility.

Characteristics of Good Meat.-Meat should have a uniform color, neither abuormally pale nor inclined to purplish. It should have little or no odor, and such as it has should give no disagrecable impression such as the sickly cadaveric smell characteristic of diseased or decomposing flesh. It should be firm and elastic, and should not pit nor crackle on pressure. On being handled, it should scareely moisten the fingers, and with keeping, the exterior should become dry rather than wet. There should be no evidence whatever of the presence of parasites.

Beef has a bright red color and a marbled appearance, due to the presence of fat between the bundles of muscular fibers. This marbling is much less apparent in the flesh of animals that have not been well fed and of old eows and bulls. Bull meat is darker than that of oxen and cows, and is coarse, stringy, and of strong flavor.

Veal is much paler than beef and less firm to the touch, and coning from a very young animal, "bob-veal," it is flabby and watery, and its fat has a tallowy appearance.

Mutton should be of a dull-red color and firm to the tonch. Its fat is white, sometimes yellowish, and hard.

Iamb is somewhat less firm to the touch and has a decidedly lighter color than nutton.

Pork is nuch less firm to the tonch than beef and mutton, and its fat is quite soft in comparison.

Horse meat, the use of which is inereasing rapidly abroad and to a much greater extent in this conntry than is commonly believed, is darker and coarser than heef and possesses a very different odor. The fat is yellow and oily and has a rather disigreeable odor.

The flesh of birds is not marbled like that of mimmals. That of wild fowl that feed on fish has a strong flavor, which is not improved by keeping. 
Comparative Digestibility of Meats.-Beef is commonly and correctly regarded as one of the most digestille of meats, but aceording to the experience and testimony of many vietims of dyspepsia it is inferior in this respect to mutton. Pork is, without douht, digested with greater diffieulty than any other meat, on account of its high content of fitt. The evidence as to veal is most conflicting, some holding thiat it is digested very easily, while others maintain the contrary view. Certain it is that many persons bear it very badly. The white meat of elickens, fowls, and turkeys, is more delicate and is digested more easily than the dark meat, probably by reason of its smaller amount of fat. The flesh of ducks and geese is harder, richer, and more diffienlt of digestion. Game birds are less fit than poultry and are often much better borne. Their habits of life are unfuvorable to the deposition of much fat. Liver, kidneys, and heart are generally regarderl as unsuitable as foods for persons with weak stomachs, but tripe and sweetbreads are usually easily borne.

"Red Meat" and "White Meat."-The prohibition of red meats (beef, mutton, venison) to patients with gouty and rheumatie tendencies dates from the time of Sydenham, whose dietetie rules allowed only the white meats (veal, goat, young pig, chicken) and fish to such persons. Today, many pratitioners extend this prolibition to those with diseases of the stomach, intestines, and kidneys, and various neuroses. The foundation of this prejudice against the red meats is the supposed presence in them of a greater percentage of the nitrogenous extractives (ereatin, xanthin, guanin, ete.), which are believed to exert injurions action in two ways: First, locally, by irritating the kidneys during the process of their elimination from the body; and second, in eases of impaired functional activity of the kidneys, by eausing systemic intoxication. Unfortunately, however, for the stability of this belief, exact analysis has shown that the very small amounts of these substances present are practically the same in both red and white meats, with the single exeeption of venison, which eontains them not, as would be surmised, in highest pereentage, but, in fuet, in lowest. Furthermore, these extractives are not eliminated as such, but as the normal ultimate product of metamorphosis, urea. It has been supposed, too, that the non-nitrogenous extractives (lactic, butyric, and acetic acids, ete.) are present to a greater extent in red than in white meats and may eanse disturbance; but as a matter of fact, these are present in extremely small amounts in both red and white meat, and cannot possibly be regarded as harmful, in view of the fact that appreciable amounts exert no influence on the system.

Composition of Meats.-In the following tables, showing the composition of the edible portions of meats, the figures given are taken, unless otherwise stated, from Bulletin No. 28 (revised edition) of the Office of Experiment Stations of the U. S. Department of Agrieulture : 'The Chemical Composition of Ameriean Foor Materials.'

${ }^{1}$ Government Printing Oflice, Washington, 1899. 
BEEF.

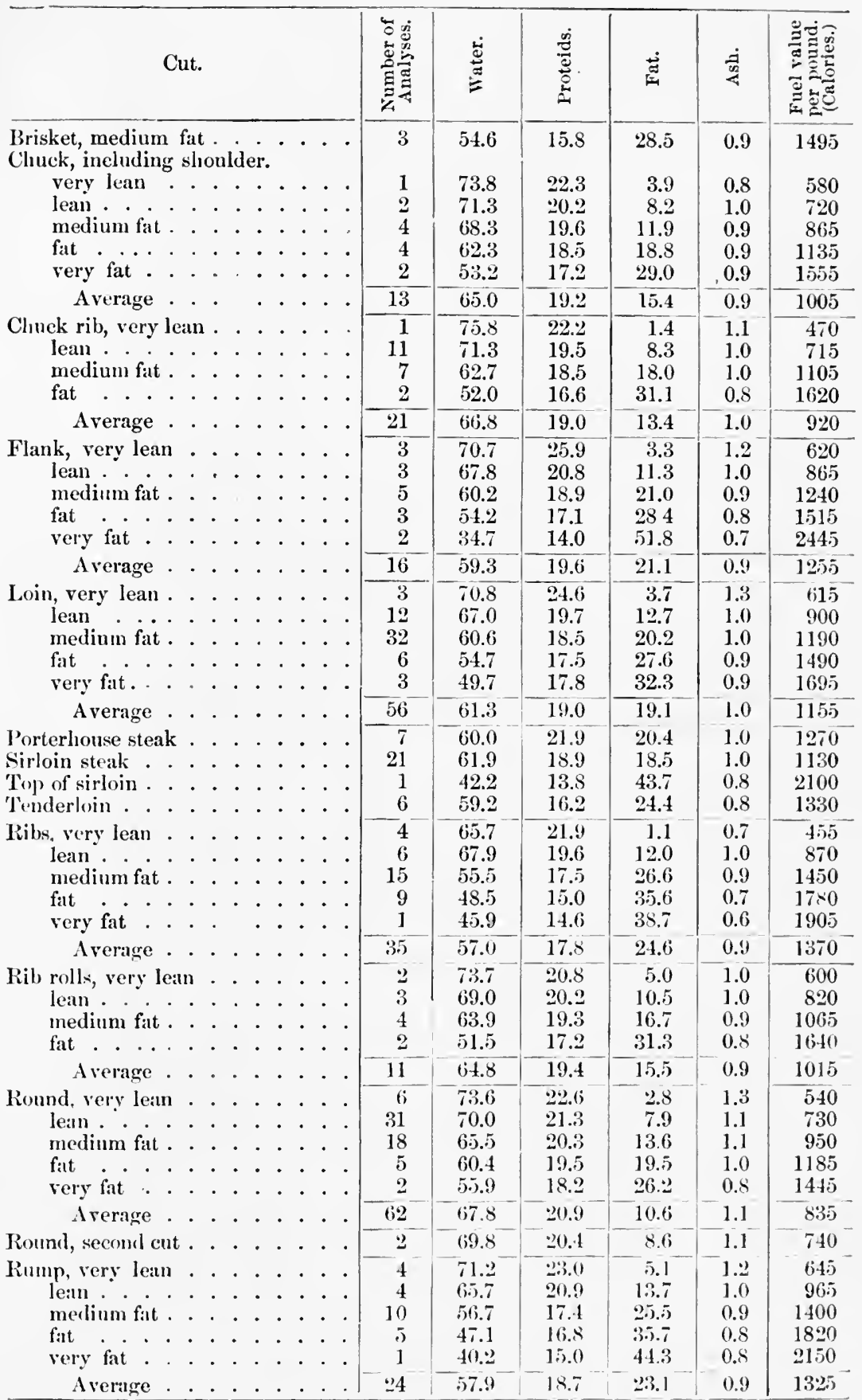


BEFF.-Continued.

\begin{tabular}{|c|c|c|c|c|c|c|c|}
\hline Cut. & & 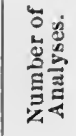 & 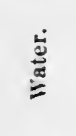 & & $\underset{\pi}{*}$ & $\frac{5}{\frac{5}{4}}$ & 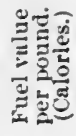 \\
\hline Beef heart & . . & 2 & 62.6 & 16.0 & 20.4 & 1.0 & 1160 \\
\hline Kidney (earbolyydrates 0.4) & . . & 3 & 76.7 & 16.6 & 4.8 & 1.2 & 520 \\
\hline Liver (earbohydrates 1.5 ). & . & 6 & 71.2 & 20.7 & 4.5 & 1.6 & 605 \\
\hline Narrow . . . . & . . & 1 & 3.3 & 2.2 & 92.8 & 1.3 & 3955 \\
\hline Tongue . . . . . & . . & 3 & 70.8 & 18.9 & 9.2 & 1.0 & 740 \\
\hline Lungs . . & . . & 1 & 79.7 & 16.4 & 3.2 & 1.0 & 440 \\
\hline Snet . . & . . & 9 & 13.7 & 4.7 & 81.8 & 0.3 & 3540 \\
\hline Roast beef (cut not specified) & & 7 & 48.2 & 22.3 & 28.6 & 1.3 & $16: 20$ \\
\hline Sirloin steak, baked. . . & . & 1 & 63.7 & 23.9 & 10.2 & 1.4 & 875 \\
\hline Broiled tenderloin . & & 6 & 54.8 & 23.5 & 20.4 & 1.2 & 1300 \\
\hline Ronud steak . . . . & & 18 & 63.0 & 27.6 & 7.7 & 1.8 & 840 \\
\hline Canned corned beef & ${ }^{\circ}$ & 15 & 51.8 & 26.3 & 18.7 & 4.0 & 1280 \\
\hline Canned roast beef. & & 4 & 58.9 & 25.9 & 14.8 & 1.3 & 1105 \\
\hline Canned whole tongue & & 5 & 51.3 & 19.5 & 23.2 & 4.0 & 1340 \\
\hline Canned tripe. . . . & & 2 & 74.6 & 16.8 & 8.5 & 0.5 & 670 \\
\hline Corned beef (all cuts) & $\cdot$ & 10 & 53.6 & 15.6 & 26.2 & 4.9 & 1395 \\
\hline Tongues, pickled & & 2 & 62.3 & 12.8 & 20.5 & 4.7 & 1105 \\
\hline Tripe (earbohydiates 0.2 ) & & 4 & 86.5 & 11.7 & 1.2 & 0.3 & 270 \\
\hline
\end{tabular}

PORK.

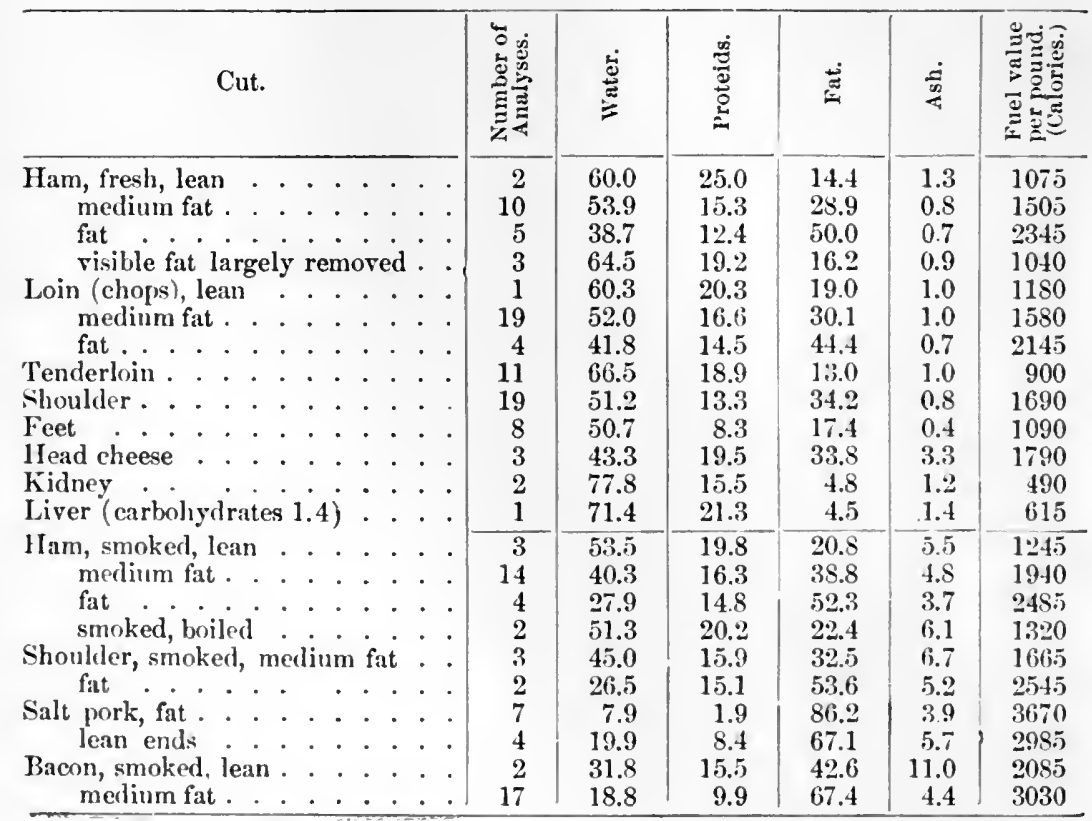


VEAL.

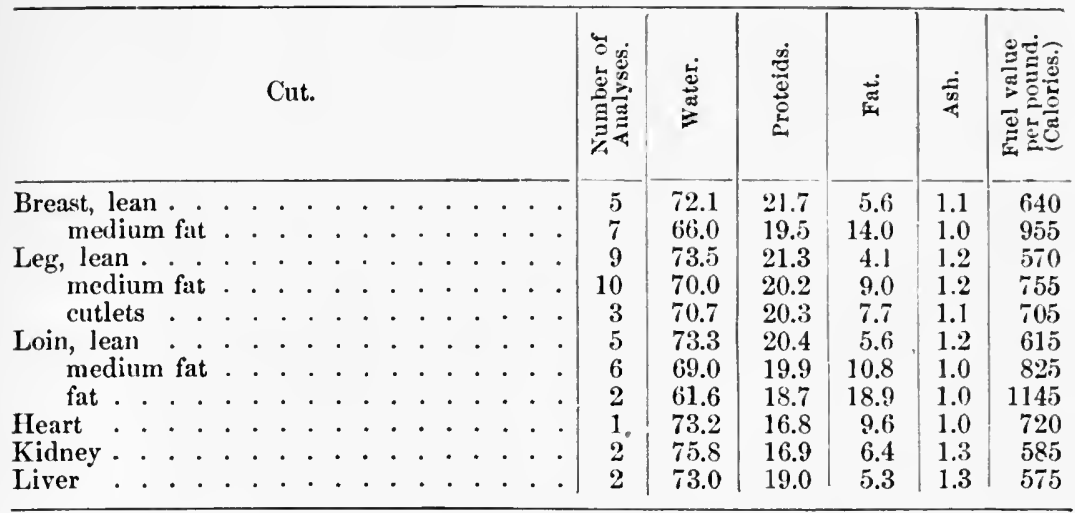

MUTTON.

\begin{tabular}{|c|c|c|c|c|c|c|}
\hline Cut. & 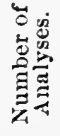 & 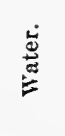 & 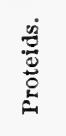 & 芯 & $\frac{\pi}{2}$ & 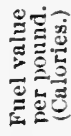 \\
\hline Hind leg & 3 & 67.4 & 19.8 & 12.4 & 1.1 & 890 \\
\hline & 11 & & & 1 & 1.0 & 1105 \\
\hline $\mathrm{fa}$ & 1 & 55 & 17 & 27 . & 0.9 & 1465 \\
\hline Loin, medium fat without kidney and tallow . & 13 & 50 & 16.0 & 33.1 & 0.8 & 1695 \\
\hline fat without kidnev and tallow & 3 & 4 & & 41 & 0. & 2035 \\
\hline without kidney and tallow & 1 & 30 & 1( & 58 & $0 . \overline{5}$ & 2675 \\
\hline Fore quar & 10 & $5 \%$ & & 30 & 0. & 1595 \\
\hline Hind av 1 & 10 & 54 & 1 & 28 & 0 & 1495 \\
\hline Roast leg, cooked & 2 & 50 & 25 & 22.6 & 1.2 & 1420 \\
\hline & 1 & 69 & 10 & 12.6 & 0 & 845 \\
\hline$r$ (carbohydrat & 2 & 61.2 & 23.1 & 9.0 & 1.7 & 905 \\
\hline
\end{tabular}

LAMB.

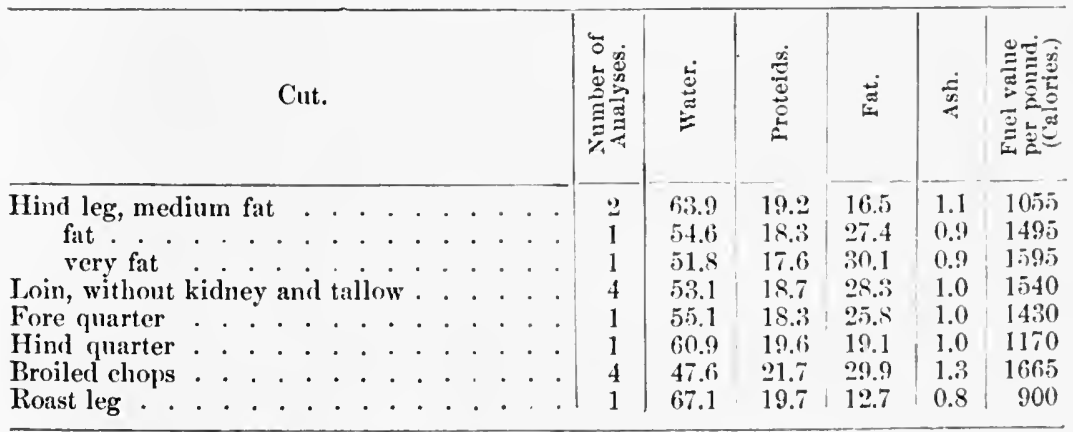


POULARY.

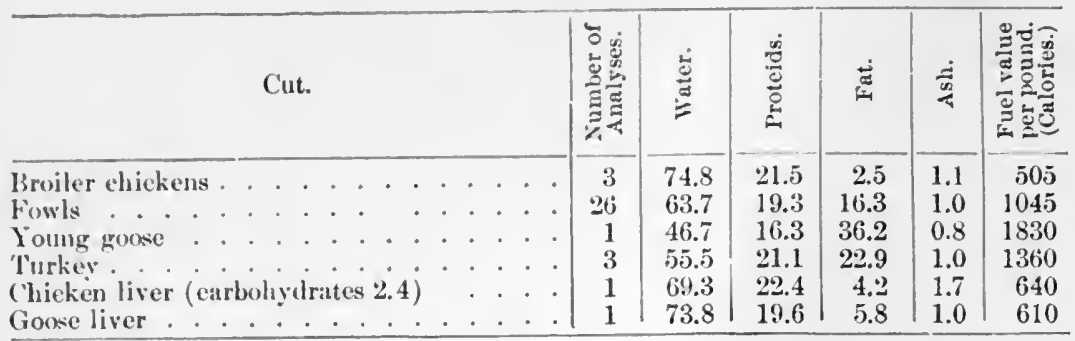

Horse Meat.-The mean of twelve analyses of horse meat as given by König ' is as follows:

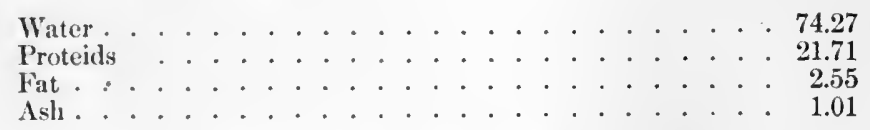

The objection to the use of horseflesh as food is very largely sentimental. It has not the pleasant flavor of beef, to which we are accustomed, but when eaten in ignorance of its true character, it makes no umpleasant impression. Its use is inereasing steadily in Europe, and is finding favor in America. In Paris, during 1898, 21,667 horses, 52 mules, and 310 donkeys were slanghtered for food, and of these but 734 horses, 1 mule, and 7 donkeys were condemned as unsalable. The meat was disposed of in 193 shops, where the best euts brought about a frane ( 19.3 cents), and the inferior parts 10 centimes ( 2 cents) per pound. In $1910^{2}$ the annual amount of horse and mule meat consumed in Paris had increased threefold, reaching the sum of 29,700,000 pounds and representing about 61,000 animals.

During 1896, 822 horses and mules were slaughtered in Strassburg, and in 1898 the number rose to 1099 . In Vienna, where the sale of the meat was permitted first in 1854, there were slaughtered, in $1899,25,646$ horses and 58 donkeys. In the whole of Prussia, there were slanghtered, in 1897 , at 367 abattoirs, 58,484 horses, and in the following year the number rose to 63,531 . In Frankfort, where, in 1847 , the first horse-meat dinner ever given occurred, about a thousand horses are slaughtered annually, at a special abattoir. In the United States, luring 1899, 3,232 horses were slanghtered and officially inspected with other food animals.

It is said that, anless the fat of some other animal or some starehy food is eaten with it, hore meat may canse diarrhœa. Whatever causes this disturbance is soluble in witer, and may thus be removed partially when the meat is boiled. From water in which horse-meat had been boiled, E. Pflïger ${ }^{3}$ separated jecorin, lecithin, and (probably) neurin. He reeommends the addition of about 25 grams of beef or

1 Tusammensetzung der mensehlichen Nahrungs- und Genussmittel, Berlin, 1882.

"U. S. Daily Consular and Trate Reports, Nov. 1, 1910, p. 420.

3 Archiv für die gesammte Physiologie, 1900, Bd. 80, p. 111. 
mutton kidney-fat to each kilogram of the meat when a mince is to be made, and that, in whatever form is is consumed, it be served with a fat gravy.

Meat Preparations.-Meat Extracts.-These are preparations which are supposed often erroneously to contain all the nutritive parts of the meats from which they are made, but they are to be regarded as stimulants rather than foods, since they represent the extractives and not the substances which determine the true food value. In point of fact, so far as their nutritive properties are concerned, it has been shown that animals will die more quickly of starvation when fed exclusively upon these stimulating preparations than when éntirely deprived of food. 'They are, however, of considerable value in their proper place, particularly in conditions of great fatigue and exhaustion.

Meat Powder.-Meat may easily be treated so as to retain all of its nutriment and yet have a very much diminished volume. The lean parts are cut into small strips, dipped for a few minutes into very hot fit (friel), drainel, and then slowly dried in an oven. When completely dry, they are ground in an ordinary spice mill or coffee mill to a fine powder, which keeps well, has an agreeable taste and a pleasant odor, is digested easily, and may be used in a great many different ways.

Sausages.-Sausage is understood generally to mean an article of fool consisting chicfly of finely chopped meat, mainly pork and beef, with or without the addition of a small amount of meal, highly seasoned with spices, herbs, and other flavorings, and stuffed into casings made from cleaned and prepared intestines. Their nutritive value is, therefore, about the same as that of average meat. As may be supposed, the best euts of meat are not used in their manufacture, but only such parts as cannot be disposed of in pieces of fair size and of attractive appearance. But there are sausages and sausages. There are those made from meat of good quality and others from materials which would not be salable in any other form.

Many of the so-called Frankforters, sold at very low rates, and the cheap Bolognas are said to consist largely of horse meat, immature veal, and the flesh of eows that are no longer in eondition to produce milk. Certain it is that a not inconsiderable number of persons gain a fair livelihood by going about in the country buying up newly boru calves and decrepit cows, tuberenlous and otherwise, and horses, and that these animals are not taken to comfortable stables and inviting pastures, but to small slaughtering establishments, the output of which is not very largely butchers' meat. 'To the cheap grades of sansages the saying of Jean Paul, "Only a god ean eat sausage, for only such can know of what it is made," applies very aptly. Even sausages made from pork, especially those which have undergone a proeess of cooking before being stuffed, are not always beyond suspicion, for the trichinous pork condemned by government inspectors at public abattoirs is neither destroyed nor converted into fertilizers, but is allowed to be sold after being subjected to a heat sufficient to kill the parasites; and cooked pork is not commonly to be found on sale as such. 
Horse meat is said to combine two advantages in the preparation of sausage: it is inexpensive, and it lends a firmness which inereases as the sausage is boiled. A number of chemical processes have been proposed for its detection, and among them the following: Dr. Nötel ${ }^{1}$ covers coarsely chopped horsemeat with a 0.1 per cent. solution of sodium hydroxide, lets the mixture stand 3 hours at $37^{\circ} \mathrm{C}$., and then separates the liquid through cheese cloth. The liquid is injected, in doses of 8 to $10 \mathrm{cc}$., subcutaneously into a rabbit at intervals of 2 or 3 days until 10 or 12 injections have been given. Six days after the list injection, the animal is bled and its serum serves as a reagent. The suspeeted food is chopped finely, covered with 0.1 per cent. sodium hydroxide, allowed to stand 2 hours in a warm room, and filtered. A few drops of the filtrate are mixed in a test-tube with about an equal amount of the serum, and other tubes containing filtrate alone are used as controls. The tubes are incubated at $37^{\circ} \mathrm{C}$, and if the suspected article contains lorsemeat, the tubes containing the serum will become cloudy in from 10 to 40 minutes.

A number of tests which depend upon the reaction of iodine with glyeogen, which is a normal constituent of horsemeat, are criticised by Niebel ${ }^{2}$ as uncertain, on account of the presence of glycogen in liver, meat extract, and very young veal.

A recent and more reliable test for horse meat has become possible through the studies of Ehrlich and his pupils ${ }^{3456}$ upon immunity. If, for example, a rabbit be inoculated with the blood serum of a horse or other alien animal, the serum of the rabbit acquires, after a time, a property, by reason of which a specific precipitation occurs when an extract of horse meat is mixed with it. This test method has been further developed hy Wassermann and his pupils, and can be applied with success to other kinds of meat. The differentiation of meat of closely allied species, however, such as that of sheep and goats, is said to be at times quite difficult.

In the manufacture of all grades of sausage, scrupulous care should be observed to secure cleanliness of the casings, which require more thorough treatment than the mere passage of water through them. Dr. Schilling ${ }^{7}$ reports the examination of prepared intestines which yielded 5 grams of excrement per meter.

Owing to the occurrence of a gray color, which is said by Meyer ${ }^{8}$ to

1 Teitschrift für Hygiene und Infectionskrankheiten, XXXIX., p. 373.

2 Zeitschrift für Fleish- und Milchhygiene, 1895, p. 86.

3 Schütze, A., Ueber weitere Anwendungen der Präcipitine. (Deutsch. med. Woch., 1902, No. 45, p. 804.)

4 Wassermann, A., u. Schütze, A., Ueber die Fntwickelıng der biologischen Methode zur Unterscheidung von menschlichem und tierschem Eiweiss mittels Prïcipitine. (Ibid., 1902 , No. 27 , p. 483. )

5 Wassermann, A., Ueber Agglutinine und Pricipitine. (\%eits. f. Hyg., etc., Bd. 42, 1903,2, p. 267.)

- Uhlenhuth, Die Unterseheidung des Fleisches verschiedener Tiere mit Hilfe spezifische Sera und die praktische Anwendung der Methode in der Fleischbeschau. (Deutseh. Med. Woch., 1901, No. 45, p. 780.)

${ }^{7}$ Deutsche medicinische Wochenschrift, 1900, p. 602.

${ }^{8}$ Chemiker Zeitung, 1900 , p. 3 . 
we due to the passage of salt by diffusion from the contents to the casing, which is rich in water and poor in salt, the eommereial value of certain varieties of sausage is impaired, and hence it becomes necessary to apply artifieial colors, or so to treat the stuffing that the change in color shall not oceur. The very red appearance which so often suggests the presence of eal-tar products may be due to the action of harmless preservatives, like niter, or the hæmoglobin of swine blood. In such ease, the extruet with alcohol, glycerin, or amyl alcohol will not dye wool, and the color cannot be precipitated as a lake.

Aceording to J. Haldane, ${ }^{1}$ the red color of eooked salted meats is due to the presence of NO-hamochromogen produced by the decomposition of NO-hrmoglobin, which is formed by the action of a nitrite on the NO-hremochromogen in the absence of oxygen and presence of redueing agents. The nitrite is formed by reduction, within the raw meat, of the niter used in salting.

Certain of the artificial sausage colors, as "Orange II.," the sodium salt of $\beta$-naphtholazobenzene, are extracted easily with acidulated water, and will dye woolen fibers immersed therein.

\section{FISH.}

In the ordinary sense of the word, fish includes, in addition to the varieties of fish in its narrow sense, mollusks (clams, oysters, mussels, ete.) and crustaceans (lobsters, erabs, crawfish, and shrimps).

Many prejudices have existed from the earliest times, and to a certain extent still exist, against the use of fish in the diet. 'The ancient belief that a fish diet is a common cause of leprosy still obtains to a certain extent, even among enlightened people, in spite of all scientific evidence to the contrary. Thus, Mr. Jonathan Hutehinson ${ }^{2}$ maintains that this disease is so caused, especially if the fish is poorly cooked or partially decomposed. He asserts that the elisense prevails near the sea and is disappearing before the advance of agrieulture; but opposed to this is the fact that, in the interior of India, the disease is very common among people whose religion forbits the use of fish, and who cannot obtain it even if it were desired.

Some varieties of fish cannot be eaten, becanse of their inherent poisonous properties. But few of these are, however, found north of the tropics. Some of them are always poisonous, and others only at certain times; and in some cases, individuals of certain species may be and others may not be noxions. Some varieties of fish are the liosts of parasites, some of which are injurious to man, but unless eaten in the raw state they are not likely to produce harm.

There is a belief that fish is partieularly valuable as a brain food, on account of the supposed high percentage of phosphorus that it contains. The amount of phosphorus is, however, so far as is known, no higher in fish than in meat and, moreover, this element is no more esiential to the brain and nervous system than any others which are present.

1 Journal of Itygiene, 1901, Vol. I., p. 115.

2 Archives of Surgery, April, 1899. 
If there were any truth in this eommon belief, we should expect naturally to find men of commanding intellect anong those whose dict consists mainly of fish, but, as is well known, such people are of a low order of intelligenee, though not by reason of their diet.

In spite of the large amount of mutriment contained, fish has not the same sitisfing properties that belong to meats, but it is an exceedingly valuable food, and in many parts of northern countries is the principal animal food. The flavor of fish is influenced greatly by the nature of the fool supply and by the content of fat. Generally speaking, salt-water fish from deep water, where the current is strong, are better than those from shallow, warm, and quiet water, and both saltwater and fresh-water fish taken from rocky and sandy bottoms are preferred to those from middy bottoms.

Condition is dependent upon a variety of circumstances. Some fish are regarded most highly during their spawning season (shad and smelts), while others are looked upon with disfivor at this period. Fish caught by the gills in gill nets die slowly, but decompose rapidly, and such are of inferior flavor and value. Fish taken from the water alive and killed at once remain firm and retain their flavor longer than those allowed to die slowly.

Digestibility. - So far as is known, the digestibility of fish and meat is about equal, but, as is true of meats, different varieties of fish are diff'rently digestible. 'Thus, those which contain the greatest percentages of fat, as salmon, eels, and mackerel, are the most difficult of digestion. The processes of drying, smoking, salting, and pickling lessen digestibility, and fish so treated are, in consequence, less suited to the needs of invalids and dyspeptics. The mollusks are regarded generally as most digestible, while the crustaceans are believed to tax the digestive powers much more than any other animal food. Many persons are unable to digest them in any form, and others who suffer no ineonvenience, so far as digestion is concerned, are obliged to practise self-rlenial, becutuse of idiosyncrasy, which manifests itself in distressing eruptive disorders of the skin, dizziness, and other nervous symptoms. Lobster and crabs are mnel alike, but the former is less likely to disagree. The claws of the lobster are more tender and delieate than the tail, which is firmer and much closer grained. Shrimps are rated generally as more difficult of digestion than lobsters and crabs, but with many they are borne more easily.

'The mollusks are more digestible in the raw state than when cooked. The comparatively tongh part of the oyster, the adductor muscle, is very trying to some persons, and for such it is best removed and rejected.

Keeping Qualities.-Fish flesh differs very greatly from meats in keeping qualities. While the latter are improved up to a certain point by hanging, fish should be eaten while fairly fresh, since decomposition sets in very quickly. Some varieties, as halibut, cod, haddock, and turbot, may be kept a week or more when properly eared for, while others begin to deteriorate almost immediately. So long as the flesh 
is firm and stiff, all fish is edible, but when it is crushed readily by gentle pressure between the fingers, it is unsound and should be rejeeted. Mollusks and erustaceans decompose very quickly, and the latter when boiled a short time after natural death have but little flavor.

The average ehemical eomposition of the edible portions of many varieties of American fish is given in the following table, eompiled from Bulletin No. 28 (Revised Edition), U. S. Department of Agrieulture, Office of Experiment Stations:

\begin{tabular}{|c|c|c|c|c|c|}
\hline Food Materials. & Water, & $\begin{array}{l}\text { Protcin } \\
\mathrm{N} \times 6.25\end{array}$ & Fat. & Ash. & $\begin{array}{c}\text { Fuel } \\
\text { value per } \\
\text { pound. }\end{array}$ \\
\hline Fresh Fish. & Per et. & Per ct. & Per ct. & Per ct. & Calor. \\
\hline Bass, striped . . . . . . . . . . & 77.7 & 18.6 & 2.8 & 1.2 & 465 \\
\hline Blackfish. . . . . . . . & 79.1 & 18.7 & 1.3 & 1.1 & 405 \\
\hline ........ & 78.5 & 19.4 & 1.2 & 1.3 & 410 \\
\hline Buffalo fish. . . . . . . . & 78.6 & 18.0 & 2.3 & 1.2 & 430 \\
\hline Butter-fish . . . & 70.0 & 18.0 & 11.0 & 1.2 & 800 \\
\hline Catfish . . . . . & 64.1 & 14.4 & 20.6 & .9 & 1135 \\
\hline ....... & 74.0 & 18.5 & 6.8 & 1.1 & 630 \\
\hline Cod, whole . . . . . . . . . . & 82.6 & 16.5 & .4 & 1.2 & 325 \\
\hline ....... & 82.5 & 16.7 & .3 & .9 & 325 \\
\hline Cusk ..... . & 82.0 & 17.0 & .2 & .9 & 190 \\
\hline Eels, salt water . . . . . . . & 71.6 & 18.6 & 9.1 & 1.0 & 730 \\
\hline Flonnder . . . . . . . . . . . & 84.2 & 14.2 & .6 & 1.3 & 290 \\
\hline Haddock. . . . . . . . . & 81.7 & 17.2 & .3 & 1.2 & 335 \\
\hline . . . . . . . & 83.1 & 15.4 & .7 & 1.0 & 315 \\
\hline ........ & 75.4 & 18.6 & 5.2 & 1.0 & 565 \\
\hline .............. & 72.5 & 19.5 & 7.1 & 1.5 & 660 \\
\hline ............... & 79.2 & 18.9 & .9 & 1.2 & 390 \\
\hline ............. & 71.1 & 15.0 & 13.3 & .7 & 840 \\
\hline ........... & 73.4 & 18.7 & 7.1 & 1.2 & 645 \\
\hline ........ & 74.9 & 19.5 & 4.6 & 1.2 & 555 \\
\hline Muskellunge. . . & 76.3 & 20.2 & 2.5 & 1.6 & 480 \\
\hline Perch, white. . . . . . & 75.7 & 19.3 & 4.0 & 1.2 & 530 \\
\hline Perch, pike (wall-eyed pike) . . . . . & 79.7 & 18.6 & .5 & 1.4 & 365 \\
\hline Pereh, yellow. . . . . . . & 79.3 & 18.7 & .8 & 1.2 & 380 \\
\hline Pickerel, pike . . . . . . . . & 79.8 & 18.7 & .5 & 1.1 & 370 \\
\hline like, gray. . . . . . . & 80.8 & 17.9 & .8 & 1.1 & 365 \\
\hline ......... . & 76.0 & 21.6 & .8 & 1.5 & 435 \\
\hline Pompano. . . . . . . . . & 72.8 & 18.8 & 7.5 & 1.0 & 665 \\
\hline P'orgy . . . . . . . . . . & 75.0 & 18.6 & 5.1 & 1.4 & 560 \\
\hline Red grouper. . . . . . . . . . & 79.5 & 19.3 & .6 & 1.1 & 385 \\
\hline Red snapper. . . . . . . . . . . & 78.5 & 19.7 & 1.0 & 1.3 & 410 \\
\hline Salmon, whole $\ldots$ & 64.6 & 22.0 & 12.8 & 1.4 & 950 \\
\hline Silmon, landlocked, whole, spent . . & 77.7 & 17.8 & 3.3 & 1.2 & 470 \\
\hline Salmon, California, anterior sections . & 63.6 & 17.8 & 17.8 & 1.1 & 1080 \\
\hline Shad . . . . . . . . & 70.6 & 18.8 & 9.5 & 1.3 & 750 \\
\hline Sheepshead . . . . . . . . & 75.6 & 20.1 & 3.7 & 1.2 & 530 \\
\hline Skate, lobe of body . & 82.2 & 18.2 & 1.4 & 1.1 & 400 \\
\hline Smelt . . . . . . & 79.2 & 17.6 & 1.8 & 1.7 & 405 \\
\hline Spanish mackerel . . : . . . . & 68.1 & 21.5 & 9.4 & 1.5 & 795 \\
\hline Sturgeon, anterior sections . . . . . & 78.7 & 18.1 & 1.9 & 1.4 & 415 \\
\hline Tomeod . . . . . . . . & 81.5 & 17.2 & .4 & 1.0 & 335 \\
\hline Trout, brook . . . . . . . & 77.8 & 19.2 & 2.1 & 1.2 & 445 \\
\hline Trout, salinon or lake . . . . . & 70.8 & 17.8 & 10.3 & 1.2 & 765 \\
\hline 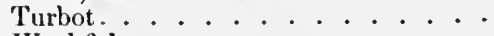 & 71.4 & 14.8 & 14.4 & 1.3 & 885 \\
\hline Weakfish . . . . . . . & 79.0 & 17.8 & 2.4 & 1.2 & 430 \\
\hline Whitefish . . . . . . & 69.8 & 22.9 & 6.5 & 1.6 & 700 \\
\hline
\end{tabular}




\begin{tabular}{|c|c|c|c|c|c|c|}
\hline Food Materials. & 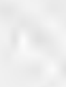 & Water. & $\begin{array}{l}\text { Protein } \\
\mathrm{N} \times 6.25\end{array}$ & Fat. & Ash. & $\begin{array}{l}\text { Fuel } \\
\text { value per } \\
\text { pound. }\end{array}$ \\
\hline Fish, Preserved and Canned. & & Per ct. & Per ct. & Perct. & Per ct. & Calor. \\
\hline Cod, salt. . &. & 53.5 & 25.4 & .3 & 24.7 & 410 \\
\hline Cod, salt, "boneless" & . . & 55.0 & 27.3 & .3 & 19.0 & 490 \\
\hline Haddoek, smoked . . & . & 72.5 & 23.3 & .2 & 3.6 & 440 \\
\hline Halibut, smoked & . . . & 49.4 & 20.7 & 15.0 & 15.0 & 1020 \\
\hline Herring, smoked & . . . & 34.6 & 36.9 & 15.8 & 13.2 & 1355 \\
\hline Lamprey, canned. & . . & 63.3 & 16.9 & 12.2 & 4.0 & 895 \\
\hline Mackerel, salt . & $\therefore$ & 42.2 & 21.1 & 22.6 & 13.2 & 1345 \\
\hline Mackerel, salt, eanned in oil. . & . & 58.3 & 25.4 & 14.1 & 4.1 & 1065 \\
\hline Mackerel, salt, dressed . . . . . . & . . & 43.4 & 17.3 & 26.4 & 12.9 & 1435 \\
\hline Minogy, pickled, canned . . . . . & . . & 56.5 & 22.0 & 18.6 & 3.0 & 1195 \\
\hline Salmon, canned. . . . . . . & 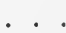 & 63.5 & 21.8 & 12.1 & 2.6 & 915 \\
\hline Sardines, canned & . . & 52.3 & 23.0 & 19.7 & 5.6 & 1260 \\
\hline Sturgeon, dried, Russia. & . . . & 50.6 & 31.8 & 9.6 & 7.6 & 995 \\
\hline Trout, brook . . . . & . . & 68.4 & 22.3 & 6.1 & 3.7 & 670 \\
\hline Tunney, canned in oil, Russia. & $\cdot \cdot$ & 51.3 & 23.8 & 20.0 & 4.3 & 1300 \\
\hline Shellfish, Fresh and Canned. & & & & & & \\
\hline Clams, long, in shell . . . & & 85.8 & 8.6 & 1.0 & 2.6 & 240 \\
\hline Clams, long, canned & . & 84.5 & 9.0 & 1.3 & 2.3 & 275 \\
\hline Clams, round, in shell . . . . . & . . & 86.2 & 6.5 & .4 & 2.7 & 215 \\
\hline Clams, round, canned . . . . . & . . & 82.9 & 10.5 & .8 & 2.8 & 285 \\
\hline Crabs, hard shell . . . . & • & 77.1 & 16.6 & 2.0 & 3.1 & 415 \\
\hline Crabs, canned. . . . . . & . . & 80.0 & 15.8 & 1.5 & 2.0 & 370 \\
\hline Crayfish, abdomen. . . . & . & 81.2 & 16.0 & .5 & 1.3 & 340 \\
\hline Lobster & . & 79.2 & 16.4 & 1.8 & 2.2 & 390 \\
\hline Lobster, canned . . & . & 77.8 & 18.1 & 1.1 & 2.5 & 390 \\
\hline Mussels, in shell. & • & 84.2 & 8.7 & 1.1 & 1.9 & 285 \\
\hline Oysters, in shell. . . . - & 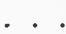 & 86.9 & 6.2 & 1.2 & 2.0 & 235 \\
\hline Oysters, canned. & 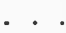 & 83.4 & 8.8 & 2.4 & 1.5 & 335 \\
\hline Shrimp, canned. . . . & . . & 70.8 & 25.4 & 1.0 & 2.6 & 520 \\
\hline Terrapin . . . . . . & . & 74.5 & 21.2 & 3.5 & 1.0 & 545 \\
\hline Turtle, green . . . . . . . & . . & 79.8 & 19.8 & .5 & 1.2 & 390 \\
\hline
\end{tabular}

Composition.-In proteids, fish rank nearly as high as meats, but they are very much poorer in fat, only a few varieties yielding over 10 per' cent. These include salmon, turbot, lamprey eels, eels, butterfish, lake tront, and herring, and are followed by shad and Spanish mackerel, with over 9 per cent. The great majority of species contain less than 5 per cent., and many of the commoner kinds even less than 1 per cent. In faet, most fish flesh yields more mineral matter than fat. Shellfish are fuirly rich in proteids and eontain notable amounts of carbolydrates, but they are very poor in fat.

\section{Meat and Fish and Parasitic Disease.}

Man is often the host of parasites through ingestion of infested meat and fish. Of these, the most common is the tapeworm, of which at least ten species are known, though only three have been demonstrated as having any conncetion with food. These are Trnia saginata (T. mediocanellata) due to measly beef, Tienia solim to measly pork, and Bothriocephalus latus to infested sturgeon, pike, pereh, and salmon. 
The latter is very rare in this country, though not uneommon along the Baltic. Of the large number of worms which infest fish, this is the only one known to be eonveyed to man. It is killed very quickly if the fish is cooked properly.

The larval forms of $T$. saginata and $T$. solium exist in beef and pork respeetively as Cysticereus bovis and C. cellulosæ. The latter is found rarely also in mutton. Meats infested with these forms are known as "measly" or "measled," and the animals from which the meats are derived are known as the intermediate hosts, man being the final host. The life history of the tapeworm is much more simple than that of many other parasites. Beginning with the adult tapeworm in man, the eyele is as follows: From each individual segment, which is possessed of a eomplete reproduetive system, great numbers of eggs are diseharged. The latter are expelled from the intestine with the feees, and some of them eventually may enter the digestive tract of cattle or swine through the food or water. In the intestine, the embryos beeome liberated from the eggs, and they then make their way in large numbers to the museular tissues, brain, liver, and other parts, where they come to rest and develop as bladder worms. The bladders are variable in size, the smallest being about $\frac{1}{25}$ inch, and the largest about $\frac{3}{4}$ inch across, and, in the flesh, are embedded between the museular fibers. The living animal shows nothing in its appearance to indicate the presence of the parasite, excepting when the eyst ean be seen in the under side of the tongue or between the tongue and the lower jaw. If now the animal is slaughtered and the meat is eaten raw or imperfectly cooked, the Cysticercus is freed from its enveloping eapsule and proceeds to develop into an adult tapeworm, and the eyele is complete. The Cysticerens bovis dies within two or three weeks after the slaughter of its lost, and, therefore, measled beef, kept for three weeks in cold storage, becomes ineapable of producing harmful effects. It is killed within 24 hours by piekling solutions of eommon salt, when brought into intimate eontact. The Cysticereus eellulosæ lives rather longer in eold storige: probably a month or more, Both of these larva are killed by exposure to a temperature of $140^{\circ} \mathrm{F}$. for 5 minutes, and as this is lower than the temperature in the interior of well-cooked meat, it is necessary only to make sure that the meat is properly cooked to eseape danger. Neither parasite is destroyed ly ordinary smoking or salting, but both are killed by lot smoking.

The sale of measled meat is pernitted in many eountries of Europe, but it must be sold as such and only in speeially designated places. It finds a ready market at a low price, and the purehasers are warned that it should be cooked thoroughly. Aceording to Virehow, since the introduction of systematic meat inspeetion, the proportion of tapeworm in the human subject dissected in Berlin has fallen from 1 in 31 to 1 in 280 .

A parasite of far greater importanee is the Trichina spiralis, which is found almost exelusively in pork and only oceasionally in the flesh of other mammals and of birds and frogs. Trichina are small, thread- 
like worms, much longer than one wonld suppose on passing examination of fairly thick mieroseopic preparations, since they are coiled with several turns within the minute oysts in which they are lodged. In Plate I., Fig. 1, is shown one of the parasites in the free state. In the pig the worm infests both the fat and the voluntary museles, but chiefly the latter, and especially the diaphragm, the intereostals, and the muscles of the jaw. When encapsulated in the flesh, their location may be evident to the naked eye as small white speeks. Thin sections of museles, treated a few minutes in weak caustic potash solution $(1: 10)$, are soon made sufficiently clear to reveal the coiled worm under a lens of low power. If very much fat is present or if the capsule has become calcareous and thick, it may be necessary to employ ether or acetic acid before applying the potash. When the parasites are very numerous, the flesh is both speckled and pale.

Our first knowledge of the serious effects which may result from eating infested pork dates back only to 1860 , although the parasite had been discovered in the museles of a human subject by Janes Paget in 1833 and named by Richard Owen. It long was regarded as a harmless parasite and curiosity, and its effects were mistaken for rheumatism, typhoid fever, and other diseases of common occurrence. The ense which finally revealed its eapacity for harm was that of a young woman admitted to the hospital at Dresden suffering, it was supposed, from typhoid fever. In a short time, a train of symptoms quite unlike those of that disease appeared, the most marked one being very acute pain involving the entire muscular system, and intensified on attempting to move. On account of the agony induced, extension of the arms and legs was quite impossible. Pneumonia supervened, and in a few days the vietim died. The autopsy revealed the parasite in vast numbers in the muscles, and this led to further investigation, which showed that, four days before the first symptoms of illness appeared, she had eaten freshly killed pork. Some of this was secured in the form of ham and sausage, and examination demonstrated the presence of the parasite.

The first extensive outbreak which eaused the disease to be looked upon as one of great importance occurred in Prussia in 1863, when more than 20 persons died within a month after a dinner in which 103 had participated, and at which smoked sausiges made from an infested pig had been served. The parasites were discovered in the muscles of those who died and in the sausages that remained. Since that time, it has been customary in most large slaughtering establishments to examine pork for evidence of the parasite, before passing it as fit for food. But examination is not atways a safeguard, even in countries where it is observed most earefully. In Germany, for instance, where all meats are supposed to be examined with serupulous care, particularly those from the United States, the disease is very common.

In 1883, on account of the alleged dangers which lurked in American meats, importation was interdieted for a time, but in the succeeding 15 years there were in Prussia alone 3,003 cases and 207 deaths, not one of which could be traced to American meat either salted, 


\section{PLATE I}

FIG. 1

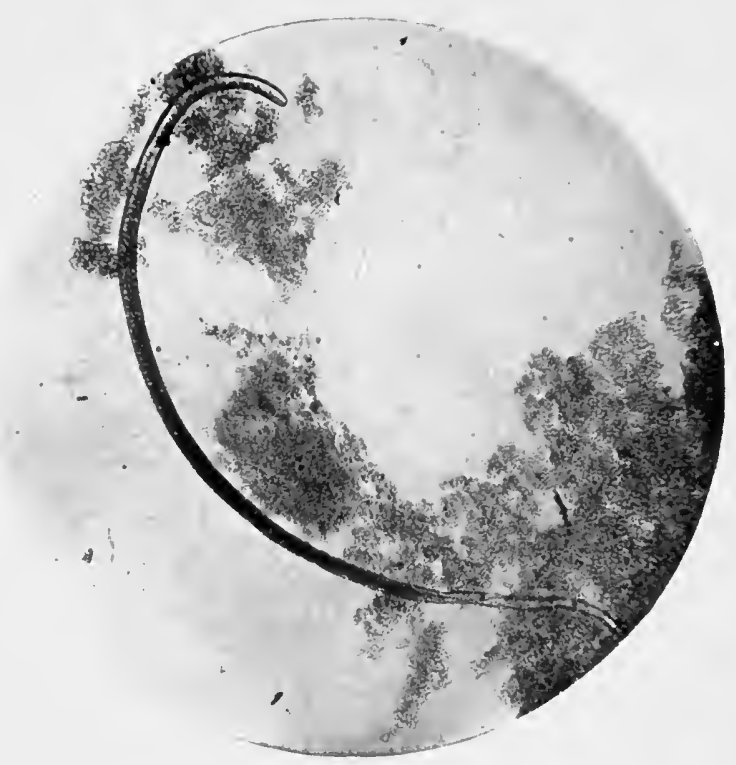

Free Trichina. $\times 38$

FIG. 2

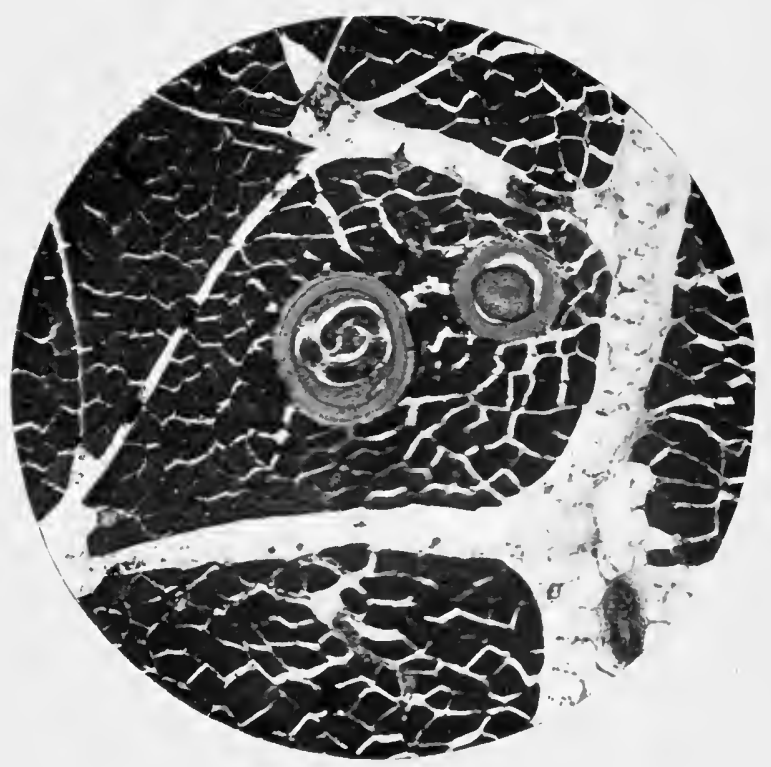

Triching in Pig Muscle. $\times 75$. 

pickled, eanned, or marle into smoked sausages. Over 40 per cent. of the cases were traced to European meat which had been passed as free from trichinæ, and the rest to European meat which had been found to contain the parasite, but had, nevertheless, been handled by the trade. During 1899, the parasites were found by the microscopists of the U. S. Department of Agriculture in 41,659 of t!e 2,227,740 hogs examined.

It is probable, as stated by Charles W. Stiles, ${ }^{1}$ who collected abcut 900 reported cases which had occurred in this country during the 36 years 1860-1895, that the disease is more common in the United States than generally is supposed. It is aceepted commonly that 1 or 2 per cent. of dissecting-room subjects show evidence of the parasite, but it would appear from the investigations of $H$. $U$. Williams ${ }^{2}$ that this estimate is much too low, for careful examination of 505 cadavers taken at random showed old eneapsulation and calcification in no less than 27 instances, or 5.34 per cent. The birthplaces of the subjects included all of the most important countries of Europe and North Ameriea, but the number of eases examined was too small to admit of aceurate conclusions as to the influence of nationality upon the frequeney of the disease. It is evident that many eases of trichinosis escape detection, and that, as Williams points out, estimates have ben based on naked-eye diagnosis.

In spite of the danger of eating trichinous meat, there are those who are not deterred by fear from eating it. In Germany, for instance, it has happened a number of times that hogs which have been condemned and ordered buried by the sanitary authorities have been dug up surreptitiously and eaten. ${ }^{3}$

'Trichinosis bears certain resemblances to typhoid fever' and to acute tubereulosis, but in addition is aceompanied by oedema and intense pain. It arises from eating the infested meat in a raw or not well cooked condition. The trichinx are killed by exposure to $155^{\circ} \mathrm{F}$, if they are not encipsulated ; otherwise by a temperature of $158^{\circ}$ to $160^{\circ}$. They are not affected by intense cold, putrefactive processes, nor ordinary smoking, but are killed by long piekling.

The first symptoms appear in a few days after ingestion, and indieate irritation of the alimentary canal. These are followed by fehrile symptoms and intense museular pains. Death may oceur within a few weeks. In case of recovery, the parasites become eneysted, and then are incapable of producing further injury to their host. The manner in which they produce their effects is as follows: When the infested meat reaches the stomach, the digestive juices dissolve the capsules, and the parasites thus are left in a fiee state. In the intestine, they find eonditions favorable to growth, and in a few days' time they grow so large that they ean be scen with the naked eye and alppear like fine tlureads.

1 Philadelphia Medical Journal, June 1, 190 l.

2 Journal of Medical Researeh, July, 1901, p. 64.

3 For an account of such a case consult Zeitschrift für Fleisch- und Milchlygiene, 1897, VII., p. 104. 
The female parasites when fully mature begin to produce young, each to the extent of upward of 500 . 'These begin at once a migration through the walls of the intestine and find their way to all parts of the body, and it is during this stage that the fever and intense pain are caused.

W. G. 'Thompson, ${ }^{1}$ as a result of observation upon 52 cases in his personal practice, believes that the differential diagnosis can easily be made if the following points are observed:

1. Acute onset usually with vomiting and abdominal cramps.

2. A high grade of eosinophilia invariably present; usually above 30 per cent. and frequently much higher - even above 80 per cent.

3. A high grade of temperature, often reaching $104^{\circ} \mathrm{F}$. or more, and lasting, in lessening degree, for two to six weeks.

4. Puffiness of the cyelids and face, with pains in the eyes occurring in one-fourth of the cases.

5. Dyspnœa and diaphragmatic breathing occurring without cyanosis in about one-fourth of the cases.

6. The generalized musele pains, cramps, soreness, and prostration, causing sometmes deceptive apparent immobility.

7. The sudden oceurrence of symmetrical circumseribed corneal hemorrhages in a patient whose bloodvessels are not degenerated should give rise to a suspicion of trichinosis.

The examination of the blood for an increased number of eosinophiles is of the greatest importance. Furthermore, if a small piece of muscle be excised under local anesthesia, the parasites can be frequently discerned under low powers of the microscope. It is not, however, always possible to secure the consent of the patient to this minor operation. For this reason an observation, made recently by Herrick and Janeway, ${ }^{2}$ is of great interest. These investigators, following a method devised by Stäubli, ${ }^{3}$ in which method a small amount of blood is laked with 3 per cent. acetic acid, were able to detect the parasite in the circulating blood.

Cross $^{4}$ also was able to demonstrate the trichinella in the blood taken from an ordinary ear puncture. The patient was taken sick on August 17, 1909. On August 24th the diagnosis of trichinosis was made, largely becuse of a differential count, showing that 20 per cent. of the white corpuseles were eosinophiles. Excision of a piece of muscle could not be done, and on August 25th a blood examination was made. One cubie centimeter of blood was squeezed from the ear and laked with 12 cubic centimeters of 3 per cent. acetic acid. The sediment obtained by centrifuge was examined under low powers of the microscope. One trichinella was easily found and two others were seen with less distinetness.

1 American Journal of Medical Sciences, August, 1910.

${ }^{2}$ Archives of Internal Medicine, 1909, April, p. 263.

3 Stäubli, Klin. und exper. Untersuch. über Trichinosis. Verhandlung. des Kongress f. Klin. Med. Wiesbaden, 1905, 354. Beitrag zum Nachweis von Parasiten in Blut. Münch. Merl. Woch., 1908, 1v., 2601.

Archives of Internal Medicine, Sept., 1910. 


\section{PLATE II}

FIG, I

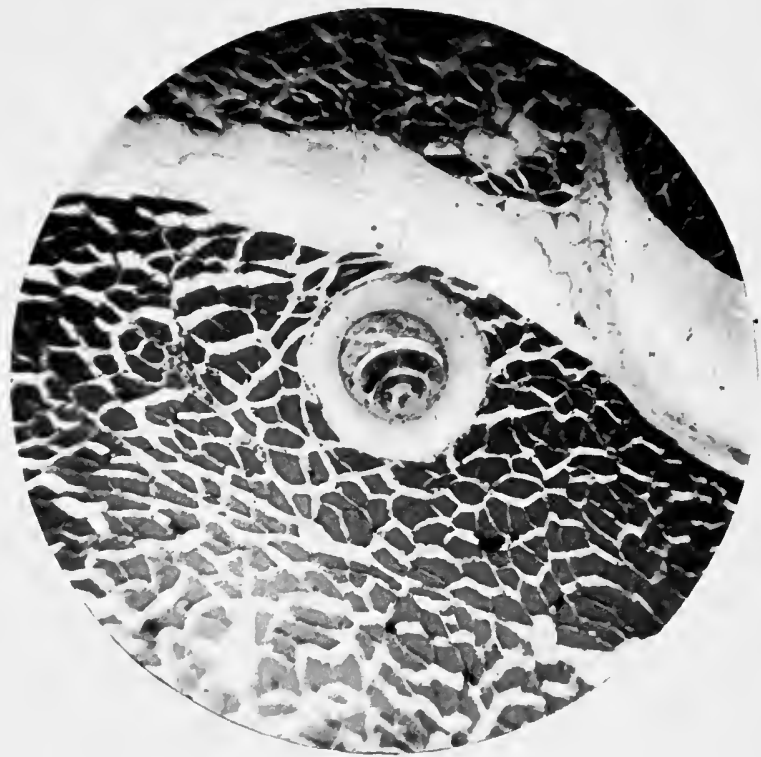

Trichinæ in Human Muscle, showing Thickened Capsule. $\times 75$.

FIG. 2

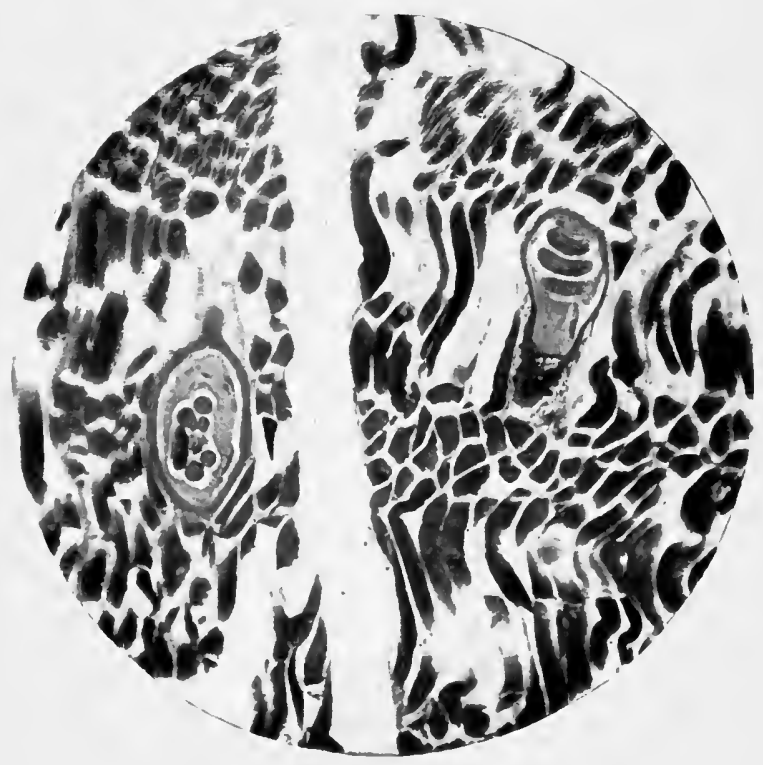

Trichinæe in Human Muscle. $\times 75$ 

In Plate I., Fig. 2, and Plate II., Fig. 1, are seen thin sections of muscle from a human subject, showing the worm coiled up and the thickened capsule formed about it. In Plate II., Fig. 2, it may be seen within the muscle of an infested pig.

The sheep disease which is known as rot, which term, it must be said, is used to include a large number of abnormal conditions, but which, in its strict application, means a parasitic disease of the liver, is believed by many to be of sufficient importance to warrant the condemnation of the flesh of the animal, but the seientifie evidenee on this point is to the effeet that no possible harm can come to the consumer, even though the liver itself be eaten. The parasite infests not alone sheep, but cattle as well, and is known as the "fluke." Of the many varieties of flukes, there are but two known in the United States; these are the common liver fluke (leberwurm, leberegel, schafegel, douve hépatique) and the large American fluke. The former infests cattle and sheep; the latter, only cattle.

The life history of the worm is exceedingly complicated, and is as follows: The adult or hermaphroditic worm fertilizes itself in the biliary passages of the liver, and produces an exceedingly large number of eggs, which pass to the intestine of the host with the bile, and are expelled in the feees. Such of the eggs as eventually reach water give rise after a longer or shorter period, according to temperature, to a eiliatel embryo, which on its escape from the egg beeomes a free swimming eiliated miracidium, and enters the body of eertain speeies of snails, where it eomes to rest. Here the organism grows, and, after a time, certain germ cells in its posterior portion develop a still different form of life, the ridiæ. These wander to the host's liver and inerease in size, and in turn develop from their germ cells the next generation, which are called eereariæ. These leave the body of the snail and swim about in the water, and some beeome attached to blades of grass, where they form enveloping eysts and undergo anatomical ehanges. For their next stage it is necessary that they be reeeived into the stomach of some herbivorous animal by being swallowed with the grass to which they are attached. On reaching the stomach, the eysts are destroyed and the parasites migrate to the liver and become adult hermaphrodites, thus completing the cycle. Oceasionally they wander to the lungs and other parts of the body. In the liver, the parasites attach themselves to the walls of the bile ducts, which may beeome completely blocked, and they cause the breaking-down of the surrounding tissues and general symptonis due to struetural ehanges. The parasite cannot be transmitted direetly from animal to man, sinee it requires an intermediate host, and in the stage preceding its final development it is not attached to material eonstituting human food. There are, to be sure, sone instances of the disease in man, though not by direet transmission from meat. The condition eaused by flukes is known variously as rot, liver rot, fluke disease, and distomatosis. 
Moreover, meat or meat food products from animals which have suffered from-

(a) Acute inflammation of the lungs, pleura, perieardium, peritoneum, or meninges.

(b) Septicenia or pyemia, whether puerperal, traumatic, or without any evident cause.

(c) Severe hemorrhagic or gangrenous enteritis or gastritis.

(d) Acute diffuse metritis or mammitis.

(c) Polyarthritis.

$(f)$ Phlebitis of the umbilical veins.

(g) Traumatic pericarditis.

(h) Any other inflammation, abscess, or suppurating sore if associated with acute nephritis, fatty and degenerated liver, swollen soft spleen, marked pulmonary hyperemia, general swelling of lymphatic glands, and diffuse redness of the skin, either singly or in combination, must be condemned as likely to produce meat poisoning.

Tuberculosis.-The eattle disease most commonly known in this country, if not elsewhere, is tuberculosis, and concerning the advisability of using the flesh of its vietims, there is much difference of opinion, here and abroad. The disease is more common in cows, especially those kept in confinement, than in steers and oxen. It is almost an unknown disease in the great herds roaming the western plains. In Berlin, in $1892-93,15.1$ per cent. of all cattle, 1.55 per cent. of swine, 0.11 per cent. of calves, and 0.004 per cent. of sheep slaughtered showed some evidence of the existence of the disease. In Copenhagen, in the years 1890-93, the figures were somewhat higher than those of Berlin, excepting in the case of sheep. They were as follows: 17.7 per cent. of cattle, 15.3 per cent. of swine, 0.2 per cent. of calves, and only one sheep out of 337,014 . At the abattoirs of Leipzig, in 1897, nearly half of the cows and about 20 per eent. of the other cattle were found to be tubereulous ; 2.78 per cent. of swine, 0.2 per cent. of ealves, and 8 sheep out of 49,559 .

Out of over 8,000 beeves of American origin landed, slanghtered, and examined at Hamburg, 4 were found to be tuberenlous, while of the same number of native animals, 640, or 160 times as many, were found to be afflicted with the disease. At that time the German press had been earrying on one of its periodical agitations against the importation of American beef cattle on account of the dangers to which native breeds were thereby subjected.

In Great Britain, 30 per cent. of the cows are estimated by MacFaydean to be tubereulous. In Belgium, of 20,850 animals tested with tuberculin in $1896,48.88$ per eent. reacted. In Demmark, of 67,263 thus tested, 32.80 per cent. reacted. In Mexico, about a third of the beeves slaughtered are tuberenlous.

In this country, while the percentage of affected animals is low, it is believed to be on the inerease, both with eattle and swine. In the State of New York, it is said by veterinarians that, in some distriets in which the herds are mainly of the hardy grades of the Ayrshire, Hol- 
stein, and Short-horn families, about 1 per cent. of the cows, and in others where Jerseys and Guernseys are more common, about 2 to 3 per cent. are tuberculous. In Massachusetts, those in a position to be best informed state that, among cows, the disease is much more frequent than in New York, but that it is rarely to be found in calves, steers, and oxen. In Pennsylvania, the State veterinarian believes that not over 2 per cent. of all cattle are tuberculous. At the large abattoirs of this country, about 1 in 2,000 cattle is found to be tuberculous. During the two years ended June $30,1899,8,831,927$ cattle were inspected by the Federal authorities, and 7,015, or 1 in 1,259 , were condemned on account of tuberculosis. During 1900, of 4,861,166 inspected, 5,279 , or 1 in 921 , were condemned. Of $23,336,884$ hogs inspected, 5,440 , or 1 in 4,290 were sufficiently affected to warraut condemnation of at least a part of the carcass.

Some Results of Tuberculin Tests of Cattle by State and Federal Officers with Tuberculin Prepared by the Bureau of Anmal Industixy, 1893, to July 31, 1908, Inclusive. ${ }^{1}$

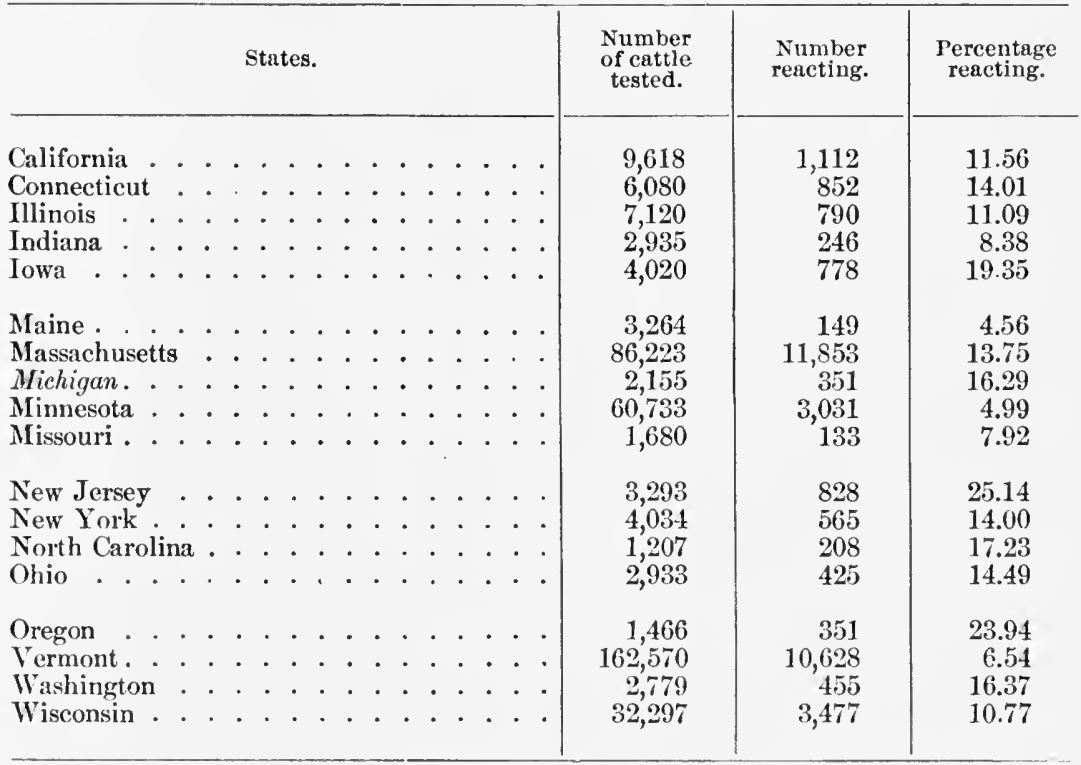

The organs involved most frequently in tubereulosis of animals are the liver, lungs, kidneys, brain, and udder. The muscles are affected very rarely, although the baeilli have been found in the expressed juice.

At what stage of the disease meat beeomes unfit for food, is a question over which there is much eontroversy. Extremists on the one side believe in condemning the entire careass on the slightest evidence of disease in any part thereof, while those on the other side maintain that the entire animal may be used as food without injury. In Eng-

${ }^{1}$ Circular No. 8, June, 1910, Michigan Agricultural College Experiment Station, Division of Bacteriology and Hygiene, page 61 . 
land, the practice is to eondemn any carcass in which the disease has made such extensive progress that the flesh has become deteriorated. The Royal Conmission on Tubereulosis ${ }^{1}$ concluded that meat from tuberculous animals may be eonsumed with impunity, if sufficient discrimination and care are exercised in slaughtering and dressing. Every part contuining tubercles should be removed and destroyed, and the whole carcass itself in advanced or general tuberculosis.

The French law exeludes carcasses with generalized tuberculosis and those in which local lesions have involved the greater part of an organ. The same is true in Austria. In Prussia, the meat is held to be unfit for food if the animal has begun to show emaciation, but is passed as fit for human consumption if the disease oceurs in only one organ, and in general, if the animal is well nourished. In Belgium, the law of September 30, 1895, permits the sale of meat of tubereulous animals after sterilization.

In the United States the following rules are given by the Bureau of Animal Industry, in reference to carcasses affected with tubereulosis : ${ }^{2}$

Section 13.-Paragraph 1.-The following prineiples are declared for guidance in passing on carcasses affected with tuberculosis:

Principle A.-The fundamental thought is that meat should not be used for food if it contains tubercle bacilli, if there is a reasonable possibility that it may contain tubercle bacilli, or if it is impregnated with toxic substances of tuberculosis or associated septic infections.

Principle B.-On the other hand, if the lesions are localized and not numerous, if there is no evidence of distribution of tubercle bacilli through the blood, or by other means, to the muscles or to parts that may be eaten with the muscles, and if the animal is well nourished and in good condition, there is no proof, or even reason to suspect, that the Hesh is unwholesome.

Principle C.-Evidences of generalized tubereulosis are to be sought in such distribution and number of tuberenlous lesions as can be explained only upon the supposition of the entrance of tubercle bacilli in considerable number into the systemic circulation. Significant of such generalization are the presence of numerous uniformly distributed tubereles throughout both lungs, also tubercles in the spleen, kidneys, bones, joints, and sexual glands, and in the lymphatie glands connected with these organs and parts, or in the splenic, renal, prescapular, popliteal, and inguinal glands, when several of these organs and parts are coincidentally affected.

Principle D.-By localized tuberculosis is understood tubereulosis limited to a single or several parts of organs of the body without cvidence of recent invasion of numerous bacilli into the systemic eirculation.

Paragraph 2.-The following rules shall govern the disposal of tuberculous meat :

1 The Veterinary Journal and Annals of Comparative Pathology, June, 1895.

${ }^{2}$ Regulations Governing The Meat Inspection of the United States Department of Agriculture, Bureau of Animal Industry, Order 150, as Amended, Effectire May 1, 1908. 
Rule A.-The entire carcass shall be condemned-

(a) When it was observed before the animal was killed that it was suffering with fever.

(b) When there is a tuberculous or other cachexia, as shown by anæmia and emaciation.

(c) When the lesions of tuberculosis are generalized, as shown by their presence not only at the usual seats of primary infection, but also in parts of the carcass or the organs that may be reached by the bacilli of tuberculosis only when they are carried in the systemic circulation. Tubereulous lesions in any two of the following-mentioned organs are to be accepted as evidence of generalization when they occur in addition to local tuberculous lesions in the digestive or respiratory tracts, including the lymphatie glands connected therewith: Spleen, kidney, uterus, udder, ovary, testicle, adrenal gland, brain, or spinal cord or their membranes. Numerous uniformly distributed tubercles throughout both lungs also afford evidence of generalization.

(d) When the lesions of tuberculosis are found in the muscles or intermuscular tissue or bones or joints, or in the body lymphatic glands as a result of draining the muscles, bones, or joints.

(e) When the lesions are extensive in one or both body cavities.

$(f)$ When the lesions are multiple, acute, and actively progressive. (Evidence of active progress consists in signs of acute inflammation about the lesions, or liquefaction necrosis, or the presence of young tubercles.)

Rule B.-An organ or a part of a earcass shall be condemned-

(a) When it contains lesions of tuberculosis.

(b) When the lesion is immediately adjacent to the flesh, as in the case of tuberculosis of the parictal pleura or peritoneun, not only the membrane or part affected but also the adjacent thoracic or abdominal wall is to be condemned.

(c) When it has been contaninated by tuberculous material, through contact with the floor, a soiled knife, or otherwise.

(d) All heads showing lesions of tuberculosis shall be condemned.

(e) An organ shall be condemned when the corresponding lymphatic gland is tubereulous.

Rule C.-The carcass, if the tuberculons lesions are limited to a single or several parts or organs of the body (except as noted in Rule A), without evidence of recent invasion of tubercle bacilli into the systemic circulation, shall be passed after the parts containing the localized lesions are renoved and condemned in accordance with Rule B.

Rule D.-Carcasses which reveal lesions more numerous than those deseribed for careasses to be passed (Rule C), but not so severe as the lesions discribed for earcasses to be condemned (Rule A), may be rendered into lard or tallow if the distribution of the lesions is such that all parts eontaining tubereulous lesions can be removed. Such carcasses shall be cooked by steam at a temperature not lower than $220^{\circ}$ F. for not less than four hours.

Meat from tuberculous cattle is infective to other animals in very 
variable degrees. As a rule, the more advanced the disease, the more likely is the meat to be infeetive. Experiment has demonstrated that infection depends to a not inconsiderable extent upon contamination of the meat, in the process of dressing, by the hands, knives, or cloths, which have been in eontact with tuberculous matter.

Although lesions in the muscular tissue itself are not at all eommon, positive results have repeatedly been obtained in experiments in which the expressed juice of the meat has been injected into susceptible animals. Thus, Kastner obtained 9 positive results in 11 injections of the juice of the neat of 7 tubereulous animals, and Steinheil transmitted the disease to guinea-pigs by meaus of juice from meat apparently sound. Arloing inoculated the muscle juice of 10 tubereulous cows into guinea-pigs and demonstrated that that from 2 of the animals was infective. Nocard produced the disease with the muscle juice of but 1 of 21 tuberculous cows with which he experimented. All of these cows had been condemned at the abattoir on account of extensive lesions. Woodhead, Galtier, Humbert, and others have met with varying degrees of suceess in similar experiments.

That tuberculosis can be transmitted to animals by feeding them on tubereulous material has been abundantly proved, but the lesions produced almost never involve the muscular apparatus, and many of the subjects escape infection altogether. It was reported, for example, by Thomassen, at the Tubereulosis Congress at Paris, that of 10 young pigs, each of which was made to eat 4.5 kilos of meat from animals with advanced general tuberculosis, but 2 were affected, and their portions had contained a quantity of splintered bone. Ravenel ' has held for a long time that food tubereulosis may appear first in the lungs and cervical glands, and eites the case of 2 cows which, fed on tuberculous material, developed extensive disease of the lungs and lesions nowhere else. As stated by Dr. D. E. Salmon, ${ }^{2}$ Woodhead, St. Clair Thompson, and Lord Lister have shown "that infection through the medium of the food may not necessarily be accompanied by disease of the intestines. The organs first attacked after feeding on tubereular material may be the mesenteric glands and liver, or even the bronchial and mediastinal glands and the lungs."

Relation between Human and Bovine Tuberculosis.-The question of the identity of the bacilli of human and bovine tubereulosis, raised in 1901 by Koch's assertion of the impossibility of transference of the disease from man to cattle and from cattle to man, has led to much experimentation and study. That the human and the bovine types of B. tuberculosis are distinet, differing in virulence, morphology, and cultural peculiarities, was demonstrated by 'Theobald Snith five years before Koch asserted that the difference is so marked that bovine tuberculosis is a negligible factor in the liuman disease. In 1902 Ravenel ${ }^{3}$ stated that the bovine bacillus shows persistent peculiarities

1 Philadelphia Medical Journal, August 14, 1901, p. 284.

${ }^{2}$ Bulletin No. 33, Bureau of Animal Industry, Washington, 1901.

3 Journal of Comparative Medicine and Veterinary Archives, 1902, pp. 65, 139. 
of growth and morphology, which enable it to be differentiated from the human variety, and that it is pathogenic, not only for nearly all of the species of experimental animals, but for man also. He says, ${ }^{1}$ moreover, that human bacilli with a high degree of virulence for experimental animals are rarely found, and that cultures highly pathogenic for cattle are still more rare. Experiments conducted by Nocard, Cipollina, and others indicate that the bovine bacillus is the more infective. Nocard ${ }^{2}$ observed that monkeys fed with material containing bovine bacilli became infected much sooner than did those whose food contained the human variety; and Cipollina ${ }^{3}$ produced general tuberculosis in a healthy ape with milk containing bovine bacilli, while a calf resisted infection with the buman variety.

The experiments of $\mathrm{V}$. Dungern and Schmidt ${ }^{4}$ gave results indicating a selective infectivity. Human and bovine bacilli were fed to anthropoid apes; the former produced tuberculosis of the lungs, the latter of the alimentary tract and mesenteric glands. In Ravenel's experiments guinea-pigs infected with human bacilli lived more than twice as long as those inoculated with the bovine variety, and rabbits were much less extensively infected and, indeed, gained in weight.

That human bacilli from different lesions are differently virulent has been observed repeatedly. Those from the lungs almost invariably fail to infect calves, but Delépine ${ }^{5}$ produced lesions in the alimentary tract of a calf to which was given 50 c.c. of mixed sputum with its food. The animal died at the end of 28 days. Bacilli from other than pulmonary lesions prove to be far more virulent. Fibiger and Jensen ${ }^{8}$ found that bacilli from 3 cases of chronic intestinal tuberculosis were exceedingly virulent, and $\mathrm{Wolff}^{7}$ produced general tuberculosis in a calf which he inoculated with material from a similar source. In 1904 the Bureau of Animal Industry experimented with 9 cultures of human origin, and found that whereas none of the 5 derived from adults was infective for calves, 2 of 4 obtained from children with generalized tuberculosis caused general infection of calves, with lesions which were quite as serere as those produced by a fresh culture of bovine bacilli. Ravenel ${ }^{8}$ found two cultures from the mesenteric glands of milk-fed children, one quite as virulent as bovine bacilli and the other more virulent thau the usual human culture. Races of human tubercle bacilli have been found that are capable of producing general tuberculosis in calves and swine very quickly. Thus Dammann, ${ }^{9}$ experimenting with bacilli from a human case of peritoneal tuberculosis, produced striking cases of pulmonary tuberculosis in hogs inoculated subcutaneously, with fatal results within 28 to 42 days.

1 Journal of the American Medical Association, June 3, 1903.

2 Journal of the Sanitary Institute, January, 1903, p. 571.

3 Berliner klinische Wochenschrift, February 23, 1903, p. 163.

4 Arbeiten aus dem Katiserlichen Gesundheitsamte, XXIII., 1906, p. 570.

5 British Medical Journal, October 26, 1901.

6 Berliner klinische Wochenschrift, September 22, 1902.

7 Ibid., November 17, 1902.

${ }^{8}$ Journal of the American Medical Association, June 3, 1903.

${ }^{9}$ Deutsche Tierïrztliche Wochenschrift, XII., 1904, p. 541. 
Orth ${ }^{1}$ has convineed himself by experiment that human and bovine tubereulosis are reciprocally transmissible, and he believes that virulence can be increased materially by passage through a series of animals. Behring ${ }^{2}$ inereased the virulence of the human bacillus by passage through rabbits and goats, until it became as virulent for cattle as any strain of bovine bacilli; and, according to Salmon, ${ }^{3}$ Mohler did the same by passage through five cats. Hamilton and Young ${ }^{4}$ noted an enormous increase in virulence on reinoculation from one calf to another and great variation in morphological character. Arloing reports positive results from inoculation of eattle, asses, sheep, and hogs with human bacilli from five sources, and Theobald Smith has found a human culture directly virulent for cattle. Eber ${ }^{5}$ inoculated a bovine animal with material from tuberculous liuman mesenteric glands, and from this one he reinoculated another, which succumbed to acute miliary tuberculosis within a week. By passing the material through a guinea-pig first and then inoculating a bovine animal, a fatal tubereulosis was produced, death occurring in 51 days.

The German Tuberculosis Commission, appointed on Koch's suggestion, found that different bovine cultures varied much in virulence, some failing to transmit the disease to other cattle. They tested 56 eultures of human origin and found 6 that eaused marked lesions in cattle, all but one from children under 7 years of age. The fact that the bacilli were from children and mainly from lesions of the intestines and mesenterie glands led Kossel ${ }^{6}$ to conclude that the children must have been infected with bovine bacilli. His experiments show that the bovines, in a eertain snall proportion of eases, may yield to human bacilli, and in endeavoring to explain the fact he admits that the reverse is also true. Orth, ${ }^{7}$ having succeeded in producing general tuberculosis in 2 out of 5 calves inoculaterl with human bacilli, asks Koch to reconeile his own negative results with the positive results of others.

The British Royal Commission on Tuberculosis examined a large number of strains of humau tuberculosis material from sputum, lungs, glands, and joints, and found a number which were capable of eausing remarkably severe tuberculosis in cattle, with lesions in various organs (lungs, spleen, liver, lymphatic glauds, etc.). Several of the less virulent strains were found to gain greatly on reinoculation from one bovine into another or into a guinea-pig. The Commission concluded that in a certain proportion of eases, especially in children, human tuberculosis is the direct result of the introduction, mainly in milk, of the bovine baeillus. Of 60 eases investigated, the elinieal histories of 28 indicated $^{\circ}$ the entrance of the exeiting eause through the alimentary canal.

1 Berliner klinische Wochensehrift, July 20, 1903.

${ }^{2}$ Beitrïge zur Exper. Therapic, No. 2.

3 Journal of the American Medical Association, March 12, 1904.

4 Public Health, September, 1903, p. 689.

5 Zeitschrift für Fleisch- und Milehhygiene, XVI., 1906, p. 218.

${ }^{6}$ Berliner klinische Wochenschrift, July 20, 1903.

7 Ibid: 
Concerning the possibility of direct transmission of tuberculosis from animal to man by inoculation, considerable evidence is offered, but in most cases the infection is local and is due to wounds received in making antopsies on diseased cattle. Pfeiffer ${ }^{1}$ records an accident of this sort which was followed in 18 months by death from phthisis, and the originally infected joint was found to be extensively tubercular. Spronck and Hoefnagel ${ }^{2}$ record a similar case. A man aged 63 years cut his finger while skimning a very tuberculous cow, and, though the wound healed quickly, the glands at the elbow beeame enlarged and, after nine months, they were excised and found to be infective for guinea-pigs. The disease was conveyed from one of these to a healthy heifer, which showed general infection after two months. The man developed a catarrl of the right apex 20 months later. Lassar ${ }^{3}$ Silw in ten years 34 cases of undoubted inoculation tuberculosis, chiefly in veterinarians, butchers, and others who handle meats. Cases of similar infection throngh milk are exceedingly rare. Salmon ${ }^{4}$ cites but 3 cases in all; one, from the application of cream to a leg supposedly poisoned by ivy; a second, from milking with a wound in one finger; and a third, from attempted removal of tattoo-marks by the introduetion of milk through needle-punctures.

Raw, who in $1904^{5}$ was led to conclude from a study of more than 3000 cases of pulmonary tuberculosis that man is subject to two kinds of tuberculosis-the pulmonary form, rare in children under twelve and due to human bacilli, and other forms, as tubercular joints, tuberculous meningitis, and abdominal tuberculosis, rare in adults and due to bovine bacilli-is still further convinced by the study ${ }^{6}$ of a total of 4000 cases, including 700 which came to autopsy, that bovine tuberculosis affects young people, attacking the tonsils, the alimentary tract, the glands, and through the blood, the meninges, bones, joints, and other parts, and that the human variety affects adults by way of the lungs. He asserts that the human type of bacillus causes phthisis pulmonalis, secondary ulceration of the intestines, and tuberculous laryngitis, and that the bovine type causes acute miliary tuberculosis, primary intestinal and mesenteric disease (including tabes mesenterica, tuberenlous peritonitis, and tubereulosis of the pelvic organs), tubereulous glands, joints and bones, tuberculous meningitis, ulceration of the cornea, and lupus. Of nearly 300 eases of tabes mesenterica observed in a period of twelve years, not one of the subjects was a breast-fed child. McCaw, ${ }^{7}$ of Belfast, relates that, during the year 1906 , more than 200 of 827 children treated in hospital were tubereulous, and lays special emphasis upon cows' milk as the cause of forms other than pulmonary. Von Hansemann ${ }^{8}$ gives particulars of 25 cases of intestinal

\footnotetext{
1 Zeitschrift für Hygiene, II1., p. 209.

${ }^{2}$ La Semaine Médicale, October 15, 1902, p. 341.

3 Dentsche medicinische Wochenschrift, October 2, 1901.

4 Bureau of Animal Industry, Bulletin 33, 1901.

5 British Medical Journal, Octoher 8, 1904.

${ }^{6}$ The Lancet, Angust 5, 1905, and March 2, 1907.

7 British Medical Journal, December 21, 1907.

${ }^{8}$ Berliner klinische Wochenschrift, 1903, Nos. 7 and 8.
} 
tuberculosis due apparently to bovine bacilli. Fibiger and Yensen ${ }^{2}$ report 2 cases of intestinal tuberculosis in infunts of four and eight months respectively, deemed by them to be due undoubtedly to milk of tuberculous cows. One had had nilk from a very unsanitary dairy in which a case of tuberculous udder lad been notorions. Their contention that abdominal tuberculosis in infancy is more frequent than is commonly supposed is borne out by the experience of Brüning ${ }^{2}$ of the Leipzig Children's Hospital, who found evidences of tuberculous lesions in 44 cases which came to autopsy ; in 25 the liver and mesenteric glands were diseased, in 20 the small intestine, in 10 the large intestine. General miliary tuberculosis was found in 25 . In 8 cases there was evidence of tuberculous infection of the intestines and mesenteric glands alone, and these must be considered as primary infections. In not one of these cases had tuberculosis been diagnosed during life, and all of the victims had died of some acute infectious disease.

Von Hansemann ${ }^{3}$ believes that infection can take place through the healthy mucous membrane, and von Behring ${ }^{4}$ is of like mind. $\mathrm{He}$ believes that the chief source of tuberculosis is infected milk, and that infection of infants is due to lack of continuity of the epithelial lining of the alimentary tract, which permits the passage of bacteria.

Evidence that infection of the lungs can occur through food without local lesions of the digestive tract is offered by several. 'Thus, Nicolas and Descas ${ }^{5}$ fed fatty broth containing large numbers of tubercle bacilli to healthy dogs, some of which, after three hours, yielded chyle containing bacilli in such abundance that they could be demonstrated microscopically; and Ravenel ${ }^{6}$ introduced a quantity of bovine bacilli in melted butter into the stomachs of 8 healthy fasting dogs, and found that the chyle and mesenteric glands, removed about four hours later, were infective for guinea-pigs, and that not the slightest evidence of abnormality of the intestinal mucosa could be seen. MacFadyen ${ }^{7}$ obtained like results with monkeys fed with tuberculous material from cattle. General tuberculosis was produced, but no lesions of the intestines were observed. Calmette and Guerin ${ }^{8}$ have proved that adult cows, as well as calves, can become infected with tuberculosis through the alimentary tract without anything in the walls of the intestine to show where the bacilli may have passed through, and they believe that pulmonary lesions in the adult are in the majority of instances of alimentary origin. In all of their experiments on animals, in which the infective material was introduced by the mouth with careful avoidance of inhalation, the peribronchial lymph-nodes became affected in 30 to 45 days, the lesions being the more marked the greater the number of infected meals.

1 Berliner klinische Wochenschrift, February 4, 1907.

${ }^{2}$ Hygienische Rundschau, November 15, 1906, p. 1257.

3 Loc. cit.

4 Deutsche medizinisclie Wochenschrift, 1903, No. 39.

5 Centralblatt für Bakteriologie, etc., 1902, XXXII., p. 306.

- Journal of Medical Research, December, 1903, p. 460.

7 The Lancet, September 12, 1903.

${ }^{8}$ Annales de l'Institut Pasteur, XX., August, 1906. 
The belief held by many that all tuberculosis originating in the intestinal tract is of bovine origin is not shared by Theobald Smith, ${ }^{1}$ who is of opinion that man has only a limited susceptibility to bovine tuberculosis, depending on certain still unknown factors. In a certain number of selected cases of alimentary tuberculosis the bovine bacillus has been found, and, he says, all the rest is uncertain and speculative. He believes ${ }^{2}$ that the ratio of cases of intestinal tuberculosis associated with bovine bacilli may be roughly estimated at 20 to 40 per cent. L. Rabinowitsch ${ }^{3}$ has summed up her observations on human and bovine tuberculosis, and concludes that while the bovine bacillus does cause tubercular lesions in man, the proportion of cases due thereto cannot be determined. According to Weber, ${ }^{4}$ infection of the humau subject with bovine bacilli is of far less importance than that due to those of human origin, since the former produces only intestinal and mesenteric lesions, and these forms of the disease are much less likely to be transmitted from one victim to another. They are, moreover, found almost exclusively among children, and possess a marked tendency to spontaneous cure. Nevertheless, since bovine infection of the huinan subject is a real danger, although insignificant in comparison with that of the human type, proper precautions should be taken to prevent its occurrence at all throngh food and, notably, milk.

The question was again discussed in great detail at the Sixth International Congress on Tuberculosis, held in Washington in 1908. It was agreed that two types of organisms exist, differentiated, first, by the manner and rapidity of growth; second, by differences of reactions in cultures of appropriate age, as pointed out by Theobald Smith; and third, by very marked differences in virulence as shown by their action upon certain experimental animals. There was an attempt, furthermore, to come to some general conclusion as to the importance of bovine tuberculosis in its relation to man, but no agreement on this point could be reached.

Koch, although he did not deny the occasional transfer of bovine tuberculosis from animals to man, insisted that such transfer was rare, and, as supporting Koch, a series of observations reported by Kossel ${ }^{5}$ is of great interest in this connection. From 1905 to 1909113 cases of tuberculosis of the udder were reported, and 628 persons had partaken of milk from these tuberculous cows. In 44 of the 113 cases the milk was said to have been cooked. In the other 69 cases it was taken raw by 360 individuals (151 children, 200 adults, and 9 of unknown age). Of these 360 individuals, only 2 became surely infected. These 2 were children, one a year and ten months old and the other a year and three months old. Both showed disease of the

1 Boston Medical and Surgical Journal, January 18, 1906.

2 American Journal of Public Hygiene, XIV., 1906, p. 516.

3 Berliner klinische Wochenschrift, 1906, No. 24, p. 784.

4 Deutsche medizinische Wochenschrift, December 6, 1906.

5 Die Sammelforschung des Kaiserlichen Gesundheitsamtes über Milchgenuss und Tuberkulose. Deutsche med. Wochenschr., Leipzig u. Berlin, 1910, XXXVI., pp. 349351. 
cervical glands. An examination of these glands showed tubercle bacilli of the bovine type. In 12 instances conditions developed which led to the suspicion only of tuberculosis. In 346 people, however, and among these 136 children, no trouble ensued.

Others, such as Ravenel, Arloing, and Fibiger, insisted that bovine tubereulosis, although it but infrequently caused disease of human beings, was a distinet mennce to health and should be given extended consideration. The best and most recent figures are those of Park and Krumwiede. ${ }^{1}$

Park and Krumwiede investigated material from 606 cases of tubereulosis, in order to determine in what percentage tubercle bacilli of the human and bovine types occurred in different varieties of the disease. The following table shows the results obtained:

Total Summary of Tabulated Cases.

\begin{tabular}{|c|c|c|c|c|c|c|}
\hline \multirow{2}{*}{ Diagnosis of Cases Examined. } & \multicolumn{2}{|c|}{$\begin{array}{l}\text { Adults } \\
16 \text { Years and Over. }\end{array}$} & \multicolumn{2}{|c|}{$\begin{array}{l}\text { Children } \\
5 \text { to } 16 \text { Years. }\end{array}$} & \multicolumn{2}{|c|}{$\begin{array}{c}\text { Children } \\
\text { Under } 5 \text { Y'ears. }\end{array}$} \\
\hline & Human. & Bovine. & Human. & Bovine. & Human. & Bovine. \\
\hline Pulmonary tuberculosis & 290 & $1 ?$ & 3 & - & 7 & - \\
\hline Tuberculous adenitis. Axillary & 1 & - & - & $\overline{1}$ & 2 & - \\
\hline $\begin{array}{l}\text { Tuberculous adenitis. } \\
\text { Abdominal tuberculosis }\end{array}$ & 13 & $\mathbf{l}$ & -14 & 12 & $\stackrel{9}{9}$ & $6 \stackrel{8}{6}$ \\
\hline Generalized tuberculosis. Alimen- & & & & & & \\
\hline tary origin ${ }_{\text {Generalized tubereulosis }} \cdots \cdots$ & $\begin{array}{r}6 \\
26\end{array}$ & 1 & \begin{tabular}{l|l}
3 & $=$ \\
3 & $=$
\end{tabular} & $\begin{array}{l}3 \\
1\end{array} \mid=$ & $\begin{array}{ll}12 & -7 \\
14 & -\end{array}$ & $\begin{array}{l}9 \\
1\end{array}$ \\
\hline $\begin{array}{l}\text { Generalized tuberculosis including } \\
\text { meninges. Alimentary origin } \\
\text { Generalized tuberculosis including }\end{array}$ & - & - & 1 & - & 3 & 8 \\
\hline meninges meningitis $\cdots \cdots \cdots$ & 4 & 二 & $\bar{i}$ & $=$ & 27 & 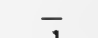 \\
\hline Tuberculosis of boues and joints . : & 17 & 1 & 16 & 1 & $\overline{15}$ & 1 \\
\hline $\begin{array}{l}\text { Genito-urinary tuberculosis } \ldots \\
\text { Tuberculosis of skin } \ldots\end{array}$ & 8 & 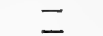 & $\overrightarrow{1}$ & $\bar{z} \cdot r+r \cdot r \cdot r \cdot r$ & $\overline{1}$ & $=$ \\
\hline Miscellaneous cases: & & & & & & \\
\hline Tuberculosis of tonsils & - & - & - & 1 & - & - \\
\hline $\begin{array}{l}\text { Tuberenlosis of mouth and } \\
\text { cervical nodes . . . . }\end{array}$ & - & 1 & - & - & - & - \\
\hline $\begin{array}{l}\text { Tuberculous sinus or abscesses } \ldots \\
\text { Sepsis. Latent bacilli } \ldots\end{array}$ & 1 & - & - & - & 1 & - \\
\hline Totals & 381 & 8 & 54 & 24 & 99 & 37 \\
\hline
\end{tabular}

Mixed or double infections, 3 cases:

Generalized tuberculosis: alimentary origin. 30 years. Human and bovine type in mesenteric node. Human type in bronchial node.

Gencralized tuberculosis : alimentary origin. $5 \frac{1}{2}$ years. Human type in spleen. Bovine type in mesenteric node.

Generalized tuberculosis including meninges: alimentary origin. 4 years. Human trpe in meninges and bronchial nodes. Borine type in mesenteric noles. Total cases, 606 .

Finally, these authors combined the cases observed by them with those reported by thirty-two other reliable observers. ${ }^{2}$ This combined

1 Park and Krumwiede. The relative importance of the bovine and human types of tubercle bacilli in the different forms of human tuberculosis, Journal of Medical Research, October, 1910, p. 205.

2 Smith, Smith and Brown, Lewis, Ravenel, deSchweinitz, Dorset and Schroeder, Mohler and Washburn, Kossel, Weber and Heuss, Weber and Taute, Oehlecker and Dieterlen, Weber, Hoelzinger, De Jong-Stuurmann, Dammann and Müssemaier, Henschen, Jundell and Svenson, Rabinowitsch, Beitzke, Royal Commission, Watt, Kitasato, Hess, Gorter, Fibiger and Jensen, and Burckhardt. 
table shows the comparative distribution of the two types of baeilli in 1042 cases, and represents the most reliable information on this subjeet at the present time.

Combined Tabulation, Casms Reported and Owy Semies of Casfs

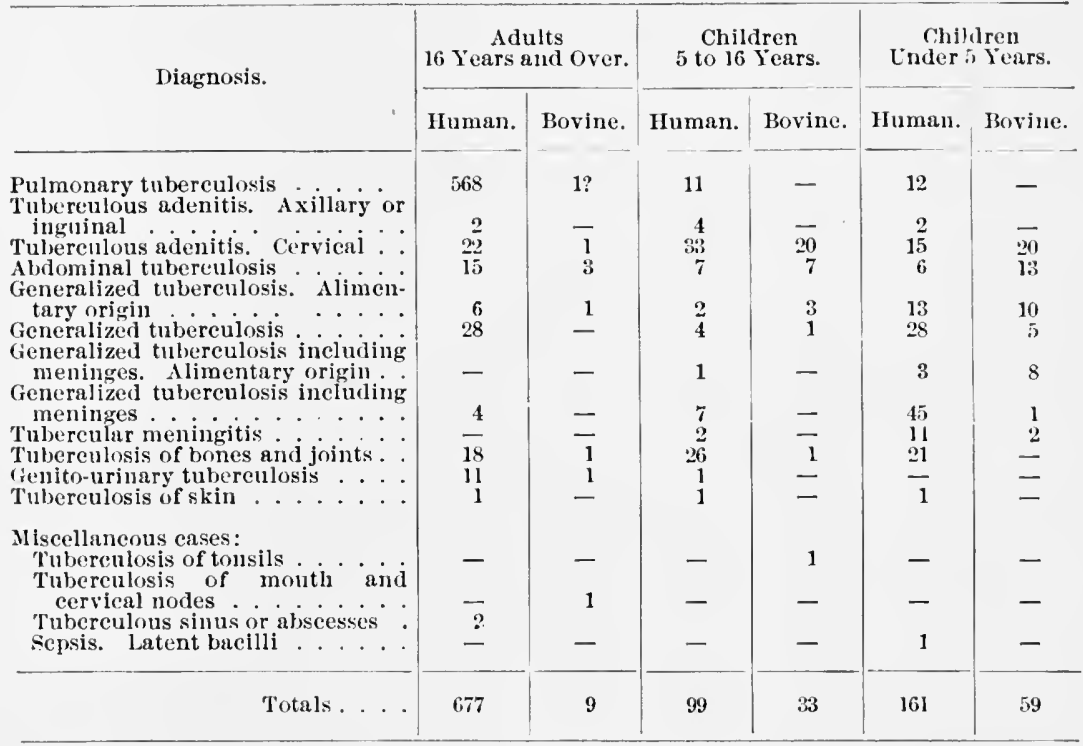

Mixed or double infections, 4 cases; total cases, 1042.

It is apparent from these tables that bovine tubereulosis deereases in importance with the inereasing age of the individual. It is furthermore manifest that the bovine type of the disease falls far below the human type in its importance to the human race.

That young elildren are subject to bovine tubereulosis to a consiclerable extent, although the amount of this infection is far less than was at one time thought to be the ase, and the great probability that this infection of children is due in the majority of instances to the drinking of milk of diseased eattle, makes it very evident that all effort should be made to restriet bovine tuberculosis, not only in the eommereial interest of the farmer, but also from the point of view of human health. As regards the eultures isolated by them, Park and Krumwiede state that 98 per cent. of all tubereulosis eultures fall into two groups so distinctive as to be surely diagnostie. The othor 2 per cent., spoken of by different authors as atypical or irregular, they prefer to speak of as viruses showing variant eharaeters.

Conecrning the possibility of transmission of tubereulosis by eating the meat of diseased animals, there is practically no evidenee of value, but whatever danger there is, if any at all, is disposed of by thorough 
cooking, since thereby the bacillus is quickly killed. Since raw meat is frequently used as food, particularly in some diseased conditions, it is best, in order to be on the safe side, to see that meat so used shall be free from infective properties.

Typhoid Fever and Cholera.-Foods of all kind may be made the bearers of infection to man, though themselves in good condition. Particularly is this noticeable with regard to oysters, which have many times conveyed the specifie organisms of typhoid fever and cholera.

In 1880, Sir Charles Cameron ${ }^{1}$ brought it to the attention of the profession, that oysters, transplanted from the coast of the County of Wexford to the northern shore of Dublin Bay, had for some years been much subject to disease and had died in large number's. Specimens which were examined were found to contain sewage matters, and investigation showed that the beds "were literally bathed in sewage." $\mathrm{He}$ offered the suggestion that raw oysters, taken from the shore close to sewer outlets, were, perhaps, as likely to act as the vehicle of typhoid fever and other diseases as contaminated water or milk, and advised that "oyster beds should not be laid down at any point on or close to the mouth of a sewer." But the warning appears to have exeited no more than a languid interest until 1893, when the late Sir R. Thorne-Thorne, in a report to the Local Government Board, stated lis belief that the sporadic cases of cholera which had oceurred at various inland places in England in that year were due to oysters and other shellfish from sewage-contaminated water at Grimsby, where there had been a small outbreak of the disease.

In the following year occurred the well-known outbreak of typhoid fever at Wesleyan University, which was so ably and conclusively traced by Professor Conn ${ }^{2}$ of that institution to polluted oysters. On Oetober 20,1894, several of the students were reported as slightly ill, with a moderate degree of fever. The number of cases grew from day to day, and shortly included several of undonbted typhoid fever. By November 1st, there were 20 cases of the disease, which number was shortly further increased to 23 . All of the victims were men; there was no illness among the 58 women students. Investigation completely absolved the water supply, the general and particular food supplies of the various boarding places, and the local conditions of the dormitories and outside lodgings of all suspicion of blame. It appeared that nearly all of the vietims were members of three of the seven college fraternities. The combined membership of the three was about one hundred. On October 12th, eight days before the development of the first symptoms, all seven fraternities had had their initiation ceremonies and had celebrated in the usual way with a supper. Investigation of the origin of the components of the suppers showed that there was but one dish from a common source, and that was oysters. The three afflicted societies and one other had obtained

${ }^{1}$ British Medical Journal, September 18, 1880, p. 471.

'Medical Record, Dec. 15, 1894, p. 743. 
their oysters from a local dealer; of the remaining threc, two had had no oysters, and the third had had some from a dealer in Hartford. Of the four supplied by the local dcaler, one had eaten the oysters cooked, and its membership was not invaded. Thus the trouble was sifted down to the raw oysters from the local dealer. But there was one rictim who was a non-socicty man, and, clearly, his case could not be traced to the initiation supper. Investigation of his dietetic history cstablished the guilt of the local oyster supply even more securely, for it was shown that he had eaten raw oysters from the same lot at the shop of the dealer. It was learned, too, that 5 men from Yale had attended the exercises of the societics in which the outbreak occurred, and inquiry developed the information that 2 of the 5 were seized with typhoid fever some weeks after their return to New Haven. Further investigation revealed the fact that the incriminated oysters had been brought from a bed in Long Island Sound, and, on October 10th, two days before use, had been stored in a bed at the mouth of the Quinnipiac River, a short distance (300 fect) from the outlet of a private drain from a dwelling, in which 2 persons lay ill with typhoid fever.

Dr. Arthur Newsholme, ${ }^{1}$ M. O. H. for Brighton, England, reported that of 53 cases of typhoid fever occurring within his district during 1894, no fewer than 15 were due to infected oysters, and 6 to other contaminated shellfish (clams, cockles, and mussels). In a later communication, ${ }^{2}$ after a thorough examination of the cases that had occurred within four years, he reported the percentages of infection duc to oysters and mussels as follows: In 1894, 38.2; $1895,33.9 ; 1896,31.8$; $1897,30.7$.

Dr. J. T. C. Nash, ${ }^{3}$ M. O. H. for Southend-on-Sea, says that prior to 1900 attacks of typhoid fever within his district were ascribed to the commonly accepted causes and occasionally to shellfish. In 1900, investigation showed that in a majority of the reported cases there was a history of consumption of shellfish within 2 or 3 wecks of the onset. In a majority of the cases reported during the last 5 months of 1901 there was a similar history. During June and July, 1902, in a majority of the 39 cases reported there was a history of eating, within a month of the onset, cockles from a sewage-polluted creek in another district, where, during June, 9 cases of typhoid fever had existed. Cockles obtained from these layings were examined and the presence of sewage bacteria was demonstrated. In a later communication ${ }^{4}$ he states that in 82 of the 102 cases of typhoid fever reported during 1902 there was a shellfish history. Diminished consunption of shellfish, the adoption of better methods of storage, and the exercise of greater care in obtaining supplies from clean layings were followed by a very decided diminution in the incidence of typhoid fever. By careful inquiry he determined that somewhat less than 5 per cent. of the

${ }^{3}$ British Medical Journal, June 8, 1905, p. 1285.

${ }^{2}$ Public ITealth, September, 1898.

3.Journal of the Sanitary Institute, January, 1903, p. 369.

* Journal of State Medicine, December, 1903, p..710. 
entire population of the distriet were eaters of shellfish, and during 1902 the attack-rate of typhoid fever per 1000 among this section was 51.25 against 3.28 for the whole population, and 0.75 for the noneaters of shellfish. The attack-rate among the dealers and their employees was no less than 160 per 1000 .

Dr. J. F. Allen, ${ }^{1}$ M. O. H. for Westminster, secured speeimens of coekles which were from the same bed as some which were supposed to have caused a number of cases of typhoid fever, and had them examined, at the Jenner Institute, for sewage baeteria. The results were positive, and the typhoid bacillus itself was found to be present. Hewlett ${ }^{2}$ records that cockles purchased at the fishmarket of Billingsgate and examined by Klein yielded the usual sewage bacteria and the typhoid organisms as well. Four cases of typhoid fever attributed to cockles from the same souree were the cause of the inquiry. Sewage contamination was demonstrated by the same authority in 11 of 18 lots of oysters from five different localities.

Chantemesse ${ }^{3}$ relates the following case: There had been no case of typhoid fever in the village of l'Herault Saint Andre de Sangonis for about a year, when, on February 15th, a shopkeeper received a consignment of oysters from Cette. The entire lot was consumed by 14 persons, all of whom were made sick. In the 6 dwellings in which the victims lived, no other inmates were sick in any way. Eight of the number were made only slightly ill, the symptoms, which included abdominal pain, voniting, diarrhoa, borborygmus, anorexia, and general malaise, lasting but 2 or 3 days. The 4 youngest, who ate but a few, were very sick for a nuch longer time (15 to 25 days), but recovered. The stools were very offensive, were passed with pain, and were dysenteric in appearance; there was tympanites with tenderness and gurgling. All 4 were greatly prostrated. The remaining 2, a woman of twenty and a man of twenty-one, developed very severe eases of typhoid fever. The woman died.

Mosny, ${ }^{4}$ to whom the French anthorities referred the whole subject of mollusk poisoning for investigation, has reported that 5 members of a family of 7 , living in a village in a suburb of Paris, in which there had been no ease of typhoid fever in 4 years, were made sick after eating oysters sent to them from Cette. Four were seized in the evening of the following day with gastro-intestinal disturbance, which lasted 24 hours. On the eighteenth day, a youth of 17 years developed unmistakable symptoms of typhoid fever, of which, 9 days later, he died. In Mareh, 1897, Chatin ${ }^{5}$ reported the case of a family, of which several members were strieken with typhoid fever after eating oysters from a bed which was eontaminated by sewage.

Klein and Boyce have shown that oysters contaminated by typhoid

${ }^{1}$ Journal of the Sanitary Institute, Jannary, 1903.

${ }^{2}$ Journal of State Medicine, March, 1903, p. 163.

"Bulletin de l'Academie de Ḿ́clecine, 1896, 35-36, p. 588 .

4 Revne d'Irgiène, January, Fehruary, and Mareh, 1900.

${ }^{5}$ La Semaine Médicale, $189^{\circ}$, p. 9. 
bacilli can retain their infective properties for 2 or 3 weeks, and it is shown that those from sewage-contaminated beds may not be eaten with entire safety until they have lain for about 2 weeks in unpolluted water. It appears, however, that in cockles the typhoid organism thrives, and that this kind of shellfish is not freed of its infective propertics by storage in clean water. Although cockles are not eaten raw, the cooking to which they are subjected is by no means thorough, for boiling for any considerable time nakes them tough and uneatable.

It was shown by Foote, ${ }^{1}$ after the outbreak at Wesleyan University, that typhoid cultures, introduced within the cells of oysters from the bed from which the incriminated oysters were derived, were virulent at the end of 48 hours, which was the period which elapsed between the gathering and consumption of those which caused the outbreak. Furthermore, it was demonstrated that, if the specimens were kept at $57^{\circ} \mathrm{F}$, the organisms were active as long as a month later.

The influence of the sewage of a large city is shown by C. A. Fuller, who collected samples of water and shellfish from various places in Narragansett Bay, into which about 14,000,000 gallons of sewage from Providence, Rhode Island, are discharged daily. Water, oysters, clams, and mussels, taken at a distance of a quarter of a mile from the sewer outlet, yielded Bucillus coli communis, Bacillus cloace, and Bacterium lactis aërogenes. The water and oysters from a bed two miles distant yielded the same organisms. Bacillus coli communis was found in 30 per cent. of the oysters, and in 60 per cent. of the samples of water from a bed situated in the line of a strong tidal current, five miles away ; and in 40 per cent. of the oysters and 70 per eent. of the water samples from another in sluggish water more than five miles away. One bed six miles distant was found to be contaminated, but those farther down than six and one-half miles were unpolluted.

These findings are in accord with the statement of Dr. E. Klein, ${ }^{3}$ that the nearer to sewer outlets oysters and cockles are planted, the greater the pereentage of specimens yielding evidence of pollution. In the examination of oysters he holds that the presence of Bacillus enteritidis sporogenes alone is not sufficient proof of recent sewage pollution, but that when the spores of this organism are found together with streptococei and Bacillus coli communis they constitute strong evidence of recent contamination.

Dr. Hibbert $W$. Hill ${ }^{4}$ has recorded interesting results of examination of clams from flats in the immediate vicinity of the sewer ontlets of a number of private dwellings. Attention was devoted solely to the bodies of the clams and not to the water contained between the shells, which was practically the same as that which surrounded them. The technique followed was such as to insure absolutely against contamina-

1 Medical News, March 23, 1895.

${ }^{2}$ Science, 1902 , No. 375 , p. 363.

${ }^{3}$ British Medical Journal, February 21, 1903.

- Report of the Board of Health of Boston, Massachusetts, for 1901. 
tion by bacteria on the surface, and the portion of the body selected as most likely to show infection was the intestines. The following were isolated and identified: Bacillus coli communis, Bacillus enteritidis sporogenes, and Bacillus aërogenes capsulatus (Welch), all three of which are found commonly in sewage. The typhoid bacillus was not found nor was it expected, since there was but 1 case in the neighborhood and the excreta were disinfected. Dr. Hill adds that the search for typhoid bacilli in sewage known to contain them is, in most cases, practically hopeless, since even in severe epidemics the number of typhoid patients contributing to the sewage is almost always small in comparison with the total contributing persons, and only a small proportion of the bacteria present in a typhoid stool are typhoid bacilli; and to hope to find, by examining a few cubic centimeters from a large mass of water, a bacillus which is present in the proportion of one to every ten or hundred gallons of water, is almost, if not quite, useless.

From a series of experiments undertaken to determine the question of viability of the typhoid organism in sea water and within the oyster, Bordoni-Uffreduzzi and Zernoni ${ }^{1}$ concluded that it will live over 2 weeks in sea water and from 3 to 4 days in oysters, without lessening of virulence. Oysters from Spezia, Venice, and elsewhere, were examined to determine the presence of the typhoid organism in the water contained between the shells or in the tissues. The results were negative on this point, but the colon bacillus was isolated from oysters from 3 different sources. Oysters immersed in sterilized sea water, which later was infected with cultures of the typhoid organism, yielded virulent bacilli from the water between their shells up to the ninth day of examination, but never from the tissues themselves.

Stokes ${ }^{2}$ examined 87 specimens of oysters from various sources and found the colon bacillus in 33 or 37.9 per cent.; 2 out of 33 clams showed the presence of the colon bacillus (6 per cent.). Altogether 120 shellfish were examined, of which 35 or 29.1 per cent. showed the presence of the eolon bacillus. The number of bacteria per cubic centimeter of the juice of the oysters varied from 0 to 14,400. For the clams the counts varied from 0 to 3600 .

Furthermore, Stokes was able to isolate two organisms from market oysters which corresponded to the typhoid bacillus in morphology, motility, staining characteristics, and all eultural properties. They were, furthermore, pathogenie for guinea-pigs.

Agglutination tests gave results which were suggestive, but not absolutely characteristic of the typhoid bacillus.

Johnstone ${ }^{3}$ examined oysters taken from deep sea beds and found them practically free from bacteria. He succeeded only once in isolating the typhoid bacillus from shellfish. This positive result was obtained in a mussel taken from a bed near a sewer outlet.

1 Giornale della Reale Societí Italiana d'igiene, 1899, p. 500.

2 Annual report, Health Departmeut, City of Baltimore, 1909.

3 Jour. Hyg., Cambridge, 1909, p. 412. 
Other observers have found the baeteria of cholera and typhoid fever, B. coli communis, B. proteus vulgaris, and other organisms, in oysters contaminated by sewage, and all unite in the opinion that the presence of $B$. coli communis should arouse suspicion and induce improvements in the management and supervision of oyster beds.

In the investigation of outbreaks of typhoid fever supposedly due to oysters, bacteriological proof of speeific infection of those eaten or of others from the same lot always has been and always will be wanting, since, long before the appearance of the first symptom of the disease, the material is no longer available for investigation. But, in view of the fact that pathogenic bacteria have been found in the water between the shells of oysters from polluted beds; that they have been known to live for days in the tissues and retained water; and that, in the cases investigated, the beds have been found to be exposed to the influence of sewage, we may, therefore, properly conclude that a causal relation is very possible.

The danger of infeetion rises wholly from the presenee of sewage in the water where the oysters are planted or stored. The remedy lies either in transferring the beds to eleaner situations or in storing the contaminated oysters in clean sea water until the bacteria either have perished or have been washed away. What constitutes a sufficient length of time to insure purification is a matter of some disagreement. Many believe that a week is enough; others, that 16 days should be allowed. Oysters should not be stored where sewage matters ean reach them through long distanees by currents along the shore, nor where prevailing winds can exert a harmful influence to the same end.

It is difficult to make a rule as to the conditions under which contaminated shellfish shall be excluded from the market. Gage, of the Lawrence Experiment Station, has given as a criterion for the harmlessness of shellfish the absence of colon bacilli from 80 per cent. of the shellfish examined. Beds which produce shellfish more than 50 per cent. of which are contaminated with colon bacilli are to be condemned. It is manifest, however, that the kind of pollution is of greater importance than its amount.

Houston ${ }^{1}$ makes the following statement:

"A pollution, trivial in amount but speeific in charaeter, is mueh more dangerous than a contamination gross in amount but not specific in nature. It is also probable that a pollution, trivial in amount but specific in character and of recent sort, is more dangerous than a pollution gross in amount, specific in character, but of remote kind."

Pease, ${ }^{2}$ after an extended investigation of the shellfish industry for the New York State Board of Health, sums up as follows :

"Human discharges and refuse from collecting boats should not be dumped into waters over oyster beds, for typhoid carriers are as likely to exist among oystermen as among milk produeers. Oyster houses

1 Fourth Report of the British Royal Sewage Commission, Vol. I., p. 36, quoted by 'ease, Loag Island Medical Journal, Sept., 1910.

${ }^{2}$ Loc. cit. 
along shore should have efficient methods for the disposal of the discharges and refuse from their employes and themselves in the vicinity. Drinking beds for oysters should be ehosen for purity of water rather than convenience. Oysters should not be transported in sunken, openframed seows through polluted water. Finally, oyster growers should investigate the problem of removing polluting bacteria by transplanting the shellfish to clean water. It is undoubtedly true that oysters grow better in water polluted by sewage. Cannot this fact be utilized and its disadvantatge eliminated by thoroughly cleaning the oysters in unpolluted water?"

That the United States authorities have taken eognizance of the shellfish situation is apparent from Food Inspection Decision 110 of the U. S. Department of Agrieulture, issued October 15, 1909, which provides in part that, "It is unlawful to ship or sell in inter-state eommerce oysters or other shellfish taken from unsanitary or polluted beds."

Crawfish and Typhoid Fever.-Chapin ${ }^{1}$ mentions an outbreak of typhoid fever which was observed by Dr. Bissell, of Buffalo, and which was in all probability due to the eating, by boys, of partially cooked crawfish taken from a lake grossly polluted with sewage.

Water Cress and Typhoid Fever.-Chajin also quotes Hamer (special representative to the Medical Office of Health, London, 1900) as having traced an outbreak of typhoid fever to water eress which had been grown in sewage polluted water. Of 110 cases 55.3 per cent. ate of the suspected water eress, and the ineidence of the disease among the water-eress eaters was three times as great as among those who did not eat it.

Celery and Typhoid Fever.-Mor:e ${ }^{2}$ reports an outbreak of 49 eases in an insane asylum which was due, in all probability, to the eating of celery which had been fertilized with material taken from a filter bed, upon which had been placed the undisinfected stools of a typhoid fever patient.

\section{Poisoning by Meat and Fish.}

Animal foods are the frequent cause of most distresing disorders which not rarely have a fatal termination. Some of these are die to poisonous properties inherent in the living animal, some to batcterial poisons formed in meats showing no evidence of unwholesomeness, and some to decomposition products developed during storage or putrefaction.

1. Poisoning Due to Substances Normally Present in the Living Organism. - As hats been stated, eertain species of fish are always poisonous and others only at times, and in some cases only individual members are so eonstituted. Certain speeies are so well known to be poisonous in perfeetly fresh condition that they never are eaten by the

1 Sources and Modes of Infection, 1910, p. 318.

${ }^{2}$ Mass. State Board of Health, 1899. 
natives of the places where they are found, except for purposes of suicide. Some have poisonous glands connected with their fins, some have poisonous ovaries, and other's are poisonous throughout. Some are poisonous only in the raw state, and others whether cooked or not. The symptoms produced vary widely, sometimes indicating gastroenteritis, sometimes involvement of the central nervous system.

The mussel is regarded not uncommonly as an intrinsically poisonous shellfish, but the weight of evidence indicates that mussel-poisoning is due to conditions of disease or infection arising from residence in polluted water. Its poisonous properties have long been recognized, and have been the subjeet of a number of dissertations by early writers; thus Behrens, De affectionibus a comestis mytulis, Hannover, 1735, and Moehring, Mytulorum quorundam venenum et ab eo nates papulas cuticulares Epistola, Nuremberg, 1744. In France, where great quantities of mussels are caten, cases of poisoning thereform are rare, owing doubtless to the fact that those taken from polluted harbors are kept for a week or more in clean water elsewhere.

2. Poisoning Due to Bacterial Products in Meats and Fish.What is known commonly as meat-poisoning, fish-poisoning, and sausage-poisoning is due to the products of a number of micro-organisms having no connection with the usual diseases of man. These toxic products eause an extremely wide variety of symptoms, which, as may be observed on examination of the collection of reported outbreaks given below, indicate the possible derangement of function of practically every part of the system. There are two groups of symptoms, however, which are fairly constant, either one of which may predominate over all the rest. These are (1) the manifestations of profound disturbance of the gastro-intestinal canal, and (2) those indicating more or less intense poisoning of the central nervous system. Prominent among these latter are impaired vision (dilated pupils, ptosis, amphodiplopia, etc.) and glosso-pharyngeal paralysis; and when those are present, the case is said to be one of "botulism." This term, which cane into existence by reason of the fact that many of the earlier observed cases of food-poisoning were traced to sausages (botulus, a sausage), is, in the light of our present knowledge, unfortunate and misleading, for the condition may be caused not only by salusage, but by any form of meat and fish or other food product which may happen to be contaminated by the micro-organisms which produce the peculiar toxin (or toxins) by which the manifestations are eaused. And it is not true, as is supposed by some, that botulism is caused by the proteid bacterial poisons alone (commonly known as toxins), but by certain of the hasie erystalline products of decomposition, known as ptomains, as, for example, mytilotoxin, a ptomain isolated by Salkowski and Brieger from contaminated mussels.

Not uncommonly, ptomains are regarded as necessarily poisonous substances. This, however, is far from being the truth. They are products of decomposition brought about by micro-crganisms which break up the complex organic matters into less complex compounds, 
which in turn are split up into products of diminishing complexity, until the final products are water, hydrogen, carbonic acid, sulphuretted hỵdrogen, ammonia, nitrogen, and salts. During this process of decomposition, at different stages, the ptomains, which are organic bases, are formed. Some are poisonous, but the great majority of those thus far isolated are wholly inert. All contain nitrogen, but not all eontain oxygen, thus resembling the vegetable alkaloids. The variety of ptomains formed depends upon the kinds of micro-organisms at work, the nature of the substance undergoing decomposition, and the conditions of temperature, access of air, and other attendant circumstances. One species of bacteria may produce no ptomains from one kind of material, and poisonous or inert ones from another. At one stage of decomposition no ptomains may be formed, at another several may be present, and later these may have disappeared completely, for they are but intermediate products.

Brieger has isolated a number of varieties of ptomains from decomposing meats and fish, including neurine, choline, and one which appears to be identical with muscarine (all three of these are antagonized in their poisonous action by atropine), and neuridine, putrescine, cadaverine, another which produces effects similar to those of curare, and others. Vaughan discovered the very important ptomain, tyrotoxicon, in milk and cheese.

Many of the poisonous componnds formed during putrefaction retain their active character long after the organisms through whose agency they have been produced have perished. This was noted as early as 1856 by Panum, who found that the poison of certain putrid meat retained its activity even after it had been boiled 11 hours, and his observation has repeatedly been confirmed by others. Naturally, no amount of cooking will suffice to render such meat harmless.

The physiological action of these poisons is widely different. Some cause intense gastro-intestinal irritation, some act directly on the heart, some on the central nervous system, and some on particular centers. Very different effects are produced in different people, owing perhaps to varying degrees of susceptibility and also to nnequal distribution of the poison through the mass of meat.

The extent to which the putrefactive process has advanced is by no means of such importance in the determination of the question of possible ill effects, as the nature of the engaged bacteria and of their products, for meat may be extremely putrid and yet not be poisonous, and, on the other hand, may be apparently normal and yet deadly in its effects. Many savage peoples prefer putrid fish and meat, and the more rotten it is, the greater their enjoyment in its consumption. In less degree, the same is true of many of the most enlightened people, who prefer game when decomposition is fiirly well advanced. On the other hand, the severest outbreaks of food-poisoning have followed the eating of meat apparently not undergoing decomposition. Indeed, the majority of persons will reject meat which has the slightest taste or odor indicating beginning putrefaction, since even this makes it repug- 
nant to the senses. In many cases, the poisonous principles appear to be developed after the meat has been eaten, through changes occurring within the intestines.

The bacteria which have thus far been shown to have been the eause of outbreaks of meat- and fish-poisoning include certain spore-bearing anaërobes isolated by Van Ermengem (B. botulinus), and Klein (B. enteritidis sporogenes), a number of derivatives of $B$. coli isolated by Gaertner (B. enteritidis), Basenan (B. bovis morbificans), Kaensehe (B. Morseelensis and B. Breslaviensis), Gaffky and Paak (B. Friedebergensis), Abel, Günther, and others, besides B. proteus vulgaris, B. proteus mirabilis, Staphylococeus pyogenes flavus, and others. The first mentioned (B. botulinus) produces an extraordinarily virulent toxin, which has been the subject of careful investigation, which has proved that it is related closely to the toxins of diphtheria and tetanus.

Study of a bacillus which Trautmann ${ }^{1}$ isolated as the cause of an outbreak of poisoning at Düsseldorf, and comparison thereof with cultures of $B$. Friedebergensis, B. enteritidis, B. Morseelensis, B. bovis morbificans, B. Breslaviensis, and of the organisms isolated by Fischer, Abel, and Günther, and also of the various strains of paratyphoid bacilli, led him to the conclusion that, while these several kinds present slight differences in morphology and cultural peculiarities, they show no fundamental difference and are merely varieties of one and the same organism. Others have called attention to the similarity of symptoms in meat-poisoning (not botulism) and paratyphoid, and the belief is growing that the differences in the nature and severity of symptoms and in the order of their appearance are dependent upon the slight racial differences in the bacteria and upon the degree of virulence and individual susceptibility. Many outbreaks of meat-poisoning have been indistinguishable from paratyphoid, and many of severe form have been mistaken for true typhoid. Trautmann believes that the typical meat-poisoning is the hyperacute, and paratyphoid the subacute, manifestation of an etiologically similar disturbance, and he places all of the exciting eauses under the general head of B. paratyphosus.

It has not been supposed that the organisms which cause meat-poisoning of the more common types, such as the Bacillus botulinus and the $B$. enteritidis of Gaertner, are widely distributed in nature, but the following statements will show that the danger of infection is not to be lightly disregarded. Klein, ${ }^{2}$ for instance, found the B. enteritidis of Gaertner in ten out of thirty-nine milk samples which had been collected for examination for tuberculosis. The number of organisms was not large, to be sure, but if this milk had been kept in suitable surroundings of temperature it could have become very dangerous. The farm from which this milk came was a very dirty one.

Conradi ${ }^{3}$ found paratyphoid bacilli in natural ice from various sources, and suggests that this may be the origin of paratyphoid

1 Zeitschrift für Hygiene und Infeetionskrankheiten, XLV., p. 139, and XLVI., p. 68.

${ }^{2}$ Centralb. f. Bakt. Orig., Vol. XXXVIII., 1905.

3 Münch. Med. Woch., May 4, Vol. L'I., pp. 897 and 952. 
infection in certain cases. He found, furthermore, that ehopped ice is mixed with the meat in certain districts in the process of making sansages.

Uhlenhuth ${ }^{1}$ examined a number of healthy hogs killed at the abattoir in Berlin ; 6 per cent. of the cases showed bacilli very similar to paratyphoid, type $B$.

Rimpau ${ }^{2}$ found twenty-six persons who were excreting paratyphoid bacilli, type B ; 10 of these were sick typhoids, 5 were typhoid bacillus earriers, and 11 were healthy individuals. His investigation brought out three important points: First, the frequent oceurrence of these bacilli in the urine; second, bacilli were present in persons who had been in contact with those sick with paratyphoid B infection; third, the occurrence of this organism in external nature. Of the 26 eases, the germs were found 15 times in the urine and stools, and 9 times in the urine alone. They may be found in the blood without causing any symptoms, and once were found in the blood of a true typhoid. He found this bacillus also in the stools of fifty presumably healthy school boys. Rimpau found it also in a perfeetly good sansage.

Hübener ${ }^{3}$ examined 100 samples of sausage and found paratyphoid organisms of this type in 6 . 'The sausage was apparently good and caused no disagreeable symptoms.

Duchan ${ }^{4}$ quotes Ford ${ }^{5}$ as having found the B. enteriticlis of Gaertner in the large intestine of a human subject. He quotes Savage also as having found members of the Gaertner group in the intestines of four pigs. In one of these they were present in large numbers.

Signs Pointing to an Epidemic.-Vagedes ${ }^{6}$ gives three chief indications for an epidemic of food poisoning. First, sudden appcarance of poisoning in persons up to that time perfeetly well; second, symptoms of illness following the ingestion of a certain food product; third, sickness in several persons who bave eaten the same food product.

Onset and Course of Symptoms.-The first symptoms in cases of poisoning by fish and meats may occur within an hour or two alfer eating or may be delayed a number of days. In one outbreak cited (see Poisoning by Herrings, page 73), in which 5 persons were seized, the initial symptoms appeared in 2, 3, 5, 7, and 9 days respectively; ordinarily they appear within a few hours-3, 6, 12. W' hen numbers of persons are affeeted by the same food, the onset is by no means uniform. In the Ellezelles case (see page 81), in which 20 persons were seized, the time in which the symptoms first were minifested ranged from 3 to 36 hours, but as a rule, it is the appearance within the same day of similar symptoms in a number of persons which ealls attention

1 Deutseh. Med. Woch., 1907, No. 11.

${ }^{2}$ Zur lirage der Verbreitung der B. aus der Paratyphus Gruppe, Deutsch. Med. Woch., 190s, 124.

${ }^{3}$ Ueber das Vorkommen ron Bakterien der paratyphus Gruppe in der Aussenwelt, Deutsch. Med. Woch., 1908, No. 24.

4 Public Health, July, 1908.

${ }^{5}$ Studies from the Rockefeller Institute, Vol. II., 1904.

${ }^{6}$ Vierteljahrschr. f. Gerichtl. Medizin., Vol. XXIX., 1905. 
to the food supply as a common cause of the trouble. Poisoning by ptomains is manifested generally within a few hours.

In cases of rapid onset, the progress either to recovery or a fatal termination is commonly short, but may be sometimes a matter of months, and in these exceptional eases eventual recovery is probable. The shortest ease on record is that of mussel-poisoning at Willelmshaven (see page 72 ), in which 1 victim died in 2 , another in 3 , and 2 others in 5 hours after eating.

A peculiar tendency to relapses often is observed. The patient begins to improve, when suddenly the original symptoms reappear with equal, greater, or diminished intensity. Improvement may be succeeded again by a relapse, and the alternation may obtain for many months. The toxins secreted by the original invading bacteria are antagonized by antitoxins produced by the system and improvement occurs; then during this interval the spore-bearers find opportmity to develop a new erop of bacteria, which, again producing toxins, cause a recurrence of the original symptoms.

Nature of Symptoms.-As has been stated, the effects produced vary very greatly, but the symptoms of abdominal disturbance and of poisoning of the central nervous system are the most constant as well as most predominant. Fever may or may not be present; usually it is not, but in some outbreaks temperatures exceeding $104^{\circ} \mathrm{F}$. have been recorded. In some cases, the temperature is subnormal. Disturbance of the circulation is more common than fever, the pulse being small and rapid, and sometimes dicrotic. In a few instances, marked embarrassment of respiration has been noted. In most of the recorded eases, no mention is made of involvement of the kidneys, but in some instances evidence of acute nephritis has been observed. Dysuria, annria, and paralysis of the bladder are not uncommon. In most cases, extreme muscular weakness is a prominent symptom, and not infiequently muscular pains and cramps. While diarrhoea, long continued, is a most common oceurrence, in many cases most obstinate constipation, sometimes following diarrhoa and sometimes present from the first, is noted. In some cases aldodominal symptons are by no means prominent, and in others they are practieally the only ones observed. The symptoms of involvenent of the nervons systen inchude those mentioned above, and drowsiness or insomnia, headache, dizziness, delirimm, diminished co-ordination of movement, numbness, cramps, convulsions, and paralyses.

Post-mortem Appearances.-The post-mortem appearanees observed in cases of poisoning are very inconstant, both as to extent and kind, and are by no mains proportionate to the severity of the symptoms. Even when a number of individuals sucembl to the same influences, the appearances may show but little in common. Thus, in the W'beck case (paige 79), one showed nothing more than a few bright red patehes in the stomach; a second, eongestion of the gastro-intestinal mucous membrane; and a third, severe parenchymatous inflammation with distention and plugging of the arterioles and apillaries of the Malpighian 
corpuscles by emboli of bacteria. The most extensive changes observed are those occurring in poisoning by mussels and oysters, in which cases the extremely rapid onset and the very short course to a fatal termination suggest the action of poisonous ptomains. Indeed, animal experimentation has demonstrated that certain of these compounds produce these very changes, which include great enlargement of the spleen, punctiform ecchymoses and hemorrhagic infaretions, and fatty degeneration of the licart, liver, and kidneys. In cases of meat-poisoning, the appearanees noted range from a few red patches in the intestines to severe gastro-enteritis with destructive changes in all the principal viscera.

Character of Meats which Cause Poisoning.-In general, outbreaks of poisoning are caused by the meat of animals slaughtered while suffering from diseases other than those which are best known to the public because of the great destruction wrought when raging in epidemic form; but they may also be traced to the flesh of perfectly healthy animals which has become contaminated, both in the raw and cooked states, by poison-producing bacteria.

The most dangerous forms of meat-poisoning are those due to the pyæmias, septicæmias, and pneumo-enteritis, and the greatest intensity of action is produced by preparations made from the entrails.

In a majority of the reported outbreaks, the meat has been consumed either raw or only imperfectly cooked, or after being kept a day or two after being cooked. The meats most commonly the cause are pork and its preparations, and veal. Both yield a considerable amount of gelatin, and this fact has been suggested as having an important bearing, since this material is a medium which offers favorable opportunities for the growth of bacteria.

Most of the reported outbrcaks have sccurred in the countries of Europe, where the meat supply, in consequence of being very restricted, is utilized to its fullest extent. Viscera which with us are rejected as refuse, and the flesh and viscera of animals slaughtered in consequence of sickness, with the consent and approval of official veterinarians, are sold and eaten. Another reason for the frequency of the outbreaks is a very common preference for scraped or minced raw meats and for sausages of domestic manufacture made under most unsanitary conditions.

Veal.-According to Vallin, in a communication to the Academy of Medicine in 1895, a large number of outbreaks of poisoning in Germany, Switzerland, and elsewhere are due to the consumption of veal from animals either sick or too immature. Darde and Drouineau ${ }^{1}$ relate that they have seen nearly the whole strength of a military company, 135 out of 147 , poisoned by eating roast veal. The symptoms appear generally in from 6 to 24 hours, and include vomiting, purging, and great prostration. Dilatation of the pupil is common, but not constant. Occasionally, skin eruptions appear.

By Vallin, ${ }^{2}$ and by others as well, it is deemed probable that veal-

1 Archives de Médecine et de Pharmacie militaires, 1895.

2 Revue d'Hygiène, 1895, XVII., p. 473. 
poisoning is due largely to the existence of septic pyæmia and septic pmeumo-enteritis in calves, and Van Ermengem has suggested that a number of septic diseases of these animals are grouped commonly under the head of diarrhea. He fed the fresh meat of one of these calres to mice and guinea-pigs, which died within a few days with enteritis. From the bone marrow he isolated an organism which appears to be related closely to Gaertner's B. cnteritidis, and which on inoculation into animals produces a fatal enteritis.

Beef.-Beef-poisoning has been noticed with considerable frequency, following the use of meat from animals slaughtered while sick, and it has been pointed out by several observers that certain septic diseases of eattle are especially prone to render meat poisonous. These include the septic form of calf paralysis, hemorrhagic cnteritis of calves, septic metritis of cows, various intestinal disorders, the septico-pyæmic diseases, and a number of others. Gaertner's B. cnteritidis was discovered by him originally in the flesh of a cow that had been slaughtered on account of a severe diarrhœa, and in the spleen of a person who died in consequence of eating it. He showed that not only the bacillus, but also its boiled bouillon cultures, are highly toxic.

Many deaths have been recorded as a consequence of cating the cooked meat of cows slaughtered on account of puerperal fever, and it was from such an animal that Basenau isolated $B$. bovis morbificans. 'This cow showed such lesions of the viscera that the director of the Amsterdam abattoir forbade the ise of the meat.

Basenau" has examined the flesh of beeves which had succumbed to a varicty of diseases, and he has isolated a number of species of bacteria bearing a close resemblance to $B$. bovis morbificans, all of which are fatal to mice. Some of them prodnce poisonous matters which withstand boiling without impairment of their properties. Ordinary inspection being useless for determining whether such neat is infected, he recommends that bacteriological and feeding experiments should be instituted togrether within 24 hours after slaughtering. If no colonies are observed at the end of 24 hours and no bacteria are scen in the tissues, the meat may be regarded as safe to eat. If colonies are yielded, the acceptance or rejection of the meat must depend ipon the results of the feeding experinents. If the mice fed on the raw meat die and those ferl on the cooked meat survive, it may be concluded that the meat is sate, if thoroughly cooked. If both die, the meat should unhesitatingly be condenned.

Sausuge.-Sausage has long bcen recognized as a very common cause of poisoning, and has a much larger record of accidents than any otlier meat or meat compound. This is due in large part to a very common practice of making use of all mamer of uninviting fiagments and seraps of meat, offil, and the flesh of sick and ill-conditioned animals in preparing sausage meat, and perhaps to a groater extent to the extremely unsanitary methods of manufacture which obtain in those districts where this form of poisoning is most prevalent. In many

1 Arehiv für Hygiene, XXXII., p. 219. 
instances the symptoms caused are due to the presence of ptomains, and in many to the contained bacteria and their toxins.

In most instances, it is impossible to fix the blame upon any individual constituent, nor aside from its scientific interest is this of special importance. The symptoms present as wide variations in character as are observed in any other form of food-poisoning

The process of smoking, to which eertain varieties of sansages are subjected, while not destructive to the lacteria of putrefaction, is often successful in masking any minpleasant smell or taste due to change.

\section{Cases Illustrative of Poisoning by Fish and Meat.}

Poisoning by Mussels. CAsF I.-At Wilhelmshaven, in 1885, several longshoremen and their fumilies, 19 persons in all, were stricken with very severe symptoms shortly after eating a meal of mussels. The symptoms were in general the same in all, regardless of the amount eaten, and included nausea and vomiting without abdominal pain or purging, trembling, constrietion of the throat, dizziness, and diminished coördination of movement similar to that dire to alcoholic intoxication. There was no fever. Speech was difficult and thick, and in a short time the legs were unable to support the body. The pupils were dilated and unresponsive to reaction tests. The extremities were cold and numb. Four deaths oceurred, one within two hours, one in three and a-half, and the others within five hours from the time of ingestion. The antopsy in the only case examined revealed enteritis, enormous enlargement of the spleen, numerous hæmorrhagic infaretions, and fatty degenenation of the heart, liver, and kidneys.

In this case, the sudden onset and rapidly fatal termination indicate a true poisoning rather than an invasion of the system by bacteria, and, indeed, the poison was proved by Salkowski and Brieger to be a ptomain, to which they gave the name nytilotoxin.

CASE II.-Dr. James S. Combe, ${ }^{1}$ of Edinburgh, reported, in 1828, an outbreak which involved a large number of persons of the lower class ranging in age from 2 to 70 years. The first ease seen was a man of 60 , who complained of thirst, heat in the month, diffieulty in swallowing, tension abont the jaws and throat. The pulse was small and weak, the respiration normal, the surface cool. The liands were numb and the legs unable to support the body. Recovery followed purgative treatment. He had supped the evening before with a friend, who dich during the night. They had eaten mussels boiled with salt, but had noticed no peculiarity of taste. The next case seen was that of a man of 30 who, on the previous evening, had picked a few mussels, not over five or six, and had eaten them raw. No effects were noticed until morning, exeepting slight burning of the lips and tongue. On attempting to get up lie found that he could not stand, although he, like the first, conld move his legs about in bed.

Although liundreds of cases, with many deaths, were said to have

I Edinburgh Medical and Surgical Journal, 1828, XXIX., p. 86. 
ocenrred, in consequence of which the magistrates issued a warning against the use of mussels, Dr. Combe found but thirty cases with two deaths. In all, the symptoms presented a striking miformity, though they varied much in severity. Most of the vietims had caten the missels boiled with salt and pepper, and none had noticed any unusual taste. In general the symptoms appeared in an hour or two.

The man who died had vomited a few hours after eating. He lay down, had occasional general trembling, was rational to the last, and died as if by inereasing weakness. On section a few dark-red patches were found in the ileum. The stomach was empty and presented no abnormal appearance. The other fatal ease was that of a woman who died in three hours after eating. The autopsy revealed a full stomach containing mussels and potatoes, and beyond a few red patches in the intestine the viscera were quite normal.

In his report, Dr. Combe referred to a ease related by Captain Vaneouver, ${ }^{1}$ a number of whose men ate a breakfast of roasted mussels. Soon, several were seized with numbness about the face and extremities, followed by involvement of the whole body. One man, who died in five and a half hours after eating, was unable to swallow, and though he conld row in the boat while sick, he was unable to stand on leaving it.

Poisoning by Herrings. - A case involving five persons, reported by R. David, ${ }^{2}$ is remarkable for the variety of manifestations, the length of time that elapsed hefore the appearance of the symptoms, and, in two of them, the severity and duration of the illness. The afflieted persons, adult members of one family, ate on Mareh 19, 1898, some raw red herrings, which gave off odor indieative of commeneing putrefaction. Fach ate the same amount, a whole fish, but whether each fish was equally advanced in decomposition eamnot, of course, be determined, and the differing degrees of severity of effects may be explained by unequal susceptibility. The father and mother aged, respectively, 65 and 67 years, suffered least; the son, arred 31, was affected more serionsly; the two danghters presented unusually severe and complicaterl symptoms.

The first effects were manifested by the son, who, on the second day, was seized with loss of appetite, disagreeable eructations, vomiting, diarrhoa, dryness of the throat, and general weakness. On the following day, he was better, but soon became worse. Diarrhea was followed liy olostinate eonstipation, which finally yielded to cathartics. Five days later, he had dimmess of sight, which was followed after a week by double vision and diffieult deglutition. The symptoms gradually abated, and on May 27 th there was distinct improvement of sight. On June 201 glasies were hardly needed.

'The mother first showel symptons on the fifth day, when nausea, constipation, and dryness of the throat appeared. Several days later she had doulsle vision and difficult deglntition.

1 Toyage of Discovery, Vol. I ${ }^{*}$., p. 45.

${ }^{2}$ Deutsche medicinische Wochenschrift, 1899, No. 8. 
'The father's case began on the ninth day and presented similar symptoms, which disappeared in six weeks.

One of the daughters was seized on the third day with bad taste in the mouth, constipation, and dryness of the throat, followed in six days by dimness of near vision, then by double vision, paralysis of aecommodation, and difficult swallowing. As was the case with the others, the temperature, circulation, and urine remained normal. On May 2d, there was complete inability to swallow and it was necessary to introduce food by means of a stomach-tube. There was slight ptosis of the right eye, then of both; the voice was nasal; the gait was affected and the pulse became very small, though not very rapid. On May 9 th, bladder symptoms, which had been gradually appearing, enlminated in paralysis of that organ, and after the $13 \mathrm{th}$, a variety of bladder and abdominal symptoms appeared. In the first part of July, she felt completely well, but a month later she suffered a slight relapse, with reappearance of constipation, difficult deghutition, and disturbance of vision, which persisted with varying intensity into September. Complete recovery did not occur until October, almost seven months after the initial symptoms.

The other daughter first showed symptoms after the lapse of a week. These were in the main like those of her sister, but were more severe and extensive. She began to improve in May, and then ensued alternate improvement and loss of ground, better one day and worse the next. On the 15th, there was pain in the left hypochondriun ; on the 17th, an eruption like that of scarlet fever over the whole body, with albuminuria, but no casts. On the 19th, severe pain in the left hypochondrium, less in the right, and tenderness in the region of the kidneys, with epistaxis, disappearance of the rash, slight desquamation, and improved vision. At the end of May, the albuminuria and pain in the region of the kidneys had nearly disappeared, and deglutition was perfect. On June 2d, heart complications appeared, which persisted into November, when hypertrophy was established. In August, after a general improvement, there was a relapse like that which occurred in the case of her sister. Improvenent was well established in October, and in November she had almost wholly recovered.

Unfortunately, it was impossible to make a bacteriological and chemical examination of the fish, because no material was obtainable.

Poisoning by Salmon.-Professor Vaughan' reports the following case: "K., a very vigorous man of 34 years, ate freely of eamned salmon. Others at the table with him remarked that the taste of the salmon was peculiar, and refrained from eating it. Twelve hours later, $\mathrm{K}$. began to suffer from nausea, vomiting, and a griping pain in the abdomen. Eighteen hours after he had eaten the fish, the writer saw him. He was vomiting small quantities of mueus, colored with bile, at frequent intervals. The bowels had not moved and the griping pain continued. He was covered with a searlatinous rash from head to

1 Ptomains, Leucomains, Toxins, and Antitoxins, 1896, p. 56. 
foot. His pulse was 140 , temperature $102^{\circ} \mathrm{F}$, and respiration shallow and irregular." After appropriate treatment he began to improve. "The next day the rash disappeared, but the temperature remained above the normal for four or five days, and it was not until a week later that the man was able to leave his house." Vanghan examined the salmon and found a micrococens present in great numbers. This organism, grown for twenty days in a sterilized egg, produced a most potent poison. The white became thin, watery, and markedly alkaline, and ten drops sufficed to kill white rats.

Poisoning by Pike.--Ulrich ${ }^{1}$ reports an epidemic of fish poisoning through the eating of pike (Meerhecht). He makes the point that the fish became more and more poisonous according to the time elapsed subsequent to cooking. In 2 patients bacillus paratyphoid $\mathrm{B}$ was isolated from the blood and 4 other patients gave positive agglutination tests with the same organism. Ulrich believes that fish shonld never be eaten later than twenty-four hours after it has been cooked.

Abraham ${ }^{2}$ reports twenty-eight cases of poisoning after eating pike. In eighteen hours there occurred severe colic, nausea, and diarrhœa. The infection had some resemblance to typhoid fever. A piece of the suspected fish presented a good appearance and showed no evidence of ptomains or metallic poisons. Prof. Neisser found in the fish bacilli of the paratyphoid or meat-poisoning group (type Aertryck). The toxin produced by this organism was resistant to heat and the blood of the patient gave with this organism positive agglutination tests. The speeific bacilli conld not, however, be found in the stools of the patients. It is, therefore, most probable that the fish was infected during life. It is said that pike favor localities like sewer outlets, and could easily become infected. There were no deaths among these patients.

Poisoning by Oysters._CAse I. - The following case, which ended fatally, is reported by Brosch. ${ }^{3}$ An officer ate a number of oysters toward midnight, and within 6 hours was seized with headache, pain in the side, nausea, dimuess of sight, difficult deglutition, retention of urine, and salivation. Toward noon, right facial paralysis, dilatation of the right pupil, and thickness of speech appenred, followed shortly by cyanosis, ptosis of the right eyelid, great muscular relaxation, and paralysis of respiration. Autopsy revealed punctiform echymoses in various parts, enlargement of the spleen, and fatty degeneration of the liver and kidneys.

CASE II.-Another fatal case is recorded by Casey :4 "H. P., about 32 years of age, ate 8 oysters for supper, reniarking at the time that one of them was bad. Others of the same lot appeared to be quite fresh and were eaten by other persons with impunity. Symptoms of poisoning began about 12-14 hours later, with pain in the back, soon followed by violent pains in the stomach, frequent romiting, and intense

1 Zeit. f. IIyg., Vol. LIII., 1906.

2 Münch. Med. Woch., 1906. No. 50, p. 2466.

3 Wiener klinische Wochenschrift, 1896, No. 13.

4 British Medical Journal, March 3, 1894, p. 463. 
thirst. The bowels did not aet. These symptoms continued until the following morning, when the pulse, which had been small and quick, became almost imperceptible, the fingers shrunken, the nails blue. The tongue was at that time dark and swollen, and swallowing difficult. There were occasional spasms of the arms. A little later, the jaw became set, and soon, after a sudden struggle for breath, he died, 41 hours after eating the oysters. At the post-mortem exammation, the heart was found to be very soft and relaxed and contained fluid blood. The kidneys and spleen were also very soft and eongested; the stomach empty and darkly congested ; the peritoneum was thickly studded with Heeks of lyniph."

Poisoning by Veal.-Boyer ${ }^{1}$ reports the following case of sextuple poisoning by veal. The persons affected were members of one household, and ranged widely in point of age, the youngest being children of 3 and 6 years. The symptoms appeared in the night, abont 6 lours after the food was taken, and began with roniting and violent colic. In the morning, all had intense gastric irritability, eoated tongue, pain on pressure, especially in the right iliae fossa, rumbling, slight tympanites, and seanty urine. The cook had markedly dilated pupils, a sensation of suffocation, constriction and dryness of the throat, and intense suffusion of the face. The child of 6 had dilated pupils and disturbance of vision, and finally pain and stiffness of the museles of the neck. The younger of the two ehildren and the mother were affected less than the others, and made a more rapid recovery. The chambermaid had at first a certain degree of aggravation of symptoms, with a tendeney to syneope and great museular weakness, which latter effects were marked also in the case of the cook, who continued for some time to be troubled by dilatation of the pupils and disturbed vision. At the end of nine days, there was no evidence of dianger, and the two most severely affeeted were well on the way to recovery.

Unfortunately, no bacteriological examination was made either of the meat or the discharges, but the nature of the symptoms leaves no room for doubt as to their cause.

CAsE II.-Drs. Wilkinson, ${ }^{2}$ Ashton, and Durham have recorded an extensive outbreak of poisoning due to imperfectly cooked veal pies. All the cases, over fifty in number, presented very similar symptoms, the ehief of which were severe and uncontrollable romiting and diarrhea, aceompanied at first by shivering, and followed by collapse. In some there were violent abdominal pains, and in several the abdomen was swollen and tender. Many had severe pains in the back. The symptoms began in from 5 to 14 hours after eating, and, as a rule, were severe from the start. The motions were first grass-green, then dark green, and highly offensive. The severity of the diarrhoa inereased on the seeond day; one patient was purged 40 or more times in a single day. In very few eases, the dejecta contained a little blood.

${ }^{1}$ Lyon médical, May 14, 1899.

${ }^{2}$ Public Health, January, 1899, and British Medical Journal, December 17, 1898. 
In the worst cases, the patients became semi-comatose, restless, and delirious in the comse of a few hours. Occasionally, there were disturbances of vision, which lasted until the temperature, which ranged from $100^{\circ}$ in the mildest to $104.5^{\circ} \mathrm{F}$. in the severest cases, became normal. The pulse was very rapid, weak, and dicrotic. Many of the patients were markedly cyanotic and had more or less diffienlty in breathing. Some had cramps, and nearly all had muscular pain and stiffness. In very many eases, herpes appeared abont the lips on the third to the sixth diy, and some had a rash followed by desquamation. Convalescence in the severe cases was prolonged; some were still weak after three and a half months. Four eases terminated fatally, and in two of these, autopsies were secured. The brain surfice showed slight congestion; the small intestines showed congested patches, which became larger and more numerous lower down, and did not correspond with Peyer's patches. 'The whole lower third was highly congested, and contained yellow diarrhoic fluid. Otherwise the organs of the body were in a fairly healthy condition.

Investigation of the cause of the outbreak yielded the following facts: On July 26th, an apparently halthy calf was slaughtered, and two days later the fore quarter and breast were delivered to a baker, who made the meat into the pies which were shown to have been the cause of the outbreak. Other portions of the animal were sold to others, who made pies which caused no trouble. A portion of a knuckle end, which was in the possession of the butcher when the investigation was begun, was to all appearances perfectly good.

The baker to whom the trouble was traced made, on the day he received the meat, 160 veal pies and 108 pork pies. The pastry was the same for the entire lot, and both kinds were treated to the same lot of jelly, which was made by boiling the veal bones with two pigs'feet in $t$ quarts of water. Inasmuch as the pork pies caused no disturbance of any kind, no responsibility could be attached to the pistry or to the jelly. The veal pies were baked in not less than 3 nor more than 5 batehes, hence the batehes would have included about 32, 42, or 5:3 pies. The time occupied in baking each batch was said to have been about 20 minutes. The number of perions affected was over 50 and as in some cases single pies were shared by 2, 3, and 4 persons, it is obvious that less thin 50 pies cansed all the trouble. Since no other parts of the animal caused any sickness, there can be no doubt that the contamination of the meat ocemred after the sale and delivery.

Aceording to the findings of Dr. Durham, based on a study of the blood of a number of the patients as to the behavior of the serum when tested for clumping properties with varions miero-organisms, with controls of serum from normal persons, the ontbreak wats due to B. enteritidis. This limitation of the inquiry was necessitated by the fact that it was impossible to secure cither one of the pies, or part of one, or any of the first ronitings. The conclusion arrived at, strengthened by the fact that all + fatal cases were from pies which 
were 2 or more days old when eaten, which period allowed enormous multiplication, makes most probable the further conclusion that one whole batch was eooked so insufficiently as to preclude the killing of the organisms, which, according to Basenau, cannot survive exposure for 1 minute to a temperature of $70^{\circ} \mathrm{C}$.

CASE III.-Brekle ${ }^{1}$ reports an epidemic of poisoning due to the eating of meat coming from a calf which had been subjected to emergency slaughter because of sickness. There were 13 cases and 2 deaths. Symptoms came on in about eighteen hours, characterized by vomiting, giddiness, chills and fever, colic, and diarrhœe. Some of the eases were quite protracted, lasting as much as four weeks. There was no especial taste to the meat which was at fault. The same organism was isolated from the infected meat, from the organs of those who died, and from the stools of the sick. 'This organism gave reactions which identified it very closely with the $B$. enteritidis of Gaertner. The toxin produced by this organism was, furthermore, resistant to heat, and therein agreed in character with the bacillus of Gacrtner.

Poisoning by Pork.-CAsE I.-Meredith Young ${ }^{2}$ records a case of pork-poisoning in which 5 persons were affected. The offending meat was three-cuarters of a pound of "pig's cheek," which was eaten at half-past four in the aftemoon, between which time and the onset of symptoms nothing else was eaten. On the following morning, Mr. A. was seized suddenly with vomiting, purging, and severe abdominal pain, and shortly afterward beeame very feverish and weak, and suffered from severe frontal headache. His wife had severe abdominal pain, and toward noon was strongly purged. She suffered nausea, retehed, but could not romit, had fever and severe beadache, and was much more prostrated and took more time to recover than her husband. She was unable to ingest food for 3 days. The daughter was taken sick at the same time and with the same symptoms, though less severely. Her ehief symptom was an overpowering tendeney to sleep. A fourth person, who ate but little as eompared with the amounts ingested by the others, was purged slightly, but suffering nothing more. The remaining member showed no effeets until during the second night. On the following morning, she was feverish, had severe headache and abdominal pain, and retched unsuceessfully. Purging did not occur until the afternoon. As was the case with the daughter, the most prominent symptom after the onset was somnolence. Recovery followed in every case. Investigation showed that the eheeks had been cooked 2 days before, and had been placed together to cool and "set." It was estimated that between 50 and 60 persons had purchased of them, but all but a small proportion were unknown to the seller, and so no systematie inquiry could be made. Only 4 could be followed up, and 2 of these reported no trouble; a third was made severely sick and lost 2 days' work, and the fourth, after eating, drank so much beer that he was made sick and lost it all by vomiting, and yet

1 Münch. Med. Woch., June 7, 1910, p. 1227.

${ }^{2}$ Public Health, June, 1899. 
was affected like the others, but not so actively. It was impossible to procure any of the meat or romited matter or dejections for bacteriological examination.

CAse: II. - At the Seventh International Medical Congress, held in London, in 1881, Ballard ${ }^{1}$ read before the section on State Medicine an account of a very serious outbreak, now generally known as the "Welbeck case." This involved 72 persons, who attended a sale of timber and machinery on the estate of the Duke of Portland at Welbeck, which lasted from Tuesday, Jume 15, 1880, through the week. Refieshments were served by the keeper of a public house, and among the articles furnished were seven hans, to which the entire trouble was traced. While many complaints were made that the ham was not sufficiently cooked, that the fat was yellowish or greenish, that it was too salt, that it "tasted queer," and that it had no true flavor of ham, many made no complaint, and no one said that it was tainted. Of the 72 persons seized, 4 died. The history of 3 of these follows :

1. W. W., aged 64, ate ham on Wednesday and Friday, and was seized on Friday night, when he complained of feeling cold. On Saturday morning, he ate but little and said he ached all over. In the course of the day, he suffered from vomiting and diarrhœa, with severe pain and clamps in the legs. The evacuations were excedingly offensive and were passed involuntarily. The pulse was 128 ; temperature not taken. On MIonday, he began to collapse, and on Friday, he died. The post-mortem examination revealed little that was noteworthy, but microscopic examination of the kidneys showed parenchymatous inflammation, and distention and plugging of the afferent arterioles and capillaries of the Malpighian corpuscles by emboli of bacilli.

2. Mrs. I., aged 62, ate some sexaps of the ham on Wednesday, and was seized on Friday with faintness, diarrhoea, vomiting, and abdominal pain. On the following day she fell into a state of collapse, and on the following Tuesday she died. The mucous nembrane of the itomach and intestines was highly congested; otherwise the autopsy revealed nothing abnormal.

3. Mr. S., aged 37, ate four sandwiches on Thursday. In the evening he vomiterl, and diarrhoa began. In the morning of the following day, he complained of burning pain in the lower part of the abdomen. The vomiting and purging continued. Though cold and clammy to the touch, he complained that he was "all on fire." He had cramps in the legs and was very restless. His mind was clar to the last. 'The discharges were, at first, watery and offensive, and later were dark green in color. He was very thirsty and drank fireely of water. He died on the following Friday. Only a partial antopsy was made. This revealed bright-red patehes on the mucosa of the stomach.

The period of incubation was accurately deternined in 51 eases; in 5 it was 12 hours or less, in 34 it was between 36 and 48 , and in 4 it exceeded 48 hours. In many cases the onset was sudden, and in other's it was preceled by greater or less indisposition. The most con-

1 Supplement to 10th Annual Report of the Local Government Board, 1881, p. 36. 
stant symptom was diarrhœa. "In about a third of the eases the first definite symptom was a sense of chilliness, usually with rigors or trembling, in one case aceompanied by dyspnoea; in a few cases it was giddiness with faintness, sometimes accompanied by a eold sweat and tottering; in others the first symptom was headache or pain somewhere in the trunk of the body, c.g., in the chest, back, between the shoulders, or in the abdomen, to which part the pain, wherever it might have eommenced, subsequently extended.

"In one case the first symptom noticed was a diffieulty in swallowing. In two eases it was intense thirst. But, however the attack may have commeneed, it was usually not long before pain in the abdomen, diarrhoea, and vomiting came on, diarrhea being of more certain oceurrence than vomiting. The pain in several eases commeneed in the chest or between the shoulders, and extended first to the upper and then to the lower part of the abdomen. It was usually very severe indeed, quickly producing prostration or faintness with cold sweats. It was variously described as 'crampy,' ' burning,' ' tearing,' ete.

"The diarrhœal discharges were in some cases quite unrestrainable, and (where a description of them could be obtained) were said to have been exceedingly offensive, and usually of a dark color. Muscular weakness was an early and very remarkable symptom in nearly all cases, and in many it was so great that the patient could only stand by holding on to something. Headache, sometimes severe, was a common and early symptom; in most cases there was thirst, often intense and most distressing. The tongue, when observed, was deseribed usually as thickly coated with a brown velvety fur, but red at the tip and edges.

"In the early stage, the skin was often cold to the touch, but afterward some fever set in, the temperature arising in some eases to $101^{\circ}$, $103^{\circ}$, and $104^{\circ} \mathrm{F}$. In a few severe eases where the skin was actually cold, the patient complained of heat, insisted on throwing off the bedclothes, and was very restless. The pulse in the height of the illness becime quiek, counting in some cases 100 to 128 .

"The above were the symptoms most frequently noted. Other symptoms oceurred, however, some in a few eases, and some in only solitary cases. These I now proeeed to enumerate. Excessive sweating, eramps in the legs, or in both legs and arms ; convulsive flexion of the hands; aching pain in the shoulders, joints, or extremities; a sense of stiffness of the joints ; prickling or tingling or numbness of the hands, lasting far into convaleseence in some eases; a sense of general compression of the skin, drowsiness, hallucinations, imperfection of vision, and intolerance of light.

"In three cases (one that of a medical man) there was observed yellowness of the skin, either general or confined to the face and eyes. In one case, at a late stage of the illness, there was some pulmonary congestion, and an attack of what was regarded as gout. In the fatal cases death was preceded by collapse like that of cholera, eoldness of the surface, pinched features and blneness of the fingers and toes, and 
around the sunken eyes. The debility of convalescence was in nearly all cases protracted to several weeks.

"The mildest eases were charaeterized usually by little remarkable beyond the following symptoms, viz., abdominal pains, vomiting, diarhoea, thirst, headache, and muscular weakness, any one or two of which might be absent."

Investigation of the hams showed absence of triehinz and the presence of a bacillus, which on inoculation into animals was found in most cases to produce a pneumonia.

The period of ineubation indicates that in these cases there was a true bacterial infection.

CAsE III.-Another epidemic investigated by Ballard ${ }^{1}$ involved a far greater number of persons and had an unusual attendant nıortality, nearly 500 persons ont of a population of about 100,000 (Middlesbrough) dying during the year of a peculiar form of pleuropneumonia.

The cause of this remarkable epidemic was proved to be the consumption of what was known as "American bacon," a food product prepared from imported salt pork at a number of loeal establishments eonducted under most unsanitary conditions. Twenty samples of bacon, some obtained at shops and some at the homes of rietims, were examined, and fourteen were found to be distinetly poisonous to animals. The lesions diseovered in the dead animals were of the same mature and extent of those in the organs of the persons who had died. These inchuded destructive changes in all the principal viscera, and more particularly in the lungs. Dr. Klein discovered in the lung a short bacillus which had never before been deseribed. Inoculation experiments on animals produced results identical with those following feeding experiments with the so-called bacon.

CAsE IV.—A remarkable outbreak due to raw pickled ham has been recorded by $V$ an Ermengem ${ }^{2}$ and earefully investigated by himself and others. More than twenty members of a musical society at Ellezelles, in Belgium, were seized with serious illness after eating the greater part of a raw pickled ham; three died within a week, and ten lay in a eritical condition. Other parts of the animal from the same pickling tub were eaten in a raw state without ill effects, and pieces of the particular ham had been consumed a short time before, also without ill effects. Only those persons who ate of the ham were seized with the very peenliar train of symptoms reeorded. Most of them were seized in from 20 to 24 hours, 3 in less than that time, and a few as late as 36 hours after cating.

'The first symptoms were gastric pain, nausea, and vomiting of undigested food and gelatinous blackish mattels. Instead of diarrhoea, which one would expect, there was obstinate constipation in all but 2 cases, and the first lejections, with or without athartics, were black and viseid. In every ease, in from 36 to 48 hours, there were profound disturbances of vision-ampholiphopia, marked dilatation of the

1 Supplement to 18th Annual Report of the Local Gorernment Board, 1889, p. 163.

${ }^{2}$ Zeitschrift für IIygiene und Infeetionskrankheiten, XXVI., p. 1. 
pupils, with absence of reaction to light, ptosis of both lids, and a peculiar fixed stare. There was burning thirst with a strangling sensation in the throat. Swallowing, even of liquids, was diffienlt or impossible, and every attempt was accompanied by choking.

In some instances, the saliva was suppressed and the mucous membrane dry and glossy. The voice was weak, and with some there was total aphonia. Dysuria and anuria were common. There was but little disturbance of respiration and circulation; the pulse never reached over 90 , respiration was quiet, temperature normal. Conscionsness and general sensibility remained unimpaired throughout, except in the fatal cases, in which alone, several hours before death, there oceurred collapse, dyspnoa, small irregular pulse, light delirium, and coma.

There was obstinate insomnia in many, during the first period. The extremities and trunk muscles showed neither eomplete paralysis nor atroply, but there was great gencral museular weakness, and slight movements caused extreme fatigue. After two or three weeks, the eve symptoms began to improve. The dilated pupils contracted, the eloudiness disappeared, and the half-paralyzed evelids regained their power. Diplopia disappeared only when both eves were fixed laterally. Paralysis of accommodation lasted a long time after the disappearance of all the other synuptoms, and normal vision did not return until after six to eight months.

Autopsy in two cases showed no characteristic ehanges in the organs, only extensive hypersemia of the kidneys, liver, and meninges, and softening and unusual friability of the stomach walls. In one, the liver showed marked degeneration, and the brain punctiform hemorrhages. Neither the liver nor kidneys showed anything unusual on bacteriological examination, but the spleen yielded an anaërobic bacillus, which proved later to be capable of causing botulism.

The pig from which the ham came was killed some months previously, and what was not eaten at once was pickled in the usual way. During the time that elapsed between the pickling and the supper, the greater part of the animal had been consumed without causing any sickness, but the ham which was nearly intact was the last to be caten, lay on the bottom of the tub, and was the only part that was immersed completely in the weak brine. What was left of it gave no odor of putridity, but had a distinet odor like that of rancid butter. 'That the ham had a bad taste, was agreed by nearly all who ate of it. It appeared normal to the eye, but was pale, like any meat that has been soaked some time in water. There was no evidence of decomposition, and no ptomains were detected.

Bacteriological examination proved in different parts the presence of a hitherto unknown spore-bearing bacillus in great abundance, the same organism as that isolated from the spleen of one of the victims. It produced an extraordinarily virulent toxin, which was isolated by Brieger from cultures supplied by the discoverer, by whom the organism was named Bacillus botulinus. The toxin is rendered inert by a temperature of $60^{\circ}$ to $70^{\circ} \mathrm{C}$, therein agreeing with other bacterial toxins thus far isolated. 
Attempts to discover the organism in the feees of various animals and in filth of various kinds, and in specimens firom where the pig was raised were negative in results.

Feeding-experiments, eondueted on various kinds of animals with the meat itself and with aqueons triturations of it added to other foods, produced, as a rule, fatal results with the same train of symptoms as above mentioned. Subentaneous injections of the watery extract produced the same results as feeding-experiments. The aqueous extraet kept in the dark in a sealed tube retained its properties unimpaired for 10 months, and small pieces of the meat kept in eotton-stoppered tubes without special precautions retained their virulence even longer. 'The poison resists the effects of putrefaction, and proved to be equally poisonous after 4 days' standing in a mixture with feees, decomposing blood and urine, and filtration through poreelain. A fresh filtrate, to which were added B. prodigiosus, B. proteus liquefaciens, B. fluorescens putrides, and $B$. coli, was found at the end of a week to be as active as ever.

Mayer ${ }^{1}$ reports an epidemic in which several persons were infeeted with para-typhoid baeillus through the eating of pork ehops which had become infeeted by uncleanly butchers. The para-typhoid germs were found in the stools of these meat venders. An extraordinary finding was noted in a man who ate of the same chops, was not siek, but in whose blood para-typhoid germs were found in large numbers. Furthermore, they persisted in the blood for two weeks. At this time no para-typhoid germs conld be found in the stools or in the urine, but as soon as they disappeared from the blood they were found in the stools and urine.

Buchan ${ }^{2}$ reports an outbreak of food poisoning due to eating pork brawn. Eighty eases ocenred and the symptoms eame on from one and one-half to four hours after eating. The brawn was made by boiling for twenty-four hours bones, skin, and other portions of the pig. The bones were then removed and the liquid placed in dishes and allowed to cool. The same article of food had been made many times in the same manner by the same butcher without deleterious effects. In this instance, however, eating of the said brawn was followed in a short time by rigors, abdominal pain, vomiting, and diarrhea. There was then a longer period of great prostration, lasting sometimes as much as two weeks. There were no symptoms referable to the nervous system.

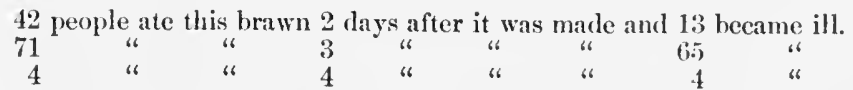

The brawn, therefore, increased rapidly in virulence with the lapse of time. It is supposed to have acquirer the invading baeterium from a slaughterhouse in elose proximity to the spot upon which it was cooled. The organisms isolated proved to be of the type of the Bacillus enteritidis of Gaertner, as proved by cultural characteristics and agglutination tests with the patients' serum.

1 Cent. f. Bakt., 1910, Bd. 53.

${ }^{2}$ The Lancet, Dec. 7, 1907. 
Poisoning by Beef.-Cask I.-In December, 1841, more than 40 cases of poisoning oeeurred in New York City from eating smokerl beef. As at rule the symptoms began several hours after cating, with pain and discomfort in the epigastrium, extending to the back and loins. Vomiting and purging were followed by great thirst and burning pain at the pit of the stomach, which became so irritable that it could tolerate neither food nor drugs. Extreme prostration followed, the fiunctions of the nervous and muscular system being greatly affected. One vietim died, and with the others convalesecnce was extremely slow. Autopsy revealed nothing beyond inflammation of the ileum.

CASE II.-In May, 1888, at Frankenhausen, 58 persons were made sick by eating the meat of a cow killed while ill with diarrhoa and passed as edible by a veterinary. The symptoms were, in general, uausea, vomiting, diarrhoa, fever, drowsiness, dizziness, and great depression. Those who ate the meat in the raw state were seized without exception, and the severity of the seizure was direetly proportionate to the amount eaten. One victim who ate a pound and a half died within 35 hours, while those who ate least suffered least. Those who ate the cooked meat fared differently. Not all were attacked, nor did the severity of the symptoms bear any relation to the amount taken. Thus, some who ate freely suffered but little, while very severe effeets were caused by slight amonnts of the meat, and even by small portions of the brotlr. Thirty-six who ate the eooked meat eseaped altogether. From a portion of the meat, and from the spleen of the person who died, Gaertner' isolated B. enteritidis, which, since then, has been shown to have been the eause of numerous other outbreaks.

CASE III.-In June, 1889, 137 persons, including 50 children, in and about Cotta, in Saxony, ${ }^{2}$ were made ill by eating the meat of a eow slaughtered on June 17 th, beeause of an inflammatory eondition of the udder. On the 11th, she had suddenly stopped giving milk and hat refused food and drink. The meat appeared to be normal in every way and was sold on the day after slaughter. The first cases appeared during the night of the day of sale. The majority of the vietims had eaten the minced meat in the raw state, others only after it had been cooked, and some had eaten only broth. The butcher who sold the meat tasted as much as would eover a knife-blade, and suffered from diarrhea, headache, and abdominal pain for three days. His assistant did the same, and fared even worse. In one ease, the symptoms began with a ehill; in another, with diffieult deglutition, double vision, and anxiety; in the rest, with nausea, vomiting, diarrhoea, headache, abdominal pain, dizziness, great lassitude, restlessness, lethargy, and nuquenchable thirst. In many eases, the eves were glassy, and the pupils much dilated. The tongue was eommonly dry and coated. The children affected were extraordinarily weak, and some had fever as high as $104.7^{\circ} \mathrm{F} . \quad \Lambda$ bacillus isolated from the meat by Johne was fonnd by Gaertner to differ in some respects from B. enteritidis.

i ('orrespondenz-1Blïter des allgemeinen ärztlichen Vereins von Thüringen, 1888, No.

${ }^{2}$ XXI. Jahresbericht ueber das Medicinalwesen im Konigreich Sachsen, p. 104. 
CAsE IV.-Poisoning by canned corned leef at Sheffield, reported by W. N. Parker. ${ }^{1}$ On October 11, 1899, a six-pound tin of corned beef was opened, and about two-thirds were sold, ehiefly in quarter pounds. Beyond the fact that the meat seemed less solid than usual and the jelly rather oily, nothing unusual was noticed. It had no odor, its taste was normal, though quite salt, and but one enstomer found its flavor disagreeable. So far as is known, none who ate escaped; 24 persons ranging in age from 2 to 89 years were affected. The following serves as an example, though each ease presented one or more symptoms peculiar to itself.

A woman of 35 ate 2 ounces of the meat at 12.30, and in 2 lours was seized with faintness, dizziness, and drowsiness, followed by nausea, and great museular weakness, especially of the legs. Persistent romiting with frequent retehing soon oecurred, accompanied by intense frontal headache, and followed by colie which was not relieved by purging. One hour after seizure, she was taken to the hospital, where she lay on a conch in a state of collapse with her knces drawn up. Her fúce was pale, with livid patehes around the eres, and bathed in perspiration. The skin was cold and clammy, the pulse small and rapid, the respiration shallow, the temperature subnormal, and the pupils dilated. Her stomach was washed out, and in a short time the pain and retehing ecased, the character of the pulse improved, drowsiness was diminished, and only the headache and purging remained. Within an hour, the condition of eollapse and other symptoms reappeared, but with less severity. The stomach was again washed out, and this time the good effects were permanent. On the following morning all that was complained of was slight frontal headache.

The approximate latent period raried between one and three and a half lours, but in only 2 cases was it more than two and a half hours. Frontal headache was present in all but 4 , vomiting in all but 1, pain in only 12, marked collapse in 12, profise discharges in all but 6 . The initial symptoms were the same in all; that is, drowsiness or giddiness, or botl.

Only one case resulted fatally, that of a boy 7 years okl, who ate 2 ounces. His symptoms were especially severe; collapse was very marked and he required constant stinulation. About 10 hours after the onset, he had a series of elonic contractions of the flexor muscles of the neek, arms, and legs. The movements were violent, rapid, and almost rhythmieal, commencing first in the neck and arms, but soon affecting the legs. The eyes were fixed and staring, and the pupils widely dilated. After lasting an hour and a half, the eonvulsions ceased. They reappeared in half an lour, affecting first the right arm and right side of the faee, but soon became general. The collapse gradually deepened, and the boy died 15 hours after seizure. Autopsy showed nothing nore than a erenenal hyperamia of the stomach and intestines, with a few hemorrhagie erosious in the gastrie mueous membrane. A mieroseopie examination of the kidney showed cloudy swelling of the cortex, with a few seattered hemorrhages.

1 British Medical Journal, November 11, 1899. 
All the other victims convalesced rapidly and were discharged from the hospital within 48 honrs. Stimulants, chicfly in the form of strychnine and brandy, were administered freely. The meat was examined bacteriologically about 11 hours after the tin was said to have been opened. In the outer parts of the meat, many speeies of organisms were found. The ouly organism present both in eultures from the centre of the meat and in those from the surface was the bacillus of Gatertner.

Case V.-An outbreak at Mansfield, in which 65 persons became ill after eating the flesh of a eow slaughtered in consequence of trattmatic periearditis, has been reported by Wesenberg.' Only those who ate of the minced meat in a raw state or of the partly cooked liver were affected; those who ate of the well-eooked meat eseaped withont exception. The symptoms were vomiting and diarrhoea, violent headache and abdominal pain, general musenlar weakness, dizziness and lassitude. The discharges were sometimes greenish, sometimes brownish, and always extremely offensive. With few exceptions, the symptoms abated in from 3 to 5 days, and all recovered except one, and that a donbtful ease of a ehild who was not known with eertainty to have partaken, and whose symptoms might have been due to other eauses.

The unconsumed meat when received for examination was already fairly well advaneed in decomposition and partly maggoty. All except one piece, which was faintly aeid to litmus papers, was alkaline in reaction. Cultures on agar and in bouillon were made from a piece taken from a part which was apparently not yet in process of decomposition. Inoeulation of the boullon cultures and of small bits of the meat into white mice produced fatal results, in some cases within from 18 to 28 hours and in others within 3 days. A guinea-pig which received a subentaneous injection of the bouillon eulture of the erushed meat died in 48 hours, having shown marked lassitude and profuse diarrhea. In all cases, section showed enlargement of the spleen, which was bluish-red in eolor, strong injection of the small intestine, and marked redness of the medullary substanee of the kidneys. Cover-glass preparations from the spleen showed fairly long and broad bacilli, and the same were developed on agar from the meat itself:

CASE VI.-G. A. Brown ${ }^{2}$ reports an outbreak of poisoning due to eating canned beef. Symptoms came on in two or three hours and were of the gastro-intestinal type. The patient's blood gave positive tests with the Bacillus enteritidis of Gaertner.

Poisoning by Horse Meat.-Gaffky and $\mathrm{Paak}^{3}$ investigated an outbreak in the district of Löwenberg, which was known to involve at least 30 and probably more individuals. The offending materials were horse meat, horse liver, and horse sausage. The patients complained very soon after eating, in one case within a half hour, of nausea, headache, abdominal pain, borborygmus, diarrhoe, dizziness,

1 Zeitschrift für Hygiene und Infeetionskrankheiten, XXVIII., p. 484.

2 The Laneet, 1907,41, p. 1029.

3 Arbeiten aus dem kaiserlichen Gesundheitsamte, VI., p. 159. 
trembling, and great thirst. The temperature rose to $104^{\circ} \mathrm{F}$. One case terminated fatally. Bacteriological examination revealed a bacillus which differed in some respects from that of Gactner.

Poisoning by Sausages.-CAsE I._-Tripe ${ }^{1}$ reported in November, 1879 , an outbreak which included 64 out of 66 persons who had eaten of a single batch of sausages. The onset was eharacterized by vomiting, purging, and dizziness, which came on after intervals of varying length. There was extreme weakness, and many had severe eramps in the legs and pains in the abdomen. In the majority of cases the vomiting and purging lasted from 36 to 48 hours. The discharges were very offensive, and looked like dirty wash-water. There was marked cerebral disturbance, and a sensation of aeridity in the throat was common. One of the victims died, but the autopsy revealed nothing unusual beyond a number of red patehes in the intestine. The remaining sausages were found to have a tainted and putrid odor.

CASE II.-The "Limmetshausen case." The liver of a healthy pig was made into sansages, which were then smoked for a number of days and hung up. On the eighth day, they were eaten by a family and a number of invited guests, one of whom, objecting to their peeuliar taste, refrained from cating and escaped the trouble that came to all the rest. The symptoms, which appeared within a short time, were the same in kind in all, but differed in severity. They included abdominal pain, vomiting, dizziness, dryness of the mouth and throat, and difficult deglutition. The pupils became dilated, and vision was much impaired and finatly lost. The muscular and nervous systems were very much affected; the pulse was rapid and weak; respiration beeame embarrassed, swallowing and speaking impossible. Death ensued in 3 eases, preceded by great lividity of the face and spasms of the extremities.

CASE III.-Van Ermengem ${ }^{2}$ relates an instance in which the remaining satusages of a lot which had eaused illness in several persons were apparently so wholesome and looked so inviting that the expert and his assistants to whom they were sent ate them and themselves beeame ill. The expert died on the sixth day, and autopsy showed gastroenteritis, acute nephritis, and fisty degeneration of the liver. Gaertner's B. enteritidis was found both in the organs and in the sausages. The latter were made of horse meat.

Case IV._. Carl Günther ${ }^{3}$ reports that, in several places in Posen, a large number of persons were made siek after eating pork sallsages and blood, all of which had been supplied by one buteher. The most important symptoms were abdominal pain, vomiting, purging, great weakness, and lassitude. One man of 47 years died after haudly a day's sickness. Gïnther examined portions of the deceased and also samples of meat and blood found in the house, and situsage and meat

${ }^{1}$ Medical Times and (iazette, Nov. 29, 1879.

${ }^{2}$ Revule d'I Iveriene, 1896, p. 761 .

${ }^{3}$ Archiv für III ygiene, XXVIII., p. 146. 
from the shop of the butcher. From the vietim's spleen and liver he isolated $B$. enteritidis, but while a number of speeies were found in the foods, this bacterium was not deteeted, perhaps having perished throngh the intluence of the other speeies present.

CAsE V.-This interesting ease of poisoning by sansage composed of pork and beef is related by Silbersehmidt, ${ }^{1}$ and serves as an illustration of the methods commonly employed in the manufacture of sausages. Nearly fifty people were poisoned by eating a kind of sausage known in Switzerland as "Landjäiger." It is made of beef, often, also, horse meat with pig fat. The materials are chopped rather coarsely, spiced, put into casings, pressed flat for al day, smoked two days, dried in the air several days more and then eaten in the raw state. The sausages in this instance were made of cow beef from animals that had been eertified as sound by a veterinarian, and pork that had been bought about two weeks previonsly and kept with preservative salt, and had appeared fresh and nuchanged when used. In the morning of the first day that the sausages were on sale, a man and his wife ate one of them together, and both were made so siek toward evening and during the night that a physician was called. In the afternoon of the same day, 19 fishermen ate of them, and on the following day it was reported that all of them had been made sick. In the evening, another man ate one, and it pleased him so much that he took one home to his wife and children. On the next day, he had abdominal pains, headache, vomiting, diarrhœa, thirst, and a chill. In the afternoon, his wife and two ehildren who had eaten were similarly seized. A boatman who ate two whole sansages suffered no inconvenience beyond a little pain on the following day. Another, who was sick eighteen days and then returned to his work, was seized again ten days later with the same train of symptoms. One man, aged eighteen years, entered the hospital in the morning of the second day, and died during the night, two days and a half after ingestion of the sansage. At the time of entrance, the abdomen was sensitive and he was passing grayish watery stools; in the afternoon, he was delirious, and his pulse was very small, irregular, and rapid. During the night he collapsed and died. Section after twelve hours showed a spleen of normal size, swollen mesenteric glands, and hyperæmia of the stomach and intestines. The follieles were much swollen, and in the ilenm were several areas from 4 to $6 \mathrm{~cm}$. in length by $1 \mathrm{~cm}$. in breadth, where the mucous membrane was discolored and eroded. Other organs were normal. Six others of those affeeted were discharged from the hospital after from seven to fifteen days' treatment. In an adjoining town, where sansages of the same lot were sold, there were 16 other cases, all with the same symptoms. Taking all the eases together, the symptoms of prominence were as follows: Very severe, partially erampy, abdominal pains; very profuse diarrhœa, the stools numbering from eight to twelve per day, and in eolor varying between gray, greenish, and yellow; usually vomiting, the rejected matters being

${ }^{1}$ Zeitschrift für Hygiene und Infectionskrankheiten, XXX., p. 328. 
watery and brownish; sunken eyes, high fever, great lassitude, tenderness over abdomen, cramps in the ealves, great thirst, and, oceasionally, meteorism. In most of the eases, the symptoms appeared on the day after eating. The duration of the illness rangerl hetween one and thirty days, the greater number recovering in two weeks, and beeoming fit for work in three.

As is commonly the ease in these outbreaks, the attention of the authorities was not drawn to the matter in either town until some days had elapsed. Chemical analyses of mused sausages were made at both places. One analyst reported negative results; the other reported the presence of ptomains, but did not further particularize. Bacteriologieal investigation revealed the presence of a variety of organisms, as was to have been anticipated, and among them, especially marked, Proteus vulgaris.

Poisoning by Kid Meat.-Hensgen ${ }^{1}$ has reported the case of a whole family stricken after eating the meat of a kid which was killed when but a few days old. A twelve year old girl was seized in eleven hours with a ehill, followed by fever, dizziness, vomiting, and violent diarrhoea. The temperature rose to $103.6^{\circ} \mathrm{F}$. She was eonfined to her bed for five days. The father, forty-nine years old, was seized with the same symptoms in twelve to thirteen honrs, and had also headache, pain in the joints, thirst, and inability to walk. The tongue was dry, the pulse rapid and small, and the pupils reacted slowly. $\mathrm{He}$ was siek eight days. The mother, who ate but little, was seized suddenly in the night with vomiting, and such great dizziness that she was unable to walk without holding on to the furniture. A boy, under. two years of age, was seized in the night with vomiting and violent diarrhœa, which soon became bloody. The stools were unusually offensive, and persisted so for several days. He was sick nine days. Three other children, who ate but very little, were sick two days with slight abdominal pain and diarrhoea. No material was obtainable for examination. The buteher said that the kid was apparently healthy, but the mother declared that the meat around the joints of the hind legs was very soft and watery, and the joints themselves enlarged (septic polyarthritis?).

\section{Meat Inspection and Slaughtering.}

'The valne and advisability of thorough inspection of meats before they are placed on sale are universally coneeded. In this country, under the inspection law of March 3, 1891, all meat intended for export is required to pass a very strict system of inpection. The animals are inspected before being slanghtered, and their enreasses are examined microseopically by officials of the Burean of Animal Industry before being packed. 'The inspection of meat for local consumption is wholly a matter of local authority ; some States have insprection laws and others have none; many eities have special regulations which are enforeed by officials who may or may not be competent throngh

1 Zeitschrift für Fleisch- und Milchhygiene, VIII., p. 181. 
proper training. In Germany, the system of inspection is very rigid, partieularly in the ease of meats from foreign countries. This is due very largely to the activity of the agrieultural interests in protecting themselves from outside eompetition; and under the benevolent plea of protecting the health of meat consumers, much care and attention are given to hunting for exeuses for excluding American meats which have already been inspected.

The Federal meat inspection service is, according to Salmon,' a sanitary rather than a commereial inspection, applied not alone to meats for export, but also to those intended for inter-state conmeree. Curionsly, however, the very important inspection for triehinæ is primarily a eommereial matter, being applied only to pork intended for shipment to certain foreign eountries which require it.

The United States inspeetors are instrueted to eondemn all female animals in an advaneed stage of gestation, and to prevent their slaughter for food, Salmon ruling that, though "the animal is, strictly speakiug, in a physiologic condition, it is not in its usual physiologie condition, nor is the ehange one which is calculated to improve the quality of the meat." Females in which parturition has recently oceurred are likewise condemned as unfit for food. Many animals are condemned on account of bruises and injuries received on their way to market; during 1900 , there were eondemned for this cause, in round numbers, carcisses or parts of carcasses of 4500 eattle, 1,000 sheep, and 12,300 hogs. In some of these, the injuries were extensive, sometimes complicated with abseesses, septie infection, and gangrene.

At the end of $1908^{2}$ it was estimated that Federal meat inspeetion covered slightly more than one-half of the entire number of animals slaughtered for food in the United States. The following table shows the diseases and conditions for which eondemuations were made on post-nortem inspection for the fiscal year $1909 .^{3}$

\begin{tabular}{|c|c|c|c|c|c|c|c|c|c|c|}
\hline \multirow[b]{2}{*}{ Cause of condemuation. } & \multicolumn{2}{|c|}{ Caule } & \multicolumn{2}{|c|}{ Calves. } & \multicolumn{2}{|c|}{ Swine. } & \multicolumn{2}{|c|}{ Sheep. } & \multicolumn{2}{|c|}{ Goals. } \\
\hline & $\begin{array}{c}\text { Car- } \\
\text { casses. }\end{array}$ & Parcs. & $\begin{array}{l}\text { Car- } \\
\text { casses. }\end{array}$ & Parts. & $\begin{array}{c}\text { Car- } \\
\text { casses. }\end{array}$ & Parts. & $\begin{array}{c}\text { Car- } \\
\text { casses. }\end{array}$ & Parts. & $\begin{array}{c}\text { Car. } \\
\text { casses. }\end{array}$ & Parts. \\
\hline Tuberculosis. & 24,525 & 40,148 & 177 & 151 & 45,113 & $791,7 \mathrm{ej}$ & 21 & 1 & . & 1 \\
\hline $\begin{array}{l}\text { Actinomyeosis } \ldots \ldots \ldots \\
\text { Ilog cholers }\end{array}$ & 589 & 44,440 & $\cdots$ & 69 & & & & & & \\
\hline $\begin{array}{l}\text { Ilog cholera } \\
\text { Septicemia, pyenia, and uremia }\end{array}$ & - 815 & $\therefore:$ & · $\dot{3} \dot{3}$ & $\therefore$ & $\begin{array}{r}-0,789 \\
7,173\end{array}$ & . & 676 & . & 3 & \\
\hline $\begin{array}{l}\text { Pnewnonia, pleurisy, enteritis, } \\
\text { hepatitis, nephritis, metritis, }\end{array}$ & & & & & & & & & & \\
\hline ete. $\ldots \ldots$ & 1,418 & . & 295 & . & 6,329 & - & 1,479 & - & 8 & \\
\hline$\therefore \therefore .:$ & $\begin{array}{r}60 \\
427\end{array}$ & $\therefore$ & 75 & . & 1,623 & . & 862 & . & 18 & \\
\hline Caseous lymphadenitls . . . & & & & & & & $1,0 \pm 3$ & 7 & 8 & \\
\hline $\begin{array}{l}\text { Tumors and abscesses } \\
\text { Pregnaney and recent wartu- }\end{array}$ & 107 & 5,989 & 28 & 43 & 1,178 & 1,609 & 102 & 37 & & \\
\hline $\begin{array}{l}\text { Pregnaney and recent partu- } \\
\text { rition. }\end{array}$ & 254 & & & & 89 & & 107 & & & \\
\hline $\begin{array}{l}\text { Injuries, bruises, etc.. } \\
\text { Immaturity }\end{array}$ & 2,261 & 1,911 & $3-11$ & 132 & 372 & 3,812 & 763 & 129 & 4 & 1 \\
\hline $\begin{array}{l}\text { Immaturity } \\
\text { Sexual odor }\end{array}$ & $\therefore$ & & 4,376 & & 1,031 & & & & & \\
\hline 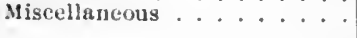 & 4,617 & 7,221 & 1,653 & 14 & 3.215 & 2,114 & 5,714 & 5 & 41 & \\
\hline Total ........ & 35,103 & 99.739 & 8,213 & 409 & 86,912 & 799,300 & 10,714 & 170 & 82 & 1 \\
\hline
\end{tabular}

3ournal of the American Medical Association, Dec. 28, 1901, p. 1715.

2 Report of the Chief of the Bureau of Animal Industry, 1908, p. 5. ${ }^{3}$ Ibid., 1909, p. 20. 
In inspecting meats, special attention should be paid to the eonnective tissue and glandular organs. The odor of a careass should be sweet, and the meat should communicate no unpleasant smell to a wooden skewer thrust into it and withdrawn. The muscle should be firm and elastic, but not tough. Any variation from the natural color should be regarded with suspieion, very dark color suggesting febrile condition, or that the animal was not slaughtered, or was slaughtered in a dying condition. Such meat undergoes decomposition much more rapidly than normal meat. Animals that have been drowned or have been killed by accident without being bled yield a dark and discolored meat that is likely to decompose more rapidly than that of animals that have regularly been slaughtered, but an animal that has been injured, but not killed, may be slaughtered, properly bled and dressed, and its meat is then perfectly good.

Animals should be kept without food for at least twelve hours before slanghter, and the carcasses shonld be hung for a number of hours to cool. Many diseases are indicated more elearly after the body has cooled.

The Jewish method of slanghtering is regarded by many as far superior to any other. According to Dembo, ${ }^{1}$ it is the most rational from a hygienic standpoint, since the animal is bled rapidly and completely, and the convulsive movements cause the meat to be more tender and of more attractive appearance. Lactic acid is developed, and through its chemical action on potassimm phosphate, potassium lactate and aeid phosphate of potassimm are formed. 'The latter hinders the development of micro-organisms, delays the formation of ptomains and other poisonous matters, and improves the taste. Rigor mortis comes on more quickly, and the meat is, therefore, more quickly available for use, and also will keep several days longer than ordinarily.

A process of slanglitering originating in Denmark appears to have borne the test of a lard three-months' trial in a very satisfactory manner, and recommends itself for adoption in the tropics, where meats decompose with exceeding rapidity. The animal is shot in the forehead and killed or stumned, and as it falls, an incision is made over the heart and the ventricle is opened for two purposes: to allow the blood to escape, and to admit of the injection of a solution of salt through the bloodvessels by the aid of a powerful syringe. 'The process requires but a few minutes, and the careass may be ent up at once.

\section{EGGS.}

Eggs form a valuable substitnte for meats, being fairly rich in fats and proteids, and are well adapted to the stomach of the invalid and convalescent when meats cannot be borne. The nutritive part of the white is practically linited to proteids, which amonnt to about $12 \mathrm{per}$ cent.; the yolk is richer in proteids, and contains in addition abont 33

'Deutsche Vierteljahrschrift für öftentliche Gesumlheitspflege, XXVI., p. 688. 
per cent. of fat. The albumin of the white is in a condition of solution in cells with very thin walls. The fatty matters of the yolk are in a condition of emulsion, being leeld in suspension by the vitellin. The entire yolk is held together by an enveloping membrane and is suspended in the white, being held in position by an albuminous band at either end :

The following table by Langworthy ${ }^{1}$ shows the average composition of eggs of different sorts :

\begin{tabular}{|c|c|c|c|c|c|c|}
\hline & Refuse. & Water. & Protein. & Fat. & Asb. & $\begin{array}{c}\text { Fuel } \\
\text { value per } \\
\text { pound. }\end{array}$ \\
\hline $\begin{array}{l}\text { Hen: } \\
\text { Whole egg as purchased .... }\end{array}$ & $\begin{array}{l}\text { Per cent. } \\
11.2\end{array}$ & $\begin{array}{l}\text { Per cent. } \\
65.5\end{array}$ & $\begin{array}{l}\text { Per cent. } \\
11.9\end{array}$ & $\begin{array}{l}\text { Per cent. } \\
\quad 9.3\end{array}$ & $\begin{array}{c}\text { Per cent. } \\
0.9\end{array}$ & $\begin{array}{l}\text { Calories. } \\
\quad 635\end{array}$ \\
\hline Whole egg, edible portion & ... & 73.7 & 13.4 & 10.5 & 1.0 & $7: 20$ \\
\hline White . . . . . . . & . . & 86.2 & 12.3 & .2 & .6 & 250 \\
\hline Yolk . & . . & 49.5 & 15.7 & 33.3 & 1.1 & 1,705 \\
\hline Whole egg boiled, edible portivi & & 73.3 & 13.2 & 12.0 & .8 & 765 \\
\hline White-shelled eggs as purchased & 10.7 & 65.6 & 11.8 & 10.8 & 6 & 675 \\
\hline Brown-shelled eggs as purehased & 10.9 & 64.8 & 11.9 & 11.2 & .7 & 695 \\
\hline $\begin{array}{l}\text { Duek: } \\
\text { Whole egg as purehased }\end{array}$ & 13.7 & 60.8 & 12.1 & 12.5 & .8 & 750 \\
\hline Whole egg, edible portion & .10 .1 & 70.5 & 13.3 & 14.5 & 1.0 & 860 \\
\hline 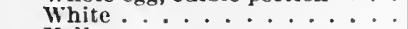 & . & 87.0 & 11.1 & .03 & .8 & 210 \\
\hline 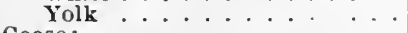 & . . & 45.8 & 16.8 & 36.2 & 1.2 & 1,840 \\
\hline $\begin{array}{l}\text { Goose: } \\
\text { Whole egg as purchased. }\end{array}$ & 14.2 & 59.7 & 12.9 & 12.3 & .9 & 760 \\
\hline Whole egg, edible portion &. & 69.5 & 13.8 & 14.4 & 1.0 & 865 \\
\hline White . . . . . . & . . . & 86.3 & 11.6 & .02 & .8 & 215 \\
\hline 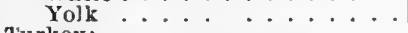 & . . & 44.1 & 17.3 & 36.2 & 1.3 & $1, \times 50$ \\
\hline $\begin{array}{l}\text { Turkey: } \\
\text { Whole egg as purchased ... }\end{array}$ & 13.8 & 63.5 & 12.2 & 9.7 & .8 & 635 \\
\hline Whole egg, edible portion & .0 .0 & 73.7 & 13.4 & 11.2 & .9 & 720 \\
\hline 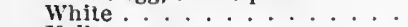 & $\ldots$ & 86.7 & 11.5 & .03 & .8 & 215 \\
\hline Yolk . . . . . . & . . & 48.3 & 17.4 & 32.9 & 1.2 & 1,710 \\
\hline $\begin{array}{l}\text { Guinea fowl: } \\
\text { Whole egg as purehased . }\end{array}$ & 16.9 & 60.5 & 11.9 & 9.9 & .8 & $6-10$ \\
\hline Whole egg, edible portion &. & 72.8 & 13.5 & 12.0 & .9 & 755 \\
\hline 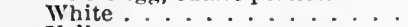 & ... & 86.6 & 11.6 & .03 & .8 & 215 \\
\hline Yolk . . . . . . . & . . & 49.7 & 16.7 & 31.8 & 1.2 & 1,655 \\
\hline $\begin{array}{l}\text { Plover: } \\
\text { Whole egg as purchased ... }\end{array}$ & 9.6 & 67.3 & 9.7 & 10.6 & .9 & 625 \\
\hline Whole egg, edible portion & $\begin{array}{l}9.6 \\
. .\end{array}$ & 74.4 & 10.7 & $\begin{array}{l}10.6 \\
11.7\end{array}$ & 1.0 & 695 \\
\hline Evaporated hens' eggs ...... & . - & 6.4 & 46.9 & 36.0 & 3.6 & 2525 \\
\hline
\end{tabular}

The proteids of eggs have been studied by Osborne and Campbell, ${ }^{3}$ who found that the yolk contains a large amount of protein which resembles a globulin, but is believed to be a mixture of compounds of protein matter with leeithin. The proteids of the white were found to include ovalbumin, ovomnein, ovomueoid, and eonalbumin.

Eggs contain a certain amount of sulphur, to which the staining of silver spoons and the odor of rotten eggs (hydrogen sulphide) are due. The rotting of eggs is supposed to be due to the admission of fermentative micro-organisms through the pores of the shell, or to those already present before the shell is formed.

It is a conmonly accepted idea in some parts of the country that eggs with brown shells are of greater richness than others, and that the degree of richness is directly proportionate to the depth of color. In some markets, on the other hand, the white egg is held in higher esteem.

' U. S. Department of Agriculture, Farmers' Bulletin, No. 128 (1901).

${ }^{2}$ Report of Connecticut Experiment Station, 1899, p. 339. 
According to the results of an extensive study of the chemical composition of eggs carried on at the California Experiment Station mainly for the purpose of determining what differences, if any, exist between them, there is no basis of fact for the popular belief. In faet, the very slight differences noted were in favor of the white eggs, but the average differences between the two kinds were less than the fluctuations between individual speeimens of the same group. The figures obtained are presented in the following table taken from Farmers' Bulletin No. $87:^{1}$

ANALYSIS OF BROWN-SHELLED AND WHITESHELLED EGGS.

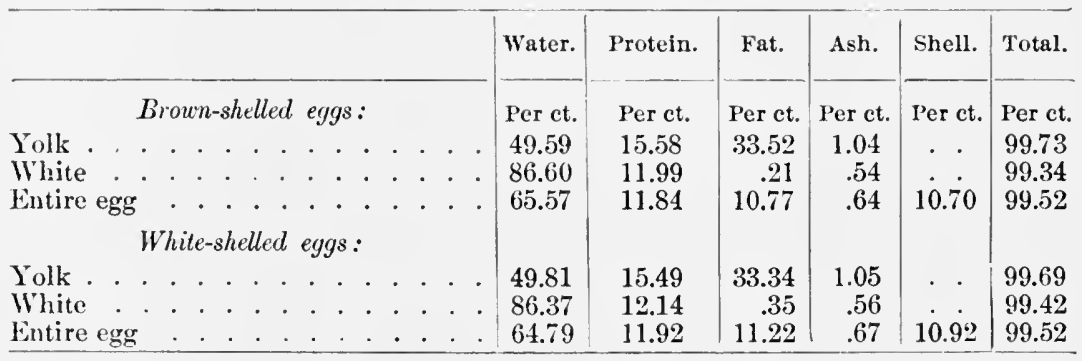

The question of influence of breed on composition has been investigated at the Michigan Experiment Station. The results showed that the variations in eomposition are too slight to be of practical value, and, as with the brown and the white eggs, so slight as to be less than the variations between individual specimens from the same breed. The influence of the nature of the feed was investigated also, and was found to be of little or no importance.

The flavor of eggs varies aceording to age, those which are perfeetly fresh having the finest flavor. It is dependent also, to some extent, upon the nature of the food consumed by the fowl, the best coming from a purely grain feed. A very nitrogenous feed causes a more or less disagrecable flavor and odor. The influence of lighly flavored feed lats been studied by Emery, ${ }^{2}$ who fed hens with a ration containing wild onion tops and bulbs. After fifteen days, the eggs having no unusual taste, each hen received daily one ounce of this addition instead of a half ounce as before, and in three days the eggs were flavored so strongly as to be repugnant to the taste.

The iron eontent of the solk of eggs is said by Schmidt ${ }^{3}$ to be increased materially by feeding saceharate of iron to hens. He asserts, also, that the iron so incorporated is more assimilable than most iron preparations given in the anemie eondition. Anfsberg asserts that by feeding certain iron eompound, the iron content can be increased eight times.

The digestibility of egras has been studied at the Minnesota Experi-

1 Govemment Printing Office, Washington, 1899, p. 24.

'Bulletin 167, North Carolina Experiment Station.

3 Veitschrift für angewande Chemie, 1900, p. 705.

- Pharmaceutische Zeitung, 1900, p. 366. 
ment Station. ${ }^{1}$ It was shown that, while the method of cooking has some effect on the rate of digestion, the total digestibility is not affeeted. Eggrs boiled three, five, and twenty minutes, and digested for five hours with pepsin solution, showed at the expiration of that time respectively 8.3, 3.9, and 4.1 per cent. of undigested proteids. Cooked for five and ten minutes in water at $180^{\circ} \mathrm{F}$. and similarly treated, they left no undigested residumm.

\section{LARD.}

Lard is the semi-solid fat of the slaughtered hog, separated from the tissues by the aid of heat. According to the parts from which it is derived, it is classified as follows: (1) Neutral lard. This is derived from the fresh leaf, which is reduced to a pulp after being cooled, and then rendered in the kettle. A part of the fat is separated at from $105^{\circ}$ to $120^{\circ} \mathrm{F}$., and the residue is sent to the rendering tanks for further treatment. The lard obtained is washed, while hot, with water containing a trace of sodium carbonate, common salt, or dilute acid. (2) Leaf lard. This is obtained from the residue above mentioned, which is subjected to steam heat under pressure. (3) Choice kettle rendered lard. This is obtained from the remaining portions of the leaf together with the fat from the backs. Both the leaf and back fat are passed first through a pulping machine. (4) Prime steam lard. This is made from the head, the fat of the small intestine, trimmings, and other fatty parts.

The spleen, pancreas, trachea, and all other refuse parts and trimmings, with the exception of the small intestine, the liver, lungs, and part of the heart, go into the rendering-kettle for what fat there may be in them, and the product is varionsly, but not graphically, designated.

"Refined lard" is a term nsed to designate a lard composed chiefly of cotton oil and stearin. It is known more often as "lard compound."

United States Standards.-Standard lard and standard leaf lard are lard and leaf lard respectively, free from rancidity, containing not more than 1 per cent. of substances other than fatty acids, not fat, necessarily incorporated therein in the process of rendering, and standard leaf lard has an iodine number not greater than 60 .

Physical and Chemical Properties of Lard.-At $40^{\circ} \mathrm{F}$, the specific gravity is 0.890 ; at $100^{\circ}$, about 0.860 ; it differs not very materially from that of the substances used as adulterants, excepting cotton-seed oil, which is notably heavier. The melting-point ranges from $39.1^{\circ}$ to $44.9^{\circ} \mathrm{C}$. $\left(102.4^{\circ}\right.$ to $112.8^{\circ} \mathrm{F}$.), according to the part of the carcass from which the fat is derived, and hence it cannot be taken as a safe guide in the determination of purity.

Pure lard, melted, and mixed with strong sulphuric or nitric acid, will give only a slight color, which may be yellowish, pinkish, or inclined to light brownish. Cotton-seed oil and other seed oils, and

'Farmers' Bulletin, No. 87, Government Printing Office, Washington, 1899, p. 25. 
mixtures containing them, similarly treated, yield any color between yellowish brown and very brownish black or even black. The refractive index of pure lard is materially lower than that of eottonseed oil.

Pure lard contains only traces of volatile fatty acids, 5 grams yielding an amount which is neutralized by $\frac{1}{5}$ or $\frac{2}{5}$ of a ec. of decinormal sodium hydrate solution. The non-volatile fatty acids are present to the extent of about 95 per eent. The iodine absorption number varies aceording to the part of the carcass from which the fat is derived, but averages about 60 . The iodine number of cotton-seed oil is about 109, and that of stearin is approximately 20 . Thus, these substances used as adulterants may be mixed in sueh proportion as to yield the normal iodine number of lard.

With nitrate of silver solution, pure lard causes no more than the very slightest amount of reduetion, and generally none at all ; but cottonseed oil causes a very marked reduction of the salt to the metallic state, with the result that the mixture has a brownish or black appearance from the minute black particles formed.

A small amount of lard, dissolved in a mixture of equal parts of alcohol and strong ether in a test-tube and allowed to stand in a cool place, will, when the solvent in large part is evaporated, show masses of crystals, which, on examination under the microscope, are seen to be rhombic and extremely variable in sizc. Beef stearin, similarly treated, shows fan-shaped and dumbbell-shaped elusters of needle erystals. Mixtures of pure lard and beef stearin will show both forms of erystals. Sometimes, when erystallization proceds rapiclly, the erystals from pure lard are extremely small, and are clustered in such a way as to be distinguished from beef stearin erystals only with great difficulty. It is essential that the erystallizing process shall proceed slowly, and that the amount of lard dissolved in half a test-tube of the solvent shall be quite small-not larger than a large pea. The mouth of the test-tube should be stopped with cotton.

\section{Section 3. MILK AND MILK PRODUCTS.}

\section{MILK.}

United States Standard.-Standard milk is the fresh, clean, lacteal seeretion obtained by the eomplete milking of one or more perfectly healthy cows properly fed and kept, exeluding that obtained within fifteen days before and ten days after calving, and eontains not less than 8.5 per cent. of solids (not fat) nor less than 3.25 per cent. of milk fat.

Milk is a solution of sugar, mineral matter, and proteids, with other proteids and fat in suspension. Its emmposition is very variable, not alone as between different species of mammalia by which it is prorlueed, but as between different individuals of the same species. Of the domestic animals, the ass and mare produce milk which most elosely approximates that of woman in composition, but our chief interest in 
milk as an article of food in general use lies in that produced by cows and, to a certain extent, in that of goats, which is very similar in composition. While the composition of milk of other animals than those already mentioned can have for most of us merely a scientific interest, it may be of some practical utility in the management of breast-milk to bear in mind that the milk of animals whose diet is largely or chiefly meat is richest in those elements, the proteids, that are most commonly at the bottom of digestive disturbances in breast-fed children.

Composition of Milk. - The composition of cows' milk of average good quality may be expressed fairly in round numbers as follows :

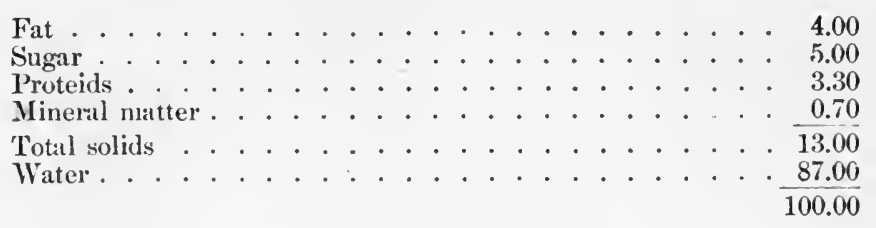

Aceording to Vieth, the average composition of more than 120,000 samples analyzed in England was:

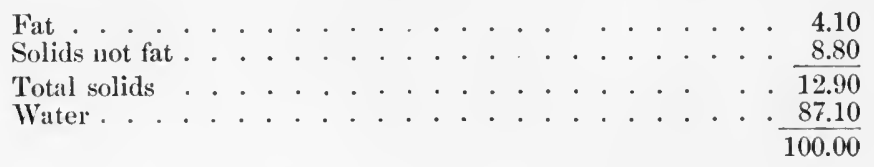

The average of a large number of analyses made in this country showed : ${ }^{1}$

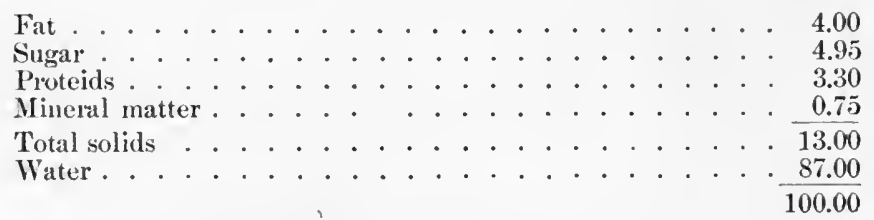

According to Van Slyke, ${ }^{2}$ the average composition of about 5500 specimens, examined chiefly at State Experiment Stations, was approximately as follows:

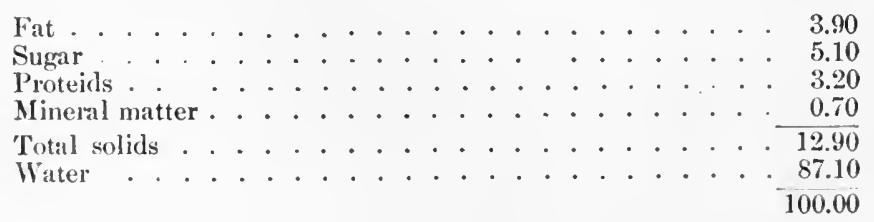

The milk vielded by 426 cows from private furms in Massachusetts, and by 175 more belonging to public institutions, was analyzed by

1 Experiment Station Reeord, V., No. 10.

${ }^{2}$ Medical Record, May 25, 1907, p. 878. 
the author and his associates, and found to give the following results : ${ }^{1}$

426 cows from private farms, total solids . . . . . . . . . 13.36

175 cows from public institutions, total solids . . . . . . . 13.00

601 cows (both classes), total solids . . . . . . . . . 13.26

At the Paris Municipal Laboratory ${ }^{2}$ the following standards are recognized :

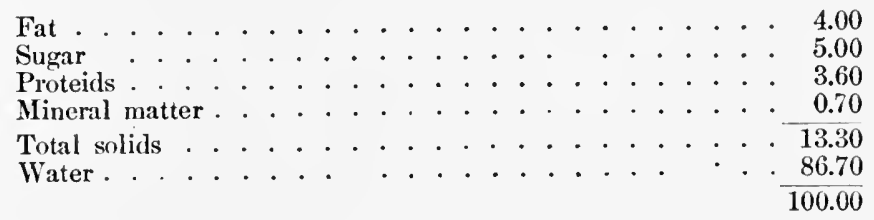

The following compilation by Leach, ${ }^{3}$ from Koenig's Chemie der nıens. Nahr. u. Genuss., gives the composition of human milk and that of a number of different animals :

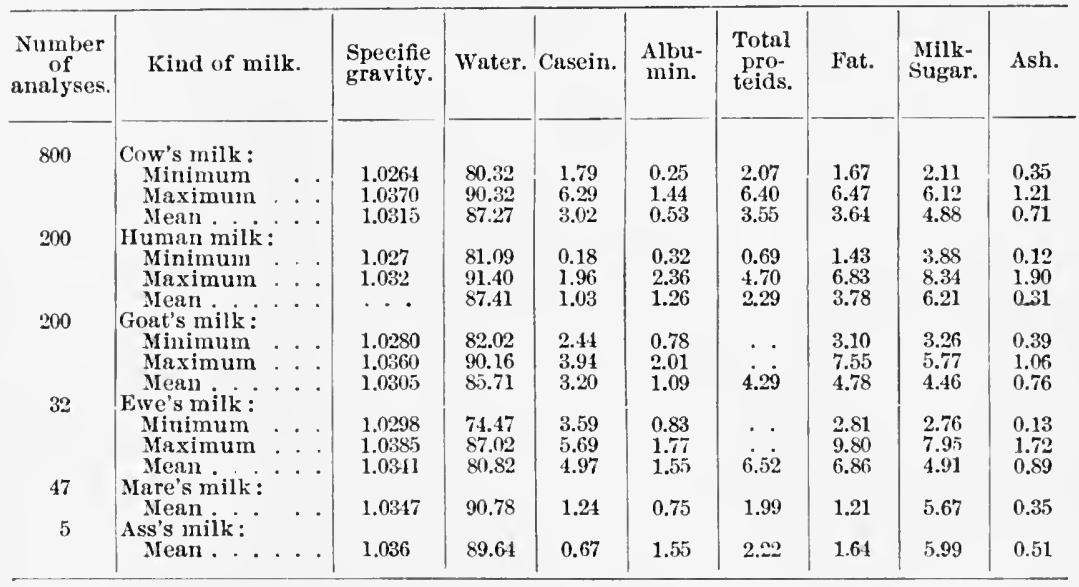

Constituents and Chemical and Physical Characteristics of Milk.-Fat.-The fat of milk exists in very minute globules which vary widely in size, the largest being between six and seven times larger than the snuallest, but the latter are most abundant. Their average diameter is about $\frac{1}{5000}$ inch. Whether or not they have an albuminous envelope is a matter of doubt, the evidence for and against being about equal and of no great importance.

It consists of glycerides of ten different fatty aeids, five of which belong to the non-volatile and five to the volatile class. The glycerides of the former group constitute by far the greater part. They are

1 The detailed analyses, with data as to breed, nature, and amount of feed, etc., can be found in the pamphlet issued by the State Board of Health: Results of Inquiries Relative to the Quality of Milk as Produced in Massachusetts. Boston, February, 1887.

2 Hygiène Générale, 1907, p. 303.

3 Food Inspection and Analysis, 1909. 
stearin, palmitin, olein, myristin, and butin; the two last are present in very minute amounts. Those of the latter group give the characteristic butter flavor. 'They are butyrin, eaproin, caprylin, caprin, and laurin ; the first two are the important ones, and together amount to over 7 per cent. of the whole fat; the three others are present in but insignificant traces.

The fat, being the lightest part of milk, tends to rise to the surface when the milk is allowed to stand, and then forms a layer which we know as eream. This contains not fit alone, but all of the constituents of the milk, and is, therefore, simply milk containing an excessive amount of fat.

It is a common error to regard the depth of the eream layer which forms on standing a given length of time as an infallible measure of the richness of the milk by which it is yielded; but ercam does not always rise well in rich milk, even after standing more than twentyfour hours. The author repeatedly has found the percentage of cream thrown up by a specimen of milk in a 100 cc. graduate in twenty-four hours, as measured by the lines of graduation, to be less than the actual percentage of fat as shown by analysis. The rapidity with which the fat finds its way to the surface depends largely upon the size of the fat globules. The largest rise first, and the very smallest may not rise at all. Again, a watered milk throws up its fat more quickly than a normal specimen, although it does not contain as much. Furthermore, according to Rosenau, ${ }^{1}$ heating of milk for one-half hour at $150^{\circ} \mathrm{F}$. $\left(65^{\circ} \mathrm{C}\right.$.) prevents entirely the rising of cream, or very materially delays it. It appears, therefore, that a milk of inferior grade may under some circumstances show a deeper cream layer than a milk of unusual richness. Generally speaking, however, a rich milk will usually show its quality on standing.

The first part of a milking is always poor in fat, the middle portion contains about the average amount of the whole, and the last portion is always the richest. The first portion is known as "fore-milk," the last as "strippings." A specimen of "strippings," analyzed by the author, gave the following results:

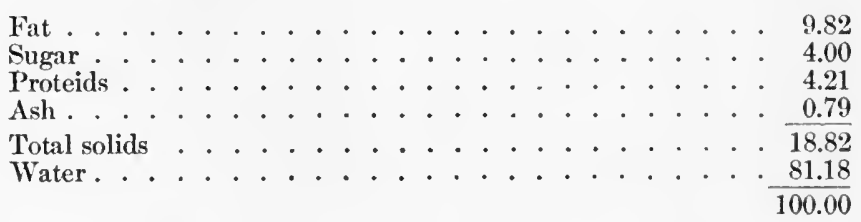

Milk-sugar.-Lactose or sugar of milk, is peculiar to milk. It is much less soluble in water than dextrose and sucrose. Heated to $100^{\circ}-131^{\circ} \mathrm{C}$., it becomes changed in color to brownish, and at higher temperatures loses water of crystallization and undergoes further change. At $175^{\circ} \mathrm{C}$, lactocaramel is formed. When heated in solution, in milk

1 Hygienic Bull., No. 41, 1908. 
itself, for example, it begins to undergo decomposition changes at $70^{\circ}$ C. and above. Through the action of the lactic ferments, it gives rise to lactic acil. In the polariscope, it is dextrorotary.

Proteids.-The greater part of the proteids of milk, about 80 per cent., is casein, or, as it is called sometimes, caseinogen. It contains both sulphur and phosphorus, and is in intimate combination with calcium phosphate. It is not coagulated by heat, but is precipitated by acids, by which the combination is broken up. In the presence of lactic acid in small amounts, due to the breaking up of lactose, coagnlation is hastened by the application of gentle heat. This phenomenon is observed very commonly in the case of milk which to the taste is apparently sweet, but which is "just on the turn."

The chief part of the remainder of the proteids is lactalbumin. This is coagnlated by heating to $65^{\circ}-73^{\circ} \mathrm{C}$, , but not by dilute acids. It contains sulphur, but no phosphorus. In amount it ranges from 0.2 to 0.8 per cent. It is much more abundant in colostrum. The remaining proteids are lactoglobulin, which is coagulated by heat ; lactoprotein, coagulable by neither heat nor dilute acids, and fibrin. Each exists in but very small amounts.

Mineral Matter.-The mineral matter contained in milk consists of phosphates and chlorides of potassium, sodium, calcium, and magnesium, and extremely minute traces of iron. Of the bases, potassium is the most abundant, with calcium, sorlium, and magnesium in the order given. The phosphates predominate over the chlorides. Part of the calcium exists in combination as phosphate with the casein, and the rest, according to Dinilewsky, ${ }^{1}$ as mono- and tricalcium phosphate and in eombination with eitric acid. Part of the magnesium, also, exists in combination with citric and other organic acids. In very small amounts, these are normal constituents of milk of various animals. In human milk, citric acid is present to the extent of about 0.05 per cent., and in cows' milk, it is about three times as abundant.

Specific Gravity.-The specific gravity of cows' milk of normal composition ranges from 1.029 to 1.034 . It increases very slightly for about five hours after the milk is drawn, and then becomes stationary. The increase is believed to be due to molecular modification of the cascin, and not to the escape of gases. It is lowered by fat and water, and by the presence of bubbles of air, and is raised by removal of cream.

Reaction.-When freshly drawn, milk shows the so-called amphoteric reaction; that is, it is acid to litmus and alkaline to turmeric. The alkaline reaction is intensified on warming, but the acid reaction is not influeneed thereby. On standing, the alkaline reaction is overcome by the lactic acid which is formed gradually from the sugar, and the acid reation is increased in consequence of the same. The original acid reaction is due to the presence of carbonic acid, acid phosphates, and dicaleium easeinogenate, the alkaline to alkaline carbonates. Human milk is normally alkaline, and that of earnivora is acid.

Appearance.-The appearance of normal milk is too familiar to need 1 Wratsch, 1901, p. 5.49, 
description; but under eertain rare abnormal conditions, milk may assume different colors, including blue, yellow, violet, and red. These changes of color are due to the action of certain bacteria, and are always evidence of unsanitary conditions to which the milk is exposed at the dairy or during distribution and storage.

Blue milk is due to the action of $B$. cyanogenes, which produces a blue color in no other food material. For its development it requires the presence of lactie ferments, and, thereforc, has no effect on milk that is sterile. Another organism capable of producing the same effect is $B$. cyancofluorescens.

A red color may be cansed by $B$. prodigiosus, $B$. lactis erythrogenes, Sarcina rosacea, and by blood. Yellow milk is caused by B. synxanthus and a number of other organisnıs. Like B. lactis erythrogencs, B. synxanthus produces the abnormal coloration only after coagulating the nilk and dissolving the curd. B. lactis erythrogenes causes red color only when the milk is kept in darkness; in the light it causes a yellow color. A violet color is produced by $B$. violaceus.

All of these milks of abnormal color are, aside from their uninviting appearance, unfit for food, since they are likely to cause gastro-intestinal irritation. Thus Eichert ${ }^{1}$ records a case of severe diarrboa, with very offensive stools, in a child of nine months, due to red milk caused by a bacillus (probably $B$. lactis erythrogenes) present in the milkduets at the time of milking.

Taste.-The flavor of milk is modified very sensibly by the character of the feed and by the absorption of gases and volatile matters of all kinds. It is affected very readily by turnips, garlic, wild onion, mouldy hay and grain, distillery swill, and damaged, rotten ensilage. A very marked taste, suggestive of turnips, is more commonly due to $B$. fretidus lactis and related species than to turnips. This organism causes also other disagreeable tastes, including sweet, bitter, and putrid.

Bitterness of taste may be due to various weeds, chiefly cruciferæ, or to bacteria. When due to feed, the taste is bitter from the very first, but when caused by bacterial ageney it develops some time after milking, when the organisms which produce it have had opportunity to produce peptone from the proteids. It may be due to inflammatory conditions of the udder, in which case it may or may not be noticeable when the milk is freshly drawn. The bacteria concerned in producing bitterness may exist in ducts of the teats, or may come from stable filth. Among them may be mentioned Micrococcus Conn, Micrococcus casci amari (Freudenreich), B. liquefaciens lactis amari (Freudenreich), $B$. Flügge, and, in addition, various yeasts.

A soapy taste, sometimes also sweetish, may be caused by various bacteria, including a bacillus found in hay and straw, discovered by Weigman, capalble of producing its effects within 24 hours; another, isolated by Eichholz, which causes first a swcetish soapy taste and then one suggestive of cow manure, and grows well at a temperature below $50^{\circ}$ F., at which the lactic aeid bacteria are inhibited; and B. saponacei.

1 Zeitschrift für Fleisch- und Milchhygiene, VIII., No. 5. 
A putrid taste is caused by $B$. foetidus lactis and a number of other species. A salty taste may be noted in milk containing pus; sometimes it is decidedly acrid. Other disagreeable tastes, as oily, fishy, and burnt, are sometimes observed, and all are due to various species of bacteria.

Odors are easily absorbed by milk, with consequent impairment of flavor, and some are retained, even after the milk is boilęd, though others are driven off. Hence strong-smelling disinfectants may not be used with entire safety in dairies. This absorptive capacity is so well recognized that milk is stored commonly in separate compartments of refrigerators, away from foods which evolve distinct odors.

Distillery swill not only causes a decidedly bad flavor, but may, in addition, and contrary to a generally accepted idea, cause an alcoholic milk. Thus, according to H. W. Weller,' ${ }^{1}$ a sample of milk derived from cows fed on distillery refuse containing 5.90 per cent. of alcohol yielded, in addition to a high proportion of milk solids, 0.96 per cent. by weight of alcohol. The milk was complained of on account of an unpleasant after-taste. Teichert ${ }^{2}$ records a case in which calves and lambs failed to thrive, and many died from a form of diarrhœa. The mothers were fed on distillery waste, and yielded milk containing alcohol. That alcohol or something connected therewith may be elininated in milk is shown by numerous cases, among which are the following: Vallin ${ }^{3}$ records that a nursing infant was seized with convulsions with great regularity on Mondays and Thursdays, but was quite well on other days. Investigation showed that the wet-nurse on Sundays and Wednesdays, her "days out," was in the habit of drinking freely of alcoholics. The curtailment of the privilege was followed by disappearance of the difficulty. Farez ${ }^{4}$ cites 2 cases which show the bad influence of alcohol on nursing children. In one, the wet-nurse drank wine at meals, and especially in the evening, and the child never ceased fretting, crying, and screaming from 9 o'clock until 11. The nurse eomplained bitterly of the naughtiness of the child, and was grieved at the suggestion that she was herself at fault through drinking too mucl, but she was induced to abstain from alcohol entirely, and from that time there was no further trouble. In the other case, the mother drank tea at noon and wine at dinner, and the child was quiet during the afternoon, but screamed and fretted all the evening and until midnight. A cliange to wine at noon and tea at dinner produced a corresponding change in the behavior of the child, the turbulent period occurring in the afternoon. When the mother eliminated wine from her dietary entirely the trouble ceased.

Koumiss and Kefir.-Alcoholic fermentation of milk, although it never occurs spontaneously, is used by some people for the production of eertain milk beverages. Among these are those kuown as koumiss and kefir.

1 Forsehungsberichte über Lebensmittel, etc., 1897, p. 206.

2 Milch Zeitung, 1901, p. 148.

4 Tribune Médicale, June 20, 1900, p. 488. 
According to Kastle," "Koumiss, originally made by the alcoholie fermentation of mare's milk, is now made from cows' milk by the addition of cane-sugar and yeast. The first action of the ferments is to hydrolyze the polysaceharides (cane-sugar and lactose), producing the simpler sugars, glueose, levulose, and galactose, all of which are fermentable by yeast. 'Two ehanges then ocenr, the alcoholic fermentation, resulting in the production of alcohol and carbon dioxide, and the ordinary lactic acid fermentation, resulting in the production of lactic acid. Kefir, a similar beverage, originating in the Cancasus, is also made from milk by an alcoholic fermentation. The fermentation is carried out in leather bottles, and is started by means of 'kefir grains,' concerning whose origin but little is known. During the fermentation thus induced a considerable quantity of the ferment is produced, which is removed and dried in the sun, and thus new supplies of the kefir grains obtained."

Colostrum. - The milk secreted before and in the early stage of lactation is known as colostrum. It is a yellow, somewhat viscid fluid, of strong odor and acid reaction. In eomposition it differs very materially from milk, particularly in its percentage of proteids. It contains, sometimes, so large a percentage of lactalbumin and lactoglobulin that it is coagulated by boiling. Its content of casein is about normal, but it is not coagulated by rennet, or at most imperfectly. In the early stages its sugar is dextrose and not lactose. Aceording to Tiemann, ${ }^{2}$ it ranges in specific gravity from 1.0299 to 1.0594 , in fat from 0.56 to 9.28 , in proteids from 4.66 to 21.78 , in ash from 0.82 to 1.25 , and in total solids from 12.93 to 32.93 . Under the mieroseope it shows large corpuseles, known as colostrum corpuscles, which disappear within two weeks at most after the time of ealving.

Consistence of Milk.- The natural consistence of milk, which is largely dependent upon the content of fat, is altered by the action of a somewhat large variety of organisms, which produce a condition of sliminess. Slimy or "ropy" milk throws up no cream, and hence cannot be used for the production of butter; but although it is most unappetizing, it causes no digestive disturbance if ingested. The most common cause of this condition is B. lactis viscosus (Adametz), which multiplies at temperatures as low as $46^{\circ} \mathrm{F}$., and acts somewhat slowly. Its ability to grow at temperatures which inhibit other organisms may enable it to predominate over them in a few hours in milk submerged in ice-water or kept in a refrigerator. Micrococcus Frendeureichii (Guillebeau) ean produce sliminess in 5 hours, and Streptococcus Hollandicus can cause it in warm milk in one day. B. lactis pituitosi causes both sliminess and a bitter taste. Karphococcus pituitoparus (Hohl), isolated from a bale of straw, was found to be capable of causing sliminess in both sterilized and unsterilized milk. Guillebeau's bacillus causes in cows a mastitis, a characteristie of which is the exceedingly ropy eondition of the milk when drawn from the udder. In addition

1 Hygienic Laboratory, Bulletin No. 41, p. 365.

2 Zeit. f. physiolog., Chenie, 1898, p. 363. 
to the organisms above mentioned, at least six others are known which produce this change in consistence.

Ferments of Milk.-Milk is not an indifferent inert fluid; it has certain actual biologic properties, which are destroyed by exposure to high tempcratures, among them being the power said to be possessed by fresh milk to destroy certain kinds of bacteria and to inhibit others. This bactericidal property diminishes materially within a few hours; is weakened by 30 minutes' exposure to $149^{\circ} \mathrm{F}$. or by 2 minutes' exposure to $185^{\circ} \mathrm{F}$.; and is destroyed at once by boiling. The lower the temperature at which the milk is kept the longer the property persists. Thus, at $68^{\circ} \mathrm{F}$., according to Coplans, ${ }^{1}$ new milk is slighly bactericidal and absolutely inhibitory for 6 hours, and partially inhibitory for 18 hours longer; at incubator temperature these periods are reduced respectively to 1 and 6 hours; and when raised to room temperature, after 24 hours' storage at $32^{\circ} \mathrm{F}$., it is absolutely inhibitory and bactericidal for 3 hours, and partially inhibitory for 9 hours more. The existence of this bactericidal property has, however, been repeatedly denied. According to Klimmer, ${ }^{2}$ neither human nor asses' nor cows' milk possesses bactericidal power against saprophytes, $B$. coli and $B$. typhosus. According to Stocking ${ }^{3}$ the ascribed property may be explained by the fact that certain species of bacteria which find in milk no suitable food material die out more or less rapidly. Kolle and others ${ }^{4}$ found an absence of bactericidal power against $B$. coli, B. typhosus, B. paratyphosus, and some other species; but B. dysenterice was inhibited and cholera spirillæ were partly killed. Koning, ${ }^{5}$ however, states that the bactericidal property appears soon after the milk is drawn, and exists in especially marked degree in colostrum. $B$. coli, B. fuorescens liq., B. acidi lactici, and other species are destroyed; and colostrum acts with especial vigor against $B$. coli. Hippius, ${ }^{8}$ too, found that cows' milk exerted a strong bactericidal action on $B$. coli and $B$. procligiosus, which was most marked during the first 3 or 4 hours and then gradually waned, and after 6 or 7 hours disappeared. It was weakened by 30 minutes' exposure to $149^{\circ} \mathrm{F}$. and by 2 minutes' exposure to $185^{\circ} \mathrm{F}$, and was killed by boiling.

More convincing are the results of the experiments of Eyre, ${ }^{7}$ who inoculated fresh clean milk with cultures of B.typhosus, and saw the number of bacilli per cubic centimeter fall from 78 to 42 at the end of 4 and 6 hours, and then increase to 46 at 8 hours, 460 at 12 hours, and 6000 at 24 hours. Thus it appears that the property was lost in 4 to 6 hours and was succeeded by first a very slow and later a very rapid multiplication of the bacteria.

The very careful experiments of Rosenau and McCoy ${ }^{8}$ led them to

I The Lancet, October 19, 1907, p. 1074.

- Centralblatt für Bakteriologie, I. Abt. 1903 , XXXIII., Ref., p. 548.

3 Storr's Agricultural Experiment Station Report, 1904, p. 89.

4 Klinische Jahrbücher, XIII., 1904.

5 A potheker Zeitung, XIV., 1904, p. 730.

6 Jahrbuch für Kinderheilkunde, etc., LXI., 1905, p. 365.

7 Journal of State Medicine, XII., 1904, p. 728.

${ }^{8}$ Hygienic Laboratory, Bulletin No. 41, Washington, 1908, p. 449. 
conclude that the diminution in numbers is largely apparent and not real, and is due, at least in part, to agglutination. There is a real restraining action which persists for some hours, and for a longer time if the milk is kept cool. Although some of the polymorphonuclear leucocytes seem to possess the power of phagocytosis, this plays no essential part, for the decrease is as marked in cell-free milk as in the sediment rich in leucocytes. 'The germicidal action, whatever its nature, is specific, the same sample restraining $B$. typhosus and Staphylococcus pyogenes aureus, but not B. paratyphosus, A or B. They found the action to be variable and feeble, but worthy of attention in good dairy methods.

In 1900 Escherich called attention to the fact that infants fed even to a slight extent at the breast could digest cows' milk perfectly, whereas with no breast-milk such was not the case. The difference was attributed by him to the presence of ferments, the study of which was taken up at once by Spolverini, ${ }^{1}$ who isolated seven different kinds. Others have since been isolated by the same observer and others, and much study has been devoted to their properties and origin. Not all kinds of milk contain the same kinds of ferments. Thus, while all of those discovered by Spolverini are present in the milk of women and bitches (carnivora), certain of them are lacking in that of cows and goats (herbivora). That those not common to both carnivora and herbivora can be made to appear or disappear by appropriate diet has been proved by Spolverini, ${ }^{2}$ who caused diastase and the salol-splitting ferment to appear in the milk of a goat put upon a mixed diet, and diastase to diminish markedly in the milk of a bitch fed twenty-two days on a vegetable diet. The ferments thus far isolated comprise the following :

Trypsin or Galactase.-This is found in the milk of the bitch, cow, and goat, and to a smaller extent in that of the ass and woman. It digests casein. Exposed to $168.8^{\circ} \mathrm{F}$. it is destroyed. According to Neumann-Wender ${ }^{3}$ it is not one, but several enzymes, and is most active at about $104^{\circ} \mathrm{F}$, and althongh it loses its power to dissolve casein on exposure to $168.8^{\circ} \mathrm{F}$., its power to decompose hydrogen peroxide is not impaired until the temperature reaches $176^{\circ} \mathrm{F}$, nor entirely destroyed under $181.4^{\circ} \mathrm{F}$.

Pepsin.-This is said by Spolverini to exist in human milk in small traces. Its existence is denied by Benoit, but affirmed by Moro.*

Diastase or Amylase.-This is present in human milk and in the milk of the bitch, and to the greatest extent in that of the ass. It is not normally present in cows' and goats' milk. This was the first ferment to be isolated from milk. It is destroyed at $167^{\circ} \mathrm{F}$.

Lipase.-This exists in the milk of all the different kinds above mentioned, and is most active in human milk. According to Gillet 5

1 Archives de Mrédecine des Enfants, December, 1901.

${ }^{2}$ Centralblatt für Bakteriologie, etc., I. Abt. Ref., 1902, XXXII., p. 321.

3 Oesterr. Chemische Zeitung, 1903, p. 1.

${ }^{4}$ Centralblatt für Bakteriologie. etc., I Abt. Ref., 1903, XXXIII., p. 10.

5 Journal de Physiol. et Path. Gén.. 1903, No. 3. 
it does not attack all of the constituents of butter fat, but only monobutyrin, and hence is not a lipase, but monobutyrinase. It is destroyed at $147^{\circ} \mathrm{F}$.

Salol-splitting Ferment.-This is not found in the milk of eows and goats, but only in human and asses milk. Its existence in any milk has been denied, but whatever the nature of the cause of salol-splitting it is killed at $149^{\circ} \mathrm{F}$.

Oxydases.-That which is commonly known as oxydase is always present in considerable amounts in cows' and goats' milk, but is hardly noticeable, though rarely absent, in human milk. According to Gillet ${ }^{1}$ it is always present in human colostrum, being united with the polynuclear leucocytes. It is killed at $176^{\circ} \mathrm{F}$. Spolverini ${ }^{2}$ makes a distinetion between direct oxydases which can utilize directly the atmospheric oxygen and indirect oxydases which cannot do so, but require the presence of a substance rich in oxygen like hydrogen peroxide. The ferment commonly known as oxydase is this anaërobic indirect oxydase, which Spolverini believes acts through two distinct enzymes, one of which decomposes hydrogen peroxide, the other fixing the liberated oxygen.

Seligmann ${ }^{3}$ divides the oxidizing ferments into-(1) superoxydase, which decomposes hydrogen peroxide and is identical with the catalase of Loew ; (2) direct oxydase ; and (3) indirect oxydase, which is active only in the presenee of hydrogen peroxide and corresponds to the peroxydase of Linnossier. Peroxydase, aecording to Yolles, ${ }^{4}$ is always present in milk, and in human milk five or six times as abundantly as in cows'. It is destroyed at $167^{\circ} \mathrm{F}$. Superoxydase, or catalase, is killed at $176^{\circ} \mathrm{F}$.

Reductases._-Fresh milk has a reducing action upon methylene-blue and other substances, which increases as time elapses, but disappears on boiling. This property is believed by some to be due to ferments, and by others to be caused by bacterial action. That it is due to bacteria is suggested by the fact, among others, that while boiled milk is inactive, it may be activated by inoculation with sour milk. According to Smidt ${ }^{5}$ fresh milk contains no preformed reductase whatever, and if methylenc-blue is decolorized by raw milk the action is due to bacteria; whereas if the reduction is accomplished in the presence of formalin (Schardinger's reagent, 2.5 per cent. each of saturated aleoholic solution of methylene-blue and formalin in distilled water), the action is due to a ferment which acts catalytically upon the formalin. This is called by Jensen ${ }^{6}$ aldeliyde catalase.

Bacteria in Milk.-In spite of all preeautions taken to exclude them, bacteria of various kinds are always present in milk in considerable numbers. Although the milk is sterile at the point of sceretion

1 Centralblatt für Bakteriologie, etc., I Abt. Ref., 1903, XXXIII., p. 197.

${ }^{2}$ Rer. Hyg. et Med. Infantile, III., 1904, p. 113.

3 Zeitschrift für Hygiene und Infeetionsklankheiten, L., 19 J5, p. 97.

4 Zeitschrift für Biologie, XLV., p. 248.

5 Archiv für Hygiene, LVIII., 1906, p. 313.

${ }^{6}$ Rev. Gén. Lait., VI., 1906, Nos. 2, 3, and 4. 
and in the eisterns of a healthy gland, it is by no means free from bacteria when it is diseharged from the milk-ducts, for the organisms gain entrance through the external orifices, and under the favoring influence of temperature and abundance of suitable nutrient material multiply enormously between milkings. They are very largely expelled with the first jets, but ordinarily they may be found in some numbers even in the last strippings, and those which persist at the completion of the operation and are left in the ducts multiply during the ensuing interval. In a study of more than 800 sections of 35 teats of cows, goats, and sheep, hardened in alcohol and appropriately stained, UhImann ${ }^{1}$ found not one in which bacteria were not present in some number, occasionally as many as a hundred, but generally only a few. The predominating forms were eocei. Similar results were obtained by von Freudeureich ${ }^{2}$ on examining the udders of 15 cows, in 13 instances immediately after slaughter.

The bacteria derived from the udder are chiefly pyogenie cocei; and when these are present in large numbers they are usually indicative of inflammatory conditions. The others, with which the milk is eommonly richly seeded when the operation of milking is concluded, fall into the pail with dust from the air, with hairs, dandruff, and other material from the animal's exterior and the person and clothing of the milker, and are also in large part derived from the pail itself, which under the best of conditions is never completely sterile. In the processes of straining and "putting up," still more bacteria are acquired. Thus, it will be seen, the production of bacteria-free milk is a practical impossibility under any circumstances, and the less the care observed the greater will be the bacterial eontent. Furthermore, inasmuch as milk is an excellent culture medium, and since warmth is the principal favoring condition for rapid multiplication, unless the product is immediately cooled, the number of baeteria present will soon be much larger.

With every possible precaution to exelude bacteria from external sourees, including tying the cow's tail to the leg on the farther side, washing the flank and udder with borie acid solution, and wiping the parts with a sterile eloth, treating the hands in the same manner, milking the cow half out, repeating the washing operation, and then drawing the rest of the milk into a sterilized covered pail through four thicknesses of sterile cheese-cloth and a layer of sterile absorbent cotton, Professor H. W. Conn and W. A. Stocking ${ }^{3}$ succeeded in securing specimens which contained in two series averages of 242 and 267 bacteria per cubie centimeter. Of small samples drawn by Bergey ${ }^{4}$ from the udders of a number of cows into sterile test-tubes, about one-third were sterile and about one-tenth eontained more than 5000 bacteria per enbie eentimeter.

Lactic Ferments. - Of the many species of bacteria whieh eommonly

1 Revue Gén. Lait, 1904, p. 163. (Abstract of Thesis, Jena, 1903.)

${ }^{2}$ Centralblatt für Bakteriologie, etc., II. Abt. X., 1903, p. 401.

3 Storr's Agrieultural Experiment Station Report, 1903, p. 52.

4 Department of Agriculture, Pennsylvania, Bulletin 125, 1904. 
gain access to milk, the greater number belong to the class known as lactic ferments, which eonvert the milk-sugar into several varieties of laetic acid after it is split into dextrose and galactose. They are of intestinal origin, and are invariably present to some extent through the unavoidable introduction of particles, minute or gross, of manure. They multiply best at temperatures from $70^{\circ} \mathrm{F}$. to about $90^{\circ} \mathrm{F}$, and are killed within 20 minutes on exposure to $140^{\circ} \mathrm{F}$.

The commonest of the lactie ferments is Streptococcus lacticis (Kruse), which is similar to or identical with B. lactis acidi (Leichmann), and, aceording to Heinemann, ${ }^{1}$ agrees morphologically and culturally with Streptococcus pyogenes. Indeed, by passage through a series of rabbits, Heinemann succeeded in raising its virulence from practically nothing to that of the latter species.

Next in importance is B. acidi lactici (Hueppe), which is apparently identieal with $B$. lactis aërogenes (Eseherich), and then follow B. coli and several of lesser importance and certain saccharomyces.

Peptonizing Ferments.-Of greater importance than the laetic ferments from a sanitary standpoint are the group known as peptonizing ferments, of which there are many species. They secrete enzymes which attack and dissolve easein (henee known also as easein ferments) and some which may produce curdling. Some form extremely resistant spores which withstand long boiling, and hence they persist in pasteurized and sterilized milk. Flügge ${ }^{2}$ isolated from market milk 12 varieties, 3 of which were pathogenie to mice, guinea-pigs, rabbits, and puppies, and he called attention, therefore, to the danger therefrom in the use of milk which has been heated to such an extent as to cause the destruetion of the far less resistant souring bacteria, which milk to the eye and in consistence appears to be normal, but which may be distinctly poisonous. These forms, which include the B. subtilis group, grow with great rapidity at $77^{\circ} \mathrm{F}$. and upward, but are inhibited in unheated milk by the lactic ferments. They are derived from stable dust and filth, and are always present in milk, no matter how great may be the effort to exclude them.

Butyric Ferments.-A third group includes the so-called butyric ferments, which are strictly anaërobie spore-bearers. They decompose milk rapidly and produce a strong acid reaction (butyric acid) and gas formation, with coagulation. They are less dangerons than the casein ferments, because of causing coagulation, and their spores are much less resistant to heat, being killed in less than 2 hours by exposure to the boiling temperature. To this elass belong $B$. enteritidis sporogenes (Klein), B. aërogenes capsulatus, and numerous others not yet thoroughly studied. Like the casein ferments, they are inhibited by the lactic acid bacteria.

Number of Bacteria in Milk. - The number of baeteria which gain access to milk while it is being drawn from clean cows with the observance of proper precautions regarding cleanly methods may be materi-

1 Journal of Infectious Disenses, IV., 1907, p. 89.

2 Zeitschrift für Hygiene und Infectionskrankheiten, XVII., 1894, p. 272. 
atly reduced by the use of covered milk pails, that is to say, of pails provided with it cover in which is an orifice sufficiently large to receive the jets of milk directed by an ordinarily skilful milker. Such a pail, of which there are at number of types, is shown in Fig. 1.

'The reduction of the opening of' an ordinary pail to a small proportion of its entire area insures a corresponding reduction in the number of bacteria-laden particles of dust, manure, and hairs which fall into the milk while it is being drawn. In one series of 8 milkings into an ordinary pail and into one of the type shown in Fig. 1, Stocking. demonstrated a difference of 85 per cent. in the number of bacteria in favor of the covered pail, and in other series, the cows being less elean, the difference was even greater, the milk in the covered pail yielding respectively onc-twentieth and one thirty-third as many as that of the

Frg. 1.

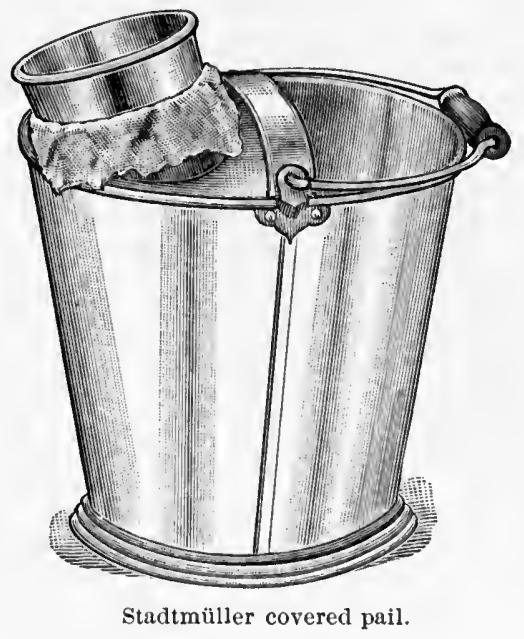

open pail ; that is to say, the dirtier the cow, the greater the advantage of the covered pail.

Stocking found the covered pail to be of great advantage in any stable in excluding dirt and bacteria from milk, the relative advantage gained depending upon the sanitary condition of the stable. The desirability of a strainer on the covered pail depends upon the style of the straining device, for the dirt which falls into the opening may be driven through the strainer by the succeding jets of milk, unless absorbent cotton in sufficient thickness is employed for the purpose.

For the purpose of excluding the bacteria of the air of the stable and the dirt from the exterior of the cow and from the hands and person of the milker, a number of types of milking machines have been de-

1 Storrs, Agricultural Experiment Station, Bulletin 48, May, 1907. 
vised; but on account of the practical impossibility of keeping in a fairly sterile condition the tubes which conduct the milk from the teats to the pail, and because of an unexplainable reduction in the yield of the cow after repeated application, their use appears to possess no particular advantage in dairies where cleanly methods are followed.

The difference in the number of bacteria which fall into milk when proper precautions are observed and when they are neglected is very considerable. Thus, Soxhlet found that the milk of a cow with a dirty udder, stalled in a dirty stable, kept sweet 50 hours at ordinary temperature, and that, when her ndder was washed and she was milked in the open air, it remained sweet a day and a half longer. Still more instructive are the results obtained by Freeman, ${ }^{1}$ who exposed plates, 3.5 inches in diameter, for two minutes as follows: one in the open air, one inside a barn, and a third in front of the milk pail under a cow in the same barn while being milked. The first plate showed 6 , the second 111, and the third 1,800 colonies. Such a number of bacteria, falling upon so small a surface within so short a time, is an index of the enormous number which may fall into a pail during the time required for a complete milking.

The enormous number of bacteria which may be commonly present in ordinary market milk, the great influence thereon of non-observance of the strictest cleanliness, and the extreme rapidity of multiplication uncler favoring conditions, are shown in most striking manner by W. H. Park, ${ }^{2}$ who exposes the inexcusable lack of cleanliness in the methods of proeuring milk, and of care in cooling, and in keeping it during tramsportation to the city. Milk from individual cows, where every reasonable means was taken to insure cleanliness, yielded an average of 6,000 bacteria per ec. when 5 hours old, and kept at $45^{\circ} \mathrm{F}$., to which temperature it was cooled soon after it was drawn. After 24 lours, the average number fell to 1,933 ; after 48 , it increased to 17,816 . Milk taken in winter in well-ventilated, fairly clean, but dusty, barns, and cooled within 2 hours to $45^{\circ} \mathrm{F}$., the visible dirt having been eleaned off the hair about the udder, the milkers' hands wiped off, but not washed, the pails and cans elean, but the straining cloths dusty, yielded the following average figures: At time of milking, 15,500; after 24 hours, 21,666 ; after 48 hours, 76,000 . Milk taken from cows kept in ordinary barns, the conditions as to cleanliness of surroundings and method of milking being about what obtain on the average farm, yielded the following average figures:

\begin{tabular}{|c|}
\hline after milking \\
\hline urs \\
\hline Afte \\
\hline
\end{tabular}

Twenty samples of average milk taken immediately on arrival in the eity, much of it having been transported more than 200 miles,

1 Medical Record, March 8, 1896.

'Journal of Hygiene, July, 1901, p. 391, 
yielded from 52,000 to $35,200,000$ bacteria per cc. (average 5,669,850). 'The average temperature of the sumples when taken from the cans was $45^{\circ} \mathrm{F}$. Milk as sold in the shops during the morning hours yielded the following averages:

\begin{tabular}{|c|c|c|c|}
\hline From tenement & id-winter & (13 samples) & $1,977,692$ \\
\hline From well-to-do & “ & $(10$ & 327,500 \\
\hline From tenement & September & 5 & . $15,163,600$ \\
\hline From well-to-do & “ & 5 & $1,061,400$ \\
\hline
\end{tabular}

Of very great importance in the bacterial contamination of milk are the dust liberated into the air of the stable when hay and bedding are thrown down and the bacteria in improperly cleaned pails and other utensils. During the placing of bedding, according to Harrison, ${ }^{1}$ from 12,000 to 42,000 bacteria were deposited per minute into a 12 -inch pail, against from 400 to 2000 per minute an hour afterward, when the dust had settled. He found from 215,000 to 806,000 bacteria per cubic centimeter in the washings of poorly cleaned cans, and from 15,000 to 93,000 in those of cans which had been washed in warm water and then scalded. Even from cans washed in warm water and steamed for 5 minutes considerable numbers of bacteria were obtainable.

The part played by cowdung in seeding milk with bacteria may readily be understood from Warington's estimate of $165,000,000$ bacteria in 1 gram of dung from a hay-fed eow, and Wüthrich and von Freudenreich's still higher estimate of $375,000,000$. Cowdung is said not to yield $B$. enteritidis sporogenes (Klein), but horsedung is said to contain it extensively, and this alone is abundant reason for condenuing the reprehensible practice of employing that material for bedding cows. The amount of stable dirt in ordinary market milk is very variable, in spite of careful straining. Straining removes only the larger particles of manure, hairs, straw, etc., but does not exelude the fine particles nor the soluble portions of the dung, which pass through with their millions of bacteria. It is to this material that dirty milk owes the so-called "cowy" taste, regarded by some as normal. The insoluble dirt has been found by Renk to run as high as 362 milligrams per liter in the market milk of Halle; but the average was 14.92, while that of samples collected in Berlin, Munich, and Leipzig was respectively $10.3,9$, and 3.8 . The milk of Hamburg has shown an average of 13.5. Ballo found that 37 samples of the milk supply of Budapest, out of 502, were dirty to the eye, and they yielded from 6.9 to 44 , and one of them as high as 110.5 milligrams per liter.

Temperature is of greater importance in the eventual bacterial content of milk than the number of bacteria which originally gain entrance, for cold inhibits the growth of all of the important speeies, and during the period of inhibition large numbers die off or are destroyed. And the number which may be present after some hours may be determined by the species present rather than by their abundance. Ac-

' Rev. Gén. Lait. 2, 1903, Nos. 20-23. 
cording to Conn and Esten, ${ }^{1}$ it happens frequently that milk containing originally but few bacteria will later yield considerably larger numbers than those in other specimens which at the outset contained more than the first, both samples being kept under precisely identical eonditions. They show that for a number of hours after milk is drawn there is no bacterial multiplication, but frequently there is a diminution in numbers. In milk kept at $68^{\circ} \mathrm{F}$., most speeies begin to multiply after the first 6 hours, some remain stationary, and others disappear. The most rapid multiplication is that of the common lactic ferments. In milk kept at $55^{\circ} \mathrm{F}$. there is but little growth, even at the end of 50 hours, when they are usually no more numerous than those present after 18 hours in milk kept at $68^{\circ} \mathrm{F}$. When nilk is iced the bacteria originally present decrease in number for a long time, and since the low temperature prevents the lactic ferments from multiplying and gaining ascendency over the other species, the latter show a relative increase over their number in milk which is kept at higher temperatures. After the periods of inhibition and slow growth have passed, the lactic acid bacteria grow with extreme rapidity, and as they multiply other species, and finally practically all others, disappear. Conn and Esten state that the lactic acid bacteria sometimes are 99 per cent. of all present. It is on aceount of the beneficent action of these bacteria against those which in their absence eause putrefactive elanges that ordinary commercial pasteurization of public milk supplies is objectionable, for stale milk may thus be kept a long time without curdling, and meanwhile deleterious changes are being eaused.

Many species of milk bacteria ean grow below $40^{\circ} \mathrm{F}$., and they grow more rapidly after several days' exposure has enabled them to beeome habituated and to adjust themselves to the unusual eondition. Thus a milk which has not been subjeeted to artificial heat may beeome unwholesome, although sweet and apparently wholesome. According to Conn, it is not unlikely that this may be the explanation of some of the eases of ice-eream poisoning so commonly observed in summer, the cream being kept at a low temperature for days, until considerable is accumulated or demand arises, and then the product when made is rich in bacteria of a suspicious character. To a poisonous substance isolated by Professor Vaughan, and shown to have been the eause of the train of symptoms commonly known as ice-cream poisoning, milk poisoning, and cheese poisoning, the name tyrotoxieon was given by its discoverer.

The influence of different temperatures on the rapidity of bacterial multiplication is well shown by Park's results, obtained after allowing portions of the same specimen to stand under otherwise similar conditions. At temperatures below $50^{\circ} \mathrm{F}$. there was at the end of 24 hours no inerease-in fact, a decrease-in the number of bacteria ; but at higher temperatures the multiplication was enormous. The original number per cc. was 3000 , and the growths at the several temperatures above $55^{\circ} \mathrm{F}$. were as follows at the end of 24 and 48 hours:

1 Storr's Agricultural Experiment Station Report, 1901, p. 13. 
Temperature.

$60^{\circ} \mathrm{F}$.,

$68^{\circ} \mathrm{F}$.,

$86^{\circ} \mathrm{F}$.,

$94^{\circ} \mathrm{F}$.,
24 hours.

180,000

450,000

$1,400,000,000$

$25,000,000,000$
48 hours.

$28,000,000$

$25,000,000,000$

Milk of fair quality from a shop was kept at $90^{\circ} \mathrm{F}$. for 8 hours, during which time its contained bacteria increased from 92,000 to $6,800,000$ per ec. ; another, of poor quality, under the same conditions, showed an increase from $2,600,000$ to $124,000,000$.

As the lactic acid bacteria multiply, they seize upon more and more of the milk-sugar and convert it to lactic acid, the amount of which is expressed in degrees per $50 \mathrm{cc}$. of milk, one degree representing the amount neutralized by 0.5 cubic centineter of decinormal sodium hydrate, which is 9 milligrams. When milk contains so much lactic acid that $50 \mathrm{cc}$. are neutralized by $22 \mathrm{cc}$. of the reagent, it begins to taste sour ; and when $42.5 \mathrm{cc}$. are required it is ready to curdle.

That public milk supplies frequently show millions of bacteria to the cubic centimeter is notorious, and both in this country and in Europe it is common to find that in some large cities the sewage is less rich in bacteria than the milk supply. Proskauer ${ }^{1}$ and others, for example, found the market milk of Berlin to average 3,500,000 in summer and more than 500,000 in winter; Newman has reported the following averages for London (city), Westminister, Halborn, Islington, and Finsbury : 4,800,000, 1,600,000, 4,800,000, 1,600,000, 2,300,000 ; Jordan's averages for Chicago market milk during April, May, and June, 1904, give a general average of $12,785,000$.

The milk of cows with garget, an inflammatory condition of the udder, the commonest of all bovine diseases, may have a far more extensive bacterial flora than that of ordinary milk. The exciting cause of this abnormal condition appears to be no single organism, but various species, among which are Staphylococcus aureus and albus, Staphylococcus mastitidis, Streptococcus mastitidis, Galactococcus fulvus, B. coli, B. aërogenes, and $B$. pyogenes bovis. Several of these species may be present in the same udder at the same time. In such milk pus is always present with the bacteria and in such amounts as to cause a salty taste. The disease may be present without any perceptible symptoms, and attention may be called to it only by the appearance of caseous masses or shreds on the strainer ; hence the product of the most conscientious dealer may be extensively infected with the causative organisms and pus, in spite of all precautions and without his knowledge.

The presence of streptococci in milk does not necessarily mean the existence of garget, for they have repeatedly been found in healthy udders. Reed and Ward ${ }^{2}$ have recorded the case of a cow, of the Cornell University herd, apparently healthy, whose milk yiclded streptococei at intervals extending over two years and a half. When she was killed the udder showed the organisms in abundance.

${ }^{1}$ Zeitschrift für Hygiene und Infectionskrankheiten, LVII., 1907 p. 173.

2 Centralblatt für Bakteriologie, XXIX., 1901, p. 496. 
Whether or not from diseased udders, many public milk supplies will yield a large proportion of samples in which streptoeocei are present in large numbers. Thus, Eastes ${ }^{1}$ discovered them in 106 of 186 samples examined ; Beck, ${ }^{2}$ in 35 of 56 samples of the Berlin supply ; Bergey, ${ }^{3}$ in 20 of 40 samples of market milk (Philadelphia) and in 3 of 59 samples from first-class dairies; Kaiser, ${ }^{+}$in 76.6 per eent. of samples taken in Graz; and Savage, ${ }^{5}$ in 45 of 68 specimens, part of which were direetly from the udder. Savage distinguished 12 different varieties of streptococci, and Müller isolated from the Graz samples three strains which produced hemolysins.

J. Baehr ${ }^{6}$ had the following results : In only 2 out of 81 milk samples was it possible to isolate the streptococens pyogenes. One of these was traced to a cow with a diseased udder. In 61 out of 81 samplesthat is to say, 75 per eent.- he isolated an organism much like Kruse's streptococcus lacticus. It seemed to lim probable that these streptococci got into the milk from the feces. He does not believe that infant troubles are caused by these streptococei, but it is possible that these germs may become pathogenic under farorable conditions.

Regarding the signifieanee of large numbers of lencocytes in milk, with or without streptococei, there is some difference of opinion. Formerly lencocytes were regarded as pus, and streptococei were looked upon as necessarily pathogenic, but it is known now that both can oecur in large numbers in perfeetly lealthy milk. Russell and Hoffmamn ${ }^{7}$ exanined many samples of milk from cows with neither evidenee of present nor history of past disease of the ndder, and found that onc-third of them gave counts higher than 500,000, and some as high as 1,800,000; and Sarage ${ }^{8}$ found that more than 75 per eent. of such cows yielded counts averaging more than 100,000 , and some as high as 4,500,000. On the other hand, Rullmann and Trommsdorff ${ }^{\circ}$ have set an arbitrary standard, and assert that if mixed milk contains 0.1 per cent. of lenencytes, mastitis is to be inferred; and Bergey ${ }^{10}$ is of opinion that only when leneocytes and streptococei, admittedly present to some extent in practically all milk, are increased to a certain extent, are they indieative of pathologic conditions; and that in practically all cases in which the number of lencocytes is high there is a relative increase in the number of streptococei, indicating the presenee of mastitis in one or more quarters of the udder, as will usually be revealed on expert palpation of the udder when empty. Bergey's statements are endorsed by Trommsdorff," who found that

1 British Medical Journal, Nov. 11, 1899.

2 Dentsche Vierteljahrsschrift für öffentliche Gesundheitspflege, 1900, p. 430.

3 American Mledicine, April 20, 1901, p. 122.

4 Archir für Hygiene, LVI., 1906, p. 51.

5 Journal of Iy giene, VI., 1906, p. 123.

${ }^{6}$ Arch. f. Ilyg., Irünchen u. Berl., 1910, lxxii, 91-158, 1 pl.

7 Journal of Infections Diseases, 1907, Suppl. 3, p. 63.

${ }^{8}$ British Medical Journal, 1905, p. 1165.

9 A rehiv für Hygiene, LIX., 1906, p. 224.

10 T'niversity of Pennsylvania Medieal Bulletin, Sept., 1907.

11 Münchener medizinische Wochenschrift, LIII, No. 12. 
whenever leucoeytes were present in large numbers innumerable streptocoeci were also present.

Miller ${ }^{1}$ comes to the following conclusions :

(1) Many leneocytes and streptoeoeci are present in the normal milk of a healthy cow.

(2) Lencocytes and streptococei are, as a rule, more numerous in the milk of cliseased than in that of healthy cows.

(3) As an aid to veterinary inspection, the number of leucocytes may furnish some information of value. If a dairy milk shows an unusually high leueocyte count, a special examination of the herd for garrget, ete., should be made.

(4) No satisfactory method has been devised for distinguishing the pathogenic from the non-pathogenic streptococei in milk. Their significance is, therefore, a matter for further study.

(5) In view of the recent researches upon streptococcus lacticus, no constant relationship may be expected between the number of streptococei and the number of leucocytes in milk.

\section{Preservation of Milk.}

The keeping quality of milk is influenced by cold, which retards the growth and nultiplication of bacteria which bring about decomposition; by heat, which destroys them; and by chemicals (antiseptics), which either kill them or retard their growth.

Cold.-Preservation by cold is, in many respects, preferable to either of the other methods. The constituents are in no way altered in character, there is no change in digestibility, and no element is introduced into the system with the milk to excrt any harmful influence upon the digestive processes. In places where ice is expensive or not obtainable, this method is not available, but where it is cheap and plentiful, it is the one in most common use. In some parts of Europe milk is frozen into solid blocks by the ammonia process, and shipperl in that form to market, or sent in large air-tight cans, into each of which a block of frozen milk, weighing about 25 pounds, is placed, to keep the milk in which it floats at a low temperature.

Heat.-Pasteurization and Sterilization.-By pastenrization is meant raising the temperature of the milk to such an extent and for a sufficiently long period as to ensure the destruction of the lactic acid bacteria and pathogenie organisms without affecting the enzymes or the lactalbumin.

As regards the thermal death points of various bacteria, writers have not been in agreement, but the results of Rosenau ${ }^{2}$ are in accord with those of Yersin, Bonhoff, Schroeder, Theobald Smith, Russell and Hastings, and Hesse, and are as follows:

The tubercle bacillus in milk loses its infective properties for guineapigs when heated to $60^{\circ} \mathrm{C}$. and maintained at that temperature for 20

1 Journal of Comparative Pathology and Therapeutics, London, March, 1909, p. 34 Vol. XXII., Part 1.

2 Pediatrics, 1908, p. 549. 
minutes, or at $65^{\circ} \mathrm{C}$. for " a much shorter time." The typhoid baeillus is killed if subjeeted to $60^{\circ} \mathrm{C}$. for 2 minutes. The diphtheria bacillus is often killed at $55^{\circ} \mathrm{C}$., but occasionally survives $60^{\circ} \mathrm{C}$, and the same is true of cholera. The dysentery bacillus is killed by $60^{\circ} \mathrm{C}$. for 10 minutes; $60^{\circ} \mathrm{C}$. for 20 minutes is more than suffieient to kill the bacillus of Malta fever. Henee, as a good working standard, $60^{\circ} \mathrm{C}$. for 20 minutes recommends itself. Furthermore, this temperature, that is to say, $60^{\circ} \mathrm{C}$. for 20 minutes, does not appreciably affect the eliemical properties of milk.

In commercial pasteurization a number of different types of apparatus are employed and different methods are followed, the temperatures ranging from $150^{\circ}$ to $185^{\circ} \mathrm{F}$, or even higher, and the periods of exposure from less than a minnte to as much as an hour, with immediate eooling thereafter, in order to preserve the flavor and to inhibit the growth of the surviving bacteria. Temperatures higher than $158^{\circ} \mathrm{F}$. cause milk to aequire a "cooked" flavor, which to many persons is unpleasant.

By raising the temperature to the boiling-point, milk is more completely sterilized than by the processes employed in pasteurization; but absolute sterilization cannot be accomplished except by boiling on successive days or by continnous heating under pressure for at least 2 hours at $248^{\circ} \mathrm{F}$, on account of the very resistant nature of the spores of various species of bacteria eommonly present in milk produced under the usual conditions.

According to Rosenan, ${ }^{1}$ boiling produces decomposition of proteins and other complex nitrogenous derivatives; diminution of organic plosphorus; increase of inorganic phosphorus; precipitation of calcium and magnesium silts and the greater part of the phosphates; expulsion of the greater part of the $\mathrm{CO}_{2}$; caramelization or burning of a certain portion of the milk-sugar (lactose), causing the brownish color; partial disarrangement of the normal emulsion and coalescence of some of the fat globules; and coagulation of the serum, which begins at $75^{\circ}$ C. Casein is, furthermore, rendered less easy of coagulation by rennin, and is slowly and imperfectly acted upon by pepsin and pancreatin. A cooked taste is caused by boiling. Crcam does not rise well, if at all. Formation of a scum begins at $60^{\circ} \mathrm{C}$. Heating kills the ferments in milk. 'These can stand $60^{\circ}$ to $65^{\circ} \mathrm{C}$. for some time. They are weakened by $65^{\circ}$ to $70^{\circ} \mathrm{C}$. They are destroyed at $75^{\circ}$ to $80^{\circ} \mathrm{C}$.

Sterilization at higher temperatures causes still further changes in the proteids, and converts part of the lactose to caramel.

Objections to Pasteurization and Sterilization.- - So far as children old enough to receive a mixed diet and adults ale concerned, there are no objections on the score of development and health to the use of pasteurized and sterilized milk, and, indeed, where it is diffieult or impossible to secure a clean and wholesome milk supply, pasteurization is a commendable and logical procedure; but, on the other hand, against the

1 Pediatries, 1908 , p. 547. 
use of pasteurized and sterilized milk for bottle-fed infants and against the substitution of commercial pasteurization for the enforcement of the strietest dairy hygiene, there are very valid objections. It is, first of all, to be recognized that proper pasteurization is, in a sense, a laboratory process, which requires considerable skill in bringing every part of the volume operated upon to the requisite temperature and not beyond it. With insufficient heating the object of the process is not accomplished; with excess of temperature the biological properties of the milk, residing in the ferments or enzymes, are destroyed, and the milk is made an unfit food for infants. Even with the best of eare, untoward results of continued feeding of infants with pasteurized milk have been so frequently observed, in both private practice and institutional experience, as to demonstrate a real danger. Sill ${ }^{1}$ relates that of about 25,000 infants that came under his charge in 5 years, those that were fed on pasteurized or sterilized milk continuously, or part of the time on the one and part on the other, no less than 97 per cent. developed rickets or scurvy, or a combination of the two. Those that were fed partly at the breast and 5 feedings per day of heated milk had the same symptoms in a lesser degree. Sterilized nilk was given only during the 3 summer months, and pasteurized milk at other seasons. Infants fed on raw milk were attacked with symptoms of rickets when they were placed upon sterilized or pasteurized milk. Again, in an English children's hospital, ${ }^{2}$ a number of cases of scurvy which failed to respond to treatment led to an inquiry, which disclosed the fact that the dairy which supplied the institution had been furnishing pasteurized instead of raw milk, without informing the authorities; and on the substitution of fresh raw milk the ehildren began to inprove. Experiments with calves and other young animals have repeatedly demonstrated the far greater and more rapid development which oceurs on raw milk. Jensen ${ }^{3}$ has shown that new-born ealves fed upon boiled milk invariably were seized with a violent diarrhœa, similar in all respects to the disease known as ealf dysentery ("Kälberruhr").

It is not, however, perfeetly clear that pasteurized milk is necessarily deleterious to the health of infants. Rosenan states that he has "made a careful compilation from the literature of the results of raising children npon heated milk, and finds hundreds of instances reeorded, especially by French observers, to the effeet that children flourish well upon heated cows' milk (loc. eit., p. 606). When all is said and done, the pasteurization of milk for infunt feeding ean neither be recommended nor discountenanced as a general proposition. The saying that 'one man's meat is another man's poison,' applies with special signifieance to the artificial feeding of infants."

Rosenau ${ }^{5}$ also insists, as regards the practice of pasteurization, that "we should protest against a word which means a generality and insist

1 New York Medical Journal, February 8, 1908.

2 Journal of the American Medical Association, June 23, 1906.

${ }^{3}$ Quoted by Behring: Therapie der Gegenwart, $\mathrm{XLV}$., No. 1.

4 IIygienic Bulletin 41, p. 607.

5 Ann. Med. Pracl., Boston, 1910, 237. 
upon all pasteurized milk being properly labeled with the degree of heat, the period of time, and also with the clate on which it was subjected to the process. It should, furthermore, be under the immediate supervision of the health office."

A very important objection to eommereial pasteurization of public milk supplies is that through the destruction of the but slightly resistant lactic acid bacteria, which Professor V. C. Vaughan has likened to the red lanterns placed as danger-signals in a highway, the most conspicuous means of indicating unfitness for use is removed. 'Stale milk thus deprived of the agents which produce souring, but containing the very resistant easein ferments and other bacteria which produce toxie substances, remains fluid and apparently wholesome for a considerable time, and yet may be a dangerous food. It has been demonstrated by Flügge, who as long ago as $1894^{1}$ called attention to the dangers of imperfectly pasteurized or sterilized milk in the feeding of infants, that these peptonizing bacteria may develop so active a poison that puppies fed upon such milk may be seized with violent and even fatal diarrhœas. Such milk, without souring, gradually putrefies, but without showing by alteration in taste or appearance the damage which it has suffered through the rapid multiplication of bacteria, which in raw milk are inhibited by the lactic acid ferments. The older the milk before pastenrization, the greater the number of these undesirable organisms and the less suceessful the process.

Another objection to commercial pasteurization and sterilization is that these processes invite carelessness in the production and handling of milk, the acceptation of their necessity implying avoidable dirt and enconraging carelessness and negligence, the effects of which can be easily corrected by the application of heat before distribution. Instead of such encouragement, there should be a general movement against the existence of the antecedent conditions which make this after-treatment necessary. In Massachusetts, the sale of milk which has been heated higher than $167^{\circ} \mathrm{F}$. is contrary ${ }^{2}$ to law, unless the vessel in which the milk is sold is plainly marked "Heated Milk."

Obligatory pasteurization of public milk supplies has, in spite of various valid objections thereto, many advocates, and it has with good reason many and more opponents. That commercially pasteurized milk is frequently excessively rich in bacteria has often been demonstrated. Thus, Pennington ${ }^{3}$ reported that samples obtained from different pasteurizing plants in Philadelphia contained 744,000 and $2,880,000$ baeteriat per eubic eentimeter, and after 24 hours respectively 785,000 and $45,900,000$; and Bergey ${ }^{4}$ has reported a sample which contained $148,000,000$ bacteria per cubic centimeter, with less than half the amount of acidity necessary for its condemnation by the acidity test. Impressed by the possibility of danger from the use of commercially

1 Zeitscrift für IIygiene und Infectionskrankheiten, XVII., 1904, p. 272.

2 Acts of 1908 , Chapter 570.

3 American Medicine, March 11, 1905, p. 381.

1 Proceedings of the Pathological Society of Philadelphia, VIII, 1905, p. 102. 
pasteurized milk, Flügge ${ }^{\prime}$ has proposed that such milk should be permitted to be sold only when labelled "Heated Milk. Not free from germs. Must be kept under a temperature of $18^{\circ} \mathrm{C}$. or used within 12 hours"; and Jensen ${ }^{2}$ says: "When we compare the advantages and disadvantages, it will be found that there is serious doubt as to whether it is advisable to endeavor to obtain general pasteurization of market milk, as has been suggested by many. A well-organized and well-eondueted large milk business may be in position to carry out pasteurization with safety and to obtain all the various advantages that result from this process, but, undoubtedly, it would be necessaly for the great majority of establishments to be kept under comprehensive, strict, and expensive control by the health authorities, which, even then, could scarcely be effective."

Chemicals.-Preservation of milk by the addition of antiseptics is unnecessary, unjustifiable, and possibly injurious. If milk is drawn properly from decently clean animals into elean vessels by clean milkers, and stored in clean places, it will keep sweet quite as long, under ordinary cireumstances and under the usual conditions of frequent delivery, as is desired by the consumer. The addition of antisejtics, which only retard growth of bacteria without destroying them, enables the vendor to supply stale milk instead of fresh, and to dispense with part of the sanitary precautions otherwise necessary. The substances commonly used are by no means wholly innocent in their action on the human system, even in very small quantities, and, moreover, it is impossible to control the amount added by a single individual or to be sure that successive handlers have not contributed additional doses. The substances used most commonly include boric acid, borax, formaldehyde, and carbonate of sodium. Less commonly used are salicylic acid, hydrogen peroxide, and ehromates.

Boric Acid and Borax.-These are used generally in combination with each other, experience having shown that the mixture is more efficient than either alone. The minimum efficient quantity of the mixture is about 10 grains to the quart, an amount which even for an adult may well be regarded as a fairly large medicinal dose. In addition to its action on the general system, it exerts a varying effect on the digestion according to the amount present.

Formaldehyde.- This has come into more or less extensive use within recent years. It is a most efficient preservative, and not alone inhibits growth, but kills many of the contained bacteria. According to tests made by Dr. C. P. Worcester, ${ }^{3} 1$ part of commereial formalin in 100,000 of milk will postpone the eurdling-point 6 hours; 1 in $50,000,24$ hours; 1 in 20,000, 48 hours; 1 in 10,000, 138 hours; 1 in 5000, 156 hours. Although nothing is known as to the action of small amounts of formaldehyde on the general system, it is not

1 Ioc. cit.

2 Essentials of Milk Hygiene. Translated by L. Pearson. Philadelphia: J. B. Lippincott Company, 1907, p. 142.

3 Twenty-ninth Annual Report of the State Board of Health of Massachusetts, 1897, p. 559. 
correct to assume that, in the absence of evidence to the contrary, it is necessarily harmless or beneficial. While the occasional ingestion of a small amount of formaldehyde may produce no effect, we cannot reason that its daily use over a long period will be equally non-productive. An oceasional drink of water containing lead will do no injury, while its daily use may cause lead paralysis, and in the same way formaldehyde may be the cause of serious disturbances attributed to something else. But whether harmful or not, the use of this agent and of others is unnecessary and unjustifiable. Aside from its possibly poisonous action, there is the objection that it alters the character of the milk proteids; the casein becomes uncoagulable by rennet, except in thick clots, and much less digestible, or wholly indigestible, by the proteolytie ferments. Certain it is that anything that imposes additional burdens on the digestive function of infants and invalids can hardly be regarded as a proper substance for use in food. Annet, ${ }^{1}$ after a study of formaldeliyde and boric acid as milk preservatives, concludes that they are injurious, especially to young infants, and suggests the possibility of a calusal relation between their use and the great infant mortality during the hot months. E. von Behring ${ }^{2}$ asserts that the presence of formalin to the extent of 1:4000 will not be perceptible to the sense of taste, and that milk containing as much as 1 part in 500 is absolutely harmless. This assertion is denied by Schaps, ${ }^{3}$ who found that in still greater dilution $(1: 10,000)$ it eauses an objectionable taste, which is still perceptible when the dilution is $1: 40,000$. He found, moreover, that although the disinfeetant checks the development of the lactic ferments, it has much less effect on staphylococei, intentionally introduced, even when the proportion is $1: 5000$. While a marked inhibitory influence is exerted upon milk bacteria by formalin in proportion of $1: 5000$ or $1: 10,000$, when the milk is kept at $50^{\circ}$ to $60^{\circ} \mathrm{F}$., Sommerfeld ${ }^{4}$ found that it has hardly any influence after twenty-four hours when the milk is kept at $68^{\circ} \mathrm{F}$. At incubator temperature the treated milk yielded about the same number of bacteria as the controls. Typhoid and diphtheria bacilli in sterilized milk containing 1 part of formalin in 5000 resisted the disinfectant when the mixture was kept at room temperature for 24 hours and at incubator temperature for 48 hours.

According to Kolle, ${ }^{5}$ while formalin added to milk to the extent of $1: 25,000$ or $1: 40,000$ extends its commercial life after 3 days, the milk bacteria multiply greatly without cansing any change in consistency, because the sonring baeteria are inhibited ; and althongh pathogenie organisms diminish in number more rapidly in such milk than in untreated milk, their presence may be detected even after 5 days. Moreover, in addition to the deleterious influence of eontinued ingestion of small amounts of formalin one must bear in mind the fact that

\footnotetext{
1 The Lancet, Nov. 11, 1899.

2 Therapie der Gegenwart, XI,V., No. 1.

3 Yeitschrift für Hygiene und Infectionskrankheiten, L., p. 247.

4 Ibid., p. 153.

5 Klinische Jahrbücher, 1904.
} 
formalinized milk may beeome a dangerous food through the persistence in it of the more hardy peptonizing bacteria. Bandini ${ }^{1}$ finds that formaldehyde tends to preveut the action of remet, the influence being greater the larger the period of contact and the larger the amount added. Iöwenstein ${ }^{2}$ asserts that the interference with the action of rennet is due not to any destructive influence upon the enzymes, but to ehanges caused in the constitution of the casein.

Carbonate of Sodium.-Carbonate of sodium is a weak agent, and does not postpone decomposition to an extent sufficient to encourage its wide adoption. So far as is known, there can be no objection to its use on the score of injury, except in so far as the assertion that sodium lactate, formed by its decomposition by the free lactic acid, acts as a mild cathartic, is worthy of credence.

Salicylic Acid.-The use of salicylic acid in milk is not extensive. It is a fairly efficient preservative even when used in very small amounts.

Hydrogen Peroxide.-Hydrogen peroxide is the least objectionable, and, on the score of deleterious action upon the system, the only unobjectionable chemical preservative used in milk. According to $\mathrm{H}$. Chick, ${ }^{3}$ who used a 3 per cent. solution, 0.2 per cent. of the agent will produce complete sterilization of milk, and 0.1 per cent. will keep it sweet for a week or more, regardless of whether, when added, the milk is freshly drawn or has stood for some time. The only objection noted was a disagreeable stinging taste, which ean be pereeived when the agent is present in far smaller amounts-even as small as 0.01 per cent. Rosam ${ }^{4}$ found that 0.2 per cent. would not make milk sterile, but that with 0.1 per cent. and heating to $176^{\circ} \mathrm{F}$. for 30 to $45 \mathrm{~min}$ utes milk may be kept 3 or 4 days at almost incubator temperature. He called attention to the fact, however, that commercial hydrogen peroxide is likely to contain compounds of barium and arsenic. Jablin-Gonnet ${ }^{5}$ suggests the use of the "12-volume" solution after neutralization with calcium carbonate, and asserts that 1 ce. will preserve a liter of milk for 2 days, 2 ce. for 4 days, and $6 \mathrm{ec}$. for 6 days, even if the temperature of the milk is allowed to be as high as $86^{\circ} \mathrm{F}$, and that the taste is unimpaired. Renard ${ }^{6}$ found that while the agent does not sterilize the milk, it postpones sonring considerably. With 1,2 , and 3 ce. of the 12 -volume solution the souring point was postponed respectively 24,26 , and 32 hours at $68^{\circ} \mathrm{F}$., the control souring in 13 hours. Nicolle and Ducloux ${ }^{7}$ kept milk containing 1 to 2 per cent. of hydrogen peroxide at temperatures of $60^{\circ}, 72^{\circ}$, and $93^{\circ} \mathrm{F}$., and found that the number of bacteria diminisherl during the first 10 hours and then gradually increased. No trace

1 Centralblatt für Bakteriologie, etc., I. Abt. Orig., XLI., 1906, Nos. 2, 3, and 4.

2 Teitschrift fiir IIygiene, XIVIII., p. 239.

3 Centralblatt für Bakteriologie, ete., II. Abt., 1901, p. 706.

4 Ibid., p. 739.

5 Zeitschrift für Untersuchung der Nahrungs- u. Genussmittel, 1902, p. 169.

${ }^{6}$ Journal of the Society of Chemical Industry, XXIII, 1904, p. 74.

${ }^{7}$ Revue d'Hygiène et de Police Sanitaire, XX̃VI., 1904, p. 101. 
of the peroxide was detectable after several hours. With their assertion that pathogenic organisms are not affected, Baumann ${ }^{1}$ does not agree. He believes that when present to the extent of 0.35 per cent. it has a strong destructive action on the bacilli of tuberculosis, typhoid fever, and dysentery, if the milk is kept at $113^{\circ}$ to $122^{\circ} \mathrm{F}$. for 2 or 3 hours, but not otherwise. Gordau ${ }^{2}$ is of opinion that in order to ensure sterilization, such an amount of the agent must be employed as to impart a taste so unpleasant as to make the milk unfit for use. All observers agree that whatever its merits as a destroyer of bacteria, it exerts no harmful influence upon the milk enzymes, with the exception of superoxydase (catalase).

The "Budde" method of preserving milk consists in adding a 3 per cent. solution of hydrogen peroxide to the fresh milk in the proportion of about 12 to $15 \mathrm{cc}$. to each liter, and then heating to $126^{\circ} \mathrm{F}$. for three or four hours, when more than 99 per cent. of the baeteria will bave been destroyed, without changing the appearance or properties of the milk in any way. Experiments made by different observers have yielded widely different results, due, according to M. Lukin, ${ }^{3}$ to differences in the quality of the commercial preparations of hydrogen peroxide and to the fact that the amount necessary to success is influenced by the age and bacterial content of the milk. Hewlett ${ }^{4}$ tested the efficiency of the process employing fresh milk, to samples of which cultures of varions organisms were added, including B.typhosus, B. paratyphosus, B. diphtheria, B. tuberculosis, B. anthracis (sporing), B. coli, B. dysenterice, B. subtilis, B. mycoides, and Penicillium glaucum, and found that the non-sporing organisms were destroyed, and the sporebearers greatly reduced in number. Hewlett states that milk properly treated by this method is unchanged in odor, appearance, taste, or otherwise, and that it will keep without apparent alteration for 8 to 10 days in hot weather, although at the end of the process the whole of the bydrogen peroxide is decomposed and no trace of it ean be detected. In ordinary milk the reduction in the number of bacteria amounts to more than 99.9 per cent.

Experiments with milk from tuberculous udders have given conflicting evidence as to the valne of this process. Thus, Bergmann and Hullmann injected 1 cubic centimeter of such milk, after routine treatment, into a guinea-pig, which, after seven weeks, showed a fairly extensive tubercular infection. A sample from an udder more extensively diseased was treated with a larger amount of the peroxide and warmed in the nsual way and injected into guinea-pigs, which in 4 to 5 weeks died of general tubereulosis. On the other hand, Svensson has obtained positive results with similar material.

An improvement upon the Budde product is known as the "Perhydrase Milk" of Drs. Much and Römer, ${ }^{5}$ who recommend placing the

\footnotetext{
1 Münchener medizinische Wochenschrift, 1905, No. 23.

${ }^{2}$ Centralblatt für Bakteriologie, ete., II. Lht., 1904, p. 716.

3 Centralblatt für Bakteriologie, etc., II. Ah., XV., pp. 20, 165.

4 Lancet, January $2 \%, 1906$, p. 209.

5 Beiträge zur Klinik der Tuberculose, V., 1906, No. 3, p. 349.
} 
hydrogen peroxide solution in the milk-pail, which should be sterile, and milking directly into it, using 1 part of the peroxide (about 30 ce. of the commercial 3 per cent. preparation) to the liter. After a period of 6 to 8 hours, the milk is warmed to $126^{\circ} \mathrm{F}$. for an hour, and then a ferment derived from beef-blood is added, in the proportion of 0.5 or 1.0 gram to the liter. After 2 hours' contact, with frequent shaking, the excess of hydrogen peroxide is destroyed, and the millk is ready for use. It is nornal in taste and is free from bacteria. Even when abundantly seeded with tubercle bacilli in the beginning, it fails to infect guinea-pigs and mice on inoeulation. The ferment, ealled by Senter "hæmase," is a yellowish fluid, containing 0.1 or 0.2 per cent. of albumin. In its place defibrinated beef-blood, watery extract of malt, or yeast may be used.

Unless the excess of hydrogen peroxide is decomposed by the catalytic agent, the milk has a bitter and otherwise disagreeable taste.

The same author's ${ }^{1}$ noted that milk that has been sterilized by hydrogen peroxide undergoes changes in color, odor, and taste on exposure to the light. Investigation showed that these changes were produced by the combined action of light and oxygen, which affect mainly the fat, and that the bottles containing the milk ought to be kept in the dark or else wrapped in red or green paper, since red and green rays are without influence, while the ultra-violet, blue, and yellow rays bring about the changes.

The assertion that no changes are produced in the constituents of milk treated by this method is denied by Professor C. O. Jensen, who insists that anything which affects the protoplasm of the contained bacteria so as to cause their destruction will probably not fail to produce changes in the proteid constituents of the milk; and, as a fact, coagulation by rennet is retarded, and the eoagulum is of a different character than that of untreated milk.

Chromates.-The ehromates are not extensively employed, but have been found present in preservative powders used in France. Deniges ${ }^{2}$ found the normal chromate of potassium in two of these preparations, and the dichromate aud chromate together in a third. The latter was recommended in the proportion of 2 grains to 50 liters of milk. According to Froidevaux ${ }^{3}$ such an amount of potassium dichromate is insufficient to retard coagulation and imparts an abnormal intense yellow color to the milk.

The further discussion of the subject of milk preservatives may be looked for below, under the general subject of Food Preservatives.

\section{Adulteration of Milk.}

This most important article of food is more subject to adulteration than any other, since it lends itself so readily to fraudulent manipula1041 .

1 Berliner klinische Wochenschrift, XLIII., 1906, Nos. 30 and 31, pp. 1004 and

${ }^{2}$ Revue International des Falsifications, IX., p. 36.

${ }^{3}$ Journal de Pharmacie et de Chemie, 1896, p. 155. 
tion. The principal adulterations are the addition of water, the abstraction of cream, and the admixture of skimmed milk to whole milk. The former diminishes the nutritive value, and, if the water used is from an unclean source, increases the possibility of disseminating disease; the latter robs the milk of one of its most valuable constituents. The detection of these adulterations by analysis is not always possible, since a rieh milk may be slightly watered or only partially skimmed and still show average quality. Again, even though the watering be fairly considerable, it camnot always be proved that the milk was not of low grade from natural causes, since some eows give milk which, on analysis, is far below average good milk. Further, a milk containing very little fat may be naturally poor in that constituent or may be the first part of a milking.

In eonsequence of the difficulty of proving the addition of water or abstraction of cream, and because of the enormons importanee of securing a public supply of at least average good quality, most States have fixed legal standards, to which milk intended for sale must conform. The standard for total solids is eommonly $13,12.5$, or 12 per eent.; and for fat, 3, 3.5, 3.7, and 4 per cent. By the adoption of a legal standard, all milk of low grade, whether so by reason of fraudulent practices 0 : be use of poor feed or individual peculiarity of the cow, must be treated alike. By prohibiting the sale of all milk not of a certain grade, it becomes unnecessary to prove fraud or eriminal knowledge, the allegation of inferior quality being sustained by the results of the analysis.

Other forms of adulteration include the addition of coloring matters for the purpose of concealing watering or skimming, or to give a creamy tint to a very white milk, and the addition of preservatives, and, oceasionally, of other foreign substances. The coloring matters commonly used are, annatto, earamel, and combinations of aniline dyes. Their detection is by no means difficult.

It is a common belief, even among people of more than average intelligenee, that milk as found in the market is very largely a mixture of chalk and water. Upon what this absurd tradition is based, it is difficult to surmise, since even though a person were led to practise such a niserable frand, he would discover that challs and water will need constant stirring to maintain even the ontward semblance of milk, and that a few minutes' standing is suffieient for complete separation into a deposit of chalk and a fairly elear supernatant liquid. A less common, but equally absurd, notion that calves' brains are a common adulterant of milk, arose about half a eentury ago from the report of a mieroscopieal examination of a milk sediment in which certain particles were detected which bore a resemblance to nerve tissue. Calves' hrains do not lend themselves readily to the making of emulsions, the supply is limited, and they find a fairly good marliet in their true character.

Cane sugar is said to have been found at rare intervals, and gelatin is used oecasionally as a thickening for cream. Stareh is believed ly many to be a common adulterant, but it is used very rarely. In the 
course of many years' supervision of a large public milk supply, during which several hundred thousand samples of milk were examined for adulterants of all sorts, but one instance of the use of starch fell under the author's notice. This was due to a shortage in the normal supply, which led a dealer to dispense a mixture of water and condensed milk, which latter component had been thickened with starch.

\section{CREAM.}

United States Standard.-Standard eream is cream containing not less than 18 per cent. of fat.

Cream, as already stated, may be defined as milk containing a large excess of fat, and correspondingly lacking in water. The degree of richness is dependent upon the method employed in its separation from the original volume of milk. That obtained by the common method of skimming contains ordinarily about 16 to 24 per cent. of fat, while that separated by the centrifugal machine contains from 20 to upward of 50 per cent., according as the machine is regulated for "light" or "heavy" cream. The latter is so thick as to give rise to a common notion that eorn starch is used as an adulterant. This substance, however, is used rarely if ever in this way. Gelatin is employed as an adulterant to a limited extent. A preparation largely advertised to the trade at one time as a "cream thickener" was analyzed by the author, and found to be a mixture of gelatin, borax, and boric acid.

More recently sucrate of lime, sometimes termed "viscogen," has been added to eream in order to increase its thickness. Lythgoe ${ }^{1}$ states that 60 out of 170 samples of cream examined by him showed the presence of calcium sucrate.

Furthermore, a machine has been put upon the market which produces an emulsion of fat globules of such exeeeding fineness as to give an impression of thickness to cream 100 per cent. above that actually present. The common adulterants of cream are preservatives and coloring agents. The former are used mostly during the hot months; the latter during the winter, when, on account of the difference in feed, the eream has not the characteristic yellow tint so highly prized.

\section{CONDENSED MILK.}

United States Standard. - Standard condensed milk and standard sweetened eondensed milk are condensed milk and sweetened condensed milk respectively, containing not less than 28 per cent. of milk solids, of which not less than 27.5 per cent. is milk fat.

Condensed milk is prepared lyy evaporating milk to about a third or a fourth of its volume in vacuum pans. It is sold in bulk for immediate use, and in hermetically sealed tin eans for use as oceasion demands. Most of that solk in tins is made from skimmed milk, and is, therefore, very deficient in fat; and much of it contains a large proportion of eane sugar, which is added to increase its keeping qualities. Condensed

\footnotetext{
1 Annual Report of the Mass. State Board of Health, 1908, p. 595.
} 
milk is, in many respects and under certain conditions, a valuable food preparation, but its use in infant feeding when other milk is obtainable is not a wise one, since it is deficient in one of the most important elements, and contains another which is not a normal constituent.

This point was brought out very plainly by Jordan and Mott, ${ }^{1}$ who found, by an examination of 14 different brands of condensed "milk, that the cost of a quart of standard milk containing 3.35 per cent. of fat, when made from condensed milk, cost anywhere from 9 to 12.6 cents a quart. Furthermore, the bacterial content per cubic centimeter of 10 brands of condensed milk varied anywhere from 900 to 10,000,000. The brands of condensed milk containing bacteria were mostly of the sweetened variety, and the reason for this contamination is said to lie in the fact that sweetened condensed milk, containing sugar, cannot be heated sufficiently without caramelizing the sugar.

\section{Milk as a Factor in the Spread of Disease.}

Milk may act as a carrier of disease or cause of functional disturbance through infectious or poisonous matters originally present, or received or evolved during handling and distribution. Thus, milk may be poisonous by reason of matters derived from the feed or of substances formed after it is drawn ; it may contain organisms of various kinds conneeted with bovine diseases ; it may become contaminated in various ways with matter containing the exciting cause of various human discases.

Poisonous Milk.-Certain plants eaten by cows may cause milk to become unfit for drinking because of toxic properties. Poison ivy and white snakeroot have long been regarded as the cause of the cattle disease known as "Trembles" and of the condition in man known as "Milk sickness," following the drinking of milk or the eating of meat from cows having the disease, but it has been pointed out by Jordan and Harris ${ }^{2}$ that trembles has never been known to exist in the Atlantie seaboard states and elsewhere where poison ivy grows in abundance, and that white snakeroot is not known in New Mexieo, where they have found a center of the typical disease. Having had an exceptional opportmity to study a somewhat extensive outbreak, they appear to have demonstrated very conclusively that the cause is not a poisonous vegetable principle, but a specific nicro-organism to which they have given the name Bacillus lactimorbi. Trembles and milk sickness were formerly of common occurrence in Ohio, Indiana, Illinois, Kentucky, and Tennessee, and occasionally in North Carolina, but have become very rare of late years. The condition caused in man is very grave, the cerebral nervous system being profoundly involved. The symptoms include great depression and muscular weakness, great thirst, labored respiration, constant retching, paralysis of the intestines, and subnormal temperature. Before death, which is the rule, the entire body becomes paralyzed. The leaves of the common artichoke are

3 American Journal of Public Hygiene, May, 1910.

2 Journal of the American Medical Association, May 23, 1908, p. 1665. 
said ${ }^{1}$ to impart to milk certain properties which eause abdominal pain, vomiting, and diarrhoea, and Decherf ${ }^{2}$ has reported an outbreak of acute enteritis among ehildren that had received sterilized milk from cows fed on beet leaves and red cabbage. A similar outbreak was observed after the use of milk of cows fed on fermented beet silage.

Under eertain conditions normal milk may undergo peculiar forms of decomposition productive of intensely violent poisonous substances. Fortunately these changes are uneommon, but when they do occur the milk betrays to the consumer no sign of its condition. The effects produced upon the consumer are various and are well illustrated by the foliowing cases :

Case I.-Reported by Dr. W. K. Newton and Mr. S. Wallace. ${ }^{3}$ On August 7, 1886, 24 guests of one hotel at Long Branch, and 19 of another hotel at the same place, were taken sick soon after supper with the same train of symptoms, which were nausea, vomiting, cramps, and collapse, dryness of the throat, and burning sensation in the osophagus; in many cases there was absence of diarrhoa, and in several there was active diarrhœea without vomiting. Many had violent vomiting followed by collapse. As a rule, the nausea and romiting were persistent and obstinate, and aceompanied by a tendency to exhaustion and collapse. A week later, 30 guests of still another hotel were scized in precisely the same manner. The onset oceurred in from one to four hours after eating, but in one instance the symptoms appeared almost immediately after drinking about a quart of milk. Investigation showed that the trouble was due wholly to milk, for only the milk-drinkers were seized, and those who had had no other food were the worst sufferers. The three hotels were served by one dealer, who made two deliveries daily. The milk of the seeond delivery was the cause of the mischief in each ontbreak. It was drawn at noon, and, without being cooled at all, was carted eight miles in the heat of the day. The eows were healthy and well fed. In a portion of the milk that caused the third group of cases, the presence of tyrotoxicon was demonstrated.

CASE II.-This was a most extraordinary outbreak, limited to a fumily consisting of father, mother, son, and daughter, of whom all but the first mentioned died. The fimily physician ealled Professor V. C. Vaughan in consultation after the fourth member of the family was seized, and from his report of the case the following facts are taken. The first one seized was the fither, a man of fifty years. When first seen, he was vomiting severely, his face was flushed, and his temperature was subnormal $\left(96^{\circ} \mathrm{F}\right.$.). There was marked throbbing of the abdominal aorta, the tongue was heavily coated, and the breathing was very labored. 'The pupils were dilated, and much of the body was covered with a rash. The vomiting continued some hours, the vomitus being colored with bile. 'The bowels had not moved, but under the infuence

1 Milchzeitung, 1891, p. 40.

${ }^{2}$ Paris letter, Lancet, February 8, 1908.

3 Medical News, Seplember 25,1886, p. 343. 
of a cathartic, a stool occurred on the following day. Reteling and voniting eontinued during that day and night, and there was persistent stupor. During the following three days, there was but little change. Then improvement began, but recovery required a month. The son, a strong youth of eighteen, was the next to be seized, fonr days after the beginning of his fither's sickness. The symptoms were similar, but were more violent, and there was no rash. On the following evening, the mother, about forty-five, was seized in the same way, and on the succeeding evening, the daughter also. On the day following the last seizure, none of the asses showed improvement. The temperatures were subnormal, $94^{\circ}$ and $95^{\circ} \mathrm{F}$. All eomplained of a burning constriction in the throat and difficult swallowing, and called frequently for ice. Two days later, the mother and son died; the daughter grew worse, became unconscious, remained so three days, and then died.

Post-mortem examination in the ease of the daughter revealed no chancteristic lesions to aceount for death. The outbreak was most carefully and thoronghly investigated from every standpoint, and the conclusion reached was that tyrotoxicon was the cause. The milk had been kept in a buttery which was in a most unsanitary condition. During three years, the family had suffered frequent attacks of like character, but they were much less severe. Fresh milk, placed in the buttery over night, and then examnined for tyrotoxicon, gave ummistakable chemical and physiologieal evidence of that poison. Fresh milk inoculated with dirt from the buttery floor also developed it, as did also other portions treated with vomitus, stomach contents, and antreous extract of the intestines, while a fifth specimen untreated remained free from it. All the evidence in this case pointed to the more or less eonstant presence of poison in the milk, and the wide variation in the time of scizure in the final ontbreak indicates that all were not affected by the same day's supply.

Milk from Diseased Cows.- -The milk of cows suffering from the prominent cattle playnes is more or less altered in eomposition, and there appears to be evidence that sometimes it may be actually dangerous.

Rinderpest.- In rinderpest the proteids are much increased-in fact, more than doubled; the mineral constituents are considerably increased, and the fit and sugar are diminished.

Foot and Mouth Disease.-In foot and mouth disease the total solids are increased considerably, or diminished at different stages, and the milk will sometimes coagulate on boiling by reason of the excessive amount of coagulable proteids. There is reason to believe that this disease may be communicated to other animals through the milk, and there is evidence that the use of the milk by man will produce local lesions in the mouth and throat. Thus, Notter and Firth mention an epidemic of sore throat at Dover in 1884, in which there were 205 catses of vesicnlar eruption in the throat or on the lips, enlarged tonsils, and in most catses enlarged glands of the neck, all occurring within at week in persons supplied by a single dairy where the disease existed.

1 'The Theory and Practice of Hygiene, London, 1896, p. 305. 
During the epizootic which occurred in New England in 1902, there were reported a number of cases of sore mouth and throat with aphthr and more or less general disturbanee.

It is said that in mild cases of this disense the nilk is unchanged, but that in severe cases it may be very abnormal in appearance and composition and may cause very severe and even fatal sickness in man.

Anthrax.-In anthrax the milk has an abnormal appearance and decomposes rapidly. The specific organisin has been isolated in active condition by Boschetti ${ }^{1}$ from milk as late as 14 days after it had been drawn.

Actinomycosis.-In actinomycosis, particularly if the udder is involved, the milk should be avoided, although there appears to be little direet evidence bearing upon transmission of the disease to man by this means. It is certain, however, that the disease does occur sometimes in man, and though in the matter of transmission of disease from animals to man nothing should be taken for granted, it is commendable in such cases of lack of positive knowledge to err on the side of safety, and to avoid and prohibit the use of such milk, even though it be true that the actinonyces have not as yet been found in milk.

Rabies.-In rabies it has been proved that the virus may be secreted in the milk, and Jensen ${ }^{2}$ says that although feeding experiments have yielded negative results, the possibility that infection may oceur through a slight lesion of the mouth or pharynx should cause the milk of cows bitten by rabid dogs to be regarded as most dangerous.

Specific Enteritis. - In specific enteritis due to the hog-cholera group of bacteria, the milk, which, perhaps, is infected through fecal contamination, if not before it leaves the cow, may be a cause of sickness. Gaffky ${ }^{3}$ has reported this case: Three persous connected with the Institute of $\mathrm{Hygiene}$ at Giessen were seized, after drinking milk from a cow suffering from such a disease, with nausea, vomiting, diarrhœa, and mental confusion. One recovered in a few days, the others in about four weeks. The milk was drunk in the raw state.

Garget, Mastitis, Mammitis.-In this commonest of bovine diseases, in which a part of or the whole udder may be inflamed, the milk is often so changed in character as to be obviously unfit for use, but ordinarily is of normal appearance on casual examinntion. Even when the udder is only slightly involved, the milk frequently contains vast numbers of streptococci. $B$. coli is almost always present, and Staph. pyogenes aureus and albus are very commonly found in large numbers. Such milk is believed by many to be a common cause of epidenic diarrhœa, and in a number of instances the connection appears to have been conclusively proved; but the most striking effects of its use are the extensive outbreaks of septic sore throat, which sometimes have passed for scarlet fever, as, for example, an outbreak of more than 200 cases in Lincoln, England. These outbreaks are often extremely se-

1 Giornale di Medicina Veterinaria, 1891.

2 Essentials of Milk Hygiene. Truns. by Pearson, 1907, p. 91.

${ }^{3}$ Deutsche medizinische Wochenschrift, 1892, No. 14. 
vere, and sometimes they present a great diversity of secondary effects, as may be observed below.

Ordinarily the disease begins with the malaise and chilly sensations characteristic of tonsillitis, with diarrhœa, high temperature, neuralgias, and, not infrequently, cervical adenitis. In these outbreaks, which are mistaken for scarlet fever, the very sore throat is accompanied by an apparently characteristic erythema; and sometimes the eruption resembles that of measles.

As examples of such outbreaks and of the variety of the symptoms caused, the following are presented:

(1) Outbreak in Woking, in 1903, reported by Pierce. ${ }^{1}$ Cases of sore throat to the number of 250 were traced back to a farmer to whom complaint had been made of the ropy character of his product. Four of his 20 cows were found to have garget, and their milk contained nuch pus and an abundance of streptococci. He and his wife and two daughters had had or were then suffering with sore throat. The majority of the victims were adults. In many instances whole families were seized, and in one house 12 of the 13 inmates were victims. Many cases were indistinguishable from ordinary follicular tonsillitis, sone were suggestive of diphtheria, and others developed into quinsy. There was a marked tendency to involvement of the submaxillary and posterior cervical glands, and in some cases the pharyux and larynx were so much involved that deglutition was exceedingly painful and difficult. In a number of cases pain and tenderness of the joints followed the throat symptoms in 3 to 7 days. In 5 instances very severe erysipelas followed the throat symptoms, and one of the persons so afflicted developed a mastoid abscess and dicd. Another, with his nasopharynx covered with a sloughing membrane, was sent to the hospital and died of pyæmia, with a postmortem temperature of $110^{\circ} \mathrm{F}$. The total number of deaths was 8 .

(2) Outbreak of sore throat with exudation, involving 98 families, reported by Axe. ${ }^{2}$ There was a common milk supply, and 4 of the cows were found to yield pus and large numbers of streptococei in this milk. The dairyman's family comprised himself and wife, two sons and two daughters, and all were affecter. In addition to throat symptoms, he and his elder son had pains in the joints, and the latter had enlarged glands.

(3) Outbreak of 140 cases, reported by Savage. ${ }^{3}$ The onset was unusually rapid, with considerable constitutional disturbance. In some cases the temperature reached $104^{\circ}$ and $105^{\circ} \mathrm{F}$. The throats were red and swollen, and in most cases the tonsils were enlarged, with projecting white plugs in the follicles. In several cases distinet patches were observed on the soft palate, and in one case on the urula also. The canse was traced to a cow with garget, whose milk was very rich in virulent streptococci.

1 Journal of State Medicine, October, 1904, p. 595.

${ }^{2}$ Ibid., December, 1904, p. 708 .

3 Public Health, October, 1905, p. 1. 
(4) Outbreak of 548 cases, and probably more, in Christiana, in March, 1908 ; reported by Sömme. 'The picture of the illness included high temperature, $104^{\circ} \mathrm{F}$. and higher, with sore throat. The surfice of the tonsils, pharynx, and downward toward the larynx was of a glistening red. In some cases the redness was confined to punctate areas, and in others there was a diphtheria-like membrane, which could be easily removed. In the majority of cases the throat was scarlatinal rather than diphtheritic. The glands of the neck were excessively painful on pressure. Complications were extremely numerous, and included the widest possible variety of streptococcal infection of the different parts of the body. The deaths numbered 5. The cause was traced to a cow with a diseased udder, from which streptococci were obtained which were identical with those taken from victims of the outbreak. Mice inoculated intraperitoneally with minute quantities of the culture died in 12 to 24 hours, and cultures could be obtained from their blood.

Tuberculosis.- There can be no doubt that the tubercle bacillus finds its way into milk, particularly if the udder is involved, but even when not. This was asserted so long ago as 1889 by Ernst, ${ }^{2}$ who, after a very extended inquiry, proved that the milk of cows with tuberculosis in any part of the body, and with no local lesion of the udder whatever, may contain the bacillus. This finding has been confirmed by a number of more recent observations. Rabinowitsch and Kempner ${ }^{3}$ obtained positive results from inoculation experiments on guinea-pigs with the milk of 10 out of 15 cows that had reacted to tuberculin. Of these 10 animals, only 1 showed clinical evidence of involvement of the udder, and only 1 other showed any sign of it on microscopical examination. Moussu ${ }^{4}$ drew, under antiseptic precautions, the milk of a number of cows showing no lesions of the udder, and inoculated therewith 57 guinea-pigs, which yielded 7 positive results. Müller ${ }^{5}$ believes that it is only when tuberculosis has reached an advanced stage without infecting the udder that the bacilli can be found in the milk, and that infectiousness of milk is chiefly referable to lesions of the udder. A study of mammary glands of tuberculous cows, by Martel and Guérin, ${ }^{6}$ showed in some cases lesions which appeared to be non-tuberculous and in others no lesions whatever; yet, inoculation experiments proved that the udder may be infectious at any stage of the disease. Among others who have obtained positive results from animals with normal udders may be mentioned Bollinger, Delépine, Bang, and Adami.

In concluding from the results of experiments with milk from normal ndders that even in the absence of tuberculous lesions the bacilli may be present, the fact shonld not be lost sight of that most milk as ordi-

1 Norsk Magazin for Laegevidenskab, through Lancet, June 13, 1908.

2 American Journal of Medical Sciences, Norember, 1889.

3 Zeitschrift für Hygiene und Infectionskrankheiten, XXXI., p. 137.

4 Comptes Rendus de la Societé de Biologie, 1904, No. 13, p. 617.

5 Journal of Comparative Pathology and Therapeutics, 1906, p. 19.

${ }^{6}$ Rev. Soc. Scient. d'Hyg. Aliment., II., 1905, p. 153. 
narily drawn from animals that are reasonably clean contains particles of manure from the flanks, tail, and other parts, and that the feees of a tuberculous cow is likely to be teeming with the bacilli.

That contamination of milk by the manure of tuberculous cows is a very serious danger is shown by the fact that Mohler, " "in a recent examination at the Bureau of Animal Industry Experiment Station, of the manure passed by twelve cows just purehased fron- dairy farms in this eity and affeeted with tubereulosis to an extent only demonstrable by the tubereulin test, tubercle bacilli were found in over 41 per cent. of the cases, both by microscopic examination and animal inoenlations."

The possibility that the positive results reported by others may have been due to such aceidental contamination was suggested by Ostertag, ${ }^{2}$ who fed calves and pigs for months with milk from cows which showed no evidence of tuberculosis beyond reaeting to tubereulin, and the experimental animals remained healthy. Stronströn ${ }^{3}$ inoeulated 83 animals with the milk of 50 reacting cows, not one of which showed clinieal or post-mortem evidenee of udder tubereulosis, and not a single one of the animals acquired the disease.

It is asserted eommonly that the use of milk from tuberenlous cows is a positive danger to public health, and attention is directed to the persistently high rate of mortality from tuberculosis in all its forms among very young children, and to improvement in the death-rates from other causes. It is asserted that this condition can be explained in only one way : that is, that a very large proportion of market milk is derived from tuberculous cows, and thus bottle-fed children, if at all susceptible, become infected.

As to the probable proportion of infected market milk, owing to the wide differences in results obtained by various investigators, no definite statement can be given. Rabinowitsch, for example, found it to be 28 per cent. ; Massone ${ }^{4}$ by inoculation experiments placed it at 9 ; Ott, ${ }^{5}$ at 11.6. Sladen ${ }^{6}$ found that more than half of the samples taken from the supply of the eolleges at Cambridge, England, ennveyed tuberculosis to guinea-pigs on inoeulation. Delépine found the bacilli in 17.6 per eent. of samples gathered in Manchester, and Robertson, in 14 per cent. of samples collected in Birmingham. Houston has estimated that about 20 per eent. of the cows in the United Kingdom are tuberculous, and that 2 per cent. have tubereulosis of the udder. Ostertag believes that the udder is involved in about 4 per cent. of tuberculous cows. Eastes ${ }^{7}$ found the bacillus in but 11 of 186 samples of milk which he examined. Aecording to Newman, ${ }^{8}$ in Liverpool about 2 per cent. of the town-produced and 9 per cent. of the country milk has

1 Hygienic Laboratory Bulletin, No. 41, p. 493.

2 Teitschrift für IIygiene und Infectionskrankheiten, XXXVIII., 1901, p. 415.

3 Zeitschrift für Tiermedizin, VI., 1902, p. 241.

4 Annali d'Igiene Sperimentale, 1897, p. 939.

5 Zeitschrift für Milch- und Fleischhygiene, 1898, No. 8.

6 'The Lancet, January 14, 1899.

7 British Medical Journal, November 11, 1899.

${ }^{8}$ Public Health, February, 1904. 
been found to be tuberculous; in Hackney, on one occasion, 22 per cent.; in Woolwich, in 1902, 10 per cent.; in Camberwell, in 1902, 11 per cent. ; in Croydon, in 1901, 6 per cent. ; in London, as a whole, 7 per cent.

Anderson ${ }^{1}$ found that 15 out of 223 samples of market milk, that is to say, 6.72 per cent., caused tuberculosis in inoculated animals. The milk, furthermore, of 11 out of 102 dairies contained tubercle bacilli. Moreover, the milk from one ont of nine charitable institutions caused tuberculosis in both guinea-pigs into which it was inoculated.

Hesse ${ }^{2}$ found virulent tubercle bacilli in 17 among 107 specimens, that is, in 16 per cent. of the milk retailed from cans in New York City.

Tonney ${ }^{3}$ found that 8.9 per cent. of 112 samples showed tubereulosis. Of 95 raw samples, 10.5 per eent. showed tuberculosis. Of 17 pasteurized samples, 0 per cent. showed tuberculosis.

Doubtless the differences are due to variations in local conditions, to differences in technic, and to accidents always attending haphazard securing of any article of food in open market.

Taking the mean of the figures given, and accepting that as a fair approximation of the extent to which public supplies are infected, it must be agreed that, if infection through milk is possible, the amount of disease so cansed is quite small in proportion to the number of the population who are exposed daily to the danger. There are but few reported cases in which the influence of other possible conditions can be excluded so thoroughly as to leave no reasonable doubt of the causal relation of milk. Single instances are necessarily of less value than groups of cases, and the latter are much less common than generally is supposed. From the number available the following are selected as illustrations:

Brouardel $^{4}$ records the death of 7 children with no hereditary taint, inmates of a convent, from tuberculosis supposedly induced by the use of milk from a cow with tuberculosis of the udder. Another ease reported by him, and quoted by Frendenreich, ${ }^{5}$ is one in which 5 of 14 girls in a boarding-school became infected and died. The milk which they had used daily came from a tuberculons cow.

Demme ${ }^{6}$ reported as the only instance in his experience in which all other causes could satisfactorily be excluded, a group of 4 infants of healthy parentage fed upon uncooked milk of tubereulous cows. They all died of tuberculosis of the intestine, and the diagnosis was confirmed by autopsy. Later, he reported ${ }^{7}$ still another death from the same cause at four months. In this case also there was albolutely no family

1 Hygienic Laboratory Bulletin, No. 41, p. 191.

2 Jour. Am. Med. Assoc., Mar. 27, 1909.

3 Ibid., Oct. 8, 1910.

4 Annales d'Hygiène publique, XXIV., p. 65.

5 Les Microbes et leur des Role dans la Laiterie, Paris, 1894, p. 45. p. 48 .

6 Jahresbericht über die Thätigkeit des Jenmer schen Kinderspitals in Bern, 1882,

7 Ibid., 1886 , p. 20. 
history of tuberculosis. After the confirmation of the diagnosis by autopsy, the cow was slaughtered and found to be tuberculous.

Mullet ${ }^{2}$ found a number of cases of undoubted connection in families of milk producers: thus, a girl of 9 years, accustomed to drink nilk directly as it was drawn from a herd of 21,19 of which were tuberculous, died of abdominal tuberculosis; a girl of 7 years with the habit of drinking large amounts of warm milk from a herd of 10 tuberculous cows, died of tubercular peritonitis ; 9 similar cases, all of death from tubereulosis other than the pulmonary form, in consequence of the use of raw milk from tuberculous cows owned by the respective families.

Some of these cases, if not all, may be accepted as very strong evidence that tuberculosis may be spread through the agency of milk. But if it is true that so large a proportion of the milk supply is from diseased cows, and that the disease is communicable in this way, it follows that with the vast majority of drinkers of raw milk the bacilli perish or are discharged without gaining entrance to the tissues.

Granting that much of the public milk supply is derived from tubereulous cows, and that it is consumed very largely in unsterilized condition by very young children, one would naturally expect, if the bovine bacillus is markedly infective to man, to find a very high death-rate from abdominal tubereulosis among the very young. It is asserted that this is the case, and claborate argmments in favor of the statement that tuberculous milk is responsible for a great part of the constantly high infuntile death-rate have been based on figures given by the late Sir $\mathbf{R}$. Thorne-Thorne, in his Harben lectures, in November, 1898, showing that, whereas in England and Wales the returns for 1891-1895, eompared with those for 1851-1860, indicate a reduction in mortality from phthisis at all ages of 45.4 per cent., and from all forms of tubereulosis of 39.1 per cent., the decrease in tabes mesenterica was for all ages only 8.5, and for children under five only 3 per cent.; and that, moreover, for children under one year there was not only no reduction, but an actual increase of 27.7 per cent. Such figures, emanating from so high an authority, would seem to admit of but one cxplanation, namely, that infected milk is a danger hardly to be overrated. But these figures are directly opposed to elinieal experience elsewhere and, as will appear, are incorrect. Dr. D. Bovaird ${ }^{2}$ points out that it is only in England that reports indicate any considerable number of cases of primary intestinal tuberenlosis, and asserts that it is very rare in and abont New York City, and that the evidence connecting tuberenlosis in children with infected milk is very meagre. Koch has ealled attention to the great infrequeney of primary tuberculosis of the intestine among ehildren in institutions in Berlin; and Biedert, ${ }^{3}$ too, asserts that the amont of tubereular infection through the alimentary canal is very small. Adami ${ }^{4}$

1 Quoted in L'Echo médical du Nord, April 2, 1903.

2 Archives of Pediatrics, December, 1901.

3 Berliner klinische Wochenschrift, November 25, 1901.

4 Philadelphia Medical Journal, February 22, 1902. 
is of the opinion that tubereulosis of young children, and especially peritoneal and intestinal tuberenlosis, is remarkably rare in the great cities of North America ; but Jacobi, ${ }^{1}$ while admitting that primary tubereular ulcerations of the intestine and primary tuberenlosis of the mesenteric glands are rare, holds that peritoneal tuberculosis is very common. Adami cites the mortality returns for Montreal for the year ended June, 1900, showing that of 935 deaths from tuberculosis, but 4 were of children under fourteen, and 3 of these were from abdominal tuberculosis in ehildren under five years. Crookshank ${ }^{2}$ dissents from the opinion that abdominal tuberculosis of children is eonnected with infected milk, but believes that not sufficient consideration is given to the possibility of infection from human sources.

The fallacy of Thorne-Thorne's figures has been pointed out by Carr, Guthrie, Donkin, and others, and all arguments based thereon must fall to the ground. In December, 1898, Carr ${ }^{3}$ showed that the vast majority of cases returned as tabes mesenterica were probably of marasmus, due to gastro-intestinal catarrh. Guthrie ${ }^{4}$ concluded from the results of 77 autopsies performed by him on tubereulous ehildren that the disease begins far more commonly in the chest than in the abdomen, and that tabes mesenterica as a cause of death in young children is practically unknown or extremely rare. Donkin, who contends that the original significance of the term "tabes mesenterica" no longer holds, says : ${ }^{5}$ "We all know that all kinds of intestinal and other disorders are constantly styled 'tabes mesenterica' by those who fail to cure them." It has been pointed ont that whereas in England about 10 per cent. of all tuberculosis and about 30 per cent. of tuberculosis of children is classed as tabes mesenterica, the respective figures for Berlin in 1898 were 1.8 and 2.8, for Paris, in 1897, 1.33 and 1.65, and for New York, in 1899, 0.47 and 2.86.

Stowell, ${ }^{6}$ who has had an unusual opportunity to study the influence of milk of tuberculous cows at the New York City Children's Hospitals on Randall's Island, relates that during two years the milk supply consisted of market milk which was pasteurized at $1.55^{\circ}$ to $165^{\circ} \mathrm{F}$. and milk produced on the island. The latter was reserved for use in the raw state by the very young and the acutely sick. In October, 1907, the herd of 28 cows and 2 bulls was tested with tuberculin, and all but 3 reacted. All the animals were slaughtered and examined. The non-reacting animals proved to be free from tuberculosis, but all the others were diseased. Of the entire number, but 1 had udder tuberculosis. Stowell's experience led lim to conclude that since, during the use of this milk, there was no evidence of any more development of tuberculosis among those who received it than among those who had pasteurized milk, the danger of tubercular infection from milk must be very slight.

${ }^{1}$ New York Medical Journal, January 25, 1902.

2 The Lancet, November 2, 1901.

3 Ibid., 1898, II., p. 1662.

5 British Medical Journal, October 14, 1899, p. 1046.

4 Ibid., 1899, I., p. 286.

6 Medical Record, June 20, 1908, p. 1023. 
Notwithstanding the pancity of eases which offer strong evidence of a causal relation between infected milk and the oecurrence of tuberculosis, and in spite of the now recognized differences between the bovine and human bacilli, the possibility of danger in individual cases cannot lightly be brushed aside. According to Theobald Smith, ${ }^{1}$ it is quite possible that something interferes with the absorption of bovine bacilli, while allowing the human bacilli to pass; and while racial differences probably prevent the absorption of bovine bacilli under ordinary circumstances, and a few bacilli are harmless, there is danger if the digestive tract is flooded with bacilli from tubereulous udders. Ostertag advoeates the culling out of all eows showing clinical evidence of tubereulosis (beyond reacting), and especially of all with lesions within the udder.

Leblanc $^{2}$ is of the opinion that the milk of tuberculous cows is dangernus, not on account of the bacilli, but on account of the toxins that it contains, for it has been proved to have toxic properties. Michellazzi has shown that sueh milk injected into tuberculous animals causes a reaction, and that the milk of a tuberculous mother will in time prove toxic to her child.

However great or small may be the danger from the use of tuberculous milk, it may be entirely avoided by using the milk of goats instead of that of eows. Wright ${ }^{3}$ has called attention to the fact that the goat is a clean animal as compared with the cow, that its feces are solid and rolled in balls and hence not likely to become attached to the flanks and udder, and that it is practically immune to tuberculosis, Nocard having fitiled to find a single case of tubercular lesions among 130,000 slaughtered goats and kids. To the common objection that goats' milk is offensive in odor, Burr ${ }^{4}$ answers that, drawn in a clean stable, the air of which is not made offensive by the presence of the male animal, goats' milk is as free from distinctive odor as cows' milk. Goats' milk appears to be quite as digestible as cows' milk, if not more so, especially if it is taken, as in some European countries, warm from the animals. Wood ${ }^{5}$ advises very strongly the use of goats' milk for bottle-fed infants, stating that not one of a number under his care so fed during the whole summer had any diarrhoea whatever.

Curiously enough, however, in its relation to another disease goats' milk has been proved to be very dangerous. For a number of years epidemies of an irregular fever on the Island of Malta remained unexplained, although the specifie organism of the discase (the Micrococcus melitensis) was discovered by Bruce in 1887. Although the disease may be spread by other means, it has been found that the ingestion of the milk of infected goats constitutes the main channel of transmission. As soon as this fact became known and the milk excluded as an article of diet, the oceurrence of Malta fever was to a large extent eliminated.

1 Medical News, February 22, 1902.

2 Lyon Médical, April 14, 1901, p. 561.

3 The Lancet, November 3, 1906 .

4 Milchzeitung, 1907, Nos. 19-21.

5 Intercolonial Medical Journal of Australasia, May, 1907. 


\section{Milk Contaminated from Without with Organisms Related to}

Human Diseases.- Milk may become contaminated with infective matter in various ways. It may receive it from the hands, person, and clothing of the milkers and others by whom it is handled, whether they are themselves sick or convalescent or acting in the capacity of nurse or attendant for others; it may acquire it from unclean vessels rinsed in polluted water, or from water with which it has fraudulently been mixed.

'The first to demonstrate that human diseases may be spread by cows' milk was Dr. Michael Taylor, who was led to the idea by the occurrence of 13 cases of typhoid fever in 7 of 14 families supplied with milk from the same farm, the prior introduction of the disease into the farmer's family by an infected domestic, and seizure of two of his children. This outbreak was reported by bim, ${ }^{1}$ but the publication excited no special interest, and, indeed, it fell to him to report also the second milk-borne outbreak discovered 10 years later, this one of 15 cases of scarlet fever in 6 of 14 families supplied by a farmer whose wife milked the 4 cows and nursed at the same time a child fatally ill with the disease. A few years later the matter of milk-borne infection began to receive attention, and now the reports of such outbreaks number many hundreds.

On account of the danger of specific contamination of milk, no person sick with or convalescent from infectious disease, and no person having to do with the care of the sick, or with the disposal of their excreta, or with the washing of their linen, should be allowed to handle milk intended for the use of others. Public authorities are rapidly becoming awakened to the importance of restrictive measures in this regard, and in many communities it has been made a criminal offence to fail to give notice of the presence of cases of infectious disease at the place of production of milk or among those engaged in its distribution and sale.

According to Anderson, ${ }^{2}$ an outbreak of typhoid fever, due to contamination of a milk supply, is characterized by the sudden outbreak of an unusual number of cases followed by a rapid decline; by the appearance of an unusual number of eases among customers of a certain dairy ; by the unusual incidence of cases among users of milk; by an excess of cases among the well-to-do as compared with the poor; and by the finding of the typhoid bacillus in the suspected milk. It is, to be sure, very rare that the typhoid bacillus can be isolated from milk, but it should be attempted, and, if successful, is conclusive.

Diphtheria.-A large number of epidemies have been reported in which a positive connection with the milk supply appears to have been fairly well made out; but so far as is known, there is no connection between any disease of the cow and that which we know as diphtheria, although a number of outbreaks of diphtheria have been reported as traced to garget. The specific organism of diphtheria may be intro-

1 Edinburgh Medical Journal, 18.58, p. 993.

${ }^{2}$ Am. Jour. Pub. Hygiene, May, 1909. 
duced into milk from the discharges of persons employed in the handling and distribution of milk before they have recovered thoronghly from the disease. Dr. J. W. H. Eyre ${ }^{1}$ found the bacillns of diphtheria in samples of milk supplied to a large school where a number of cases of the disease had oecurred. It has been found repeatedly in suspected milk by others, including Bowhill, Klein, Dean, Todd, and Marshall. The last mentioned found ${ }^{2}$ an unusually virulent strain in milk supposed to have caused two cases of the disease.

Of an outbreak of 72 cases reported by the author, ${ }^{3}$ the cause was found to have been disseminated in milk which was handled by the person who at the same time was nursing a child sick with the disease.

"Of the 23 diphtheria epidemies reported as spread by milk and compiled since 1895 by Trask, ${ }^{4} 15$ occurred in the United States and 8 in Great Britain ; cases of the disease occurred at the producing farm, distributing dairy, or milk shop at such a time as to have been the possible cause of the outbreak in 18 cases; the diseased person milked the cows in 4 ; the same person nursed the sick and handled the milk in 1 ; the outbreak was supposed to be due to disease of the cows in 2; all cases of the disease were reported as living in households supplied with the suspected milk in 15 instances; measures taken upon the presumption that milk was the carrier of infection were reported as followed by subsidence of the outbreak in 5 cases; the Klebs-Löfler bacillus was isolated from the suspected milk in 2 of the epidemies."

Cholera.-Undisputed evidence of the eonnection between milk and Asiatic cholera is not very common. There is some disagreement as to the viability of the cholera organisms in milk; thus, Hesse 5 found that fresh, raw milk exerts a destructive influence on them; that, in fact, they begin to die as soon as they are mixed with it. He found that they die at ordinary room temperature within 12 lours, and at incubator temperature in from 6 to 8 hours. The age of cultures, the nature of the culture media, and the addition of the latter to the milk with the bacteria, appear not to affect the result. Sterilized milk was found to be a better culture medium. Basenau ${ }^{6}$ disagrees with Hesse. He found that uncooked milk does not kill the organisms in 10 hours, that they are active after 38 hours, and that up to the point of coagulation of the milk they increase considerably in number. He found that in polluted milk they remain active at least 32 hours at different temperatures (room temperature, $24^{\circ}$ and $37^{\circ}$ C.), and that they remain active even after the milk has coagulated.

Weigmann and Zirn ${ }^{7}$ found that the length of time cholera bacteria remain active depends upon the ratio they bear to the number of other organisms present, and that in order to survive for many hours they would have to be added to milk in exceedingly large numbers.

1 British Medical Journal, September 2, 1889.

2 Journal of Hygiene, VII., 1907, p. 32.

${ }^{3}$ Boston Medical and Surgieal Jourual, June 27, 1907.

- Hygienir Iaboratory Bulletin No. 41, p. 36.

5 Teitsehrift für Iygiene und Infectionskrankheiten, XVII., p. 238.

- Arehir für Hygiene, XXIII., p. 170.

7 Centralblatt für Bakteriologie, etc., 1894, No. 8. 
The evidence that cholera can be disseminated through the ageney of milk is exceedingly limited, and abont the only case firee from doubt is that recorded by Simpson, ${ }^{1}$ who relates that 9 eases of choleru oceurred suddenly on a ship in the harbor of Calcutta, 10 men of whose erew had obtained milk from a native. One drank but little and escaped, 4 died of undoubted cholera, and 5 were very sick with diarrhoa. Eight others who nsed condensed milk only, and those who used no milk whatever, were unaffected. It was learned that the vendor had diluted the milk about one-fourth with water from a tank to which dejections from cholera patients had gained acess and in which the elothes of the patients were washed.

Scarlet Fever.-In December, 1885, occurred what has become commonly known as the Hendon ontbreak of scarlet fever, due to a discase of cows, and since that time a number of other epidemics have Teen traced apparently to a common milk supply. In the Hendon case, a number of eows were or had been sick with an infections eruption of the udders, and there can be no doubt that the disease under considerittion was spread through the agency of milk coming from this dairy; but other cows having the same disease caused no trouble, and the possibility of contamination from human sourees could not be excluded absolitely. A number of other outbreaks of the disease have somewhat doubtfully been aseribed to similar teat eruptions, but in no ease is the evidence conclusive. On the other hand, there is undoubted evidence that the disease has many times been spread by milk from farms where children and others were sick with it.

In tracing epidemies of this and other diseases to a common cause, there is always danger of lending too much importance to coineidence, and of eoming thereby to unwarranted conclusions. As an illustration, the following case nay be cited: In 1897, in one of the outlying wards of Boston, a large number of cases of scarlet fever occurred with some suddenness among children ehiefly of the well-to-do class. Naturally there was much disturbance of the public mind, and an investigation was undertaken immediately. It was ascertained that nearly all of the families concerned were supplied by one milkman, who "raised" all the milk which he handled, and the responsibility for the ontbreak was at onee laid at his door. His prenises were examined by the health anthorities and found to be in execllent eondition. No case of discase or indisposition had oceurred in his family or among his help within a number of months, nor had he or anybody on the place, so far as could be ascertained, been in contact with any ease of searlet fever or of any other infections disease. His cows were examined by a thoronghly competent veterinarian and pronounced in every respect healthy. Nevertheless, public excitement ran so high that his business fell away very considerably. Had a single cow shown the slightest evidence of an eruptive discase of the teats, the epidemie might have been hailed as another Hendon outbreak, and been quoted in sanitary history as a noteworthy example. The fact that the great majority of

1 Indian Medical Gazette, May, 1887. 
cases oceurred among his patrons was easily explainable, for he was known to be a careful, cleanly, honest dealer, and was, therefore, the very sort of man to attract the particular class whose homes were invaded. The children affected belonged to closely affiliated groups of playmates. Further investigation revealed the fict that the first case was of a lad whose family was not a eustomer of the suspected dealer, and that, immediately before taking to his bed, he had been playing with a number of those who were among the next to be seized. 'These in their turn had been associated with others, and so the infection had spread. Thus, what might have served as a most useful example of a milk-borne epidemic of scarlet fever fell to the ground, and the unfortunate dealer was absolved from responsibility.

"Of the 51 scarlet fever epidemics reported as spread by milk compiled by Trask, ${ }^{1} 25$ oceurred in the United States and 26 in Great Britain ; all cases enumerated in the outbreak were reported as living in houses supplied with the suspected milk in 27 of the epidemics; a case suffering from the disease at such a time as to have been the possible source of infection was found at the producing farm, the distributing dairy, or milk shop in 35 cases; the outbreak was supposed to have been due to bottles returned from infected households and refilled without previous sterilization in 3 cases; the diseased person or persons were mentioned as handling the milk or milk utensils in 3 ; the sick milked the cows in 12 ; the same person nursed the sick and milked cows in 1 ; the outbreak was supposed to be due to disease of the cow in 2 ; it was reported that measures taken upon the presumption that milk was the cause of the epidemic were followed by abatement at the outbreak in 22 cases."

Typhoid Fever.-There can be no doubt that, in the spread of typhoid fever, milk plays a part only second in importance to that of drinkingwater. A very great number of epidemies have been traced beyond a possibility of dispute to milk coming from farms where cases of the disease have occurred. The contamination is brought about by the hands of the milkers or other handlers, who, in addition, assist in nursing, or by the addition of infected water, or through washing pails, cans, and other vessecls in such water.

From time to time, tabulated analyses of ontbreaks supposed to be due to eontaminated milk have been published, but a very large proportion of the cases included are based on very insufficient evidenee, sometimes exceedingly slight, such as that a cow had drunk from water into which drainage from the barnyard had had access. But within reent years, a number of extensive epidemics in this country and elsewhere have been traced with as much definiteness to the milk supply, as have others to the water supply, and with the same and only defect that the bacteriological proof has been lacking. As in the ease when outbreaks occur from polluted water, when attention is drawn to the possible cause, the bacteriologieal evidence is no longer

1 Hygienie Laboratory Bulletin, No. 41, p. 29. 
obtainable, the conditions having clanged during the period of incubation.

The State Board of Health of Massachusetts has traced a number of extensive epidenies to the use of polluted milk, but in no instance has the organism been found in the milk. In the eity of Boston also, where the loeal authorities keep a constant eve on the reports of typhoid fever cases with particular reference to the possibility of dissemination through milk, a number of small outbreaks have been traced definitely to mitk supplies derived from small farms where persons siek with the disease were nursed by those who had milked the cows and handled the milk, and in these instances also the bacteriological evidence is lacking.

That the organism can retain its vitality in milk, and even in sour milk, has definitely been settled. Hein found the organism in sour milk at $13^{\circ}-18^{\circ} \mathrm{C}$. after thirty-five days, but not after forty-eight. Hesse has found it in sterilized milk after four months. Drs. Fraenkel and Kister, ${ }^{1}$ having reason to believe that the unusual amount of typhoid fever at Hamburg during the summer of 1897 was due in part to infected buttermilk, undertook the study of the question whether $B$. typhosus ean exist in that fluid, concerning which point there had been more or less of conflicting testimony. Obtaining some samples, they first investigated the number and identity of the contained bacteria, and learned that, while the number varied widely, the species were always about the same. Finding no pathogenic organisms, they sterilized specimens in test-tubes a half hour a day for three days, then planted the typhoid bacillus in them and kept them at different temperatures; on ice and at $22^{\circ}$ and $37^{\circ} \mathrm{C}$. Loops were taken from each from time to time and planted, and each yielded positive results. The speeimen kept at room temperature was under observation nine days; the others were not examined after the third. The specimens of fresh buttermilk containing all its bacteria were planted and kept under the same conditions, and from them the same results were obtained. Yet there was this difference, that there was always a diminution in the number of the pathogenic organisms, and this was the more marked, and sometimes very rapid, with increasing temperatures.

A typical example of the spread of typhoid fever through the medium of milk is shown in the following deseription of an epidemic reported to the State Board of Health of Massachusetts : ${ }^{2}$

In September, $1905, \mathrm{X}$, a farmer, after having been in poor health all summer, and after a two weeks' trip to Maine, was taken sick with typhoid fever. 'The fever ran for 21 days: then he had a relapse, and in all he was in bed 8 weeks. In January, 1906, Mrs. X became ill. She ran no fever and did not think she had typhoid. She was in bed but 1 week, and considered herself merely nervously tired. Since his sickness $\mathrm{X}$ has been in unusually good health. He has bad no jaundice and no abdominal pain.

1 Münchener medicinische Wochenschrift, February 18, 1898.

${ }^{3}$ Monthly Bulletin of the State Board of Health of Mass., Dee., 1909. 
In $1906 \mathrm{X}$ began to keep 2 eows, and since that time cases of typhoid fever have oecurred among his milk eustomers as follows :

No. of Cases.

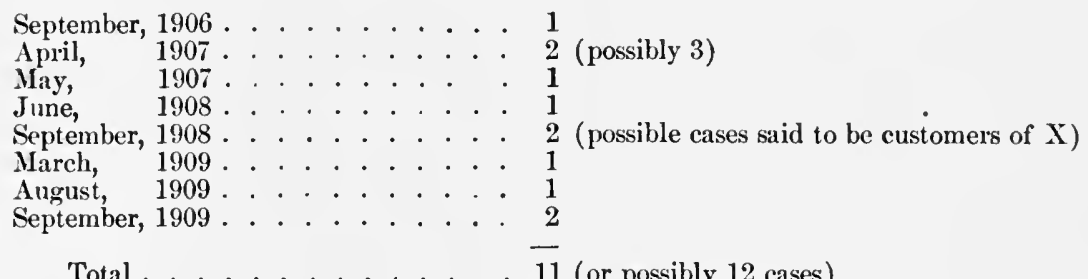

These eases of typhoid fever have been confined to a residence portion of the town about half a mile square, centering about $\mathrm{X}$ 's house. The region is in the better portion of the town, well elevated, with good hygienic conditions, and not close to the mills or the river.

The people are seemingly of moderate means, not foreign born, and of good intelligence. The houses have separate cesspools. There is no town sewer. The water supply is the same all through the town. The ice for the whole town comes from the same source-the river.

There is a well in the neighborhood used by a large number of people. Several of the typhoid cases did not use this well, and many other uninfected persons did get some of their drinking water there. $\mathrm{X}$ did not use this well.

The hygienic condition of X's place is quite unsuited for the produetion of milk. The cesspool is not earefully sealed. The barn is filthy and fly infested. An unguarded privy drains into the cellar, where the manure and a pig are kept. Complaints have been made by the neighbors of the smell from the place.

$\mathrm{X}$ has kept two eows, which have yielded him about two $8 \frac{1}{2}$-quart eans daily. He milks the eows and strains the milk himself. Mrs. X washes the cans. The milk is peddled about the neighborhood by $\mathrm{I}$ soon after it is milked. It is not ieed.

Specimens of feces and urine from $\mathrm{X}$ showed no typhoid haeilli in the feees, but there was an abundant growth of motile bacilli in the urine. The bacilli corresponded in cultural and agglutination characters to typhoid bacilli.

$X$ was informed of his condition and forbidden to distribute any more milk.

At the beginning of the year 1910, four and a half years after his typhoid fever attack, this man shows a constant typhoid bacilluria. $\dot{H}$ e has no symptoms of eystitis, and feels better than he did before being sick.

A year later it was found that several more cases of typhoid fever occurred in the same town, and investigation brought out the fact that 
this farmer $\mathrm{X}$, although forbidden to sell his milk, had been giving away to his neighbors an excess which he had, in the absence of his wife. Those individuals, however, who were unfortunate enough to aceept these gifts, promptly eame down with typhoid fever, thus showing that the farmer, with his filthy habits, had been again responsible for infeeting his milk supply.

Another epidemic reported to the Massachnsetts State Board of Health affected 59 persons who took breakfast at a eertain hotel on Labor Day, 1909. This epidemic was traeed to a waitress, who, in the prodromal stage of typhoid fever, had aecess to and undoubtedly did infect a can of milk. This can of milk, improperly iced and therefore of a temperature favorable to the growth of the bacilli, was used at breakfast by the affeeted persons.

"Of the 179 typhoid epidemies reported as spread by milk compiled by Trask, 107 oceurred in the United States, 43 in Great Britain, 23 in continental Europe, 3 in Australia, 1 in New Zealand, and 2 in Canada; all eases enumerated in the outbreak were reported as living in houses supplied with the suspected milk in 96 of the epidemies; a case, suffering from the disease at such a time as to have been the possible sourec of infeetion, was found at the producing farm, distributing dairy, or milk shop in 113 eases; the outbreak was supposed to have been due to bottles returned from infeeted households and refilled and distributed without previous sterilization in 4 cases; the diseased person or persons were mentioned as handling the milk or milk utensils in 2 ; the sick milked the cows in 6 ; the same person nursed the sick and handled the milk or milk utensils in 6 ; same person was mentioned as nursing sick and milking cows in 10; ice eream was given as the infeetive medium in 3 ; whipped eream in 1 ; typhoid dejeeta were reported as thrown on the ground in such a way as to have more than probably contaminated the well water used for washing the milk utensils in 4 ; in many eases mention was made of special incidence of the disease among persons in the habit of drinking milk; the Eberth bacillus was isolated from the milk in 1 ease (Konradi); it was reported that measures taken upon the presumption that milk was the cause of the epidemic, and looking to the removal of this as a factor, were followed by abatement of the outbreak after due allowance for the nsual period of ineubation from the distribution of the last infected milk in 78 of the cases."

In reporting milk epidemies, some of the points of special interest, as given by Trask, ${ }^{2}$ are the following:

" 1 . The number of eases of the discase existing in the involved territory during the time eovered by the epidemic.

" 2 . The number of houses invaded by the disease.

"3. The number of invaded houses supplied in whole or in part, directly or indireetly, by the suspected milk.

1 Hygienic Laboratory Bulletin No. 41, p. 24.

${ }^{2}$ Ibid., p. 47. 

plied.

“4. The number of cases oecurring in invaded houses so sup-

"5. The number of houses supplied with the suspected milk.

" 6 . The relative proportion of houses so supplied to those supplied by other dairies.

" 7 . The time covered by the epidemic.

"8. The location of the case or cases from which the milk beeame contaminated.

"9. The relation of the original ease to the milk.

"10. The time relation of the original case to the epidemie.

"11. The speeial ineidence of the disease among milk drinkers.

"12. The elimination of other common carriers of infeetion.

"13. The effect upon the epidemic of closing the dairy or taking such measures as will eliminate possibility of milk contamination from the suspected foeus.

"14. The finding of the specifie organism in the milk."

When a typhoid epidemie occurs it oftentimes takes several days before the cause of the epidemic can be located and eliminated. During this time, however, the health officer can be doing very effieient work through advice to the inhabitants of the region affected. Information desirable at such a erisis has been very well epitomized by Hill, Epidemiologist to the Minnesota State Board of Health, in an article entitled, "The Typhoid Tourniquet," in the Ameriean Journal of Public Hygiene, May, 1909. Hill states that on finding a typhoid outbreak in a town, we issue in the papers, display on the streets, and address to every householder the following placard:

\section{To the Citizens of -}

\section{Typhoid Fever is Epidemic in - .}

The Minnesota State Board of Health is investigating this epidemie to find its exact source. Meantime govern yourselves as follows :

1. Typhoid fever is contraeted solely by the mouth. If you do not put the poison of typhoid fever into your mouth you will never contract typhoid fever. Therefore, watch the mouth.

2. Do not eut or drink anything (water, milk, oysters, fresh vegetables, or anything else) unless it has been first boiled, broiled, baked, roasted, fried, or otherwise thoroughly heated through and through.

3. Do without all food or drink whieh has not first been thus heated. (Canned or bottled foods or drinks, otlier than milk or water, are not inclurled in this.)

4. If living in the same house with a typhoid fever patient, do not handle your own food, or food intended for any one else, even if it has been heated, except with hands that have been thoroughly washed with soap and very hot water. (Preferably also with antiseptie; ask your physieian about the antiseptic to use.) Wash before crery meal in this 
way, and before cooking, serving, or eating anything, or putting the fingers in the mouth.

5. If there are flies about, see that all food and drink is protected from them at all times. Flies often carry typhoid poison to foods and drinks.

6. The poison of typhoid fever does not show itself for two weeks after it enters the body. Therefore, for the next two weeks typhoid cases may develop from typhoid poison already taken in. But any case which develops on and after (a date two weeks later than the date of the placard) will be due solely to neglect of this notice and failure to carry out minutely the directions here given.

Cholera Infantum.-In every large community, it has become customary to expect as a normal condition a large death-rate among children with the advent of hot weather. This increased death-rate is limited very largely to the very early age periods and to children fed on cows' milk, and while children of the poor are the ones most commonly attacked, those of the well-to-do are by no means free. During the siege of Paris, the infant mortality was reduced to a half of its yearly average, although the general death-rate had doubled. This unusual condition was attributed, no doubt correctly, to the fact that mothers were obliged to nurse their infants when they could, on account of the great scarcity of cows' milk and other foods.

The common milk bacteria are ordinarily harmless, but it appears that some species under certain conditions produce toxins in sufficient amounts to cause gastric and intestinal disturbances. According to Baginsky, a large part of the annual amount of cholera infantum is due to these products (see under Garget).

Dr. E. W. Hope ${ }^{2}$ investigated over a thousand cases of antumnal diarrhœa, and found that, of 233 deaths of infants under three months, only 16 had not received other than their natural food. That is to say, the deaths among artificially fed children under three months of age were fifteen times as numerous as among those nursed. In no less than 22 per cent. of the whole number of fatal cases, other members of the household had suffered from diarrhea. The most striking instance of the communicability of the disturbance was that at an infants' home in which were 10 children under the age of five months, all in perfect health. An infant of two months was admitted in July with vomiting and diarrhœa, and within a few days 6 of the other infants and the nurses were sick in the same way. The 4 other children were taken away at once. The admitted child and the 6 that became infected all died. The 4 that were taken away were saved.

Bacteriological examination of milk has shown the presence of extremely active organisms, including $B$. enteritidis sporogenes of Klein, ${ }^{3}$ which has been found by its discoverer in the ileum contents of chil-

1 Berliner klinische Wochenschrift, 1894, Nos. 43 and 44.

2 Public Health, July, 1899.

${ }^{3}$ Centralblatt für Bacteriologie, etc., XXII., Abth. I., Nos. 20 and 21 ; XXIII., Abth. I., No. 13. 
dren and adults with diarrhœal conditions, but not in a condition of health. It has been found by Andrewes in the diseharges of cases of sporadic diarrhœe of adults, and by Klein in three different outbreaks among the inmates of a single hospital. It is a common saprophyte found in sewage, in polluted rivers, and in manured garden soil, and is very commonly detected in milk, the use of which has not been followed by untoward results. Under certain unknown conditions, it becomes highly pathogenic, and recent milk cultures are intensely virulent when inoculated subcutaneously in guinea-pigs.

It is probable that to this organism was due an outbreak of milkpoisoning in Malta, described and investigated by J. Zammit. ${ }^{1}$ In one village, 5 families comprising 12 persons were scized with vomiting, diarrhœa, and cramps, and 2 children succumbed. Post-mortem examination revealed nothing except congestion of some of the viscera. Subsequently, in another village, 17 persons in 5 houses were attacked with severe gastro-enteritis and collapse. The symptoms, which came on in all eases about three hours after drinking milk, included vomiting, diarrhœa, acute pain in the stomach and bowels, cramps in the extremities, weak and irregular pulse, and cold and clammy skin. The persons eoneerned in both outbreaks obtained their milk from the same dealer, whose eans, which had a sour smell, yielded on bacteriological examination a bacillus having all the characteristies of the one mentioned. Families which were supplied by the same dealer, but directly from the goats, showed no symptoms, and the goats themselves were free from disease.

Andrewes ${ }^{2}$ has described 3 much more extensive outbreaks, referred to above, due to the same organism, in one of which the offending food was found to be rice pudding made with milk. The first and second outbreaks, in which no one article of food could be incriminated, involved respectively 59 and 146 patients; the third involved 86 . In all 3 outbreaks, the great majority of the attacks were mild, but in some of the more severe cuses, the discharges contained mucus and blood. In all 3, the organism was found in the stools, and in the second, it was found in the milk given out on the previous day. In the third, it was impossible to obtain any of the milk, but the pudding made with it yielded the organisms, in spite of the heat to which the compound had been subjected during its preparation. It was found by direct experiment that the interior of such a pudding did not attain a temperature above $98^{\circ} \mathrm{C}$. during cooking, a temperature below that necessary for the destruction of the spores, which are among the most resistant known.

1 British Medical Journal, May 12, 1900, p. 1151.

2 The Lancet, January 7, 1899. 


\section{Analysis of Milk.}

For ordinary purposes of determining the quality of milk, the presence or absenee of added water, and whether it has been robbed of its crean, a complete chemical analysis is by no means always necessary, since much may be learned from

Fig. 3. simple inspection by means of the FIG. 2.

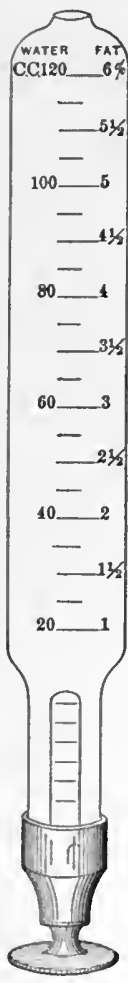

Feser's lactoscope.

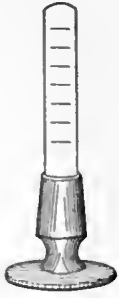

. lactodensimeter and the lactoscope. The lactodensimeter (Fig. 3), or lactometer, is merely a large hydrometer with a stem graduated to show specific gravities ranging from 1.015 to 1.040 . The lactoscope, invented by Professor Feser, is an instrument designed to indicate the approximate fat content of milk. It consists of a glass cylinder, into the base of which a smaller cylinder of white glass, elosed at the top and mounted on a metallic base, is fitted. The larger eylinder is graduated along the side; the smaller one bears a number of black horizontal lines. The instrument is shown in Fig. 2.

The prineiple of the instrument is based upon the fact that the opacity of milk is due mainly to the fat globules in suspension, and that, therefore, the richer a milk is in fat, the greater is its opacity, and the more it must be diluted to reduce the opacity to such an extent as to permit the passage of light.

The method of use is as follows: Four ec. of the specimen are delivered from a pipette into the cylinder throngh the opening in its upper end, and then water is added in small portions and thoronghly mixed by inversion of the instrument, the orifiee being kept elosed by the tip of the forefinger. As soon as the sucessive additions of water have redued the opacity of the mixture to such an extent that the black lines on the white eylinder ean be diseerned so distinctly that they may be eounted, the height of the liquid on the scale is noted and the percentage of fat indicated is read. Four ce. of skimmed milk will require so little water that, when the lines ean be seen, the level of the mixture will be very low on the seale, while with rich milk it will be 
correspondingly high, and with cream the whole cylinder will be filled, and even then the lines cannot be made out.

Control analyses show that the instrument gives very fairly accurate results. Neither of these instruments alone can be depended upon to indicate the true quality of milk, excepting in the ease of samples which are either very good or very bad. The specific gravity alone is especially fallacious as a guide for the following reasons: The specific gravity of normal milk at $59^{\circ} \mathrm{F}$. ranges between 1.029 and 1.034 . The removal of cream causes it to rise; the addition of water causes it to fall. A normal milk when robbed of its cream may show a specific gravity of 1.036 , and then if a small amount of water is added, the gravity is brought down to 1.032 ; that is to say, within normal limits. Thus, a milk after being doubly treated so as to reduce its nutritive value, may show a normal specific gravity, and, on this test alone, be classed as pure. Nor is this the only objection to a system of inspection of this most important food based upon the use of the lactometer, since milks exceptionally rich in fat have a specific gravity below the normal, and thus may be condemned as watered.

The lactoscope alone is also not to be depended upon in all eases, since a milk which shows a normal content of fat may be one of considerable richness in that constituent and extensively watered. Thus, a speeimen containing originally 4.50 per cent. of fat may be watered very considerably, and yet show 3.75 per cent. by the lactoscope.

By combining the use of both instruments, however, the fallacies of either are exposed. A normal specific gravity shown by the one and a normal fat content revealed by the other will indicate that, even if the milk has been tampered with, it yet possesses arerage richness. A normal specific gravity with a low percentage of fat will indicate skimming and watering; low speeific gravity with normal or low fat, watering; and high specific gravity with low fat, skimming. Low specific gravity with very high fiat will indicate unusual richness; thus, cream has a very low specific gravity, due to its preponderance of fat. As a test of the accuracy of this process of examination, the author ${ }^{1}$ caused to be analyzed under his supervision 1,714 specimens which appeared by those tests to be of gool quality, and of this number but 8 were found to have deriated materially from the statute requirement of 13 per cent. of total solirls.

Determination of Specific Gravity.-In taking the specific gravity by means of the lactodensimeter, the milk is mixed thoronghly, in order to insure homogeneity, by pouring from one vessel into another; a cylinder of sufficient depth to allow the instrument to float freely is filled with the milk, and the instrument is earefully inserted, not dropped, down to the bottom, and then released. When it comes to rest, the realing of the stem at the level of the smrfice of the liquid is noted. It shonld be borne in mind that air bubbles are retained rather tenaciously by the milk, and tend to lower the density, and, therefore,

1 Thirty-first Annual Report of the Inspector of Milk, Boston, 1889, p. 11. 
in mixing the milk, too violent action must be avoided, and a short time should be allowed for the bubbles present to rise to the surface and escape.

Inasmuch as the gravity varies with the temperature, and the instrument is graduated for $59^{\circ} \mathrm{F}$., either the milk should be brought to that temperature, or a correction should be made accord-

Fig. 4. ing to the deviation above or below that point. If the milk is colder, the reading will be too high, and, if
warmer, too low. It is more convenient to make a cor-
rection for temperature than to heat or cool the speci-
men to the normal point. The deduction of a half de-
gree of gravity for each five degrees of temperature below
$59^{\circ}$, or the addition of the same anount for each four
degrees above $59^{\circ}$, will be found to be approximately
accurate corrections.

Determination of Fat.-For the accurate determination of fat, several methods are in use, including the following:

I. The Paper-coil Extraction Method.-This process requires strips of thick filter-paper, free from substances soluble in ether and alcohol, about 6.25 by $62.5 \mathrm{~cm}$., and a Soxhlet extraction apparatus. The most approved form of the latter consists of three scparate pices which fit together by ground-glass joints (see Fig. 4). The top and bottom pieces are, respectively, an upright Liebig condenser and a flask. The middle piece, which is the part in which the extraction process occurs, consists of a glass cylinder, closed at the bottom, from which a narrower cylinder with open end projects downward. The two cylinders are connected by a side tube which opens into the upper portion of each, and also by a siphon which opens from the side of the bottom of the large cylinder, extends upward, then turns upon itsclf, pierces the middle part of the wall of the lower cylinder, and terminates within and just below its lower end.

When in use, the substance to be extracted is placed within the upper cylinder, upon the bottom of which is placed a wad of absorbent cotton, which prevents the entrance of solid particles to the siphon tube, or it is confined within a cartridge of thick filter-paper which fits loosely within the cylinder. When the cartridge is used, tion apparatus.

it is best to plug its open end with absorbent cotton, in order to prevent the escape of fine particles of the contained substance.

The three separate parts are joined together and then mounted on a water-bath. The ether or other extracting medinm is contained in the flask, the exact weight of which has been determined. The heat of the water-bath causes the ether to volatilize, and the vapor passes upward 
through the side tube into the extractor and thence to the condenser, where, coming in contact with the eold surface of the inner tube thereof, it condenses and falls upon the substance to be extracted. As the process continues, the condensed liquid aecumulates and gradually rises until it reaches the bend of the siphon, which, when full, begins to act and discharges downward into the flask until the entire liquid is returned to its starting-point. During its accumulation, it aets upon the substance within the eylinder, and extracts more or less of the fat or other substance, as the ease may be, which is carried in solution into the flask. The volatilization continues, and the process is repeated again and again as long as is necessary, and in this way the whole of the extracted matter is finally within the flask, since, being itself non-volatile, it remains behind, while the liquid by whish it is extracted is sent continually on its errand. On the completion of the process, the ether is sent up again into the eylinder, and before it reaches the level of the siphon the flask is disjointed. The remaining ether is expelled cautiously, and the flask with its contents is placed in an air-bath, maintained at $100^{\circ} \mathrm{C}$, and dried until its weight is constant. The increase in the weight of the flask represents the amount of matter extracted.

In determining the fat of milk by this process the method is as follows: To one of the strips of filter-paper, made into a coil, a definite weight of milk, about 5 grams, is applied in either of two ways. A small beaker eontaining about the required amount is weighed and then the eoil is thrust into it, kept there until nearly the whole has been absorbed, and then carefully withdrawn and placed dry edge downward upon a sheet of glass. The beaker is then weighed again, and the loss in weight, which represents the amount of milk absorbed, is noted; or the beaker containing the milk and a small pipette is weighed, and then the necessary amount of milk is transferred to the coil from the pipette, after whiclı operation the weiglst of the beaker, pipette, and the remaining milk is noted, and the difference set down as the wcight of the nilk absorbed. The eoil is then dried in an air-bath at $100^{\circ} \mathrm{C}$. for an hour or more, at the expiration of which time it is ready for insertion into the extractor.

$\Lambda \mathrm{fter}$ it has been acted upon by the ether about a dozen times, the flask is detached and treated as above mentioned. After being allowed to cool, the weight is noted and the percentage of fat calculated arithmetically.

Exanpis.-The amount of milk absorbed by the coil was 4.950 grams. The increase in the weight of the flask was $0.173 \mathrm{gram}$. Then the amount of fat present in the sample is obtained by the equation, $4.95: 0.173:: 100: x$, wherein $x=3.49$.

2. The Werner-Schmidt Method.-In this process, equal volumes of milk and hydrochlorie acid, about 100 ce. of each, are mixed in a testtube and boiled for about a minute and a half, or heated on a waterbath or steam-bath until the mixture is dark brown in color. It is then cooled, and the mixture shaken with 30 ec. of ether. When the 
two liquids have separated, the supernatant ether is withdrawn by means of a pipette or blown out with the assistance of a double tube such as is used in wash-bottles, the delivery tube extending into the ether layer very nearly as far as the line of demareation between the ether and the acid mixture. The operation is repeated with several fresh smaller portions of ether, and the whole of the ether used is colleeted in a weighed flask. Then the ether is distilled off, and the flask with its residuum of fat is heated to constant weight in an airbath, cooled, and weighed. The process may be shortened considerably by treating the milk in a graduated tube and, after thorough shaking with ether, removing an aliquot part of the latter by means of a pipette and evaporating to dryness. From the weight of this residue, the amount of fat in the whole volume of ether can readily be determined. Since the milk taken is measured, and not weighed, a correction must be made for gravity.

Example.-Amount of milk used $=10$ ce. Specific gravity of specimen $=1.032$. Weight of milk used $=1.032 \times 10=10.32$ grams. Amount of fat found $=0.397$ gram. Percentage of fat in the original milk $=x$ in the equation, $10.32: 0.397:: 100: x ; x=3.84$.

3. The Babcock Centrifugal Method.-In this process, equal volumes of milk and sulphuric acid are mixed in flasks of special design with narrow, graduated necks, and then whirled in a centrifugal machine for a definite length of time. On the completion of the proeess, the details of which are given below, the fat in a pure condition is within the graduated neck, and the percentage is read direetly off.

The kind of flask used is shown in Plate III. It has a capacity of about 40 ce. The graduated portion of the neck his a capacity of 2 ec. The details are as follows : $17.6 \mathrm{cc}$. of the milk are measured by means of a pipette and introdnced into the flask. Then an equal volume of sulphurie acid, specific gravity 1.800 , is added, and the two liquids are mixed thoroughly by gentle rotary motion. Then the flask is placed in a centrifugal machine made especially for the purpose, and whirled for five minutes, at the expiration of which time hot water is added up to the beginning of the neck. The flask is whirled again for two minutes, and more hot water is added so as to bring the fat laver well up into the neck. After further whirling for one minute, the depth of the fat layer is determined by reference to the scale.

This process gives sufficiently aceurate results for all practical purposes, and is in common use at experiment stations in this country. It is much used at ercameries for determining the butter value of milk sent in from the surrounding country.

The employment of sulphuric acid having a higher specific gravity than that given, say 1.820, is objectionable in that it frequently happens that it is impossible to obtain a clear fat layer. The fat itself nay be turned a very dark color, and the sugar of the milk may be attacked to such an extent that charred portions of it will separate and accumulate within and beneath the column of fat, and so prevent a satisfactory reading. If the acid used is weaker than 1.800 , all the casein may not 


\section{PLATE III}

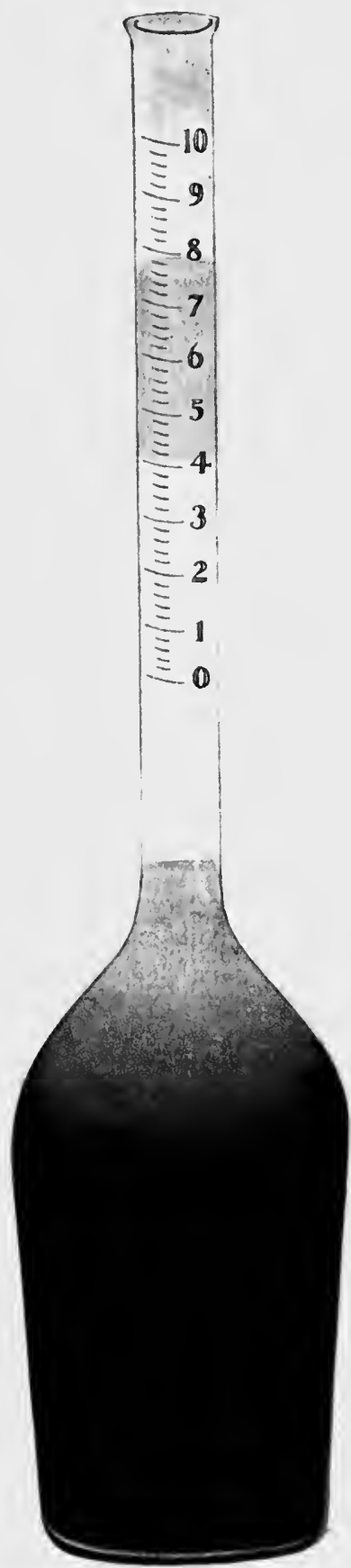

Babcock Flask, showing Fat in Neck. 

be held in solution, and portions of it may mingle with the fat and destroy the aecuracy of the test.

In Plate III. is shown the fat layer in the stem as it should be, free from alteration of color and from charred sugar and particles of casein. It will be observed that the line of demareation between the water and the fat in the stem is very sharp. For cream, a flask with a much broader neek is employed.

4. The Babcock Asbestos Method.-In this method, the dried total solids obtained by the method described below (No. 2) are extracted in a Soxhlet extraction apparatus.

Determination of Total Solids.-1. Weigh into a flat-bottomed platinum (lish of about 2 inches $(5 \mathrm{~cm}$.) diameter, 5 grams of milk. Place on a water-bath for an hour and a half. Remove to a hot-air bath, maintained at $100^{\circ} \mathrm{C}$., until its weight is constant. Cool in a desiccator and weigh. The difference between this weight and that of the dist alone represents the total solids of the amount of milk taken, and, multiplied by 20 , expresses the percentage of total solids in the sample. If for any reason it is desired to use the total solids for extraction in the Soxhlet apparatus, the dish may be partly filled before weighing with fine, clean, dry sand, or with fieshly ignited woolly asbestos. One objection to the use of the total solids in this way is that it is extremely difficult to remove the whole amount fiom the dish, to the sides and bottom of which a portion will adhere with great tenacity, and ean be removed only by burning. To obviate this difficulty, Dr. C. L. Spaulding has suggested lining the platinum dish with very thin tinfoil, which, after the weight of the total solids has been noted, is withdrawn with the sand or asbestos, and with it inserted into the extraction apparatus.

Formerly, the residue of the milk dried in the dish alone without sand or asbestos was used for the determination of fat by the Wanklyn process, which eonsists in filling the dish with freshly distilled naphtha or with ether, and allowing it to act upon the residue and dissolve out the fat, several portions being used, after which the dish is dried again and weighed, and the loss in weight taken as the measure of the fat containel. Inasmuch as the solvent cannot penetrate the horny layer which forms on the bottom of the dish, not all the fat can thus be extracted, and the figures obtained are ordinarily about 0.5 too low.

2. The Babcock Asbestos Method.-In this process, the milk is weighed into a cylinder of perforated metal or into a filter-paper cartridge filled loosely with freshly ignited woolly asbestos, subjected to a temperature of $100^{\circ} \mathrm{C}$. until the weight is constant, and then cooled and weighed. The gain in weight represents the total solids of the amount of milk taken. The eylinder may then be slipped into the extraction appariatus and used for the determination of fit.

3. Determination of Total Solids by Formula.-Knowing the correct specific gravity and the amount of fit, it is possible to determine fairly accurately the amount of total solicls by the use of the formula of Hehner and Richmond. This formula is as follows: $F=0.859 \mathrm{~T}$ 
$-0.2186 G$, in which $F$ represents fat, $T$ the total solids, and $G$ the figures of the specifie gravity beyond the first decimal place.

ExAMPLE.-The specifie gravity of a specimen of milk is found to be 1.030 , and its fat content 3.95 . Then applying the formula, we have

$$
\begin{aligned}
& 3.95=0.859 T-(0.2186 \times 30), \text { or } \\
& 3.95=0.859 T-6.558, \text { or } \\
& 0.859 T=6.558+3.95=10.508, \text { and } T=12.23 .
\end{aligned}
$$

In other words, multiply 0.2186 by the figures expressing specific gravity, add the percentage of fat to the produet, and divide the result by 0.859 .

The formula may also be used to determine the percentage of fat, the specific gravity and total solids being known.

Determination of Milk Sugar.-The amount of lactose may be determined either chemically or by means of the polariscope.

1. Method by Fehling Solution.-Reagents required: Solution A. Dissolve 34.639 grams of pure sulphate of copper in distilled water and dilute to a liter. Solution B. Dissolve 173 grams of potassium sodium tartrate (Rochelle salt) in distilled water, add $100 \mathrm{ec}$. of sodium hydrate solution of 1.393 specific gravity, and dilute the mixture with distilled water to a liter.

In making a determination, 10 ec. of each solution are mixed in a boiling flask of about 300 cc. eapacity. The amount of copper contained in 10 cc. of solution A requires for its reduction 0.050 gram of dextrose, or $0.0667 \mathrm{gram}$ of lactose.

Process.-Into a porcelain evaporating dish of suitable size, discharge from a pipette $25 \mathrm{cc}$. of milk. Add three or four times as much water and heat to $40^{\circ} \mathrm{C}$. Add acetic acid, a drop at a time, with constant stirring, until the mixture separates into curds and a fairly clear whey. Transfer the whole to a graduated $500 \mathrm{cc}$. flask, and dilute with water to the 500 mark. Filter a portion through a dry filter, and use the filtrate for titration. Dilute the mixed reagents in the boiling flask with water and boil over a Bunsen flame. From a burette graduated in tenths, add the filtrate from the curds a little at a time, and eontinue the boiling after each addition. As the blue color begins to appear faint, the addition should be made cautionsly, in order not to overstep the end reaction., As soon as the blue color is discharged eompletely, note the reading of the burette.

The calculation is exceedingly simple. Since $0.0667 \mathrm{gram}$ of lactose is required to reduce the copper in the reagent, it follows that that amount of the substance is contained in the number of ce. of the whey used, and the percentage is obtained by the application of the rule of three.

EXAMPLE.-The color is discharged by 24.3 ce. of the diluted whey. Then in the whole amount of milk taken the amount of sngar will be $x$ in the equation $24.3: 0.0667:: 500: x . \quad x=1.372$. The amount of milk taken was 25 cc., hence in 100 ec. the amount would be 5.49 , 
and this amount divided by the specific gravity gives the percentage by weight. Supposing the specific gravity to be 1.030 , for example, the 100 cc. of milk weigh 103 grams, and the percentage of sugar will be $x$ in the equation $103: 100:: 5.49: x . \quad x=5.33$. Inasmuch as the meaus of the first equation are constants, the reckoning resolves itself into dividing four times their product, 33.35 , or 133.4 by the number of ec. used, and dividing this result by the specific grarity of the specimen.

2. Method of Polariscopy.-The determination of lactose and other sugars by means of the polariscope combines the advantages of accuracy and of rapidity. The instruments in common use are of two kinds: those of which the normal sucrose weight, that is to say, the amount of sucrose which, dissolved in water and made up to $100 \mathrm{cc}$, will show 100 degrees on the seale when observed through a $200 \mathrm{~mm}$. tube, is 26.048 grams, and those in which it is 16.19 grams. Of the former, the Ventzke-Scheibler and the Schmidt and Haensch modification, and of the latter the Laurent instrument, may be regarded as types. The Schmidt and Haensch triple field, half-shadow instrument possesses the advantage of doing away with the matching of colors, and hence may be used by those who are color-blind, and even with those not so afflicted gives, on the whole, the most satisfactory results.

Process.-Into a flask graduated on the neck at 102.6 ec. if the instrument used is one of which the sucrose normal weight is 26.048 grams, weigh 65.95 grams of milk, or into one graduated at $101.6 \mathrm{cc}$., if it is one of the other class, weigh 40.99 grams, add $1 \mathrm{cc}$. of solution of mereuric nitrate of pharmacopœial strength, shake well, and dilute with water up to the mark. Filter through a dry filter-paper, fill the $200 \mathrm{~mm}$. observation tube, and note the reading of the scale when the field of observation is uniform. The reading divided by 2 equals the percentage by weight of lactose.

The weights 65.95 and 40.99 represent twice the normal lactose weights of the respective types of instruments. The graduations 102.6 and 101.6 are adopted instead of $100 \mathrm{cc}$., since the dried precipitated curds from the respective amounts of milk of average specific gravity have a bulk equal to the excess over $100 \mathrm{cc}$.

Determination of Ash.- The ash may be determined by igniting the residue obtained in the determination of total solids, provided no other substance has been introduced into the dish witl the milk. The ignition should be condueted at a low red heat until the ash is perfectly white. Then the dish is cooled in a desiccator and again weighel. The difference between this final weight and the original weight of the empty dish represents the amount of mineral matter in the amount of milk taken. Or a larger amount of milk, say 20 grams, may be evaporated with a few ec. of nitric acid and the residue ignited as above.

Determination of Proteids.-Having determined the total solids, fat, sugar, and ash, the proteids may be reckoned by difference-that is, by subtracting the sum of the fitt, sugar, and ash from the total solids, or they may be determined directly by the Kjeldahl process, 
which depends upon the conversion of the nitrogenous matter into ammonium sulphate, which then is decomposed by an excess of strong alkali, ammonia being set free. This is expelled by heat, condensed with the accompanying steam, and received in acid of known strength.

The proeess is as follows: Into a Kjeldahl digestive flask introduce a definite weight, say 5 grams of milk, about 0.7 gram of mercuric oxide, and 20 ce. of sulphuric acid of 1.840 specific gravity, free from nitrates and ammonium sulplate. Place the flask in an inclined position and heat below the boiling-point of the acid for from five to fifteen minutes, or until frothing ceases. Then raise the heat until the mixture comes to boiling, and continue the process until the liquid is clear and has a very pale straw color. This will require ordinarily less than an hour. Withdraw the lamp, and drop in, in small quantities at a time, permanganate of potassium, until, after shaking, the liquid acquires a permanent green or purple color. This addition is not always or even usually necessary to secure complete oxidation, but since it is sometimes required, it is best to make it a part of the routine. Allow the contents to cool, and then transfer them with about $200 \mathrm{cc}$. of distilled water, plus sufficient for thorough rinsing, to a distilling flask of about $550 \mathrm{ce}$. capacity, fitted with a rubber stopper and a bulb tube connected with a very long Liebig condenser, the delivery end of which is fitted with a glass tube bent at right angles, so that it may dip beneath the surface of the acid into which the distillate is to be received. Add a few pieces of pumice or granulated zine, or about 0.5 gram of zine dust, to prevent bumping, and $25 \mathrm{cc}$. of a 4 per cent. aqueous solution of sulphide of potassium, to prevent the formation of compounds of ammonium and mercury, which are not wholly decomposable by alkalies. Shake, and then add of a saturated solution of sodium hydrate, free from nitrates, sufficient to make the reaction strongly alkaline, pouring it down the side of the flask so as not to mix at onee with the acid contents. Next connect the flask with the condenser, mix the contents by gently rotating, and apply the flame. Distil, and receive the distillate in a vessel containing $50 \mathrm{ec}$. of decinormal sulphurie acid. When about 175 ce. have passed over, it may be assumed that all ammonia has been expelled, and then the distillate is titrated with decinormal alkali, using cochineal or methyl-orange as an indicator. From the difference in strength of the deeinormal acid, the amount of ammonia is calculated, and from this the amount of nitrogen; and this multiplied by 6.38 gives the total proteins.

Detection of Added Water.-One of the most difficult problems which eomes to the food and drug analyst is that of determining whether a sample of low standard milk is such because it comes from a variety of cows normally giving such low standard milk or whether the deficiency in quality is due to the addition of water. In determining this question the use of the Zeiss immersion refractometer is of the greatest assistance. This method of analysis was first thoroughly investigated by Leach and Lythgoe' of the Food and Drug

${ }^{1}$ Report of the State Board of IIealth of Mass., 1903, p. 483. 
Department of the Massachusetts State Board of Health. "The construction of this instrument is such that, as its name implies, it may be direetly immersed in a solution, the degree of refraction of which, within limits, may be determined upon an arbitrary scale." Fig. 5 shows this instrument. ${ }^{1}$

The use of this method, as now embodied in the practice of the Association of Official Agrieultural Chemists, is as follows": "To 100 cubie centimeters of milk at a temperature of about $20^{\circ} \mathrm{C}$. add 2 cubie centimeters of 25 per eent. acetic acid (sp. gr. 1.0350) in a beaker, and

FIG. 5.

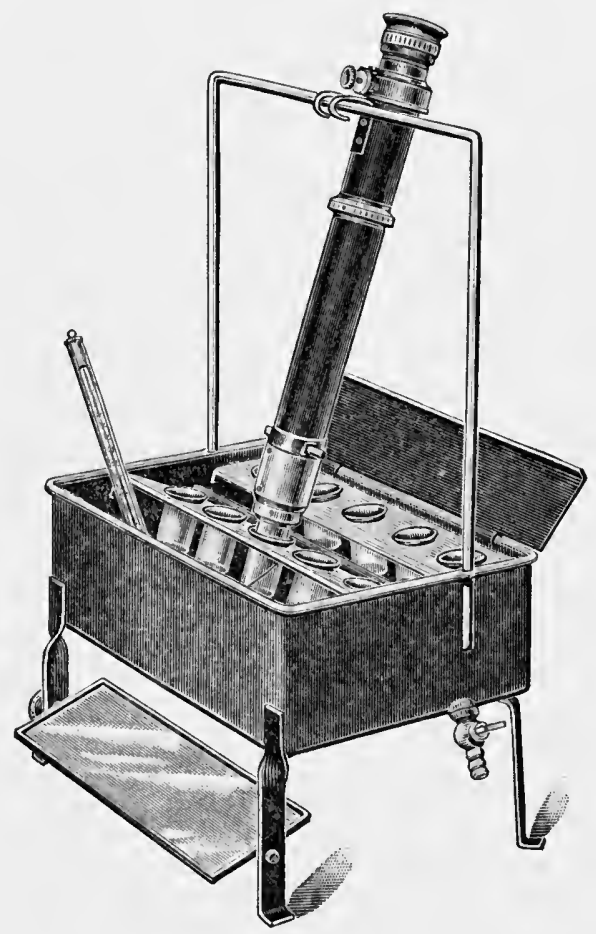

Zeiss' immersion refractometer.

heat the beaker, covered with a watch-glass, in a water-bath for twenty minutes at a temperature of $70^{\circ} \mathrm{C}$. Then place the beaker in ice water for ten minutes, and separate the curd from the serum by filtration through a 12.5-centimeter plaited filter.

"Transfer about 35 cubic centimeters of the serum to one of the beakers that aecompanies the eontrol-temperature bath used in eonnection with the Zeiss immersion refractometer, the bath being of the type

1 For a detailed description of this instrument the reader is referred to the Journal of the American Chemical Society, Vol. XXVI., October, 1904.

${ }^{2}$ Report of the State Board of Health of Mass., 1906, p. 383. 
with openings in the top for ten beakers. Place the beaker in one of the openings, use the gromnd glass strip at the bottom of the bath, and by means of the regular refractometer heater or similar device maintain a constant temperature of exactly $20^{\circ} \mathrm{C}$. in the water surrounding the beaker, using a delicate thermometer, reading to tenths of a degrce. Immerse the end of the refractometer in the serum in the beaker, and when the temperature is exactly $20^{\circ} \mathrm{C}$. take the reading on the seale.

"If the temperature varies from $20^{\circ} \mathrm{C}$., the reading may be calculated on that basis by means of a correction table. A reading below 39 indicates added water, between 39 and 40 the same is suspicious."

Another method for the detection of added water in milk depends upon being able to show abnormal chemical or physical constants which ean be explained only by the addition of water, there being no test which will distinguish between the water which may be added to the milk and the water naturally present. It is incumbent, therefore, upon persons engaged in the chemical examination of milk to become familiar with the chemical and physical properties of milk of known purity.

A study of the published analyses of milk shows an extreme variance, yet if we study the methods of analysis in connection with the figures, a great deal may be explained by incorrcetness of the methods then in use. In general, all milk completely drawn from healthy cows will vary between the following limits: ${ }^{1}$

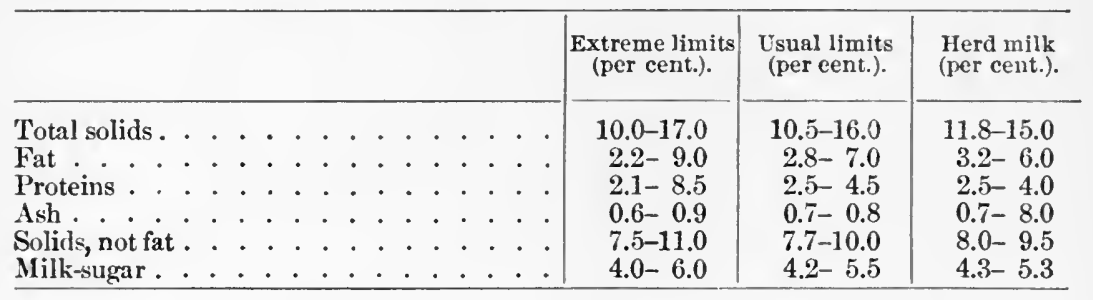

If we depend upon the solids, fats, or proteins to indicate added water, it is evident that considerable adulterated milk will cscape detection, but if a minimum figure is employed for ash, solids, not fat or sugar, more adulterated milk will be discovered. The most successful methods for the detection of added water are based upon the milk-sugar content, and for this purpose it is usual to prepare a'milk serum, because the most variable constituents (the fat and the proteins) remain in the curd, while the serum will contain the sugar and the ash, which are the least variable. The serum may be prepared by allowing the sample to sour spontaneously, ${ }^{2}$ by heating with acetic acid ${ }^{3}$ or calcium chloride, ${ }^{4}$ or by treating in the cold with asaprol citric acid solution ${ }^{5}$

1 Personal communication from H. C. Lythgoe, Chemist, Food and Drug Department, Mass. State Board of Health.

2 Matthes and Miiller, Zeit. öflentl. Chem., X., 173.

${ }^{3}$ Leach and Lythgoe, Jour. Amer. Chem. Soc., XXVI., 1195.

- Ackerman, Zeit. Nahr. Genussm., XIII., 369.

5 Baier and Neumann, Zeit. Nahr. Genussm., XIII., 369. 
or eopper sulphate. ${ }^{1}$ The copper sulphate method used in the food inspection laboratory of the Mass. State Board of Health is as follows :

"Dissolve 72.5 grams of erystallized copper sulphate in water and dilute to 1 liter. This solution should be adjusted, if necessary, so that it will refract at 36 on the seale of the Zeiss immersion refractometer at $20^{\circ} \mathrm{C}$, or have a specific gravity of 1.0443 at $20^{\circ} \mathrm{C}$, , compared with water at $4^{\circ} \mathrm{C}$. To one volume of the copper solution add four volumes of sweet milk, shake well, and filter. The filtrate will usually be clear after the first few drops have passed through. A determination of the refraction or specific gravity may be made upon the clear serum, and if below the minimum for pure milk the sample may be deelared watered.

"If the sample is sour it should be filtered and determinations of refraction, specific gravity, or ash made upon the serum."

The examination of 412 samples of milk of known purity from individual cows, 361 being obtained by the Massachusetts State Board of Health, and 51 being examined in the New Jersey Board of Health, gave the following results:

The samples varied in total solids from 17.17 per cent. to 10.12 per cent., in fat from 7.7 per cent. to 2.35 per cent., in solids not fat from 10.65 per cent. to 7.55 per cent.

The refractions of the copper serum were found to be between the following limits :

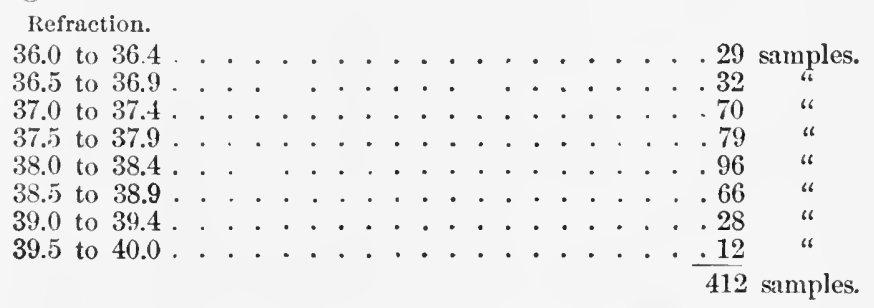

The examination of the milk of 28 herds of cows gave the following results :

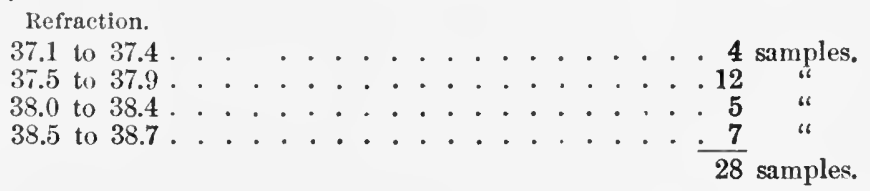

It is not necessary to possess a refractometer in order to examine serum ; in fict, it is a waste of money to purchase one if it is to be used for no other purpose, or unless so many samples are to be examined each day that the saving in time would more than offset the price. The specific refraction of the copper serum $\frac{n^{2}-1}{n^{2}+2} \cdot \frac{1}{d}$ is not exactly a constant, decreasing slightly as the refraction grows less, but it is sufficiently uniform for refraction values between 34 and 38 , that if we

1 Lythgoe, Report Mass. State Board of Health, 1908. 
know the refraction at $20^{\circ} \mathrm{C}$. we may calculate the specific gravity at $20^{\circ} \mathrm{C}$. compared with water at $4^{\circ} \mathrm{C}$. by the formula-

$$
\frac{n^{2}-1}{n^{2}+2} \cdot \frac{1}{d^{20}}=0.20526
$$

The value of $n_{\mathrm{p}}$ corresponding to the scale reading of 36 on the immersion refractometer is 1.34124 . Substituting in the above formula we find that $d_{4^{\circ}}^{200}=1.0245$; therefore, if a refraction less than 36 indicates added water, the same may be said of a specific gravity less than 1.0245 at $20^{\circ} \mathrm{C}$. referred to water at $4^{\circ} \mathrm{C}$.

The relation between the refiaction and gravity of the serum from spontaneously soured milk is expressed by the formula-

$$
\frac{n^{2}-1}{n^{2}+2} \cdot \frac{1}{d^{200}}=0.20607 \text {. }
$$

As $38.3^{1}$ represents the lowest refraction at $20^{\circ} \mathrm{C}$, the lowest gravity at $\frac{200}{4} \mathrm{C}$. is 1.0229 .

For the purpose of studying the influence of added water upon milk a sample of milk above the average in solids not fat and refraction was obtained, and to this sample water was added in varying amounts. The samples were then analyzed and the results appear in the following table:

Composition of a Sample of Milk Systematically Watered.

\begin{tabular}{c|c|c|c||c|c|c|c}
\hline & & & \multicolumn{4}{|c}{ Copper serum. } \\
$\begin{array}{c}\text { Added } \\
\text { water } \\
\text { (per cent.). }\end{array}$ & $\begin{array}{c}\text { Solids } \\
\text { (per cent.). }\end{array}$ & $\begin{array}{c}\text { Fat (per } \\
\text { cent.). }\end{array}$ & $\begin{array}{c}\text { Solids not } \\
\text { fat (per } \\
\text { cent.). }\end{array}$ & $\begin{array}{c}\text { Refraction, } \\
20^{\circ} .\end{array}$ & $\begin{array}{c}\text { Specific } \\
\text { grarity, } \\
20^{\circ}\end{array}$ & $\frac{n^{2}-1}{n^{2}+2} \cdot \frac{1}{a}$ & $\begin{array}{c}\text { Solids (per } \\
\text { cent.). }\end{array}$ \\
\hline 0 & 13.18 & 4.20 & 8.98 & 38.5 & 1.0272 & 0.20529 & 6.09 \\
10 & 11.86 & 3.78 & 8.08 & 36.4 & 1.0249 & 0.20526 & 5.57 \\
20 & 10.54 & 3.36 & 7.18 & 34.4 & 1.0233 & 0.20523 & 5.05 \\
30 & 9.23 & 2.94 & 6.29 & 32.4 & 1.0211 & 0.20520 & 4.56 \\
40 & 7.91 & 2.52 & 5.39 & 30.6 & 1.0194 & 0.20518 & 4.10 \\
50 & 6.59 & 2.10 & 4.49 & 28.6 & 1.0174 & 0.20516 & 3.54 \\
\hline
\end{tabular}

A study of the above table shows that each 5 per cent. of added water lowers the refraction by one scale division, and, therefore, in order to detect 10 per cent. of added water in milk the milk before watering must give a serum refracting below 38 .

Detection of Added Coloring Matters.-Annatto.-To about 100 cc. of milk in a cylinder abont 1.5 inehes in diameter, add a few cc. of sodium carbonate solution, to insure a strongly alkaline reaction during the examination, and then introduce a strip of heavy white filter-paper about 0.5 by 5.5 inches, and set the whole away in a dark place over night. If any annatto color is present, it will, through selective affinity, pass from the milk to the fibre of the paper, which thereby acquires a salmon tint, the depth of which is dependent naturally upon the amount of the substance present. The strip is withdrawn from the

1 Lowest of 125 known purity samples. 


\section{PLATE IV}

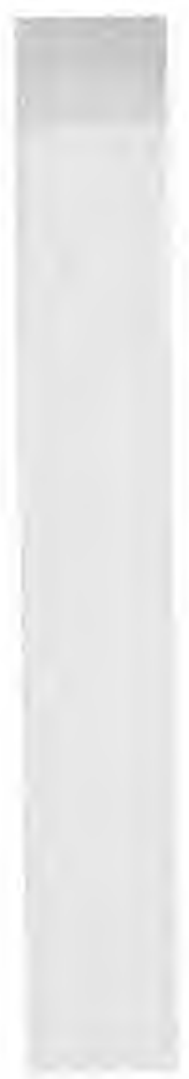

A

A. Strip of Filter Paper Dyed hy Immersion in Milk Colored with Annatto.

B. Same after. Treatment with Solution of Protochloride of Tin. 



\section{PLATE V}
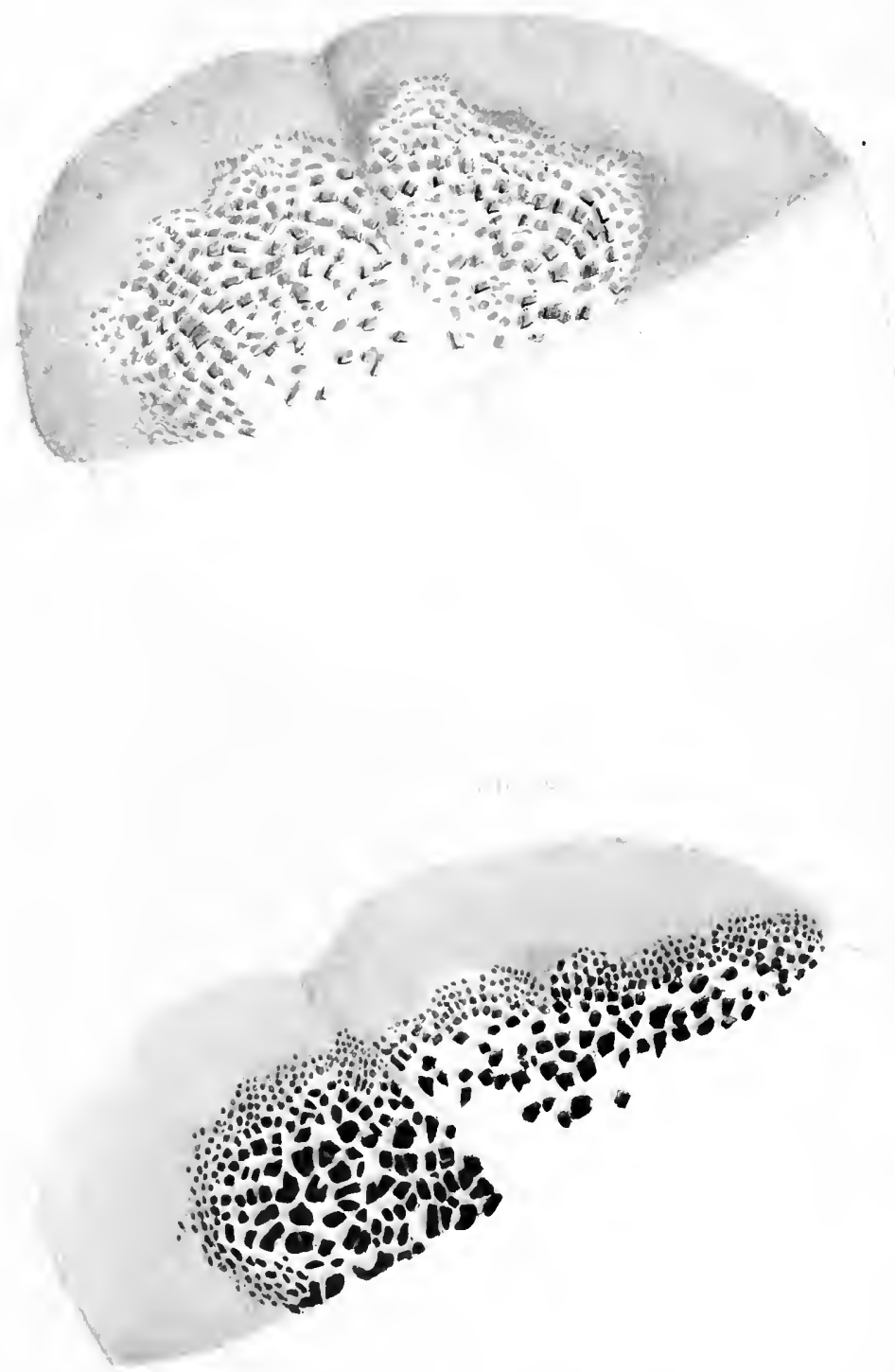

milk, washed gently in running water, and laid upon a piece of paper of the same kind as itself. If so much as 1 part of the annatto solution in 100,000 is present, the strip will show a distinet salmon tint. On dipping the strip into stannous chloride solution the color is changed to pink.

Another method, by means of which all the color in the amount of milk operated upon may be concentrated in a form best adapted for preservation and for exhibits in court, is as follows: Coagulate from 100 to $150 \mathrm{cc}$. of the specimen by the application of heat and acetic acid, and separate the coagulum by straining through a piece of eheesecloth. The coloring matter, being insoluble in acid media, is precipitated with the curd, which, however, will show to the eye scarcely any indication of its presence. The curd is placed in a mortar and triturated with 50-75 ce. of ether, which next is transferred to a stoppered separating fumnel and shaken with 10 ce. of a 1 per cent. solution of caustic soda. When the two liquids become separated, the latter, which now contains the annatto color, is drawn off into two porcelain or glass dishes about an inch in diameter, in each of which a disk of filter-paper is placed. They are then set aside in the dark and left over night. The disks are then removed and washed in fresh water. If annatto is present, they will have acquired a color varying in depth aceording to the amount of the dye in the sample. One disk is immersed in stannous ehloride solution, the other in weak sodium carbonate, and then dried and mounted on a white card. The colors yielded by a specimen of milk to which no unusual amount of the adulterant has been added are shown in Plate IV.

Caramel.-Pour 125 to 250 ec. of the suspected sample into an equal volume of 95 per eent. alcohol, and filter. The filtrate, if not perfeetly clear, should be returned and passed throngh until it is quite free from turbidity. Any caramel present will be in solution in the alcoholic filtrate, and may modify considerably its color, which normally is yellowish or greenish according to season, the latter obtaining in spring and summer. To $100 \mathrm{ec}$. of the filtrate add 2 ee. of solution of basic acetate of lead, which will preeipitate the caramel together with any remaining proteids, the precipitate showing a slight brownish color if caramel has been used in sufficient amount to bring about the improved appearance which is the object of its employment. Filter, wash with distilled water, and dry in an air-bath. Aecording as the amount of earamel present is large or small, the horny residue on the filter-paper will have a more or less deep ehocolate tinge. The residue yielded by a pure milk will be either almost colorless, or vellow, or slightly inclined to brownish, but not to ehocolate color. The appearance of the two kinds of residue is slown in Plate $\mathrm{V}$.

Caramel may also be shown if we proceed aceording to the second method deseribed for the deteetion of ammatto. The curd, after being freed from the whey and triturated with ether, gives up to this solvent only fat and annatto. If caramel or anilins are present, the eurd will appear brownish in the one ease and more or less intensely yellow in 
the other. If the curd is now shaken with hydrochloric acid, one of the following changes will be olsserved: If anilin-orange is present, the color becomes bright pink almost immeliately; with caramel it becomes gradually brownish blue; if neither is present, the change is to blue.

Anilin-orange.-See preceding paragraph. A more direct method is proposed by Lythgoe. ${ }^{\prime}$ Place 15 ce. of milk in a porcelain dish and add about the same volume of hydrochloric acid (specific gravity 1.200). Agitate gently, to bring about thorough mixing and to break up the resulting eurd into rather coarse lumps. If anilin-orange is present, the curd will be eolored pink; if none is present, it will be white or yellowish.

Detection of Preservatives.-Borax and Boric Acid.-These substances are detected easily either in the milk itself or in the ash after ignition of the residue. In the latter case, moisten the ash with a drop or two of strong sulphurie acid, and after a few minutes add 3 or 4 ce. of strong alcohol. Dip a strip of turmeric paper into the mixture and allow it to dry without the aid of heat. In the presence of either of the substances sought for, the paper will have, when dry, the characteristic red color due to boric acid, instead of the yellow color which will be maintained in its absence. While the paper is drying, place the dish in a dark place and ignite the contained alcohol. If boric acid or its sodium compound is present, the flame will show at its outer edge a characteristic greenish coloration. This is shown most strongly directly after the alcohol is ignited.

In the original milk, the test may be made in the following manner: Mix a few drops of the milk and an equal amount of fresh tincture of turmeric in a small porcelain dish and evaporate on a water-bath to dryness. Moisten the surface of the residue with dilute hydrochloric acid, and dry again. If either of the substanees is present, the residue will be light pink to dark red in color, and the addition of a drop of ammonia-water will change this to a green or greenish bluc, according to the amount of the preservative present.

Salicylic Acid.-1. Coagulate about 75 to 100 cc. of milk with mereuric nitrate solution or hydrochloric acid, and separate the whey by filtration. Shake the whey with ether, decant the ether into a wateh-glass, and allow it to evaporate. To the residue on the watehglass, apply a drop of nentral ferric chloride. If salicylie acid is present, the characteristic purple coloration is produced. 2. Mix the milk with phosphoric acid and strain through cloth. Place the liquid in a flask, connect with a eondenser, and distil. Test the distillate with ferric chloride from time to time. Any salicylic acid present will go over with the steam, most of it toward the end of the operation.

Formaldehyde.-Many processes for the detection of this substanec in milk have been devised, some exceedingly simple and others quite complicated. Those which give the best results and the greatest satisfaction are, on the whole, those which are the simplest in application

${ }^{1}$ Report of Massachusetts State Board of Health for 1900, p. 647. 
and require the least expenditure of time. The test should be applied within a few days after the addition of the preservative, since after a time it cannot be detected.

1. Method by Decolorized Fuchsine.-Through a solution of fuchsine $1: 500$ pass a current of sulphurous acid gas, obtained by heating copper wire or foil with sulphuric acid, until the color is discharged. Preserve in a glass-stoppered bottle. To $10 \mathrm{cc}$. of milk, add $1 \mathrm{cc}$. of the reagent and let stand ten minutes. Add 2 ec.' of strong hydrochloric acid and shake or stir briskly. The color which appears in the first instance is discharged completely by the acid if no formaldehyde is present; otherwise, a violet-blue tinge remains. If the amount present is large, the end color will be correspondingly intense. This method will detect the admixture of 1 part of formalin in 50,000 of milk. If the milk be distilled first, and the first part of the distillate treated with fuchsine solution, the test is delicate to the extent of revealing 1 part in 500,000 .

2. Method by Phloroglucin.-Add to 10 ec. of milk in a testtube 2 or 3 ce. of a 0.10 per cent. solution of phloroglucin and 5 to 10 drops of a 10 per cent. solution of sodium hydrate, and shake. In the presence of formaldehyde a gradual red coloration appears; otherwise, no such change is observed. This test is said to reveal 1 part in 50,000, but such a claim appears, according to the experience of the author and others, not to be justified.

3. Metriod by Ferric Chloride.-Mix in a porcelain dish 10 ce. each of milk and hydrochloric acid (specific gravity 1.200) and 1 drop of ferric chloride solution. Heat and stir vigorously. If formaldehyde has been added, a violet color will appear before the boiling-point is reached, varying in intensity according to the amount present. This process is exceedingly delicate, and will detect 1 part in 500,000 in the fresh condition.

4. Metion by Commercial Sulphuric Acid.-This test is exceedingly delicate and very easily applied. It cannot be performed with pure sulphuric acid, since the presence of a trace of iron is necessary. If one desires to use a pure acid rather than the ordinary eommercial grade, the addition of a very small amount of ferric chloride will be sufficient.

Take about 15 to $20 \mathrm{cc}$. of milk in a test-tube and pour about $5 \mathrm{cc}$. of the acid gently down the side so that it shall pass under, rather than mix with, the milk. Let stand a few minutes, and then note the color at the junction of the two liquids. If formalin is present, even in the slightest traces, a violet coloration appears at the line of junction. Inasmuch as pure milk will show a somewhat purplish color when in contact with strong sulphuric acid, a color which may readily be mistaken at first for that due to formaldehyde, and since also the charring that occurs at the line of junction will often obscure the reaction, the process as originally recommended is somewhat fiulty. The objections are removed, however, by diluting the strong acid with water so that its specific gravity is reduced from 1.840 to 1.700 . The action of the 
stronger acid on pure milk is shown in Plate VI., Fig. 1, which shows the dark eolor due to charring and the purplish color, above spoken of, due to the same cause.

In Plate VI., Fig. 2, is shown the appearance of the line of junetion of pure milk and the diluted aeid. It will be observed that the color produced is but a faint yellow. In Plate VI., Figs. 3 and 4, are shown the zones produced in milk eontaining formallehyde in the proportions of 1 part to 25,000 and 1 to 50,000 by the use of the diluted acid. As may be inferred, the reaction is produced rather more slowly with the weaker acid. It is best to allow the eontact to continue at least an hour before noting a negative result.

5. Luebert's ${ }^{1}$ Method by Potassium Sulphate.-Place 5 grams of coarsely powdered potassium sulphate in a 100 ce. flask and distribute over it 5 ce. of milk by means of a pipette. Then pour carefully down the side of the flask 10 ce. of sulphuric acid (specific gravity 1.840 ), and allow the whole to stand quietly. If formaldehyde is present, a violet coloration of the potassium sulphate occurs within a few minutes, and gradually diffinses through the entire liquid. If none is present, the mixture will at once assume a brown color, which rapidly changes to blaek. This test is sensitive to 1 part in 250,000 .

Chromates.-Froidevanx ${ }^{2}$ recommends dissolving the ash of about 10 cc. of milk in a few drops of water acidulated with nitrie acid and, after nentralizing with magnesium carbonate, adding a few drops of testsolution of nitrate of silver, whereby a red precipitate, chromate of silver, is formed. As a control test, he recommends taking up another portion of ash with water acidulated with sulphurie aeid, and adding little by little tincture of guaiaeum. In the presenee of ehromates, an intense blue color is produced, which disappears very quiekly. This process will detect 1 part in 50,000. Guerin ${ }^{3}$ claims greater delicacy for the following method: To 5 or $10 \mathrm{cc}$ of milk add 2 drops of a 1 per eent. solution of sulphate of copper and 2 or 3 drops of freshly prepared tincture of guaiacum. Pure milk gives a greenish eolor, while milk containing 1 part in 100,000 will give an intense blue, which reaches its maximum in a few minutes.

Methods of Distinguishing between Raw and Cooked Milk.-To determine whether or not milk has been cooked, Saul ${ }^{4}$ recommends the addition of $1 \mathrm{ce}$. of a 1 per cent. solution (fresh) of ortol (Orthomethylaminophenol sulphate) to $10 \mathrm{ec}$. of milk, and then 1 drop of eommercial hydrogen peroxide solution. Raw milk develops a red color almost inmediately, but milk heated beyond $75^{\circ} \mathrm{C}$. remains unehanged.

Dupouy ${ }^{5}$ gives the following tests:

1. Guaiacol. Equal volumes of milk and a 1 per cent. solıtion of guaiaeol in water are mixed and then treated with hydrogen peroxide.

' Journal of the American Chemical Society, September, 1901, p. 682.

2 Journal de Pharmacie et de Chemie, 1896, p. 155.

${ }^{3}$ Chemiker Yeitung, 1897, p. 174.

4 British Medical Journal, March 24, 1903.

5 Journal de Pharmacie et de Chemie, 1897, p. 397. 


\section{PLATE VI}

Fir. 1

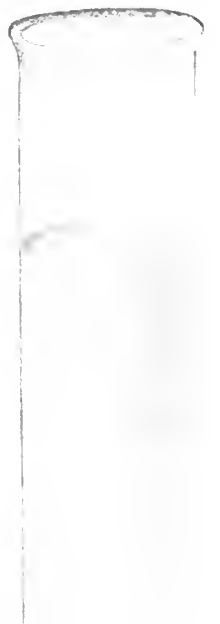

$+$
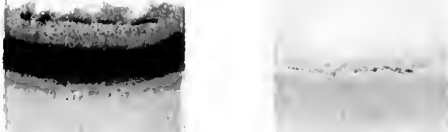

FIC. 3

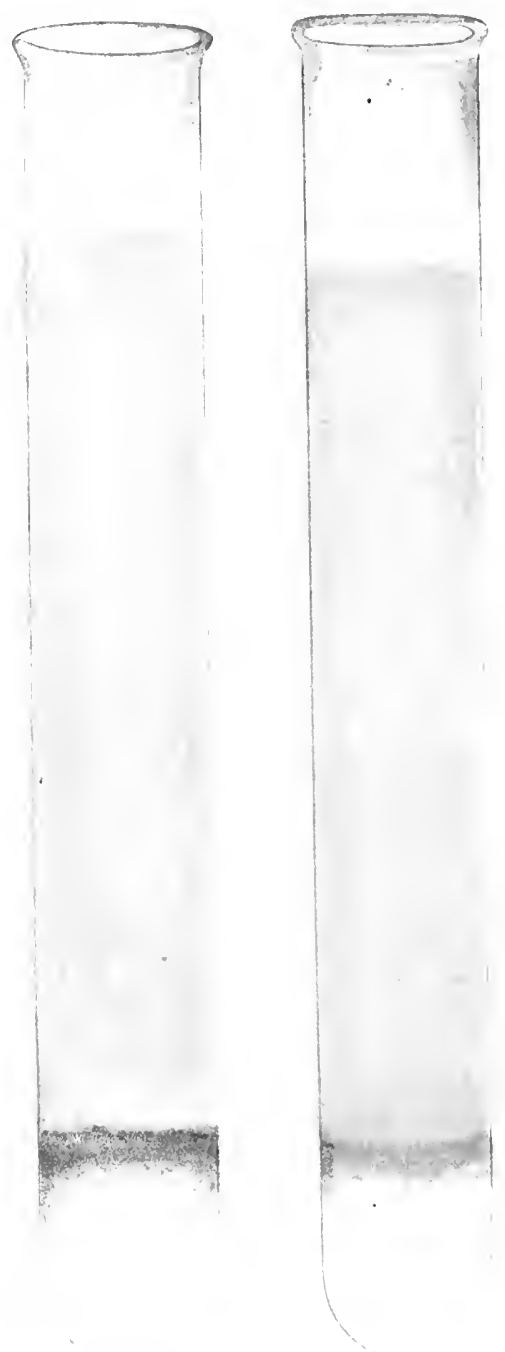

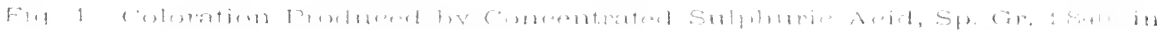

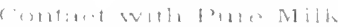

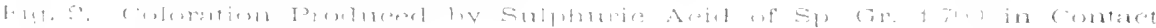
wilh lilt. NI!li

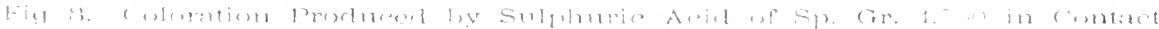

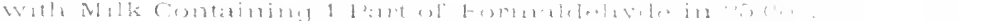

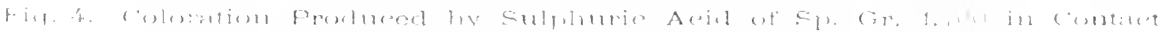

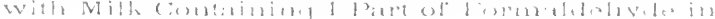



The immediate production of a yellow color indicates that the speeimen has not been boiled.

2. Hydroquinone. Three ee. of milk are mixed with 1 ce. of a fresh 10 per cent. aqueous solution of hydroquinone and 15 drops of hydrogen peroxide. If the milk has not been boiled, a rose color immediately appears, and in a few minutes green crystals are deposited.

3. Pyrocatechin. Equal volumes of raw milk and an aqueous 10 per cent. solution of pyroeatechin are brought together and treated with hydrogen peroxide. With raw milk a yellowish-brown color is produced ; with boiled milk no eolor appears.

4. $\alpha$-Naphthol. Raw milk gives with an aqueous solution of $a$-naphthol and hydrogen peroxide a violet-blue color. Boiled milk gives none.

Storch's method ${ }^{1}$ is as follows : To 10 ec. of milk, add 1 drop of a 0.2 per cent. solution of hydrogen peroxide and 2 drops of a 2 per cent. solution of $\mathrm{p}$-phenylenediamin and shake violently. If the milk has not been heated to $78^{\circ} \mathrm{C}$. $\left(172.4^{\circ} \mathrm{F}\right.$.), an immediate blue color will appear; if it has been heated to $80^{\circ} \mathrm{C} .\left(178^{\circ} \mathrm{F}\right.$.), the blue color appears in about a half minute; and if it has been heated higher than this, the blue will not appear at all. Sour milk should be neutralized with lime-water. Formaldehyde prevents the change to blue, but permits the oceurrence of a faint red. The p-phenylenediamin solution keeps, in dark glass, about two months.

Bernstein ${ }^{2}$ proposes the following: To 50 ec. of milk, add 4.5 ec. of normal acetie aeid, shake gently until eoagulation oecurs, and filter. Heat the filtrate. If the milk has not been pasteurized, a heavy precipitate of lactalbumin will form. The higher the milk has been heated, up to $90^{\circ} \mathrm{C}$. $\left(194^{\circ} \mathrm{F}\right.$.), the smaller will be the preeipitate; and if it has been heated beyond this, no precipitate at all will form.

Detection of Gelatin in Cream.-For the detection of gelatin in eream, to which it sometimes is added to give it body, Stokes ${ }^{3}$ recommends the following procedure: Dissolve a quantity of mereury in twice its weight of strong nitric acid (specifie gravity 1.420); dilute with water to 25 times its bulk. To about $10 \mathrm{ec}$. of this solution add a like quantity of the eream and about 20 ce. of eold water. Shake the mixture vigorously, let stand for five minutes, then filter. If much gelatin be present, it will be impossible to get a elear filtrate. To the filtrate, or to a portion of it, add an equal bulk of a saturated aqueons solution of pierie acid. If gelatin be present, a yellow preeipitate will immediately be produeed. The whole operation is performed in the cold, and if the mercury solution is ready, the test will not take more than ten minutes. Pierie acid will show the presence of 1 part of gelatin in 10,000 parts of water.

1 Zeitschrift für Untersuehung der Nahrungs- und Genussmittel, 1901, p. 898,

${ }^{2}$ 'Teitsehrift für Fleisch- und Milchbygiene, 1900, p. 80.

\$ The Analyst, December, 1897. 
Detection of Sucrate of Lime in Cream.-Lythgoe's modification of Baier and Neuman's test for detecting sucrose, as given by Leach ${ }^{1}$ is as follows:

"To 25 ce. of milk or cream, add 10 ce. of a 5 per cent. solution of uranium acetate, shake well, allow to stand for 5 minutes, and filter. To 10 ec. of the clear filtrate (in the case of cream use the total filtrate, which will be less than $10 \mathrm{cc}$.) add a mixture of $2 \mathrm{cc}$. saturated ammonium molybdate and 8 cc. dilute hydrochloric acid (1 part 25 per cent. acid and 7 parts water), and place in a water-bath at a temperature of $80^{\circ} \mathrm{C}$. for 5 minutes. If the sample contains sugar, the solution will be of a Prussian blue color. This should always be compared in a calorimeter with the standard Prussian blue solution, prepared by adding a few drops of potassium ferrocyanide to a solution of 1 cc. of 1 per cent. ferric chloride in 20 cc. of water."

\section{BUTTER.}

United States Standard.-Standard butter contains not less than 82.5 per cent. of butter fat. By acts of Congress, approved August 2, 1886, and May 9, 1902, butter may also contain added coloring matter.

This valuable milk product is the result of violent agitation of cream until its fat coalesces into granular particles, which are then separated from the residual buttermilk, "worked" to expel as much of the latter as possible, and, with or without the addition of salt and coloring matter, formed into "prints" or "pats," or packed in bulk in boxes and firkins. Its natural color varies with the season, the so-called June butter, made when the cows from whose milk it is produced are feeding on grass, being bright yellow, while that made when they are stalled, and fed on hay and other winter feed, being almost white. The popular demand being for a yellow article the year round, it is customary to secure this color out of season by the addition of annatto and other harmless vegetable coloring agents, the use of which has almost universally the sanction of law.

The flavor is influenced much by the character of the feed, by the care excreised in manufacture, by the amount of added salt, by age, and by the conditions of storage. Like milk, it absorbs odors very readily, both those which improve and those which impair its flavor. Taking advantage of this fact, it is the custom in the valley of the Var and in some other localities to place the freshly made product in proximity to jismine, violets, tuberoses, and other flowering plants, in order that their fragrance may be absorbed. This practice is known as " enfleurage." The most delicately flavored butter under natural conditions is that to which no salt has been added, but it has the disadvantage that within a short time it acquires a "cheesy" flavor, due to dccomposition processes. Owing to its lack of keeping qualities and to the very general preference for a more pronounced taste, the addi-

${ }^{1}$ Food Inspection and Analysis, 1909, p. 197. 
tion of salt in varying amounts is the rule. Butter of good quality has but slight odor, but that which has undergone the common ehanges due to bacterial action has the eharacteristie odor and taste of rancidity. This is due to decomposition of the small amount of curd which is entangled in the making, and which cannot wholly be excluded. The fat itself, when separated from the eurd by melting, keeps unchanged for long periods. In raneid butter, bntyrie and other acids are liberated, and others, as formic, are formed by absorption of oxygen. Under some unusual conditions not wholly understood, butter, without becoming raneid in the usual sense, undergoes a change to a perfectly white substance with a marked tallowy odor.

Butter varies eonsiderably in composition, but a fair average may be stated as follows:

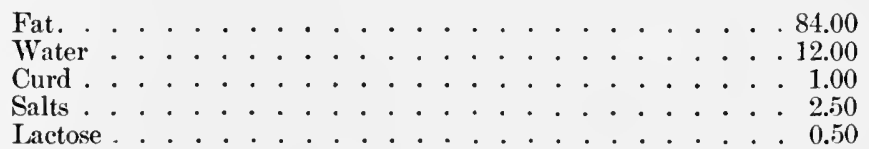

It may be made to contain a much higher pereentage of water, with correspondingly less fat.

The fat is composed of glycerides of two groups of fatty acids, which have been mentioned in the deseription of milk. Those of the insoluble non-volatile acids, oleie, stearie, and palmitic, constitute about 92.25 per cent. of the whole; and those of the soluble volatile acids, butyric, caproie, caprylie, and caprie, make up the remainder. It is to the seeond group that butter owes its distinetive flavor.

The amount of water depends largely upon the thoroughness with which the buttermilk is worked out. In order that more water may be held, and thus a greater profit realized, some makers employ gelatin as an adulterant. One gram of this substance will take up about 10 grams of water, and, when mixed with butter in the right proportion, will hold water in the above ratio without affeeting the eonsistenee injuriously. Others employ glueose both for this purpose and as a preservative.

The salts include those natural to milk and those alded for the prevention of rapid decomposition. The usual addition is eommon salt, but the use of borie aeid and horax is extending gradually.

Apart from the use of preservatives and of agents to assist in retaining water, butter is not much subject to adulteration, excepting in the sense that substitution of an article of less value when butter is called for is a form of adulteration. This substitute is known variously as artificial butter, butterine, oleomargarine, and margarine. Under the United States statutes, all butter or substitutes therefor made to resemble it, containing fats other than eream, shall be known as oleomargarine.

Following the original process, oleomargarine is made from fresh beef suet, whieh, after being eooled, washed, and cut into very fine pieces by machinery, is subjected to a temperature of abont $110^{\circ} \mathrm{F}$. 
for several hours, in order to separate the fat from the tissue. It is then drawn off and kept for a time at $80^{\circ}$ to $90^{\circ} \mathrm{F}$, at which temperature the stem rin solidifies, and then is separated by pressure from the "oleo-oil." The latter is chumed with milk or with milk and genuine butter, colored with annatto, and otherwise treated like butter. At the present time, oleomargarine is made not alone from beef suet, but to a much greater extent from " neutral lard," a product of leaf lard. Cotton-seed oil is used to some extent, but naturally it is not so well adapted to the purpose as the solid fats.

Oleomargarine has been misrepresented to the public to a greater extent probably than any other article of food. From the time of its first appearance in the market as a competitor of butter, there has been a constant attempt to create and foster a prejudice against it as an unwholesome article made from unclean refuse of varions kinds, a vehicle for disease germs, and a disseminator of tapeworms and other unwelcome parasites. It has been sail to be made from soap grease, from the carcasses of animals dead of disease, from grease extracted from sewer sludge, and from a variety of other articles equally unadapted to its manufacture. The publication of a great mass of untruth cannot fail to have at least a part of its desired effect, not solely on the minds of the ignorant, but even on those of persons of more than average intelligence. So a prejudice was ereated against this valuable food product, but it is becoming gradually less pronounced.

The truth concerning oleomargarine is that it is made only from the clcanest materials in the eleanest possible manner; that it is equally as wholesome as butter; and that when sold for what it is and at its proper price it brings into the dietary of those who camnot afford the better grades of butter an important fat food much superior in flavor and keeping property to the cheaper grades of butter, which bring a higher price. Oleomargarine cannot be made from rancid fat, and in its manuficture great care must be exercised to exclude any material however slightly tainted.

Oleomargarine is not and cannot be made from fats having a marked or distinctive taste, and its flavor is derived wholly from the milk or genuine butter employed in its manuficture. It contains, as a rule, less water than does genuine butter, and consequently any difference in food value is in its favor. It undergoes decomposition much more slowly, and, indeed, may be kept many months without becoming rancid. Much has been said concerning its digestibility, and alarmists have gone so far as to elaim that it is very indigestible, and likely to prove a prolific cause of dyspepsia, quite forgetting that the materials from which it is mate have held a place in the dietaries of all civilized peoples sinee long before butter was promoted from its position as an ointment to that of an article of food. Many comparative studies have been made on this point, and the results in general have shown that there is little if any difference. H. Lührig ${ }^{1}$ has proved by careful experiment that the

${ }^{1}$ Zeitschrift fül Untersuchung der Nahrungs- und Genussmittel, June, 1899, p. 484. 
two are to all intents and purposes exactly alike in point of digestibility.

Oleomargarine has becn the subject of a vast amount of restrictive legislation wherever it is made or sold. This has been passed in the interest of dairymen and because of the ease with which it may be sold fraudulently as butter at butter prices. To the practice of fraud in its retail sale, is due very largely the passage of prohibitive laws, many of which, however, have been declared unconstitutional. In Massachusetts, for example, it had at one time a very large sale, and in the eity of Boston alone were nearly 200 licensed dealers. But the amount of fraudulent dealing was so great that the Legislature passed an act prohibiting its sale if it contained any ingredient causing it to look like butter; in other words, no annatto or other substance which would eause it to be yellow could be used in its manufacture. Since its natural color is almost white, and since white butter does not appeal to the eye, the resnlt was practically the withdrawal of the article from open sale.

In Germany, on account of fraudulent practices in the adulteration of butter with oleomargarine, the government passed, in 1897, a statute requiring the latter to contain 10 per cent. of oil of sesame, so that any subsequent admixture with butter may readily be detected by Bandouin's reaction. This is a red coloration brought about when oil of sesame, furfurol, and liydrochloric acid are brought together ; and it is sufficiently delicate to show the adulteration of butter with 2.5 per cent. of oleomargarine containing the oil in the proportion stated. Experiment has shown that butter made from the milk of cows fed on sesame does not yield the reaction, but the fat of the nilk of goats fed partly on sesame has been found to give it.

The principal chemical difference between butter and oleomargarine lies in the relative amounts of glycerides of the soluble and insoluble fatty acids. Genuine butter-fat contains nearly 8 per cent. of butyrin, caproin, caprin, and euprylin, while the artificial product contains these glycerides only as they are introdnced in the amount of milk or butter with which it is churned, for they are not present in suct, lard, and other animal fats.

Of late years, high-grade butter has found another formidable competitor in what is known varionsly as renovated butter, process butter, and hash butter. The material from which this is made is gathered from dairies seattered over a wide expanse of country, and differs widely in color, texture, age, and flavor. It is melted, purified of its rancidity by wishing, given the desired yellow eolor, and rechurned.

Butter as a Carrier of Disease.-Since milk is known to be a carrier of the germs of certain diseases under some conditions, the possibility that butter may act in the same way snggests itself, and the more strongly since, in ordinary creaming of milk, all but a very small proportion of the bacteria rise with the cream. Ordinary butter contains millions of bacteria to the gram, but whether the pathogenic forms can long survive has not been investigated very extensively, exeept in the 
case of the bacillus of tuberculosis. The bacteria of cholera and typhoid fever have been known to survive several days after being planted in butter, but beyond this we have little knowledge.

Brusaferro, in 1891, produced tuberculosis in a rabbit through the injection of butter made from the milk of a cow with a tuberenlous udder. Roth, in 1894, got similar results, and found, moreover, that 2 out of 20 market samples of butter used by him yielded positive results. Schuchardt got negative results from 42 samples, while Obermüller fonnd the bacillus in every sample of Berlin butter used in his first series of experiments. Dr. Lydia Rabinowitsch ${ }^{1}$ examined 80 samples obtained partly in Berlin and partly in Philadelphia, and found genuine tuberele bacilli in not a single instance. She did, however, find a spurious organism, which produced in guinea-pigs changes which required very careful examination for the determination of its nontuberculous character. It was present in 28.7 per cent. of the samples. Petri ${ }^{2}$ found it in 37.2 per cent., the genuine bacillus in 32.4 per cent., and neither the one nor the other in 30.4 per cent. Obermüller, ${ }^{3}$ using salted butter in a sceond series, determined that the injection of the butter-fat itself introduced a cause of irritation, and used, therefore, in his next set the watery fluid separated from the butter by heat and centrifugation. Four samples out of 10 from the same source as his first lot gave undoubted evidence of the presence of genuine tuberele bacilli. Otto Korn ${ }^{4}$ found them in 23.5 per cent. of samples purchased in Freiburg, and Dr. C. Coggi ${ }^{5}$ in only 2 out of 100 samples purchased in Milan, though in a number of them the spurious organism was present. Morgenroth ${ }^{6}$ has subjected oleomargarine to a similar investigation, since milk is used in its manufacture, and has reported positive results from 9 out of 20 samples. Annett ${ }^{7}$ examined 28 samples of oleomargarine ( 15 from Berlin and 13 from Liverpool), and found virulent tubercle bacilli in only 1 .

We have as yet no evidence whatever that tubereulosis has ever been spread through the ageney of butter, but the subject deserves most thoughtful consideration.

As regards the possible transfer of the typhoid bacillns through butter, Lumsden ${ }^{8}$ quotes Bruck as having denonstrated the bacillus typhosus in butter 27 days after the butter had been experimentally infected with this organism. It would appear, however, as pointed out by McCrae, ${ }^{9}$ that danger from this source, under ordinary conditions, would be quite small, owing to the presence of many vigorous saprophytes, the washing ont of large numbers of bacteria in the buttermilk, and the salting process incident to the making of butter.

\footnotetext{
1 Zeitschrift für Hygiene und Infectionskrankheiten, XXVI., p. 90.

2 Arbeiten aus dem kaiserlichen Gesundheitsamte, 1898, p. 27.

3 II ygienisclie Rundschau, 1899, No. 2.

4 Archiv für IIygiene, XXXVI., p. 57.

${ }^{5}$ Giornale della R. Societa italiana d'igiene, July, 1899, p. 289.

${ }^{6}$ Hygienische Rundschau, 1899, No. 21.

7 The Lancet, Jannary 20, 1900.

${ }^{8}$ Hygienic Iaboratory Bulletin No. 41, p. 151.

${ }^{9}$ Osler's Modern Medicine, Vol. II.
} 
Analysis of Butter.-Ordinarily, the examination of butter is limited to the determination of whether or not it is mixed with or replaced by oleomargarine, but for the determination of its food value it is necessary to ascertain the proportions of fat and water. It is sometimes of interest also to determine the amount of salt and the presence of other preservatives.

Determination of Water.-Weigh a gram or two of the sample into a platinum dish, such as is used in the analysis of milk, and dry to constant weight on a water-bath.

Determination of Fat.-Extract the residue from the preeeding determination with ether or freshly distilled naphtha, being eareful not to remove any of the particles of eurd or salt. The process of extraction is very simple, eonsisting in filling the dish about half full of the solvent and after a short time decanting it carefully into another vessel, and repeating the operation until nothing is extracted. The solvent, or an aliquot part thereof, may be evaporated in a weighed beaker, or the dish may again be heated to a constant weight and the fat determined by difference. The residue now represents the eurd, lactose, and mineral matters.

Determination of Salt, etc.-Ignite this residue at as low a temperature as possible, and thus burn off the easein and lactose. Their combined weight is ascertained by weighing the dish anew. What now remains in the dish is mineral matter, eomprising the salts natural to milk and those added. Common salt may be determined by treating the final residue with water acidulated with nitric acid, and titrating in the usual way with standard solution of silver nitrate, using potassium chromate as an indicator.

Another method of determining salt is as follows: Shake a known weight, 5-10 grams, of the sample with hot water in a stoppered separating funnel until it is melted eompletely, let stand until the fat gathers on the surface of the water, and then draw off the latter through the stopeock. Repeat the operation with sucessive portions of about 20-25 ce. of hot water until a few drops of the washings, tested with silver nitrate, fail to show a eloudiness, due to silver chloride. Allow the combined washings to cool, and then, in an aliquot portion, determine the ehlorine by standard silver nitrate solution in the usual way.

Determination of the Nature of the Fat.-To determine whether or not a specimen is or eontains oleonargarine, an examination of the nature of the fat is necessary. As has been pointed out, genuine butter contains a considerable amount of volatile fatty acids, while the artificial product eontains very little; but, on the other band, the genuine article is eorrespondingly poorer in the insoluble non-volatile fatty acids. It is upon these differences in the two kinds of fat that the determination of the question of genuineness depends. The usual examination is limited to the determination of the volatile fatty acids in a given weight of the melted fat freed from water, eurd, and salt. The fat is saponified, the resulting soap is dissolver in water and then decomposed by means of sulphuric acid, and the volatile fatty acids, 
thus freed from combination, are then distilled over, and their amount estimated by means of decinormal sodium lydrate. Five grams of genuine butter-fat will yield an amount which will require at least 24 cc. of the alkali for complete neutralization, while an equal weight of oleomargarine yields so small an amount that, as a rule, less than $1 \mathrm{cc}$. is required. Mixtures give results between these limits, and from them one can estimate approximately the proportion of butter present.

Process.-Heat a small piece of the sample on a water-bath in a suitable beaker until it is melted completely, and the contained water, salt, and curd have collected at the bottom. Decant a sufficient amount of the supernatant fat into a dry filter and allow it to pass into a shallow beaker. When about 10 grams have been collected, place the beaker in a basin containing water and ice, and allow the fat to become hard. Place a small filter paper on one of the pans of the balance and counterbalance it exactly witl weights on the other. Then weigh out as rapilly as possible 2.5 grams of the fat, transferring it to the paper by means of a spatula. Place the paper and fat in a 300 cc. Erlenmeyer flask, add 10 cc. of a 20 per cent. solution of caustic potash in 70 per cent. alcohol, and then place the flask on a water-bath. In a short time, especially with gentle rotation of the flask, the fat becomes completely saponified. Continue the heat until the alcohol is expelled, and remove the last traces of the vapor by blowing into the flask with a bellows or by swinging it in the air. Add $50 \mathrm{cc}$. of hot water, and when the soap is brought completely into solution, add 25 cc. of 10 per cent. sulphuric acicl. The latter breaks up the soap, setting free both the soluble and insoluble fatty acids, the latter in the form of curds. Connect the flask with a Liebig condenser, after introducing several pieces of punice stone to prevent bumping, and then, with the flask supported on a square of wire netting over a Bunsen lamp, distil slowly until $50 \mathrm{ec}$. have been collected. Titrate the distillate with decinormal sodium hydrate, using phenolphthalein as an indicator. With the amount of fat taken, at least 12 cc. of the alkali will be required for nentralization, if the specimen is genuine butter.

Many analysts prefer to employ 5 grams of fat and correspondingly larger volumes of water, and to distill $110 \mathrm{ce}$, whereof 100 is titrated. Some prefer also to earry on the process of saponification in a roundbottomed flask under pressure. Some measure the fluid fat directly into a weighed flask from a pipette, and ascertain the amount taken by reweigling after the fist has cooled and solidified. The saponifying agent is applied in different forms, and many other variations in detail are recommended, but the end result is practically the same. The process described has been found in the experience of the author to be most satisfactory.

The Leffmann-Bean proeess has much to recommend it, particularly in the saving of time. The saponifying agent is prepared by mixing 20 cc. of 50 per cent. caustie soda solution and $180 \mathrm{ec}$. of pure concentrated glycerin. To 5 grams of fat in an Erlenmeyer flask add 20 cc. of this solution, and then heat over a Bunsen flame until saponification 
is complete. This requires but a few minutes; the completion of the process is shown by the clear condition of the mixture. The soap is diluted with $135 \mathrm{ec}$. of boiled water, added at first in very small amounts to prevent foaming. Then 5 cc. of dilute sulphuric acid (200 cc. in 1000) are added, and the preparation is ready for immediate distillation. Distil 110 ec., mix thoroughly, and pass through a dry filter, titrate $100 \mathrm{cc}$, and to the result add $\frac{1}{10}$ for the remaining $10 \mathrm{cc}$.

If one wishes to determine the amount of insoluble fatty acids, it may be done in the following manner, but it should be said that the process requires much more time, and that the results are not always satisfactory, since the upper limit in the ease of butter is so near the lower limit in that of olemargarine that samples yielding results close to the dividing line may need further analysis before an unqualified opinion of the nature of the specimen can be given. A mixture of genuine butter and oleomargarine may give results well within the normal limits of butter.

Process.-Into a weighed beaker deeant a few grams of the fat, and, when the latter has cooled, ascertain the amount taken by reweighing. Saponify as above described, evaporate the alcohol, dissolve the soap in water, and decompose it by the addition of an excess of acid. Heat until the precipitated insoluble acids are melted, then allow the whole to cool. When the fatty layer has assumed the character of a solid erust, break a small hole through it at a point on its circumference and another on the opposite side. Weigh a funnel and a dried filter of suitable size, place the latter within the former, wet it thoroughly, and then filter the liquid from beneath the crust. Break up the crust, add boiling water, and transfer the whole to the filter. Wash repeatedly with boiling water until the washings have no longer an acid reaction, then let drain until no more water is discharged. The filter-paper being wet, the melted fatty acids do not pass through with the washings. Place the funnel and its enntents in the beaker and dry in an air-bath at $100^{\circ} \mathrm{C}$. to constant weight. The increase in the combined weights of the beaker, funnel, and paper represents the amount of insoluble fatty acids in the amount of fat taken.

Examination of Fat by Means of the Butyro-refractometer.-A simple and quick method of ascertaining the nature of butter-fit without recourse to chemical analysis is that by means of the butyro-refractometer or other instrument designed for the purpose of measuring the refraetive index. The instrument is shown in Fig. 6, with the prism casing wide open. Its application requires so little time that, after a little practice, a person working alone can examine readily 15 or 20 samples in an hour. The method of use is as follows: The surface $A$ and that to which it is opposed when the prism casing is closed should first be eleaned by means of a soft piece of linen moistened with alcohol or ether. Place the instrument so that the surface of the prism $B$ is horizontal, then apply 2 or 3 drops of the elear fat, best from a small filter paper held between the fingers. Close the prism easing and fasten it by means of the pin $C$. The surfaces of the two prisms are now 
separated from each other only by the very thin layer of fat. With the instrument in its original position, the mirror $I$ a adjusted so as to illuminate the field elearly, and the upper part of the ocular so adjusted that the scale within is most clearly defined, read off at what point of the seale the line between light and shade falls. Since the degree of

FIG. 6.

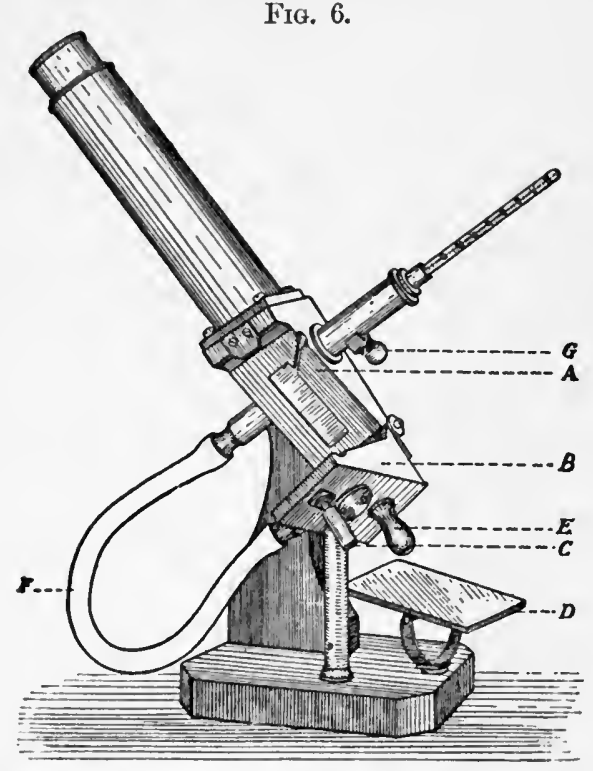

Zeiss butyro-refractometer.

refraction is influenced by the temperature, it is necessary to have some means of determining accurately the temperature of the specimen between the prisms. This is seeured in the following manner: A current of warm water is conducted by means of a rubber tube connected with the inlet $E$ into the prism casing, thence through the rubber tube $F$ to the upper part, from which it escapes through the outlet $G$. 'The bulb of a thermometer projects into the eurrent of water. The standard temperature for observations with this instrument is $25^{\circ} \mathrm{C}$., and at this temperature natural butter, which has a refractive index of $1.459-1.462$, will give a reading of from 49.5 to 54 on the seale, while oleomargarine, which lias a refractive index of 1.465-1.470, will show 58.6 to 66.4 , and mixtures of the one with the other will give from 54 upward, according to the percentage of oleomargine present.

According to Wollny, to whom the invention of the instrument is largely due, any specimen which at a temperature of $25^{\circ} \mathrm{C}$. gives a higher reading than 54 will invariably be found on chemical analysis to be adulterated; but he suggests thiat, in order to remove all chance of adulterated butter eseaping detection, this limit be reduced to 52.5, and that all samples giving the latter reading be examined ehemically. 
With temperatures other than $25^{\circ} \mathrm{C}$, it is necessary to make eorreetions of 0.55 of a seale division for each degree C. The following table shows the maximum reading for pure butters at different temperatures :

\begin{tabular}{l|c||c|c|c|c||c|c}
\hline Temp. & Sc. div. & Temp. & Sc. div. & Temp. & Sc. div. & Temp. & Sc. div. \\
\cline { 2 - 5 } $25^{\circ}$ & 52.5 & $31^{\circ}$ & 49.2 & $37^{\circ}$ & 45.9 & $43^{\circ}$ & 42.6 \\
26 & 51.9 & 32 & 48.6 & 38 & 45.3 & 44 & 42.0 \\
27 & 51.4 & 33 & 48.1 & 39 & 44.8 & 45 & 41.5 \\
28 & 50.8 & 34 & 47.5 & 40 & 44.2 & & \\
29 & 50.3 & 35 & 47.0 & 41 & 43.7 & & \\
30 & 49.8 & 36 & 46.4 & 42 & 43.1 & & \\
\hline
\end{tabular}

There arc other processes for the investigation of the character of butter-fat, including the determination of the specific gravity, meltingpoint, iodine absorption number, and saponification equivalent; but for all practical purposes the determination of the refractive index or of the volatile fatty acids is ordinarily sufficient, and the other determinations are merely corroborative.

\section{CHEESE.}

United States Standard.- Standard eheese is the sound, solid, and ripened product made from milk or cream by coagulating the cascin thereof with rennet or lactic acid with or without the addition of ripening ferments and seasoning, and eontains in the water-free snbstance not less than 50 per cent. of milk fat. By Act of Congress, approved June 9, 1896, cheese may also contain added coloring matter.

For thousands of years cheese has been known as a very valuable food, and much attention has been paid to different methods of manufacture. At the present time many varieties are made, their nature depending upon that of the raw material, the method of producing the curd, the proportions of the several constituents, and the method of ripening. Most varieties are made from cows' milk; some are made from that of ewes, and others from that of goats.

The milk is userl either in its natural condition, or skimmed, or with the addition of cream. Generally, it is used in its natural eondition. Whatever the kind, the following is the general process of manufacture. The milk, with or without coloring matter as desircd, is heated to $80^{\circ} \mathrm{F}$. or above, and then curdled by means of rennet or by the acids formed by the ordinary milk bacteria. Usually, rennet is employed; sometimes, sour whey. The coagulation should be complete in from forty minutes to an hour. Too rapid coagulation causes the curd to be hard, tough, and unsuitable for the subsequent manipulation; too slow action produces a soft curd difficult to work and not uniform in character. After the process of coagulation is complete, the curd is ent or broken into small pieces, and the whey is drawn off. Then the curd is gathered into a healp and covered, and allowed to stand for an hour or longer, during which time its increasing acidity assists in its hardening and promotes the separation of the remaining 
whey. When the curd has attained the proper consistence, it is placed in a cheese press and subjected to gradually increasing pressure, and after this process is completed it is removed to the enring place. For the proper ripening of eheese, it is essential that the curd be of the proper consistence throughout, and that only the fuvorable organisms be present, and these in not too great abundance.

The curd produced by the action of sour whey is highly acid and inelined to be greasy. Owing to its high degree of acidity, it is not a favorable ground for the growth of many of the bacteria to which is dne the production of the different kinds of flavor, and so the number of varieties possible of manufacture by sour whey is limited. Rennet, on the other hand, produces a eurd which is elastic and not greasy or sticky, and which is a good eulture medium for the bacteria whose assistance is needed. It aets best in milk which is slightly acid, for if the milk is neutril or only very slightly acid, the coagulation proceeds very slowly and the eurd will not contract sufficiently to expel the whey; if the milk is too acid, the process of coagulation is too rapid and the product too tongh. A soft eurd retains too much whey, and the fermentation of the milk sugar of the whey causes "huffing," or swelling, for the prevention of which, preservatives sometimes are employed. The bacteria concerned in the process of ripening exist in the original milk or in the air of the place of manufacture. Sometimes the varieties which produce cheese "faults" gain a foothold on the premises, and ean be eradieated only by means of thorough eleaning and disinfeetion. The ripening process is earried on at about $70^{\circ} \mathrm{F}$. It is essentially a process of decomposition, in which enzymes, bacteria, and moulds are concerned; and for the production of the same kind of eheese the same varieties of organisms must be present, and the particular variety producing a partieular flavor must find the conditions such as are favorable to its predominanee. It is not possible to start with milk that is entirely sterile, and then to inoenlate with the partienlar varieties wanted, sinee to sterilize milk completely requires the application of such a degree of heat as will produce changes in the casein, interfere with the proper action of the rennet, injure the consistence of the eurd, and destroy the enzymes.

Ripening does not proceed satisfactorily when the eurd has been produced through the action of acids. In ordinary ripening, the casein is attacked by the organisms present, and ammonia, leucin, tyrosin, and several kinds of fatty acids are produced. The latter unite with the lime salts, which up to this point have been in combination with the casein. The acids formed inelnde butyric and valerianic. From the lactose, we have, in addition, laetic acid. 'The process goes on at different rates with different kinds of cheese, and it may be short or long. In the production of certain forms of American and English cheeses, the individual specimens are sealed hermetically in tin boxes and kept at a favorable temperature for as long as four years, the hoxes being turned each day. The ordinary grades of eheese, however, undergo comparatively short periods of ripening. 
Composition of Cheese.-The composition of cheese varies very much according to the nature of the raw material and the process of manufacture. The fat shows the greatest variation in amount, according as the cheese is made from whole milk, skimmed milk, or milk enriehed with eream. The most common American cheese is made from whole milk, as are also the leading varieties of English cheese, as Cheddar and Cheshire. The familiar Edam (Dutch) cheese is made from partially skimmed milk. English Stilton is a type of cheese made from milk enriched with eream. The cheese richest of all in fat is what we know as eream cheese, but, strietly speaking, this is not eheese at all, being simply fresh eurd very rich in fat and not subjeeted to any process of ripening. The eheeses poorest in fat are those made from skimmed milk. They are tough, dry, and of but little flavor, and such as they have is inclined to be umpleasant. American cheeses of good quality may be said in general to contain about 36 parts of fat, 30 of proteids, 30 of water, and the remainder salts. The leading English cheeses, excepting Stilton, contain rather more water (about 35 per cent.), and correspondingly less fat. Swiss cheese has practically the same composition, but contains rather more proteids and correspondingly less fat. Skimmed milk cheeses are particularly rich in proteids, containing often as high as 50 per cent. With the exception of those made from skimmed milk, it may be said in general terms that cheese is about one-third fit and one-third proteids.

Of the many varieties of cheese put up in small bulk, mostly for use as a relish rather than as a substantial article of diet, the following may be mentioned: Roquefort is made from the partly skimmed milk of ewes; it does not vary much in its percentage of fat and proteids from American and English cheeses. Gorgonzola is very similar to Roquefort in composition and also in the method of mamnfacture. Both are ripened with the assistance of monlds, which are mixed with the enrd with the powdered bread erumbs on which they have been enltivated, and the cheeses are inoeulated also after being shaped. Parmesan cheese is made from partly skimmed goats' milk; it is very rich in proteids but eontains only about half as much fat as Ameriean eheese. Camembert cheese is a soft eheese contaning rather more than 50 per cent. of water and about 20 per cent. each of fat and proteids. It is ripened by a peeuliar process which gives it a mueh more pronouneed and permeating odor thim almost any other known variets.

Adulteration of Cheese.-At the present time, the only extensive form of adulteration of cheese eonsists in the substitution of lard for the usual and proper kind of fat. Lard and skimmed milk colored with annatto are mixed together, heated to about $140^{\circ} \mathrm{F}$. in tanks, and emulsionized with the assistance of appropriate machinery ; the mixture then is coatgulated in the same way as in the ordinary process of making cheese. Such cheese is designated in the United States statutes as "filled checse," which includes "all nilade of milk or skimmed milk with the admixture of butter, animal oils or fits, vegetable or any other oils, or compounds foreign to such milk." 
A decree promulgated in Belgium on September 21, 1899, defines cheese as a prodıct obtained from pure millk, skimmed milk, milk eoagulated by the aid of remet or acidifieation, or any other product obtained by heating milk mixed or not with coloring matter, salt, and spices, and subjected to pressure and fermentation. It forbids the sale, exeept when properly labeller in such way as to reveal its true nature, of all eheese containing any other substance than those mentioned, such as oleonargarine or other foreign fat, potatoes, and bread. An exception is made, however, in favor of Roquefort, in which bread crumbs are present, not as an adulteration, but for the serving of a useful purpose. The sale of eheeses mixed with mineral matter other than salt and with antisepties in general is forbidden.

In some parts of Germany, bean meal and potatoes are used to some extent as adulterants, and there and elsewhere a great varicty of substanees are said to have been used to a greater or less extent in times gone by. In general, it may be said that, aside from lard and other foreign fats, the only adulteration of any importance consists in the admixture of preservatives. These are added more eommonly to skimmed milk cheeses than to those of good quality.

\section{Analysis of Cheese.}

Determination of Water.-Cut the specimen into small bits or thin slices. Weigh out abont 5 grams in a platinum dish containing sand or asbestos fiber, and dry to constant weight.

Determination of Ash.-Ignite the dried residue at as low a temperature as possible, and, after cooling, note the increase in weight over that of the dish and its original eontents.

Determination of Fat.-Triturate about 25 grams of the specimen in a mortar with an equal bulk of fine beach sand. Transfer the whole to a Soxhlet extractor, and proeeed in the manner described under the Analysis of Milk.

Determination of Proteids.-Proceed in the manner given under Analysis of Milk, using about 2 grams of the sample.

Determination of the Nature of the Fat.-For the detection of foreign fats, the method of procedure is the same as deseribed under the Analysis of Butter, after obtaining the fat in a pure condition. The residue obtained in the determination of the amount of fat will serve for this purpose.

\section{Cheese as a Cause of Poisoning.}

For many years, eheese has been known to be an oceasional cause of single and multiple cases of poisoning, and various theories eoncerning the nature of the poisonous agent have been promulgated. It was not until 1884 that the eause was revealed by Professor V. C. Vaughan, whose attention was drawn to outbreaks in Michigan during 1883 and 
1884 , in which more than 300 persons were affected. He traced the whole trouble to twelve different cheeses, from several of which he isolated the poisonous principle, a ptomain, to which he gave the name "tyrotoxicon." The symptoms observed in the outbreaks referred to included vomiting, diarrhoea, abdominal pain, dryness and constriction of the throat, feeble and irregular pulse, and marked eyanosis. In some eases, vomiting and diarrhoea were followed by marked nervous prostration. In some the pupils were dilated.

Within a short time after Vaughan's discovery, the poison was found by Wallace ${ }^{\mathrm{I}}$ in some cheese that was the eause of poisoning of not less than 50 persons out of about 60 who had eaten of it. The onset appeared in from two to four hours. The most constant and severe symptoms were vomiting and ehills. These were suceeded by severe epigastrie pain, cramps in the legs and fect, purging and griping, numbness especially marked in the legs, and very marked prostration. Vomiting and diarrhoca lasted from two to twelve hours ; ehills and eramps from one to two hours. No deaths oceurred, and all reeovered within three days. The severity of the symptoms bore no relation to the amount eaten; some of the severest eases were of persons who ate but sparingly.

More recent work by Vanghan and his associates and others has demonstrated that tyrotoxicon is not the only canse of cheese-, milk-, and ice-cream-poisoning, and that it is, indeed, a somewhat rare poison. Other toxic substances have been isolated from cheeses that yielded no tyrotoxicon.

\section{Section 4. VEGETABLE FOODS.}

The vegetable foods may conveniently be divided into several classes as follows :

1. Farinaceous seeds :

(a) Cereals ; (b) Legumes.

2. Farinaceous preparations.

3. Fatty seeds (nuts).

4. Vegetable fats.

5. Tubers and roots.

6. Herbaceous articles ("vegetables").

7. Fruits used as "vegetables."

8. Fruits in the narrower sense.

9. Edible fungi.

10. Sacelarine preparations.

The words fruit and vegctable are eapable alike of broad and narrow meanings. In the strict sense, the cereals, legumes, nuts, and many of the articles commonly called vegetables are fruits; but popular usage has narrowed the latter term to include the pulpy substance enclosing the seerls of varions trees and plants, and only such as are pleasint to the taste and elible in the raw state, with the single exception of the quinee, which is edible only when eooked. Vegetables in the ordinary sense include any part of herbaceous plants, as the stem, root, 
leaves, and fruity products used commonly in the cooked state or in the form of salads. Thus, in the popular usage of the terms, squashes and melons, which are the fruits of plants of the same family, are classed respectively as vegetables and fruits, and the cereals and nuts are classified under neither head.

First in importance of vegetable foods are the farinaceous seeds; they are of very high nutritive value and easily digested.

\section{Farinaceous Seeds.}

(a) CEREALS.

The cereals include wheat, rye, barley, oats, corn, buckwheat, and rice. They are very largely starchy, and agree in general composition; but they differ in the proportions in which their several constituents are present. These include proteids, carbohydrates, ether extractives, mineral matter, and moisture. The proteids include a large number of closely related compounds, as yet only imperfectly studied, which will be mentioned in the consideration of each member of the group. The carbohydrates inelude those which are soluble, sugar and dextrin, and those which are insoluble, stareh, cellulose, pentosans, and gelactans (H. W. Wiley). The ether extraetives include fits, resins, chlorophyll, and volatile oil "which constitutes the source of the odorons quality possessed by the grain" (Wiley). The mineral matters are ehiefly phosphates of calcium, and magnesium, silica, and salts of sodium and potassium. The cereals contain also certain ferments, the most important of which, and the only one which has been studied with any thoroughness, is diastase. This acts upon starch, converting it into sugar. The others include some which act upon the proteids.

\section{Wheat.}

Wheat is elassed very properly as the most useful of the vegetable foods. The grain consists of a hard outside layer which is indigestible and useless as food, and the cortex, softer and more frialle, which yields flour of high mutritive value. The hard ontside layer, which constitutes the greater part of bran, irritates the alimentary canal, and, while useful to some extent in eonditions of habitual constipation, should be aroided in all irritable eonditions of the bowel. It caluses waste by unduly promoting peristalsis, so that much of the nutritive portion is hurried along in an undigested condition.

'The proteids of wheat include, according to Osborne and Voorhees,' a globulin, an albumin, a proteose, gliadin, and glutenin. The two last-mentioned constitute between 80 and 90 per cent. of the whole; in the presence of water they unite to form the very important substance gluten, so essential in the conversion of flour into bread. According to Wiley, they unite in almost equal proportions; but in the opinion of E. Fleurent, ${ }^{2}$ the closer the composition of gluten approaches the 


\section{PLATE VII}

FIG. 1
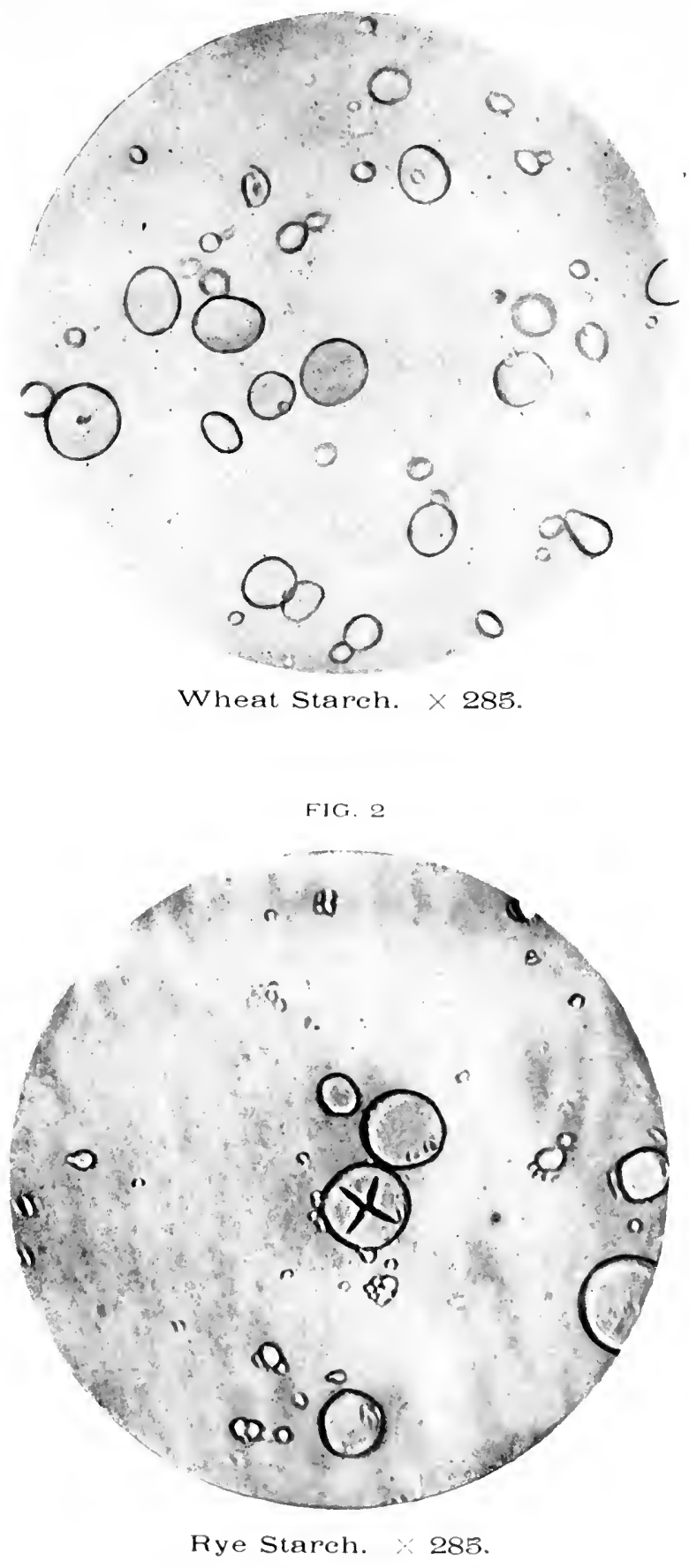

relation of 25 parts of glutenin to 75 of gliadin, the more valuable the flour.

The carbohydrates constitute the greater part of wheat as well as of the other cereals. They include starch, by far the most important, cellulose, sugars, dextrin, and a number of other compounds of comparative unimportance. The starch granules are exceedingly variable in size, ranging from about 0.002 to $0.05 \mathrm{~mm}$. in diameter. They are eircular and flat, and many of them show a central hilum and concentric rings. The latter appear with greater distinctness in flour that has been subjected to heat, as, for instance, in the baking of crackers. The wide variations in size are illustrated in Plate VII., Fig. 1. The other carbohydrates exist in but very small proportions.

Composition of Wheat.-The vast number of analyses of wheat show important variations in the pereentage of its several constituents, for its quality is influenced considerably by elimate, character of the soil, and other conditions. According to $\mathrm{H}$. W. Wiley, a typical Ameriean wheat of the best quality should yield approximately the following results :

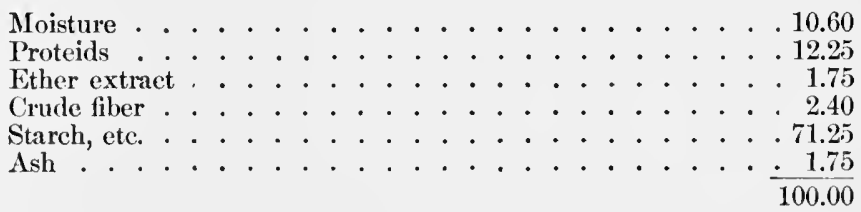

These figures do not vary materially from the averages of a large number of analyses of samples of miscellaneous origin compiled by König, execpting in the proportions of moisture and stareh, in which respects Wiley's typical specimen shows superior value, being less rich in the one and richer in the other constituent.

\section{Wheat Flour.}

In the manufacture of flour, the wheat kernels are subjected first to a process of thorough eleaning, and then are eracked, erushed, and ground until the required state of fineness is attained, the bran and other undesirable portions being removed by bolting. All flour is by no means the same in composition and quality ; in fict, several graules of flour may be made from the same wheat by the employment of different processes of manufacture. Flours are graded according to eolor or appearance, those which make the whitest bread ranking highest, although not equal in mutritive value to those classed as low grade. The flours of the several grades are known commereially as "patent," "family," "bakers"," and other names which to the public have no special signifieance. Typieal flours of the grades known as "highgrade patent" and "bakers" should have, aceording to Wiley, approximately the following composition:

1 U. S. Department of Agriculture, Division of Chemistry, Bull. 13, Part 9, p. 1189. 


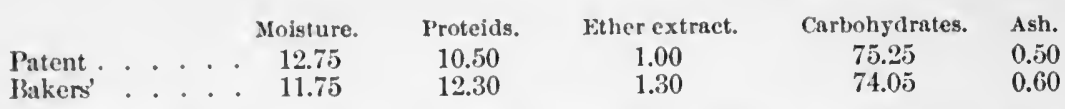

The average composition of 210 samples of wheat flour of high and medium grades and of grades not indicated is, as given by Atwater and Bryant, as follows:

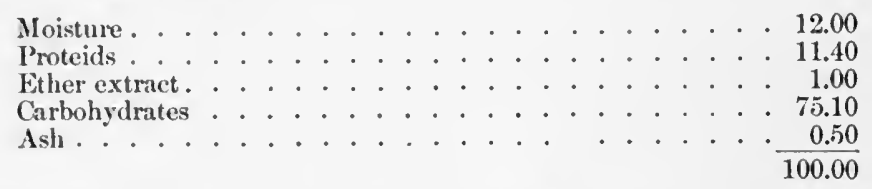

Thirteen samples of low grade averaged as follows:

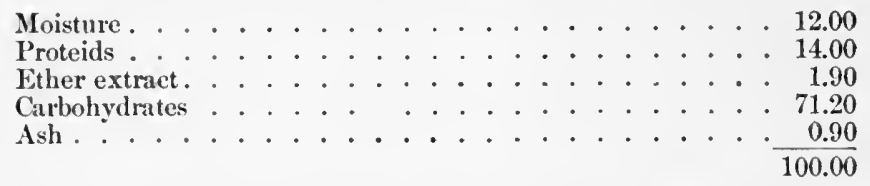

It will be noticed that the high grade flours are poorer in proteids and fat, and correspondingly richer in starch. Other grades of flour include those known as graham and entire wheat. Graham flour is understood generally to be a product containing all of the constituents of the original grain in their same proportions. When it came first into use, such, indeed, it was; but at the present time it is an unbolted or partially bolted product of thoroughly cleaned and dusted wheat. Entire wheat flour is understood also to contain all of the original constituents of the grain, but is, in fict, made from wheat deprived of its onter coverings. It makes a somewhat dark-colored bread which is very palatable.

Parenthetically, it may not be ont of place to refer here to the absurd views maintained by a large part of the community as to the superiority, from a hygienic standpoint, of foods containing all of the constituents of the cereals from which they are prepared. It is difficult to understand how the nutritive value of any food ean be increased by the retention of matters which are completely indigestible and to a certain extent irritating to the digestive tract. It is argued that an all-wise Creator made wheat, for example, in the form in which we see it, and that it is not for us to attempt to improve it, as we think, by disearding the outer layers. But this sort of reasoning might be extenderl si ats to favor the consumption of the peel of oranges, the bones of fish, the feathers of birds, and other innutritious and undesirable waste produets.

Preparations of Wheat Flour.-Bread._First in importance of the preparations of whent flour is bread. In the broad sense, brear includes all forms of baked flour, whether leavened or unleavened; in the common nse of the term, it includes only those in which leavening agents are used, the other forms being designated as pilot bread, erackers, biscuits, etc. 
The adaptability of wheat flour for bread-making is due to its gluten content. 'This substance, by reason of its tenacity, is capable of entangling the gas generated in the process, and by reason of its solidification by heat, furnishes a porous or spongy product easily penetrated and acted upon by the gastric juice. Not all cercals are capable of being made into bread, since, as will be seen, in most of them this very essential agent is lacking.

For the preparation of bread of good quality, the flour should contain not much in excess of the average amount of moisture, and should be so cohesive that, after being compressed in the hand, it will keep ịts shape on being released.

In the making of bread, the flour is mixed with warm water or milk, salt, and yeast, kneaded into a stiff dough, and set aside in a warm place. The yeast attacks the sugar and splits it into alcohol and carbonic acid gas; the latter by its evolution and expansion causes the dough to become porous and to "rise." The fermentative process gives rise also to variable amounts of lactic and acetic acids. The raised dough is then baked in suitable pans, and its porous character is increased by the further expansion of the gas by heat and is made permanent by the solidification of the gluten by the same influence. If the fermentation is not allowed to proceed far enongh, the resulting bread will be soggy or "heavy"; if too far, it will be sour.

In place of yeast as a leavening agent, bicarbonate of sodium, commonly known in the household as saleratus, and baking powders are employed very extensively. For the evolution of carbonic acid gas from sodium biearbonate, the presence of an acid is necessary, and this is secured by the use of sour milk. First, the flour is mixed thoroughly with the bicarbonate and then made into a dough with the milk. Bread made by this process is rarely of good quality, since it is difficult to determine the proper amounts of the two agents for the hest results, and any excess of the biearbonate causes discoloration and disagreeable flavor. A better plan is to employ baking powder, which consists of sodium bieabonate and an acid salt combined in such proportions that all of the available gas is set free from the alkaline salt and no unpleasantly tasting residue is left. The only advantage posisessed by baking powders is the saving of time and labor ; the resulting bread is distinetly inferior to that made with yeast. The composition of the various elasses of baking powders will be stated farther on.

Another process of securing leavening is that of spontaneons fermentation brought about by the enzymes present normally in flour. 'This process, known as "salt rising," is not in common use, requires much more manipulation than any other, possesses no advantages, and, therefore, deserves no further mention.

Freshly baked bread is much less digestible than that which has been kept a day or two. Its softness favors its eloggring during mastication into a close mass which is attacked less easily by the gastric juice. In this country, however, it is the almost universal custom to eat bread, particularly in the form of brealifast rolls, not only in 
the fresh condition, but also hot from the oven. When bread is kept for a day, it loses part of its moisture and acquires increased firmness and friability, which help maintain its porosity during mastication.

The following table by Helen W. Atwater ${ }^{1}$ gives the composition of various sorts of bread and some other food materials :

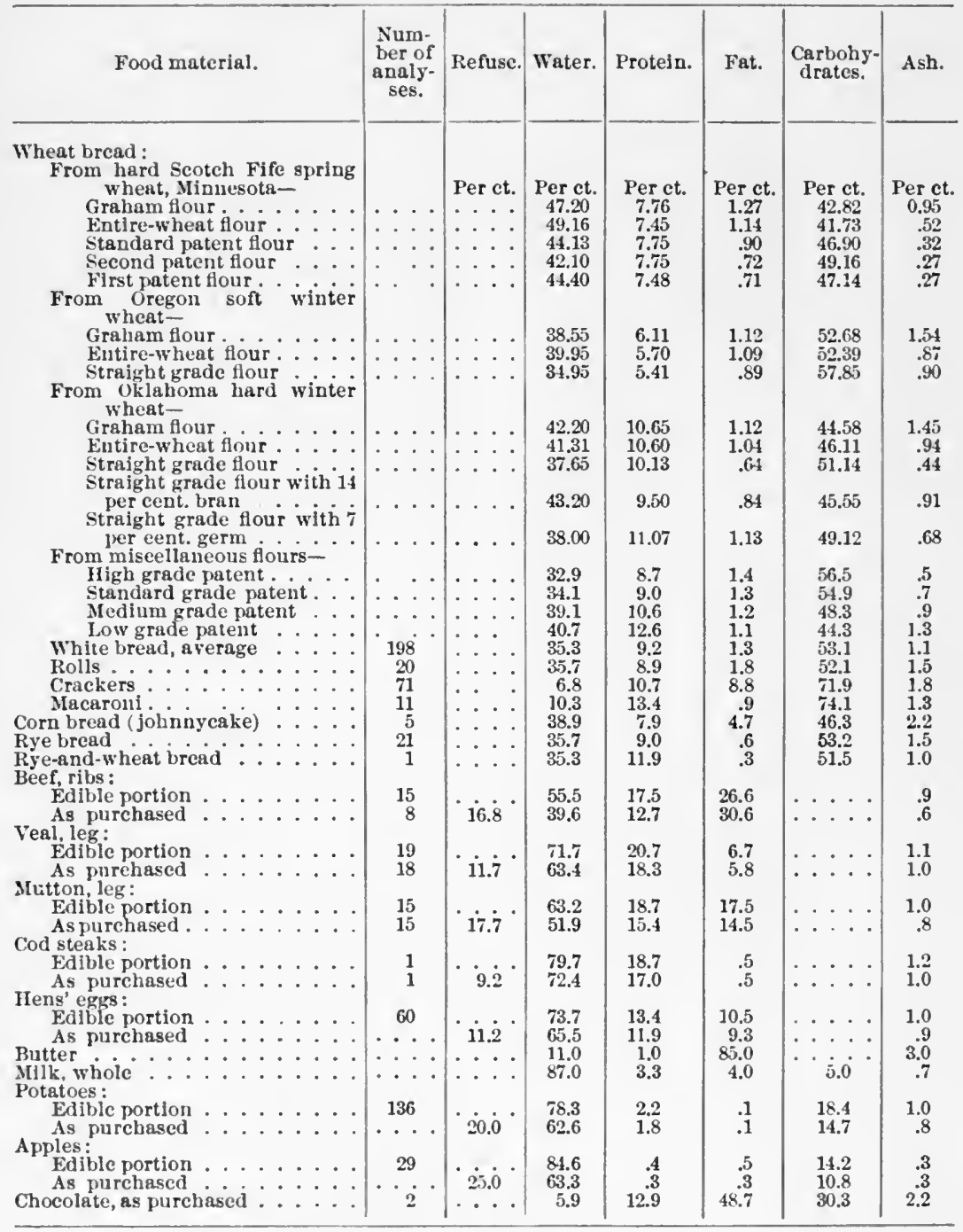

Bread may acquire unwholesome properties on keeping, due to changes brought about in the presence of moisture by micro-organisms. Good bread is only slightly acid; but if kept in a moist state, it is likely to become markedly so, and then may cause gastrie derangement and

' Farmers' Bulletin 389, U. S. Department of Agriculture, p. 38. 
diarrhœa in those not habituated to its use. Bread in this condition is undergoing fermentative changes that are hastened by the body temperature, with consequent evolution of gaseous products which eause flatulence and discomfort, and of irritating eompounds which induce abdominal pain and diarrhoa. Bread made from old and partially spoiled flour is likely to have a distinetly sour taste and to be unwholesome in the manner above deseribed. Mouldy bread also is likely to be a eause of digestive derangement.

Composition of Whent Bread. - Since wheat flour itself is of variable composition, and sinee in the domestie manufacture of any artiele of food the processes employed are subject to slight or eonsiderable variations, analyses of wheat bread necessarily must show great differenees in the proportions of the several eonstituents. Averages obtained from examination of samples of all sorts and of miscellaneous origin can hardly represent the composition of bread of good average or high quality.

Toast. - In the process of toasting, a large part of the moisture is driven off, the surfices are seorched, grcater firmness is acquired, and the produet is more easily digestible. Good toast eamot be made from perfietly fresh bread, on account of the moisture present, which causes sogginess; it ean be made only from bread at least a day old. The slices should not be thiek, since then, while the surface is scorched, the interior acquires increased softness under the action of heat and becomes less digestible than the original bread.

Rusks are much like toast. Instead of being subjected to the direct action of hot eoals, the bread slices are baked for a time in a moderately hot oven.

Pulled Bread is the crumb of freshly baked loaves pulled out in small masses and baker again like rusks.

Crackers, or biscuits, are preparations made from unleavened dough and baked so dry as to be brittle. They keep well for a long time without losing their palatability. If not properly stored and cared for, they may, of course, become damp, musty, and mouldy. In eomposition they vary but little from the flour of which they are made; they are drier, and what they lack in moisture they make up in fat, which, in the form of butter or lard, is added to prevent them from becoming too hard and dry.

Other preparations of wheat flour include eakes, which, on aceount of the contained butter, eggs, and sugar, are richer than bread; pastry, which, on aecount of its content of lard, is more diffieult of digestion; and flour puddings, which, being very "close," require much time for" digestion and often eanse sensation of "weight and oppression.

Macaroni, spaghetti, and vermicelli are preparations made with hard wheat rich in gluten. The flour is marle into a stiff paste with hot water, and the eompound then is pressed through holes or moulds in a metal plate and dried. They are exceedingly nutritions, but they are not as easy of digestion as other preparations of wheat, on account of their eloseness. They were first made on a small scale in Sicily, but 
now are produced in enormous amounts in Italy, France, Germany, and other countries. In their manufacture, American wheats are not held in high esteem, containing not sufficient gluten and too much starch. The best wheat for the purpose comes from a particular district in Russia and from Algeria. Formerly, a grain from sonthern Italy was regarded as the most snitable.

Adulteration of Flour.-Up to within comparatively recent years, flour has not been much subject to adulteration. Occasionally, certain mineral substinces, as magnesium carbonate, gypsum, and ground chalk, have been reported in European samples; but such have been employed as adulterants very rarely, if, indeed, at all in American flours. Alum has been added sometimes to flour of inferior quality to improve its color or to eheck beginning decomposition. Whether this addition is objectionable from a hygienic standpoint is a subject over which there is decided disagreement. It is believed by some that the amount of alum added is sufficient to exert an injurious effect on the digestive tract on account of its astringent action, and to bring abont constipation and dyspepsia ; others believe that it can do no harm whatever, either to the consumer or to the mutritive value of the food; and still others hold that, while it is not injurious to health, it lessens the nutritive value of the flour by forming insoluble aluminum phosphate, and thus depriving the system of the phosphates which otherwise would be absorbed. It is a fact that flour, treated with alum on account of beginning deterioration, has caused untoward effects, but it would be impossible to determine how much influence should be ascribed to the alum and how much to the products formed by the fermentative processes in operation before the addition. The weiglit of evidence, however, is in favor of the view that alum is not incapable of producing injury when taken into the system habitually in small amounts, and that it should be excluded from all articles of food intended for man.

On account of the growing tendency to mix other mill products of inferior value with wheat flour, such, for instance, as rye and corn flour, a law was passed by Congress in June, 1898, to meet the evil, and incidentally to make it a source of revenue. All adulterated flour is, by the act referred to, designated as " mixed flour," which term "shall be understood to mean the food product made from wheat mixed or blended in whole or in part with any other grain or other material, or the manufactured product of any other grain or other material than wheat." Under the provisions of the law, all persons engaged in the business of making mixed flour are required to pay a special annual tax, every package must be labelled plainly, the names of the ingredients being set forth, and upon every package of 196 pounds a tax of 4 cents shall be paid. Under the regulations of the Treasury, the term "mixed flour" is held not to include " the milling product from corn, rye, buckwheat, rice, or other cereals than wheat put upon the market as the flour or meal derived from such cereals, although the product may contain a percentage of wheat flour." 
The detection of other cereals and starches in wheat flour is accomplished best by means of the microseope, sinee, as will appear, each has its characteristic appearance. According to Vogel, 70 per cent. aleohol containing 5 per cent. of hydrochloric acid remains eolorless after being used to extract pure wheat or rye, turns pale yellow if barley or oats be present, and orange-yellow if mixed with pea flour.

Bleaching of Flour.-Within the last few years there has been introduced in the flour industry a process by which flour is bleached through the use of nitrogen peroxide. According to Leach," "Nitrogen peroxide destroys almost immediately the yellow color which is associated with the fat of the flour, thus increasing the whiteness of the product. It also combines with the moisture of the flour, forming nitrous and nitric acids, the nitrous acid (free or combined) being especially noteworthy beeause of the ease of detection."

Whether or not this bleaching of flour constitutes a menace to the public health is still undecided. As a test for the bleaching of flour, Leach ${ }^{2}$ gives the following test, based on observations of Alway :

"Gasolene test. Place 25 grams of the flour in a four-ounce, widemouthed, glass-stoppered bottle, add sufficient gasolene to nearly fill the bottle, shake, and allow to settle. If the flour is unbleached the gasolene will be distinctly yellow; if bleached, it will remain nearly colorless."

\section{Rye.}

In external appearance, rye presents a close resemblance to wheat, but the kernels are darker in color and smaller in size. It is by no means so important as wheat as an article of food in this country, but in some parts of Europe it constitutes the main food supply of the peasantry.

According to Wiley, a typical American rye should have approximately the following composition :

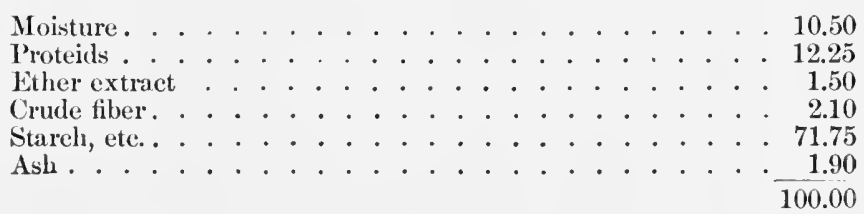

American rye is smaller than that grown abroad, and contains less moisture. 'The proteids of rye are more like those of wheat than those of any other cercal, and in consequence rye stands next to wheat in adaptability for bread-making. The yield of gluten is inferior in amount to that obtainable from wheat.

1 Food Inspection and Analysis, 1909, p. 325.

${ }^{2}$ Ibid., p. 321. 
The starch of rye is mueh like that of wheat. The granules are rather more variable in size, the smallest of each kind being about equal, but the largest of rye somewhat surpassing those of wheat. There is but one point of difference in mieroscopic appearance which has any value in deteeting the admixture of rye with wheat, namely, that a certain fair proportion of the larger sized granules of rye present irregular crosses or fractures. This is illustrated in Plate VII., Fig. 2.

Bread made from rye flour is but little inferior in mutritive value to that from wheat, but it is less pleasing to the eye, being of a brownish tint, and it has a peeuliar sour taste, not altogether agreeable on first aequaintance. Not uneommonly, its use by one not habituated to it causes a tendency to diarrhoea, which, however, is soon overeone.

\section{Barley.}

This important eereal is used mainly in the manufacture of beer, and but to a limited extent as a food. Deprived of its husk and rounded and polished by attrition, it is known as "pearl barley," and in this form is used more or less in the preparation of barley-water, a drink for invalids. In its composition, barley is very similar to wheat and rye, but as its proteids yield no gluten, it eannot be made into bread. It is mixed sometimes with wheat flour for purposes of bread-making, but the product is less palatable and less digestible than ordinary bread.

Wiley gives the following as the approximate emposition of a typical American unhulled barley:

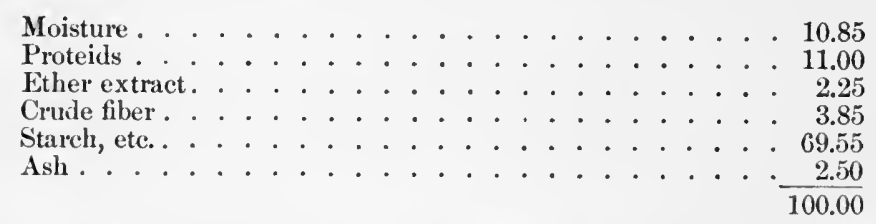

The proteids include, as in all cereals, a number of complex substances, chief of which is hordein. The stareh granules are like those of wheat, but are less variable in size. (See Plate VIII., Fig. 1.) In the manufueture of malt from barley for brewing, a peeuliar nitrogenous product, diastase, is formed, which has the property of converting starch to sugar.

\section{Oats.}

Oats are much used as human food in the form of oatmeal, which is the product of grinding the kiln-dried seeds deprived of the husk. The meal has a peeuliar taste, which is both sweet and bitter.

The composition of unhulled Aneriean oats, as given by Wiley, is as follows: 


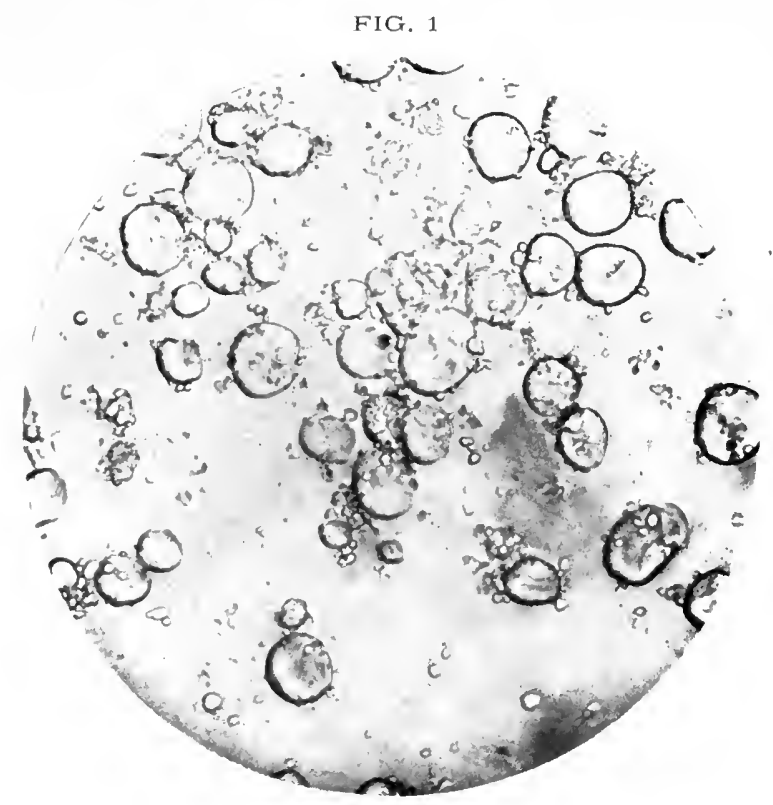

Barley Starch. $\because 285$.
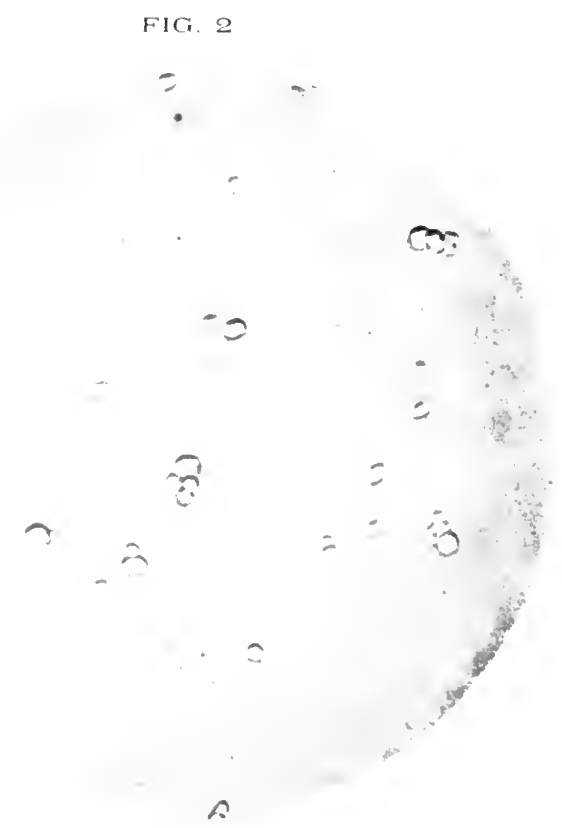

Oats Stareh. $\times 285$. 



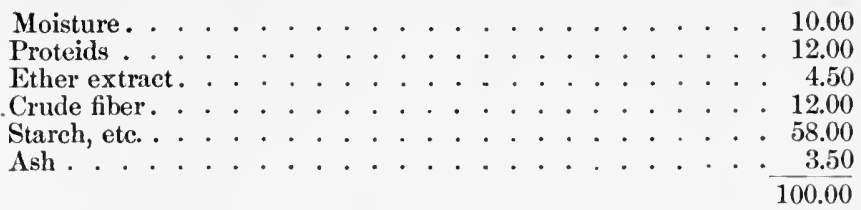

The mean composition of oatmeal, aceording to Blyth, ${ }^{1}$ is as follows :

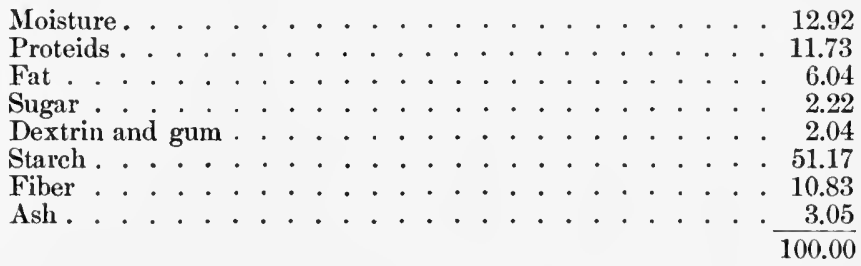

The proteids of oats yield no gluten, and henee this article of diet cannot be made into bread, though with water it ean be made into thin eakes, which are most palatable. Fat is present is greater abundanee than in any other cereal. The stareh granules are very small polyhedra which show neither hilum nor concentrie rings. They tend to adhere together in masses of variable size, which are disintegrated easily by trituration in a mortar. The single granules are shown in Plate VIII., Fig. 2.

Oatmeal is a very nutritious artiele of diet, used largely as a breakfast food in the form of porridge. It has a somewhat laxative aetion, and, therefore, should not be eaten in irritable conditions of the bowel. It is also likely to disagree with some dyspepties, because of its tendeney to cause acidity and heartburn.

\section{Corn.}

In the American usage of the word, corn ineludes the several varieties of Indian corn or maize. In England, the term is applied generally to wheat, rye, oats, and barley, and more specifically to wheat; in Scotland, it conmonly. means oats. In the United States, eorn is in many ways the most important of the eereals, constituting in some parts of the country the chief bread food, and being the main sonree of stareh and glueose.

The ehief varieties are dent eorn, showing a depression in the outer end of the kernel; flint corn, having a hard smooth exterior; sweet corn, rich in sugar and shrivelling when ripe; and pop-corn, a very flinty variety with small kernels, which contain a considerable amount of oil, which, in the process of roasting, explodes and causes the extrusion of the starchy interior in the form so universally fimiliar. The varicty in most conmon use, from which the severil kinds of meal, hominy, and samp are derived, is the flint corn. Hominy is the produet obtained by grinding coarsely the kernels deprived of the hull by soaking. Samp is the whole, or practically the whole, of the kernel

${ }^{1}$ Foods: Their Composition and Analysis, London, 1896, p. 210. 
minus the germ and hull. Indian meal, or corn meal, is the product obtained by grinding the kernels between stones or by other processes of milling, and removing more or less of the bran by sifting or bolting. According to the process employed, we have coarse and fine, and white and yellow meal. Prepared without removal of the germ, which is rich in oil, the product is prone to become raneid and monldy on keeping.

From a large number of analyses, Wiley deduces the following as the approximate composition of typical Indian corn :

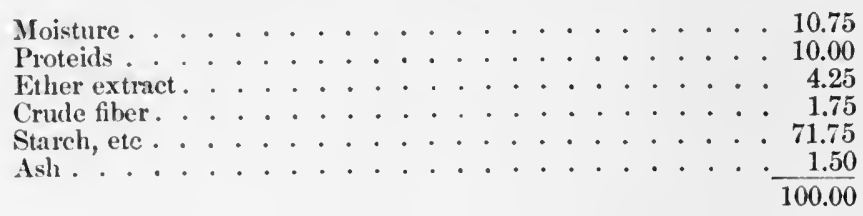

The average of 19 analyses of samples of sweet eorn by Clifford Richardson, quoted by Wiley, shows:

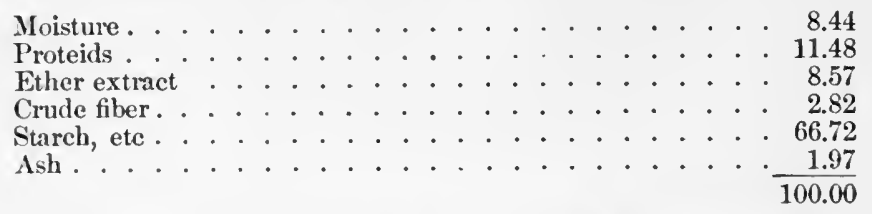

The composition of fine meal is given by Wiley as follows :

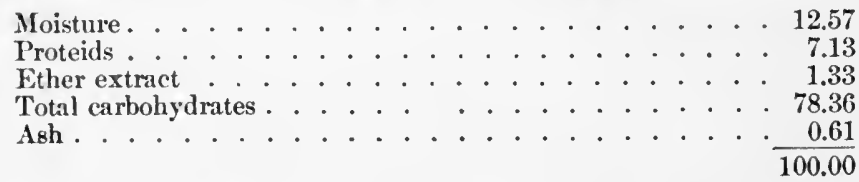

The lowered percentages of proteids and fats here shown are due to the removal of the germ, rich in fat, and of the finer envelopes, rich in proteids.

The proteids of corn, as determined by Chittenden and Osborne, are made up of several globulins, ineluding myosine and vitelline, two clisses of albumins, and two of zeins. The stareh granules are polyhedral with rounded angles, and have a punctiform, sometimes stellated, hilım. 'They are much larger than those of oats, which they resemble somewhat in form. 'They are shown in Plate IX., Fig. 1.

On acconnt of its defieiency in gluten, corn meal is not well adapted to the making of leavened loread, but it is used in many forms of substitutes therefor. It is mixed with salt and water, sometimes with the addition of milk or eggs, and balked into not over-thick cakes, which, aceording to the method of preparation and baking, are known as jolnnycake, corn dolger, corn pone, and eorn bread. Sometimes, yeast and baking powder are employed. Corn meal is used extensively in the form of hasty pudding, or corn mush, and of Indian pudding. In whatever form used, corn meal is a most nutritious and wholesome food. 
FIG. 1

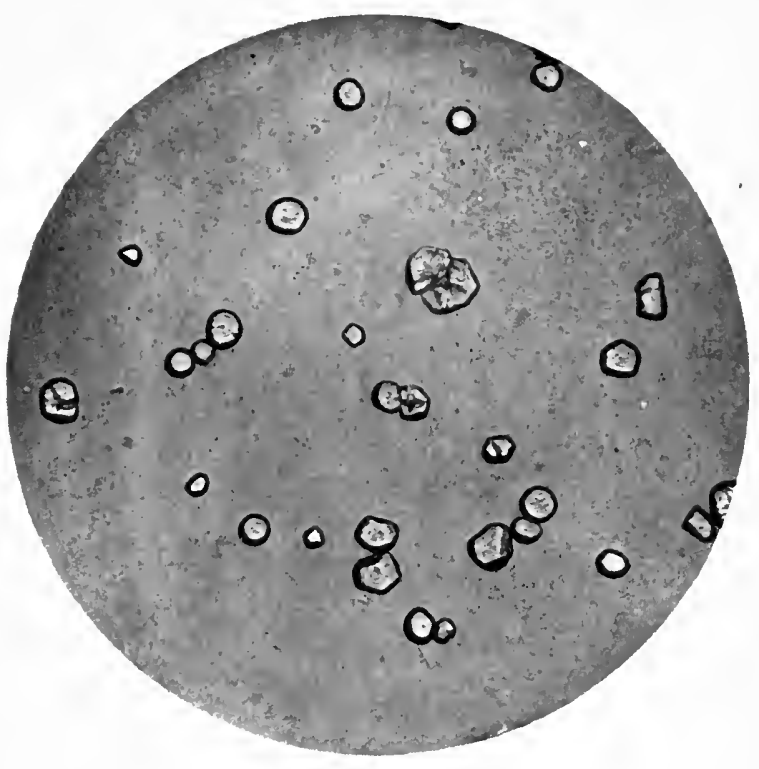

Corn Starch. $\times 285$.

FIG. 2

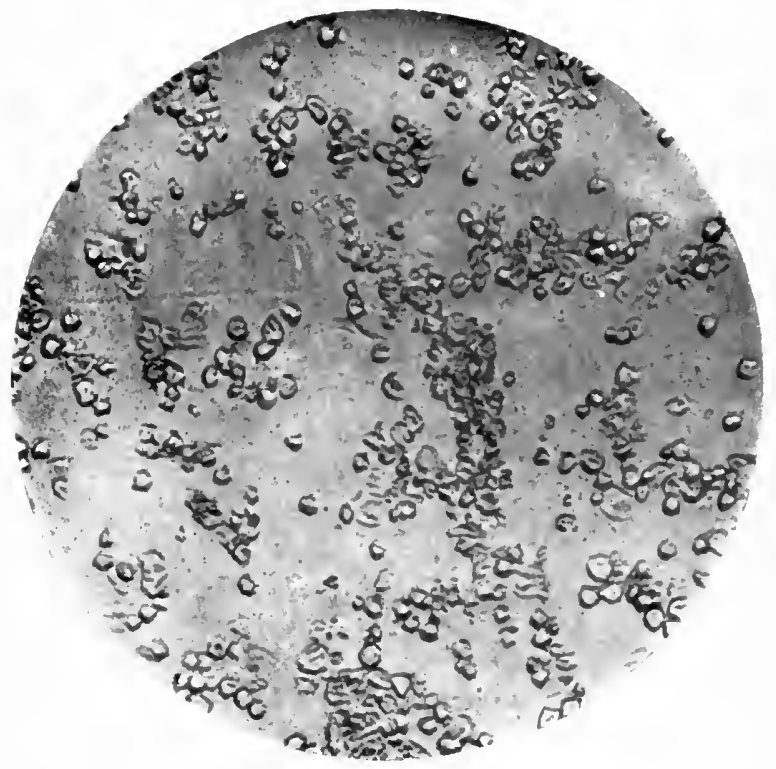

Rice Starch. $\times 285$. 

Rice.

Rice is the prineipal food of a very large part, estimated at about a third, of the human race. Being, as will be seen, too poor in proteids, fat, and mineral matter to satisfy alone the needs of the body, the deficiencies are met by other vegetable products, as beans and peas, which are rich in these constituents.

The form in which rice is seen in the household is the result of a polishing process which removes the reddish cuticle which the grain shows on removal of the husk. Wiley's figures, representing the composition of typical polished rice, are as follows:

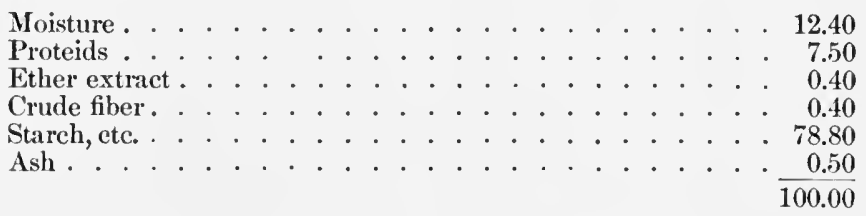

Rice is the richest of the cereals in stareh, and the poorest in all other respects. The proteids have not yet been studied systematically. Its stareh is very easily digestible, and is very useful in all disordered conditions of the digestive traet when other solid foods cannot be borne. Under the mieroscope, the starch granules are seen to be much like those of corn, but are much smaller and have sharper angles. They are separated less easily from one another, and are conmonly in groups of variable size. They are shown in Plate IX., Fig. 2.

Rice eannot be made into bread, but sometimes is mixed with wheat flour, in order to give whiteness to the bread. It is used most commonly in the freshly boiled condition or in the form of puddings. The most approved method of cooking it is steaming. This has the advantage of not taking away any of the already deficient proteids and salts, which to some extent are extracted in boiling, and also that it leaves the kernels distinct in themselves, and not aggregated in the form of a soggy mush, such as is produced often by improper boiling.

\section{Buckwheat.}

This valuable cereal is used very extensively in this country as a breakfast food in the form of pancakes eaten hot with syrup or with butter and sugar. As it is devoid of gluten, it eamnot be made into bread.

The composition of typical American buckwheat is given as follows:

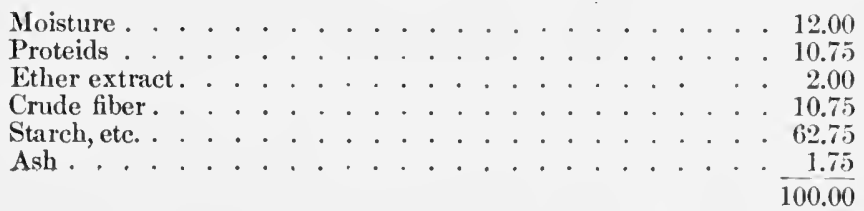


The crule fiber is removed very largely in the milling, and is almost wholly absent fiom the white flour, a sample of which, analyzed by Wiley, had the following composition:

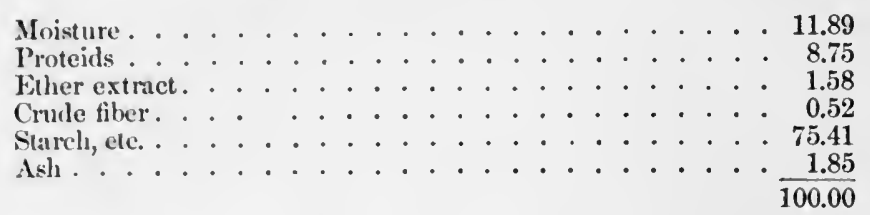

Buckwheat is the most expensive of the cereals, and consequently is the most subjeet to adulteration with the eheaper members of the class. The almixture is detected readily by the mieroscope, since the starch grauules have a very characteristic appearance, being small and angular, and of nearly uniform size. Ordinarily they are seen in fairly large masses which are not disintegrated in the process of milling. The starch is shown in Plate X., Fig. 1.

\section{(b) LEGUMES.}

This group comprises peas, beans, and lentils. It is characterized by richness in proteids, which may be present in more than double the amount found in wheat. The chief proteid is legumin, which much resembles casein, and is known commonly as vegetable easein. Aceording to E. Fleurent, ${ }^{1}$ the proteids of this group consist of vegetable casein, composed of legumin and glutenin, and vegetable fibrin, composed of albumin and gliadin. Thus:

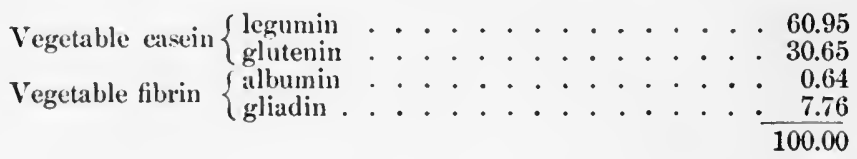

Their high content of proteids makes them more satisfying than other vegetable foods, and enables them to act as a fair substitute for animal fool. The millions of rice-eaters who, by reason of poverty or religious scruples, are denied the use of animal food, depend upon the legumes to supply the demands of the body for nitrogen. The East Indian, for instance, has no diffienlty in satisfying his bodily needs with a handful of beams alded to his daily ration of rice. While legumes possess a very high untritive value, they must be ranked as much more diffieult of digestion thin the cereals. They require prolonged boiling when exokerl whole, but are prepared more quickly and digested more completely when ground into meal and cooked with milk. Even under the most favomble conditions, a large part of the proteids is lost in the excreta. Rubuer has shown that a fifth to a third is not digested and

'Comptes rendus, 1898. 


\section{PLATE $X$}

FIG. 1

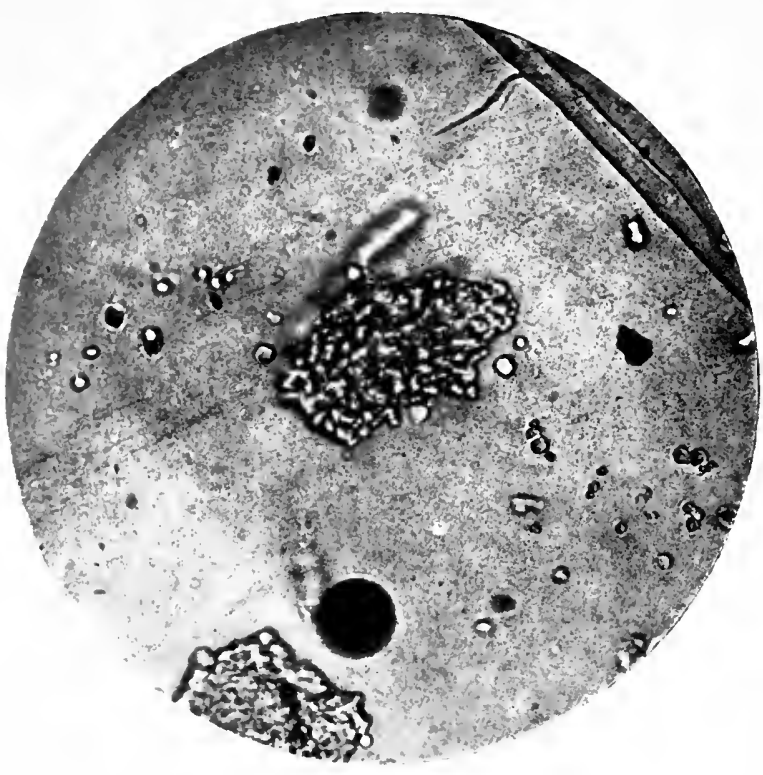

Buckwheat Starch. $\times 285$.

FIG. 2

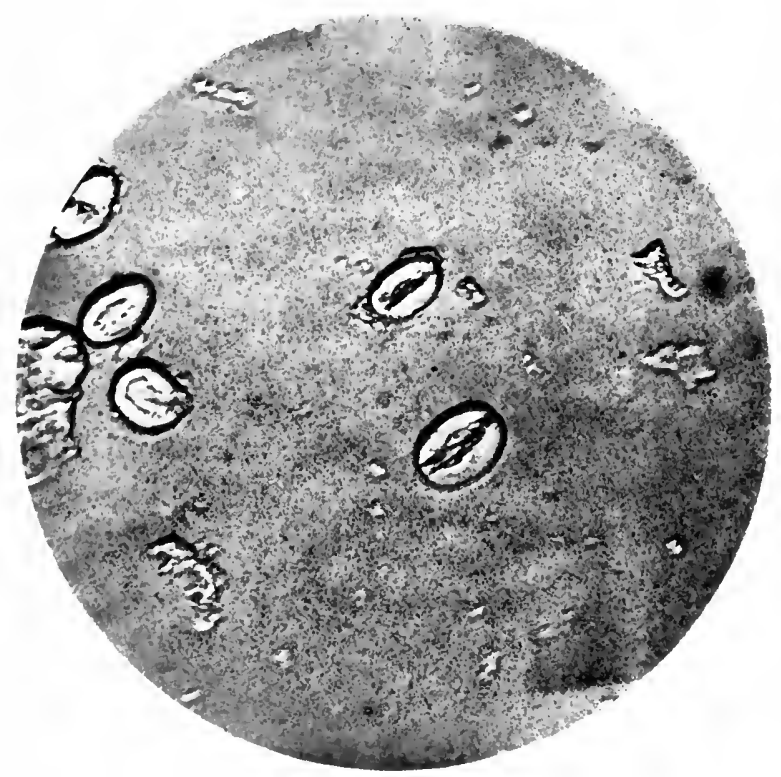

Pea Starch. $\times 285$. 

absorbed, whereas in the case of bread the proteid loss is less than a seventh.

Some individuals are obliged to forego the use of peas and beans, on account of flatulence due to the formation of sulphuretted hydrogen from the sulphur in the legumin. This objection does not apply to lentils, since they contain no sulphur.

\section{Peas.}

The average of 61 analyses of peas, compiled by König, is as follows :

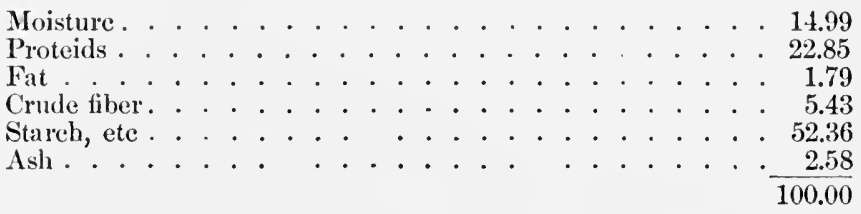

When dried peas become old, no amount of boiling will make them soft, and they should then be soaked and crushed and cooked in some other way. The immature pea, so highly prized as a spring and summer vegetable, has a very different composition. Five analyses, compiled by Atwater and Bryant, ${ }^{1}$ yielded the following average results :

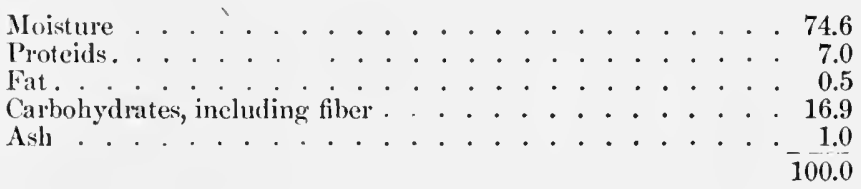

The eamed pea appears to contain eonsiderably less nutriment. Of 88 samples reported by the same authorities, none contained less than 77.5 per cent. of water, and some eontained as much as 92.7. Their average composition was as follows:

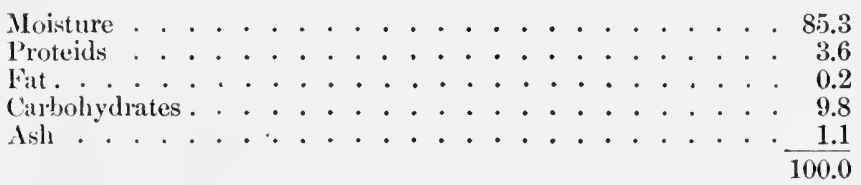

The stareh gramules of peas are represented in Plate X., Fig. 2.

\section{Beans.}

There are many varieties of beans belonging to the two large grouls, the broad beans and the kidney beans, but their composition is in general quite similar. Forty-one analyses of broad beans 
and 10 of kidney beans compiled by König give the following averages :

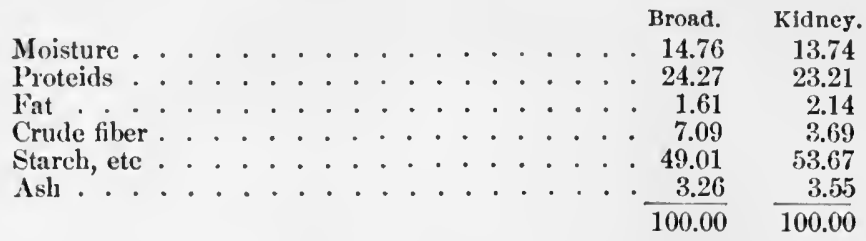

Eleven analyses compiled from American sources by $\Lambda$ twater and Bryant yield averages not materially different.

Five analyses of string beans in the fresh state and 29 of canned samples yield the following averages, showing, as in the case of peas, that the canned variety is less nutritious :

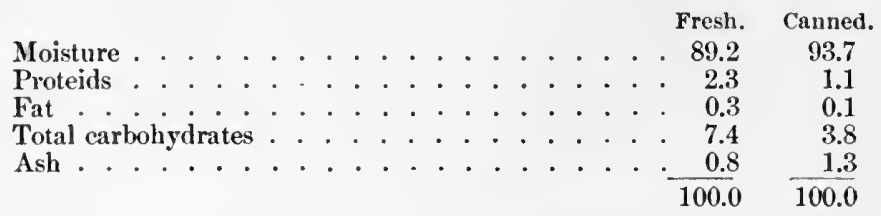

The Soja bean, which has been recommended highly in some quarters as a suitable food for diabeties, is remarkable for its high content of fat, and contains, in addition, so large an amount of starch as to make it quite unsuited to the dietary of the diabetic. König has compiled 21 analyses from all sources, and Jenkins and Winton ${ }^{1}$ have collected 10 more from American sources. The two groups give the following averages :

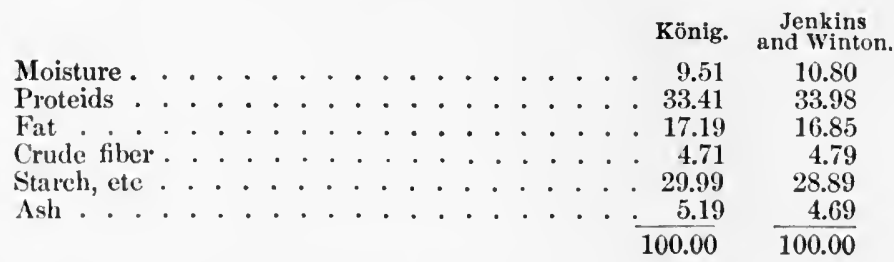

Bean stareh is shown in Plate XI., Fig. 1.

\section{Lentils.}

Lentils are the most nutritious of the legumes, but are not a popular food in this comtry, excepting among ecrtain of the foreign-born population. Their use is, however, on the inerease. The averages of 14 analyses compiled by König are as follows:

1 Experiment Station Bulletin, No. 11, Washington, 1892. 
PLATE XI

FIG. 1

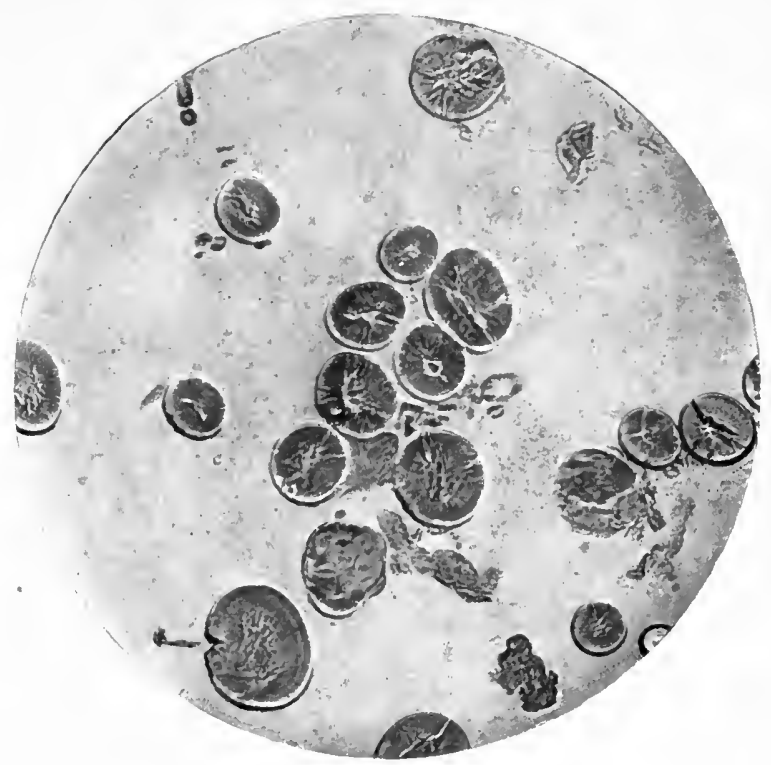

Bean Starch. 285.

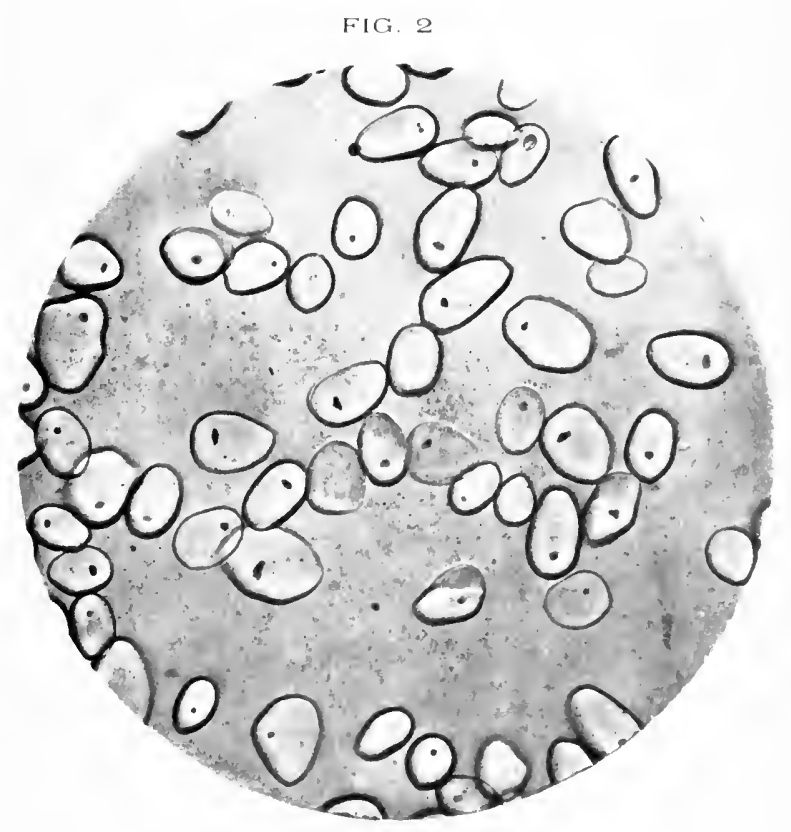

A rrow root Starch. 285. 



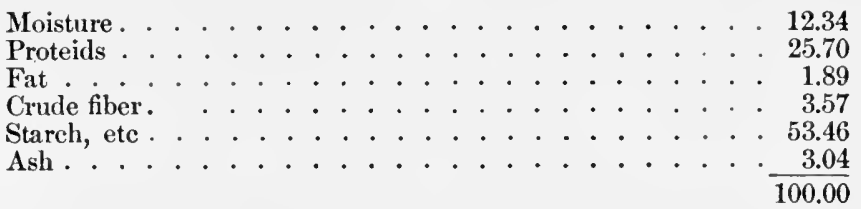

\section{Farinaceous Preparations.}

Under this head are included sago, tapioca, and arrowroot.

\section{SAGO.}

Sago is derived from the pith of the stems of a number of species of palms. The pith is extracted and ground to a powder, which then is mixed with water and strained. The starch granules pass through with the water, and are deposited as a sediment, which constitutes the sago flour. From the flour, made into a paste, the various forms of granulated sago are prepared.

Sago is an important stareh preparation, and serves as a light and digestible food for invalids and dyspeptics, but its use is not restricted to these alone. It absorbs the liquid in which it is cooked, and becomes soft and transparent, but retains its original form.

\section{TAPIOCA.}

Tapioca is derived from a thick fleshy tuberous root called "manihot." The starch, which is extracted by a method similar to that employed in the preparation of sago, is heated in a moist state on hot plates and stirred with iron rods, and thus forms irregular masses of transparent granules. In the process of heating, many of the stareh granules become ruptured, and are then partially soluble in cold water. Tapioea, like sago, is useful for both sick and well.

\section{ARROWROOT.}

Arrowroot is a pure form of starch from the tuberous root of the maranta. Its name is derived from the fact that the maranta root is believerl to counteract the effects of arrow poison. It is used chiefly as a bland article of food in the sick-room in the form of light pudding or other desserts, but may be eombined with other starch foods and made into bread. There are several varieties, the best of which come from Bermuda and Jamaica. Corn starch is employed frequently as a fair substitute. Arrowroot starch is shown in Plate XI., Fig. 2.

\section{Fatty Seeds (Nuts).}

Nuts are rieh in fat and proteids, but contain no starch. They are of high nutritive value, but on accomt of their richness in fat they are not easily digested, even when reduced to a fincly divided state, 


\section{ALMONDS.}

In the countries where they are produced, the almond is eaten both in the green and dry conditions. The ripe kernel has a skin, with a bitter disagreeable taste. When this is removed by soaking for a time in warm water, the almond is known as "blanehed."

There are two varieties of almond, the sweet and the bitter, both of which contain more than 50 per cent. of oil, about half as much proteid material, gum, sugar, and erude fiber. Both eontain emulsin, a substance which, in the presence of water, acts upon the glueoside anygdalin, present only in the bitter variety, to form hydrocyanic acid, glucose, and benzoic aldehyde. On aecount of this reaction, the bitter almond is not always safe, and fatal results have occurred from its ingestion.

When almonds are baked, they are made more brittle, and are reduced more easily to a powder.

\section{COCOANUTS.}

The fleshy white kernel of the cocoanut contains about 70 per cent. of fat. The milky interior is chiefly water, but contains nearly 7 per cent. of sugar.

\section{WALNUTS.}

All of the trees of the genus Juglans yield nuts classed as walnuts. The different varieties, though varying in outward appearance and in taste, have practically the same composition. They contain about 60 per cent. of fat, about 16 per cent. of proteids, and about 7 per cent. of sugar and gum. The hazel nut, which belongs to the oak family has about the same composition.

\section{PEANUTS.}

The peanut, known also as ground nut and goober, is less rich in fat, but richer in proteids than other nuts. It contains about 45 per cent. of the former and about 30 per cent. of the latter.

\section{CHESTNUTS.}

The ehestnut is not of this elass, but for convenience will be considered here rather than with the farinaceous seeds, in which class it properly belongs. It contains but little fat and proteids, about 15 per cent. of sugar, about 25 per cent. of stareh, and about 50 per cent. of moisture. It is very indigestible in the raw state, and even when conked is very trying to the digestion of those with weak stomachs. It is used very extensively as a food by the French, Spanish, and Italian peasantry in various cooked forms, and largely in the form of bread. 


\section{Vegetable Fats.}

The vegetable fats include the oils derived from the olive, cottonseed, peanut, and other seeds. They are used in the preparation of salads and for frying. The most important are the two first mentioned.

\section{OLIVE OIL.}

United States Standard.-Olive oil is the oil obtained from the sound, mature fruit of the cultivated olive tree (Olea europœa L.), and subjected to the usual refining processes; is free from rancidity; has a refractive index $\left(25^{\circ}\right.$ C. $)$ not less than 1.4660 and not exceeding 1.4680 ; and an iodine number not less than 79 and not exceeding 90 . Virgin olive oil is olive oil obtained from the first pressing of carefully selected, hand-picked olives.

Olive oil is a bland fixed oil derived from the fruit of the many varieties of the olive tree. It is known by various names which designate the grade, but is sold for the most part as virgin oil, which is the choicest grade of all and not extensively marketed. Virgin oil is made from the choicest olives, about three-fourths ripe, which are bruised only slightly in the mill, so that only the olive pulp, and not the stone, is erushed. The crushed mass is gathered in a heap, and the oil is allowed to drain away without pressure or other influence of any kind. The product has a greenish tint and a far more delicate taste than that made in the manner to be described.

In the manufacture of the grades ordinarily seen in the market, the olives, both pulp and stones, are ground into an oily paste, which is packed into bags marle of woven grass. These are placed in piles and subjected to pressure. As the oil drains away, boiling water is applied to the bags to keep up the flow, and that which is thus obtained constitutes the lower grade. Sometimes, the pressed pulp is thrown into water and separated from the broken kernels, which sink to the bottom. The pulp is then gathered up and pressed again.

On account of the cost of pure olive oil, adulteration with other cheaper oils is practised very extensively. The principal adulterant is cotton-seed oil, which is exported from this country in large quantities for this and other purposes. Nuch of the oil sold in this country as olive oil is cotton-seed oil put up in the eheapest kinds of bottles, adorned with gandy labels bearing inscriptions often not remarkable for accuracy in the use of the French language. The author has seen, for example, labels which indicated that the contents of the bottles had been "virginated."

Adulteration of olive oil to only a slight extent with the cheaper oils is by no means easy of detection, but when the fraurl is fairly extensive it may be shown by chemieal tests and by the use of the refractometer, the refractive index of olive oil being less than that of the eheaper substitutes. The iodine number and saponification equiv- 
alent of olive oil are both less than those of its adulterants. The behavior of olive oil in contact with nitrie acid or with alcoholie solution of nitrate of silver is markedly different from that of the cheaper oils. Thus, equal volumes of strong nitrie acid and olive oil, mixed together and agitated in a flask, give a product which has either a greenish tinge or at most one inclining to orange, and no marked change is perceptible on standing for five or ten ninutes; whereas cotton-seerl oil similarly treated yields almost immediately a reddish color, which shortly darkens and becomes dark brown or almost black.

Again, if 12 ee. of a suspected sample are mixed in a test tube with 5 ce. of a 2.5 per cent. solution of nitrate of silver in 95 per eent. alcohol, and placed in a beaker of boiling water, the resulting change of color gives indications as follows: if olive oil, the color is greenish; if cotton-seed oil, it becomes black; if sesame oil, it is dark reddishbrown; if peanut oil, it is at first reddish brown, then greenish and turbid; if poppy oil, it is greenish yellow. For further details of chemical tests, the reader is referred to the standard works on the adulteration of foods.

\section{COTTON-SEED OIL.}

United States Standard.-Cotton-seed oil is obtained from the seeds of cotton plants and subjected to the usual refining processes; is free from rancidity, has a refractive index $\left(25^{\circ}\right.$ C.) not less than 1.4700 and not exceeding 1.4725 ; and an iodine number not less than 104 and not exceeding 110.

This very important and cheap vegetable fat is a perfectly wholesome and desirable article of food. It is much used under its own name as a substitute for lard and olive oil for frying, and in place of the latter as an ingredient of dressings for salads. It lacks the fine flavor of olive oil, but its substitution in dressings can be deteeted only by the edueated palate. From a hygienie standpoint, there is absolutely no objection to its use in the preparation of foods. The same may be said of the other cheap vegetable oils.

\section{Tubers and Roots.}

In the cooking of tubers, roots, and other vegetables, the albumins and globulins are coagulated, the fibrous matters in the cell walls are softened and ruptured, the starch granules swell and burst, the starch itself becomes somewhat changed in eharacter, and the whole mass is made more digestible. When boiling is the process employed, part of the mineral matter and more or less of the other soluble substances, including certain proteid material, are extracted and lost.

\section{POTATOES.}

The potato is the most important member of this group. It was introdueed into Spain from Peru abont the middle of the sixteenth century, and later, in 1585, into Ireland from Virginia, by Sir Walter Raleigh, 


\section{PLATE XII}

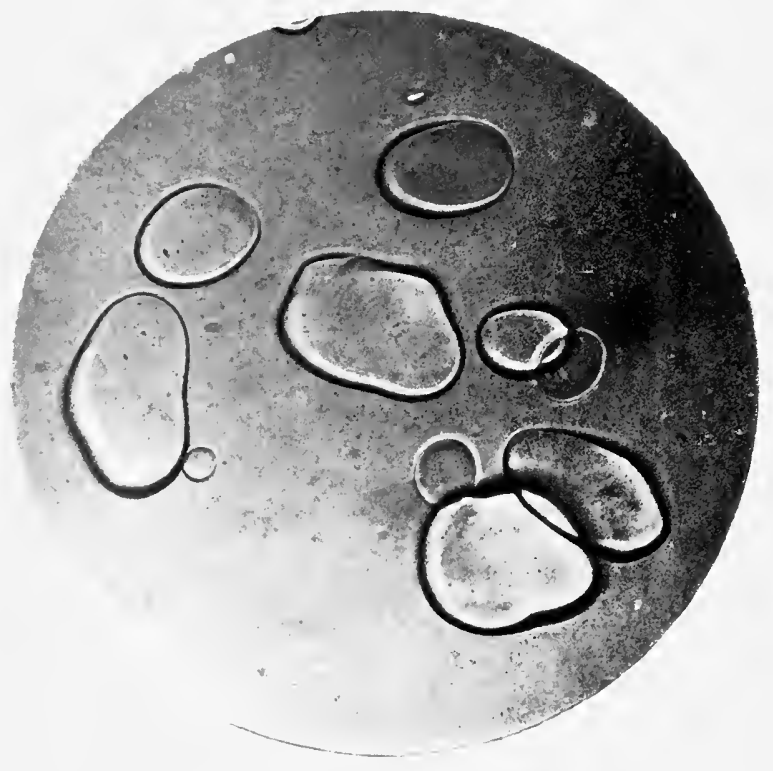

Potato Stareh. $\times 285$ 
is 
who, in the following year, introduced it also into England. Prior to that time, and even later, what was known in England as the potato and the "common potato" mentioned by Gerard in his Herbal (1597), were sweet potatoes, "batata," introduced from Spain.

The averages of 136 analyses (American samples) compiled by Atwater and Bryant are as follows:

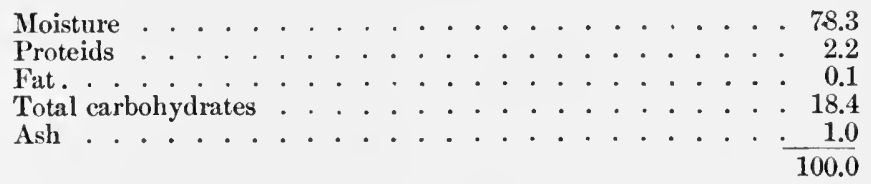

These figures differ but slightly from the averages of 178 analyses of European samples.

The proteids of the potato are chiefly in the albuminous juice between and in the eells. Most of the mineral matter is salts of potassium, and this, too, is almost wholly in the juice. The starch was discovered by Lenbert and Georgiewsky to be acted upon much more readily by the salivary enzyme than any of the cereal starches. The starch granules are much larger and more irregular in shape than any of those thus far shown. The hilum and concentric rings are quite distinct. (See Plate XII.)

In the process of cooking, the albuminous juice is coagulated and its watery part is absorbed by the starch grannles, which swell and consequently distend the cells in which they are lodged. The coherence of the cells is reduced, and then they are separated casily into a mealy mass. If the watery part of the juice is not wholly absorbed, the cells are separated with more or less difficulty, the potato remains firm instead of becoming mealy. and is then spoken of as close, waxy, or watery. In this state it is digested much less easily, and may, indeed, be very trying to the stomach. The same condition is noticed in the case of potatoes which have been frozen; they are very watery and of inferior flavor however they are cooked.

According to Balland, ${ }^{1}$ the mealy condition is due not, as supposed, to an especially high content of starch, but to a low pereentage of albumin, for a potato ris in this substance keeps its shape and neither cracks nor falls apart. He also points out that beneath the skin there are three well-defined layers, which may readily be seen by holding a thin cross-section against a strong light. The ontermost is richest in starch and poorest in proteids, but in the innermost these conditions are reversed; the middle layer represents the mean composition of the whole.

The loss which occurs on boiling is much less when the skins are left intact than when removed; the greatest loss oceurs when the potatoes are pecled first and then soaked in cold water. When cooked by steaming, there is no loss whatever. The material lost in boiling

1 Journal de Pharmacie et de Chemie, 1897, VI. 
has been determined by H. Snyder ${ }^{1}$ as follows : Skins removed, soaked 3 hours : total nitrogen, 46 per cent.; ash, 45.6 per eent. Skins removed, not soaked : total nitrogen, 16.9 per cent.; ash, 17.9 per cent.

FIG. 7.

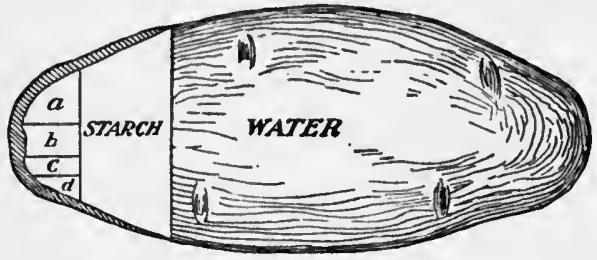

$a$, fiber, peetose, fat, etc. ; $b$ non-albuminoid nitrogenous matter; $c$, albuminoid nitrogenous matter; $d$, mineral matter. The hatehed portion represents the loss. (After SNyDER.) tion, but with foods rich in proteids, such as meats, beans, or peas, they are valuable and economical.

The juice of the potato contains citrie acid and eitrates of potassium, sodium, and calcium, which fact accounts for the antiscorbutic value of this vegetable.

Attention has often been called to the fact that the potato belongs to a poisonous botanical family, which includes belladonna, stramonium, hyoseyamus, and tobaceo, all powerful narcotic plants; and it has been pointed ont as a paradox that this valuable food possesses no poisonous properties. This, however, is not true, for the potato has been the frequent cause of more or less extensive outbreaks of poisoning, and it has long been known that the normal potato contains about .006 per eent. of solanin, and that, when sprouting, the solanin content is materially inereased. Between 1892 and 1898, many outbreaks of poisoning oecurred in the 15th (German) Army Corps, which were traced by Schmiedeberg and Meyer ${ }^{2}$ to solanin in sprouting or completely ripe potatoes. Schmiedeberg's assertion that solanin formation in potatoes is caused by bacteria has been proved by $\mathrm{R}$. Weil, ${ }^{3}$ who demonstrated that at least two organisms, Bacterium solaniferum non-colorabile and Bacterium solaniferum colorabile, have the property of producing solanin from substanees normally present.

A noteworthy instance of potato-poisoning is that recorded by Pfuhl. ${ }^{4}$ Fifty-six soldiers of a company of the German Army were seized with symptoms of acute gastro-enteritis. The sickness began with ehills, fever, headache, colic, vomiting, and diarrhoea. In a number of cases there was collapse, with more or less jaundice. None of the cases ended fatally, nor were there any relapses or sequelæ. Investigation showed that the men had eaten sprouting potatoes, a sample of which yielded .038 per cent. of solanin, and that, therefore, those who had eaten their

${ }^{1}$ Department of Agriculture, Office of Experiment Stations, Bulletin No. 43, 1897.

- Arehiv für experimentelle Pathologie und Pharmakologie, 1895.

${ }^{3}$ Archiv für Hygiene, XXXVIII. (1900), p. 330.

- Deutsehe medicinisehe Wochensehrift, 1899, p. 753. 
full portion of the vegetable had ingested about 0.3 gram of the poison, a quantity which may easily induce serious symptoms.

\section{SWEET POTATOES.}

The average composition of sweet potatoes (95 analyses) is given by Atwater and Bryant as follows :

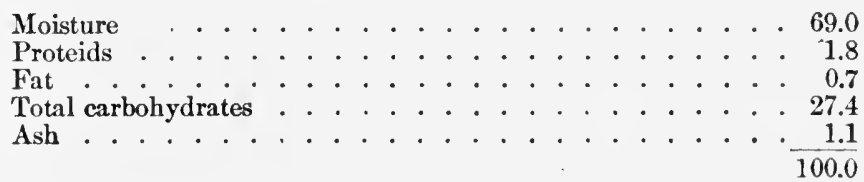

Starch constitutes much the greater part of the carbohydrates; the remainder is mainly sugar.

\section{ARTICHOKES.}

The Jerusalem artichoke is so named, not after the city of Jerusalem, but from a corruption of the Italian word girasole, meaning sunflower, to which family the plant belongs. This tuber is quite sweet to the taste, but it is not so agreeable as the potato. It contains no starch, but yields about 15 per cent. of sugar. It is about twice as rich in proteids as the potato. When cooked, it becomes soft and watery.

\section{ROOTS.}

The earrot, beet, parsnip, turnip, oyster plant, and radish agree in a general way in composition, and may be considered together. They are very poor in proteids, and contain but a small amount of other nutrients. All of them are valuable on account of their antiscorbutic properties, for providing variety in the diet, and for flavoring other foods. Their average composition, according to Atwater and Bryant, is set forth in the following table:

\begin{tabular}{l|c|c|c|c|c|c}
\hline & $\begin{array}{c}\text { No. of } \\
\text { analyses. }\end{array}$ & Water. & Proteids. & Fat. & $\begin{array}{c}\text { Carbo- } \\
\text { hydrates } \\
\text { inelud. } \\
\text { ing fiber. }\end{array}$ & Ash. \\
\hline Beets. . . & 24 & 87.5 & 1.6 & 0.1 & 9.7 & 1.1 \\
Carrots. . . & 18 & 88.2 & 1.1 & 0.4 & 9.3 & 1.0 \\
Oyster plant & 1 & 80.4 & 1.0 & 0.5 & 17.1 & 1.0 \\
Parsips . . & 3 & 83.0 & 1.6 & 0.5 & 13.5 & 1.4 \\
Radishes . . & 4 & 91.8 & 1.3 & 0.1 & 5.8 & 1.0 \\
Turnips . . & 19 & 89.6 & 1.3 & 0.2 & 8.1 & 0.8 \\
\hline
\end{tabular}

Snyder represents diagrammatically the composition of the carrot and the loss of nutrients when boiled. (See Fig. 8.) On account of the general re-

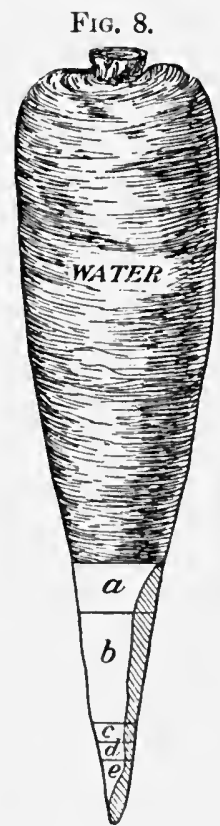

$a$, fiber, starch, fat, etc. : $b$, sugar: $c$, nonalbuminoid nit rogenous matter: $d$, albuminoid nitrogenous matter: $e$. mineral matter. The hatehed portion represents the loss when medium-sized picees were boiled. (After SNYDER.) semblance in composition, this diagram may be taken fairly to represent the whole group.

\footnotetext{
1 The figures for oyster plant are taken from König.
} 


\section{Herbaceous Articles.}

These include various leaves, stems, and shoots. They contain but little nutriment, but are valuable for their salts, and for the variety which they give to the diet. It is to be noted, however, that in proteids they are, as a class, equal or superior to the tubers and roots. They contain unimportant amounts of fat and sugar. The cabbage and allied plants are not casily digested, and on aceount of containing more or less sulphur, may give rise to disagreeable flatulence, and are not suited to weak digestions. Spinach is regarded as slightly laxative. Celery is not easily digested in the raw state, but is easily borne when stewed. Lettuce, cresses, and similar articles for salads are wholesome and digestible. Asparagus, while containing but little nutriment, is prized particularly for its delicate flavor. Onions and lecks, being modified stems, belong in this group. They eontain volatile oils which act as gentle stimulants.

The following table, compiled from Atwater and Bryant, gives the composition of the members of this group :

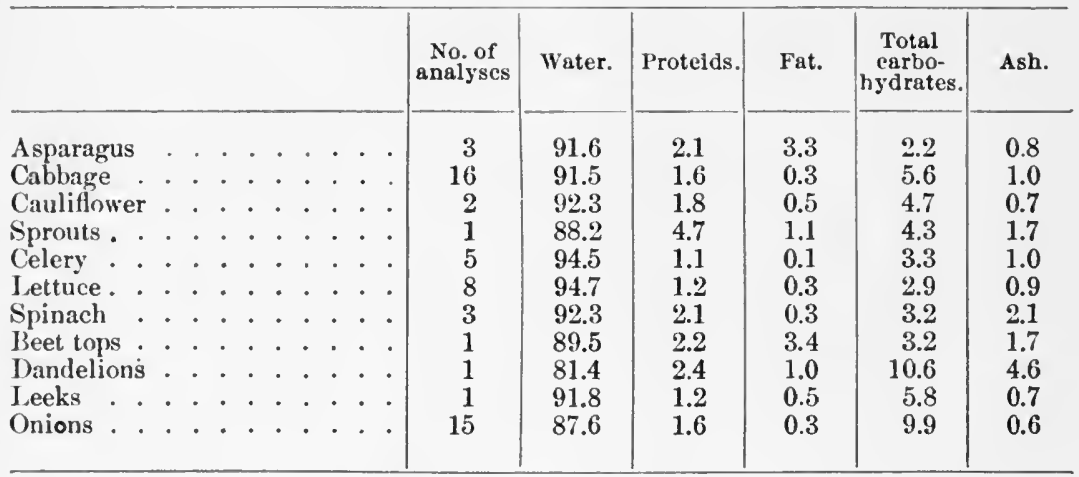

Fig. 9.

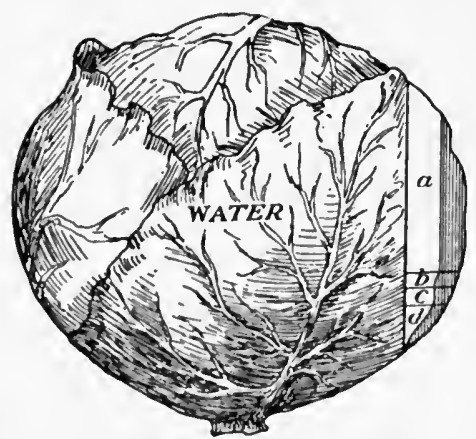

$a$, starch, sugar, fiber, fat, ete. : $b$, non-albuminoid nitrogenous matter; $c$, albuminoid nitrogenous matter; $d$, mineral matter. Tbe batched portion represents the loss. (After SNYDER.)

The composition of the cabbatge and the loss incurred through boiling are shown in the accompanying figure (Fig. 9), by Snyder. 
In a general way it may be accepted as representing the entire group.

\section{Fruit Products Used as Vegetables.}

These include the tomato, cucumber, squash, pumpkin, egg-plant, and vegetable marrow. The tomato is consumed largely in the raw state as a salad, and in several cooked forms. It contains less than 6 per cent. of solid matter, and in this respect has about the same nutritive value as celery and lettuce. Its chief solid matter is sugar. Its mineral constituents are free from earthy salts. The cucumber in the raw state, in which condition it is eaten most commonly, is not easy of digestion; but when stewed, is light, wholesome, and agreeable. As a nutriment it stands even lower than the preceding, containing less than 5 per cent. of solid matter. The squash, pumpkin, vegetable marrov, and egg-plant have about equal nutritive value. They contain about 90 per cent. of water, are very poor in proteids-less than 1 per cent.-but are fairly rich in carbohydrates.

\section{Fruits.}

As stated above, the word fruits is used here in its narrower sense to designate those products which, being of an agrecable taste in the raw state, are suitable for use as a dessert. The agreeable taste depends upon the relative proportions of pectin, sugar, gum, acids, and other constituents. Some fruits with but a small percentage of sugar and considerable acid have a sweeter taste than others richer in sugar and with no more acid, because of the masking of the free acid by the gum and pectin. Thus, the peach, for instance, is comparatively poor in sugar, but its content of acid is prevented from being prominent by the large content of gum and pectin. Some fruits contain usually but little of these constituents.

Fruits contain but little proteid matter, and their chief food value lies in the sugar, salts, and regetable acids which they contain. Eaten in moderation, they exert a favorable influence on the system, but when taken in undue proportion to other foods, and especially in unripe or too ripe states, may cause digestive derangements. On account of their richness in vegetable acids and their salts, which in the system are decomposed and converted to carbonates, they tend to diminish the acidity of the urine.

\section{APPLES.}

In the raw state, apples are not very easy of digestion, but when cooked they are much more so, and when baked are reputed to be slightly laxative and, therefore, useful in habitual eonstipation, but not suitable in the reverse condition. From the many analyses which have been eompiled by various authorities, it may be stated that this fruit contains about $8 \dot{5}$ per eent. of water, 7.5 per cent. of sugar, 1 of malic 
acid, 0.4 of ash, besides variable amounts of pectin, pectose, fiber, and other matters.

\section{PEARS.}

Pears are somewhat richer than apples in sugar and poorer in malic acid. They are fairly rich in pectin.

\section{PEACHES.}

In this fruit, the sugar is comparatively low, but the pectous matter is exceptionally high and covers the acidity. Peaches contain nearly 1 per eent. of malie acid.

\section{APRICOTS.}

The sugar content of apricots is about equal to that of peaches. The pectous matter is also about the same in amount, but the acidity is higher.

\section{PLUMS.}

Plums contain, as a rule, less sugar and pectin and more malic acid than are found in peaches and apricots. They are much more likely than most other fruits to disagree and produce derangement of digestion.

\section{CHERRIES.}

Cherries are notable for their large content of sugar, over 10 per cent., surpassing in this respect all of the foregoing. They contain somewhat less than 1 per cent. of malic acid and are low in pectin. The popular idea that, even in ripe, sound condition, they are a dangerous article of food if eaten in conjunction with milk, has no foundation in fact; but when unripe or unsound, they have a tendency to cause disorder of the bowels.

The average composition of the foregoing fruits is shown in the following table, compiled from König:

\begin{tabular}{|c|c|c|c|c|c|c|c|}
\hline & Water. & Sugar. & Acid. & Proteids. & Pectin, etc. & Fiber. & Ash. \\
\hline Apples & 83.79 & 7.22 & 0.82 & 0.36 & 5.81 & 1.51 & 0.49 \\
\hline Pear: & 83 & & 0.2 & 0 & 3. & 4. & 0.31 \\
\hline Peaches. & 80.03 & 4.48 & 0.92 & 0.6 & 7.1 & 6.06 & 0.69 \\
\hline Apricots & 81. & & 1. & & 6. & 5.27 & 0.82 \\
\hline Plums & 84.86 & 3.56 & 1.50 & 0.40 & 4.6 & 4.34 & 0.66 \\
\hline Cherries . & 79.82 & 10.24 & 0.91 & 0.67 & 1.56 & 6.07 & 0.73 \\
\hline
\end{tabular}

\section{ORANGES.}

The orange contains nearly 2.5 per cent. of citric acid and about 4.5 of sugar. The juice is particularly agrecable in almost any condition of health or sickness, and is extremely unlikely to cause any disturbance of the system. 
The average composition of oranges (23 analyses), according to Atwater and Bryant, is as follows:

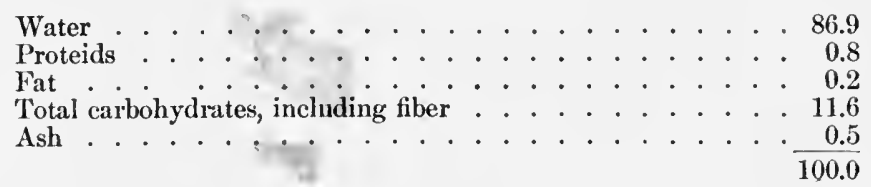

\section{GRAPES.}

The juicy pulp of the grape is wholesome and refrigerant, and when eaten in large amounts exerts a gentle laxative action. Since the number of varieties reaches into the thousands, it follows that wide variation in composition must occur.

Twelve analyses compiled by König yield the following averages :

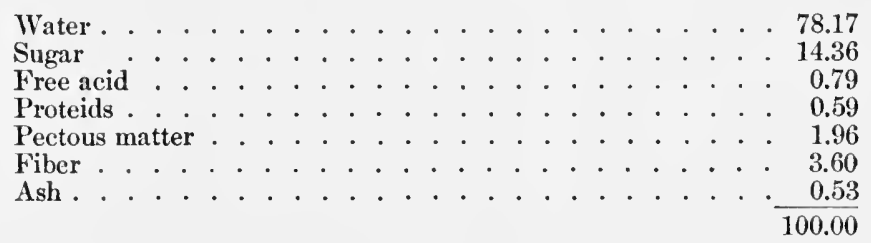

Five analyses compiled by Atwater and Bryant yield averages which are expressed somewhat differently, as follows:

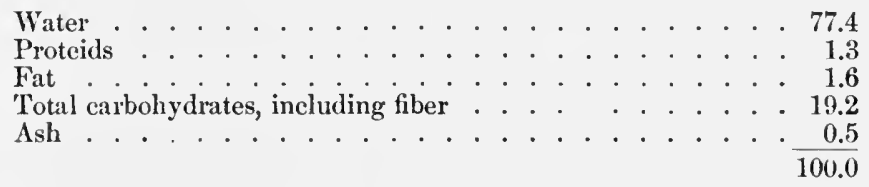

When dried in the sun or in ovens, the product is raisins. Those dried in the sun are the better. Raisins are less digestible than grapes, and are not infrequently the cause of derangement of the intestinal canal.

What are known commonly as dried currants are raisins made from small seedless grapes. They eome from the Levant, and are shipped from Corinth, whence their name in a corrupted form. They are exceedingly indigestible, and are likely to traverse the entire digestive tract without undergoing change.

\section{MELONS.}

The edible portion of melons is very watery, but the small amount of nutriment contained is not unlikely to cause in many persons digestive disturbances accompanied by amnoying eruetations. Not many analyses have been recorded. Storer, ${ }^{1}$ quoted by König, has reported three analyses, which give the following averages:

${ }^{1}$ Report of Connecticut Expcriment Station, 1879, p. 159. 


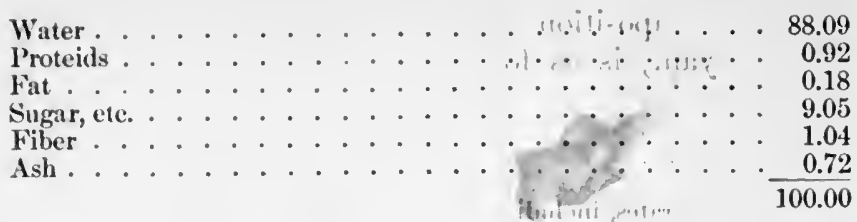

Two analyses of watermelons noted by Atwater and Bryant give the following a verages :

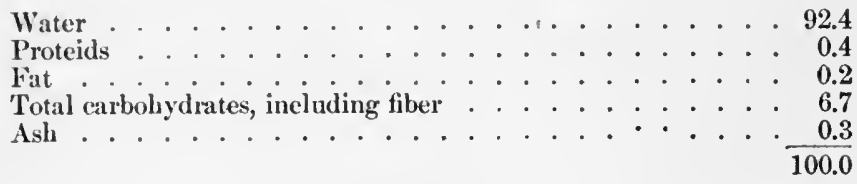

\section{BANANAS.}

Bananas and plantains are among the most nutritious of fruits; in many parts of the tropies, they constitute the chicf food of those who are too lazy to perform any kind of manual labor. The edible part yields about 20 per cent. of sugar (cane and invert), about 2 of proteids, 0.5 of stareh, and rather more of fat.

\section{FIGS.}

The fig in the fresh state is about equal to the banana in nutritive properties. In both the fresh and dried forms, it is esteemed highly as a mild laxative. The dried fig contains about 30 per cent. of water, 50 of sugar, 4 of proteids, and 3 of ash ; the remainder is chiefly seeds and fiber.

\section{BERRIES.}

The various berries are notable for their content of free acids and sugar. Two kinds, the cranberry and the barberry, are too sour to be eaten raw, and must be cooked with sugar in order to be made palatable. The composition of the several members of this group is set forth in the following table, compiled from König:

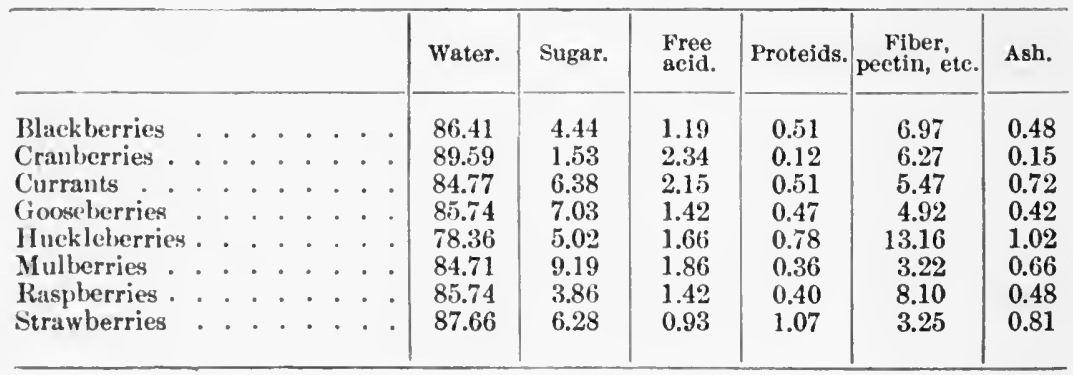




\section{Edible Fungi.}

\section{MUSHROOMS.}

Mushrooms are reputed to be extremely rich in nitrogen and other nutrients, and accordingly they are recommended as a valuable food material. It is true that they are somewhat rich in nitrogen, but it should be said that a large proportion of this element present is in combinations (amido compounds) which are uscless as food. As a matter of fact, the total solid matter of mushrooms averages about 12 per cent., and is largely woody matter. Mushrooms are rather difficult of digestion, and are not at all adapted to weak stomachs. They have been called "the poor man's meat," and nuch has been done to encourage the poor to seek for them in the fields and woods, in order to add to the larder. Inasmuch as the market price of mushrooms for the tables of the rich is generally high, and since their food value is decidedly overrated, it would appear that, where there is a market for them, the poor can do much better for their nutrition by disposing of their findings and converting the proceeds into cheaper, more digestible, more nutritious, and less cloying articles of food.

Truffles contain more nitrogen than is found in mushrooms, but they are very much more woody, and can hardly be looked upon as valuable from the point of view of nutrition.

\section{Saccharine Preparations.}

Sugar was known to the ancient Greeks and Romans, and its manufacture has been conducted by the Chinese sinee the earliest times. It is very soluble and diffusible, and, therefore, is digested easily. Dextrose is ready for assimilation, but sucrose, maltose, and lactose must undergo first a splitting process within the digestive tract.

\section{CANE SUGAR.}

United States Standard.-Standard sugar is white sugar containing at least 99.5 per cent. of sucrose.

Cane sugar is obtained from the sugar cane, sugar beet, sorghum, and sugar maple. It is very soluble in water, but quite insoluble in absolute alcohol. Heated with dilute mineral acids or with citric acid, it splits into dextrose and lrvulose, and then is known as invert sugar from the fact that the polarization becomes inverted. Cane sugar rotates the plane of polarized light to the right; the two substances into which it is split, dextrose and levulose, rotate respectively to the right and left, but the action of lievulose is so much the stronger that the mixture gives left polarization.

Heated above $180^{\circ}$ C., sugar yields caramel, which is not a simple substance, but a complex mixture of brown products of dehydration. It is used as a coloring for low-grade milk and other articles of food, and somewhat as a flavoring.

Cane sugar is sold in various forms : eut or loaf sugar, granulated, and powdered. The cheaper" grades, known from their color as "brown 
sugars," contain variable amounts of invert sngar, gummy matters, and other impurities.

Sugar is not much subject to adulteration, though there is a popular idea that glucose and sand are common admixtures. It is probable that sand is as lare an adulterant of sugar as chalk is of milk. Glucose rurely is mixed with sugar, but is used considerably as a substitute for it in the manufacture of cheap jellies, jams, and candies. Sugars that are somewhat "off" color" are treated sometimes with ultramarine in the final processes of manufacture. This corrects the fault and makes the product white. Occasionally, the amount added is suffieient to cause great alirm in the household when large quantities of sugar are made into syrup with hot water in the preparation of preserves and jellies. The blue material comes to the surface as a scum, and its unlooked-for appearance gives rise to suspicion of poison.

\section{MAPLE SUGAR.}

United States Standards for Maple Products.-Maple sugar is the solid product resulting from the evaporation of maple sap, and contains in the water-free substance not less than 0.65 per cent. of maple sugar ash.

Maple syrup is syrup made by the evaporation of maple sap or by the solution of maple concrete, and contains not more than 32 per cent. of water and not less than 0.45 per cent. of maple syrup ash.

This form of cane sugar is prized highly for its agreeable flavor. It is a much more expensive article than ordinary sugar and is used more as a confection. In the form of syrup, it is used very extensively on buckwheat cakes and with other cereal breakfast foods. It is much subject to adulteration and substitution. A large part of the syrup in the market is wholly artificial, being made of ordinary sugar or glucose, appropriately colored, and correctly flavored by means of extract of lickory bark. The sugar itself is imitated in the same way, but one not infrequently sees specimens which are absolutely devoid of any flavor save that of brown sugar. The substitution by flavored cane sugar is easily proved by determining the amount of precipitate of lead malate yielded by 5 grammes of the suspected sample in 10 c.c. of water on the addition of basic lead acetate solution. Five grammes of pure maple sugar so treated should yield, after centrifugation, 2.5 c.c. of precipitate, while pure cane sugar yields none. The presence of glucose is revealed by the behavior of the specimen under polariscopic analysis.

\section{GLUCOSE. DEXTROSE.}

Dextrose, or grape sugar, is inferior in sweetening power to cane sugar, and is not erystallizable to the same extent. It is much less soluble in water, but is soluble in glycerin and in alcohol of ordinary strength. It is found in grapes and in many other fruits and vegetables, but always associated with levulose. By fermentation with yeast, it splits into carbonic acid and alcohol; in the presence of ferments which disorganize proteids, it vields lactic acid. It exerts a strong reducing power on Fehling's solution. 
Commercial glucose is obtained by heating starch, usually cornstarch, with diastase or dilute sulphuric acid. Before the final process of concentration of the solution, the acid is neutralized completely by the application of marble dust, and the resulting sulphate of calcium and the excess of the neutralizing agent are removed. The product always contains considerable proportions of maltose and dextrin, and its rotatory power is, therefore, much greater than that of pure glucose, such as is obtainable from diabetic urine.

Glucose is produced in enormous quantities both in the solid form and as a thick colorless syrup. It is used in the manufacture of cheap candies, jams, and preserves, in the brewing of beer, and as an adulterant of molasses and honey (see under Beer).

\section{MOLASSES.}

United States Standard.-Standard molasses contains not less than 25 per cent. of water nor more than 5 per cent. of ash.

Molasses is a thick, viscid, dark-colored liquid, which drains away in the process of the manufacture of sugar. It contains from 65 to 72 per cent. of sugar, part of which is sucrose and part fruit sugar, various salts, gummy matters, extractives, and water. It is graded according to color from the cheapest, almost black article known as "black strap," to the finest, which is light yellowish brown. When refined, it is brilliant and transparent, and is known as syrup.

All grades, but especially the higher, are adulterated extensively with glucose syrup. This reduces the sweetening power, but gives body and a finer appearance. The fraud is detected readily by the use of the polariscope, since the adulterated article gives a much higher reading, and on inversion, instead of giving left polarization, continues to give a reading to the right almost as high as before. Another, and, from a sanitary point of view, a more important adulterant of molasses, is the protochloride of tin, known also as "tin crystal " and "salts of tin." "This is added for the purpose of reducing the amount of color, thus giving a fictitious added value. It combines with part of the coloring matters, and the resulting compound separates and tends to deposit. Thus a large proportion of the amount added to a hogshead may be found in the "foot," or sugar sediment, which is used quite commonly in the making of cheap candies, such as cocoanut taffy. Only a part, however, is deposited, and hence a specimen thus adulterated will yield notable traces of the salt on incineration and analysis. It is useless to attenpt to scparate the tin in the ordinary way without previous incineration, since the organic matters present prevent precipitation of the sulphide. Inasmuch as the protochloride of tin is an irritant poison, and since its addition can serve no legitimate useful purpose, this form of adulteration should be prohibited and punished. Sometimes tin is present in molasses, not as an adulterant, but because of a practice, followed by some makers of crude sugar, of treating their product with this agent to improve its color before it leaves the centrifugal machines, and thus it finds its way into the by-product. 


\section{HONEY.}

Honey is classed sometimes as an animal food, since it is a product stored up by bees, but it can hardly be so considered, since it is obtained from the nectaries of flowers, although during its storage in the bee's crop it undergoes some change. After this alteration by the secretions of the crop, it is disgorged and deposited in the cell of the honey-comb.

Honey is a concentrated solution of sugars, ehiefly dextrose and levulose, with small amounts of sucrose and manuite, contaiuing also small amounts of wax, organic acids, proteids, mineral matter, pollen, and odorous and other priuciples. 'The flavor, color, and odor vary' according to the nature of the flowers from which the honey is obtained. Sometimes, when derived from poisonous plants, it has toxic properties; this fact has been noted by both ancient and modern writers. Xenophon, for example, has recorded most serious symptoms of intoxication due to its ingestion, and a number of small outbreaks resembling ptomain-poisoning have been reported by recent writers in this country. Xenophon" says: "As to other things here, there was nothing at which they were surprised; but the number of beehives was extraordinary, and all of the soldiers that ate of the combs lost their senses, vomited, and were affected with purging, and not one of them was able to stand upright; such as had eaten ouly a little were like men greatly intoxicated, and such as had eaten much were like madmen, and some like persons at the point of death. They lay upon the ground, in eonsequence, in great numbers, as if there had been a defeat; and there was general dejection. The next day not one of them was found dead; and they recovered their senses about the same hour they had lost them on the preceding day; and on the third and fourth days they got up as if after having taken physic."

Dioscorides speaks of a kind of honey that made those that ate it mad, and ascribes its poisonous properties to the great abundance of rose-liturel and other similar poisonous plants. Strabo speaks of honey that made men stupid and melancholy; and Diodorus, of a certain kind in Colchos which produced such profound weakness in those that ate it " that they appeared for a whole day together like dead men."

Honey from the flowers of the yellow jasmine has been known to produce serious and even fatal results, and that derived from a species of rhododendron growing in the neighborhood of the Black Sea has long been recognized as poisonous.

The power of honey to exert a medicinal influence is sometimes turned to good accomnt. Thus, in Abyssinia, where the flowers of the cusso tree are the universal remedy for tapeworm and ascarides, with which a large proportion of the population is afflieted, swarms of bees are kept by order of King Menclek in gardens where no other plant is cultivated, and the honey which they store has been found to have all the good qualities of the drug with none of its unpalatability or unpleasant effects, such as nausea and vomiting.

By microscopic examination, which will show numerous pollen

1 Aṇabasis, Book IV., Chap. 8. 
grains, one ean determine easily from what kind of a flower honey was gathered.

Honey contains abont 73 per cent. of sugar. In eonsequence of the preponderant influence of the lævulose on the rotation of the plane of polarized light the polariscope reading of a pure sample is almost always to the left; when not to the left, the reading is not more than a few degrees to the right. The percentage of water averages about 18 or 19 ; occasionally specimens are found to contain as much as 25 .

Honey is an important sugar food; it is very agreeable to the taste and easily assimilated. On account of its comparatively high price, it is very subject to adulteration with glucose and eane sugar. That which is sold in the comb, the comb still in its frame, is almost invariably genuine. The extracted honeys sold in bottles and tumblers are very commonly mixtures of the genuine article with glueose or eane sugar, and often contain no honey whatever. In order to convey the idea of genuineness, it is a eommon praetice to insert a small piece of comb. At least one ingenions fabrieator of glucose-honey has been known to add to each tumbler of his product a dead bee, to serve as a silent false witness of its origin.

The detection of adulteration with glucose or came sugar is an easy matter, since all samples so made give a strong reading to the right on polariscopie examination. On inversion of the sample, the righthanderl reading persists if the adulterant is glucose, and is changed to the left if cane sugar. It is said that inverted eane sugar sometimes is mixed in proper proportion to make an artificial honey which will give the normal polariseopic test of the gennine article; and that to imitate the latter still further, so that mieroscopieal examination also may attest its genuineness, pollen grains are arlded in suffieient amounts. The ash of such a product alone will reveal the fraud, since it will contain no phosphoric aeid, while genuine honey contains about 0.03 per eent. of that substance.

\section{CONFECTIONERY.}

Candies are preparations made of sugars or substances containing them, such as molasses and honer, with or without the admixtnre of other foor materials, such as nits, fruits, and chocolate, starehes and fats to give body and consistenee, and flavoring and coloring agents. The addition of substances which serve no legitimate niseful purpose, snch as terral alla, which is said to be arded sometimes to lend weight, and of injurious color's and flavors, may properly be regarded as adulteration; but the use of glucose sugin, cocoa butter, and other sulstances of a larmless nature, and possessing value as nutriment, caunot be so regarded. Many, some say most, of the cheaper eandies, contain valriable amounts of glucose and stareh, but nothing is to be said against the use of these substances on the score of wholesomeness. The use of terra alba is supposerl popularly to be very common, but numerous analyses by many chemists throughout the country show 
that this substance is an exeeedingly uncommon ingredient of even the very cheapest candies.

'The flavoring agents commonly employed are, as a rule, harmless. The colors used, however, are not infrequently of a poisonous nature, especially in those States which have no laws against food adulteration, or which, having them, make no provision for their enforeenent. 'These injurious eoloring agents include the chromates of potassium and lead, tin lakes, and certiin of the coal-tar products, such as Martius yellow, dinitroeresol, and dinitroso-resorcinol. The employment of chromate of lead and of ehromate of potassium is frequently denied, but these substanees, nevertheless, are used not uneommonly, and have been detecter by the author in many specimens of yellow sugars used for decorating eakes, and in yellow eandies made in the shape of beans. The majority of the colors used are, however, of a harmless nature.

\section{JELLIES AND JAMS.}

Jellies are semi-solid glutinous preparations made by boiling fruit juices with sugar and allowing to cool; jams are somewhat similar preparations, which include the pulp of the fruit as well as the juice.

Many of the jellies found in the shops are made with glucose syrup, eane sugar, gelatin, artificial flavorings and colors, and extracts made by boiling the refuse of canning establishments. Jams, likewise, are largely factitious, being made with glueose syrup, flavorings, colorings, various kinds of seeds, and nearly tasteless vegetable tissues, such as summer squash and boiled white turnips.

\section{Section 5. BEVERAGES.}

\section{Stimulant Beverages Containing Alkaloids.}

These include tea, coffee, and cocoa, and certain others not nsed to any large extent in this country. The alkoloids of these products are known, respectively, as theine and caffeine, which are chemically identical, and theobromine, which is very elosely related.

\section{TEA.}

The virtues of tea were discovered, according to Chinese tradition, more than 2700 years before the Christian era. It was used first in England in the seventeenth century (about 1657), and eame there into general use about 1675. It was introduced into America in 1711.

Tea is the dried leaf of a shrub, Then Chinensis, indigenous to China and other parts of Asia, and eultivated in India, Japan, and Ceylon. Formerly, the varieties of the plint prodneed by different methods of long eultivation were believed to be distinet species, and were known as $T$. Bohea, T. viridis, etc. The differenees in the varieties found in commerce depend upon the age of the leaves when gathered and their position on the stem, and upon special methods of drying and preparing them for the market. The choicest varieties, for example, are those 
which include only the terminal leaves, and the poorest those made up of the largest and coarsest leaves from the lower end of the twig.

Tea is elassed eommonly as green or black. Both kinds come from the same shrub, lut are different in point of age, and are enred in lifferent ways. Green tea is made from young leaves, which are roasted quickly shortly after being gathered, and then rolled and again roasted. Black tea is from older leaves, which are allowed to wilt, and then are gathered into heaps and left withont farther manipulation for about a hilf day, during which time they undergo a fermentative process and change color. Next, they are rolled by hand and then heated, and these processes may be repeated several times alternately. Finally, they are dried slowly over burning ehareoal.

The comprosition of tea is very variable, and it is impossible to give figures which may be acepted as indieating the approximate constitution of a typical specimen. König has colleeted 16 analyses, which give the following averages:

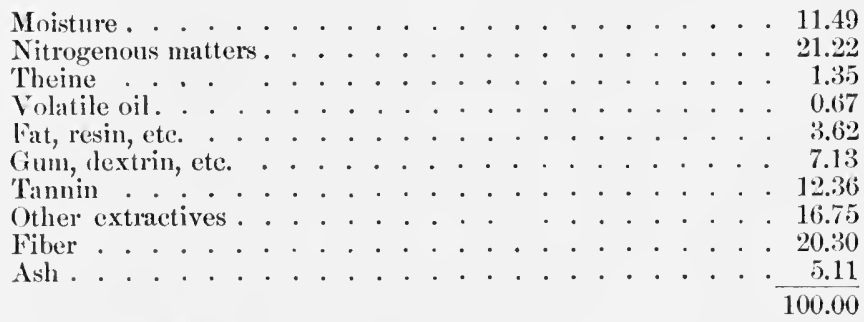

But it should be said that the rariations in the amounts of individual eonstituents of these 16 specimens are very wide: for instance, water, 4.59) to 16.06 ; theine, 0.40 to 4.94 ; tamnin, 4.10 to 20.88 ; fiber, 15.11 to 25.06. Dragendorff found, in 2:3 speeimens, from 1.36 to 3.09 per cent. of theine, 7.10 to 12.66 of moisture, and from 24.80 to 44.50 per ecut. of total soluble contituents. The ash of pure tea is fairly constant in amount, and almost never reaches as high as 7 per cent.; ustally, between 5 and i per eent.

Tea shoukl be used only in the form of an infusion, made by pouring boiling water upon the requisite amount of leaves, and allowing it to stand a short white to "dlaw." It is used not meommonly in the form of a decoetion; that is, by boiling. This proeess is oljocetionalble in two ways: first, the delieate aroma is lost by the expralsion of the very volatile eswential oil ; and second, the leaves are made to vield all their tannin and other extractives, which tend to bring about, sooncr or later, derangenent of the digestive function and a catarrhal condition of the stomach. The finest and most delieate portion of an infusion is that which is poured off within three or four minutes, for in this will be found a maximum of flavor with a minimm of hitterness and astringeney. The excellence of an infinsion is influenced eonsiderably by the eharacter of the water, which, if very hard, is slow in extracting the desirable soluble constituents, while, if very soft, it extracts not only these, but far too rapidly the less desirable prineiples. 
When properly made, tea in moderation is a wholesome, agreeable, and refreshing stimulant beverage, particularly grateful in conditions of mental or physical wariness. Used in excess, it exerts a harmful inthence upon the nervous system, and in a too strong form injures the digestive tract and function.

The abuse of tea as a beverage leads, according to Bullard, ${ }^{1}$ to ringing in the ears, tremor, nervousness, headlache, neuralgia, hysteria, irregularity of the heart, dyspnoea, dyspepsia, and constipation.

Dr. Hayes, the Aretic explorer, has testified to the value of tea and coffee in enabling men to endure cold and hardship of all sorts, tea being especially soothing at the end of a hard day's work.

While tea by itself ean hardly be looked upon as an article affording any important amount of nutriment, as commonly consumed it serves as a vehicle for other substances, as sugar, nilk, and eream, having high nutritive value.

Adulteration of Tea.-It is commonly stated and generally believed that tea is adulterated extensively with other kinds of leaves, including those of the beech, sloe, willow, and hawthorn; but at the present time, it is extremely improbable that such adulterants ever are mixed with tea known to be intended for export to this country. Whatever the conditions may have been prior to the enactment of the national law governing tea importation, the fact now is that our tea supply is practically free from this form of adulteration. The detection of spurious tea leaves would be an easy matter, since the genuine have a very eharacteristic appearance which can hardly be confused with that of any of the possible substitutes; and even when broken into small bits, the characteristic differences in venation and serration, and in the stomata as well, are plainly discernible.

Nore probable forms of adulteration include the admixture of wholly or partially exhausterl laves; the addition of astringent matters, such as catechu, to lend color and apparent strength to the infusion; the presence of foreign mineral matter; and the practice of "facing."

The presence of any large proportion of exhausted leaves ean be detected by the low anount of total soluble extract and by the small amount of soluble ash, which should not be less than 3 per eent. of the weight of the leaves. The presence of important amounts of aceidental or added mineral matters is shown in the total ash, which in a genuine specimen rarely amounts to 7 and never to 8 per eent. The substances most often found are sand and soapstone ; the first named is found sometimes in amomts exceeding 25 per eent.

Catechu is applied occasionally to exhausted tea leaves with the aid of solutions of gummy nuatters, for the purpose of adding astringency and color to the infusion. Teas so treated have but little, if any, of the true aroma, and their infusions yield a sediment in which the particles of "ateehu can readily be seen.

The olject of "facing" is to make the product appear to be of greater value, and the practice is, therefore, properly speaking, one which eomes within the definition of frandulent adulteration. Damaged

1 Boston Medical and Surgical Journal, April 8, 1886, and September 8, 1887. 
or otherwise inferior leaves are treated with Prussian blue, plumbago, indigo, and other substances, and the small amount which adheres improves their color and general appearance. This amount is too small to be of any sanitary significance. The presence of facing materials may be detected by the use of the microscope and by chemical analysis.

\section{COFFEE.}

Coffee is the sceds of the Coffea Arabica, dried and deprived of their fleshy covering. The fruit is a small pulpy berry containing, usually, two seeds. The tree is said to lave originated in Abyssinia, where, however, in the seventeenth century there were few, if any, specimens, and to have been introduced into Arabia in the fifteenth century. It is now grown very extensively in Brazil, Java, Peru, Ceylon, West Indies, and other hot countries. The first European to mention it was Prosper Alpinus, of Padua, who included it in an account of Egyptian plants, published in 1592. The first work devoted wholly to coffee was a small Iatin treatise, De saluberrima potione cahue, by Faustus Nairo, Rome, 1671. Coffee was first sold in London by a Levantine, in 1650, and some ycars afterward was introduced into France. The first whole cargo introduced into this country arrived in 1809, but coffee houses were licensed in Massachusetts as carly as 1715 .

The world's production of coffee for the year ended June 30, 1900, was estimated at almost 900,000 tons. ${ }^{1}$ This country alone consumes more than the whole of Europe: in 1897 we consumed 318,170 tons against 305,150 . The total consumption by Germany was 136,390; by France, 77,310 ; by England, 12,420 ; and by Italy, 12,500 tons.

$A s$ is the case with tea, coffee must undergo a process of roasting before it is fit for use, althongh it is said that the Arabians and other Eastern peoples make a decoction of the raw article and swallow the grounds as well as the liquid. The roasting is conducter at about $200^{\circ} \mathrm{C}$. until the natural color, which is greenish, grayish, or drab, is changed to a rich dark brown. During the process, certain volatile aromatic principles are developed, the alkaloid caffeine is dissociated from its union with tamnin, the moisture is very largely expelled, the sugar is caramelized, gases are formed (largely carbonic dioxide) which cause the berry to swell, and much rupturing of the cell layers oceurs. The berry thus loses in weight and gains in bulk. The process must be condueted earefully, else the quality will not be what is desired, since if the roasting is not pushed sufficiently far, there will be insufficient development of aroma ; and if it is carried too far, the volatile matters are expelled and the product acquires an unpleasant taste. On account of the volatile nature of the aromatic principles developed, eoffec should be roasted only as the demands of commerce make it necessary. On long keeping, exeept in hermetically sealed containers, it undergoes extensive deterioration. For the same reason, the roasted berries should be ground only as needed.

1 Consular Reports, Vol. LX., p. 258. 
Coffee contains less caffeine (theine) than is found in tea ; thus, Drangendorff' found the amount in 25 samples to vary between 0.64 and 2.21 per cent., whereas in about the same number (23) of samples of tea, the range was 1.36 to 3.09 . It contains eonsiderable amounts of fat, generally over 12 per eent., about the same amount of nitrogenous matters, small, quite unimportant anomints of sugars, gummy matters, and other substances, and about 40 per cent. of fiber.

Coffee is uncrl in infusion and as a decoction. Like tea, it loses its pleasant aroma when boiled, but its decoction is less bitter and astringent than that of tea. In order to enjoy both the fragrance of an infusion and the strength and body of a decoction, it is not an uncommon practice to make first the one and pour it off, and then, with a fresh portion of water, to boil the grounds for a few minutes, and then to mix the two liquids together.

Coffee acts als a decided stimulant to the nervous system, enables one better to perform arduous work, and diminishes the sense of fatigue. In small anounts, it increases the force and frequency of the pulse, but taken in excessive quantities, it eanses palpitation and intermission, besides general nervousness and derangement of digestion. It has a marked inhibitory influence on gastric digestion, and is more oppressive to the stomach than tea and, hence, should be used with eantion by dyspeptics. With some persons it stimulates peristalsis, and thus aets as a gentle cathartic. It increases the secretions of the skin and kidneys.

Coffee is adulterated very extensively with a variety of substances of widely different nature; including chicory, dandelion, and other roots, roasted cereals and legumes, sawdust, date stones, red slate, acorns, and other cheap articles. It is not alone in the ground form that it is fulsified, for even the beans are imitated with mixtures of flour and other materials, moulded to the correet shape and earefully roasted and colored.

The detection of adulterants in coffee requires but little time. Of great assistance is the fact that coffee contains absolutely no starch, while most of the commoner adulterants contain it in abundance. Therefore, if a specimen under examination is boiled and filtered, and the filtrate gives a dirty blue reaction with test-solution of iodine, one may be sure that adulteration has been praetised. But not all of the adulterants are starehy in their nature and, therefore, other examination is necessary. Microseopical examination will deteet not only the starehy, lout the non-starehy matters as well. Under the microseope, ground coffee has a characteristic appearance which camnot be mistaken for anything else. Clicory and other roots, date stones, and all other berries and seeds have their own characteristies. For the mere determination of the question of purity, only a knowledge of the microscopical appearance of coffee itself is required, and this is aequired easily and quickly by direct study. For the identification of the adulterants present, one necessarily should be familiar with the appearance of all of the substances used.

Chicory is the root of the Cichorium intybus, a perennial herb, grow- 
ing wild and extensively cultivated in this country and in Europe. The roots are eleaned, eut into pieces, dried in kilns, roasted in iron eylinders, and ground into a coarse powder. Like coffee, ehicory when roasted contains a volitile principle and a bitter. It is used both as ąn adulterant and ass a substitnte for eoffee. Mixed with eoffee, it lends both color and flavor to the infusion, and by many is regarder as a desirable addition. It itself is subject to adulteration by cheaper roots, such as mangelwurzel and dandelion.

Coffee and chicory behave very differently when thrown into cold water: the former floats and retains its firm consistence, while the latter absorbs water very quickly and sinks, and in its deseent leaves streaks of eolor: Coffee which has been roasted too much will, however, sometimes sink, and elicory which has been treated with fatty substanees will float. Mixtures of the two can often be detected by the difference in resistance when placed between the teeth. The partieles of eoffee are mueh harder than those of ehicory, which yield very readily to pressure and also have a sweetish taste.

Inferior and damaged raw coffees not infrequently are eolored and faeed, in order that they may be improved in appearance or be made to imitate better grades. The facing agents used are mixtures eontaining variable amounts of ultramarine, indigo, clay, gypsum, chromate of lead, and coal dust.

A ecording to G. Wirtz, ${ }^{1}$ inferior grades of coffec are treated largely at Antwerp, Rotterlam, Hamburg, Bremen, and elsewhere, by washing, coloring, and finally drying by centrifugation with sawdust, the result being a fine white produet of an apparently greater value.

Package eoffees sold under varions manes, sneh as "French Breakfast Coffee," “Vienna Coflee," and “Eureka Breakfast Coffee," are rarely anything more than roasted and ground eereals and peas. It is to be said, however, that their ehanacter usnally is indieated in the directions for nse printed on the labels, which eommonly begin by advising the use of "a third more than you would nise of gemnine coffee." Mirroseopical eximination and the iodine test will reveal their composition very quickly.

Many efforts have been made to remove the eaffeine from coffee in such a way that the good qualities of eoffee may not be affeeted. One process, patented in Germany, has been investigated by Lendrieh and Murdfield, ${ }^{2}$ who found that while the proeess does not remove all the alfeine, the quantity remaining is from 0.14 to 0.26 per cent., or about $\frac{1}{6}$ of that in untreated coffee.

\section{COCOA.}

Coeoa, a corruption of Cacao, and in no way related to the cocoanut, is derived from the seeds of the Theobroma cucuo, a native of tropieal America. It is estimated that the annual production of the seeds amounts to about $150,000,000$ pounds, more than a fifth of which is

1 Zeitschrift für Untersuchung der Nahrungs- und Genussmittel, 1898, p. 248.

2 (Quoted by Leach, Food Inspection and Analysis, p. 391. 
exported by Eenador alone. Nearly a fifth of the ammal erop is consumed within the United States.

The fruit of the cocoa tree is a pod; about a foot long and half as wide, filled with "beans," or "chocolate muts," about as large as almonds, imbedded in five rows of from four to ten each in a pulpy matrix. When ripe, the pods are gathered and eolleeted into heaps, and left for a day or longer; then they are ent open and deprived of the seeds, which are allowed to undergo a process of fermentation in earthen vessels or in holes in the ground. This process, which must be regulated very carefully, has for its oljeet the removal of an acrid, bitter taste and consequent improvement in flavor. Sometimes, the seeds are dried in the sm as soon as removed, but the prodnct is then of much less value; sometimes, the entire pod is buried until the pulp becomes rotten and softened. When the fermentation process is completed, the seeds are dried carefully in the sum, and then beeome hard, brittle, and reddish or reddish brown in color.

In the preparation of cocoa for the market, the seeds first are cleaned and carefully roasted. As is the case with coffee, the roasting must be carried to a certain point to insure the development of the desired flavor, but not so far beyond as to impair it. During this process, the thin husks of the seeds become more detachable, and before the next operation they are removed. Then the seeds are crushed lightly and freed from their hardened germs, and in this form are known as "nibs." These are ground in a special form of mill into a paste ("flake cocoa"), which is monkled into eakes and allowed to harden. In this form, the product is known as plain chocolate. The swect and flavored chocolates are made with the addition of sugar, vanilla beans, cinnamon and other spices. Inferior vanilla chocolate is made with artificial vanillin and coumarin, in place of the far more expensive and better flavored vanilla bean.

For the preparation of powdered eocoa, it is neessary to remove a part of the oil, which, when present in its normal amonnt, favors caking. This removal is accomplished by hydraulic pressure, and the paste is then passed through sieves of exceedingly fine mesh.

The so-called soluble cocoas are prepared with sugar and starches, particularly arrowroot, but the cocoa itself is not soluble in water. The apparent solubility is due to the fineness of the powder and to the increase in the specifie gravity of the liquid due to the sugar in solution, looth these conditions favoring prolonged suspension withont sedimentation. Some of the Dutch soluble coeoas are treated with alkalies, for the removal of the crude fiber and for their effect upon the coloring matters. These cocoas thereby lose part of their natural flavor, but the loss is made up somewhat by the addition of fragrant foreign matter,

Cocoa was introduced into Europe by the Spaniards after their invasion of Mexico under Cortez, in 1519. It was not known in England until 1657, when it was sold first in London by a Frenchman. In this country, it first was prepared and sold at Danvers, Massachusetts, in 1771, from raw material brought from the West Indies by the fishermen of Gloucester. 
Unlike tea and coffee, which in themselves can hardly be regarded as adding any nutriment to the diet, cocoa is an exceedingly valuable food, which possesses the advantage of much nutriment in small bulk, and hence is particularly suited to the needs of those engaged in expeditions removed from eivilized centers. It makes a wholesome, agreeable, stimulant beverage, and is eaten in the form of chocolate, and as an addition to eakes, puddings, and other compounds. The cocoa nibs and plain chocolate contain about 50 per cent. of a whitish solid fat of agrecable taste and smell, commonly known as cocoa butter. It contains variable amounts of the alkaloid theobromine (dimethylxanthine), which is related very elosely to eaffeine and theine (trimetlylxanthine), and has nearly the same physiological action, although somewhat less stimulant and rather more diuretic. The amount is said to average about 1.50 per cent. Cocoa is rich in nitrogenous matter, contains more than 10 per cent. of a stareh with small round granules, and about 3.50 per cent. of ash, which is largely phosphate of potassimn.

Sixteen analyses of the kernels, compiled by König, give the following averages :

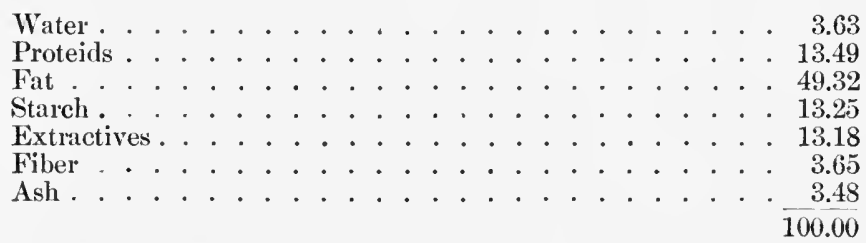

The husks, commonly known as "shells," are used in the preparation of a cheap and wholesome beverage. They contain little fat, but are about equal to cocoa in nitrogenous matter, and contain more than 40 per cent. of nitrogen-free extractives.

Cocon and chocolate are subject to extensive adulteration with substances having much less commercial value, though perhaps equally nutritious. Among those used, are starches of various kinds, as wheat, rye, potato, arrowroot, and riee, sugar, vegetable oils, mutton tallow and other fats, Venetian red, elay, and brick dust. Various flavorings are employed, such as vanillin, coumarin, elove, mace, eardamom, and nntmeg; but unless these are used under the name of vanilla or of other flavorings than themselves, they cannot be regarded as adulterations.

Milk Chocolate.-This is a mixture of chocolate, sugar, milk powder, and cocoa butter.

\section{Fermented Alcoholic Beverages.}

\section{BEER.}

Beer is the generic term which includes all fermented drinks made from malt-lager beer, ale, porter, and stout. As commonly nuderstood, beer is an infusion of malted barley, flarored with hops and 
fermented with yeast; but on account of the fact that wholesome substitutes for malt and hops may be employer in its manufacture, it is defined also at a "fermented saceharine infusion to which some wholesome bitter has been added." In this comtry, the term beer is restricted eommonly to the produet generally known as lager beer. Porter is a beer with a high percentage of alcohol, and is made from malt dried at a high temperature. Stont contains less aleohol and hops, but more malt extract. Ale is a pale beer antaining more hop extract and less malt extract than porter or stont, and brewed by " top fermentation."

Beer was made by the Eryptians many centuries before the Christian era. It is related that, for public reasons, the suppression of beer-shops was attempted by their government more than forty centuries ago. The ant of brewing wats tanght by them to the aneient Greeks and Romans; thus, beer was a common drink in Greece prior to 700 B. C., and was one of the prineipal beverages of the soldiers of Caesar. In the time of 'Tacitus, it was in common use in Germany ; and Pliny speaks of its use in Spain. 'The ancient Britons, at the time of the Roman conquest, made it from barley: At the time of the Norman conquest, the words beer and ale meant in England the same thing: a drink made of malt withont hops. Later, the word beer fell into disnse; but in the fifteenth and sixteenth centuries, after the introduction by the Flemish of beer made with hops, the term was revived, and then meant hopped ale. 'The use of hops was forbidden in 1530 by Henry VIII., who regarded them as an adulterant, and in the first year of the reign of Richard III., the authorities of London laid a fine of $6 \mathrm{~s} 8 \mathrm{~d}$ on every barrel of beer containing them. Later, this was rednced one-half.

The prejudice against the use of hops in brewing is expressed by one of the earliest English writers on dieteties, Andrew IBoorde, ${ }^{1}$ who says : "Ale is made of malte and water; and they the which do put any other thynge to ale than is rehersed, exeept yest, barme, or godesgood, doth sofystieat theyr ale. Ale for an Englysshe man is a natural drynke. Ale must have these propertyes: it must be fresshe and cleare, it muste not be ropy nor smoky, nor it must hame no weft nor tayle. Ale shunld not be drunk under v. dayes olde. Newe ale is v'nholsome for all men. And sowre ale, and daide ale the which doth stande a tylt, is good for no man. Barley malte maketh better ale than oten malte or any other corne doth: it doth engendre grose humonres; bnt yette it maketh a minn stronge. Bere is made of malte, of hoppes, and water: it is the naturall drynk for a Dutche man. And nowe of late dayes it is moche vsed in Englande to the detryment of many Englysshe men ; speeyally it kylleth them the which be troubled with the colyeke, and the stone, \& the strangulion; for the drynke is a eolde drynke; ret it doth make a man firt, and inflate the bely, as it doth appere by the Dutche mens farces delyes. If the bere be well serned, and be fyned, \& not newe, it doth qualyfy the heat of the lyuer."

1 A (ampendyoms Regyment, or A Dyetary of Ilelth, made in Mountpylier, compyled hy Andrewe Brorde of Plysyche Doctour, London, 1543. 
The ancient Germans made beer from all kinds of grains, and for flavoring used oak bark, sage, and leaves of the laurel, ash, and tamarisk. Hops were used nore or less from the ninth century, and came into general use in the eleventl.

Beer being the eommon drink of most European peoples before the establishment of colonies in America, it followed naturally that the early settlers of this country brought the art of hrewing with them. In 1629, the enltivation of hops had been carried on for some time in New Amsterdam, and hop roots were sent for from England by the authorities of Massachusetts. In nearly all the eolonies, the brewing of beer was regarded as quite as essential an aceomplishment of women as the ability to make good bread.

The first law regulating the sale of alcoholic beverages in Massachnsetts was made in 16:3:3 ; it preseribed that no person should sell wine or spirits withont a permit, but mate no reference to beer. In the following year, it was ordered that no one should eharge more than a penny for a quart of beer, and in $16: 37$, that no inn-keeper or victnaller should sell any intoxicating drink but beer; and this they were prohibited fiom brewing themeclves, but must obtain from a licensed brewer. In the following year, owing to the fict that the only one of this elass was unable to meet the demand, they were allowed to conduct the process themselves. In 1649, it was ordered further that every imn-keeper and victualler shonld keep always on hand a supply of good, wholesome beer. In 1651, the eourt undertook to stimulate the production of a hetter grate of beer in the belief that therehy the growing tendency to the use of wine and spirits and the inereasing habit of drunkenness would be checked, and permission was granted to charge one, two, and three penee per quart, aceording to the amount of malt used prer barrel.

A duty of a shilling per bushel of imported malt, imposed in 1654, callerl forth a protest from Buston merehants, on aceount of the very great importance of beer as a bevelage of the people. In the following year, in order to promote home production of malt, importation wats prohibiterl, but this order was repealed in 1660 . In 1667, the use of molasses as an adulterant of beer was pmishable by a fine of five pound.s. Similar laws relating to beer were passed from time to time by the anthorities of all the original eolonies.

Process of Manufacture of Beer.- The first step in the lorewing of beer is the preparation of the malt. The barley tirst is steeped in water for several days, and then is removed and arranged in heaps, which, after a time, are spread out and turned repeatedly until germimation hats proceceled to the requisite extent. Next it is dried in kilns at a temperature below or about $90^{\circ} \mathrm{F}$, and then is heated to from $125^{\circ}$ to $180^{\circ}$, according to the eolor desired. This process develops flavor, eompletely cheeks germination, and determines the eommercial eharacter of the product. The stepping of the malt is done best in water containing eonsidemable of the mineral salts that cause hardness; a soft water exerts too much solvent alction on the 
proteid matters, which, soon after extraction, are likely to uridergo decomposition. During the progress of germination, the ferment diastase is developed, and proceeds to convert the starch into dextrin and maltose. After the germs and rootlets have been removed by proper sereening and sifting, the malt is crushed, and then an infusion, the "wort," is made with water at about $160^{\circ} \mathrm{F}$. 'This is drawn off" from the exhausted malt, and then boiled for an hour or two with hops, which, besides giving a characteristic bitter flavor, assist in elarification by the action of their contained tamnin on some of the proteid matters. Then the boiled bitter wort is cooled rapidly, run into vats, mixed with yeast, and allowed to ferment for several days, during which time alcohol and carbonic aeid are formed from the maltose. The nature of the product is influenced very largely by the purity of the yeast and by the method of fermentation followed. Top fermentation is carried on rapidly, and at a comparatively high temperature, the yeast growing at the surface; in bottom, or sedimentary, fermentation, the yeast grows at the bottom, the process is slower, and is carried on at a lower temperature. The chief advantage of the employment of yeast which grows at a low temperature is that other, perhaps molesirable, growths may be unable to proceed. Whatever the process of fermentation followed, not all the sugar should be allowed to be eonverted, for then the flavor would be not what it should, and the keeping qualities would be impaired. On the completion of fermentation, the beer is separated from the yeast and transferred to vats, where it is clarified. As clarifying agents, a variety of materials are used, the chief of which are chips or shavings of eertain woods, as hazel or beech, which attraet and hold the particles which cause turbidity. These materials affect in no way the taste of the beer. Other substances used include gelatin, isinglass, flax-seed, and earrageen. After elarification is aceomplished, the product is stored for a time in storage casks, where it undergoes a further slow fermentation at a low temperature, after which it is ready for use.

Substitutes for Barley Malt._While barley is reeognized miversally as the grain best suited to the brewing of wholesome beer, any other cereal may be used. Sometimes, unmalted grains are added to the malt before the infusion is made, for the diastase of the malt is anpable of converting not only the starch with which it naturally is associated, but a large amount of other starehes; and so, rice, corn, and other eereals may be employed. Glueose and cane sugar are used somewhat, but the product is decidedly inferior in quality, since these substances are lacking in some of the clements, as proteids and mineral matters, which contribute to the desirable character of the best beers.

Concerning the use of gluense, which adds strength to the wort, there can be no objection on the score of being in any way deleterious to health. The popular belief in the unwholesomeness of glueose made from corn starch led the U. S. Treasury Department, in 1882, to request an investigation of the subject by the National Academy of Sciences. 'This was conducted by a committee of eminent scientists, 
including Professors Gibbs, of Harvard; Brewer, of Yale; Remsen, of Johns Hopkins ; Barker, of Pennsylvania ; and Chandler, of Columbia, whose conclusions were: that the processes employed in the mannficture are unobjectionable; that the product is of execptional purity, and in no way inferior in healthfulness to cane sugar; and that there was no evidence adduced to show that, even when taken in large quantities, either in its natural condition or fermented, it has any injurious effects upon the system. Fron a recent experience in Ëngland it appears, however, that not all manufacturers produce a pure article; and that if sulphuric acid made from arsenical pyrites is used in the process, the resulting sugar may contain sufficient arsenic: to cause serious and even fatal poisoning. In November, 1900, Dr. E. S. Reynolds ${ }^{1}$ called attention to a number of eases, characterized by paralysis, wasting of certain muscles, and loss of function of certain sensory nerves, which, after considerable study, he decided to be arsenical poisoning. Shortly afterward, an increase was noticed in the number of cases of, and deaths fiom, peripheral neuritis in different eities and towns, and it appeared that, in Manchester and Salford alone, there were about 3000 eases, and that the vietims were drinkers of beer. The beer in nise wats examined, and found to be distinetly arsenical, and it was learned that, in its manufacture, glucose and invert sugar, made at a factory near Liverpool, had been employed. Specimens of the glucose were found to contain from 0.02 to 0.05 per cent. of arsenions oxide, and examination of the various beers made therefrom showed from 0.10 to 1.50 grains of arsenie per gallon. The amount of beer consumed by the victins varied from a pint to two gallons per day; many drank a gallon each. A parliamentary commission, appointed to investigate the matter, reported finding from 0.56 to 9.17 grains of arsenic per pound of glneose, 1.40 to 4.34 grains per pound of invert sugar, 0.25 to 3 grains per gallon of beer, and 1.40 to 2.60 per cent. of arsenic in the sulphuric acid with which the sugars were made. Between November 25, 1900, and Jannary 10, 1901, there were no less than 36 deaths in Manchester alone, which were attributed to arsenical poisoning. The symptoms observed in this extensive ontbreak began, as a rule, with disturbances of digestion, followed soon by laryngeal and bronchial catarrh and acute skin eruptions, and then by disturbances of rensibility and motor paralysis. The eases were grouped into those in which atl the above srmptons were fairly well narked, and those in which the prineipal lesions were, respectively, of the skin, heart, and liver, and paralytic.

Substitutes for Hops.-Various substances have from time to time been reported as being used in place of hops to give bitterness to beer. These include nearly everything having a bitter taste, such as strychnine, ehirata, calumba, eocenlus indieus, aloes, and pieric acid. Coceulns indiens was mentioned in Holland as early as 1620 as an adulterant. This and its active prineiple pierotoxine, and picric acid, have been employed oceasionally in England and clsewhere; but at the present tince, it is safe to say, none of these substances is used. Of 476 sam-

${ }^{1}$ British Medical Journal, Nov, 24, 1900. 
ples of beer examined for the State Board of Health of New York, in 1885, not one was found to contain any hop substitutes whatever.

No objections can be alleged arainst such wholesome bitters as quassia, gentian, calumba, and chirata. Evidence that they ever are employed is exceedingly slight. As a matter of fact, there is no satisfactory substitute for hops, which grive not alone litternoss, but other flavors and a peeuliar aroma, due to the resinous matter which they contain. In the sixteenth and seventeenth centuries, various other flavorings were used, such as sage, coriander, laurel leaves, pepper, grains of Paradise, orris, and essential oils.

Physical Properties and Chemical Composition of Beer.-Beer should be perfectly elear and bright. The presence of any turbility denotes either imperfect brewing or the occurrence of undesirable decomposition processes. The latter are accompanied generally by disagreeable odors. The taste should be pleasantly bitter and inclining to sweetness rather than to acidity. There sliould be a sufficient amount of carbonic acid to make a pleasant impression in the mouth, such as is not produced by flat beer. 'The specific gravity ranges from about 1.005 to 1.025 , averaging below 1.020 . In bock beer, which is a special brew containing a considenable increase in malt extractives, the specifie gravity is notably higher, rumning as high as 1.035, and averaging more than 1.021 .

The most important constituents of beer are the extract and alcohol. The extract includes all of the non-volatile matters in solution, and eonsists of proteid matters, dextrin, sugar, hop resin, and other substanees left as a residue on complete evaporation. The amomt is variable; it is lighest in porter, stont, and bock beer, and lowest in the light-eolored lager beers. In the former, it averages about 7.50, and in the latter, about 5.50 per cent. 'Twenty-eight speeimens of Ameriean beers, ales, and porter collected in IV ashington, and analyzed by Mr. C. A. Crampton, ${ }^{\prime}$ averaged 5.53 per cent.

The average extract of 182 analyses of specimens of beers of the lighter kinds, compiled by König, is stated at 5.49 (range, 1.98-9.23); of 211 lager beers of all kinds, at 5.78 ; of 50 export beers, at 6.48 ; and of 56 bock beers, at 7.20 .

The amount of alcohol is also variable. The speeinens examined by Crampton, averaged 4.63 per cent. by weight and 5.79 by volume. The light beers above mentioned (König) averaged 3.46 per eent. by weight; the second group, 3.95 ; the third, 4.31 ; and the fourth, 4.74 .

Adulteration of Beer.-Beer is supposed pepularly to be extensively adulterated, and the substanees alleged to be in common use make up a list remarkable for length and variety, including such poisonous drugs as opium, belladonna, henbane, and strychnine, many of the aromatics and aromatic bitters, eorrosive acids, drastic eathartics, and many other substances. The actual adulteration of locer, however, is restrieted practically to the use of preservativers, such as sodium fluoride and salieylic acid, of sodium bicarbonate to correct acidity

${ }^{1}$ U. S. Department of Agriculture, Division of Chemistry, Bulletin 13, p. 282. 
and to increase the "bead," and of salt to correet bad taste and to inspire thirst for more.

The use of preservatives is the only form of adulteration which is of practical hygienic importance, and in several countries is punishable by heavy penalties. In Germany, preservatives are interdicted very strictly, except in beer intended for export; and the permission extended is accepted so freely that it is rare to find in this country a specimen of German bottled beer which does not contain a liberal dose of salicylic acid. Many Ameriean brewers use this agent with a generous land, under the benevolent plea that it is a prophylactic against rheumatism. By the same process of reasoning, one might contend just as well that opium in food and drink would prevent pain, and biniodide of mereury keep the system free from syphilitie infection.

\section{Analysis of Beer.}

In the analysis of beer, the most important processes are the determination of the percentage of alcohol and of extract, and the detection of preservatives.

Determination of Alcohol.-For the determination of the pereentage of alcohol, a sufficiently large portion of beer should be shaken in a capacions flask until the carbonic acid is expelled, and then a measured rohme should be subjected either to distillation or to partial evaporation in an open vessel.

(a) Determination by Distillation.-Introduce into a flask eonnected with a Liebig condenser $100 \mathrm{ec}$. of the well-shaken beer, at $60^{\circ} \mathrm{F}$, and distil into another flask eonneeted with the discharging end of the condenser by means of a bent glass tube. Continue the distillation until somewhat more than 50 ce. of listillate have been collected, when all of the contained aleohol will have been expellerl and condensed. Add sufficient water to the distillate to make $100 \mathrm{ce}$. at $60^{\circ} \mathrm{F}$, detemine its speeific gravity by means of a pienometer or Westphal balance (a speeific gravity spindle is not sufficiently aecurate), and asecrtain from this, by referenee to the appended table, the pereentage of aleohol by weight or volume.

(b) Determination by Open Evaporation,-This methor involves less manipulation and gives equally acenrate results. The specific gravity of the heer is determined first in the manner above mentioned. Then place 100 ce. at $60^{\circ} \mathrm{F}$. in a glass or poreelain evaporating dish, and by the applieation of heat drive off rather more than half the amonnt. Remove, cool, make up with water to the original volume at $60^{\circ} \mathrm{F}$., and again determine the specific gravity. Divide the original gravity by the latter, and the result equals that of the alcohol which has been expellerl. Refer to the talsle, and obtain therefrom the pereentage of alcohol in the berer.

The following table, by Mr. Edgar Richards, is the one used by the Association of Official Agricultural Chemists :'

${ }^{1}$ U. S. Department of Agriculture. Division of Chemistry, Bulletin No. 46 , Wash. ington, Government Printing Office, 1899. 
TABLES SHOWING PERCENTAGE OF ALCOHOL BY WEIGHT AND BY VOLUNE.

(Recalculated from the determinations of Gilpin, Drinkwater, and Squibb, by Edgar Richards.)

\begin{tabular}{|c|c|c|c|c|c|c|c|c|}
\hline $\begin{array}{c}\text { Specific } \\
\text { gravity at } \\
60^{\circ} \mathrm{F}\end{array}$ & $\begin{array}{l}\text { Per cent. } \\
\text { alcohol by } \\
\text { volume. }\end{array}$ & $\begin{array}{l}\text { Jer cent. } \\
\text { alcohol by } \\
\text { weightt. }\end{array}$ & $\begin{array}{l}\text { Specific } \\
\text { gravity at } \\
60^{\circ} \mathrm{i} \text {. }\end{array}$ & $\begin{array}{l}\text { Per cent. } \\
\text { alcohol by } \\
\text { volume. }\end{array}$ & $\begin{array}{l}\text { Pcr cent. } \\
\text { alcohol by } \\
\text { weight. }\end{array}$ & $\begin{array}{c}\text { Specific } \\
\text { gravity at } \\
60^{\circ} \mathrm{F} \text {. }\end{array}$ & $\begin{array}{l}\text { Per cent. } \\
\text { alcohol by } \\
\text { volume. }\end{array}$ & $\begin{array}{l}\text { Per cent. } \\
\text { alcohol by } \\
\text { weight. }\end{array}$ \\
\hline 1.00000 & 0.00 & 0.00 & 0.99629 & 2.50 & 1.99 & 0.99281 & 5.00 & 4.00 \\
\hline 0.99992 & .05 & .04 & 622 & .55 & 2.03 & 274 & .05 & .04 \\
\hline 984 & .10 & .08 & 615 & .60 & .07 & 268 & .10 & .08 \\
\hline 976 & .15 & .12 & 607 & .65 & .11 & 261 & .15 & .12 \\
\hline 968 & .20 & .16 & 600 & .70 & .15 & $25 \overline{5}$ & .20 & .16 \\
\hline 961 & .25 & .20 & 593 & .75 & .19 & 248 & .25 & .20 \\
\hline 953 & .30 & .24 & 586 & .80 & .23 & 241 & .30 & .24 \\
\hline 945 & .35 & .28 & 579 & .85 & .27 & 235 & .35 & .28 \\
\hline 937 & .40 & .32 & 571 & .90 & .31 & 228 & .40 & .32 \\
\hline 930 & .45 & .36 & 564 & .95 & .35 & 222 & .45 & .36 \\
\hline .99923 & 0.50 & 0.40 & .99557 & 3.00 & 2.39 & .99215 & 5.50 & 4.40 \\
\hline 915 & .55 & .44 & 550 & .05 & .43 & 208 & .55 & .44 \\
\hline 907 & .60 & .48 & 543 & .10 & .47 & 202 & .60 & .48 \\
\hline 900 & .65 & .52 & 536 & .15 & .51 & 195 & .65 & .52 \\
\hline 892 & .70 & .56 & 529 & .20 & .55 & 189 & .70 & .56 \\
\hline 884 & .75 & .60 & 522 & .25 & .59 & 182 & .75 & .60 \\
\hline 877 & .80 & .64 & 515 & .30 & .64 & 175 & .80 & .64 \\
\hline 869 & .85 & .67 & 508 & .35 & .68 & 169 & .85 & .68 \\
\hline 861 & .90 & .71 & 501 & .40 & .72 & 162 & .90 & .72 \\
\hline 854 & .95 & .75 & 494 & .45 & .76 & 156 & .95 & .76 \\
\hline .99849 & 1.00 & 0.79 & .99487 & 3.50 & 2.80 & .99149 & 6.00 & 4.80 \\
\hline 842 & .05 & .83 & 480 & .55 & .84 & 143 & .05 & .84 \\
\hline 834 & .10 & .87 & 473 & .60 & .88 & 136 & .10 & .88 \\
\hline 827 & .15 & .91 & 466 & .65 & .92 & 130 & .15 & .92 \\
\hline 819 & .20 & .95 & 459 & .70 & .96 & 123 & .20 & .96 \\
\hline 812 & .25 & .99 & 452 & .75 & 3.00 & 117 & .25 & 5.00 \\
\hline 805 & .30 & 1.03 & 445 & .80 & .04 & 111 & .30 & .05 \\
\hline 797 & .35 & .07 & 438 & .85 & .08 & 104 & .35 & .09 \\
\hline 790 & .40 & .11 & 431 & .90 & .12 & 098 & .40 & .13 \\
\hline 782 & .45 & .15 & 424 & .95 & .16 & 091 & .45 & .17 \\
\hline .99775 & 1.50 & 1.19 & .99417 & 4.00 & 3.20 & .99085 & 6.50 & 5.21 \\
\hline 768 & .55 & .23 & 410 & .05 & .24 & 079 & .55 & .25 \\
\hline 760 & .60 & .27 & 403 & .10 & .28 & 072 & .60 & .29 \\
\hline 753 & .65 & .31 & 397 & .15 & .32 & 066 & .65 & .33 \\
\hline 745 & .70 & .35 & 390 & .20 & .36 & 059 & .70 & .37 \\
\hline 738 & .75 & .39 & 383 & .25 & .40 & 053 & .75 & .41 \\
\hline 731 & .80 & .43 & 376 & .30 & .44 & 047 & .80 & .45 \\
\hline 723 & .85 & .47 & 369 & .35 & .48 & 040 & .85 & .49 \\
\hline 716 & .90 & .51 & 363 & .40 & .52 & 034 & .90 & .53 \\
\hline 708 & .95 & .55 & 356 & .45 & .56 & 027 & .95 & .57 \\
\hline 99701 & 2.00 & 1.59 & .99349 & 4.50 & 3.60 & .99021 & 7.00 & 5.61 \\
\hline 694 & .05 & .63 & 342 & .55 & .64 & 015 & .05 & .65 \\
\hline 687 & .10 & .67 & 325 & .60 & .68 & 009 & .10 & .69 \\
\hline 679 & .15 & .71 & 329 & .65 & .72 & 002 & .15 & .73 \\
\hline 672 & .20 & .75 & 322 & .70 & .76 & .98996 & .20 & .77 \\
\hline 665 & .25 & .79 & 315 & .75 & .80 & 990 & .25 & .81 \\
\hline 658 & .30 & .83 & 308 & .80 & .84 & 984 & .30 & .86 \\
\hline 651 & .35 & .87 & 301 & .85 & .88 & 978 & .35 & .90 \\
\hline 643 & .40 & .91 & 295 & .90 & .92 & 971 & .40 & .94 \\
\hline 636 & .45 & .95 & 288 & .95 & .96 & 965 & .45 & .98 \\
\hline
\end{tabular}




\begin{tabular}{|c|c|c|c|c|c|c|c|c|}
\hline $\begin{array}{c}\text { Specific } \\
\text { grarity at } \\
60^{\circ} \mathrm{F} \text {. }\end{array}$ & \begin{tabular}{|} 
Per cent. \\
alcoliol by \\
volume.
\end{tabular} & $\begin{array}{l}\text { Per cent. } \\
\text { alcohol by } \\
\text { weight. }\end{array}$ & $\begin{array}{l}\text { Specific } \\
\text { gravity at } \\
60^{\circ} \mathrm{F} \text {. }\end{array}$ & \begin{tabular}{|} 
Per cent. \\
alcohol by \\
volume.
\end{tabular} & \begin{tabular}{|c|} 
Per cent. \\
alcohol by \\
weight.
\end{tabular} & $\begin{array}{l}\text { Specific } \\
\text { gravity at } \\
60^{\circ} \mathrm{F} \text {. }\end{array}$ & $\begin{array}{l}\text { Per cent. } \\
\text { alcohol by } \\
\text { volume. }\end{array}$ & $\begin{array}{l}\text { Per cent. } \\
\text { alcohol by } \\
\text { weight. }\end{array}$ \\
\hline 0.98959 & 7.50 & 6.02 & 0.98603 & 10.50 & 8.45 & 0.98273 & 13.50 & 10.90 \\
\hline 953 & .55 & .96 & 597 & .55 & .49 & 267 & .55 & .94 \\
\hline 947 & .60 & .10 & 592 & .60 & .53 & 262 & .60 & .98 \\
\hline 940 & .65 & .14 & 586 & .65 & .57 & 256 & .65 & 11.02 \\
\hline 934 & .70 & .18 & 580 & .70 & .61 & 251 & .70 & .06 \\
\hline 928 & .75 & .22 & 575 & .75 & .65 & 246 & .75 & .11 \\
\hline 922 & .80 & .26 & 569 & .80 & .70 & 240 & .90 & .15 \\
\hline 916 & .85 & .30 & 563 & .85 & .74 & 235 & .85 & .19 \\
\hline 909 & .90 & .34 & 557 & .90 & .78 & 230 & .90 & .23 \\
\hline 903 & .95 & .38 & 552 & .95 & .82 & 224 & .95 & .27 \\
\hline .98897 & 8.00 & 6.42 & .98546 & 11.00 & 8.86 & .98219 & 14.00 & 11.31 \\
\hline 891 & .05 & .46 & 540 & .05 & .90 & 214 & .05 & .35 \\
\hline 885 & .10 & .50 & 535 & .10 & .94 & 200 & .10 & .39 \\
\hline 879 & .15 & .54 & 529 & .15 & .98 & 203 & .15 & .43 \\
\hline 873 & .20 & .58 & 524 & .20 & 9.02 & 198 & .20 & .47 \\
\hline 867 & .25 & .62 & 518 & .25 & .07 & 193 & .25 & .52 \\
\hline 861 & .30 & .67 & 513 & .30 & .11 & 188 & .30 & .56 \\
\hline 855 & .35 & .71 & 507 & .35 & .15 & 182 & .35 & .60 \\
\hline 849 & .40 & .75 & 502 & .40 & .19 & 177 & .40 & .64 \\
\hline 843 & .45 & .79 & 496 & .45 & .23 & 172 & .45 & .68 \\
\hline .98837 & 8.50 & 6.83 & .98491 & 11.50 & 9.27 & .98167 & 14.50 & 11.72 \\
\hline 831 & .55 & .87 & 485 & .55 & .31 & 161 & .55 & .76 \\
\hline 825 & .60 & .91 & 479 & .60 & .35 & 156 & .60 & .80 \\
\hline 819 & .65 & .95 & 474 & .65 & .39 & 151 & .65 & .84 \\
\hline 813 & .70 & .99 & 468 & .70 & .43 & 146 & .70 & .88 \\
\hline 807 & .75 & 7.03 & 463 & .75 & .47 & 140 & .75 & .93 \\
\hline 801 & .80 & .07 & 457 & .80 & .51 & 135 & .80 & .97 \\
\hline 795 & .85 & .11 & 452 & .85 & .55 & 130 & .85 & 12.01 \\
\hline 789 & .90 & .15 & 446 & .90 & .59 & 125 & .90 & .05 \\
\hline 783 & .95 & .19 & 441 & .95 & .63 & 119 & .95 & .09 \\
\hline .98777 & 9.00 & 7.23 & .98435 & 12.00 & 9.67 & .98114 & 15.00 & 12.13 \\
\hline 771 & .05 & .27 & 430 & .05 & .71 & 108 & .05 & .17 \\
\hline 765 & .10 & .31 & 424 & .10 & .75 & 104 & .10 & .21 \\
\hline 759 & .15 & .35 & 419 & .15 & .79 & 099 & .15 & .25 \\
\hline 754 & .20 & .39 & 413 & .20 & .83 & 093 & .20 & .29 \\
\hline 748 & .25 & .43 & 408 & .25 & .87 & 088 & .25 & .33 \\
\hline 742 & .30 & .48 & 402 & .30 & .92 & 083 & .30 & .38 \\
\hline 736 & .35 & .52 & 397 & .35 & .96 & 078 & .35 & .42 \\
\hline 730 & .40 & .56 & 391 & .40 & 10.00 & 073 & .40 & .46 \\
\hline 724 & .45 & .60 & 386 & .45 & .04 & 068 & .45 & .50 \\
\hline .98719 & 9.50 & 7.64 & .98381 & 12.50 & 10.08 & .98063 & 15.50 & 12.54 \\
\hline 713 & .55 & .68 & 375 & .55 & .12 & 057 & .55 & .58 \\
\hline 707 & .60 & .72 & 370 & .60 & .16 & 052 & .60 & .62 \\
\hline 701 & .65 & .76 & 364 & .65 & .20 & 047 & .65 & .66 \\
\hline 695 & .70 & .80 & 359 & .70 & .24 & 042 & .70 & .70 \\
\hline 689 & .75 & .84 & 353 & .75 & .28 & 037 & .75 & .75 \\
\hline 683 & .80 & .88 & 348 & .80 & .33 & 932 & .80 & .79 \\
\hline 678 & .85 & .92 & 342 & .85 & .37 & 026 & .85 & .83 \\
\hline 672 & .90 & .96 & 337 & .90 & .41 & 021 & .90 & .87 \\
\hline 666 & .95 & 8.00 & 331 & .95 & .45 & 016 & .95 & .91 \\
\hline .98660 & 10.00 & 8.04 & .98326 & 13.00 & 10.49 & .98011 & 16.00 & 12.95 \\
\hline 654 & .05 & .08 & 321 & .05 & .53 & 005 & .05 & .99 \\
\hline 649 & .10 & .12 & 315 & .10 & .57 & 001 & .10 & 13.03 \\
\hline 643 & .15 & .16 & 310 & .15 & .61 & 97996 & .15 & .08 \\
\hline 637 & .20 & .20 & 305 & .20 & .65 & 991 & .20 & .12 \\
\hline 632 & .25 & .24 & 299 & .25 & .69 & 986 & .25 & .16 \\
\hline 626 & .30 & .29 & 294 & .30 & .74 & 980 & .30 & .20 \\
\hline 620 & .35 & .33 & 289 & .35 & .78 & 975 & .35 & .24 \\
\hline 614 & .40 & .37 & 283 & .40 & .82 & 970 & .40 & $\therefore 9$ \\
\hline 609 & .45 & .41 & 278 & .45 & .86 & 965 & .45 & .33 \\
\hline
\end{tabular}




\begin{tabular}{|c|c|c|c|c|c|c|c|c|}
\hline $\begin{array}{l}\text { Srecific } \\
\text { gravity at } \\
60^{\circ} \mathrm{i} .\end{array}$ & \begin{tabular}{|c|} 
Per cent. \\
alcohol by \\
volune.
\end{tabular} & $\begin{array}{l}\text { Per cent. } \\
\text { alcohol by } \\
\text { welghts. }\end{array}$ & $\begin{array}{l}\text { Suecific } \\
\text { gravity at } \\
60^{\circ} \mathrm{F}\end{array}$ & \begin{tabular}{|} 
Per cent. \\
alcohol by \\
volmuse.
\end{tabular} & \begin{tabular}{|c|} 
Per cent. \\
alcohol by \\
weight.
\end{tabular} & $\begin{array}{l}\text { Specific } \\
\text { gravity at } \\
60^{\circ} \mathrm{F} \text {. }\end{array}$ & $\begin{array}{l}\text { Per cent. } \\
\text { alcohol ly } \\
\text { volume. }\end{array}$ & $\begin{array}{l}\text { P'er cent. } \\
\text { alcohol by } \\
\text { weight- }\end{array}$ \\
\hline 0.97960 & 16.50 & $13.3 \bar{T}$ & 0.97658 & 19.50 & 15.81 & 0.97355 & 22.50 & 18.34 \\
\hline 955 & .55 & .41 & 653 & .55 & .88 & .350 & .55 & .38 \\
\hline 950 & .60 & .45 & 648 & .60 & .93 & 345 & .60 & .42 \\
\hline 945 & .65 & .49 & 643 & .65 & .97 & 340 & .65 & .47 \\
\hline 940 & .70 & .53 & 638 & .70 & 16.01 & 335 & .70 & .51 \\
\hline 935 & .75 & .57 & 633 & .75 & .05 & 330 & .75 & .55 \\
\hline 929 & .80 & .62 & 628 & .80 & .09 & 324 & .80 & .59 \\
\hline 924 & .85 & .66 & 623 & .85 & .14 & 319 & .85 & .63 \\
\hline 919 & .90 & .70 & 618 & .90 & .18 & 314 & .90 & .68 \\
\hline 914 & .95 & .74 & 613 & .95 & .22 & 309 & .95 & .72 \\
\hline .97909 & 17.00 & 13.78 & .97608 & 20.00 & 16.26 & .97304 & 23.00 & 18.76 \\
\hline 904 & .05 & .82 & 603 & .05 & .30 & 299 & .05 & .80 \\
\hline 899 & .10 & .86 & 598 & .10 & .34 & 294 & .10 & .84 \\
\hline 894 & .15 & .90 & 593 & .15 & .38 & 289 & .15 & .88 \\
\hline 889 & .20 & .94 & 588 & .20 & .42 & 283 & .20 & .92 \\
\hline 884 & .25 & .98 & 583 & .25 & .46 & 278 & .25 & .96 \\
\hline 879 & .30 & 14.03 & 578 & .30 & .51 & 273 & .30 & 19.01 \\
\hline 874 & .35 & .07 & 573 & .35 & .55 & 268 & .35 & .05 \\
\hline 869 & .40 & .11 & $56 \mathrm{~S}$ & .40 & .59 & 263 & .40 & .09 \\
\hline 864 & .45 & .15 & 563 & .45 & .63 & 258 & .45 & .13 \\
\hline .97859 & 17.50 & 14.19 & .97558 & 20.50 & 16.67 & .97253 & 23.50 & 19.17 \\
\hline 853 & .55 & .23 & 552 & .55 & .71 & 247 & .55 & .21 \\
\hline 848 & .60 & .27 & 547 & .60 & .75 & 242 & .60 & .25 \\
\hline 843 & .65 & .31 & 542 & .65 & .80 & 237 & .65 & .30 \\
\hline 838 & .70 & .35 & 537 & .70 & .84 & 232 & .70 & .34 \\
\hline 833 & .75 & .40 & 532 & .75 & .88 & 227 & .75 & .38 \\
\hline 828 & .80 & .44 & 527 & .80 & .92 & 222 & .80 & .42 \\
\hline 823 & .85 & .48 & 522 & .85 & .96 & 216 & .85 & .46 \\
\hline 818 & .90 & .52 & 517 & .90 & 17.01 & 211 & .90 & .51 \\
\hline 813 & .95 & .56 & 512 & .95 & .05 & 206 & .95 & .55 \\
\hline .97808 & 18.00 & 14.60 & .97507 & 21.00 & 17.09 & .97201 & 24.00 & 19.59 \\
\hline 803 & .05 & .64 & 502 & .05 & .13 & 196 & .05 & .63 \\
\hline 798 & .10 & .68 & 497 & .10 & .17 & 191 & .10 & .67 \\
\hline 793 & .15 & .73 & 492 & .15 & .22 & 185 & .15 & .72 \\
\hline 788 & .20 & .77 & 487 & .20 & .26 & 180 & .20 & .76 \\
\hline 783 & .25 & .81 & 482 & .25 & .30 & 175 & .25 & .80 \\
\hline 778 & .30 & .85 & 477 & .30 & .34 & 170 & .30 & .84 \\
\hline 773 & .35 & .89 & 472 & .35 & .38 & 165 & .35 & .88 \\
\hline 768 & .40 & .94 & 467 & .40 & .43 & 159 & .40 & .93 \\
\hline 763 & .45 & .98 & 462 & .45 & .47 & 154 & .45 & .97 \\
\hline .97758 & 18.50 & 15.02 & .97457 & 21.50 & 17.51 & .97149 & 24.50 & 20.01 \\
\hline 753 & .55 & .06 & 451 & .55 & .55 & 144 & .55 & .05 \\
\hline 748 & .60 & .10 & 446 & .60 & .59 & 139 & .60 & .09 \\
\hline 743 & .65 & .14 & 441 & .65 & .63 & 133 & .65 & .14 \\
\hline 738 & .70 & .18 & 436 & .70 & .67 & 128 & .70 & .18 \\
\hline 733 & .75 & .22 & 431 & .75 & .71 & 123 & .75 & .22 \\
\hline 728 & .80 & .27 & 426 & .80 & .76 & 118 & .80 & .26 \\
\hline 723 & .85 & .31 & 421 & .85 & .80 & 113 & .85 & .30 \\
\hline 718 & .90 & .38 & 416 & .90 & .84 & 107 & .90 & .35 \\
\hline 713 & .95 & .39 & 411 & .95 & .88 & 102 & .95 & .39 \\
\hline .97708 & 19.00 & 15.43 & .97406 & 22.00 & 17.92 & .97097 & 25.00 & 20.43 \\
\hline 703 & .05 & .47 & 401 & .05 & .96 & 092 & .05 & .47 \\
\hline 698 & .10 & .51 & 396 & .10 & 18.00 & 086 & .10 & .51 \\
\hline 693 & .15 & .55 & 391 & .15 & .05 & $0 \$ 1$ & .15 & .56 \\
\hline 688 & .20 & .59 & 386 & .20 & .09 & 076 & .20 & .60 \\
\hline 683 & .25 & .63 & 381 & .25 & .13 & 071 & .25 & .64 \\
\hline 678 & .30 & .68 & 375 & 30 & .17 & 065 & .30 & .68 \\
\hline 673 & .35 & .72 & 370 & .35 & .21 & 060 & .35 & .72 \\
\hline 668 & .40 & .76 & 365 & .40 & .26 & 055 & .40 & .77 \\
\hline 663 & .45 & .80 & 3 ito & .45 & .30 & 049 & .45 & .81 \\
\hline
\end{tabular}




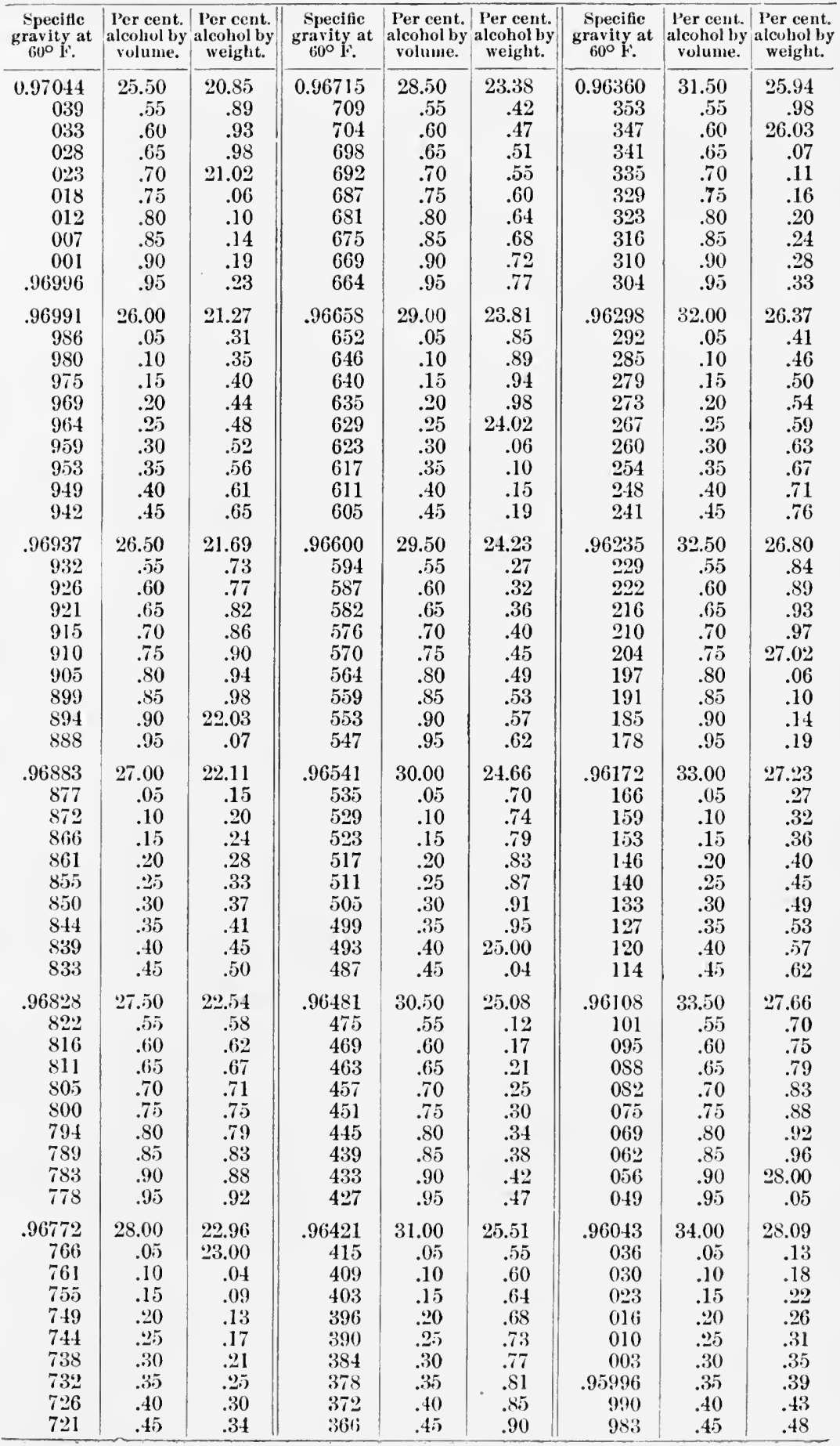




\begin{tabular}{|c|c|c|c|c|c|c|c|c|}
\hline $\begin{array}{l}\text { Specific } \\
\text { gravity at } \\
60^{\circ} \mathrm{F} .\end{array}$ & $\begin{array}{l}\text { l'er cent. } \\
\text { alcohol by } \\
\text { volume. }\end{array}$ & $\begin{array}{l}\text { Per cent. } \\
\text { alcohol by } \\
\text { weight. }\end{array}$ & $\begin{array}{l}\text { Specific } \\
\text { gravity at } \\
60^{\circ} \mathrm{F}\end{array}$ & $\begin{array}{l}\text { Per cent. } \\
\text { alcohol by } \\
\text { volume. }\end{array}$ & $\begin{array}{c}\text { Per cent. } \\
\text { alcohol tyy } \\
\text { weight. }\end{array}$ & $\begin{array}{c}\text { Specific } \\
\text { gravity at } \\
60^{\circ} \mathrm{F} .\end{array}$ & $\begin{array}{c}\text { Per cent. } \\
\text { alcohol by } \\
\text { volume. }\end{array}$ & $\begin{array}{l}\text { Per cant. } \\
\text { alcohol by } \\
\text { weight. }\end{array}$ \\
\hline $\begin{array}{r}0.95977 \\
970 \\
963 \\
957 \\
950 \\
943 \\
937 \\
930 \\
923 \\
917\end{array}$ & $\begin{array}{r}34.50 \\
.55 \\
.60 \\
.65 \\
.70 \\
.75 \\
.80 \\
.85 \\
.90 \\
.95\end{array}$ & $\begin{array}{r}28.52 \\
.56 \\
.61 \\
.65 \\
.70 \\
.74 \\
.78 \\
.83 \\
.87 \\
.92\end{array}$ & $\begin{array}{r}0.95560 \\
552 \\
545 \\
538 \\
531 \\
523 \\
516 \\
509 \\
502 \\
494\end{array}$ & $\begin{array}{r}37.50 \\
.55 \\
.60 \\
.65 \\
.70 \\
.75 \\
.80 \\
.85 \\
.90 \\
.95\end{array}$ & $\begin{array}{r}31.14 \\
.18 \\
.23 \\
.27 \\
.32 \\
.36 \\
.40 \\
.45 \\
.49 \\
.54\end{array}$ & $\begin{array}{r}0.95107 \\
099 \\
091 \\
083 \\
075 \\
067 \\
059 \\
052 \\
044 \\
036\end{array}$ & $\begin{array}{r}40.50 \\
.55 \\
.60 \\
.65 \\
.70 \\
.75 \\
.80 \\
.85 \\
.90 \\
.95\end{array}$ & $\begin{array}{r}33.79 \\
.84 \\
.88 \\
.93 \\
.97 \\
34.02 \\
.06 \\
.11 \\
.15 \\
.20\end{array}$ \\
\hline $\begin{array}{r}.95910 \\
903 \\
896 \\
889 \\
883 \\
876 \\
869 \\
862 \\
855 \\
848\end{array}$ & $\begin{array}{r}35.00 \\
.05 \\
.10 \\
.15 \\
.20 \\
.25 \\
.30 \\
.35 \\
.40 \\
.45\end{array}$ & $\begin{array}{r}28.96 \\
29.00 \\
.05 \\
.09 \\
.13 \\
.18 \\
.22 \\
.26 \\
.30 \\
.35\end{array}$ & $\begin{array}{r}.95487 \\
480 \\
472 \\
465 \\
457 \\
450 \\
442 \\
435 \\
427 \\
420\end{array}$ & $\begin{array}{r}38.00 \\
.05 \\
.10 \\
.15 \\
.20 \\
.25 \\
.30 \\
.35 \\
.40 \\
.45\end{array}$ & $\begin{array}{r}31.58 \\
.63 \\
.67 \\
.72 \\
.76 \\
.81 \\
.85 \\
.90 \\
.94 \\
.99\end{array}$ & $\begin{array}{r}.95028 \\
020 \\
012 \\
004 \\
.94996 \\
988 \\
980 \\
972 \\
964 \\
956\end{array}$ & $\begin{array}{r}41.00 \\
.05 \\
.10 \\
.15 \\
.20 \\
.25 \\
.30 \\
.35 \\
.40 \\
.45\end{array}$ & $\begin{array}{r}34.24 \\
.28 \\
.33 \\
.37 \\
.42 \\
.46 \\
.50 \\
.55 \\
.59 \\
.64\end{array}$ \\
\hline $\begin{array}{r}.958+2 \\
835 \\
828 \\
821 \\
814 \\
807 \\
800 \\
794 \\
787 \\
780\end{array}$ & $\begin{array}{r}35.50 \\
.55 \\
.60 \\
.65 \\
.70 \\
.75 \\
.80 \\
.85 \\
.90 \\
.95\end{array}$ & $\begin{array}{l}29.39 \\
.43 \\
.48 \\
.52 \\
.57 \\
.61 \\
.65 \\
.70 \\
.74 \\
.79\end{array}$ & $\begin{array}{r}.95+13 \\
405 \\
398 \\
390 \\
383 \\
375 \\
368 \\
360 \\
353 \\
345\end{array}$ & $\begin{array}{r}38.50 \\
.55 \\
.60 \\
.65 \\
.70 \\
.75 \\
.80 \\
.85 \\
.90 \\
.95\end{array}$ & $\begin{array}{r}32.03 \\
.07 \\
.12 \\
.16 \\
.20 \\
.25 \\
.29 \\
.33 \\
.37 \\
.42\end{array}$ & $\begin{array}{r}.94948 \\
940 \\
932 \\
924 \\
916 \\
908 \\
900 \\
892 \\
884 \\
876\end{array}$ & $\begin{array}{r}41.50 \\
.55 \\
.60 \\
.65 \\
.70 \\
.75 \\
.80 \\
.85 \\
.90 \\
.95\end{array}$ & $\begin{array}{r}34.68 \\
.73 \\
.77 \\
.82 \\
.86 \\
.91 \\
.95 \\
35.00 \\
.04 \\
.09\end{array}$ \\
\hline $\begin{array}{r}.95773 \\
766 \\
759 \\
752 \\
745 \\
738 \\
731 \\
724 \\
717 \\
710\end{array}$ & $\begin{array}{r}36.00 \\
.05 \\
.10 \\
.15 \\
.20 \\
.25 \\
.30 \\
.35 \\
.40 \\
.45\end{array}$ & $\begin{array}{r}29.83 \\
.87 \\
.92 \\
.96 \\
30.00 \\
.05 \\
.09 \\
.13 \\
.17 \\
.22\end{array}$ & $\begin{array}{r}.95338 \\
330 \\
323 \\
315 \\
307 \\
300 \\
292 \\
284 \\
277 \\
269\end{array}$ & $\begin{array}{l}39.00 \\
.05 \\
.10 \\
.15 \\
.20 \\
.25 \\
.30 \\
.35 \\
.40 \\
.45\end{array}$ & $\begin{array}{r}32.46 \\
.50 \\
.55 \\
.59 \\
.64 \\
.68 \\
.72 \\
.77 \\
.81 \\
.86\end{array}$ & $\begin{array}{r}.94868 \\
860 \\
852 \\
843 \\
835 \\
827 \\
820 \\
811 \\
802 \\
794\end{array}$ & $\begin{array}{r}42.00 \\
.05 \\
.10 \\
.15 \\
.20 \\
.25 \\
.30 \\
.35 \\
.40 \\
.45\end{array}$ & $\begin{array}{r}35.13 \\
.18 \\
.22 \\
.27 \\
.31 \\
.36 \\
.40 \\
.45 \\
.49 \\
.54\end{array}$ \\
\hline $\begin{array}{r}.95703 \\
695 \\
688 \\
681 \\
674 \\
667 \\
660 \\
653 \\
646 \\
639\end{array}$ & $\begin{array}{r}36.50 \\
.55 \\
.60 \\
.65 \\
.70 \\
.75 \\
.80 \\
.85 \\
.90 \\
.95\end{array}$ & $\begin{array}{r}30.26 \\
.30 \\
.35 \\
.39 \\
.44 \\
.48 \\
.52 \\
.57 \\
.61 \\
.66\end{array}$ & $\begin{array}{r}.95262 \\
254 \\
246 \\
239 \\
231 \\
223 \\
216 \\
208 \\
200 \\
193\end{array}$ & $\begin{array}{r}39.50 \\
.55 \\
.60 \\
.65 \\
.70 \\
.75 \\
.80 \\
.85 \\
.90 \\
.95\end{array}$ & $\begin{array}{r}32.90 \\
.95 \\
.99 \\
33.04 \\
.08 \\
.13 \\
.17 \\
.22 \\
.27 \\
.31\end{array}$ & $\begin{array}{r}.94786 \\
778 \\
770 \\
761 \\
753 \\
745 \\
737 \\
729 \\
720 \\
712\end{array}$ & $\begin{array}{r}42.50 \\
.55 \\
.60 \\
.65 \\
.70 \\
.75 \\
.80 \\
.85 \\
.90 \\
.95\end{array}$ & $\begin{array}{r}35.58 \\
.63 \\
.67 \\
.72 \\
.76 \\
.81 \\
.85 \\
.90 \\
.94 \\
.99\end{array}$ \\
\hline $\begin{array}{r}.95632 \\
625 \\
618 \\
610 \\
603 \\
596 \\
589 \\
581 \\
574 \\
567\end{array}$ & $\begin{array}{r}37.00 \\
.05 \\
.10 \\
.15 \\
.20 \\
.25 \\
.30 \\
.35 \\
.40 \\
.45\end{array}$ & $\begin{array}{r}30.70 \\
.74 \\
.79 \\
.83 \\
.88 \\
.92 \\
.96 \\
31.01 \\
.05 \\
.10\end{array}$ & $\begin{array}{r}.95185 \\
177 \\
169 \\
161 \\
154 \\
146 \\
138 \\
130 \\
122 \\
114\end{array}$ & $\begin{array}{r}40.00 \\
.05 \\
.10 \\
.15 \\
.20 \\
.25 \\
.30 \\
.35 \\
.40 \\
.45\end{array}$ & $\begin{array}{r}33.35 \\
.39 \\
.44 \\
.48 \\
.53 \\
.57 \\
.61 \\
.66 \\
.70 \\
.75\end{array}$ & $\begin{array}{r}.94704 \\
696 \\
687 \\
679 \\
670 \\
662 \\
654 \\
645 \\
637 \\
628\end{array}$ & $\begin{array}{r}43.00 \\
.05 \\
.10 \\
.15 \\
.20 \\
.25 \\
.30 \\
.35 \\
.40 \\
.45\end{array}$ & $\begin{array}{r}36.03 \\
.08 \\
.12 \\
.17 \\
.21 \\
.23 \\
.30 \\
.35 \\
.39 \\
.44\end{array}$ \\
\hline
\end{tabular}




\begin{tabular}{|c|c|c|c|c|c|c|c|c|}
\hline $\begin{array}{l}\text { Specific } \\
\text { gravity at } \\
60^{\circ} \mathrm{F} \text {. }\end{array}$ & \begin{tabular}{|c|} 
Per cent. \\
alcoliol by \\
volume.
\end{tabular} & \begin{tabular}{|} 
Per cent. \\
alcohol by \\
weight.
\end{tabular} & $\begin{array}{c}\text { Specific } \\
\text { gravity at } \\
60^{\circ} \mathrm{F} \text {. }\end{array}$ & $\begin{array}{l}\text { Per cent. } \\
\text { alcohol by } \\
\text { volume. }\end{array}$ & $\begin{array}{l}\text { Per cent. } \\
\text { alcohol by } \\
\text { weight. }\end{array}$ & $\begin{array}{c}\text { Specific } \\
\text { gravity at } \\
60^{\circ} \mathrm{F} .\end{array}$ & $\begin{array}{l}\text { Per cent. } \\
\text { alcohol by } \\
\text { volume. }\end{array}$ & $\begin{array}{l}\text { Per cent. } \\
\text { alcohol by } \\
\text { weight. }\end{array}$ \\
\hline 0.94620 & 43.50 & 36.48 & 0.94188 & 46.00 & 38.75 & 0.93824 & 48.00 & 40.60 \\
\hline 612 & .55 & .53 & 179 & .05 & .80 & 815 & .05 & .65 \\
\hline 603 & .60 & .57 & 170 & .10 & .84 & 805 & .10 & .69 \\
\hline 595 & .65 & .62 & 161 & .15 & .89 & 796 & .15 & .74 \\
\hline 586 & .70 & .66 & 152 & .20 & .93 & 786 & .20 & .78 \\
\hline 578 & .75 & .71 & 143 & .25 & .98 & 777 & .25 & .83 \\
\hline 570 & .80 & .75 & 134 & .30 & 39.03 & 768 & .30 & .88 \\
\hline 561 & .85 & .80 & 125 & .35 & .07 & 758 & .35 & .92 \\
\hline 553 & .90 & .84 & 116 & .40 & .12 & 749 & .40 & .97 \\
\hline 544 & .95 & .89 & 107 & .45 & .16 & 739 & .45 & 41.01 \\
\hline .94536 & 44.00 & 36.93 & .94098 & 46.50 & 39.21 & .93730 & 48.50 & 41.06 \\
\hline 527 & .05 & .98 & 089 & .55 & .26 & 721 & .55 & .11 \\
\hline 519 & .10 & 37.02 & 080 & .60 & .30 & 711 & .60 & .15 \\
\hline 510 & .15 & .07 & 071 & .65 & .35 & 702 & .65 & .20 \\
\hline 502 & .20 & .11 & 062 & .70 & .39 & 692 & .70 & .24 \\
\hline 493 & .25 & .16 & 053 & .75 & .44 & 683 & .75 & .29 \\
\hline 484 & .30 & .21 & 044 & .80 & .49 & 679 & .80 & .34 \\
\hline 476 & .35 & .25 & 035 & .85 & .53 & 664 & .85 & .38 \\
\hline 467 & .40 & .30 & 026 & .90 & .58 & 655 & .90 & .43 \\
\hline 459 & .45 & .34 & 017 & .95 & .62 & 645 & .95 & .47 \\
\hline .94450 & 44.50 & 37.39 & .94008 & 47.00 & 39.67 & .93636 & 49.00 & 41.52 \\
\hline 441 & .55 & .44 & .93999 & .05 & .72 & 626 & .05 & .57 \\
\hline 433 & .60 & .48 & 990 & .10 & .76 & 617 & .10 & .61 \\
\hline 424 & .65 & .53 & 980 & .15 & .81 & 607 & .15 & .66 \\
\hline 416 & .70 & .57 & 971 & .20 & .85 & 598 & .20 & .71 \\
\hline 407 & .75 & .62 & 962 & .25 & .90 & 588 & .25 & .76 \\
\hline 398 & .80 & .66 & 953 & .30 & .95 & 578 & .30 & .80 \\
\hline 390 & .85 & .71 & 944 & .35 & .99 & 569 & .35 & .85 \\
\hline 381 & .90 & .76 & 934 & .40 & 40.04 & 559 & .40 & .90 \\
\hline 373 & .95 & .80 & 925 & .45 & .08 & 550 & .45 & .94 \\
\hline .94364 & 45.00 & 37.84 & .93916 & 47.50 & 40.13 & .93540 & 49.50 & 41.99 \\
\hline 355 & .05 & .89 & 906 & .55 & .18 & 530 & .55 & 42.04 \\
\hline 346 & .10 & .93 & 893 & .60 & .22 & 521 & .60 & .08 \\
\hline 338 & .15 & .98 & 888 & .65 & .27 & 511 & .65 & .13 \\
\hline $3 \% 9$ & .20 & 38.02 & 879 & .70 & .32 & 502 & .70 & .18 \\
\hline 320 & .25 & .07 & 870 & .75 & .37 & 492 & .75 & .23 \\
\hline 311 & .30 & .12 & 861 & .80 & .41 & 482 & .80 & .27 \\
\hline 302 & .35 & .16 & 852 & .85 & .46 & 473 & .85 & .32 \\
\hline 294 & .40 & .21 & 842 & .90 & .51 & 463 & .90 & .37 \\
\hline 285 & .45 & .25 & 833 & .95 & .55 & 454 & .95 & .41 \\
\hline .94276 & 45.50 & 38.30 & & & & & & \\
\hline 267 & .55 & .35 & & & & & & \\
\hline 258 & .60 & .39 & & & & & & \\
\hline 250 & .65 & .44 & & & & & & \\
\hline 241 & .70 & .48 & & & & & & \\
\hline $23:$ & .75 & .53 & & & & & & \\
\hline 223 & .80 & .57 & & & & & & \\
\hline 214 & .85 & .62 & & & & & & \\
\hline 206 & .90 & .66 & & & & & & \\
\hline 197 & .95 & .71 & & & & & & \\
\hline
\end{tabular}

Determination of Methyl Alcohol. ${ }^{1}$ - Method of Leach and Lythgoe. ${ }^{2}$ - This method depends upon the fact that the specific gravities of the two alcohols are nearly alike, but that the refractions are very different. Starting with methyl alcohol at 0 per cent. (water) and increasing the

${ }^{1}$ Personal communication from H. C. Lythgoe, Chemist, Food and Drug Department, Mass. State Board of Health.

${ }^{2}$ Jour. Am. Chem. Soc., 1905, p. 964. 
amount of alcohol, the refraetion inereases until it reaches a maximum at about 50 per eent. aleohol, beyond which point, with inereasing aleohol, the refraction diminishes until absolute methyl aleohol is reached, which has a lower refraetion than water. With ethyl alcohol, starting as before at 0 per eent., the refraction inereases with increasing aleoholie strength much more rapidly than is the ease with metylıl alcohol, reaching a maximum at about 78 per eent. It then decreases slightly, absolute ethyl alcohol having about the same refraction as 51 per cent. alcohol.

'To determine methyl aleohol, prepare the alcoholic distillate as usual, determine the specific gravity, and obtain the per cent. of aleohol from the table. Determine the refraction of this distillate at $20^{\circ} \mathrm{C}$. by meaus of a Zeiss immersion refractometer. This refraction should be then compared with those given in the table for that per eent. aleohol. If the refraetion corresponds to that of ethyl alcohol, the aleohol is pure ethyl alcohol. If it corresponds to that of methyl alcohol, the alcohol is pure methyl aleohol. If it is between these figures, the alcohol is a mixture of ethyl and methyl alcohols.

Two or three examples of actual cases, as found in the routine inspection of foods and drugs in Massachusetts, will best illustrate the method of calculation. For determination of total alcohol from the specific gravity, Hehner's alcohol tables were used.

(1) A lemon extraet, found by the polariseope to eontain 4.9 per cent. of lemon oil by volume and 90.20 per cent. of alcohol by volume at $15^{\circ} \mathrm{C}$., was freed from lemon oil by diluting four times with water, treating with magnesia in the regular manner, and filtering. A measured portion of the filtrate was then distilled, and the distillate made up to the measured portion taken. This distillate was found to have a specifie gravity of 0.9736 , corresponding to 18.38 per cent. alcohol by weight, ${ }^{1}$ and to have a refraction of 35.8 on the Zeiss immersion refractometer.

By interpolation in the table the readings of ethyl and methyl aleohol eorresponding to 18.38 per cent. alcohol are 47.2 and 25.4 respectively, the difference being $21.8 .47 .2-35.8=11.4$. $\quad(11.4 \div$ 21.8) $100=52.3$. In this case 52.3 per eent. of the alcohol present was methyl.

(2) An orange extract was found with 1.5 per eent. of orange oil and 83.2 per cent. of aleohol by volume at $15^{\circ} \mathrm{C}$. Speeific gravity of the $\frac{1}{4}$-strength distillate, freed from oil as in the case of the lemon extraet, was 0.9754 , corresponding to 16.92 per cent. alcohol by weight. Refraction of the distillate at $20^{\circ} \mathrm{C}$. was 42.0 . Readings of ethyl and methyl alcohol of 16.9 strength are, according to the table, 44.3 and 24.5 respectively. Difference, $19.8 .44 .3-42=2.3$. $(2.3 \div 19.8)$ $100=1.2$. Thus 1.2 per eent. of the aleohol present was methyl.

1 Our methyl-ethyl alenhol tables being most conveniently worked out on the weight per cent. basis, the per cent. by weight rather than by volume of the dilute distillate is here taken. Percentage of total alenhol in the extract, as well as of lemon oil, we eommonly express by volume. In this casse the specific gravity, 0.9736 , corresponds to 22.55 per cent. aleohol by volume. The per cent. by volume of total alcohol in the extract, 90.20 at $15^{\circ} \mathrm{C}$., is found by multiplying 22.55 by 4 to correct for the dilution. 
Readings of Experimental Mixtures of Metiry and Ethyl Alcohols.

\begin{tabular}{|c|c|c|c|c|c|c|}
\hline \multirow{2}{*}{ Sp.gr. $15^{\circ} \mathrm{C}$. } & \multirow{2}{*}{$\begin{array}{l}\text { Per cent. } \\
\text { alcohol by } \\
\text { weight. }\end{array}$} & \multirow{2}{*}{$\begin{array}{l}\text { Scale } \\
\text { reading, } \\
20^{\circ} \mathrm{C} \text {. }\end{array}$} & \multicolumn{2}{|c|}{ Methyl aleohol. } & \multicolumn{2}{|c|}{ Ethyl alcohol. } \\
\hline & & & $\begin{array}{l}\text { As prepared, } \\
\text { per cent. }\end{array}$ & $\begin{array}{l}\text { As found, } \\
\text { per cent. }\end{array}$ & $\begin{array}{l}\text { As prepared, } \\
\text { per cent. }\end{array}$ & $\begin{array}{l}\text { As found, } \\
\text { per cent. }\end{array}$ \\
\hline 0.8190 & 91.36 & 33.9 & 68.52 & 69.88 & 22.84 & 21.48 \\
\hline 0.8190 & 91.36 & 54.9 & 45.68 & 47.41 & 45.68 & 44.95 \\
\hline 0.9239 & 47.41 & 51.9 & 35.56 & 35.42 & 11.85 & 11.99 \\
\hline 0.8190 & 91.36 & 76.3 & 22.84 & 23.75 & 68.52 & 67.61 \\
\hline 0.9326 & 43.43 & 62.4 & 21.71 & 21.38 & 21.71 & 22.05 \\
\hline 0.9643 & 25.64 & 37.2 & 19.23 & $19.76^{\circ}$ & 6.41 & 5.88 \\
\hline 0.9207 & 48.86 & 77.5 & 12.21 & 11.77 & 36.65 & 37.09 \\
\hline 0.9753 & 17.00 & 34.0 & 8.50 & 8.92 & 8.50 & 8.08 \\
\hline 0.9666 & 23.92 & 50.2 & 5.98 & 6.48 & 17.94 & 17.44 \\
\hline
\end{tabular}

Scale Rfadings on Zeiss Tmanersion Refractometer at $20^{\circ} \mathrm{C}$. Corresponding to Each Per Cent. by Weight of Ethyl and Methyl Alcohols.

\begin{tabular}{|c|c|c|c|c|c|c|c|c|c|c|c|}
\hline \multirow{2}{*}{ 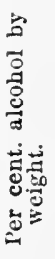 } & \multicolumn{2}{|c|}{ Scale readings. } & \multirow{2}{*}{ 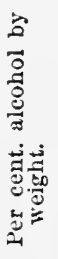 } & \multicolumn{2}{|c|}{ Scale readings. } & \multirow{2}{*}{ 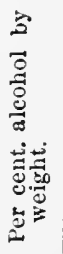 } & \multicolumn{2}{|c|}{ Seale readings. } & \multirow{2}{*}{ 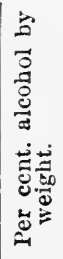 } & \multicolumn{2}{|c|}{ Scale readings. } \\
\hline & 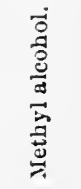 & 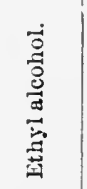 & & 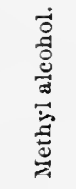 & 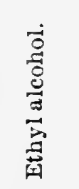 & & 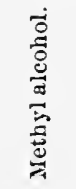 & 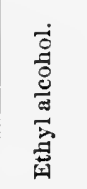 & & 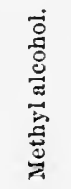 & 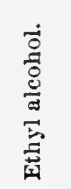 \\
\hline 0 & 14.5 & 14.5 & 30 & 32.8 & 69.0 & 60 & 37.9 & 96.2 & 90 & 16.1 & 98.6 \\
\hline 1 & 14.8 & 16.0 & 31 & 33.5 & 70.4 & 61 & 37.5 & 96.7 & 91 & 14.9 & 98.3 \\
\hline 2 & 15.4 & 17.6 & 32 & 34.1 & 71.7 & 62 & 37.0 & 97.1 & 92 & 13.7 & 97.8 \\
\hline 3 & 16.0 & 19.1 & 33 & 34.7 & 73.1 & 63 & 36.5 & 97.5 & 93 & 12.4 & 97.2 \\
\hline 4 & 16.6 & 20.7 & 34 & 35.2 & 74.4 & 64 & 36.0 & 98.0 & 94 & 11.0 & 96.4 \\
\hline 5 & 17.2 & 22.3 & 35 & 35.8 & 75.8 & 65 & 35.5 & 98.3 & 95 & 9.6 & 95.7 \\
\hline 6 & 17.8 & 24.1 & 36 & 36.3 & 76.9 & 66 & 35.0 & 98.7 & 96 & 8.2 & 94.9 \\
\hline 7 & 18.4 & 25.9 & 37 & 36.8 & 78.0 & 67 & 34.5 & 99.1 & 97 & 6.7 & 94.0 \\
\hline 8 & 19.0 & 27.8 & 38 & 37.3 & 79.1 & 68 & 34.0 & 99.4 & 98 & 5.1 & 93.0 \\
\hline 9 & 19.6 & 29.6 & 39 & 37.7 & 80.2 & 69 & 33.5 & 99.7 & 99 & 3.5 & 92.0 \\
\hline 10 & 20.2 & 31.4 & 40 & 38.1 & 81.3 & 70 & 33.0 & 100.0 & 100 & 2.0 & 91.0 \\
\hline 11 & 20.8 & 33.2 & 41 & 38.4 & 82.3 & 71 & 32.3 & 100.2 & & & \\
\hline 12 & 21.4 & 35.0 & 42 & 38.8 & 83.3 & 72 & 31.7 & 100.4 & & & \\
\hline 13 & 22.0 & 36.9 & 43 & 39.2 & 84.2 & 73 & 31.1 & 100.6 & & & \\
\hline 14 & 22.6 & 38.7 & 44 & 39.3 & 85.2 & 74 & 30.4 & 100.8 & & & \\
\hline 15 & 23.2 & 40.5 & 45 & 39.4 & 86.2 & 75 & 29.7 & 101.0 & & & \\
\hline 16 & 23.9 & 42.5 & 46 & 39.5 & 87.0 & 76 & 29.0 & 101.0 & & & \\
\hline 17 & 24.5 & 44.5 & 47 & 39.6 & 87.8 & 77 & 28.3 & 100.9 & & & \\
\hline 18 & 25.2 & 46.5 & 48 & 39.7 & 88.7 & 78 & 27.6 & 100.9 & & & \\
\hline 19 & 25.8 & 48.5 & 49 & 39.8 & 89.5 & 79 & 26.8 & 100.8 & & & \\
\hline 20 & 26.5 & 50.5 & 50 & 39.8 & 90.3 & 80 & 26.0 & 100.7 & & & \\
\hline 21 & 27.1 & 52.4 & 51 & 39.7 & 91.1 & 81 & 25.1 & 100.6 & & & \\
\hline 22 & 27.8 & 54.3 & 52 & 39.6 & 91.8 & 82 & 24.8 & 100.5 & & & \\
\hline 23 & 28.4 & 56.3 & 53 & 39.6 & 92.4 & 83 & 23.6 & 100.4 & & & \\
\hline 24 & 29.1 & 58.2 & 54 & 39.5 & 93.0 & 84 & 22.8 & 100.3 & & & \\
\hline 25 & 29.7 & 60.1 & 55 & 39.4 & 93.6 & 85 & 21.8 & 100.1 & & & \\
\hline 26 & 30.3 & 61.9 & 56 & 39.2 & 94.1 & 86 & 20.8 & 99.8 & & & \\
\hline 27 & 30.9 & 63.7 & 57 & 39.0 & 94.7 & 87 & 19.7 & 99.5 & & & \\
\hline 28 & 31.6 & 65.5 & 58 & 38.6 & 95.2 & 88 & 18.6 & 99.2 & & & \\
\hline 29 & 32.2 & 67.2 & 59 & 38.8 & 95.7 & 89 & 17.3 & 98.9 & & & \\
\hline
\end{tabular}


(3) 6.3 ce. of tincture of iodine, after titration with $\mathrm{N} / 10$ sodium thiosulphate (in the regular manner for determining its strength aceording to the United States Pharmacopœia), was neutralized with N/10 sodium hydroxide and distilled, colleeting 25.2 ce. of the distillate, corresponding to a dilution of $1: 4$ of the sample. The distillate contained 20.92 per eent. alcohol by weight; refraction 27.5 at $20^{\circ} \mathrm{C}$., indicating 99.0 per cent. of the alcohol to be methyl. There is no donbt that the alcohol in this case was entirely methyl, the slightly high refraction of the distillate being due to the presence of a slight amount of volatile substance formed by decomposition of the tineture of iodine.

The accuracy of the method is shown in a general way by a series of experiments, the results of which are tabulated on page 231 .

Determination of Extract.-The extract may be determined directly or, with the aid of a table, from the specific gravity of the dealcoholized beer. The direct method is more accurate, and is carried out as follows: Into an accurately weighed platinum dish, such as is used in the analysis of milk, weigh 5 grams of beer; evaporate to complete dryness, and multiply the weight of the residue by 20 .

Approximately accurate results are obtained by reference to the following table, after Schultze-Ostermann :

BEER EXTRACT TABLE.

\begin{tabular}{|c|c|c|c|c|c|c|c|c|c|c|}
\hline $\begin{array}{l}\text { Specific } \\
\text { gravity. }\end{array}$ & 0 & 1 & 2 & 3 & 4 & 5 & 6 & 7 & 8 & 9 \\
\hline 1.011 & 2.87 & 2.90 & 2.92 & 2.95 & 2.97 & 3.00 & 3.03 & 3.06 & 3.08 & 3.11 \\
\hline & 3.13 & 3.16 & 3.18 & 3.21 & 3.24 & 3.26 & 3.29 & 3.31 & 3.34 & 3.37 \\
\hline 3 & 3.39 & 3.42 & 3.44 & 3.47 & 3.49 & 3.52 & 3.55 & 3.57 & 3.60 & 3.62 \\
\hline 4 & 3.65 & 3.67 & 3.70 & 3.73 & 3.75 & 3.78 & 3.80 & 3.83 & 3.86 & 3.88 \\
\hline 5 & 3.91 & 3.93 & 3.96 & 3.98 & 4.01 & 4.04 & 4.06 & 4.09 & 4.11 & 4.14 \\
\hline 6 & 4.16 & 4.19 & 4.21 & 4.24 & 4.27 & 4.29 & 4.32 & 4.34 & 4.37 & 4.39 \\
\hline 7 & 4.42 & 4.44 & 4.47 & 4.50 & 4.52 & 4.55 & 4.57 & 4.60 & 4.62 & 4.65 \\
\hline 8 & 4.67 & 4.70 & 4.73 & 4.75 & 4.78 & 4.80 & 4.83 & 4.85 & 4.88 & 4.90 \\
\hline 9 & 4.93 & 4.96 & 4.98 & 5.01 & 5.03 & 5.06 & 5.08 & 5.11 & 5.13 & 5.16 \\
\hline 1.020 & 5.19 & 5.21 & 5.24 & 5.26 & 5.29 & 5.31 & 5.34 & 5.36 & 5.39 & 5.41 \\
\hline 1 & 5.44 & 5.47 & 5.49 & 5.52 & 5.54 & 5.57 & 5.59 & 5.62 & 5.64 & 5.67 \\
\hline 2 & 5.69 & 5.72 & 5.74 & 5.77 & 5.80 & 5.82 & 5.85 & 5.87 & 5.90 & 5.92 \\
\hline 3 & 5.95 & 5.97 & 6.00 & 6.02 & 6.05 & 6.08 & 6.10 & 6.13 & 6.15 & 6.18 \\
\hline 4 & 6.20 & 6.23 & 6.25 & 6.28 & 6.30 & 6.33 & 6.35 & 6.38 & 6.40 & 6.43 \\
\hline 5 & 6.45 & 6.48 & 6.50 & 6.53 & 6.55 & 6.58 & 6.61 & 6.63 & 6.66 & 6.68 \\
\hline 6 & 6.71 & 6.73 & 6.76 & 6.78 & 6.81 & 6.83 & 6.86 & 6.88 & 6.91 & 6.93 \\
\hline 7 & 6.96 & 6.98 & 7.01 & 7.03 & 7.06 & 7.08 & 7.11 & 7.13 & 7.16 & 7.18 \\
\hline 8 & 7.21 & 7.24 & 7.26 & 7.29 & 7.31 & 7.34 & 7.36 & 7.39 & 7.41 & 7.44 \\
\hline 9 & 7.46 & 7.49 & 7.51 & 7.54 & 7.56 & 7.59 & 7.61 & 7.64 & 7.66 & 7.69 \\
\hline 1.030 & 7.71 & 7.74 & 7.76 & 7.79 & 7.81 & 7.84 & 7.86 & 7.89 & 7.91 & 7.94 \\
\hline & 7.99 & 8.01 & 8.04 & 8.06 & 8.09 & 8.11 & 8.14 & $8.16^{\circ}$ & 8.19 & 8.21 \\
\hline
\end{tabular}

The figures at the head of the several eolumns represent the fourth decimal place of the specifie gravity. Example: Specific gravity, 1.0187 ; referring to 1.018 in the left-hand column and running out to the column headed by the figure 7 , we find 4.85 as the percentage of extract for that gravity. 
Detection of Preservatives.-The principal preservative used in beer is salicylic acid; next in importance is fluoride of sodium, which, however, is not used to any considerable extent as yet in this conntry.

Salicylic Acid.-The ordinary method of extracting by means of ether and testing the residue left on evaporation of the latter with ferric chloride, cannot be used in the examination of beer, since kilndried malt contains a prineiple which gives a reaction identical with that of salicylic acid. The following method, devised by Spica, is, however, satisfactory and reliable: Acidify $100 \mathrm{ce}$. with sulphuric acid, extract with ether, allow the separated ether to evaporate spontaneously, and warm the residue gently with a drop of strong nitric acid, whereby, if salicylic acid is present, picric acid is formed. The addition of a few drops of ammonia or of sodium hydrate produces the corresponding picrate with its bright-yellow color, which may be imparted to a woollen thread immersed in the liquid.

Fluorides.- Several methods are recommended, and among them the following:

Method of Hefelmann and Mann.-Expel the carbonic acid from $500 \mathrm{cc}$. of beer, and then add 1 cc. of a solution containing 5 per cent. each of calcium and barium chlorides, and follow it with 0.5 ce. of 20 per cent. acetic acid and 50 ce. of 90 per cent. alcohol. Let stand twenty-four hours and filter. Dry the filter and precipitate collected thereon without washing, and transfer to a platinum crucible. Add strong sulphuric acid, and cover the crucible with a waxed watchglass with some lines scratched through the wax coating, then heat at $100^{\circ} \mathrm{C}$. for two hours, and observe the effect on the exposed glass. This method is said to be of sufficient delicacy to detect the presence of 7 nilligrams in a liter.

Branid's Method.-To 100 ce. of beer made slightly alkaline with ammonium carbonate and heated, add 2 or 3 ce. of a 10 per cent. solution of calcium chloride. Boil for a fow minutes, filter, and dry the filter and contents. Then proceed as in the method just described. In either process, it is best to place a lump of ice in the concavity of the watch-gliss to keep the latter cool; the water should be removed from time to time by means of a pipctte so that it may not overflow.

Other Determinations. - Of minor interest are the determinations of acidity and ash.

Total Acidity._-To 10 ec. of beer freed from carbonic acid by shaking, add a few drops of nentral litmus solution, and then add decinormal sodium hydrate until the end reaction is observed. Express the results in parts of acetic acid. One ce. of decinormal sodimn hydrate equals 0.006 gram of acetic acid.

Fixed and Volatile Acidity.-Concentrate $10 \mathrm{cc}$. of beer to a third of its bulk by evaporation, add water up to the original volume, and proced as above. The difference in results is due to the acetic acid which has been driven off. The fixed aleidity is due chiefly to lactic acid, and, if desired, may be so expressed. One ec. of the decinormal solution is equivalent to 0.009 gram of lactic acil. The other acids present include succinic, malic, and tannic. 
Ash.-The residue obtained in the direct determination of the extruet may be utilized for the cistimation of the ash. It should be ignited very cantiously and at as low a temperature as possible until the ash becomes white.

\section{WINES.}

Properly speaking, wine is the fermented juice of grapes, though the term is applied also to other products of fermentation of saccharine licpuids and fruit juices. It las been in use as a drink from the very earliest periods of eivilization. At the present time, wines are produced in infinite variety and of many qualities. The character and properties depend upon a great number of fictors, including the variety of the grape, the nature of the soil npon which the vine is cultivated, the elimate in general, and the state of the weather in partieular when the grapes are ripening, the degree of ripeness when gathered, the method followed in the preparation of the must, and the eare with which the other steps in the making of the final produet are eondueted. Of very great influence is the extent to which the seerls, skins, and stems of the fruit are allowed to be acted upon. The seeds yield considerable amounts of tamnic aeid, and the skins lend color, flavor, and to some extent astringeney. The most important constituent of the juice of the grape is the sugar, and this is present in greatest abmdance when the firuit is fully ripe.

In the making of wine, the first step is the preparation of the must. The grapes, with or withont preliminary careful examination and sorting, usually without, are erushed by machinery or by the naked feet of men, so that the juice is set free. Sometimes, the stems are first carefully eliminated, and particularly good individual grapes are cut ont and set aside for speeial nse. In the crushing of the fruit, the method of treading has in its favor the fact that the seeds are not thereby affected, and so do not give up so muel of their astringent principle. If a white wine is to be made, the must is freed at once from the skins and stalks; but if the produet is to be red, these are retained during the process of fermentation. The juice of both the white and the black varieties of grapes is practically without color; but when the dark skins are left in eontanct with the fermenting mass, the alcohol formed extracts the yellow and blue coloring matters, which berome red under the action of the firee acids formed at the same time. The constitnents of the must are water, sngar, proteid matters, gummy sulstances, pectous matter, organic acids and their salts, and mineral mattciss.

The must, with or without the skins and seeds, is fermented in vats of wood, marble, or stone, the process starting very quickly, being induced by organisms whieh grow on the skin itself. The temperature at which this is allowed to proeed exerts in important influence in determining the character of the wine: conducterl between $5^{\circ}$ and $15^{\circ}$ C., the process is companatively slow and the aroma of the wine is rich; while at higher temperatures, the rate is more rapid and the bonquet is 
less marked. The termination of the process is made evident by cessation of the evolution of carbonic acid, the diminution of specific gravity, and the sinking of matters which before had formed part of the scum.

Whether all of the sugar is used up, depends somewhat "pon the amount of proteid nutrient material for the growth of the organisms by which the conversion is carried on. If this is exhansted first, there will be a residne of sugar, and the product will be eorrespondingly sweet; if there is an abundance of proteid matter, the sugar will be the first to be exhausted, aud the wine will be "dry." It is sometimes necessary to add nitrogenons matter, such as egg allumin or gelatin, in orler to keep the process from ceasing too early.

As the percentage of alcohol in the fermenting must rises, the bitartrate of potassium present is deposited gradually, owing to its insolubility in alcohol. The deposit is known eommercially as argol, and is the source of cream of tartar.

When the first fermentation is completed, the alcoholic liquid is drawn off into casks, in which it is kept for a number of months, the vessels being kept constantly filled. It now undergoes a sceond slow fermentation, which brings about changes which are not understood excepting in their gross result, which is the production of the "bouquet" or flavor. In this second process, there occur a farther deposition of argol and an oxidation of aldehyde to acetic acid. The bonquet is due to a combination of ethers, the chief of which is onanthic ether, supprosed to be produced from the aleohol through the agency of the organic acids normally present.

The wine next is racked off into other casks, and in some eases it is necossary to do this several times. Sometimes, the appeamen of the wine is such that "fining" is necessinly. This consists in the addition of eggr albumin, isinglass, or other gelatinous matter, which in its descent attracts and enmeshes the fine particles of matter which not only prevent brillianey, but later on may impair the keeping quality of the wine.

Classification of Wines._Wines are classified varionsly according to color, strength, sweetness, and content of carbonic aciol. Aceording to eolor, they are elassed ats red or white, the latter term applying not only to the very light, almost colorless kinds, lout also to those having a decided yellowish or even yellowish-brown color, such as is possessed hy "white port." The red wines inchule those generally known as Clarets and Burgundies, though both these kinds exist in the white forms. The white wines include the white Clarets eommonly designated as Santernes, white Burgundies of which Chablis is a type, the Rhine and Moselle wines, and others.

Accorling to strength, wines are classed as natural and fortified. The natural wines contain of aleohol only that which is formed in the process of natural fermentation; the fortified wines, such as Sherry, Port, and Marleira, eontain, besides, a eonsiderable amomnt in the form of adkled spirits. 
Aceording to their content of sugar, wines are classed as sweet or dry, Some of the sweet wines contain added sugar and that which has escaped the aetion of the yeast plant. In the dry wines, all or nearly all of the sugar has been converted into alcohol. Not all of the sugar, however, in any wine is converted into alcohol and earbonie acid, small amounts going to form glycerin and suceinic acid.

According to their content of carbonic acid, wines are elasser as still or sparkling (effervescent). The natural wines contain practically no carbonie acid ; the sparkling, or effervescent, wines, as Champagne and sparkling Moselle, are in a sense artificial in that they are subjected to a process of fermentation in the bottle, sugar being added for the purpose. They are flavored also with liqueurs.

Composition of Wines.-Alcohol.-The most important eonstituent, the active principle, of wine is ethylie alcohol. The higher alcohols, propylic, butylie, and amylic, are always present in traces. The amount of alcohol is variable, ranging in natural wines from 6 to 14 per cent. by weight, but ordinarily present between the limits of 9 and 12 per cent. In fortified wines, the amount ranges from 12 to about 22 per cent., but is usually about 17 per cent.

Sugar.-While the amount of sugar in the original must ranges between 12 and 33 per cent., in the natural finished product it is as a rule quite low, ordinarily considerably under 0.5 per cent., and often none at all. The sweet Tokays contain exeeedingly variable amounts, ranging from 3 to 26 per cent., Ports and Madeiras about 4, and Sherries somewhat less; but American Ports, Sherries, and Madeiras are commonly fairly rich in sugar. Domestic Champagnes, also, contain notable amounts, but those of foreign origin, even those ordinarily classed as sweet, contain but small amounts, the impression of sweetness being largely due to the flavorings of the liqueurs added. Four specimens analyzed by the author, one of which (No. 4) is well known as an extra sweet wine, yielded the following results :

\begin{tabular}{|c|c|c|c|}
\hline Brand. & Sugar. & Extract. & $\begin{array}{l}\text { Aleohol by } \\
\text { weight. }\end{array}$ \\
\hline 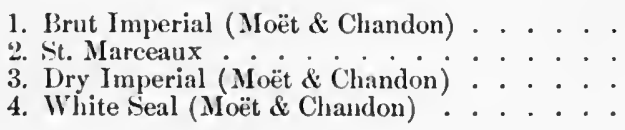 & $\begin{array}{l}1.35 \\
1.52 \\
1.56 \\
4.76\end{array}$ & $\begin{array}{l}3.27 \\
3.21 \\
3.18 \\
6.88\end{array}$ & $\begin{array}{l}11.15 \\
10.38 \\
10.85 \\
10.23\end{array}$ \\
\hline
\end{tabular}

Extract.-The extract, or residue, represents the sum of the nonvolatile constituents, including sugar, nitrogenous matters, tartarie and other aeids, mineral and organic salts, coloring and astringent principles, glyeerin, ete., all of which are present in but small quantities. In sweet wines, the principal constituent of the residue is sugar. The actual food value of the residue is, apart from the sugar, practically nil.

Adulteration of Wines.-Wines have been subject to a wide variety of adulterations from the earliest times, and measures against 
the practice of their sophistication were enforced long before those against the adulteration of bread and other foods were thought of. The ancient Greeks and Romans, for example, enacted stringent laws and appointed officials whose duty was to detect and punish those who offended.

At the present time, adulteration of wines is practised very exiensively, and includes the addition of water, of coloring agents, of preservatives, of glyeerin to impart sweetness and body, of alum to heighten color and of decolorizing agents to remove it, the substitution of wholly artificial compounds, and processes for the "improvement" of the natural product. The flavoring and eoloring agents are as a rule quite harmless. They are employed chiefly in the manufacture of factitious wines, and not uncommonly the same agent serves in both eapacities. Prunes, raisins, dried apples and peaches, and dates are commonly so employed. Varions berries, logwood, alkanet, red beets, eoal-tar products, and a wide variety of other substanees are said to be used for imparting color.

The addition of alcohol is recognized as a legitimate practice in the case of the fortified wines; that of glyeerin has no sanitary significince. The amount of alum used for heightening color is so small as to be productive of no harm. The employment of decolorizing agents is, like the substitution of artificial products, a fiaud pure and simple; but the use of preservatives, such as salicylic acid, formaldehyde, and sulphites, is objectionable on aceount of danger to health.

Fol the improvement of wines, a number of processes are in vogne. Chicf of these is "plastering," which consists in the addition of gypsum to the must for the purpose of seeming a more brilliant appearance and increasing the keeping qualities. This agent decomposes the potassium bitartrate, forming tartrate of ealcium and acid sulphate of potassimm, which latter eventually is converted into the neutral sulphate. Chaptalizing eonsists in the nentralization of the acidity of the must by the use of marble dust, and the addition of eame sugar or glueose. This process diminishes the natural acidity and inereases the yield of alcohol. Gallizing consists in diluting the must so as to reduce its acidity to a given standard, and adding a sufficient amount of cane sugar or glucose to insure the production of the proper alcoholic strength.

The Pasteur treatment of wines is resorted to sometimes as soon as evidence of untoward fermentations producing the so-called "wine diseases" appears. The wine, best in the bottle, is lieated to from $55^{\circ}$ to $65^{\circ} \mathrm{C}$. aceording as the alcoholic strength is high or low, whereby the existing germs are killed and the preservation of the wine is made permanent.

The manuficture of artificial wines is carried on extensively in this comntry and abroad, in spite of the faet that fair grades of the genuine product are obtainable at very low prices. A number of hand-books and guides to the "art of blending and componnding" are published for the use of wholesalers and retailers of wines and liquors, and from several of these the following are selected as examples of the 
methods given : (1) Port: eider, 30 gallons; alcohol, 5 gallons; syrup, 4 gallons; kino, $\frac{1}{3}$ pound; tartaric acid, $\frac{1}{4}$ pound; port wine flavor, 6 ounces. (2) Claret: California hock, 40 gallons ; extract of kino, 8 ounces; essence of malvey flower, 8 ounces. (3) Sherry : equal parts of Spanish sherry and California hock. (4) White wine: dissolve 25 prounds of grape sugar and 1 of tartaric aeid in 25 quarts of hot water, add 75 quarts of eold water and 50 pounds of grape pulp, stir, cover, let ferment for four or five days, and strain.

In Franee, an artifieial sulstitute for wine, known as "piquette," is manufactured very extensively from raisins and dried apples. It is estimated that in 1898 no less than 50,000,000 gallons were made and consumed. The process is execedingly simple. To each gallon of water used are added 1 pound of raisins and 1 of dried apples; the mixture is plaeed in an open vessel and allowed to stand three days. It is then bottled with $\frac{1}{2}$ teaspoonful of sugar and a small picee of cinnamon in each bottle. It is said to be a pleasant and harmless horerage.

\section{Analysis of Wines.}

Determination of Alcohol.- The process for the determination of alcohol is the same as that followed in the analysis of beer, except that the distillation or evaporation is carried farther. At least 60, or better 75 ec., are collected by distillation or driven off by open evaporation.

Determination of Extract.-The specific gravity of the de-alcoholized wine gives, as with beer, an approximate estimate of the amount of extract, and the same table may be used. The direct determination is made by evaporating $50 \mathrm{ce}$ of the wine in a weighed platinum dish on al water-bath and drying to constant weight in an air-bath. With sweet wines, a smaller amount is preferable.

Determination of Acidity.-The total acidity, due to bitartrate of potassium, tartaric, malic, and other acids, is reckoned as tartaric acid. 'Twenty-five ec. of the wine are titrated in the usual way with decinormal sodium liydrate, 1 ec. of which equals 0.0075 gram of tartaric atciil.

'The volatile acids are reckoned as acetic acid. Fifty ec. of the wine are placed in a distilling flask connected by means of its outlet tube with a Liebig condenser, and, by means of a bent tube passing throngh its stopper and projecting well below the surfice of the wine, with a flask contaning $250 \mathrm{cc}$. of water. The contents of both flasks are brought to the boiling-point, and then the flame beneath the wine is turned down and the eurrent of steam passed through until 200 ce. of distillate are collected. 'This is titrated with decinormal sodium hydrate, and the result is expressed as acetic acid. The determination of the amounts of the individual acids is of no lygienie interest.

Determination of Sugar.- The amount of sugar in wine is determined by reduetion of Fehling's solution, by the nethod of Allihn, and by polariseopy. For the details of these methods, the reader is referred 
to any of the standard works on wine analysis, for the small amount of sugar ordinarily present is of but little hygienic interest, and the description of the processes would require an amount of space vastly out of proportion to the importance of the subject.

Determination of Ash. - The residue olstained in the determination of extract can be utilized for the determination of the ash. It should be ignited at as low a temperature as possible.

Detection of Coal-tar Colors. - While the presence of eoal-tar colors is not difficult of detection, the identification of the individual nembers of the group is by no means easy. The following tests give reliable indications of the presence of this class of colors. Equal volumes of wine and ether, agitated in a flask, and let stand and separate, will show in the ether layer a red coloration, if anilin colors are present. In place of ether, nitro-benzene may be used; this removes fuchsin, eosin, and methylen-blue, but does not take up any of the vegetable colors, safranin, or indigo-carmine. Amyl alcohol, also, will beeome reddened when agitated with wine containing anilins, but the wine must first be made slightly alkaline. If white woollen threads are immersed for some time in the colored liquids, they will take up the colors and become dyed.

Cazenenve's test is performed as follows: To 10 cc. of wine add 0.20 gram of mercuric oxide, then slake for one minute, boil, let stand, and filter. The filtrate should be clear, and in the absence of anilins should be colorless; if it is red, an anilin color is present. Absence of eolor is, however, not conclusive evidence of purity, since a number of the anilin colors, as eosin, methylen-blue, and others, are wholly precipitated, and so do not appear in the filtrate Safranin, methyl-eosin, Poncean red, and a number of other colors are precipitated partially or completely.

A number of these, including safranin, Bordeaux red, and Ponceau red, may be separated by the following process : 'To 200 ce. of wine from which the aleohol has been expelled, ald 4 ce. of 10 per cent. hydrochloric acid and some white woollen threads, and boil for five minutes. WVithdraw the threads and wash them with eold water acidulated with hydroehloric acid, next with hot water similarly acidulated, and lastly with distilled water alone. Boil the threads in 50 ee. of distilled water containing 2 ec. of strong ammonia water, remove them, and immerse new ones. Make acid with hydrochloric acid and boil for five minutes. Varying shades of rose-red will be imparted to the threads if any of these colors are present.

Fuchsin may be deteeted by the following methods: (1) To $100 \mathrm{ce}$ of wine ald 5 ce. of ammonia water and 30 ce. of ether, and shake. Remove the ether, which will have no color, plaee it in a wateh-glass with a white woollen thread, and let it evaporate to dryness. If even a trace of fuchsin is present, the threal will show a distinct rose-cololation. (2) Mix '2 volumes of wine and 1 of solution of basic acetate of learl, warm gently, and shalie. Filter, ald to the filtrate a small anount of amyl alcohol, shake again, and remove the amyl alco. 
hol. If this has a red color, it may be due to fuchsin or to orseille. To a portion of the colored liquid add hydrochloric acid; if the color is discharged, it wats due to fuehsin. Tri another portion add ammonia witer; if the color is changed to purple violet, it was due to orseille,

Detection of Preservatives.-Salicylic Acid.-Spica's method for detecting salieylic acid in wine is as follows: Acidify $10 \mathrm{cc}$. of wine with a few drops of hyclrochloric acid, and shake with an equal volume of ether. Remove the ether, filter it if necessary, and evaporate to dryness. Aild a drop of nitric acid, warm gently, and add an excess of ammonia and 1 ec. of water. Inmerse a white woollen thread, apply gentle heat, and then withdraw the thread, wash it, and dry it between pieces of blotting-paper. A yellow color indicates that salieylie acid was present in the wine.

Another method, for which great delieacy is claimed, even to a tenth of a milligram in a liter, is the following: Acidify $50 \mathrm{cc}$ of wine, beer, or other liquid with sulphuric acid, and shake it with an equal volume of a mixture of equal parts of ether and naphtha. Separate the ether, filter, and evaporate down to $5 \mathrm{cc}$; then add $3 \mathrm{cc}$. of water and a few drops of very dilute solution of ferric chloride, and filter through a wet filter. In the presence of salicylic acid, the watery portion will have a violet color. A modification of this method consists in extrating with ether alone, and then extracting the ether residue with nathltha; the residue on evaporation of the naphtha is treated with water and very dilute ferric chloride.

Formaldehyde.-To $10 \mathrm{ce}$. of wine, add a few drops of milk known to be free from formaldehyde, and shake in a test-tube. Next pour down the side of the tube about $4-\overline{5}$ cc. of strong commereial sulphurie acid, and note the color at the line of contact of the two liquids. (See under Milk.)

Sulphites.-To 200 ce. of wine (or beer) add 5 cc. of phosphoric acid ; distil 100 ec., nsing a Liebig condenser with a bent delivery tube which dips below the surface of $20 \mathrm{cc}$. of decinormal solution of iodine. By distilling in a current of washed $\mathrm{CO}_{2}$, the danger of back suction is avoiderl. The reaction which is brought about is as follows: $\mathrm{SO}_{2}+2 \mathrm{H}_{2} \mathrm{O}+\mathrm{I}_{2}=\mathrm{H}_{2} \mathrm{SO}_{4}+2 \mathrm{HI}$. The amount of $\mathrm{SO}_{2}$ may be determined by estimating the excess of iodine by means of standard sodiun thiosulphate, or the distillate may be acidified with hydrochlorie acid and the contained sulphuric acid precipitated as barium sulphate by the addition of barium chloride. One milligram of barium sulphate is equivalent to 0.2748 milligram of $\mathrm{SO}_{2}$.

\section{CIDER.}

Cider, or "apple wine, is the fermented juice of the apple. It is made very extensively wherever apples are grown, and is a very important product, viewed either as a beverage or as the basis of what is regarded generally as the best kind of vinegar.

A very large, if not the greater, part of the cider produced is made 
without special care by a very simple process. The apples used are ordinarily those not marketable on account of small size, greenness, over-ripeness, or bruises ; but often perfect fruit is used when the crop is so abundant that there is more profit in converting it into eider and vinegar than in sending it in barrels to market. The fruit is ground to a pulp and pressed, and the juice is drawn into barrels and allowed to ferment. If the sane amount of care is taken as is given to the making of wine from grapes, the product is of a superior grade, and keeps very well; but as ordinarily made in the country, its life is short, mless treated with salicylic acid or other preservative to check fermentation. In France, where the yearly yield is very great, the best grades are made with dne regard to the temperature at which the fermentation proceeds, and to the importance of racking off" and fining.

Cider of good quality contains usually from 3 to 5 per cent. and sometimes as mueh as 8 per cent. by weight of alcohol. Very new sweet cider may contain less than 1 per cent. The total extract, which is largely sugar, is in inverse proportion to the amount of alcohol; in average samples, it amounts to from 4 to 6 per cent., while in new sweet cider it is commonly nearer 9 per cent. The free acids, chiefly malic, amount to less than 0.75 per cent., and average about 0.40 .

The adulterants of eider are water and salicylic aeid. The latter is found very commonly in that which reaches the city markets.

\section{PERRY.}

Perry, or " pear cider," is the fermented juice of pears. It is made in the same way as cider. Pear juice being richer in sugar than apple juice, it follows that the average content of alcohol is somewhat higher than in eider.

\section{Distilled Alcoholic Beverages.}

Spirits, or distilled liquors, are the product of distillation of fermented sugar solutions. Their most important constituent is ethylic alcohol, which is ordinarily present to the extent of abont 45 per cent. When freshly mate, they contain variable small quantities of higher alcohols, furfurol, fatty acids, and other volatile principles, which together constitnte what is known as fusel oil, the chief constituent of which is amylic alcohol.

Each kind of grain or other raw material from which the fermentable sugar solution is obtained yields a different kind of fusel oil ; different because of the changing relative proportions of its constituents, which inchude butylie, propylic, and amylic alcohols, and their corresponding acids, butyrie, propionic, and valerianic, and other matters. That which is found in potato spirits is richest in amylic alcohol, and is the most toxic, while that from graipes contains by far the least and produces the least ham. During the process of aging, the constituents of the fusel oil undergo chemical changes which result in the formation of conanthic, acetic, and butyric ethers, acetate and valerianate of amyl, and other compounds, which together constitute the aroma or "bou- 
quet." Thus, a spirit is improved in two ways by long storage: it loses in toxicity and gatins in flavor.

The relative toxicity of the several alcolols and of other eonstituents of fined oil hass been determined by Dujardin-Bcaumet\% and others, who show that the poismons properties increase with the boiling-point and molecelalar weightit. Jeffroy and Serveanx' determined the amomts in grams neessiry per kilogram to kill a mabit, as follows: ethylie alcohol, 11.70; propylic alcohol, 3.40 ; butylic alcohol, 1.45 ; amylie alcohol, 0.63 ; furfurol, 0.24 . Daremberg ${ }^{2}$ found by experiment that artificial spirits and wines made with pure rectified alcohol are less toxic than the genuine products, by reason of the absence of the constituents of finsel nil. Ronbinowitch, ${ }^{3}$ speaking of the greater toxieity of the higher aleohols, calls attention to the fict that the distillates from cider, perry, and fermented grains, potatoes, and molasses, are much more toxic thin brandy.

Most spirits are colored artificially by the addition of harmless coloring arents, the most willely used of which is caramel. As the practice of coloring is in response to the demand of the consumer for a darker color than can be obtained otherwise, it can hardly be regarded as an idulteration.

\section{BRANDY.}

Brandy is obtained by distilling wines of the poorer qualities, often mixed with the "lees," or dregs from the wine easks, and the " mare," or solid refuse left after pressing the grapes. The lees and mare are nsed also alone for the production of a highly odorous brandy, which is much used for improving the flavor of other brandies, and for giving flavor to the artificial brandies made from pure aleohol and water. From this mare brandy is obtained the oily substance, enanthic ether, which is known commerejally as "oil of wine."

Brandy is produed very largely in Frunce, and much less extensively in Spain, Portugal, and Germany ; in California and in the winegrowing region of the Ohio and Mississippi Valley, it is produced in large ruantities and of most excellent quality.

The colorless distillate is stored for some time in oaken easks, from which a small trace of tamnin and a varying depth of amber color are acruired. The thavor, which in generil depends upon the kind of grapes, their condition when pressed, and the care observed in the making of the wine, becomes improved during storage. The liquor is then colored and luttled for the market.

Good brandy should contain from 39 to 47 per cent. of alcohol by weight, shonlel have an agreeable odor and taste, and shonld be free from substances adder to impart sharp taste and apparent strength. 'The nearly dry residne from 100 c. very slowly evaporated on a waterbath should hitve a pleasunt orlor, and its taste shonld be neither sweet nor sharp; a sharp ixtor points to the presenee of fissel oil derived from

1 Arehives de Mralecine expéfinentale et d'Anatomie pathologique, 1595, p. 569.

2 Ibiden, 1. 719.

3 (iazette des Hôpitax, 1895, p. 237. 
potato or cereals; a sweet taste is indicative of added sugar or glycerin ; and a sharp taste is suggestive of eayenne or otler spice.

Much of the brandy of commerce is a purely artificial product made from alcohol or potato spirits, water, and flavorings. The formula for making brandy are very numerous, and not a few require what is known as brandy essence, an article made with ethers and other substanees in varying proportions. By one formula, it is made with 5 parts of oenanthic ether, 4 of acetic ether, 3 of tincture of galls, 1 of tincture of pimenta, and 100 of aleohol; by another, it consists of 15 parts of acetic ether, 12 of sweet spirit of nitre, and 1 of rectified wood spirit. One part of either of these mixtures is sufficient to flavor a mixture of 1000 pauts of aleohol and 600 of water.

As examples of the way in which factitions brandy is made, the following will serve: (1) Boil 5 ommees of raisins and 6 of St. John's breal in water, filter, and make up to 10 quarts; mix this with 20 quarts of alcohol, 10 ounces of biandy essence, and $\frac{1}{2}$ ounce of essence of violet flowers. (2) Dissolve 1 ponud of argols and 3 of sugar in a gallon of water, add 40 gallons of alcohol, $\frac{1}{4}$ pound of acetic ether, 2 onnces of tincture of kino, 6 pounds of bruiser raisins, and a suffieient anount of caramel, and let stand for fourteen days; strain and bottle.

\section{WHISKEY.}

Whiskey is the product of distillation of the fermented mash of grain or potatoes. The raw materials from which the mash is made inclucle malt, wheat, rye, corn, ants, and potato. In the process of mashing, the starch of the grain is ehanged to sugar by the cliastase of the malt; and since this ferment is ealpable of converting other starch than that with which it is associated, it is customary to mix malt and raw errain in the proportion of 1 to from 5 to 9 parts. A bushel of grain makes abont 2.5 gallons of spirits. In this eountry, the grains employed are ahiefly eorn, wheat, and rye; in Great Britain, barley, oits, and rye are used together; potatoes are 11:eel to a greater or less extent on the eontinent. The nush for Seoteh whiskey is very commonly prepared from 2 parts of malt, 7 of barley, and 1 each of oats and rye; that for Irish whiskey is the same, with the exception of the rye.

As soon as the fermentation of the mash through the agency of yeast is complete, the distillation is begme. The first distillate, known as "low wine," is re-clistilled. 'The second distillate is stronger and less rich in fusel oil, which, heing less volatile than ethylic alcohol, comes over chicfly in the later portions. The new whiskey is stored for several years, in order that it may acquire the flavor due to the formation of new componds from the eonstituents of the finsel oil. During storage, it takes up a trace of tammin fiom the oak of the casks.

The flavor of whiskey depends mpon the nature of the raw material, and langely upon the aging process. The disagreable flavor and orlor of new whiskey are due to fusel oil ; the smoky taste of Seotel and Irish whiskies is due to the smoke of the pout and turf fires over which the malt is dried. Indian corn whisky has a much ditferent flavor 
from that of rye whiskey ; this flavor is regarded highly by many to whom rye whiskey is unpalatable and insipid, and at the same time it is so full that to others it is rank and nauseating. The pecnliar flavor of Bourbon whiskey, so-called beause originally produced in Bourbon Connty, Kentueky, is due to the corn from which, with rye, the mash is prepisured.

Whiskey of good quality should contain about 45 per cent. of alcohol by weight, and shonld yield not more than 0.25 per cent. of residue, which should have a slightly aromatie odor and but little taste.

Whiskey is manufietured very largely from alcohol, water, and various flavoring compounds, some of which can hardly be looked upon as wholly innocuous. The following directions are taken from a small work, the object of which is, aceording to the preface, "to give the dispenser of liquors thorough and practieal information by which he will be enabled to compound, and blend liquors for his own purposes, and thus secure the additional profit."

1. Bourbon Oil.-Take of fusel oil, 64 ounces; acetate of potassium and sulphurie acid, each, 4 ounces; and black oxide of manganese, 1 ounce. Dissolve $\frac{1}{2}$ ounce each of sulphate of copper and oxalate of ammonium in 4 ounces of water, mix all in a glass pereolator, and let rest for twelve hours. Then pereolate and put into a glass still, and distil 64 ounces.

2. Rye Oil._Mix 64 ounces of fusel oil, 8 each of menanthic ether, chloroform, and sulphurie aeid, and 2 of ehlorate of potassium in 8 of water, place in a glass still, and distil 64 ounees.

3. Beading Oil.-Mix together 48 ounces of oil of sweet almonds and 12 of sulphuric acid, and when cool neutralize with ammonia and dilute with double the volume of proof spirit. "This is used to put an artificial bead on inferior liquors." For making the lowest grade of whiskey, one is directed to mix 32 gallons of alcolol and 16 of water, 4 ounces of caramel and 1 of beading oil. By adding oil of rye or oil of Bourbon, "making the result rye whiskey or Bourbon, as the case may be," the value is said to be increased.

From another similar souree the following reeipes for factitions whiskcy are taken :

1. Bourbon Whiskey_Proof spirit,' 100 gallons ; pear oil, 4 ounces ; pelargonie ether, 2 ounces; oil of wintergreen, 13 drachms in ether; wine vinegar, 1 gallon; caramel color, a sufficient quantity.

2. Old Bourbon.-Alcohol, 40 gallons; Bourbon whiskey, 5 gallons; sweet spirit of nitre, 2 ounces; fusel oil, 2 ounces. Mix and let stand four diays.

3. Old Rye. - Soak a half peek of roasted dried peaehes, put them

'Proof spirit is defined by an act of Parliament as a diluted spirit which at $51^{\circ} \mathrm{F}$. shall weigh exactly twelve-thirteenths as much as an equal measure of distilled water. It contains half its volume of aleoluol of sp. gr. 0.7939 at $60^{\circ} \mathrm{F}$, or 49.5 per cent. by weight, or 57.27 per cent. by volume of absolute alcoluol. Its sp. gr. is 0.91984 . Over and under proof mean that a spirit is stronger or weaker than proof spirit, and the excess or ileficiency is expressed as so many degrees over ol under proof. The expression, for example, 25 under proof, means that the specimen consists of 25 parts of water and 75 of proof spirit; 25 over proof meatus that 100 parts nay be diluted with 25 of water to bring it to the strengtls of proof spirit. 
into a woollen bag and leach with common whiskey sufficient for a barrel, and add 12 drops of strong ammonia.

4. Scotch Whiskey.-Alcohol, 46 gallons; genuine Scotch, 8 gallons ; water, 18 gallons; ale, 1 gallon; creasote, 5 drops in 2 ounces of acetic acid; pelargonic ether, 1 ounce ; honey, 3 pounds.

5. Irish Whiskey. - Same as above, substituting Irish for Scotch, and omitting the honey.

\section{RUM.}

Rum is made by distilling fermented molasses or the skimmings of sugar boilers, with, not uncommonly, other substances, as pineapples and guavas, to give flavor. 'The characteristic flavor of rum is due to butyric ether. The alcoholic content of rum is very variable, ranging from 30 to over 60 per cent. by weight. Like other spirits, rum is very largely an artificial product of alcohol, water, and flavorings known as rum essence. One of these consists of 15 parts of butyric ether, 2 each of acetic ether, essence of vanilla, and essence of violet, and 90 of alcohol. Another consists of 32 parts each of rum ether and acetic ether, 8 of butyric ether, 16 of extract of saffiron, and $\frac{1}{8}$ of oil of birch ent in strong alcohol. The rum ether required is a product of the distillation of alcohol, sulphurie acid, pyroligneous acid, and black oxide of manganese. Prune juice is also a common addition to factitious rum for its flavor and color.

\section{GIN.}

Gin is an alcoholic liquor flavored with juniper berries and a great variety of other substances, including eardamom, coriander, cassia buds, calamus, orris, angelica root, orange peel, licorice powder, and sugar. It should contain about 40 per cent. of alcohol, and not over 6 per cent. of total residue, including sugar.

\section{Liqueurs.}

Liqueurs, or cordials, are inanufactured compounds of alcohol, essential oils, eane sugar, and coloring matter. They contain usually about 40 per eent. of alcohol by weight, and from 25 to 50 per eent. of cane sugar. The colorings are, as a rule, of vegetable origin, but sometimes the coal-tar colors are employed. Even in the small amounts ordinarily taken, their use ean hardly be advised, in view of the adverse report (March 10, 1903) of the Committee of the Academie de Médecine, to whom the question of their wholesomeness was referred by the French government. The essential oils are the objectionable ingredients, apart from the alcohol. Especially deleterious is one which is taken commonly with considerable water before meals, namely, absinthe. By some the poisonous constituent is held to be the oil of wormwood (Artemisia absinthium), by others the oil of star anise (Illicium), both of which it contains. To which constituent the blame belongs is of no great consequence, the drink being one which should be 
shumned ahove all others as a poison, without regard to the imnoemousness of most. of its constituents; but it is unlikely that its disastrous effects are dne to wormwood, which as a drug has little or $n$ action, and which enters into the composition of another drink, vermuth, which enjoys a good reputation, but is not a cordial. It is a fortified white wine in which certain herbs and other vecetable matters have been infused. The ordinary French vermuth is male from wormwool, bitter-orange peel, water germander, orris root, chamomile, Prruvian bark, aloes, cinnamon, nutmeg, ecntaury, and rasplberry, but many other substanees are used by different makers. The fresh product has a very pronomeed flavor, which is mellowed by ance. The wines most used in making French vermuth are from the Rhone Valler, Pieponl, and from the sonthernmost parts of France. Italian vermutli differs materially from the French; it is a much weaker infusion with a fur more bitter taste. The materials used are in the main the same, but they are employed in very different proportions. Vermuth contains about 17 per cent. of aleohol.

\section{Section 6. CONDIMENTS, SPICES, AND BAKERS' CHEMICALS.}

The condiments inelude a large number of food acessories which, while they are themselves of no nutritive value in the amounts which it is possible to cat, serve a very useful purpose in imparting flavor, and in stimulating appetite and digestion. Among them are some which act through free acids, some through volatile oils, some through resinous matters, and one, perlaps the most important of all, common salt, throngh itself alone. Some are simple substances; as vinegar, salt, and the spices; while others are combinations of a number of ingredients blended according to definite and, as a rule, secret formulas; as sauces, chutneys, catsups, and eurries. Only when these compounded articles eontain sulsstances injurions to health ean they be regarded as adulterated. The tomato eatsups are preserved very eommonly with salierlic acid or other preservatives, and colored with anilin dyes. Thus, of 25 samples of different makes examined in 1897 by the health anthorities of San Francisen, 20 contained salicylic acid, 2 contained this agent together with borax, and 1 contained formaldehyde; 16 were artificially colored, mostly with coal-tar colors. Of 39 examined by the Masiachusetts State Board of Health during 1899, 15 contained salicylic acid and 13 benzoic acid.

\section{VINEGAR.}

Vinegar is a weak solution of acetic aeid resulting from the acetous fermentation of sareharine solutions which have undergone aleoholie fermentation. It contains, in addition to acetic acid, small and unimportant amonnts of alcohol and aldehyde, and extractive matters in varying amounts, arenreling to the nature of the original liquid. The 
acetic acid eontained in the product of oxidation of aleohol through the agency of Mycorlerma aceti, a fungus which forms what is known as the "mother of vinegar." Thus, the change from sugar to acetic acid involves two separate fermentative changes through the ageney of two lifferent organisms, Sacharomyces cerevisice and Mycoderma aceti.

There are several kinds of vinegar in eommon use, as follows:

Cider Vinegar.-In this country, eider vinegar is regarded very generally as the most desirable kind. It eontains no aldehyde, abont 4.50 to 5.50 per cent. of acetic acid, marked traces of malic acid, and about 2 per cent. of total residne, or " cider-vinegar solids."

United States Standard.-Standard eider vinegar is the product made by the alcoholic and subsequent acetous fermentations of the juice of apples, is lævo-rotatory, and contains not less than 4 grams of aectic aciil, not less than 1.6 grams of apple solids, of which not more than 50 per cent. are redueing sugars, and not less than $0.25 \mathrm{gram}$ of apple ash in $100 \mathrm{ce}\left(20^{\circ}\right.$ C.) ; and the water-soluble ash from $100 \mathrm{cc}$ $\left(20^{\circ} \mathrm{C}\right.$.) of the vinegar contains not less than 10 milligrams of phosphoric acid $\left(\mathrm{P}_{2} \mathrm{O}_{5}\right)$, and requires not less than 30 ee. of decinormal acid to neutralize its alkalinity.

Wine Vinegar.-In wine-producing countries, the vinegar in common use is made from the cheaper kinds of wine. It has color or not, according to the kind of wine from which it is made. The so-ealled white wine vinegar in common use in this country among the foreignborn population is a colorless product of the oxidation of dilute spirits. Wine vinegar eontains rather more acetic acid than cider vinegar, but far less residue.

United States Standard.-Standard wine vinegar is the product made by the alcoholic and subsequent acetous fermentations of the juice of grapes, and contains in 100 cc. $\left(20^{\circ} \mathrm{C}\right.$.) not less than 4 grams of acetic acid, not less than 1.0 gram of grape solids, and not less than 0.13 gram of grape ash.

Malt Vinegar.-In England, which is neither a cider-producing nor a wine-producing country, the vinegar in commonest use is made from a wort prepared from malt and unmalted grain. It is less strong in acetic acid than the vinegars alrealy described, but commonly contiins sulphuric acil, which, under the English law, is a permissible admixture to the extent of not exceeding 0.10 per cent.

United States Standard.-_Standard malt vinegar is the prodnet made by the aleoholic and subsequent acetous fermentations, without distillation, of an effiusion of barley malt, or eereals whose stareh has been converted by malt, is dextro-rotatory, and contains in $100 \mathrm{cc} .\left(20^{\circ} \mathrm{C}\right.$.) not less than 4 grams of acetic acid, not less than 2 grams of solids, and not less than 0.2 gram of ash; and the water-soluble ash from $100 \mathrm{ec}\left(20^{\circ} \mathrm{C}\right.$.) of the vinegar entains not less than 9 milligrams of phosphoric acil $\left(\mathrm{P}_{2} \mathrm{O}_{5}\right)$, and requires not less than 4 ce. of decinormal acid to neutralize its alkalinity.

Sugar Vinegar. - United States Standard. - Standard sugar vinegar is the product made by the alcoholie and subsequent acetons fermen- 
tation of solutions of sugar, syrup, molasses or refiners' syrup, and contains in 100 ce. $\left(20^{\circ}\right.$ C. $)$ not less than 4 grams of acetic acid.

Glucose Vinegar.-United States Standard.-Standard glucose vinegar is the product mite by the alcoholic and subsequent acetous fermentations of solutions of starel, sugar, or glucose, is dextro-rotatory, and contains in $100 \mathrm{cc}$. $\left(20^{\circ} \mathrm{C}\right.$.) not less than 4 grams of acetic acid.

Molasses Vinegar.-A very large part of the domestic supply of vinegru is manufuctured from fermented molasses. It is made to imitate cider vinegar in eolor, and is sold commonly under the name of that article. It yields about the same amount of acid, but is very defieient in residue. The latter has a very bitter taste, and after complete ignition yields an ash containing no potassium salts, while that from eider vinegar gives a decided indication.

Spirit Vinegar. - Spirit vinegar, also known as "Quick Process" vinegar, is made from diluted alcohol. The process used is the same as that employer in the making of malt vinegar and molasses vinegar. A series of suitable vats is constructed and filled with bech or birch shiwvings or twigs, which by appropriate treatment become coated with Mycodeme aceti. 'The alcoholic liquid is allowed to percolate through, and in its passage the alcohol is transformed. The temperature of the room is maintained at about $70^{\circ} \mathrm{F}$.

United States Standard.-Standard spirit vinegar is the product made by the acetous fermentation of dilute distilled alcohol, and contains in $100 \mathrm{cc} .\left(20^{\circ} \mathrm{C}\right.$.) not less than 4 grams of acetic acid.

Adulterations of Vinegar.-The principal adulterations of vinegar are the addition of water and the coloring of inferior grades so that they may be sold as cider vinegar. Where laws are in force establishing standards of acidity and residue for eider vinegar, a very common friud is the addition of cider jelly or of a preparation made from apple pomace to a elieap vinegar of the proper strength, colored, if necessary, with caramel. Such compounds always show but slight or no reaction when tested for malic acid. 'The addition of mineral acids is not a common practice in this country.

Examination of Vinegar.-Acidity.-To 6 cc. of the specimen in a porcelain casserole, add a few drops of phenolphthalein solution and about $20 \mathrm{ce}$. of distilled water. 'Titrate with decinormal sodium hydrate solution, adding little by little until the appearance of a faint pisk colnation. The number of ce. of the reagent used, divided by 10, equals the pereentage of absolute acetic acid.

Residue.-Eviporate 5 grams in an accurately weighed platinum dish to complete dryness over boiling water. After the residue is weighel, it may be ignited for its yield of ash.

Genume cider vinegar should give no more than a faint cloudiness on being testerl with nitrate of silver and chloride of barium (absence of more than traces of chlorides and sulphates), and should yield a fairly copious precipitate with solution of subacetate of lead (presence of malic acid). 'The residue should not taste bitter (absence of caramel). Cirler vinegar to which water has been added is likely, according to 
the nature of the water, to show more than the usual results on testing for ehlorides and sulphates, and to yield notable traces of lime. Molasses vinegar generally yields marked indications of lime salts and a more or less pronouneed odor of rum.

\section{LEMON JUICE AND LIME JUICE.}

Lemon juice is the expressed juice of the ripe fruit of Citrus limonum. It is a somewhat turbid yellowish liquid, with a very acid taste and a slight agreeable odor, due in part to the presence of a small trace of volatile oil from the rind. It should contain about 7 to 10 per cent. of citric acid, and should yield from 0.50 to 1.00 per cent. of ash. Its specific gravity should be not less than 1.030 , and is usually above 1.040. As it is quick to undergo decomposition in its natural condition, a number of methods have been proposed for its preservation, the best of which appears to be, first to elarify it by means of strong alcohol, next to filter or deeant from the precipitated matters, and then to expel the aleohol by heat. The elear juice may then be bottled and sterilized.

Lime juice is the expressed juice of the sour lime, Citmus acida, and of the sweet lime, C. limettc. It contains usually somewhat less aeid than lemon juice, and has a lower specific gravity. It is preserved by the same method.

As antiscorbutics, lemon juice and lime juice are of about equal value, and far superior to vinegar.

Adulteration.-Lemon juice is much more subject to adulteration than lime juice, but both are falsified and imitated extensively. In fact, it would not be overstating the case to say that by far the larger part of the lemon juice sold in this country is wholly factitions. Commonly, it is nothing more than an aqueous solution of eitric acid ; sometimes, it is flavored with oil of lemon. Its taste is nuch sharper and less agrecable than that of the genuine article. The residue is very different in character and appearance, and leaves practically no ash on ignition. Other acids are used sometimes in place of or in addition to citric acid. The one most commonly employed is said to be tartaric; this is detected readily by the gradual formation of bitartrate of potassium on addlition of the acetate. The mineral acids are said to be added not infrequently; they are deteeted without diffieulty by the common tests.

\section{SALT.}

The best grades of common salt are white, dry, free from dirt, and completely soluble in water. Many specimens of good quality contain traces of ehloride of magnesium, which causes ealing. In humid weather, even the best grade of salt absorbs moisture sufficient in amount to cause it to lose its dry, powdery nature. The addition of about 10 per eent. of corn stareh serves to keep it dry and powdered. 


\section{MUSTARD.}

Mustard is the flour of the seed of the black and the white mustard, Simpise niger and st. alba. The first mentioned is much the more pumgent of the two; on being wet with water, a volatile oil is developed from two of its constituents. The white mustard yields no volatile oil by this treatment, but develops an acrid principle. Both varictics of secels contain a bland fixerl oil to the extent of $20-25$ per cent. As this ands mothing to the flavor, makes grinding more diffieult, and cxerts an injurions influence on the kecping qualities, it is removed from the whole secels by pressine.

Mustard is largely silbject to adulteration with wheat, rice, and eorn flour, with the farther addition of turmeric to restore the color lost by dilution. These substances are deteeted very easily by mous of the microseope. Furthermore, since starch is wholly absent from pure nustarl flour, if a small portion of a suspected sample, boiled in a little water in a test-tube and cooled, gives a blue or bluish-black color on the addition of compound iodine solution, it unquestionably is achulterited.

\section{PEPPER.}

Pepper is the fruit of Piper nigmom, a perennial climbing shrub. The muripe berries, dried for several days after being picked; are known as Black Pepper. The ripenerl berries, dried and decorticated, are known as White Pepper. In the powdered form, in which they are retailed most commonly, both are adulterated very extensively with substances of a harmless nature. These include ground shipbread, cormmeal, cocoannt shells, rice, buckwheat, outmeal, mustard hulls, charcoal, olive stones, and a variety of other substances of little or no value, eapable of being reduced to powder.

'The simplest method of determining the purity of this or any other' form of spice is to reduce a specimen of the gentine unground substance to powdered form and study its appearance under the mieroscope, and then to compare it with the sample in question. Fach kind has its chatacteristic appearance, and so with a little practice one is enabled to determine very quickly the question of purity. By a similar study of the microsepic appearances of the common adilterants, these may rendily be identified in the mixture. The chemical analysis is intricate and tedions, and not always conclusive.

\section{CLOVES.}

Cloves are the flower buds of Eurgeniu caryophyllata, picked while red and Iriol in the sun. They contain about 16 per cent. of volatile oil, easily removed and of ensiderable value. In the powdered form, cloves are aldulterated commonly with allspice, elove stems, spent chores, coesomut shell., and other worthless matter. The presence of spent "loves can be dotermined only by estimation of the amomnt of volatile oil present. Clove stems show mieroseopically a very large 
proportion of the so-called stone cells. Other sulustances are detected in the manner deseribed under Pepper.

\section{CINNAMON AND CASSIA.}

Cinnamon is the inner bark of Cimnamomum zeylunicum. Cassia is the bark of several species of Cinnamomum. In the unground state, cimmonon is thin and delicate; cassia is thick and comparatively coarse. Cinnamon is the richer in volatile oil, and for this reason and because it is found much less abundantly, is considerably more expensive than cassia. Ground cinnamon is practically never found in the market, the substance sold under that name being almost invariably eassia. The common adulterants of cassia include ground shipbread, mut shells, and cedar sawdust.

\section{ALLSPICE OR PIMENTO.}

Allspice is the diried unripe berries of Pimenta officinalis. Although one of the cheapest of spices, it is adulterated extensively with gromnd shiplread, eharcoal, nut shells, clove stems, and mustard hulls.

\section{GINGER.}

Ginger is the rlizome of Zingiber officinale. It is one of the most commonly adulterated of condiments. The substances used inclurle ground shipbread, rice, mustird hulls, eayenne, turmeric, cormmeal, clove stems, and exhansted ginger from the mamufacture of the tincture. It is very rich in starch, which is differentiated easily from other starches.

\section{NUTMEG.}

Nutmeg is the inner kernel of the fruit of Myristica fragrans. It is not commonly sold in the powdered condition, but when so sold is generally aduiterated with the substances nsed as admixtures of other sipices.

\section{MACE.}

Mace is the dried membranous covering, the arillode, of the nutmeg. It is adulterated with wild mace, cormmeal, and other cheap materials.

\section{CAYENNE PEPPER.}

Cayenne is not a true pepper, but the powdered pods of sereral species of Capsicum, induding C. ammum and C. fastigiatum. Its appearance under the mieroseope is very chatreteristic. The commonest alulterant is cornmeal. Among others are rice, mustard hulls, turmeric, and ground shipbread.

\section{BAKING POWDERS.}

Baking powders, like concliments, are in no sense foods, but boing employed in the preparation of lorarl, in which are retained the ulti- 
mate products of the reations of their component parts upon each other, they are of hygienic interest. 'They are employed for the production, within a short time, of at result which, when eaused by the action of reast, is only slowly brought about; namely, the leavening of bread. Teast produces the leavening gas, earbon dioxide, throngh slow fermentation of a part of the carbohydrates; while with the use of baking powders, this gas is disengaged as a result of chemical action of one of the constituents upon another in the presenee of moisture, and chemical substanees foreign to yeast-learened bread are left as a residuum in the bread. Whether this residum is objectionable on the seore of its inflnence upon the system, depends upon the nature of the ingredients of the powder' but iside from the question of disadvantage or inferiority on this aceount, it is a fict, generally acknowledged, that bread made with baking powder is lacking in a certain agreeable flavor developed by the action of yeast.

Balking powders are combinations of an acid or acid salt with sodium licarbonate in about the proper proportions for ehemical union, together with an amount of starch sufficient to keep the ingredients in a dry state, and hence mutually inactive. When the combination is introduced directly into the flour, and water is added to make the dough, the reaction oceurs and carbon dioxide is set free. They are known, aceording to the nature of the acid salt, as tartrate, phosphate, and alum powders. Tartrate powders are made usnally with "cream of tartar" (potassimm bitartrate), but oceasionally with tartaric aeid, which is not only more expensive, but is objectionable from a practical standpoint on account of its readier solubility, which causes a too rapid evolution of gas. The reaction which oecurs between potassium bitartrate and sodlum biearbonate has, as results, earbon dioxide, water, and potassimm sodium tartrate, or "Rochelle salt"; as follows:

$$
\mathrm{KHC}_{4} \mathrm{H}_{4} \mathrm{O}_{6}+\mathrm{NaHCO}_{3}=\mathrm{KNaC}_{4} \mathrm{H}_{4} \mathrm{O}_{6}+\mathrm{CO}_{2}+\mathrm{H}_{2} \mathrm{O} \text {. }
$$

The eommereial advocates of other kinds of powders dwell upon the undesirability of aperient substanees in bread, but the residuum of Rochelle salt in the amount of bread which one could eat in a day would be very much under the minimum dose from which any results conld be expected.

Cream of tartill, as retailed, is adulterated very commonly with gypsum, chalk, alum, and starch; but as furnished to the manufacturer by the refiners, it eontains but a very small percentage of a normal impurity, tartrate of calcium. The usual ehemical tests and microseopic examination reveal fraudulent adulteration rery quickly. Good speeimens contain at least 94 per cent. of bitartrate; and 2 decigrams, dissolverl in hot water and titrated with decinormal sodium hydrate, require for complete neutralization not less than 10 nor more than 10.6 ce. The prescnee of a small amount of tartrate of caleium is of no sanitaly importance whatever, statements to the contrary in advertising matter notwithstanding.

The phosphate powders are made with acid phosphate of ealcium, 
which contains ordinarily more or less sulphate as a natural impurity. The reaction with sodium bicarbonate is expressed as follows :

$$
\mathrm{CaH}_{4}\left(\mathrm{PO}_{4}\right)_{2}+2 \mathrm{NaHCO}_{3}=\mathrm{CaHPO}_{4}+\mathrm{Na}_{2} \mathrm{HPO}_{4}+2 \mathrm{CO}_{2}+2 \mathrm{H}_{2} \mathrm{O} .
$$

There is 110 well-grounded objection to the use of this class of powders.

Alum powders are made usually with soda alun and a very large amount, frequently as high as 50 per cent., of starch "filling." 'Their leavening power is almost invariably far below that of tartrate and phosphate powders of good quality. The cheapest class of powders, the sale of which is promoted by gifts or "premiums" of cheap crockery and glass, are made with alum and the maximum amount of filling. The reaction between alum and sodium bicarbonate is expressed as follows:

$$
\mathrm{Na}_{2} \mathrm{Al}_{2}\left(\mathrm{SO}_{4}\right)_{4}+6 \mathrm{NaHCO}_{3}=\mathrm{Al}_{2} \mathrm{O}_{6} \mathrm{H}_{6}+4 \mathrm{Na}_{2} \mathrm{SO}_{4}+6 \mathrm{CO}_{2}
$$

Whether the alum exerts any injurious effect upon the bread itself, and whether the resulting hydrate or any excess of alum has any sanitary importance, are questions which have been the subject of extensive controversy. Without reproducing the arguments and claims of both sides, it should be said that the weight of scientific evidence is deeidedly against the employment of alum in the making of bread. Some of those who believe alumina to be harmless in the amounts consumed, regard powders eontaining both alum and potassium bitartrate as highly objectionable, the complete precipitation of alumina being prevented. Powders containing alum and acid phosphate are held also to be objectionable, on account of the formation of aluminum phosphate, which is supposed to inhibit gastric digestion.

In addition to sodium bicarbonate, ammonium carbonate is used more or less as a source of leavening gas. While this agent when administered therapeutically may exert a marked temporary influence, the amount used in baking powders is too small to be hurtful to the system.

The amount of starch filling used in making baking powders is very variable. The best grades contain considerably under 20 per cent., and anything over that amount may rightly be regarded as in the nature of unnecessary and fraudulent dilution.

\section{Section 7. FOOD PRESERVATION.}

Foods of a perishable nature are preserved in many different ways, but not all methods are equally applicable to all foods. Thus, freezing and salting, while well suited to meats and fish, can hardly be employed with fruit and vegetables; and preservation in sugar syrup, while well adapted to fruits, is not suited to meats. The methods in general use include the employment of low temperatures, desiccation, salting, smoking, canning, and chemical treatment. 
Cold.-For the best results of preservation by cold it is not always essential that the ford shill be firowen; but muless the temperature to which it is axposed is near or below the frecoing-point, the influence is only temporary. Packing in ice serves very well for short periods to ship meats and fish through long distances, and to keep them in satisfarcory eondition for reasomable periods in the homes of the consumers. There are several methods of applying cold on a large scale in coldstomige warehouses, ocean steancrs, and public markets, the principal one heing known as the ammonia process, by means of which any desired temperature down to $0^{\circ} \mathrm{k}$. may be obtained with but slight flnctuation, provider the walls, floor, and roof of the space oecupied ate rendered non-conducting by liair-felt, air spaces, and other means. Mesits and fish are preserved indefinitely and without deterioration when frozen, but should not be allowed to thaw and freeze; eggs and fruits may be kejt many months in dry air at just above the freezing-point.

The advantages of cold as a preserving agent are that, unlike any other, it involves neither the abstraction of any constituent of the food nor the ardlition of any foreign matter; it neither imparts a new taste nor alter's the natural flavor; it eamses neither a loss of nutriment nor diminished digestibility; and on the withdrawal of its influence the material is left in its original condition. It should be said, however, that after restoration to the natural condition, the keeping qualities appear to be somewhat impaired, and in consequence the material should be used within a shorter time than is the case with similar fresh food that has not been frozen.

Drying.-Drying is eftieient aceording to the thoroughness of the process. The method is not so well adipted to meats as to vegetables, since it leads to more or less loss of the natural flavors, which are likely to be replaced by others less agreable in character. Dried meats are, morover, considerably less digestible than fresh meats. When thoroughly dried and properly stored, both meats and vegetable products can be kept without limit of time. Drying does not insure safety against parasites.

Salting.-In the process of salting, the soluble organic constituents of meat and fish are removed in large part, and the fibers beeome harrened. The mutritive value and digestibility, therefore, are diminisher eorrespondingly. Brine silting of tish is one of the oldest procescess of preservation known.

Smoking.-Snoking eonsists in exposing the meat or fish to the action of the smoke of wood fires after, as a rule, a preliminary salting. 'The exposed material, alrearly deprived of part of its natural moisture, becomes dried still farther, and is partly penetrated by acetic acid, rensote, and other precervative elcments of smoke. In the quick smoking proeess, the meat is lrushed over with or dipperl into pyroligneous acid at definite intervals, and finally dried in the air.

Canning.-In 1804, M. Appert, of P'aris, discovered that meats and other fools in sealed vesisels wonld kerp indefinitely, if, after being sealed, they were kipt for an lour in boiling water, In 1810, he 
introducer the method of sealing the vessel after the heating process hats driven out the air and replaced it with stean, so that when cooled a valeum is formed. At the present time, the chief method followed is to pack the cans full and close them completely, excepting a small hole, then to subject them to the temperature of boiling water, or higher, and to elose the hole with solder. They are then reheated and finally allowed to eool.

Much has been said for and against this method of preserving foods. 'The elief' objections have been that the natural acids of the foods may corrode the inner surfiee of the eans and form metallie salts, and that terne plates, that is to sily, sheet iron or steel coated with an alloy of two parts of lead to one of tin, may be used instead of the best quality of tin plates. As to the latter objection, while there is in this country 110 legal restriction as to the character of the tin employed, it is a fact that terne plates are never used. With regard to the possibility of corrosion of the metallic surfice, it must be admitted that not only the very acid foods, but even those which are neutral and even alkaline in reaction, almost in variably will yield traces of tin ; but there is, at the same time, absolutely no evidence that the small amount present in the entire contents of a can is capable of eausing the slightest injury.

There are, it is true, numerous eases of poisoning reported as due to metallic eontamination of camned foods, but not one of those which lave fallen under the view of the author will stand the test of exclusion of other possible and nore probable causes. Of the small amounts of tin found in canned foods, Professor $A$ ttfield says that they are undererving of serions notice, and he questions that they represent the amount regularly worn off of tin saucepans and kettles. Furthermore, it is the nearly manimons opinion of writers of works on toxicology that the only eomponnds of tin that are in any way poisonous are the chlorides, and even these are ignored completely by most of the leading anthoritics.

On the other hand, there is no limit to the testimony regarding the very great value of eamned foods, especially in military operations on a large seale, and in expeditions of various kinds away from market centres and other sources of supply. Lientenant Greely, Dr. Nansen, and other Arctie explorers are manimons in their praise. Gredy, for example, says: "No illuess of any kind oceured prior to our retreat, and those mont inclined to eamed firnits and vegetables were the healthiest and strongest of the party." Lord Wolseley, in spealing of their use-fulness in hot climates, says that "tinned provisions, meat or vegetables put (1) separately or combined in the form of soups, are practically undamageable by any elimatic heat" provided they are of the best quality and lave been properly cooked and endosed in perfectly sound airtight tins. " (iven these enditions, nothing can be more admirable; failing them, nothing more deleterions." In military operations in the tropies, where beef eattle eamnot be taken along on the hoof and refrigerated beef cammot be transported overland on aceount of speedy decomposition, canned meats ane indispensable. 
How long properly canned foods will remain in good condition, can hardly be determined, but the evidence at hand points to indefinite prescrvation. In 1824, aceording to Lethely, a number of tins of mutton were cast ashore from the wreck of a ship at Prinee's Inlet; eight years later, they were found by Sir John Ross, and those which he opened were in good condition, although exposed during this time to alternate freezing and thawing. Sixteen years afterward, they again were found by men from the ship Inestigator; and in 1868, forty-four years from the time they were cast ashore, the remaining tins, opened by Lethely, were found to be in a perfectly sound state. Tyndall ${ }^{1}$ makes mention of tins in the Royal Institution that had remained in good condition sixty-three years.

Professor A. H. Chester, of Hamilton College, relates that in the summer of 1875 he hid a number of eans of corned beef under a stump in woods in the northern part of Minnesota, and five years later found them to be perfectly sweet, although they had been exposed to the heat and cold of five suecessive summers and winters. Again, a number of cans of meat and fruit, washed into the Genessee River in 1865 , were dug ont of the mud sixteen years later, and found to be unaltered.

It is an unfortunate fict that the cupidity of some of our largest packing-houses has led to the eanning of what is practically refine meat, from which the constituents to which the desirable flavors are due have been extraeted, and that in consequence the public mind has largely become imbued with a prejudice against canned meats in general. But it is not alone in this country that canned meats are sometimes not what they purport to be. It is related that in Franee, in 1899, a packer of meats was sentenced to pay a fine and to serve eight months in prison for putting upon the market an immense amount of camned game and poultry, all of which had been made from the flesh of broken-down cab horses.

Chemical Treatment.-Chemical preservatives are substances or eombinations added to foods with the object of delaying or preventing their decomposition. They are used on the assumption that, while they accomplish the desired objeet, they are incapable of exerting any larmful influenee upon the system of the consumer-an assumption that has not been demonstrated as based on sound reasoning. It is assumed that bad effeets cannot be cansed, because they are not manifested at onee after the ingestion of small doses by persons in good health; but this is no proof that eontinued use may not result in serious trouble which may be referred to some other possible cause.

It is said that the preparations employed are in common use as valuable remedies in the treatment of the sick; but it should be taken into consideration that, when used as remedies in morbid eonditions, they are given for only a limited time, for the purpose of counteracting abnormal influenees, and that the doses are regulated carefully under proper professional supervision. Their action in eonditions of health

${ }^{1}$ Floating Matters in the Air, New York, 1882, p. 293. 
and disease may be very different; but whether so or not, one can find no excuse for the ingestion of curative remedies by a person in a state of health, whose system needs no such aid, for indefinite periods and with no regulation of the size of the lose. Salicylic acid, for example, is a remedy holding a high position in the treatment of rhenmatism, but its value in this condition is no valid exeuse for its administration day in and day out to those who never have felt the twinges and pain of this disease. It is much more reasonable to assume that drugs which exert a powerful influence for good in morbid states will exert an equal degree of influence for harm in conditions of health. Moreover, it is to be considered that the object of chemical treatment of foods is not to benefit the unconscious consumer, but to bring the largest possible financial return to the manufacturer and purveyor, to whom the health of the consumer may be a matter of little concern. In all fairness to the consumer, chemically preserved foods should be so labelled that the purchaser may be informed of the nature and amount of the added substance, so that those who object to the dietetic nse of drugs may not have the same forced upon them without their knowledge.

The addition of preservatives to foods offered for sale is forbidden in alnost all civilized countries, and several governments have enacted laws specially directed against individual drugs. Thus, France names boric acid, borax, salicylic acid, and sodium bisulphite; Austria names salieylic acid; Germany prolibits all antisepties, and especially boric acid and borates, and imposes additional penalties for the sale of chemically preserved foods to the navy. Massachusetts prohibits all preservatives except salt, sugar, niter, vinegar, and alcohol, unless the purchaser is informed of the nature of the substance used. In milk, all preservatives whatsoever are prohibited uneonditionally.

The substances used as chemical preservatives include boric acid and borax, salicylic acid, sulphurous acid, sulphites and sulphates, benzoic acid, formaldehyde, hydrogen peroxide, sodium fluoride, and others of minor importance. Many of the commercial preparations in common use are combinations of two or more of these and other substances. Thus, Venzke and Schorer ${ }^{1}$ report the ingredients of 38 meat preservatives, analyzed by them, as follows: Salt, sugar, and saltpeter, (1); salt and sodium sulphite and sulphate (4); sodium sulphite and sulpliate (4) ; the same, plus sugar and salt (1); salt and sodium bicarbonate and nitrate (1); salt, boric acid, saltpeter, and sodium sulphate (3) ; salt, boric acid, and sodium sulphate (1); salt, boric acid, gypsum, and sodium sulphate $(1)$; salt and boric acid $(6)$; salt, saltpeter, sodium and calcium sulphates, and cochineal (1); salt and borax (1) ; salt, borax, and saltpeter (2); salt, borax, and sodium nitrate (2); salt, borax, sodium and ealeium sulphates, and salicylic acid (1); borax and sugar (2). The rest consisted of single substances.

A large proportion of 24 ineat preservatives examined by Känmerer were found to be mixtures of borax and boric acid, and borax and sodium sulphite; 31 others examined by Kionka were, as a rule, sodium

\footnotetext{
${ }^{1}$ Deutsche Fleischerzeitung, 1893, XXI., Nos. 20, 21, and 24,
} 
sulphite and sulphate, but 14 licpind preparations consisted chiefly of alcium suphite and sulphate, and sodium sulphite, bisulphite, and sulphate. Kirchmaier has reported one as eonsisting of salicylic acid and sodium salicylate and phosphate. Polenske found boric aceid (alout 60 per (ent.), saltpeter (about $12-14$ per cent.), sugar, salt, and sorlium salicylate (about 7.50 per cent.) in a specimen of sausage salt, and in a number of other preparations sold under fancy names. Of 7 other meat preservatives examined by him, ${ }^{1}$ one contained salt, sodium sulphite and sulphate, iron chloride, and vanillin, and the rest were combinations alleady described.

A. C. Chapman ${ }^{2}$ has reported a most extraordinary combination of alumimm sulphate, salt, sodium nitrate, benzoie acid, iodic acid, sulphurous actid, and chloral.

Another, examined by Töllner, proved to be ammonimm bromide, borie acid, borax, and sugall. Another, known as "Mayol," eontained word aleohol, ethylic alcohol, borie acid, ammonium fluoride, and grlycerin. Mrats preserved by means of it are said to show no trace of boric acid or ammonimm fluoride beneath the brown coating, which forms to a depth of a millimeter.

In this comntry, the favorite mixture is one of borax and boric acid, and this: is sold under many different names.

Boric Acid and Borax.- These substanees generally are used together, for the reason that, althongh the acil has greater power as an antiseptic than the salt, the combination of the two is still more efficient. It is user very largely in butter to the extent of about a tenth of an ounce to the pound, and is dispensed with a generous hand in oysters, clams, and other fish, in salusages and other meat produets, and in milk.

With regard to the effeets of borie acid and borax on the system, there is a decided difference of opinion among those who have investigated the subject, but it should be said that a number of the reports firorable to the use of these agents, published by commereial houses, suggest that the conchusions arrived at were inspired somewhat by financial eomsiderations. Our knowledge of possible ill effects is derived chiefly from the elinical experience of those who have used the druns interially and as washes and injections. It is a fact that many patients ean take large doses of both substances for long periods with no apparent harm, but it is equally true that small doses and local :1pplications have been a frequent cause of serious and even fatal resilts. Deaths have been reported from the use of 5 per cent. solutions in washing ont the plenral cavity and lumbar abscesses, and from washing ont a stomach with a solntion of half that strength. Numerous cases of tronblesome entaneous eruptions and of serious gastro-intestinal disturbances following internal and extemal use have been reporterl within recent years. Plant ${ }^{3}$ has shown that internal use may be followed by ante parenchymatons nephritis, and his conelusions have heen entorest by the experience of Féré, mentioned below.

1 Arlwilen ans dem kaiserlichen (ixwusheitsimte, VIII., p. 686 .

2. Anilỵis, Lec., 1898. 3 Intugunal dissertation, Würzburg, 1889. 
In 1876, the admixture of borax to butter was sanctioned officially in France; but seven yars later, a committee of scientists, who investigated the matter with great care, concluded that continued ingestion is likely to eause deterioration of the blood eorpuseles; and when, somewhat later, this finding was confirmed by the investigations of Ponchet, the use of borax was prohibited by the government, not only in butter, but in all artieles of food. In 1891 , the subject was presented by the Kensington Vestry to Sir Andrew Clark, Sir Henry Thompson, and Professor Lauder Brunton, who concurred in pronouncing boric acid in large doses, or in small doses taken for long periods, as dangerous to health. The Local Government Board, in 1891, reported that, while large doses are undoubtedly injurious, they had not sufficient evidence to hold that minute anounts added to foods ean affect the system harmfully.

As is well known, borax has been used extensively in the treatment of epilepsy and other diseases of the nervous system. Professor H. C. Wood states that, in his experienee, the most marked result from its use in this dircetion was severe gastro-intestinal irritation. Dr. Féré ${ }^{1}$ has given a valuable report of his results in the treatment of 122 cases of epilepsy by this drug, which was given in begimning doses of 30 grains, increased to as mueh as 5 drachms a day. In more than 70 per cent. of the cases, the treatment had no beneficial result; in about 20 per cent., some temporary or doubtful improvement was seen; and, in 9 per eent., there was distinet gain. But the great drawback was the frequency of toxic effects and the danger of producing or aggravating lesions of the kidncys, even when given in small doses. Among the most eommon results were loss of appetite and burning pain, followed by nausea and vomiting. Cutaneous affections were very common, and complete baldness was eaused not infrequently. (This result has been noted by many other practitioner's.) In some eases, a cachectic condition, eharacterized by wasting, a waxy tint of the skin, puffiness of the face, and even general oedema, was observed. In a number of cases of general cedema, uræmia developed with some suddenness.

Dr. Grumpelt ${ }^{2}$ has reported a ease in which headache, nausea, and intense dryness of the skin followed the use of an injection containing a tablesponful of boric acid the pint. The effects disappeared with cessation of the treatment, but eame on again with its renewal. Dr. J. J. Evans ${ }^{3}$ has found, as a common result of the continued use of boric acid in eystitis and urethritis, an erythema followed by desquamation. Internal doses of 10 to 20 grains twice daily for five weeks caused in one instance total baldness.

Experiments on man and animals, by Professors Mattern, Förster, Chittenden, and Schlenker, have demonstrated that boric aeid and borax interfere with digestion and nutrition. Mattern reported profound disturbanees in dogs after a few daily doses of 8 grains;

'Revue de Médecine, September, 1so:5.

" British Medieal Joumal, Jan. 7, 1899.

${ }^{3}$ Ibidem, Jan. 28, 1899. 
diarrhea and other signs of gastro-intestinal irritation, and in some instances even fatal results were caused. He himself took 30 grains, and suffered violent abolominal pain and diarrhoea. Förster and Schlenker have shown that doses of 8 grains have a decided effect in preventing absorption of nutriment and causing intestinal irritation.

1). Annett, of Liverpool, fed a number of kittens with milk containing 20 grains of boric acid to the quart, and all of them died in an emaciated condition at the end of the third or fourth week. As to the effect of these agents on the different processes of digestion, there is no agreement. Chittenden, for example, believes that horic acid increases the digestion of proteids, and that even 25 per cent. will not cheek gastric digestion of egg albumin. He has noted also a marked stimulant effect on pancreatic digestion of proteids following the use of bolux. Leffmann and Beam, and others, however, have observed effects directly contrary to those reported by Chittenden. Chittenden's first experiments were made to determine the possible influence of borax and boric acid upon the processes of salivary, gastric, and pancreatic digestion. He calls attention to the fact that his results throw no light upon the influence of the agents upon the secretion of the digestive fluids. He shows that borax inhibits the action of saliva on stareh, and borie acid in small amounts increases it, and also the power of the gastric juice to digest proteids. Later experiments by Chittenden and Gies ${ }^{i}$ lead them to the conclusion that the two substances have no peculiar action on nutrition, and that, since elimination is complete within thirty-six hours, the possibility of cumulative action must be very small, even when moderate amounts are ingested daily.

Tunnieliffe and Rosenheim ${ }^{2}$ concluded, from a series of metabolism experiments on young elildren, that boric acid in doses up to 1 gram per day, continued for some time, exerts no influence on proteid or phosphorus metabolism, has no effect on the assimilation of fat, and exerts no inhibitory effeet on intestinal putrefaction ; that borax in continued doses of 1.5 grams may or may not improve assimilation of fat, and tends to increase intestinal putrefaction; that both boric acid and borax are eliminated quickly; and that neither will affect the general health and well-being.

Halliburton, ${ }^{3}$ experimenting with borax and milk in vitro, found that 1 part of borax in 1000 completely prevents the action of rennet, and that smaller amounts delay it.

On the other hand, Liebreich, ${ }^{4}$ experimenting with dogs, found that neither borax nor boric acid has any influence on metabolism; that boric acid in saturated solution has no effect on the mucous membranes of the stomach and intestine, while borax in 2 per eent. solution has a

1 New York Medical Journal, February 26, 1898.

2 Journal of II ygiene, April, 1901, p. 168.

3ritish Medical Jourual, July 7, 1900, p. 1.

- Vierteljahrsschrift für gerichtliche Mediein, 1900, p. 83. 
markedly injurious effect, thongh not so much as 1 per cent. of sodium hydrate or 0.5 per cent. of saltpeter ; that 5 per cent. of boric acid and 0.25 per cent. of borax have no influence on gastric digestion, but 0.5 per cent. of borax has slight inhibitory action; that neither has any effect on the digestion of starches; and that both are eliminated quickly, and have no tendency to accumulate in the system.

During a period of 19 weeks the author ${ }^{1}$ fed borated meat to 6 of 12 healthy cats, which were kept in separate cages under precisely similar conditions. Of the other 6,1 was kept as a control, and 5 were fed on meat containing another kind of preservative. The average daily dose of borax ranged from 544 to 857 milligrams. During the experiment only 3 of the 12 cats showed any acute sickness, but they were all members of the borax group. One of them died at the end of the sixth week, but the others recovered and were apparently well when the experiment was brought to a close. The cats were killed and all (including the one that died) were subjected to careful microscopical examination. The control-cat showed no lesions whatever, and those fed on non-borated food showed only slight and inconstant changes in various organs; but the borax-fed animals showed without exception lesions of the kidneys of the same general character, yet differing in intensity, and analogous to those found in subacute and chronic nephritis in man. In some cases the degeneration was of an intense character.

Considering all the evidence, conflicting though it be, and the many reports of untoward results of large and small medicinal doses and from absorption of both agents from local applications, it seems not unreasonable to conclude that the daily ingestion of variable amounts in food and drink by persons of all ages cannot be wholly free from objection. A very common practice is the addition of a mixture of the two or of either alone to milk, in the proportion of 1 part in 500 or 1000 ; a pint will, therefore, contain a fair-sized adult dose, an amonnt which, taken twice daily, or oftener, by a bottle-fed child, can hardly fail to have some effect not wholly for its well-being.

Salicylic Acid.- Salicylic acid is more efficient than borax and boric acid as a preservative, but camnot be nsed so generally, because of its tendency to cause unpleasant flavors in foods having a bland taste. It is used extensively in jams, jellies, tomato eatsups, bottled beers (especially those from Germany), the heavy beers innocently consumed by total abstainers under the name of "malt extracts," fruit juices, sodawater syrups, eider, wines, and other saccharine preparations, and preserved vegetables. Concerning its objectionable nature as an addition to foods, there is practical unanimity. It not only exerts an inhibitory action on digestion, but acts also as an irritant, especially to the kidneys, by which organs it is excreted. Its addition in any quantity to articles of food or drink is forbidden expressly in many European and South American countries. Its addition to beer and other articles intended for export is permitted in Germany.

1 American Journal of the Medical Sciences, September, 1904. 
Sulphites.-Sodium sulphite and bisulphite and sulphurous acid are used more or less extensively for preserving meat, beer, wine, and for bleaching vegetables (especially asparagus and corn), put up in cans and glass jars. Sendtuer has found from 26.4 to 482.6 milligrams of sulphurons acid in 32 specimens of such vegetables, and Kämmerer and others have reported amounts ranging from 3 to 250 milligrams per liter in red and white wines. The anthor ${ }^{1}$ found from 0.061 to 1.225 (average 0.335 ) per cent. by weight of sodium sulphite in 50 specimens of "Hamburg steak" bought in the markets of Boston.

Kionke ${ }^{2}$ has shown that large doses of sulphites exert a marked and sometimes fatally poisonous action on warm-blooded animals, and that small doses, long continued, may affeet dogs very seriously. The author ${ }^{1}$ fed a number of eats for 20 weeks with meat containing 0.20 per cent. of sodium sulphite, which is the amount recommended as a preservative, and at the expiration of that time the cats were killed and examined. In each case the kidneys showed extensive degenerative changes.

Sodium sulphite is used very eommonly in sausages and chopped meat (Hamburg steak), both as a preservative and to cause the brightred eolor of the fresh meat to be retained unaltered. Chopped meat keeps its color but a very short time, and as the purchaser will not aceept it when not bright red, the vendor is driven to make its appearance acecptable. Thus, the purehaser, insisting upon having what to his eye is freshly chopped wholesome meat, may be served with stale meat containing a most undesirable chemical preservative. In 1898, the Imperial Board of Health of Germany forbade the use of sodium. sulphite in fords, beeause of its dangerons properties.

Formaldehyde.-On aceount of its property of hardening tissues, formaldehyle does not lend itself to general use as a food preservative. Fish and meats are rendered so hard by very dilute solutions, even 1 to 5,000 , as to be worthless commereially. It is used most commonly in milk and other liquids, and aets most effieiently in delaying and preventing decomposition. Its use in milk is, however, far from commendabie, for althongh efficient as a preservative, it alters the character of the proteids, which are thereby made less digestible. The cascin, when precipitated, does not separate in fine clots, but in tough, heavy curds, which yield only with much resistance to pepsin and hydrochloric aeid. Weigle and Merkel ${ }^{3}$ have shown that the proteids are male much less digestible, and their conclusions are in agreement with those of most investigators of the subject. Bliss and Novy, after a most careful and exhatstive inquiry into the effeets of formaldehyde on the digestive ferments, fomd that pepsin and trypsin have diminisher action upon fibrin which lais been altered by it in very wak solution; that easein is altered rapidly, and, as a result, is not

I lusiton Medical and Surgical Journal, May 25, 1904.

2 \%sitschrift für IIygiene und Infeetionskrankheiten, XXII., p. 351.

${ }^{3}$ Forschungsberichte über Lehensmittel, ete, 1895., II., p. 91.

- Journal of Experimental Nedicine, 1899, 1. 47. 
coagulated by rennet or, at best, very slowly, and is not readily digested by the proteolytic ferments; and that pepsin and rennet are themselves not affected by fairly strong ( 4 and 5 per cent.) solutions acting for several weeks. Pepsin was found to be affected quickly by very dilute solutions, trypsin to be affected according to the amount of organic matter present, and amylopsin and ptyalin to be not destroyed by very dilute solutions. The latter, however, were found to be destroyed by strong solutions.

Halliburton ${ }^{2}$ found that 0.5 per cent. of formalin renders gastric digestion of fibrin almost impossible; and that 0.05 per cent. considcrably delays it. Its effects on pancreatic digestion were even more marked.

Tumnicliffe and Rosenheim, ${ }^{2}$ experimenting with young children, found that, in doses of 1 part in 5,000 of milk or 1 in 9,000 of total food and drink, formaldeliyde exerts no appreciable effect on nitrogen and phosphorns metabolism or on fat assimilation, but in larger doses, or long continued, it may tend to diminish phosplorus and fat assimilation, on account of its effect on panereatic digestion. With delicate children, the $1: 5000$ dose has a measurable deleterious effeet on the nitrogen, phosphorus, and fat assimilation, and exerts a slight irritant action on the intestine. They eonclude, however, that, as used, the substance has no influence on the general health and well-being of children. On the other hand, feeding experiments, eondueted by Dr. Annett with kittens, demonstrated that, as the amount mixed with the milk was increased, the retarding action on their development was more marked.

Whatever may be the results of experiments tending to show the effects of formaldehyde on metabolism and growth, everybody who has occasion to handle even very dilute solutions can testify to its irritant effects on the skin; and, this being the case, it scems hardly reasonable to assert that the much more delicate mucous membranes of the digestive tract can be subjected to its action and wholly escape injury. Formaldehyde is not generally regarded as a poison in small doses, but a number of deaths have been attributed to its use as a milk preservative, though it should be said that the evidence in these ases will hardly hear eritical analysis. One undoubted case of non-fittal poisoning has loen recorded by J. Kliiber. ${ }^{3}$ The subject was a man of forty-seven, who swallowed some aperient water into which formalin had been introduced aceidentally He lay for a long time in a state of eoma, and late amuria nineteen lours. Formie acid was eliminated in the urine during recovery.

Hydrogen Peroxide.-This agent is reeommended as the least dangerous of all ehemical preservatives, and is believed by some to exert $n 0$ deleterious effect whatever. It is well adapted for use in wine, beer, and fruit juices. One part in 1,000 is said to prevent entirely the

1 Loco citato.

${ }^{2}$ Jommal of Hygiene, July, 1901, p. 321.

a Müchencr nedicinische IVochenschrift, Octoher 9, 1900. 
alcolonlic fermentation of grlucose solutions, and in somewhat larger amounts to prevent the formation of lactic acid in milk.

Sodium Fluoride. - So far as is known, solium fluoride exerts no ynisonous action, but its effect on digestion has not been studied thoroughly. Perret ' asserts that it has a decided influence in inhibiting the development of lactic and butyric ferments. Using himself and a number of dogs, he undertook a series of feerling experiments, and concluded therefiom that the salt is in no way poisonons, and may be used without danger as a food preservative. Specimens of milk containing 3 parts in 1,000 and kept at $38^{\circ} \mathrm{C}$, remained unchanged long after the controls had become coagulated. A dozen tubes of milk containing it, and planted with butyric ferment, and another dozen containing untreated milk similarly planted, were kept side by side at $38^{\circ}$ C. ; on the day following, the latter were coagulated, but the former were unchanged. Subeutaneous injections of the salt to the extent of 0.08 grum per kilogram of weight eaused in a dog slight salivation and diuresis; but larrer doses caused marked salivation, diuresis, thirst, and refusal of food. Intmenous injections of 0.10 per kilogram caused immediate rise of pulse and respiration, followed by abundant salivation, nausea, convulsions, and death in thirty-five minutes. Leffmann and Beam " have noted that sodium fluoride interferes but little with the digestion of starch.

Sollum fluoride appears to be weak as a general preservative, but prevents alcoholic fermentation completely when present to the extent of 1 part in 2,000. The fluorides and hydrochloric acid are used by some brewers for the prevention of undesired fermentations.

Sodium Bicarbonate.-This agent seems to be as little objectionable as any, but it is rery weak in its preservative action and is too ineffective for general use. It is used somewhat in Sweden in conjunetion with sugar for meat and fish. A more common use is to overcome beginning aeidity of milk; against this is urged the possibility of purgative effects in infants, through the sodium lactate produced.

\section{Section 8. CONTAMINATION OF FOODS BY METALS.}

Not infrequently, small amounts of metallic salts are present in foods, either through accident or by reason of intentional admixture for some definite end. The most common are compounds of copper and of lead, and these are regarded as of greater hygienie importance than the salts of zine, tin, and nickel occasionally present.

Copper.-Copper gains entrance through the improper use of cooking ntensils of brass and copper, and through the use of its salts for greening peas and other vegetables ("reverdissage"), and for improving flour of inferior grade. Copper and brass kettles yield small amonnts to aejd, fatty, and other foods allowed to stand therein, espe-

1 Annales d'Hygiene et de Médecine légale, Jnne, 1898, p. 497.

2 Journal of the Franklin Institule, 1899. 
cially if the contents are exposed to the air. Their yield is much greater if they are not kept thoroughly elcan and well polished. Lehmann ${ }^{1}$ found 36.8 milligrams of copper in a liter of broth made in a brass vessel and allowed to stand 24 hours, $8.7 \mathrm{mgr}$. in 100 ec. of raneid fat allowed to stand 2 weeks, $21 \mathrm{mgr}$. in a liter of sour wine, and 61 in the same volume of vinegar after 24 hours. Mair has reported $24 \mathrm{mgr}$. in a liter of rice soup after 24 hours.

The use of copper for greening vegetables is excecdingly common. It serves no usefill purpose other than to please the eye. The peas or other vegetables are boiled in a very dilute solution of copper sulphate, drained, washed, and, finally, put up in cans or glass jars. ' The artificial color, which is often much more intensely green than the natural, is due to an organie compound of copper which is insoluble in water. The claim sometimes urged, that the eopper serves to fix the chlorophyll, and is not itself retained, is preposterous, for if a solution of chlorophyll is heated with dilute copper sulphate, the eolor is destroyed and a brown preeipitate is produced; while if perfectly white beans are boiled for a short time in a solution of the same strength, they take on a deep-green color through the formation of a new eompound with the contained legumin or some other proteid. Potatoes, being very poor in proteids, are affected but slightly by similar treatment, but eggs may be colored intensely green.

The liquor of canned greened vegetables is commonly free from copper, and the testing of specinens by adding ammonia to a portion of the liquor, in the expectation of producing a blue color in ease the vegetable has been so treated, is, therefore, without result. In order to determine the presence of eopper, a few grams of the substance may be incinerated in a porcelain eapsule, the residue therefrom treated with dilute hydrochlorie acid, and the filtrate subjected to the nsual tests.

The question of the hygienie importance of small amounts of copper has been the subject of a number of extensive investigations on the part of individuals and foreign governments, and while it can hardly be said to be proved that danger can arise therefrom, nevertheless no good reason ean be advaneed in favor of the practice of greening. Two stndents in Lehmann's laboratory took daily doses of copper salts with no pereeptible disturbance; one took 39 milligrams of copper sulphate daily for 50 days, and then donble that amount for 30 more; the other took the acetate for 51 days in doses ranging from 16 to 96 milligrams. These amounts are larger than an average eater would be likely to take into his system from camned vegctables in the course of a day, for the entire contents of an ordinary tin-somewhat less than half a poundcommonly yield less than 50 milligrams of eopper.

Aceording to Banm and Seelinger, ${ }^{2}$ whose numerous experiments extended over a period of three years, small daily doses are, as a rule, completely absorbed and again eliminated ; larger doses are not completely absorbed. Complete elimination may require as long as five

1 Seventh International Congress of IIygiene, 1891.

${ }^{2}$ Zeitschrift für öffentliche Chemie, 1898, p. 181. 
months from the date of the last dose. Long-continued ingestion of small doses may bring about a condition of chronic poisoning.

(oppere appears to be a normal constituent of some articles of food. The assertion, made originally by Meyer, of Copenhagen, that wheat and oats often contain minute traces, esprecially in their lusks, has repeatedly been proved. According to Lehmann, ${ }^{1}$ the species of plants has far less influence on the amount taken up than the amount of eopper present in the soil. He fonnd the metal in a great variety of plants growing in a eoper soil : rye, oats, hops, potatees, dandelion, juniper, violets, cherries, ete. In woody plants, the greatest amomnt of copper is in the bark. According to Karsten, ${ }^{2}$ the spraying of grapevines with copper solutions is not wholly free from objection, since that which adheres to the frouit may be sufficient to make their yield of wine toxic. He instances a mumber of casses of diarrhoea and vomiting due to wine which yiekled trices of eopper.

Lead.-Traces of lead are of common ocenrrence in various articles of food, especially those wrapped in foil or enclosed in cans having exposed seams of leat solder. A number of speeimens of wrappling-foil, analyzed by Dr. Clandes P. Woreester, ${ }^{3}$ yielded lead in amounts ranging from traces to 89 per cent. They are used largely for wrapping eream eheeses, chocolate, and other foods. The metallic eaps used for elosing glass jars of preserved firuits and vegetables are also sources of danger. One specimen examined by Woreester contained 93.5 per cent. of lead. Patent stoppers, consisting of a metallic disk with a border of rubber, ased in bottles for summer beverages known to the trade as "soft drinks," commonly contain lead, as is shown by Worcester's examination of 28 specimens, which yiekled from 3.5 to 50.7 per cent. The contents of the several bottles yielded lead without exeeption ; the largest amount was 1.05 milligrams.

Dr. William R. Smith thas drawn attention to the common occurrence of land in eitrie and tartaric acids. The former is used considcrably in making summer drinks, and the latter in effervescing powders and baking powders. Of a dozen speeimens examined by him, only one was uncontaminated; the highest amount found was 0.037 per cent.

At the present time, camned foods are less likely to show traces of lead than formorly, when the cans were made with less care. In 1893, Wiley reported traces in 132 ont of 248 samples examined.

Coneerning the hygienic importance of small daily doses of lead, there is but one opinion. It is quite improbable that the oceasional nuse of camned vegretahles containing but a fraction of a milligram in an entire ean will lead to serions injury, but the eonstant daily ingestion of appreciable amomts of learl is likely to lead to serious consequences in at least a fuir proportion of cases.

'Archiv fiir Hygiene, XXVII., p. 1.

2 ('hemiker-\%eitumg, 1896, p. 37 .

$394 h$ Annual Report of the State Boarl of lealth of Massahusetts, p. 570.

- Jourual of State Medicine, Octoler, 1892.

separtment of Agriculume, Division of Chemistry, Bulletin No. 13, Part VIII. 
Especially to be avoided are the acid drinks contained in bottles with lead stoppers. The amount of lead present is small, and an occasional indulgence is unlikely to cause harm ; but cases of serious injury have oecurred. In one, in which the canse of the trouble was investigated by the author, the patient, a temperance lecturer, lad for some weeks been passionately addieted to the use of a particular brand of efferveseent drink known as "strawberry tonic," a carbonated, acidnlated solution of sugar, flavored with an artifieial compound ether, and colored with an anilin dye. Evidence of chronic lead poisoning developed with some suddenness, and in a short time not only wrist-drop, but also toc-drop appeared. Specimens of the beverage were examined. The stoppers were almost pure lead, and the contents of each bottle yielded notable traces of the metal.

Zinc.-Z'Zine sometimes oceurs in small traces in eanned foods from the use of the chloride in soldering. With improved methods, in which another flux is employed, this contamination is becoming uncommon in this class of foods. It appears to be a conmon aceidental impurity in dried apples, from contact with galvanized iron wire racks on which they are eured. Kämmerer ${ }^{1}$ fonnd it in 4 out of 9 specimens of American dried apples; the average amount, reekoned as malate, was 0.0656 per cent. Bujard ${ }^{2}$ found it in 37 out of 54 ; in 20 , the amount present ranged from 0.03 to 0.49 gram to the kilogram, reckoned as oxide; in 17 , it was present only in traces. We have no evidence that these small anomts are of the slightest sanitary importance.

Nickel.-Nickel is employed sometimes in place of eopper for greening peas. About a quarter of a gram of the sulphate suffices for a kilogram of peas. It is dissolved in boiled water to which 10 ee. of a 2 per cent. solution of ammonia are added, and then the solution is diluted with boiled water in snfficient amount to cover the peas, which then are boiled for a few minntes, drained, and washed. According to E. Isulwig," nickel is given off in small amounts to all sorts of foods eooked in nickel dishes. He found from traces to 12.9 milligrams per 100 grams of the food examined. There is no evidenee that these amounts ean produce injury.

Tin.-Contamination with compounds of tin is excedingly common, and, so farr as is known, is harmless and unimportant, the componnds, other than the chloride, being apparently incapable of producing any physiological or local action.

Metallic Contamination from Kitchen Utensils.-Much has been said, from time to time, concerning the possible danger of poisoning by small amounts of lead and other metals taken up by foods firom kitehen utensils, and especially from glazed eurthenware; but a number of extensive investigations have demonstrated that this danger is very remote. Mussi thas shown that, if the firing of leal-glazed pottery

\footnotetext{
1 Chemiker-7eitung, 1897 , p. 721.

${ }^{2}$ Forsehtmgsbericht über Ixbensmittel, ete., 1897, IV., p. 218.

${ }^{3}$ ( )esterreiche Chemische \%eitming, 1898, 1.

- Giornale della K. Sociétà Italiana d'igiene, January 30, 1900, p. 1.
} 
has been done properly, no trace of lead will be taken up by acid foods, such ats tomato soup, or even vinegar; but he advises that all new vessels should be eleatused very carefully before using, on aceount of the common presence of lead dust on the glaze when fresh from the kiln. Riche' also determined that with properly fired ware the danger of solution of lead is practically nil, the specimens used yielding no traces to boiling dilute acetic and nitrie aeids and salt solutions. But improperly fired ware will yield traces.

Enamelled ware is believed commonly to contain lead; and the enamel, having a different coefficient of expansion from that of the iron, being likely to erack and chip off; especially with careless handling, is thonght to be dangerous ; but Barthe ${ }^{2}$ found no trace of lead in a number of enamels examined, and asserts that very hard enamels need neither lad nor any other poisonous compounds in their preparation. This accords with the experience of the author and other American investigators, and it may eonfidently be said that the enamelled ware in common use is lead-free.

Aluminumware, which has of late come into extensive use, is less acted upon by acid foods than tin, but is affeeted considerably by alkalies, the impurities present in commereial aluminum acting as favoring agents to its corrosion. But the resulting compounds are innocnous in the small amount ingested. This kind of ware is kept elean very casily and offers the great advantage of lightness.

Nickelware is attacked but slightly by ordinary food materials, and the amounts taken up are withont sanitary significance. But its cost is against its extensive use, and, moreover, it imparts sometimes a greenish tint, whieh is repugnant to the eye.

1 Revue d'IIygiène, August 20, 1900, p. 704.

'Journal de Pharmacie et de Chemie, 1898, p. 105. 


\section{H A P T E R I I.}

\section{AIR.}

AIr is a mixture of gases, and not a chemical compound. Until the latter part of the seventeenth century (1669), it was supposed to be an element, but Jean Mayow then proved it to be a mixture of gases; and later, Lavoisier discovered the two gases, oxygen and nitrogen, which, a hondred years later, were separated by Priestley and by Scheele.

Air is a colorless and apparently odorless mixture of oxygen, nitrogen, argon, carbonic acid, aqueons vapor, and traces of other substances. It is not, however, under ordinary conditions orlorless, but, on the contrary, it contains various seents, to which we are so accustomed that, unless present in unusual degree, owing to local conditions, they are not pereeived. This is noticed on returning to an ordinary atmosphere from one where the causes of the usual odors are absent or nearly so, as, for instance, from deep subterranean caves; or from a room where the air is foul and oppressive, as, for instance, from a heated, overcrowded hall or street car. The air of the Aretic regions contains but little odor, on account of the absence of bodies which give rise to odors, and the proximity of any source of smell is noticed quickly. 'The explorer Nansen ${ }^{1}$ speaks of the pervading smell of soap which he noticed when, after months of wandering, he met Jackson, who had been housed comfortably with all the common necessities of man.

While air is a mixture of gases, it is one of tolerably constant composition, partienlarly in the ease of its ehief constituent, nitrogen. Under the conditions of life, the more important, but less abundant element, oxygen is subject to more or less variation. In the presence of regetable life, particularly by day, it is increased slightiy; in the presence of animal life, it is diminished more or less.

\section{OXYGEN.}

The normal amount of oxygen is stated usually at just below 21 per cent. by volume. A. Ledue gives it at exactly 21 , with 78.06 of nitmgen and 0.94 of argon. Different observers have reported the following as averages of large numbers of analyses of pure ontdoor air :

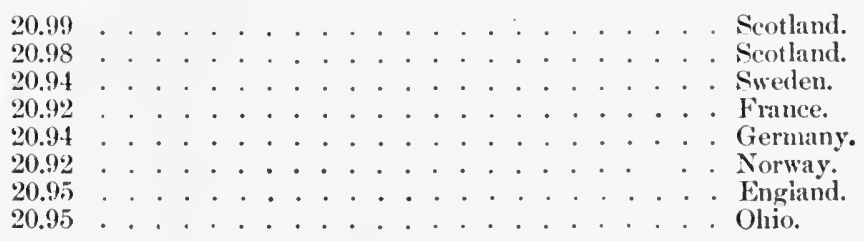

${ }^{1}$ Farthest North, Vol. II., p 529. 
The mean of a mumber of analyses by Bunsen was 20.924 by volume, amil of a humdrent at l'aris by liegriault, 20.960. For the sake of convenience, we maty disregard the very slight difference between 21 and the tigures olutaned by exaet antlysis, a difference in the second place of decimals, and accept 21 as a normal. At great heights, the proportion of oxygen is less than at the surface. For instance, on the Fanlhorn, in Switzerland, 20.75 has been observed as the mean of a number of determinations. Under certain conditions, there is very slightly more than 21 parts; for instance, in the immediate vicinity of vegretation, especially by day, there may be an excess of oxygen, but it is very small; sai at, taken in mid-ocean, has yielded 21.59 , but ordinarily contains less than 21. It is less, hy very small fractions; in the streets of eities thin in the open eountry, and in towns than at seat.

Oxygen is the element in air that supports all life. It is constantly being withdrawn from the air in the process of respiration, and is returnel to it in chemieal mion with earbon as carbon dioxide. This is absorbed by vegetation and split up, the carbon being retained, and the oxygen for the most part released and returned to the air. Thus, the processes of animal and vegetable life combine to maintain the equilibrium.

All animals do not breathe in the same degree; birds have the most active respiration, and next eome mammals; and all consume more oxygen when-aetive than when asleep.

Oxygen is essential to the germination of seeds, and to the growth of plants. Although plants take up carbon dioxide and exhale oxygen, they also breathe as do animals, absorbing the latter and exhaling the former. Even the anaërobic organisms consume oxygen, although living where air is wanting, for they split up combinations of oxygen and other elements. Thus, in dilute sugar solutions they withdraw some of the oxygen and split up the sugar into carbon dioxide and alcohol.

lior sustaining animal life, it is essential that the air shall contain not far from the normal amount of oxygen; that is, that it shall be neither much diminished nor yet over-rich in that element. Human life is impossible in air which contains but four-fifths of the normal amount, and (cfually so in an artifieial atmosphere containing materially more than the normal.

In man and animals, the tissues do not receive oxygen in the free condition, for when the air is inspired, the oxygen is taken up by the red blood corpuscles and unites with the hemoglobin to form an unstable eompound, oxyhemoglohin, which, as the blood eireulates through the tissues, is decomposed ; the oxygen is then taken up by the cells, amb eventually returned to the blood in the form of carbon dioxide, and climinated ats such from the body. In an artifieial atmosphere containing an excessive amomnt of oxpgen, the hacmoglobin becomes saturated with the gats, part of which becomes dissolved in the blood serum, and then acts ats a poison to the tissues and destroys them. 
Inspired air loses about a fourth of its oxygen, and is returned to the atmosphere rich in impurity ; but diffision occurs so rapidly that the atmosphere of a thickly settled eity shows no very material variation from that of the open country.

The lungs are never filled with pure air after the first respiration at birtl, since they are never wholly emptied, and they consequently contain an inpure residue of air after each expiration. The upper part of the respiratory tract is the only part that receives strictly pure air. Professor Richet has demonstrated that, if the respiratory traet be lengthened artificially by means of a rubber tube, pure air will never reach even the upper air-passages, and the animal will die of asphyxia.

The amount of oxygen absorbed varies with age, eoudition of health, and activity. According to Professor Foster, an ayerage person inlales in 24 lours about 34 pounds of air, which corresponds to a little more than 7 pounds of oxygen; and as the lungs absorb about a fourth of the oxygen inlualed, it appears that the average amount of oxygen absorbed daily is nearly 2 pounds.

\section{NITROGEN.}

The principal constituent of the air, nitrogen, takes no part in respiration, and is not increased in expired air; but although it is indifferent and inert, it is, nevertheless, by no means unimportant. In the first place, it serves to dilute the oxygen, so that the latter is respirable; and in the second place, it plays an important part in the growth of plants, the original source of all nitrogenous food, for that which we eonsume in the form of meat is from animals that have built up their tirsues from vegetable food. As a diluent of oxygen, it serves to prevent too great activity of that element, which eamnot be breathed with impunity for any length of time when present in an atmosphere to a greater extent than its normal amount.

IIow nitrogen is absorbed by plants, we know only in part. Certain low forms (nycelia, cte.) secm to ahsorb it direetly firon the atmosphere when exposer fiecly to light and air. Some of the higher forms (peas, beams, elover, ete.) aroquire it through the ageney of certain microorganisms which are present in nodules in their roots, and withont which they will not thrive. These miero-organisms take the nitrogen from the atmosphere and give it in some form to the plants. That this is so, is proved by the fact that the plants will thrive in a soil quite free from nitrogen (in clean sand, for instance), and store up in their tissues an anionnt of nitrogen fur in excess of that which was originally present in the seeds, provided these micro-orgamisms are present in the nodules of the roots. If they are not present, the plants will not thrive, hut may be made to do so by the applieation of water containing cultures of the oreanioms. Of the doubtless many spreeies which can fix atmospluerie nitrogen, or which aid in doing so, the following may be mentioned: B. megretherinm, B. fluoresecens liquefaciens, B. proteus vulyaris, B. butyricus, B. mycoides, B. mesentericms vulyatus. 
On the other hand, certain plants, grown in the open air in soils fre from nitrogen, and potected from receiving ammonia and nitrates from the min, will show no more nitrogen in their whole organization than was present in the seeds from which they sprang. The subject is one which has been investigated but partly, and future research will doubtless show that, under natumal conditions, all plant life takes up in some way more or less nitrogen from the atmosphere, as well as from nitrogenous compounds in the soil.

\section{ARGON.}

$\mathrm{U}_{p}$ to the time of its diseovery, the element argon was ineluded under nitrogen in the tables of eomposition of the air. How much is present, is not yet aceurately determined. It was discovered in 1894, by Lord Rayleigh and Professor Ramsay, by whom later it was estimated ats composing about 0.75 per cent. of the atmosphere. Ledue gives its amount as 0.94, and Sehloesing as 0.84. It is quite inert, and camnot be made to combine with any other element, although it has bcen combined by Berthelot with benzene under the influence of electric discharge.

\section{HYDROGEN.}

According to the extensive researches of Armand Gautier, hydrogen is present in sea air and other pure air in fairly constant amount-about 0.015 per eent. It is believed to be due to various fermentative proeesses, and to be contributed also by mineral springs and volcanoes. So far as known, its presence is devoid of sanitary importance.

Other elements, as krypton, neon, and metargon, also discovered by Professor Ramsay, coronium, discovered by Nasini, and several others, are interesting solely from a purely scientific standpoint.

\section{CARBON DIOXIDE (CARBONIC ACID).}

All air contains carbon dioxide as a constant eonstituent. The normal average amount in pure air is but slightly in excess of 3 parts in 10,000 , or abont 0.03 per cent., and not 4 parts, as commonly is stated. As little as 2.03, and even 1.72 , has been observed in the air on mountain-tops, although generally we expeet more rather than less than the normal amount at high elevations.

Carbon dioxide is a result of oxidation of organic matter, and owes its presence in the atmosphere to respiration, fermentation, combustion, and chemical action in the soil. An average man exhales about 20 liters in an hour, and very nearly a lilogram in a day; women exhale less, and children and aged persons still less. The amount exhaled is inereased by museular exertion and diminished by rest. Birds send out more in proportion to weight than other animals. The respiration of millions and millions of human beingss and animals is constantly throw- 
ing into the atmosphere comntless tons of the gas; every ton of coal in burning yields more than 67,000 cubic feet; every cubie foot of coal gas yields about double its volume; every pound of eandle nearly three times its weight (2.769); every gallon of oil and kerosene, and every picee of wood used as fuel, contributes its proportion. Huge volumes are sent forth continually by the soil air, which contains it in abundance, and by mineral springs, the waters of which contain it under pressure. It has been estimated that, from all sourees, 5,000 million tons are discharged anmually into the atmosphere. It is slightly more abundant in eities than in the comntry, and at night than by day. It is highest in amount at a given location during autumn, and lowest in winter. It is more abundant inland than on the coast. It increases sonewhat as we ascend from sea-level-aceording to Schlagintweit, up to 11,000 feet. Its removal from the atmosphere is mostly through the agency of growing vegetation, but materially also by absorption by bodies of water, which, at ordinary temperature and pressure, will take up its own volume of the gas. It has been calculated that the ocean contains about ten times as much as the whole atmosphere. All green plants absorb it by day, and by means of their ehlorophyll break it up into earbon and oxygen, the former being used in building tissue, and the latter returned to the air as a waste product. This process of nutrition goes on only under the influence of light, and consequently by day; but there is also a respiratory function that is active both day and night, and has the same effect on air as that of the respiration of animals; namely, the consumption of oxygen and discharge of earbonic aciel. But the respiratory process has but a trivial influence in comparison with the chlorophyllian function. It is estimated that an acre of woodland withdraws in one season about four and a half tons, retains more than one and one-fifth tons of earbon, and returns three and a quarter tous of oxygen to the air. The slight inerease at night is due supposedly in part to its cxhalation by plants in their respiration, and also to currents of soil air, which ascends as soon as the air at the surface becomes eolder, and consequently heavier, than itself. During the day, the soil air is colder and remains stationary.

Carbon dioxide is a heary gas, incapable of supporting combustion or respiration, and serving no useful purpose in animal tissues. It constitutes about 4 per cent. of expired air, in which it is an excretion of the body. It is in itself inert, and incapable of exerting any poisonous action, but will eause asphyxia when present in sufficient amount to interfere with the atmospheric oxygen in the performance of its function.

An atmosphere of respired air, containing 4 per cent, of carbon dioxide and about 16 per cent. of oxygen, will not support life longer than a short time, since the blood camot get sufficient oxygen for the needs of the cells and tisisues, and, in addition, cammot rid itself of its $\mathrm{CO}_{2}$. Gas exchange between the blood and inspired air depends upon the tension of the gas in both media, and, therefore, as soon as the tension of the $\mathrm{CO}_{2}$ in the atmosphere excects that of the $\mathrm{CO}_{2}$ of the blood, the 
blood corpuscles cannot excrete it, but must retain it. In consequence, asphyxia necents.

The gnestion as to how much $\mathrm{CO}_{2}$ is permissible in air, has been answered variously. We assume? parts in 10,000 as the normal amount, and all in excess as impurity due to respiration and combustion. A total of 6 or 7 parts in 10,000 is regarded by the best authorities as the permissible limit, and 10 in 10,000 as distinctly harmful. When the amount reaches 10 parts in 10,000 , the air begins to be "close"; and when it reates 15 in 10,000 , it is likely to cause headache in those unacenstomed to impure air. In erowded assembly rooms, als churehes, theatres, and sehools, the amount may reach 100 parts in 10,000 ; and more than twice as much hats been found in a Swiss stable crowded with men and animals. The air of the hall in which the German Public Health Society (Deutscher Verein für öffentliche Gesundheitspflege) met in Nïremberg in Oetober, 1890 , contained 24.10 in 10,000 at the beginning of one of the addresses, and 43.20 at its elose.

A large amount of earbon dioxide may be present in air without producing any ill effeets, if there is plenty of oxygen present. Thus, Regnault and Reicet have proved that animals can live in a mixture of 25 per cent. carbonic acid, 30-40 per cent. oxygen, and nitrogen.

It has been held generally that $\mathrm{CO}_{2}$ up to $20: 10,000$ is in itself harmless; that the deleterious agents in polluted air are organic matters thrown off by the skin and lungs in company with it; and that it serves als a convenient index of their amount. It has been the custom to say, "The more earbonic acid we find, the more organic matter we infer." These poisonous organic matters, however, though much sought after, have never been isolated, although a number of observers, using faulty methols, have from time to time obtained erroneous results. This subject will be considered farther on.

\section{OZONE.}

Ozone is a normal but by no means constant constituent of the air. It is generally absent from the air of large towns and eities, and is almost never present in the air of an inhabited room or near decomposing matter. It is found in minute amounts (maximum, $1: 700,000$ ) in the open air of the country and sea. It is most abundant at sea and near woods, and somewhat more abundant on mountains than in valleys and on plains. It is more abundant in the morning in the eolder monthe, and in the evening during hot weather; it is more abundant in winter than in summer. It is stated that it is most abundant directly after a thunder-storm, but beyond the fact that it is produced by the passage of the electric spark, there is nothing to substantiate this statement. As a matter of fact, the origin of o\%one in the atmosphere is $u n k n o w n$.

Ozone is an allotropic form of oxygen, consisting of molecules containing three atoms of that element. It has been liquefied under great pressure (127 atmospheres), and in that condition, and, indeed, in the 
gaseous form, has a deep-blue color. It is produced by the passage of the electric spark, by slow oxidation of phosphorus, and in the electrolysis of water; but, as has been said, its origin as a normal constituent of the atmosphere has not been explained satisfactorily. It has an odor not imlike that of diluted ehlorine. It has very strong oxidizing power, much more so than oxygen, which it exereises most actively both on metals and on organic matter ; hence its absence from the air of inhabited rooms and of densely populated areas, eharged with organic matter and dust of all sorts, is easily explainable. To this property, its dimimution in autumn, when decomposition products are generated most actively, may properly be attributed. Its presence in the air of any place is fair evidence of fireedon from oxidizable matters.

Ozone has an excedingly irritating effeet on the respiratory mucous membranes, and when inhaled with oxygen in the proportion of 1 part in 240, quickly produces death in animals subjected to it. It is believed to exert a pernicions influence in inflammatory conditions of the lungs and bronchi, even when present in not much more, if any, than the ordinary amount in the atnosphere. We actually know little or nothing of the effects of ozone on the system in the amounts ordinarily present in air, but the absurdity of the expression so often used, that one has "gone to breathe the pure ozone" at a health resort is manifest.

Peroxide of Hydrogen $\left(\mathrm{H}_{2} \mathrm{O}_{2}\right)$ is believed to exist in minute traces in the atmosphere, and to exert some influence in the process of oxidation.

\section{AMMONIA.}

Ammonia is constantly present in the air in very slight traces. It exists in the free state and in combination as nitrate and carbonate. Daily analysis of the air at Montsouris for five years gave as a mean for ammonia 2.2 milligrams per 100 cubie meters. It proved to be lighest in amount in summer and lowest in winter. It is diminished in rainy weather, beciuse it is absorbed by the rain during passage through the atmosphere; it is increased with rising temperature some time after rain has ceased falling. $A s$ it is one of the products of decomposition of nitrogenous organic matter, perhaps nowhere more observable than in stables, where it is plainly perceptible to the sense of smell, it is hardly necessary to point out that its sources are various and innumerable.

\section{NITROGEN ACIDS.}

Nitrous and nitric acids are also present in small traces, due in part to the union of atmospherie oxygen and nitrogen throngh the agrency of electrical discharges, and in part to the action of ozone on ammonia. Nitric acid is found in comparative aloundance in buildings lighted by means of the are light, but it is not probable that the amount present is of simitary importance. 


\section{AQUEOUS VAPOR.}

Aqueous vapor is a normal constituent which occurs in variable amounts, influenced by a number of natural conditions, the chief of which is the temperature. It is an invisible gas, lighter than air and very unequally diffused. Its sources are numerous; some comes from the evalporation of water, some from soil moisture, some from the lungs and skin of animals and man, some from the laves of growing plants, some from combustion. Indoors, a considerable amount is communieated to the air through the combustion of illuminants.

According to Profeswor Foster, an adult man gives off, under ordinarily favorable eonditions, about 4 pounds of watery vapor from the skin and lungs during twenty-four hours; $2 \frac{1}{2}$ pounds by the skin, and the remainder (Pettenkofer and Voit saly 10 ounces) by the lungs. An adult healthy tree of fiar size grives off an amount which is cnormous in comparison. The amount of water exhaled by plants has been estimated by Hellriegel to vary from 250 to 400 times the weight of the dry organie matter formed during the same time, which means that during the growth of each ton of green grass or leaves of any kind, there have been exhaled therefrom many tons of water, and that in the production of each pound of dry matter, an average of 325 pounds of water has been discharged. 'The evaporation of water from foliage has, among other important functions, that of keeping the temperature below the proint where the vital processes would be interfered with.

The amount of aqueons vapor which a volume of air will absorb and retain depends on the temperature. For each degree of temperature, a volume of air can take up a definite amount of rapor, and no more; and when it has taken up this amount it is said to be "saturated." The higher the temperature, the greater the amount it can hold; and hence when a volume of air completely saturated is subjected to a change in temperature, one of two things will oecur: if the temperature is inereased, it can take up more vapor, and hence is no longer saturated; if it is diminished, the aqueous vapor is in excess of the amount required for saturation at the new temperature, and the excess will be condensed and preeipitated as moisture. At $0^{\circ} \mathrm{C}$., a volume of air takes up $\frac{1}{160}$ of its weight of aqueous vapor; at $15^{\circ}$, it takes up twice as much; at $30^{\circ}$, four times, at $45^{\circ}$, eight times, and at $60^{\circ}$, sixteen times as much. Thus it appears that, with each inerease of $15^{\circ} \mathrm{C}$. in temperature, the calpacity for aqueous vapor is doubled. At $15^{\circ} \mathrm{C}$. $\left(59^{\circ} \mathrm{F}\right.$ ), a eubie foot of air will hold nearly 6 grains of water vapor ; at $30^{\circ} \mathrm{C}\left(86^{\circ} \mathrm{F}\right.$.) it will hold twice as much.

Evaporation cannot go on when the surrounding air is saturated; therefore, the presence of a body of water will add nothing to a saturater atmosphere. But plants and animals ean continue to give off the vapor to an alrearly siturated atmosphere, which, however, condenses and deposits the exeess at once, perhaps on the very surface where it is originated, as on the leaf of a tree or on the skin of man. The difference between evaporation and transpiration, which is the 
proper term for the giving off of vapor by animals and plants, is that the one is merely physical, while the other is a vital process due to the action of living cells.

The rate of elimination of water by the body in a state of rest depends upon the amount of humidity present in the air. Determinations by Rubner and ron Lewasehew ${ }^{1}$ demonstrated the great influence of hmmidity in this partienlar. At $15^{\circ} \mathrm{C}$. in moist air, the daily elimination fell to 216 grams, while in dry air at the same temperature it rose to 871 . The rate rises with the temperature in both moist and dry air, and the more promptly, the greater the dryness. The outer air contains commonly from 60 to 75 per cent. of the amount necessary for saturation. In some places noted for the dryness of the air, the amount is much below ; in others, where the opposite is the ease, it is above.

Relative humidity is the degree of approach to saturation at any given temperature. Thus, "relative humidity 80 " means that at the observed temperature, the air holds but 80 per cent. of the amount which it ean take up. Absolute humidity is the actual weight of moisture in a given air space.

Aqueous vapor exerts a most important influence. By day, it absorbs part of the sun's heat and tempers it; by night, it aets as a proteeting blanket to the earth by preventing too great loss of heat by radiation. At night, the earth gives up part of the heat which it has absorbed during the day; and when the air is very dry and the sky very elear, the temperature falls much more than when there is more vapor present to prevent loss by radiation. In the Sahara, after the hottest days, the nights are generally very cool, the temperature falling sometimes 30 to 40 degrees C. in a few hours. At high altitudes also, where the blanket of vapor is thin, the fall in temperature at night is very marked. Absenec of aqueous vapor permits the cooling proeess to begin as soon as the sun gets low, and iee may form in a few hours where, during the day, the sun's heat had been intolerable. This is seen in the great deserts and at high altitudes.

It is noticed commonly that the first frosts of autumn and those which come oceasionally in the middle and later parts of spring oceur only on very elear nights with low humidity.

An amount of watery vapor approaching saturation gives rise to discomfort, whether the temperature be high or low. The "sticky" days of summer and the "raw" ones of winter owe their disagrecableness to their high relative humidity. In a hot saturated atmosphere, while transpiration ean proceed, evaporation cannot, and henee the eooling influence of evaporation is missing. The sweat stays on the skin in the licunid form instead of passing into the air as a vapor, and the word "sticky" becomes singularly appropriate. On the other hand, with low himidity and high temperature, the sweat does not condense and remain on the skin, but passes into the air, and transpiration is not impeded in the lungs. Hence the great bearability of dry heat as

${ }^{1}$ Archiv für Hygiene, XXIX., p. 1. 
compared with moist. Saturation at low temperature has as great, if not greater, influcner on bodily eomfort. It does not follow that since one ferds the heat more acutely with high relative humidity, this eondition will enable one to withistand the opposite discomfort of cold. lublecl, the reverse is true. At low temperatures, saturated air causes a greater withllawal of heat than dry air, and intensifies the semsation of cold ; for moist air is a muel better beat conductor. Cold dry air is much more comfortahle than air some degrees warmer but materially moist. In the very eold elimate of eastern Siberia, the air is so dry that $50^{\circ}$ to $60^{\circ}$ below zero $\mathrm{F}$. is no handship, provided one wears eompletely dry clothing, while with moist elothing one would perish in a very short time. Some parts of Siberia are both cold and damp, and hence uninhabitahle. Atmospherie moisture las, therefore, directly opposite effects; it intensifies the effects of heat and also those of cold.

\section{DUST AND MICRO-ORGANISMS.}

Another normal constituent of the atmosphere-one of enormous importanee-is dnst; normal, becunse it is everywhere in the atmosphere, and because a perfectly dustless air is an artificial product obtained only with the observanee of great eare. The individual particles are very small, but at the same time very variable in size, ranging from those plainly discernible to the naked eye, to those of extreme minuteness.

Dust is organic and mineral, and has its origin in countless processes. It includes particles of animal matter, vegetable substances of every kind ineluding baeteria and moulds, sea salt, matters swept from the soil by the action of winds, those discharged by voleanoes, ${ }^{1}$ others from manufacturing establishments, from chimneys, and from the millions of meteorites which daily fall from interplanetary space. The ordinary combustion of illuminating gas yields millions and millions of particles of arbon for every individual cubie foot.

Organic dist exists only in the lower strata of the atmosphere, but that of mineral origin is everywhere. Miero-organisms are very abmulant in the air of inhabiterl rooms, and in general in that of towns and eities, less abmudant in the comntry, and least at great heights and at sa. Experiments have shown that at an elevation above 6,300 feet the air is free from them. Pasteur exposed a large number of flasks of hroth at an altitude of 6,000 feet, and obtained a growth in but one. 'Tymball exposed 27 flasks at 8,000 feet, and got no growth whatever. I) Fisher. ${ }^{2}$ has shown that on the ocean, 120 miles from land, the air is uslally free from organisms, and that at lesser distances-90 miles, for example-it contains but few.

The ail of cities contains thousands in every cubic meter, against

'After the great eruption in . Java in 1883, a haze of extremely fine particles of puniec, estimated to he from seven to more than twenty miles above the earth, was risible in all parts of the world for soveral months.

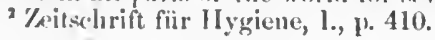


less than a hundred in the same volume of country air. It has been calculated that, in densely populated places, such as London and Manehester, an individual inhales in the course of an hour upward of $4,000,000$ of germs and spores. But this figure is enormonsly in excess of the fignre given by Flïgge, ${ }^{1}$ who estimates that in seventy years a man may inhale $25,000,000$ bacteria, which, he says, is about what one swallows in 25 ec. of ordinary milk.

The number of bacteria in air is influeneed very greatly by dry winds and aqueous vapor. The former, sweeping them up from the surfice, increases their number; the latter, by condensing on them and on the dust partieles to which they adhere, eauses them to fall to the ground. They are washed out of the air by rain, and are killed by long exposure to bright sunshine. Moulds, on the other hand, have been observed by Miquel to increase rapidly after a rainstorm, and to be much less affected by winds.

The average number of organisms found at Montsouris in an investigation which lasted six years was 455 per cubic meter. The lowest results were observed in February and the lighest in July. During the sane period, the number in the air at the center of P'aris was 3,910 ; the smallest figures were yielded in Jannuary and the highest in May.

All organisms are less numerous in the air at nighlit, since then there is less mechanical disturbance of the carth's surface.

While the number of bacteria in outdoor air may be fairly high, it should be borne in mind that the majority of them are of the harmless varieties, and that the pathogenic kinds constitute only an infinitesimal proportion.

Dust, as has been said, is of enormous importance. Without it there would be no rain, no fog, no clonds; the air would be saturated with moisture, and every object would be continually wet.

Dust is largely hygroscopie, and, therefore, attracts the watery valpor of the atmosphere, thus becoming the nucleus for a drop of rain or particle of mist. Were it not for its presence in the air, the aqueous vapor wonld condense without rain on every tree and plant, every rock, every dwelling, every living ereature, and, in short, on every object to which air has aceess.

That atmospheric dnst is neessary for the production of rain and fog, may he demonstrated very simply by condensing moisture from a saturated atmosphere through lowering of the temperature, and noting

1 Grundriss der IIygiene, 1897. 
what occurs when dust is present or absent. For this purpose a simple apparatus, such as is shown in Fig. 10, is all that is required. This consists of a large flask fitted with a rubber stopper, through which pass two pieces of glass tubing, to the free ends of which pieces of rubber tubing with pincheocks are attached. The glass tubes project beyond the shoulder into the borly of the flask. If we pour into the flask an aurount of water rather more than suffieient to fill the neck when the flask is inverted with the stopper in position, we have the eonditions necessary for complete saturation of the eonfined air with watery vapor. If now we withlraw by suction through one of the rubber tubes a small amount of the contained air, the temperature falls at once; and inasmuch as the air within is already saturated, and since the lowering of the temperature of a saturated atmosphere is accompanied by condensation of part of its moisture, such a condensation oceurs within the flask, and is manifested by the formation of a distinet haze which fills the whole air space. If next we restore the original pressure by readmitting sufficient air to abolish the partial vacuum, the mist disappears instantly. The proctuction and dissipation of the mist cloud may be repeated indefinitely so long as nothing is done to remove the dust from the air ; but if we wash the air thoroughly by shaking the flask vigorously for a few minutes, and then repeat the experiment, no visible mist is produced.

\section{CARBON MONOXIDE, ETC.}

Other matters found in air include, under ecrtain conditions, traces of sulphuretted hydrogen, sulphurous, sulphuric, and hydrochloric acids, carbon disulphide from rubber factories, marsh gas, carbon monoxide from illuminating gas, fumes of zinc, arsenic, and phosphorus, organic vapors from offensive trades, and other gaseous and solid matters too numerous to mention.

The most important of these is carbon monoxide, a very powerful poison, often present in the air of inhabited rooms from leaking gas pipes, imperfect combustion of illuminating gas, and defects in heating apparatus fed with coal. It is yielded in great abundance by burning chareoal, and is given off in small amounts from stoves of cast iron, which material in a red-hot condition absorbs it in considerable amounts from burning coal. This was noticed first by Dr. Carret, ${ }^{1}$ of Chambéry, who describert an outbreak of sickness triced by him to this cause. Later, this property of east iron was established beyond a doubt by others. Another by no means insignificant source is burning tobacco, $1 \mathrm{gram}$ of whieh, aceording to Gréhant, ${ }^{2}$ yields $82 \mathrm{ce}$. of the gas. Its presence in the air of rooms in which smoking is earried on was illustrated by Kunkel, ${ }^{3}$ in 1888 , before a society of scientists, by exposing a small amount of blood solution to two puffs of tobaceo smoke, and

Comptes rendus, 1865, p. 793.

Annales d'Ingiene publique, 1879, p. 115.

3 Sitzungsbericht der physikalisch-medicinische Gesellschaft zu Wïrzburg, 188s, p. 89. 
demonstrating the absorption of the gas by means of the speetroscope. The most important source of all is illuminating gas, which contains it in varying amounts, according to its mode of manufacture. Under ordinary eonditions, the leakage of gas from the mains into the soil and thence into the atmosphere is enormons. Pettenkofer ${ }^{1}$ reckoned that in badly jointed systems at least a fifth of the annual output is lost in the ground, and Wasserfuhr ${ }^{2}$ has calculated the annual loss in Paris due to leaks as $15,000,000$ cubic meters. Leakage oceurs from imperfect joints, faulty cocks, and corroded iron pipes. Besides that due to leakage, we have to reckon with that due to imperfect combustion. While an Argand or other burner acting normally gives off no trace of carbon monoxide, a certain proportion of the gas will escape oxidation and mingle with the air of the room together with other impurities, if the gas supply is not properly regulated. The use of gas stoves is responsible for more or less contamination due to imperfect combustion, for when a cold object is put into the flame, the latter is cooled, and part of its carbon monoxide is given off as such. Imperfeet combustion of kerosene is still another source which should not be overlooked, for a smoking lamp exerts a very decided influence on the respirability of the air of a room, aside from the discomfort caused by the particles of soot.

Less than 0.25 per cent. by volume in the air will cause poisoning, and but 1 per cent. is rapidly fatal to animal life, owing to the fact that it unites very readily with the hamoglobin of the blood corpuscles, forming a stable chemical compound, earboxyhæmoglobin, which will neither take up and carry oxygen to the tissues nor promote the elimination of carbon dioxide. As a consequence, asphyxia occurs.

In fatal cases of poisoning, carbon monoxide produces a rapid parenehymatous degeneration of the liver, kidneys, spleen, and heart.

Carbon monoxide has been proved by L. de Saint Martin ${ }^{3}$ to be present in minute amounts in the blood of animals living in cities. Nicloux ${ }^{4}$ has gone farther, and demonstrated its existence in that of animals in the country, and, indeed, in about the same amounts $(0.16$ volume per cent.). Nicloux finds by experiment that it is not derived from the air, but is developed directly in the system, and that its amount is diminished by bringing about slight asphyxiation. Potain and Drouin "s he shown that, at ordinary temperatures, it is oxidized gradually to carbon dioxirle.

Contamination of the air of dwellings with gas from leaking street mains is quite common, and fatal results are not infrequent, the gas travelling through the soil for considerable distances and being drawn up through cellars by the force of aspiration bromght into play by the difference between intermal and external temperatures. Many eases of

${ }^{1}$ Ueber die Vergiftung nit Leuchtgas. Nord und Sud, January, 1884.

${ }^{2}$ Deutsche Vierteljahrschrift für öflentliche Gesundheitspflege, XVII., 1885, p. 309.

3 Comptes rendus, CXXV1., p. 1036.

4 Ibidem, CXXVI., pp. 1526, 1595.

5 Ibidem, CXXVI., p. 938. 
fatal poisoning lave been recorder in which the gas was aspirated through the soil for more than a hundred feet. Such accidents are naturally more likely to oceur in streets which, being well paved, present in obsticle to the escape of the gats upward. The odorous "onstitnents of the gas serve a rery useful purpose in pointing out the danger, hut sometimes they are held back by the earth and camnot perform that office.

Dr. J. S. Haldane has pointed out that air vitiated by gas combustion to such an extent as to show 30 parts of $\mathrm{CO}_{2}$ in 10,000 will eontain about 1 part of $\mathrm{SO}_{2}$ per 500,000 , and that this amount is sufficient to eause marked diseomfort. The air of a room lighted with oil was not unpleasant, exeept for the heat, when the $\mathrm{CO}_{2}$ eontent rose to $7 \overline{5}$; but when gats was burned it was distinctly unpleasant when the $\mathrm{CO}_{2}$ rose to 40 in 10,000 .

\section{"SEWER GAS."}

Another impurity is what commonly but improperly is called "sewer gat.." This is simply sewer air which may be more or less foul by reason of containing the emanations of sewage matters. Its ehemical composition depends upon the extent to which the gases of decomposition are generated, and upon the rate of ventilation. It may be almost as pure as the ontside air ; it may be as rieh in carbon dioxide as the air of badly ventilated rooms; and it may be mueh worse. From 10 to 30 volumes of $\mathrm{CO}_{2}$ in 10,000 are found quite eommonly. Dr. W. J. Russell found as high as 51 volumes in 10,000 in the air of me of the London sewers, and Letheby as high as 53.2 in that of another, while in an muventilated sewer in Paris as high as 340 volumes have been reported. Sulphuretted hydrogen and ammonium sulphide are ordinarily present in small amoumts or mere traces, and may be wholly absent; but in old unventilated sewers, they may be present in notable amounts. The highest reeorded, 299 volumes in 10,000, was found by Parrent-Dnchatelet in an old ehoked sewer in Paris. Marsh gas, ammonia and eompound ammonias, and other gaseous produets of decomposition of organic matter, may be present in variable amounts, accorling to circumstances.

Sewer air contains miero-organisms and animal and vegetable débris, just ats loes the outer air ; but, as a matter of fiet, the number of bacteria is invariably small, and they are often wholly absent. This was shown first in 1883 by Miquel, whose results have bcen corroborated by those of a number of other investigators, including Carnelly and Haldane, Laws and Andrews, and Perey Frankland. The first mentioned conducted a most claborate chemical and baeteriological examination of sewer air, and proved that from both points of view it wmpares fivorably with the air of schools and small dwellings, and that batetoriologically it is, indeed, fat superior. It contains fewer organisms than the air of the streets above or of any kind of dwelling, 
and such as are present come entirely or chiefly from the onter air, and not from the sewage.

Laws and Andrews arrived at the same conclusions after a similar research. In each sample of sewage examined, $B$. coli communis was found in numbers varying from 20,000 to 200,000 per ce., and elosely allied speeies in even greater abundance; but neither the one nor any of the others was found in the many samples of air examined. They found, farther, that the number of organisms existing in sewer air depends entirely upon the number present in the outside air in the immediate vicinity, and that while sewage bacteria are largely of the liquefying varieties, such are practically absent in the air.

The chicf importance of "sewer gas" lies not in its power to produce disease, but in its eapacity for being the vehicle for odors which make the air disagreeable, but not necessarily. dangerous to health, except that appetite and digestion, and henee general mutrition, may be interfered with.

As a matter of fact, sewer air has served for a long time as a most convenient seapegoat in investigations of the cause and spread of ontbreaks of typhoid fever and other infections diseases, and as a most useful aid in explaining obseure questions of varions sorts. Many believers in the sewer-air theory of dissemination of typhoid fever hold that the coarser dust particles carry the germs on their surface, and may be blown about through considerable distanees before the organisms lose their vitality ; but the great oljection to this explanation is that in sewers and cesspools the typhoid bacillus is destroyed speedily by other organisms, and that, even though it be present in an active state in liquirl sewaige, it is extremely unlikely that it will be released therefrom into the air. No orlinary stirring up of the water will throw the germs into the air ; although, aceording to the rescarches of Frankland, ${ }^{1}$ the bursting of gas bubbles generated by decomposition will throw into the air traces of ehemical salts which have been mixed and dissolver in the sewage, and in the same way may throw out bacteria as well. But it has been shown by Nägeli that baeteria cannot be given off from moist surfaces.

Another explanation, offered by Dr. C. R. C. Tichbourne, ${ }^{2}$ is that the disease germs are seattered into the air by the fermenting sewage, and carried by a mist formed when the warm sower air, saturated with moisture, meets the colder external air at the points where ventilating outlets are placed. Then each minute droplet of mist, earrying one or more microbes, is transported through longer or shorter distanees in the air, perlaps into dwellings, and eventually, by the influence of the heat of the sun or by other matural ageney, beeomes dissipated as vapor, and leaves the organisms. suspended in the atmosphere.

The majority and the best of the German invertigators, as Fligge,

1 Proceedings of the Royal Socicty, 1879.

${ }^{2}$ Dublin Journal of Medical Siciences, July, 1897. 
Rubner, Gärtner, Soyka, Prausnitz, and others, maintain that sewer air and sewer gases are incapable of conveying the germs of typhoid fever and other infective diseases.

This whole question of the distribution of diseased germs through sewer gas was again brought prominently to the front by the positive results of the investigations reported by Horrocks ${ }^{3}$ in 1907, and confirmed by Andrews. ${ }^{4}$

Horrocks, in his experiments, made use of the B. prodigiosus, which, because of its distinctive color, can be easily recognized upon infected plates, and, by introdueing this organism in large quantities into various portions of drainage systems, was able to demonstrate that the organisms were carried by air currents in one instance 9 feet above an experimental running trap into which they had been introduced. In another instance the typhoid bacillus, or $B$. prodigiosus, which were used to infect slowly moving and quiet sewage, were found upon plates exposed in a vertical pipe 11 feet 9 inches above the liquid.

Finally, B. prodigiosus, introdueed into actual drainage systems, were found to penetrate into all parts which were in open connection with the original seat of infection, even to a height of 50 feet above the traps. The possible dangers of sewer gas as a means of spreading infectious diseases being thus brought again into prominence, the question was again investigated by Winslow 5 in a report made to the Sanitary Committee of the National Association of Master Plumbers.

Winslow repeated very carefully the experiments of Horrocks, and, although he confirmed in the main the results of the English investigators as far as their qualitative character was concerned, he proved very conclusively that quantitatively " the amount of air infection, even under extreme conditions, is so slight that one would scarcely expect the general air of sewers and house drains to be appreciably affected under normal conditions." For instance, Winslow found that only 48 out of 200 liters of air coming from house drainage systems contained any organisms capable of developing at $37^{\circ} \mathrm{C}$. "Sewage bacteria were found in the air of the house drains only four times out of 200 liters, and then in the presenee of mechanical spraying of sewage at the point of collection. The general air of the house drainage system, aside from this local infection, was, as far as examined, free from sewage organisms. These results aceord well with those obtained by Miquel, Petri, Carnelley and Haldane, and Laws and Andrewes in street sewers and with those reported by Uffelmann for drain air."

It is true that some of the gases given off in the putrefactive proeesses which go on in sewers are more or less poisonous, but whether they are capable of producing injurious effeets depends very much on

3 Proceedings of the Royal Society, Series B, Vol. LXXIX., No. B-531, p. 255.

4 Supplement to the Thirty-sixth Annual Report of the Local Goverument Board containing the Report of the Medical Officer for 1906-07, p. 183.

${ }^{5}$ Report of the Sanitary Committee, National Association of Master Plumbers of the United States for 1907, 1908, and 1909. 
the amount inhaled and on the degree of concentration. In any event they are certainly incapable of producing any infective disease in the absence of the specific germ.

In any well-constructed and properly ventilated sewer, no great amount of putrefaction will go on, since the sewage matters soon patss on and are discharged; consequently not much gas will be evolved, and, with proper rentilation, whatever is evolved, is soon dissipated in the outer air. Offensive gases and odors are much more likely to be given off by unclean unventilated house-plumbing than by well-built sewers.

It is asserted commonly that the inhalation of small amonnits of this air will produce headache, anæmia, loss of appetite, sore throat, albuminuria, diarhoea, and other symptoms, and that it may be the exciting or anxiliary cause of typhoid fever, measles, diphtheria, scarlet fever, dysenterv, and other infective diseases. But in the eases which are accepted as proving the causal relation, inference has taken the place of proof, no other means of infection being ascertainable. In not a single case has the supposed relation been demonstrated bacteriologically.

In answer to the well-known stubborn fact that the workmen employed in all the large systems of sewerage-men whose occupation involves the daily and constant inhalation not of traces, but of large volumes, of sewer air-are as a class unusually healthy and strong, with a high mean age at death and a low death-rate, it is asserted that they becone inmmuized by daily contact, and thus escaje. If we accept this theory, however, we should go farther, and say that large doses are a benefit in that they confer immunity, and that, therefore, all precantions against the admiswion of sewer air to the air of dwellings are misdirected, and should be abandoned.

The air of properly eonstructed sewers is in constant motion, brought about by differences in temperature and mechanically through influx of sewage. During the colder months, the temperature within the sewer is higher than that of the air above, and it is influenced materially by the fact that the entering sewage is largely warm ; therefore, sewer air tends to rise and escape through the openings in the man-hole covers. During the warm season, the natural interchange is much lessened, since then the conditions as to temperature are reversed. At night, however, at all seasons, the temperature of the air of the sewer is higher than that of the atmosphere above, and thus ventilation goes on by natural laws the year round. Much air is displaced by the entering sewage; in fact, disregarding the effect produced by the warmth of the sewage, for evrry enbic foot of sewage which enters, a cubic foot of air is forced out, and ats the sewage is discharged, more air enters to take its place.

Owing to the prevailing belief in the noxions character of sewer air, it was formerly the custom to place baskets of chanceal in the ontlet shafts of the man-loles, but as this material loses its alsorptive property with aceess of moisture, the plan was abandoned. It was also 
regarded as an advantage to comnect the sewer with chimneys, which act as rentilators, but in the light of farther knowledge and because of exeessive aletion, that method of ventilation fell into disuse.

\section{ORGANIC MATTERS.}

Among other impurities griven off' to the air, the organic matters from the processes of the body are, in a way, of considerable importance. 'These include particles of epithelinm, the constituents of sweat (butyric, anpric, capronic, and caprylie acids, lactate, butyrate, and other salts of ammonimm), and volatile matters from foul mouths, decalying terth, and the digestive tract, and excrementitious matters deposited on muclean elothing. In addition to these, it has been asserted that other matters of a poisonous chamacter are given off in the process of respiration, which natters will be referred to later on in the disenssion of the effeets of impure air on liealth. That the air of inhabited eonfined spaces may contain organic animal matter, is apparent to the senses when one enters such an atmosphere from one not thus contaminated.

\section{Effects of Vitiated Air.}

The effects of foul air on the system are of great importance, and vary in degree within very wide linits. For proper aëration of the blowd, it is necessally that the oxygen of the air shall be present in the normal proportion in the free state, and not in chemical union with arbon as a waste product. Farther, it is necessary for the proper exeretion of the carbon dioxide of the blood that the difference in the tension of that gas in the air and of that in the blood shall be as wide as possible; that is to say, the less the amount of carbon dioxide in the inspired air, the greater the ficility with which the blood can disengage that which it carries to the lungs. Any interference with this most inportant function of the body must have an injurious effect on the general health, and it is aceepted generally that impurity of the air is, without doubt, the most important of the predisposing causes of disense.

It is well known that, other conditions being equal, in proportion as a people are drawn to employments indoors, the diseare-rate and deathrate are increased. This is particularly true as regards phthisis, which is preeminently associated with overcrowding.

Overerowding means the association of two or more people in a space so confincd as to preclude the admission of a constant supply of fresh air suffieient in amount to maintain a proper dilution of their exeretory products and a normal supply of free oxygen. It was recognized long ano as a most important fiactor in the produetion of a high death-rate among oceupants of erowded jails, balracks, and hospitals; and experience has demonstrated repeatedly that increase in space allowance is followed always by decrease in siekness- and death-rates. At one time, for example, the Einglish army areraged 11.9 deatlis per 
1,000 men anumally, from phthisis alone; more efficient barrack ventilation and increase of average air space caused immediate improvement, and the phthisis-rate fell gradually to 1.2 per 1,000. The same general result has been observed in the armies of France, Russia, Germany, and Belgium.

What is true of overcrowding applies not alone to human beings, but to animals as well, and it is a well-known fact that crowded stables show high mortality among cows and horses. It has such a remarkable influence on egrg production and growth of fowls that practical poultrymen are exeeedingly careful on this point.

The immediate effeets of inhalation of impure air are disconfort and oppression, which may amount to headache, dizziness, faintness, and even nausea. Continued exposure is likely to bring about a gradual impairment of health, shown by pallor, languor, anæmia, skin troubles, loss of appetite, and diminished power of resistance to the exciting causes of discase, and this is especially true of those whose daily work is carried on in crowded spaces.

It is customary to eite as extreme cases of overerowding and its effects, the Black Hole of Calcutta, the ship Londonderry, and the prison at Austerlitz; but the eonditions that obtained in each of these instances were most musual, and the cases are of historical rather than sanitary interest, since the confining of a number of persons in a space from which air is practically excluded can have but one outcome.

The Black Hole of Calcntta is the name applied to the military prison of Fort William, where, in June, 1756, Surajah Dowlah confined 146 persons over night in a space of less than 5,900 eulic feet, with two small windows in one side. Within an hour, all broke out in a profuse sweat, and were tortured with thirst and difficult breathing; in three and a half hours, a majority were delirions, and when the place was opened in the morning, 123 of the prisoners were found dead.

In the ease of the Londonderry, which, in December, 1848, left Sligo for Liverpool and ran into a storm, 200 steerage passengers were confined over night in a space 18 by 11 by 7 feet, with no means of ventilation. In the morning, when they were released, it was found that over 70 had expired.

In the other extreme case, that at Austerlitz, 300 captured soldiers were confined in at small cellar, and within at few hours all but 40 were deacl.

To what one or more conditions of impure air are the ordinary effects due? We have seen that $\mathrm{CO}_{2}$ is in itself not an active poison, and that its action is to interfere with the proper oxygenation of the blood within the lungs. The acueons vapor of respiration and from the skin, and that produced in the combustion of illuminating material, constitutes an important part of a vitiated atmosphere, and is responsible for at least a part of the discomfort produced ; but it is also true that a deficieney in watery vapor in the air of woll-ventilated rooms has equal or greater disadvantages, ats will appear in the considention of Ventilation. 
Concerning the effect of usual amounts of ordinary dust in inlabited rooms, there is little to be said. The micro-organisms, most of which are non-pathogenic, vary in number with efficiency of ventilation. In pure air, the bacteria and monlds approximate each other in number ; but in vitiated air, the bacteria increase in number, while the moulds are much less affected. The experiments of Carnelly, Haldane, and Anderson showed a progressive increase in both bacteria and monkls with diminished ventilation. Thus,

\begin{tabular}{|c|c|c|c|}
\hline \multirow{2}{*}{ Character of air space. } & \multicolumn{2}{|c|}{ Number organisms in 10 L. air. } & \multirow{2}{*}{$\begin{array}{c}\text { Ratio of } \\
\text { moulds to } \\
\text { bacteria. }\end{array}$} \\
\hline & Moulds. & Bacteria. & \\
\hline $\begin{array}{l}\text { External air } \\
\text { 4-roomed houses } \\
\text { a-roomed houses } \\
\text { l-roomed houses }\end{array}$ & $\begin{array}{r}2 \\
4 \\
22 \\
12\end{array}$ & $\begin{array}{r}6 \\
85 \\
430 \\
580\end{array}$ & $\begin{array}{l}1: 3 \\
1: 21 \\
1: 20 \\
1: 48\end{array}$ \\
\hline
\end{tabular}

The increase in bacteria is not due to respiration, though a diminution in their number might be thus explained; for the great majority of inhaled bacteria are filtered out by the nose, and the expired air is almost completely free from germs, although they may be thrown out in the act of conghing or sneezing.

Investigation thus far has not proved that the bacteria of infection are commonly introduced into the system through the medium of respired air.

As has been mentioned, it is held by many that the effects of vitiated air are not due to carbon dioxide, but to the organie matters and aqueous vapor given off by the lungs and skin, and that these are estimated eonveniently by determining the amount of carbon dioxide with which they are discharged. It is said also that, while considerable carbon dioxide escapes even under the most imperfect system of ventilation, the organic matters and watery vapor do not so readily pass out, but are deposited on walls, furniture, hangings, and clothing, where they putrefy and become offensive. As proof of this, is eited the fact that a room in which a person has slept withont adequate ventilation has an unpleasant smell in the morning, and that this persists even after prolonged airing.

Brown-Séquard and d'Arsonval, in 1888, obtained from condensation of the aqueous vapor of men and animals a liquid which, injected into rabbits, caused death with greater or less rapidity, according to the size of the dose. They believed the toxic element to be of the nature of a volatile alkaloid, and that it was exhaled dissolved in the aqueous vapor of the breath. In the same year, Wurtz, reporting a similar resenrch, elaimed to have found a toxic substance.

Merkel, ${ }^{1}$ in 1892, claimed to lave obttined positive results, and concluder that respired air from persons in health contains a minute quantity of a volatile organie base, which is poisonous when free, but innoc-

\footnotetext{
${ }^{1}$ Archiv für Iygiene, XV., p. 1.
} 
uous after contact with an acid. Dr. Sivierato ${ }^{1}$ collected the aqueous vapor of the breath of persons suffering from diseases of respiration, both with and withont fever, of persons with no respiratory disease, but with fever, and of persons in health, and injected it into rabbits. That from those with respiratory diseases produced fever and diminished reflexes lasting three to six days; that from eases of fever with no respiratory discase caused little or no disturbance; and that from persons in health produced no results whatever.

Formánek ${ }^{2}$ concluded, after much study, that no poisonous substance originates in the lungs; that the ammonia sometimes found is not a prodnct of metabolism, but of decomposition in the mouth cavity (carious teeth, etc.) and in the trachea and lungs after tracheotomy, and in pinmonary tuberculosis; that, in the experiments which led to the theory of an unknown alkaloid, ammonia was used, and might have caused the observed effects; and that the results of overerowding cannot be due to any one cause.

Many other experimenters, French, German, Italian, American, and English, working along the same lines, but with extra precautions to exchude matters from the nose and mouth, have failed to obtain toxic effects from the condensed vapor; others have demonstrated that the lungs exhale no organic matter except in minute amounts, and that these have no poisonous influence.

Arloing pursued the subject further, in the belief that the constituents of the sweat are concerned in the harmful effects. He soaked the underclothes of a man who had spent a long evening in dancing, and injected the watery extract into dogs and rabbits. From the fact that the animals showed various evidence of intoxication and died he concluded that sweat is toxic. Experiments in the author's laboratory, however, with sweat obtained directly from well-scrubbed forearms and injected in considerable amounts into rabbits and other animals yielded negative results. Sweat vaporized in small confined spaces was equally innocent of harmful results to men and animals exposed thereto. At present the weight of evidence leads to the conclusion that the injurious action of vitiated air is due to the diminution of oxygen and to the increase of carbon dioxide, both of which factors, alone or together, interfere with the intake of oxygen and the excretion of carbon dioxide from the lungs. Yet, diminution in oxygen, which even in very crowded rooms does not proceed very far, is met by increase in the respiratory function, which, however, eannot increase the difference between the tension of the carbon dioxide of the air and of the blood. Not even in very imperfectly ventilated mines does the oxygen fall much below 20 per cent. by volume, and thus we see that the whole range of fluctuation in the oxygen of pure and of very foul air is but little more than 1 volume per cent.

Smith and Haldane ${ }^{3}$ have shown that in a leaden chamber containing

1 Archives Italiennes de Biologie, 1895.

2 Archiv für Hygiene, XXXVIII. (1900), p. 1.

"Journal of Pathology and Bacteriology, I., 1892. 
air which harl suffered hut slight diminution in oxygen, but which contained 384 parts of carbon dioxide in 10,000, two men suffered from headache immediately on entering.

As a lule, vitiated air is associated with high temperature and saturation with aqueous vapor, which latter interferes with evaporation fiom the skin. Less often it is associated with low temperature, and with this condition comes an increased demand for oxygen to meet the requirements of the oxidation processes.

It seems probable that where the carbon dioxide is not present in any great exeess, and the oxygen is not markerly deficient, the conclusion arrived at by Drs. Weir Mitehell, Billings, and Bergey is true ; namely, that the discomfort suffered is due largely and ehiefly to heat and disagreable odors arising from the occupants in varions ways : from bad breath, unclean skin, unclean elothes, sweat, and gases from the bowels. Such may induce very disagreable sensations, amounting even to nausea, in those who are not habituated to such influenees; but, on the other hand, those who are aceustomed to such air notice no discomfort.

Disagreeable smells do not aet directly as a eanse of specifie disease, but appear to have an influence on the appetite, and hence on the general well-being of persons not accustomed to them. Much is due also to the imagination; a disagreeable smell from a source known to be elean (chemicals, for instance) has not ordinarily as much influence as another of equally offensive character supposed to be from filth. It seems probable also that there is much to learn encerning the real effeets of disagreeable smells, and that they may be more extensive than we now commonly believe; but in order to determine this, we shall need methods which will reveal the nature of the odoriferous substanees and make their isolation possible.

Other causes of diseomfort may be sought for in the presence of traces of carbon monoxide from heating apparatus or incomplete combustion of illuminating gas, and in excessive dryness of the air due to furnace or steam heat.

It should not be overlooked that impure air nay affeet the vitality and baetericidal power of the cells of the air-passages and of the alimentary tract, and thus lessen the power to resist the action of infective material.

\section{The Air as a Carrier of Infection.}

On the ageney of air in spreading infectious matter, much has been said and written, and much carefinl researeh has been conducted, but the eonclusions reached are by no means in agreement or eonclusive. It is coneded generally that pathogenie organisms in the air are arlherent to particles of dust of varions kinds, and that their retention of virulence depends upon the amount of hygroscopic moisture with which they are associated. The conditions favorable to their continuance as living organisms are naturally more likely to olstain in indoor air, with imperfect ventilation, than in the outer air, where they are diluted and blown about and exposed to the disinfectant action of the direct 
rays of the sun. Indoors or outdoors, the more they are protected by hygroscopic dust particles, the longer they will retain the moisture which is essential to their viability. It appears, too, that, conditions being equal, certain micro-organisms retain vitality longer than others, some being but slightly, others very tenacions of life.

With regard to the transmission of pulmonary tuberculosis through the air, it should be said that while there can be no doubt that this discase is connected preëminently with overerowding and vitiated air, there is a very deeided difference of opinion as to the method of emvevance, sone contending that dust, and others that tuberculous miterial, thrown into the air in eonghing, speaking, and sneezing, is the vehicle.

Buchner has found B. tuberculosis in an active state in the dust of a room a year after the death of its occupant from the disease. G. Cornet ${ }^{1}$ demonstrated its presence in more than a third of 147 samples of dust collected in hospitals and other public institutions, and in private houses inhabited by phthisical persons, and sueceeded later in producing the disease in 46 out of 48 guinea-pigs exposed to air containing dust from dried tuberenlous sputum. Some of the animals were placed 8 inches from a glass vessel containing dried pulverized sputum from an alvanced ease; others were placed on shelves 8 to 28 inches from the floor of a room, on the carpet of which, sputum, mixed with dust, had been spread and dried and, at the end of two days, stirred up by sweeping; others were allowed to stay in the room without disturbance of the dust.

Klein obtained positive results with guinea-pigs placed in the ventilating shaft of a consumptives' hospital; but Heron ${ }^{2}$ obtained but 2.7 per cent. of positive results in 74 guinea-pigs inoculated with dust from the ventilating shaft of the London Hospital for Diseases of the Chest; and Kirehmer ${ }^{3}$ got but 1 positive result out of 16 pigs inoculated with the dust from a military hospital. Flïgge, on the other hand, was wholly unsucessful in inducing the disease in guinea-pigs exposed to such dust; and concluded that the transmission from one person to another is chiefly by means of the finest droplets thrown into the air in speaking, coughing, and sneezing. From later experiments, conducted under his stpervision by Laschitsehenko, Heymam, Sticher, and Benimle, he concluded that in rooms in which tubereulous sputum is dried on the floor or other places, and where the air is filled with coansc dust through dry eleaning and air currents, or, as in railway cars, by continual mechanical jarring, infection may arise; and that, under these conditions, long-continued exposure offers a certain degree of probability of infection. Therefore, dry cleaning is to be avoided in rooms in which consumptives are employed with others, and the rooms should not be occupied so long as the air is pereeptibly dusty. The great possibility of infection through matters thrown off' in coughing and sneer-

1 Teitschrift für IJygeine, V., p. 191.

${ }^{2}$ The Lancet, Jimuary $6,1894$.

3 \%eitschrift fïr IYygiene und Infectionskrankheiten, XIX., p. 153.

"Ibidem, XXX., p. 107. 
ing is insisted upon as of paramount importance. This danger is to be presented by requiring the person coughing to hold a hatndkerchief or the hand before the mouth during the act, and by the avoidance on the part of others of approaching within a meter.

Answering Flïgrge, Cornet ' contends that the number of baeilli thrown into the air during the act of coughing must be extremely small. He catused 18 consumptives to hold dishes before the mouth while coughing, and obtained 2 positive results therefrom on inoculation into guinea-pigs; repeating the test with 15 others, he got none; but Heymann ${ }^{2}$ was more suecessful, for glass plates exposed in the immediate vieinity of coughing consumptives, confined for an hour and a half in a glass cabinet of three cubic meters' capacity, were proved to have become contaminated by the speeific organism. The plates were rubbed up with small amounts of broth, which was then injeeted intraperitoneally into guinea-pigs, mostly with positive results.

Experiments conducted by Königer ${ }^{3}$ enfirm Flügge in his estimate of the danger of transmission by droplets. In order to give the expelled droplets a character which would admit of their being traced, he rinsed his mouth with liquid rich in B. prodigiosus or B. mycoides, or with very dilute caustic soda, and, in order to trace them, he exposed Petri dishes and glass plates coated with phenolphthalein, which agent, turning pink in contact with an alkali, would show not only the number of droplets, but their size as well. It was found that no droplets are thrown out in ordinary exhalation nor in rowel formation, but with consonants, as $t, k$, and $p$, the number is very great, and is largely dependent upon the amount of foree with which the air under pressure in the mouth eavity is released in their formation, and, therefore, upon the manner of pronouneing. Loudness and rapidity of speech have but little influence; whispering may, indeed, under some conditions, cause a greater number of droplets than loud speech. Even with subdued speech and a quiet atmosphere, it was found that the organisms expelled reached the most distant parts of the room, which was more than 20 feet in width, and in all directions. They were found to remain in suspension in the air not longer than an hour, and it was noticed that they fell upon the plates in groups, sometimes as many as 40 close together, which suggests that they fall not as dry dust particles, but that the droplets themselves, with their contained or adherent organisms, are deposited. In coughing and sneexing, more droplets are expelled than in speaking, and they are projected to a greater distance, because of the greater force engaged. The preeautions recommender apply not alone in tuberculosis, but also in diphtheria, whooping-cough, and other diseases in which the respective speeific organisms are found in the air-passages.

Hutchison ${ }^{+}$found that bacteria, sprayed in minute droplets upon

1 Berliner klinische Wochenschrift, May 13, 1899.

2 'Zeitschrift für Hygiene und Infectionskrankheiten, XXXVIII. (1901), p. 21,

3 Ibidem, XXXIV. (1900), p. 119.

4 Ibidem, XXXVI. (1901), p. 223, 
objects, perish in a short time, the main factor in their destruction being the influence of sunlight. Sprayed directly into the air, most of them were found to have become deposited within a half hour, when the air of the room was allowed to remain undisturbed, but numbers of them were kept in suspension for considerable periods by slight unavoidable air eurrents in the lower strata. He showed that, with favoring air currents, the suspended bacteria may be conducted through very narrow crevices, as into closed bureau drawers, and from one room to another throngh keyholes and cracks. While the danger of disseminating bacteria by walking over an infected floor was found to be slight, those thrown up by the elastic rebound of the boards failing to infect plates suspended 4 inches above them, ordinary sweeping was found to contaminate the atmosphere throughout its whole extent, even to the ceiling, thus confirming Fliigge's statement as to the undesirability of dry eleaning.

Closely similar results were obtained by Kirstein, ${ }^{1}$ who concludes that ordinary air eurrents cannot detach living organisms from surfaces upon which they have been deposited and become dried, but concedes that, when the bacteria are sprayed upon fine dust particles, they may easily be borne about in the air. Yet how slight the danger of this method of infection is, so far at least as typhoid fever is concerned, is shown by the marked rapidity with which the typhoid organisms die when sent forth in the form of spray. Other non-spore-builders, sprayed into the air, retained their vitality for only a eomparatively short time, because of the influence of light and air; and he believes that the marked sensitiveness of the tubercle baeillus to the influence of light makes early destruction of this organism most probable when it is thrown into the air in minute droplets, and that thus may be explained the fact that, even in consumptive wards, in which there is, withont doubt, a constant discharge of bacilli into the air, attempts to deteet living organisms in the dust, ete., fail, excepting in those cases in which the sputum itself has, through lack of care, become disseminated.

Positive results of examination of droplets expelled by consumptive patients during conghing have been recorded by Curry, ${ }^{2}$ Boston, ${ }^{3}$ and others. Curry experimented with 12 patients, who conghed toward plates suspended from 1 to 3 feet distant; he found the bacilli in the larger droplets expelled by half the subjects. Boston, observing fine droplets being ejected from the mouth of a patient with advanced disease in each act of conghing, concluded that such constant spraying at the table and elsewhere might afford an explanation why patients in the early stage of the disease did not do well in the institution where his observations were made, in which every possible attention is given to ventilation, light, and disinfection of sputum. By means of a simple device, the spray sent out by 50 patients was collected, and then sub-

1 Teitschrift für Hygiene und Infectionskımkheiten, XXV. (1900), p. 123.

2 Boston Medical and Surrical .Jommal, October 13,1898.

3 Journal of the American Medical Association, Sept., 14, 1901. 
jected to examination for the specific organism, which was found in 76 per cent. of the cases. The smallest number found in any specimen was 4 , and in fully a third the hacilli were very numerous.

Ravenel's ${ }^{2}$ experiments with tubereulons eows have proved that they, too, send forth the bacilli in great numbers in the act of coughing.

Experiments eondueted at the Adirondack Cottage Sanitarium by Dr. I. H. Hance, ${ }^{2}$ for the purpose of determining the degree of danger of infection when all possille sanitary measures for disinfection of sputum are enforeed, support the view that dust in the air is of seeondary importance, but that, where carelessness in this regard obtains, the danger is a real one. A complete examination was made of the group of buildings, some of which had been oceupied by consumptives for eleven years. Dust was collected from places most likely to be infected, and with it 81 guinea-pigs were inoculated. Four inoenlated with dust from the infirmary (a building where all the acutely siek are sent), and from the main building (in which are a parlor, sitting-room and library), died of other infections on the third to the sixth day. Five of the ten inoculated with dust from the oldest cottage, which was ocenpied by a man who had been complained of for promiscnous spitting, beeame tuberculous. Those inoculated with the dust from the other buildings gave negative results. During eleven years, not one of the 20 to 25 attendants employed had developed the discase.

As to typhoid fever, too, opinions are at variance. Dr. John Brownlee reported before the Glasgow Philosophical Society an experiment proving that the specific bacilli can live in ordinary dust. Buchner is of the opinion that neither typhoid nor other fevers can thus be spread.

Perhaps the most extensive research on the subject of transmission of this and other diseases is that condueted by Dr. Eduardo Germano. ${ }^{3}$ In his experiments, he nsed varions kinds of dust and dirt, and from his results, he concludes that the typhoid germ is unable to withstand complete drying, and hence cannot be transmitted to man through dust sufficiently dry to be disseminated by air currents. Experiment showed that the germ can live for a long time in moist surroundings, even in an apparently dry condition, that is, when adherent to or encompassed by matters which contain a certain amount of moisture, such as clothing, particles of dirt, and fecal filth. Most of the bacilli die as drying progresses, but some are more or less resistant, though not necessarily dangerous on admission to air enrrents, since then complete drying and conserquent death oecur. 'They are dangerous only in case of introduction into the system through contact with the fingers, food, or eating utensils.

${ }^{2}$ University Medical Magazine, November, 1900.

${ }^{2}$ Merlical Keeord, Decenber 28,1895 .

3 \%itschrift für IIygiene mud Infectionskrankheiten, XXIV., p. 403; XXV., p. 439; XXl1., pp. 66 and 273 . 
With regard to diphtheria, Germano found that the bacillus withstands long drying in membranes, tissues, and dust, even when the drying process is assisted by sulphuric acid; and that its resistance is greater according to the amount of enveloping material which retards oxidation. When completely dry, it preserves its virulenee up to the time it dies. Hence his belief that this disease may be disseminated by air eurrents.

With regard to pneumonia, erysipelas, and other streptococcus infections, Germano finds that the resistance of the organism to the drying process is always high, thongh it varies with the method followed and the nature of the enveloping material, and may persist a number of months. Transmission through the air is extremely probable. The diplococci, in general, bear drying for a long time; some varieties live longer when dried than if moist, and some possess but little resistance; lut the rapidity of the drying process with medium temperature does not affect the result. He found that the eholera organism retains its virulence only so long as it remains moist, and dies quickly on drying, particularly if the process is hastened. He coneluded that dissemination by air is most highly improbable.

Germano's work with the plague bacillus confirms the results announced by Kitasato and Wilm. This organism does not withstand drying, but lives a long time in a moist condition. It remains active fairly long when dried on eloth, because then complete drying requires a long time, and thus maly be explained the danger of infection reeognized to exist in infected elothing.

Germano's experiments with the diplococens of epidemic cerebrospinal meningitis agree in results with those of Jäger, who found thè organism in an active condition in a handkerchief six weeks after use by a patient sick with the disease. Germano shows that it belongs to the elass of bacteria which oppose the greatest possible resistance to drying, whether the process is slow or quick, and whether assisted by the action of sulphurie acid; and concludes that it may withont difficulty enter the air in the form of dust, and thus spread the infection. This view is supported by Buchanan, ${ }^{1}$ who argues from the fact that, of 60 eases which came under his observation, 57 were in men who followed ocenpations in which they were exposed to dust, the specific organisms are thus conveyed.

Dr. Max Neisser, ${ }^{2}$ working in the same line as Germano, with an apparatus of his own devign, which maintains a constant aspimation current of dusty infected air, disagrees as to the pnemmococens, inasmuch as, while mice, inocnlated with infected dust, died from the infection withont exception, 24 others, inoculated with the dust after it had been sent throngh the apparatus in a current of air, gave absolutely negative results. His experiments with various organisms led him to the conchusion that dust infection is impossible with the organisms of diphtheria, typhoid fever, cholera, plagne, and pneumonia, but

1 British Medical Journal, September 14, 1901.

${ }^{2}$ 'Zeitschrift für llygiene mul Infectionskrankheien, XXV'1., p. 175. 
possible with Staphylococcus pyogenes aureus, B. pyocyaneus, B. anthracis, B. tuberculosis, and meningococens.

Neisser's conchusions, so far as they relate to diphtheria, are opposed to the results obtained by Richardière and Tollemer, ${ }^{1}$ who made a series of examinations of the air of diphtheria wards of the Hôpital Tronsseau. In one set of experiments, the wards had not been disinfected for several weeks; and in another, the examinations were made after disinfection had been carried out. The results showed that active diphtheria baeilli were present in the air which had not undergone disinfection. The bacteriological tests were controlled by inoculation experiments with animals.

With regard to the possibility of spreading cholera germs through the agency of moving air, Dr. N. William ${ }^{2}$ has reported that, while that means has been regarded as most favorable, in actual experiment it fails. Mixed with dry dust, the germs live but a short time, and perish more quickly when a current of air is conducted through the dust. When the dust is distributed through large volumes of air, the germs die rapidly, and when the impregnated dust is let fall upon a suitable culture, only a very small proportion of living organisms can be found. In other words, cholera germs, adherent to dust particles floating in and moved about by air, do not retain their activity for any length of time nor through any considerable distance.

The experiments of Honsell $^{3}$ indicate that the cholera organism finds no favoring conditions for its passage into the air from its situation in privy vaults.

The subject of danger of cholera infection by dust from baled rags was considered thoroughly at the Dresden Cholera Conference, and it was found impossible then to quote a single case in which infection could be traced to this source.

According to Dr. E. W. Hope, ${ }^{4}$ atmospheric dust is largely responsible for the spread of infantile diarrhoea in cities and large towns, where, from unavoidable causes, the air bccomes more or less laden with filth. $\mathrm{He}$ presents evidence of the association of rainfall and its attendant cleansing of the atmosphere with diminished mortality from choleraic diarrhœa, as follows :

\begin{tabular}{|c|c|c|c|}
\hline Period. & $\begin{array}{l}\text { Average rainfall } \\
\text { June to } \\
\text { September. }\end{array}$ & Conditions. & $\begin{array}{l}\text { Annual average of deat hs } \\
\text { from diarrhoea during } \\
\text { third quarter of year. }\end{array}$ \\
\hline 6 years & 13.8 inches & Average wet sum- & 373 \\
\hline 14 " & 10.9 " & $\begin{array}{l}\text { mers. } \\
\text { A verage dry sum- } \\
\text { mers. }\end{array}$ & 573 \\
\hline $\begin{array}{c}\text { Extreme years. } \\
1891 \\
1895\end{array}$ & $\begin{array}{r}16.0 \text { " } \\
7.7 \text { " }\end{array}$ & $\begin{array}{l}\text { Wettest summer. } \\
\text { Driest sllmmer. }\end{array}$ & $\begin{array}{l}203 \\
819\end{array}$ \\
\hline
\end{tabular}

1 Gazette des Maladies infantiles, No. 10, 1899.

2 Teitschrift fiir Hygiene und Infectionskrankheiten, XV. (1893), p. 166.

${ }^{3}$ Arbeiten aus dem patholog-anatomischen Institut zu Tübingen, 1896.

- Public Health, July, 1899. 


\section{Influence of Fog.}

Dust and moisture together in the form of fog affect the health of large communities in a marked degree. In a still air nearly or completely saturated with aqueous vapor and containing ordinary dust and smoke, a fall in temperature causes each particle of dust and soot to become the nucleus of a minute droplet of condensed moisture. These countless droplets in a state of suspension form a more or less dense blanket of fog, which impedes dispersion of the impurities given off by natural processes and as products of combustion. While ordinary country and seashore fogs are not known to exert deleterious effects, in smoky cities, like London, the case is quite different.

It is a well-recognized fact that, during periods of heavy fogs in manufacturing centers, the morbidity and mortality from respiratory disease are increased very greatly, and that, as the atmosphere clears, a sharp decline follows. In London, for example, the usual death-rate from all causes has been known to become almost doubled during a fortnight of continued dense, smoky fog, and then to return to its normal figure with the advent of clear weather, the increase being due particularly to bronchitis and other affections of the respiratory tract, attributed to the irritating influence of the finely divided particles of soot and the acids which accompany them.

During the prevalence of thick fogs, the air being necessarily in a stagnant condition, it has been observed that the carbon dioxide content increases progressively. During one such period following bright weather, the air of London acquired, in four days, three and a half times its normal content of this gas.

The importance of smoke, both as a promoter of disease and on account of its corrosive and disfiguring action on buildings, and also on account of the obstruction of light, has led to much legislation and to the exereise of inventive genius for devising means for the prevention of its discharge in objectionable amounts into the atmosphere of cities. Many patents have been granted for smoke-consuming devices, the majority of which have been found to work unsatisfactorily: The most effective invention, which gives promise of solving the problem most completely, is one which has been brought to the attention of the Department of State by Consul General Mason. ${ }^{1}$ This process consists in distributing heated and slightly compressed air through hollow grate bars to the whole lower surfice of the furnace. Not only is practically perfect combustion attained, but immense saving of expense is possible, since what are ordinarily unsalable low-grade coals can be employed to greatest advantage.

\section{Examination of Air.}

For all practical purposes, the examination of air may be restricted to the determination of the amounts of aqueous valpor and carbon dioxide. The essential element, oxygen, fluctuates within such very

${ }^{1}$ Consular Reports, 1899, p. 491. 
narrow limits that its estimation is a matter of purely scientifie interest, and, moreover, the process is one which demands a much higher degree of manipulative skill than is possessed by those to whom the task of making sanitary exannations ordinarily falls. The chief constituent, nitrogen, is practically constant in amount, and its determination would serve no useful purpose. Whatever is the cause of the deleterions effects of an atmosphere vitiated by respiration, whether it he earbon dioxide or the organie matters given off by the body, this at least is certin, that the amount of carbon dioxide serves as an index of impurity, and that the amount of aqueous vapor is of considerable sanitary importance. In special eases, it is important to look for that most dangerous contanination, carbon monoxide, which, coming even in very small anounts from leaking gas pipes and other sources, exerts a decidedly deleterious influence. In the minds of many, the test for ozone is also of importance.

In addition to chemical analysis, the determination of the amount of dust and the number and varieties of miero-organisms present may be of interest and importance.

Determination of Aqueous Vapor.-As has been stated above, a volume of air at a given temperature can hold a definite amount of moisture, and no more, and when this amount is present the air is said

FIG. 11.

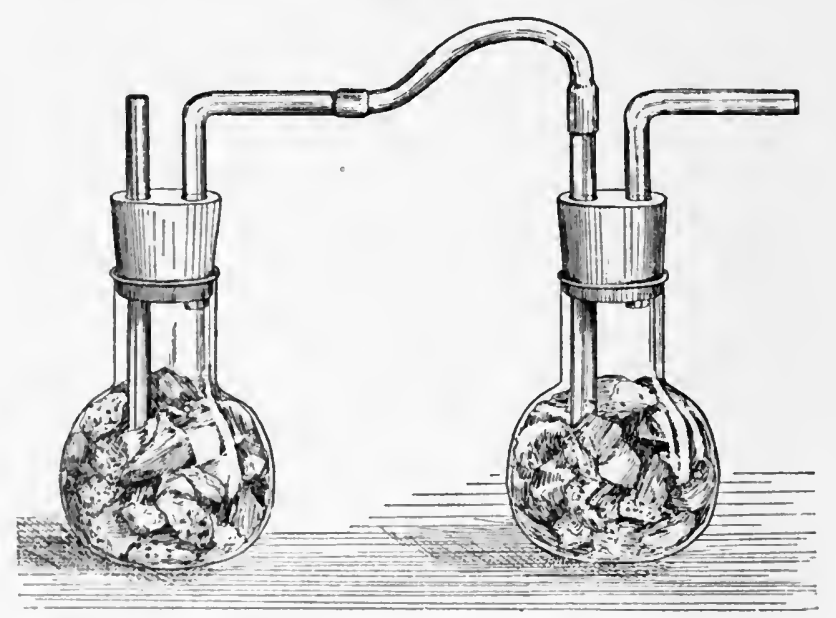

Apparatus for direct determination of moisture.

to be saturatel. The amount which a volume of air contains constitutes its absohnte humidity, and the difference between this and the amount which it is possible for it to hold is known as its saturation defieieney. The ratio which its absolute humidity bears to its possible content is known as its relative hunidity.

Direct Determination of Moisture by Weighing.-Prepare two widemonthed flasks of about 150 cc. eapacity in the following manner: 
Provide each with a tightly fitting rubber stopper with two perforations, through which are inserted two pieces of glass tubing bent at a right angle. One of these reaches to the bottom of the flask, and serves as an inlet; the other extends only a short distance below the stopper, and serves as an outlet. Fill the flasks with small pieces of pumice which have been heated to a high temperature over a Bunsen burner, dropped while hot into concentrated sulphuric acid, removed therefrom, and quickly drained. The two flasks thus filled, and with stoppers tightly inserted, are then to be connected by means of a short piece of rubber tubing, the inlet of one joining the outlet of the other. 'They are then weighed. The flask with the free outlet tube is now to be connected with an aspirator, by means of which from 20 to 50 liters of air are drawn through. As the air comes in eontact with the pumice saturated with sulphuric acid, its moisture is absorbed and retained. At the expiration of the aspirating process, the flasks are disconnected from the aspirator and again weighed. The increase in weight represents the amount of moisture in the volume of air used. The apparatus is shown in Fig. 11. Knowing the temperature of the air, one can then casily determine the relative humidity by reference to the table below, which shows the maximum humidity possible at differeut temperatures.

TABLE OF MAXIMUM WATER CAPACITY FOR TEN LITERS OF AIR.

\begin{tabular}{|c|c|c|c|c|c|}
\hline $\begin{array}{l}\text { Tempera- } \\
\text { ture centi- } \\
\text { grade. }\end{array}$ & $\begin{array}{c}\text { Corre- } \\
\text { sponding } \\
\text { degrees } 1 .\end{array}$ & Grams. & $\begin{array}{l}\text { Tempera- } \\
\text { ture centi- } \\
\text { grade. }\end{array}$ & $\begin{array}{c}\text { Corre- } \\
\text { sponding } \\
\text { degrees } 1 .\end{array}$ & Grams. \\
\hline-10 & 14.0 & 0.021 & 13 & 55.4 & 0.113 \\
\hline-8 & 17.6 & 0.027 & 14 & 57.2 & 0.120 \\
\hline-6 & 21.2 & 0.032 & 15 & 59.0 & 0.128 \\
\hline-4 & 24.8 & 0.038 & 16 & 60.8 & 0.136 \\
\hline-2 & 28.4 & 0.044 & 17 & 62.6 & 0.145 \\
\hline 0 & 32.0 & 0.049 & 18 & 64.4 & 0.151 \\
\hline 1 & 33.8 & 0.052 & 19 & 66.2 & 0.162 \\
\hline 2 & 35.6 & 0.056 & 20 & 68.0 & 0.172 \\
\hline 3 & 37.4 & 0.060 & 21 & 69.8 & 0.182 \\
\hline 4 & 39.2 & 0.064 & 22 & 71.6 & 0.193 \\
\hline 5 & 41.0 & 0.068 & 23 & 73.4 & 0.204 \\
\hline 6 & 42.8 & 0.073 & 24 & 75.2 & 0.215 \\
\hline 7 & 44.6 & 0.077 & 25 & 77.0 & $0.2 \div 9$ \\
\hline 8 & 46.4 & 0.081 & 26 & 78.8 & 0.242 \\
\hline 9 & 48.2 & 0.088 & 27 & 80.6 & 0.256 \\
\hline 10 & 50.0 & 0.094 & 28 & 82.4 & 0.270 \\
\hline 11 & 51.8 & 0.100 & 29 & 84.2 & 0.286 \\
\hline 12 & 53.6 & 0.106 & 30 & 86.0 & 0.301 \\
\hline
\end{tabular}

Determination of Relative Humidity by the wet and dry Thermometer Bulbs. 'This instrument, which is known also ats the psyehromoter, consists of a pair of accurate thermoneters on an upright support. The bulb of one is free; that of the other is eovered with at

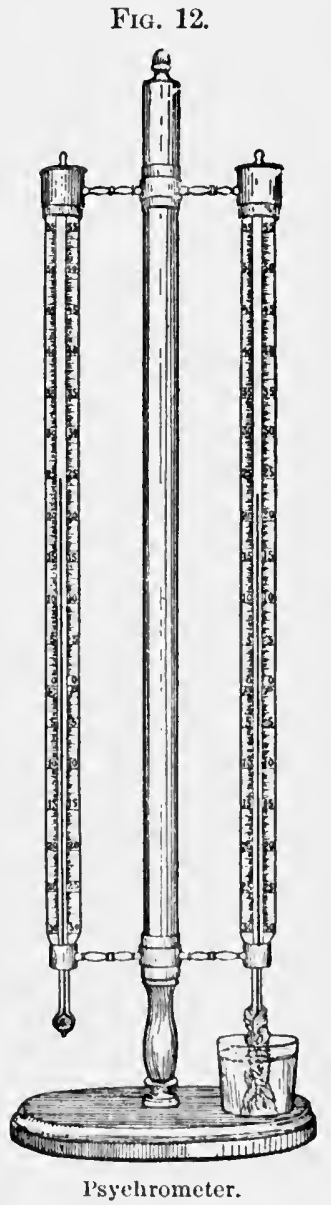


layer of muslin kept moistened by means of a pieee of wicking which dips into a small vessel of water beneath. (See Fig. 12.) In a saturated atmosphere, no evaporation ean oceur from the wet muslin; but in one not saturated, the process goes on with varying rapidity. Evaporation is a process which requires heat and causes a lowering of the temperature of the moist surface; the more rapid its rate, the greater the abstraction of heat. 'The drier the atmosphere, the greater the rate of evaporation, and, therefore, the greater the fall in temperature. If the instrument is placed in a saturated atmosphere, the two thermometers will give the same readings; but in one not saturated, the wet thermometer will fall gradually until the temperature of the surface of its bulb is nearly as low as that of the dew-point; that is, falls to that point at which air at the indicated temperature is so saturated that a farther lowering would be followed by condensation of moisture. As a matter of fact, the wet thermometer does not fall so far in a quiet air, since its bulb becomes surrounded by a layer of stagnant saturated air, and reeeives more or less heat from the surrounding warmer atmosphere. Again, in a saturated atmosphere, the wet thermometer may stand slightly higher than the dry one, owing to the fact that its covering proteets it from loss of heat by radiation.

GLAISHER'S TABLE.

\begin{tabular}{|c|c|c|c|c|c|}
\hline $\begin{array}{l}\text { Reading of } \\
\text { dry bulb } \\
\text { thermometer. }\end{array}$ & Factor. & $\begin{array}{l}\text { Reading of } \\
\text { dry bulb } \\
\text { thermometer. }\end{array}$ & Factor. & $\begin{array}{l}\text { Reading of } \\
\text { dry bulb } \\
\text { thernometer. }\end{array}$ & Factor. \\
\hline $\begin{array}{l}10 \\
11 \\
12 \\
13 \\
14 \\
15 \\
16 \\
17 \\
18 \\
19 \\
20 \\
21 \\
22 \\
23 \\
24 \\
25 \\
26 \\
27 \\
28 \\
29 \\
30 \\
31 \\
32 \\
33 \\
34 \\
35 \\
36 \\
37 \\
38 \\
39 \\
40\end{array}$ & $\begin{array}{l}8.78 \\
8.78 \\
8.78 \\
8.77 \\
8.76 \\
8.75 \\
8.70 \\
8.62 \\
8.50 \\
8.34 \\
8.14 \\
7.88 \\
7.60 \\
7.28 \\
6.92 \\
6.53 \\
6.08 \\
5.61 \\
5.12 \\
4.63 \\
4.15 \\
3.60 \\
3.32 \\
3.01 \\
2.77 \\
2.60 \\
2.50 \\
2.42 \\
2.36 \\
2.32 \\
2.29\end{array}$ & $\begin{array}{l}41 \\
42 \\
43 \\
44 \\
45 \\
46 \\
47 \\
48 \\
49 \\
50 \\
51 \\
52 \\
53 \\
54 \\
55 \\
56 \\
57 \\
58 \\
59 \\
60 \\
61 \\
62 \\
63 \\
64 \\
65 \\
66 \\
67 \\
68 \\
69\end{array}$ & $\begin{array}{l}2.26 \\
2.23 \\
2.20 \\
2.18 \\
2.16 \\
2.14 \\
2.12 \\
2.10 \\
2.08 \\
2.06 \\
2.04 \\
2.02 \\
2.00 \\
1.98 \\
1.96 \\
1.94 \\
1.92 \\
1.90 \\
1.89 \\
1.88 \\
1.87 \\
1.86 \\
1.85 \\
1.83 \\
1.82 \\
1.81 \\
1.80 \\
1.79 \\
1.78 \\
1.77\end{array}$ & $\begin{array}{r}71 \\
72 \\
73 \\
74 \\
75 \\
76 \\
77 \\
78 \\
79 \\
80 \\
81 \\
82 \\
83 \\
84 \\
85 \\
86 \\
87 \\
88 \\
89 \\
90 \\
91 \\
92 \\
93 \\
94 \\
95 \\
96 \\
97 \\
98 \\
99 \\
100\end{array}$ & $\begin{array}{l}1.76 \\
1.75 \\
1.74 \\
1.73 \\
1.72 \\
1.71 \\
1.70 \\
1.69 \\
1.69 \\
1.68 \\
1.68 \\
1.67 \\
1.67 \\
1.66 \\
1.65 \\
1.65 \\
1.64 \\
1.64 \\
1.63 \\
1.63 \\
1.62 \\
1.62 \\
1.61 \\
1.60 \\
1.60 \\
1.59 \\
1.59 \\
1.58 \\
1.58 \\
1.57\end{array}$ \\
\hline
\end{tabular}


For the purpose for which it is intended, the instrument is exposed until the wet thermometer ceases to fall, and then the reading of both is noted. From these data, with the assistance of Glaisher's factors (see table on page 300 ), the dew-point is easily calculated in the following manner: Multiply the difference in the two readings by the factor opposite the figure in the table corresponding to the temperature of the dry bulb, and subtract the product from this temperature.

TABLE OF TENSIONS.

\begin{tabular}{|c|c|c|c|c|c|c|c|}
\hline $\begin{array}{c}\text { Tempera- } \\
\text { ture. } \\
\text { Fahrenheit. }\end{array}$ & $\begin{array}{l}\text { Corre- } \\
\text { sponding } \\
\text { degrees } \mathrm{C} .\end{array}$ & $\begin{array}{l}\text { Tension } \\
\text { in inches of } \\
\text { mercury. }\end{array}$ & $\begin{array}{l}\text { Tension } \\
\text { in mm. }\end{array}$ & $\begin{array}{c}\text { Tempera- } \\
\text { ture. } \\
\text { Fahrenheit. }\end{array}$ & $\begin{array}{c}\text { Corre- } \\
\text { sponding } \\
\text { degrees } \mathrm{C} .\end{array}$ & $\begin{array}{l}\text { Tension } \\
\text { in inches of } \\
\text { mercury: }\end{array}$ & $\begin{array}{l}\text { Tension } \\
\text { in mm. }\end{array}$ \\
\hline $1^{\circ}$ & $-17.2^{\circ}$ & 0.046 & 1.17 & $51^{\circ}$ & $10.6^{\circ}$ & 0.374 & 9.50 \\
\hline 2 & -16.7 & 0.048 & 1.22 & 52 & 11.1 & 0.388 & 9.86 \\
\hline 3 & -16.1 & 0.05 & 1.27 & 53 & 11.7 & 0.403 & 10.24 \\
\hline 4 & -15.6 & 0.052 & 1.32 & 54 & 12.2 & 0.418 & 10.62 \\
\hline 5 & -15.0 & 0.054 & 1.37 & 55 & 12.8 & 0.433 & 11.00 \\
\hline 6 & -14.4 & 0.057 & 1.45 & 56 & 13.3 & 0.449 & 11.40 \\
\hline 7 & -13.9 & 0.060 & 1.52 & 57 & 13.9 & 0.465 & 11.81 \\
\hline 8 & -13.3 & 0.062 & 1.57 & 58 & 14.4 & 0.482 & 12.24 \\
\hline 9 & -12.8 & 0.065 & 1.65 & 59 & 15.0 & 0.500 & 12.70 \\
\hline 10 & -12.2 & 0.068 & 1.73 & 60 & 15.6 & 0.518 & 13.16 \\
\hline 11 & -11.7 & 0.071 & 1.80 & 61 & 16.1 & 0.537 & 13.64 \\
\hline 12 & -11.1 & 0.074 & 1.88 & 62 & 16.7 & 0.556 & 14.12 \\
\hline 13 & -10.6 & 0.078 & 1.98 & 63 & 17.2 & 0.576 & 14.63 \\
\hline 14 & -10.0 & 0.082 & 2.08 & 64 & 17.8 & 0.596 & 15.14 \\
\hline 15 & -9.4 & 0.086 & 2.18 & 65 & 18.3 & 0.617 & 15.67 \\
\hline 16 & -8.9 & 0.090 & 2.28 & 66 & 18.9 。 & 0.639 & 16.23 \\
\hline 17 & -8.3 & 0.094 & 2.38 & 67 & 19.4 & 0.661 & 16.79 \\
\hline 18 & -7.8 & 0.098 & 2.49 & 68 & 20.0 & 0.684 & 17.37 \\
\hline 19 & -7.2 & 0.103 & 2.62 & 69 & 20.6 & 0.708 & 17.98 \\
\hline 20 & -6.7 & 0.108 & 2.74 & 70 & 21.1 & 0.733 & 18.62 \\
\hline 21 & -. 6.1 & 0.113 & 2.87 & 71 & 21.7 & 0.759 & 19.28 \\
\hline 22 & -5.6 & 0.118 & 3.00 & 72 & 22.2 & 0.785 & 19.94 \\
\hline 23 & -5.0 & 0.123 & 3.12 & 73 & 22.8 & 0.812 & 20.62 \\
\hline 24 & -4.4 & 0.129 & 3.28 & 74 & 23.3 & 0.840 & 21.34 \\
\hline 25 & -3.9 & 0.135 & 3.43 & 75 & 23.9 & 0.868 & 22.05 \\
\hline 26 & -3.3 & 0.141 & 3.58 & 76 & 24.4 & 0.897 & 22.78 \\
\hline 27 & -2.8 & 0.147 & 3.73 & 77 & 25.0 & 0.927 & 23.55 \\
\hline 28 & -2.2 & 0.153 & 3.89 & 78 & 25.6 & 0.958 & 24.33 \\
\hline 29 & -1.7 & 0.160 & 4.06 & 79 & 26.1 & 0.990 & 25.15 \\
\hline 30 & -1.1 & 0.167 & 4.24 & 80 & 26.7 & 1.023 & 25.98 \\
\hline 31 & -0.6 & 0.174 & 4.41 & 81 & 27.2 & 1.057 & 26.85 \\
\hline 32 & -0.0 & 0.181 & 4.60 & 82 & 27.8 & 1.092 & 27.74 \\
\hline 33 & +0.6 & 0.188 & 4.78 & 83 & 28.3 & 1.128 & 28.65 \\
\hline 34 & 1.1 & 0.196 & 4.98 & 84 & 28.9 & 1.165 & 29.59 \\
\hline 35 & 1.7 & 0.204 & 5.18 & 85 & 29.4 & 1.203 & 30.55 \\
\hline 36 & 2.2 & 0.212 & 5.38 & 86 & 30.0 & 1.242 & 31.55 \\
\hline 37 & 2.8 & 0.220 & 5.58 & 87 & 30.6 & 1.282 & 33.56 \\
\hline 38 & 3.3 & 0.229 & 5.82 & 88 & 31.1 & 1.323 & 33.60 \\
\hline 39 & 3.9 & 0.238 & 6.04 & 89 & 31.7 & 1.366 & 34.69 \\
\hline 40 & 4.4 & 0.247 & 6.27 & 90 & 32.2 & 1.410 & 35.81 \\
\hline 41 & 5.0 & 0.257 & 6.53 & 91 & 32.8 & 1.455 & 36.95 \\
\hline 42 & 5.6 & 0.267 & 6.78 & 92 & 33.3 & 1.501 & 38.12 \\
\hline 43 & 6.1 & 0.277 & 7.04 & 93 & 33.9 & 1.548 & 39.31 \\
\hline 44 & 6.7 & 0.288 & 7.32 & 94 & 34.4 & 1.596 & 40.53 \\
\hline 45 & 7.2 & 0.299 & 7.59 & 95 & 35.0 & 1.646 & 41.80 \\
\hline 46 & 7.8 & 0.311 & 7.90 & 96 & 35. 6 & 1.697 & 43.09 \\
\hline 47 & 8.3 & 0.323 & 8.20 & 97 & 36.1 & 1.749 & 44.42 \\
\hline 48 & 8.9 & 0.335 & 8.51 & 98 & 36.7 & 1.802 & 45.77 \\
\hline 49 & 9.4 & 0.348 & 8.84 & 99 & 37.2 & 1.856 & 47.14 \\
\hline 50 & 10.0 & 0.361 & 9.17 & 100 & 37.8 & 1.911 & 48.54 \\
\hline
\end{tabular}


Having now deternined the dew-point, the next step is to aseertain the elastic tension of the vapor puesent in the air, that is, the tension of the dew-point, and the tension of that necessary for saturation at the temperature of the dry bulb, which data cau be obtained by reference to the table on pagre 255 .

from these several data the relative humidity is caleulated as follows: I )ivide the tension of the dew-point by that of saturation at the actual temperature, and multiply by 100.

liximple:

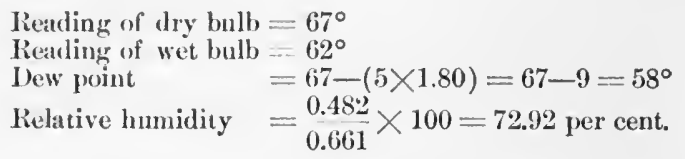

More aecurate determination may be made by employing the "whirled" or "sling" thermometers. These are fastened to a string of such a length that the distanee from the bulbs to the held end is exactly a meter. In use, they are whirled in a horizontal plane 100 times at the rate of one revolution per second. By their use, the

FIg. 13.

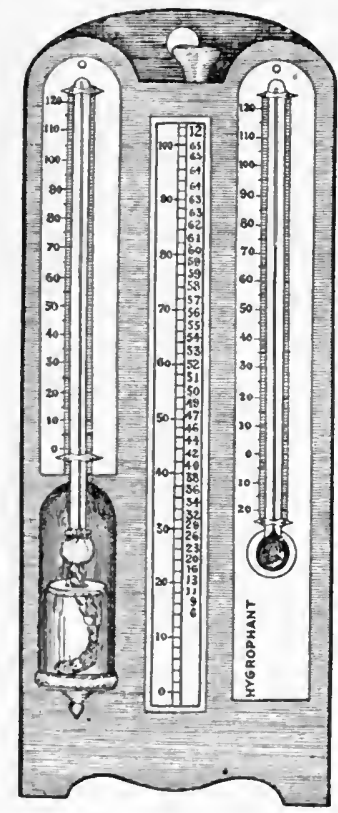

Ifygrophant. errors mentioned as likely to oceur when the observations are made in still air are eliminated. For all practical purposes, the use of the thernometers in the ordinary way gives suffieiently aeeurate results.

In making determinations out of doors when the temperature is below the freezingpoint, the wick may be dispensed with, and the bulb is then wetted by dipping it into water, the exeess being removed by means of filter-paper or common blotting-paper, or water may be applied with a camel's-laair pencil. Below the freezing-point, however, the relative humidity is of little hygienie interest, sinee the anount of moisture which air then ean eontain is but slight.

A very convenient instrument for quick approximate determinations without the necessity of tables and eomputation is known as the hrgrophant of Winlock and Huldleston. It consists of a pair of thermoneters and a cylinder, upon which is inscribel a series of 22 columns of figures numbereel from 1 to 22 , any one of which may, ly at turn of a knob, be brought into apposition with a fixed scale on the asing. (See Fig. 13.) To ascertain the relative humidity, note the difference in the readings of the themometers, turn the cylinder, mutil the column liaving at its top the number corresponding to the difference appears ofposite the seale, 
and read the figures opposite the number corresponding to the temperature of the wet bulb.

Example :

$$
\begin{aligned}
& \text { Reading of dry bulb }=72^{\circ} \\
& \text { Reading of wet bulb }=60^{\circ} \\
& \text { Difference } \\
& =12^{\circ}
\end{aligned}
$$

The cylindor is turned until colum 12 appears. Opposite 60 of the seale, the reading is 46 ; and this is approximately the pereentage of saturation present.

Determination of Carbon Dioxide.-For the collection of samples of air for this determination, it is well to provide a number of bottles of about a gallon capacity. These should, first of all, be measured very carefully. This mav be done by filling them with ice water and noting the number of ec. required, or by determining by means of platform seales sensitive to 5 grams the difference between their weights empty and filled. It is well to place a distinguishing number and the figures denoting its eapacity on each bottle, either on a label, or, better, by means of a writing diamond. When used, the bottle should be perfectly elean and dry.

When it is necessary to employ the same bottle again, time being an object, the drying process is lastened very much by washing first with water, then with a little aleohol to remove the small amount of water which will not drain away, and, finally, with a little ether for the removal of the resiluun of alcohol. The small amount of adherent ether may then be removed by blowing a current of air into the bottle by means of a bellows. A number of tightly fitting rubber caps should be provided in place of corks or rubber stoppers, though if these are not at hand, the latter may be nsed; but note should be made of the volume of air which they displace when they are inserted.

Solutions Required.-1. Solution of BARIUM HYblite.-Dissolve about 4.5 grams of barium hydrate and 0.5 of batrium chloride in a liter of distilled water which previonsly has been boiled, in order to expel any earbon dioxide which it may contain. It is well to prepare an amount sufficient for future needs, say 4 liters, and to kecp it in a bottle such as is shown in Fig. 14. This is provided with a rubber stopper with two perforations, through one of which a bent tube, reaching to the botton, and intended for withdrawal of the reagent, is inserted. Through the other is carried a tube extending only into the neek, and communicating at its onter extremity with FIG. 14.

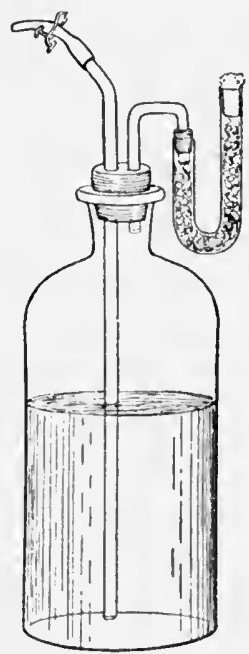

Bottlo for barium ligilate. a U-tulse filled with picees of pumice soniked while hot in a strong solution of caustic potash. The delivery tube carries at its outer 
end a piece of closely fitting rubber tubing, which is kept closed by means of a pincheock.

In withdrawing the reagent for use, a $100 \mathrm{cc}$. pipette is inserted into the free end of the rubber tube, suction is applied, and the pincheock is opened. When the pipette is filled to the mark, the pressure is removed from the pincheock and the pipette released. As the reagent is withdrawn, air flows in through the other opening, and is robbed of its carbon dioxide by contact with the caustic potash with which the pumice has been chiarged. This reagent is used for the absorption of the carbon dioxide eontained in the sample of air under examination. The reaction is expressed by the following formula:

$$
\mathrm{BaO}_{2} \mathrm{H}_{2}+\mathrm{CO}_{2}=\mathrm{BaCO}_{3}+\mathrm{H}_{2} \mathrm{O} \text {. }
$$

The function of the barium chloride is explained below.

2. Standand Solution of Oxalic ACID.-Dissolve 2.808 grams of pure oxalic acid in a liter of distilled water. One ec. of this solution is equivalent to 0.5 ce. of carbon dioxide; that is to say, will neutralize the same amount of barium hydrate as will combine with carbon dioxide to form barium carbonate.

3. Solution of Phenolphthalein.-Dissolve 0.5 gram of phenolphthalein in $100 \mathrm{ec}$. of alcohol. This solution is used as an "indicator" of alkalinity.

Process of Analysis.- The process of analysis depends upon the fact that when a volume of the barium hydrate solution is brought into contact with carbon dioxide, its alkalinity is diminished by the formation of barium earbonate, which is a neutral body. The greater the amount of earbon dioxide to which it is exposed, the greater will be the reduction of its alkaline strength. A preliminary determination of the amount of oxalic acid solution which $100 \mathrm{ce}$. of the reagent will neutralize is made by titrating $25 \mathrm{cc}$. contained in an Erlenmeyer flask and colored by means of a few drops of the phenolphthalein solution, and multiplying the result by 4 . After the reagent has been subjected to the influence of the gas in the air sample, a similar determination is made. The difference between the two results, divided by 2 , indicates the number of ce. of carbon dioxide present in the amount of air employed.

The sample of air is obtained in the following manner: One of the bottles above mentioned is placed in the situation from which the air is to be obtained, and its air content is displaced by means of a bellows provided at its outlet with a rubber tube of sufficient length to reach nearly or quite to the bottom. A half minute's pumping is sufficient to insure that the original air is replaced by that under observation. One is sometimes admonished to be careful not to breathe in the direction of the mouth of the bottle, but this is an unnecessary precaution, since the current issuing from the bottle is much too powerful to admit of the entrance of any air except that propelled by the bellows. A much more and very necessary precatution to be observed is that the operator shall not allow his breath to reach the inlet holes of the bel- 
lows. After a half minute's pumping, the rubber cap is affixed, and the bottle may then be carried to the laboratory, or, better, the treatment of the contained air may be proceded with on the spot. Another method of collecting the sample is often recommended in place of the one deseribed. It consists in filling the bottle with water and emptying it where the air is to be taken. By this process, the space originally oceupied by water is filled with air, but the method is objectionable in that the water cannot drain away completely, and that that which remains serves to dilute, slightly it is true, the charge of barium hydrate next to be introduced, and thus brings in an error at the very ontset.

Next, 100 ce. of the barium hydrate solution are introdueed by drawing aside the edge of the rubber cap and inserting, into the opening so made, the point of the filled pipette, and allowing its contents to flow unaided into the bottle. The beginner will often incline inadvertently to gain time, and assist the emptying of the pipette, by blowing into it, thereby vitiating his results with the impurities of his own respiration. As soon as the pipette is emptied, it is withdrawn and the edge of the cap is replaced. The bottle is then shaken thoroughly for about ten minutes, care being observed not to wet the eap, since in that event some of the reagent may escape by capillary attraction. At the end of that time it may be assumed that all of the contained carbon dioxide has been brought into eontact with and absorbed by the barium hydrate, which is then to be poured quickly from the bottle through a fairly large funnel into a glass-stoppered bottle of rather more than 100 ec. capacity. The solution, which is now more or less turbid from the presence of barium earbonate, is allowed to stand until, through settling of this substance, the supernatant liquid is clear. Three successive portions of $25 \mathrm{cc}$. each are next to be withdrawn by means of a pipette of the proper size, and, after addition of the indicator, titrated in Erlenmeyer flasks with the standard oxalic acid solution until the pink color eaused by the former is made to disappear. So long as any color remains, one knows that barium still exists in the form of hydrate, and that the contents of the flask are still alkaline, for phenolphthalein gives a pink tinge only in the presence of the alkalies. When the pink color disappears, the process is finished, and the reading of the burette is noted. The three portions of $25 \mathrm{cc}$. each are titrited in turn, and the mean of the results is multiplied by 4 . The difference between this product and the figure obtained in the preliminary test of the strength of the reagent, divided by 2 , indicates the number of ce. of carbon dioxide in the volume of air taken for analysis.

In filling the 25 cc. pipette from the bottle containing the used reagent, great eare should be observerl not to stir up the sediment of barium earbonate. To perform the operation properly, it is necessary to insert the point of the pipette well below the surface, and to fill it up to the mark, or just beyond it, by one uninterrupted act of suction. If one stops to regain breath, part of the liquid already within the 
pipette will escape downward during the interval with sufficient force to stir up the sediment. When the pipette is filled, the point of the tongue should be applied to its uppere end, and the tip shonld then be withdrawn from the bottle. Then by placing the end of the foretinger over the opening of the tip of the pipette, the escape of its contents is preventerl, while the forefinger of the other hand is replacing the point of the tongue. The reason for such careful avoidance of stirring up the sediment is that the presence of barium earbonate introduces a slight crror in the titration. The slight excess of oxalic acid present when the eolor of the phenolphthalein is discharged attacks the suspenderl barium calbonate, forming barium oxalate and setting free the conbined carbon dioxide. Thus:

$$
\mathrm{H}_{2} \mathrm{C}_{2} \mathrm{O}_{4}+\mathrm{BaCO}_{3}=\mathrm{BaC}_{2} \mathrm{O}_{4}+\mathrm{H}_{2} \mathrm{O}+\mathrm{CO}_{2} \text {. }
$$

The free carbon dicxide then attacks more of the carbonate and forms barium bicarbonate, which, being soluble and of alkaline reaction, causes the pink color to reappear.<smiles>O=C(O)C=C(C(=O)O)C(=O)O</smiles>

The reason for adding barium chloride in making the barium lyydrate solution is that most barium hydrate contains, in addition to small amounts of carbonate, traces either of canstic soda or of caustic potash. When either of these substances is brought into contact with birium chloride, mutual deeomposition oceurs, and we have as 'results barim hydrate and sodium (or potassium) cliloride. If the impurity were disregarded, it would canse errors, as shown below. The barium hychate solution when titrated with oxalic acid would behave aceording to the following formula :

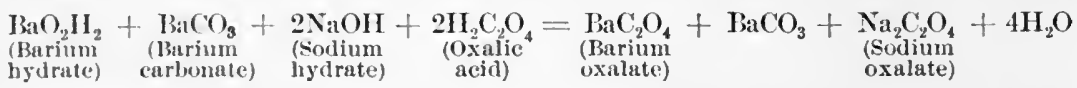

In practice a very slight excess of oxalic acid is also present, and the reaction then proceeds still farther. The sodium oxalate attatcks the barium carbonate, forming barium oxalate and sodium carbonate. Thus

$$
\mathrm{Na}_{2} \mathrm{C}_{2} \mathrm{O}_{4}+\mathrm{BaCO}_{3}=\mathrm{BaC}_{2} \mathrm{O}_{4}+\mathrm{Na}_{2} \mathrm{CO}_{3} \text {. }
$$

Next, the sodium carbonate nentralizes the traces of fice oxalie acid, and any supplus canses a reappearance of the pink color and necessitates farther aldition of oxalie acil. This caluses the formation of more solium oxalate, which in its turn attacks another portion of the harinm carbonate, with the same results as before; and so the eyele continues until the last trace of suspended carbonate is decomposed. If the hydrate contains no impurities, the addition of chloride is unnecessiary. 
Corrections.-In figuring the results of the determination, certain corrections are necessilry. First, the volume of the barium liydrate used (100 ce.) must be subtraeted from the capacity of the bottle, sinee its introduction displaces an equal volume of air ; and next, allowances nutust be made for any departure from standard temperature and barometric pressure, since the eapacity of the sample bottle is reckoned for air at $0^{\circ} \mathrm{C}$. and $760 \mathrm{~mm}$. pressure. In order to make the neeessary correetions for temperature and pressure, the thermometer and barometer should be noted at the time of taking the sample.

In determining the amount of correetion, we are guided by two physical laws : that for each degree of temperature, air expands a constant fraction of its own volume (Law of Charles); and that the volume of a gas is inversely proportionate to the pressure (Law of Boyle). For each degree eentigrade above or below $0^{\circ} \mathrm{C}$, air expands or contracts 0.0036648 of its volume; and this figure is known as the eoefficient of expansion for centigrade degrees. For each degree Fahrenheit above or below $32^{\circ}$, air expands or contrats 0.002036 of its volume; and this is known as the coefficient of expansion for Fahrenheit degrees. Thus, 1 liter of air, heated to $40^{\circ} \mathrm{C}$., will expand to $1+(40 \times 0.0036648)$, which equals 1.146592 liters; or heated to $104^{\circ} \mathrm{F} .\left(104^{\circ} \mathrm{F} .=40^{\circ} \mathrm{C}.\right)$, it will expand to $1+(72 \times 0.002036)$, which equals 1.146492, as before. Again, the same volume cooled to $-15^{\circ} \mathrm{C}$., will contract to $1-(15 \times 0.0036648)$, or 945 ec. ; or cooled to $5^{\circ} \mathrm{F} .\left(5^{\circ} \mathrm{F} .=15^{\circ} \mathrm{C}\right.$. $)$, it will become $1-(27 \times 0.002036)$ or 945 ce., as before. So an apparent volume of 1,000 ec. at any temperature above freezing is in reality a smaller volume expanded to that size; and at ally temperature below, is a larger volume brought to that size by contraction.

To correet volume for temperature, we must divide the apparent volume by 1 plus the produet of 0.0036648 times the number of degrees away from $0^{\circ} \mathrm{C}$, , or in case of temperatures below freezing, by 1 minus that amount. If the Fahrenheit scale is used, the appropriate coefficient and fictors must be substituted. Thus we maly employ a set of formulie as follows:

$$
\begin{aligned}
& \text { For temperatures above } 0^{\circ} \mathrm{C} . . . V=\frac{V^{\prime}}{1+0.0036648 . t^{\circ} \mathrm{C} .} \\
& \text { For temperatures below } 0^{\circ} \mathrm{C} . . . V=\frac{V^{\prime}}{1-0.0036648 . t^{\circ} \mathrm{C} .} \\
& \text { For temperatures above } 32^{\circ} \mathrm{F} . . . V=\frac{V^{\prime}}{1+0.002036\left(t^{\circ} \mathrm{F}-32\right)} \\
& \text { For temperatures below } 32^{\circ} \mathrm{F} . . \cdot V=\frac{V^{\prime}}{1-0.002036\left(32-t^{\circ} \mathrm{F} .\right)}
\end{aligned}
$$

In the above, $\mathrm{I}^{r}=$ eorrect volume.

$$
V^{\prime \prime}=\text { apparent volume. }
$$

Inasmuch as volume is inversely proportionate to pressure, the true volume at any observed pressure is obtained by multiplying the apparent volume by the barometric pressure expresised in millimeters 
or inches, and dividing the product by 760 or by 29.92 , as the ease may be. We may use, then, this formula:

$$
V=\frac{V^{\prime} \times B}{760}
$$

Applying it, we find that an apparent volume of 1,000 ce. at $750 \mathrm{~mm}$. becomes

$$
\frac{1,000 \times 750}{760}=987 \mathrm{cc} .
$$

or using the other scale, the barometer standing at 29.53 inches $(29.53$ in., $750 \mathrm{~mm}$.), it becomes

$$
\frac{1,000 \times 29.53}{29.92}=987 \mathrm{cc} .
$$

If the barometer reads higher than the standard pressure, the true volume will be greater than the apparent. Thus, suppose the pressure to be 30.22 inehes, then 1,000 ce. will represent

$$
\frac{1,000 \times 30.22}{29.92}=1,010 \mathrm{cc} \text {. }
$$

Instead of going through two separate calculations, we may make both corrections at once by means of one formula which is a combination of the two kinds already used. For temperatures above $0^{\circ} \mathrm{C}$. the correct volume is obtained by means of the following:

$$
V=\frac{V^{\prime} \times B}{\left(1+0.0036648 . t^{\circ}\right) 760} .
$$

By changing the plus sign to minus, the formula is adapted to temperatures below freezing. If the Fahrenheit thermometer is used, and the barometrie pressure is expressed in inches, the formula is as follows :

$$
V=\frac{V^{\prime} \times B}{\left[1+0.002030\left(t^{\circ} \mathrm{F}-32\right)\right] 29.92} .
$$

and if the temperature is below $32^{\circ}$, it must be ehanged to

In these formulx :

$$
V=\frac{V^{\prime} \times B}{\left[1-0.002036\left(32-t^{\circ} \text { F.) }\right) 29.92\right.}
$$

$V=$ eorrect volume.

$V^{\prime}=$ apparent volume.

$B=$ barometric pressure.

$t^{\circ}=$ temperature.

In order to avoid the tedious process of multiplication and division which the working of these formulæ involves, recourse may be had to the admirable tables of Dr. Walter Hesse, ${ }^{1}$ wherein can be found the correction to be made for all temperatures between $-2^{\circ}$ and $30^{\circ} \mathrm{C}$. and for all pressures between 680 and $770 \mathrm{~mm}$., by simple reference to the proper column.

1 Tabellen zur Reduction eines Gasvolumens auf $0^{\circ}$ und $760 \mathrm{~mm}$. Brunswick, 1879 . 
For all practical purposes, the eoefficients of expansion may be shortened to 0.00366 and 0.002 , thus avoiding much figuring which has very little influence on the end results.

Example of Method of Reckoning $\mathbf{C O}_{2}$ - Capacity of sample bottle, 3,885 ce. 25 ec. of barium hydrate solution require $21 \mathrm{ce}$. of standard solution of oxalic aeid, henee $100 \mathrm{cc} .=84 \mathrm{ce}$. After contact, $25 \mathrm{ce}$. require $17.2 \mathrm{ec.} \mathrm{;} 100 \mathrm{ec}$. require $68.8 \mathrm{ec}$.

Difference in oxalie acid required $=84-68.8=15.2 \mathrm{ec}$.

1 ec. of oxalie acid solution $=0.5$ ce. of $\mathrm{CO}_{2}$; henee, $15.2 \mathrm{ec} .=7.6$ cc. of $\mathrm{CO}_{2}$.

The air in the bottle contained, therefore, 7.6 ec. of $\mathrm{CO}_{2}$.

Determination of volume of air taken :

$$
\begin{array}{ll}
\text { Capacity of bottle } & =3,885 \\
\text { Amount of barium solution } & =100 \\
\text { Apparent volume of air } & =3,785 \\
\text { Observed barometric pressure } & =29.60 \text { inches. } \\
\text { Observed temperature } & =65^{\circ} \mathrm{F} . \\
V=\frac{112,036}{[1+(0.002036 \times 29.60} & =\frac{112,036}{31.93}= \\
3,509 \text { cc. }=\text { actual air volume examined. }
\end{array}
$$

Then 3,509 ec. of air contain $7.6 \mathrm{cc}$. of $\mathrm{CO}_{2}$. It being customary to express results in parts per 10,000, this rate is determined as follows :

$$
3,509: 7.6=10,000: x \quad x=21.66 \text {. }
$$

Hence the air eontains 21.66 volumes of $\mathrm{CO}_{2}$ in 10,000 .

Determination of $\mathrm{CO}_{2}$ by Wolpert's Method.-This process is designed for what may be ealled roughly approximate work in testing the air of school rooms and similarly erowded spaces. It requires no ehemical training on the part of the operator, and for practical purposes gives fairly satisfactory results, indicating that the air is good, fair, poor, or very bad. The apparatus consists of a graduated glass eylinder with a movable piston reaching to the bottom and kept in proper position by a metallie eap, through the center of which the shaft protrudes. The shaft is a glass tube of narrow caliber, open at both ends. The reagent used is a standard solution of alkali, eolored with phenolphthalein.

In making a test, the piston is removed and 2 ec. of the solution are introduced into the eylinder by means of a pipette. The piston is replaced and pressed down until all air is expelled through the shaft and the liquid appears within the bore. The piston is then drawn up until its lower edge is opposite the first mark, and in the process the space so made is filled with air which enters through the shaft. The apparatus is now shaken vigorously for one minute. If the liquid beeomes colorless, it is proof that the air of the room is bad. If, on the other hand, the color persists, the piston is raised to the next graduation, and the shaking is renewed for another minute. If the reagent still retains color, the piston is raised further and more air is admitted. The proeess is continued until repeated additions of air and renewed 
shakings cause the color to be discharged. At this point, the reading of the scale indieates the character of the air. The greater the amount of air required for eomplete decolorization, the less the relative amount of impurity. The apparatus is shown in Fig. 15.

Determination by Fitz's Method.-A modification of this process, giving results which are in close angrement with parallel analyses by the Pettenkofer method above deseribed, has been devised by Dr. G. W. Fitz. ${ }^{1}$ 'The alpparatus is very simple, and eonsists of a small cylinder of glass with a rounded bottom, and a smaller open one

Fra. 15. which slips into the other through a collar of rubber tubing

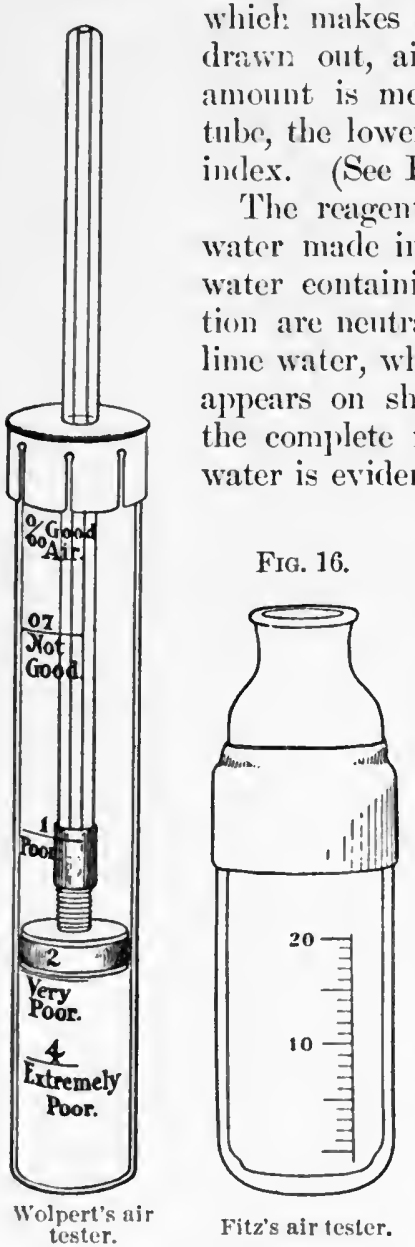
which makes a tight joint. As the inner cylinder is drawiz out, air enters through its upper end, and its monnt is measured by the graduations on the outer tube, the lower margin of the inner tube serving as an inlex. (See Fing. 16.)

The reagent used is a 1 per cent. solution of lime water made in the following manner. About $95 \mathrm{cc}$. of water eontaining a few drops of phenolphthalein solution are neutralized by the addition, drop by drop, of lime water, which canses a pink color that at first disappears on shaking. As soon as a faint tinge persists, the complete neutralization of the carbon dioxide of the water is evident. One cc. of saturated lime water is next added, and the whole is then made up to $100 \mathrm{cc}$. The solution shonld be made as needed, since it retains its full strength but about twelve hours.

In making a test, $10 \mathrm{cc}$. are introduced into the outer cylinder; the immer one is inserted as far as it will go and then raised to the 10 ee. mark on the seale, which means the presence of $20 \mathrm{cc}$. of air, since the tube itself contains $10 \mathrm{ec}$. The apparatus is then elosed by applying the end of the forefinger, and shaken vigorously thirty times. If the pink color persists, the inner eylinder is pushed to the bottom and then drawn up again, and the operation is repeated until the color disappears. At this point, the amount of air used is noted, and by reference to a table, the number of parts per 10,000 is ascertained. ${ }^{2}$ Dr. Fitz asserts that, in the hands of an ordinarily careful man, the process is aecurate within 1 part of $\mathrm{CO}_{2}$ in 10,000 .

\footnotetext{
1 Journal of the Massachusetts Association of Boards of Health IX., p. 5.

${ }^{2}$ The apparatus and complete directions for use are obtainable of the Knott Apparatus Company, Boston.
} 
This is substantiated by Professor L. P. Kinnicutt, ${ }^{1}$ of the Worcester Polytechnic Institute, who has employed the process himself and controlled its use by others with parallel analyses by the Pettenkofer method.

Determination of Carbon Monoxide.-While a number of processes have been devised for the deteetion and determination of earbon monoxide, none has been discovered as yet that is wholly satisfactory for other than qualitative work. The gas may be detected qualititively by exposing water eontaining a small amount of fresh normal blood to the air under examination, and then examining the same with the spectroscope. If no carbon monoxide is present in the air, the chanacteristic absorption bands of oxyhemoglobin, shown by the spectroseope, are changed to a single band in the space between on the addition of a reducing agent, such as ammonium sulphide. If, however, the gas is present, no ehange ocenrs.

The test is applied in the following manner: $\Lambda$ few drops of blood well diluted with water are exposed to the air in a jar, and brought into intimate contact by vigorous shaking. A few drops of ammonium sulphide are next added, and the mixture is again well shaken. If on spectroscopic examination but a single band is observed, the absence of the gas in amount equal to 3 parts per 10,000 may be inferred, for this is the limit of delicacy claimed. If, however, the eharacteristic two bands of oxyhemoglobin appear, the presenee of the impurity to that extent is proved, since otherwise the reagent wonld have exerted its normal effect.

The following process, devised by Fodor, ${ }^{2}$ is said to be of sufficient delicacy to detect 1 part in 20,000 . Fresh defibrinated bood is mixed with 10 volumes of water and introduced into a large jar eontaining the suspected air. After being allowed to stand for about an hour without shaking, it is transferred to a small flask provided with a rubber stopper earrying two glass tubes, one of which dips beneath the surface and connects at its outer end with a potash bulb eontaining palladinm ehloride solution. The other tube serves as an ontlet, and is connected with a series of three potash bulbs containing respectively learl acetate solution, dilute sulphurie acid, and palladium chloride so diluted that it has a bright-yellow color. The terminal bulb is connected with an aspirator, which, when set in action, draws a current of air throngh the five different picees. The flask eontaining the blood is heated on a water-bath for fifteen to thirty minutes with oceasional shaking, and meanwhile a slow current of air is drawn through the apparatus. When the blood begins to change eolor, the earboxyhamoglobin deemposes and yields its $\mathrm{CO}$, which reduces the palladium contained in the terminal bulb. The chloride of palladium in the first bull, is used for removing any traces of the gas and of other redncing agents in the aspirated air. At the close of the operation, if the blood contained CO, the palladinm chloride in the terminal bulb shows

1 Loco citato, P. 8.

${ }^{2}$ Deutsche Vierteljahrssch rift für öflentliche Gesundheitsplleger, Vo'. 12. 
a precipitate of rednced palladium and the liquid has a somewhat darker tint. The lead acetate and dilute sulphuric acid serve to remove any traces of sulphuretted hydrogen and ammonia, both of which substances will eanse precipitation of the palladium.

Other qualitative tests of greater or less delieacy include the following:

1. Mix 5 ce. of exposed blood solution and 15 ce. of a 1 per cent. solution of tannic acid. The resulting precipitate, which settles very slowly, has a brownish-red color, if $\mathrm{CO}$ was present in the air ; otherwise it is grayish-brown.

2. Mix 10 ec. of the blood solution with 5 ec. of a 20 per cent. solution of potassium ferrocyanide and $1 \mathrm{cc}$. of acetic acid (1 part of glacial acetic acid to 2 of water). A reddish-brown precipitate is indieative of the presence of the gas, and one of grayish-brown shows its absence.

3. Bring together on a poreelain plate 1 drop each of exposed defibrinated blood and sodium hydrate solution of a specific gravity of 1.300. With CO blood, the color is bright red, while with normal blood it is brownish or blaekish.

4. In place of the above reagent, use a mixture of 1 part of the same with 3 of calcium chloride solution. $\mathrm{CO}$ blood gives a carmine, and normal blood a light-brown or brownish-red, eolor.

5. Draw air through a tube containing a solution of cuprous chloride, which, in the presence of $\mathrm{CO}$, deposits a characteristic precipitate, which, aceording Berthelot, is $\mathrm{Cu}_{2} \mathrm{Cl}_{2} \mathrm{CO} .2 \mathrm{H}_{2} \mathrm{O}$.

Quantitative Determination.- Nicloux ${ }^{1}$ has devised a colorimetric method for which he claims great accuracy. It is based upon the fact that, by the action of earbon monoxide on iodic acid, definite amounts of iodine are set free. He combines this with an alkali, acidulates and shakes out with ehlorform or carbon disulphide, and then compares the color with solutions containing known amounts of iodine. From the amount of iodine, the amount of $\mathrm{CO}$ which eansed its liberation may be reekoned.

Gautier ${ }^{2}$ allows the liberated iodine to act upon copper foil, and determines the amount of $\mathrm{CO}$ from the inerease in weight. He also determines the $\mathrm{CO}_{2}$ produced by the action of iodine pentoxide on $\mathrm{CO}$; the result indicates volume for volume. Potain and Drouin ${ }^{3}$ recommend a colorimetric method by means of dilute palladium chloride solution.

Determination of Ozone.-The allotropic form of oxygen acts upon potassium iodide in the presence of moisture and eonverts it to hydrate, with liberation of iodine, aceording to the following formula:

$$
2 \mathrm{KI}+\mathrm{H}_{2} \mathrm{O}+\mathrm{O}_{3}=2 \mathrm{KOH}+\mathrm{O}_{2}+\mathrm{I}_{2} \text {. }
$$

This reaction is the basis of most of the proeesses which have been proposed for qualitative and quantitative determination, none of which may be regarded as of value, since there are many sources of error to

I Comptes rendus, CXXVI., p. 746.

${ }^{2}$ Ibidem, CXXVI,. pp. 871, 931, 973.

s Ibidem, p. 938. 
be taken into account, sources impossible to eliminate and of importance impossible to compute.

The presence of ozone in the air is supposed to be demonstrated when, on exposure of paper saturated with starch paste containing potassium iodide, a blue color gradually develops, owing to the action of the liberated iodine on the stareh. Quantitative determinations are made by comparing the tint with a standard scale, the depth of color being dependent upon the amount of iodine liberated, and this upon the amount of ozone prescnt. The papers are prepared in the following manner: From 2.5 to 10 grams of starch are taken, according to the recommendations followed, and, after trituration witk' a small amount of eold water, are boiled for about ten minutes in about 200 ce. of water, and filtered. One gram of potassium iodide in solution is next added gradually with constant stirring. Strips of stout filter-paper, wet with distilled water, are soaked in the starch preparation until they are thoroughly impregnated (about two to four hours), then removed with the aid of forceps, spread flat, and dried in the dark. When used, they are hung up out of the direct sunlight and exposed for a definite time, then removed, moistened with water, and compared with the scale. The objections to the process are that a number of other substanees which may be in the air, such as certain volatile organic acids, chlorine, nitrous acid, and hydrogen peroxide, canse this same chemical reaction; that the blue color is destroyed by other substances, as sulphuretted hydrogen and sulphurous aeid; and that light, moisture, heat, and wind exert very decided modifying influenees. Thus, wind brings more air into contact, sunlight bleaches the color, moisture hastens the bluing, and heat dissipates the free iodine.

In order to differentiate between ozone and nitrons acid, it has been proposed to use neutral litmus (violet) paper instead of ordinary filter-paper in making the strips. The $\mathrm{KOH}$ formed in the reaction will change the violet to blue, while nitrous acid, chlorine, and organic acids will convert it to red, or bleach it, or leave it unchanged.

In spite of the fallacies mentioned, the weight of evidence thus far obtained in ozonimetry shows that the reaction with starch is most marked in pure air at the seashore and at great heights, and that but little reaction oceurs indoors.

Determination of Dust.-Dust is determined quantitatively in two ways, and the results are expressed in terms of weight or of number. In order to ascertain the weight of the dust contained in a given volume of air, a chloride of ealcimm tube, containing perfectly dry absorbent cotton or glass wool, is weighed aceurately, and then attached to a water suetion-pump with an air-meter between. A large amount of air, say 500 liters, is then drawn through as quickly as possible. When a sufficient amount has passed, the tube is detuched and placed either in a drying-oven or in a desicentor over sulphuric acid, and kept until it ceases to lose weight (moisture). The 
net increase in weight represents the amount of dust in the volume of air aspirated.

To determine the number of dust particles in a given volume, the method of Aitkin is employed. The appanatus includes a shallow metallic box with glass top and bottom etched in squares. Into this box, containing air which has been fired from dust by filtration throngh cotton, and is kept saturated with moisture by means of wet filterpaper, a small measured amount of the air under eximination is introduced. By eatusing the formation of a partial vaeum, each particle of dust beemes coated with condensed moisture and hence tends to fall upon the etehed squares of the bottom. The number deposited is counted with the aid of a magnifying glass. The number of particles varies, according to Aitkin's olservations, fiom 8,000 to 100,000 per cubic inch in the country, and from 1,000,000 to 50,000,000 in eities.

Bacteriological Examination.-The method which involves the least trouble and requires a minimum of apparatus, and which for all practical purposes gives greatest satisfaction, consists in exposing gelatin plates or Petri dishes for a definite period, and then covering them and letting the colonies develop. After the proper interval, the number of growths may be comted, and the individual speeies isolated and studied. This method is very useful for comparative work, the results being given as the number of eolonies which develop after a given exposure.

For more accurate quantitative work, Petri ${ }^{1}$ devised a process of sand filtration. A glass tube, 9 by $1.6 \mathrm{~cm}$., serves to earry two small filters, which are arranged in the following manner: Two small tightly fitting diaphragms of fine wire gauze are inserted into the tube at a point midway between the ends. Into one side, a quantity of fine quart\% sand is packed, and upon it, to keep it in place, another diaphragm is driven. Above this, the space is filled with a cotton plug. The tube is now reversed and a second filter of sand is made in the same way. After complete sterilization, the eotton plug in one end gives way to a rubber stopper with a single perforation, through which passes a glass tube conneeted with an aspirating pump. The other cotton plug is removed and the process of suction begun. When a sufficient amount has been drawn throngh, the two filters are renoyed, cach by itself, and mixed with the mutrient gelatin from which plates are next to be made. The first filter should contain all of the organisms, the second serving as a eontrol.

Fieker suggested an improvement in the construction of the filters, substituting for sand, which to a certiin extent, masks the colonies, powdered glass, which has not this disadvantage. A still better material is fine sugar, the use of which was suggested first by Selgwick. The advantage of this is that it is dissolved in the liquefied gelatin, and thus disappears from view, and, therefore, neither masks the eolonies nor can be mistaken for them in counting.

' 'Teitschrift für Hygiene, III., p. 1. 
Sedgwick's method of collecting organisms and obtaining cultures is one which, on the whole, is preferable to any other that has been sugrgested. His apparatus, known as the aërobioseope, is a glass tube about 14 inches in length, shaped like a hydrometer and open at both ends. The narrow portion, which is rather less than half the length of the tube, has an internal diancter of 0.2 inch; the broader portion has an internal diameter of 1.8 inches, and at its free end is constricted for an inch to about half its size. Into the outer end of the narrow portion, a diaphragm consisting of a roll of fine wire gauze is inserted to act as a plug for the sugar filter. The two open ends are stopped with cotton, and the apparatus is then sterilized. The plug at the larger end is next removed and the sugar, snfficient in amount to fill the small tube above its contained diaphragm, is introduced. The plug is replaced, and then the whole is sterilized at $120^{\circ} \mathrm{C}$. for several hours. In use, the apparatus is held in a vertical position with the narrow portion down, the plugs are removed, and a neasured volnme of air is drawn through by means of an aspirating apparatus connected by a rubber tube to the lower end. When the desired amount of air has been aspirated, the sugar with the bacteria which it has alrested is bronght, by proper manipulation, into the broad part, into which, by means of a bent funnel, a sufficient amonnt of liquefied mutrient gelatin is introduced. The plug is replaced, and the tube is then rolled and chilled on jee, and set aside for the development of colonies. After the proper interval, the count is made in the nsinal mamner.

The methods above given have generally superseded that of Hesse, who was a pioneer in this branch of investigation. His apparatus consists of a glass tube, 28 inches long and abont $1 \frac{1}{2}$ wide, supported in a horizontal position upon a wooden tripod. One end is covered with two rubber caps, the imer of which has a single perforation; the other end is elosed with a rubber stopper with an outlet tube of erlass phugged at each end with cotton and comnected with a pair of aspirating flasks of a liter capacity. The tube is sterilized and charged with 50 ce. of getatin, which is allowed to solidify hefore nse. In condueting the operation, the onter eap is removed, thus exposing the inner perforated one, and a corrent of air is drawn slowly through by the antion of the aspirating flask, which, filled with water, empties itself into the other. By reversing the flasks, any number of liters of air may be drawn through. In its passage, the air deposits its hacteria on the grelatin. The proeess las many disadvantages, and can make no great claim to accuracy. 


\section{CHA P'TER I I I.}

\section{THE SOII.}

Notwithstandivg the constant and necessarily intimate relation of all life to the soil upon which we build our habitations, from which we derive in such great part our supply of drinking-water, into which we east vast quantities of organic filth, and to which we consign our dead, the subjeet of the sanitary importance of the soil has not until within comparatively reeent years received the attention which it merits. That the soil exerts important influences on the publie health, was recognized long before the time of Hippoerates, and extensive researches on the subject figure among the earliest investigations of the modern liggienist, but by far the greatest part of the attention paid to the study of the soil has been due to considerations of public wealth rather than of public health. With the gradual development, however, of a more aceurate knowledge of the causes of disease, has come an increasing interest in the relations of the soil to those causes, and what has hitherto been a rather negleeted field of exploration now bids fair to be well and thoroughly tilled.

That portion of the earth's crust in which we as hygienists are interested ineludes the superficial layer, known as tilth or arable soil, which is the result of the disintegration of rocks and decay of animal and regetable life, and the subsoil, which lies directly beneath. The former varies from a few inches to several feet in depth; the latter extends few or many feet downward to the hardpan or other impermeable stratum.

Soil is a mixture of sand, clay, and other mineral substances, with humus, or organic matter, and living organisms; and it is elassified aceording as one or another of its constituents predominates. The usual elassification of soils includes sands, elays, loams, marls, humus, and peats.

Sandy soils consist almost wholly, or at least more than four-fifths, of pure sand of any kind.

Cleys are stiff soils consisting chiefly of silicate of aluminum and other very finely divided mineral matters. Clay exists in particles of the smallest possible size, is very cohesive, possesses a high degree of plasticity, and plays a very important part in determining the fertility of soils, their texture, and their capacity for holding water. Its plasticity is due to the presence of a small proportion of hydrated silicate, and is modified very greatly by the addition of less than a hundredth part of caustic lime. It is excedingly impermeable to water, and when wet dries with great slowness. 
Loams are mixtures of sand, clay, and humus; hence their properties partake of the characteristies of these substances according to the extent to which each is present. When sand predominates, they are designated as light; and when clay prevails, they are known as heavy. These terms, however, have no reference to weight, but to the ease or difficulty with which they are worked in the processes of agriculture; and, indeed, those soils which are the lightest in this sense are the heaviest in actual weight. Since loams consist of varying proportions of the chief constituents, it is obvions that the word loam may have but little significance without some qualifying term, and they are, therefore, divided into five classes, as follows:

1. Heavy clay loan, containing . . . . 10-25 per cent. of sand.

2. Clay loam, containing . . . . . . . . . . . . . . . . . . $40-40$ "

4. Sandy loam, containing . . . . . . 60-75 " " "

5. Light sandy loam, containing . . . " .

Mixtures containing less than 10 or more than 90 per cent. of sand are elassed, respectively, as elay or sand.

Marls are mixtures of clay, sand, and amorphous calcium carbonate in various proportions, and contain, often, potash or phosphates from the fauna and flora of the sea. From their content of carbonate of calcium they are known often as lime soils, and according as one or another constituent predominates they are designated as clay marl, sand marl, and shell marl. All contain varying amounts of humus.

Humus is a term used to designate the entire product of vegetable decomposition in the various intermediate stages of the process. It is the essential element of vegetable mould, and is necessarily of most complex eomposition—so complex, indeed, that it cannot definitely be determined. It is composed of a great number of elosely related definite chemical compounds, ehief among which are ulmin and ulmic acid, which are supposed to characterize brown humus; humin, and humic acid, which dominate dark, or black humus; and crenic and apocrenic acids. Its principal characteristic is its high percentage of nitrogen, especially marked in some of our prairie soils and in the "black soil" found in the provinces of the Ural Mountains, which, accordiug to Von Hensen, ${ }^{1}$ contains as much as from 5 to 12 per cent. of organic matter. Its complete decay is most rapid in warm welldrained soils permeable to air, and in such soils the amount of humus present at any one time will be relatively small, while in soils which are damp, not well ventilated, and, for months at a time, frozen, its accumulation is favored. While its ultimate products of decay are of the greatest importanee to vegetable growth, it does not follow that its complete absence renders a soil necessarily sterile, or even poor, provided the necessary nitrogen is supplied in the form of nitrates. But its presence is necessary to the growth and life processes of the soil bacteria, without whose assistance many plants would fail to thrive.

Peat, muck, and humus soils contain large amounts of humus, but differ 1 Zeitschrift für wissenschaftliche Zoologie, XXVIII., p. 360. 
according to the conditions under which they are formed. Peat and muck result from the incomplete decaly of vegetable matter under water; the former term applies to that which is compact and fibrous ; the latter is less compant, not fibrous, and, when dry, easily reduced to powder. They contain but a small amonnt of mineral matter. Hunus soils are soils which contain large percentages of vegetable mould with ordinary soil constituents.

The expression rocky soil applies to any kind of soil containiug malsies of rock.

Gratelly soils are those which contain notable amounts of gravel, which consists of small fragments of rock more or less worn by the action of water, and larger and coarser than sand.

Allaline or salt soils are soils which contain considerable amounts of soluble salts, especially carbonate and sulphate of sodium and salts of ealcium.

Constituents of the Soil.-The chief constituent of the soil is silieit, which, it is estimated, forms about two-thirds of the entire earth's crust. Next in abundance is aluminum, chiefly in the form of elay (silieate of aluminmm). Lime and magnesia are large constitnents, existing eliefly as carbonates in the form of limestone. Both are indispensable to the growth of plants, and lime exerts a marked influence on the physical condition of the soil and upon the processes of nitrification. Although its principal combination is carbonate, it exists also largely as phosphate and sulphate.

Iron is universally present, and is of very great importance to vegetation, although but a small amount is needed. The red and yellow colors of soils are due to the presence of iron compounds. Manganese stamds second to iron in abundance among the heavy metals, but is of much less importance. It is a constituent of many plants, notably of tea. Chlorine is not a large constituent; it oceurs ehiefly in combination with sodium, potassium, and magnesium. Its total amount in ordinary unpolluted soil seldom exceeds $\frac{1}{1000}$ part of the whole. Sulphur occurs as sulphides and sulphates, the latter usually in combination with ealcium. It is very neeessary to vegetable growth, as it is an essential element of vegetalble albumin. Phosphorns in the form of phosphates of lime, magnesia, jron, and alumina, is another essential element, widely distributed in small amounts. Sodium and potassium are present, chiefly in the form of insoluble silicates and partly as chlomides. Their total in combination seldom exceeds 4 per eent.

Nitrogen exists in soils in three distinet forms : proteids, ammonia and its salts, and nitric aeid and nitrates. In average soils, the total nitrogen is not large in amomi-considerably less than 1 per eent.but in some exceptionally rich lumus soils 4,5 , and even 6 per cent. are found. In the organic combinations (proteids) it is not available as plant food, consequently these must be broken up into simpler forms in order to be of direet use. In their deeomposition, the second form, ammonia, is produced, but not all the ammonia of the soil is from this source, for some is brought into it from the air by rain. And in the 
second form, also, it appears to be not available as plant food, but even, according to Bonchardat and Cloëz,' seems to act ats an energetic poison when absorbed by plant roots from solutions of 0.1 to 0.01 per eent. strength. So it is probable that complete oxidation to the third form is necessary for the alsorption of any form of nitrogen. As soon as the ammonia is oxidized in its turn to nitric acid, this latter combines with sodium, potassium, or calcium, and the resulting nitrates are then ready for absorption.

All of these changes from the complex proteid to the simple nitrate are earried along by different gronps of micro-organisms, but no great acemulation of the end products occurs, because, while vegetation is flomrishing, they are removed as fast as formed, and when it has ceased, they are washed down into the subsoil by the rain and melting snow.

The amount of organic matter in soils varies widely according to circumstances, but the amount necessary for vegetation is quite small, although certain erops, as tobacco and wheat, require much more than others, as oats and rye. The soils richest in organie matter are the peats and mucks; next come the very rich humus soils, which may yield more than a fourth of their weight. From 10 to 15 per cent. denotes unusual richness, and about 6 per cent. may be regarded as a fatir amount for a productive soil.

Physical Properties of Soils.-Pore-volume.-In all soils, no matter how closely the individnal particles are packed, there must exist a greater or less amount of interstitial space, which may be filled with water or air, or both together. The sum total of these interstitial spaces is known as the porosity or pore-volume, and is expressed in percentage of the volume of the soil. Its amount depends not upon the size of the soil particles, but upon their uniformity or lack of uniformity of size, and upon their arrangement. If we lave, for instance, a

Firi. 17.

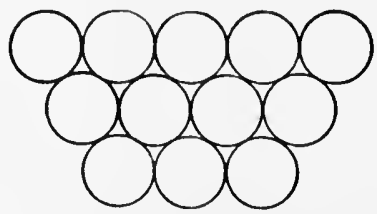

Fir. 18.

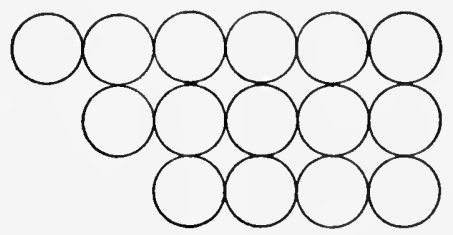

very coarse soil, consisting of particles of uniform size as large as peas, and another of miform particles the size of small shot, we shall find, on determining their poro-volume, that it is practically the same in each ase, and is probably not far from a third of the whole. Packed in the most solid mamner possible, which is that in which each sphere rests on three beneath it (arranged like the familiar pyramid of marbles), helps support three in the layer above it, and comes in contact with others at six equiclistant points along its equator, as in Fig. 17, the volume of interstitial spare will apual 25.95 pror eent. of the whole. Packed as loosely as possible, so that cach rests upon but one, sup-

$$
{ }^{1} \text { Dentsche medicinische Wochenschrift, } 1886 .
$$


ports another, and comes in contact with but four of its neighbors in the same layer as itself, as in Fig. 18, the volume of the interstices will be 47.64 per eent. ${ }^{1}$ Thus a soil composed of spherical grains of uniform size would have, regarlless of the coarseness of the grains, a pore-rolume of not less than 25.95 per eent.

That the size of the individual grains makes no difference, may easily be demonstrated in a practical manner. If we take two cylindrical glass vessels of the same size, fill them to the same height with water, and then add to the one a measure of large shot and to the other an equal measure of much fincr shot, and seeure as solid packing as possible by gentle tapping, it will be found that the water in each cylinder has risen to practically the same height; that is, that the actual volume of each is about the same. There will be, perhaps, some slight difference one way or the other, owing to the impossibility of securing absolute uniformity of packing, and to the error due to the inequality of the spaces along the circumference of the cylinders. But in nature we do not deal with perfect spheres or with soils made up of particles all of the same size, but with soils composed of angular pieces of varying size. The greater the variation in size of the partieles, the greater the possibility of variation from the limits of pore-volume as given above. With varying size, the small particles may fall into the spaces made by the larger ones, and the spaces between the new comers may be trespassed upon by still smaller grains, and so on until the interstitial space has been reduced to a minimum.

To illustrate this diminution in a practical way, fill a large beaker with marbles, then pour into it, from a graduate, sufficient water to displace all of the air in the interstices, and note the amount of water required, which is the pore-volume of the mass. Next, pour out the water as completely as possible and run on to the surface of the marbles a quantity of coarse sand or shot, and shake the vessel gently in all directions so as to favor their descent into the spaces below. When all have penetrated that ean, pour in water again until it appears at the surface, and note the amount required; this is smaller than before, on account of diminished air spaces. Now pour off the water a sccond time, add still finer shot, and repeat the operation as beforc. So long as new matter can be added, so long will the porevolume show a diminution.

Irregularity of size and shape of the particles may also have an influence in the other direction, and cause the formation of large spaces and increased pore-volume.

All soils, even the most compact rocks, have a certain anount of pore-volume, and some apparently compact masses, such as sandstone, have as much as 30 per eent. In soils which are ecmented into homogeneous masses, the pore-volune sinks to a minimum, but in ordinary soils it amounts to about 40 per cent.

Permeability of Soils.- The permeability of a soil to air depends not, as it might appear, upon the amount of its pore-volume, but upon

' Soyka, Der Boden, Leipzig, 1887. 
the size of the individual spaces. In fact, a soil of high pore-volume may be almost impermeable to air in comparison with one of less porevolume, as will be shown; and the pore-volume is of itself no measure whatever of permeability, which diminishes in an extraordinary degree with diminution in the size of the soil particles. The greater the number of the individual spaces, the greater the number of angles and the greater the frietion of the entering air ; and, conversely, the less the number, and eonsequently the larger the size of the spaces, the less the number of angles and the less the obstruction. A series of experiments condueted very earefully by $\operatorname{Renk}^{1}$ with different kinds of soil in cylinders of equal height, through which air was foreed under the same degree of pressure, yielded the following interesting results :

\begin{tabular}{|c|c|c|c|c|c|}
\hline Nature of soil. & Diameter of grains. & $\begin{array}{c}\text { Pore- } \\
\text { volunie } \%\end{array}$ & $\begin{array}{c}\text { Pressure } \\
\text { in mm. of } \\
\text { water. }\end{array}$ & $\begin{array}{l}\text { Amount of } \\
\text { air in } \\
\text { liters per } \\
\text { minute. }\end{array}$ & Ratio. \\
\hline $\begin{array}{l}\text { Fine sand } \\
\text { Medium sand } \\
\text { Coarse sand } \\
\text { Fine gravel } \\
\text { Medium gravel }\end{array}$ & $\begin{array}{l}\text { Less than } \frac{1}{3} \mathrm{~mm} \text {. } \\
\frac{1}{3} \text { to } 1 \mathrm{~mm} \text {. } \\
1 \text { to } 2 \mathrm{~mm} \text {. } \\
2 \text { to } 4 \mathrm{~mm} \text {. } \\
4 \text { to } 7 \mathrm{~mm} \text {. }\end{array}$ & $\begin{array}{l}55.5 \\
55.5 \\
37.9 \\
37.9 \\
37.9\end{array}$ & $\begin{array}{l}20 \\
20 \\
20 \\
20 \\
20\end{array}$ & $\begin{array}{c}0.00133 \\
0.112 \\
1.280 \\
6.910 \\
15.540\end{array}$ & $\begin{array}{r}1 \\
84 \\
961 \\
5,195 \\
11,684\end{array}$ \\
\hline
\end{tabular}

Thus it is seen that a fine sand with a pore-volume of 55.5 per cent. permitted the passage of but 1 volume of air, while a gravel of medium eoarseness with much lower porosity permitted the passage of 11,684 times as much in the same unit of time. Renk showed, further, that with soils of the finer textures, permeability to air is direetly proportionate to pressure, but that this is not true of those of coarser grain.

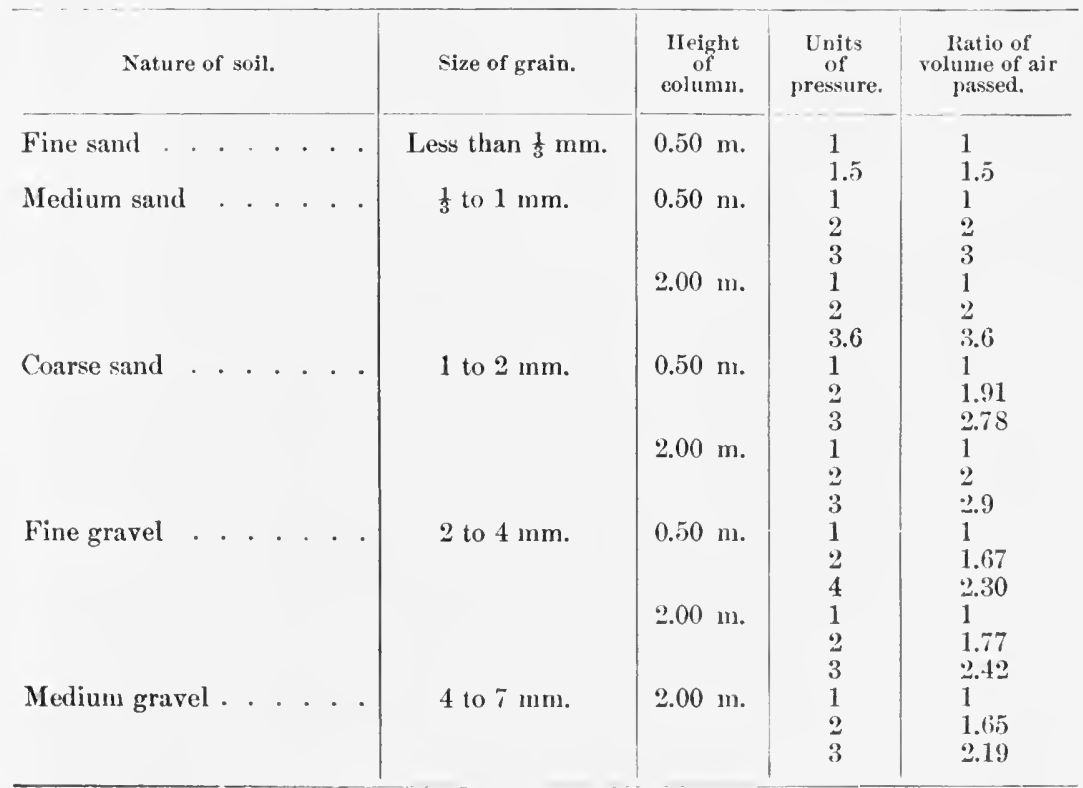


The alsence of any connection between pore-volnme and permeability has been shown also by von Welitschkowsky, 'from whose results the following table has been construeted:

\begin{tabular}{|c|c|c|c|c|}
\hline Nature of soil. & l'ore-volume $\%$. & $\begin{array}{l}\text { l'ressure } \\
\text { in mum. } \\
\text { of water. }\end{array}$ & $\begin{array}{l}\text { Amount of air } \\
\text { in Jifers } \\
\text { jer minule. }\end{array}$ & Ratio. \\
\hline $\begin{array}{l}\text { Fine sant } \\
\text { Mellium sand } \\
\text { Coarse sand. } \\
\text { Fine gravel }\end{array}$ & $\begin{array}{l}41.87 \\
40.64 \\
37.38 \\
35.47\end{array}$ & $\begin{array}{l}50 \\
50 \\
50 \\
50\end{array}$ & $\begin{array}{c}0.0058 \\
0.8990 \\
7.399 \\
33.651^{2}\end{array}$ & $\begin{array}{r}1 \\
155 \\
1,276 \\
5,802\end{array}$ \\
\hline
\end{tabular}

Since permeability diminishes with fineness of texture, it follows that clay and similar soils possess this property in the smallest degree, and thit when these are mixed with sandy soils they must necessirily lessen it to a very marked extent. But clays and loams may oceur in very open erumbly form, that is, in loose fragments of varying size, each consisting of myriads of small particles held together by the aid of moisture; and such soils show a high permeability, due to their large interstitial spaces.

The degree of permeability to air is influenced very greatly by the amount of contained moisture, the maximum influence being exerted by decided wetuess. This is due to the fact that the greater the amount of water present in the interstices, the greater the diminution in the space available for the passage of air and the greater the obstruction to its movement. Thus the complete ocelusion of the interstices by water is equivalent to absolute impermeability, except when the pressure of air is sufficient to displace the water and move it along.

In the case of soils that are only partially wet, the diminution in permeability valries according as the moisture enters from above by rain or from below by capillary attraction from the water in the subsoil. This is owing to the fact that when the soil is wetted from above by min, the superficial interstices are ocehded more or less completely, and the air in those below is restrained in its movement; while when the moisture is derived by eapillary attruction, the air is displaced upward, and the superficial interstices are more or less completely open. The action of downward and upward moistening has been investigated by Renk, ${ }^{3}$ whose results, in part, are given in the following table:

\footnotetext{
${ }^{1}$ Beilrag zur Kenntniss der Permeabilitït des Bodens für Luft: Arehiv für Hygiene, II., p. 483.

2 The height of the column of material in this experiment was three-fonrths of a meter, instend of a haIf, as in the cosse of the three others. Witl an equal height the result would have been much larger.

${ }^{3}$ Loco citato.
} 


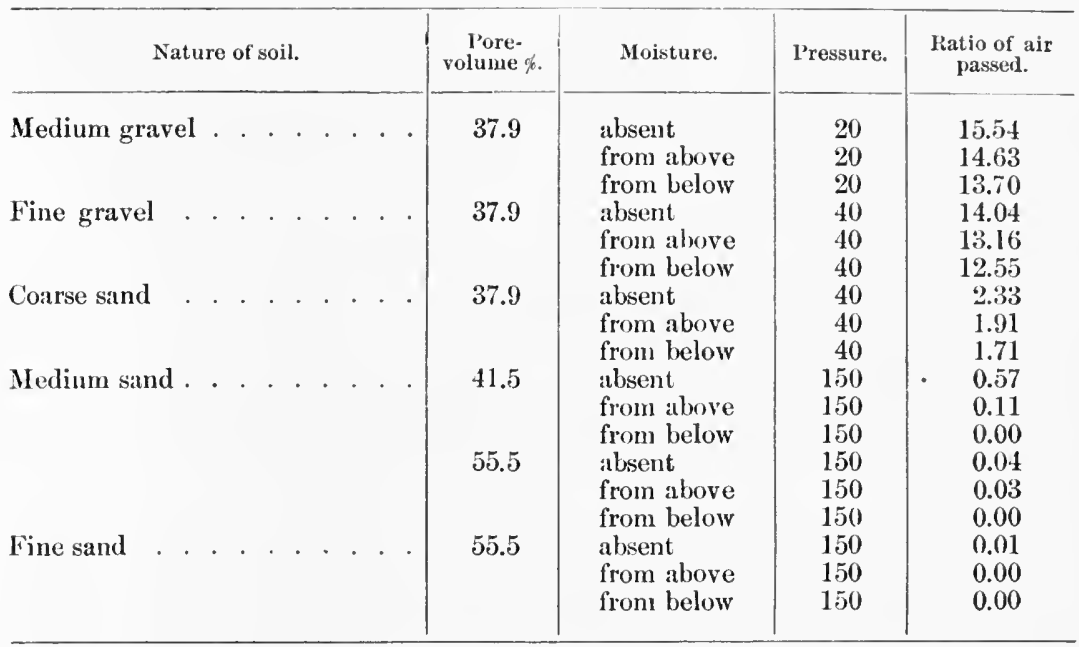

Permeability is lessened also by freezing temperatures, by reason of the fact that the contained moisture expands about one-eleventh of its volume as it freezes, and so oceupies that much more space in the interstices. Moreover, when frozen, the moisture is in a fixed rather than a movable condition, and caluses the production of a compact mass more or less resembling stone. The finer the grain, the more solid the product, and the greater the diminution of permeability. Renk ${ }^{1}$ determined the diminution in the permeability of soils of different grain size due to freezing, as follows:

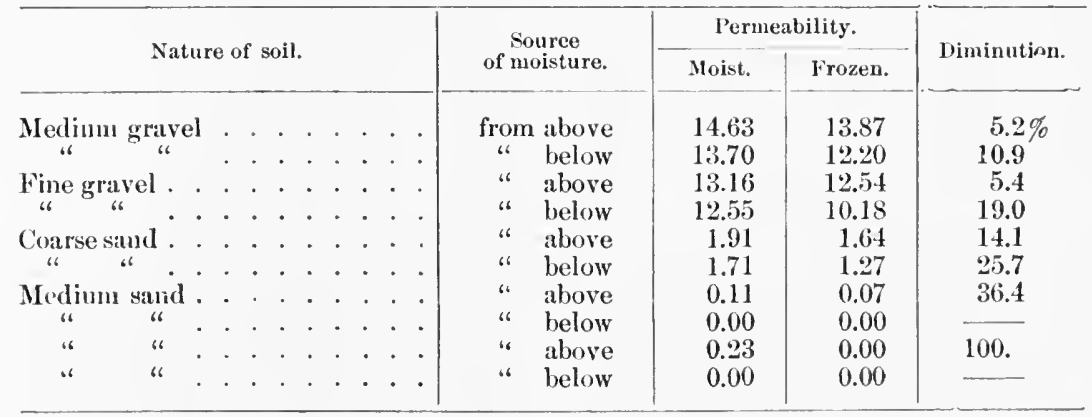

The degree of permeability of soil to water, like that of permeability to air, is noverned by the texture rather than by pore-volume, as is shown by the following results obtained by von W'ititschkowsky, who determined the rates at which water would pass through columns of soil of differing fineness packed in eylinder's of equal dianeter. Each

${ }^{1}$ Beitrag zur Kenntniss der Permealilitait des Bodens für Luft: Arehiv für Hygiene, II., p. 483.

'Fxperimentelle Intersuchung über die Permeabilitït des Bodens für Wasser, Irehiv für llygiene, Il., p. 499. 
specimen was first completely saturated and then kept so during each experiment, the water supplied being kept at constant level.

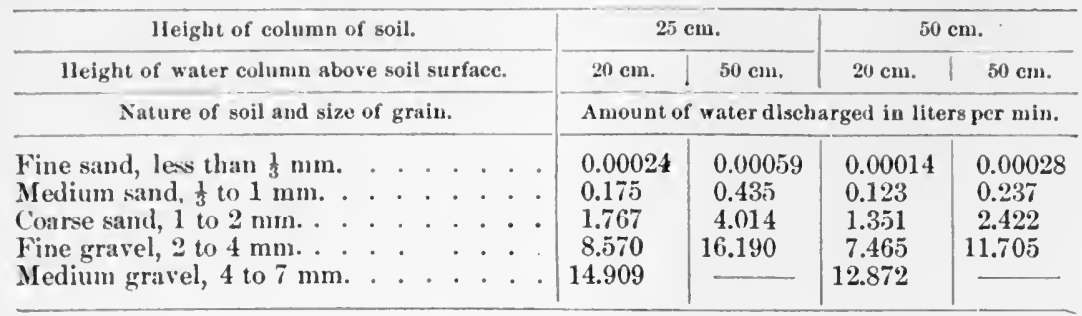

Comparing these results with those obtained by the same investigator in his experiments on permeability to air, it will be noticed that the total pore-volume has here even less significance.

\begin{tabular}{|c|c|c|c|c|c|}
\hline \multirow{2}{*}{ Nature of soil. } & \multirow{2}{*}{ Height. } & \multirow{2}{*}{ Pressure. } & \multirow{2}{*}{$\begin{array}{c}\text { Pore- } \\
\text { volume } \%\end{array}$} & \multicolumn{2}{|c|}{ Ratio of permeability. } \\
\hline & & & & To air. & To water. \\
\hline 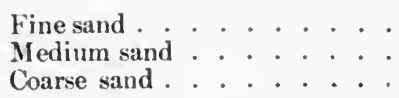 & $\begin{array}{l}50 \mathrm{~cm} . \\
50 \mathrm{~cm} . \\
50 \mathrm{~cm} .\end{array}$ & $\begin{array}{l}50 \mathrm{~cm} \\
50 \mathrm{~cm} \\
50 \mathrm{~cm}\end{array}$ & $\begin{array}{l}41.87 \\
40.64 \\
37.38\end{array}$ & $\begin{array}{r}1 \\
155 \\
1,276\end{array}$ & $\begin{array}{r}1 \\
846 \\
8,650\end{array}$ \\
\hline
\end{tabular}

\section{Capacity for Water, and Water-retaining Capacity.}

If to a volume of any soil packed into a cylinder of glass or metal we add water in such a way that all of the air in the interstices is displaced, the soil is then saturated and the amount of the contained water represents the total "water capacity," which, it is seen, equals the pore-volume. The "water-retaining capacity," is quite another thing, and depends upon the structure and composition of the soil, and, in a minor degree, upon other considerations. If for the impervious bottom we substitute one of wire gauze or coarse cloth, the contained water will begin to drain away, owing to the force of gravity, and the flow will by degrees become less and less, and finally cease. Then the interstices, which originally were filled with air alone and next with water, are filled in part with the one and in part with the other.

By comparing the original weight of the volume of soil with its weight in its now wet condition, its power to retain water is easily determined. This power is the result of two forces acting in opposition to the force of gravity ; namely, surface attraction of solids for liquids, and capillary attraction. The water which is simply adherent to the surfaces of the soil grains is known as hygroscopic water, while that which is held in the capillary spaces is called eapillary water; and it is the latter which, in any but the coarsest soils, constitutes by far the larger part of the retained moisture.

Not all of the interstices of a soil form capillary spaces, but only those of which the boundary walls are separated only by intervals 
which come within the limits of capillary magnitude. Thus, a coarse soil may contain comparatively few such spaces, while one of a fine texture may have its particles so closely approximated that all of its interstitial spaces are capillary. It follows, therefore, that compact soils possess greater retaining power than those with large interstices which permit rapid percolation, and that when the texture is so fine that all the spaces are capillary, the maximum retaining power is attained.

The influence of soil texture on capacity for holding water may be seen in the following table of some of the results obtained by Hofmann : ${ }^{1}$

\begin{tabular}{c|c|c|c|c}
\hline $\begin{array}{c}\text { Diameter of grain } \\
\text { in mm. }\end{array}$ & $\begin{array}{c}\text { Pore-volume per } \\
1,000 \mathrm{cc}\end{array}$ & $\begin{array}{c}\text { Amount of con- } \\
\text { tained water in cc. }\end{array}$ & $\begin{array}{c}\text { Amount of con- } \\
\text { tained air in cc. }\end{array}$ & $\begin{array}{c}\text { Per cent. of pore- } \\
\text { volume filled with } \\
\text { water. }\end{array}$ \\
\hline 5 & 434 & 55 & 379 & 12.7 \\
3 & 418 & 77 & 341 & 18.4 \\
2 & 410 & 98 & 312 & 23.9 \\
1 & 400 & 150 & 250 & 37.5 \\
0.5 & 413 & 270 & 143 & 65.4 \\
less than 0.5 & 413 & 347 & 66 & 84.0 \\
\hline
\end{tabular}

The water-retaining capacity of soils is determined very largely also by the amounts of organic matter present; a soil rich in organic matter will, other conditions being the same, show more water than another of less richness. The extreme influence is observed in the case of humus, which can hold ten times its weight of water. In view of this influence of organic matter, it is very clear that one way to help keep a soil dry is to avoid discharging filth into it, and thus keep it clean.

For the purpose of illustrating the influence of very fine soil particles (clay) and of organic matter (humus), the following results of an investigation by $\mathrm{Wolff}^{2}$ may be quoted. He packed soils of varying clay and humus content into a metallic vessel with a permeable bottom, saturated them completely with water, then superimposed a column of water of equal cross-section and $8 \mathrm{~cm}$. high, and observed the time required for the added water to be delivered below :

\begin{tabular}{|c|c|c|c|c|c|}
\hline \multirow{2}{*}{ Nature of soil. } & \multicolumn{2}{|c|}{ Percentage of clay. } & \multirow{2}{*}{$\mid \begin{array}{c}\text { Percentage } \\
\text { of } \\
\text { humus. }\end{array}$} & \multicolumn{2}{|c|}{ Time required. } \\
\hline & Per cent. & Ratio. & & Hours. & Ratio. \\
\hline Very fine sandy loam & 15.74 & 1. & 0.88 & 20.3 & 1. \\
\hline Very fuse sandy loam & 15 & 1. & 1. & 25.8 & 1.27 \\
\hline Black, rich, chalky loam & 18.17 & 1.15 & 6.87 & 31.0 & 1.52 \\
\hline Very fine sandy loam . & 25.93 & 1.64 & 0.92 & 75.8 & 3.73 \\
\hline Very clayey st & 42.56 & 2.70 & 0.66 & 133.0 & 6.55 \\
\hline Soil with considerable clay & 29.76 & 1.89 & 2.19 & 188.0 & 9.26 \\
\hline
\end{tabular}

It will be observed that the soil which permitted the passage of the water in the shortest time was poorest in clay and almost so in humus,

1 Archiv für Hygiene, 1., p. 273.

${ }^{2}$ Anleitung zur chemischen Untersuchung landwirthschaftlich wichtiger Stofle, 1875. 
and that the one which required the longest time combined a considerable amomnt of elay, not the highest, with a high percentage of humus, also not the highest. 'The highest percentage of clay was associated with the lowest amount of hmmus, and the highest of lumus with a low content of elay; but these two soils (Nos. 5 and 3) were both less impermeable than that (No. 6) which contained less clay than the one and less lumus than the other. It is to be noted, however, in the case of the soil with the highest proportion of clay and lowest of humus, that it contained 12.8 per cent. of chalk as against 2.28 per eent. in the most impermeable, and that this substance, as has been mentioned, has a very great influence in diminishing the degree of plasticity of elays.

\section{Soil Temperature.}

The sources of heat in the soil are three in number; namely, the sun's rays, chemical changes, and the original heat of the earth's interior. The prineipal somree is the sun. The heat derived from chemical changes is not great, and, indeed, is not even worthy of consideration, execpt in soils very rich in organie matter; and here the ehanges occur only in the presence of comparatively high temperature due to the action of the sun. The third source is constant and of much importance.

The soil temperature is influenced by a number of conditions, including exposure, atmospherie temperature, color, eompactness, eomposition, and moisture. Naturally, the surfaces exposed to the greatest amount of sunshine get more heat than others. The nearer the angle of ineidence of the sun's rays approaches a right angle, that is, the more perpendicularly the rays strike, the greater the amount of heat received.

The rapidity with which soils are affected in either direetion by changes in atmospherie temperature varies widely, but with any soil it is only in the very uppermost layers, the very surfaee in faet, that any immediate corresponding rise or fall is observed. Great sudden ehanges affeet the soil below the surface very slowly, and in the deeper layers the maximum and minimum temperatures oecur mueh later than in the atmosphere above. The ammual variation diminishes as the distance from the surface increases; at fifteen feet the amplitude is, as a rule, less than 10 degrees F., and between fifty and eighty feet the temperature is constant the year round.

The color of a soil exerts an important influence in the determination of its temperature. As is well known, a black surface exposed to the sun absorbs the heat rays more than a white one. A common illustration of this fact is the greater rapidity with which snow melts when its surface is dotted over with dirt and soot than when it is elean and white, owing to the absorption of lieat by the dark particles and its eommunication by conduction to the snow beneath and about. In the same way, soot and cinders work their way downward into the ice on a pond. Another illustration is the greater feeling of 
warmth eonferred by black elothes than by white in the bright sunshine.

So, other conditions being the same, a dark soil is warmer than a light one, which reflects the heat rays instead of absorbing them. Observation has shown a difference of more than 25 degrees $F$. in the temperature of black and white sands exposed side by side to the direet rays of the sun, but the white sand by reason of reflecting the heat rays will appear to be much hotter than it really is.

The influenee of eompactness on soil temperature varies with the season. Aceording to King, ${ }^{1}$ the general tendency of rolling the land is to make it warmer during bright, sumny weather, but in celoudy or cold weather it tends to promote eooling. He laas observed that, at the depth of 1.5 inches below the surface, a rolled field may have a temperature 10 degrees $\mathbf{F}$. higher than a similar soil not rolled, and at double the distance he has noted a difference of 6.5 degrees. This is due ehiefly to the fact that a eompact soil is a better eonductor of heat than one containing large interstices filled with air.

The character of the mineral and organie eonstituents of the soil and the amount of its content of water exert the very greatest influence upon its temperature. Rocks, sands, and mineral substances in general are better heat enduetors than water, organic matter, and air, and they differ also one from another in eonductivity. Organie matter is a particularly poor eonductor of heat, and hence the greater the amount of hunus a soil contains, the slower its response to the action of the sull.

The great influence of moisture on soil temperature is duc to the high speeifie heat of water, and to the loss of heat which acempanies the process of evaporation. The speeific heat of ordinary dry soils varies fiom a fifth to a fourth of that of water, although in exceptional eases it may amount to nearly a half; and the wetter the soil is, the higher will be the speeific heat of the mass, that is, the greater the number of heat units necessary to warm a given weight 1 degree. Thus it happens that a light-colored dry soil may, in spite of the crreat influenee of eolor, attain a much greater degree of warmth than a dark one which is damp. The different soil eonstituents have different specific heats, ranging from about 0.16 for certain sands and claps, to about 0.44 for dry humus, that of water being unity. Thus, to raise the temperature of 100 pounds of water 1 degree will require 100 units of heat, while to perform the same office for equal weights of dry sand, weathered porphyry, weathered granite, and humus, will require respectively 16, 20, 30, and 44 units. Therefore, the same amomt of heat necessary to raise a given weight of water 1 degree will raise the equivalent weights of these substances respectively $6.67,5.00,3.3 .3$, and 2.27 degrees.

But although the high speeifie heat of water is of importance in determining soil tomperatures, the chief influence of moisture in this direetion is due to the great loss of heat which aeempanies the process

\footnotetext{
1 The Soil, New York, 1898.
} 
of eraporation, for the change from the liquid to the gaseous form is accomplished only at the expense of heat. 'The greater the amount of water evaporated from a given soil, therefore, the greater the expenditure of heat and the greater the lowering of the soil temperature. Conversely, the drier the soil, the less the evaporation, and the greater its wamth. Water does not, however, always tend to produce lowering of the temperature, for, in point of fact, it may and often does have the opposite effeet. In the spring, for instance, when the frost is not yet out of the ground and when the interstices are filled with cold water derived from the melting ice and snow, the warmer rain hastens the removal of frost, and, as it sinks into the soil, displaces downward the colder water and consequently raises the temperature.

\section{Changes in the Character of Soils Due to Chemical and Biological Agencies.}

Chemical action is constantly at work in the soil, not alone on the organic constituents, but upon the mineral matters as well. The changes which oceur in the latter are of importance to the hygienist almost solely in so far as they affect the quality of the drinking-water. Complicated processes involving the decomposition of organic matters give rise to quantities of carbon dioxide which, being taken into solution by the water in the interstices, assists in the production of still more complicated processes which engage the mincral constituents.

The elanges which, from a public health point of view, are of the greatest interest are those which are in progress in the process known as the "self-purification" of soils, in which the complex organic matters are broken up and reduced to simple chemical substances through the intervention of bacterial life. In the end, the carbon is oxidized to $\mathrm{CO}_{2}$, and the nitrogen either is set free, or is combined with hydrogen in the form of ammonia, or is oxidized to nitrie acid and nitrates.

The process requires the presence of atmospheric air and of moisture not in excess, and is favored by temperatures between $53^{\circ}$ and $131^{\circ}$ $\mathrm{F}$., the most favoralule being $98^{\circ}$. It proceeds most vigorously and perfectly nearest the surface, and virtually ceases at a depth of more than three feet, little or no action occurring in the subsoil beyond that depth. If too much organic filth and its attendant moisture are present, the soil becomes boggy and the changes camnot proceed.

An influence of very great importance in its effects on the physical and chemical characteristics of soils is that exerted by earth worms, which live chiefly on half-decayed leaves, which they drag into their burrows to be used as food and as linings and plugs for the burrows as well. According to Charles Darwin, ${ }^{1}$ their castings contain 0.018 per cent. of ammonia, and the humus acids, which have been proved to play a very important part in the disintegration of various kinds of rocks, appear to be generated within their bodies. They swallow earth both in the process of excavating their burrows and for the

1 The Formation of Vegetable Mould through the Action of Worms. 
nutriment which it may contain, and exert an important mechanieal action on the soil grains, reducing their size by attrition within their gizzards. After filling themselves with earth, they soon come to the surface for the purpose of emptying themselves.

"In many parts of England a weight of more than 10 tons of dry earth annually passes through the bodies of worms, and is brought to the surface on each acre of land, so that the whole superficial bed of vegetable mould passes through their bodies in the course of every few years." From various data, Darwin calculated that the castings, spread out uniformly, would form, in the course of ten years, a layer varying from 0.83 , in the case of a very poor soil, to 2.2 inches in ordinarily rich soils. Their mechanical action and that of ants, moles, and other burrowing animals have much to do with keeping soils open and friable.

\section{Soil-air.}

The air in the interstices of the soil differs from that of the atmosphere mainly in its richness in carbon dioxide, which arises from the decomposition of organic matters. It is also poorer in oxygen, but by no means always in a corresponding degree, and it is usually quite humid by reason of the presence of soil moisture.

The amount of carbon dioxide varies very widely in different soils and at different depths of the same soil, and it fluctuates very considerably also under differing conditions at any given point in the same soil. Other conditions being the same, the amount is most marked in soils rich in organic matter undergoing decomposition-changes. In soils poor in this respect, the amount may be no greater than in the atmosphere. Pettenkofer, for instance, found in the air of desert sand, which was devoid of organic matter, the same amount as was present in the air immediately above it.

In ordinary soils, the amount increases with the distance from the surface, as has been shown by Fodor, ${ }^{1}$ who made a great number of analyses of air at different depths at a number of places, the observations extending over several years. The average amounts found at depths of $1,2,3$, and 4 meters, expressed in parts per 1,000, were as follows:

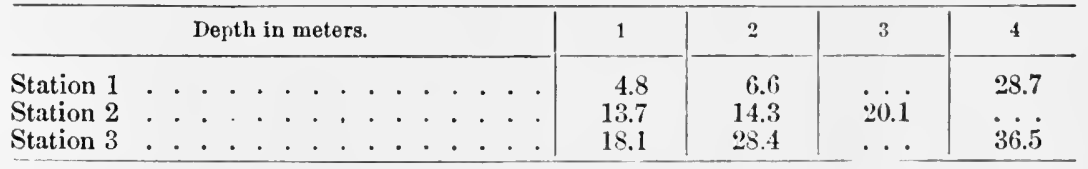

The influence of season also was shown by him to be very coniderable, the highest amounts oceurring during the hot months, and the lowest in winter. The averages by months are presented in the following table :

${ }^{1}$ Boden und Wasser, Braunschweig, 1882. 


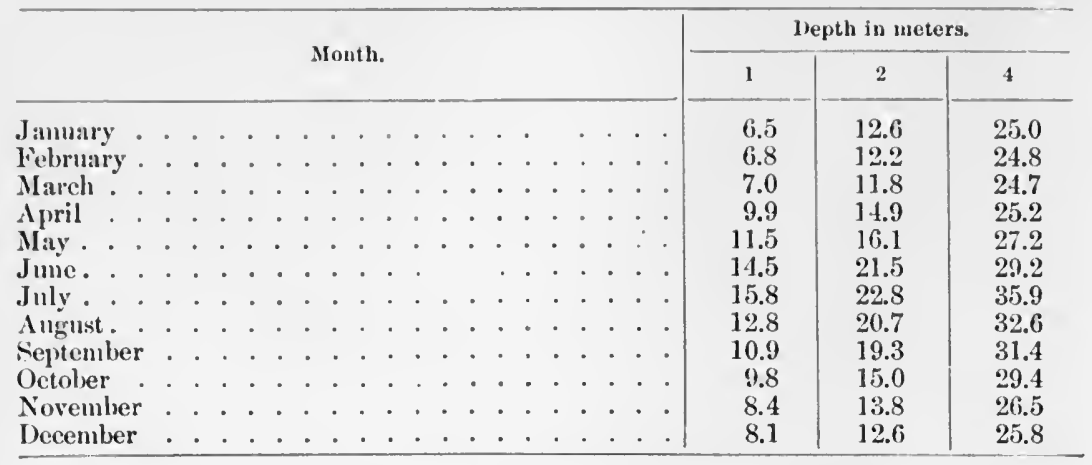

These results are only such as might be expeeted when we eonsider that decomposition of organic matters procceds most vigorously within certain limits of high temperature.

Fluctuations in the amount present at any given point are due to a number of conditions which include rainfall, the action of the wind, the rise and fill of the subsoil-water, and differences in atmospherie pressure and temperature.

Rainfall, by filling the superficial interstices of the soil with'water, interferes with the natural process of soil ventilation and eauses an

Fia. 19.

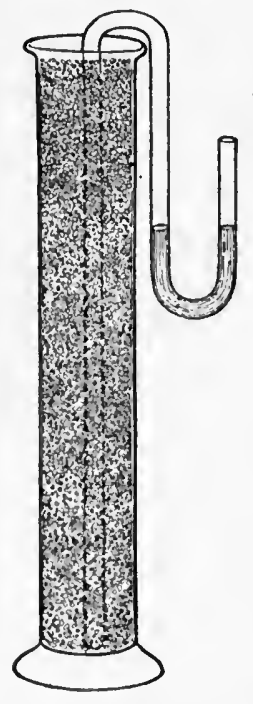

Apparatus to show action of wind on soil ajr. immediate accumulation of carbon dioxide, which, however, is shortly followed by a diminution due to absorption of the gas by the water, which thus acquires an increase in its power of attacking and dissolving the mineral constituents of the soil. Inasmuch as the bulk of the absorbed rainfall is held by the upper strata of the soil, its influence is more marked there than at greater depths. As it sinks downward, however, in very wet weather, it drives the air before it, and causes its escape at points where its egress is not obstructed.

The action of wind is exerted in two ways: by perflation and by aspiration. By blowing strongly across the surface of the soil, it aspirates the air in the upper layers and causes an upward movement in the air below, or it may suck it ont at one moment and take its place the next. Again, it may blow with such foree against the surface as to drive the contained air downward before it, so that the interstices become filled with ordinary atmospheric air. The action is more marked in soils of ordinary coarseness of texture than in very open soils with large interstices, which permit freer movement in the upper strata. This may readily be demonstrated by means of a simple experiment with the apparatus shown in Fig. 19. Here we have a glass cylinder, inside which is a glass tube extending from the bottom 
and bent over at the top so as to form a $U$, into which an amount of water sufficient to form a seal may be introdneed. If now we fill the intervening space up to the top with sand, and then direct against the surface of the latter a current of air by means of a bellows or by hlowing sharply through a tube of glass or other material, the whole volume of air in the interstices is set in motion, which is communicated to the air within the enclosed tube, so that the water in the U-shaped depression is cansed to oseillate. If the water completely fills the short leg of the $U$, it may be forced over and eaused to drip. If, however, instead of employing sand, we fill the cylinder with coarse gravel, the oscillation of the water will be either less noticeable or entirely absent, the air which enters at one point on the surface communicating its motion only to that immediately adjacent in the upper part.

The rise and fall of the water in the subsoil assist in the production of variations in the amount of carbon dioxide; on the one hand, by its rise, forcing the rich soil air npward and outward, and, on the other hand, by its fall, drawing the soil-air downward and eatsing its place in the upper strata to be filled with atmospherie air with low content of the gals.

Differences in temperature and barometrie pressure have also been mentioned as exerting influence on the motion of the ground air. In spring and summer, the grouml air is colder and denser; and in autumn and winter, it is warmer and lighter than the air above. Hence in the former, it tends to remain stationary or to sink; while in the latter, it rises and mingles with the atmosphere, which, under proper conditions, replaces it. Again, these changes may occur in both directions within the same space in twenty-four hours. For instance, at evening and at night the atmospheric air, being colder, enters the soil ; while by day, being warmer, its dircetion is reversed, and air is drawn up from below.

Movement due to temperature differences is almost constant, sinee it is only rarely that the temperatures of the air and soil are in agreement. The influence of barometric pressuro-changes is not very groat; with fall in pressure, the tendency is toward npward movement, and with rise, toward downward movement; but Fodor found from the study of a large number of observations that the actual observable changes were insignificant.

With the various influences at work causing morement of the soilair in all directions, it is plain that the soil, especially if highly permeable, is endowed with a sort of respiratory finction which keeps it more or less well ventilated.

Formerly, it was helieved by Pettenkofer and others of the " Munieh School" that the amount of carbon dioxide in soil-air might serve as an index of the amount of impurity and of the rate at which the latter is decomposing, and that comparison of the amounts obtainable from different soils would serve to indieate their relative cleanliness. But such is not the ase with soils equally permoable, owing to the influence exerted on soil ventilation by so many varying and conflieting causes. 
Indeed, it has been proved by Fodor that a permeable soil extensively contaminated by organic filth may yield less of this index of impurity than one fir cleaner, but less susceptible to ventilating influences.

\section{Soil-water.}

The moisture contained in the soil may be designated in three different ways, according to its position and the forees by which it is leeld in place; namely, hygroseopic, eapillary, and gravitation.

Hygroscopic water is that which artheres to the surfaces of the soil particles in the presence of air. A certain amount of moisture is condensed upon the surface of most solid substances exposed to ordinary dampness, and it adheres with great tenacity. The amount of water so obtained differs, other conditions being the same, according to the nature of the soil, some soil constituents surpassing others in their power to attract it. Thus, soils rich in organic matter (humus) have a greater degree of hygroscopicity than others in which this constituent is present to a lesser extent. In some soils, the amount of hygroseopic water is very marked by reason of the large amount of organic matter, and because also of the large surface area presented by the soil particles. Some idea of the tenacity with which this moisture is retained nay be derived from the fact that air-dried soils which appear to be quite dry - the dust of country roads, for instance-may yield as much as a tentl of their weight of water on eomplete drying by ordinary laboratory methods. Both the moisture absorbed from the air and the water held on the soil grains by surface attraction after a condition of decided wetness has been changed by the draining away of the rest, may be termed hygroseopic.

The eapillary moisture is that which is held within those spaces which have been spoken of as capillary in their nature. Under ordinary conditions, these are intermingled with spaces which may not be so designated and which contain air, and so the eapillary moisture does not ordinarily equal the pore-volume. The water in the capillary spaces may be that which is retained after thorough wetting from above, or it may have erept upward or laterally from points completely saturated. Capillary movement oceurs in all directions, but it is most marked from below npward to points where water is being withdrawn by evaporation or by the demands of growing vegetation.

The height to which water may rise by virtue of this force depends upon the diamcter of the spaces; the smaller the diameter, the greater the rise. Jurin's law of capillary movement is, that the height of ascent of one and the same liquid in a capillary tube is inversely as the diameter of the tube. Thus, water will ascend ten times as high in a tube having a diameter of $0.1 \mathrm{~mm}$. as it will in another with a diameter of $1.0 \mathrm{~mm}$. It follows, therefore, that capillary movement is most marked in soils of fine texture.

Capillary movement is influenced materially also by temperature and by the nature of substances held in solution. It diminishes as the 
temperature rises, and inereases as the temperature falls, so that cooling a soil uniformly will cause inereased capillary movement, and heating it will eause a fall. But with meven temperatures, the motion will be different aceording as the temperatures vary. Thus, if the lower part of a column of soil be cooled, the surface tension of its contained water will be increased at that point, and water will be attracted from the parts above, gravity assisting; whereas, if it be heated, its contained water will be attracted upward.

In saturated soils, motion of the water in any direction is influenced very greatly by temperature, because of the effect of heat in ehanging the viscosity of water. The higher the temperature, the greater the diminution in viscosity and the freer the movement.

The influence of dissolverl substances depends upon their nature, some favoring, and others retarding, movement. The rate is inereased by the presenee of nitrates, and is diminished by common salt and sulphate of caleium; but the faroring influence of the presence of nitrates is counteracted most markedly by organic substances produed in the decomposition of matters of vegetable origin, for a minute trace of these completely neutralizes the effect of such amounts of the former as are eommonly present in cultivated soil.

It is self-evident that anything tending to the diminution of capillarity of a soil diminishes the rate of eapillary flow. When the soil is worked in such a way, therefore, as to produce an open, crumbly condition in place of one of eompaetness, the rate of capillary movement within it is diminished very greatly.

We eome now to the third division, which has been designated as gravitation-water. This is the water which has drained away through the soil by the foree of gravity and aceumulated in the subsoil over an impermeable stratum which has arrested its farther downward journey. This is what is commonly known as ground-water, or subsoil-water. Its zone extends from the surface of the impermeable barrier upward to that point where the interstices of the soil cease to be eompletely filled with water, but are filled partly with air. This point is known as the ground-water level. The zone above it, through which water is moved in the eapillary spaces, is known as that of the eapillary soilwater, and extends as far as the water is moved through that force. Above this, at and near the surface, is the zone of evalporation, from which water is evaluorated into the atmosphere.

The impermeable stratum beneath the subsoil-water may be either very fine sand, compaet clay, or rock. It may be thin or thick, aceording to circumstances. Below it, there may be a sucecsion of alternating permeable and impermalble strata, so that in driving deep wells a variety of strata are pierced, and waters of varying composition may be seeured. Dense elay is practically impermeable to water, but ait the same time it ean coinmunieate its moisture to surfaces with which it comes in immediate contact, a fact which renders necessary the interposition of damp-proof material in the foundations of houses built upon it. 
Roeks vary greatly in impermealility; the densest of them contain very small amounts of moistnre in their pores, while others are so porous that they may eontain as much as a third of their volume of water. Again, most rock deposits are more or less fissured and seamed, and thus permit to a grater or less degree the passage of water at these points.

The water-bearing stratum is usually gravel or sand, but may be porous or fissured rock. Its depth is exceedingly variable, depending upon loeal geological conditions, and at two points not widely separated, it may be respectively slight and considerable.

'The ground-water is in constant motion both laterally and vertically. Its lateral movement, whatever its rate, depends upon the eonfiguration of the impermeable layer below, and not upon that of the surface of the land. Generally speaking, the direetion of the movement is toward the nearest large body of water, be this the sea, a lake, or a river; but it is not often possible to determine, exeept in a general way, from surface observations, whether at any given point the flow is in one direction or another. This is especially true when the water-bearing stratum is thin and underlaid by an impermeable stratum of very irregular conformation.

The rate of movement is also exceedingly variable; it may be fast, or slow, or hardly perceptible. In Munich, for instance, according to Pettenkofer, it amounts to about fifteen feet daily, while at Berlin, it is only very slight, and at times is wanting. It is influeneed by the eonfiguration of the subsurface, by the permeability of the subsoil, by the amount of the accession of moisture from rainfall and melting snow, by the obstacles interposed by the roots of trees and other plants, by others at its outfall, and by the withdrawal of moisture by the needs of vegetation and of communities of men.

The rise and fill of the ground-water-that is, its vertical movement-depend chiefly upon the amount of rainfall; and, on the other hand, upon the rate of withdrawal by evaporation, vegetation, and water supply of communities, and upon the freedom of, or obstacles to, the outflow.

The effect of rainfall is generally not immediately pereeptible, for so much time intervenes between havy falls and penetration that a falling of the gronnd-water level may continue to be observed for a long time after a period of great wetness; but when the level rises, it is a proof that additions have been received from above, though perhapes the aceession has travelled through a long distance in the soil. When the level fatls, it is a sign that the npper strata have become dry throngh evaporation, and that capillary attraction has carried moisture upwarl to replace the loss.

The rise and fall of the ground-water level may be determined by measuring from day to day the distance between the surface of the soil and the height of the water in a number of wells in a given locality. This may readily be done by means of a tape-measure or chain to which 
is attached a rod hearing a number of shallow metallic cups which are lowered into the water. 'The distance between the point on the ehain at the mouth of the well and the uppermost eup in which water is found indicates the position of the water-level with respect to the surface.

By removing obstacles to the outfall of the undergromel river as it sometimes is called, and by ereating new outfalls by diteling more or less deeply, according to individual conditions, by sinking drainage wells, or by laying drain tile beneatl the surface at such deptlss as may appear to be advisable, the level of the ground-water may be considerably lowered, and the soil thereby rendered correspondingly drier, and also, by reason of the influence of water on soil temperature, warmer.

Sources of Soil-water._The principal source of soil-water, it is hardly necessary to say, is the rainfall, but by no means all of the water precipitated from the atmosphere during a storm penetrates to the subsoil. Iight mains may be wholly lost by evaporation, and heavier ones, especially during active vegetation, may penctrate but very slightly beneath the surface. In early spring and in antumn, the amount which pereolates downward is natmally much larger in proportion. A by no means insignificant amount of moisture is that derived by absorption and condensation from a moist atmospliere. In periods of dronght, this power of dry soil to absorb water from humid aiv is of the greatest value to vegetation. The amomit absorbed differs according to the mature and hygroseopicity of the soil elements. Thus, a soil rich in humms will attract more water than another composed wholly of sand. Condensation of water occurs when the surfice is cold and in contact with moist air. This condensation may occur from above or from the rising moist soil air just below.

A third source of moisture, of no great importance, is the brealing up of organic matter into its constituent elements, in which procesis the lydrogen is in great part nltimately released in combination with oxygen as water. Another and exceedingly important souree of soil moisture, important not becanse of the amount, but because of the quality of the water, and becanse of its possible effect on the supply of drinking-water and on public health, is the waste waters incident to human life, which in so great a proportion of commmities are discharged directly into the soil, where, being ont of sight, they are equally out of mind.

Loss of Soil Moisture by Evaporation.-The amount of water which a soil loses hy evaporation is influeneed by a number of fictors, which indude the water content of the soil, the liejght of the permeable layer, the comprosition and structure of the soil, and the chatacter of its surface, and, partiendarly, whether it is oovereyl. In other words, the rapielity of the process is proportional to the enmbined anea of surfaces exposed, and to the fiteility for replacing the losis by withelrawals from below. 
Influence of Vegetation on Soil Moisture.-The amount of water in soils is influenced greatly by growing vegetation, which requires a vast supply for the proper maintenance of its functions. It withdraws it by absorption by the roots, which extend downward to surprising depths, the roots of wheat, for instance, attaining sometimes a length of eight feet and more. From the roots, the water passes into the circulation of the plant, assists in the varions physiologieal processes, and then, for the most part, is given off from the leaves into the atmosphere. It has been calculated by Pettenkofer that an oak evaporates more than eight times the rainfill, and that the Eucalyptus globulus is even more active. The difference between the rainfall's contribution and the amount exhaled represents the amount which has been withdrawn by the roots from the capillary spaces and from the water-table itself. As the water in the capillaries is relinquished by them, more comes up from below to take its place. Thus it is that a plant or tree acts during the growing season as a constantly working suction apparatus tending to dry the ground, and so may be explained, in part at least, the condition of wetness that is acquired by some lands after removal of trees.

All growing crops withdraw enormous amounts of water, and after the growth becomes well advanced, it is the capillary water upon which dependence is placed, for the rainfall penetrates but a short distance into cultivated land, and most of it is lost by evaporation. Were it not for the capillary water supply, no crops could be raised, except under most extmordinary conditions of weather and by artificial irrigation, since but a short period of drought would suffice to produce wilting. According to Stockbridge, "The quantity of water thus required and evaporated by different agricultural plants during the period of growth has been found to be as follows:

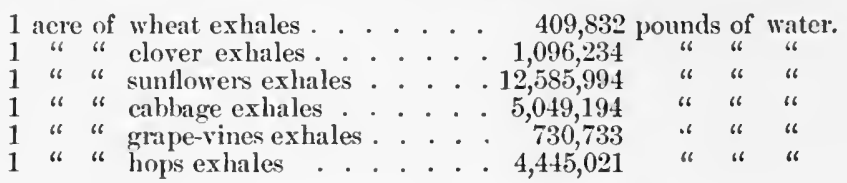

But the influence of vegetation on the water content of the soil is not limited simply to its withdrawal and evaporation into the atmosphere, for it acts in the other direction to impede surface flow and subsurface drainage. This is seen more particularly in the case of trees and forests. The forest cover keeps the soil granular and promotes downward percolation; the tree roots, penetrating in all directions, present an effective obstacle to rapid lateral movement through the soil. Removal of forests and clearing away the surface of the forest litter promote sudden and destructive freshets in the springtime and dronght when, later in the year, the water is needed. 'The ill effects of deforestation are noticed particularly in parts of Maine and in the Adironlacks, where streams that formerly ran full the ycar round are raging

${ }^{1}$ Rocks and Soils, New York, 1888. 
torrents when the winter's snows are melting and but insignificant brooks or wholly dry during the summer months. It has been stated by Major Raymond, of the U.S. Engineers, that, in forest areas, fourfifths of the rainfall are saved, while in eleared land the same amount is lost by evaporation and surface flow.

Other Effects of Vegetation Upon the Soil.-In addition to its influence on the movement of soil-water and on its amount, vegetaltion is an important factor in the determination of soil temperature and of the amount of mineral matter available for succeding growths. The deeply penetrating roots bring to the tissues of the growing plants a large amount of mineral matters from the subsoil. On the death and decay of the plant, these matters are returned to the soil at its surface, where they are available for reabsorption as plant food.

The effect of vegetation on soil temperature is of much importance in both hot and cold climates. A barren soil or one from which vegetation has been stripped absorbs the heat rays of the sun more rapidly and becomes much hotter than one which is protected by growth of any kind. The air above the soil becomes hotter, too, because of greater heat radiation, and the difference in the surface temperature of bare ground and that covered by grass or other vegetation is further increased by the cooling effeet of evaporation of moisture from the leaves. Herbage acts as a protection against excessive heating in hot climates, and as a blanket to prevent loss of heat in cold ones. In summer, the areas covered by vegetation are cooler than those which are unproteeted against the direct rays of the sum, and in winter, they are warmer because of the obstacle to heat loss.

Trees obstruct the sun's rays and impede wind eurrents, and thus the soil is cooler and at the same time suffer's less losis of moisture by evaporation. The obstruetion of the wind eurrents deprives the soil air of one of the influences having to do with its movement, and thus interferes with soil respiration. The obstacle opposed by trees to the motion of air is so great that, in the interior of a piece of wooks, the air may be quite cahn while a gale is blowing outsisle. In winter, the olsstruction of the sun's rays aids in the eonservation of the soil heat by preventing the aceumulated snow from melting, and thus kecps the surface protected by a blanket.

In eold elimates the influence of trees may be at the same time pernicions and beneficial; that is to say, pernicious, in that the ground is colder and moister than it would be harl the sun's rays frec aceess, and beneficial, in that the trees afford protection against winel. The judicious removal of trees will often render a climate more equable. In hot elimates, as in eold, trees should be remorerl only in case of necessity and after due consideration of the probable results. The hottest spots in hot comntries are those cleprival of the beneficial infuenees of vegetation.

It may not be ont of place here to mention the supposed ageney of woodlanel in protecting communities from "malarial exhalations" from swamp localities. That the interposition of a belt of trees has been 
followed in a number of instances by deciled improvement in public health so far as malaria is eoneerned, camnot well be denied; but the improvement is not owing to the fancied property of leaves to condense upon their surfices the malarial poison, but to the fict that the winged bearers of this poison, blown along by the wind, are filtered out of the air by the leaves, or themselves seek the proteetion thus afforded against farther involuntary movements, and attach themselves to the leeward side of leaves and trunks.

\section{Pollution of the Soil.}

The soil receives polluting matters of infinite variety and in widely differing amounts, but their nature and their amount are of less importance relatively than their point of entrance. Some of these pollutions are unavoidable, and these, indeed, are the ones concerning which we may give ourselves the least concern; others are avoidable, thongh not always, or even usually, without the ineurring of expense.

The unavoidable pollutions include the urine and droppings of animals, the eareasses of such as have died and have escaped the notice of other animals that act as seavengers, and vegetable matters of every conceivable kind in various stages of decay. Exeepting under very unusual conditions, such, for instance, as may exist in time of war or flood or epidemies, when large numbers of horses, cattle, and other animals are killed or die, these, lying at or near the surface, are of comparative mimportanee, since, exposed to natural processes of purification, they are resolved into simple innocuous substances, which are absorbed by plant life or washed downward into the soil.

The aroidable pollutions are mainly those which man deposits beneath the surface, and these are first, and of minor importance, the bodies of the dead, and seeond, of vast importance, the exereta and other organic filth that constitute sewage. The temporary storage of filth in water-tight receptacles built under ground ean, of course, do no harm to the surrounding soil, but it is not into such that man usually chooses to deposit his waste. Water-tight cesspools gradually become filled and then require to be emptied, while those with pervious bottoms permit the eseape of the contents downward, require no thought or eare, and are, therefore, a souree of eontentment and of saving of expenditure. 'The filth thus introduced is, however, below the zone of bacterial activity of the beneficent kind, and becomes stored up in the subsoil or is washed away gradually by the ground-water, which therdyy is made unfit for human consumption. Organic matters depositerl in the upper strata of the soil are resolved into their constituent elements with greater or lesser rapidity acerding to loeal conditions of distance from the surfiee, temprerature, degree of moisture, and permeability to air, the proeess advaneing most rapidly in a wellventilated, moderately dry soil near the surface, and most unfarorably in wet, compact soils, far from the surface.

The influence of the physieal condition of the soil is observed fre- 
quently in the exlumation of bodies for one cause or another after varying periods of interment. Thus, in open soils, bodies may disippear almost completely in the course of a few years, while in stiff wet clays they may be found even after twenty and more years to be putrid masses, still undergoing a most gradual process of disintegration. Indeed, it is stated that in exeavating an ancient churehyard in London, the soil of which was a wet elay, bodies were removed that showed, after two centuries of interment, no materially different appearance from that of others which had been buried not over a seore of years. Recently, Dr. A. Riedel' had an opportunity to comprare the results of decomposition proceeding in bodies buried for about the same period in soils that were respectively loose, well-drained, and well-ventilated, and compact, wet, and impermeable to air. In the first instance, the remains were fairly dry and quite inoffensive to the sense of smell ; in the other, they were a slimy, loathsome mass of rottenness, which galve out such a horrible stench that the erowd of idlers that had gathered was quickly dissipated, while those whose duty compelled them to remain were made unpleasantly sick, and could not rid thenisches of the smell, which clung to them until several days latd elapsed.

In the decomposition of organie substances in the soil, no offen-ive emanations are noticed, if a substantial layer of earth is interposed between them and the atmosphere. Just as it has power to retain water in its interstices and on the surfice of its constitnent particles, so has the soil the faculty of absorbing gases and vapors, a property which eannot have escaped the notice of any person acquainted with the common earth-eloset. The soil aets in this respect like charcoal, and can take up not only odors, but also coloring matters and other substances.

Perhaps the most striking illustration of the affinity of soil for olors is the fact that illuminating gas from leaking street mains has in its journey through the soil been known to be divested of its culurous eonstituents to such an extent that, being drawn into homses with the soil-air, its presence escaped observation until the production of poisonous effects drew attention to the existence of an unusual comdition of the air.

$A$ like retaining action is manifested in a less marked dengree toward substances in solution, ${ }^{2}$ which are held baek by surfice attlic-tion, a fact which has been noted repeatedly hy hyerienists and agrieultural chenists. 'This is more noticeable in soils of' the grain, since such present a far greater area of grain surface. Hofluam ${ }^{3}$ tillext two eylinders of equal size with sand of different degreess of fineness, but with the same total pore-volume, and to each was atded from albove an equal volume of solution of common salt, and then daily, for ten days, an equal volume of distilled water. The drainage of cacil day

' Münchener medicinishe Wochensehrift, June 6, 1899.

2 See page 341 for an musually striking example.

3 Teher das Findringen von Veruncenigungen in Boden und firundwasser. Archiv für Hygiene, 11., p. 145. 
was tested as to its content of salt, and it was found that, whereas that from the eoarser sand yielded salt on the second day and gave the highest results on the third, from which time the yield progressively dwindled, that from the finer showed no trace until the sixth day, and its maximum on the seventh. Repetition of the experiment in the same way in all partieulars yielded identical results. 'Thus it is shown that pollution travels more quickly in coarse soils than in fine.

In the decomposition of proteid substances in the soil, hasic substances are believed by some to be formed, which may be taken into the system, and so affeet the resistance of the body to disease as to favor infection. 'This, however, is purely hypothetical.

As has been remarked, the presence of baeteria is essential for the resolution of organic matters in the soil. This has been illustrated in a striking manner by Duclaux, ${ }^{1}$ who treated sterile soil with sterile organic matters, such as milk, sugar, and starch paste, and then planted therein peas and beans. Although the resulting plants were well cared for, they did not thrive, but remained as thin and weak as though growing in distilled water. The organic matters in the soil were of no value in their growth, for they could not be absorbed as such, but only after decomposition. The addition of a little unsterilized earth sufficed, however, to start the required process, and then the growth improved at once.

\section{Bacteria of the Soil.}

The bacteria of the soil are found almost wholly in the superfieial layers, and below a deptl of twelve feet their number is relatively few. Is they need organic matter for their growth and multiplication, it may be inferred that the greater the amount present, the greater will be their number. Thus, they are far more numerous in rich garden soil than in ordinary sand and elays.

The conditions most favorable to their development are, in addition to the presence of the organic pabulum, moisture and certain limits of temperature. Dryness and extremes of heat and cold are all unfavorable; saturation with water may or may not be, aceording to the variety, for there are some that in a wet rich soil can go on decomposing organie matters.

In ordinarily rich soil, the number of bacteria ranges from hundred thousands to millions per cubie centimeter in the surface layers, below which they diminish in number very rapidly, until, at ten to twelve feet below the surface, the soil is practically sterile, exeept for those that have been washed down or carried by burrowing animals, or, as above stated, deposited by man in organie filth.

The soil bacteria are mainly of the beneficent varieties, the saprophytes which perform only useful offices, inchuding the numerous varieties of the nitrifying organisms. While different speeies of pathogenic bacteria have been fonnd in the soil, and although certain of

I Comptes rendus, $\mathrm{C}$. 
them, the bacilli of tetanus and of malignant mdema, are very generally present, this elass of organisms finds, as a rule, the conditions present in the soil unfavorable to development.

In the first place, the temperature is too low, excepting in the rery uppermost layers in warm weather; and, furthermore, the pathogenic kinds eamnot thrive in the presence of the enormously numerons saprophytes, which, in some manner not as yet satisfactorily explainerl, bring about their destruction. This action has been demonstrated repeatedly by Koch and others, who showed that anthrax baeilli and other pathogenie varieties can grow in sterilized, but not in unsterilized, soil.

Klein ${ }^{2}$ insists that pathogenic organisms in buried bodies cannot maintain vitality in the presence of $B$. cudaveris sporogenes, which is always present in decomposing bodies, and that, in most cases, a month is suffieient time to insure destruetion. He buried guinea-pigs containing varions kinds of miero-organisms within the ablominal cavity, and at different times exhumed them and made search for living speeimens. He found that $B$. prorligiosus lived 4 weeks, but not 6 ; strophylococcus aureus, about the same; Sp. cholere, 19, but not 28 dars; B. typhosus and B. diphtherice, not longer than 2 weeks; B. pestis, 17 , but not 21 days, and $B$. tuberculosis, not 7 weeks.

It is believed that, in the deeper layers, away from the salprophytes, the spores of pathogenic species may find a lodgensent fivorable to storage, but not to development, and that there they may remain with dormant vitality.

Many examinations of graveyard soils and of bits of coffins lave been made by Dr. E. H. Wilson, of Brooklyn, to determine, if possible, the presence of pathogenie baeteria as well as the number of bacteria as compared with those in other kinds of soils. He found no more bacteria than in others, and no pathogenie kinds whatever.

There is one kind of soil that has been fonnd andin and again to have a destructive action on pathogenic baeteria, and that is peat, which kills then very quickly, probably through the contained organie acirls.

The soil aets as a very good filter, and holds baek most of the organisms, but by the aid of flowing ground-water or water cutering from above, they may be carried through consiclerable distanees. Thus, Drs. Abba, Orlandi, and Rondelli, ${ }^{2}$ experinenting on the filtration capacity of the soil about the filter galleries of the Turin water supply, found that cultures of Micrococess prodigiosus, poured with large volmomes of liquid into the ground at various points, made their appran rance 200 meters away in 42 hours, and 12 and 27.5 meters away in 7 hours. In these experiments the property of the soil for holdiug hack sulstances in solution was manifested in a renarkible degren, methyl-eosin and uranin, substances which inpart intense red and rrecu eolorition to water, and which were added with the cultures, not appenring until

1 Twenty-eighth Annual Report of the Losal Government Board, Supplement.

${ }^{2}$ Zeitschrift für Hygiene und Infeetionskrankheiten, XXI., p. 66. 
long after the organisms had passed through. In the instance in which they appeared in 42 hours, the coloring agents could not be detected until after 75 hours had elapsed.

The relation of the soil to the varions pathogenic bacteria will be discussed farther under separate headings.

\section{Soil and Disease.}

The influence of the soil on health and disease is admitted very generally, but is little mulerstood. We know that certain soil comlitions favor the ocenrenee of eertain diseases, but why this is so remains a problem for fiuture researeh to solve.

Our notions concerning the causal relation of the soil are probably greatly in error with respect to certain diseases, being donbtless exaggerated as regards some, and equally undeveloped with others. Composition, permeability, temperature, moisture, evaporation, soil-air, and flnctuations of the level of the subsoil-water, all are supposed to bear important relations to many of the diseases of mankind and of animal life in general.

Such evidence as bears on the relation of the soil to diseases is given in general terms below.

Soil Dampness and Disease in General.-It has long been universally noticed that dampness in and near the surface of the soil injuriously affects the health of those dwelling nearby. It causes coldness of the soil and dampuess of the atmosphere immediately above, and appears to conduce more particularly to rheumatism, neuralgias, and diseases of the respiratory tract. It has been noticel by many who lave investigated the subjeet, that the general health of those dwelling over damp soils is much inferior to that of those more favorably circumstanced in that regard, and instances of improvement on removal from damp to dry localities are too commonly known to need illustration.

It is generally agreed that a soil in which the ground-water level is high, five to ten feet, for instance, from the surface, is not farorable to health; and that a deep level, fifteen feet and more, is unobjectionable on the score of dampness. This being admitted, it might reasonalbly be inferred that artificial lowering of the ground-water will be followed by increase in salubrity, and, as a matter of fact, that is precisely what does oceur. But it should be stated, in order to be historically acenrate and in all fairness, that while increased healthfulness is a consequence, as a rule it is not the object songht, for, as a gencral thing, soil drainage, especially on a large scale, has been carricel out to meet the demands of successful agrieulture rather than in consequence of solicitude for public health.

The methods employed may be stated generally as inereasing the outlet and removing obstructions to the outfall. Ditching and the construetion of undergromel channelways by means of drain tile or puble and fieldstones are the most common methods of drain- 
ing. Sometimes, drainage wells are driven at intervals down through the impermeable stratum into an open subsoil, into which they then drain.

The difficulties in the way of draining extensive areas of mulealthy and agriculturally moproductive land lie chiefly in the lack of individual coöperation. Such undertakings must necessarily be aurricl on in a systematic mamner, and ought always to be under the direction of some central authority-municipal, state, or national.

By means of under-drainage, thousands and thomsands af acres in various parts of this comtry, notably in Illinois and Indiana, and vast areas of land in England and on the eontinent, have been eonverted from unhealthy, malarious, and more or less unproductive tracts, into healthy and richly productive comntry; but the scheme is not always successful in relieving a locality of disease, especially of malaria, as has been proved in parts of Italy, Australia, and dsewhere.

Soil and Pulmonary Tuberculosis. - There is an undoubted connection between this disease and soil dampmess, which is most manifest when one investigates the prevalence of the discase over the same soil before and after soil drainage, by which it will always be found to be diminished. Why this is so we ean only eonjecture.

We know that dampness is one of a possibly considerable number of factors in prodneing predisposition to the discase. We know that, other eonditions being the same, the discase is far more common on low damp soils than on elevated dry ones. We know alio that the diseatse is comparatively rare in some parts of the earth where the soil is exceptionally dry.

The distribution of the disease and its relation to soil dampuess were first brought to public notice by Dr. Henry I. Bowlitell, ${ }^{1}$ of Boston, at the ammal meoting of the Massachusets Medieal Fociety, in 18(i2, who submitted two propositions, the results of most extensive investigation, which were, in sulsstance, that dampmess of the soil, whether inherent or acquired by reason of proximity of bodies of water, is an exciting canse of consumption, which discase ean be cherelial in its course or even prevented by proper attention to soil conditions. Shortly afterwarl, similar conchusions wore promulgated in Eneglamel by Di. Buchanan, who had been making observations along the same line, not knowing that Dr. Bowditel was similarly ongunerl. There propositions were aceepted by the profession, and haive heen maintained ever since.

Typhoid Fever.-It is bolieved quito genomally that this diseaso is connected in some way with soil conditions as woll ats with drinkingwater. Indeed, there are some anthorities who remind the soil as of infinitely rreater importanee in the cansation of apiclemies of this disease and of elolera than drinking-water, whioh to these minds has absolutely no influenes one way or another. The Pettenkofor theory of the cause of these outheraks attributes it to the soil, fiom whinh the

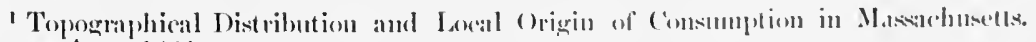
Transactions, $1860^{2}$.
} 
exeiting cause is distributed by the ground air, which, as has been stated, is in constant movement.

According to the distingnished originator of the soil theory, the unknown poison is introlueed into the soil, where, under proper conditions of organic filth, and other influences, a species of fermentation oceurs, the end product of which is the exciting canse, which is then capable of inducing the disease in those by whom it is inhaled. All important in this process is the vertical movement of the ground-water, and it is certainly true that over a long period of years of obscrvation at Municl, there was a most remarkable coincidence between epidemies of typhoid fever and fluctnations in the ground-water level.

The condition most favorable to high morbidity was demonstrated to be a rapid fall after an musually high level. The highest deathrates during the time covered oceurred during the years of lowest level, and the lowest rates in the years of the highest level. A similar coincidence has been noticed elsewhere, but by no means in all or even a majority of the localities where investigations have been made.

The theory had, for a time, many adherents, and the controversy between the soil-theorists and the "water-fanatics," as Pettenkofer called them, was carried on at times with exceding bitterness. But within the past deeade, the water theory has been so thoroughly proved as the chief, if not the sole cause of extensive ontbreaks, that interest in the theory has fallen off, and its supporters are now few in number. Pettenkofer ${ }^{1}$ himself, however, was to the end as uncompromising as in the beginning, and found no difficulty in applying it to the great epidemic of cholera in Hamburg, in 1892.

The contention that the extraordinary endemicity that prevailed so long at Munich was due to the filthiness of the subsoil, which was honeycombed with eesspools, cannot lightly be brushed aside, for it is a fact that, with discontimuance of these abominations, and with a system of improved sewerage, the typhoid fever rate fell from its position as a leader down among the lowest known. Nor was this fill due, as has been elaimed, to change in the water supply, for the great epidemies had ceased, and the fall had long continued, before the water supply was ehanged.

Experiment has shown that the typhoid organism may retain its vitality in the soil for considerable periods under favoring conditions of warmth and moisture. Robertson ${ }^{2}$ removed sods from several places in a field, and wet the exposed soil with diluted typhoid cultures, one at the surface, one at a depth of nine inches, and a third at eighteen inches. After 130 days, the bacilli on the surface had multiplied, and where they had been placed eighteen inches below, they could also be found in the surface layer. Iater on, in the winter, no results conld be obtained; but in the spring, he moistened the patches with sterile bouillon in very dilute condition, and afterward succeded in obtaining growths.

1 Münchener medieinische Woehenschrift, May 2, 1899.

2 British Medical Joumal, Jan. 8, 1898. 
This positive result accords with the views of Germano,' who found that typhoid bacilli will live for months when ineompletely dry ; but according to Flügge, they do not survive complete drying longer than fiftecn days. In air-dried condition they appear to have unimpared vitality for some days, according to Brownlee, ${ }^{2}$ who dried and sterilized ordinary soil and then infected it with a broth eulture of trphoir and kept it at $98^{\circ} \mathrm{F}$. for a day. It was then left exposer to the air for a week, during which time it became sufficiently dry to be easily seattered by the breath. Cultures from this gave positive roults. But it should be remembered that air-dried soil contains considerable hygroseopie water; eonsequently his bacilli were doubtless fairly well supplied with the necessary moisture. Of more importanee, apparently, than the question of moisture-for all soils possess some-is the nature of the contained organic matter. Dr. Sidney Martin ${ }^{3}$ has shown that unpolluted (virgin) soils are inimical to the typhoid bacillus, regardless of the amount of their contained organic matter of vergetalble origin, while specimens containing polhuting material of animal origin favor its existence. Such, after sterilization, were planted successfully, and it was learned that, in the presence of moisture, differences in temperature had but little influence. Thus, the organism thrived alont equally well when specimens were kept at $98^{\circ} \mathrm{F}$, at ordinary room temperature, and as low as $37^{\circ} \mathrm{F}$. By no means the least interesting observation made was with regard to the duration of viability of the baeillus. In one of the sterilized polluted soils, the organism wats still active at the expiration of 456 days; and even then, after thorough drying and pulverization, active growth could be obtained. In company with various species of bacteria, anong which the predominant kinds were members of the $B$. coli group, it was recovered after 50 days' exposure to temperatures ranging between $37^{\circ}$ and $61^{\circ} \mathrm{F}$.

Later experiments, ${ }^{4}$ in which the typhoid organism was planted with different soil bacteria, proved that varions species from a particular soil had the power of eompletely externinating it within as shrort timo, while others had no influence whatever. Therefore, it would alpeser, whether or not the typhoid organism ean exist in a given soil, will depend upm the kinds of soil bacteria present, as well as upon special connditions of temperature and dampness. Dr. Martin found the period of vitality in unsterilized soils to be about 12 days, but in no ease did the organism appear to multiply. An experiment condueted by Levy and Kalyser to determine the duration of infectivity of this ormanism yiedded most interesting results. The fees of a typhoid patient were discharged into a cemented vault, remained therein 5 months, and were then spread on a clay soil, from which, after 15 days of winter weather, the speeific organism was isolated. They came to the natural conclusion that

'Zeitschrift für IIvgiene nnd Infectionskmankheiten, XXIV., p. 403.

${ }^{2}$ Public Health, Jinuary, 1899, p. 272.

${ }^{3}$ Report of Local Government Board, 1898, London, 1899.

- Ibidem, 1900, London, 1901.

${ }^{5}$ Centralblatt für Bakteriologie, ete., March 20, 190:3, Abth. I., XXXIII., p. 488. 
typhoid stools ought always to be disinfected before being discharged into a privy vault.

The effect of temperature ehanges due to the presence of animal exereta mixed with the soil is shown by Gaertner ${ }^{1}$ to be considemble. He introdnced enltures of varions organisms in wire baskets into the interior of compost heaps of various composition, which became heated to different extents, and observed that the bacilli of typhoid and cholera were the least resistant of all. With rapid and marked heating, their life was short; but it appears probable that in the alosence of heat, even with the given surroundings, they may live through the winter. Under the ordinary heating that oceured in the compost, these two organisms were destroyed in a week, while the bacillus of tubereulosis remained virulent a number of months.

But asicle from what we glean from scientifie research with the speeifie organisms, we know from experience that there are many places with polluted soils where typhoid fever was unknown until the importation of a single case from withont, and that, afterward, sporadic cases, for which no convineing explanation is afforded, have oceurred at varying intervals. And in country distriets, whose inhabitants are not given to travelling much beyond the confines of their farms, it is noticed frequently that single cases oceur in the same household at intervals of a year or longer.

In such cases, it seems hardly reasonable to say that the original case has left nothing as the exciting canse for later attaeks, and that fresh introductions of the specifie organism must have occurred from some unknown source, for it is not unlikely that the variety of conditions that affeet the viability of the organism may, in some cases, act to keep it alive, and, on occasions, stimnlate it into a condition of angmentel activity.

Cholera.-Coneerning the relation of this disease to the soil, there is but little to be sairl. Prior to the diseovery of the specifie organism, the soil theory of the origin of epidemic outbreaks had considerable vogue; but now it is known that, even in times of greatest prevalenee of the disease, the organism has never been found under natural conditions in the soil. It ean be kept alive under certain favorable conditions of moisture and heat for varying periods; but under natural conditions it is one of the least resistant bateteria and quickly dies. We have no evidence whatever that cholera is a soil disease.

Bubonic Plague.-This has been regarded as a soil disease; and it has been believed, from the fact that rats have been conspienous as vietims of it in the early stages of its devastating ontbreaks, that these animals have aequired the infection in the soil, and have brought it to the surface, and thus acted as its earriers. But rats are notorions as frequenters of places where filth of all kinds aceumulates, and it is not strange that where they and filth abound, they become diseased, if the infective agent is present.

The whole qunestion of etiology of plague has been eleared up by the 1 'Keitsehrift für IIygiene und Infectionskrankheiten, XXVIII., p. 1. 
discovery that fleas, and especially the common rat flea (Pulex pallidus, Ceratophyllus fasciatus) of tropical climates, act as an intermediate host for the bacillus of plague. Thus the reciprocal transfer of the specific organism between man and rats, together with other rodents, such as ground squirrels, has been demonstrated repeatedly.

Diphtheria.-Although there is no proof that the lacillus of diphtheria is fomd even as an oceasional lodger in the soil, there is a general agreement that a elose comnection exists between soil dampmess and the prevalence of this disease. It is true that experiment has demonstrated the viability of the organism in moist soils for limited poriods, but it has never been fomd in soils other than those in which it was deposited intentionally. The common belief is that a moist soil is an invariable concomitant of unnsual prevalence, and that in times of comparative freedom from the disease, the soil is dry and the level of the ground-water low. "As long as the soil is well washer by the winter's high tide and afterwards dried and aërated dnring the summer's low tide, all goes well : but so soon als these salutary movements are arrested or their order disturbed, diphtheria prevails, raching its acme of prevalence when stagnation at a relatively high level is most complete."

Aceorling to Dr. S. M. Copeman, ${ }^{2}$ there appears to be no direct relation between epidemies and rise or fall of the gromel-water, "provided that the structure and atmosphere of the homses are not affoeted. Many districts, which, usually dry, are liable to oceasional floods, are remarkably free from the disease, so that it appears that a persistent impregnation of the soil with moisture is of more importance than fluctuations in the height of the ground-water, particulary if these have any eonsiderable lange."

Opposed to the views above expressed are the conchsions based on a most eareful and extensive investigation by Dr. Arthur Newsholme, ${ }^{3}$ of epidemies of diphtheria in all civilized comntries and thrip ineident conditions of rainfill and soil moisture. Dr. Newsholme's aminonee as a skilful interpreter of the value of statistics, and the fact that no such exhanstive inquiry into this question has ever before boen made, entitle his conclusions to more than ordinary weight. Adnitting that personal infection is the ehiof means by wheh diphtheria is spreal firom town to town, and fiom comtry to country, he summarizas his observations on the relation hetween rainfall and ground-watre and the origin of epridenic diphtheria as follows:

"1. An epidenic of diphtheria never originates, in the towns and eomintries in which I have been able to collert ficts, when there hats been a series of years in which each year's rainfall is above the avolage anomint.

"2. An epidemie of diphtheria never originates or continuss in a wet year (i. e., a year in which the total anmal rainfill is materially

1 Notter and Firth, Treatise on IJygiene, 1896, p. 463.

2 Stevenson and Murphy, Treatiscen II yeiene, 1s92, Vol. I., 1. 338.

3 'The Origin and Sprenil of P'andenic Iiphthera, London, 1898. 
above the average amount), unless this wet year follows on two or more dry years immediately preceding it.

" 3 . The epidemies of diphtheria, for which acenrate data are available, have all originated in dry years (i. $e$, years in which the total annual rainfall is materially below the average amount).

" 4. The greatest and most extensive epidemies of diphtheria have occurred when there have been four or five consecutive dry years, the epidemic sometimes starting near the beginning of this series, at other times not until near its end.

"5. Dry years imply low ground-water, and we find, therefore, in the years of epidemic diphtheria that the ground-water is exceptionally low. The exact variations in the ground-water which most favor epidemic diphtheria cannot, with the data to hand, as yet be stated; but it is probable that when this is cleared up it will become clear why in exceptional years which have a deficient rainfall epidemic diphtheria is either absent or but slight."

It has often been pointed out that local soil conditions causing dampness of habitations even in dry years, such dampness, for instance, as obtains in houses built over wet impervions clays, conduce to outbreaks of diphtheria in the dwellers therein ; but, as is well known, such dampness acts as a very important depressant of the vital forces, and prepares the mucous membranes of the respiratory tract for the favorable reception of specific organisms of varions kinds.

Malaria.-It has ever been held that the most intimate relation exists between the soil and malaria, especially prominent in districts abounding in marsh lands. It has been noticed repeatedly that in malarions countries the upturning and excavation of wet or damp soil are commonly followed by the occurrence of the discase among the laborers so engaged; that infection is more common among those who go about at night, and especially among those who slcep out-of-doors; and that the draining of marsh lands is often followed by the disappearance of the disease. All of these facts are compatible with the theory of transmission by mosquitoes, and it is now accepted generally that malaria is connected with soil conditions only in so far as the latter permit the breeding of the specific mosquitoes. (See Chapter XII.)

Yellow Fever.-There is no evidence of connection between the soil and outbreaks of yellow fever, although for many years such a relation was assumed to exist. The work of American investigators has proved this disease, also, to be mosquito-borne.

Tetanus and Malignant Edema.- It is well known that the organisms of these two diseases are found very commonly in most garden soils, in road dust, and in soil in general which has been enriched by the addition of decomposing organic matter. But in spite of the fact that opportunity for infection through abrasions, euts, and wounds of the hands, feet, and other parts is a matter of daily occurrence with a large proportion of the people, these discases are companatively uncommon. They are noticed most eommonly in cases of severe 
injuries, such as compound fractures, and in shattering wounds due to explosives. According to some authorities inoculation of spores alone is without effect.

An unusual number of cases of tetanus is noticed in various localities in this country after every annual celebration of Independenee Day, due chiefly to wounds caused by cannon-crackers and blank cartridges fired in toy pistols.

In the following table ${ }^{1}$ is given the number of cases of tetanus that have occurred in the United States in the years 1903 to 1910 inclusive, together with the probable source of the infection:

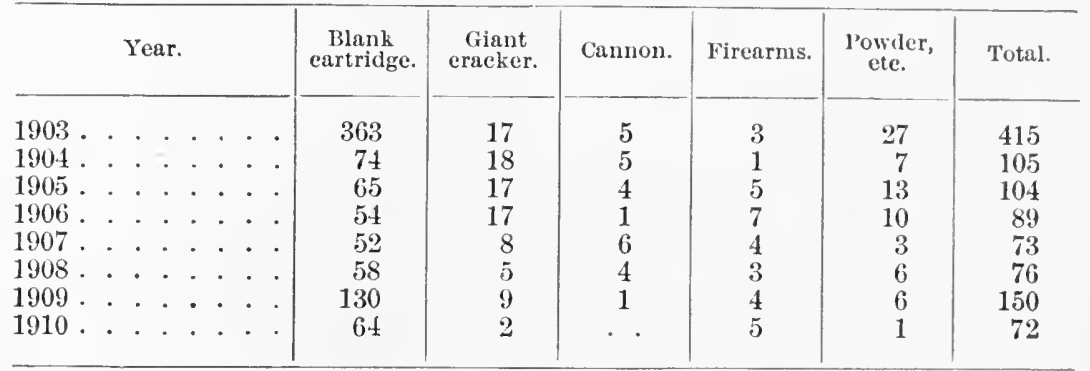

Examinations of cannon-crackers by Dr. Harold Walker and of blank cartridges by Dr. H. G. Wells for tetanus organisms have yielded negative results, and it is probable that infcetion is due to organisms already on the hand of the celebrant when the accident occurs.

Anthrax.-The bacillus of anthrax has been found in the soil of pastures in which infected animals have been confined, and it was thought at one time that, following the burying of animals dead with the disease, the soil coukl be infeeted thoronghly through spore formation, the spores being brought to the surface by earthworms, there to be the cause of fresh infections. Now, however, this view is regarded as untenable, since the spores are not formed within the putrefying eareass, and the bacillus itself is soon destroyed in the process of decomponition of the tissues. Thus when a body is buried, the organisms are soon rendered incapable of reproduction or of continuing their own existence.

The theory that the spores are brought to the surfice by burrowing earthworms, was demolished by Koch, ${ }^{2}$ whose comelusions were haticel upon direct experiment, and was abandoned by Pastemr himself, who first suggested it becanse of finding spores in the superficial layer of soil at a spot where, two years previously, a eow, deal of the disease, had been burierl at a depth of over two meters, a depth not ordinarily reached by arthworms in their burrowing.

Therefore, it secms most likely that fresh outbraks among attle grazing on fields where others have died and have been buried are due not to the buried organisms, but to those which in one way or an-

1 'The Jonrnal of the American Merlical Assuciation, Fept. 3, 1910, 1. 865.

" Mittheilungen ans dem kaiserlichen Gesundheitsamle, 1881. 
other, from the blood or dejecta of former cases, have been deposited on the surface.

The question as to whether pathogenic micro-organisms can be bronght to the surface by vegetables and deposited upon their stens and leaves in the process of growth has been investigated reently by Remlinger and Nonri.' These observers used in their experiments B. prodigiosus, B. inthraeis, B. typhosins, and B. cholere.

In the first experiment a large box was filled with earth with furrows depressed 10 or 12 eentimeters below the ordinary level. The box was under observation from Augnst to December, was open, but it was not exposed to smin or rain. Radishes, potatoes, peas, and beans planted in the box were irrigated every second day in the furrows with water eontaminated with enltures of typhoid, eholera, anthrax, and $B$. prodigiosus. From time to time the whole surface of the box was sprinkled, without especial eare, with tap water. When the plant had grown sufficiently, specimens of the stems and leaves were taken at a height of from 2 to 20 eentimeters and tested for the above-named organisms. B. prodigiosus alone was found, and that upon only one of ten leaves.

In the seeond experiment wheat grains and radish seeds were planted 2 centimeters deep. Immediately after planting, the soil was watered with enltures of the same organisms. After the plants lad grown sufficiently, eultures were again made from the leaves and stems, and the baeillus of anthrax was found twice out of eight times and the bicillus prodigiosus four out of ten times.

In the third experiment peas and beans were soaked in the above enltures and then planted 5 centimeters deep. B. prodigiosus was found twiee ont of six times and baeillus of anthrax once out of six times on the leaves and stems.

In the fourth experiment, wheat, radish seeds, peas, and beans were placed in wet absorbent eotton and later were moistened with the abovenamed enltures. Bacillus of anthrax was found on the leaves 25 days after inoculation and B. prodigiosus 30 days after inoculation. No typhoid bacilli or cholera baeilli were found, although they persisted in the wet eotton.

In the foregoing experiments it is apparent that typhoid and cholera organisms do not tend to appear on the stems and jeaves of plants if the soil in which those plants are placed is artificially infeeted. If they have any tendency to he present on the loves, they are apparently killed off' by exposure to air and light. 'These experiments, however, would seem to show that animals night be infected with anthrax by eating vegetable matter growing from polluted soils.

Uncinariasis. -The disease which stands forth pre-eminently as a true soil-disease, eoneerning whose etiology there is no dispute, is uncinariasis or hook-worm disease, known also ats ankylostomiasic, niners' anemia, brickmakers' disease, Egrytian ehlorosis, and St. Gothard tunnel disease. It was first bronght to publie notice in 1879 by Per.

1 Compt. rend. Soc. de biol., Par., 1910, LXVIII., 10j-107. 
roncito, who investigated the epidemic which occurred anong the workmen engaged in driving the St. Gothard tumnel, and discovererl the cause of the profound anæmia to be the parasite Ankylostomum duodenale, which is a worm about half an inch in length, which attaches itself, sometimes in enormous numbers, to the villi of the upper portion of the small intestine, through which a constant drain is made on the blood. Not until recent years, however, has the disease attracterl the attention that its importanee deserves, although it las long been known to be very prevalent in Brazil, Egypt, Indial, and varions parts of Europe, and especially in mining distriets and briekfields, whence the names "miners' anæmia" and "brickmakers' disease." In 1900, Dr. Bailey K. Ashford ${ }^{1}$ made known its presence in the West Indies and brought it to notice as the cause of the tropical anxmia, which, in Porto Rieo, canses great misery and an enormous death-rate; and in 1902, Dr. Charles Wardell Stiles ${ }^{2}$ announced that, in sonte parts of the South, it is the most eommon disease of man, and that it is more prevalent on the farms and plantations of the sand distriet than in the mining districts. Stiles discovered that, in this country, it is due to a species of ankylostomum, not before described and not found in the Old World, which differs in some important respects from Ankylostomum duodenale (Uncinaria duodenalis), but produces the same effects. This parasite he named Uncinaria Americana. Shortly after this announcement by Stiles, Harris ${ }^{3}$ reported that a study of malaria in Southern Georgia and Florida, in a region where profound anemiat is most eommon, proved that, instead of malaria, he had to deal with uncinariasis, the sufferers showing generally no malaria parasites, but being ahmost invariably infested with hook-worms. In 190:3, Ashford and King ${ }^{4}$ declared uncinariasis to be the great seourge of fully 90 per eent. of the agrieultural laboring classes (about 600,000 persons) of Porto Rieo. As an indieation of its prevalence in the Sonth, the experience of Dr. L. M. Warfield ${ }^{5}$ is of great interest. He examinerl 60 boys, inmates of an orphanage near Savannah, and found that no fewer than 48 were infested. Dr. Clande $\Lambda$. Smith, ${ }^{6}$ speaking of its prevalenee in the South, says: "It seems as though the entire country was literally satmmated with it. It is found on the highlands ats well as on the lowlands, and on the mountains as well ats on the seaboard."

Within recent years the disease has been found to exist in many parts of Europe (England, Belgium, IImgary, Germany), where its presence never before was suspected, but the vietims have been chiefly miners, and the diseatse has been reganded ats peculian to coal-mining and other underground oceupations. The fate that this is no more the case in Europe than in this country is shown by the observations of

I New York Medieal Journal, $\Lambda_{\text {pril 14, } 1900 .}$

2 Public Health lieports, Oetober $24,1900^{\circ}$.

3 American Medicine, November 15, 1902.

- Ibiden, September $5,190: 3$.

5 Ibidem, Januiry 9, 1904 .

- Journal of the American Medical Association, Aregrat 27, 1904. 
the Drs. Iberer, ${ }^{1}$ who exanined large numbers of peasant lads, who never had worked in the mines, but who, nevertheless, yielded in many instances large numbers of the parasites, which fact leads to the conclusion that the disease is endemic on the farms. Many of these young men after an absence of 3 year's, during which time they were doing military service, were found to be still infested; but they had, nevertheless, suffered in no way in consequence. Of the miners examined, no less than 94 per eent. yielded the parasites, and yet no more than one-fourth were even temporarily incapacitated.

So long ago as 1895 the disease was declared by Thornhill ${ }^{2}$ to be far more serious in India, Assam, and Ceylon than eholera, on account of the vast number of people affected and the aggregate direct and indirect mortality. He called attention to the fact that, instead of uncinariasis, ancenia, debility, dropsy, malarial cachexia, and diarrhœa were given as diagnoses. This is of especial interest when we read that, in the distriet studied by him, Harris has shown that most cases of malaria prove to be uncinariasis. The disease is essentially one of the poor, and its spread is due to the habit of discharging feces upon the surface of the ground. The eggs of the parasite are produced in great numbers and escape with the feces. Deposited on moist soil, they hatch in about 24 hours, and the embryos, after twice shedding their skin, are ready in from 4 to 5 weeks to infest man. Baker ${ }^{3}$ accounts for the prevalence of the disease by the habits of the people where it is most common. They live without regard to ordinary sanitation; they are dirty in their habits; they discharge their feces wherever they happen to be ; they eat with dirty hands, and often eat the dirt itself. Ashford and King say that, in the parts of Porto Rico where the disease prevails, there are practically no privy vaults, and a bit of soil as large as a pea may contain as many as 50 larvæ.

While it is generally accepted that the chief portal of infection is the mouth, to which the parasites are conveyed on food contaminated by dirty fingers or by dirty dishes, or on unwashed vegetables or fruits likely to be spattered with mud, or perhaps in muddy water, there appears to be ground for the belief that a large proportion of cases are due to infection of the skin. The first to assert that the parasites can reach the intestine through the skin was Looss, ${ }^{4}$ who rubbed the larvæ into the backs of puppies and later found that the animals contained the parasites within their intestines.

Boyeott and Haldane ${ }^{5}$ believe that infection can oceur through the skin, and Smith ${ }^{6}$ appears to have proved it. He bound some earth containing 4-day-old larve to a man's wrist and allowed it to remain in contact for 1 hour. Almost at once the spot began to itch and

1 Münchener medicinische Woehenschıif, 1903, No. 22, p. 992.

2 Indian Medical Gazette, September, 1895, p. 339.

${ }^{3}$ British Medical Journal, March 28, 1903. p. 330 .

4 Centralblatt für Bakteriologie, etc., 1. Abt. XXIX., p. 733; XXXIII., Orig.,

5 Journal of Tropical Iygiene, January 1, 1903.

6 Journal of the American Medical Association, August 27, 1904. 
tingle. The stools, which were examined at the time with negative results, were examined twice each week thereafter and continued to be normal until the middle of the seventh week, when eggs began to appear. In a prior communication 1 he asserted that ground-iteh is the most common disease in the South, due to the habit of going barefoot; and Warfield ${ }^{2}$ states that of the 48 boys in whom he found the parasite, 45 gave a history of ground-itch. Warfield suggests, however, that the way in which the patients with ground-iteh become infected internally is very simple: that they scrateh their feet and break the vesicles and thus get the embryos on their fingers, by which they are conveyed to the month. But, however it hapjens, the infecting material comes from the soil. Nicholson and Rankin, ${ }^{3}$ also, are of the opinion that ground-itch is the most important factor in the transmission of uncinariasis. They have noted that where there is no grounditch there is little or no uncinariasis, and that where one is conmon, the other is also. Nearly every one of a large number of cases studied by them gave a history of ground-itch.

Out of 148 southern-bred recruits examined at Fort Slocum, N. Y., up to November 17, 1909, there were 115 infected with hookworm. At Jefferson Barracks, Mo., all southern-bred recruits enlisted were examined for hookworm and 10 out of 148 were found to be infected.4

The principal measure of prophylaxis is, naturally, the discontinuance of the practice of polluting the surface of the ground; but it is difficult in all countries to persuade those who have never been aceustomed thereto to use latrines of any kind. In a privy-vault, the embryos, which cannot live without air, will speedily die. They are destroyed also by freezing and by complete drying, but soil which is apparently dry often contains considerable moisture. Other preventive measures, which are so obvious as hardly to need mention, inelude the wearing of shoes, the observance of personal cleanliness, especially of the hands, and discouragement of the halsit of dirt-eating.

The worms can be largely, if not absolutely, eliminated by treatment with thymol in proper doses. ${ }^{5}$

Goitre.-The various theories connecting individual constituents of the soil with goitre have now been well-nigh universially abandonerl, since no one of them has been found to hold good in different localitics having the same general soil characteristics. 'Thus, the magnesian limestone theory, which in some quarters is still in firvor, ean liardly stand in the face of the fact that, in some vast tracts of snch formation, as in parts of New Kealand, for instance, the disease is practically unknown. Similarly, the metallic sulphides escape ronviction, for in distriets where they abound extensively, the discase may be absent, and in other's where they are unknown it may prevail.

1 Journal of the Ameriean Medical Association, September 19, 1903.

2 Loc. cit.

3 Ifedical News, November 19, 1904.

4 Report of the Surgeon-General of the U. S. A., 1910.

5 Details of treatment may be obtained by consulting articles on the subject by Dr. C. Wardell Stiles, of the Public Health and IIarine IIospital Serrice, Washington, D. C. 
Epidemic Diarrhœa.-The great prevalence of diarrhoal diseases, especially among very young children, during the hotter months of the year, hats long engagerl the attention of samitarians as a tremendous firetor in the alway's ligh death-rate of the first age periods; but beyond the observance of a few coincidences, no connection hals been proved to exist between it and the soil.

In the investigation of milk supplies in single cases and in groups of eases in single houscholds and in institutions, various very virulent organisms, including B. enteritidis sporogenes, have heen found, and it is not unlikely that the infective agent, whatever its origin, owes much of its dissemination to being blown about in the dust of the air. Observations made by Drs. Hope, Newsholme, and others indieate that in rainy summers, when the dust is kept down, the incidenee of diarrhoe falls notably, and in unusually dry summers it shows a corresponding rise.

\section{Examination of Soils.}

The complete examination of a soil includes chemical, physical, and bacteriological determinations, but inasnuch as the chemical analysis, beyond the estimation of water and organic matter, is of no especial interest to the sanitarian, though of great importance to the agricultural chemist, we shall, with the exceptions noted, confine ourselves to the processes involved in the physical and bacteriological tests.

In taking samples, a place should be selected which fairly represents the locality, and under some circumstances a number of specimens should be obtained. These may or may not be mixed and treated as one. About two pounds of the soil may be broken up by being passed through a coarse sieve, then spread out and left for one or several days exposed to the air, and to that extent dried. To determine the relative proportion of the grains of different sizes, a weighed amount of the sample is now passed through a series of sieves of varying coarseness, made of metal or porcelain with cireular open spaces, which in each sieve are of uniform diameter. Those used by the German scientists have openings respectively $\frac{1}{3}, 1,2,4$, and $7 \mathrm{~mm}$. in diameter, by means of which a specimen is separated into grains of less than $\frac{1}{3}$, from $\frac{1}{3}$ to 1 , from 1 to 2 , from 2 to 4 , from 4 to 7 , and over 7 $\mathrm{mm}$. in diameter. Other sized openings may be nsed, but these fulfil all requirements. The speeimen is passed first through the coarsest of the set, and then, in order, down to the finest. If the particles adhere firmly, the separation is done best with the assistance of water; and should it be necessary, a pestle covered at the working end with rubber may also be employed. The separinte parts are then dried and weighed, and their respective amounts expressed in preventages of the whole.

The finest particles, that is, those of less than $\frac{1}{3} \mathrm{~mm}$., may be separated still further by the process of washing in an elutriating apparatus, of which there are several kinds, none of which, however, gives results that are more than approximately accurate, since so many different 
forces and conditions come into play to influence the process. With some, the separation is effected by causing the particles to scttle downward through a volume of water, the heaviest ones reathing (theoretically, but not wholly in practice) the bottom first, and the lightest settling out last or remaining a long time in suspension.

An apparatus of this sort is shown in Fig. 20, which requires no explanation. Another, known as Knop's silt cylinder, is shown in Fig. 21. This is a cylinder carrying lateral tubes fitter with stopeocks, situated at equal distances $(10 \mathrm{~cm}$.) apart. The sample is placed in the cylinder, which is then filled with water and well shaken. After a given time the upper stopeock is opened and the water above it is drawn off: 'Then after the lapse of auother interval, the second is openeel,

FIa. 20.

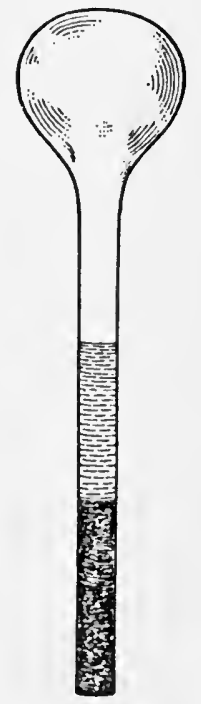

A pparatus for separation of fine particles of soil.
FIG. 21.

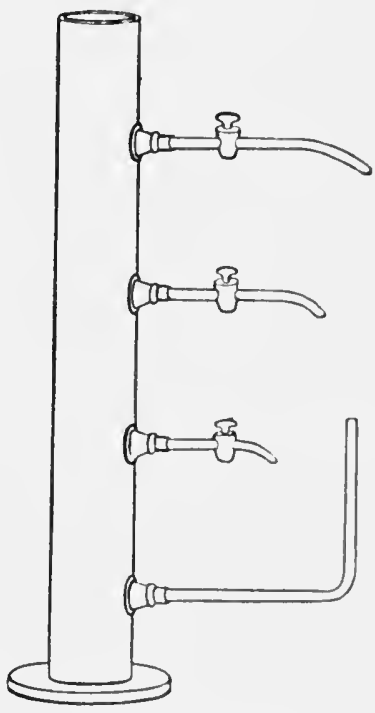

Knop's silt cyliuder.

and next, in the same way, the third. The process is repeated until the wash water comes away elear, then the lowest tube is opened, and the rest of the water above the remaining material drawn off. 'The different portions may then be collected, dried, and weighed, and their relative proportions expressed as before in percentages. Or the residue may be dried and weighed and the remainder estimated by difference.

By another method, the washing is carried out by means of an upward flow of water in a conical vessel, at the bottom of which the sample is placed. The water, delivered through a tulo reatehing to near the bottom of the vessel, carries the lighter finer particles upward and out through the exit tube near the top. Such an apparatus, known as Schultz's, is shown in Fig. 22.

Pore-volume.-The pore-volume is determined very simply ly adding to a volume of water in a graduated eylinder a kinown volume 
of soil in the dry state, and noting the height to which the water rises. If, for instance, to a liter jar eontaining water up to the 500 ec. mark, we add 500 ce. of dried soil

Fig. 22.

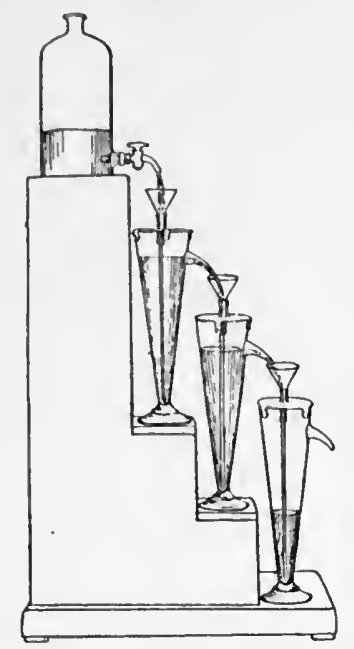

Schultz's elutriating apparatus. in as nearly as possible its natural state of compactness, and observe that the level of the water is in consequence raised to the 850 ee. mark, it follows that the inerease, 350 ec., represents the actual bulk of the soil grains, and that the difference between this and the volume ocenpied originally by the sample (500 ce.), that is to say, 150 ec., represents the amount of interstitial space filled with air. Then, since 500 cc. of soil contains $150 \mathrm{ce}$. of air space, it follows that the pore-volume of the sample is $x$ in the equation $500: 150:: 100: x$, or 30 per cent.

In order to approximate more elosely the natural condition of eompactness, the sample may be taken from the soil by means of a metallie cylinder with a cutting edge. It is then dried in order to expel the contained water, which otherwise would constitute a source of error, and is then added to the water in the liter jar as before.

Permeability to Air.-Permeability to air may be determined by forcing measured volumes of air under constant pressure through a eylinder elosely packed with the sample, and noting the amount which is delivered during any given unit of time. In making comparison tests between different soils, the same conditions must be observed in every case; that is to say, the length of the column of soil in the cylinder, the pressure employed, and the unit of time. A still farther condition which should be observed, but which is commonly disregarded, is the temperature of the air, for, as is the case with liquids, the viscosity of gases varies with changes in temperature, though not in the same direetion. The viseosity of liquids is inereased with diminished temperature, whereas in the ease of gases the reverse is true. Disregard of this fact leads to important degrees of error.

The apparatus for this determination, shown in Fig. 23, comprises a gas-holder $(A)$, a gas-meter $(B)$, and a cylinder $(C)$ provided with a manometer $(D)$. For the purpose of keeping the soil in position, tightly fitting perforater disks ( $E$ and $F^{\prime}$ ) of metallic gauze are introduced into the cylinder at both ends of the column of soil.

In the preparation of the eylinder, the disk $F$ is first introduced, and then the soil is added a little at a time, and made as compact as possible by striking the lower end of the eylinder downward with reasonable foree agrainst the table. When the desired length of column has been reached, the disk $E$ is introduced, between which and the inlet end $(G)$ an air space of sufficient size is left to insure uniform pressure 
against the entire surface of the disk. The inlet end is elosed by means of a tightly fitting rubber stopper having two perforations, one of which carries the inlet tube from the gas-meter, and the other the manometer indicating the pressure employed.

The pressure is obtained by means of a column of water communieating with the chamber of the gas-holder, which is connected by a rubber tube with the inlet of the meter; and it is regulated by a serew

Fig. 23.

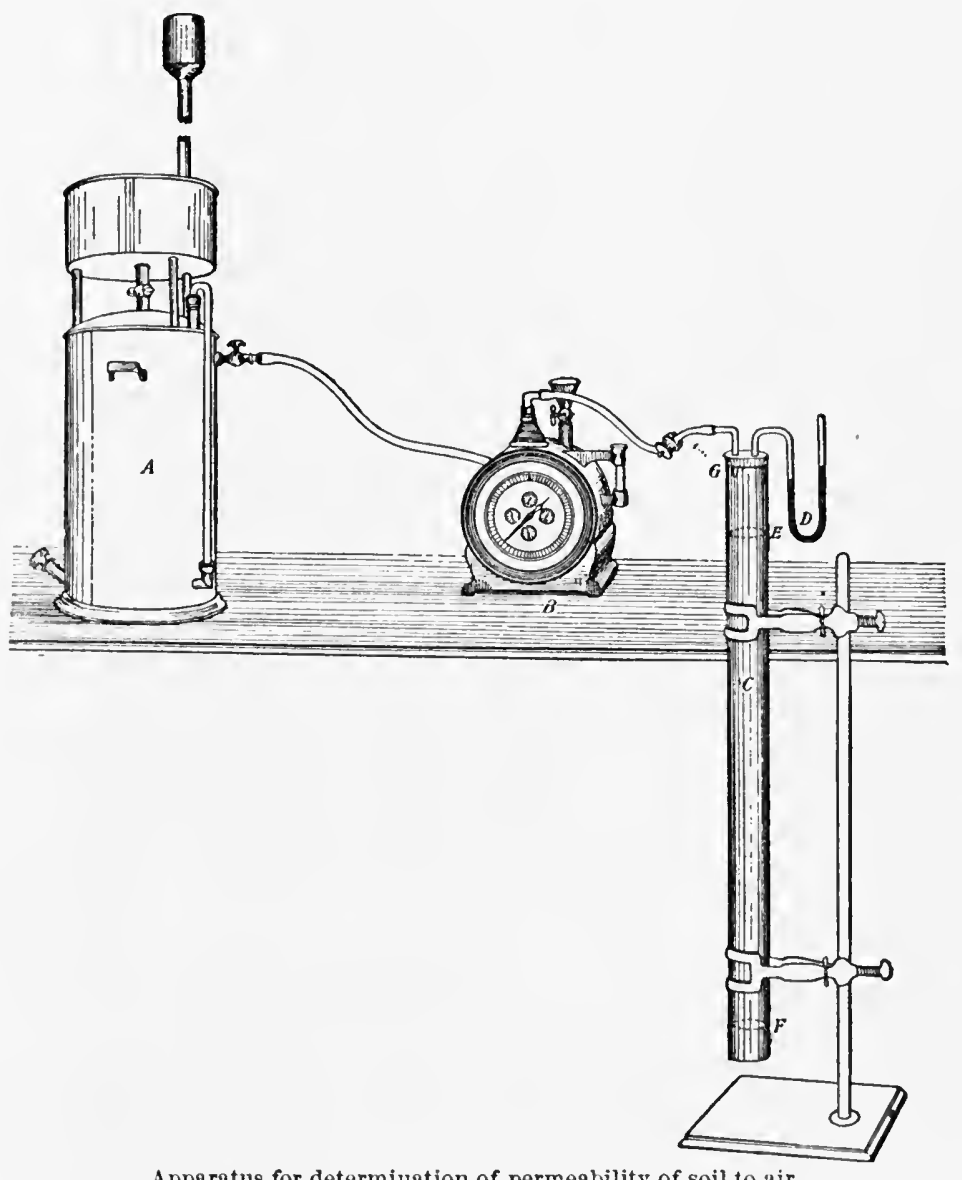

Apparatus for determination of permeability of soil to air.

pincheock on the outlet tube of the latter. The foree is applied, the reading of the meter is noted, and at the expiration of the unit of time, one, five, or whatever number of minutes it may be, the reading of the meter is taken again.

Permeability to Water.-The permeability of a soil to water is expressed in terms indicating the amount of water which will pass fron above downward through a column of saturated soil during any 
given unit of time under a given pressure. The apparatus for this determination, shown in Fig. 24, consists of a metallic cylinder $(A)$ with a perforated or gauze bottom on which the sample of soil is packed closely, and another cylinder (B), likewise of metal, provided with a number of outlet tubes $(c)$, at regular intervals, preferably of 5 or $10 \mathrm{~cm}$. The lower end of $B$ fits tightly into the upper end of $A$, and the joint is made impervious to water by means of adhesive plaster, sealing-wax, or other suitable material. The soil within the lower cylinder is kept in place, and its surface kept intact, by means of a

FIG. 24.

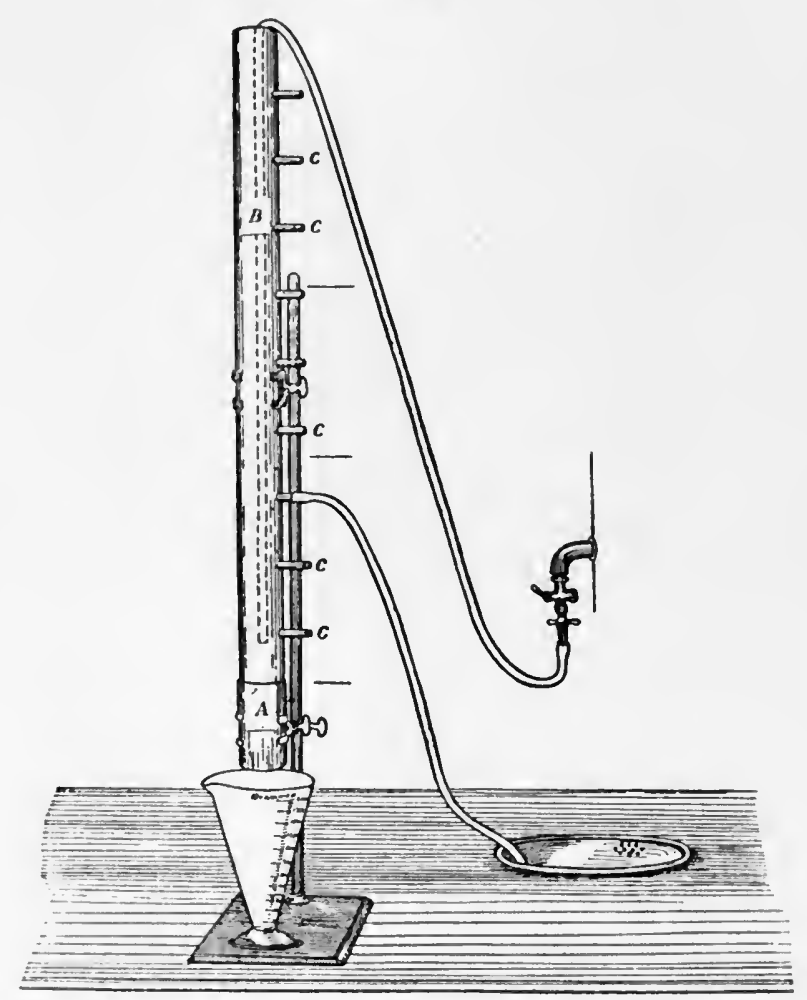

A pparatus for determination of permeability of soil to water.

superimposed disk of gauze or coarse eloth. The ontlet tubes, provided with cocks, serve to maintain a constant level, and, therefore, a constant pressure of water as desired. Water is admitted in a constant stream to the eylinder through its upper end, by means of a rubber tube connected with a water fancet. If it be desired to employ the highest pressure obtainable with the apparatus, all the corks of the outlet tubes, exeept the upper one, are kept in place. In this case, the pressure would be expressed by the distance between the top of the soil under investigation and the uppermost outlet, through which the excess of 
water from the fancet is allowed to escape, by way of a rubber tube leading to a sink. Similarly, any other height and pressure may be employed by removing the cork of the corresponding outlet, which thus becomes the effluent. Whatever the height maintained, it is necessary to keep the delivery end of the inlet tube below the surface of the water

The process is as follows: Having chosen the pressure and adjusted the waste tube to the proper ontlet, the water is allowed to run in and foree its way down through the soil until the latter becomes saturated. In order to insure complete saturation, it is best, however, to immerse the soil eylinder, in order that all the air may thereby be displaced upward. When this has been accomplished and water begins to run or drip through the gauze bottom, the time is noted, and the discharged water is received in a suitable graduate. At the expiration of the unit of time, the latter is removed and its contents measured. The experiment may be repeated as often as may seem advisable, and the effects of varying pressures may also be determined.

Water Capacity.-The power to hold water is determined by means of a metallic cylinder of known capacity with a gauze bottom. This is weighed, then filled with the dried sample, and again weighed. The soil next is saturated completely by immersion of the cylinder in water, and then it is allowed to drain as long as water continues to eseape. When the water ceases to drain away, the eylinder is wiped dry ontside, and the weight of the whole is taken again. The increase in weight is the amount of water retained, and it may be stated in percentige of the pore-volume, which should have been determined previously.

Capillarity.-The height to which water will rise in a column of soil by capillary attraction is determined by packing the sample tightly into a graduated glass tube, the lower open end of which is eovered with coarse linen tied securely on, so as not to slip. The tube is supported with its cloth-covered end resting in a shallow dish filled with water, which is kept at constant level. The height to which the water rises throngh the column of soil is noted from time to time, until ascent ceases. The change in the color of the soil, due to wetting, indicates the progress of the action.

Moisture.-The amount of moisture in a soil is determined most aceurately by taking a sample in its natural condition, by means of a brass cylinder with a eutting edge, weighing a portion of it, and then drying it in an air bath at $105^{\circ} \mathrm{C}$. until it ceases to lose weight. The difference between the original and final weighings represents the amomnt of water in the griven weight of soil. If it is desired to know the amount of water which the same soil will absorb from a siturated atmosphere, the thoronghly dry sample may next be placed with a dish of water under a bell-glass. The eonfined air will become saturated with aqueous vapor in a short time, and this will he absorbed by the soil up to the limit of its capacity, which is shown when its weight no longer continues to inererse. 
The hygroseopic moisture of a soil may be determined roughly by air-drying a sample and then taking a known weight of it and heating it in an air-bath at $105^{\circ} \mathrm{C}$; or by exposing it to a dry atmosphere in a bell-glass containing an open clish of coneentrated sulphuric acid, until it ceases to lose weight.

Organic and Volatile Matters.-Sinee it is impossible to determine by ordinary processes the exict amount of organic matter present in any soil, it is necessary to designate the diminution in weight which occurs on subjecting a sample to such a heat as will burn off the organie matter, and which represents other losses than the latter, as "loss on ignition" or "organic and other volatile matter." For this determination, the soil which was used for the estimation of moisture, or another sample, thoroughly dried, may be placed in a platinum dish and heated over a Bunsen flame at no higher temperature than is sufficient to keep the dish at a dull-red heat. When all the organic matter has been destroyed, the residue is allowed to cool, and is then moistened with a little saturated solution of earbonate of ammonium, in order to restore the carbou dioxide that belongs to the inorganic constituents, then dried and gently ignited to expel the excess of ammonia, and finally weighed. The loss represents organic matter, ammonium salts, nitrates, water of erystallization, ete.

Determination of $\mathbf{C O}_{2}$ in Soil Air.-The analysis of soil air is conducted upon the same principles as that of ordinary air, but the method employed is necessarily different so far as the obtaining and handling of the sample are concerned. The reagents are the same as required in the analysis of atmospherie air ; the apparatus, however, is quite different. It consists of a number of sections of water-pipe with serew joints, one having a pointed foot, above which are a number of perforations within a limited area; an absorption tube, in which the barium hydrate solution is held and through which the air is drawn, and an aspirator. (See Fig. 25.)

The seetion with the pointed end is driven into the soil, and the pipe is lengthened by the addition of the other sections, so that any desired depth may be reached, and thus the air of any stratum may be withdrawn. The upper extremity is connected by a rubber tube with the inlet tube of the absorption apparatus, which latter may be a plain glass tube about an inch in diameter with a bend of about 130 degrees near one end. Better, however, is the apparatus shown in the illustration. Here the short leg of the bent tube is a large bulb, and the long leg is a series of small bulbs, the communieations between which are of small diameter. In either case the inlet tulue passes through a tightly fitting rubber stopper and extends to a point just beyond the bend. The other end of this apparatus is connected by means of a rubber tube with the inlet of the aspirator. Any form of aspirator may be used, but preferably one of a capacity of about twenty liters. A measured amount of the dilute solution of barium hydrate, sufficient to oceupy the greater part of the long leg, is introdueed into the absorption apparatus, and the connections throughout are tested to prove the absence 
of leaks. When the outlet cock of the aspirator is opened, the eseape of the contained water ereates a partial vaeum, which is relieved by suction of air from the soil and through the whole apparatus. As the air emerges from the inlet tube of the absorption apparatus, it passes upward in the form of bubbles through the reagent, to which it gives up its content of $\mathrm{CO}_{2}$. The reason for preferring the bulbed tube is that each bubble of air in its passage from one bulb to the next above is necessarily brought into more intimate and prolonged contact with the reagent than is the ease when the plain bent tube is employed, for

Fra. 25.

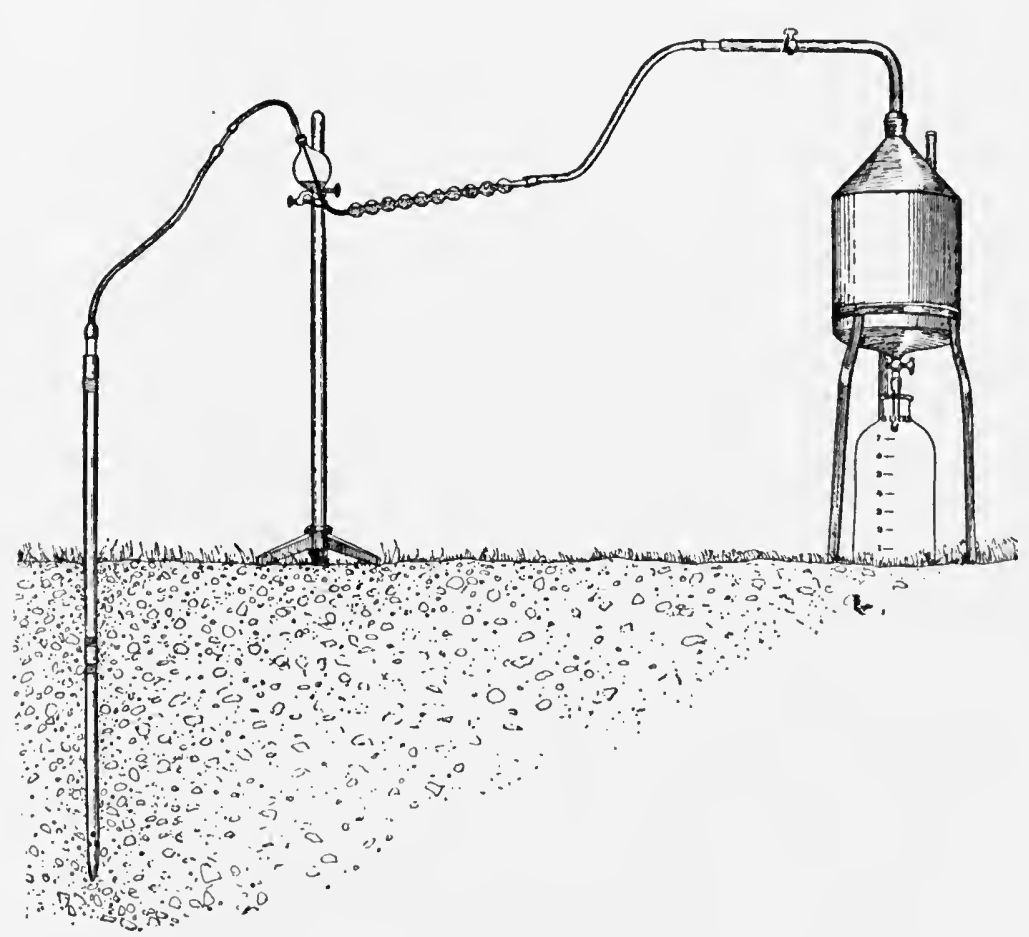

Apparatus for determination of $\mathrm{CO}_{2}$ in soil air.

here the air bubbles pass quickly along the upper inner surface of the tube, and are not so exposed to the reagent as to lose all the contained $\mathrm{CO}_{2}$. For this reason, it is necessary to draw the air through a second, and, perhaps, a series of such tubes, but one bulbed tube ats pietured above is sufficient.

The water from the aspirator is measured carefully, and its amomint indieates the volume of air that has been sucked up out of the soil to take its place. When the desired amount has been acted upon, the stopeock of the aspirator is elosed, and the reagent in the albsorption 
tulhe is transferred quickly to a glass-stoppered bottle of suitable size. From this point, the determination is the same as deseribed in the chapter on Air.

\section{Bacteriological Examination of Soil.}

The bacteriologieal examination of the soil requires necessarily an intimate acquaintanee with bateriological technique, a subject beyond the scope of this work. It may be stated briefly that many of the organisms that inhal,it the soil may be isolated by adding small portions of the sifted sample to liquefied gelatin and then plating, or by sprinkling over the surface of a nutrient medium, or by shaking with distilled water and transferring thence to the proper media.

The many anaërobic forms require, of course, the special treatment of their class, and some of them may be grown on ordinary eulture media ; but many of the saprophytes, notably the nitrifying organisms, cannot be isolated by the ordinary methods. For the details involved in the separation and identification of the numerous varieties of soil organisms, the reader is referred to the standard works on bacteriology. 


\section{CHAPTER IV.}

\section{WATER.}

Ansolutely pure water, that is, the substance composed wholly of hydrogen and oxygen, and represented by the symbol $\mathrm{H}_{2} \mathrm{O}$, is never fousd in nature, and is never seen, except in small amounts as a laboratory euriosity. In the broad sense, however, the word pure as applied to water eonveys the iclea of freedom from harmful ingredients and of wholesomeness and suitalility for drinking and for the preparation of food. In nature, all water contains more or less of gaseous and solid substanees in solution and suspension, and so long as these are not present in such amounts as to affect the quality injuriously, and so long as they are not intrinsically dangerous to health, the adjective is commonly held to be appropriate. But in the sense that purity involves the limitation of the amount of contained substances of a harmless nature, it becomes a diffieult question where to draw the line where water ceases to be pure, and what term to apply as an antonym. In the sense that it involves eomplete absence of matters intrinsieally dangerous, the line ean be sharply drawn, and water which fails to satisfy the requirements of the term may be designated indifferently as impure, polluted, or contaminated.

In the elassie reports of the State Board of Health of Massachusetts on publie water supplies, waters are classed as " normal" or "polluted" aceording as they are or are not free from direct or indirect pollution by the waste produets of human life and industry. Under this classifieation it follows, naturally, that normal waters must vary very willely in appearance, composition, and general charaeter, and that a normal water is not neeessarily suitable for drinking, althomgh incapable of causing speeific disease. 'The nature and amount of' the dissolved matters cannot but have considerable influence in modifying the properties and effects of a water.

Waters may be elassified according to souree as follows:

1. Rain and snow.

2. Surface-water (rivers, ponds, basins, etc.).

3. Ground-water (also known as subsoil-water).

4. Artesian or deep well-water.

\section{RAIN.}

Rain is the original source of all matural waters of whatever elass. It results from condensation of the aquenus vapor of the atmospliere, and in its descent to the earth it takes up salicens and smspended mattors from the atmosphere, which to that extent hecones therehy puri- 
fied. In the open country, after the air has been washed for a while, the collected rain is very clean, and is, in fict, the purest form of natural water. If its fall is accompanied by wind from dusty localities, it cannot be obtained in so clean a condition within so short a time, on account of the greater amount of suspended matters to be washed down. Near the sea, it contains more or less salt; and in eities and large towns, it may have a slightly acid reaction.

In its passage downward through the atmosphere, rain absorbs considerable air, or, more properly, constituents of air ; that is, oxygen, nitrogen, carbon dioxide, and ammonia compounds. Since each gas has its own coefficient of solubility in water, and as air is a mixture and not a chemical union of gases, it follows that water will absorb the constitnents of air separately and according to their respective solubilities. So it happens that the absorbed air has a very different composition from that of atmospheric air, being much richer in oxygen and poorer in nitrogen, its oxygen content being 35 instead of 21 per cent. On reaching the earth, some of the rain is evaporated, some sinks into the soil, and some runs over the surface to streams or other bodies of water. The amount that sinks into the soil depends upon the permeability of the latter to water. Thus, a sandy or gravelly soil will take up more of the rainfall than a elose-grained elay. The amount which is returned to the atmosphere by evaporation is surprisingly large. It has been reckoned by Dalton that in the whole of England and Wales, about 50 per cent. of the total annual rainfall is lost by evaporation. In the watershed of the Rhine, the loss is reekoned at 50 per cent.; in that of the Rhone, at 42 ; of the Seine, at 67 , and of the Garonne, at 35.

\section{SURFACE-WATERS.}

Surface-waters are collections of water running along or stored upon the earth's surface in contact with the atmosphere. Under this head are included rivers and smaller streams, ponds, lakes, and impounding basins. They vary according to the different characters of the areas which they have drained or traversed, or in which they are stored. Thus, a water that has flowed over a rocky soil is more likely to be free from organic impurity than one that has flowed over loamy soil or has stood in swamps; and one that has flowed through sandstone bottoms is more likely to contain mineral impurities than one that has flowed over the virgin soil of a forest.

Surface-water means something more than the rain of the district plus the impurities of whatever character, organic and mineral, which it has collected. Rivers and lakes, for example, are made up of rain that has run over the surface of the ground, dissolving in its course small amounts of easily solnble matters, and of water that has come up from the soil below through springs, or that has trickled in from the upper layers of the soil ; and these latter contribute matters which may be of very widely different character from those obtainable along the 
surface, aceording to the geological character of the soil strata that have been acterl upon.

A river may take its origin in a spring, and consist for some time of ground-water alone, but usually it is not long before it receives aceessions of surface-water and soon aequires the characteristies of the latter. Again, some lakes and ponds are fed almost wholly by springs at their bottoms and sides; but even so, their waters soon change in ehatacter and acquire the various forms of aquatic life.

Surface-waters may contain much or little or no organic matter, aceording to circumstances. 'They may be colored or colortess; they maty be rich or poor in mineral substances. Those which come largely from the ground will naturally possess largely the characteristics of ground-water, and those free from accessions from this source will approximate more nearly the character of rain. The quality of surfacewaters is influenced by the seasons, by drought and rainfall, by vegetation, by rate of movement, and by other conditions.

\section{GROUND-WATERS.}

Ground-water is that which penetrates the soil, sinks to various deptlis, according to the nature of the soil, and accumulates on some more or less impervious stratum. It is not exposed to light and the atmosphere, like surface-water. It varies widely in character according to the nature of the soil over which it has once flowed and through which it has pereolated. It enters with more or less air and $\mathrm{CO}_{2}$ in solution, and comes in contact with the soil air in the interstices, which is much richer than atmospheric air in this gas. With the assistance of the $\mathrm{CO}_{2}$ which it has brought, and that which it farther aequires in the interstices, it dissolves various mineral constituents of the soil. That which penetrates very deeply has its solvent power increased by increased temperature and pressure. As it enters the soil, it brings with it whatever organic matters it may have dissolved out of the surface layers, and in its deseent it may lose them entirely through the action of the saprophytic bacteria of the soil, or it may aequire still more if the soil be polluted and so permable as to permit rapid passage downward. It passes slowly or rapielly through the interstices until it reaches an impermeable stratum, over which it accumulates, filling the interstices completcly. 'The soil at this point is said to be saturated, and the upper limit of saturation is known as the gromul-water level, or water table. Between this and the surface, the water is in contact with the air of the interstices, and is known as eapillary moisture. The water table is by no means necessarily horizontal, but follows in a general way the contour of the surface of the soil, and often it is much more irregular, and, by reason of local geological conditions, even quite different from what the surface formation would indicate. Thus, at one point in a level strotch of country, the table may be quite near the surface, and at another, a short distance 
away, it may be situated much more deeply, owing to abrupt changes of level of the impermeable stratum.

Irregnlarity of the surfice of the water table is dne largely also to the rainfall, which, coming at frequent intervals, falls npon surfaces of differing permeability, so that while one part is still draining its water downward, another has eompleted the process and is ready for more. When drought ocenrs, however, the level becomes more and more uniform until it may beeome quite horizontal. With return of rainfall, the level rises, and irregularity of the surface of the water table is again produced. The level at any point is influenced also by the amount of water withdrawn from the soil by the demands made upon wells. When the amount of percolation is exeeded by the amount of withdrawal, the level falls; when the conditions are reversed, the level rises.

The water table in its irregular course touches the surface of the ground bere and there, and gives rise to springs which may flow the

Fig. 26.

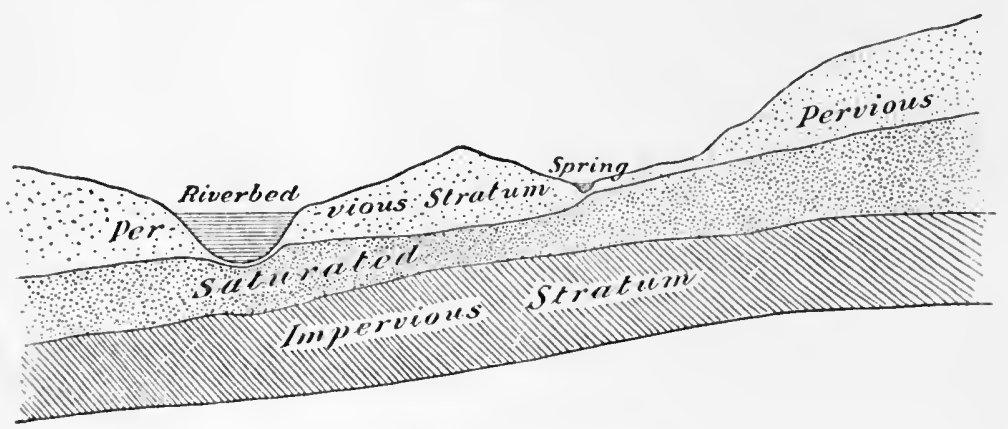

Outcropping of water table.

year round regardless of drought, or may dry up completely with fall of the level. Similarly, all permanent ponds are onteroppings of the water table, and the beds of rivers as well, but the level of the table in the near vicinity is almost invariably higher than the surface of these bodies. Sometimes, however, the water level is so near the surface that, without emerging in the form of springs, it extends in a broad sheet just at or below it and eauses marshy conditions. In Fig. 26 the manner in which the water table crops out in springs and feeds lakes and other bodies of water is shown.

By some, the water table is spoken of as an undergronnd river, a term which is very misleading, in that it suggests a body of water rather than a condition of saturation of the soil. There are, to be sure, in some localities, especially in limestone districts, bodies of water flowing between impermeable strata, and instances are known of disappearance of streams into fissures of rocks and emergence at a distance elsewhere, but these streams are not a part of the water table as generally understood and may not properly be classed as ground-water.

In most cases, and exeept where the water lies in deep depressions 
or pockets with no side outlets, the ground-water is in constant lateral motion in the direction of the outfall, and this is commonly the nearest large body of water, either a lake, or a river, or the sea. In its onward course over an irregular impervious stratum, the movement is at times inelined upward and at times downward, but ever in the same general direction laterally.

The rate of movement is determined by a number of influences, among which the most cffective are the degree of permeability, the melination, and the barometrie pressure. The degree of permeability, dependent upon the coarseness of the soil partieles, is of "very great importance, the more rapid flow oceurring through the soils of coarser texture. The inclination, or, in other words, the influence of contour in promoting or preventing the assistanee of gravity, has a very decided effeet.

The barometric pressure affects the rate of movement through its effects on the air in the interstices above the water level. While this air is itself in constant movement, it cannot move quickly because of the great amount of friction created. Lessened pressure above the ground causes the soil air to expand, and as this oceurs, the tendeney is along the lines of least resistanee, namely, upward and, under eertain conditions, laterally, so that the water in the interstices is assisted in its flow. But the influence of diminished barometrie pressure is felt almost at onee at the outfalls, because of lessened back pressure on the water. 'This influence may be measured by noting the fluetuations in the water levels in wells which rise as the barometer falls, and fall as it rises. Thus, resistance is removed at the outfall, and coincidently the water is being pushed along by the expansive force of the air in the interstices. With increased barometrie pressure, these conditions are reversed and the flow becomes less rapid.

The rate of movement being so dependent upon local conditions, it follows that it varies widely in different soils. In some places it is so slow as to be almost unmeasurable; in others it is extremely rapid ; and even within a restricted area, it may be excedingly variable at different points. At Budapest, for example, Fodor ${ }^{1}$ determined the rate of movement at five different points to be $95,125,199,209$, and 210 feet daily. The average of these figures, 167.6 , represents umbsially rapid flow. At Munich, the daily rate of flow toward the Isar has been alculated by Pettenliofer as a trifle more than 15 feet.

\section{Physical and Chemical Characteristics of Water.}

At the standard barometric pressure, $760 \mathrm{~mm}$. of 29.922 inches, water boils at $100^{\circ} \mathrm{C}$. or $212^{\circ} \mathrm{F}$. With lower pressures, it boils at correspondingly lower temperatures; on very lijgh land, for example, it boils at sueh low temperatures that meat and vegetables cannot be thoroughly cooked in it. Evaporation oceurs at all temperatures, even below the freezing-point.

${ }^{1}$ Boden und Wasser. Brunswick, 1882. 
Water has its maximum density at $4^{\circ} \mathrm{C}$, above and below which point it expands. At $0^{\circ} \mathrm{C}$. it freezes, and in doing so, it expands to the extent of about 9 per cent. of its volume, and thus acquires a speeific gravity less than that of unfrozen water, in which, therefore, it floats. As the surface freezes, it gives ont heat to the layer immediately beneath and thereby causes a retardation of the process. As this layer beeomes cooled, the ice formation continues, and thus the growth in thickness of the ice cover proceeds downward. Its specific heat is high, and is taken as the standard of comparison. As a conductor of heat it stands very low.

Water is the most universal solvent known, there being but few substances which are not acted upon by it to some extent. It takes up all known gases, and its solvent power for them is greater according as the temperature is depressed and the pressure increased. In the case of substances other than gases, with few exceptions its solvent power is increased with increased temperature.

Appearance.-Pure water is clear, and, in proportion as it contains dissolved air and carbon dioxide, is bright and sparkling. Brilliancy of appearance is, however, by no means conclusive evidence of purity, some extensively contaminated waters showing remarkable brightness. Turbidity of water is due to organic and mineral matters in suspension; the organie matters may be ordinary dead vegetable and animal substances or microscopic living plants and animals.

Some public supplies derived from rivers are distinetly muddy in appearanee. The slight degrees of turbidity designated as milliness and opalescence are due commonly to very minute clay particles, which may remain in suspension for a long time, even when the vessel containing the water is allowed to stand undisturbed. Sewage matters also may give these same appearances. Turbidity due to elay may be removed readily by the addition of various substances, as lime, alum, and sulphuric acid, which eause the particles to agglutinate and settle out. Water which is apparently clear when viewed in an ordinary glass vessel may be seen to have decided turbidity when viewed through a depth of a foot or two against a pure white surface.

Some ground-waters which are quite clear when drawn may aequire a turbid appearance on standing, due to the presence of compounds of iron which undergo changes in composition and become precipitated. In such eases, the turbidity is aceompanied by the development of color, which, however, disappears on the completion of the process of oxidation of the iron compounds and their separation by sedimentation.

Color.-Water may have color or not, aeeording to eireumstances. Surface-waters may derive it from contact with grasses, leaves, woody matters in general, and peat, the degree of color being dependent upon the length of time of contact and upon the eharacter of the substances. Different kinds of leaves, for example, impart different shades and kinds of color, but not always to the extent that their appearance would indicate. The dark-colored dried leaves of the oak, for instance, might be expected to yiek a much darker infusion than the much 
lighter colored leaves of the maple, but such is not the case, as may be proved readily by experiment; and those of the butternut give a color that is surprisingly light in comparison. Long contact with swamp regetation canses a deep reddish-brown color, which is often very stable on long keeping. Not all surface-waters, however, are exposed to color-imparting substances, and waters of this class may be firee from color.

Ground-waters of good quality are ordinarily colorless or appear to have, when viewed through considerable depths against a whițe surface, a faint bluish or greenish-blue tinge. Sometimes they contain iron and organie matter in combination, and have in consequence a brownish tint, which, by reason of very slow oxidation, may persist for a long time. Color derived otherwise than from contact with vegetable matter is accompanied usually by more or less turbidity. Absence of color is not a sign of purity, for polluted waters may be quite free from it; nor is its presence an indication of unfitness for domestic nse.

Reaction.-The dissolved carbon dioxide in water tends to give it a slightly acid reaction, but most potable waters are very faintly alkaline to delicate indicators, owing to minute amounts of alkaline carbonates. Rain-waters, especially in the vicinity of cities and large towns, are generally slightly acid on account of impurities of the atmosphere, arising from combustion. Peaty waters also are slightly acid on account of organic acids produced by the action of the peculiar bacteria existing in peat. River-waters in mining districts often contain considerable amounts of free mineral acids.

Odor.-Pure water has no odor, but good surface-waters containing coloring matters have more or less odor, which is especially marked on lieating. It is generally suggestive of vegetable matter, and may be characterized variously as grassy, peaty, ete., aceording to the impression produced. Such odors may persist even on long boiling, while those due to dissolved gases will disappear quickly on heating. Many otherwise good surface-waters are particularly prone to the development of disagreeable odors attributable to minute living organisms.

The subject has been studied very extensively by Mr. Gary N. Calkins, ${ }^{1}$ who states that odors in drinking-waters "may be produced he the putrefactive deemposition of the body plasm through the ageney of bacteria, and by the excretion of certain products of growth, or ly the liberation of products by the physical disintegration of the body or breaking down of the enclosing cell walls. These three canses give rises to three classes of odors, as follows: (1) orlors of chemical or putrefactive decomposition, (2) odors of growth, and (3) orlors of physical disintegration."

'The group of plants popularly known as "blue-crreen algae" (Schizophycex) is a very common cause of the woll-known "pig-pen" and "grassy" odors so frequently observed in shallow, stanguint, and relatively warm waters. Certain of the Diatomacee frequently calse serious trouble by imparting aromatic (geranimu) and fishy odors

${ }^{1}$ Report of the State Board of II ealth of Mfassachusetts for 1892, p. 355. 
and disigreeable taste. Of these, the most prominent is Asterionella formoset, found very conmonly in large ponds and reservoirs of surfacewater, and growing with especial luxuriance in open reservoirs of groundwater. Aceording to Whipple and Jackson, ${ }^{1} 3000$ asterionella per ec. of water may, under fivorable conditions, impart an odor easily recognized by the consumer. Several species of Uroglena, commonly, but areording to G. T. Moore, ${ }^{2}$ perhaps incorrectly, elassed with the Infusoria, (autse much trouble by the liberation, during disintegration, of oil globules which imprart fishy, oily odors and tastes. These oil globules are yielded by many other varieties of water organisms.

While sewage matters inpart monldy or musty odors to water, it should not be inferred that these odors are of themselves indicative of sewage pollution, for good surface-waters sometimes aequire them on standing.

Sometimes it will be noticed that water on long boiling not only continues to evolve a vegetable odor, but gives it off in greater intensity. This is true particularly of waters rich in alga. If they are first filtered, the odor will not be given off on boiling. But other waters may continue to evolve odors even after filtration. Peaty waters, for instance, often persist in yielding olor on long boiling, and this is not affected in any way by filtration. Waters containing products of physical disintegration and various other substances also are not influenced by filtration.

Odors which disappear on boiling may develop again after a time if their cause is not removed; if, however, the matters from which they are derived are no longer present, the odor will not return. Some most troublesome odors are known to be the results of decay. The public supply of Boston was, in 1878, scriously affeeted in this way, and gave off' an odor which was likened to that of cueumbers. This was investigated by Professor Ira Remsen, who found the cause to be decomposition of a fresh-water sponge.

Water sometimes contains sulphuretted hydrogen from reduction of sulphates by bacterial action, and sometimes mixtures of products of organic decomposition which suggest that gas. Very marked and most offensive odors are due often to the presence of dead animals, such at toads and mice in wells, and, when they arise, the remedy is obvions. Some wells beeme stagnant at the bottom, and if organic matter is present, it may eause foul odor, suggestive of dead aninals, by putrefaction in the absence of a sufficient supply of dissolved oxygen. Stagnation may be prevented by connecting the pump nearer the bottom, or by filling up the unneessary space with clean gravel and sand.

Odors in water are not necessarily indicative of danger to health, but distinetly unpleasant ones are quite suffieient as a disqualification, on aceount of the repugnance which their use for drinking and other domestic purposes would cause. On the other himd, as in the case of

1.Journal of the New Fngland Water-Works Association, September, 1899.

2 American Journal of Pharmacy, Jamnary, 1900. 
color, absence is not indicative of purity, for dangerous waters may be inodorous.

Taste.-Pure water has no distinct taste, and, whatever the impression made, it is due to dissolved gases. That this is so, is most evident when one compares the taste of a well-aërated water, before and after heating to the boiling-point with subsequent cooling. Saline constituents impart no distinct taste unless they are present in quite large amounts, as in waters of a high degree of permanent hardness. The only substance which imparts taste when it is present in very small quantities is iron. Dissolved organic matters cause no taste, unless present in considerable amount and, as a rule, accompanied by odor.

Water containing very little coloring matter is often said to taste distinctly, but it should be remarked that the senses of taste and smell are often influenced mneonsciously by the sense of sight, and colored water supposed to have both odor and taste may, if drunk in the dark, give no impression of either.

Badly tasting water, whether dangerous or not, is objectionable on the same grounds as mentioned under odor. Not only is absence of bad taste no evidenee of purity, but it is well known that waters containing the products of oxidation of sewage are often renarkable for unusual palatability.

\section{Substances Found Normally in Water.}

These include :

1. Gases in solution.

2. Organic matters in solution and in suspension.

3. Mineral matters in solution and in suspension.

1. Gases.-First in importance is air. Strietly speaking, water contains no air as such, but only the constituents of air, for the oxygen and nitrogen, dissolved by water, are not present in the same proportion in which they exist in the atmosphere. In salt water, the variations in their proportions are less wide. We shall, however, eonsider the two gases as air. The dissolved oxygen is the important element. One lundred volumes of water at $15^{\circ} \mathrm{C}$. will dissolve nearly 3 volumes of oxygen (2.99), and at $20^{\circ}, 2.80$ volumes, and it is not altogrother removed by boiling.

The amount of oxygen in solution is fairly constant in waters of uniform composition freely exposed to the atmosphere, but when they receive additions of sewage and other oxidizable matter's they begin to lose it. River-waters may thus show notable differences in the amount of dissolved oxygen present in samples taken above, within, and below towns situated on their hanks. 'The 'Thames and the Serine, for instance, show this in a remarkible derree. The progressive diminution is due to the constant access of organie matter, which undergoes oxidaltion at the expense of the discolved oxygen. When a river-water is depriverl of its dissolved oxyeren in this manner, or by reason of chemical changes due to the inflow of sewage from manufacturing 
establishments, containing compounds-ferrous, for instance-having a strong affinity for oxygen, fish life cannot be supported. Absence of fish in polluted streams is due much more to diminution of dissolved oxygen than to the poisonons effeets of organic sewage.

Aëration of water is influeneed very largely by the dust which falls into it, for each particle carries with it more or less adherent air, as may readily be seen when one drops small particles into water and observes their deseent. Aëration of water proceeds to great depths, as is shown by chemical analysis of samples of water obtained by deep sounding, and also by the fact that great numbers of organisms which require oxygen for their respiration are found far beneath the surfice; but water at 40 and 50 feet below the surface may contain no oxygen. Water from deep wells is very commonly free from dissolved oxygen, because of abstruction by compounds of iron or manganese, organic matters, and other substances.

The presence of considerable dissolved oxygen in water leads to beneficial changes in the organic matter present. Diminished oxygen permits the development of low forms of vegetable life, which frequently give rise to unpleasant tastes and odors. 'Their growth is inhibited by a large degree of aëration, and their disagreeable effects are thereby prevented.

Carbon Dioxide.-The carbon dioxide contained in water is derived largely from the atmosphere, and in great part from the soil, where it is present in abundance. Its amount in any water depends upon a number of circumstances: upon the amount carried in by rain and dust, the character of the soil, and the extent of oxidation of organic matter occurring in the interstices. It is greatest in amount at great depths, and it may eonstitute almost the entire content of dissolved gases. It has been calculated that the ocean contains about ten times as much as the entire atmosphere.

2. Organic Matter.-The organic matters in water are of both animal and vegetable origin, and consist of organisms, products of organic life, and results of disintegration and decomposition. The animal matters include dead and living organisms and dissolved and suspended products of animal life and decay, such as albuminous substances, urea, and tissues. In the tropies and subtropics, ova and young of various parasites are common. Ordinarity our interest in organic matter from animal sources is confined to the products of human life as represented by sewage, which may contain the exeiting canses of specific diseases (see Bacteria in Water, page 379). Vegetable organic matter exists as living and deal organisms and tissues in suspension, soluble and suspended substanees given off during life, and soluble matters extracted by the water after death.

The vegetable organisms are represented by very numerous species of microseopic plants, which act beneficially by absorbing the products of organic decomposition for their growth, but which may, on the other hand, under favorable conditions, beeome the source of much trouble by over-abundant growth, disintegration, and decay. They may prop- 
erly be regarded as normal constituents of surface-waters, for they are always present in such, and, moreover, they develop quickly in stored ground-water exposed to light and air. When they die, most species appear to decay rather slowly, and the products of their decomposition are absorbed by new growths; but when present in great abundance, the progress of decay may exceed that of growth, and then their produets may accumulate and eause fouhness.

There is one form of microscopie organisms, belonging to the elass of fungi, which merits special mention : Crenothrix Kühniana. This is a filamentous plant with cells no larger than the ordinary hacteria. It grows chiefly in ground-waters which contain organic matter and iron, the latter of which ingredients it fixes in the form of ferric oxide in the gelatinous sheath of its filaments, which thereby become yellow, yellow brown, or brown in color. It eanses great annoyance by the rapidity with which it grows in water-pipes, the lumen of which is not infrequently completely oceluded. This may oceur more readily where the surface presents roughness and imperfeetions, to which the growths may attach themselves. When the filaments are broken off and become disseminated through the water, the latter is rendered unfit for laundry use on account of the iron-rust. Sometimes, it gives rise to disagreeable odors and an inky taste. It may be very troublesome within the tubes of driven wells, or in the reservoirs, as well as in the distributing pipes. Sometimes, it may be seen in large aggregated masses floating about on the surface of stored water. By its extensive growth in pipes, it may seriously affeet a whole public supply.

The presence of living forms, either vegetable or animal, indicates that the water contains at least whatever food materials are neessary for their existence, but not necessarily that these are in excess. Algxe, for instance, require mineralized nitrogenous matter (nitrates), and other substances; fungi suggest the presence of carbohydrates, proteids, and mineral substances common to domestic sewage; infusoria suggest organic decomposition. Dissolved vegetable matters ordinarily amomt to but little in weight. Even in some very brown waters, whose appearance would suggest large amounts, they may be present to the extent of not more than 1 or 2 parts in 100,000 .

The organic matters, both animal and vegetable, which are of interest to the sanitarian, consist chiefly of carbon, hydrogen, oxygen, and nitrogen, with, in many cases, small amounts of phosphorus and sulphim. In the process of decomposition, which owes its inception, progress, and completion to bacterial activity, the carbon is combined with oxygen to form carbon dioxide, and the hydrogen unites in part with nitrogen to form ammonia, the presence of which in water indieates that the process of decomposition is under way. In its turn, as will be shown later, the ammonia is eonverted eventually to nitrie aeid, which unites with bases to form nitrates.

Ammonia.-From the standpoint of sanitary significance, anmonia in water is of prime importance. Only under very unmsual conditions does it exist in the form of hydrate, but usually as chloride or car- 
bonate. We speak of it commonly as free ammonia, for, on boiling the water, these salts are decomposed and the ammonia is expelled in the steam. Among the direct sonrees of ammonia in water is rain, which brings it down out of the atmosphere in varying amounts according to location. Ratin always contains it, but more is present in that of thickly populated distriets than in the open country. In one instanee, reported by Drown, ${ }^{1}$ it was found to the large extent of 0.0564 in 100,000 . Its presence, however, in surfice- and ground-waters is due for the most part to decomposition of nitrogenous organic matter. It is not abundant in ordinary unpolluted waters, but is present often to a very considerable extent in that of deep driven wells. Here its origin is not always elear; in some cases it is supposed to be referable to coal deposits, in others to reduetion of accumulated nitrutes.

Under ordinary conditions in surface-waters, ammonia, after eonversion to nitrates, is absorbed very quickly by growing vegetation, and the more aetive the conversion and the growth, the greater the appropriation. For this reason, water from the same souree will often show less on analysis in summer than in winter. But activity of regetation is not responsible alone for this difference in amount, for in the ease of large bodies of water, as lakes and ponds, the rate of movement of the water has great influence. During the warmer months, when the upper layers are warmer and consequently lighter than the lower, the latter become neeessarily stagnant and stratified. The ammonia which accumulates in these lower strata does not, therefore, eome to the surface until cold weather approaches. Then the upper layers beeome more dense and tend toward the bottom, eausing a displacement of the lower layers toward the surface and general uniform mixing of the entire volume of water. Another element in the stirring up of the water of ponds and lakes is the action of wind, which, lowever, does not extend beyond twenty feet. Still another influence to be considered is that of springs at the bottom and sides, which tend to keep the water in motion. In the ease of flowing rivers, the water is of eomparatively uniform composition at all depths.

Ammonia is very characteristie of sewage pollution, the oxidation of which yields it in abundance under conditions which do not permit it to be rapidly oxidized to nitric acid.

Ammonia as it oceurs in drinking-water is of itself incapable of producing harmful effects. Its amount, however, is of greater or lesser signifieance aceording to eircumstanees: that from clean and properly stored rain-water is of far less significanee than that from other waters. In the one, it may be considerable in amount and mean but little; in others, it is usually evidence of deemposition of organie matter. Its amount in good water is not large, and on account of oxidation and absorption by vegetable growth it does not acemmulate. And even in sewage-polluted waters, when regetation is aetive, oxidation and

'Massachusetts State Board of Health: Report on Water Supply and Sewerage. Boston, 1890. Part 1, 1. 562. 
absorption may so diminish its amonnt that, taken alone, it might lead to false conchusions as to the character of the water.

Albuminoid Ammonia.-The so-called allominoid ammonia is ammonia which is produced in the proeess of amalysis of water by the action of allatine permanganate of potassium on nitrogemons organic matter hitherto undecomposed. The result of the action is a splitting II) of the organic matter and the eonversion of the nitrogen to ammonia, which, as is the case with "free" ammonia, passes ont of the water in the ste:m. This matter may be of either amimal or vegetalble origin, and its character is of far greater importance than the amount of the yield. 'Thus, a water grosisly polluted by sewage may vield less than another quite free from sneh contamination, but rich in dissolved regetable matter of no great sanitary importance.

Animal organie matter is decomposed much more rapielly than vegetable matter, some kinds of which are remarkably permanent, such, for instance, as the substances which impart the brown color to the waters of swamps. Animal matter is richer in nitrogen than vegetal)le matter, and eonsequently a stated amomt of alluminoid ammonia represents decomposition of al larger amomnt of the latter than of the former. In other words, a small amonnt of animal matter will vickl as much albuminoid ammonia as a large amount of vegetal,le matter.

Inasmuch as animal matters are of fur greater significanec than vegetable matters, it must be elear that the amomnt of albuminoil anmonia is of less importance than its origin. And sinee, in the analysis of water, the anmonias themselves give no indication of their origin, theil signifieance can be measured only with the aid of estimations of other substinces; and often, also, a knowledge of the somre of the water and its surroundings will be required.

Nitrites and Nitrates.-The anmonia formed in the first stage of decomposition and that washed out of the air by rain are oxidlized eventually to nitrates under the influence of the so-ealled nitrifying bacteria, and this stage marks the eompletion of the procers. The nitrie acid formed, coning in contact with earthy and alkaline arbonates, attacks them and unites with the bases to form nitrates and, in so ching, liberates carhon dioxide. The nitrifying process oecurs not alone in the body of the water itself, but to a much greater extent in the interstiecs of the soil, so that a water rich in all mamner of organic substances undergoes, under farorable conditions, this purifying process in the fullest degree when it enters the soil at the surfince and pereolates showly downward. Before the stage of eomplete nitrifiation is renched, there is an intermediate stage, that of nitrous acid and nitrites, but it is probalble that the time cluring which a given amome of nitrogen on its way to mincralization remains in the nitrous form is extremely short; in fact, the step from ammonia to nitric alcil is pratically instantaneous. Nitrates are seldom alowent in either surface or gromol-waters, and may be present, espectially in the latter, in quite larger anmenut (as mueh as 6 or 7 or more parts in 100,000); while, on the other hand, nitrites are 
not ordinarily present in unpolluted waters, and as little as $\frac{1}{1000}$ part in 100,000 of any water is looker upon as "high."

It is a fact that nitrates are reduced very readily to nitrites, and farther back to ammonia, and even to nitrogen gats itself, by a variety of organisms which aet in the absence of oxygen. These are known as the denitrifying bacteria, and while these species are doubtless very numerous, only a limited number have been isolated and identified. Their action is inhibited by oxygen, as has been proved by Stutzer and Maul,' who found that the process of denitrifieation ceases in cultures through which a stream of oxygen is passerl. This was confirmed by Weissenberg, who observed, further, that when the bacteria were cultivated in small volumes of nitrate bouillon in flasks of such shape that the surface of the liquid was very great in comparison to its depth, and exposed to the air, they did not act.

These bacteria are common in sewage in which the conditions for their growth and activity - absence of dissolved oxygen, for instanceare present. Grimbert ${ }^{2}$ has shown that B. typhosus and B. coli communis reduce nitrates and amido prineiples in culture media. The production of gas appears to be a result of the secondary reaction on the amido compounds by the nitrous acid formed through bacterial action.

Small amounts of nitrites in water may be derived from the air by absorption or by the cleansing action of rain, and may be due to contact of metallie surfaces, brickwork, and new masonry with the nitrates in solution ; but they are almost never present in what are called large amounts (one part in a hundred million) except as an indication of sewage pollution.

The disproportion between the amounts of nitrites and nitrates in water may also, perhaps, be explained as follows: The nitrates are the final stage of complete oxidation; they do not go on to a higher form, but, being permanent in eharaeter, accumulate in the water, unless withdrawn by vegetable life or reduced. The nitrites cannot accumulate as such, but are converted to the higher form. Thus, the lower form is constantly passing into the higher, and is stored as such.

Nitrates vary cousiderably in amount, owing to various causes. They are almost always present in both surface- and ground-waters, unless there is some process at work eausing a reduction to nitrites. In unpolluted surface-waters they are usually low in amount, but such waters generally contain more nitrogen in this form than as ammonia. They do not accumulate greatly in such waters during the warmer months, for they are absorbed largely by growing vegetation. Hence they are more abundant in winter. In the warmer months they may be absorbed almost wholly by growing algæe.

Ground-waters contain little or much, according to circumstanees ; in virgin and thinly settled distriets the amount is small ; in others, it is usually fairly high. In the former, it is mainly from the ammonia

${ }^{1}$ Centralblatt für Bakteriologie, Abth. II., Bd. 2, 1896, p. 473.

2 Annales de l'Institut Pasteur, Jan., 1899. 
of the rain and that formed in the decay of the organie matters naturally in the soil; in the latter, it is due largely and mainly to the ammonia of domestic sewage.

Ground-waters rich in nitrates, when exposed to light and air, generally become more or less rich in vegetable growth, and poorer in nitrates.

Like ammonia, nitrates in water are not of themselves in any way harmful in the amounts found. They simply represent what was onee organic nitrogen, but now completely mineralized. Nor is their presence any indieation of the nature of the original organic matter, whether animal or vegetable, and this ean be inferred only when other constituents are considered. When present in eonsiderable or very ligh amounts, they indieate a corresponding degree of past pollution, perhaps nearby existing pollution, and the possibility of future danger from its recurrence. Therefore, ligh nitrates should sometimes be looked upon with suspicion.

And, furthermore, it should be borne in mind that the evidence of extensive mineralization does not prechde the existence of present processes and the presence of active pathogenie micro-organisms, for organie matter may be oxidized rapidly in the presence of living pathogenie germs. Sometines, very large amounts of nitrates are found in the waters of very deep wells, so large that they camnot be explained by the supposition of oxidized sewage. In these cases the cause is surmised to be fossil remains or natural nitrate deposits.

The presence of nitrites in water is of far greater importance than that of nitrates. It means that fermentative changes are in progress, and that oxidation is not being eompleted. When this condition obtains, nitrites may be very persistent. Sonetimes, they mean a reduction of the nitrates, which takes place mainly under the influence of denitrifying organisms, quite likely to be present in large numbers in decomposing organic matter. Sometimes, neither nitrates nor nitrites are present in sewage-polluted water; in such asses, either they have not been formed or they have been eompletely rediced.

When nitrites are present at the expense of the nitrates by the action of metallic surfaces, lead and iron, for example, the metals themselves are present in at least detectable traces.

3. Mineral Matters.-Chlorine as common salt is a normal constitnent of all waters. Rain-water takes it up from the air in small traces, particularly near the sea eoast. In the specimen of rain referred to on page 374 as rich in ammonia, the chlorine content was 0.13 per 100,000, which is mueh in excess of that found in many inland waters. The anount of chlorine normally present in the water of al district depends: on location and other eonditions. It is influenced very greatly by proximity to the sea, the air above which eontains necessarily more than that at a distance inland. It varies in amomnt in the same water with differences in the amount of rainfall and evaporation, and in the direction of the wind.

Chlorine increases directly with the population, and its amount is 
influeneed very greatly by a proper system of sewerage which carries the sewage matter, rich in common salt, beyond the limits of the drainage area. When its amount rises above the normal of a locality, it is indicative of sewage, though not necessarily of recent pollution. $A$ s we have seen, the organie matters beeme mineralized, and no longer exist in their original form ; but no such change ocenrs in the chlorider, which remain fixed and unchanged, and they may be the only evidence remaining. 'Thus a water polluted by sewage may have its organie nitrogen enverted to nitrates, and these in turn may be absorbed by vegetable growth; it may be elear, colorless, odorless, and palatable, free from pathogenic bacteria, and in every waty suitable for drinking, but, nevertheless, the chlorine remains as a witness that pollution has oceurred in the past.

Aecording to Professor Drown, in a general way 4 families, or 20 persons, per square mile will add on an average 0.01 part of chlorine per 100,000 to the water of a district in seasons of average flow, and more in time of drought.

Other Mineral Matters. - The total amount of dissolved mineral matter in any drinking-water depends upon the character of the soil with which the water has been in contact, upon the length of time of exposure, and upon the amomt of earbon dioxide held in solntion. Not even the hardest and most insoluble roeks wholly eseape the solvent power of water: no mineral is absolutely insoluble. Silicate of aluminum, which is least acted upon, is soluble to the extent of abont 1 part in 200,000 . Silicions rocks in general are attacked only very slightly, while limestones are dissolved with comparative ease, and yield eonsiderable caleium and magnesium carbonates, especially if the water is rich in free carbon dioxide. Gypsum also is acted upon very freely.

Some waters eontain very large amounts of mineral matter, derived from deeply situated natural deposits. The Carlsbad springs, for example, are said to bring annually to the surface enormons amounts of sodinm chloride and calcium earbonate, besides 2,500 kilos of caleium fluoride, 600,000 of sodium earbonate, and 11,000,000 of sodium sulphate.

Besides the ordinary salts of the alkalies and alkaline earths, most natural waters eontain at least very minnte amounts of iron. Appreciable amounts of iron make water unsuitable for general domestic and technic purposes. It eanses staining of clothes if used in the laundry; and headache, dyspepsia, and eonstipation if used habitnally for drinking. It cannot be used for dyeing, and as little as 1 part in 1,000,000 makes it unsuitable for use in blencheries. A quarter of a grain per gallon is sufficient to impart a distinet chalybeate taste.

The permissible total amount of dissolved mineral constituents cannot be stated, but 50 parts in 100,000 are generally held to be excessive.

Hardness.-Hardness is the capacity a water has for decomposing soap. It depends on the amount of salts of $\mathrm{Mg}$ and Ca in solution, and hence upon the character of the soil with which the water has been 
in contact. Water from rocks which yield lime and magnesia will probably be hard, while that from those eomposed of alumina, silica, ete., will probably be soft. Some sandstones will yield soft and others hard water, aceording to the nature of the cement which binds the grains together. The elements causing hardness, particularly the ealcium salts, have the property of making new combinations with the fatty acids of the soap, and preventing the formation of a lather until they have been satisfied: 1 grain of chalk, for instance, will use up 8 of ordinary soap before any effect can be produced; henee. enormons waste of soap oceurs from the use of hard water.

Hardness is divided into "temporary" and "permanent." The former is due to salts which are removable by boiling; the latter, to those which are not thereby affeeted.

Water containing eonsiderable free $\mathrm{CO}_{2}$ can take up and hold considerable carbonate of lime by means of this gas. Some elaim that the carbonate is changed to biearbonate, but this componnd has never been isolated. If the gas be expelled by heating, the solvent power no longer remains, and the amount so held is preeipitated, and then can exert no more influence in eansing hardness. The chloride and sulphate of calcium are not affected by boiling. Magnesium earbonate is precipitated, but redissolves on cooling.

The differenee between the original hardness and the hardness remaining after boiling is the "temporary" hardness. Permanent hardness is, then, due to those salts not affeeted by boiling, that is, to ealeium sulphate and ehloride, and magnesium salts; and if above 5 parts in 100,000, is commonly regarded as excessive and injurious. Calcium sulphate is not alone objectionable in drinking-water, but also in water used in boilers, sinee it is less soluble in hot than in cold water, and thus forms a "seale." Scale is of two kinds: that due to the temporary hardness, easily removed; and that from $\mathrm{CaSO}_{4}$ which is hard, very adherent, and removed with diffienlty. The latter is deposited the more freely, the higher the temperature of the water.

Boiler seale sometimes is due also to other eauses. For instanee, A. Reichard' has reported a ease where serions difficulty was cansed by the formation of a seale of silica and lime from a water which contained only 2.30 parts of lime and magnesia, but as much as 2.60 of silica. Boiler scale eauses great loss of finel, by interfering with the transmission of heat to the water. Hardness is not only undesirable in water used in the laundry and bath, but also in that uned for cooking purposes, for it makes eertain of the vegetables hard and indigestible.

\section{Bacteria in Water.}

The ordinary water bacteria are of the harmless and beneficent kinds, which, depending upon dead organie matter for sustenance, bring albout its conversion into simple chenical substanees. Ilow miny species of these saprophytic organisms exist in water camnot be said, but abont

1 Chemiker ' Zeitming, 1896, p. 6.5. 
two hundred varieties have thus far been deseribed. They may be present in snall or in enormously large numbers without being necessarily of hygienie significance, although usually their existence in large numbers indicates the presence of an abundance of organie matter, and yet they may thrive and multiply enormously in water containing almost no organic food materials. Indeed, multiplieation oceurs more rapidly in pure than in polluted water, but diminution in number is also more rapid. In inpure water, they multiply slowly, but their growth is persistent, and, under ordinary natural conditions, sudden marked diminution in number does not oceur.

The ordinary water bacteria are found in much greater abundance in surface-waters than in those derived from the soil. Indeed, many observers, including Koeh and Fraenkel, have maintained that waters from the unpolluted subsoil are practically sterile. This, however, has been shown by Sedgwick and Preseott ${ }^{1}$ to be not the case. Using improved methods of investigation, and paying speeial attention to the nature of their eulture media, these observers demonstrated conelusively that wholly unpolluted springs, wells, and tube wells may yield considerable numbers of bacteria and sometimes a greater abundance than is contained in some surface-waters. In their paper they state " that the plates are remarkable not only for the slow growth of the species present, but also for the absence of liquefying colonies, and, in many cases, for the abundance of chromogenie varieties. These facts are especially important as indicating the total absence of contanination by ordinary surface-water, and, as far as they go, they strengthen the confidence with which well-protected ground-waters may be regarded as sources of public water supplies." Their conclusions and results have been confirmed a number of times by other competent investigators elsewhere. Ground-waters, when brought to the surface and exposed to the air, soon become rich in the ordinary forms of bacteria, which find in them the conditions necessary for extraordinarily rapid multiplication.

Surface-waters vary very mueh in their bacterial content according as the conditions present at any one time favor or retard growth and accessions. Sunshine, influx of food material or of substances inimical to bacterial life, sedimentation, and growth of higher organisms act for or against increase. Suspended matters in their descent carry down with them the bacteria that have gathered upon them or have been entangled by contact. The diminution in their number by this means is more marked in still waters than in rivers with rapid motion. The growth of algæe and other water plants canses diminution by removal of the nutrient materials upon which the bacteria depend, and probably through some other influence not yet diseovered. The increase in bacteria, sometimes noticed during the colder months, is explained by Frankland ${ }^{2}$ by the fact that in winter much water runs in over the surface from mannred fields.

1 Report of the State Board of Health of Massachusetts for 1894, p 435.

2 The Bacterial Purification of Water, London, 1897. 
Besides those forms whose natural habitat is water, others are often present whose natural habitat is the bodies of man and animals, and which, in water, are, therefore, in an unnatural medium. These forms, which inelude the pathogenic varieties, probably do not inerease in number in water, whether the latter be pure or extensively polluted. They live for a certain time, retaining their virulence in undiminished degree, and then tend to become modified in this respect and rapidly to disappear. The germs of elolera have been found in Seine water in an active state after seven days, and in ordinary drinking-waters as long as twenty days after addition. The typhoid fever organism will live for longer or shorter periods, aceording to eireumstances; it has been found in very pure water after more than seven weeks, while in badly polluted water its life is very short. Sunshine and temperature appear to have very deeided influence upon its vitality. The influence of sunshine is modified by the depth of the water in which the organism is suspended. Buchner' has shown that the rays of the sun will kill cultures of the typhoid baeillus at a depth of about five feet in four and a half hours, while at double that depth their effects are hardly perceptible. While it is true that this organism survives longer in eold than in warm wenther, it eannot be said definitely that the reason lies in any inherent greater resistance to the influence of cold than to that of heat; and, indeed, it seems more proballe that the explanation is to be found in the faet that in warm weather the conditions are more favorable to the growth of the eommon species of water baeteria which are believed to secrete substanees which exert a toxic influence on pathogenic varieties and cause them to disappear. The belief that such toxins are seereted is strengthened by the researches of Frankland, who shows that waters which do not favor bacterial multiplieation are changed in this particular on being boiled. $\mathrm{He}$ found that, while anthrax spores were mueh diminished in number or actually destroyed in a short time in unsterilized water, their numbers were not redued and their virulence remained unimpaired in sterile water after upward of seven months. These toxic substanees are presumably not seereted by all forms of water bacteria, but only by certain species which may or may not be present in any given water, and it is regarded as most likcly that they are not ininieal to the same extent to all varieties of pathogrenic bacteria, but that substances harmless to one kind may aet fatally on another. In general, it may be stated that pathogenie bacteria whieh form spores retain their vitality and virulence longest in any kind of water.

Concerning the significance of $B$. coli communis, which is exceedingly eommon in drinking-water, there is much difference of opinion. Kruse, ${ }^{3}$ in 1894 , asserted that this organion is so ubiquitons that it camnot be regarded as characteristic of sewage, and in this position he has received the support of a number of other in westigators, who have

\footnotetext{
1 Centralblatt für Bakteriologie und Patalsitenkunde, XI. p. 781

2 Journal of State Medieine, Jaunary, 1 s.9.

3 Weitschrift für IIygiene und Infectionskrankheiten XVII., p. 1.
} 
succeded in isolating the organism from all waters examined, although in many eases it was necessary to employ large volumes of the samples.

The eommittee of the Laboratory Section of the American Publie Health Association, to which the question of the significance of $B$. coli in water supplies was referred, reported ${ }^{\prime}$, in October, 1903 , that, in spite of the fact that numerous investigators lave found the organism where it eould not direetly be traced to sewage or fecal pollution, the colon test of water is a safe index of pollution; that their number rather than their mere presence should be used as a criterion of recent sewage pollution ; that evidence of the presence of $B$. coli in a majority of 1 ec. samples should be required for a conclusion that a water is sewage polluted; and that the examination of large (100-1000 ec.) samples for $B$. coli should be discouraged (oue of five members dissenting). On the question of the desirability of isolating streptococei as well as $B$. coli, to confirm suspicious evidence of pollution offered by $B$. coli, there was no agreement, but great diversity of opinion.

According to Clark and Gage, ${ }^{2}$ of the Lawrence Experiment Station, whose conclusions are based on the results of examination of some 16,000 samples of water from all sources and of more than 2000 miscellaneous samples of shellfish, sea-water, ice, milk, dust, excrement, ete, the colon bacillus, occurring more numerously than all other bacteria in normal sewage, is the most valuable index of sewage. When a considerable number of samples from the same source are examined, $100 \mathrm{cc}$. samples frequently give more information as to quality than do single cubic centimeter samples. In filtered polluted water, bacterial tests are of greater value than chemical analysis; and disturbing factors in filtration, shown slightly or not at all by ordinary bacterial counts, are often shown strongly by $B$. coli tests.

\section{WATER SUPPLIES.}

Immediate sourees of water supply comprise: 1. Stored rain. 2. Surface-waters, inchuding rivers, lakes, and gathering basins. 3. Ground-waters, including wells, filter galleries, and springs.

\section{STORED RAIN.}

Where other water is not obtainable, and where the natural water is unfit for drinking or for washing and other domestic purposes, stored rain-water is used. If this is collected under proper precantions to prevent the presence of extraneons matters of undesirable character from the receiving ares, and properly stored, it constitntes a most wholesone supply. But exeepting where rainfull oceurs with regularity and frequence, the nneertainty of supply, especially in periods of drought, acts as a great drawback. An inch of rainfall is equivalent to 5.61 U. S. gallons per square yard, or 27,152 gallons per acre, but

1 Public IIealth Papers and Reports, XXIX, p. 356.

Ibidem, 1. 386. 
only a small proportion of this falls upon surfaces (roofs, ete.) from which it may be eollected.

The total collecting area of the roof of any building depends not upon the shape and style of the roof, but upon the amount of ground ocenpied by the building. Thus, a house 40 feet square will have practically 1,600 square feet of watershed, or, allowing for the projection of the eaves, somewhat more, and this whether the roof be flat, pitched, gambrel, mansard, or irregularly disposed. Upon such an alrea, 1 inch of rain will yield nearly a thousand (997) gallons. The mean anmual rainfall of Massalchusetts is $4: 3.17$ inches, and on this bassis, a roof of this size would receive in a year over 43,000 gallons, which wonld allow for all the needs of the occupants, for drinking, cooking, bathing, laundry, and other purposes, nearly 120 gallons per liem. But under ordinary conditions of storage in cisterns, a very large amount of loss occurs through evaporation, and thus the daily allowance would fall somewhat below this figure.

In collecting rain from roofs, it is very necessary to insure cleanliress of the supply, by allowing the first flow to run to waste, thereby aroiding contamination by dirt, leaves, bird-droppings, soot, and other matter's deposited upon the roof and collected in the gutters. A number of automatic devices are in use for the purpose of diverting the first washings away from the conductors. After this las been done, they change position, so that the subsequent fall is saved and stored.

Irregularity in preeipitation is, as has been remarked above, a serious dlawlack to reliance upon rain as a sole supply. Partly owing to a general belief that great battles, in which large quantities of explosives are used, are commonly followed by heavy rain, numerous experiments have been tried toward breaking dronglit by discharging powerfiul explosives in the upper strata of the atmosphere, but without snecess. As a mattel of fact, the idea of comection between battles and rainfall is by no means new, and has, indecl, come down from times antedating the use of gumpowder in warfare. Furthermore, investigation of government records las shown that the popular belief laas $n$ foundation in fact, and that great battles lave becn as often followed by periods of fair weather as by days of storm.

Rain-water requires no äration, for in its descent it laas absorbed considerable air ; but melted snow and ice should be shaken with air or poured repeatedly from one vessel to another, in order that they may lose the flat taste so characteristie of unaërated water. Moreover, their use in the flat condition is believed to conduce to gastric derangement. snow-water is usually more impure than min, became the snowflakes, by rason of their larger surface, are more efficient in removing dust and lirt from the air.

(isterns for storage of min should be so constructed and arranged as to admit of easy inspection and clansing. They should be liept "overed, so as to exclude dirt and dust of all kinkls, insects, mice, and other animats, and to shut off light as well, for the presence of light is an important aid to the development of lower plant forms. The 
best materials for their construction are bricks, stone, cement, and slate. Cement makes a good lining if one is lesired; mortar, however, is objectionable on account of the solvent power of water upon lime, which will cause progressive increase in hardness. Cisterns should be provided with overflow pipes diseharging into the open air rather thin into the house sewer, and their exits should be protected by wire netting against the entrance of leaves and small animals.

\section{SURFACE-WATERS.}

For public supplies, especially of large communities, surface-waters, as rivers, lakes, and collecting loasins, are generally more available than ground-waters.

Large rivers and lakes are, unfortunately, very commonly subject to most extensive pollution by sewage of large communities and manufacturing establishments along their borders, and by the waste products discharged into them from sailing vessels and steamships. Many rivers are subject to progressive increase of pollution by reason of serving as the most convenient receptacle for the sewage of a succession of towns and cities located at intervals from the source to the mouth. Thus, one town takes its water from a point above and discharges its sewage at another place below; a second, farther down, takes the already contaminated water, and in its turn discharges its sewage at another convenient point, and so on for the rest of the course. On account of the dangers attending the use of such waters, some process of treatment is imperatively demanded to remove the objectionable elements. The different processes available for this work are considered elsewhere.

The public mind is being awakened gradually to the wrong practised upon one community by another by the discharge of untreated sewage into what is its only available water supply. In the case of cities located upon the shores of the Great Lakes and other large bodies of fresh water, it is commonly the case that the intake of the water supply is located at no very great distance from the outfall of the main sewers. Smaller rivers and lakes may be subject to the same influences, though in lesser degree; but, in general, it maly be said that these are controlled more easily, especially when they lie wholly within the jurisdiction of a single law-making power.

Basins for the collection and storage of rainfall and surface-waters are constructed by throwing a dam across a valley or other convenient depression. Experience has taught, that, even though involving large expenditure, it is best to strip off the surface layers in order to get rid of all organic matter and vegetation, which, if left in place, may prove fruitful sources of trouble. The water which gathers in them luas opportunity to rid itself of much of its suspended matters by sedimentation, and is more often used without further treatment than otherwise.

All surface-waters contain more or less active vegetation, and on that account should alway's be kept exposed to light and air, otherwise 
the minute plants will die, and in their decomposition give rise to unpleasant odor, appearance, and taste. Storage reservoirs should have sufficient depth to prevent the water from becoming heated to an unpleasant degree during the warm months of summer. In shallow reservoirs, this is found to be a eommon occurrence.

All sources of surface-water for public supply should be carefully guarded against sewage contamination. It is often necessary to secure protection from pollution by taking great tracts of land and keeping them free from human habitations and industrial plants.

\section{GROUND-WATERS.}

Some large communities and many small ones where no suitalle bodies of surface-water are available for public supplies, and the majority of thinly settled districts which do not admit of public waterworks, depend upon the ground-water as the source of supply. For public distribution, the water thus derived is stored in suitable reservoirs, which often must be covered, in order to exclude light. Ground-water is destitute of plant life, but is generally more or less rich in mineral constituents-nitrates, and lime salts, for example-which constitute appropriate plant food. If exposed to air and light, vegetable growth may start up and become very luxuriant, and give rise to unpleasant tastes and repulsive odors, while exclusion of light and air prevents the diffienlty.

For individual domestic supply, storage is not ordinarily necessary, the water being obtained only as immediately needed or pumped periodieally into small distributing tanks.

In general, unpolluted ground-water of not excessive hardness is preferable to surface-water, on account of the greater exposure of the latter to the many risks of pollution. But it shonld be borne in mind that all sources of supply, both surface- and ground-waters, may, under one condition or another, be subject to polluting influences, and that the eonditions prevailing in one locality are likely to be quite different from those in another.

Ground-water is obtained from springs, or by sinking wells, or by constructing filter galleries.

Springs are merely local outcroppings of the water-table, and are very subjeet to variations in the volume of ontflow. In time of drought, they sometimes cease their flow completely, becaluse of fill in the level of the ground-water ; and this may happen even in the ase of those located at the foot of high hills or mountains. The popular mind endows springs with a remarkable and unvarying degree of purity, but they share with other waters the likelihood of beconing polluted. 'The possibility of contamination after and even at the point of issuance from the gromind is too often overlooked.

Springs are common to some localities and rare in others of similar contour, their presence or absence being determined by conditions not of the surface, but of the geologieal formations below. In Figs. 27 and 28 are shown in profile two depressions having the same contour, 
but with very different arrangement of the underlying strata. In Fig. 27 the formation favors the outeropping of springs; in Fig. 28 the opposite is the case.

Fig. 27.

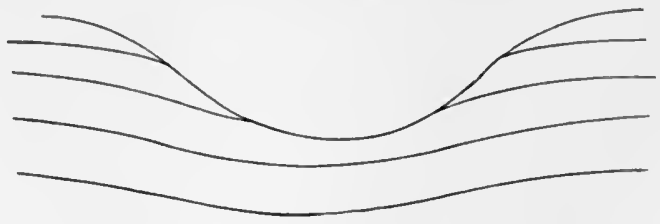

FIG, 28.

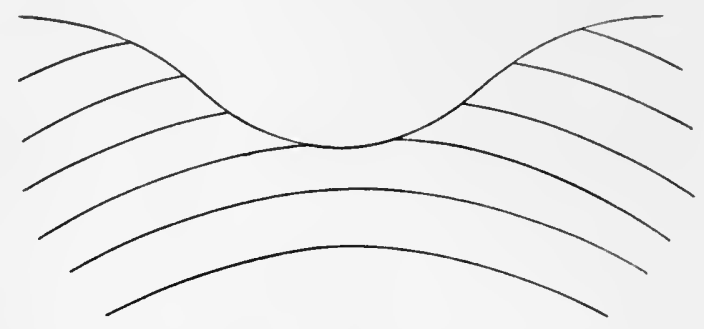

Wells may be classed as dug, driven, and bored. Sometimes they are divided also into deep and shallow; bat these terms as a basis of elassification are of doubtful utility, sinee there can be no general agreement as to the line of division between them, and because of the absence of any necessarily distinctive peeuliarities in the water yielded by ordinary wells of different depths. It is not uneommon to meet with general statements that the water of shallow wells is dangerous to health, and should, therefore, be avoided, and that all shallow wells should be condemned and filled. As will be seen, however, shallow wells are not necessarily dangerous, nor are deep ones always safe by reason of mere depth.

By some writers, the term deep is applied to wells which obtain their water from below the first impervious stratum, through and beyond which they have been extended; while the term shallow is applied to those which draw from what we designate as the ground-water; that is, that collected over the stratum above mentioned, regardless of the depth at which it lies. With these meanings, it follows that a shallow well may extend farther downward than another classed as deep.

The ordinary dug well is a hole dug in the soil down as far as is necessary to reach water, and lined with brick or stone, or, better, with earthenware tubes of large diameter made for the purpose in short lengths with bevelled edges to secure good joints. All brick and stone linings should be well bedded in eement, except near the bottom, and should be ficed with the same material thronghout their npper part. The impervions lining is necessary for the prevention of the entranee of surface washings; but it is very generally the case, in some parts of 
the country at least, that the well is lined simply with field-stones, without cement, not for the purpose of insuring freedom from surface impurities, but to prevent the sides from caving in. With a proper lining, no surface-water can enter until it has passed through a depth of soil sufficient to insure proper filtration and purification.

A dug well should not be left open, but should be elosed eompletely against the entrance of dirt, leaves, and animals, such as toads, moles, mice, and rats. The eover should be supported on a well-set curb, and be sufficiently tiglit to prevent the return of water spiller or allowed to run to waste. A manhole with a trapdoor should be provided as a means of inspection and eleaning.

For bringing the water to the surface, pumps should be used, and not buckets worked by windlass or well-sweep. In country districts it is a common practice to employ buckets made from kegs, originally used as containers for white lead. It is hardly necessary to eall attention to the injury which may be eaused by the use of snch vessels.

The pump may stand direetly in the well or away from it and conneeted therewith by means of a pipe rumning laterally and downward. The latter is the better way, as any water wasted at the pump is prevented by location, if by nothing else, from running lack into the well, and, moreover, the eovering of the well, if of wood, is not continually subjected to wetting, which promotes its decay. The best form of pump is the simple lifting pump, made of iron or of wood, and consisting of an evenly-bored barrel, elosed at the lower part by a valve opening upward, and a piston containing another. The upward stroke of the piston, by producing a vacum, causes the water to pass through the lower valve, and its downward stroke forces the water confined in the barrel through the upper valve, and then the suceceling strokes lift and discharge it continuously. The old-fashioned elain pumps cannot be used without more or less chance of exposure to contamination from above.

The action of the wind is very commonly employed as a labor-saver for pumping water not only from the well, but upward into reservoirs and distributing tanks. For this purpose a variety of wind-mills have been put upon the market.

There are also a number of makes of hot-air engines that are very effieient and not unduly expensive.

Driven wells, otherwise known as "Norton's tube wells," "Ameriean," and "Abyssinian" wells, are made by driving iron tubes of a diameter varying from $1 \frac{1}{4}$ to 4 inches, according to the needs of indivirlual cases, into the ground until water is reached. The first length driven in is provided with a pointed perforated foot, through which the water enters the tube. When this length is driven sufficiently far, another is serewed to it and the driving is continued, atditional lengths being serewed on as necessary. When water is reached-and this is ascertained by means of a weighted string let down inside the tube from time to time-al pump is applied and the water lifted. The first that comes contains sand or fine gravel and dirt, and ats this is more 
and more removed from below, a pocket is formed which constitutes an underground reservoir.

FIก. 29.

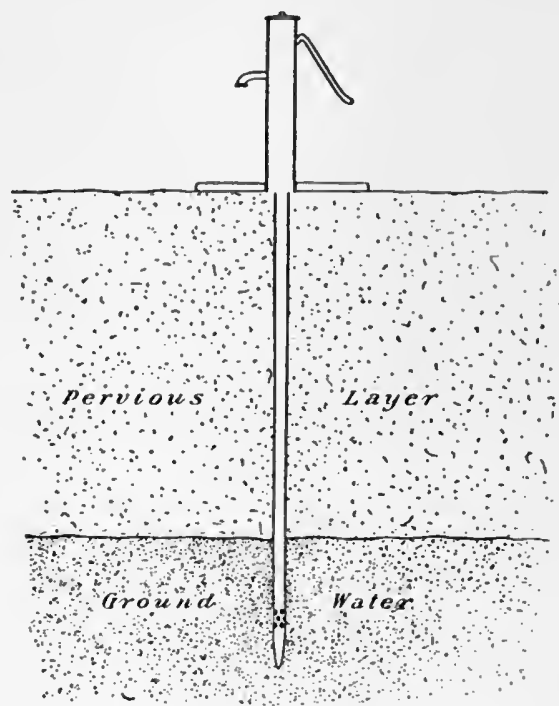

Norton tube well.

Bored wells differ but little from tube wells; in fact, they are practically the same except in the method of their making. They are drilled or bored through solid rock and other strata, and are lined or not with iron pipe, backed with eement according to circumstances. Their cost is much greater than that of the ordinary Abyssinian well, since the labor required is much greater. Sometimes it is necessary, after proeceding several hundred feet with no results, to resort to blasting at the bottom, so as to shatter the rock and form waterways to the well.

It is self-evident that wells of these two kinds last mentioned cannot, under ordinary circumstances, become contaminated with surface washings. Both forms are used very commonly not only for individual, but for public, supplies. In the latter ease, they are driven in groups, or "gangs," the size of which varies according to the amount of water required. Increase in demand shonld be met by extension of the system rather than by over-foreing, for the latter will cause an undue lowering of the water level and tend strongly to bring water downward from the upper strata at such a rate as to preclude the purification which normally is brought about by the saprophytic bacteria of the soil.

In the case of an ordinary well, the bottom should be considerably below the level of the ground-water, so that when this falls, the well will not run dry, and also because the farther the withdiawal by pumping carries the level of the well below that of the water-table, the 
faster will be the flow toward the well, and the greater the supply immediately available. But deepening a well for the purpose of increasing the supply sometimes has the very opposite effect, and may even cause it to run practically dry. Suppose, for example, the impervious layer is underlaid by a thick stratum of coarse gravel, and in the process of deepening the well this stratum is entered : instead of an inerease in the supply, it then may happen that the water flowing into the well finds a ready exit downward by the foree of gravity into the interstices of the gravel, and the usefulness of the well is terminated. (See Fig. 30.)

Included under bored wells are those known as Artesian. These are bored through impervious strata until a stratum is reached in which the water is under hydrostatic pressure sufficiently strong to force it to the surface, or at least to a point nearly as high, the rise

FIG. 30.

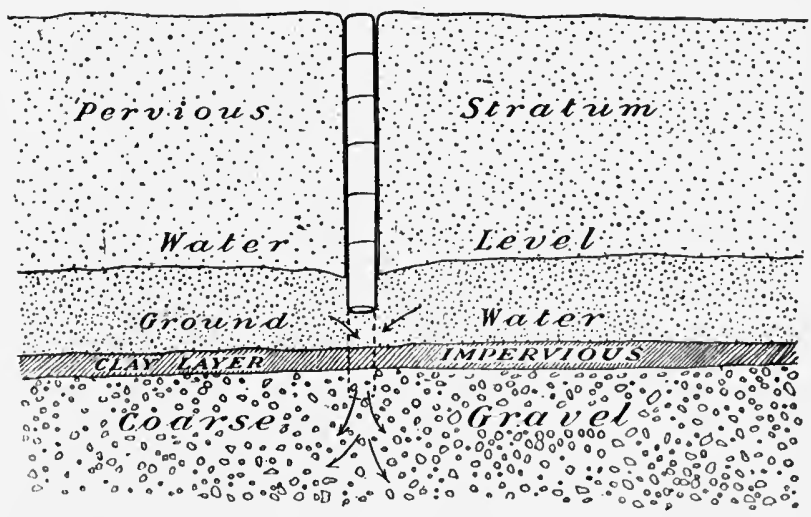

How a well may be spoiled by being deepened.

depending upon the height reached by the water-bearing stratum in higher land elsewhere. In Fig. 31 is shown a formation favorable to the ohtaining of water by means of this class of wells. The water in the soil above the first layer of elay may be reached by sinking wells: of the ordinary kinds. Below this is a second supply confined between two impervious strata inclining upward. The higher this formation extends above the level of the outlet $A$ of a well sunk into it at that point, the greater will be the pressure at $B$ and the higher the rise of the water. Thus, if it extends upward to $C$, for eximuple, the water will not simply fill the tube, but will be thrown some distance into the air. In some eases, although the head developed is very considerable, the water does not eome to the surface, because of the extent of leakage into the upper pervious strata of tho soil.

Sometimes the wells are eonneeted with true underground rivers, and sometimes with apparently inexhanstible reservoirs which have held the water in storage for ages. Sometimes they derive their water 
from fissures draining away the water of surface rivers and lakes, as is proved by the occasional occurrenee in the overflow of small fish with eyes.

Artesian wells have been known in China and Egypt from very ancient times, and centuries ago they were introduced into the province of Artois (Artesium), from which their name is derived. They are exceedingly numerous in the western and sonthwestern parts of the United States, where they have produced enormous results in converting arid, waste lands into fertile farms. Some of then are exceedingly deep, and pass through stratum after stratum of different formations before water is reached.

Since the temperature of the earth increases 1 degree Fahrenheit for about 55 feet of depth, it follows that water from these very deep wells

\section{FIG. 31.}

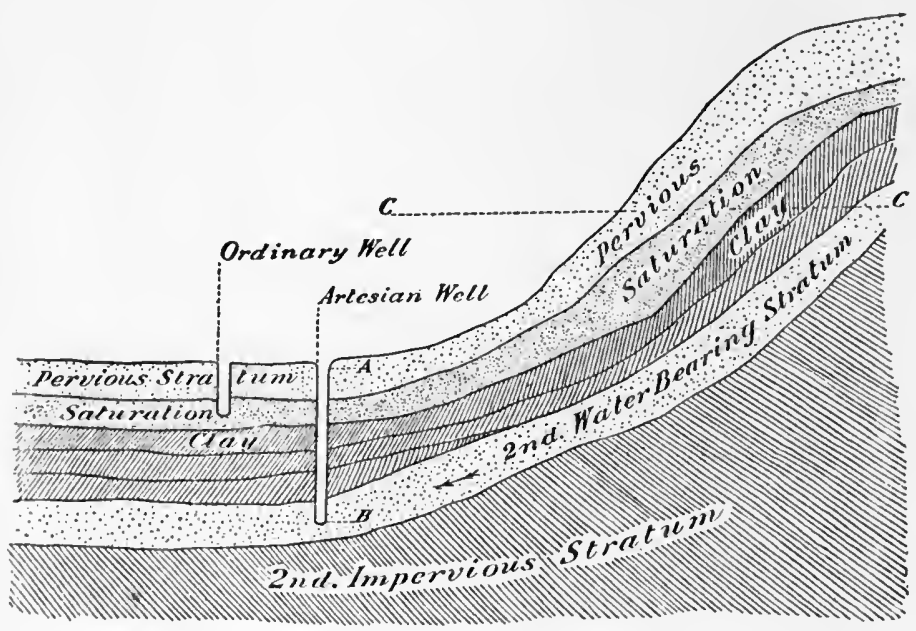

Geologieal formation favorable to the obtaining of water by means of artesian wells.

is materially warmer than that from the npper subsoil. Distinctly hot water from deep sources is rarely fit for ordinary domestic purposes, becanse of the large amount of mineral matters present in solution by reason of the greater solvent power of water when hot than when cold. Thus they acquire an abundance of salts, which, taken into the body, influence its functions and act as medicines. The presence of organic matters is of importance on account of their reducing power. The sulphuretted hydrogen so common to mineral springs is due to the action of these matters on sulphates.

Irrespective of the changes wrought by increased temperature, the water yielded by this class of wells varies very widely in character. It may bear no resemblance whatever to the other waters of the same district, nor is there any reason why it should, for the conditions at the surface and at points hundreds of feet below are quite 
different. Moreover, one cannot know how far the water has travelled from where it originally entered the soil to the point where it makes its escape.

Of waters from four such wells sunk within the limits of the eity of Boston to depths of from 870 to 2,503 feet, two were extensively impregnated with common salt and other mineral matter, one was very rich in both vegetable and mineral substances, and the fourth was rich in both these and sulphuretted hydrogen.

Drainage Area of Wells.-As to the amount of soil which is drained by a well, there can be no general rule. It is commonly assierted that the amount drained may be deseribed as an inverted eone, having the bottom of the well as its apex, and a base with a radius equal to twice the depth of the well. But much depends upon the nature and configuration of the surrounding soil, and the extent to which pumping is carried. If the soil be sandy and open, the base will be mueh larger than if it be elayey and close. If extensively pumped, the well will drain a greater area than if the demands be moderate; in fact, the amount of water removed by pumping has a greater influence in determining the drainage area than mere depth. But other things being equal, the nature of the water-bearing stratum determines the distance to which the measurable influence of pumping is felt.

Pollution of Wells.-In general, it may be stated that, as between wells of different depths, the shallower are more subject to pollution than the deeper, becanse of the fact that the latter have the advantage of the greater opportunity for perfect filtration through the soil. But both are subjeet to pollution by unoxidized matters which enter the soil below the upper few feet in which the nitrifying organisms already referred to are found, as, for instance, from leaching cesspools and leaking drains. It is a practice only too common, even on estates of considerable size, where the exeuse of limited area cannot obtain, to loeate the well and the cesspool very near together. To aroid the neeessity of having to remove the contents of the cesspool as occasion demands when this receptacle is made water-tight, and to avoid the expense attending this kind of construction, the bottom is generally left open, so that the house sewage may drain away into the surrounding soil. Conncetion between the cesspool and the well may take consideralule time or may oceur quickly, but, once estahlished, contamination goes on uninterruptedly. Often it happens that the direction of the flow of filth through the soil is wholly away from the well, and contamination may never oceur; but this is a point that can never be determined in advance.

It is a common belief that, if the well is loeated in higher ground than the eesspool, there ean be no danger of pollution of its water. This, however, is a most fallacious proposition, for it is not so much the location of the outlet of the well that determines the possibility of pollution, as the relative position of the cesspool and the point where the water enters the well. In Fig. 32 is illustraterl the manner in which the supply yielded to a pump placed at a point considerably 
above the location of the cesspool is polluted direetly by the liquid filth issuing from the litter. Again, the geological formation may be such that a cesspool on higher ground than the nearby well will have no influenee on the purity of the water. Thus, a ledge of roek may erop up between them, as shown in Fig. 33, and divert the flow of polluting matters away from the well.

Fig. 32.

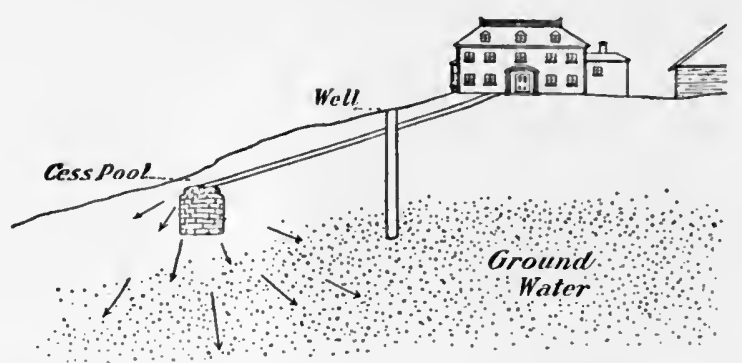

How a well located on high ground may be polluted by the contents of a cesspool lower down.

In locating wells and cesspools, property owners not infrequently lose sight of the fact that, while they can govern the disposition of the surface of their respective estates, the conditions that obtain in the soil below are quite beyond their control. In ennsequence, they may attempt to guard against pollution of their own water supplies by their own exeretory products, without regarding the possibility of contamination by those of their neighbors.

Fra. 33.

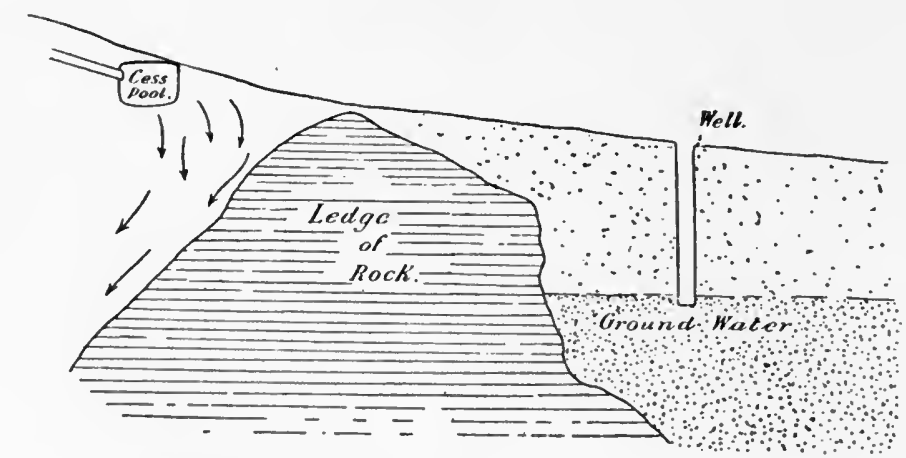

IIow a cesspool located on high ground may fail to pollute a well lower down.

The water of newly dug wells is often of such a eharaeter as to lead to the perhaps false conclusion that it is probably polluted by sewage. It is generally turbid, and may, on analysis, yield results which, in ease the analyst has not full information concerning it, may seem to warrant a condemnatory report. It may yield figures indicating a high content of organic matters, which may disappear as the use of the 
water becomes established. It may even show undeniable evidence of the presence of human wastes, for those engaged in the digging and the stoning may be more interested in the completion of the work than in the perfeet purity of the supply, and may be disinclined to go up to the surface for the purpose of relieving the calls of nature. On all accounts, therefore, it is better to await the results of a later examination, than to condemn and abandon too hastily a supply, which, within a short time, may prove to be of exceptional purity.

Very deep wells may become badly polluted by filth which gains access through open channel-ways, as fissures in rock. $\mathrm{A}$ good example of this is recorded in the Sanitary Inspector for December, 1896: A well bored 500 feet into red sandstone drained, through fissures, all the shallow wells in the vicinity. These being of no use as wells, were then utilized as eesspools, and, draining again through the fissures, caused the well to become so foul that it had to be abandoned. Dr. A. C. Houston ${ }^{1}$ shows how deepening a well may, in a similar manner, eause its ruin. A well of pure water, 114 feet deep, was deepened by farther boring to 294 feet, when its yield was then found to be impure. At a distance of 800 fect was an old quarry, into which drained the sewage of 25 persons. By fissures in the sandstone, this reached the water stratum tapped by the extension of the well and thus spoiled the water.

On account of the possibility of contamination of shallow wells by the entrance of surface washings from above, Koch recommends that pipes be placed in position so as to reach the water stratum, and that then the wells be filled up, first with stone and coarse gravel, and toward the top, for at least six feet, with fine sand. By this procedure, the well is converted really into an Abyssinian well, and is protected from surface contamination quite as well as though it had originally been driven instead of dug.

Filter Galleries.-A filter gallery is a large underground tunnel sunk parallel to a river or lake and near to it; it is in reality nothing more than a horizontal well. The idea which led to their construetion was that in this way the river water, pereolating outward from its bed throngh the soil, would be seeured in a filtered state, and would aceumulate in the underground reservoirs. Although this method of obtaining water has been attended by most exeellent results, the fact remains that the water so collected comes not from the river, but from the ground on its hither side; that is to say, it is the ground-water intercepted on its way to the river.

The water of a river does not, except under unusual conditions, pereolate outward, for the silty matters deposited in its flow elog the interstices in the soil of its bed and banks, and act ats a valve against its egress. The ground-water, flowing to the river, fincks its way in through the silt, which gives way inward against the side of least resistance. Thus the silt yields to ingress, and is a bar to egress of water.

${ }^{1}$ Edinborough Medical Journal, Nov., 1894. 
The fact that the flow of ground-water is toward rather than away from rivers and other large bodies of water is well shown by the faet that fresh water is obtainable from wells sunk in elose proxinity to high-water mark on the sea-coast. Such may be not even slightly braekish, although sometimes they are distinetly so by backward diffision of the salts. In the latter case, removal a short distance backward obviates the diffieulty.

That the water derived from a filter gallery is not due to pereolation from the river along which it lies, is farther proved by the finet of differenee in composition, and especially in hardness.

\section{Classification of Waters from the Sanitary Standpoint.}

From the standpoint of wholesomeness, waters may be divided into two elasses: 1. Those free from sewage contamination. 2. Those polluted by sewage.

Unpolluted waters are not necessarily suitable for domestic use, presenting as they do, wide variations in character. They may be clear, colorless, odorless, and palatable, and contain but little organic and mineral matter; or they may have high eolor, turbidity, disagreeable odor and taste, and a high content of dissolved and suspended substances. A water which, by reason of appearance, odor, and taste, dne, for instance, to luxuriant growth of alge or other forms of life, is repugnant to the senses, should not be recommended for use, although ineapable of producing a speeific disense. Such an one requires no chemical analysis to determine its fitness, the evidence of the senses being quite sufficient.

Unpolluted waters free from such qualities as render them repugnant to the senses, and of low eontent of organic and mineral matters, are suitable for general purposes withont regard to their elassification as surface- or soil-waters. But, in general, it is held commonly that an unpolluted soft ground-water of good composition is preferable to one of surface origin.

Polluted waters may be divided into two elasses, aceording as the pollution is direct or indirect. Direct pollution by sewage is, it is hardly necessary to say, of prime importance, because of the danger of transmission of specific diseases and of lowering the physiological resistance of the system. But even direct pollution may be productive of no harmful results, provided sufficient time elapses between the entrance of the sewage at a given point and the use of the water at a distance to permit of the disposal of the noxious elements by natural processes. Thus, a volume of sewage entering the upper part of a large system of public supply may not reach the distributing pipes for several months, during which time its dangerous qualities will have disappeared. Notwithstanding this fact, however, direct pollution of drinking-water should be prevented by all means avialable, on aceount of possible risk, and even on xsthetie gromds alone.

Indireet pollution is of far less importance than direct. In indirect 
pollution the organic matters of the scwage, including bacteria, are filtered through the soil, in which they are held baek mechanieally and more or less completely oxidized before the containing water reaches its ultimate destination. As to what may be called a safe limit of distance from sources of pollution, no fixed rule can be given : cach case must be judged aceording to its eircumstances. The soil as a whole has enormons capacity for purifying water of its contained organic substances and bacteria, both by mechanieal retention and by oxidation processes set in motion by the bacteria which inlıabit it. But all soils have not this power in an equal degree, and the conditions faivorable to its exercise are not always present to the same extent. The soils most favorable for perfect filtration and purification are sandy and gravelly; in these, the water is exposed in thin layers on the individual grains to the air in the interstices. The latter shonld be neither too coarse nor too fine. If too coarse, the passage of water is too rapid ; if too fine, not sufficient air ean be present at the same time. The organisms are found only in the upper few feet of soil, and it is here also that the contained air is richest in oxygen. When the necessary eonditions for filtration are present in a given soil, the water which pereolates through and reaches the ground-water is quite free from bacteria of any kind, even though the surface is contaminated extensively. Where the soil is very open and permeable to water or fissured, polluting materials may pass through so rapidly that they undergo but slight change on the way, while with a not too fine soil, through which water passes with slowness, purification by bacterial action may be completed within a very short distance.

A gain, there may be greater safety at a point quite near to, but on one side of a center of pollution, than at another at a considerable distance away on the other side, owing to the direction of the flow of water. Thus, in Fig. 34, the point $s$, located quite near the point of

FIt. 34 .

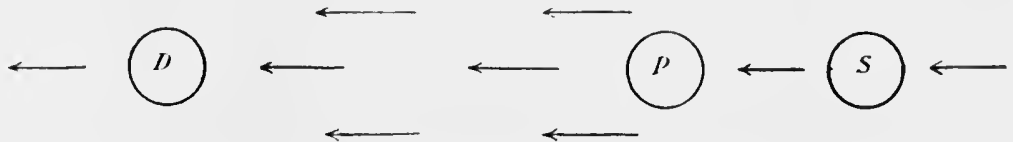

cutrance of the polluting material $P$ into the soil, is far better situated in respect to possible contamination of water by $P$, than the point $I$ on the other side but farther away, since the movement of the water in the soil is, as indieated by the arrows, from $S$ toward $I$ ), and all impurities entering between the two move from the one toward the other. Similarly, the point $S$ may stand in the relation of point $I$ ) to some other polluting influence.

For the determination of the question whether a given well is receiving pollution from any given point, reeourse is hall to the diffusibility of eoal-tar eolors, such as fluoresecin. An ounce of this substance will impart a very decided color to an enormous volume of 
water; and when it is added to the contents of a leaching cesspool, it will aceompany the escaping pollution and reveal to the eye the presence of the latter in any neighboring well-water. Pollution may thus be traced sometimes through hundreds of feet of fairly close soil.

\section{Purification of Water.}

Before proceeding to the consideration of methods employed to bring about purification of water supplies, a few worls are necessary on the subject of "self-purification" of surface-waters. A river shows, for instance, at a given point in its course a certain amount of impurity ; at another point further down, this is found to be considerably lessened ; and farther yet, the diminution is still more marked. This progressive lowering is attributed to the property the water possesses of bringing about its own purification. The practical beginning of this theory was the assertion, made, in 1869, by the British Royal Commission on Water Supplies, that sewage, diluted twenty times or more by riverwater into which it is discharged, will be completely oxidized before it has travelled more than a dozen miles. Two years later, the Rivers Pollution Commission reported strongly against accepting this idea, and concluded that oxidation proceeds with such extreme slowness, even when the polluting matters are diminished very largely by pure water, that not only will a flow of a dozen miles not suffice, but that there is no river in the United Kingdom sufficiently long to accomplish the result claimed. It was then believed that whatever changes occur are the combined result of oxidation and subsidence. It is now recognized that these ageneies, assisted by more important ones, namely, dilution, vegetation, and bacterial action, do in many cases produce very great ehanges, while in others the results are only partial and of no especial value. Drs. R. Emmerich and F. Brunner ${ }^{1}$ showed that in spite of the large amount of sewage matters poured into the Isar in its course through Munich, the water after two hours' flow below the city was practically as pure ehemically as it was before it reached it. Jordan ${ }^{2}$ has shown that, after thirty-four miles' flow, the Illinois River is practically free from sewage bacteria. E. Duclaux ${ }^{3}$ has shown the same to be true of the Seine, and other observers have proved it of certain other rivers in England, Germany, and elsewhere. On the other hand, opposite results have been obtained by other workers in the same field.

Oxidation undoubtedly plays a more or less important part in some, but by no means in all, eases. Dr. T. Meymott Tidy proved experimentally that water containing sewage could lose about half its organie matter in from six to nine hours when made to run one mile in glass troughs with abundant aëration. Professor William P. Mason, ${ }^{4}$ on the other hand, agitated water in a bottle fastened to the connecting rod of a horizontal engine with a ten-inch stroke of 75 to the minute,

'Die chemischen Verïnderungen des Isarwassers, Munich, 1878.

2 Journal of Experimental Medicine, Dec., 1900, p. 271.

3 Annales de l'Institut Pastenr, 1894.

4 Water Supply, New York, 1897, p. 175. 
and found that after 9,000 coneussions there was but a trifling diminution in the amount of organic matter. A large measure of purification, so far as numbers of bacteria are coneerned, is caused by agitation when there are solid particles in suspension in the water. This has been well shown by Perey Frankland, ${ }^{1}$ who observed a decrease of 96.65 per cent. in the number of bacteria.

Dilution by access of rain, melting snow, ground-water, and other clean influents, affects chemical composition favorably, but assists, for a time at least, increase in the numbers of pathogenic and other bacteria. Professor Kebrehl's ${ }^{2}$ daily bacteriological examinations of river-water at Prague proved that, in general, the number of baeteria inereases with rising water, and is subject to very wide variations, due to a number of eauses, among which he mentions changes in the rate of flow, with consequent alteration of conditions influencing scdimentation, and the influx of temporary pollutions, such as washings from streets and dungheaps, which, under some circumstances, have greater influence than the regular unclean influents.

Sedimentation, which formerly was believed to play a very great part in the improvement of river-waters, acts to only a slight extent in those which, like the Isar, move swiftly. It is favored by slowing of the current, especially at the river month; and when it occurs it has a very marked influence on the number of bacteria, especially if the water be muddy. This has been shown by Bruno Krüger, ${ }^{3}$ who, by a series of experiments, proved that chemically indifferent substances in a state of minnte subdivision exert a greater influence, the more slowly, up to a certain limit, they settle; while other matters, which act both mechanically and chemically, sueh as lime and hard wood ashes, produce still greater effects. In still water, as small lakes and ponds, sedimentation goes on unobstructed.

Bacterial action as a purifying agent is farored by alkalinity and retarded by acidity. It may be important or not, according to circumstances. Destruction of pathogenic speeies by the saprophytic elass is delayed by dilution by mpolluted water, which, as above stated, fivors their increase for a short time, after which they rapilly decline in number.

Vegetation was not taken into aceont by the eurlier olservers, but has now been placed at the head of the important influences in the process. Pettenkofer ${ }^{4}$ asserted that the greater part of self-purification is due to the growth of algae and other low forms of vegretalble life, which clean the water of its impurities in the same way that the higher forms take up and dispose of the manurial matters of cultivated land. This riew is endorsed by T. Bokorny, ${ }^{5}$ who proved that these plants

1 Journal of State Nedicine, January, 1894.

" Pacteriologisehe und kritische Studien ïber die Verunreinigung und Sellstreinigung der Flïsse. Arehiv für Iygiene, $\mathrm{XXX}$, p. 32.

3 Die physikalisehe Einwirkung ron Sinkstoflen anf die iun Wasser befindlichen Mikroorganismen. Zeitsehrift für IIygiene, VIl, p. 8ti.

4 Zur Selbstreinigung der Flïsse. Archiv fiir IIvgiene, XII., p. 269.

${ }^{5}$ Ueber die Betheiligung chlorophyllführender l'flanzen an der Sellstreinigung der Flüsse. Archiv für Hygiene, XX., p. 181. 
take up all manner of organic sulstances, including volatile fatty acids, amido acids, glueose, and urea. He showed that the water of the Isar contains vast numbers of algre to whose aetion much of the changes noted by Emmerich and Brunner were undoubtedly due.

The important effeet of temperature on the ability of streams to purify themselves was brought out by Ruediger at the Amnual Meeting of the American Publie Health Assoeiation in 1910. Ruediger found that colon bacilli and typhoid bacilli disappeared from river water much more rapidly in summer than in winter. In producing this result the most important factor was found to be microseopic plants and other organisms, which, in their growth, manufactured dialyzable substanees harmful to the bacillus coli and the bacillus typhosus. These mieroseopie plants do not grow at a temperature below $0^{\circ} \mathrm{C}$. Furthermore, in the winter time, the water being eovered with snow and ice, the bactericidal action of the sun's rays becomes ineffective. These facts aecord with the experienee that typhoid epidemies, due to polluted water supplies, and oceurring in northern cities, frequently take place in the winter time. Such a winter epidemic, in fact, occurred at Mimneapolis in 1909.

Methods of Purification.-The methods employed for the purification of water embrace:

1. Chemical treatment.

2. Boiling and distillation.

3. Filtration.

1. Chemical treatment is employed to cause the formation of insolnble precipitates, which settle out and entangle suspended matters, ineluding bacteria, in their descent.

Alum, for instance, added to the extent of a quarter of a grain to a grain per gallon of natural water containing a moderate amount of $\mathrm{CaCO}_{3}$, is decomposed, and forms an insoluble gelatinous hydrate, which combines with the organic matters imparting color and settles ont as a floceulent precipitate, which entangles the suspended matters, including the bacteria. The sulphurie acid, set free by the decomposition of the silt, unites with the lime or other lases present, and is thus nentralized, and the calcium sulphate thus formed carries down suspended matters in the same manner. If an exeess of alum is added, it will necessarily appear in the purified water, and be oljectionable on aecount of its effect on the system, and in the bath and in washing.

In case of deficieney in $\mathrm{CaCO}_{3}$, lime-water sometimes is supplied, and identical results obtained. The addition of freshly preeipitated alumina serves the purpose equally well, and avoids the presence of the sulphuric acid resulting from the decomposition of alum.

Alum removes practically all the bacteria, as has been proved by $\mathrm{V}$. and A. Babes, ${ }^{1}$ Professor E. Ray Lankester, and others. 'The use of alum in the purification of water is not of reecnt origin: it was de-

${ }^{1}$ Centralblatt für I3akteriologie und P'arasitenkunde, 1902, XII., p. 45. 
scribed as early as 1830 by Felix d'Arcet, ${ }^{1}$ who mentions its extensive use in Egypt.

Lime-water or milk of lime, added to water eontaining ealcium carbonate held in solution by earbon dioxide, canses precipitation of the former by uniting with the litter. It thus withdraws the solvent from active service, causes precipitation of that which was held in solution, and, beeoming itcelf converted to an insoluble substance, is precipitated. So a double precipitation occurs. But water thus treated is not necessarily limited in its changes to a removal of its excess of calcium carbonate, for, in the precipitation of this substanee, considerable other matter may be carried down meehanieally, and baeteria are lessened decidedly in number.

Permanganate of potassium is used more or less, particularly in wells in India during the prevalenee of cholera epilemies. Enough is added to secure a slight pink tinge, which indicates a slight excess. 'This acts as an oxidizing agent with good results. For' eximple, Dr. P. W. O'Gorman ${ }^{2}$ relates that during an ontbreak at Midnapore, the number of cases, 117, was supposed to have been kept down by its nse. These occurred in all parts of the town, exeepting in the European quarter and at the jail. The former used water which was filtered or boiled and filtered, and at the jail especial care was taken of the water supply. Forty-six public and private wells were disinfeeted with the salt, and the outhreak thereupon ceased. An ounce or onnee and a hilf or more, according to the size of the well, was dissolved in a bucket, poured into the well, and stirred about. If after half an hour the water showed a red tinge, it was considered that enongh had been added; if not, more was added until a tinge was seen. Aceording to Hankin, ${ }^{3}$ enough of the salt to insure a reddish tint lasting twenty-four hours should be added; but care should be taken not to add so much that fish, frogs, and turtles, put into wells to keep the water elean, are killed and the water spoiled by their putrefuction. Dhingra ${ }^{4}$ states that this method ean be relied npon only under ecrtain conditions, and even then its action is not continuous. The anent must expend itself first in oxidizing organic matter and nitrites before attacking organisms, which, for their destruction, require it in fairly strong solution. He believes the method to be fillacious in theory, defective in technie, and impossible of practical application.

The hypochlorite treatment of publie water supplies has received new impetus during the last few years. The value of the method was recognized, to be sure, as early ats 1888 by the late Thonlas M. Drown, but up to 1908 the use of hypochlorites had not received serious consideration.

Clark and Gage, ${ }^{5}$ in a paper entitled "Disinfection as an Adjunct to Water Purification," state that "the action of hypohlorites and permanganates in water are quite similar; both are oxidizing agents, and

1 Note relative à la clarifieation de l'eau du Nil, et en général des eaux contenant des substances terreuses en suspension. Amales d'llygiene publique, IV., p. 375.

2 Indian Merlical (iazette, July, 1896.

3 Ibicl., July, 1896 .

4 British Medieal Journal, Aug. 17, 1901.

s Juurnal of the New England Water Works Association, 1909, p. 302. 
it is to this oxidation that their disinfecting action is due. Unlike copper salts, neither of them retiins its identity for any length of time in the water, and the slight inerease in the permanent hardness eaused by the amounts of bleach ordinarily used in water purification, or the suall traces of manganese which may remain in solution after permanganate treatment, probably lave no physiological action upon the consumer." 1

"When bleach (a double salt of caleium hypochlorite and caleium chloride) is used in combination with sulphate of alumina in mechanical filtration, a satisfactory bacterial removal may be obtained at much less expense for ehemicals than when sulphate of alumina is used alone. In such a proeess the disinfection occurs in the coagulation basin before the water reaches the filter, and subsequent filtration introduees a factor of safety which greatly adds to the effective purification of the water, and greatly reduces the chances of the occasional failure of the process. Experiments showed that an effluent of better quality bacterially was obtained by the use of about 0.9 grain sulphate of alumina and abont 0.7 grain of soda per gallon in combination with bleaching powder equivalent to 0.11 part per 100,000 available chlorine than when nearly double the amounts of sulphate of alumiua and soda were used without the disinfectant."

These writers state, furthermore, that no form of disinfection should be practised without competent bacteriological supervision, for "such disinfection would tend to introduce a feeling of false security, which, in case of the failure of the process, at any time, might result in serious consequences to the health of the consumers. For this reason alone, if for no other, disinfection should be followed by filtration, which would tend to reduce the chances of failure."

Johnson ${ }^{2}$ states the following to be the advantages and disadvantages of the use of hypochlorites in connection with water purification :

\section{Advantages of the Process.}

1. Substantially complete destruction of objectionable bacteria, particularly those of intestinal origin.

2. Reliability and ease of application of the chemical, together with the small variation in the required dose.

3. Total absence of poisonous features, either in the chemical product, as applied to the water, or in any of its resulting decomposition produets.

4. Merely nominal eost of the chemical and its application.

5. Speed of reaction, making unnecessary any substantial arrangements as to basins other than storage facilities.

6. Substantial saving in the cost of coagulation of waters that are of sufficiently unsatisfactory appearanee to require elarification or filtration.

7. Permitting rates of filtration materially in excess of those possible where high bacterial efficieney is required of the filtration process in the absence of sterilization.

1 Journal of the New England Waterworks Association, 1909, p. 318.

2 Engineering Record, Sept. 17, 1910. 
8. Reduced clogging of the filter beds, with a consequent lengthening of the runs between cleanings, due to the destruction of various forms of algæ.

\section{Limitations of the Process.}

1. Inability to remove or destroy all of the spore-forming bacteria, but which linds of bacteria are not considered to be pathogenic to man, at least those common to water.

2. Inability to remove bacteria which are embeded in particles of suspended matter.

3. Inability to remove turbidity.

4. Inability to remove appreciable amounts of color or dissolved vegetable stain.

5 . Inability to remove organic matter appreciably.

6. Inability to remove swanpy tastes or odors.

7. Inability to remove creosote tastes or odors coming from the cleaning of stills used in the destructive distillation of wood.

8. Inability to soften water; as a matter of fact, the addition of hypochlorite of lime usually results in a slight increase in the hardness of the water, although this is not ordinarily measurable, notwithstanding the fact that the commercial product usually contains a little free quicklime, which reduces slightly the carbonic acid in the water.

9. Difficulties encountered in applying this process, except with the greatest eare, to waters which contain substantial quantities of reducing agents or compounds capable of oxidation, such as nitrites and unoxidized iron.

Johnson and other experts also believe that "the use of hypochlorites camnot be considered in the light of a substitute for filtration. . . . As an adjunct to filtration processes it has a distinet field of applicability, for at a moderate cost it is feasible to obtain water practically above suspicion ; and, furthermore, there is brought about a substantial economy in the first cost of a filtration plant. It is made possible by the use of higher rates of filtration than are ordinarily used, and the required filter area may also be reduced. It also effects a substantial economy in the cost of operation.

Bromine also has its aldrocates as a chemieal purifier, both on a small and on a large seale. Schumburg ${ }^{1}$ recommends a process which is said to kill in five minutes nearly all of the ordinary basteria and all pathogenic organisms found in water. Ite nses a solution of 20 parts each of bromine and potassic bromicle in 100 of water, 1 ece. of which suffices to sterilize 5) liters of 'Spree water. After five minutes' contact, the bromine is neutralized with ammonia, and the result is a clear, tasteless, sterile water. Vory hard waters and grossly polluted river and marsh water's require larger amonnts, becanse of the presence of lime salts in the former and of ammonia in the latter, which combine with the bromine before it has opportmity to act as al germicide. With such waters it is neessary to ack anough of the solution to produce a yellow tinge which will persist at least half' a minute. In

1 Deutsche medicinische Wochenschrift, March 4, 1897. 
any ease, whatever the amount of the bromine solution used, an equal volume of a per cent. anmmonia water shonld be added. (In a later communicution, sodium sulphite is recommended.) This process is recommented particularly for use in the army, and in the tropies, for ships' supplies, and for individual use in times of epidemies. A kilogram of bromine is said to suffice to sterilize 16,000 liters of ordinary water. In practice, however, the process lass not met with a large measure of sneeess. Schïler ${ }^{1}$ has tried the seheme, and finds it mreliable. It was tested in the Soudan Expedition in 1898, but the diffienlties attending its use were enough to lead to its abandonment.

Treatment with metallic iron in the form of borings and punchings is employed in a number of places in Europe with nost successful results. The best known of the processes in which this agent is employed is that of Anderson, in which the water is delivered into long iron cylinders, on the inner surface of which are eurved partial diaphragms which, as the apparatus slowly revolves, carry upward the pieces of iron, which fill albout a tenth of the volume of the eylinder, and cause them to shower constantly downward through the water in its passage. The earbon dioxide in the water attacks the iron and forms ferrous carbonate, which, when the water is discharged into the open air, becomes oxidized and converted to ferric hydrate. This flocculent matter entangles much of the organic matters, including the bacteria, and then the whole is passcel through sand filters, the effluent from which is very pure and practically sterile. The process is unnecessarily expensive, involving as it does, in addition to the first cost of the plant, considerable ontlay for power and other items, while the same results in the end may be obtained by the more simple process of sand filtration alone. Moreover, it appears that with peaty waters, the organic constituents of which form soluble compounds with the iron, the results are unsitisfactory.

The use of ozone has been reeommended as a very eflicient method of sterilizing drinking-water, and experinents on a large seale have yielded favorable results. Experimenting on very small quantities with a Siemens-Halske apparatus, $\mathrm{W} \mathrm{eyl}^{2}$ found that 2.3 milligrams of ozone were sufficient to destroy 99 per cent. of the baeteria contained in 200 cc. of water from the Tegel Lake. With 3 and 4 milligrams, he obtained complete sterilization of 0.5 liter of water containing 6,000 bacteria to the ec. For purification on a large scale, the impure water is eaused to percolate through a tower filled with pebhles, throngh which the ozonized air passes upward. The Siemens-Halske apparatus used will produce 20 grams of $0 \%$ ne in an hour. The bacteria are reduced at least 99 per cent. and the percentage of organic matter is greatly diminished, but the process is at present very inperfect, for more than 70 per cent. of the ozone produced is lost. The ozonized water, althougl free from odor, las an muplcasant taste, and with many persons its use canses derangement of the stomach. This fiult necessitates further electrolytic treatment with alnminum electrodes, whereby

I Veitschrift für Hygiene und Infectionskrankheiten, XXXVII. (1901), p. 307.

2 Centralblatt für Bakteriologie, XXVI. 
aluminum hydrate is formed and the water is clarified and freed from ozone.

Sodimm bisulphate has been recommended by Parkes and Ricleal 1 in the proportion of 15 grains to the pint. They state that R. typhosus is killed within five minutes, but recommend a contact of fifteen minutes, in order to insure sterility. Warner" has found that this is sufficient to cunse a striking reduetion in the number of adder germs, but not complete sterilization. In most cases, B. typhosus is destroyed in thirty, and $B$. cholerce in ten, minutes. Contrary to the. statement that the agent imparts an agreeable aeid taste, Warner finds that to some persons the taste is unpleasant, and to all would probably become irksome. Moreover, a person consuming 5 pints of water in a day wonkd swallow 75 grains of the salt, which would tend to increase rather than to quench thirst.

Chemical purification of water sometimes occurs withont the intervention of processes espeeially provided, of which fuet Professor Leffmamn ${ }^{3}$ records a conspicuous instance. The Schuylkill River in the upper part of its course receives much refise mine-water, and becomes impregnated with iron salts and free mineral acids. "In its coure of" about one hundred miles it passes over an extensive limestone district, and receives several large streams highly charged with calcium carbonate. 'The result is i nentralization of the acid and a precipitation of the iron and mueh of the ealcium. 'The river beennes purer, and at its junction with the Delaware River, at Philadelphia, it contains neither free sulphuric nor hydrochloric aeid, only traces of iron, and but a small amount of ealcium sulphate. In this manner there is prodneed a soft water, superior to that of the river near its source, or to the hard waters of the middle Sehuylkill region."

Ultra-violet Rays.-One of the most recent methods of sterilization of potable water, but one still in its experimental stage, is by means of the ultra-violet rays of light. In 1906 the bactericidal aetion of these rays was demonstrated by Nogier and Therenot, and Nogier conceived the idea that the rays might be utilized for the sterilization of water. Two kinds of apparatus have been devised, one of which is immersed in the water to be sterilized and the other acts from the outside. 'The water must be fairly clear. Turbidity greatly interferes with its action.

The following experiment by 'Thresh and Beale ${ }^{4}$ will illustrate the marked sterilizing power of these rays :

"Water from main run into a dirty cistern and well stirred. Samples of treated water talken at half-hour intervals. Rate of flow, 30 gallons per hour throughont. Under the head of 'gelatin' is recorded the number of bacteria per ce. capable of growing on jelly in four darys at $20^{\circ} \mathrm{C}$, and under 'agar' the number' of bacteria jer ce. growing in two days at $37^{\circ} \mathrm{C}$. upon an agar medium :

1 Transactions of the Epidemiological Society, London, XX., 1900-1901.

2 Public Health, July, 1901, p. 700.

3 Examination of Water for Sanitary and 'Techuical Purposes, I'lila., 1895, p, 14

4 The Lancet, Dec. 24, 1910. 


\begin{tabular}{|c|c|c|c|}
\hline & Gelatin. & Agar. & Bacillus coll. \\
\hline $\begin{array}{l}\text { Untreated water. } \\
\text { Treated water, } 1 .\end{array}$. & $\begin{array}{r}3200 \\
0 \\
2 \\
4\end{array}$ & $\begin{array}{r}1180 \\
0 \\
3 \\
0\end{array}$ & $\begin{array}{l}\text { Present in } 100 \mathrm{cc} . \\
\text { Absent in } 500 \mathrm{cc} . \\
\text { Absent in } 500 \mathrm{cc} . \\
\text { Absent in } 500 \mathrm{cc} .\end{array}$ \\
\hline
\end{tabular}

The water was thus pratically sterilized and freed from the Bacillus coli."

With a fairly clear water, therefore, the ultra-violet rays converted a dangerously polluted water into a safely potable water. In view of the fact, however, that turbid waters are not much affeeted by this agent, such waters will have to receive a preliminary treatment through filtration before this method of disinfection can be applied.

2. Boiling and Distillation.-Boiling as a means of purifieation has been practised from very early times, and, in fact, was advised by Hippoerates ( $460-377$ B. C.) for the avoidance of enlargement of the spleen. This process is quite efficient so far as destruction of the miero-organisms is eoncerned, but it does not diminish the amount of organic matter. It does, however, reduce the amount of dissolved mineral matter, in that calcium carbonate held in solution by carbon dioxide is precipitated, and caleium sulphate, being less soluble in hot than in cold water, tends to separate out. Boiling is available only to a limited extent; that is, it is a process which can be carricd out in the houschold, but not on a large scale before public distribution of water. Boiled water is not palatable until aëration has restored the proper taste, but this is easily accomplished by passing it from one vessel to another, or by agitation in contact with air.

Distillation constitutes a most efficient process for obtaining pure water. This process produces necessarily a sterile water, which, however, needs thorough aëration. In the apparatus used in the United States Navy, the steam goes to the condensers in company with air, so that condensation and aëration oceur coincidently. While no bacteria from the original water can pass over into the distillate, other volatile matters can and do, and instances are common to prove that the distillate of a foul harbor water may produce nausea and diarrhoea in all who drink it.

3. Filtration is a process of purification which is most efficient and available for large water supplies. It is employed on an extensive seale by unmerous large eities in Europe and in this country. Before deseribing the process, however, it is in order to consider filtration in the louschold.

\section{DOMESTIC FILTERS.}

The domestic filters in common use are, as a rule, useless except for the removal of suspended matters, such as iron-rust, dirt, and other enarse particles, and worse than useless in respect of bacteria, the removal of which is claimed but not accomplished, in that they engender a false sense of safety, while they favor the growth and multiplication of organisms. Most of them are small affairs for attachment to a water faucet, filled with a filtering medium of coarse sand, animal char- 
coal, sponge, ground glass, wool, felt, and other substances which strain out the visible suspended matters not a whit better than the simple flannel bag in common use in New England and elsewhere al quarter of a century ago. They permit the passige of a good stream, and this fict itself is proof of their inefficieney as bacteria filter's, for any material sufficiently coarse to permit rapid passage of water is not sufficiently fine to hold back such exceedingly minute suspended matters as bacteria. Most of the materials used become very foul in a short time, and in ennsequence the water is richer in bacteria on issuing than it was before entrance. Theoretically, animal chareoal, on acconnt of its oxidizing action, should he an ideal filtering medium, and at first it will remove a large proportion of the bacteria and more or less of any coloring matters. But very shortly it becomes foul; the calcium phosphate which it contains is of great assistanee to the growth of bacteria ; cleaning is impossible, and the eftuent, if stored, soon becomes very foul and unpleasant.

The only domestic filters worthy of the name are those which remove meehanically all the bacteria of the water and, at the same time, add nothing of their own substance to the water. Such are the Chamberland-Pasteur, the Berkefold, and others based on the same principle. In these, the filtering medium is unglazed, wellbaked, hollow, poreelain cylinders closed at one end like a test-tube, enclosed within a metallie or glass jacket, with sufficient intervening space for the water, which enters direetly from the tap

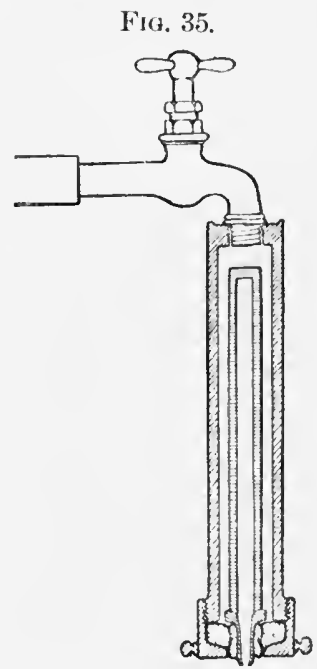

Chamberland-Pasteur filter. under its usual pressure or "head." The open lower end of the cylinder discharges the water, which passes directly through the walls of the evlinders, or " bougies," in the same way in which it would go through blotting-paper. The material is such a very fine strainer that it excludes all suspended matters whatsoever. (Sce Fig. 35.)

The bongies of the Chamberland-Pasteur filter are made of wellbaked kanlin of the proper degree of porosity and hardness; formerly those of the Berkefeld filter wore made of a soft frialle infinsorial earth peculiar to Germany, ealled Kieselguhr, but as they were very brittle and very liable to fracture while being cleaned, they are now made of a special hlend of clays used in the manufacture of the fincst poreelain. Bongies of other makes are of porcelain of varying grades.

All these filtering tubes are purely meehanical in their action, and remove none of the matters, poisonous or otherwise, in solution. While they remove and retain on their external surface all the bacteria, they cannot prevent the growth of the organisms from without inward through their walls, and, indeed, this oceurs so quickly that, in order to secure absolutely sterile water eontinuously, it is necessary to elean and sterilize the bougies daily, and thus it is advisable to have two sets, one of which can be eleaned while the other is in use. 
It has been proved repeatedly that normal water and water artificially and extensively infeeted will yield on the first day of the use of a eleain bongie a perfectly sterile filtrite, and that on the seeond or third day a very small number of bacteria will most likely be present; but these are invariably ordinary water baeteria, and if the pathogenie varieties occur in the filtrate, they come considerably later. Repeated experiments with water infected with $B$. coli communis, B. typhosus, and $B$. choleve have failed to prove the passage of any of these organisms, while the ordinary water bacteria go through very readily. To secure a regular supply of wholesome if not completely sterile water, it is, therefore, sufficient to clean the tubes by serubbing and boiling or by baking about twice a week. It appears, however, that the Chamberland-Pasteur and Berkefeld bougies are not equal in efficiency, for Horrocks ${ }^{1}$ has succeded in growing $B$. typhosus through the walls of the latter. He attributes this result to the larger size of the lacunar spaces and to the consequently diminished immobilizing and devitalizing influences. Since the shortest time required for the bacilli to traverse the bougie is four days, sterilization by means of boiling water should be carried out every three days, in order to insure complete safety

In general, the requirements of a satisfuctory domestic filter may be stated as follows: It shonld yield a sufficient supply of elear, colorless water, free from taste derived from the filter itself; should arrest all bacteria and their spores; and should be simple in construction, and offered at a low price. Thus far, those made on the prineiple of the Chamberland-Pasteur filter have met these requirements best. Their introduction into use in the French army in 1889 was followed within two years by a reduction of more than 50 per cent. in the number of cases of typhoid fever occurring therein.

\section{Filtration of Public Supplies.}

Filtration on a large scale is accomplished by the aid of fine sand in filter beds of proper construetion, which act both mechanically and biologically. The first beds of which we have accurate knowledge were those construeted by Simpson in London, in the year 1829, which were intended primarily for the removal of dirt and other suspended matters eausing turbidity. The process was regarded at that time as a purely mechanical one, and though in course of time this kind of filtering medium eame into very extensive use, it was generally believed that as earried on there was no marked ehemical ehange in the water, and that what did oceur was attributable to oxidation of organie matter by air in the interstices of the sand. 'This was, indeed, the view held generally up to the time when the extensive researches begun by the State Board of Health of Massachusetts in the summer of 1887 proved the great influence of biological agencies, although it had been shown by Meade Bolton, Heræus, Plagge, Proskatuer, and others, that filtration removed all but a trifling percentage

1 British Medical Journal, June 15, 1901, p. 1471. 
of micro-organisms, and that water bacteria exerted some influence on the amount of the usual constituents of water.

Although sand filtration of public supplies is of comparatively recent origin, its use for individual house supplies antedates Simpson by at least a century and a half, for Pontins, ${ }^{1}$ writing in 1685, relates that the Venetians were aceustomed to filter their drinking-water through layers of sand within their eisterns, in order to rid it of disagreable odor and taste.

The first beds constructed by Simpson were broad basins twelve feet in depth, with impervious bottoms and sides, eontaining layers of stones, gravel, and sand, which oceupied half their depth. Beneath the stones were laid ordinary drain pipes, through which the filtered water was diseharged. As the top layers of sand becane elogged, they were seraped and renewed. The beds of the present day are constructed on very similar lines. They are virtually immense tanks of varying size, shape, and construction. The walls are sometimes vertical, but more often sloping, sometimes built of stone or concrete, and sometimes consisting of ordinary embankment. Upon the pared bottom of a bed is laid a system of perforated or disjointed drain pipes leading to a central culvert or well, from which the filtered product is drawn. Above the drains are successive layers of coarse gravel, fine gravel, coarse

FIg. 36 .

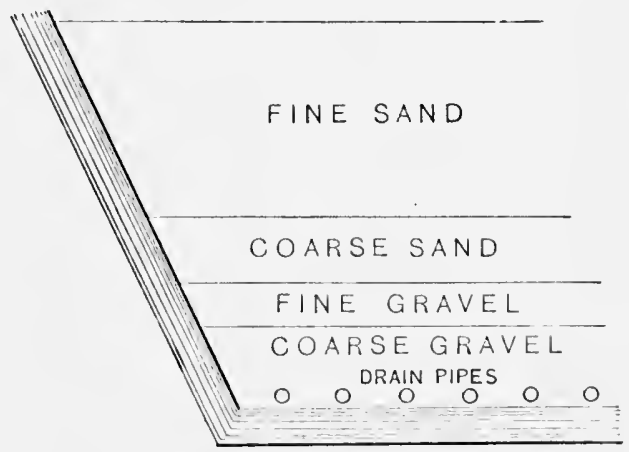

Partial vertical section of one form of filter led.

sand, and, at the top, one of fine sand fiom three to five feet in depth. (See Fig. 36.)

The fine sand is sharp-grained in eharacter, such as is obtainable at the seashore, and it should not eontain elay or other material of similar minnteness of particle; if present, such should be removed completely by thorough washing. As to the size of the sand partieles, it may be stated generally that the finer the grain, the better the efluent; but, it should be added, the more rapidly it beeomes elogged and the more fiequently it needs to be seraped off; and finally, the more diffienlt it is to wash for finture use. With the finest sands, the bacteria are removed absolutely, but filtration proceeds so slowly that

1 De militis in castris sanitate tuenda, anctore Iaca Antonio Portio, Vienua, 168j). 
their use is not practicable. The most effective size of grain is a matter on which opinions differ; but whatever the size adopted, it is important that care be taken to insure uniformity. It is stated variously to be from a fifth to one millimeter in diameter, that is, the diameter of a sphere in volume equal to that of the grain without regard to the shape of the latter. The higher figure is the one adopted by the authorities at Hamburg.

Before the water is applied to the bed, it may be advisable-and if it is from a turbid river, it will be necessary - to allow it to stand several days in a settling basin or reservoir, in order that the suspended matters may subside, and thus the too rapid elogging of the interstices of the sand with mud be prevented or retarded. Observance of this precaution will result in lessened necessity of frequent cleaning. Not only are the suspended matters lessened in amount, but organie matters in solution may be destroyed more or less completely by bacterial action, and the bacteria, too, may be diminished in number by being earried down with the settling matters with which they are in contact, and by the death of the less hardy varieties. In the case of waters from ponds and lakes, the preliminary sedimentation proceeds in situ and the settling tank is not needed.

The water is delivered continuously at the surface of the bed by devices antomatically regulated, and percolates downward through the various layers of sand and gravel to the outlet pipes. Except with very fine sands, the first water of the effluent is not much, if any, purer than the original, but in a short time a sediment layer is formed on the surfice and a slimy algoid growth oceurs. This superficial layer acts both meehanically and by its contained bacteria to cause the removal and oxidation of organic matter and destruction of baeteria. The resulting effluent is quite pure and practically sterile. The Lawrence filter, for instance, removes more than 97.50 per cent. of the organisms present in the water as delivered, and the reduction is still more marked at the house service pipes, where 99.17 per cent. is recorded, the increase in purification being supposedly due to the fact that their necessary food material has been removed, and henee they cannot long survive. At Hamburg, Altona, Stuttgart, London, and other places, the reduction in bacteria is about the same as at Lawrence.

All organic matters are not acted upon to the same extent during filtration; some are decomposed very rapidly and mineralized, while others are attacked so slowly that complete removal during the short period elapsing between entrance and exit is often quite impossible. This latter elass includes the brown eoloring matters so commonly present in surface-waters. These are very stable compounds: they persist during long storage and are nitrified but slowly. In the process of chemical treatment with alum, lowever, they are coagulated and removed very quickly.

The slime layer, mud layer, or "schmutzdecke," is believed by some to constitute the sole actual filtering medium, the sand beneath aeting only as a means of support. But experiments conducted at Lawrence and elsewhere show that this is not true, and that if the 
greatest eare to be exercised not to disturb the immediately underlying sand, almost the whole of the slime layer may be stripued off without causing any change in the bacteria count. The greater part of the work is done in the upper layers of the hed, and yet bacterial effieiency is not necessarily established as soon as a coating has been formed. A perfectly new filter does not show its hest results mutil it has been in use for some little time, during which the sand particles for a considerable depth become coated with the jelly-like deposit.

The active agents in bringing about the death of the bacteria contained in the efllnent and in accomplishing the destruction and mineralization of the organic matters are of the same elass of nitrifying organisms as are constantly at work in the soil. The deatl of the bacteria is not direetly due to the process of nitrification, for it has been proved that a very marked increase in the process is not necessarily accompanied by any diminution in the number of organisms which manage to pass through to the drains. It is possible that the supposed relation of cause and effect is merely a coincidence of conditions, that is, that the conditions favorable to nitrification are unfavorable to the vitality of the ordinary bacteria. It is also possible that through nitrification the latter are deprived of at least part of the food materials necessary to their continued existence and multiplication.

Nitrification sometimes ceases suddenly after it has been proceeding for a long time at a proper rate, and then, after an interval, hegins again without apparent reason. One explanation offered is that the process begins only when a certain amount of nitrogenous matter has accumulated within the interstices, that it then proceeds nutil the store is consumed, and that pending a further accumulation the process lapses. In winter it does not begin again until the temperature of the effluent reaches at least $39^{\circ} \mathrm{F}$, but after it is once started it is unaffected by a fall to $35^{\circ}$. The most farorable temperatures for the process are those of the hot summer months.

As to the rate of filtration, it is important that, whatever the rate, it shall be uniform all over the filter. It has been proved loy the Matsachusetts State Board of Health that 2,000,000 gallons prer day can be filtered through each acre of filter bed with the removial of sulsitantially all the hacteria originally present. The Imperial Bond of Health of Germany fixes 2,500,000 gallons per aere as the maximum amount permissible. Koch's three rules of filtration are that the rate of downward morement should not exeed 100 millimeters an hour, that the filtrate of each section should be examined daily while the bed is at work, and that filtered water eontaining more than 100 barcteria to the ec. should not be allowed to enter the pure water reservoir, but should be rejected or refiltered. The bacteriologieal test is much superior to ehemical analysis for watehing the efficieney of a filter, and a simple comt is quite sufficient without attempting to identify the speeies.

When the filter hegins to discharge slowly on aecount of the extent of the algoid growth at the surfitee, it is not safe to increase the press- 
ure unduly by flooding the bed with an increased depth of water, for, as was shown by an experience at Berlin, such a procedure may foree the baeteria, which have acemmulaterl largely in the meshes of the growth, down throngh the filter at such a rate that they are not destroyed by the usual agencier. In this ease the water level was raised two feet, with the result that the portion of the eity which was supplied with the water of that particular bed was visited by an epidenic of typhoid fever. The sime sort of aceident occurred at Altona some years ago, when, a year after suceessfully going through the cholera epidemic which devastated the neighboring eity of Hamburg so extensively, a defect in the filter beds was followed by an ontbreak of cholera, which discase had then dien out in Hamburg.

When the sediment layer beeomes so thick and dense that with the maximum pressure allowable the required amount of water fails to pass, it becomes necessary to scrape off the inch or so that has formed, and then to proceed as though the bed were new.

It will require, as a rule, several days for the formation of a new sediment layer, and until it is well developed the effluent shonll either be rejected or pumped back. The frequency with which a bed will require to be seraped depends upon individual eircumstances, such as the size of the grains, the eharacter of the water as applied, the rate of movement, the season of the year. The removil of the top is not lifficult. It is quite compact and distinet from the sand beneath it, and is readily pared off with shovels or other tools. Suceessive cleanings may take place withont replacement of the sand, until the depth of the filtering matcrial is redueed to about 15 inehes, but not below 12. The seraped-off' sand may be washed thoroughly in a machine for the purpose until a sample in a beaker yields no turbility to clean water, and it may then be stored until needed for future applieation.

Experiments have been tried repeatedly in Massachusetts, Berlin, and elsewhere in sterilizing sand by boiling it in water or otherwise subjecting it to high temperatures, and then determining its efficieney. The results have proved invariably that more bacteria are found in the filtrate than in the original water, and this is explained by the supposition that the bacteria that enter find in the cooked organic matter a food supply most farorable to enormons multiplication, and that the bacteria in the washed sand are necessary for the destruetion of organic matter and of some of the varieties of water bacteria.

During and immediately after the seraping process, the bed is necessarily out of use, and, therefore, it is necessary, in order to insure continuons filtuation, to have a number of separate beds, and to serape them in tum. In this way, while one is out of use, the others ean carry on the work.

In cold weather, owing to increased viscosity of the water, the rate of filtration is less than in the warmer months. In very cold climates, the formation of thiek ice makes proper cleansing of the surface impossible; and imperfect seraping eamses imperfect filtration. The removal of the ice angments considerably the cost of maintenanee, and this item alone is one of sufficient importance to warrant the expense 
of covering the beds. But aside from cost, the efficiency of the process is so much greater and the danger of epidemies of water-borne disease is so much diminished that the plant in a cold elimate should always he covered. With an uneovered filter subject to freezing temperatures, imperfect filtration is almost sure to oceur periodically, and this is indieated by an increase in the daily bacteria eount. Thus, Wallichs ' has noted that after freezing had oceurred in the filters of Altona in Fehruary, 1886, January, 1887, Fobruary, 1888, and Jannary, 1891, the number of germs in the filtered water rose considerably, and in each instance, in the following month, there was an unusual increase in the amount of typhoid fever.

Frecing of the surface causes imperfect filtration by bringing it about that the bed is orerworked in those places which are still pervious. The application of water to the frozen surface thaws the ice slowly and unequally, and where the filter is active, it is doing the work of its frozen neighloring areas.

Scraping of a bed below the ice cake is performed with a machine which runs between the sand and the ice, ents the layer and receives it in a bag as fist as it is removed. It is dragged from side to side without breaking the ice above it.

Covering a filter is advantageons in another direction, for by the exclusion of light, growths of alga are inhibited, and there is, therefore, less need of frequent eleaning.

On the other hand, open filters get the benefit of the sterilizing influence of direct sunlight, but this is more than offset by the promotion of luxuriant growth of alge and other microseopic plants in the warmer montlss. It is sometimes hardly possible to keep filters in food working order in summer owing to these growths, which elog the interstices very quiekly and cause diminished effieieney just at a time when the demand for water is greatest. The eoincidence of greater demand and more frequent cleaning does not permit of sufficient intervals of rest after the completion of the seraping process.

In what is known as "intermittent filtration," the filter bed is need for the reception of water huring part of one day, say sixteen hours, or even during several days, and then is allowed to drain off and rest for a while. $\Lambda_{s}$ the water drains away, the interstices of the sand become filled with air, that is, the bed becomes aêrated, and thus the nitrifying bacteria which hring abont the de-truction of organic matter and its suberenent mincralization to nitrates are aswisted to maintain their vitality. The intermittent proeess is superior to the antinuous in that nitrification proceeds more strongly, the organic matter is, therefore, more eompletely remosed, and the ordinary bacteria do not survive so long in ärated rand; lunt, on the other hand, it is inferior in that, being so much out of active use, the main plant needs to be so much the larger for the aceomplishment of a griven amount of work. As a matter of fact, however, all sand filters alre at one time or another internittent, sinec each time a bed is seraped the water is drained away, and the space formerly oeconpind by it is then tilled with air. Sometimes

'Dentsche medieinische Wochensehrift, 1891, 1. 25. 
it is proposed to put the water through a process of double filtration, that is, to pass the filtrate on to another bed for still firther purification. But if the first filtration has been earried out properly, the filtrate will have been deprived of all the materials neeessary for the formation of the real filtering surface on the second bed. Thus the passage of the water through a second filter would be mueh in the nature of a mere form, for it would patss practically unchangerl.

Sand filtration, when properly nanaged, has proved itself so efficient that the number of eities and towns making use of it is growing almost daily. Although protection of a supply at its source may be preferable to pollution followed by sand filtration, it is not always so trustworthy, since pollution ma ereep in by accident at any time in the best guarded supplies. The ideal eourse is protection at the source, followed by filtration before distribution. This is the methor now adopted by the authorities of a number of eities in Europe.

"Mechanical Filtration."-In some plaees, particularly in the United States, the water supply is treated in what are known as mechanical filters, of which there are a number of varieties, all based on a common principle. Such a machine consists ehiefly of an iron or wooden eylinder filled with rather coarse sand or crushed quatz, through which the water passes by gravity or is driven under pressure at a much faster rate-from 50 to 150 times fister than it moves in a bed. To take the place of the sediment layer which forms in the latter, an artificial film is produced by the use of alum as a eoagulant. This is formed quickly and serves the same purpose, though not with the same thoroughness. The filter is ealled mechanical only because power and mechanical devices are employed in regulating the rate, pressure, the applieation of the alum solution, and the raking and shaking of the sand in the process of eleaning, which process it is necessary to carry out at short intervals. Instead of removing the top layer, the whole body of sand is thoroughly agitated and washed. Filtered water is pumped through from below for five or ten minutes, and the sand layer is agitated by revolving rakes or by compressed air introduced from below. The process is not suited to all water supplies, but for the highly colored and turbid waters so common in the Sonth and West it is particularly well adapted, and is eheaper, more efficient, and more easily managed than filtration through beds of sand. W'ith careful management, upward of 99 per cent. of hacteria are removed.

Within the last two years the combination of mechanical filtration and chemical disinfection with hypochlorites has been found to be more effieient than either process alone, and has been recommended by competent authorities.

\section{Destruction of Algæ.}

For the destruetion of overgrowths of algx, Moore and Kellerman ${ }^{2}$ recommend the use of copper sulphate in extreme dilution (about 1 part of the erystals to 4 or 5 .millions of water). In the practieal applieation of this agent to ponds or reservoirs, the crystals are placed in

${ }^{1}$ U. S. Department of Agriculture, Bureau of Plant Industry, Bulletin 64. 
gunny sacks, which are then drawn through the water by means of row-boats, which traverse the area in concentrie lines from 25 to 40 feet apart. The process has been tried in various places with results varying from complete success to utter failure. In some instances, the destruction of one species of algæ has been followed by overgrowths of equally objectionable and more hardy forms. The assertion that the copper is quickly precipitated is disputed by many who have given the process a trial, and the claim that pathogenic bacteria are destroyed with the alge appears to have little, if anything, to support it.

\section{Removal of Hardness.}

On account of the enormous waste of soap as well as loss of time which the nse of hard waters in washing entails, and of the injury to which boilers and hot-water pipes are subject from their action, it often beeomes necessaly to apply some remedy whereby the degree of latrdness may be lessened. This may be aceomplished by the aid of heat or by the atdition of chemicals. Boiling, as we have seen, drives off the contained earlon dioxide and causes preeipitation of the carbonates which have been held in solution by this agent, but it has no effect on the salts which cause the permanent hardness. For use on a large scale for public supplies, this means is hardly applicable, on account of the cost of plant and of finel; but for domestic purposes the eost is comparatively slight, in that the fuel necessary in cooking may be utilized coincidently for the purpose of heating water. For the chenical treatment of hard waters, the first process devised was that of Clark, patented in 1841. 'This process is based upon the affinity of canstic lime for carbon dioxide, with which it forms the practically insoluble earbonate.

On the addition of lime water to water containing chalk and magnesium carbonate held in solution by earbon dioxide, the reaction ocenrs, and a double precipitation of the carbonates present and of that formed is brought about. 'The process is very ceonomical so far as eost of material is concerned, in that at few cents' worth of lime will remove an amount of harehess which will decompose many dollar' worth of soap. Lime water, however, does not affect the chlorides and sulphates, and henee, like boiling, reduces only the temporary hardness. For the employment of this process on a large seale, varions forms of apparatus have been invented, consisting of chambers, or tanks, in which the line is mixed with water and from which the mixture passes into other larere reeseptackes, wherein it meets the wates to be treated. Thence, aceording to the nature of the apparatus, the water pasices on to settling tanks or to mechanieal filters, where separation of the preepipitate is completed. The largest plant of this lined in the world is located at Sonthamptom, England, where 2,000,000 gallons of water are treated daily at what may well be regalded ats all almost insignifieant cost. The buthling in which it is installed rovers less than as seventh of an acee, and is sufficiently large to aceonmodate achlitional apparatus wherely its working eapacity may he increased ly halt: "Whaterer the forms of apparatus employed, the process must be carefilly supervised, 
and the amount of lime arder must be constantly regulated f for if too little is cmployed, the finll extent of possible softening is not reached, while with too much, the water is made alkaline and the carbonate of magnesium is retained.

Canstie soda may be used for softening waters containing carbon dioxide and the salts causing permanent hatdness. Added in proper annount to combine with all of the free carbon dioxide, it forms carbonate of sodium, which, in its turn, attacks and decomposes the other salts and causes their precipitation. Sodimm carbonate itself may be added in the absence of free carbon dioxide to bring about the same result. In some proecsses for softening water, both lime and caustic conla or sodium carbonate are employed, the object being the reduction of both temporary and permanent hardness.

\section{Removal of Iron.}

Some ground-water's contain iron in such amounts as to be objectionable, both on aecount of its influence on the system and becanse of its production of stains on linen and other textiles in the lanndry. There are two principal methods of removing it, both of which depend upon the conversion of the ferrons compunds into the ferrie form, with consequent separation as a precipitate. These are filtration and aëration. Filtration may be conducted through sand or coke or animal charcoal, and with either material the iron in solution is exposed to the action of air in the interstiees and becomes oxidized to the sesquioxide, which is left on the filtering material. If the air supply is insufficient, and if there is much organic matter present in the water, the sesquioxide may be reduced to the ferrous form and again pass into solution. When ground-water eontaining less than 3 parts of iron per 1,000,000 is exposed in large volumes to air, the iron will settle out almost completely within a day or a day and a half.

Another method of removal by chemical treatment involves the use of ferric chloride and canstic lime in the proportion of 1 and 5 to 10 grams respectively to each 100 liters of water. By this, the "Kronke" method, all the iron ean be remover, but it necessitates the use of a mixing tank, constant attention, and eventual filtration for the removal of the preeipitated iron.

\section{Action of Water on Lead and Other Metals.}

Action on Lead.-The question as to the hest material for housemains and distributing pipes is always an interesting one, and never more so than when a considerable number of persons in a community begin to show srmptoms of lead-poisoning, and evidence is presented which incriminates the water supply. Aside from the matter of cost, the advantage of using lead pipes lies in the comparative ense with which lead is worked, since it may be bent to any neeessary extent, and thus may be fitted to all manner of irregularities of construction without the neerl of the freculent entting, thread-making, and coupling, which the use of inflexible material inyolves. 
All ordinary waters have a greater or lesser tendency to attack lead, acording to the nature and amount of the substances held in solution. The commonly aceepted statement, that pure soft water is prone to attack lead, and that hard waters tend to protect it by forming incrustations over the exposed surface, is true only in part, for some very pure sof't waters exert only very slight action, while some very hard ones aet with unnsual intensity.

Waters containing very small amounts of organic and mineral matters aet or not, according as they contain much or little dissolved oxygen or carbon dioxide, or both.

A chemically pure water wonld probably exert no action whatever on ehemieally pure lead, but commonly neither the one substance nor the other is seen in such a state of purity. Ordinary distilled water, however, which is a nearer approach to absolute purity than any other natual water cau be, will, under certain conditions, act very corrosively, the conditions being the presence of the above-mentioned gasers. It is held generally that either oxygen or carbon dioxide alone in water has but little influence, but that the two together act with varying intensity up to a certain point, directly proportionate to the amomt of carbon dioxide. This belief, hased on experimental olservations of Müller,' wass strengthened by Drs. Antony and Benelli," who found that the highest results in lead eorrosion were obtained by the use of ä̈rated water eharged with carbon dioxide. Investigating the plumbosolvent property of a particular water, $A$ Liebrich ${ }^{3}$ eame to the same conclusion: that the simultaneous presence of air and aubon dioxide favors action, while either alone has no power. Recently, however, a very extensive inquiry into the subject of metallie contamination of water supplies has been conducted by Mr. H. W. Clark, ${ }^{4}$ ehemist of the State Board of Health of Massachusetts, whose results indicate that oxygen is the more actively eorrosive, and that either gals can act alome. He employed distilled water, freed in the first place as empletely as possible from these and all other gases, and theon impregnated with known amounts of eithere or both. Clean bright lead pipe in equal amounts was placed in hall-gallon bottles filled with water containing the gatses in the proportions stated below, then sealed and ret aside at a temperature of $68^{\circ} \mathrm{F}$. for one week, at the end of which time the amount of lead taken up was determined. The results are shown in the following table:

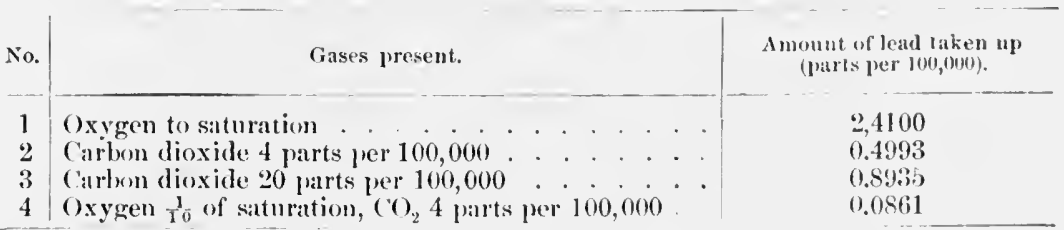

${ }^{1}$ Journal für praktische ('hemic, Series $2,36, p .317$.

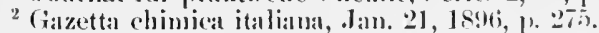

" \%eitschrift fïr angewandte chemice, 1s98, p. 703.

4 Annual Report for 1 sis, 1. 541. 
A specimen of lead in a bottle containing water from which the oxyen had heen boiled out as completely ats possible, and the carbon diexide remored by barium liydrate, was liept at $82^{\circ}$ F. for a week unchanged. At the end of the second week, slight aetion was discemible in spots on the surfice, and analysis showed 0.0774 part per 100,000 of watel. A specimen of ordinary distilled water in a bottle with a small air space in the upper part attacked a similar piece of lead pipe to stech an extent that it yielded 10.58 parts per 100,000 . In this case, the temperature at which the water was kept wats $81^{\circ} \mathrm{F}$.

Inasmuch as all drinking-water contains more or less air in solution, oxygen is always present in some amount, and since, furthermore, carbon dioxide is also generally present, it follows that, unless substances with a decidedly deterrent influence are present, more or less corrosion is to be expected. Numerous instances of chronic leat-poisoning due to water rich in earbon dioxide are on record. At Sommerfeld, ${ }^{1}$ for instance, where, in 1888, numerous cases ocenrred, it was found that the very pure water, rich in this gas, dissolved lead to the extent of about 6 milligrams per liter. At Lowell, Massachusetts, numerous cases were observed during the year's 1898 and 1899 , and it was discovered that one source of supply was rich in dissolved oxygen, and that the other, which eansed by far the greater number of eases, was rich in carbon dioxide.

Professor A. W. Hoffmann believes that a moderate amount of carbon dioxide lessens corrosion by forming a protective coating of carbonate, but that an excess of the gas dissolves it as bicarbonate. The gats is said also to have no action on lead coated with suboxide.

Water containing free acid of any kind attacks lead. Sulphurie acid, which is supposed erroneonsly to form an absolutely insoluble compound, the sulphate of lead, is particularly active. In the ordinary chemical sense, sulphate of lead is insoluble in water; but in the hygienic sense, it is suffieiently soluble to be capable of producing serious symptoms. This acid is not an uncommon constituent of water in minute amounts, especially in the vicinity of eities and large towns, where it exists in the atmosphere as an impurity due to the combustion of coal. The peat acids also have considerable action on lead, but they are not always present in waters from peaty deposits. Some very brown waters appear to exert but slight action, while others are intensely corrosive. The peat acids are due supposedly to the growth of eertain miero-organisms foumd in peaty soils, for a neutral sterilized decoction of peat to which a small amonnt of fresh peat is alded will in a short time develop, an acid reation and ability to dissolve lead. Liebrich ${ }^{2}$ reports a peaty water poor in carbon dioxide and carbonates which took up 300 parts of lead per 100,000 over night, and more when calcium carbonate was added.

The ammonium compounds and the nitrates have been supposed commonly to have a marked corrosive action on lead. That this sup-

${ }^{1}$ Dentsche Virrteljahrssch rift fiir iffentliche (iesundheitspflege, Suppl. XXIV.

${ }^{2}$ \%eitsehrift für augewandte Chenie, 1898, p. 703. 
position is correct, has been provel amply by Mr. Clark's researches; but intense action is manifested only when the water eontaining them is exposed to air.

The constituents of water which tend to bring alont corrosion of lead are, then, carbon dioxide, oxygen, ammonia, nitrates, and fiee acids. The substances which, on the other hand, cxert a protective action include chlorides, carbonates, and silicates, and, probably, sulphates. Aceording to Crookes, Odling, and Tidy, 0.5 grain of siliea to the imperial gallon is sufficient to afford complete protection in all but exceptional cases, even when fiee acids are present; but certain waters containing considerable amounts of silica are known to be corrosive to a decided extent. The protection due to siliea may he obtained by allowing the water to flow throngh broken flint, flint and chalk, or limestone, but such treatment sometimes has the undesirable effect of increasing eorrosive power.

Sodium and calcimm carbonates are very efficient. The bicarbonate of solium is gencrally present in those very soft waters which have the slightest action; calcimm carbonate is efficient whether or not carbon dioxide is present in the water at the same time. Four grains per gallon are gencrally considered to be quite sufficient to afford protection under most cirenmstances. As an illustration of the influcnce of this agent, may be cited the fact that the very pure water with which Glasgow is supplied has, before its entrance to the aqueduct, a marked jlumbo-solyent property, but loses it entirely in its passage to the city, owing to contact with this substance. In 1887, the water of Dessau was treated successfully with calcimm carbonate. Sodium earbonate is even more efficient than the calcium salt, but is not always equal to the bicurbonate. At Emden, in 1897, treatment with the latter was suecessful after the carbonate had failed.

Inasmuch as the influences for and against corrosion are numerous and conflicting, the surest method of determining whether a given water will attack lead is to ascertain the truth by actual experiment.

Regarlless of the character of a water itself, it may be said that its action is greater if the lead is in contact with other metals, so that a galvanic comple is formed. Such may ocem, for instance, when a tinlined lead pipe is bent so that the lining is fiactured. Then the two metals being in contact with each other in a more or less saline liquid, the lead, being the more casily oxidized, is dissolved. Again, the tin lining may develop weak spots which may become corroded, and as soon ats the lead easing is reached, galvanic action becomes established. Learl pipe containing a small pereentage of tin will yield more lead to water than will ordinary lead pipe, especially if free carbon dioxide is present.

A new lead surface will yield more than an old one, as is shown by Professor Mason, who foumil that the same water, stored for three and a lalf montlis in contact with new and old learl, yiekled 58.10 and 3.65 parts per 1,000,000, respectively. 
Hot water is more cormenive than cold; and in the ease of either, the solvent power is increased by presinte.

The result of the continuons ingestion of minute amounts of lead may be nil or the production of more or less marked manifestations of ehronie lead-poisoning. From the fact that lead-pipe is in very general use for house-mains and distributing pipes, and that chronie lead-poisoning is, comparatively speaking, a not very common trouble, it seems reasonable to conclucle that with the great majority of persons the metal is eliminated with sufficient rapidity to prevent aceumulation and cumulative action. In Massachusetts, notwithstanding the enormons use of lead for service-pipes, in but few communities has there been any considerable amount of lead-poisoning reported, and in all of these the water-supply comes from driven wells.

Occasionally, fatal lead-poisoning is caused. In one sueh case, reported by $\dot{V}$. Sehneider, ${ }^{i}$ the water was very soft (hardness 1.40 ) and contaned 0.95 milligram of lead per liter. After three months' use of the water, a girl of seventeen died with all the eharacteristic symptoms of lead-poisoning. Analysis of the organs yiekded lead to the extent of 7.5 milligrams from the cesophagus, stomach, and duodenum, and 24.7 milligrams from the kidneys, liver, and spleen.

Action on Iron.-Corrosion of iron is fatwored by the presenee of nitrates, nitrites, ammonium compounds, mineral and organic acids, chloride of magnesium, oxygen, and carbon dioxide. The latter is especially active, as has been shown by Professor Leffmann and by $R$. Petit. The latter, ${ }^{2}$ investigating the cause of the destructive action of water rich in this gas and poor in lime, placed a certain amount of iron filings in each of three vessels, one of which contained orlinary water, the seeond contained water through which a stream of carbon dioxide was conducted for several minutes, and the third was filled with water to which suffieient caustic lime had been added to. bind the dissolved carbon dioxide and to give an alkaline reaction to phenolphthalein. After a time, the iron in each specimen was determined, with the following results, which prove the great influence of the gas:

1. 3.15 milligrams per liter.

2. 200.60 miligrams per liter.

3. Only traees.

Both east-iron and wrought-iron pipes may be acted upon rapidly unless their inner surfices are covered by some protective coating, such as asphaltum, and even then at the joints where the proteeting surface is not continuous or beeomes detached. Some surfice-waters form a protective layer of vegetable matter on the surface of the pipe, and this is far more efficient than artificial applications, and possesses the additional merit of imparting no unpleasant taste.

Action on Zinc.-On account of the action of water on plain iron pipes, pipes of galvanized iron, that is, iron eated within and withont with metallie zinc, have been recommended. This lining, however, is

\footnotetext{
${ }^{1}$ Gesundheils-Ingenieur, March 31, 1897.

${ }^{2}$ Comptes rendus, 1896, p. 1278.
} 
corroded very easily, especially if the water contains oxygen, carbon dioxide, ammonia, or nitrates, and the water is made milky by the oxide and carbonate in suspension.

Whether or not the rinc compounds occurring in water can be productive of harm, is a point on which authorities differ. But at least it must be admitted that they may cause chronic and obstinate constipation, even when present only in small amounts, and that rine is not a cumulative poison. Dr. Johu C. Thresh ${ }^{1}$ mentions a case of obstinate constipation in a child, due to the use of drinking-water which passerl through a half mile of galvanized pipe. Relief followed discontinuance of the supply.

Gimlette ${ }^{2}$ has reported an extensive outbreak of poisoning attributed to water stored in galvanized iron tanks. Of 56 consumers, 43 were attacked with gastro-intestinal tronbles, the symptoms presented being colic, diarrhœa with consequent anæmia and emaciation, and a spurious kind of dysentery. Analysis of the water revealed large amounts of zinc.

Analysis of water drawn from galvanized pipes often has revealcd very large amounts of zinc. Messis. J. A. and E. W. Voeleker ${ }^{3}$ reeord an interesting ease in which the hot-water pipes of a house supplied by water piped a half mile through galvanized iron, were blocked completely by a deposit of zine. The water was very pure and soft, and contained but 6 grains of total solids per gallon. 'The deposit contained 64.32 per cent. of basic carbonate and 21.96 per cent. of oxide of zinc.

Zine is sometimes a normal constituent of water. Myelins ${ }^{4}$ fonnd about 0.5 grain per gallon in the water supply of Tutenderf, and Carl $T$. Mörner ${ }^{5}$ has reported the presence of 0.015 part of zinc carbonate per 1,000,000 in the water of a well near Upsala. This well, which was about fifteen feet deep, had been in use for more than a year. The water was submitted for analysis solely on aceonnt of its peenliar taste, and beyond the fact that it yielded zine, the sonrce of which conld not be determined, the results of the analysis were very faroralle. No mupleasant effects had been noted among those who used the water. Two springs in Missonri, according to Hillehrand, ${ }^{6}$ yickl much larger amounts. In both, the zine exists in the form of sulphate. The yield anounts to 120.5 and 132.4 parts per 1,00,000, respectively.

Action on Tin.-It is supposed commonly that tin is maffected by water, but such is far from being the ealsc. 'T'in is attacked by water to a considerable extent, although not so realily as the other metals mentioned; but the compounds formed are, so fir as we know, incapable of causing the slightest injury to the system, and this metal

\footnotetext{
1 Water and Water Supplies, Iondon, 1896.

${ }^{2}$ British Medical Journal, s'ppt. $7,1901$.

3 The Analyst, July, 1896.

4 llidem, IV., P. 51 .

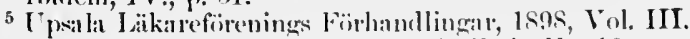

6 United States Geologinal Survey, Bulletin No. 13.
} 
is recommended highly as a lining for iron pipes. Its cost alone prevents it from supplanting lead for house-mains and distributing pipes.

\section{Water and Disease.}

The use of impure water for drinking and other domestic purposes may he a direet canse of disease, and such water is supposed also to aet upon the system in such a way as to lower the resistance of the body to the action of infectious matters; but it shonld be borne in mind that the nature of the polluting material is of far greater importance than its mere amount. 'To maintain that water containing any considerable anount of organic matter, regardless of its elatacter and source, will tend inevitably to produce a general impairment of health, is an great an error as to underrate the danger possible to arise from a small amount of specific contamination. It is quite as improbable, for instance, that the amount of dissolved vegetable matter necessary to yield albuminoid ammonia in what may be designated "considerable" amomint can do any great injury, even when constantly ingested, as that an infusion of tea, which, by the same process of analysis, would yicld resnlts which would be starting in comparison, could of itself conduce to the development of an infeetious disease.

Alarmists may reject as unsuitable for household purposes a water containing an amount of vegetable matter sufficient to give a yellowbrown eolor, and accept as sufficiently pure another containing less organic matter and less mineral matter, but with it the micro-organisms of infectious disease. They go to the extreme of saying that organic matter in solution must "lower the tone," and should, therefore, be avoided, and if asked why this is so, fall back on "general principles" and "common sense," upon which so much illogical, unexplainable theory is based. As a matter of fact, we know that water which is in a sense impure, but not specifically polluted, may be used year in and year out without injury. We know, further, that water containing much less organic matter, but infected with hacteria of certain kinds, is likely to cause disease in at least a proportion of those who use it once, oceasionally, or habitually. We know also that a water once specifically polluted may, under similar conditions, be polluted again, and in the interval may be of good quality.

We know that water containing large amounts of discolved vegetable matter in process of decomposition or of a definitely poisonous character may produce disturbances of a very serious nature; that an abundance of minute water plants, as alge, and animal organisms, as infusoria, may produce ill effects; that decomposing animal matters sometimes yield toxic substances of great potency, and that excessive mineral matter in suspension or solution is not without its deleterions effects.

Therefore, it may be laid down as a general rule, regardless of the fact that all impurities do not necessarily breed disease or undermine the health, that all water containing or likely to contain domestio 
sewage, abundant growths of minute vegetable and animal organisms, decomposing matter of animal origin, dissolved vegetable matter of an inherently toxie nature or undergoing decomposition, or exeessive amounts of mineral matter, should not be accepted as fit for human consumption. Especially shonld we bear in mind that polluted water which is quite free from disease organisms and toxic matters to-day may contain them in abundanee to-morrow.

Disorders Connected with Mineral Matter.-It is noticed very commonly that when one changes suddenly from the use of a soft water to another that is quite hard, there follows a temporary disturbance of the functions of the digestive apparatus. The most marked effect is usually constipation with oceasional diarrhoa. Loss of appetite and slight nausea are not uneommon. The effects are dine to the influence of the salts causing permanent hardness. Change from hard to soft water is quite as likely to cause unacecustomed looseness of the bowels from the withdrawal of this influence on the intestinal secretions. Just how mueh of any one of these salts may be said to be distinctly injurious to health is a matter of doubt, but commonly from 10 to $15^{\circ}$ parts in 100,000 of water are regarded as undesimalie. It has been asserted that the use of hard water is one of the chief camses of stone in the bladder, but such a connection is extremely improbable. How the use of carbonate and sulphate of ealeium can bring about a deposit of uric acid, or of oxalate of ealcium, or of phosplates in the bladder, can hardly be explained. The fact also that stone is very eommon in some distriets where water is soft, and rare in some others where it is hard, suggests that the eanse is to be looked for rather in the individual himself-his food, his metabolism, his habits of life, and, perhaps, hereditary predisposition.

Suspended mineral matter, as elay and marl, will often cattse diarrhoea in persons not habituated to its ingestion, and not infrecgnently in those who are.

The disease most commonly comected with mineral matters in water is goitre. That this disease may be produced by drinking-water, ean hardly be doubted, for it is a well-known fact that in Switzorland and France, for instance, there are wells which yield waters which are lised suecessfully for the intentional production of the discase, with the view to eseape compulsory military service. The enlangement is mot neressarily a permanent disfigurement; disuse of the water may be followed by disappearanee of the swelling, but oftentimes the disease thus intentionally aequired persists.

The exeiting eanse has been attributed to the presener or absence of certain mineral substanees, but the wide variety of the supposed agents is, of itself, strong evidence of the poor fondution "pon which the mineral matter theory rests. It is notieed, for instance, that in some distriets where the disease is especially prevalent, the soil is largely magnesian limestone, and that, as night be supposed, the ground-water is rieh in lime and magnesium salts. Therefore, it is reasoned, magrnesian limestone must be the eause; hut there are many such districts 
where goitre is muknown. More than that, the disease is endemie in some quarters where the water is soft and almost free from lime and magnesium salts. Again, it has been attributed to the presence of certain salts of iron, but this theory also cannot bear the test, for these may be present where no goitre is seen, and may be absent where the disease prevails. Absenee of iodine is another explanation based on nothing worthy of eredenee.

The most probable cause is now believed by some to be an organism which flourishes in the water. The first to promulgate this theory were Italian observers, who, in 1890 , reported facts of interest bearing on the question, since whieh time, other observers, partienlarly in India, have contributed farther evidence of its probable truth.

The most striking facts have been presented by Surgeon-Lieutenant E. E. Walters, ${ }^{1}$ whose observations were pursued in a distriet in India 2,000 feet above sea-level, with extremely porous soil and a water supply eontaining but slight amounts of organic and mineral matter, and but minute traces of iron. The inhabitants, who live under the same elimatic conditions, but with different ocenpations, may be divided into two classes: the native Bhutias and the Sepoy troops from the northwest provinces. The former are carriers and coolies; they are omnivorous, but, by reason of poverty, mostly vegetarians. Their chief diseases are goitre, syphilis, and malaria. The temporary inhabitants, the Sepoys, are all vegetarians, and are a healthy lot, practically free from syphilis, and living under excellent hygienic eonditions. They had been in the district twenty months. Examination of 169 Bhutias showed that more than 75 per cent. had goitre; nearly 70 per cent. of those over twelve years of age were afflicted. Of 380 Sepoys examined, 54 per cent. had goitre. The Bhutias say that their goitres inerease during the rainy season, and this is borne out by the out-patient register and regimental admission book for 1895. All the British officers, too, had suffered from enlarged thyroids during the preceding rainy scason. Their drinking-water wats passed through a Pasteur filter; all other water used was taken as tea or soda. Taking up the several eonditions which have been alleged as the cause of the process, he shows them to be not at fiult in this particular distriet. Iron was present in the water in only minute quantities, and the highest degree of permanent hardness wals but 3.5. As to lime as a canse, it appears that many of the Bhutias without goitres are great eaters of lime, while of the Sepoys, who never touch it, more than 50 per cent. developed goitres within twenty months after arrival. The theory that the disease is due to carrying heavy loads up and down hills, might satisfy in the case of the Bhutias, but not in that of the Sepoys, who, though not carriers, yet have goitre. Farther, as to age, it appears that 5.5 per cent. of the children under twelve had no goitres after living there all their lives, or about the same pereentage as developed them among the Sepoys after a visit of only twenty months. He believes the disease to be due to an organism of the amoba type, with a selective power against the

${ }^{1}$ British Medical Journal, September 11, 1897. 
thyroid or its secretion. For a time the system opposes it, and sometimes successfilly; but when the cause overpowers the phagocytic resources of the system, the thyroid enlarges in the effort to combat the poison. Under thyroid feeding (two 5-grain tabloids daily) the records show a weekly diminution of a quarter to half an inch in the cireumference of the Sepoys' necks, but when the treatment c'ases, the gland again increases in size. That is to saly, additional resisting power is conferred by thyroid tabloids, which keep the poison in eheck and allow the gland to reeover its normal size; but on withdrawing the acessory agent, there is diminished resistance and then again an increase in size.

Disorders Connected with Organic Pollution.-Ordinary vegetable matter in suspension and abundant growths of alga and other water plants sometimes cause diarrhoal tronbles, but they do not cause specific disease. Peaty matters in solution have now and then appeared to be connected with intestinal derangement, but we have no absolute knowledge that they actually have been or can be a eause of such trouble.

We know three epidenic diseases which we may say with eertainty can be carried by water. These are: cholera, typhoid fever, and dysentery, but it is said commonly that water is a great factor in the spread of diphtheria, yellow fever, and malaria. In the ease of diphtheria, the weight of evidence is certainly against its being a water-borne disease. There is some evidence of its spread through the use of a common water supply, but in these eases there is usually a common drinking vessel, and probably a preëxisting case of the disease among the drinkers. The diphtheria organism cannot long survive in water which is not very extensively polluted.

As to yellow fever, there is no evidence whatever of valne, but in the older literature of hygiene many ontbreaks attributed to polluted water are recorded. In the light of our present linowledge, these instances have, naturally, no standing, but in justice to those, who recorded them it must be said that, before the discovery that the disease was mosquito-borne, the evidence presented seemed to be uneontrovertible. For example, outbreaks oceurring at sca aboard ships that recently had been in infeeted ports, where the water-casks had been refilled, could not be attributed to telluric influences, and the replenished water-supply offered the only explanation.

As with yellow fever, so with malaria, abundant evidence of connection with water as a eause has been recorded, although the fact has long been known that water from malarial districts may be used by communities at a distance without harm, as is the ease with the eity of Rome.

One of the best eases which have been accepterl as proof of transmission by water is that reported by Laveran, who firled, however, to furnish certain facts whieh onr present knowledge would require. A detachment of soldiers drank at a ecrtain well, and then enjoyed a hearty meal; another detachment ate first, and later drank from the same well. Of the former, all becanc sick with malaria ; of the latter, 
not one was affected. The difference in the results was thought to be due to the fact that those who escaped took no water until the gastric juice was secreted in the process of digestion. Quite at number of cases are recorded in which men on shipboard have used the water of eertain casks which others had dechined, the former becoming sick with malaria, and the latter escaping.

There is evidence that certain animal diseases may be spread by water containing the speeifie organism. Hog cholera and anthrax have certainly been spread by water into which the bodies of those that had died of these discases had been thrown, and glanders may be spread from horse to horse by the use of a common drinking trough.

The diseases of greatest interest in eonnection with drinking-water are two which we know can be spread by infected water-cholera and typhoid fever. The first-mentioned happens, with us, to be one of minor interest, inasmuch as it is a most uneommon visitor; the other, however, is always with us, and we have, therefore, constant opportunity for observation of the influence of polluted water in its causation.

The strongest proof of the value and efficieney of the purifieation of water by filtration through sand is the drop which occurs in the mortality from typhoid fever when a eommunity abandons the use of nintreated polluted water, and adopts this method of improving the quality without changing the souree of supply. The city of Lawrenee, Massachusetts, for example, prior to and ineluding part of the year 1893, used the unfiltered water of the Merrimae River, into which is poured the sewage of a succession of large eities and towns having an aggregate population of several hundred thousands. In the year mentioned, the process of filtration was adopted, and good results were almost immediately evident. Following are the death-rates from typhoid fever per 10,000 of population for the four years immediately preceding and for the same period following the ehange:

\begin{tabular}{c|c|c}
\hline Prcceding change. & Year of change. & Following change. \\
\hline $1889 . .12 .7$ & $1893 . .8 .0$ & $1894 . .4 .7$ \\
$1890 . .13 .4$ & & $1895 . .8 .1$ \\
$1891 . .11 .9$ & & $1896 . .1 .9$ \\
$1892 . .10 .5$ & & $1897 . .1 .6$ \\
\hline
\end{tabular}

It is but fair to add that about half the deaths from the disease in 1894 and 1895 were of persons who persisted in drinking unfiltered water directly from the canals.

The city of Hamburg adopted filtration in May, 1893, after a most devastating epidemic of eholera in the preceding year. Typhoid fever hat always elaimed a very large number of vietims anmully, and during the four yoars 1890-1893, the death-rate from the discase was 2.6 per 10,000 ; but in the next two (1894-1895), it fell to 0.75 . 
The experience of Philadelphia within recent years furnishes a most instructive example of the danger of using polluted water. During the first six months of the year 1899 , in a population of over a million, 7038 cases of typhoid fever, with 800 deaths, were recorded. During the first five weeks of 1902,510 cases occurred, with 49 deaths. Between January 1 and April 11, 1904, in a population of about $1,300,000$, there occurred nearly 2500 cases; and of these, no fewer than 389 were reported in a single week, this number being the largest ever reported in any week in the history of the city. In that part of the city to which the new supply of filtered water was furnished, there was an almost inmediate fall in the typhoid rate, the immediate neighborhood not so supplied continning to maintain a much higher rate.

Typhoid Infection of Water Supplies.-Typhoid infection of a water supply may be direct or indirect. Direct infection oceurs through the entrance of ordinary sewage containing the cssential organism, or of faeces or urine discharged along the banks of a river or lake, for example, by persons suffering with or convalesent from the disease. Indirect infection oceurs from discharges deposited in or upon the soil, and thenee washed by rain into bodies of water or downward into wells. Ordinary sewage pollution is not sufficient to bring about an outbreak of the disease, nor will specific pollution necesarily always be followed by the occurrence of cases. The specific organism has only a limited temnre of life, and, in the absence of conditions favorable to its existence, it may perish before it reaches the eonsumer. Moreover, the number present may be very small and the effects produced so slight as to oceasion little notice. It is to be borne in mind that not every mouthful of a polluted supply contains the oryanism, and that not every person to whose system it gains access must necessarily come down with the disease.

Until quite recently, it has been supposed that the infeeting organisms had their origin only in the feces of preexxisting eases; but it is now known that this is far from being the case, and that they exist in the freal discharges during only the early stages of the discatse, or "IP to the twenticth day or, perhaps, even somewhat later. Petruschky" has shown that the urine may contain millions of living hacilli in each cubic centimeter, and that they may be found for many weeks, and eren after convalescence is well established. They may alpurar as carly as the fifteenth day, when, perhaps, they are no longer demonstrable in the fieces. Dr. Mark W. Richardson ${ }^{2}$ found them in very large numbers and in practieally pure culture in the urine of nine ont of thirty-eight patients. They appeared late in the course of the disarse, and continned to be eliminated in several of the cases after discharge from the hospital. These observations of Petrusehky and Richarroon have been confirmed by other baeteriologists. It appears, then, that an apparently well person is capable of infecting a water supply to a greater extent and with less optieal evidenee, or none at all, by at dischisge of urine

1 Centralblatt für Bakteriologie und l'arasitenkumle, 1898, XXIII., No. 14.

2 Journal of Experimental Melieine, May, 1898. 
into a water conrse than an evidently sick one by a deposit of his fieces into it or upon its balnks.

Whatever the mode of infeetion of a public water supply, the results, if any, are seen in an increase in the number of eases ordinarily oecurring in the community supplied, and, except in those instances where the disease is spreal by infected shellfish or other foods, any considerable angmentation of eases points unmistakably to the consumption of polluted water, even thongh the system of filtration is followed. In the latter instance, investigation almost certainly will show some defeet in the filters, or that their eapacity has been overtaxed. Even after subsidence of the outbreak, the disease may continue to be more prevalent than usual for some little time, espceially in the absence of a proper system of sewerage.

Influence of Introduction of Public Water Supplies on Typhoid Rates.-Contrary to what might loe expected, the highest death-rates from typhoid fever in thickly settled countries are, generally speaking, not in the crowded eities, but in the towns which have no public water supplies. In Massachusetts, for example, the 5 towns highest in this respeet had, during the eighteen years prior to 1890 , an average typhoid death-late of $\mathbf{1 2 . 8 2}$ per 10,000 of population, while the average of the five lighest rates for eities with public supplies was but 7.65, and of all the eities of the Commonwealth only 4.62. In the town with the highest mortality, Ware, the average for fifteen years prior to 1866 was 16.5 in 10,000 ; in that year a public supply was introduced, and at the expiration of four years the mortality had diminished 60 per eent.

In 1870, only 20 eities and towns in Massachusetts had modern publie supplies; at the end of 1896 , all of the 32 cities and 127 of the 322 towns, comprising 89.8 per cent. of the entire population, were thus provided, and but 3 towns with populations exceeding 3500 had none; at the end of 1904 , but 8 per cent. of the entire population of $2,805,000$ were without public supplies, and this was made up very largely of the very small towns with scattered inhabitants, where the introduction of pullic works would be beyond the finaneial possibilities. As a result of this very general introduction of a common supply in place of that derived from individual wells, largely of the open variety and sitnated in elose proximity to sources of pollution, a decided decline in typhoid fever las been notieed. 'This result is by no means peculiar to Massachusetts, but is found to be the consequence wherever the selection of the souree is made with judicious care and measures are taken to protect it from avoidable pollution. It is not to be supposed, however, that the mere introduction of a common supply without the observance of this neessary precaution will best serve the interests of the publie health. In the following table, compiled by Mr. Hiran F. Mills, ${ }^{1}$ is shown the change in the typhoid death-rates per 10,000 in each of the cities of Massachusetts which introduced water within the years 1869 to 1877 :

122 d Annual Report of the State Board of Health of Massachusetts, 1890, p. 534. 


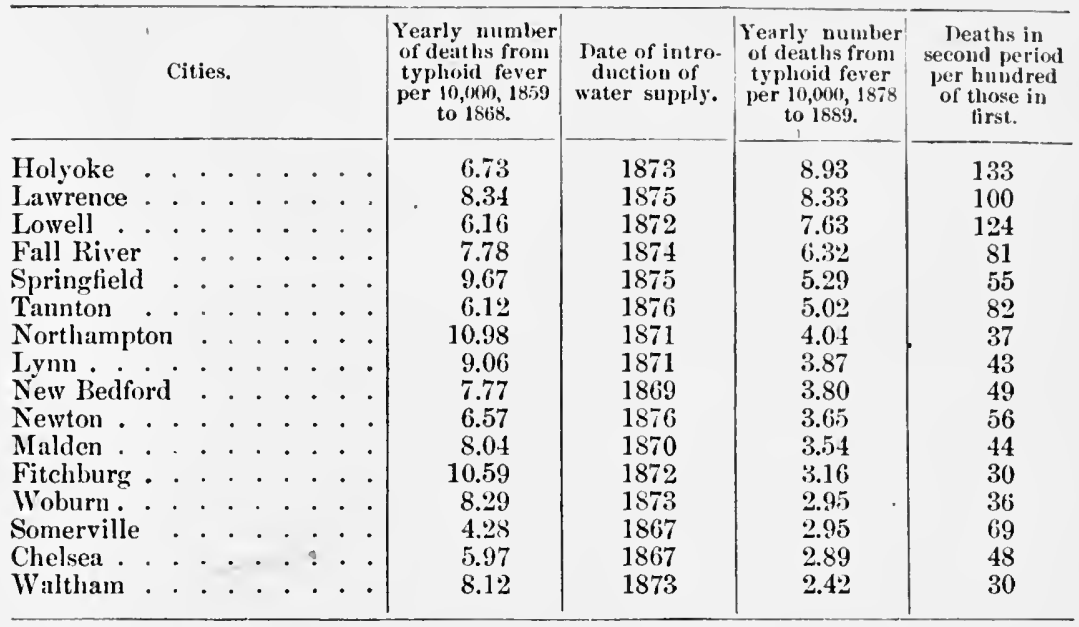

It will be noticed that of these sixteen eities there were three which showed no improvement, and two of these were worse off' than before. The reason for this is clear. All three are mannfacturing eities, situated on rivers polluter by sewage. At Holyoke, while the public supply is but slightly liable to contamination, the operatives in the faetories used water from two other sources, subject to gross pollution; namely, from the eanals, the entranee of one of which is situated close to the outlet of one of the main sewers of the eity, and from wells indireetly supplied by the camals. Comparison of the death-rates from typhoid fever among those of different occupations, brought out the fatet that the operatives in the mills which used canal water suffered from the disease three times as much pro rata as all other persons. Lowell and Lawrence, at the time mentioned, were using the polluted water of the Merrimae River. Lowell took its supply fourten miles below the point of entrance of the sewage of Nashuil, N. H., and consumed it withont treatment. Lawrence drew upon the same supply, after its enrichment by the sewage of Lowell, at a point but nine miles below the ontfill of the latter's sewagre. In 1891, Lowell sutferel unnsually from typhoid fever by reason of the additional contamination by faecs of typhoid patients discharged into Stony Brook, a small tributary of the Merrimac, only three miles above the intalke of the water-works.

The conditions of all three places have since been changed. At Holyoke, warnings were posted for the benetit of the operatives; Lowell abandoned the river in fivor of ground-water in 189:3, and in the same year Lawrence instituted filtration. In all of the three citics the expected happened; namely, a markerd diminution in the death-rate.

Examination of the alove tible reveals the fiset that in the majority of the sixteen cities the recluetion in the typhoid death-rate was most pronomned. In some of them, the diminution has proceded to a much greater extent than is shown here. In 1896 , thre eities with an 
aggregate population of 70,000 showed less than 1 death per 10,000 from this disease, and in one of them, Woburn, there was none at all.

That the favorable effects produced by filtration of water supplies have not been confined to the decreased incidenee of typhoid fever is shown by the following fict: In 1893 it was noticed, independently, by Hiran F. Mills, C. E., of the State Board of Health of Massachusetts, and Dr. J. J. Reincke, of Hamburg, Germany, that not only was there a marked decrease in the incidenee of typhoid fever subsequent to the installation of filtration plants, but that the general deathrate also suffered an equal or larger decrease. $\Lambda$ s a fictor in this decrease in the general death-rate the mortality of children under one year of age undoubtedly plays a consirlerable part, as will be seen by the following table, taken from one of Dr. Reincke's annual reports and referred to by Sedgwick and MacNutt. ${ }^{1}$

The following table shows the deaths of infants under one year of age in Hamburg from gastro-intestinal diseases :

\begin{tabular}{|c|c|c|c|c|}
\hline \multicolumn{3}{|c|}{ Preeding ehange. } & Year of change. & Following change. \\
\hline 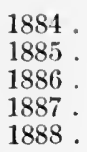 & $\begin{array}{l}.1143 \\
.1159 \\
.1601 \\
1758 \\
.1063\end{array}$ & 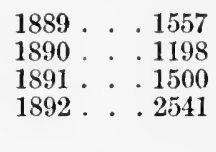 & $1893 \ldots 857$ & $\begin{array}{l}1894.708 \\
1895 . .918 \\
1896 . .767\end{array}$ \\
\hline
\end{tabular}

In 1904 this decrease in the general mortality, due to the purification of publie water supplies, was defined numerically by Hazen in the following statement, which has eome to be known as Hazen's Theorem :

"When one death from typhoid fever has been avoided by the use of better water, a certain number of deaths, probably two or three, from other causes have been avoided."

Sedgwick and MacNutt, as a result of further investigation of this subject, came to the eonclusion that Hazen's estimate of the decrease in the general mortality has been, if anything, too eonservative. In fact, the improvements noted at Lawrenee, Mass., and Lowell, Mass., seened to indicate that in the former eity 4.4 deaths and in the latter city 6 deaths were avoided from causes other than typhoid fever, where 1 death from typhoid fever had been avoided by the substitution of a pure for a polluted water supply.

The following talbles, taken from the article by Sedgwick and MaeNutt, show graphically the effect of this substitution, both upon the typhoid fever death-rate and upon the total death-rate, minus the typhoid component, for the eities of Lawrence and Lowell, Mass. It will be noted that the unused portions of the seale below each eurve have been eut off, so that no base lines are shown:

' On the Mills-Reincke Phenomenon and IIazen's Theorem eoncerning the decrense in mortality from diseases other than typhoid fever, following the purification of public water supplies. Journal of Infectious I iseases, Aug., 1910. 
FIg. 37.

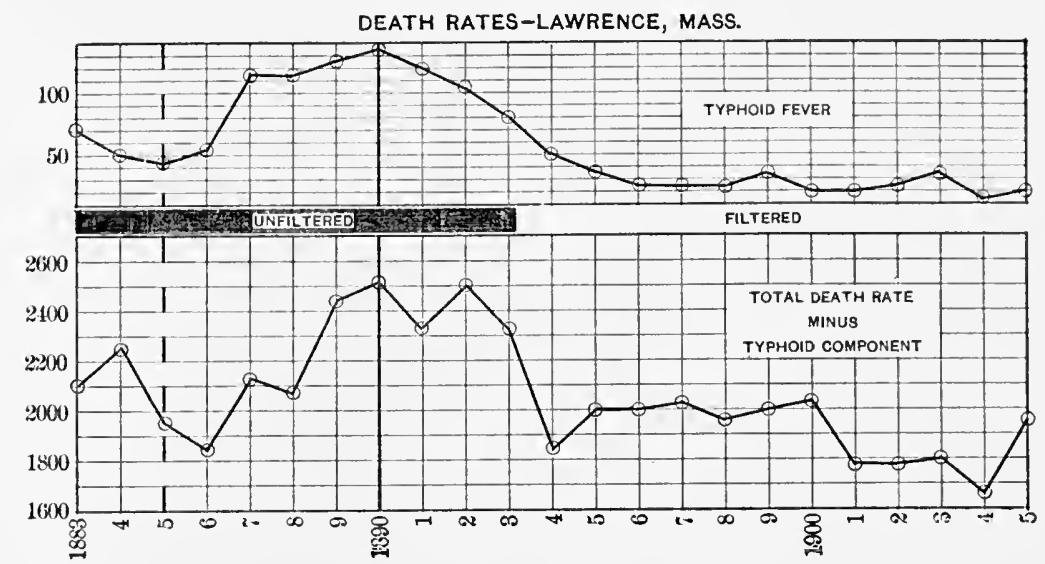

Fig. 38.

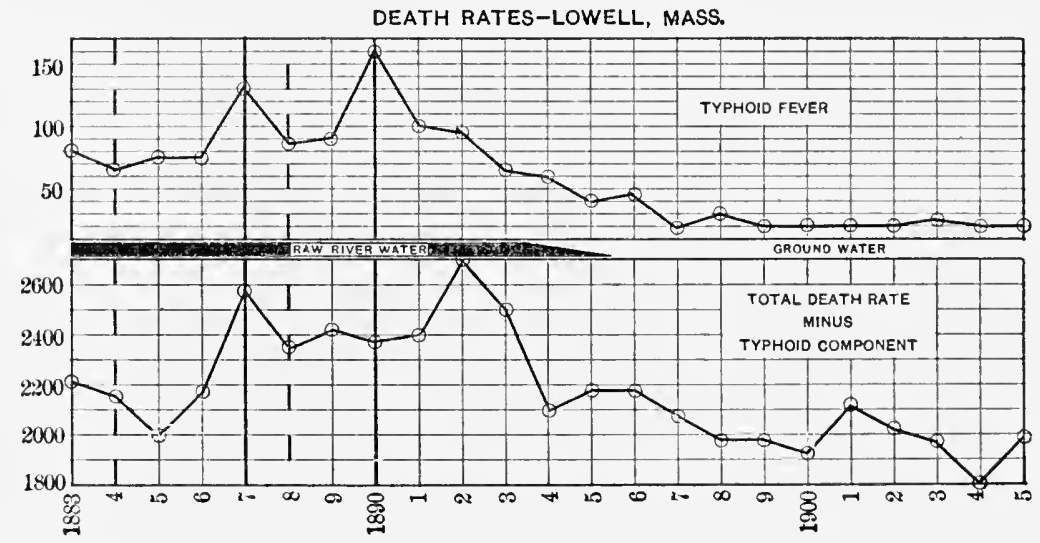

Examples of Typhoid Fever Epidemics and of Limited Outbreaks Traced to Infected Water.-For the purpose of illustrating to what an extent specifically polluted water can, under favorable conditions, bring about a sudden outbreak or explosion, the following eases have been selected from the many which are to be found in the literature of hygiene.

Epidemic at Lausen, Switzerland.-This best known and most often quoted of epidemies of typhoid fever was practically the first one of any considerable extent to be tracerl undisputably to the use of specifically polluted water, although many outhreaks, large and small, had been aseribed to the use of water "containing considerable organie matter," and only supposedly infected.

$\mathrm{Up}_{1}$ to 1872 , this village of 780 inhabitants had not been visited by typhoil fever, even in sporadie cases, for sixty years. On Angust 7th, with no previons warning, ten persons were scized, and during the next ten days nearly sixty more. 'The number of eases increased 
from day to day until 130 persons, or one-sixth of the entire population, had been seizcd. So large a pereentage of involvement pointed to some common cause, and the immunity enjoyed by the inmates of a group of houses not connected with the public water supply directed attention to the latter, which was derived from a spring at the foot of a ridge about 300 feet high, between the village and the Fiihrler valley. In this valley, at a point between one and two miles distant from Latusen, was an isolated farm where dwelt a man who, on June 10th, shortly after his return from a visit, was taken sick with typhoid fever. Before the end of July, three cases more developed in the same house. The discharges of all four were thrown into a brook in which the family washing was done, and which served to irrigate the meadows below. Whenever it was dammed up for this purpose, the volume of the water supply beyond the ridge was noticeably increased. Between July 15 th and the end of the month, the meadows had been submerged by this process, and in three weeks from the beginning of the operation, the explosion occurred in Lalusen.

The sequence of events was, then, the appearance of the initial case on June 10th, and of three more in the same house before the end of July, the daily pollution of the water of the brook, the damming of the brook in the middle of July, and the appearanee of the first eases in Lausen on August 7th. Everything pointed to direct connection between the impounded water and the spring a mile or more distant on the other side of the ridge, and its existence was established by dumping abont a ton of salt into the brook and noting its speedy appearance in the Lausen spring. As a very large amount of flour, deposited at the same place, gave no evidence of its appearanee, even in traces, it was proved that the water passed through a coarse filtering medium rather than through an open underground passage.

The Plymouth, Pa., Epidemic.-The town of Plymouth, Pennsylvania, had, at the time of the epidemic in 1885 , a population of about 8,000 people. The general water supply was derived from a mountain brook, which was dammed at intervals so as to form a series of impounding reservoirs, but a large part of the population was supplied hy individual wells. A citizen who spent the Christmas holidays at l'hiladelphia returned in January to his home, ill with typhoid fever, and had a very protracted sickness. During the entire period, his excreta, which were in no way disinfected, were thrown upon the snow and ice on a slope not forty feet away from the brook, at a point midway between two of the dams. At this time the brook was frozen over, and it remained so until the approach of spring. During the last third of the month of Mareh, there was a sudden period of warmth, and the snow and iee began to melt. Shortly afterward, the warm spring rains began, and the ice and snow and frozen excreta uport the slope were melted, and the entire accumulation was washed into the brook, and thence into the water mains. Within three wecks thereafter, eases of typhoid fever by the score male their appearance throughont the town. On some days, more than a hundred new eases were reported, and on one, the number reached nearly two 
hundred. The total number of seizures has variously been stated, the lowest estimate being 1,000 and the highest 1,500. The number of deaths was not less than 114, and has been placed as high as 150 .

It was discovered that the epidemie was limited practically to those whose honses were supplied hy the town mains, and to those who, while supplied at home hy wells, drank of the public supply while absent from home during working hours. 'This distribution was partienlarly emphasized in one street, where the houses on one side all had one or more eases, while those on the other had none at all. The former were supplied by the town mains, and the latter depended upon wells.

Outbreak at Uvernet.-A somewhat similar outbreak, on a much smaller scalc, is reported by Dr. Dupard ${ }^{1}$ as oceurring at a small vil-

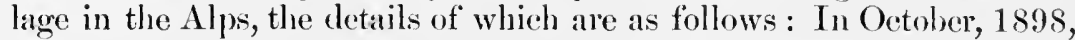
a detachment of 157 infantry soldiers were quartered in four houses in the village, each house sheltering approximately a fourth of the men. In one, where 37 were quartered, there appeared within a few weeks 2:2 cases of typhoid fever, 6 of which terminated fatally. At the time of seizure, there were no other eases in the village, nor did any appear in any other house than this one. Investigation revealed the fact that, a few days before the arrival of the troops, a child of ten years had been taken ill with the disease in another house situated on higher ground, about 400 feet away from the house in question. Where the ehild lay ill, there was no privy, and his exereta were thrown upon the ground in a neighboring field. His soiled clothes were washed in the spring nearby. At the time of the soldiers' arrival, a number of heary lains occurred, by which the surface impurities of the soil in the neighborlood of the house where the child lived wonld, hy reason of the inclination of the ground, be washed toward the house ocenpied by the soldiers. This was supplied by water from a small stroum through a rude main eonstructed of worm-eaten hollow logs laik in a shallow depression in the surface of the soil. There could be no question of the probability of contamination of this supply by the faecal dischanges thrown upon the ground in the vicinity, and in the absence of any othel eases and with the high percentage of seizures in the one house, no other explanation appears to be possible.

Epidemic at Ashland, Wisconsin, in 1893-94.-This ontbreak is one of peculiar interest, in that, in addition to serving as an exceellent illustration of the danger of using the same boly of water as a place for the disposal of sewage and as a source of drinking-water, it was made the basis of an action at law, which established the liability of water companies and municipalities in ease of sickness and death caused by the distribution and use of infeeted water.

The city's supply is derived from an arm of Iake Superior, Chequamegon Bay, npon whieh the eity is situaterl. This bay, which is about twelve miles long, and of an areme wilth of five, varies fiom eight to thirty-six feet in depth. North of the city, and extendine ontward in a northwestwanly direction, is a breakwater constructed

1 Ly̧on médical, Jan. 1, 1899, p. 5. 
for the protection of the harbor against uortherly gales; and between it and the eity the month of the water intake is located about a mile from the shore. (See Fig. 39.) The sewage of the eity is disebarged further to the west and south. The currents in the bay follow the course indicated by the arrows in the figure, and earry the sewage toward the breakwater and over the mouth of the intake. This condition of affairs was brought to the attention of the company by the health boards of the city and state repeatedly, but withont results. That the water was polluted, was evident on mere ocular inspection, for it was often cloudy or markedly turbulent. During the winter of 189:3-94, typhoil fever made its appearance in the city, and from the initial eases a disastrous epidemic developed, which led to the establishment of a model filtering-plant.

The action at law referred to above, was brought by the widow of one of the vietims. In evidence, it was shown that he lived eontimuonsly in Ashland, and drank no water other than that supplied by the

Fic. 39 .

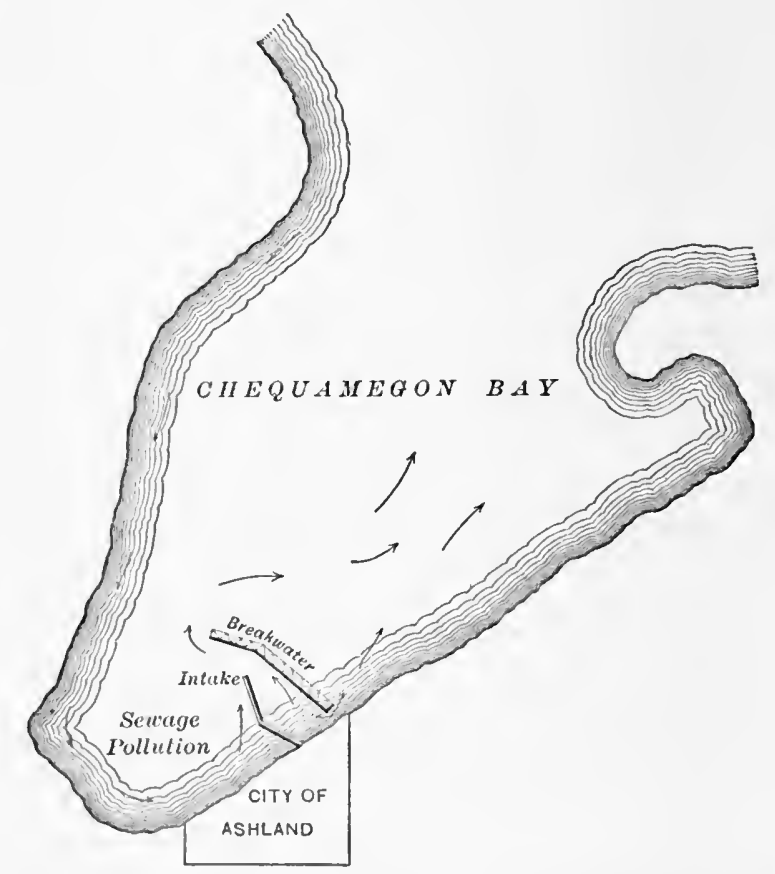

Conditions obtaining at Ashland, Wis., prior to the epidemic of 1893-94.

water eompany ; that previous to his scizure the disease had prevailed in the eity, and that the discharges fiom the antecedent eases had passed into the waters of the bay by way of the eity sewers. The cont found for the plantiff in the sum of $\$ 5,000$.

Epidemic at Luneburg in 1895._-The ancient town of Lüncburg, with a population of 22,000 , has a system of sewers which empty at two 
points into the small River Ilmenau. The public water supply is in the hands of a number of separate corporations, which had their origin in mediaval gnilds; and as the two principal ones supply the same parts of the town, it happens that their mains run through the same streets, and that not alone adjoining houses, but even different stories of the same building are supplied by either one according to circumstances. 'The Raths Company furnishes a ground-water which is perfectly good, except for its rather high content of iron, which sometimes has caused more or less trouble. The other large corporation, known as the Abts Company, obtains its water from the Ilmenau, usually at a point above the town; but between July 15 th and 20 th, it drew it from a place in the middle of the town, opposite the pumping-station, where the water was extremely impure. Previous to these dates, typhoid fever, which was always present in some amount in the town, lad begun to appear to an unusual extent; and in the first half of August, there was a sudden and remarkable increase in the number of caties. On the termination of the outbreak, 205 cases had been reported, 169, or 82.44 per cent., of which were anong families supplied with the water of the river.

It was proved that, for a period of some days, whieh included the dates above nentioned, the diarmoic discharges of a young girl, sick with typhoid fever, were thrown, withont being disinfeeted, into the river at a point about 300 feet above the intake and on the same side. In addition to this one sonrce of the causative agent which produced such a sudden rise in the curve, it was known that the river had been polluted by the discharges of another patient in May, and that the epidemic had its real beginning in June. It is eonceivable that in a town where the house supplies are so eomplieated that different stories have different kinds of water, a fair pereentage of the victims of an epidemic may acquire the disease through neighborhood visiting, thongh their own domestie supply is of the proper quality. In this whole outbreak, only 17.56 per eent. of the cases were among people whose prenises were supplied by the other companies.

Epidemic at Zehdenick in 1897. - This was a local outhreak traced to the eontamination of a well by the diseharges of a child sick with typhoid ferer. The water was ased by the inmates of the homses in the immediate vieinity, and the disease was limited to them alone. Of $: 30: 3$ persoms making up the 29 houscholels of the neighborhool, 94 , or nearly a third, were seized within a short period, while not anotler case. was known in the town. The inmates of nine louses within the inforeter area, who obtained their water from another source, were mitouched.

Limited Outbreak Among Soldiers.-An infiutry regiment, returning from the autumn manouves, passed through a small village where typhoid fever existed, and halted for water. Two days afterwand, 3 men were seized with grat sudelenness, and within two weeks, 36 men were down with the disease. They had been exposed to no other sonree of infection, and other troops who pasiod through the same village without stopping for water were nnaffected. Knowing the day 
when the infection oceurred, and since in every case the onset was marked by very acute srmptoms, Dr. Emil Jauchen" was able to determine the exact period of incubation : 3 were seized on the second day, 7 on the third, 6 on the fouth, 4 on the fifth, 4 on the sixth, 5 on the serenth, and 7 between the ninth and the fourteenth. The short periods are explainable by the fact that the men were in a state of exhaustion at the time of drinking, and all took copious dr:ughts.

Epidemic at Butler, Pa., in 1903.-Butler, Pennsylvauia, is a thriving city of about 16,000 inhabitants, supplied with water from three sources, two of which are situated at different points on Connoquenessing Creek, and the third is an impounding reservoir on Thorn Run, which is the chicf tributary of the creek. On August 28, 1903, the dam at Boydstown, some seven or eight miles above Butler, was carried away, and the main source of supply being thus lost, the water company was obliged to use water from the 'Thorn Run reservoir and to pump directly from the ercek at the pumping-station. Before distribution, the water wis treated in a rapid mechanical filter, from which it was sent to the city reservoir. On October 21, the filter plant was shut down for repairs, and during the next ten days the eity was supplied with unfiltered water, taken directly from the creek at the pumping-station. On November 2, an epidemic of typhoid fever began, and so rapidly did it spread that, by December 17 , no less than 8 per cent. of the population (1270 cases) had been attacked, and 56 persons had died. That the epidemic was due to the water-supply was emphasized by the fact that a portion of the city, known as Springdale, with a population of about 2500, not provided with eity water, but supplied by deep wells, wals almost wholly exempt, there being but 2 cases within the district. 'The source of the infection was not far to seek. Throughout the summer and autumn, fairly numerous cases of typhoid fever had occurred at various points on the watershed, and there was ample opportunity for the dejecta to be carried into the numerous small tributiries and thence into the ereek. In one house, for example, provided with a privy overhunging a small stream which empties into the ereek within a short distanee from the pumping-station, there occurred, subsequent to October 1, no fewer than 5 cases of the disease. In another house near Thorn Run dam there was a case about the middle of August, and this was followed by 3 others.

Epidemic at Ithaca, N. Y., in 1903.- At the time of this outbreak, Ithaca, New York, the seat of Cornell University, was a city of about 13,000 people, with an additional student population of nearly 3000 . Its loeation and surroundings are, in general, unusually favorable to health; in 1900 , the death-rate from all causes was but $16 . \dot{3}$ per thousand. The public water-supply was furnished by three creeks, which flow into Lake Cayuga, but many of the population depended upon private wells, of which there are about 1500 within the corporate limits. The water company which supplied the city proper derived its water from Six-mile Creck and Buttermilk Creek; the University was supplied by Fall Creek, under its own management. The watersheds of these three

1 Wiener klinische Wochenschrift, July $7,1898$. 
creeks are not large and they are more or less quickly populated. Abundant opportunities exist for direct infection of all three crecks, privies and outhouses being situated in many instances within a few feet of the banks. On Six-mile Creek alone, according to Dr. George A. Soper, the probable sources of infection at the time of the epidenic numbered a hundred or more. The conditions existing within the watershed of Buttermilk Creek are said to have been equally bad, while those along Fall Creek were even worse, although, as will be seen, this source of supply appears not to have been specifically polluted. In addition to the usual sonrces of contamination of the water of Six-mile Creek, there were employed during November and part of December, 1902, about 60 laborers in the construction of a dam, but careful inquiry failed to show the existence of any sickness anong them during the period of their employment.

The public supply had long been viewed with suspicion, and many of the population who used it were acenstomed to boil the water before drinking it. Diarrbœal disturbances and a mild form of typhoid fever, known as "Ithaca fever," had for many years been very common. During January and February, 1902, it is said that there were nearly 100 cases of typhoid fever in the eity. During the spring of that year, repeated bacteriological and chemical analyses of the water of Six-mile Creek, taken from the service pijes, yielded results which indicated dangerous pollution, and the people were warned through the newspapers against its use without previous boiling. On January 1,1903 , several eases of undoubted typhoid fever were reported, and thereafter the number reported daily increased to such an extent that, on February 2, there were no fewer than 237 cases under treatment. By the middle of March nearly 800 eases had been reported, but the actual number of persons affected was undoubtedly much larger. It is asserted that more than 1000 cases existed at that time, and that during the first six months of the year there were more than 1300 .

Investigation showed that those infected were users of the water supplied by the water company, and that practically no cases occurred among those who drank well-water from Fall Creck. Although the University was supplied by the latter, a large proportion of the student body lived in boarding-houses supplied by the company, and among these the epidemic foumd many victims. Accounts as to the number of students seized are very variable, for a large proportion left town during the height of the outbreak and were sick elsewhere; but they agree that several hundred were seized and more than 40 died. According to Coville, about 200 students had typical typhoid after leaving town.

Although it was evident that the cause of the disease was the water of Six-mile Creek and perlaps that of Butternilk Creek, it was impossible to trace the original infection; but the head-waters of the former drain a district within which considerable typhoid fever had been known to exist within previous years, and, as has been stated, there was abundant opportunity for iny infective material to have

1 American Medicine, January 19, 1904. 
reached the water directly. Furthermore, the rate of flow is so great and the total volume of water so small that infective matter discharged into the head-waters could have reached the pumping-station within four hours ; and, there being no storage, it could have been delivered in a fresh condition to the consumers.

Asiatic Cholera.- This disease, which is endemic in India, whence it makes periodical excursions to other parts of the world, sometimes most widespread and with the most disastrous results, is, perhaps, more exclusively than typhoid fever, a water-borne disease. Since the liscovery by Koch of the exciting eause, and the detection of the same in drinking-water during epidemies of the disease, the older theories of its method of spread have been abandoned save by the few remaining adherents of the "localist" theory, whom not even the facts revealed during and after the great epidenie of 1892 can move from their dogged attachment to the ereed of their revered teacher.

During the course of the widespread devastating epidemic of 1892 , which in its journey from the valley of the Ganges through Persia claimed 20,000 vietims in Teheran alone, and in its course through Russia destroyed 215,157 more, and which extended through Germany, Austria, Franee, Belgium, Holland, and even to the harbors of the Western Hemisphere, no more instructive example of the connection between the disease and polluted water and of the immunity conferred by the use of a pure supply could have been yielded or desired than the experience of Hamburg, Altona, and Wandsbeck. These eities adjoin one another so elosely that there is no visible line of demarkation, and in a geographical sense they may be regarded as one place. In one important respect, however, the three places differ very materially ; namely, their public water supplies. Wandsbeek was supplied with filtered water from a lake but little subject to pollution; Altona drew upon the Elbe at a point below the entrance of the sewage of Hamburg, but filtered the water through sand; Hamburg used unfiltered water from the Elbe above the eity. During the summer of 1892, or between August 17th and Oetober 23d, Hamburg, with a population of 640,000 , had nearly 17,000 cases of eholera, of which slightly more than half terminated fatally ; Altona, with a population about a quarter as large, had but 500 eases, or only one-thirty-fourth as many (400 of these are supposed to have come from Hamburg), and Wandsbeck had practically none. Very noticeable was the fact that where Hamburg and Altona eome together, the Hamburg side was plentifully sprinkled with eases, while the other was comparatively free (see Fig. 40), and this was still more particularly remarked along a certain street that for a distance formed the boundary line, in which the houses on the Hanburg side had plenty of cases and those opposite had none. Almost as though intended for the purpose of marking yet more sharply the distribution of the two kinds of water, it happened that a group of tenement houses on the Hamburg side of the boundary was supplied with water from the Altona mains, and in these houses, densely peopled by 
the laboring elass, not a single ease occurred, while in neighboring houses the disease was raging.

Thus we have a most eloquent instance of the value of sand filtration, and of the danger of using polluted supplies. Hamburg's unfiltered water came from above the eity, while Altona had to depend upon water which, before being filtered, had received the entire sewage of more than three-quarters of a million people. The initial specific pollution of the river-water was traced back to Russian emigrants, herded in barracks on one of the wharves pending their embarkation for the United States. At the time of the outbreak, there were, on an average, about a thousand of these people on hand all the time. Many of them came from distriets in Russia which had been and were then suffering severely from cholera, and all were well supplied with dirty elothing and blankets, some of which they washed while they were being detained. It is believed that among the thousands that had

FIG. 40.

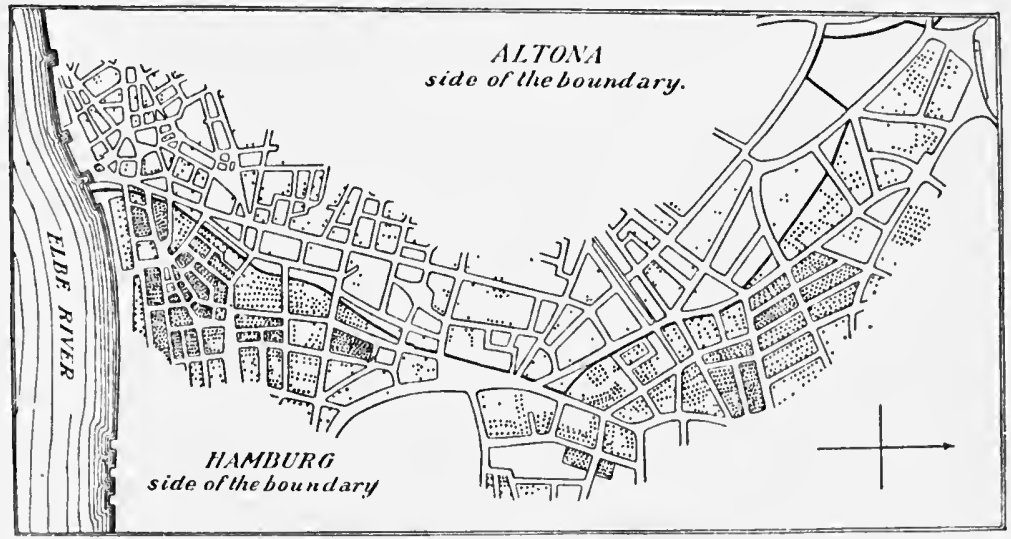

Portion of the boundary line between IIamburg and Altona. The dots indieate eases of cholera.

arrived, there must have been some mild cases of the disease, or at least some eonvaleseents with cholera germs still in their evacuations two or three weeks after recovery. All of the sewage matters of every deseription from these people were discharged direetly into the river at the wharf.

With the exception of a few straggling cases, there was no cholera in either of the two cities from Octolyer 2:3d to December 6th, when a small outbreak ocenred in Hamburg. This reacherl its culminating point, 5 eatses in one day, on the $26 \mathrm{th}^{2}$, and then the disease began to reappear in Altona, but under very different conditions from those which eharacterized the epidemie in Angust. Of the 500 cases which then ocenrred, abont 400 were enmected in one way or another with Hamburg, but in the later outhreak, most of the patients were of the well-to-rlo class of workmen whose oecupation dirl not eall them to Hamburg-women, young childeen, inmates of hospitals, and others 
having no reason to go there. Consultation of the records of bacteriologieal examination of the Altona filtered water showed an inerease in the first week of December, and again in the last days of that month, and at intervals in January, which indieated that some disturhance must have oceurred in the working of the filters. Investigation showed where the fiult lay, and also its nature: the surface of the sand had been frozen under the mud layer, and had thawed over only a part of its area, so that the whole work of the filter was thrown upon a part. The imperfeet working in early December was not followed by cholera, for at that time the river was practically free from the germs. Then came the few new eases in Hamburg, 27 in number, and reinfection of the Ellse, followed by faulty working of the Altona filters, and consequent distribution of a small amount of infective material through the water mains. The organisms were found in the water just below the mouth of the main sewer of Hamburg, and also in one of the settling basins of the filter plant, where the water stood prior to delivery to the beds.

The Propagation of Cholera in India.-As has been stated, the home of cholera is India, and so long as the natives are faithful to their religion and to the observance of old-established enstoms, just so long will that country supply the rest of the world with oceasional infection. Considering the extreme conservatism of all classes of East Indians and the national reverence of the Hindoos for holy places, it may be safe to predict that before any marked change for the better is accomplished, the rest of the civilized world will have advanced so far in sanitary affairs that eholera will be feared no more than varicella. As illustrative of what sanitary reform in India would have to encounter, the following extracts from the report of Dr. Simmons, quoted by Professor Mason, will be found of interest. It may be stated by way of explanation that Orissa, below mentioned, is a province covering more than 24,000 square miles, every part of which is holy ground. Every town contains consecrated land and is filled with temples, and every little hamlet has its shrine.

"The drinking-water supply is derived from wells, so-called 'ianks' or artificial ponds, and the water-courses of the country. The wells generally resemble those in other parts of Asia. The tanks are exeavations made for the purpose of collecting the surface-water during the rainy season and storing it up for the dry. Necessarily they are mere stagnant pools. The water is nsed not only to quench thirst, but is said to be drunk as a sacred duty. At the same time, the reservoir serves as a large washing-tub for elothes, no matter how dirty or in what soiled condition, and for personal bathing. Many of the watercourses are saered; notably the Ganges, a river 1,600 miles long, in whose waters it is the religions dnty for millions, not only of those living near its banks, but of pilgrims, to bathe and to east their dead.

"The Hindoo eannot be made to nse a latrine. In the cities he digs a hole in his habitation; in the country he seeks the fields, the hillsides, the banks of streams and rivers, when obliged to obey the calls 
of nature. Hence it is that the vieinity of towns and the banks of the tanks and water-eonrses are reeking with filth of the worst deseription, which is of necessity washed into the public water supply with every rainfall. Add to this the misery of pilgrims, their poverty and disease, and their terrible crowding into the numerous tows which contain some temple or shrine, the object of their devotion, and we ean see how India has become and remains the hot-bed of the cholera epidemic.

"In the United States official report, the horrors incident upon the pilgrimages are detailed with appalling minuteness. W. W. Hunter, in his Orissa, states that 24 high festivals take place annually at Juggernant. At one of them, about Easter, 40,000 persons indulge in hemp and hasheesh to a shoeking degrce. For weeks before the car festival in June and .July, pilgrims come trooping in ly thonsands every day. They are fed by the temple cooks to the number of 90,000. Over 100,000 men and women, many of them unacenstomed to work or exposure, tug and strain at the car until they drop exlansted and block the road with their bodics. During every month of the year a stream of devotees flows along the great Orissa road from Calcutta, and every village for three hundred miles has its pilgrim encampments.

"The people travel in small bands, which at the time of the great feasts actually touch each other. Five-sixths of the whole are females, and 95 per cent. travel on foot, many of them marehing hnndreds and even thousands of miles, a contingent having been drummed np, from every town or village in India by one or other of the three thomind emissaries of the temple, who scour the eountry in all directions in search of dupes. When those pilgrims who have not died on the roarl arrive at their journey's end, emaciated, with fect bound np in rags and plastered with mud and dirt, they rush into the sacred tanks or the sea, and emerge to dress in elean garments. Discase and death make havoe with them during their stay ; corpses are buried in holes scooped in the sand, and the hillocks are eovered with bones and skulls washerl from their shallow graves by the tropical rains.

"The temple kitehen has the monopoly of cooking for the multitude, and provides food which, if fresh, is not unwholesome. Unhappily, it is presented before Jugrernat, so beeming too sicred for the minutest portion to be thrown away. Under the influence of the heat it soon mulergoes putrefactive fermentation, and in fortr-cight hours much of it is a loathsome mass mufit for human food. Yot it forms the ehief sustenance of the pilgrims, and is the sole nomishment of thomsands of becrgars. Some one cats it to the very last crain. Injurious to the robust, it is dearly to the wak and warrorn, at least half of whom rach the place suffering under some form of howel eomplaint. Barly as they are fod, the poor wretches ale worre lodgerl.

"Those who have the temporary shelter of four walls are housed in hovels built mpon mul platforms about four fret high, in the erenter of each of which is the hole which receives the ordure of the household, 
and around which the inmates eat and sleep. The platforms are covered with small cells without any winclows or other apertures for ventilation, and in these eaves the pilgrims are packed, in a country where, during seven months out of twelve, the thermoneter marks from $85^{\circ}$ to $100^{\circ} \mathrm{F}$. Hunter say's that the scenes of agony and suffocation enacted in these hideous dens baffle deseription. In some of the best of them, thirteen feet long by ten feet broad and six and one-half high, as many as eighty persons pass the night. It is not, then, surprising to learn that the stench is overpowering and the leat like that of an oven. Of 300,000 who visit Juggernaut in one season, 90,000 are often packed together for a week in 5,000 of these lodgings. In ecrtain seasons, however, the devotees ean and do sleep in the open air, eamping out in regiments and battalions, eovered only by the same meagre cotton garments that elothe them by day.

"The heavy dews are unhealthy enough ; but the great festival falls at the beginning of the rains, when the water tumbles in solid sheets. Then lanes and alleys are converted into torrents or stinking canals, and the pilgrims are driven into the vile tenements. Cholera invariably breaks out. Living and dead are huddled together. In the numerous so-called corpse-fields around the town as many as forty or fifty bodies are seen at a time, and vultures sit and dogs lounge lazily about gorged with human flesh. In fact, there is no end to the recurrence of incidents of misery and humiliation, the horrors of which, says the Bishop of Caleutta, are unutterable, but which are eclipsed by those of the return journey. Plundered by priests, fleeed by landlords, the surviving victims reel homeward, staggering under their burdens of putrid food wrapped up in dirty clothes, or packed in heary baskets or earthenware jars. Every stream is flooded, and the travellers have often to sit for days in the rain on the bank of a river before a boat will venture to eross.

"At all these points the corpses lie thickly strewn around (an English traveller eounted forty elose to one ferry), which accounts for the prevalence of cholera on the banks of brooks, streams, and rivers. Some poor ereatures drop and die by the way; others erowd into the villages and halting-places on the road, where those who gain admittance eram the lodging-places to over-flowing, and thousands pass the night in the streets, and find no cover from the drenching storms. Groups are huddled under the trees; long lines are stretehed among the earts and bullocks on the roadside, their hair saturated with the mud on which they lie; hundreds sit on the wet grass, not daring to lie down, and rocking themselves to a monotonous chant through the long hours of the dreary night.

"It is impossible to compute the slaughter of this one pilgrimage. Bishop Wilson estimates it at not less than 50,000. And this deseription might be user for all the great Indian pilgrimages, of which there are probably a dozen ammually, to say nothing of the lumblreds of smaller shrines seattered through the peninsula, each of which attracts its minor hordes of credulous votaries. So that cholera has 
abundant opportunities for spreading over the whole of Hindostan every year by many huge armies of filthy pilgrims; and the country itself well deserves the reputation it universally possesses of being the birthplace and settled home of the malady."

\section{Parasites and Drinking-water.}

There is abundant evidence of the agency of drinking-water in the spread of certain of the animal parasites, but with respect to certain others the danger is much over-rated (tape-worms), or, indeed, imaginary (trichina).

Round worms, Ascaris lumbricoides, undoubtedly are spread in part by water. 'The female deposits enormous numbers of eggs in the small intestine, and these are expelled in the fieces. Whether the freshly discharged eggs are eapable of reprodueing the worm, is a matter of doubt; but it seems probable that the intervention of another host is necessary. Wherever this parasite is known to prevail extensively, the people use polluted water for drinking.

Pin worms, or seat worms, Oxyuris vermicularis, are spread probably by water. They locate in the exenm and upper eolon, where the female deposits egrgs in large numbers, which, reaching a water-supply after being discharged through the bowel, may be taken into the stomach, where the envelope of the embryo is disintegrated by the gastric juice. The larve develop in the small intestine and eome to maturity in about foul weeks.

Guinca worms, Dracunculus medinensis, are said to invade the body through the skin during bathing or through the stomach in rhinkingwater; the evidence of the latter method is definite. In the stomach, the embryos are developed rapidly, and soon the impregnated female procechs from the alimentary canal to the subeutaneous tissues in various pants of the body, where she finally breaks through the skin and escapes. 'The living embryos which are then liberated, finding their way into fresh water, enter the bodies of the common fresh-water flea, Cyclops quadiromis, which acts as the intermediate host and conveys the organism to the human stomach. In a case reported by Dr. John Patterson, ${ }^{1}$ the patient had an abseess on the upper part of the left tibia, from which, when it was exeised, a portion ( $t$ inches) of a worm was removed. Later, he had an abseess and sinus of the left ealf, followed by a swelling back of the inmer malleolus, and in this a portion of a worm, 25 inches in length and devoid of a head, was found. Dr. Edward Francis ${ }^{2}$ had under observation for six weeks at the U.S. Immigrant Hospital (N. Y.), a native of the Gold Coast, who arrived in June, 1901, with a history of having been troubled with these parasites during the preceling three months. During his stay at the hospital five worms appeared : one on the front of the right ankle, one on the dorsum of the right foot, one on the front of the left ankle, one

Medical Record, October 7, 1899 .

2 American Medicine. October 26, 1901. 
below the left external malleolus, and one on the dorsum of the left foot, near the toes. One worm presented 26 inches in one piece; the others mensured 10 to 18 inches, but were removed in pieces.

Whip worms, Trichocephalus dispar, which are said to be extremely common in Paris and some other places ontside the tropies, are spread wholly by water, without which the embryo eannot develop within the egg. 'Taken into the stomach, the envelope is dissolved and the liberated larva attaches itself to the wall of the intestine, where it proceeds very slowly to develop. It does not reach full maturity until about a year has elapsed.

Filaria sanguinis hominis, the parasite whieh produces chyluria, hamatochyluria, and elephantiasis, is believed to find its way into the svsten throngh water contaminated by mosquitoes which have sucked the blood of persons suffering from the parasite. The adult female produees an enormons number of minute embryos, which pass into the blood; and when these are taken into the stomach of the mosquito, they wander to other parts of the insect, where they beeome farther developed, and later may be transferred to water, through which they are believed to pass into the human stomaeh, where the cyele is completed. This parasite is not confined wholly to the tropies, and oeeasionally is seen in our Southern States. (See Chapter XII.)

Bilharzia hæmatobia, the cause of a peeuliar hæmaturia common in parts of Africa, is believed by many to be transmitted by drinkingwater contaminated by the urine of persons suffering with the discase. The embryos probably enter the system of some other organisms, which play the part of intermediate hosts and advance their development one stage.

Ankylostomum duodenale (Uncinaria duodenalis), the cause of the anæmia formerly supposed to be peculiar to miners and others engaged in underground operations, was until recently believed to be disseminated chicfly by polluted water; but, as has been said in the consideration of the relation of soil to disease, this idea is no longer tenable, the chief, if not the only, souree of infection being soil polluted by the intestinal discharges of those already infected with the parasite.

Strongyloides intestinalis, the parasite of an endemic diarrhœa of Cochin China, first described by French investigators who discovered its rhabditiform embryos in the stools of soldiers returning from China in 1876, was found by Perroncito to oceur in association with Ankylostomum duodenale in the discharges of" laborers afllieted with "St. Gothard tunnel anæmi:a", has been reported in various countries of Europe, in Egypt, Brazil, the Indies, and Philippine Islands, and within recent years in. various parts of the United States. Aceorling to Dr. M. I. Price ${ }^{1}$, the oceurrence of eggs in the stools is very rarely observed, unless there coexists an uncinarial infection, and the parasite is probably introduced by way of the mouth as the filariform embryo, though infection of animals has been produced by means of the eggs. He belicves that the vehicle by which the parasite gains access to the

1 Journal of the American Medical Association, September 12 and 19, 1903. 
system is frequently the drinking water, but that fresh vegetables from land manured with human excreta play a part. It is the belief of Stiles that the geographical distribution of the parasite in this country will be found to correspond to that of uncinaria.

\section{ICE.}

It is a common idea that ice is necessarily pure, because, in freezing, "water purifies itself:" Ice may, however, be quite as impure as the original water or very pure, aceording to eireumstances. T'he first formation is quite likely to eontain impurities, such as the dust and other matters floating on the surface. Under ordinary conditions, the impurities will be limited to this layer, for, in the growth of the ice from above downward, all but traces of dissolved substances and practically all of the suspended matters are excluded.

Ice may become impure in several ways. If snow falls upon it and becomes wet either by rain or by water from below, and then freezes and becomes part of the ice, it will eontain all the impurities which have been washed ont of the air. If, while the ice is thin, holes are cut so as to permit flooding from below, it will contain all the impurities of the water. Cut from shallow ponds, it will be pure or impure aceording to the quality of the water and the depth to which it fieczes. Water from such ponds, if polluted by surface washings or sewage matters, is likely to yield ice which, when melted, will give off offensive odors.

It is a common belief that bacteria are killed in ice, but many varieties will retain their vitality in it for a very long time. As early as 1871, Burdon Sanderson showed that even the purest ice is likely to contain them in some degree. Chantemesse and Widal proved in 1882, Prudden in 1887, and Riche, Fränkel, and other's at different times, that pathogenic bacteria may maintain their vitality to a surprising degree in ice, and that the bacillus of typhoid fever is particularly resistant. Prudden ${ }^{1}$ showed that ice, made from water which contained them to an innumerable extent, yielded at the expiration of 10:3 days no less than 7,348 per ce.

Bacteria are resistant not only to the ordinary low temperature of iee, for Pietet and others have proved that even the extraordinary cold of liquefied air, - $315^{\circ} \mathrm{F}$., is not sufficient to destroy them. On the other hand, Sederwick and Winslow, ${ }^{2}$ W. II. Park, ${ }^{3}$ and H. W. Hill, who have made independent investigations of the pmsible danger of ice as a cause of outbreaks of typhoid fever, angee that it is but slight. Sedgwiek and Winslow found that the bacilli perish lapidly; 50 per cent. at the end of the first week, $90 \mathrm{per}$ cent. in two weeks, and practically all (2 or 3 in 1000 remained) after twolve weeks. It is pointed ont by the several observers named that the majority of baeteria in water are eliminated in the process of freezing; that the majority of those included die within a few weeks; that the bacteria

${ }^{1}$ Medical Record, Mareh $26,1887$.

2 Abstract in Revne Scientificue, April $28,1900$.

s Journal of the Boston Sociely of Medienl siences, IV., p. 213.

4 Boston Medieal and Sureriend Junrual, November 21, 1901. 
in ice are conmonly harmless in elaracter; and that eities which use ice from polluted streams (e.g., New York, Lowell, Lawrence) suffer applarently none at all therefiom. The State Board of Health of Massachusetts says (Anuual Report for 1900), concerning the bacterial content of the domestie supply, "In not one instance of the still freezing of ordinarily polluted water.... have we been able to find $B$. coli in the ice formed."

Recent experience at Ogdensburg, N. Y., seems to indicate that ice taken from a polluted river having a fairly rapid flow may, however, be a source of dinger. In Oetober, 1902, after almost total freedom from typhoid fever for nearly two years, an outbreak oceurred among the inmates of the St. Lawrence State Hospital, the water-supply of which was beyond reproach. The attack was purely local, other users of the water not being affected. The possibility of infection from other sources having been eliminated, attention was direeted to the ice, and it appeared that, about six days before the development of the first cases, a new supply taken from the St. Lawrence River and stored for more than seven months had been brought into use. Specimens of the ice yield a' black sediment, which, on examination by Hutchings and Wheeler, 'was found to contain baeilli, eultures of which responded to the tests for B. typhosus, including elumping when treated with serum from a typhoid patient.

Artificial ice is frozen in blocks of the size and shape of the tanks in which the water is held. As the entire mass of water in each tank is frozen, it maturally must contain in its inner portion, which is the last to freeze, all of the matters originally contained. Unless the water used is pure and colorless, the iee will not be of good quality, and, particularly in the center, will not be of good appearance. When colored or impure water is used, it is a common practice to remove the impurities and coloring matters by tapping the eenter before the freczing process is completed, and drawing off the liquid in which they have become concentrated. On account of the possible retention of part or all of the contained impurities and bacteria of the water from whieh it is made, artificial ice should be manufactured only from distilled water or from natural water of the highest degree of purity.

\section{CHEMICAL EXAMINATION OF WATER.}

Collection of Samples.-In taking samples of water for chemical analysis, great care is necessary in order to secure speeimens which shall be fiirly representative of the supply under investigation. They shonld be taken only in elean glass bottles or demijohns of from half at gallon to a gallon eapacity, and never in stone jugs, tin cans, or worden kegs. The best form of bottle has a glass stopper, but a perfectly elean cork is unobjectionable. In spite of directions most carefully given, one often sces speeimens sent in stone jugs stopped with woolen plugs wrapped with old cotton rags or pieces of news-

1 American Journal of the Medical Sciences, October, 1903, p. 680. 
paper to secure a tighter fit, and sometimes smeared with shoemakers' wax, pitch, or even tallow. Analysis of such specimens is likely to give results of no value whatever, for it should be remembered that we are dealing with exceedingly small amounts of ammonia and other products, and that anything short of absolute cleanliness of receptacles introduees error.

The bottle, supposedly clean at the start, should be rinsed thoroughly with the water to be sampled, then filled to the neck, and securely stoppered. If the sample comes from a pump, the barrel of the latter should be emptied completely of the water which has been standing in it for any length of time; if from a pipe, the water should be allowed to run to waste, until the whole of the original contents has escaped; if from a pond or other boly of water, the bottle should be plunged sufficiently far beneath the surface to avoid the entranee of floating matters, and at a sufficient distance from the banks to avoid matters that hug the shore.

After the sample is secured, as little time as possible should elapse before beginning the analysis, because of the rapidity with which changes occur in the organie matters, ammonia, nitrites, and nitrates.

\section{Determination of Free Ammonia and Albuminoid Ammonia.}

Solutions Required: 1. Standard Solution of Ammonium Chlorids.-Dissolve 3.138 grams of pure dry ammonium chloride in 1 liter of distilled water free from ammonia. One ec. of this solutiou represents $1 \mathrm{mgr}$. of ammonia.

2. Standard Dilute Solution of Ammonium Cinloride.Dilute 10 ec. of the strong solution up to 1 liter with water firee from ammonia. One ec. of this solution represents $0.01 \mathrm{mgr}$. of ammonia.

3. Solution of Sodium Carbonate.-Dissolve $200 \mathrm{grams}$ of pure sodium carbonate in 1 liter of water free from ammonia.

4. Alkaline Potassium Permanganate.-Dissolve 8 grams of potassium permanganate and 200 grams of caustie potash in 2 liters of distilled water, and boil down to 1 liter, to gret rid of any free anmonia present. Fifty ee. of this solution are required for ach analysis. The author finds it convenient to omit the boiling-down proeess when the solution is prepared, and to take $100 \mathrm{ec}$ and boil down to 50 at the time of analysis. This insures freedom from ammonia when used, and avoids the bumping which is so likely to oceur when the cold solution is added during the process of distillation.

5. Nessterr's Rragint.-Dissolve 35 grams of potassium iodide in 150 ce. of distilled water. Dissolve about 16 grams of corrosive sublimate in $300 \mathrm{ce}$. of distilled water. Add the latter to the former, both solutions being eold. Then add 200 grams of canstic sodat dissolved in 0.5 liter of distilled water, and mix thoroughly. Next add, with constant stirring, a saturated solution of eorrosive sublimate until the preeipitate which forms is permanent; then dilute the whole to 1 
liter. Let stand until elear, when the supernatant liquid should have a pale-straw color.

6. Ammonia-Free Water.-This may be obtained by distilling water made slightly acid with sulphuric acid. The first $25-50 \mathrm{ec}$. of distillate should be rejeeted, and the next 50 cc. should be tested with Nessler's reagent. If no color appears, the distillate is ammonia-free, and the operation may then be continued until the contents of the retort are redueed to very small volume. If the test shows traces of ammonia, snecessive portions should be tested until a negative result is sceured. It is well to prepare a groodly supply, and to keep it on hand in glass-stoppered bottles.

Apparatus Required.-Distilling Apparatus.-Some analysts prefer glass retorts ; otliers, distilling flasks with side tubes. Whichever is used, the connection with the Liebig condenser should be tight. The author prefers a distilling flask, with a side tube of such a size that it enters the condenser tube casily, but without making a loose joint. A bit of elean rubber tubing on the side tube may serve to make the joint more perfect at the point of entrance. The mouth

Frg. 41.

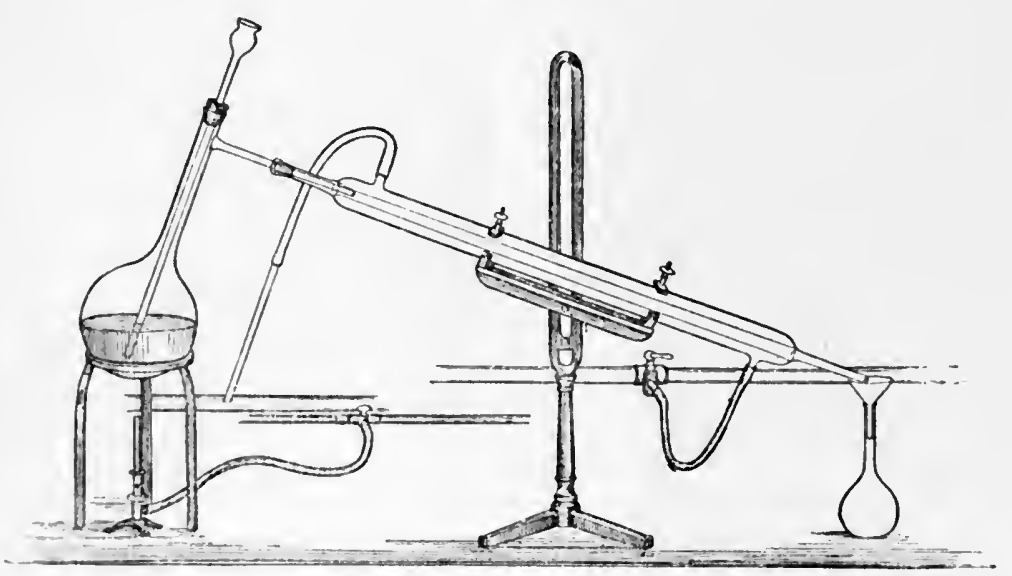

Distilling apparatus used in determining the ammonias in water.

of the flask should he elosed with a rubber stopper with a single perforation, carrying a fumnel tube which reaches to the bottom of the flask.

The flask or retort may be heated either by a rose burner or by the free flame of a Bunsen lamp. In laboratories where water analysis is conducted on a large seale, it is found convenient to have the distilling flasks, arranged in the form of batteries, connected with block tin condensing tubes which pass through a common cooling-tank fed by a single tap.

In Fig. 41 is shown the form of apparatus which the author finds convenient for ordinary work. 
Nesslerizing Tubes.-For making the determination of ammonia by the eolorimetric method, tubes of colorless glass, about $12 \frac{1}{2} \times \frac{5}{8}$ inches, with a mark at the 50 ee. point, are required.

Determination._'The flask and condenser are rinsol with ammonia-free water, 0.5 liter of the water and 5 ce. of sodium carbonate solution are introduced into the flask, and heat is applierl. The distillate is collected either in the Nessler tubes or in 50 ee. flasks, from which it is transferred to the tubes; and when three portions of 50 ee. each have been collected, all of the free ammonia in the sample will have passed over.

On beginning the distillation, $100 \mathrm{ce}$ of the meoncentrated alkaline permanganate solution are heated in a small flask and boiled down to $50 \mathrm{ce}$, and on the completion of the distillation for free anmonia, the hot reagent is adder through the fummel tube, and boiling is continued. If the reagent has been concentrated in advance, 50 ce. are added. The nitrogenous organic matter is now attacked by the permanganate solution and more ammonia is crolved. While this in no way differs from the fiee ammonia, it is given the distinguishing name "albuminoid ammonia," to indieate its origin. The process is now continued as long as ammonia passes over, but usually no reaction is observed after four portions of 50 ce. lave been collected. In the laboratory of the State Board of Health of Massachusetts, it is the enstom to fill fire tubes, and then to case distilling. To each of the tubes containing the ammonias, 2 ce. of Nesiler's reagent are added. In the presenee of ammonia, a yellowish-lorown color is produced, the depth of which depends upon the amomnt of ammomia present. Some exceptionally rich waters vield such an amount of anmonia that a precipitate is formed on ardition of the reagent. Then it is neessary to repeat the process, and to take an aliquot part of the distillate and dilute it with ammoniafree water to $50 \mathrm{co}$. hefore nesslerizing. Should a precipitate again ocenr, a smaller part should be taken, and so on until the proper reaction is obtained. The amomnt in the whole distillate may then be letermined mathematically. Having nesslerized the sevelal tubes, the next step is to determine the amomits present by comparison of colors with a scale made as follows: Into a series of tubes, held in a rack, different amounts of the wakker solution of ammonium ehloride are introduced, then ammonia-fiee water is added to aich up to the 50 ec. mark, each tube inverted to insure thomongh mixing, and, finally, 2 ee of Nessler's reagent adeled to each. A convenicnt seale is secured hy using $0.25,0.50,0.75,1.00,1.50,2.00,2.50,3.00$, $3.50,4.00$, and 5.00 ce., representing $0.0025,0.00 .50,0.0075,0.010$, $0.015,0.020,0.025,0.0: 30,0.035,0.040$, and $0.0 .50 \mathrm{mgr}$. of ammonia. The first of these will have a very faint yellowish-brown tint, and the last a very decided reddish-bown color, while the intervening tubes show a progressive deepening. With these tubes, the distillates are compared, and the mateling of colors gives the desired results. It a given tube falls between any two of the seale, a new eomparison 
tube may be prepared ; but the practised eye ean determine very aceurately without this extra aid. Having read the color of each tube, the amounts of those representing the free ammonia are added together, and the total multiplied by 2, to get the amount per liter of water; the same process is carried ont for the determination of the albuminoid anmonia. The results represent parts per million, since 1 liter equals $1,000,000$ milligrams.

ExampLE.-The three frec-ammonia tubes show $0.023,0.006$, 0.000 : total $0.029 \mathrm{mer}$; multiplied by $2=0.058$ per liter. By moving the deeinal point one place to the left, we have 0.0058 part per 100,000, in which terms the results ordinarily are expressed.

Precautions. - Since the depth of color caused by Nessler's reagent is affected more or less by temperature, and since in all processes of comparison the conditions must be the same so far as is possible, the reagent should not be added until the distillates and the contents of the comparison tubes have the same temperature. Equality in this respect is seenred without any manipulation or tronble by leaving the tubes over night, so that all will aequire the temperature of the room. It is hardly necessary to point out that the air of the room in which the distillation is condueted should be quite free from laboratory fumes, such as ammonia and sulphuretted hydrogen, which, being absorbed by the distillate, wonld, in the one ease, give erroneous results, and, in the other, react upon the mereury salt in the Nessler's reagent.

The heat applied to the distilling flask should be so regulated that the time required for each portion of $50 \mathrm{cc}$. will be about fifteen minutes, since with more rapid distillation there is likely to be some loss of ammonia by imperfect eondensation.

The realing of the tubes should not be undertaken until at least five minutes have clapsed after the addition of the reagent. The extreme depth of color obtainable is reached somewhat within that time.

The practice of some analysts of distilling the free ammonia ont in one lot of 150 or 200 ce., collecting the albuminoid ammonia in another single portion of 200 or 250 ce., nesslerizing a portion of each, and calculating the total amount of each by multiplication by the proper factor, gives correct results; but it has been shown that by proceeding in this way, one may lose useful information obtainable from a knowledge of the rate at which the ammonia is evolved, sinee organic matter, well advaneed in decomposition, yields it more copionsly in the first distillate, whereas fresh material yickds it more slowly and uniformly.

Some analysts make duplicate distillations of one water at the same time, determining the free ammonia in one specimen, and, by adding the permanganate at the start in the other, deternining the total free and albuminoid ammonia together. By subtracting the lesser from the greater, the amount of albuminoid ammonia is obtained. 
Permanent Ammonia Standards.-In order to avoid the necessity of preparing standards each time they are required, for those made as above soon undergo change, Mr. D. D. Jackson ${ }^{1}$ has proposed making a permanent set with potassium platinic chloride and cobaltous chloride, with which, with a little practice, the Nessler solution may be prepared to fit exactly. Sinee his method of preparing the latter differs materially from that above deseribed, it is reproduced here: "Dissolve 61.75 grams of potassium iodide in 250 ee. of redistilled water, and add a cold solution of mereuric ehloride which has been saturated by boiling wjth excess of the salt. Pour in the mereury solution cautiously, and add an amount just sufficient to make the color a permanent bright red. With a little practice, the exact depth of color ean be easily duplicated. It will take a little over $400 \mathrm{ee}$. of the mereuric ehloride solution to reach this end point. Dissolve the red precipitate by adding exactly $0.75 \mathrm{gram}$ of powdered potassium iodide. Then add 150 grams of potassium hydrate dissolved in 250 ec. of water. Make up to 1 liter. Mix thoroughly and allow the preeipitate formed to settle. It is best to make up a large amount of Nessler solution, and if by its use the ammonia standards do not fit the artificial ones prepared from the platinum and eobalt solutions, a little more mereurie ehloride to increase sensitiveness, or potassium iodide to decrease it, will bring the Nessler solution to the point where, if just 2 ec. are used, the regular ammonia standards will exactly fit the artificial ones. . . . Of course, each new lot of Nessler solution should be eompared, to see that it has the proper degree of sensitiveness to fit the standards."

To prepare the permanent standards, two separate solutions, one of potassium platinie chloride and one of cobaltons chloride, are necesiary. The first is made by dissolving 2 grams of the salt in a small amount of water, adding 100 ce. of strong hydrochlorie acid, and diluting to 1 liter. The second, by dissolving 12 grams of the salt in water, adding $100 \mathrm{ece}$ of strong hydrochloric acid, and diluting to 1 liter.

"Varying amounts of these two solutions are required, because the color of the Nessler standards becomes more and more redelish as the ammunt of anmonia increases. The standards are made up in 50 ce. Nessler tubes $1.7 \mathrm{em} .\left(\frac{\left.11^{\prime \prime}\right)}{116^{\prime}}\right)$ in diameter and $21 \mathrm{em}$. ( $\left(8 \frac{1}{4}^{\prime \prime}\right)$ from the bottom to the 50 ee. mark." Sixteen standards are prepared with distilled water up to the $50 \mathrm{ec}$ mark, as follows:

\begin{tabular}{|c|c|c|c|c|c|c|c|c|c|}
\hline $\begin{array}{c}\text { I't. solution. } \\
\text { ce. }\end{array}$ & & $\begin{array}{c}\text { Co. solution. } \\
\text { ec. }\end{array}$ & & $\underset{\mathrm{mgr} \text {. }}{\operatorname{Ammonia}}$ & $\begin{array}{c}\text { I't. solution. } \\
\text { ec. }\end{array}$ & & $\begin{array}{c}\text { Co. solution. } \\
\text { ce. }\end{array}$ & & $\begin{array}{c}\text { Ammonia. } \\
\text { mgr. }\end{array}$ \\
\hline 1.0 & + & 0.0 & $=$ & 0.000 & 12.7 & + & 2.2 & $\Rightarrow$ & $0.0 \div 0$ \\
\hline 1.8 & + & 0.0 & $=$ & 0.001 & 15.0 & + & 3.3 & $=$ & 0.025 \\
\hline 3.2 & + & 0.0 & $=$ & 0.003 & 17.3 & + & 4.5 & $=$ & 0.0830 \\
\hline 4.5 & + & 0.1 & $=$ & 0.005 & 19.0 & + & 5.7 & $=$ & 0.035 \\
\hline 5.9 & -1 & 0.2 & $=$ & 0.007 & 19.7 & + & 7.1 & $=$ & 0.040 \\
\hline 7.7 & + & 0.5 & $=$ & 0.010 & 19.9 & $-1-$ & 8.7 & $=$ & 0.045 \\
\hline 9.4 & + & 0.9 & $=$ & 0.013 & 20.0 & + & 10.4 & $=$ & 0.0 .50 \\
\hline 10.4 & + & 1.3 & $=$ & 0.015 & 30.0 & -1. & 15.0 & $=$ & 0.060 \\
\hline
\end{tabular}

1 'Technology Quarterly, X111., No. 4, Ixember, 1900. 
While these agree perfectly with the regular Nessler ammonia standards on lengthwise examination, they do not at all agree on side view, the artifieial standards appearing decidedly pink, instead of brownish rellow.

Determination of Other Nitrogen Compounds.-Preliminary Treatment.- Should the specimen of water have an appreciable color, due to dissolved regetable matters, it is necessary, before attempting the determination of the above-mentioned substanees or of the chlorides, to decolorize a sufficient volume by means of milk of alumina. 'This is prepared by mixing gradually very dilute solutions of sodium hycluate or ammonia and alum or aluminnm sulphate; the resulting precipitate is allowed to settle, and is then washed several times by decantation. The water nsed in washing should be free from chlorides, nitrates, and nitrites. If strong solutions are used, the gelatinous precipitate soon undergoes change both in appearance and character. It becomes ehalky and loses its property of removing color. In order to remove all coloring matter, 0.5 liter of the water may be shaken in a flask with a few ce. of the thick "milk," and then filtered through paper. By this means, the most highly colored swamp waters are made colorless in a very few minutes.

Determination of Nitrogen as Nitrites.-Solutions Required.-1. Sulpilavilic Acid Solutiox (paramidobenzene-sulphonic acid).-Dissolve $0.50 \mathrm{gram}$ in 150 ce. of acetic acid (sp. gr. 1.040).

2. Naphthylame Solution ( $a$-amidonaphthalene).-Dissolve 0.10 gram. in 20 ce. of boiling water, filter, and add $180 \mathrm{cc}$. of acetic aeid (sp. gr. 1.040).

3. Standard Sodium Nitrite Solution.-Dissolve $0.275 \mathrm{gram}$ of pure nitrite of silver in pure distilled water and add a dilute solution of pure sodium chloride until precipitation ceases. Dilute to 250 ec. and preserve in the dark in an amber bottle.

4. Standari Difute Sodium Nitrite Solution.-Dilute $10 \mathrm{cc}$. of the preceding to 1 liter with pure distilled water and preserve in the same way. One ec. equals $0.001 \mathrm{mgr}$. of nitrogen as nitrite.

Procfss.-To 50 ce. of water in a Nessler tube, or to 100 ec. in a tube of larger diameter, add 2 ce. of each of the two first-mentioned solutions. If nitrites are present, a pink to a garnet color is developed within a half hour, the intensity of color depending upon the amount of nitrite present. If no clange is observable at the end of a laalf hour, nitrites may be recorded as absent; if, on the contrary, a coloration is produced, the test may be repeated, and at the same time one or more eomparison eylinders prepared. In similar tubes, dilute to the mark with distilled water free from nitrites $0.25,0.50$, and 1 ce. of the dilute sodium nitrite solution, and add to each the proper amounts of the test-solutions. At the end of half an hour, compare the color aeçuired ly the water sample with the standards, and multiply by the proper fictor, to determine the amonnt per liter.

Since the air of laboratories in which gas is burning is very likely to contain traces of nitrites, which are absorbed readily by water, it is 
well to keep the tubes corked or otherwise protecter. A tube left open some hours is almost sure to develop more or less color.

The eolor reaction is due first to the action of the nitrite present on the sulphanilic aeid, whereby a new componnd (diazobenzene-sulphonic anliydride) is produced, which is then acted npon by the naphthylamine and converted into another (azo- $a$-amidonaphthalene-parazobenzenesulphonic acid) which imparts the color.

Permanent Nitrite Standards.-Mr. Jackson has proposed employing permanent standards for the nitrite determination also. They are made from two solutions, one made by dissolving 24 grams of cobaltous ehloride in distilled water, adding 100 ce. of strong hydrochlorie acid, and diluting to 1 liter ; and the other by dissolving 12 grams of dry cupric chloride, adding $100 \mathrm{ec}$. of strong hydrochloric acid, and diluting likewise to 1 liter. The standards are made np in 100 ec. tubes, $3 \mathrm{~cm} .\left(1 \frac{1}{8}^{\prime \prime}\right)$ in diameter and $13.2 \mathrm{~cm} .\left(5_{4}^{1 \prime \prime}\right)$ to the $100 \mathrm{ce}$ mark. The following table gives the proportions of each solution to be made up to the 100 ce. mark :

Co. solution.
ec.
1.1
3.5
6.0
12.5
20.0

$\begin{array}{cc} & \text { Cu. solution. } \\ & \text { ce. } \\ + & 1.1 \\ + & 3.0 \\ + & 5.0 \\ + & 8.0 \\ + & 8.0\end{array}$

$\begin{array}{cc} & \begin{array}{c}\text { Parts of } \mathrm{N} \text { as nitrite } \\ \text { per million. }\end{array} \\ = & 0.001 \\ = & 0.003 \\ = & 0.005 \\ = & 0.010 \\ = & 0.015\end{array}$

The method of determining nitrites, as given by Mr. Jackson, is as follows: Fill a 100 ee. Nessler tube with the water to be tested, ard 1 ec. of hydrochlorie acid (1:4), then 2 ec. of sulphanilic acid (8 grams per liter), and finally 2 ec. of naphthalamine hydrochlorate (8 grams per liter with 10 ece of strong hydrochloric acid); allow to stand twenty minutes until the full development of the color appears. If 100 ec. of water develop a color corresponding to the second of the above standards, for example, it contains 0.003 part per $1,000,000$ of nitrogen as nitrite.

Determination of Nitrogen as Nitrates.-Solutions Required.-1. Puncomisumpionic ACID.-Heat together for six hours in a waterbath 5.55 grams of strong sulphurie acid and t.5 grams of pure phenol. Should the resulting componnd solidify on enoling, it may be liepuefied again in the bath and then poured into a number of small bottles provided with ground stoppers. Then, as needed, one of them may be placed in the bath and the eontents liquefied.

2. Staxdari) Solution of Potassium Nithate-Dirolve 0.722 gram of pure potassinm nitrate in 1 liter of pure distilled water. One ece equals $0.1 \mathrm{mgr}$. of nitrogen as nitrates.

Process.-Evalporate 10 ce. or more of the water with 1 drop of sodimm carbonate solution to dryness in a small poreelain dish. 'To the residue, ardd 1 ae of phenoldisulphonice acid, which should be brought into eontact with every particle by means of a glass rod. Dilute with water, make strongly alkaline with ammonia or canstic 
potash, and, finally, make up to 50 or 100 ec. with water. Evaporate measured volumes of the standard nitrate solution, treat the residues with a like amount of the reagent, and proceed in the same way to make a comparison seale. The addition of the alkali converts the pieric acid, formed by the action of the nitrate on the phenoldisulphonic acid, into the corresponding picrate, which imparts a brightyellow color, the intensity of which depends upon the amount of nitrite present. The comparison of tints may be made directly in the porcelain dishes or in tubes of the same sort as used in the nitrite determination.

The accuracy of the test is diminished by the presence of chlorides in notable amounts, say more than 2 parts in 100,000 , but not by nitrites. On this account, Mason recommends the addition of corresponding amounts of sodium chloride in the preparation of the color scale.

The standards made as above do not change on keeping, and hence may be made up in sets and preserved.

Determination of Chlorine.-Solutions Required.-1. STANDARD Solution of Silver Nitrate.-Dissolve 4.797 grams of pure silver nitrate in 1 liter of distilled water. One ec. of this solution is the equivalent of $1 \mathrm{mgr}$. of chlorine.

2. Solution of Potassium Chromate.-Dissolve 5 grams of potassium chromate in $100 \mathrm{ce}$. of distilled water, add nitrate of silver solution, for the removal of any traces of chlorides present, until a red precipitate of eliromate of silver is formed. Let stand, and separate the precipitate by decantation or filtration. This solution is to be used as an indicator.

Process.-Place in each of two beakers of similar size 100 cc. of witer and 5-10 drops of the indicator. The beakers standing side by side upon a white surface of porcelain or filter-paper, the silver nitrate solution is added to one of them from a burette little by little until, in spite of stirring with a glass rod, a faint reddish tinge begins to be perceptible. This is seen more easily by comparison with the water in the other beaker. The burette reading is now taken, and then a drop or two more of the reagent will, by intensifying the red color, show that the end point has been reached. 'The process depends upon the fact that silver has a greater affinity for chlorides tham for chronates, and that, so long as any of the former is present, no permanent union will occur with the latter. When, however, all the chlorine has combined with the silver, the red chromate begins to form, and makes its presence known by the change of color. On completion of the process, the amount of the standard reagent used indicates the amount of chlorine present, each cc. used representing 1 milligran.

Inasmuch as a certain amount of the reagent is required to give the begimning tint in $100 \mathrm{ec}$. of distilled water, a correction should be made before setting down the result. This amount differs somewhat with different observers, since all eyes are not equally quick to discem the appearance of the reddish tint, and hence the best method of fixing 
the amount to be subtracted is for each one to determine it himself by experimenting with $100 \mathrm{ec}$. of distilled water containing the requisite amount of the indieator.

Should the amount of ehlorine in a given sample be so small that the end reaction appears on the addition of but a few drops of the silver solution, it is best to concentrate 250 or 500 ec. of the water to 100 ec., and repeat the titration.

Determination of Residue.-Evaporate $100 \mathrm{ec}$ of water to dryness in a perfectly clean, dry, accurately weighed platinum dish. When completely evaporated, transfer the dish from the water-bath to an airbath kept at $105^{\circ} \mathrm{C}$, and leave it for an hour, at the expiration of which time, place it in a desiceator to eool. Reweigh and note the gain in weight, which represents the amount of total solids in the volume of water taken. The number of milligrams gained represents the number of parts per 100,000. The weighing should be done as quiekly as possible, in order to avoid error due to the absorption of atmospherie moisture by hygroscopie matters in the residue.

In order to determine the amount of volatile substances, the dish is next heated to dull redness on a platinum triangle over a Bunsen lamp. The organie matter, in the process of burning off, gives rise to more or less blackening, and may also evolve odors which often eonvey some idea of its nature. The blackening may disappear quickly or may persist for some time, especially in the case of woody matters, sueh as are present in brown swamp waters. Animal matters callse an odor like that of burnt horn ; vegetable substanees, one suggestive of burning peat. The loss in weight represents not only the organic matter, but also the nitrates, nitrites, ammonium salts, combined carbonic acid, and, if the temperature has been raised too far, part of the chlorides. The residue after ignition represents the "fixed solids."

Determination of Hardness.-For the detemination of hardness, a number of processes are in use; but for practical utility, that known as the "soap method" is to be preferred.

Solutions Required.-1. Standard Solution of Calcium ChioRIDE.-Weigh out $1 \mathrm{gram}$ of pure calcium earbonate, dissolve it in as little as possible dilute hydrochloric acil, and evaporate to dryness. Add to the residue a little distilled water, and again evaporate to dryness. Disisolve in distilled water and make up to 1 liter. One ec. represents 1 milligram of calcium carbonate.

2. Standand Solution of Soap.-Scrape about 10 grams from an old dry piece of pure Castile soap free from sodium lyydrate and earbonate, and dissolve it in 1 liter of diluted alcohol. Let stand over night and filter. This should next be standardized in the following manner: To $100 \mathrm{ce}$ of distilled water eontained in a glass-stoppered bottle of about 250 ec. eapacity, run in, from a burette, successive small portions of the soap solution until, on vigorons shaking, a lather is formed which persists at least two mimutes, and note the anount nsed.

Repeat the operation with $99 \mathrm{ce}+1$ ce. of the standard solution of 
calcium chloride, and then with 2, 3, 4, 5, 6, 7, 8, 9, and 10 ec. of the same solution made up to 100 ce. with distilled water, and note the amount used in each test. It will not suffice to determine the amount necessary to produce a lather with distilled water and with $10 \mathrm{ec}$ of the calcium chloride solution, made up to the same volume, and divide the diflerence by 10 , since as we go up in the scale a gradual lessening of the amomnt of increase for each degree is noted. In this way we obtain a seale of values for the particular lot of soap solution made at one time. It will save some trouble if one makes up a number of liters, but it is necessary to make occasional tests to see that the strength does not deteriorate, or', if it does, to correct the scale.

Prockss.-To 100 ec. in the bottle above mentioned, add the soap solution in the same manner as employed in making the scalr, and, when the end point is reached, note the amount used, and, by reference to the scale, ascertain the number of degrees of hardness. Shonld the water be harder than 10 degrees, it is best to take a smaller amount and make it up to $100 \mathrm{ec}$. with distilled water and then proceed anew, remembering at the end to ealculate accordingly.

The result obtained expresses the "total hardness." If it be desired to ascertain the temporary, or removable, hardness, $100 \mathrm{ce}$ of the water may be boiled five minutes and then allowed to cool. The original volume is restored by the addition of the necessary amount of distilled water, and then the operation is repeated. The second result indicates the permanent hardness, and the difference, if any, is the temporary harduess.

Determination of "Oxygen Required."-All organic substances are susceptible of oxidation ; but as they are widely variable in character, they require very different amounts of oxidizing agents for the attainment of the same result. The several methods proposed for determining the oxygen-consuming capacity of drinking-waters have, therefore, only a limited value; but, in general, it may be said that a high requirement indicates an amount of organic matter inconsistent with purity when it cannot be accounted for by the presence of ferrous salts. Since the amount of organic matter is indicated pretty fairly by the ammonia and albuminoid-ammonia determinations, the estimation of the "oxygen required" serves only as eonfirmatory evidence.

Solutions Required.-1. Standard Solution of Potassium PerMaxGaNate.-Dissolve $0.395 \mathrm{gram}$ in 1 liter of distilled water. One ce. is equivalent to $0.1 \mathrm{mgr}$. of a vailable oxygen.

2. Standard Solutiox of Oxalic Acid.-Dissolve $0.7875 \mathrm{gram}$ in 1 liter of distilled water. One ce. eorresponds to an equal measure of the permanganate solution.

3. Dilute Sulipiluric Acid, $1: 3$.

Process. - The determination is based on the faet that potassium permanganate gives up its oxygen readily to organic matter, especially in the presence of acid and with the application of heat. The reaction is expresised in the following equation:

$$
4 \mathrm{KMnO}_{4}+6 \mathrm{H}_{2} \mathrm{SO}_{4}=2 \mathrm{~K}_{2} \mathrm{SO}_{4}+4 \mathrm{MnSO}_{4}+6 \mathrm{H}_{2} \mathrm{O}+5 \mathrm{O}_{2} .
$$


Thus 4 molecnles of permanganate will yield 5 of oxygen, or, differently expressed, 632 parts by weight of the one will yield 160 parts by weight of the other; hence, 3,950 of permanganate equals 1,000 of oxygen.

In this operation, eleanliness of vessels is of the greatest importance. A poreelain casserole or evaporating dish of snfficient size is made fit for use by boiling it in distilled water acidnlated with sulphuric acid, and adding permanganate solution until no further decoloration is observed.

Place 200 ec. of the sample in the dish, add 10 ec. of the dilute sulphuric acid, and heat to boiling. Add from a burette sufficient of the permanganate solution to eause a very distinet redness, and boil again, adding the permanganate as the color tends to fade, so as to retain as nearly as possible the original color. When further boiling for five to ten minutes fails to diminish the intensity of the color, oxidation is complete. Add now $10 \mathrm{ec}$. of the oxalie acid solution, which will discharge the color if the permangamate has not been added too freely. Should the color not be discharged by $10 \mathrm{ce}$, add 10 more. Having now a colorless solution, add more permanganate until a slight pink color again appears. Note the total amount of permanganate used, subtraet from it that used up by the oxalic acid, mnltiply the number of ec. remaining by 5 , in order to arrive at the amount which would be consumed by 1 liter, and divide by 10 to express the result in milligrams of oxygen. Inasmuch as any nitrites present are oxidized to nitrates, a correction should be made for them. This can be done very readily, since 16 parts of oxygen are required for 14 parts of nitrogen as nitrites.

Since the permanganate solution is not wholly stable, it shonld be titrated against the oxalie acid solution every time it is nsed. This may be done most eonveniently by adding, after the operation is completed and the reading of the burette is noted, $10 \mathrm{ec}$. more of the oxalic solution and titrating to the same point as before.

The oxalic solution keeps better, if a few ec. of strong sulphuric acid are added when it is being diluted to 1 liter.

Determination of Color.- The color of water may be observerl by viewing a suffieient depth of the specimen in a glass eylinler against a white surface. Color may be expressed quantitatively by comparison with the standards for the ammonia determinations.

Determination of Odor.- Place about $200 \mathrm{ce}$ of water in a 500 ec. beaker, cover with a watch-glass, and heat to about $40^{\circ}$ C. Give the beaker a rotary motion, so that the water is set in motion, remove the wateh-glass, and with the nose well inside the boaker note the character of the odor. Some analysts prefer to heat the water in a glass-stoppered bottle, the use of which permits a much more thorongh agitation of the water before applying the nowe. The oxlor should be designated aceording to the sulstamee which its presenere sugurests.

Determination of Reaction.-I most delieate reacent for alkalinity in water is a 1 per cent. solution of toluylene-red. Fifty ece of water 
distinetly alkaline will become intensely yellow on the addition of 2 or 3 drops. A less degree of alkalinity will canse an orange or palered color. It is so delicate a test that 1 part of alkaline carbonate in $1,000,000$ is revealed by it.

The presence of acids is shown by another sensitive indicator, lacmoid. This is not affeeted by carbonic acid, nor by ferrous and other metallic salts which are acid to litmus, but is affected by ferric salts. It may be used as a 1 per cent. solution in diluted alcohol. Phenolphthalein solution, 0.5 per cent., is colorless in neutral and acid solutions, and pink in alkaline. It is affected by carbonic acid.

In the determination of reaction, a drop or two of the indicator may be added to a volume of the water in a long glass tube. A very faint change, due to acids or alkalies, is perceptible on looking down through the column against a white background. If the reaction is acid, the sample should be boiled, then cooled, and tested again to ascertain if the acidity is due wholly or in part to carbonic acid. Acidity and alkalinity are determined quantitatively by titration with eentinormal solutions of sodium hydrate and hydrochloric acid, using lacmoid or phenolphthalein and methyl-orange as indicators.

Determination of Turbidity.-For the determination of the degree of turbidity, several methods are in use, among which the following may be mentioned: Mason ${ }^{2}$ recommends standards made by adding weighed amounts of kaolin to distilled water, each representing parts per $1,000,000$ of kaolin. Whipple and Jackson ${ }^{2}$ employ finely powdered diatomaceous earth, instead of kaolin, because of the greater unifornity in the size of the particles. Hazen ${ }^{3}$ measures it by determining the depth at which a $0.1 \mathrm{~mm}$. platinum wire can no longer be seen.

Detection and Determination of Lead.-Many processes have been proposed for both qualitative and quantitative determination of this most undesirable contamination. The simplest test, but by no means the best, consists in adding a drop or two of ammonium sulphide to a volume of water in a tall glass eylinder, and noting the character of the discoloration produced. If darkening oecurs, dne to the formation of a metallic sulphide, the addition of dilute hydrochloric acid will distinguish between lead and iron, the sulphide of the latter being soluble. To those who have had practical experience in detecting minute amounts of metals in water, this method is far from satisfactory. More or less color is imparted by the ammonium sulphide, and more or less turbidity is produced commonly on the addition of the acid. Moreover, when unconeentrated water is nsed for the test, no reaction may occur, although the poisonous metal is present in minnte traces.

Another simple test, depending upon the formation of lead chromate, has been offered by S. Harvey, who claims that water eontaining 0.30

${ }^{1}$ Journal of the American Chemical Society, XXI., p. 516.

${ }^{2}$ Technology Quarterly, XIII., No. 3, September, 1900.

s Journal of the Franklin Institute, 1899, p. 177.

The Analyst, April, 1890. 
milligram of lead in 1 liter will show a turbidity from chromate when $250 \mathrm{cc}$. are treated with 0.10 gram of potassimm bichromate; and that in twelve hours the precipitate will settle and become still more distinet.

Since small amounts of lead sulphide remain in solution, and can be separated only with great difficulty when the volume of water is large, it is best to concentrate the specimen to a very small bulk before attempting to precipitate the lead. From this point onward the methods employed vary very considerably.

Liebrich ${ }^{1}$ precipitates the lead as sulphide in acid solution, converts it to sulphate by treatment with nitric and sulphurie acids, and dissolves this by warming with a few ec. of caustic potash $(1: 10)$. The solution is filtered and made up to $20 \mathrm{ec}$, and 2 cc. of ammonimm sulphide are added, whereby a brown color is produced, which may be compared with the shades produced by similar treatment of equal volumes of distilled water containing known amounts of a solution of lead sulphate in caustic potash.

Antony and Benelli ${ }^{2}$ reeommend the addition of mercurous chloride before precipitation as sulphides, believing that thereby no trace of lead ean escape complete separation. The combined sulphides are filtered and dried, then heated to such an extent that the mereury salt is driven off', leaving the lead as a residue.

Mr. H. IV. Clark, ${ }^{3}$ after trying all known methods, finds most satisfaction in the following process devised in his laboratory : 3,500 ce. are evaporated to $25 \mathrm{or}^{\circ} 30 \mathrm{cc}$., 10 or 15 cc. of ammonium chloride solution added to assist separation of the sulphides, and a considerable excess of strong ammonia. Hydrogen sulphide is then added and the dish allowed to stand some hours, after which more ammonia and hydrogen sulphide are added. After boiling to expel the excess of hydrogen sulphide, the precipitate is filtered off. It contains any lead, iron, copper, or zinc as sulphides, and other suspended organic and mineral substances. It is washed once with lot water, and the paper is then boiled in dilute nitric acid (1:5). It is then filtered, and washing is continued as long as any acid is removed. The filtrate and the washings are concentrated to abont 10 or $15 \mathrm{ce}$, cooled, and then mixed with 5 ce. of concentrated sulphuric acid (specific gravity 1.84) and heated until copions fumes of sulphurie acid are evolved. In the absence of more iron than 0.025 in 100,000 , acetic acid and ammonia are added directly. 'The mixture is next boiled and filtered, all the iron, dehydrated silica, and insoluble organic matter being left on the paper. The filtrate is then used for the colorimetric determination of lead by means of comparison of the shade produced by the addition of hydrogen sulphide solution with a set of standards containing known amounts of leart.

With more than 0.025 iron in 100 ,000, the process is somewhat different: the learl sulphate is washed into a beaker with aleohol and

${ }^{1}$ Chemiker-7eitung, 1898, XXII., p. 22:5.

2. Journal de pharmacie et de chemie, $1898, \mathrm{~N}_{0.7,7.72 .}$

Loco citato, p. 582. 
water, and allowed to stand over night, and then filtered off and washed with 50 per ecint. aleohol until free from iron. The lead sulphate is then dissolved by boiling the filter with ammonimm acetate in a porcelain dish. Experienee hats demonstrated that this process is extremely acenrate and reliable.

The anthor finds the following process simple, rapid, and acenrate. Evaporate 3,000-4,000 ec. of water to about 15-20 ce. in a porcelain dish, add, little by little, and with gentle heat, sufficient dilute hydrochlorie acid to dissolve any inerustation of salts on the sides and brittom, and to grive a slight acid reaction; then add 5-10 ce. of hydrogen sulphide water of good strength. Any lead present is preeipitated in a very fine state, but not so fine but that the entire amount can be collected on a Swedish filter. Wash twice, and then treat on the filter with boiling dihute nitrie aeid until the black deposit is wholly dissolved. Wash with hot water as long as the washings are acid, and and them to the nitric acid filtrate. Evaporate to dryness in the original dish, add distilled water, and again dry. Dissolve the residue in hot distilled water and make up to $50 \mathrm{ce}$. Take 5-10 cc. and dilute to about $80 \mathrm{ce}$. with distilled water in a glass conparison tube of $100 \mathrm{ce}$. capacity, add hydrogen sulphide water in sufficient amount, make up to $100 \mathrm{cc}$. with distilled water, and mix thoronghly by inverting the tube a number of times. Compare the depth of eolor with those of a series of tubes containing known amounts of lead as lead nitrate, treated with hydrogen sulphicle in the same way.

The standard solution is made by dissolving 0.160 gram of pure lead nitrate in 1 liter of distilled water: 1 ce. represents 0.1 milligram of lead. A eonvenient scale is made with $1,2,3,4,5,6,7,8$, 9, and $10 \mathrm{ce}$. of the solution in $100 \mathrm{ec}$. If the hydrogen sulphide water is added after diluting to about $80 \mathrm{ec}$, the result is a series of sufficiently elear standards showing sharp and regular stages of color. If the reagent is added before the lead salt has been sufficiently diluted, the standards are very turbid, and are lacking in the very essential gradation of color.

Should the depth of color obtained in the preliminary test be greater than that given by No. 10, a smaller amount should be taken and the experiment repeated. Should the eolor be very faint, the whole of the remainder may be treated and compared. From the result obtained by matching the colors, the amount of lead in parts per 100,000 is easily ealculated.

ExAMPLE.-Ten ec. treated as above gave a color reaction midway betwcen standards 6 and 7 ; henee, one-fifth of the whole eontains 0.65 milligram of lead, and the entire amount contains 3.25 milligrams. The amount of water eoncentrated was 3 liters. Hence 1 liter of water contains 1.08 milligrams, and $100 \mathrm{cc}$., or 100,000 milligrams of water, contain 0.108 milligram of lead.

Detection of Zinc.-One is reasonably safe in assuming that water which has been in contact with galvanized iron will show the presence of zinc. This may be determined quantitatively by evaporating a 
quantity of water to a small bulk, heating the latter with a sufficient amount of dilute lydrochloric acid in order to take up any oxide or carbonate, and then proceeding to the precipitation of the sulphide after making alkaline with ammonia. For qualitative purposes, a volume of water is made slightly alkaline with ammonia, boiled, and filtered. The addition of a few drops of test-solution of potassium ferrocyanide to the filtrate will, in the presenee of traces of zine, cause a white precipitate, or at least an opaleseenee, which, however, may not be distinet within a lialf hour.

Detection of Tin.-Although, so far as known, tin in water has no sanitary significance, it sometimes is desirable to ascertain its presence in water and in other substances. For rapid testing for this metal, the method reeommended by C. Deniges may be employed. This depends upon the fact that stannous componnds cause a reddish-riolet color with nitrate of brucine. The brucine solution is made by dissolving $0.5 \mathrm{gram}$ of brucine in 5 ec. of nitrie acid, diluting to 250 ec. with distilled water, boiling for fifteen minutes, and, after cooling, making up the volume to 250 ce. again. The water is evaporated to dryness with a little hydrochloric acid. The residue is dissolved in a very little water, and to it is added $1 \mathrm{ce}$. of the brucine solution. If so little as the twentieth part of a milligram of tin is present, the color ehange will be distinctly shown even in the presenee of iron and eopper.

Detection and Determination of Iron.-This very common and frequently troublesome constituent of water is detected rery casily by concentrating a sufficient volume of the sample to a small bulk, converting the iron present from the ferrous to the ferric form by boiling with a little nitric acid, and adding a few drops of a solution of potassimm sulphocyanate, which causes a deep-red coloration. By means of a seale made with known amounts of ferric iron treated with the same volume of test-solution, the amount of iron may be determined cuite accurately. A standard solution of iron may he made by dissolving 0.10 gram of pure metallie iron in aqua regia and diluting to 1 liter with distilled water: 1 ce. represents 0.10 milligram of iron. The comparison seale is made by diluting progressively increasing volumes with distilled water up to nearly 100 ece, adding a few ee. of a 5 per cent. solution of potassium sulphocyanate, and then making up to $100 \mathrm{ec}$.

For other determinations of a strictly technie character, the reader is referred to the many excellent treatises bearing on the subject.

\section{Inferences as to Character of Water from the Results of Sanitary Chemical Analysis.}

It is impossible to fix any alowolnte standards by which to pass upon the potalbility of water without referenee to its origin, for surficewaters cannot be judged by the same standarrs as gremul-waters, and,

' Revue Internationale des Falsifications, VIII., p. 98. 
moreover, those which apply to waters of either class from one locality may be wholly inapplicable to those from another. A surface-water, for instance, may withont prejulice yield an amonnt of albuminoid ammonia which would be most suspicions in the case of a groundwater; while the latter may contain, under some circumstances, an amount of free ammonia inconsistent with purity in the case of the former. Again, an amount of chlorine which in a water from near the sea would be normal, wonld indieate in another from far inland the presence of sewage matters.

Ammonia may be expeeted in some amount in any water; it is elaracteristic of decomposition of organic nitrogenous matter of innocent charater as well as of sewage, and it may be present in considerable amounts in both normal and polluted waters. Furthermore, it mily be present in higher anounts in water from an uncontaminated deep-bored well or in stored rain, than in polluted water that has undergone chemieal change. Albuminoid ammonia may be yielded in equil amounts by a water contaminated by sewage, and by one quite free from it, but rich in dissolved vegetable matter derived from leaves. Richness in mineral matter may be present equally in normal and polluted waters. A pure water may be rich in nitrates, while a sewagewater may have lost them by reduetion. Either may be colored or not, elcar or turbid, and odorous or odorless.

There is one constituent, however, the presence of which in more than measurable quantity is a tolerably sure indication of pollution, that is to say, the nitrites; but their absence is not a guarantee of purity, for in grossly polluted waters they may be wholly wanting. In general, however, it may be set down as a safe rule, that nitrites and high free ammonia together mean recent pollution; occurring continuously, they indicate constant pollution ; and, with chlorine fairly above the local normal, ordinary sewage contamination. High ammonia with nitrites, but with no marked increase in chlorine, may indicate contamination by matters from manured farming land.

The results obtained in the chemical analysis of a specimen of water are often quite suflicient for the formation of an opinion of its suitability or unfitness for general domestic purposes, but more often a knowledge of the source and the surroundings thereof is necessary for their intelligent interpretation. They may be such as to indicate that, whatever its source, the water which yielded them is very good or distinctly bad; but, on the other hand, they may be such that full knowledge of all the facts is imperatively necessary for the formation of a correct judgment. A water yielding the following results, for instance, may unhesitatingly be pronounced to be of undonbted purity so far as chemistry can determine, quite irrespective of souree (the figures express parts per 100,000):

Free ammonia . . . . . . . . . . . 0.0002

Albmminoid anmonia . . . . . . . . . . . . 0.0018

Nitrogen as nitrates . . . . . . . . . . . . 0.0240

Nitrogen as nitrites . . . . . . . . . . . . . . 0.0000 
Chlorine . . . . . . . . . . . . . . . . . . .

Volatile residue. . . . . . . . . . . . . . 1.25

Fixerl residue . . . . . . . . . . . . . . . . . . . . . 1.60

Total residue . . . . . . . . . . . . . . . . . . 2.85

Hardness . . . . . . . . . . . . . . . . . . . . . . 1.00

Appearance, clear and bright.

Color, absent.

Odor, absent.

Changes observed on ignition of residue, no blackening.

In this case the figures indieate almost total absence of organie matters, and but slight amounts of mineral eomstitnents. There is no suggestion of contamination of any kind, and the only conclusion that ean be drawn is that the water is pure and soft, and suitable for all domestic purposes.

On the other hand, the following results may, in the same way, be sufficient for unqualified condemnation.

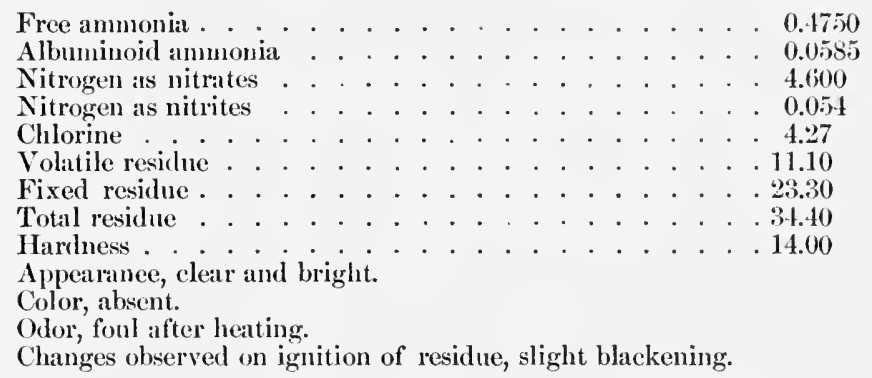

These results, which are actual ones obtained from a speeimen sent to the author with no statement of origin, warranted a report of gross pollution, regardless of souree, for the presence of sewage matters was undeniable, and under no cireumstances of geographical location conld any other report be marle. Incuiry concerning the origin of the water bronght the information that the well from which it. came was located at no great distance from a leaching cesspool, and was used only when the usual source of supply, a spring, lan dry. Repeated atticks of illness of no great serionsness had heen noticed whenever, during the preceding three rears, this water had been need.

These two waters may serve as good examples of undoulted purity and extensive pollution. Both are ground-waters, and, what is not without interest, they came from one and the same small inland town.

Such results as the ahove require no long consideration-they speak for themselves. But it very eommonly happens that even a single ingredient may eause suspicion of sewage pollution to arise when information as to the location of the supply is withledd. 'Thus, the amount of chlorine may be very enniderably higher than the lowest normal commonly observed inland, and yet well under the amomt which exeites no anlverse comment in a water from the coast. Thus, 3.85 parts in a woll-water from an island in Beston Harbor, and 1.3 .5 in another from the lorrders of I fong Istand Sommd, may be regarded 
as fairly low ; while if found in springs in the Green Mountain range, they would be most alonormally high and of much signifieance.

Again, such an amomnt might come in eonnection with firir vicks of the ammonias, and then under one class of conditions the organie matters would appear to be of vegetable origin and in another to be a part of sewalge.

It is also impossible to dlaw sharp dividing lines between small, comsiderable, and ligh amounts of the ammonias; but, in general terms, it may be stated that up to 0.005 or 0.006 part per 100,000 may be reganded as low, from thereabouts to 0.015 or 0.020 as considerable, and beyond as high. Measurable amounts of nitrites are most significant, while nitrates may run up to several whole parts per 100,000 . 'Thus, it may readily be understood that, in the majority of citses, the results should be.considered in conjunction with all material ficts connected with souree, surroundings, and opportunity for receiving pollution.

\section{Bacteriological Examination of Water.}

The bacteriologieal analysis of water may be divided into quantitative and qualitative determinations. The former is commonly extended over long periods, and has for its object the determination of the normal bacterial content of a given water supply and the observance of any unusual variation therefrom; while the latter is pursued for the purpose of determining the nature of the organisms, and, more particularly, whether they are such as are to be found in the excreta of the body. The finding of such does not mean necessarily that the use of the water will inevitably produce disease, but it indicates the possibility and probability that water containing non-pathogenic organisms from this source may, if not to-day, to-morrow, or later, become infected with others from the same source, capable of acting as the exeiting cause of grave disaster.

As is the ease with chemical analysis, it is impossible to fix any standard of safety hased on the mere amount expressed by the 'flintitative results, since it is the nature and not the anount of the contaminating matters which determines the question of potability. But sudken deviations from the seasonal normal suggest unnsual aceess of contamination, and serve as wamings of possible dimerer.

The isolation and systematic study of the various species of baeteria in a given water to determine whether or not they may be pathogenie, involve much labor and an intimate knowledge of bacteriological technie which ean be acquired only by thorough training in a barerenological laboratory. Fimiliarity with the methods of prepalring colture media and making enltnies, of isolating species and studying their characteristies, is, therefore, a neessary qualification for the pursuit of bacteriological examination of water, and anything more than a brief outline of special methods employed in this par- 
tienlar field of researeh would be beyond the seope of a work of this charater.

Collection of Samples.-In taking samples, it is, of course, necessary to observe the most rigid preautions against the introduction of extraneous organisms. All vessels should, therefore, be absolntely clean and sterile. Collection may be matle either in small bulb tubes, drawn out into a point and sealed by closure in a lamp flame, or in bottles of about 200 ce. capacity with ground stoppers. The bulbs are made easily by anybody who has had ordinary experience in qualitative analysis. By the application of the heat of a lamp immediately before sealing, or by vaporizing a drop of contained water by the same means and sealing just ats the list of the steam is eseaping, they will contiin but little air, and when nsed are filled easily through the inHuence of the partial valcum.

In taking the sample, the point is introduced below the surface of the water and then broken off with sterile forceps. The bulb is filled partly almost immediately, and then the broken point is sealed as before by the application of heat from a gas flame or alcohol lamp. If bottles are used, they should first be washed on the outside in the water to be sampled, and then plunged beneath the surface. The stoppers are then withdrawn, and, when filling is eompleted, they are replaced.

If any considerable time must elapse before cultures ean be made, the wamples should be packed in ice, in orrer to retard multiplication of the eontained bacteria; and since very low temperatures have no harmful influence on the vitality of the organisms, the aldition of a small amount of salt to the ice may be of advantage, although freering should not be permitted, on aceount of the danger of bursting the containers.

Planting the Samples.-If possible, the planting should be accomplished on the spot, on aceount of the multiplieation which is inevitable with delay. If this is not possible, no greater delay should be permittel than is alsolutely necessary.

For qualitative determinations, two sets of plates should be made: one on regulatr agar and one on litmus lactose algar. On the second and third days the regular agar plates should be looked over, and any which show bat spreaders or a munber of eolonies so large that danger of obseuring the eount would result if they were incobated longer should be transferred to the refrigerator. On the fourth day all the regular anar plates slould be removed amb eounted. The temperature at which they should be kept is $20^{\circ} \mathrm{C}$. The litmus lactose angur plates should be inculated at $40^{\circ}$ ( $\because$ for 18 to 24 hour's only, after which thes should be removed for eounting.'

When working on a water of moknewn chatracter hitherto unexamined, different anounts of the sample-1, 2, :3, and more drops-should loe deded, sinee one ean have no definite idea of its hacterial richness.

${ }^{1}$ Personal communieation from Mr. II. Wr. ('lark, chemist in charge of the Lawrence Experiment Station of the Massachusetts Fiate Bondrd of II athlh. 
In quantitative work, the amounts taken should be measured with the greatest accuracy, especially when preliminary determinations have shown such a number of organisms ats to make great dilution with sterile water necessary, for any departure from absolute accuracy introduces an error which will be multiplied aceording to the degree of dilution.

When bulb tubes are user, their contents are expelled with the aid of gentle lieat, which causes the small amount of contained air to expand and foree the liquid throngh the stem, which is broken at the point by pressure from sterile forceps. The expelled water is received in a sterile tube, from which it may be withdrawn in a sterile graduated pipette.

Quantitative Determination.-The value of quantitative determinations lies in the comparisons which one is enabled to make from a series of periodical examinations of the same water, for the information to be derived from a single examination has very limited utility. By means of periolical counts, one is enabled to form an idea of the conditions normally present under different circumstances, and to note at once any disturbing influence. Quantitative determinations are of special value in noting changes in the efficiency of sand filtration of public supplies.

Knowing from preliminary tests or from past experience how much water should be taken for each plate, and the degree of dilution necessary, two sets are made, one on regular agar and one on litmus lactose agar, and the growths allowed to develop. Regular agar cultures are kept at $20^{\circ} \mathrm{C}$.; the litmus lactose agar plates are kept at $40^{\circ} \mathrm{C}$. The lower of these two ranges of temperature is much more favorable to the multiplication of ordinary water bacteria than the higher, and consequently it will be found that the colonies developing on the regular agar will be decidedly more numerous than those on the litmus lactose agar. In expressing results, therefore, mention should be made of the culture-medium employed; and in making comparisons of one day's results with those of another, the importance of limiting them to figures obtained under like conditions of culture-medium and temperature is too obvious to need further mention.

In counting colonies the following method is pursued at the Lawrence Experiment Station :

The plate is placed on a glass plate ruled in centimeter squares, a modification of the Wolffhïgel counting frame, and the number of colonies is counted with the aid of a four-inch reading-glass. The total number of colonies on the regular agar plates, and both the total number and the number of red colonies on the litmus lactose agar plates are counted, the results being entered upon the record slip, together with the date and the initial of the bacteriologist who makes the count. On plates containing less than 300 colonies all the colonies are comnted. On plates containing more than 300 colonies a fractional part of the plate is counted and the result multiplied by the proper factor. On plates containing hetween :300 and 800 colonies one-half of the plate is comnted. On plate's containing more than 800 colonies 
a line across, $i$. e., a strip one centimeter widle through the mirldle of the plate, is comted, while on plates which contain colonies in great excess a number of small areas may be comted, as, for cximple, five selected square entimeters. The appropliate fictor for these two latter counts for plates of different diameters is shown in a table attached to the counting frame. It is easier and more accurate to make plates of two or three dilutions of a sample in order to obtain a plate eontaining from 50 to 300 colonies than it is to attempt to eount crowrled plates. With special samples, however, and with those fluctuating widcly it is not always possible to do this, and the fiactional count is appropriate in such cases.

Qualitative Determination.-The chicf interest in qualitative examination of drinking-water lies in the solution of the question whether or not intestinal hacteria are present. Plates may be prepared and preserved in the same manner as for quantitative work, except that the amount of water planted needs no accurate measurement, but, on aceount of the usual great preponderance of the common harmless bacteria, it is rarely the ease that one can isolate the pathogenie varieties without recourse to special methods.

The test for B. coli, as carried out at the Lawrence Experiment Station of the State Board of Health of Massachusetts, ${ }^{1}$ may be divided into three steps : (a) preliminary cultivation, $(b)$ plating out and isolation of the pure cultures, (c) idlentification or confirmation of the cultures.

(a) The preliminary tests are of two kinds, those made in fermentation tubes and those made in bottles. The fermentation tube tests are made by introducing 1 ce., or a fractional part of 1 ce., of the water under examination into a fermentation tube containing dextrose peptone solution. This is conveniently done at the time that the water is pipetted into the plates during the process of plating; tests of larger volumes than 1 ce, usually 100 or $1000 \mathrm{cc}$, are made in bottles, 10 per eent. by volume of phenolated dextrose peptone solution being mixed with the required volume of water in a glass-stoppered bottle. The fermentation tubes and bottles are ineubated over night at $40^{\circ} \mathrm{C}$. In catse fermentation occurs in the tube, it will be manifest by a collection of gats in the closed arm. In ease no gas is olsserved, the bacteria of the colon type are not present and the test is eomplete. The tests in larger volumes, upon being removed from the incubator, are given one quick, hard shake and held up toward the light. In ease active formentation has oceurred, the gas will separate from the liquid and rise slowly, giving the same appearance as when a bottle of highly carbonater water is opened. In ease the shake test in negative, it should be confirmed by placing about $\frac{1}{2} \mathrm{ce}$. of the enlture in a fermentation tube with dextrose peptone solution and incubating 24 hours. When making the preliminary tests, a record slip or day eard is made, upon which each sample testerl and the results of the tests are indicated by plus and zero signs. Final reeord slips, containing the name of the sample, the date, the volume of the test, and its result are made from the day

1 Personal communication from Mr. II. W. Clark, clienist in charge. 
card after the tests are completed, the volume tested, and the result being placed in the upper right-hand corner of the slip, the date in the center at the top, and the sample number in the upper left-hand corner.

(b) The positive tests, either in fermentation tubes or in the bottles, are now plated out on litmus lactose agar. The record slips of the positive tests are arranged on the plating table, and sterilized Petri dishes, each containing 5 drops of litnus solution, are placed thereon. With a straight, sterile platinum needle a minute quantity of the preliminary culture is transferred to the litmus, the plates are poured with lactose agar, placed in the refrigerator for one hour, turned, and incubated 24 hours at $40^{\circ} \mathrm{C}$.

(c) On removing the plates from the incubator they are examined to determine whether or not red colonies have developed. In case no red colonies have developed, the result is negative, and is so recorded on the slip. In case red colonies are present, two colonies from each plate are transferred with a sterile, platinum needle to agar streaks, the agar streaks being incubated 24 hours at $40^{\circ} \mathrm{C}$. After incubation the characteristic colon streak should be luxuriant, smooth, white, and glossy, and should not be stringy to the needle. Tubes showing a very scanty growth of small colonies following the track of the needle are examined under the microscope for the presence of streptococcus forms. They are not $B$. coli. Tubes which are stringy to the needle or which show a wrinkled growth are also not $B$. coli, and are recorded as negative, and tubes which show no growth at all are so recorded. From the tubes which show the characteristic appearance of $B$. coli transfers are made with a loop needle to a fermentation tube containing dextrose peptone solution to tubes of nitrate solution, Dunham's solution, and with a straight needle a stab culture is made into a tube of gelatin. The fermentation tubes and tubes of nitrate and Dunham's solutions are incubated at $40^{\circ} \mathrm{C}$.- - the first two for 24 hours and the Dunham's solution for three days. The gelatin tubes are incubated at $20^{\circ} \mathrm{C}$. for fourteen days. At the end of 24 hours the fermentation tubes are examined for the presence of gas in the closed arm, and the nitrate tubes are tested for the presence of nitrites with the usual Griess reagents. At the end of three days the Dunham's solution tubes are tested for the presence of indol by adding 1 ce. of $1: 1$ sulphuric acid and $1 \mathrm{cc}$. of a solution of potassium nitrite containing 0.02 of 1 per cent., the presence of indol being manifested by the appearance of a pinkish or purplish coloration. The gelatin tubes are examined on the fourth, seventh, tenth, and fourteenth days for the occurrence of liquefaction, the form of liquefaction and the date on which it occurred being recorded in ease it is observed. In recording these tests no record is made of tests which are characteristic of $B$. coli, $i$. e., if fermentation occurs, nitrites are formed, indol is produced, and no liquefaction occurs, the culture is finally recorded as of the colon type. In case any one of these tests is negative, it is repeated with the same culture before being recorded, and in case a second negative is obtained, the negative record is made, and the culture is recorded as not of the colon type. These records are conveniently made in a book ruled for 
the purpose, the streak cultures being numbered serially, a record of the sample, date, volume, etc., from which they were obtained being recorded in the book at the time the streak cultures were made, the tubes of confirmatory media being carried through under the serial number. It is usual to rack up the streak cultures in order and fish to confirmatory media at convenient intervals. As soon as the fermentation, nitrate, and indol tests are complete, the streak cultures may be destroyed, since they may be recovered, if necessary, at any time within fourteen days from the gelatin stab cultures.

\section{Comparative Value of Chemical and Bacteriological Analysis of Drinking-water.}

As the science of bacteriology began to develop and take the position to which its importance gave it a title, its disciples conceived a strong prejudice against and contempt for any opinion as to the potability of a particular water based upon chemical analysis, maintaining, quite correctly, that minute amounts of ammonia, albuminoid ammonia, and ehlorine are incapable of acting as the exciting caluse of infective disease, and that not these substanees, but only speeific organisms not demonstrable by chemical processes, can so act. It must be conceded that, for a time prior to the discovery of the nature of the infective agents, the importance of the results of chemical analysis was grossly exaggerated, and that arbitrary standards, such as were established by the River's Pollution Commissioner's, upon which conclusions were based, have, in the light of farther experience, been abandoned ats absurd and untrustworthy. But it must also be coneeded, even by those who were most canstic in their eriticism, that chemistry is to-day equal, if not superior, to bacteriology in indicating possible danger from the use of water exposed to contaminating influences.

In the earlier days, much capital was made by bacteriologists of the fact that a sample of water, inoculated with a culture of the bacillus of typhoid fever, was reported by a chemist of high standing as of great purity and eminently suitable for domestic purposes. Such a test, however, is unworthy of the slightest consideration, sinee under natural conditions a water showing a high degree of chemical purity is not likely to be infected with a pure culture of a pathogenic organism, and the submission of a pure water so treated is a mere trap, the setting of which is no more praiseworthy than would be the sending of a sterile solution of cyanicle of potassium or of sulphate of strychnine to a bacteriologist with a request for an opinion from the standpoint of his specialty as to its desirability as a beverage.

Chemical analysis ean show the presence of organic and mineral impurity such as accompanice infeetions matters from the intestine and bladder. It cannot give gromnds for a positive assertion that the nise of a water thus polluted will inevitably canse diseatse, but it ean and does serve to point out possible danger. It ean detect the presenee of sewage matters, and while it eamnot prove the presence of infections material therein, it can at least point out that the oceurrence of typhoid 
fever in the community furnishing the sewage is likely to be followed by other cases of the disease in the community which uses the polluted water. It exmnot distinguish typhoid pollution from any other exeremental contamination, since a healthy body yields the same chemical substances as one that is diseased. In the case of waters containing no evidence of contamination, it can supply the basis of an opinion as to safety, but it camnot furnish any guarunty that the condition is permanent.

Bacteriologieal analysis differentiates between pathogenic and nonpathogenic contamination, but it is only rarely that it serves to point out danger in advance. Even when an outbreak of typhoid fever has oceurred and attention is drawn thereby to the condition of the water supply, the results of bacteriological examination are generally negative. The reason for this is twofold. In the first place, the examination for the detection of the specifie organism is not ordinarily begun until attention is drawn to its necessity by an outbreak of the disease, which does not appear until about two weeks from the time eontamination has oeeurred. Unless the contamination is continuous, by the time the examination is instituted, the polluting materials have either passed on or the speeifie organisms have perished. In the second place, even although they are present, with our present methods it is not an easy matter to isolate them, and we ean determine in most cases only the probability of their presence.

It should be borne in mind that the organisms are particulate bodies in suspension in great dilution, and that their distribution is not homogeneous as is the ease with substances in solution, and that, therefore, the amomint of water taken for planting plates may not eontain them. But in the unsuceessful search, it is not uneommon to find $B$. coli communis, and where this organism lurks, the other may have been present.

As a rule, bacteriologieal seareh for the typhoid bacillus has given negative results. Laws and Andrews failed to find it in the sewage of London, although it must have been present; and they had but slight snceess in the examination of sewage from a hospital where forty eases of the disease were being treated. The reason for this may be that through absence of suitable food material and favorable temperature, and by reason of the antagonistic influence of the ordinary sewage baeteria, the typloid bacilli had lost their vitality ; or it may be that they were so diluted that the volumes used for planting failed, as a rule, to contain them. Examination of the water supposed to be concerned in the unusual outbreak at Maidstone yielded absolutely negative results, although no reasonable doubt ean exist that at some time they had been present.

Professor Perey Frankland, who has had a large experience in dealing with miero-organisms in air and water, says: " "The detection of specific pathogenic bacteria in drinking-water is now known to be almost beyond the range of practical politics, and the search for such bacteria is, in general, only carried on in deference to the special request of the layman, the uninitiaterl, or the hopelessly ignorant, whilst it cannot be repeated often enough that any feeling of security which may

' Journal of the Sanitary Institute, October, 1899, p. 393. 
be gathered from an unsuccessful seareh for pathogenic baeteria is wholly illusory and in the highest degree dangerous. . . By far the most important service which has been rendered by bacteriology is the means which it affords of controlling the effieiency of filtration and other purification processes. The slightest irregularity or defect in the proeess of filtration is at once laid bare. Baeteriologieal purity of wellwaters can also be satisfictorily controlled."

Professor W. H. Horroeks, ${ }^{1}$ too, remarking on the fact that, if a considerable time has elapsed since the oceurrence of pollution, the bacteriological deteetion of the same, especially when waters of great original parity are concerned, beeomes more and more liffieult, adds : "It is, therefore, evident that a bacteriological examination has its limits of usefulness, and a slavish adherenee to it under all eonditions, combined with negleet of the hints to be obtained by chemical means, may lead to a perfectly erroneous judgment. Still, there is one branch of hygienie study in which bacteriology must always reign supreme; it is now acknowledged on all sides that the working of sand filters for public water supplies eannot be properly kept under control exeept by appealing to bacteriological methods of examination."

A positive result, the first instanee in which the organism isolated responded to every test, inelnding growth on gelatin, potato, litmus milk, bouillon and glucose bouillon, agglutination, and Pfeiffer's test with animals, is reeorded by Drs. Kübler and Nenfeld. ${ }^{2}$ In this ease, the cause of the disease lay in the use of water from a well infected by the urine of a person sick with the disease. Four wecks from the time of the first examination when the baeillus was isolated, a seend analysis was made, whieh yielded bacilli whieh responded to all the tests excepting Pfeiffer's, which exeeption was supposedly due to modified virulence. No colon baeilli were present either time.

A seeond instanee is recorded by Fiseher and Flatan, ${ }^{3}$ who isolated the organism from a well-water in Rellingen. Similarly, a second attempt, made four weeks later, was unsuceessful.

G. Mayer ${ }^{5}$ elaims to have isolated typhoid baeilli "massenhaft" from well water. Jaekson and Melia ${ }^{6}$ were able, by the use of lactose bile media, to isolate the typhoid bacillus from-(1) Grass liver, a souree of water supply for Canton, New York; ( 2 ) from a pond or stream used as a private water supply at Hastings, New York; and (3) from two points in the Iudson hiver. Nevertheless, it still remains true that the isolation of the typhoid organisms from suspected water supplies is very rarely accomplished.

From what has gone before, it may be said that neither chemical nor bacteriological analysis is infallible. Each has its uses, and each may be helped by the other. The value of eithor lies in the skill displayed in interpreting the results, and this requires as much knowledge as the making of the examination itself.

1 Bacteriological Fxamination of Water, London, 1901, p. 3.

2 /eitschrift für IIygiene und Infectionskinkheiten, XXXI., 1899, p. 133.

3 Centralblatt für Bakteriologie, etc., XX1X., p. 329.

4 Ibid., 1910, Bd. LIII., p. 25ti.

5 Journal of Infectious Diseases, 1909, Vol. VI., p. 203. 


\section{CHA P T E R V.}

\section{HABITATIONS, SCHOOLS, ETC.}

\section{Section 1. GENERAL CONSIDERATIONS.}

IT is essential to health that the houses in which we dwell shall be built upon proper sites, free from dampness and organic pollution; they should be provided with adequate means for heating, ventilating, and lighting; they should be well supplied with water for general domestic purposes, and provided with a proper system of plumbing for the removal of sewage; they should be eonstrueted with proper precautions against dampness from without or below. Heating, ventilation, lighting, and plumbing are considered below under their several headings.

Aspect.-It is conmonly directed that habitations should be placed so as to face the south ; but, unfortunately, one is not always in a position to be over-particular in the matter of points of the compass, and, indeed, there seems to be no particularly good reason why that side of the house in which is located the main entrance should face south and the others respectively north, east, and west. The southerly side of a hill is very much to be preferred to the northerly, because of the greater amount of sunlight and of protection against the eold winds from the north; but in a plain and elsewhere, whichever wall of the house finces south, there must be, if the structure be rectangular, one to the north. Far better is a location with the corners of the house pointing north and south, for in that case every window must receive some direct sunlight at some part of the day, whereas with sides facing directly north and south, the windows of the former receive no direet sunlight and the rooms are dull and eheerless. In large eities, aspect is commonly a minor consideration, the desirability of a house being determined mainly by other eireumstances. In general, it may be said that, when possible, a lhouse should be so situated as to insure an abundance of light and air with protection against the cold winds of winter.

Construction and Arrangement.-Consideration of building materials and the details of arrangement of rooms and division of floorspace are beyond the scope of a work of this nature, and it is necessary only to eall attention to the importance of insuring dryness, light, and air, and such thoronghness of construction as shall not permit a too generous amount of natural ventilation with consequent waste of heat.

Of the very greatest importance is the character of the cellar, that part of the house which is most negleeted during both eonstruetion and occupancy. Unless the site is onc of unusual dryness, the cellar floor 
should consist of a generous layer of cement impervious to moisture from below and to soil-air and its contamination, such as gas from leaking mains. The foundation walls should be tight and dry, and should contain in their upper part a sufficient number of windows of a size to admit an adequate supply of light.

The walls should be made as far as possible proof against wind and weather. In exposed positions, it may be that a clapboarded wall is far drier than one of brick, for the latter material, if very porous, is not uncommonly wet through by driving rain, and does not quickly become dry again. Sometimes it becomes necessary to cover an entire brick wall with a protective coating of paint, or even with a sheathing of tin plate. For protection against dampness and cold, external walls may be built with an intervening air space, which acts like that of a double window; the outer and inner faces of the wall are joined at intervals by bonding bricks or ties of various materials, including hard nonporous bricks, glazed brieks, and iron.

Roofs should be tight and protected against the backing up of water from melting snow and ice when the gutters are filled with ice. As a covering, slate is much to be preferred to shingles, thongh its initial cost is much greater ; it is permanent in character, impermeable, and requires but little repairing, while shingles wear out in course of time, and, by taking up moisture, lead to rotting of the timbers beneath. Tin is tight and impermeable, but is very hot in summer. Tar and gravel are well suited to nearly flat roofs, the gravel protecting the tar from the action of the sun, and the combination being very durable.

Care of Habitations. - The proper care of a house and its surroundings is a subject that can hardly be tanght; with many, it is a natural instinct; with more, very little is required to satisfy the understanding of the term. A large class distribute house sanitation with an uneven hand, insisting upon the perfection of care of those parts which they inhabit and in which the outside world is reeeived, and neglecting those where filth is most likely to accumulate, but to which, perhaps, the general overseeing eye never penetrates. In a way, the most important parts of a house are the cellar and the kitchen, and these should receive more careful attention than the drawing-room, where, presumably, organic filth can hardly gain access in appreciable amounts. The otherwise careful housekeeper, to whom a burnt mateh on the hearth of an open fire is an abomination, will, perhaps, view with placid face the boxes, baskets, and even.barrels of rotten firuits and vegetables, dirty cans, and other refuse brought to the surface from the eellar onee each year at the time given over to "spring eleaning." 'The perfectìy kept house knows no eleaning scasons.

\section{SCHOOLS.}

Schools, even more than labitations, require the best of situations with reference to light and air. Windows should be large and numerous, and, according to the estimates of different authorities, their com- 
bined area should equal from a tenth to a fourth of the total floor area. In the arrangement of school furniture, the main consideration lies in the direction of the light. 'The desks are placed best so that the light comes from the left of the pupils ; coming from the right, it casts annoying shadows of pen or pencil in exercises requiring writing; crosslighting may eause still greater annoyance by casting double shadows. Iight from the front is execedingly trying, as may readily be appreciated by attempting to read a clock placed between two windows; from behind, it casts shadows of the body upon the work on the desk.

Cloak rooms should be spacious and well ventilated, and provided with anple hanging facilities permitting sufficient space between the individual garments.

Water-closets and urinals demand more than usual care, for children are prone to carelessness in their use; and since they are commonly placed in the basement, they are very likely, if not kept in scrupulously clean condition, to pollute the air of the rooms above.

School Furniture.-School furniture is well known to be one of the most important influences in the development of lateral curvature, and much careful study has been pursued in improving its construction. Desks and chairs should not be supplied with reference to age, but according to the size of children, and should be adjustable to each child. Common faults of chairs include improper shape of back, improper height, too great depth or breadth of seat, too much slope from front to back, and improper horizontal distance from the desk. Common faults of desks include insufficient or too great height, and improper slope of the surface.

Chairs should be of such a height that when the leg and thigh form a right angle the foot shall be squarely on the floor. If too high, the child eannot touch the floor, and fiuls to obtain the needed assistance from the fect and legs for the maintenance of an upright position; if too low, the position is cramped and awkward and the child is forced to extend the legs in one direction or another, and to contort the body accordingly. The seat should be sufficiently wide to support both thighs comfortably, but not so wide as to permit the assumption of bad postures in which the back is not well supported. It should not be too deep from front to back, since then proper attitude is impossible. It should slope very slightly from front to back, or be made slightly concave, in order that the tendency to slip forward may be counteracted. 'The back should be curved forward, so as to support the child's back, and to be comfortable in whatever legitimate attitude he may assume, for he requires changes in position for the relief of downward pressure and strain of muscle and ligaments, since any attitude long maintained results in fatigue. With chairs of the best form of construction, faulty attitudes are less eomfortable than proper ones.

Desks should be of such a height that the forearms of the child may be rested without causing, on the one hand, stooping, or, on the other, raising of the shoulder and curving the spine. If too high for the 
child, the work is brought too near, and eanses straining of the eyes. The top should have a proper slope downward of from ten to twenty degrees, and its edge shonkl project slightly over the forward erlge of the chair, so that the body and head may not be inclined forward too far.

Proper height of seats and desks and correct horizontal distance between the two are attained by the adoption of adjustable furniture, of which there are many varieties.

Blackboards should be dull black, and never shiny, for if they are shiny they reflect light, and what is written thereon is difficult to read from eertain points in the room. They should be kept well eleaned, in order that the contrast with the ehalk shall be sharp. The chalk should be white or yellow; blue, green, and red ehalk marks are much more difficult to read. Blackboards should never be placed between windows, on account of glare. Copying from blackboards is very trying to the eyes, on account of the constant necessary change of focus.

\section{Section 2. VENTILATION AND HEATING.}

We have seen how necessary it is to life that the $\mathrm{CO}_{2}$ given off by the blood in the lungs to the inspired air shall be diselarged continuously from the body, and we know that whatever other effects the impurities of vitiated air may produce, the effect of undue $\mathrm{CO}_{2}$ in the air is to interfere with the function of respiration. Therefore, it follows that the air which we breathe should be as free as possible from the impurities which we continually discharge into it, and that this condition can be obtained only by constant dilution of them by a constint supply of fresh air. In the open air, this dilution goes on without artificial assistance and requires no consideration; but in confined spaces, we have to a certain extent a reproduction of the conditions that obtain in the lung; namely, the presence of a volume of vitiated air, separated from the purer surrounding air, and requiring to be discharged and replaced. In other words, the air in the first eonfined space, the lung, is discharged into the sceond confined space, the room, and thence must be removed to the ontside and replaced ly an equal amonnt of normal air. The eonstant dilution and removil of impurities due to the necessities of life, so that their amount shall be so small as to be harmless, are the function of ventilation, which may be regarded as the respiration of a building.

It is, of course, not to be expected that the air of an inhabited room can under the usual conditions be maintained in a state of purity like that of the ontcloor air, even though but one candle or one person be present to exchange earbon dioxide and water for oxygen, but the impurities can be reduced to a minimum by the introduction of a proper amount of fresh air. What shall be considered a propere amount of continuous air supply depends upon what we adopt as a limit of permissible impurity, measured by the amount of $\mathrm{C}^{\left(\mathrm{C}_{2}\right.}$ present. 
For the maintenance of a fair degree of vigor and stability through proper oxidation of the blood and dilution of the effete matters discharged, and for the maintenance of the fullest and most perfeet funetional activity, one requires respectively about 30 and 50 cubic feet of air per minute. Less than 30 will inevitably produce impaired vitality ; more than 50 can be productive of no gain in improvement, so far as the effects of the ordinary vitiating matters are concerned. At the latter rate, then, an hourly supply of 3,000 eubic feet is neeessary for the proper dilution of the respired air of each individual present in a confined spaee. Thus, a room of 3,000 eubic feet capacity, inhabited by one person, should receive its full eapacity of fresh air once every hour. But this renewal should be a continuous process, so as to prevent the accumulation of impurities which would occur if the air were replaced simply in bulk by an hourly aëration by opening windows for the requisite few minutes. Nor should it be supposed that even with constant fresh supply the air of the room can have the same composition as that which enters from without, for the impurities of each respiration are not renoved in separate, distinct lots, but are mingled in the general bulk. If the occupant's head were in a conduit bringing the constant supply of fresh air and earrying away the products of respiration, no such amount of air would be necessary, and no contamination of the general supply would oceur. Under ordinary eircumstances, with an hourly supply of 3,000 eubie feet per eapita, the amount of $\mathrm{CO}_{2}$ will not range above 6 or 7 volumes in 10,000 , and any system of ventilation that will keep it down to this may be ealled good.

Other impurities than those of respiration are to be considered in all questions of ventilation. The influence of burning illuminating material on the composition of air is very great, both as to the consumption of oxygen and the production of $\mathrm{CO}_{2}$ and other impurities, and it is not insignificant in its relation to the temperature. The impurities from 1 cubie foot of ordinary illuminating gas are such in amount as to require, according to various estimates, from 500 to 1,800 cubic feet of air for their proper dilution. They include not only carbon dioxide and water, but carbon monoxide, sulphur acids, nitrogen acids, marsh gas, ammonia compounds, unconsumed carbon, and other matters. Different forms of burners consume different amounts of gas to produce the same illumination; ordinarily from 3 to 6 cubic feet are used per hour, requiring 1,500 to 10,000 cubic feet of air-supply for proper dilution of the impurities produced by each burner. Therefore, on both hygrenic and economic grounds, the burner which produces the maximum of light from the minimum of gas is the best for use, it being understood that a given volume of gas will yield the same amount of impurities, whatever the burner employed.

The impurities from candles and lamps are less in number and variety, but, measured by their comparative illuminating power, they are larger in amount than from gas. For example, the combustion of 
an amount of candle or kerosene oil necessary to produce the same intensity of light as 1 cubie foot of gas will produce from 40 to 160 per cent. more impurities, and requires, therefore, proportionately more air for their proper dilution.

The subject of ventilation, involving, as it does, the continuous introduction of pure air to displace that which has become vitiated by whatever cause or heated to such a degree as to be inconsistent with comfort; having to deal with buildings and rooms of various sizes, designed for different uses; and, as it is chiefly in the colder months that its importanee is greatest, being intimately connected with the problems and cost of heating, is a very complex one which will not permit the adoption of inflexible rules applicable to all cases.

\section{Amount of Space Required for Good Ventilation.}

If it be agreed that for the most perfect results an adult requires an hourly supply of 3,000 eubic feet for the removal of his own effete matters, to say nothing of the accessory impurity dependent upon illumination, the next question is as to the amount of eubic space necessary per eapita, that is to say, through how small a space that amount of air ean be drawn hourly without disagreeably perceptible dranghts. The sensation of draught is governed very largely by the temperature of the moving air, a cold slowly moving current being more perceptible than a warm one moving at a greater rate of speed. Draughts which are prodnetive of discomfort are more dangerous than the ordinary vitiation of the air, and, therefore, eomplete ventilation with dranghts is worse than partial ventilation without draughts.

It has been shown by Pettenkofer that, with the aid of delicate apparatus and mechanical power, about 2,500 cubic feet can be pasied without draughts through a space of 424 cubic feet in an hour; that is to say, through a room 8 feet square and 6.5 high, the air can be renewed six times.

The minimum space within which one ean receive, under artificial conditions, six eomplete changes of air in one hour is, therefore, 424 cubic feet; but in order to get 3,000 cubic feet in one hour, the air would have to be ehanged seven times, and so the required minimum space would be 500 eubic feet. In larese spaces, however, it is possible to obtain more frequent ehanges without danger from dranghts. Thus, in a hall 40 by 20 by 15 feet, 40 per'sons may be supplied with 3,000 cubic feet each per hour, and each one will have 300 eubic feet of air space. Therefore, in dealing with large spaces, we may assume 300 cubie feet per eapita rather than 500.

In the ventilation of small spaces, there is, in addition to the possibility and danger of dranghts, the grave difficulty that the inlets and outlets are necessarily so near together that much of the air will pass directly from the one to the other without having mingled with the 
main body of air, and without, therefore, doing the slightest service in diluting the inpurities present. In large air spaces, this objection does not apply with equal force, for the opportunity for diffusion is greater, the larger the space, although, of course, here, too, the inlets and outlets may be so placed as to fivor the formation of direet eurrents.

In the ventilation of large spaces in which large numbers of people gather, as ehurehes, theatres, schools, and lecture-rooms, we are at once confronted by the fact that 300 cubie feet of space is a more liberal per capita allowinee than is often practicable, and that this space is incompatible with a draughtless ventilation by the necessary air volume. If; then, the question be asked, how to provide the neeessary amount, there is but one answer; namely, that it cannot be done. Fortunately, however, the danger from impure air is proportionate to the length of time of exposure, an oceasional short time spent in a crowded room or public eonveyance filled with bad air being less harmful than prolonged and habitual oceupancy of a room in which the air is less vitiated, but yet not good.

In general, it may be said that the importance of ventilation varies with the particular air spaces; those which are used only at intervals and for short periods have much less need of it than those which are used uninterruptedly; those which are not erowded demand less than those that are; those used only for the moment need no eonsideration whatever, the natural forees at work at all times being sufficient for their needs.

To insist upon thorough ventilation of every part of a house at all times, as most amateur hygienists do, is to demand a needless waste of energy and money, for except in the warm months when the windows and doors are left freely open for the sake not alone of ventilation, but of general comfort, ventilation goes hand in hand with heating and divides the expense.

Nor can one suceessfully insist upon any rule that each person must have at least 1,000 eubic feet of air space with renewal of the contained air once in twenty minutes, for to do so is to urge in the case of the poor of large cities an impossibility, since space is costly, and, with ventilation to the proper extent, is beyond their means.

\section{Natural Forces in Ventilation.}

Before proceeding to the subject of systems of ventilation, we must consider the natural forces which are at work in the presence or absence of all schemes and systems. These forees are diffusion and gravity.

Diffusion and Gravity.- The rate at which gases diffuse is by no means the same for all, the lighter diffusing much more rapidly than the heavier. In fact, the rate varies inversely as the square roots of their densities. The province of diffusion in ventilation is limited to bringing the air to a condition of more or less complete 
homogeneity by causing the gaseous matters to become distributed throughont the unass; but in an inhabited room it can do but little toward kecping the air at its normal eomposition. By reason of the law governing the rate of diffusion, there must of necessity be a constant, though slow, removal of gaseous impurity into the cxternal air, for wherever two gases are brought into contact, diffusion will occur, whether the meeting place be large spaces, as rooms, or small spaces, as pores in the plastering, bricks, mortar, stone or other material which forms the boundaries of that room. 'This force is, however, very inadequate, and can be of service only as an assistant to another. Moreover, it can affect only gaseons and not suspended matters.

Of vast importance, however, is the other forec, that of gravity. Equal volumes of air at the same temperature and under the same pressure will have the same specific gravity; if the temperature of one of them be raised, it expands a definite amount for each degrec, and thus has less specific gravity than the other the more it is heated. Being surrounded by air which is heavier than itself, it rises, or, more properdy, is forced upward by the heavier air, which deseends to oceupy its place in the same way that a volume of light oil in a cylinder is foreed upward when water is poured upon it. If, on the other hand, it is cooled, its volume contracts, its specific gravity is increased, and it siuks downward through the warmer lighter air below it. In this way, differences in temperature cause constant movements in bodies of air, and currents are established. In an inhabited room this force is always at work, for there must necessarily be some souree of heat, even though it be only the body of the occrpant. The air in eontact witl the body becomes heated, and is then displaced by the colder air about it; this in its turn is suljected to the same influences, and the whole of the contained air rises in temperature and is correspondingly expanded. As it becomes lighter than the surrounding air, the latter forces itself in and the original air out throngh all the available openings, and thus a certain amount of rentilation is aceomplished.

Under the ordinary conditions of ocenpancy of a house or room, we have additional sourees of heat in the combustion of fuel and illuminating materials, and no matter how imperfoct the applied system of ventilation may be, and in spite of all efforts to exchude the external air, a very considerable amount of interchange of air is inevitable. It is only in a chamber that is to all intents and purposes hermetically sealed that no ventilation will ocenr when there is a difforence between the internal and external temperatures. Heated air will aseape through flues, through cracks around windows and doors, between the boards of the floors and of the general structure, and even through the interstices of mmpainted plastering and mortar, and thromgh the pores of brieks. That a large volume of air will pass through eracks, needs no demonstration; the passage of air through bricks, plaster, and mor- 
tar may easily be shown. If to the opposite sides of a brick, we fasten by means of sealing wax two ordinary glass funnels, and then smear its entire exposed surface with a liberal coating of the same material, all of the external pores exeepting those within the spaces covered by the funnels are made impervious to air. If now we connect by means of a rubber tube the funnel on one side with a bottle in which air can be compressed by means of water pressure, and by the same means the

FIG. 42.

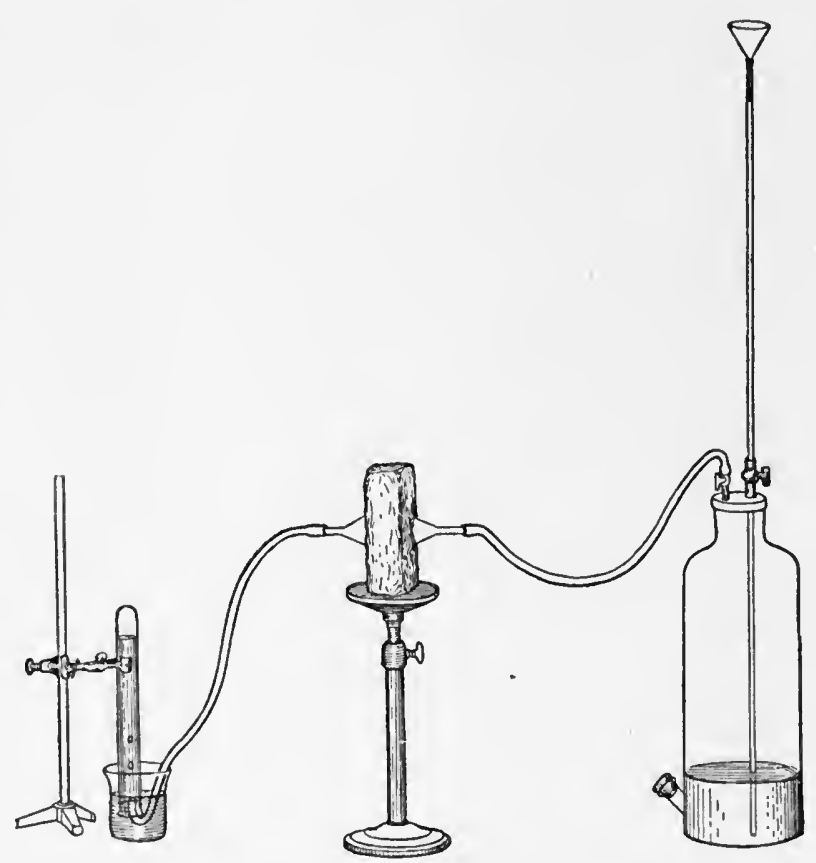

Apparatus for demonstrating the permeability of bricks, ete., to air.

other funnel with an inverted tesi-tube filled with water, and apply pressure, the passage of air through the pores of the brick will be manifested in a few minutes by the escape of bubbles from the outlet tube upward through the water. (See Fig. 42.)

The passage of air through plastered walls is much impeded by wall paper, and may be totally prevented by oil paint and moisture.

Numerous experiments have proved that with varying differences between the internal and external temperatures, the air of a room or building will be renewed partly, wholly, or repeatedly every hour, even when efforts are made to prevent as far as possible the entrance of the outside air. The results vary with the difference in conditions, the highest effects being produced when the temperature differences are wide, the opportunities for leakage great, and the external air in 
active motion. With perfect calm and equal temperature, the result will be nil.

Perflation and Aspiration.-Inequalities in outside temperatures give rise to the larger eurrents of air which we know as winds. These have a very great influence on ventilation both by their perflating action and by aspiration. The highest results of perflation are those obtained when obstacles to the free admission and exit of wind are removed, as, for instance, by opening windows in its path. The quiekness and frequency of renewal of contained air by this means will necessarily depend

FIG. 43.

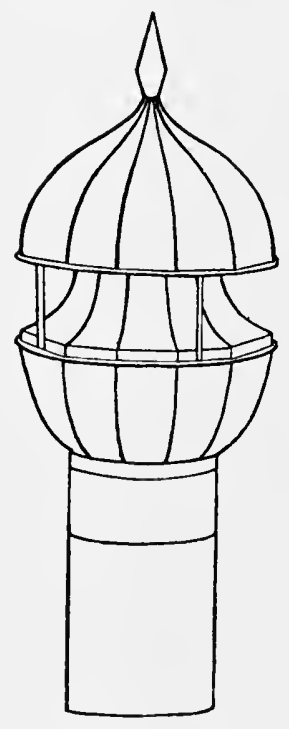

Common forms of stationary ventilating cowls.
FIG. 44.

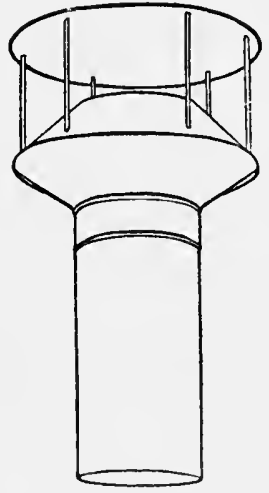

FI(s. 45.

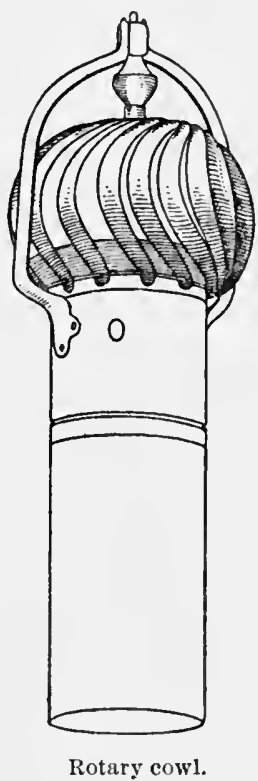

upon the size of the openings and the velocity and direction of the wind. The least effeets are produced, whatever the velocity and direetion, when the obstacles to entrance are greatest.

The aspirating influence of wind is shown by the upward currents produeed in flues when the internal and external temperatures are equal. A current of air, moving swiftly aeross the outlet of a flue, has the same effect on the contents of the flue as that of a common hand atomizer has on the contents of the tube. The air in the upper part is carried along mechanieally, a partial vacum is formed, and that which is below rises to take its place, and is in turn carried away. In the case of the flue, air from below is constantly drawn up and dissipated; in the ease of the atomizer, the liquid into which the tube dips is lifted and blown into spray. This influence is utilized and assisted by various forms of cowls placed over outlet flues; some of these, 
however, although they seem to be an aid, are really a hindrance to the outflow, as may casily be demonstrated.

In Figs. 43 and 44 are shown forms of cowls which offer some assistance to the aspiratory influence of winds, and in Fig. 45 is shown another very popular kind, the rotary cowl, which offers an obstruction to the passage of air. As the wind causes the top to revolve, the impression is made that work is being performed ; that in its revolutions it is creating a suction which canses an upward current of air. As a matter of fact, however, it is doing no such work, but is, on the contrary, interposing an obstacle to the passage of air. This may easily be demonstrated by measuring by means of an anemometer the amount

\section{FIG. 46.}

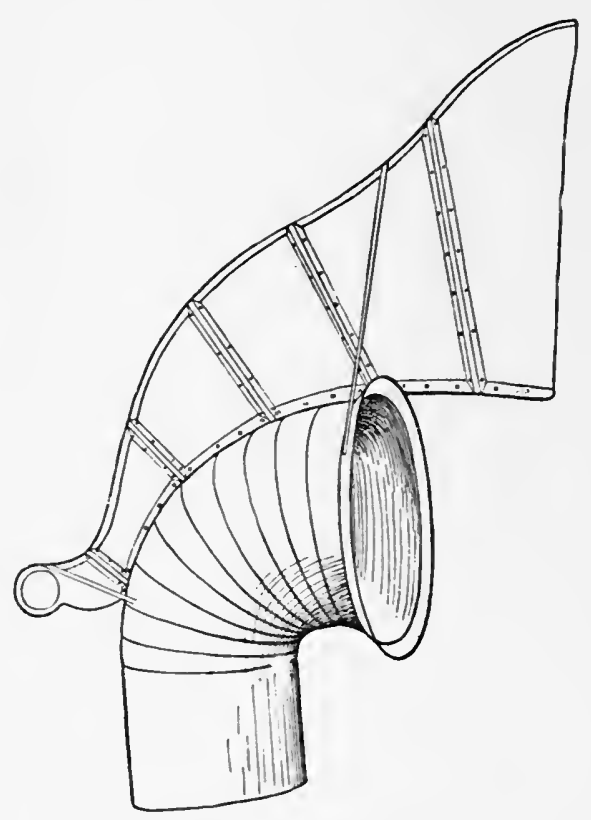

Aspirating cowl with vane.

of air discharged through the flue during a given period while the revolving top is in place, and again during an equal period while it is removed. The difference between the results obtained will invariably be in favor of the period during which the cowl is absent.

Other forms of cowls, constructed so that their outlets are turned by means of a vane away from the wind, are useful in assisting aspiration. Such a form is shown in Fig. 46. By reversing the position of the vane, the month of the cowl is turned toward the wind so that the flue is converted into an inlet for fresh air. 


\section{Natural Ventilation.}

Ventilation that proceeds from the operation of natural forces is known as "natural ventilation." For the attainment of the largest results, these forces must be assisted to the extent of removal of ohstaeles to their action $\rightarrow$ firr as may be advisable. It is not well to depend upon the ehance cracks and upon the migration of air through the pores of building materials, but necessary openings, both inlets and outlets, should be provided. 'The greater the obstacles to the eseape of heated air, the less the opportunity for successfinl natural veintiation.

The extreme of obstruetion to the eseape of contained air may be illustrated by an hermetically sealed metallic box or by a closed glass bottle. Suppose we provide one small opening in the side of the box or in the stopper of the bottle to act as an outlet and inlet, and observe the result. According as the contained air is warmed or cooled, the opening will aet as an ontlet or as an inlet, but only to a limited extent. The expansion due to heating will cause the escape of a portion of the contents ; the contraction due to cooling will eause the indrawing of some of the outer air; but in either case, the movement is all one way, and there is no real interehange. Suppose, however, two openings are supplied; then one may act as an outlet, the other as an inlet, and a constant inward and outward current may be maintaineel.

The more tightly fitting we make our windows and doors, and the more impervious to air we make our walls by means of paint and sheathing paper, the more do we oppose natural ventilation. On the other hand, the intelligent placing of inlets and outlets furthers the object to be achieved.

In addition to permanently installed inlet and ontlet flues, temporary openings may be ntilized whenever desirable. The most arailable of these is the opened window, which may be utilized so as to avoid too voluminous exchange and unbearable dranghts. The area of the opening may be very simply regulated, and the air may be deflected upward or the eurrent may be broken up by the interposition of fine wire ganze, flannel, or other pervious materiai.

A very eommon plan is to place a board lengthwise moter the lower sash, so as to fill completely the opening made by raising the window, and thus establish an inlet or ontlet where the sashes overlap earch other, for the barrier to the movement of air, formed by the juxtaposition of the lower border of the upper sash and the upper border of the lower one, no longer exists, and the entering current, moreover, is given an upward direetion. Instead of a board, a frame, over which a diaphragm of flannel is fastened, may be used. This arongement is pervious to air but impervions to dirt, which, therefore, is filtered out. Movable panes, either slinling or swinging by the side or end, are frequently employed, especially in donble winkows. There are also numerous patented deviens for window rentilition, all designed with the islea of dividing or deflecting the current of aturtted air. 
As has been remarked above, the most important foree in natural ventilation is that dependent upon unequal temperatures of bodies of air ; in a perfect ealm and with equal temperatures, natural ventilation would have to depend wholly on the force of diffusion.

The enormous influence exerted by the heating and lighting of a building or room on its ventilation becomes, then, self-evident, but it is not simply as a motive force that the relation between heat and ventilation is so close and important, for the incoming air must be raised to an agreeable temperature in order that the space may be habitable. Thus, a very large share of the cost of heating is ehargeable to ventilation, whatever the system of ventilation be. In the matter of expense, the amount of leakage through cracks and other small openings is, in a certain class of eases, of very great importance. In our dwellings, it is important that the interchange of air shall proceed continuously in the inhabited parts, but in buildings which are used only by day, and perhaps for only a few hours daily (schools, ete.), it is not essential that the air shall be renewed constantly at other times; and here it is wise to obstruct the leakage as much as possible by perfect construction and by dampers. in the fiues, so that waste of heat, fuel, and money may be prevented.

For the promotion of the process of natural ventilation, a number of "systems" have been devised, many of which can be productive of no results other than incomes for their promoters. As a rule, most of those noticed in works of this character are either ill-adapted to the conditions of our climate or incompatible with our methods of building, and will, therefore, not be considered here.

The only system of natural ventilation worthy of advocacy is that which provides proper inlets and outlets and a suitable means of heating.

Inlets and Outlets.-As to the size, location, and number of inlets and outlets, no hard-and-fast rules can be applied for all cases, since the conditions are widely varying, and many different circumstances have to be taken into aecount. But gencral rules may be laid down.

If several inlets are to be provided in a room, it is essential that they should be distributed in such a manner as to insure a thorough blending of the admitted air. They should not be so placed, with reference to outlets, as to favor the forming of direct eurrents between them, whereby a large proportion of the inflowing air is discharged without having fulfilled its function-al not unusual condition, which illustrates that the amount of air admitted is not by any means a measure of thoronghness of ventilation. Their location is not such an important matter as the placing of the outlets, but, in general, an inlet is placed hest on an inner wall where it shall be most nearly central in relation to the outside walls.

With reference to the floor, if the ineoming air is heated, inlets may be placed high or low; lout if it is admitted cold, they should be at a higher level than the heads of the oceupants, and provided 
with arrangements for deflecting the current toward the ceiling. This may be accomplished by causing the eurrent to impinge upon a surface slanting upward. The results of this deflection are that the fresh air becomes mixed with the warmer air, and that more time is required for it to reach the lower parts of the room, when it will have become sufficiently warmed not to eause discomfort. The interposition of the deflecting surface also spreads the current rudially and reduces its velocity. The incoming air becomes mingled with the general supply and joins the currents which are constantly in motion. That which eomes in contact with cooling surfaces, such as windows and outside walls, is cooled, and, therefore, falls toward the floor, and that which takes its place as it falls is cooled in its turn and follows after, so that eurrents are established, which tend to keep the whole bulk in more or less rapid motion. As these currents reach the floor, their natural trend is across that surface toward the inner warmer walls, where they become heated and are inclined toward the ceiling, reaching which, they are pushed by the force behind and drawn by the one in front toward the outer walls and windows again. In the meantime, some of the air is escaping through outlets, and diffusion of the impurities is proceeding, so that a more or less even character is brought about throughout the air of the room.

Outlets may be placed at the level of the floor, in the ceiling, or at any height in the walls, aceording to the conditions of each individual case. If the incoming air is not heated, the outlets should be placed high up, for where only unheated air is admitted, the warmest air must be the oldest and its location will be in the upper air space. If, on the other hand, the air is heated, the outlets may be anywhere so far as height is concerned, but there is some choice in locations with respect to inner and outer walls. Outlets placed beneath windows or near outer walls will withdraw the falling currents of the only recently introduced air before it has had an opportunity to become well mixed by passage across the floor to the other side, and before it has in any proper degree fulfilled its functions; but if its passage through the lower strata is not interrupted in this manner, it is enabled to mix with and dilute the impurities of the air already vitiated, and thus effect a large measure of work, and so when it reaches the other (inner) side and finds an outlet for its escape, there is no objection to its withdrawal, and, indeed, its removal then is highly desirable. Hence, and for another reason as will appear, outlets should be plaed in inner walls rather than near or in outer eooler ones, and near the floor where they may intereept the air before it may again become a part of the ceiling currents.

If but one outlet is to be provided, it should be placed with reference to the most even movement of the current over the whole area, having in mind the fact that the air movement toward it is convergent, and the direct reverse of the flow from the deflecting and diffusing surface at the inlet.

As to size, it may be said, in general, that a single outlet, or the 
aggregate if there be more than one, should be of such size as to insure the possibility of removal of such an hourly air supply as the space is likely to require under the ordinary conditions of its usual occupaney ; that it should not materially exceed this limit; and that the final velocity of the outflowing current should not be productive of the sensation of disagreeable draughtiness.

Is to the shape of inlets and outlets, it is self-evident that, with equal areas, that which has the smallest periphery will offer the least frictional resistance, and is, therefore, best adapted. Thus, a circle enclosing an area equal to a square foot has a smaller periphery than a square enclosing the same area, and a square has a smaller one than in oblong rectangle. Take, for instance, a square foot; it may be insluded within boundaries:

\begin{tabular}{|c|c|c|c|}
\hline \multirow{2}{*}{\multicolumn{4}{|c|}{ iches, a }} \\
\hline & 9 & & \\
\hline $8>$ & 8 & " & \\
\hline & 6 & " & \\
\hline $36 x$ & 4 & $"$ & oblong rectangles. \\
\hline $72 \times$ & $\stackrel{\circ}{2}$ & “ & \\
\hline $144 \hat{x}$ & 1 & " & \\
\hline
\end{tabular}

With these boundaries, the periphery ranges from 4 feet (the smallest) to 24 feet 2 inches. The frictional resistance will, therefore, be greater in proportion as the shape varies from the circle and square.

The shafts eommunicating with the inlets and outlets should be so disposed in the general plan as to offer the least resistance to the inflow and outflow of air. Unless they are heated artificially, inlet flues should not be loeated in onter walls, on account of the likelihood of the formation of down draughts due to cooling of the air column. Their inner surface should be as smooth as possible, in order to bring to a minimum the loss of movement due to friction, and they should be eylindrical, if possible, for the same reason. They should be as free as possible from angles, and especially right angles, because of the very scrious loss of motion which these cause, each right angle diminishing the current about half; thus, after passing one right angle, the flow would be half; after a seeond angle, the half would be reducerl to a quarter, and after a third, to an eighth. The neglect to take into account the loss of flow by friction, bends, and angles is responsible for the failure of many a plan for ventilation.

What has been said concerning the impossibility of making general rules for the sizes of inlets and outlets applies with equal force to the fixing of sizes of flues, for these depend upon the many and varied conditions which, even under the best favoring cireumstances, affect the rite of flow.

In planning inlet and outlet shafts, it is to be borne in mind that something more is necessary for their proper working than the dictum that this one is for fresh air and that one for foul, for natural forces have no respect for mere names and plans, and the current in a flue will be upward or downward, inward or outward aceording to natural 
laws. Outlet shafts may become eonsiderably cooled by low external temperatures; they may be invaded by rain and snow, the evaporation of which eauses cooling and, therefore, increase in gravity; or there may be an insufficiency of inlet air, so that a partial vaenum is formed by the eurrent of one large ontlet flue, which thereby eauses a reversal of that of a smaller one, so that one flue draws against another. It is from any one of these causes that a chimney may fail to discharge smoke upward-a circumstance noticed more often in summer than in winter.

\section{Mechanical Ventilation.}

Mechanical ventilation consists in the propulsion or extraction of air by means of blowers or exhaust fans driven by steam or electricity. That in which the air is propelled by the action of a blower is known as the "plenum" system, and the other, in which it is withdrawn by an exhaust fan, is known as the "vacuum" system.

In the plenum system, the air is drawn into a box, in which the revolving blades of a fin are located, and it is then driven into a central conduit, and from there through appropriate shafts to the spaees for whieh it is intended. When it is desired, the air may be received from or blown first into a chamber where it may be heated. The air supply may be regulated very easily by diminishing or inereasing the number of revolutions per minute, but it should always be in slight excess of the real need, in order to produce a slight outward pressure, which will prevent inward leakage.

In the vacumm system, the ail is extracted from the various rooms through pipes leading to a eentral shaft, where it is drawn into the fan and discharged outwardly. This system has among other disadvantages that of great inequalities in draught in the different discharge tubes, and that the vacuum condition fivors the inward leakage of cold air through cracks, walls, and about windows, and tends to cause cold floors and disagreeable small draughts about windows. In eonsequence, more fuel is needed for the maintenance of a proper temperature, and the system is, therefore, a source of greater expense.

The advantages of mechanical ventilation lie in the fact that the olject somght is attainable in any and all conditions and variations of weather, and that less space is required for shatts than in the case of natural methods.

Mechanical ventilation on a comparatively small scale is employed commonly in erowded offiees and other spaces by mons of small extrateting fins r'un by the airl of electricity (comnection being made with the electrie light system) in specially provided loeations connected with outlet flues, or directly in a space made by removing window panes.

\section{Artificial Heating in Its Relations to Ventilation.}

First, for the proper understanding of the suljoet of heating in its bearings on ventilation, it is necessaly to consider the different ways 
in which heat is imparted. These are three in number : radiation, conduction, and convection.

Radiation.-Radiant heat passes from its source through the air to bodies by which it may be absorbed, transmitted, or reflected. Air, being "transparent" to heat, is not materially affected, and the drier the air, the less heat it will retain. It passes directly from its source in waves, like the waves of light, to the object upon which it falls, and the amount reflected or absorbed varies with the nature of the object, its color, the character of its surface, and its temperature. Its intensity varies inversely as the square of the distance between the souree and the object upon which it falls; thus, the amount received by two objects 1 and 5 feet respectively distant, will be inversely as 1 and 25 ; at 1 and 10 feet, inversely as 1 and 100 ; at 5 and 10 feet, inversely as 25 and 100 ; that is, the nearer will receive in the first instance 25 times; in the second, 100 times; and in the third, 4 times as much as the farther object.

As an instance of radiant heat, we may take that which proceeds from an open fire. The heat passes in direct lines through the air to the walls, floor, ceiling, furniture, and other objects in its path, and these absorb some and reflect the rest to other parts of the room. It directly warms only that surface of an object that is directly opposed to it. The objects by which it is opposed then disseminate it in two ways: by conduction and convection.

Conduction.-Conducted heat is that which passes from one particle of matter to another in direct eontact; that is, from one particle to another of the same object, or from one object to another which it touches. Conduction acts through all solid substanees, but by no means to the same extent, some being good, some indifferent, and others bad conductors. The best conductors are metals, and these vary within very wide limits; copper, for instance, is a very much better conductor than iron or zinc. Wood is a poor conductor, and woven and felted materials and asbestos are very poor. Through liquids and gases, heat is conducted to only a very limited extent, but there is no substance known that is absolutely non-conducting.

Good conductors permit a rapid flow of heat through their substance; poor ones, only a slow transmission. Good conductors relinquish their heat rapidly to their colder surroundings, whether air or anything else, and withdraw heat from bodies which are warmer than themselves.

Convection.- Convection is the process by which heat is communicated to gases and liquids, acting through their mobility, which permits those parts that have been expanded by reason of beconing heated to be displaced upward by cooler portions, which, in their turn, receiving heat, give way to others, until the whole mass hecomes raised in temperiture by continued application of heat and consequent maintenance of circulation.

Fvery warm body with which air eomes in contact communicates its heat to those portions in its immediate vicinity ; these expand and are forced onward by the cooler heavier parts nearest them ; these in their 
turn give way to others, and conveetion currents are established to such an extent that the air of a room takes on a very complicated state of activity.

Convection currents are established by every person in a room so long as the temperature is below that of the body. They are established by the warmer walls, floor, furniture, hot-water pipes, ste:m radiators, close stoves, and other warm objects, and in this way the air becomes heated. The air which enters rooms through shafts communieating with the air chambers of furnaces and "indirect radiation" apparatuses are convection currents in the largest sense. The direct rays of the sun, passing through windows and absorbed by the floor, walls, and other objects which they strike, also cause upward convection currents.

Methods of Warming.-The prineipal methods of heating houses and rooms are: 1. Open fires. 2. Stoves. 3. Furnaces. 4. Hotwater pipes. 5. Steam pipes. The method most applicable in any particular case will depend upon the size of the room and the number of rooms in the building. In general, it may be stated that the smaller the space, the more simple the method. For a single room, an open fire or a stove will be sufficient; for a small house, stoves or a furnace; for a large one, one or more furnaces or hot-water or steam apparatus; and for large buildings_office buildings, for instance_- "direct" or "indirect" steam.

1. Open Fires.-Practically the whole of the heat supplied by an open fire is radiant. If the fuel is held in a grate, there is, of course, a certain amount of conduction from the bars, and of eonvection eurrents in the air in its immediate vicinity. But this heat does not get out into the room, because it is immediately carried up the flue by the draught of the ehimney. The radiant heat is absorbed, reflected, and distributed in the manner already described, but reaches directly only those surfices which are opposed to its sonrec-which accounts for the saying that, in a cold room with an open fire, "one side roasts while the other freezes." Only a small part of the total heat of the fuel consumed is available for heating, sinee most of it-about seveneighths-is carried at once up the chimney. An open-fire stove, such as the old-fashioned "Franktin," which stands out in the room, and is connected with the flue by stove piping, vickls a large amount of its heat, sinee the material of its construction is heated by conduction and then gives it off to the air by convection.

Open fires cause the introduction and removal of large volumes of air, but these are by no means always well mixed with the whole mass of contained air. Nevertheless, a large measure of ventilation is accomplished, a certain amount of heat, perhaps sufficient for immediate needs, is given off, and there is also an nnmeasumble addition to the general eheerfulness. Ther may cause too much draught, and they are certainly not economical, but as aceessories to other heating methods they may be most usefill.

2. Stoves.-Close stoves have more direct results in heating and less 
in ventilating than the open fire, for more of the heat produced is available, and they discharge into the chimney only the air volumes that have passed through them. The materials used in their construction, iron, soapstone, brick and fireclay, conduct the heat and give it off to the air with varying rapidity ; cast iron yields it about as rapidly as it is received, soanstone and brick give it off only gradually, but for a longer period.

When east-iron becomes red hot, it may be decidedly objectionable for two reasons: first, that the organic dust particles in its immediate vicinity become charred and yield odors; and second, that it absorbs and transmits considerable carbon monoxide from burning coal. Stoves may be so arranged as to act not alone as heaters, but as ventilating apparatuses, and this fact is of very great value in the case of small school buildings in country districts. The stove, standing out in the

FIg. 47.

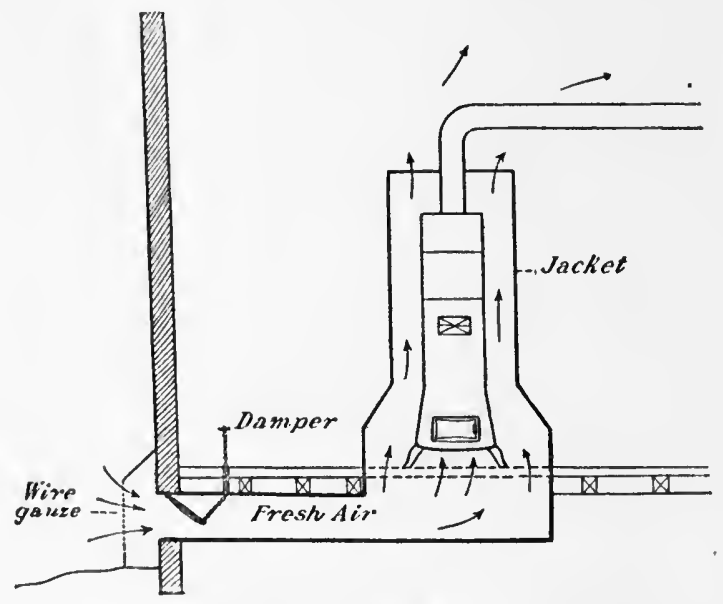

Jacketed ventilating stove.

room, may be surrounded by a cylindrical jacket from the floor upwarl, leaving a sufficient air space between the two. Through the floor within the enclosure, is an opening into an air duet communieating with the outdoor air. The heat of the stove is communicated to the air between the latter and the jacket and an upward current is formed, which draws upon the fresh-air conduit, so that a constant current of warmed pure air is thrown into the room. (See Fig. 47.) It goes without saying, that here, as elsewhere, the incoming air must be taken from points where its purity cannot be interfered with by local conditions.

Gas stoves and oil stoves have the advantage over others that they are more prompt in results, more casily controlled, and more quickly put out of use. They have the disadvantage, however, that the produets of their fuel combustion are discharged directly into the air of the room. In the case of the oil stove, this is not such a serious matter, 
since the perfeet combustion of good oil results in carbon dioxide and water; but with gas the products are more numerous and varied, and include some that are irritating and poisonous. With proper ventilation, however, in the ease of both, no harm will be done.

3. Furnaces.-Hot-air furnaces are not only of very great importance as heaters, but of enormous influence in ventilation. In their use, the cold outdoor air is brought in by a conduit, the "cold-air box," to a chamber in the upper part of the furnaec, above and surrounding the "dome," where it comes in eontact with the very hot surface and is heated by convection. Thence it passes upward through separate tin tubes to the several places for its diseharge. In a house which is unprovided with special inlet and outlet flues for ventilation-and most of our houses are so construeted-a furnace of ordinary heating capaeity performs an amount of ventilating work quite suffieient for all needs, and for which it rarely receives eredit. It discharges into the varions rooms a constant supply of warmed fresh air. Where and how it all escapes is a matter of seeondary interest and importance, for it gets out wherever it may find its way.

4. Hot-water Pipes.-Hot-water heating depends upon the cireulation of water by convection eurrents through a system of pipes which may extend all through a large-sized building. The water is heated in a boiler below and passes through a main, leading from the upper part thereof. As one portion of water comes in contact with the heating surface and expands, it is moved along, and the circulation becomes established just as with air. The "main" gives off branches where needed, and these at their extremities turn back and become "returns," which eventually connect with each other and form the "main return," which, conveying the eooled water, enters the boiler at its lowest point. The first part of this system may be compared with the arteries, and the "returns," with the veins of the body. Vents are provided for the escape of dissolved air liberated from the water, and "cut-offs" are inserted for the shutting out of any part of the system as desired. It is very necessary that air should not be allowed to accumulate in the pipes, since it will stop the flow. In low-pressure systems, a small cistern is provided to allow for the expansion of the water and to prevent its overflow. The hot-water system may be of either high or low pressure. With high pressure, the pipes are smaller and necessarily stronger, and the water is heated to a ensiderably higher temperature $\left(300^{\circ} \mathrm{F}.\right)$, and henee circulates more rapidly. With the low-pressure system, the water does not go much, if any, above $212^{\circ} \mathrm{F}$.

With the hot-water system of heating, the air is heated mainly by convection, though from polished pipes a certain amount of radiation oceurs. With high pressure, the air may easily be overheated.

5. Steam Pipes.-In steam heating, the system is very like that of hot-water heating, execpt that steam is the eireulating medium instead of water. With steam, and, indeel, with hot water, heat may be distributed by the "direet" or "indirect" motherls. In the "direct" method, the pipes are distributed within the spaee to be heated, and the 
air of each room is heated separately. In the "indireet" method, the heating surfaces are all concentrated in the basement, and are enclosed in galvanized iron conduits, which receive and conduct the air just as in the case of the hot-air furnace. The two methods, it will be noticed, vary widely in the matter of assisting ventilation; the direct brings in no air, but leats that which is at hand ; the indireet brings in large volumes of lieated fresh air, and thus insures change of air.

In conclusion, may be mentioned the considerable heating and eirculating influence of burning illuminating gas. By means of suitable outlets above the burners, gas may be made not only to discharge the products of its own combustion, but to send out large volumes of otherwise vitiated air as well. Nor is the heat of the sun so insignificant that it may be passed by without notice in the planning of systems of ventilation. Inasmuch as the difference in temperature of the outside air on the north and south sides of a house averages about 5, and may reach 10 , degrees $F$., just that amount of advantage may be gained by taking the air for ventilation from the warmer side. In gravity ventilation, the inlets should be where they may face the prevailing winds.

\section{Regulation of Temperature.}

In carrying out any scheme of efficient ventilation, it is necessary to guard against overheating, which may not be noticed until it becomes so marked that it eannot help attracting attention. When such is the case, the common practice is to cause a lowering of the temperature to the desired point as soon as possible by opening windows to admit the colder air. The consequence is the production of a distinetly cold atmosphere, more so than ordinarily is shown by the thermometer, which does not react very promptly to sudden ehanges. This produces chilly sensations which call for a return to the original condition. In the meantime, a lot of heat has been wasted and the foundation for a cold has, perhaps, been laid. If windows are left open in the upper storics, as often happens in overheated buildings, there are constant ontflow and waste of heated air, with a corresponding inflow of unwarmed air below, which requires the expenditure of additional finel in order that the lower stories shall be properly warmed. In overheated buildings, there is also the additional loss from outward leakage through all possible outlet channels.

To prevent waste of heat in properly heated buildings, we have recourse to donble glazing and double windows. Double glazing is aceomplished by fitting two panes into each space, instead of one, with a spaee of a quarter or a half inch between them. By this means, the loss of heat occurring throngh ordinary windows is reduced abont one-third, which means a saving of considerable fuel, since the loss of heat by conduction through glass windows is very considerable. Double windows are still more effieient as heat-savers. Here the outer window is made to fit as accurately and elosely as possible by 
the use of listing, and we have between the two windows a fairly deep space filled with air, which is a very poor conductor of heat. It is on the same principle that we use loosely woven woollen goods and furs, which hold within their meshes and between the hairs a large amount of this poor conductor. The loss of heat through walls is lessened when a similar air space exists within them; a solid wall will conduct a very large amount of heat and waste it, while the same amount of building material, or eonsiderably less, may be so disposed as to bring this loss down to a minimum.

Loss of heat is caused also by dampness of walls, for a continual evaporation goes on from their surface, and this requires heat and produces cooling. Every ounce of moisture so vaporized requires the consumption of extra fuel.

\section{Necessity of Providing Moisture.}

Concerning the need of insuring a normal amount of moisture in the air of heated buildings, there is more or less difference of opinion, but the weight of evidence from a medical standpoint and from our own sensations points to the advisability of introducing an amount of moisture sufficient to bring the relative humidity of the air to 50 or 55 per cent.

The lower the temperature of a body of air, the less the amount of moisture it can hold, and what would be saturation at a low temperature would be but a very low relative humidity at a high one. For instance, a volume of air at $0^{\circ} \mathrm{F}$., eontaining its fullest possible amount of aqueous vapor, admitted to the cold-air box of a furmace and then heated to $85^{\circ} \mathrm{F}$. before being conducted to the rooms of a house, will have at its new temperature but a very small relative humidity. It will be so much drier than any outside air, that that of the driest climate in the world will be moist in comparison. The great majority of U. S. Signal Service Stations have a mean relative humidity of 65 to 75 per cent.; only twenty-four show below 60 or over 80 , and the very lowest is in the hottest part of Arizona, where newspapers erack when handled, glued furniture falls apart, and the skin becomes hard and dry. At this place, Fort Yuma, the mean relative humidity is 35 per cent.

When ontdoor air is heated so as to maintain an even temperature of $70^{\circ} \mathrm{F}$., but with no addition of watery vapor, its capacity for absorbing moisture is very much increased, and it will take it up from all moist objects with which it comes in contact. It will take it from the skin, from the mucous membranes of the mouth, nose, and respiratory tract; from furniture made from wood which, in the process of kiln-drying, was never brought to such dryness; from the leather bindings of books, eausing them to erack and fall to pieces; and from plants, which, in consequence, wither and die. It thus causes more or less dryness of the skin, irritation of the throat, and cough. It causes also need of a higher temperature to give the sane sensation of warmth 
and comfort than is the ease with air containing a normal amount of moisture. It is on aceomnt of the disigreeable and destructive effeets of extreme dryness that water-holders are attached to furnaces and stoves so as to give moisture to the heated air. But even when attention is paid to keeping them full, which is not often, they are very inadequate for the purpose.

Air at $25^{\circ} \mathrm{F}$., saturated with moisture and then heated to $70^{\circ} \mathrm{F}$., would need more than 0.5 pint of water in every 1,000 eubic feet to give it a humidity of 65 per eent., and this is far in excess of the eapacity of the ordinary waterpot of the furnace, as is seen when we reekon what 0.5 pint per 1,000 cubic feet means in the course of a day.

Moisture may be imparted to the air by exposing pans or porous vessels of water to the heated current, or by means of the "humidifier," which exposes to the air passing throngh the register's a surface of cotton wicking communicating with the reservoir of water. (See Fig. 48.) With this device, Dr. H. J. Barnes, of Boston, reports

FIG. 48.

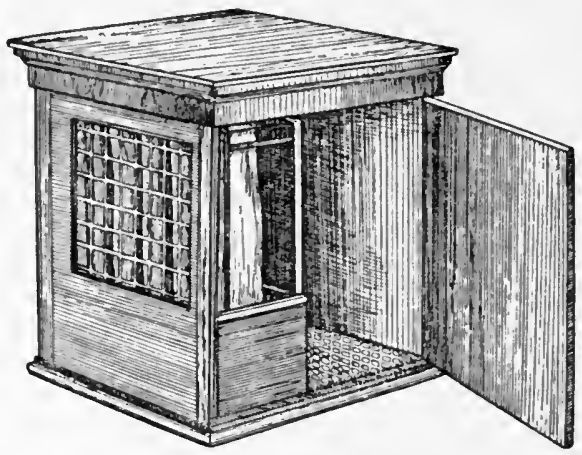

Humidifier.

that he is able to keep his office at 53 per cent. relative humidity by evaporating an average of 4.5 quarts of water per day. At the same time, he finds a temperature of $65^{\circ}$ to be perfectly comfortable where before he had required $70^{\circ}$ or $71^{\circ}$.

On a larger seale, water may be vaporized into the air in the form of steam from a boiler. In the building of the American Bell Telephone Co., in Boston, a building having a capacity of 450,000 cubie feet and a day-time population of more than 450 persons, the air, which is distributed by the mechanical system, is drawn into the building at the rate of 26,000 cubic feet per minute, heated to about $100^{\circ} \mathrm{F}$. in the stack room, and moistened so as to contain about 50 per cent. relative lumidity. For the production of this condition, no less than 675 gallons of water in the form of steam are given to the air in ten hour's, or about one and a half barrels per hour. Certain parts of the building which, before the adoption of this process, had 
been heated with some diffieulty, are now made more comfortable, and in the whole building 3 degrees less heat are required for the maintenance of an agreable temperature. According to Mr. C. J. H. Woodbury, ${ }^{1}$ under whose direction the plant was installed, "another feature indieating the greater comfort of the building was the absence in winter of the eonghing by those employed there, a cough of the bronehial kind or from the larynx, a congh which ends with a squeal, which is so prevalent in New England during the winter, especially in those employed in offices."

Filtration of Air.-Here may be given an instance of the benefit derived from filtering large volumes of air introduced into a building for purposes of ventilation. In the building above mentioned, the air is drawn into and through a system of large cotton bags 30 feet in length, in which all dirt and dust is retained. About a peek per month is separated in this way from the air, which is drawn not from the street level, but far above it. An analysis, chemical and microseopieal, made in April, 1897, showed 22.67 per eent. of organie and 77.33 of inorganic matter. The material consisted of all manner of animal, mineral, and vegetable substances ordinarily present in the dust of large cities.

\section{Determination of Rates of Ventilation.}

The estimation of the amount of air entering and leaving a room through inlet and outlet flues is a very simple matter, but the results may not be accepted as an indication of the efficiency of ventilation, since it so often happens that much of the effluent air has failed to perform its full duty in diluting the impurities arising from respiration and combustion. Nevertheless, such a deternination may yield important indications.

In order to ascertain the volume of air passing through an opening, whether inlet or outlet, it is necessary to know the area of the opening and the volocity of the current. The former is casily calenlated arithmetically; the latter can be found only by the nse of an anemometer, an instrument of very delieate construetion, which registers the distance travelled by a current of air in any period during which it is exposed.

A current of air, passing through an opening, has not the same velocity at all points of its cross-section. It moves in the same manner as a river-faster at its center, where it is least subject to the influence of frietion. Therefore, the velocity should be taken at different points, and the mean of the results acepted as its true rate of movement. 'The anemometer is held for' a given time, say half' a minnte, at a point at the periphery of the opening, and then moved along a short distance and held for an equal period, and so on, from point to point, until the whole area has fairly been traversed. "Tle reading of the instrument is then noted, and the distanee indieated is divided by the mumber of

1 'Transactions of the New England Cotton Manufactures' Association, Vol. 63. 
points where stops have been made. The quotient equals the distance travelled by the whole eurrent during the unit of time employed. It will be found most eommonly that the movement at the periphery is very slow, and that, as the center is approached, the velocity becomes greater and greater, the maximum being attained at the center. Knowing the average movement in feet or meters, the volume is caleulated by multiplying this by the area in square feet or square meters, the product being the volume in cubic feet or cubic meters passing during the unit of time. From this result, the volume per hour is easily made known.

Example.-The size of the opening is 2 by 3 feet; the area is, therefore, 6 square fect. The anemometer, held at twenty-four points for fifteen seconds each, registers 228 feet. The mean of this is 9.5 feet, and the current is moving, therefore, at the rate of 38 feet per minute. The eross-section of the current being 6 square feet, the volume discharged in a minute equals $6 \times 38$, or 228 cubic feet, and, in an hour, 13,680 cubic feet.

By determining the rate of discharge through all inlets and outlets in this manner, an idea is obtained of the amount of ventilation oceurring through means provided, but, as has been stated, not of its efficieney. The sum of the inlet discharge will almost never agree with that of the outlet, since much air enters and leaves a room through other openings. Knowing the eapacity of the room, we learn from the amount of inlet air the number of times the air of the room bas been replaced.

The full measure of ventilation and its efficiency may be determined very elosely by methods originated by Pettenkofer. One of these consists in first ereating an unusual degree of impurity either through respiration of a large number of persons, as, for instance, by children oceupying a schoolroom, or by burning a number of candles, or by other chemical processes, then, after taking a specimen of the air for analysis, keeping the room elosed for an hour or two. At the expiration of the allotted time, a second sample is taken, and from the results of the two analyses, the rate of ventilation is ascertained by means of Seidel's formula, which is as follows:

in which

$$
C=2.303 \mathrm{~m} \cdot \log \frac{p_{1}-a}{p_{2}-a}
$$

$C=$ amount of air which has entered.

2.303 is a constant.

$m=$ capacity of the room.

$p_{1}=$ amount of $\mathrm{CO}_{2}$ originally present.

$p_{2}=$ amount of $\mathrm{CO}_{2}$ at the end of the experiment.

$a=$ amount of $\mathrm{CO}_{2}$ in the external air.

EXAMPLF. - The air of a schoolroom of 500 cubic meters capacity, accommodating 34 children, contains at the end of the session $18.5 \mathrm{cc}$. of $\mathrm{CO}_{2}$ in 10,000 , or $0.00185: 1$. At the end of an hour, a second analysis shows 8.5 ce. of $\mathrm{CO}_{2}$ in 10,000 , or $0.00085: 1$. The outer air contains 3.5 ce. of $\mathrm{CO}_{2}$ in 10,000 , or $0.00035: 1$, 
Then

$$
\begin{aligned}
C & =2.303 \times 500 \times \log \frac{0.00185-0.00035}{0.00085-0.00035} \\
& =1151.5 \times \log \frac{0.0015}{0.0005} \\
& =1151.5 \times \log 3 \\
& =1151.5 \times 0.4771213 \\
& =549.4 \text { cubic meters of air in an hour. }
\end{aligned}
$$

Thus, the air of the room is renewed but once and a tenth per hour, and the result shows that the per eapita ventilation is about a fifth of what it should be.

The other method consists in imparting to the air of a room a continuous supply of earbon dioxide by means of burning eandles, and making periodical analyses of the eontained air. Candles of pure stearin, 1 gram of which yields 1.404 liters of the gas, are employed. A preliminary analysis of the air is made, and then a number of the eandles, the combined weight of which is noted, are placed about the roon and lighted. At stated intervals, the room is entered, and after the air has been well mixed by vigorous fanning, samples are taken for analysis. At the end of the experiment, the eandles are put out and reweighed, and from their loss in weight and the results of the analyses, the amount of ventilation is calculated by means of a most complicated formula devised by Hagenbach.

Other methods have been proposed by Recknagel, Petri, and others, but they present no advantages, and are, in general, so complicated that in the hands of other than expert physicists they are quite useless.

\section{Section 3. LIGHTING.}

Natural Lighting.-In natural lighting, the light enters the room direetly or by reflection through the windows, and is then reflected to different parts of the interior, which receive different amounts of light according to eireumstances. Thus, white and light-eolored walls, floors, and articles of furniture reflect and disperse the light, while dark walls, draperies, and other objects absorb it. Large rooms having but small window area and all rooms, however generonsly provided therewith, looking on narrow alleys or streets in whieh the opposite buildings are so high that the sky-angle is small, eannot be illuminated uniformly by diffused daylight without some assistance.

The means employed are exceelingly simple, and the diseovery of their utility for this purpose was due to ehance. In order to obstruct the view into factory workrooms from the outside, and to lessen the temptation to operatives to waste time in looking out, ribbed glase was introduced instead of ordinary glass for use in windows, and it was noticed that not only was the desired end attained, but that the light from the windows was projceted farther into the rooms, and to such an extent in some instances, that artificial lights, required before in the brightest part of the day, could be dispensed with. Attention being thus drawn to the great advantage and saving of expense, a num- 
ber of different kinds of glass with uneven surface have been placed upon the market and have come into very extensive use. The best of these, which is the most expensive, is known as "prismatic glass" from the fact that one surfice consists of a series of prisms running horizontally. The entering light, instead of falling directly to the floor, is

Fı. 49.

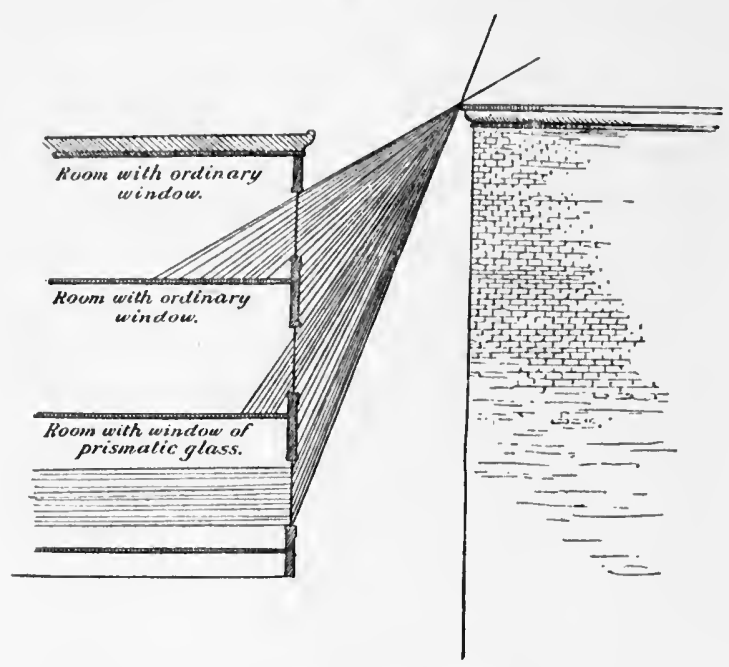

Action of prismatic glass in projecting light.

tipped up and projected toward the opposite sides of the room, as shown in Fig. 49. Vertieal section of a sheet of the glass is shown at $A$ in

Fra. 50 .

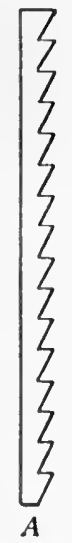

Fig. 50. By varying the angle of the prisms, the conditions obtaining in any situation can be met and light may be projected in any desired direction. Naturally, the prisms cannot be used indiscriminately, for a series adapted to light the entire lower part of the room with a certain sky angle might, when applied to another, throw the light toward the ceiling instead of to the parts where it is required. 'Therefore, to meet all conditions, the glass is made with a great range of angles, and the particular kind needed in any situation is determined by measurement. Where the sky angle is very small, canopies, hung at the proper angle above the windows, serve to throw inward a flood of light. The disadvantage of prismatic glass is its great cost.

Ribbed glass is very efficient and much less expensive. 'This is marle with $4,5,7,11$, and 12 Vertiral section of pris matic and ribbed glass.

ribs to the inch, and of different thickness and weight, since the fewer the ribs, the deeper they must be ent, and the thicker, therefore, the 
glass. Vertical section of a sheet of ribbed glass is shown at $B$ in Fig. 50 .

Artificial Lighting.-The methods of artificial illumination comprise electric lighting and those dependent upon the combustion of oils, gases, and hard fats. The oils employed are chiefly of mineral origin, but animal and regetable oils are used to some extent, although not very much in this country. Hard fats in the form of eandles are used very extensively in all conntries, on account of safety, cheapness, and general availability. The gases in eommon use are derived from coal and hydrocarbons. Of late, acetylene gass, obtained by the action of moisture on calciam carbide, has eome into extensive use.

Luminosity of Flame.-In the combustion of a candle, it will be observed that the flame consists of four parts, the lowest of which, blue in eolor, gives ont pratically no light; the middle portion, dark in color, eonsists of hydrocarbon gas generated from the substance of the candle; next is the luminous yellow portion ; and outside of this, is an almost invisible envelope. The atmospheric oxygen, moving toward the inner portion of the flame, unites with the carbon escaping outward from the luminous portion, and forms earbon dioxide; more oxrgen passes onward and inward, meets the hot gas from the eentral part of the flame, and, being insufficient in amomnt to unite with both the hydrogen and carbon constituents, combines by reason of greater affinity with the hydrogen, leaving the carbon free, but so much raised in temperature that it becomes incandescent, thus furnishing light during the extremely slight interval elapsing in its passage to the ontermost portion of the flame, where, as has been stated, it is oxidized to carbon dioxide. The same process goes on in the combustion of ithminating gats and oils, the luminosity of the flame being due to the inemrlesecnt particles of carbon in the breaking up of the hydrocarbon eompounds into their elements. A mixtme of gas and air, such as oeenrs in the use of the Bunsen bumer, gives off little or no light, since eateh particle of earbon is provided with sufficient oxyen to convert it at once into carbon dioxide, and so incandesence camnot ocenr. If the air supply to the interior of the flame is shut off", luminosity is produced at once.

If the area of the onter surface of an ordinary gas flame is so small that atmospherie oxygen camnot be taken up sifficiently fast to unite with all the carbon alriving at the outer part of the flame, the mnoxidized carbon beeomes cooled below the ignition point and is given off in the form of smoke. Defects in the burner or excessive richness in hydrocarbons may cause smoking during combustion, the supply of air being too small to consume the carbon. The introduction of a cool surface into the luminous portion of the flame cances deposition of soot thereon. If the area of the flame is made too large lyy turning on a large volume of gas muler high pressure, the gats is projected so far that it eomes in eontict with sufficient atmospherie oxveren to burn a larece part of its earbon and hydrogen simultaneonsly, aml, as a result, the excess of gas is consumed without luminosity and wasted. 
Gas Burners.-The best of the burners in most common use is known as the but's-ring, from the shape of the flame. 'The tip is hemispherical, and is provided with a single straight slit, through which the gas emerges in a thin flat sheet. Another, known as the fish-tail, contains in its tip two small orifices, through which the gas issues and then spreads out into a flat flame, shaped as the name indicates. 'This burner is inferior to the bat's-wing in that its flame is less luminous with the same amount of gas, and the orifices are much more easily fouled and oceluded.

The Argand burner consists of a hollow ring, provided with a circle of small holes and attached by hollow arms, through which the gas is supplied, to a socket serewed to the pipe. The gas, issuing from the holes, forms a circular flame, which is provided with an abundant air supply which passes upward through the perforations of the holder for the chimney, which is an essential part of the apparatus, and through the central hole of the burner as well. The chimney should be of proper diameter and height to insure an air supply adequate for complete combustion of the gas.

The Welsbach burner, which may be taken as a good representative of the class of incandescent lamps, consists of a modified Bunsen burner, over which is suspended a mantle composed of incombustible material, which becomes intensely luminous when heated in the Bunsen flame, and thus transforms non-luminous heat energy into luminous light radiation. The mantles are made in different ways, of different materials, and are exceedingly fragile. One of the most eommon and best sorts is made by saturating a delicate network of cotton in a strong solution of several earthy oxides (cerium, zirconium, lanthanum, thorium), then baking, and finally heating it until the cotton fibers are destroyed, thus leaving a gauze composed of the oxides alone. No single earth is efficient by itself. The flame and mantle are protected by a cylindrical glass chimney, which serves also to steady the flame, and the whole is enelosed commonly in some form of globe or shade to modify the intensity of the light. By providing a suitable burner to insure the requisite degree of heat, any kind of combustible gas or oil vapor may be used. . Lamps are made on the same principle for kerosene burning. The incandescent mantle not only gives out much more light than an ordinary or Argand flame, but does so at a much smaller expenditure of gas.

Objection is often made that the Welsbach light is very trying to the eyes. This is true; but the same objection may be urged against the sun and other intensely bright objects when looked at directly. The lights should be so placed that they will illuminate those parts where light is needed; and if they are likely to try the eyes, they should be enclosed in globes designed to soften the glare and diffuse the rays uniformly. 


\section{Varieties of Illuminating Gas.}

Coal-gas is made by heating bituminons coal in fire-clay retorts, in which process the compounds of hydrogen and carbon are transformed into gaseous and other produets. The gas is eondueted by pipes to condensers and purifiers, where it is freed from ammonia, hydrogen sulphide, tarry matters, and other impurities, and then is carried to storage tanks. The purified product consists of about 50 parts of hydrogen, 35 of marsh-gas, 6 or 7 of carbon monoxide, and the remainder of ethylene and other hydrocarbons, and nitrogen.

Water-gas is made from coke or anthracite coal, steam, and petroleum. The coke or coal is placed in an air-tight cylinder lined with fire clay, and then is ignited and blown up to a white heat by means of a blast of air. The air is then shut off and a current of steam is blown through. This is decomposed by the great heat into hydrogen and oxygen, the former passing on uncombined, and the latter uniting with carbon to form carbon monoxide. The resulting mixture is then carried to a gas-holder, from which it is conducted to the "carburetter," where it is enriched, in order that, when burned, it shall produce a luminous flame. This is a chamber of fire-brick kept at red heat. Here, vaporized petroleum is injected with the hot gas until the requisite percentage of carbon in the mixture is attained. The fiual product has much the same odor as coal-gas, but is of very different composition, and much more poisonous in character, eontaining about 30 per cent. of carbon monoxide, 35 of hydrogen, 20 of marsh-gas, and the remainder of ethylene and nitrogen. Water-gas may also be made by pumping erude petroleum in a small stream into a red-hot gas retort, where it is converted at once into vapor, which, with a current of superheated steam, is then driven throngh a long coil of pipe heated to a high temperature. The chemical reaction is the same, the carbon uniting with the oxygen of the steam to form carbon monoxide, leaving the hydrogen free.

The poisonous properties of both coal-gas and water-gas are due solely to the contained earbon monoxide, which, as shown originally by Claude Bernard, makes a definite compound with the oxygen carrier of the blood, the hamoglobin, which then becomes incapalble of performing its function. 'This being the case, the vastly greater danger attending the use of water-gas is self-evident. The odor of the two gases is practically the sime in kind, but not in degree, so, in order to have the same value as a warning of danger from leaks, that of watergas should be much more pronounced, since so much less of the gas is required to bring the air into a poisonous condition.

Usually about 0.4 per cent. of carbon monoxide in the air is required to produce fatal results, but less may be fatal after long exposure. In recovery from poisoning, the earbon monoxide is not oxidized in the body, but is driven out of its combination by the oxygen of the inspired air ; but although after a few hours the blood may nearly be freed from the poison, the damage already done to the brain and other tissues 
through the temporary partial deprivation of oxygen may be severe and lasting. Reeovery is accompanied commonly by severe headache, persisting for a long time, often with numsea and vomiting.

The inereased danger of gals-poisoning when coal-gas is supplanted by water-gas with its high carbon monoxide content is well shown by the statisties bearing on the subject at Boston, Massachusetts. In 1888 , when but 1 fer cent. of the gas sold was water-gas, there were no deaths, suicidal or accidental, from gats-poisoning. In the following year, there wals but 1 . In 1890, the pereentage of water-gas rose to 8 , and there were 6 deaths, 4 accidental and 2 suicidal. In 1892, as a result of permissive legislation, 52 per cent. of the gas sold was water-gas, and the deaths rose to 15 . In 1897 , the percentage rose to 93 , and the deaths to 47,32 of which were accidental and 15 suicidal. In the five years ended September 1, 1899, 169 deaths had occurred.

On account of the danger, a commission appointed in England in 1899 , reported adversely on all illuminating gas containing more than 20 per cent. of carbon monoxide, which proportion corresponds approximately to a mixture of equal volumes of coal-gas and water-gas.

Acetylene gas, $\mathrm{C}_{2} \mathrm{H}_{2}$, is an unstable componnd of carbon and hydrogen. It has a strong, disagreeable odor. Mixed with air in the proportion of 1 to 19 , it is violently explosive. It is poisonous, but not to the same extent as ordinary coal-gas; an animal exposed to an atmosphere containing it becomes uneonscious after a time, with no manifestations of nervous or respiratory excitement, and, if removed at once, recovers in a very short time. Prolonged exposure is fital. Blood will absorb about 0.8 per cent. of its volume of acetylene, but the solution gives no characteristic spectroscopic appearance. If any compound is formed with hemoglobin, it must be very unstable. If a high percentage of oxygen be present, animals may survive its action many hours.

Acetylene is made from calcimm carbide, a reddish-brown or gray material prepared by subjecting a mixture of lime and coke to very intense heat. When this substance is wet with water, a double deconposition oceurs, the calcium uniting with the oxygen of the water to form quicklime, and the carbon with the hydrogen to form acetylene. Between four and five enbic feet of the gas are yielded by a pound of the ordinary commercial carbide.

Burned in ordinary gas-burners, the flame cannot secure a sufficient supply of oxygen for the complete combustion of the carbon, and in conserquence it smokes and fails to exert its full power of illumination. By using a tip with an exceedingly thin slit, and foreing the gas through under heavy pressure, the flame is greatly enlarged and is of great brilliancy. Its illuminating power is about 15 times greater than that of ordinary gas.

Acetylene is liquefied at a temperature of $64^{\circ} \mathrm{F}$. by a pressure of 1,200 pounds to the square inch, and may be stored in eylinclers of steel. Apparatus for its use should not be made of copper or silver, 
since these metals are attacked by it, and the resulting compounds are very explosive.

In some appraratuses in use, the water is dropped on to the carbide by an antomatic alrangement, so that the yiekd of gas is regulated, but the gats continues to be evolved after the water-supply is shut off, since the moistened earlide camnot be prevented from undergoing decomposition. In other's, the carbile is introduced into 10 times its volume of water in a vessel commected with a gas-loolder of sufficient capacity.

Whether acetylene is likely to have a great field in the future, camnot in the present state of development be predieted, but many changes and improvements are necessary before it ean be looked upon as laving any great practical value.

Gasolene gas is a mixture of gasolene rapor and air, the function of the latter being to dilute the former until the proportion of carbon in the mixture is equivalent to that in common gas. Gasolene is a mixture of light hydrocarbons, a product of the distillation of erude petroleum. Its specific gravity ranges from 0.629 to 0.667 . It volatilizes slowly at low temperatures and rapidly at $70^{\circ} \mathrm{F}$. and above. It is exceelingly inflammable.

Gasolene gas is generated and foreed through supply pipes to the burners by special forms of apparatus which recuire but little attention. It is well snited to single houses and small groups of houses where no public supply exists.

Impurities Given off in Lighting.-In the combustion of illuminants of all kinds, considerable amounts of decomposition products are given off to the air, and their removal by means of effieient ventilation is important. These products are least in amomnt and importance in lighting with eandles and oil lamps, being eliefly earbon dioxide and watery vapor. The impurities given off in the combustion of gases include sulphur dioxide, very variable in amonnt aceording to the extent of purification; carbon monoxide, also variable aeeording to the completeness of combustion ; carbon dioxide; ammonium eompounds, and aqueous vapor.

Gas Pipes.-Street mains are commonly made of cast-iron pipes of rather light weight, which vary much in texture and density, and not infrequently are perforated with blow-holes of varying dianeter or otherwise defective. On aceount of the damgers of extensive leakage and of the financial loss due to waste of gas and the eost of making repairs, all pipes should be tested thoronghly before being haid. Pipes which show no leaks when new mar soon he corroded in the soil at points where bubbles oecor in the walls with hut a thin layer of metal on either side. Wrought-iron pipes ane corroded more quickly in the soil, but are more miform in density and texture than cast-iron and pequire fewer joints in a given distanee. Both kinds should be proteeted by a generous eoating of asphaltum or other suitable material.

Honse pipes are most commonly of wronght iron, thomgh sometimes softer materials are employed. The latter are more expensive, and 
possess the additional disadvantage of being easily punctured by nails and gnawed by rats and mice. The entire systen of distributing pipes should be joined most earefully, in order that no leaks shall wecur. When they do oceur, the search for their location should be condueted with all possible precautions against risk of explosions, since mixtures of gats and air in the proportion of about 8 per cent. of the former are violently explosive if brought in eontact with a flame. The gals should be shut off at the meter, and the apartments where the smell is pereeived should be aired thoroughly. The examination should then be begun at the meter and its connections, and if defects are there found, the meter, if at fault, should be removed, or the eonneetions put in proper eondition with new washers. The fixtures should next receive attention, every joint and eock being tested, the gas being turned on again at the meter. Smearing the joints with some viseid material, such as strong soapsuds, will show small leaks by formation of bubbles. The examination of the joints of the distributing pipes is a matter of considerable difficulty, and may require much disturbance of structural parts.

Fixtures should be so located as to avoid hot-air currents from registers in the floor and walls, on aceount of the great annoyance eaused by flickering of the flame. Flickering is caused also by the presence of condensed moisture in sags in the pipes and bends in the fixtures, which causes the gas to issue in a series of bubbles with consequent unsteadiness of the flame. The remedy consists in interposing drip cups and draining off the water.

The proper arrangement of fixtures is frequently a difficult problem, particularly in large rooms. In general, it may be said that they should be well distributed rather than clustered in eentral ehandeliers. Fairly uniform diffusion may be secured by the use of globes of prismatic glass, which act in the same way as the ribbed and prismatic window glass deseribed above.

Electric Lighting.-Ineandeseent electric lighting possesses certain notable advantages over all other systems of artificial illumination. It requires no oxygen and produces no decomposition compounds, and hence in no way alters the eomposition of the air. It imparts but little heat to the surrounding air, and henee has but a limited influence in causing convection currents and raising room temperature.

\section{Section 4. PLUMBING.}

Whether we view the subject from the standpoint of possible danger of infection through inhalation of sewer air or from that of xstheties, we should reeognize the great importance of the removal of all sewer wastes from the habitation throngh a system of plumbing that is so perfect that it shall leak neither liquid nor solid matters, nor foul air and smells. For the attainment of the best results, all large communities adopt plumbing ordinances designed to prevent faulty construction and the admission of the dreaded "sewer gas," which, to the lay 
mind, and very generally to the professional mind as well, is a most potent cause of disease. While the weight of evidence is against the aceeptanee of the doetrine of the transmission of disease through this ageney, it must be coneeded that foul odors, besides being disagreeable, exert on the sensitive individual a decidedly injurious action through the imagination, and, more partieularly, through their effects on the appetite and digestion. Most of the foul smells coming from plumbing fixtures are not from the sewer at all, and hence may not properly be ealled sewer gas or sewer air ; they are due to decomposing organie matters within the pipes or traps, or in some otner part of the fixture, which, with ordinary use, does not become thoroughly eleansed. Thus, it is often found that the odor from a wash-basin is due to decomposing soapy matters and other deposits in the horn leading from the overflow holes, but it is difficult to eonvince the timid that such is the faet, exeept by oeular and other demonstration.

The most perfeet system of plumbing needs eareful supervision, for no pipe or other part subjected to frequent contact with filthy matter's can be kept permamently elean unassisted; and any such surface not ent off from eontact with the free air of the room must inevitably, under certain conditions, give rise to a certain amount of nuisance. The reduction of these possibilities for nuisance to the lowest limits is one of the main objects of the many ingenious plumbing applianees of one kind and another that are almost daily increasing in number and variety.

Broadly speaking, plumbing may be divided into two classes : good plumbing and bad plumbing. The former eosts more in the beginning; the latter, in the end; the former is installed by the capable and honest plumber; the latter, by the trickster who has given his alling such a bad name that he finds it more to his liking to hide behind the more pretentious title of "sanitary plumbing engineer," just as sone barbers become "tonsorial artists."

The better elass of plumbers, in undertaking the installation of a system of plumbing, attempt to attain such a degree of perfection that repairs are only oceasionally necessary ; the other elass, either intentionally or because of inability to do good work, produce a system requiring constant repairs and consequent expenditure. This class of workmen also are quiek to take every advantage of loosely drawn or ambiguous specifications, whereby the owner suffers eventually more than the original financial injustice. But the responsibility for poor plumbing is not by any means always to be placed upon the plumber, for an owner unwilling to pay the price of good work can hardly blame the plumber for unwillingness to provirle labor and first-elass material at less than eost, and so gets cheap matcrial and cheap workmanshfip in return for his inadequate appropriation.

A good system of plumbing calls for sommd materials, absolutely tight joints, thorough ventilation, and a plentiful water supply to insure thorough flushing without wastefiulness. It should be so planned that the various fixtures on each floor shall be in relatively the same 
locations, thus aroiding unneessiry and expensive extensions of waste and supply pipes. The wastes should be easily accessible, and are best run in full view, so that any leakage may be detected at once. When hidden from view, lealis may exist undetected until much damage has resulted. Open plumbing, furthernore, insures good workmanship, and makes repairs simpler and much less expensive. The pipes need not be a disfigurement to a room, for they may be neatly painted or brouzed, and will then have no worse appearance than those used in stem leating. If they must be placed in recesses or within walls, they may be eoncealed by boards or panels fastened by serews, and easily removable.

The important fixtures, sueh as bathtubs and water-closets, should be placed where ventilation ean be seeured and where dependenee upon artificial light is not altogether neessary. The ideal place is in an outer room with a window through which the sun's rays and fresh ontdoor air may enter.

The Soil-pipe and Main Drain.-The soil-pipe receives at various points, through the several waste-pipes, the contents of wash-bowls, sinks, bathtubs, urinals, water-elosets, and other fixtures, and conduets them to the drain, by which they are carried on to the sewer or cesspool, as the ease may be. In this country, the material almost universally used for soil-pipe is cast iron; but in England lead is preferred. The advantages of iron over lead are many; it is lighter, stiffer, stronger, eheaper, and more durable, and is not subject to aecidental perforation by driven nails and gnawing rats. Lead pipe of large diameter sags by reason of its weight, and it is difficult to secure it strongly wherever its weight is borne by the fastenings. It is very easily corroded, dented, flattened, and perforated.

Cast-iron soil-pipe is made in two grades ; light, or "standard," and "extra heavy." Only the latter should be employed, the former being much too thin and flimsy. The walls of the extra heavy grade should not be less than an eighth of an ineh in thiekness. The pipe is made in lengths of five feet, exclusive of the socket, or hub, which is an enlargement of one end for the reception of the spigot end of the next length, so that no irregularities shall be caused in the ealiber of the pipe where joints ocem, but, on the eontrary, that the inner surface shall be flush throughout. Each length should be of uniform wall thickness throughont and fiee from flaws, sand holes, and other imperfeetions, and should be subjected to strength tests at the place of manufineture. The inner surface should be perfeetly smooth.

In joining the lengths together, the spigot end of one is inserted as straight as possible into the lunb of the next, and a gasket of oakum is inserted into the intervening space by means of a caulking tool, and rammed hard so as to fill about half the depth of the hub. The object of the gasket is to prevent the entrance to the bore of the pipe of any of the molten lead nsed in the next proeess. The next step is the filling of the rest of the space with molten lead from a ladle. Since this metal shrinks on cooling, and sinee moisture and dirt prevent its 
adherence to the iron, it is necessary next to expand it and drive it down by mechanical means. This process requires eare and involves much risk of fracture, since the blows of the caulking tools must be quite heavy ; in fact, much heavier than the lighter grade of pipe can withstand. Against this form of pipe and its jointing, certain objections are urged, not the least of which is the opportunity given for boteh-work and fraud. Instances of filling the space with mortar, sand, putty, and other material have been not uncommon. Some unserupulous plumbers gloss over the fraud with a thin layer of lead; some make the joint properly and neglect to caulk it ; some make as perfect a joint as possible in places where ocular inspection is easy and probable, and omit to eaulk, or even to insert the oakum, where the joints are hidden, but without forgetting to make the usial charge.

Another objection to this form of joint is the possibility of its becoming loose through alternate expansion and eontraetion due to ehanges in temperature. The expansion is unequal, especially when due to hot water in the pipe, and the spigot expands more than its smrounding socket and compresses the interposed lead, which, when equilibrimm becomes reëstablished, does not resume its original shape, but remains in its new form. In this way, it is possible, but not very probable, that a minute space may be created all about the spigot, and that through this space, leakage of liquid, but more especially of air, may ocenr. In an upright pipe, leakage of liquid is most unlikely to ocenr, since the hub end of each joint is uppermost.

Still another objection is the great difficulty encountered in unjointing, when, for any reason, it is neeessary to remove a length of pipe in making repairs and alterations. The usual and easiest conrse to pursue in such a case is to break the pipe and remove it in pieces.

To meet the several objections to this form of pipe, the Sanitas flanged pipe was devised by Mr. J. Piekering Putnam, of Boston. This makes a joint which is deseribed as an adjustable flanged joint with lead washers or gaskets for packing. The gaskets, which are star-shaped in eross-section, are squeezed between the flangres of the two adjoining pipes and erushed to half their original thickness by serewing up the bolts set in square recesses in the flange ears. These are screwed simultancously, so that the pressure on either side is equalized and the gasket is compressed uniformly. The gasket for a four-inch pipe weighs a half pound. For this joint, are elaimed cheapness and security. The time required to make it is reckoned in seconds as against minutes, the amount of lead consumed is much less, and the unjointing is simple and involves no breakatue.

The diameter of a soil pipe should ordinarily not exeed four inehes, but in very large buildings, in whieh are numerous water-elesets and other fixtures, five-ineh pipe is sometimes usel.

Soil pipes should run as nearly vertically and with as few deviations from a straight line as practicablic. When these are necessary, rightangled bends, such as are shown in Fig. 51, should he avoided, and instead thereof, obtuse-angled elbows, is in Fig. 52, should be em- 
ployed. Where waste-pipes and branches connect, the junctions should be made with Y-branches and not at right angles. (See Fig. 53.)

FIG. 52.

Frg. 51.

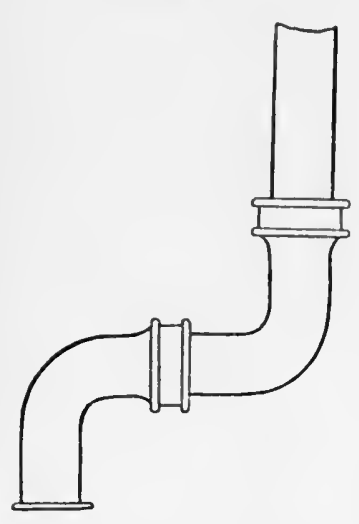

Improper bends in soil-pipe.

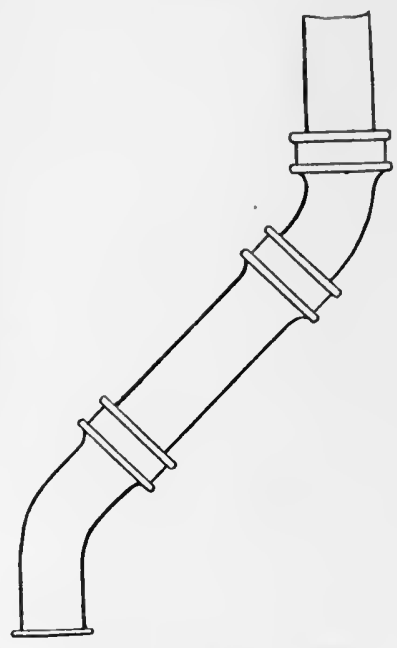

Proper bends in soil-pipe.
Fig. 53.

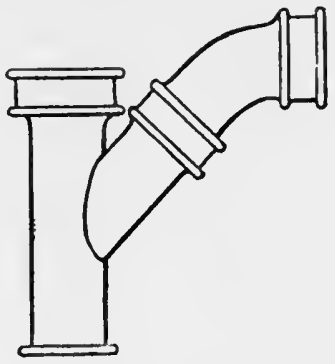

Y-branch to soil-pipe.

These junctions are made differently when a lead pipe is to be connected with an iron one. The lead pipe is first "wiped" on to a brass ferrule by means of solder, and then the ferrule is caulked into

FIG. 54.

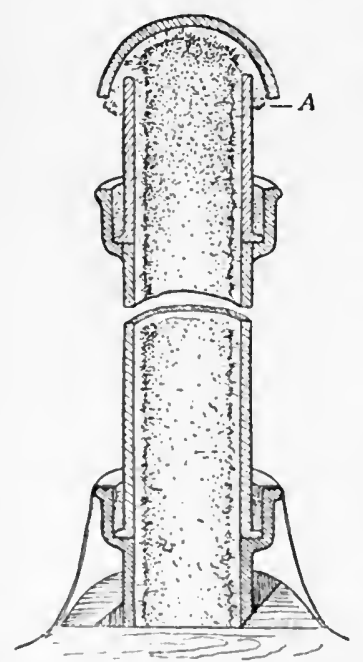

Occlusion of outlet of soll-pipe by frost. the hub. With the flanged Sanitas pipe, the connection is obtained more easily and cheaply; here the lead pipe is flanged out and bolted to the iron by means of cast-iron rings with ears and bolt-holes corresponding to those on the pipe.

Each soil-pipe should be extended in full size through the roof for about two feet, and its outlet should not be obstructed by a cap or cowl, as is commonly done. The cap serves no useful purpose, and the passage for air is so narrow that, in winter, when the warm, moist air ascends, a coating of frost is formed all over the inner surface of the exposed pipe, and this may grow in thickness so as to occlude the ontlet completely, as is shown at $A$ in Fig. 54. In all cases, one should make provision for the expansion and contraction of the column of metal, for while the movement either way is slight, its force is very great; therefore, the fastenings should not be too rigid, but should allow a little play. The soil-pipe should be very firmly supported at the bottom, and 
its junction with the main drain should be made with a bend of as large a radius as possible. The best support is either a brick pier or a wooden post, or other firm and unyielding structure. The connection should under no circumstances be at a right angle, but with an elbow bend supported on a foot, as in Fig. 55. If the pipe must be carried along a cellar wall, it should be supported either by a shelf or by wrought-iron pipe-hooks.

From the point where the soil-pipe departs from the perpendicular and tends toward the sewer or cesspool, it is commonly known as the drain, whether other soil-pipes enter it or not. The drain should consist of iron as far as a point well away from the foundation of the house and from all danger of fracture due to settling. Under no circumstances should an earthenware drain-pipe be employed within the house or beneath the foundation, or through a soil in which a well of drinking-water is situated. The main drain may be carried along the wall of the cellar in the manner above described, or it may be suspended by wrought-iron hangers from the joists of the floor of the first story ;

FIG. 55.

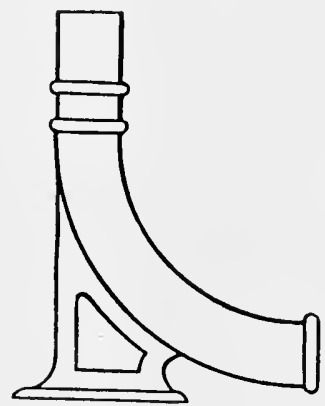

Elbow bend and support.
Fig. 56.

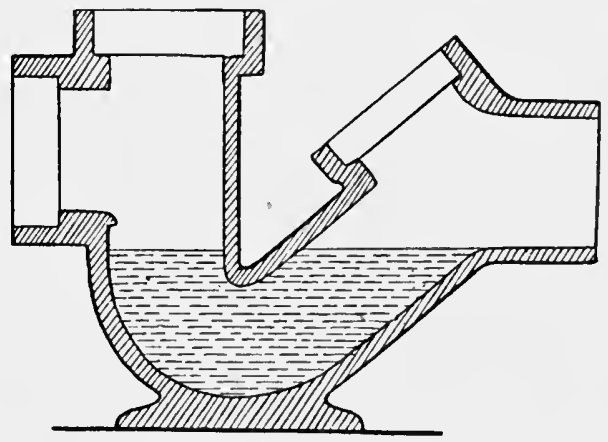

Intercepting trap. (Running trap.)

or, if there are water-closets or other fixtures in the cellar, it may run below the floor. In the latter case, it should be easily accessible.

The drain should have all the fall that can conveniently be given, and this should be as nearly uniform as possible throughout its length. No part of it should run flat or sag. The greater the piteh, the more completely the pipe is scoured out by each passane of water. It shonld have a fall of at least a quarter of an inch to the foot, or, preferably, more.

Before the drain passes beneath the foundation wall, or, if this is impossible, at a point outside in a manhole, an intercepting trap is placed, provided with elean-out holes eovered with air-tight covers. This trap, known sometimes as the running trap and main trap, is of the same diameter throughont as the drain itself. This kind of trap is manufactured in an immense variety of forms, one of the best of which is shown in Fig. 56. This has an inlet and an outlet for sewage, an inlet for fresh air, and a clean-out and inspection bole on the 
FIG. 57.

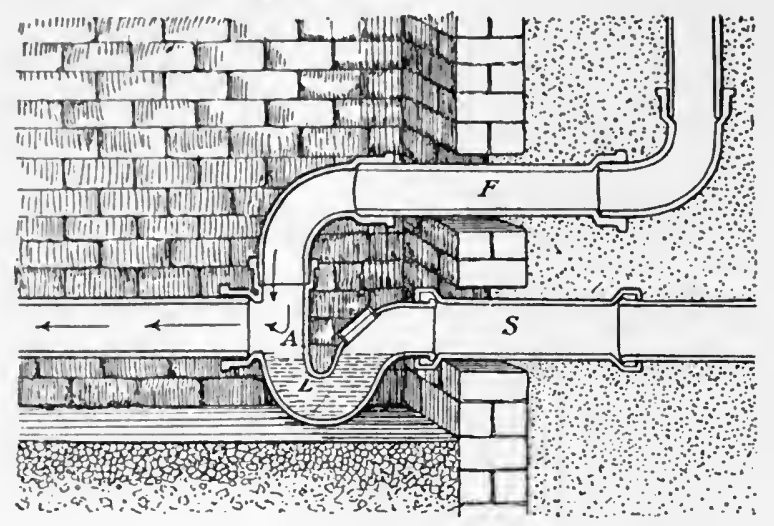

Objeetionable arrangement of intereepting trap and rentilating pipe.

outfall side. The sewage enters by the inlet at the left, which is slightly higher than the outfall at the right. 'The uppermost opening

Fra. 58.

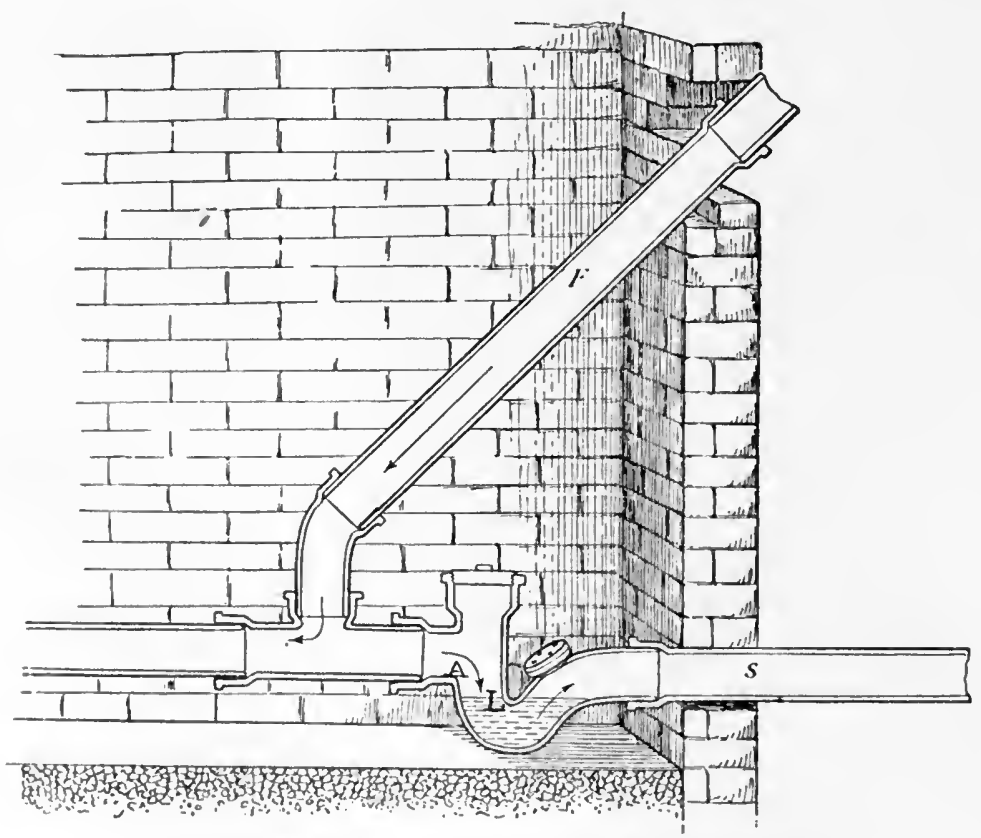

Preferable arrangement of intercepting trap and rentilating pipe.

is for the fresh-air inlet. The latter is for the purpose of insuring a complete eireulation of fresh air throughont the entire length of the drain and soil-pipe, and communicates with the external air by means 
of a pipe of the full diameter of the drain, running from the house side of the trap to some point outside.

In Fig. 57 is shown an arrangement very eommonly adopted, but open to serious objections. Here, the filth may be thrown up ayainst the entrance of the fresh-air pipe $F^{\prime}$ at $A$ and form an aecumulation. The floor of the drain and of the outlet $S$ are at the same level, as is shown by the two sides of the water seal $L$, and there will be, therefore, not head enough to force all light solids easily beneath the dip of the trap.

A much better arrangement is that shown in Fig. 58. In this, the inlet of the fresh-air pipe $F$ is situated at a point some distance away from and on the house side of the trap, where splashing and aecimulation of filth eannot occur. At $A$, the entering sewage falls throngh a distance of about two inches at $L$, and can force any solid matter under the dip and onward through $S$. It will be noted by the direction of the arrows in both figures that the normal direction of the air current is inward, but under some conditions of internal and external temperatures, as, for example, in summer, the direction is likely to be reversed. In winter, owing to the higher temperature of the honse, the movement in the soil-pipe is naturally upward and outward, and in the pipe $F$ is downward and inward.

Waste-pipes.-The pipes connecting fixtures with the soil-pipe are known as waste-pipes. They are made commonly of lead, although cast-iron, wrought iron, and galvanized iron are employed also. The

Firt. 59 .

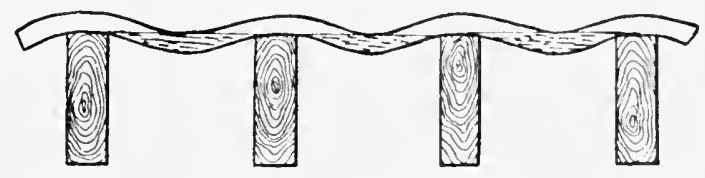

Sags in an improperly laid pipe.

advantage of using lead is that it is more easily run, especially in places where bends and angles are neeessary, and requires, therefore, a smaller number of joints. The disadvantages are the liability to perforation by nails earelessly driven and by gnawing rats, and the posithility of the formation of air-locks throngh sagreing of a pipe improperly laid. These oceur sometimes when a pipe is not properly supported or where high points and low points oceur in a crooked mon. This is shown in exaggerated form in Fig. 59. Here we see a series of low points, in which water will stand and where sediment may accumulate, and a eorresponling number of high points containing air. These imperle the flow of water onward, and if the pressure is low, a series of them in a single run may stop it altogether.

Iron pipes possess whatever advantage attaches to rigidity, and while they are not so easily adapted to crooked rums and require more joints, it must be said that the latter are marle guickly and easily when serew couplings are employed. Some joints are made by serew- 
ing directly into hubs and some by means of ordinary couplings, the result in either case, as shown in Fig. 60, being perfectly flush fittings.

Ordinarily waste-pipes need not be larger than 1.5 inches in diameter, nor heavier than three pounds to the foot. In those cases where the supply pipes deliver a heavy stream of water under high pressure, it may be necessary to use a larger size, in order to insure the removal of all the water without danger of overflow. Too large pipes and too

Fıg. 60.

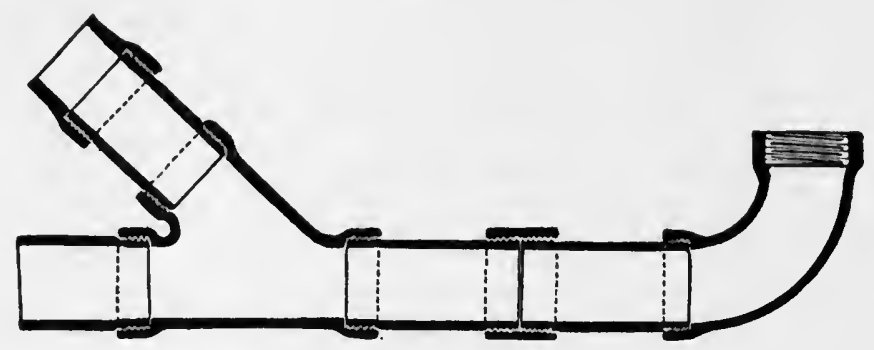

Flush fittings with screw couplings.

small pipes are equally bad. If too small, the overflow is retarded and they are choked easily; if too large for the fixture from which they lead, they eannot possibly be flushed thoroughly, but are soon coated with grease and other filth, and eventually become completely oceluded. Thus, a 2 -inch waste-pipe, attached to a fixture by a 1.25 inch joint, would be quite too large and out of place.

Lead waste-pipes may be joined to iron soil-pipes in the manner already described, and to wrought iron by brass screw nipples wiped on to the lead with solder and screwed with red lead into the thread of the fitting. Lead should always be joined to lead by wiped solder joints, and never by cup or "eopper bit" joints, excepting when the operation of wiping is elearly impossible.

Traps.-Each separate fixture connected with the soil-pipe, that is to say, each water-closet, wash-bowl, bathtub, etc., should be provided

Fı. 61 .

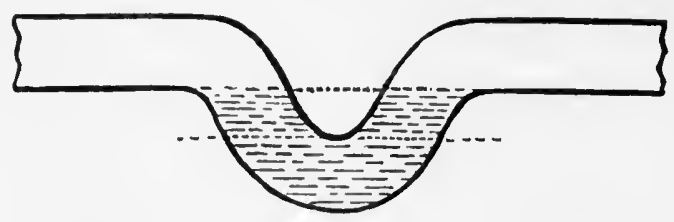

Running trap.

with some form of trap situated as near it as possible. A good trap will wholly prevent the passage of all air or gas or odor from the waste-pipe or soil pipe backward into the air of the house, while per- 
mitting the free passage of liquids and suspended solids toward the sewer. It should be of such construction as will admit of ready inspection and cleaning, and under ordinary circumstances should be self-cleansing. Improperly trapped or untrapped fixtures are as much to be avoided as leaks, the result in either case being the same so far as the passage of offensive odors is concerned.

FIG. 62.

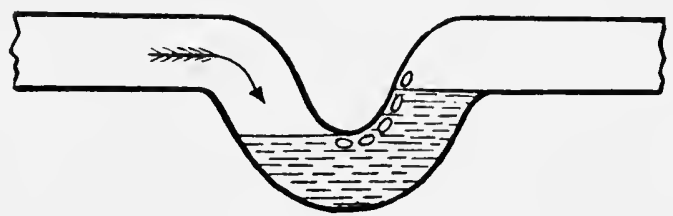

Forcing of seal of running trap.

The simplest form of trap, ealled running trap, consists of a downward bend in a horizontal pipe, as shown in Fig. 61. When water is discharged through such a pipe, the depressed portion will be found to stand full of water when the discharge ceases, and this body of water

FIG. 63.
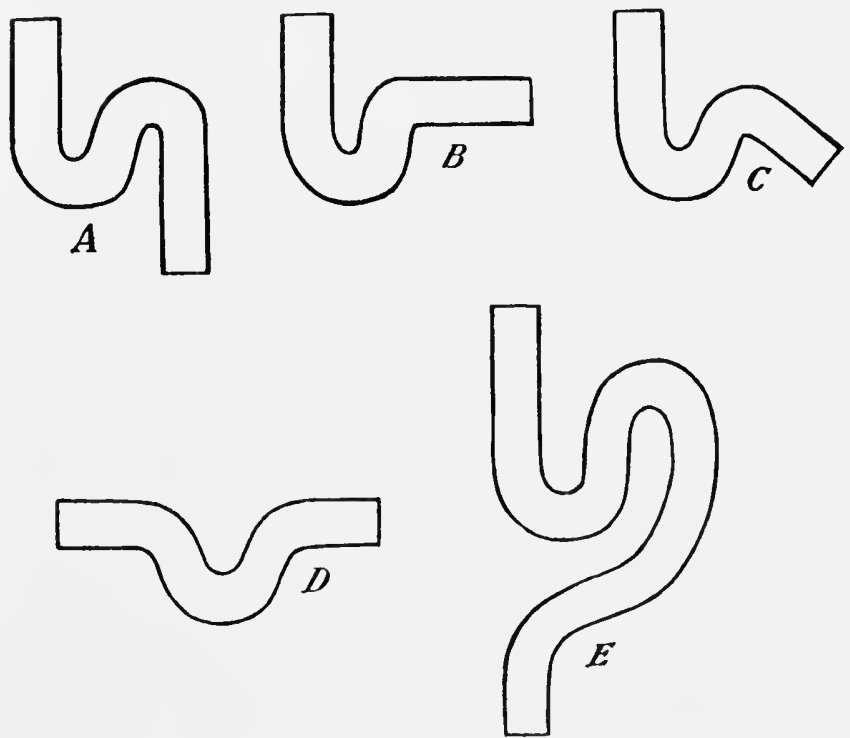

Forms of round-pipe traps.

will prevent the passage of air in either direction; but if sufficient pressure is exerted on either side to foree the level of the water on that side down to the lowest point of the hend, air may be forced through, as is shown in Fig. 62. The water between the water level and the 
lowest point of the upper internal surface of the bend is known as the seal, and this should never be less than 1.5 inches in depth. In Fig. 61 , the seal is that which lies between the dotted lines. 'This form of trap is one of a class called round-pipe traps, and to this class belong a number of forms, five of which are shown in Fig. 63. These are the $S$-trap $(A)$, the $I$ alf-S $(B)$, the Three-quarter $S(C)$, the Running $(D)$ already described, and the Double-S or Hunchback $(E)$. These several forms are in all cases of the same size throughout and, therefore, will palis anything that ean gain entrance. With proper flushing, they are cusily kept elean, but they are quick to lose their seal by a sudden flow of water through them or by disturbance of atmospherie pressure prohluced ly the sudden discharge of water through pipes with which their own pipes are eonneeted. The means for the prevention of this ocenrence are eonsidered below.

Another elass of simple trips includes all those known as Bottle or Pot traps. In one form of the bottle trap, the principle of which is shown in Fig. 64, the end of the inlet-pipe dips several inches into the pool of water. In order to drive air backward throngl the inlet-pipe $A$, it would be necessiry to exert pressure sufficient to force the water within the chamber $B$ upward through $A$ until its

Firi. 64. level is brought down to the lower end of $A$. Under

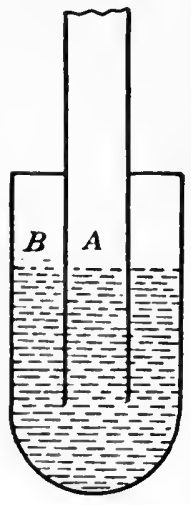
ordinary circumstances, such a pressure would be quite impossible. To drive air in the other direction through $A$ into $B$ is less difficult, but this will require a pressure sufficient to depress the water standing within $A$ down to the outlet of the pipe.

In Fig. 65 is shown a trap of this kind, in which there are two inlets; the prineipal one, the pipe $I$, and the sceond, which connects with the overflow of the fixture, the pipe $B$. The arrows indicate the direction of movement of the sewage through the pot. As the level rises, the excess runs off through the outlet $O$ and discharges downward. The upper portion of the pipe marked $V$ connects with the ventilating pipe, in which frec circulation of air is maintained. The object of this is explained below. This form of trap is made to lose its seal only with great difficulty, although a part of it may be lost by siphonage. The oljection to this form of trap is the likelihood of the accumulation of filth, for, unlike the round-pipe trap, they are not self-eleansing, sinee the whole contents are not set in motion each time the fixture is userl.

Another, simpler, form of pot-trap is that shown in Fig. 66. Here the inlet-tube $I$ is not immersed in the liquid, but communicates dircetly with the lower part of the ehamber ; the outlet $O$ starts from the upper part of the chamber, and the communication with the ventilating pipe has its exit at the crown. It will be observed that in both these forms the seal is quite deep. The undue accumulation of filth in these traps should be guarded against, and for this purpose 
clean-out holes, closed with metallic screw-caps, are provided. A large accumulation of filth in one of these traps makes siphonage of the seal more easily brought about. This class of trap is used only under sinks, basins, baths, and washtubs; never under any circumstances under water-closets.

Fia. 65.

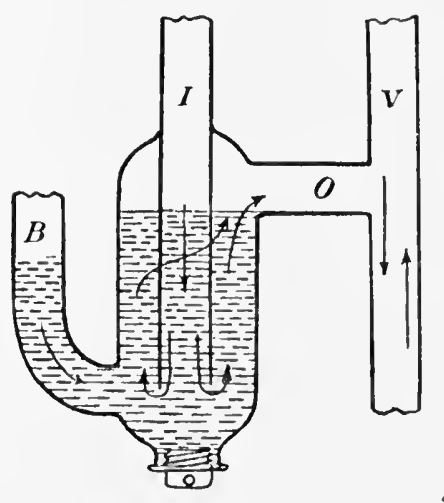

FIG. 66.

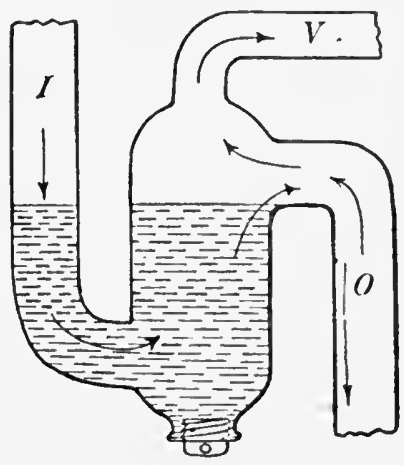

Two forms of ventilated bottle traps.

Among the traps depending upon mechanical devices to assist the water-seal, the Ball-trap may be taken as a type. In this form (shown in Fig. 67), the up-cast limb of the trap consists of a chamber considerably broader than the inlet branch, and contains a ball, the specific gravity of which is slightly greater than that of water. This, when

FIG. 67.

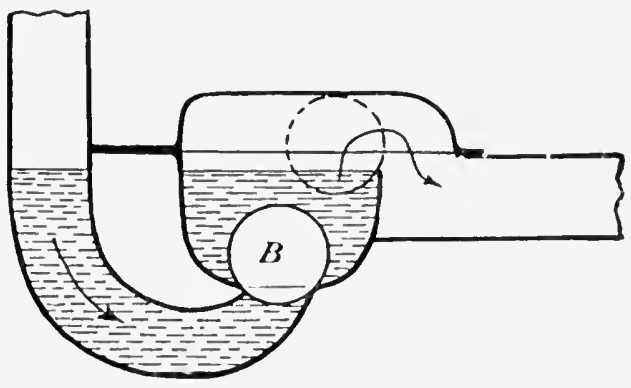

I3nll-trap.

the contents of the trap are at rest, rests on its seat and makes a gastight joint. When liquid is discharged into the trap, the ball $B$ is thrown upward into the position indicated by the dotted line ; and when the flow ceases, it drops into its orignal position. It cannot escape from the chamber, since there is not space enough for it to 
pass between the lip of the pot and the top of the cover. This form of trap cannot he siphoned out, because of the size of the pot, but, with disuse, it may lose its seal by evaporation. In such an event, however, the ball retains its seal and closes the joint. 'The great objection to this trap is that, even although nothing which should otherwise be disposed of is thrown into the fixture, as, for instance, matches and other objects, the seat of the ball is likely to become the point of deposit for hair, bits of cotton, linen fiber, and sponge, and then a gastight joint cannot be made with the ball. As a matter of fact, indeed, all mechanical devices in traps are much inferior to the ordinary waterseal.

Another form of trap, much used in kitchen sinks, is known as the Bell trap. (See Fig. 68.) In this, the delivery pipe $D$ projects for

F19. 68.

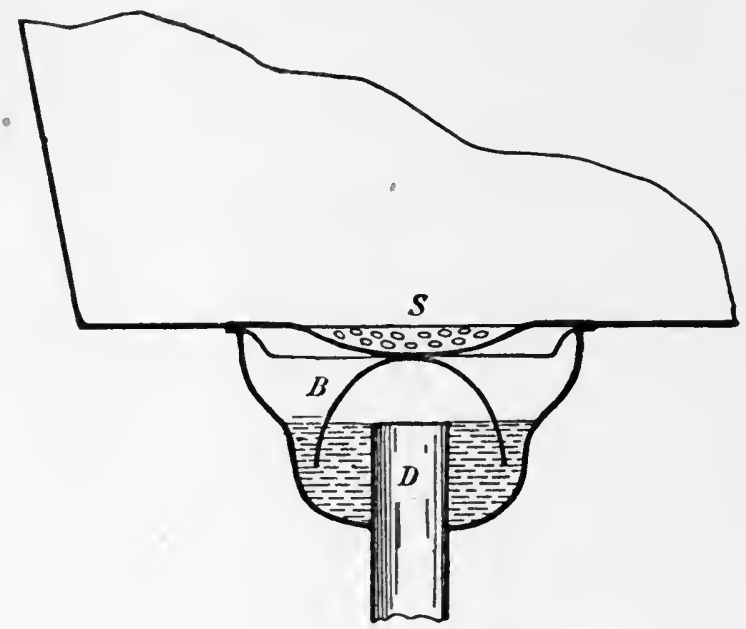

Bell trap.

some distance upward into the reservoir; the inlet consists of a strainer, $S$, to whieh is attached the bell $B$, which dips into the pool of water in the reservoir and eneloses the outlet of the pipe $D$. There is, it will be seen, no direct communication between the air contained within the bell and that above. The waste reaches the reservoir through the holes in the strainer, and as the level of the liquid rises, it escapes through $D$. This form of trap is quite likely to be choked by deposits of small bits of food material and other substances forced through the holes of the strainer with the aid of a sink brush. It is also easily siphoned, and, furthermore, being easily removed, it happens very commonly that the fixture is utilized by lazy servants for the disposal of waste matters which should be deposited elsewhere.

Grease traps are devices for preventing the choking of drains by 
grease, which, discharged in the liquid state with hot water, solidifies when it eomes in contact with the cold surfaee of the waste-pipe and adheres thereto with great tenacity. The eoating which it forms becomes thieker and thicker through suceessive applications, and eventually may occlude the pipe so completely that the trouble must be attacked from the outside, the remedy requiring sometimes the removal and ineidental destruetion of an entire length of pipe. Grease traps may be located beneath the sink or, preferably, in a place provided therefor outside the house.

A eommon type of this device is shown in Fig. 69 . The greasy water runs into the reservoir through the inlet $I$, and

FIG. 69.

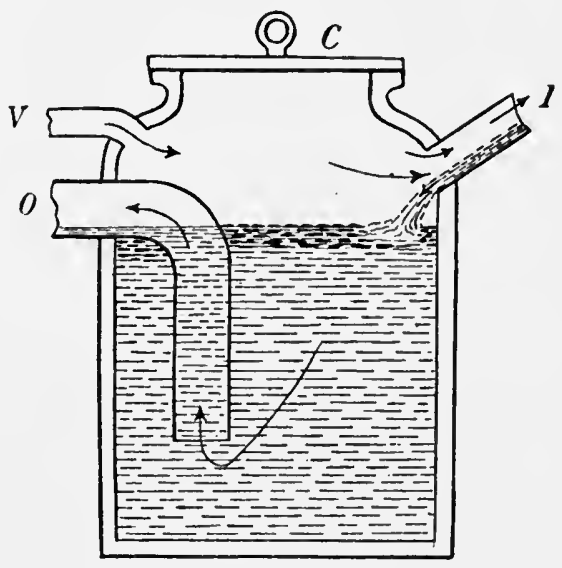

Grease trap. the liquid grease, being lighter than the water, rises to the surface and forms a seum, which, when eold, solidifies into a cake. The outlet $O$ of the trap dips far beneath the surface, and so discharges none of the

Fig. 70.

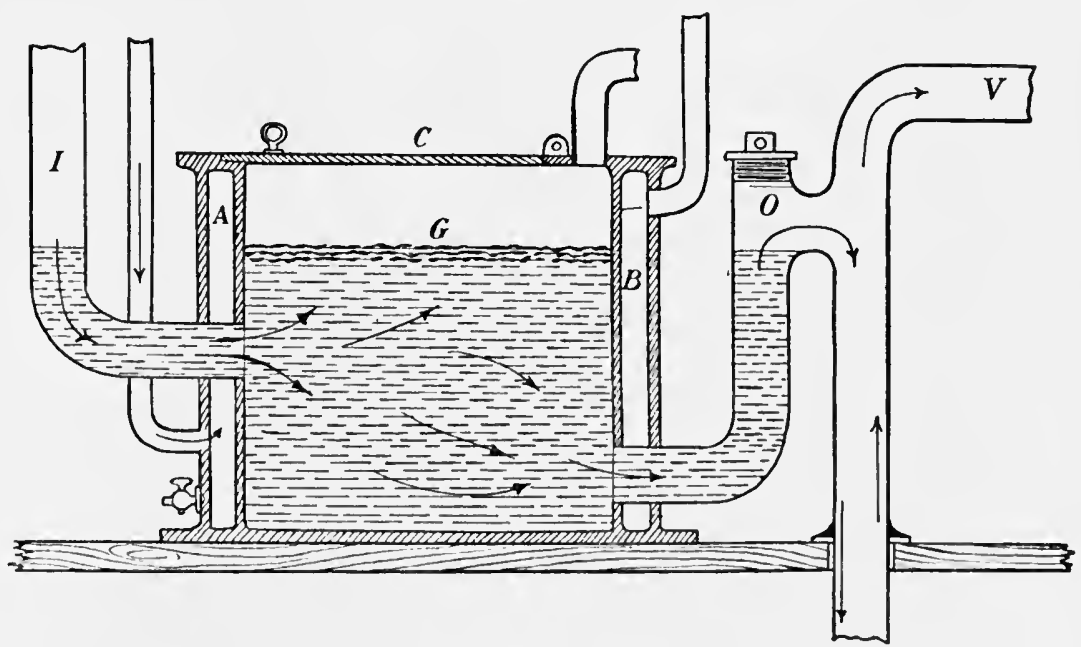

Jacketed grease trap.

accumulated grease. Air is admitterl through $r$, and can circulate thence through the inlet pipe $I$, as indicated by the arrows. The aeenmulated grease should be removed periodically through the clcan-out. 
which is elosed by the cover $C . A$ larger and more complieated apparatus is shown in Fig. 70. Here the ehamber is enelosed in a jacket, $A B$, through which cold water is allowed to eirculate. The dirty water enters through $I$ and diseharges from the upper branch $O$, which is vented through $I$. 'The greasc aceumulates at $G$, and is removed through the top, which is closed by the hinged cover $C$.

There are many other forms of grease intereeptors, but none is perfect, for under the most favoring eireumstances some grease will escape and may congeal on the surface of the waste-pipe or drain. All grease traps should be attended to at short intervals, else they may become alnost completely filled with solid grease.

Loss of Seal.-CTraps may lose their seal in varions ways: by siphonage, by evaporation, by back pressure, by leakage, by accumulation of sediment, and by capillary attraction. The most inuportant

FIG. 71.

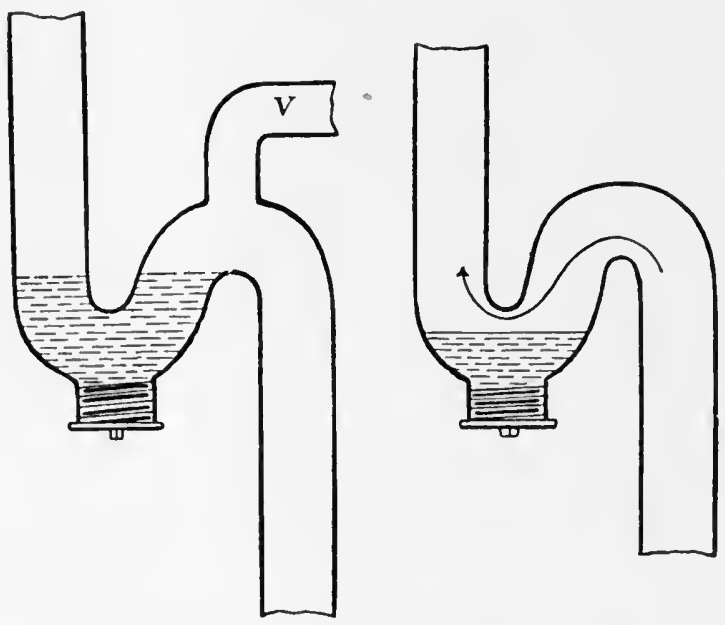

Effects of ventilation and non-ventilation of traps.

of these is siphonage, for the prevention of which two methods commonly are employed. In one, the up-cast limb of the trap is widened so that it becomes a pot or reservoir. A large reservoir will resist siphonic action much more successfully than a small one; an 8-inch pot cannot be siphoned through a pipe of ordinary size, a 4-inch pot resists only when its seal is unusually deep, and anything less than 4 inches is inadequate.

This form of trap, however, offers deeided objection. In the first place, it is likely to acemmulate much sediment; and in the second, it constitutes a miniature cesspool, the presence of which in a system of plumbing should not be countenancel, since sewage matter should be discharged in as fresh a condition as possible, and not in a state of putrefaction, which, if cesspools are employed, will inevitably be 
brought about. Moreover, this form of trap is very expensive and bulky. In the other method, the up-cast branch is eonneeted with a ventilating pipe by a branch from its upper portion. Unless one or the other of these two methods is adopted, the contents of the trap, particularly in the ease of a round-pipe trap, are likely to be siphoned over when its fixture is used or when a large volume of water is discharged from some other fixture into the soil-pipe, and in its descent causes a partial vaenum. In the former case, the trap is self-siphoned; in the latter, the partial vacuum draws the water over and breaks the seal. If the trap communicates with a ventilating pipe, this disturbance of equilibrium cannot oceur, since the deseending mass of water causes a downward suction of air through the vent pipe to satisfy what would otherwise be a partial vacuum. In Fig. 71, the diagram

Fig. 72.
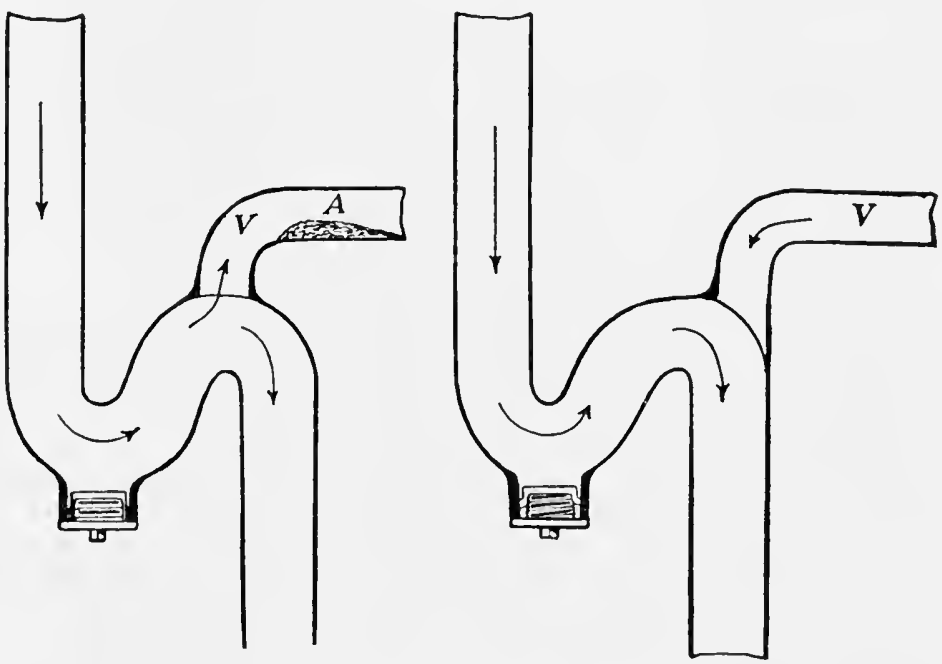

Improper and proper positions of vent pipes.

on the right shows the condition after siphonage has oceurred; the greater part of the water has been drawn over until air can be sueked throngh, and that which remains has fallen back into place. The result is that a free communication exists between the fixture above and the soil-pipe below. The diagram on the left shows the condition of the seal if the trap is connected with a ventilating pipe through $V$.

In venting traps in this way, the position of the vent pipe is of considerable importance. Ordinarily, it is placed as shown in the figure. The oljection to this procedure and the proper method are shown in Fig. 72. If the pipe enters in the middle of the bend, each discharge of sewage into the trap eanses a projection of the liquid upward into the pipe $V$, and after a time an accumulation is likely to oceur at $A$. If the pipe is sitnated farther to the right, as in the drawing on the right, this aceumulation is not likely to oceur, and 
the sewage and the air take the directions indicated by the arrows. The vent pipe is more easily joined to the trap, however, in the manner to which objection is made.

The ventilating pipes from the different traps of a system of plumbing eonnect with a main ventilating pipe, which may be joined to the soil-pipe, alongside of which it runs, at a point in its upper part, before its projection through the roof. It is important that the

Fig. 73.

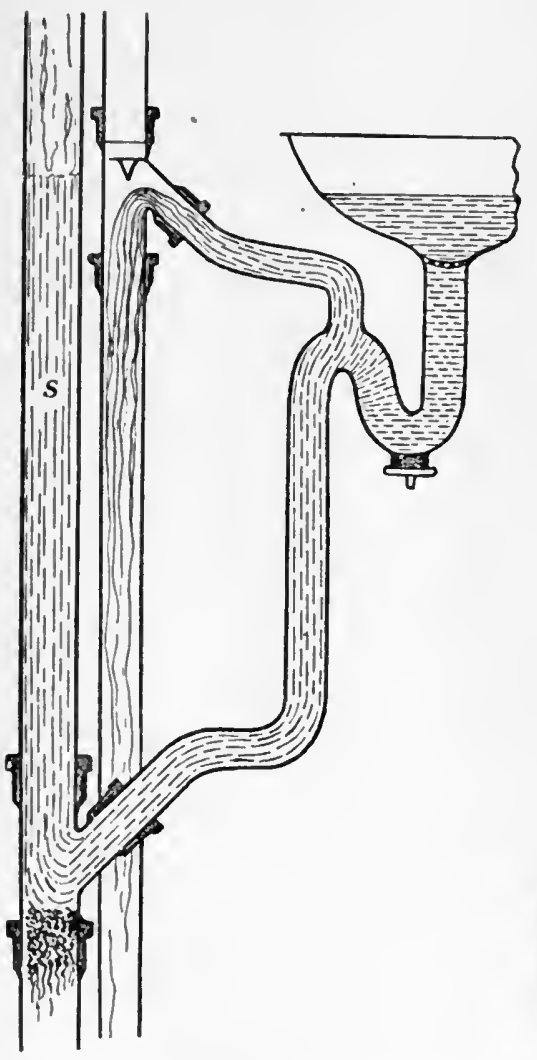

Improper junction of vent pipe with main vent. junction of each vent pipe with the main shall be at a point above the fixture, since, in case of an obstruction in the soil-pipe below, the water may back up through the trap and discharge through the vent pipe into the main vent, as shown in Fig. 73. Here, the soil-pipe $S$

Frg. 74.
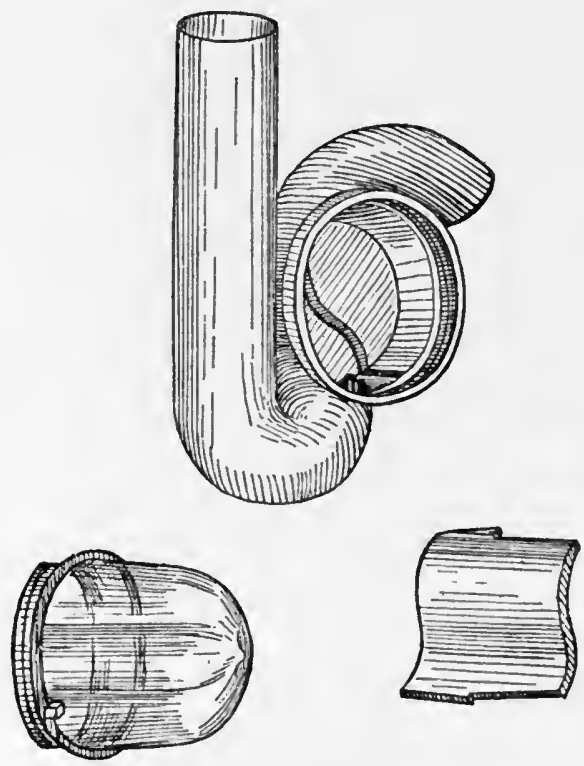

Sanitas trap (taken apart).

has been obstructed at a point just below the entrance of the wastepipe from the fixture, and water has accumulated throughont the entire length of waste-pipe and is discharging into the main ventilating pipe at $\mathrm{V}$. If the point $\mathrm{V}$ were higher than the upper margin of the bowl, this could not oceur, since the bowl itself would fill and overflow into the room, and thus call attention to the obstruction.

Non-siphoning Traps.-A number of traps known as non-siphoning have been devised to obviate the neeessity of back-venting. Among 
these may be mentioned the "Sanitas," invented by Mr. J. Pickering Putnam, and the "Hydric."

The Sanitas trap, shown in Fig. 74, is made proof against siphonic action by a deflecting partition within the chamber, which permits the passage of air above the water and throws back a volume of water sufficient to maintain a seal over three inches in depth, which resists evaporation for a long time and cannot be destroyed by capillary attraction. When attached to fixtures with large outlets and quick discharge, it is also self-cleansing, even when ashes and similar unusual constituents of sewage are thrown into it. In the figure, the several parts are shown separatcly : the main structure, the chamber, and the deflecting partition.

The Hydric trap, shown in Fig. 75, contains no deflecting partition or other mechanical device, but depends upon the aetion of the upper surface of the body of the trap in defleeting and throwing back the water during the sucking of the air through the chamber and over the

Fig. 75.
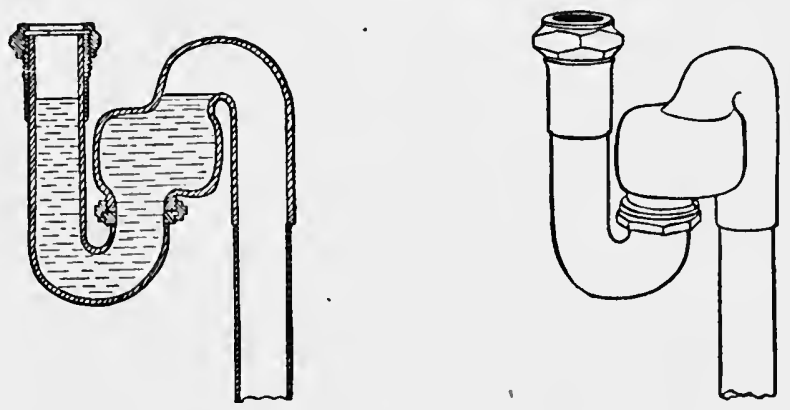

Hydric trap.

water. When the siphoning action is finished, a sufficient volume of water remains to form a permanent seal.

Evaporation of the seal does not commonly occur except after long disuse. It is favored by trap ventilation, since, when a current of air comes in constant contact with a body of water, constant absorption is in process. In order to prevent loss by evaporation in case of long disuse, two processes are in voguc. One is to employ a trustworthy person to visit the premises weekly during the absence of the oceupants and flush each fixture. The other, and, on the whole, the more economical, is to pour into each fixture a sufficient amount of glycerin, which, being hygroscopic, will take water from rather than yield it to the atmosphere, or of oil, which will float on the surfice of the water and prevent its absorption by the air.

Back pressure is a force which is not much to be feared. In former times, when it was not customary to ventilate the soil-pipe, back pressure was caused not uncommonly by winds and the aetion of tides, so that the air in the whole plumbing system was compressed and the seal 
forced backward. Sometimes, a trap situated near the bottom of a tall stack is forced by back pressure, brought about by the descent of a column of water pressing the contained air ahead of it.

Leakage as a cause of loss of seal is too evident to require explanation. Accumulation of sediment may be so extensive as to replace the water in great part, and thus render siphoning much easier. Capillary attraction is a not infrequent eause of loss of seal when accumulations of hair, threads, and other like substanees occur in a non-scouring trap at the outlet and drain away, little by little, the fixture side of the seal into the outfall.

It is hardly necessary to say that nothing should be thrown into traps excepting those matters which are recognized as constituents of normal sewage, that is to say, neither matches, nor rags, nor broken china, nor wads of newspaper, nor stiff writing paper not easily disintegrated by the action of water. All such substances are likely not only to clog traps and break the seal, but also to form obstructions in soil-pipe, particularly where bends oceur.

The extremists who cling to the sewer-air theory of transmission of disease are not always satisfied with ordinary trapping, feeling sure that the water in one branch of the trap will absorb disease germs from the sewer air and discharge them on the fixture side. To avoid this, a system of donble trapping has been advocated, with which assurance is made doubly sure. With this arrangement, we have two traps in immediate succession, so that the waste from the first must pass through the second; thus we have two seals, and any poison absorbed from the farther one and disengaged backward will then meet with a second obstruction. Besides the manifest absurdity of such extreme precaution, there is a decided objection to this arrangement, since solid matters are likely to lodge in the second trap and cause it to be obstructed. While the head of water may be sufficient to drive the waste through one trap, it is by no means certain that it will be strong enough to drive it through two, and, as a matter of fact, it usnally is not. Moreover, between the two traps an air lock is likely to form, and that in itself is a decided objection, as has been explained.

Water-closets.-By reason of the fact that their general employment is a matter of comparatively recent times, it is believed very commonly that water-elosets are the invention of the last half century. They date back, however, many centuries, for in a somewhat simpler form they were in use in ancient Rome and Pompeii, and probably even earlier in Asia and Africa. These primitive forms, however, were devoid of the mechanical appliances, flushing tanks, etc., of the closets of the present day. It is said that the prototype of the present closet was in use in France and Spain before the sixteenth century, but, so far as is known, no liagrams of their construction are extant. In England, the first water-eloset with a flushing apparatus was constructed under the direction of Sir Joln Harington, at his country seat at Kelston, near Bath, and described by him in a satirical, semi-political work, "An Anatomy of the Metamorphosed Ajax," printed in 1596, 
from which work Figs. 76 and 77 are taken. Fig. 76 shows the details of the apparatus deseribed by him as follows:

FIG. 76.

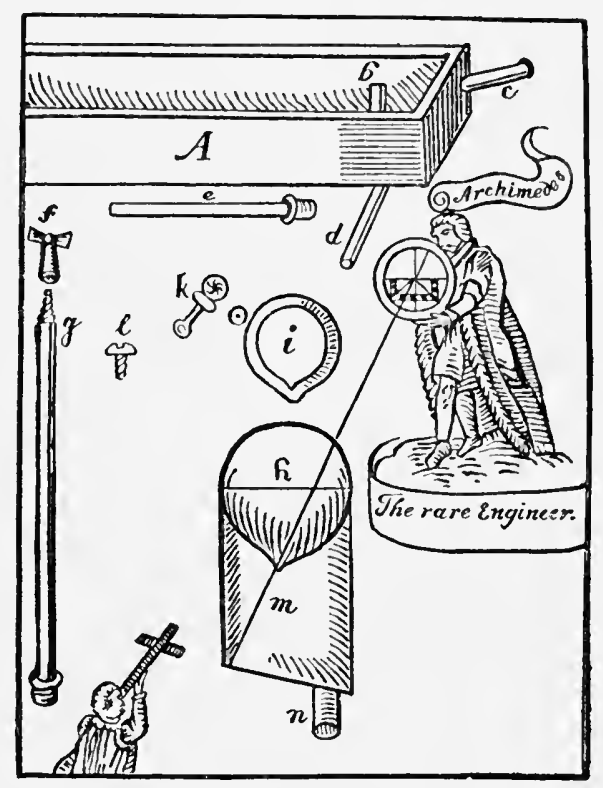

Redueed faesimile of the oldest known (1596) drawing showing details of a water-closet.

"Here are the parts set down with a rate of the prices, that a builder may guess what he hath to pay.

\footnotetext{
" $A$ the eistern; stone or brick. Price.

$b, d, e$ the pipe that comes from the eistern, with a stopple to

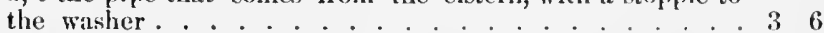

c a waste-pipe . . . . . . . . . . . . . 10

$f, g$ the stem of the great stopple, with a key to it . . . . . 16

$h$ the form of the npper brim of the ressel or stool-pot. . .

$m$ the stool-pot, of stone. . . . . . . . . . S 0

$n$ the great brass sluiee, to which is three inches eurrent to send it down a gallop into the Jax . . . . . . . . . 100

$i$ the seat, with a peak devant for elbow-rom. The whole charge thirty shillings and eight pence; yet a masoul of my masters was oflered thirty ponnds for the like. Memorandnm. The seale is about half an inch to a foot."
}

Fig. 77 shows the apparatus set up and during flushing. "Here is the same all put together; that the workman may see if it be woll. A the eistern. B the little washer. (c the wasterpipe. I) the seat board. $e$ the pipe that comes from the eistern. $f$ the screw. $g$ the scallop shell, to eover it when it is shit down. II the stool pot. $i$ the stopple. $k$ the enrrent. $l$ the sluice. $m, N$ the vanlt info which it falls; always remember that ( ) at noon and at night empty it, and leave it 
half a foot deep in fair water. And this being well done, and orderly kept, your worst privy may be as sweet as your best ehamber."

We have evidence that even among peoples not classed among the highly civilized, the use of water-closets is by no means of recent date. Thus, Ogilby in his elaborate work on Afrien, published in 1670, deseribing the city of Fez, says, on page 187: "The River Fez which Paulus Jovius calls Rhasalme, passes through the City in two Branches; one runs Southward towards New Fez, and the other West; each of these subdividing into many other clear running Channels through the Streets, serving not onely each private House, but Churehes, Inns,

FIG. 77.

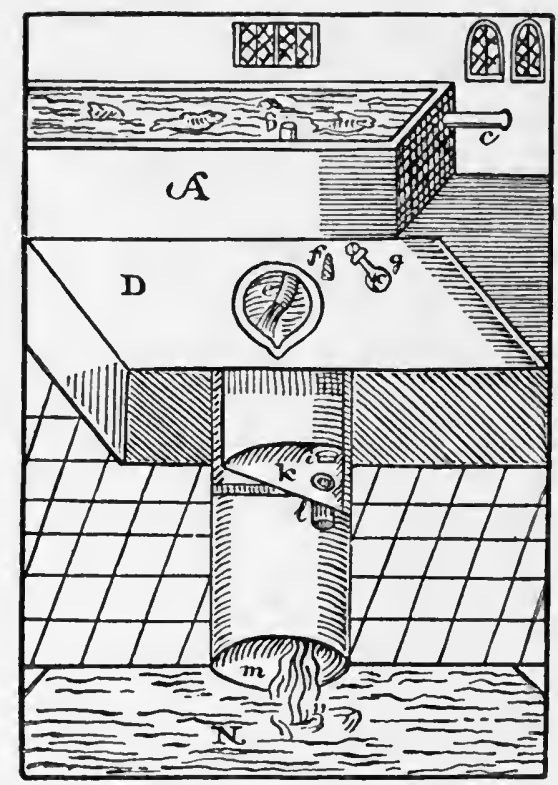

Companion to Fig. 72, showing parts put together.

Hospitals, and all other publick Places to their great conveniences. Round about the Mosques are a hundred and fifty Common-Houses of Easement, built Four-square and divided into Single-Stool-Rooms, each furnished with a Cock and a Marble Cistern, which scoureth and keeps all neat and clean, as if these places were intended for some sweeter Employment."

The water-closets of the present day may be divided into two classes: those having movable internal mechanism, and those having none. To the former elass belong the plunger, or plug, eloset, the pan closet, and a number of others; to the latter belong the hopper eloset, the various wash-out elosets, the siphon closets, and the siphon jet closets. To attempt to describe all the different forms on the market would be a tedious and useless task, for the patented devices alone run up into the 
hundreds. Therefore, in the following pages, only those which may be taken as types of the worst and best will be described. First will be deseribed those of distinetly objeetionable construetion. These include a number whieh, while they are no longer introduced in eommunities having modern plumbing regulations, exist in thousands of houses, into which they were introduced at a time when they were regarded as absolutely perfect.

The Pan Closet.-The principle of this apparatus is shown in Fig. 78 , which is a vertieal seetion of the working part of the closet, free from the cabinet work in which it is usually enelosed. It consists of a hopper $H$, provided with a flushing rim and elosed at its outlet by means of a hinged pan $P$, which is released by a mechanism which it

FIG. 78.

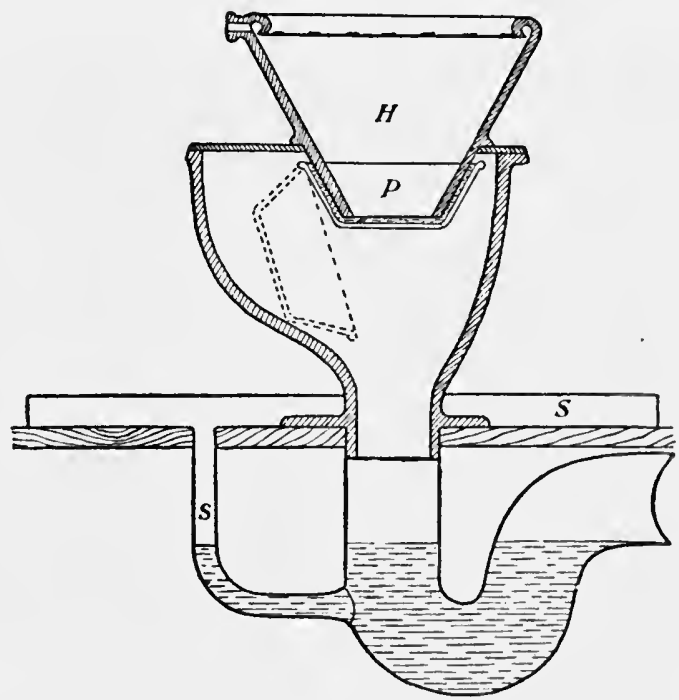

Pan closet.

is unnecessary to illustrate or explain. When the pan is in the horizontal position, it is partly filled with water, into which the excreta are discharged, although ordinarily they come in eontact first with the surface of the hopper above the water level. The eloset is emptied by pulling a knob or handle which releases the pan, which then takes the position shown in the figure by the dotted lines. The contents are thus thrown into the lower ehamber, and fall into the trap below. The mechanism which releases the pan also starts a flush of water through the flushing rim over the surface of the hopper. This flush is supposed to seour the interior and to be sufficiently voluminous to drive the excreta over the bend of the trap and forward toward the soil-pipe. When the pan is brought back to its original place, the flush continues until the pan is filled to the same level as before.

As a matter of fact, the flush of these closets is ordinarily little 
better than a mere dribble. The front wall of the receiving chamber, against which the excreta are thrown by the pan in its descent, is invariably in a filthy eondition, which cannot be improved by any amount of such flushing as the apparatus is capable of giving. The consequence is that each time the pan is dropped, a volume of foul air is displaced upward into the room. The inlet side of the trap is commonly a miniature eesspool, since the flush has so little head that it is unable to drive objects of lighter specifie gravity than that of water through the trap. In the illustration, $S$ represents what is known ats a "safe" to catch all drippings from any souree, and from this, the pipe $s$ conducts them to the bend of the trap. This whole contrivance, formerly the pride of the plumber's craft, is now generally and justly regarded as an abomination.

The Plunger, or Plug, Closet.-This apparatus, shown in Fig. 79, is far less objectionable than the pan closet. It consists of a receiver $B$,

Fig. 79.

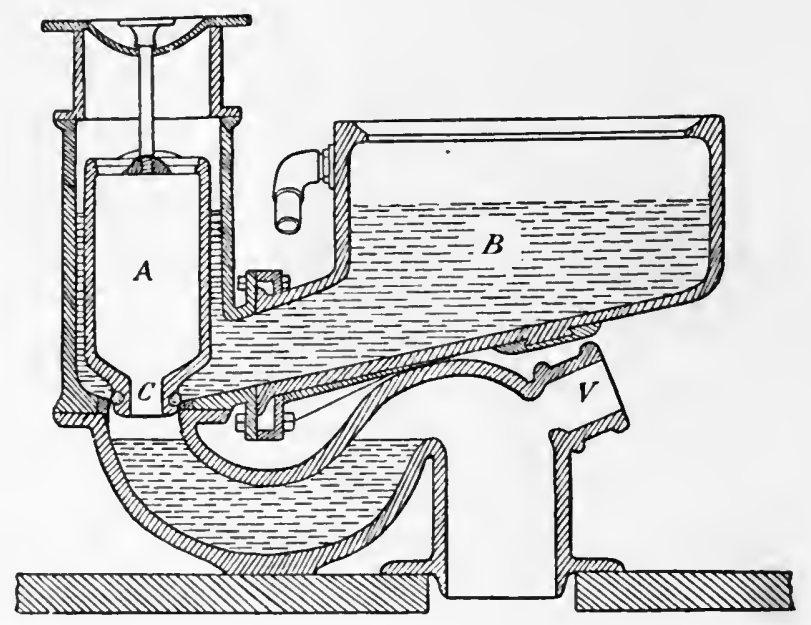

Plunger closet.

in which a large volume of water ean be retained when the plunger, or plug, $A$, is in place. When $A$ is lifted, the contents of $B$ eseape downward into the trap, which is rented at $V$. The plunger $A$ not only controls the emptying of the receiver, but also acts as a standing overflow, for should the water in the reservoir rise higher than the upper level of the plunger, it will flow over into $A$, and from it through $C$ into the trap. This fixture requires a large amount of water in order to obtain a proper flush, for unless the flush is generous, bits of paper and other material may adhere to the edge of the outlet, so that when the plunger is in place the valve is not tight. Naturally, with a loose joint, the contents of the receiver will ooze away and leave it in a dry condition.

These two forms suffice as illustrations of the objectionable class of 
closets, and it may be said, in general, that all closets depending upon internal, meehanical, movable parts are objectionable, and all of them are likely to beeome exceedingly foul.

A properly constructed water-closet should have a flush of water that will wash the whole of the interior surfuce of the bowl most thoroughly, carry onward all the filth and other material beyond the trap, and leave the bowl filled to the proper height with elean water. It should be cleaned so thoroughly every time it is used, that no filth may remain deposited at any point, and it should be free. from disagreeable odor.

Hopper Closet.-The simplest form of non-mechanical closets is known as the Hopper, which is shown in Fig. 80. The illustration hardly needs explanation, the device eonsisting of a hopper connected with a simple S-trap, ventilated in the usual way. Hoppers are known variously as short and long. The long variety presents no advantage over the short, and is kept much less easily in proper condition. The long hopper has its trap beneath the floor; the short hopper, above it. The short hopper is less likely to become foul, on account of the smaller surface presented, and because the level of the water in the trap is nearer the seat. The hopper should be provided with a generous flush from a flushing rim, for otherwise it is likely to become foul, since, from the shape of the receiver, fouling of its posterior interior surface is inevitable. This is more marked with the long than with the short hopper. Unless the flush is a generous one, it is necessary to pour down an oceasional

FI(i. 80 .

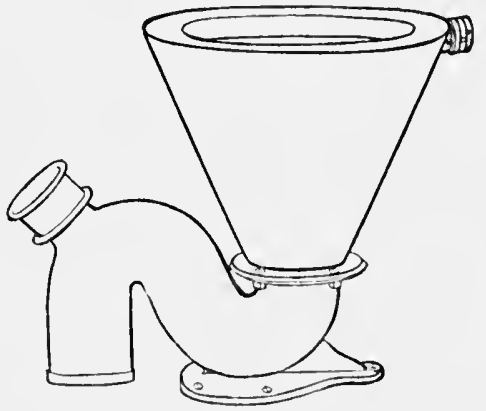

IIopper closet. pailful of water, and also to apply the closet brush at least daily.

Open Wash-out Closets.-The open wash-out closet is designated variously as front or back or side wash-out, aecording to the direction which the contents of the howl take toward the trap. In Fig. 81 is shown a front wash-out in vertical section. The bowl, provided with a flushing rim $F$ fed by the supply pipe $P$, holds a pool of water, into which the exereta are projected. The greatest depth of this volume should not exceed 1.75 inehes. In use, the contents of the bowl are swept by the water from the flushing rim into the trap $s$, which is ventilated at $V$ in the usual manner, and the flow is sulficiently voluminous to foree the exereta down and under the partition.

If the volume of water in the bowl is deeper than above stated, it is possible that the flush may sweep beneath any floating excreta, which, in consequence, may be retained. If no pool at all, or only a very much shallower one, be kept, the excreta may adlhere to the bisin with such tenaeity that they are not easily dislodger by a single flush. For 
the wash-out closet, it was intended to secure the combined advantages of the hopper and the plunger closets, that is, the advantage of a large surface of water in the bowl in addition to that in the trap, without the intervention of any mechanical contrivance. The objections to the wash-out closets are: (1) that the principal office of the flush is the eleansing of the basin; (2) that after each using, the excreta and paper are likely to remain in the inlet side of the trap until the fixture is used again; and (3) that the surfuce against which the excreta are thrown during the flushing is likely to become fouled and remain so until cleaned mechanically by means of a brush or other appliance.

Another form of wash-out eloset has the basin so constructed as to form a trap. Closets of this class are much like the hopper, but hold

Fig. 81.

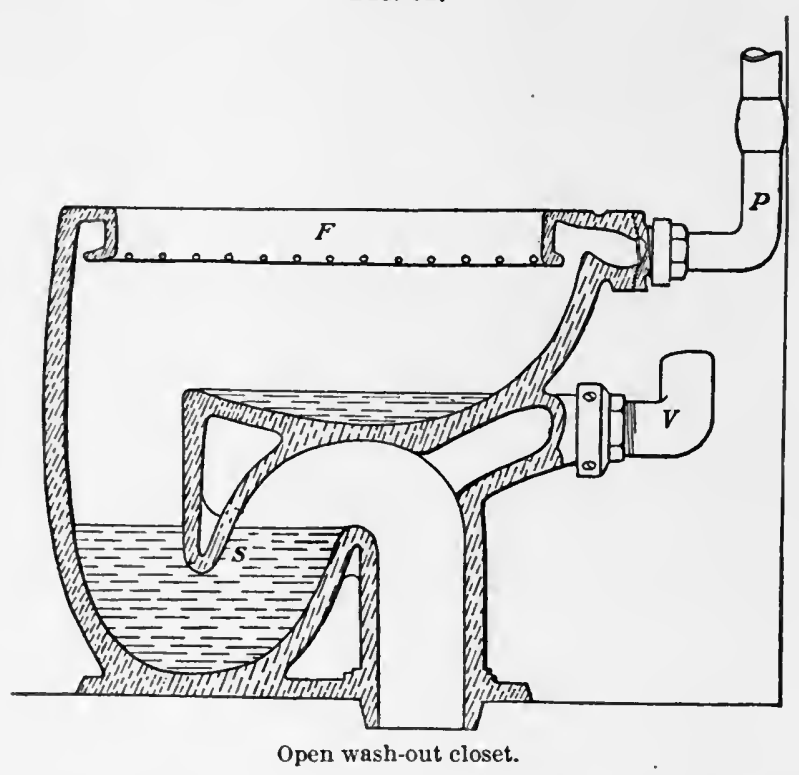

a much greater depth of water. They are known more commonly as "wash-down" closets. In both the wash-out and the wash-down closets, the lip of the trap should dip not less than 1.5 inches beneath the water level; less than that increases the risk of loss of seal by evaporation, and more requires a larger flush than is ordinarily obtainable to force the exereta, ete., downward and onward.

Siphon Closets.-Another type of wash-down closet is known as the siphon jet. In this, the eontents of the receiver are drawn out by siphonage, and at the same time are propelled by a jet of water from the front. In Fig. 82, one of these closets is shown. Here the chamber is divided into two sides of a trap by the partition $S$. As the flush is brought into play, a jet of water comes down with some force through $A$ and pushes the eontents of $B$ over into the ehamber $C$, and, as the flush continues, the chamber $C$ becomes the long leg of 
a siphon, so that when the flush ecases to act, the siphon continues to suck out the contents of the receiver until the water level is brought down to the point $S$, when air is admitted and the siphon becomes thereby broken. The after-flush raises the water level again to its original point.

Fí. 82 .

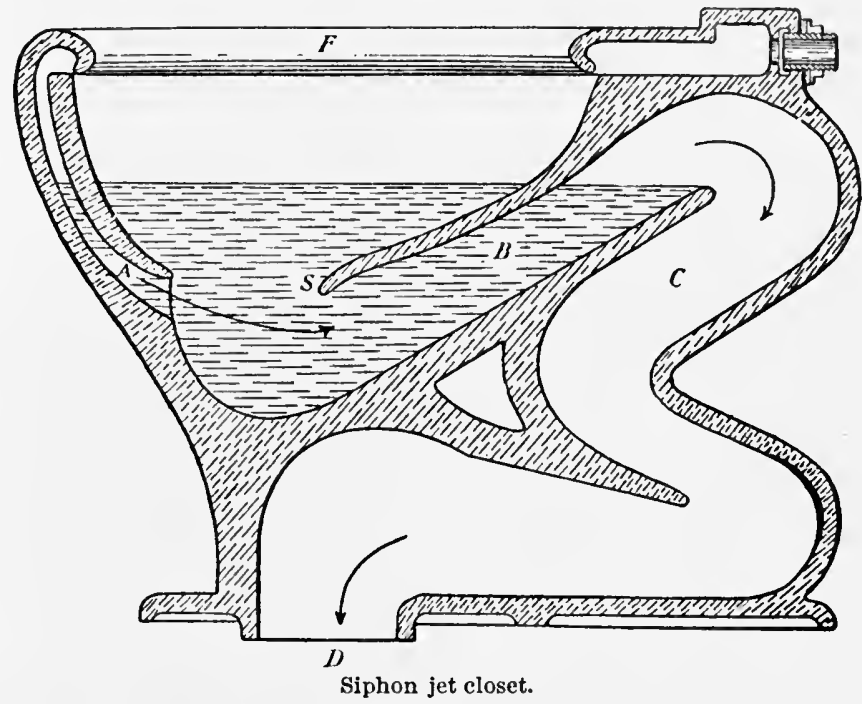

Another form of siphon closet, which acts without the assistance of a jet is known as the Dececo. This is a very simple and efficient fixture, invented by the late Colonel George E. Waring, Jr. The receiver is very deep, and maintains several inches of seal. The apparatus is shown in Fig. 83. To assist in eharging the siphon, a weir-chamber,

Fig. 83.

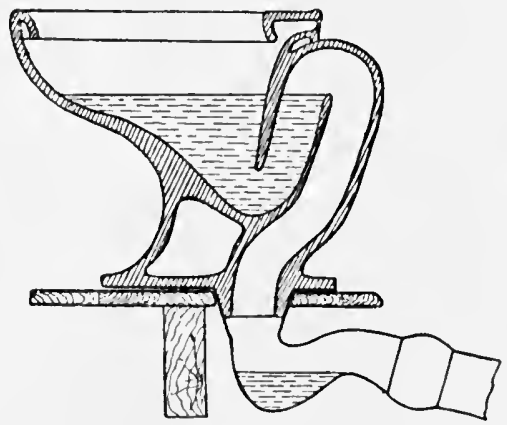

Dececo closet.
Fic. 84.

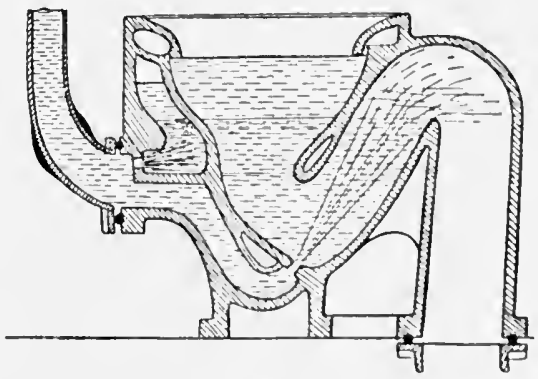

Sanitas closet.

situated below the receiver and just beneath the floor, is employed. When the flush is set in action, the water in the basin overflows aud falls into the weir-ehamber below. 'This hats a constricted ontlet, which is closed very quickly by the descending water, and thereby the 
entrance of air from the soil-pipe side is prevented. As the water rushes into the long leg of the siphon, it pushes the contained air onward, the leg is soon filled with water, and the siphon is eompleted. When the contents of the bowl have been sucked down to the lower border of the partition, the siphon it broken by the admission of air at that point, and the bowl is then refilled by the after-flush.

Still another eflicient form of closet is the Sanitas, shown in Fig. 84. In this apparatus, invented by Mr. J. Pickering Putnam, the flush is accomplisher by the pressure of water in the supply pipe. This pipe enters the bowl below the normal water level and stands permanently full through its entire length up to the cistern. The water is held in the pipe by atmospheric pressure. The upper end of the pipe is closed by the eistern valve, and the lower end by the water beneath the water level of the receiver. The lower portion of the supply pipe is perforated at two different points, through the first of which, water is supplied to the flushing rim, and through the second, a jet is set in action, as in the ordinary siphon jet eloset. When the flush is set in operation, the eistern valve is opened, and the water descends and eseapes throngh the two outlets; through the upper, the passage leading to the flushing rim is filled, and through the lower, the water is projected from the bottom of the receiver up into the siphon. The action is very quick and practically without noise. When the cistem valve is again closed, the water ceases to escape through the openings, and that in the flushing rim and passages leading thereto falls back into the bowl and restores the normal level.

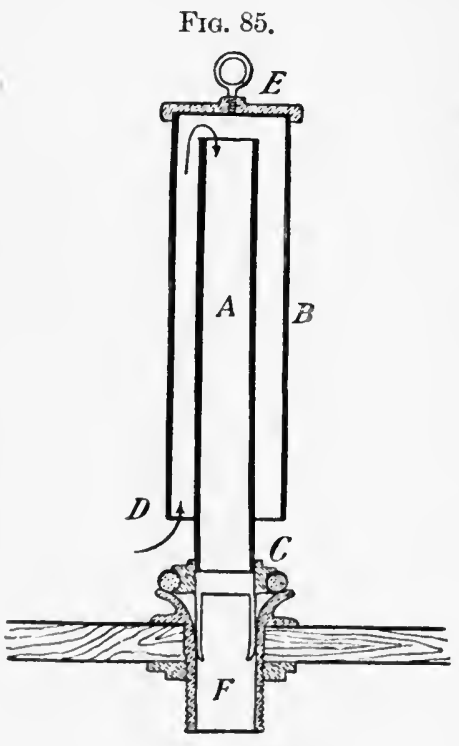

Valre of siphon tank.

Flushing Apparatus.-The object of a flushing apparatus is the thorough removal of all adhering excreta from the sides of the fixture, and its propulsion through and beyond the trap. The flushing rim is connected with a supply pipe of about 1.25 inches diameter, connected with the eistern. Through this pipe, the water is delivered with a rush, and is spread out by the flushing rim in small jets against the sides of the bowl. With some forms of flushing cisterns, the flush continues as long as the lever which opens the valve is held down or until the cistern is emptied completely.

Another form of flushing eistern is known as the siphon tank, the valve of which is shown in Fig. 85. This consists of a double tube, $A$ and $B$, the inner tube $A$ being the longer, and the two tubes forming a siphon. The lower end of the long leg of the siphon $A$ rests on 
a rubber ring at $C$, and forms the valve. The siphon is started in operation by lifting the valve off its seat by means of a chain fastened to the ring in the eap $E$. 'The water rushes downwarl through the flush pipe $F$, sueks the air ont of $A$, and fills the siphon with water. The valve is then dropled back, and the discharge enntinues flowing into the siphon at $D$, and downward through $A$, as indieated by the arrows. The discharge continues until the level of the water is brongint down to the point $D$, when, air being sucked in, the siphon is broksn. Witr this apparatus, the flush tank is emptied every time the fixtmre is used, and the valve needs to be opened only long enough to start the siphon in motion, which object is accomplished in a few seconds.

Still another form of flushing apparatus is shown in Fig. 86. This is emproyed to furnish a large flush and a small after-flush, by means of which the bowl of the fixture may receive water after the main

FIG. 86 .

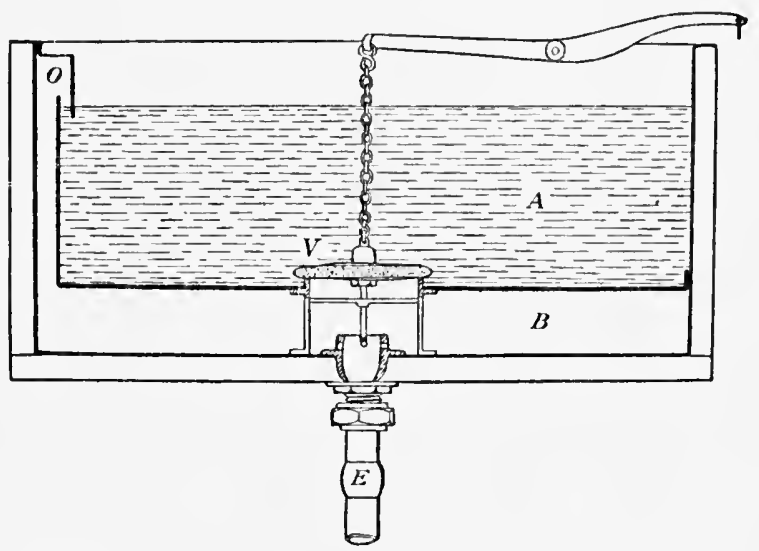

Flushing tank.

flushing has been accomplished. The tank is divided into two chambers, $A$ and $B$. The valve $V$, worked by chain and lever, is 4 inches in diameter. When opened, it discharges water more rapidly than it ean flow through the pipe $E$, and, in consequence, the surplus fills the chamber $B$. When the valve is closed, the main flusll ceases, and a smaller flow continues until the chamber $B$ is empticl. It the point $O$, is the overflow for the chamber $A$ into $B$.

A flushing tank should contain not less than 4 gallons, and, except in the case of the Sanitas closet, should be not less than 6 feet above the closet bowl.

Water-closet Connections.-The ordinary method of eonneeting a modern water-eloset with the soil-pipe branch is hy means of what is known as a brass floor-plate joint. The soil-pipe branch is fastened by means of solder to a brass flange, which is screwerl to the floor. The eloset flange is set npon an intervening rubbor gasket, and the two are then serewed or bolted together. The eommon putty joint should not 
be used, for although it may not leak water, it is usually pervious to air and odors. In screwing up the poreelain branch, great care should be taken to avoid breakage. Some closets are made in two pieces, the bowl being of porcelain, and the trap of iron or other metal with a porcelain lining. With these, the danger of breakage is redueed to a minimum.

Urinals.-The urinal is a fixture which should not be tolerated in a private house, since, with the best of care, they are almost inevitably offensive and, with ordinary eare, are sure to be a decided nuisance. They are necessary only in large buildings, and there they require abundant and frequent flushing and constant care. The waste-pipe is commonly coated on the interior as far as the trap with a deposit derived from the urine, and does not yield it readily to flowing water. The application of washing soda or of solution of ordinary potash is ineffective, but hydrochloric acid in 10 per cent. strength, followed shortly by a generous flush of water, will remove it. Weak sulphuric acid, about 2.5 per cent., is also efficient.

Wash Basins. - Wash basins are made of metal, as copper, enamelled and galvanized iron, and of earthenware and porcelain. Most commonly, they are of glazed earthenware. In shape, they are either cireular or oval. The latter form is generally preferred, as it affords more space for frec action of the arms than a circular one of the same

FIG. 87.

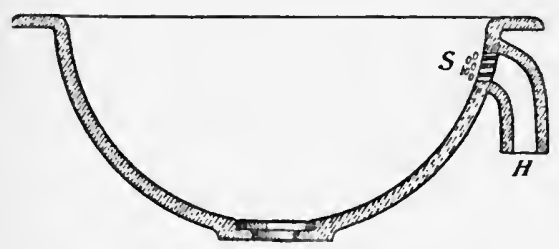

Wash basin with overflow.

eapacity. Some bowls are made with a flushing rim at the top, through which hot and eold water are introduced together on all sides, and thus the entire surface of the bowl is more easily kept clean. In the upper part of the commonest form of basin (see Fig. 87) a number of perforations $(S)$ communicate with the overflow horn $(H)$ eonnected with the waste-pipe. Ordinarly, these outlet holes are unable to deliver water as rapidly as it enters through a fancet with moderate head, and eonsequently too mueh dependence should not he placed on them in the prevention of overfilling of the basin. In some bowls, the entire overflow horn is an integral part of the fixture, opening just beneath the plug, as shown in Fig. 88. Where the horn does not so extend, its junction with the waste-pipe is not infrequently wrongly made; sometimes, it is connected below the trap; sometimes, at the crown of the trap, iuto or near the vent pipe. The 
overflow horn, especially with long use of the fixture, is very likely to become foul, on account of the soap and filth which become deposited

FIG. 89.

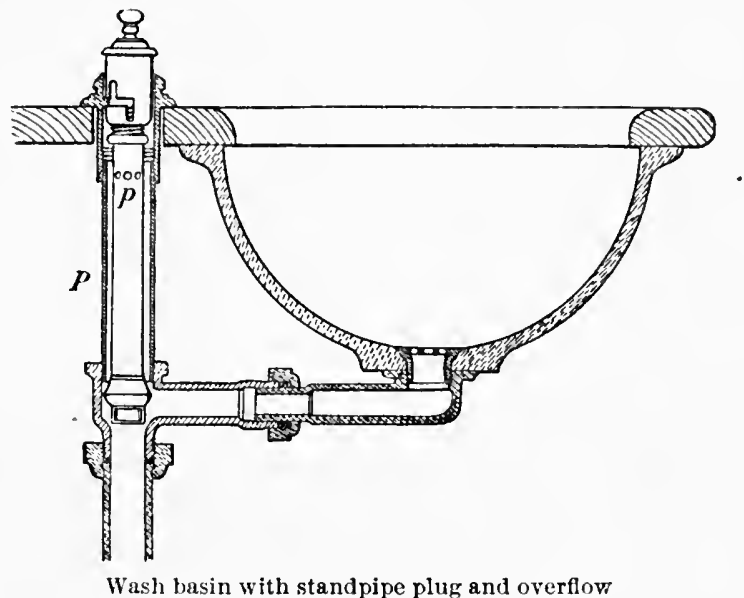

Wash basin with standpipe plug and overflow

along its inner surface. In fact, the odor which is ascribed commonly to "sewer gas" eomes from the horn and from the waste-pipe between the bowl and the trap. Another source of odor of much less importance

FIg. 90.

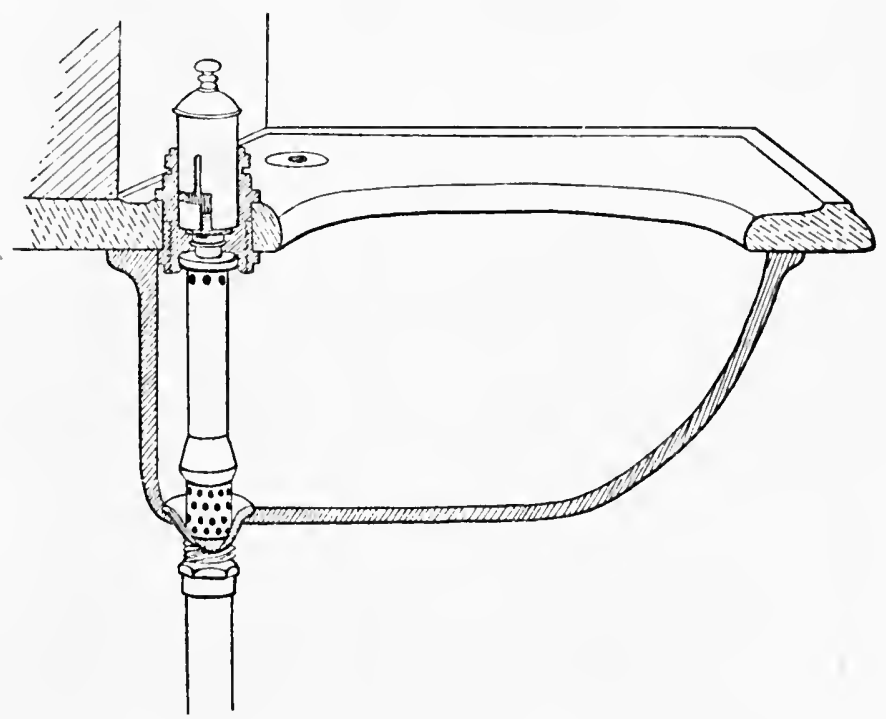

Improved standpipe overflow.

is the ehain attached to the plug. This gradually collects within its links the same kind of deposit, which is removed completely only with 
some difficulty and much scrubbing with a brush. On account of the fonling of the chain and the inconvenience of having it in the way of the hands, some forms of basins are equipped with a standpipe, which acts as plug and overflow at the same time. In Fig. 89. such an arrangement is shown; the bowl presents no irregularities of surface, not even a plug. 'The standpipe $p$, enelosed in the pipe $P$ ', acts as a valve when it is dropped into place, and the surplus water, rising between $P$ and $p$, escapes through the holes in the upper extremity of $p$. The device is lifted by a knob, and is kept off the seat hy means of a bayonet cateh. In the illustration, the pling is off the seat.

'The principal objection to this form of waste-valve is that the ontlet is situated at a considerable distance from the outlet of the bowl, and the entire surface between these two points is certain to become foul. Furthermore, small bits of lint and hair are likely to be deposited near the seat and canse it to leak so mapidly that the bowl cannot hold water for any length of time. A better form is shown in Fig. 90. Here the standpipe overflow llas its seat directly in the outlet of the basin, and may easily be got at and eleaned.

Bathtubs.- Bathtubs are made of various materials in a number of forms. The finest grade of tubs are made of porcelain or of fine earthenware with a heavy enamel of poreelain. They are made in various shapes and very commonly are decorated somewhat ornately. They are very heavy and quite expensive. The plainest varieties have most commonly the shape shown in Fig. 91. They are usually set

FiG. 91.

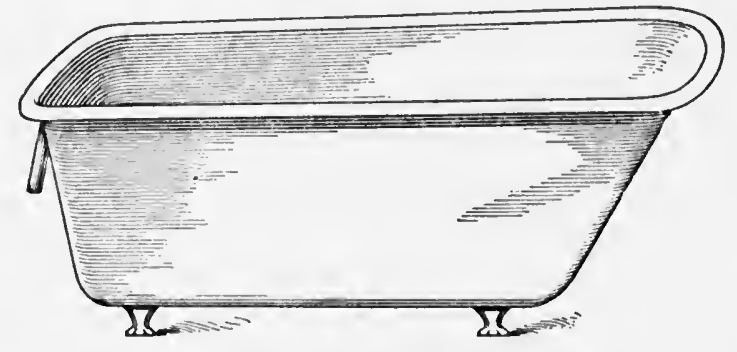

Porcelain or iron bathtub.

upon slabs of marble. Tubs of iron with a lining of porcelain enamel also are made in this form. These are open to the objection that the enamel is chipped off very easily. Within recent years, a cheap form of tub in this shape, made of ordinary tin plate, has been introduced. In spite of the iron frame with which it is surrounded, it is constructed very flimsily.

The commonest form of bathtub used in this country is made of tinned and planished eopper, weighing from 10 to 24 ounces to the square foot. In Fig. 92, this form of tub is shown in vertical section. Inasmuch as the copper is to all intents and purposes the lining of a box, it is necessary, for the sake of appearances, to bave an outside 
casing of cabinet work. The ordinary tub is provided with a waste plug, chain, and overflow, as shown in the figure. Not nneommonly, the chain and plug are supplanted by an ordinary pipe of the desired length,

Fig. 92.

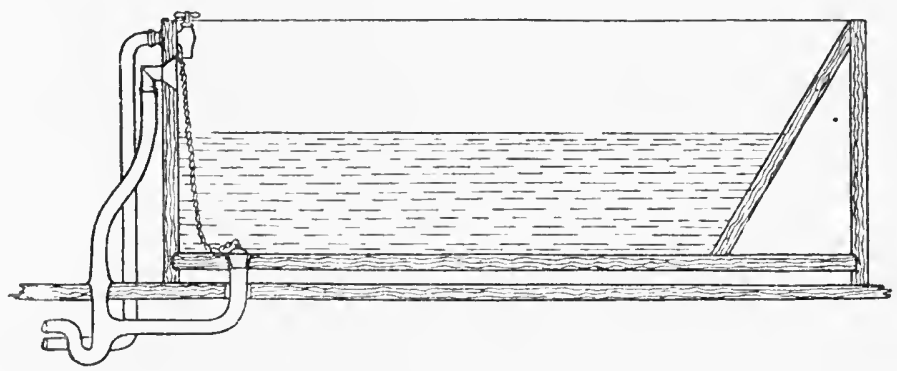

Vertical section of commonest form of bathtub.

which fits into the outlet of the tub, and thus acts both as plug and overflow. In some of the tubs of more claborate construction, a standing overflow and waste-pipe, shown in Fig. 93, is used. In this, the

Fia. 93.

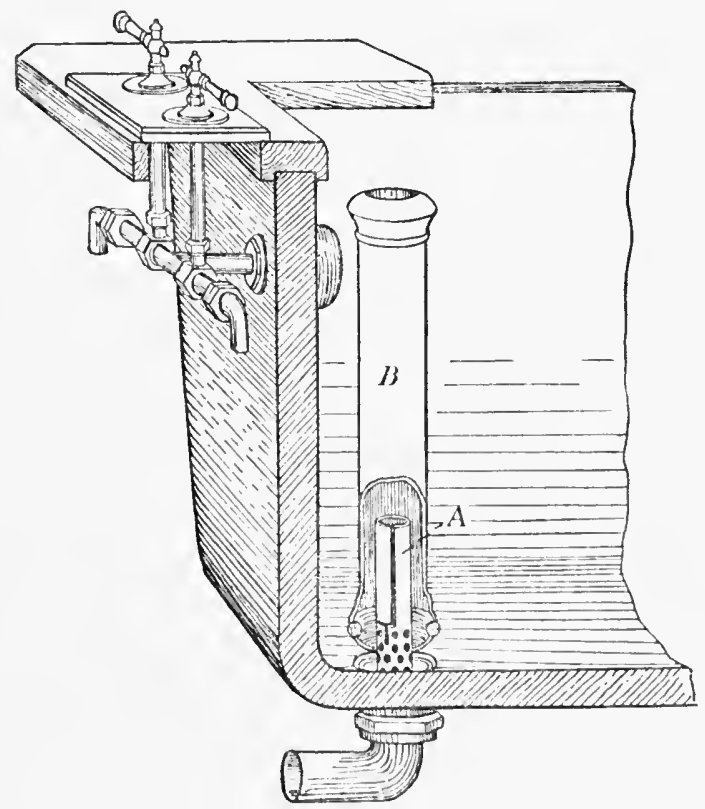

Standing overflow and waste-pipe.

overflow passes over and into the pipe $B$ and escapes through the bottom. When the tub is to be emptied, the tube is lifted, and thereby the perforations at the bottom of the inner tube $A$ are exposed. On 
the whole, this form is in no way superior to the ordinary standing overflow, but possesses certain disadvantages which do not apply to that device, which can be removed completely from the outlet each time the tub is emptied.

Other forms of baths, including the sitz-bath, foot-bath, showerbath, douche, and needle-bath, and bidets are found ordinarily only in the very elaborately fitted bath-rooms of the very wealthy. As plumbing appliances pure and simple, they possess no special hygienic interest, the matter of waste-pipes, trapping, ete., differing in no essential respects from what has been described in connection with other fixtures. The shower-bath, which consists mainly of a large sprinkler from which water is delivered downward in fine streams, is very commonly set above the ordinary bathtub, with a screen of wood or curtain of rubber eloth or other suitable material to prevent splashing the floor. Smaller arrangements, consisting of a sprinkler, such as is attached to the nozzle of a watering-pot and a rubber tube to conneet with the faucet of the bathtub, are very commonly used. If desired, the rubber tube may be attached to a mixing pipe, which in its turn is attached to both cold and hot water faucets, and thus the temperature of the shower may be regulated.

Sinks.-Under sinks are included pantry sinks, kitchen sinks, and slop sinks. These are made of various metals, including cast-iron, enamelled iron, steel, and copper, and of soapstone, slate, earthenware, and porcelain.

Cast iron is easily kept clean with ordinary care, but on account of danger of the breaking of dishes and other articles which are washed or otherwise handled in them, a grating of wood not uneommonly is laid on the bottom. This easily becomes foul, particularly if it is allowed to stand in the wet sink when not in actual use. All such gratings should be kept scrupulously clean, and when not actually needed in the sink, should be hung up in the air.

Enamelled iron is much more desirable than plain iron, and presents a much better appearance. Unfortunately, however, the enamel is very easily eracked and detached.

Steel sinks are not so durable as ordinary cast iron, but they are light and eheap. They are very commonly enamelled, and then they are necessarily open to the objection above mentioned.

Tinned and planished copper is much used for pantry sinks, which are made commonly with rounded, but, better, with perfectly flat bottoms. The copper should have a weight of not less than 18 to 24 ounees per square foot.

In some quarters, soapstone is the favorite material for kitchen sinks. Ordinarily, it is quite durable, particularly if it has been subjected to a preliminary oiling, but some specimens show a tendeney to disintegrate very rapidly, and to become so pitted as to present a honeycombed appearanee.

Farthenware sinks are thick and heavy, and present no advantages over soapstone. 
Porcelain is expensive, and, if thin, is easily broken. It is not extensively used in ordinary sinks.

All sinks should be provided with a not too fine strainer over the outlet. Kitchen and pantry sinks are connected best with a grease trap. The common practice of constructing cupboards or closets beneath sinks should be discouraged, since these spaces are commonly maintained as clutter-holes in which to store unwashed pots, kettles, and other utensils, which, in unclean condition, would not be tolerated in positions where they are open to inspection.

House-maids' sinks, commonly known as slop sinks, are located generally in small, dark, unventilated closets in the upper story. This form of fixture is made rather deeper than an ordinary sink, and is sometimes shaped like a hopper. They are made best with a flushing rim, which will assist in lieeping the entire surface elean and free from odor. On account of the nature of the refuse poured into these receptacles, and becanse of the great probability of the occurrence of splashing when vessels are emptied, these sinks are often extremely foul, and the elosets in which they are placed are then always necessarily offensive. The greatest eare is necessary to insure eleanliness.

Laundry Tubs.-Laundry tubs are made of practically the same materials as sinks. 'The eheapest kind is made of stout planking with well-fitting joints drawn tight by iron bolts. This form is not very durable, since the alternate drying and wetting soon ruins the joints and causes the wood to decay. Those made of porcelain and earthenware are heavy and expensive, but are very durable and readily kept elean. The soapstone tub is regarded generally as the most satisfactory, but it should be made of naterial of the best quality, since otherwise it is liable to chip and erack off from constant contact with hot water. All enamelled tubs are likely to lose their enamel, which is separated easily from the metal and chipped off.

House Service Tanks.-With most plumbing systems, it is essential that, in the upper part of the building, above the highest fixture, there shall be a service tank to feed the hot-water boiler and the various flushing eisterns connected with water-elosets and other fixtures. These tanks are eommonly placed in positions where acess to them is not easy, and, in consequence, they are, as a rule, examined very infrequently. No matter how carefully they are eovered and regardless of the kind of water that enters them for storage, they aceumulate more or less clust, dirt, organie matter, and other sediment. All this adheres to and aceumulates on the bottom, forms a slimy eoat upon the sides, and there remains until removed by some externil force. It is hardly neeessary to say that this eondition should not be permitted. The tank should be inspeeted periodieally and thoroughly eleaned. Fortunately, it is neither neeessiry nor enstomary in ordinary dwellings to use water from the service tank either for drinking or for cooking, sinee the coldwater service pipes connect directly with the strect main, and are tapped at intervals with fancets and terminate at the tank, where their delivery is regulated by means of ball-cocks. Inasnuch as the water from the 
tank is not used for drinking and cooking, excepting in houses not connected with the public supply, but served from a tank filled periodically by pumping, it makes no very great difference from a hygienie standpoint of what material the tank is built. $A$ very good tank is made of riveted iron plates lined with eement of proper quality. Wooden tanks are much used, and give satisfaction if they are kept full and clean. The tank which, on the whole, is most satisfactory is constructed of wood, with the sides secured to the ends by long bolts, and lined with timed copper of good weight. Lead forms a poor lining, for it is corroded easily by water. Galvanized iron and sheet zine also make poor lining material. In large office buildings in which all the fixtures, including those from which water for drinking is obtained, are supplied from a main tank in the upper story, it is advisable that the lining of the tank should be of tinned copper, and under no circumstances should it be of lead.

Service Pipes.-The method of installing the water service is of slight interest to the hygienist and requires no discussion, the nature of the pipes having been considered in another chapter; but there is one minor trouble connected with them which may be a cause of great annoyanec, especially to persons of nervous or irritable nature. This trouble is commonly known as water-hammer, and is something more than an annoyance, since its occurrence has a weakening effect on the entire pipe system. This is the quivering and rattling that occur from end to end when the eurrent of water within them is checked suddenly by the quick closure of a cock or valve. In order to prevent this, it is necessary to make some provision for a cushion, particularly where the water pressure is very great. This not infrequently runs as high as a hundred pounds to the square inch, and even higher. To cushion the blow, an air chamber, commonly made by turning the pipe upward for a foot or two above the eock, is used. This extension will at the outset contain a volume of air, which, on being compressed by the force of the water, makes an elastic cushion. Sometimes, however, the air originally eontained becomes gradually absorbed by the water which is driven into the chamber, and thus it becomes replaced by water and the cushion is destroyed. In such an event, it is well to shut off the water and empty the pipes so that air may again fill the chamber. Another form of air chamber recommended is made by extending the pipe with a piece of larger diameter, eovered at the top with a tightly fitting screw cap. Within this extension, may be placed two or more rubber balls, upon which the foree of the blow of the water-hammer may be expended.

Water-hammer of a most annoying and persistent kind is oceasioned often by the too easy movement of a light ball-cock controlling a current of high pressure in a small tank. For example, the water in the tink becomes lowered through the use of some fixture below, the ball, floating on the surface, opens the valve of the cock, and water is admitted to take the place of that which has been drawn off. The water, entering with much foree, sets the whole contents in motion. 
The ball is thrown up and shuts off the water with great suddenness and falls again ; another jet of water is thrown in, and thus, with alternate quick jets and movement of the ball, the hammering eontinues, until finally the level of the water has been restored to its original point.

Testing Plumbing.-Tightness of joints throughout a system of plumbing may be determined in several ways. For testing the joints of soil-pipes and main drains, a most important and searching test is that known as the water-pressure test. This is applied bifore any fixtures lave been joined to the wastes and soil-pipe. All outlets are closed with appropriate plugs, made for the purpose and kept in place by means of bolts, and then the entire pipe with its branches is filled with water. Should there be leaks in any part of the system, the fact will be made manifest by the sinking of the water, and the points of eseipe may easily be found on inspection.

The other methods applicable to the entire system inelude the smoke test and the peppermint test. In the smoke test, the system is filled with smoke by means of a device known as an asplyyxiator. If leaks exist, the fact will be made evident in two ways : first, to the sense of smell; seeond, to the sense of sight. Besides the asplyxiator, a number of other deviees, including the smoke rocket, have been invented. The common method of testing plumbing in this eountry is known as the peppermint test. For this test, the presence of two persons is necessary; one to apply the peppermint, and the other to detect its presence in the air of the building. Abont two ounees of oil of peppermint are used for each stack of soil-pipes. This very pungent oil should be earried through the house in very tightly eorker vials, in order that no odor shall be given off in transit. The vent openings are elosed first with plugs, and the oil of peppermint is then poured into the soil-pipe, and is followed by a quart or two of hot water, to assist its volatilization. The outlet is then closed securely. On account of the elinging quality of the odor, the person who empties the peppermint should remain on the roof, with the seuttle elosed, until thorough inspection of the premises has been made. The vapor of the oil permeates all parts of the soil-pipe and its connections, and in case of defective seal or any other imperfection in the system, it escapes and makes its presence known in the rooms through its effect on the sense of smell. During the examination, it is important that no water-eloset be pulled and that no bowl, bath, or sink be used, since thereby the whole of the peppermint may be driven out of the system into the sewer. 


\section{CHAPTER VI.}

\section{DISPOSAI, OF SEWAGE.}

THE composition of sewage varies aceording to the character of the community by which it is produced. To the lay mind the word conveys the idea of a mixture of urine, frecs, and paper, with the waste water from bath-tubs, laundries, kitchen sinks, etc. This is domestic sewage, and may be taken as the type of that from purely residential districts. The sewage of a large community, however, in which all manner of manufacturing is carried on, is necessarily of a more complex character, containing, as it does, in addition to domestic waste, that which is produced by various industries. Establishments like paper mills, tanneries, dye houses, woolen mills, etc., frequently produce large volumes of industrial sewage; in fact, one industrial plant often produces as much liquid waste as the residential portion of a fairly large town, and such manufacturing sewage often contains much more organic and other matters than does domestic sewage. Where the water supply is abundant, domestic sewage contains but a small fraction of 1 per cent. of organic matter. It is this very small percentage, however, which is the important constituent of sewage, and which may be the cause, direct or indirect, of injurious effects upon health. The importance of the quick removal and disposal or purification of sewage is a matter of great importance to thickly settled communities. In such communities systems of sewerage, to which each house is, or should be, connected, are generally installed, and sewage from these sourees shonld either be disposed of by dilution, as can often be done by large communities on the seashore or those situated upon large rivers or lakes, the waters of which are not used for domestic water supply, or it can be disposed of upon land or by more modern methods of purification, to be considered later. Where residences are so situated that eonnection with sewers is impossible, as on country estates, etc., the oldfashioned cesspool is still much used, and when properly constructed and located can be used without danger to the health of the neighborhood, but upon large estates, both in this country and abroad, small installations of modern purification plants are growing in popularity.

Before proceeding to the consideration of the various methods of disposil and purification, it may be well for a moment to consider sewage from an economic standpoint. Until well into the nineteenth century the sewage problem, as now known, was little heard of or discussed. The disposal of filth was a health problem almost entirely, needing, of course, care and attention in cities and towns-more care and attention probably than was paid to it. With the invention of the 
water-closet in 1810 and the more general introduction of public water supplies, the problem of the disposal of large volumes of polluted waste water became more pressing, and sewage disposal began to be, to a considerable extent, an engineering problem. Previously, the wastes from human life were conserved in such condition that they were of fertilizing value, but with the introduction of public water supplies, the valuable constituents of sewage were so diluted in enormous volumes of water that their economical recovery became an almost hopeless task.

In the minds of many, however, the belief still remains that municipal sewage possesses great manurial value, and that disposal of it without previous treatment for the purpose of reclaiming its valuable constituents is wasteful. This idea of its value has, doubtless, never been more forcibly expressed than by Victor Hugo in the following passage: ${ }^{1}$

"Paris casts twenty-five millions of franes annually into the sea; and we assert this without any metaphor. How so, and in what way? By day and night. For what object? For no object. With what thought? Without thinking. With what object? None. By means of what organs? Its intestines. What are its intestines? Its sewers. Twenty-five millions are the most moderate of the approximate amounts given by the estimates of modern science. Science, after groping for a long time, knows now that the most fertilizing and effective of manures is human manure. The Chinese, let us say it to our shame, knew this before we did; not a Chinese peasant-it is Eckeberg who states the fact-who goes to the city but brings at either end of his bamboo a bucket full of what we call filth. Thanks to the human manure, the soil in China is still as youthful as in the days of Abraham, and Chinese wheat yields just one hundred and twenty fold the sowing. There is no guano comparable in fertility to the detritus of a capital, and a large city is the strongest of stercoraries. To employ the town in manuring the plain would be certain success ; for if gold be dung, on the other haud, our dung is gold.

"What is done with this golden dung? It is swept into the gulf. We send at a great expense fleets of ships to collect at the southern pole the guano of petrels and penguins, and cast into the sea the incalculable element of wealth which we have under our hand. All the human and animal manure which the world loses, if returned to land instead of being thrown into the sea, would suffice to nourish the world. Do you know what those piles of ordure are, collected at the corners of strects, those carts of mud carried off at night from the streets, the frightful barrels of the night-man, and the fetid streams of subterranean mud which the pavenent conceals from you? All this is a flowering field, it is green grass, it is mint and thyme and sage, it is game, it is cattle, it is the satisfied lowing of heavy kine at night, it is perfumed hay, it is gilded wheat, it is bread on your table, it is warm blood in your veins, it is health, it is joy, it is life.

"So desires that mysterious creation, which is transformation of earth

1 Les Miserables, part 5, book 2. 
and transfiguration in heaven ; restore this to the great erucible, and your abundance will issue from it, for the nutrition of the plains produces the nourishment of men. You are at liberty to lose this wealth and consider me ridieulous into, the bargain ; it would be the masterpiece of your ignorance. Statisties have calculated that France alone pours every year into the Atlantic a sum of half a milliarl. Note this : with these five hundred millions, one-quarter of the expenses of the budget would be paid."

Notwithstanding this and other statements as to the fertilizing value of the organic matter, the fact remains that when these matters are so diluted that they amount to less than a thousandth part of the whole, to reelaim them in concentrated form involves an expense far in excess of their value. A fair estimate of the value of the manurial matters contained in a ton of crude sewage of average composition places it somewhat less than four cents, an amount so small as to make its reeovery from about two hundred and fifty gallons of water highly impracticable. The value of the sewage of eities with a large water consumption is even less than this. The sewage of Boston has been estimated by the Massachusetts State Board of Hcalth to be worth about one cent per ton, and that of New York even less. To separate this small amount of valuable organic matter sedimentation and chemicals are necessary. The resulting body known as sludge has a certain agricultural value, but that value is not such as to warrant generally the cost of handling and transportation. In the London sewage disposal seheme, for instance, thousands of tons of wet sludge are produced daily, and anybody who wishes for it ean have it free of eharge. Notwithstanding this, practically none of it is taken, and it is carried out to sea in sludge ships to Barrow Deep, fifty miles away, and dumped.

The disposal of the sludge, or the organic matters in suspension in sewage, raises the chief difficulty in sewage treatment at the present day, for only an oceasional municipality is able to give away or sell this sludge for agricultural use. In considering sewage disposal, it should be borne in mind that it is a public necessity as much as police and fire patrol ; that it costs money and that it cannot be a source of ineome over expenditure. No community expeets a peeuniary return on an investment for steam engines or for police stations, much as they are needed for the protection of life and property; so, too, a system of sewage and sewage disposal is necessary for the protection of health, and is not to be treated as if primarily intended as a source of public revenue. Any return, however, which may be possible, either from the sale of sludge or crude sewage, may be regarded as a welcome diminution in the cost of maintenance.

\section{METHODS OF SEWAGE DISPOSAL.}

The methods of sewage disposal include:

1. Dilution by discharge into the sea or other bodies of water.

2. The "dry method" or pail system. 
3. Chemical treatment followed by dilution or filtration.

4. Irrigation or "sewage farming."

5. Filtration or biological disposal.

1. Discharge into the Sea.-In communities on and near the coast, it is a comparatively easy matter to get rid of sewage by discharging it into the ocean and having it carried away by the outgoing tide. If it be disebarged in a fiesh condition, it becomes so enormously diluted in a very short time that only under exceptional cireumstances can it ever be a nuisance in any way. This, of course, presupposes a reasonable rise and fall of the tide and the consequent production of currents of considerable velocity. With slow movement, less than one and a half miles per hour, deposits are more than likely to be formed and a nuisance eansed. Thus it happens that, even on the seaboard, it may be necessary to at least partially purify sewage before discharging it, and the problem of successful and economical purification may be one of the most difficult and important in the whole range of sanitary science.

In inland communities situated on rivers of considerable size, delivery at a point below the town is the easiest method of sewage disposal; but other communities farther down may properly object on more than one ground to such action, for the sewage itself may be a nuisance.

In both rivers and harbors, in order to prevent nuisance from untreated sewage, the eurrent should be sufficiently volmminous and strong to afford large dilution and prevent deposition.

Studies by the Massachusetts State Board of Health, in regard to the volume of sewage that can be disposed of in rivers by dilution, are summarized in the following words of $\mathrm{X}$. H. Goodnough, Chief Engineer to the Board, in a report to the Committee on the Charles River Dim, 1903 :

"Omitting reference to objections eaused by the manner of diseharge of sewage aud objections which may be due to various other cireumstanees, and considering only the question as to whether objectionable conditions exist in the various streams into which sewage is discharged by reason of the quantity of sewage diseharged, an examination of all information available from the investigations that have been made shows that where the flow of a stream exceeds 6 cubic feet per second per 1000 persons discharging sewage, objectionable conditions are unlikely to result."

2. The Pail System.-This is limited in its application to the disposil of exereta in pails containing dry earth, peat powder, or other material, and although it is in operation in several places of considerable size in England and on the Continent, it is better adapted to the needs of isolated houses and small villages. It was the natural outgrethth of the very extensive adoption of the earth-closet, a derice invented by the Rev. Henry Moule, in which the solid exereta are discharged into a receptacle of suitable size and covered after each addition with dry earth, peat powder, or ashes. As often as necessary the pails are collected and emptied, and their contents are removed to a distance, treated or not with ehemicals, according to circumstances, and buried 
or used as manure. From the fact that the collection is made at night arose the common term night-soil, and later, from this one, another to designate an important part of house plumbing, the soil-pipe.

It is a primitive sort of system, but it has points in its favor as well as against. It is not expensive, there is no pollution of streams, and the manurial value of frees is not wasted. But it requires the collection, drying, and storage of a large amount of earth, or other material, not always easy to obtain ; the emptying. of the pails is neeessarily accompanied by the escape of more or less odor; it may possibly give rise to a nuisance at or near the place of final disposal; and additional provision must be made for the removal of liquid refuse.

The materials ised in the pails are ehiefly dry earth and peat, both of whieh substanees are very absorbent. The earth is ordinarily cither simply dried or thoroughly baked, but drying is preferable to baking, because the influence of the saprophytic bacteria of the soil is not destroyed.

Sawdust also is reeommended for use in earth-closets, and as an absorbent for urinals where there is no water supply. Experiments eonducted by Dr. G. V. Poore ${ }^{1}$ with various materials proved its value for the latter purpose and yielded interesting results. A flannel bag, two and a half feet long and a foot broad at the bottom, containing 6 pounds of dry sawdust, received in the course of two months 39 pounds of urine; after about a year 45 pounds more were added during a period of three months. Notwithstanding that the bag had become so rotten as hardly to hold together, the contents were not in the least offensive, and had never given off any offensive odor. Of the 84 pounds of urine added, only 6 pounds had filtered through, while the rest had evaporated or had been retained. The filtrate was dark brown in eolor, thick, and of high speeifie gravity, but never offensive; nor had it shown, after lying about for months, any tendeney to putrefy or beeome offensive. Filtration through earth, old stueco, and peat moss gave identical results. With fresh earth, fresh stuceo, and fresh ashes the filtrate was almost eolorless and odorless, but the power of ashes to give this result is short lived.

The pail system, whatever may be said in its favor, has had its day in large communities, and where it still obtains, it is being superseded gradually by systems more suitable and satisfuctory.

3. Sedimentation and Chemical Precipitation.-As has been stated, the ehief difficulty in sewage purification is proper and adequate removal from the sewage of the matters in suspension in it, and of the disposal of the sludge so formed. Practically every sewage-disposal system of any considerable size is provided with settling tanks through which the sewage passes before reaching the filters. At a few plants in America, and at many plants in England and on the Continent, all the sewage eoming to these plants is treated ehemically before passing to the filters.

"The reason that chemical precipitation is employed so largely

1 British Medical Journal, Aug. 31, 1895. 
where modern filters are in use in England is that by such chemicals and sufficient sedimentation a liquor can be produced containing only about one-third as much suspended matter as the same sewage after passing through ordinary septic or settling tanks. To be sure, the sludge produced is almost three times that remaining after successful septic tank treatment, but a clear liquid is of the utmost importance in obtaining good and economical results from many English contact and sprinkling filters." 1

Chemical precipitation has, then, for its object the separation of the suspended matters, and precipitation and consequent separation of some of the putrescible matters in solution. Whatever precipitant is used, the process requires constant and careful supervision in order that the best results may be achieved with a minimum amount of chemicals. In this method of treatment the sewage is first screened ordinarily, and in this way the coarser matters in suspension are removed; it is then treated and thoroughly mixed with the chemicals on its way to large tanks, through which tanks it passes slowly, allowing the precipitate to separate by subsidence. Various methods are in vogue for the treatment of the sludge thus produced. At many chemical precipitation plants it is treated in hydraulic presses for the removal of water, and then disposed of in the cheapest way possible. In England it is frequently buried or used for filling in low lands, and the same holds true of the sludge produced at American precipitation plants.

The chemicals mostly used as precipitants are alum, lime, and ferrous sulphate. In England alumino-ferric, a crude sulphate of alumina, is largely used. Alum and other soluble salts of aluminum form, in the presence of lime or ammonia, a very bulky or gelatiuous precipitate, which carries down matters suspended in the sewage, together with a large proportion of the bacteria present, leaving a fairly clear supernatant fluid. With an excess of alum the effluent is acid in reaction, but it does not form unsightly compounds with sulphur, as is seen when iron and other substances, which form black sulphids, are used. Line in the form of milk of lime is used both alone and in connection with ferrous sulphate or alum. The amount of precipitant depends entirely upon the character and strength of the sewage treated, but on an average the amount required is about one ton per million gallons. The English Royal Commission on Sewage Disposal estimates that the average cost of chemical precipitation treatment, including loan charges, is about seventeen dollars per million gallons.

At the Lawrence Experiment Station, during five years from 1893 to 1897 inclusive, station sewage was treated with sulphate of alumina in the proportion of 1000 pounds per million gallons, followed by sedimentation for four hours. The result of this treatment was an average removal of 66 per cent. of the total organic matter, determined as albuminoid ammonia, and 78 per cent. of the organic matter in sisspension, determined as albuminoid ammonia ; 68 per cent. of the bac-

1 H. W. Clark, "Some Observations of Methods, Costs, and Results of Sewage Purification Abroad." 
teria were removed and 59 per cent. of the fitty matters. These figures represent average ehemical precipitation results.

4. Sewage Irrigation.-In the "broad irrigation" or "sewage farming" system, sewage is utilized in the growing of crops which take up and dispose of much of the water and dissolved solids, while, at the same time, oxidation processes in the interstices of the soil destroy the bacteria and convert the remaining organic matter to simple, harmless products. For the disposal of large volumes by this method very large sewage firms are required. The necessary area will depend upon the nature of the soil, its permeability and water capacity, and upon the amount of annual rainfall.

This method has been adopted very extensively in England, where there are hundreds of sewage farms, and in Germany, France, India, Ameriea, and elsewhere; and everywhere it has been found that no hard and fast rules as to area per thousand of population can be followed. In England the idea obtains very generally that every hundred of population will require one acre of sewage farm; but this varies with the composition of the sewage and its volume per capita. The volume of sewage ordinarily disposed of upon English sewage farms varies from about 2000 to 10,000 gallons per acre daily; but in dry countries, with a more sandy or gravelly soil, this volume may be increased.

Of the very first importance is the selection of a suitable tract of land for the establishment of the plant. It should be neither too permeable nor too close. If too coarse, it will permit the passage of the sewage so rapidly that imperfect purification will occur, and the effluent will be unfit to be discharged from the underdrains into a watercourse; if too close, as will be the case with a very dense clay, the water will be absorbed so slowly that it will fall far below the amount of loss by evaporation. The best soil for the purpose is one of sandy loam with fine interstitial spaces, which will permit not too rapid percolation, and wherein the processes of nitrification may go on most thoroughly. Very dense clay may be rendered suitable by the admixture of sand or lime and by tile underdraining, and then will perform its office in a satisfactory manner. With a proper plant and intelligent supervision the purified sewage makes a clear, bright, and practically sterile effluent.

In order to earry out the seheme so as to achieve the best results, the farm should be divided into sections, not neeessarily of equal area, but of equal absorbability, each of sufficient capacity for the disposal of the entire sewage of a single day. Each section should be worked in its turn, but the capacity of none shonld be overtaxed, lest the soil become clogged and the work of oxidation cease. In this condition it is said to be "sewage sick."

The farm is often laid out in broad ridges and furrows, the latter reeeiving the sewage at regular intervals; the crops grow on the broad ridges between. It should be underdrained naturally or artificially at intervals of about six feet, so that the purified filtered water may be removed and allowed to diseharge into any convenięnt watercourse. 
As has been stated, the daily dose per acre will vary widely according to fineness or coarseness of the soil, its permeability, its unsaturated open or interstitial space, and the rankness of vegetation. On a elose soil, in a cold climate, but a few thousand gallons per acre can be discharged, while on an open soil, in a hot country, with rank vegetation, as in Madras, as much as 75,000 gallons daily may not be excessive. The crops best grown are those which can bear heavy flooding of the soil.

As regards profit, it may be said that this system is the only one which can possibly yield a revenue, due in part to the value of the manurial constituents of the sewage and partly to the water itself, which puts the crops outside the danger of drought and beyond the need of rain. In some climates, crop follows crop the year round, and the annual yield is large; in others, the season is so short in comparison that the yield is much less. At the Berlin farms a yearly yicld of 25 tons of grass per acre, equal to 5 of hay, is regarded as large and satisfactory, while at Krishnampett, in Madras, where eight erops per year are harvested, the output, according to Dr. J. N. Cook, ${ }^{1}$ was in one year 69 tons per acre, equal to about 23 of hay, and worth nearly 200 dollars. The eity of Berlin purchased and set aside 20,000 acres of land for its sewage farms, and, notwithstanding an outlay of more than 13,000,000 dollars for the entire plant, receives a yearly profit of 60,000 dollars from its operation, the labor costing nothing except for maintenance of the meu engaged, these being condemned thereto for various minor nisdemeanors.

Whether there be a profit or not, this aspect of the question should ever be kept in the background and the primary object ever in view. When the farms are let out to eontractors, it is always advisable, and even necessary, that they be under the supervision of municipal authority, to insure that the public good is not subordinated to private gain.

It is not to be supposed that, even in very cold weather, the use of the system must be suspended, for when vegetation ceases, the soil continues the process of purification. At St. Laurent College, near Montreal, for example, the small sewage farm was found to act efficiently in disposing of the usual amount of sewage in a January (1898) temperature of $-20^{\circ} \mathrm{F}$.

Influence of Sewage Irrigation on Health.-Concerning the influence of sewage farms upon the health of those dwelling on and near them, the evidence is entirely on one side, and in opposition to what would naturally be supposed to be the case. It is the same from Berlin, Paris, Edinburgh, and the hundreds of other places where the system is in use, and all to the effect that in no way is it injurious. It is true that not infrequently the sewage gives rise to more or less disagreeable odor, especially if it be stored too long; but the fields themselves are generally quite free from nuisance, and even though odor be present, it produces no harm. At the Berlin works, in a population of more than

1 Indian Medico-chirurgical Review, Dec., 1895, p. 676. 
1,500 there was one death from typhoid fever in five years, the general death-rate was very low, and the zymotic death-rate exceedingly so ; in fact, during one year it was nil.

Complete freedom from infeetious disease is by no means unique, but is, indeed, a common condition in the experience of sewage farming. At the farms at Gennevilliers, where the sewage of Paris is received, the population is constantly increasing, the general health is excellent, and the general death-rate is low and continually decreasing. An extensive epidemic of typhoid fever in Paris would be supposed to be the forerunner of another of greater comparative severity where its sewage, containing all the bowel discharges and urine of sick and well alike, is treated, but experience has demonstrated that such is by no means the case, for in 1882, for instance, when Paris suffered from an unusually extensive outbreak of that disease, there was not a single case at Gennevilliers.

So far as is known, there is as yet no proof that sewage irrigation has ever been responsible in any way for the occurrence of extensive outbreaks of typhoid fever, dysentery, or cholera, or, indeed, of entozoic tronble. Nor is there reason to look askance upon the products of the farms, despite assertions to the contrary based on surmise and inexperience, for the facts show that grass and other erops are of good quality, make good fodder, and bring good results in milk and butter when fed to cows.

Ferrélhas, it is true, reported an outbreak of typhoid fever in a girls' boarding-school at Jurançon, which was presumably due to vegetables from a garden watered with the contents of an infected cesspool; and another localized outbreak of the same disease due to infected celery has been reported by the State Board of Health of Massachusetts. This occurred in September, 1899, at the Insane Asylum at Northampton, in which, prior to September 10th of that year, but 4 cases had occurred during ten years. Then cases began to appear, and in fifteen days the number had reached 39, and later a few more. Investigation proved beyond reasonable doubt that the outbreak was due to celery grown in beds which received the sewage of the institution. The method of banking employed in the cultivation of the plants made them a favorable medium for transmitting the disease. It should be noted, however, that neither of these outbreaks was due to produce from a large farm receiving the diluted sewage of a distant municipality.

Aside from local considerations of health, what are the results attained? This question can be answered in a few words. The organic matters of the sewage are destroyed completely by the saprophytic bacteria, which also dispose of their pathogenic brethren; the greater part of the water is taken up by growing vegetation and evaporated into the atmosphere, and the remainder in practically sterile condition sinks into the subsoil or is carried away by the underdrains and discharged into a stream.

According to Kinnicutt, Winslow, and Pratt," "the availability of

1 Annales d'Hygiène et de IIédecine légale, Jan., 1899, p. 23.

2 Sewage Disposal, 1910, p. 219. 
broad irrigation, as a practical method of sewage treatment, obviously depends to a high degree on varying local conditions. In dry countries, where every drop of water is precious, there can be no doubt that it is the ideal procedure. In California and similar regions of the United States it is likely to be the prevailing method of sewage treatment. In India the rice fields at Madras and elsewhere are irrigated with sewage, with marked suceess. On the other hand, it seems quite as certain that sewage farming on heavy land is a nistake. The English communities, which have clung to serwage farming under adverse natural conditions, have demonstrated that it may be a failure, and a costly one."

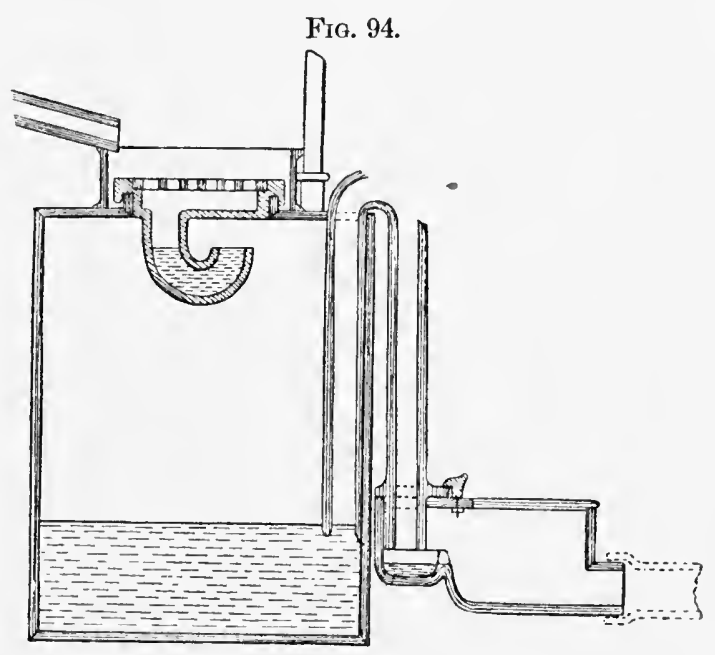

Field flushing tank.

The Waring System of Irrigation.--Irrigation on a small seale, known in this country as the "Waring system," is resorted to very commonly for the treatment of sewage of single houses and small settlements. As begun by the Rev. Mr. Moule, the inventor of the earth-closet, it was a scheme for the disposal of the liquid wastes which could not be eared for by earth-closets. The plant consisted of an open-jointed tile drain laid a little below the surface of the ground, parallel with and elose to a row of grapevines. It was next enlarged by Mr. R. Field by the addition of a reservoir or flushing tank, shown in Fig. 94, by means of which the whole drain eould be flooded throughout and intermittently. Brought to the notice of Colonel Waring, he adopted the system for his own house, and proceeded to improve it in several directions and to bring it into common use. Under him, the system was brought to its present state of perfection.

The plant consists of a reservoir into which the sewage runs, a wire sereening basket to separate the paper and other matters not easily oxidizable, an antomatic siphon by which eomplete discharge is secured 
as often as the reservoir becomes filled, and a gate-chamber by means of which the flow is diverted to any of the three outlets, which lead to a miniature sewage farm. The drain pipes are laid, with open joints, not more than ten inches below the surface, and the ground where they discharge may be used for grassplots or gardens. The results are most satisfactory in every way; the organic wastes are oxidlized by the soil bacteria, and the water which sinks into the snbsoil is incapable of causing pollution such as oceurs when ecspools with open bottoms below the zone of saprophytic bacteria are employed.

Within recent years, the tendency has been to do away with the drains where sufficient land is available, and to discharge the sewage directly upon the surface. Fresh sewage thrown upon grass is ineflensive, except to the sight, unless deposited in such amounts in the same place as to cause miring of the ground, cessation of oxidation, and consequent putrefaction. It is, of course, necessary that the screened matters be removed frequently and buried or burned, and that the reservoir be cleansed at regular intervals.

5. Sewage Filtration.-The method of intermittent filtration of sewage is the same in principle as the process deseribed in the chapter on Water. Like that, it is more than a mechanical separation of suspended matters : it is a process of sereening, oxidation, and eventually almost complete purification, much like sewage irrigation. As early as 1836, Bronner, of Heidelberg, endeavoring to learn the reason why the constituents of fertilizers in solution failed to reach the deeper layers of the soil, filled a bottle, having a small hole in the bottom, with sifted garden soil and poured in gradually a thick stinking manure juice, and observed the eharacter of the effluent, which he found to be almost odorless and colorless, and devoid of fertilizing properties.

But the system of sewage purification by means of filtration had its beginning within recent years at the Lawrence Experiment Station of the Massachusetts State Board of Health, and is now in actual use by many municipalities in this country and abroad. The filter-beds are made best of sand, not finer than $0.2 \mathrm{~mm}$. grain size, and gravel. Ordinary loams, elays, and peat are praetically useless as filtering materials, on aceount of the difficulty with which water passes through them. The purifying agents are the bacteria which are soon established within the interstices, and these include both anaërobic and aërobic varieties. In order that both kinds may perform their office, the application of the sewage should alternate with thorough aëration of the bed. Unless the application be intermittent, the anaërobic action alone is encouraged and the process fails. Where sand of the right sort is not obtainable, many other materials, as coke, burnt clay, coal-dust, and cinders, have been used as substitutes.

The essential facts in regard to the working of sand filters may be summarized as follows : ${ }^{1}$

"(1) Better effluents can be obtained by sand filtration of sewage than by any other method of sewage treatment; (2) rates of filtration

1 Clark and Gage, Report of Massachusetts State Board of Health for 1908, p. 349. 
must be low compared with the rates that can be maintained with contact and trickling filters; (3) with sewage as strong as that at Lawrence-probably stronger than average American sewage-it is inadvisable to undertake to operate the best sand filters at a rate exceeding 75,000 gallons per acre daily, and with fine sands the rate must be mueh less; that is, these rates cannot be exceeded if absolute permanence of the filter area is desired; (4) sand filters properly cared for and not overworked are practically permanent; (5) sand removal is at times necessary, especially if systematic care is not given to the filters, and if the rate of application and the quality or strength of the sewane overloads the filter; in other words, if the rate maintained eauses the application of a greater body of organic matter than the biological life of the filter can adequately care for; (6) a certain portion of the suspended organie matter in sewage retained by sand filters is stable, and resists for long periods changes due to chemical and biological forces-it is practically as stable as the organic matter of soil ; (7) the rate of filtration should be proportioned to the strength of the sewage, as shown by the organie matter contained in a given volume of water, and espeeially the organic matter in suspension; (8) when the rate of application of sewage goes beyond a certain normal point, sand removal becomes neeessary. Furthermore, the amount of sand that nust be removed increases more rapidly than the rate; (9) preliminary treatment of sewage allows sand filters to be operated more or less satisfactorily at rates mueh greater than is possible with untreated sewage."

The Lawrence Experiment Station sand filters, from the operation of which most of the data given above were accumulated, have been in operation more than twenty years, and have produced clear, highly nitrified effluents, containing minimum amounts of unoxidized organic matter and small numbers of bacteria. Nearly thirty municipalities in Massachusetts dispose of their sewage upon intermittent sand filters, and many are in operation in other States.

It should be borne in mind that the sewage of some kinds of manufaeturing establishments is not well purified by sand filters or other processes which depend for their efficiency on micro-organisms. Such sewage contains oftentimes chemicals which, unless removed by preliminary treatment, will destroy the life of these necessary agents. Thus, in tanning at least two substances are used which interfere with bacterial growth. In the first place, green skins are frequently preserved by means of ehemical disinfeetants, and, in the second place, when the skins are soaked preparatory to the removal of the hair, large quantities of such chemicals as arsenie sulphide and lime, mixed together, are used to facilitate the process. Sewage containing these substances in suffieiently large amount, if applied directly to a sand filter, will quiekly interfere with its efficiency by destroying the nitrifying organisms. Sewage from this industry contains, in addition, so much organic matter in suspension that if applied directly to a sand filter it eauses elogging very quickly. Industrial sewage of this oljectionable character should, therefore, be submitted to sedimentation, or other 
appropriate treatment, as a preliminary to sand filtration. It has been found that arsenic, for instance, may be removed completely by passing tamnery sewage through coke breeze. "The removal is probably due to a combination of the arsenic with the iron in the coke, and the formation of an insoluble double salt of iron and arsenic, which is retained in the coke." 1 Filtration through coke has also been found efficient in removing the organic matters, even when the sewage is applied at the rate of 250,000 to 300,000 gallons per acre daily. Moreover, industrial sewage may contain other objectionable substances which tend to $\log$ the filter, such as grease, soap, and other materials, and these may require special treatment. The importance of guarding against injury to the nitrifying organisms by special sewages should be borne in mind, and also that if the process be stopped in winter, it cannot be renewed until the return of warm weather.

Contact Filtration.-While intermittent sand filters allow a greater volume of sewage to be purified per acre than sewage farming, yet in England, where sandy soil suitable for filtration is the exception rather than the rule, some method was needed by which larger volumes of sewage could be treated upon a given area. This necessity gave rise to investigations of the purification by coarser materials than the sands first experimented upon at Lawrence, and from this call for higher rates arose the so-called contact filter of Dibdin. This filter and the contact method of operation had their origin in attempts to pass sewage continuously through a bed of coke breeze during experiments on the treatment of London sewage made by Santo Crimp and Dibdin at Barking from 1893 to 1895 . In these experiments the filters wele first operated continuously, then from eight to twelve hours a day, and eventually the contact, or fill and empty procedure now so well known, was adopted. The filter is simply a bed of coke or other coarse material, with retaining walls and tight bottom, and with an outlet which can be closed. Sewage is applied in one or several doses until the filter is filled and the sewage stands just at its surface. After a period of standing, the sewage is allowed to drain away slowly. As the sewage drains, the interstices of the bed become again filled with air, and the process of standing, filling, and emptying may be repeated several times daily.

The first contact filters were constructed of coke, but other materials, such as burnt ballast, einders, elinkers, broken stone, and brick are quite generally used. By this method of treatment of sewage the rate depends not only upon the superficial area, but upon the depth of the filter and its open space. In contact filtration the average rate of operation ean be abont ten times that generally obtained with sand filters or, perhaps, 700,000 gallons per acre daily with a contact filter 5 or 6 feet in depth. Such filters are in operation in many large cities and towns in Great Britain, those at Manchester and Sheffield being notable examples of this type. The effluent produced by well-construeted and well-operated contact filters is generally purified to such

1 Report of the State Board of Health of Massachusetts for 1896, p. 430. 
an extent that it is stable and non-putrescible, but very far from being the clear, highly oxidized product seen as the output of good intermittent sand filters.

According to Clark and Gage, " it is evident that the nature of the material, the method of operation, and the character of the applied sewage have very considerable effeets upon the quality of the effluents from contact filters. The filters composed of coke or clinkers, that is to say, of rough material, gave at all times more satisfactory effluents than those composed of smooth material. . . This may have been due, in part, to the porosity of the coke, which allows an absorption of the colloidal and soluble organie matter within the material itself, when first started, resulting in a more satisfactory formation of a surface coating upon the material. Another effeet of the rough material is to hold back the suspended matters and prevent their free passage toward the outlet of the filter. . . Experiments with brick and roofing slate showed that these materials, though more or less porous, as in the case of brick, were unsatisfactory when so arranged that the surfaces were vertical. The function of a scwage filter is to hold back the organic matter to allow time for the biological processes to take place, and this result was not accomplished with the brick and slate filters.

"The material should also be of such a character that it does not break down readily. . . . The size of the material also plays a considerable part in the action of the filter. If the material is tos coarse the voids are large, and the sewage does not come intimately in contact with the surfaces. If, on the other hand, the material is too fine, clogging oecurs, and the action within the filter becomes largely that of mechanical straining; moreover, putrefactive reactions abound, inasmuch as the entrance of oxygen is largely precluded. . . . The question as to the proper depth of contact filters appears to be one of engineering rather than of sanitary interest . . . and has very little relation to its biological activity. The difference in depth, however, does make a great difference in the volume of sewage which ean be disposed of upon a given area. From this point of view deep beds are better than shallow ones.

"The method of operating contact filters also has considerable effeet upon the character of the effluent. . . . The question of how long the sewage should remain within the filter has not been determined absolutely. . . . Systematic resting of the filters for a period of one week in every six has proved to be beneficial in every case. . . .

"The character of the applied sewage also plays an important part in the quality of the effluent. The best effluents and the best filter operation is secured when the applied sewage receives some preliminary treatment to remove suspended matters."

Trickling Filters.-The fourth method of purifying sewage by the use of micro-organisms is purification by means of what are now known as trickling filters. These filter- are an outgrowth of studies in regard

1 Massachusetts State Board of IIealth Report, 1908, p. 444. 
to the bacterial purifieation of sewage made at the Lawrence Experiment Station during the first three years of its operation. In June, 1889 , al filter of gravel stones was started there, some of these stones being not less than three-fourths of an inch in diameter nor more than one and one-quarter inches. To such a filter sewage was applied and good nitrification occurred. In summarizing the results of this filter, it was stated that "the purifieation of sewage by nitrification and the removil of bacteria is not to any essential degree a mechanical but a chemical change; that the experiments with gravel stones give us the best illustration of the essential character of intermittent filtration of sewage, - the slow movement of the liquid in films over the surface of the stones with air in contact." Such filters were operated at Lawrence as early as 1890 at rates as high as 200,000 gallons per acre daily, and the sewage was applied frequently, often sixty to seventy doses a day being given.

Dr. Dunbar, Director of the Hamburg (Germany) State Hygienic Institute, makes the following statements :

"Of much more general importance, however, are the experiments which have been carried out at the Experiment Station erected at Lawrence. By selecting the most suitable soil attempts were made to increase the efficiency of the method, and finally such coarse material was used that the sewage passed straight through without spreading over the filter. Automatic devices had to be adopted to distribute the sewage. The London anthorities became aware of these experiments and had them repeated. In 1892 Santo Crimp prepared experimental filters of similar coarse material at Barking. . . . It is not generally known that simultaneously and independent of Dibdin, J. Corbett, the Borough Surveyor of Salford, worked out a biological method of purification. His method was likewise based on the Massachusetts experiments, but in its further development it has surpassed the London methods. . . . Corbett attempted to apply the principle laid down by Sir R. Frankland and recognized to be correct by the Massachusetts authorities, viz., that an intermittent filtration liquid should always be allowed to flow freely away. . . . The chief difficulty to be overcome was to obtain a uniform distribution of the sewage over the entire surface of the filter. After many experiments in various directions, Corbett adopted for this purpose fixed spray jets from which the sewage was distributed under pressure in the form of a fountain."

At the present time trickling filters are in nse purifying sewage of a large number of English eities and towns, and at least three good purification plants of this type are in operation in America, namely, Columbus, O., Reading, Pa., and Baltimore, Md. Such filters, both in Europe and America, are generally constructed of broken stone, although in many places abroad hard clinker is used. These filters are usually from five to ten feet in depth, and of material so coarse that the sewage passes through freely, the open space in the filtering material being so large that there is abundant and constant supply of air. By this method of filtration rates from three to four times as great as those possible 
with contact filters can be maintained with the production of a highly nitrified and non-putrescible effluent. At Birmingham, England, there is at the present time the most extensive purification plant of this type. At this plant the sewage of about 800,000 people is purified by means of septic tanks and trickling filters.

Two experimental filters of this kind have been in operation at the Lawrence Experiment Station for about twelve years at average rates of more than 2,000,000 gallons per acre daily, and are still in good condition and practically free from elogging. In order to obtain good results from these filters, fairly perfect distribution of the sewage over them is necessary. The spray jets first used by Corbett have been adopted at many of the large plants of this type, but many other distribution methods are used. Some of these distributors, such as the Fiddian and the Simplex, give better distribution results than can be obtained with nozzles or jets of the Corbett and allied types, but generally are more expensive, especially for the first installations. The Fiddian distributor is constructed in the manner of an overshot wheel and is self-propelled. It is well adapted for circular beds, such as are constructed at scores of places in England and on the Continent, and with the use of certain automatic contrivances can be used upon rectangular beds.

"The main difference between trickling filters and intermittent sand filters is that, owing to the size of the open spaces between the particles of filtering material in the trickling filters, much greater rates can be maintained and still allow the free entrance of air. Trickling filters are not a substitute for sand filters, which remove practically all the matter in suspension in sewage, but are simply devices for the modification of sewage, or, in other words, the quick oxidation of the putrefying matters present while allowing the larger body of stable matters and matters rendered stable by filtration to pass through. . . . The grade of filtering material used may be varied according to the character of the applied sewage; that is, a finer material may be used with a supernatant sewage from sedimentation or chemical precipitation than when the sewage contains much suspended matter. It follows, of course, that the finer the filtering material and the clearer the sewage the better the effluent, but too fine a material cannot be used, as surface pooling ensues and air is excluded." 1

The type of filter to be erected at any locality is often determined by certain engineering limitations. Contact filters can be used at places where trickling filter installations are almost impossible. This is clearly described in the following paragraph :

"Another distinct advantage of the contact bed under certain conditions is the low head under which it ean be operated. A trickling filter requires at the least 8 feet of head for the bed itself and for the distributing apparatus; while a double contact bed could, if necessary, be crowded into 5 feet. Altogether a contact installation lends itself to compact and inconspicuous construction, which is of much practical

1 Clark and Gage, Massachusetts State Board of Health Report for 1908, p. 387. 
importance in the design of small plants for institutions or for private houses. The contact bed produces less odor than the trickling filter and does not breed flies as the trickling filter does. It may, therefore, safely be installed much nearer to dwellings. Another advantage in the contact system for small disposal plants lies in the fact that it adapts itself more readily to marked irregularities of flow than does the trickling bel. If, however, plants of this type are designed to work under the control of automatic apparatus, it must be remembered that a lack of careful supervision will mean certain and inevitable failure." 1

The Cameron Septic Tank.-What is now known as the septic-tank process was first proposed by Donald Cameron, Borough Engineer of Exeter, England, where the first attempt at preliminary treatment of a town sewage by this system was installed. A septic tank is in. a sense simply a cesspool on a large scale, but more scientifically operated than the ordinary cesspool. The process is one in which the anaërobic bacteria are utilized for the purpose of hastening the decomposition of organic matter in sewage. By the process as proposed by Cameron, sewage is passed slowly through large tanks, so slowly that not only does organic matter in suspension settle out and remain in the tank, to be worked over by the bacteria of putrefaction, but the sewage itself when passing from the tank has also been submitted to the work of these bacteria for a considerable period of time.

The initial plant at Exeter consisted of an underground covered tank, 64 feet long, 18 feet wide, and of an average depth of a little more than 7 feet. At this place the crude sewage before entering the tank passes first into a brick chamber, where the coarser and heavier matters settle out. The sewage is not strained, but passes to the septic tank proper after passing through the brick chamber, and enters the tank through inlets five feet below the surface. After this tank had been in operation for a period of a year or two, it was stated that 80 per cent. of the organic matter in suspension and retained in the tank was passed into solution or escaped in gaseous form, hence did not appear in the tank effluent. At the present time such tanks have been in operation upon a large seale for a number of years at many places in England and in America, and it is now the general opinion from the results of their operation that even under the best conditions they do not destroy more than 25 per cent. of the suspended organic matter retained by them. At certain large installations, as at Hanley, England, and at Birmingham, England, the destruction does not seem to be greater than 10 per cent. They are, however, undoubtedly of considerable value at certain places as adjunets to sewage purification, and are well recognized as one of the prominent forms of preliminary treatment of sewage before purification.

Septic Tanks for the Digestion of Sludge Only.-The Lawrence Tank, Hampton Tank, and Imhoff Tank.-A modification of the septic tank for the concentration and digestion of sludge only was first put into operation at the Lawrence Experiment Station in 1899. This modifi-

1 Kinnicutt, Winslow, and Pratt, "Serrage Disposal," 1910, p. 313. 
cation consisted of a tank with two compartments, the lower compartment retaining the settled sludge for septic action or digestion, while the main body of the sewage was not retained. (Report of Mass. State Board of Health for 1899, p. 422.) This tank, judging from present knowledge, was successful in accomplishing all that could be expected of it in sludge digestion. Since the operation of that tank, the Travis tank at Hampton, England, and the German modification, known as the Imhoff tank, have become well known, and are, apparently, of much promise. Both are based upon the principle of the Lawrence tank of 1899 , namely, the retention of sludge only for digestion, while the main body of sewage passes quickly to the purification area.

Dr. 'Travis makes the following statement: ${ }^{1}$

"The conception of the 'Hydrolitic Tank and Oxidizing Beds' is the result of a close study of the numerous experiments conducted at Lawrence under the State Board of Health of Massachusetts, etc. . . . This being so, an acknowledgment of the source from whence the ideas were derived and a recital of the conclusions having special reference thereto are, as a matter of common honesty as well as of courtesy, equally desirable."

The Imhoff tank is based upon the Travis tank, and consists generally of two cylinders with conical bottoms conneeted with an upper rectangular tank through which the sewage flows. As the sewage passes through this tank at a slow rate the solid particles settle, slide along the sloping walls, and are deposited finally in the cylindrical liquefying chambers, reaching perhaps thirty feet below the surface of the sewage in the tank. In these lower chambers the sludge undergoes putrefaction, but the gas evolved is prevented by an arrangement of baffles from passing up through the sewage in the upper tank. The sludge is held in these lower chambers for a series of months, and is forced out from time to time through pipes connected with the bottom of these chambers, pressure of the sewage in the upper tank being utilized for this purpose. The sludge is spread upon suitable sludge beds, where it dries quickly and can be removed easily to the place of final disposal. The advantage of this type of tank is that the sludge is very concentrated and practically free from odor. 


\section{CHAPTER VII.}

\section{DISPOSAI, OF GARBAGE.}

Garbage comprises all manner of waste material, and its disposal is of very great economic and sanitary importance. 'The daily accumnlation in towns and cities is enormons, and its removal at regular intervals is a matter of great coneern to munieipal administration. From a hygienic standpoint, the proper disposal of kitchen waste and other decomposable material far ontweighs in importance the removal of such matters as waste paper, ashes, disearded boots and shoes, tin cans, bottles, and other rubbish, which in no way can affect the public health, but which for various reasons, may not be allowed to accumulate in the honsehold. In rural distriets, the disposal of garbage in general is exceedingly simple; but in erowded communities it entails great expense, and is usually a very complicated problem. Sinee this work is eoneerned solely in matters of sanitary interest, and not in economies, the eonsideration of this subject will be restrieted to the methods of disposal of those matters, the retention of which on oceupied premises may be regarded as detrimental to health, namely, those known as kitchen refuse, or swill.

The methods of disposal of these matters comprise those which may be carried out by the individual householder on the spot, and those adopted by municipal authority after house-to-house collection.

In many households, refuse is disposed of by burning in the kitchen fire with or without a preliminary proeess of drying, for which a number of simple apparatuses have been devised. A very efficient arrangement in eommon use consists of an enlargement in the lower part of the stovepipe, forming a chamber into which, through a doorway in the end or side, the refuse, in a suitable metallic holder with perforated sides and bottom, is introdueed. Through this the hot air, gases, and smoke from the fire pass on their way to the ehimney flue, and thus eomplete drying and partial carbonization are bronght about. The dried residue is disposed of finally by burning in the stove, where it serves a useful purpose as fuel.

In country and suburban districts, kitchen waste is advantageously disposed of by feeding it in a fresh and sweet condition to swine and poultry, and depositing in the soil such matters as they will not eat. Burying in the soil is a simple and effective method of disposal, entailing but little labor, since it is best not to deposit it very deeply. Near the surface, decomposition oceurs rapidly, and so a covering of earth a few inches in depth is sufficient to prevent contamination of the atmosphere with noisome odors.

Very recently small household incinerators have been devised for use 
in buildings already piped for gas consumption. The grate used in this incinerator is of a special type which, although it prevents the liquid portions of the garbage from passing through, allows the waste material to be exposed to great heat from a large Bunsen gas flame. The moisture of the garbage is driven off by the heat and the remaining material is then reduced quickly to the condition of dry ash. Smoke and steam are removed through a connection with a chimney flue.

The methods adopted by municipal authorities comprise dumping into the sea, disposal to farmer's for swine-feeding, utilization as food for herds of swine kept for the purpose, and reduction and incineration in furnaees of special eonstruction, known as destruetors.

Dumping into the sea is open to the objeetion that, under favoring conditions of winds, tides, and eurrents, much material may be washed ashore, and become a nuisance and eyesore to the immediate neighborhood.

Disposal to farmers involves eartage over miles of road in wagons, which, if not leaky for liquid matters, at least permit the eseape of nauscous odors, to the annoyanee of dwellers and travellers along the route. It involves, also, storage for at least a short time after collection, unless the garbage wagons can themselves be sent into the country-a proceeding which can hardly be regarded by taxpayers as consistent with the proper management of municipal revenues. This period of storage is, in effeet, a continuation of that which has, perhaps, extended alroady through several days or a week before collection, during which time, various fermentative proeesses have been active in the production of compounds of offensive eharacter.

Incineration at special stations for the destruction of swill and all other conbustible rubbish is being widely adopted by large communities, and, in many places, has proved to be not only the most economieal method of disposal, but even a souree of gain. 'To such a station are brought the daily collections of garbage, which at once undergo a process of sorting. Paper and pasteboard are utilized in the furnaces as finel or are sold to be used in the mamufacture of the cheaper grades of paper and cardboard; old shoes and boots are disposed of to makers of artifieial leather, and rubbers and overshoes to manufacturers of rubber goods; tin eans are heated to recover the solder; pieces of unconsumed coal are collected and used or sold for fuel ; broken furniture, boxes, barrels, and other wooden objects are split up into lindling, and excelsior stuffing is utilized in the furnaces. In short, almost every kind of rubbish may he utilized in some way to advantage. The late Colonel George E. Waring, Jr., experimenting in New York with a long travelling belt, on which the combustible waste from a district eontaining 200,000 people was deposited and picked over, found that 90 per cent. of it was salable, and but 10 per cent. remained to be destroyed by fire. In some establishments now in operation, a long, travelling, endless belt of steel plates is employed, the carts dumping upon it at one place. As the material passes along, it is sorted over quickly by men on either side, and what is left is conveyed 
onward to a bin, from which, in time, it passes to the furnace, to serve to destroy the kitehen waste.

It would be impossible, even if it were not unnecessary, to give in detail a description of the many varicties of machines and furnaces which have been invented for the incineration of refuse. In general, it may be said that a destructor consists of a furnace with a chamber, provided with grate-bars, in which the dry or partially dried offal is burned; and a sceond ehamber, in which it is subjected to a preliminary process of drying. This second chamber is placed behind the front compartment, which receives the dricd garbage and other combustible material serving as fuel. In the best forms, two fires are maintained: one at the forward end, and the second at the stack end of the furnace, the latter being designed to insure complete combustion of vapors and dust before entrance to the chimney, from which, otherwise, they might issue in such a form as to create scrious nuisance, not alone to the immediate neighborhood, but even at considerable distances.

The burning of the smoke and fumes is very essential, and failure to provide therefor, or the unsuceessful operation of the fume cremator, has caused the abandonment of many plants, which, with better installation, should have worked successfully and to public satisfaction. In many English cities, destruetor furnaces have been in operation for years in elose proximity to dwellings, sehools, and hospitals without causing offence. At Ealing, for example, the furnace is located at a distance of 180 yards from two hospitals; in Whitechapel, within a very few yards of dwelling honses in the midst of a very populous district; at Leicester, but a very few yards from a large school and immediately adjoining a considerable number of dwellings.

The fume eremator consists of a reverberatory arch with rings of firebrick, placed in the direction taken by the gases. Projecting ribs deflect the vapors to the top of an intensely hot fire, in which they are destroyed. Provision is made for rapid removal of ashes, and for drafts of air at needed points to maintain a continuous temperature above $2.000^{\circ} \mathrm{F}$. The heat produced is commonly utilized in the production of steam for the engine which does the necessary hoisting and other work, and drives the shafting eonnected with the endless belt and other appliances. Another most useful and economical application is the utilization of the great store of energy for maintaining electriclight plants for lighting the premises, and even the public streets. In New York and Boston, the surplus energy is utilized, but at most other plants in the 54 cities and towns of this country which, in 1899, were using the process, the heat is wasted.

At the beginning of 1899,81 eommunities in Great Britain were employing incincration as the ehief means of disposal of refuse, and 76 of them turned the developed heat to some useful purpose. About a third of the number use the power for electric lights for the works or streets, or both together; nearly two-thirds maintain mills for grinding materials for mortar and clinkers for pathways ; six employ the steam 
for the purpose of public disinfeetion; several, for pumping sewage, and others, for various useful purposes. In one eity, 3,000,000 gallons of sewage are pumped through a twenty-foot lift, the works are lighted by electricity, the shops and forges of the municipal service are supplied with power, and other work also is performed.

Reduction.- In the reduction proeess, the kitchen garbage is stored in tanks which permit the draining away of most of the water, which is conducted directly to a sewer. Next it is dried in cylindrical steam-jacketed chambers, into which hot air and superheated. steam are conducted, the process requiring about six hours. The material loses about three-fourths of its weight, which passes off in the form of aqueous vapor and is condensed and discharged into the sewer; the noncondensible stinking vapors are disposed of in the vapor eremator conneeted with the boilers in which the steam is generated. The dried residue is next introduced into tanks of naphtha, and the whole is heated by steam coils until all grease has been removed, when the naphtha solution is separated. This is then distilled, the naphtha passing over and being reclaimed for repeated use, and the fit remaining behind as a valuable produet. The extracted residue is dried again and worked up into fertilizer.

Reduction methods are applieable only to large eities, and sinee it is almost impossible to condnet the works without creating a nuisance, these should be located at such a distance from a eommonity that the value of property may not be impaired, and the daily enjoyment of life may be in no way sensibly abridged. If the amount of collectable kitchen waste is sufficiently large, say that from a population of at least 150,000 , and if the works can be so plaeed as to cause no nuisance and, at the same time, not to necessitate a long and expensive haul of the material, reduction has been found to fulfil both the sanitary and the economie requirements, the yield of grease and fertilizer having considerable value, thus reducing materially the eost of disposal. But, as in the case of sewage, it should be borne in mind that the removal and disposal of waste are sanitary measures, and should not be viewed too much from the standpoint of profit-making.

If the quantity of garbage collected is too small to warrant treatment by reduction processes, it may be burned to advantage in destructors. A combination of the two methods, reduction and remation, would seem to be the most advantageous for communitics producing a very large daily amount of general wastes. But the possibility of nuisanee from all reduction works, a nuisance which has caused the abandonment of the great majority of the plants which have been installed in this country, should ever be borne in mind, even though the misance be limited to a small percentage of the population, who, if they eomplain, are regarded by the rest as unduly sensitive, prone to mangnify small disconforts and give them a factitions importanee, and inconsiderate of the general welfare, which, even if true, can not deprive them of their right to appeal to the eourts for the abatement of the cause of their diseomfort. 


\section{CHA PTER VIII. \\ DISINFECTANTS AND DISINFECTION.}

Disinfectists, or germieides, are agents which bring about the destruction of bacteria in general, and, more particularly, of those that aet as the exciting causes of disease. While they are all to be elassed as antiscptics, the latter, ats a elass, are by no means necessarily disinfeetants, sinee many of them act simply to delay or prevent the action of fermentative agents, without exerting any destructive influence upon them. Cold, for example, is a most efficient antiseptie; but while it may inhibit growth and aetivity of micro-orgauisms, it does not neeessarily deprive them of vitality.

Deodorants are agrents which remove or mask disagreeable odors, but they are not neeessarily disinfectants. Some deodorants are efficient disinfectants, but not all disinfeetants are effieient deodorants. The latter are largely substances which, being of strong, peeuliar odor, are used to overcome or supersede disagreeable odors, but without exerting any influence upon the eauses thereof. Odors may or may not be a concomitant of infeetious matter aecording to cireumstances; and when so, the mere fact of their being overwhelmed by a more powerful rival smell has no influence on the vitality of the bacteria present. Some deodorants remove smells without the ereation of another, and without exerting any aetion upon their eauses; such are eharcoal and ordinary earth.

The function of disinfectants is the destruetion of morbifie agents so that they shall not spread infeetive diseases. They are not curative of the infeeted person, but are preventive of the spread of the disease from that person to others. An efficient disinfeetant for general purposes should possess the property of killing not this and that species of bacteria, but one and all, and their spores as well. Some pathogenie bacteria have a tolerance for eertain disinfectants, and may acquire one gradually for certain others. Such agents eamnot, therefore, be included among the efficient class for general use. For special work in destroying the infective agents of certain diseases, disinfectants which have been proved to exert a destruetive influence on the particular organisms may be used, although they have failed to show an equal power against other, more resistant, varieties. Disinfectants may be divided into two elasses, namely : 1. Physieal agents. 2. Chemical agents.

\section{PHYSICAL AGENTS.}

The physical agents are: 1. Iight. 2. Heat.

Light.-Direct sunlight is one of the most important disinfeetants known. It retards the growth of many organisms, and, after a vary- 
ing number of hours of exposure, completely destroys the vitality of a number of the most important pathogenic bacteria, including some generally recognized as highly resistant. Diffused daylight and electrie light also are effective, but in a much diminished degree.

The destructive effect of sunlight on bacteria was demonstrated first by Downes and Blunt, ${ }^{1}$ in 1877 . They inoculated flasks of broth with bacteria and exposed part of them to sunlight and kept the others in ditrkness; the former remained elear, while the latter became turbid by reason of bacterial multiplication.

Mitehell and Crouch ${ }^{2}$ exposed tuberculous sputum to direct sunlight for varying periods up to $25,30,35,45$, and 55 hours and then inoculated it into guinea-pigs, with the result that those which received sputum exposed longer than 25 hours remained healthy, while the others became infected.

Koch ${ }^{3}$ announced, in 1890, that the bacillus of tuberculosis is killed by direct sunlight in from a few minutes to several hours, according to the thickness of the layer of material in which it is contained, and by diffused light in from 5 to 7 days. Migneco ${ }^{4}$ exposed tubereulous sputum on linen and woolen fabries to direct sunlight, and found that, provided the layer was not too thick, tbe bacilli could not resist longer than from 24 to 30 hours. The virulence was observed to diminish gradually after 10 to 15 hours, and to disappear completely after 24 to 30 hours.

Jousset ${ }^{5}$ fonnd that tuberculous sputum containiug virulent bacilli was rendered innocnous by 4 hours' exposure to diffused sunlight and after drying and exposure to direct sunlight for 1 hour.

Janowski, ${ }^{6}$ experimenting with $B$. typhosus, discovered that that organism failed to grow when planted in bouillon and exposed for 6 hours to direct sunlight; and that, in bouillon, exposed 8 hours out of every day to diffused light and kept in the dark the rest of the time, its development was much delayed, but in the same medium, kept wholly in the dark, cloudiness was observed in from 16 to 20 hours. That this action is not due to inerease in temperature was shown first by Silverio, ${ }^{7}$ who exposed gelatin cultures of the organisms of typhoid fever, anthrax, and cholera, and Staphylococcus pyogenes aureus, to sunlight and electric light for from 2 to 47 hours, and made careful observations of the temperatures within the tubes. He cliscovered that the most energetic action was not coincident with high temperatures, althongh the latter hastened the beginning of the process. Anthrax spores were destroyed almost as quiekly as the bacilli, and after a certain length of time their virulence progressively diminished. The red and infra-violet rays appeared to exert no bactericilal properties.

1 Procedings of the Royal Society, XXVI., p. 488 ; XXVIII., p. 199 ; XL., p. 14.

2 Journal of Pathology and Bacteriology, May, 1899, p. 14.

3 Vortrag auf dan zehnten internationalen medicinisehen Congresse, 1890.

4 Archiv für IIygiene, XXV.. p. 361.

${ }^{5}$ Comptes rendus de la Société de Biologie, Nor. 2, 1900, p. 884.

${ }^{6}$ Centralblatt für Bakteriologie, VIII., p. 6 .

7 Annali dell' istituto d'igiene sperimentale della reale universita di Roma, II., Serie 2, p. 121. 
Geissler ${ }^{1}$ found that direct sunlight exerts a more powerful influence on enltures of the bacillus of typhoid fever than an electric light of a hundred-candle power at a distance of a meter, and advanced the proposition that the effects on the bacteria are due in part to changes brought about in the character of the culture media. That the action of sunlight is chemical is shown by the differences in the capacity of the different rays for producing results, the ultra-violet being endowed with the greatest power.

This change in the character of the culture media has been noted also by Kruse, ${ }^{2}$ who found that liquid media, containing complex nitrogenous substances, are so altered by the influence of light that they acquire antiseptic properties against the bacteria and that the change is proportionate to the intensity of the light and the duration of the exposure. But it is not alone through changes in the media that bacteria are killed, but through changes brought about within themselves as well. And, indeed, it has been demonstrated that not alone bacteria, but their toxins also, are affected. According to Fermi and Celli, ${ }^{3}$ the toxin of tetanus, diluted with distilled water and exposed to direct sunlight at temperatures between $40^{\circ}$ and $50^{\circ} \mathrm{C}$., is rendered inert in 8 hours, and at $37^{\circ} \mathrm{C}$. in 15 hours. In elried condition it loses its power after 4 hours. Rattlesnake venom, however, is not injured by sunlight, even by 14 days' exposure.

Moisture and access of air are also important factors, as has been shown by Momont, ${ }^{4}$ who found that anthrax bacilli in a moist state were killed in 2.5 hours with free access of air, and survived more than 50 hours when air was excluded. Dry bacilli were killed with access of air in 5 hours; dry spores, exposed in glass without air, were virulent after 110 hours, and proved to be more resistant than others in a moist state.

The rapidity of action of sunlight is influenced also by the number of bacteria present-the greater the number, the longer the time required for the bactericidal effect to be instituted.

Weinziel ${ }^{5}$ asserts that the methods employed in older recorded experiments were defective, not only with regard to the bacilli of tubereulosis, but with other non-sporing bacteria, in that the medium employed absorbed considerable sunlight and that the glass covers both reflected and absorbed it. Direct exposure of bacteria on paper or glass to sunlight sufficed to destroy $B$.tuberculosis in about 10 minutes, and B. coli, B. typhosus, B. prodigiosus, and others in less time; but if the bacteria were clumped, they resisted longer.

The sterilizing influence of sunlight on the bacteria of drinking-water and sewage has been demonstrated by Procaccini, Buchner and Minck, and others to be very considerable, especially at and near the surface.

1 Centralblatt für Bacteriologie, XI., Nos. 6 and 7.

2 \%eitschrift für Hygiene und Infectionskrankheiten, XIX., p. 313.

3 Centralblatt für Bacteriologie, XII., No. 18.

4 Annales de l'Institut Pasteur, 1892, p. 28.

5 Journal of Infectious Diseases, Suppl., Vol. III., May, 1907, p. 128. 
Procaccini ${ }^{1}$ obtained positive results at a depth of from 26 to 30 centimeters. Minck and Buchner ${ }^{2}$ found that water containing 100,000 $B$. coli communis to the cubic centimeter was rendered sterile in an hour. The bacilli of typhoid fever and cholera, and $B$. pyocyaneus also were found to be destroyed. Cultures of $B$. typhosus, exposed at a depth of about 5 feet, were sterilized in $4 \frac{1}{2}$ hours, but at twice that distance beneath the surface the action virtually ceased. Buchner ${ }^{3}$ found, further, that diffused light has a strong influence, even as late in the year as November, on B. coli communis and B. pyocyaneus. The action of light is considerably interfered with by particles in suspension, but with fairly clear water the effects are perceptible at a depth of about 6 feet. The action of sunlight on bacteria in the presence of water is believed by many to be due to the production of hydrogen peroxide. Thiel and Wolf, ${ }^{4}$ however, investigating this question, found no evidence whatever that this agent plays any part.

The relation of sunshine to the well-known resistance of the natives of tropical Africa to ordinary infections has been studied by Martin, ${ }^{5}$ whose experiments were carried on in a district where the summer temperature in the open averages $77^{\circ} \mathrm{F}$. in the early morning and at night and $144^{\circ} \mathrm{F}$. at noon. Bacteriological examinations of indoor and outdoor air and of the soil showed an abundance of non-pathogenic and a scarcity of pathogenic bacteria ; and exposure of pure and mixed cultures of pathogenic bacteria to the action of the sun convinced him that while the sun's heat played a considerable part, much influence is exerted by the bactericidal action of the light rays.

The obvious disadvantages of relying upon sunlight for practical disinfection are that its supply is beyond control, and that, even on the brightest days, it is impossible to apply it to all parts of a house. Nevertheless, its beneficent action may, under favoring conditions, be taken advantage of in the treatment of furniture, hangings, and decorations, often the most troublesome objects to disinfect, especially in a country practice.

Heat.-For purposes of disinfection, heat is employed as "dry heat," $i . e$, hot air, and "moist heat," $i$. e., steam and boiling water. Steam is employed under various pressures in both the saturated and superheated conditions. In both conditions it is actually dry, although, as very commonly understood, saturated steam is associated with the idea of moisture. "Wet" steam is partially condensed saturated steam, and contains suspended particles of water. The temperature at which steam is formed depends upon the pressure; and whatever the temperature and pressure, as ebullition begins and proceeds, the water is maintined at that temperature, and is converted constantly into steam, in which the heat employed becomes latent. Until all the 437.

1 Annali dell' istituto d'igiene sperimentale della reale universita di Roma, III., p.

${ }^{2}$ Centralblatt für Bacteriologie, etc., XI., p. 781.

3 Archiv für Hygiene, XVII., p. 177.

4 Ibid., LVII., p. 29.

Münchener medizinische Wochenschrift, December 18, 1906. 
water has become converted, the resulting steam is said to be saturated, since any vilpor in the presence of the liquid from which it originates and in thermal equilibrium is necessarily saturated. In the saturated state, it can neither do work by expansion nor be cooled without undergoing partial condensation.

When saturated steam is farther heated, its temperature rises, and it is then known as superheated; and then, having a temperature higher than the condensing point corresponding to its actual density and volume, it may be cooled and can do work by expansion without being condensed. When very much superheated, it behaves more and more like a perfect gas, while saturated steam differs, as a rule, considerably. If water at the temperature of superheated steam be mixed with the latter, some of it will be vaporized and taken up; but mixed with saturated steam at the same temperature, no such action will oceur.

According to Rideal, ${ }^{1}$ the first recorded experiments in the sterilizing of organic matter by the application of heat were those of Needham, made prior to and during the year 1743, and the first application of this agent to disinfection on a large seale was made in 1831 by Dr. Henry, F.R.S., who treated infected clothing with hot air, and slinwed that the clothing of scarlet fever patients, subjected to a temperature of $200^{\circ} \mathrm{F}$. for two to four hours, would not propagate the disease if worn by healthy persons. The first use of direct steam as a disinfectant was made under the direction of Dr. A. N. Bell, U.S.N., in the ease of the steamer Vixen and schooner Mahones, which were infected with yellow ferer while on service in the Mexican war in 1848. Knowing of this use and its observed results, at the Quarantine and Sanitary Convention held in Boston, Mass., in June, 1860, the committee recommended that "steam generators and steam jackets or vats be provided for the disinfection of all personal, hospital, and ship's clothing and bedding, together with such other infected goods or things as may properly be subjeeted to high steam heat." ${ }^{2}$

In 1862 , according to Dr. Bell, the U. S. Transport Delaware was disinfected by steam at the New York Quarantine Station on account of yellow fever, this being the first disinfection of a vessel at that station, and probably the first at any of the port quarantines. According to the same authority, Commander Ralph Chandler, of the U. S. S. Don, from Santa Cruz, W. I., reported to the Nary Department that his ressel had been infected with yellow fever in its worst form (23 cases with 7 deaths), and that he had disinfected the ward room and berth deck successfully by means of steam. He recommended that vessels destined for service in the West Indies be provided with means of steaming the lower decks and holds.

Dry Heat.-Dry heat is much less effective than moist heat, even at much higher temperatures and with longer exposure. Thus, air at $300^{\circ} \mathrm{F}$. requires three or four times as long to accomplish the same work as steam at $212^{\circ}$, and possesses the additional disadvantage of

1 Disinfection and Disinfectants, London, 1898, p. 20.

? The Sanitarian, June, 1897 . 
injuring fabries and other objects exposed to it. Most fabrics of eotton, linen, and silk will withstand an exposure of several hours to dry heat at $230^{\circ} \mathrm{F}$., but beyond this point, evidence of impaired tensile strength is soon manifested. Even at $302^{\circ} \mathrm{F} .\left(150^{\circ} \mathrm{C}\right.$.), dry heat was found by Koch and Wolffhïgel to be not always effective, even after two hours, while boiling water and streaming steam at $212^{\circ} \mathrm{F}$. were found to produce the desired results in a very short time. But Schumburg ${ }^{2}$ has shown that air heated to $212^{\circ} \mathrm{F}$. will destroy the common non-sporing pathogenic baeteria if it contains 55 to 65 relative humidity. This condition can be secured by placing pans of water within the space where the infected objects are treated.

Steam.-Although steam had been recommended and used for purposes of disinfection as early as 1848, and although Pastenr, Tyndall, Cohn, and others had demonstrated in a number of extensive scientific investigations the sterilizing action of moist heat on putrefactive bacteria and other miero-organisms, and Tyndall had shown the necessity of discontinuous boiling for the sterilization of spore-bearers, the first investigation of the action of steam on the vitality of the bacteria associated with infective diseases was that conducted by Koch, Wolffhügel, and their associates, the results of which were published in 1881 . They demonstrated the very great superiority of steam over much hotter air, and showed that the most resistant spores are destroyed within a few minutes. They studied its effects on the different kinds of articles, such as clothing, bedding, furniture, and other objects, which in sanitary praetice may require to be disinfected, showed its applicability to all excepting a limited number, such as furs, leather, and veneered furniture, and led the way to the installation of public disinfecting plants for municipalities, hospitals, and quarantine stations.

A varicty of apparatuses, both fixed and portable, have been devised, and their use is steadily on the increase, not alone in large communities, but, especially in Europe, in thinly settled districts as well. For the latter, the portable apparatus on wheels is especially adapted, for it is beyond the limits of reason to expect small towns in which, perhaps, infective diseases of the kinds that call for thorough disinfection are only oecasional visitors, to establish and maintain public stations, whereas a number of such communities may have joint ownership in a portable machine which may be despatched on demand to the point where its services are required.

The general plan of the stationary and portable machines is essentially the same. They consist of one or more chambers of sufficient size to arlmit objects as large as or larger than a rolled nattress; and a boiler for the generation of steam, which is admitted through pipes controlled by valves. The most approved machines are so eonstrueted that, after the objects have been introdueed and the doors closed, the contained air may be withdrawn and a partial vacum of abont 20 inches produced, the object of which will be explained later. This is pro-

1 Mitheilungen ans dem kaiserlichen Gesundheitsimte, l., p. 301.

"Zeitschrift für Iygiene und Infectionskrankheiten, X LI., p. 167. 
duced best through the ageney of a steam jet rather than by a punp, since the latter is much slower in achieving the same results and exerts no disinfecting action on the germs that are contained in the air withdrawn. The best machines are provided also with a steam jacket, which assures a more uniform diffusion of heat in the chamber walls and a lessened opportunity for condensation, and a non-conducting outside casing of asbestos or asbestos-magnesia composition, to prevent loss of heat.

Statiouary apparatus is usually so placed that the receiving and discharging ends of the chamber open respectively into rooms having no direet communication with each other, as shown in Fig. 95, ${ }^{1}$ which is the ground plan of the first publie station installed in Berlin, $G_{1}$ being the

Fig. 95 .

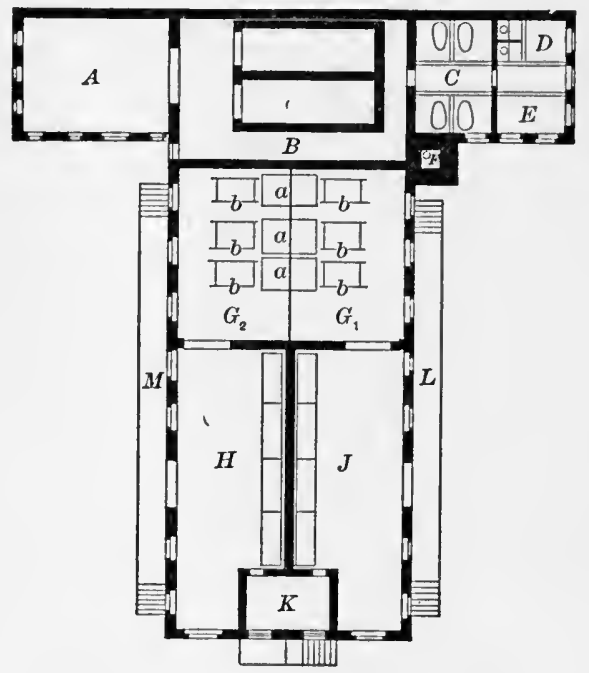

Ground plan of public disinfecting station.

room into which infected material is brought from the receiving platform $L$ or store-room $J$ and loaded into the trucks $b, b, b$. These are pushed into the steam chambers $a, a, a$, the doors of which are then securely closed. After the operation of steaming is completed the trucks are drawn into the room $G_{2}$, from which the materials may be taken to the discharging platform $M$ or store-room $H . \quad A$ is a repair shop and storeroom for coal; $B$, the boiler-room; $C$ and $D$ are bath-rooms and waterclosets for the employees; $E$ is a store-room for chemicals; and $K$ is the office, from which the work ean be directed by telephone, being completely shut off from $H$ and $K$, a full view of which is possible through hermetically sealed windows.

In operating the machines of the latest design, as soon as the articles are in place and the doors fastened (usually by turn-buckles), the air is

1 Merke-Vierteljahrschrift für gerichtliche Medizin und äffentliches Sanitätswesen, XLV., p. 137. 
removed from the chamber by means of a steam jet, which produces a vacuum of about 20 inches, and then the steam, under about 10-15 pounds' pressure is admitted very rapidly. After 15 minutes' exposure the steam jet is again employed to secure a vacuum of 20 inches, and then the fresh-air inlet is opened and a current of air is drawn through the chamber for about 10 minutes, after which the articles can be removed and exposed to the air to cool and dry, for which but a few minutes are required.

From a chamber not provided with a steam-jet, the air can be removed in great part by turning on the steam and allowing the air to blow off from time to time through a valve opened for a few seconds for the purpose.

The value of the removal of the air from the chamber lies in the fact that the confined air causes great delay in bringing the infected articles to the desired temperature, and interferes much with the penetrating action of the steam. The influence of air was overlooked by Koch ${ }^{1}$ when he asserted, because a liter-flask of water, exposed for 30 minutes to steam under about 15 pounds' pressure, attained a temperature of but $85^{\circ} \mathrm{C}$., instead of $120^{\circ} \mathrm{C}$, , that steaming steam was superior to steam under pressure. The necessity of removing the air was demonstrated first, in 1887, by Heydenreich, who, in a similar experiment, but with the air removed in part, sneceeded in attaining the desired result in 5 minutes, whereas Koch's specimen was 35 degrees away at the end of 30 minutes. In experiments with and without the assistance of the vacuum, reported by Doty, ${ }^{2}$ self-registering thermometers, placed within packages of newspapers, sheets, blankets, and rugs, showed differences ranging from nothing to a 100 degrees $(F$.$) after 3$ minutes' exposure, the higher temperature in each case being reached in the experiment with vacuum, and the smaller differenees occurring when the articles were loosely wrapped. With longer exposure, the differences were considerably smaller.

Another point in favor of the vacuum is the lessened opportunity for condensation of the steam in the interior of bundles and in the interstices of fabrics. It has been found to be advantageous to fill the chamber several times at short intervals with a fresh eharge of steam, and when the vacuum appliance is at hand, the time required for this series of operations is lessened materially.

The penetrating power of steam is greatly dependent upon the amount of pressure; the lower the pressure, the less the penetration. With machines in which low-pressure steam-a pound or two, for instance-is employed, penetration is, therefore, very slow and uncertain; and when bulky articles, such as rolled carpets and bedding, are treated, the results are likely to be unsatisfactory. For such articles it is agreed generally that a pressure of at least 20 pounds is none too great; but for smaller articles, such as clothing, towels, dressings, and sponges, a pressure of 10 pounds is ample. But whatever the pressure enployed, penetration may be much assisted by arranging

${ }^{1}$ Loc. cit.

${ }^{2}$ New York Assembly Document No. 58. 
the contents of the chamber so that too solid packing is avoided. This is secured by the interposition of wooden slats and gratings, which leave spatees between the different layers, through which the steam is distributed more readily.

With low-pressure steam, condensation is mueh more likely to be troublesome than when high pressures are employed; but ordinarily even then but little, if any, injury is suffered by the most delicate fabries beyond a slight impairment of gloss or the acquirement of a slight yellowish tinge; but woolen garments undergo a naterial shrinkage in size, and for this reason the method of exposure to air heated to $212^{\circ} \mathrm{F}$. and containing 55 to 65 degrees of humidity is preferable.

The relation of pressure to temperature is shown in the following table :

Pressure (pounds).

0

5

10

15

20

40

\begin{tabular}{cc}
\multicolumn{2}{c}{ Temperature. } \\
Fahreuheit. & Centigrade. \\
212 & 100 \\
228 & 109 \\
240 & 115.5 \\
251 & 121.5 \\
260 & 126.5 \\
287 & 141.5
\end{tabular}

Steam disinfectors are used extensively for purposes other than the destruction of disease germs ; they are most useful for renovating bedding and in the treatment of elothing infested with lice, which with their eggs are killed quickly by steam at any pressure.

Boiling Water.-Articles not injuriously affected by boiling water may be disinfected most conveniently in the household by being boiled for a few minutes. This suffices to kill all varieties of bacteria and the most resistant spores of pathogenic baeteria ; in fact, all organisms excepting the spores of a number of non-pathogenic bacteria which are not destroyed even after several hours' boiling. This method is adapted particularly to bed-linen and body-linen and, in short, to all washable fabries except woolens. It has the disadvantage of fixing stains, so that they become permanent; therefore, sheets, night-dresses, and other articles stained with blood or excreta, should have a preliminary soaking in cold water, so that the spots may be removed.

Although but a few minutes' exposure to the boiling temperature is quite sufficient to destroy all pathogenic organisms, it is common through abundant caution or through ignorance of the thermal deathpoints of these bacteria to continue the boiling for a half hour or longer. One who recommends pasteurization of milk at $160^{\circ} \mathrm{F}$. as a certain means of ensuring the consumer against all danger from streptocoeci and other pus organisms and the exciting causes of tubereulosis, typhoid fever, epidemic diarrhœa, diphtheria, and other diseases, is not unlikely to insist that on surgical instruments these same organisms require for their destruction much higher temperature and more prolonged exposure. Yet, the most resistant pathogenic organisms known -inthrax spores-have been proved by Sternberg ${ }^{1}$ to be incapable of

1 Infection and Immunity, New York, 1903, p. 44. 
resisting 4 minutes' boiling; and all known non-sporing pathogenic bacteria perish at $160^{\circ} \mathrm{F}$, or above, within 10 minutes. Experimenting with a number of strains of the most resistant of the pyogenie baeteria-Staphylococcus aureus-the author found not one that could resist boiling more than a minute and a half.

Fig. 96 shows a sterilizing hopper devised by F. A. Washburn, M. D., Superintendent of the Mitssachusetts General Hospital. This hopper is used instead of ehemieal agents for the disinfection of typhoid stools and urines.

In common daily use the gate valve of the hopper is open, the eover is up, and the steam, of course, is not turned on. When it is to be used for sterilizing purposes the gate valve is closed, the bedpan is washed out by means of water through the rubber hose attached to the faucet and water is allowed to enter the hopper to the line marked "H." Experience has shown that this is the line of safety; that if water is introduced above this line very vigorous boiling may cause the contents to overflow. Steam is then introduced into the donble jacket by opening the valve of the steam pipe inlet, the cover is closed, and, with 70 pounds' pressure of steam, boiling is almost instantaneous. When five minutes have elapsed, the gate valve is opened, the cover is raised, and the bopper is flushed out by means of the hose attached to the fancet.

Bedpans and urinals are also boiled in a small copper tank with a steam coil in the bttom.

The following is a copy of the sign which hangs over the sterilizing hopper :

"To use sterilizing hopper, close valve at bottom by pushing lever toward hopper and fill with water to level of ring painted on outside. Open steam valve and heat for five minutes. Flush hopper thoroughly after using."

There is no obnoxious odor connected with the use of this apparatus, provided the cover is shut from the time boiling is started until a short time after the sterilized eontents have been discharged into the sewer.

It is not necessary to use nearly as much steam pressure, although a lower pressure means a longer wait before boiling oceurs.

Cold.-Although eold is a very effieient antiseptic, but not commonly classed as a disinfectant, it appears to have destruetive power over eertain pathogenic bacteria, but none whatever over certain others, even when extremely low temperatures are employed. During the cholera epidemic in Germany, in the winter of $1892-93$, Uffelmann, ${ }^{1}$ experimenting with cholera germs, conchuded that they have considerable power to withstand cold for periods varying with the temperature. Renk ${ }^{2}$ placed the limit of endurance in ice at 8 days. Inoculated water, containing 620,000 per cc., was frozen at $-9.6^{\circ} \mathrm{C}$. and kept at that temperature for 39 bours; the ice was then melted and tested, and

1 Berliner klinisehe Wochenserift, 1893, No. 7.

${ }^{2}$ Fortschritte der Medicin, May 15, 1893. 
FrG. 96.

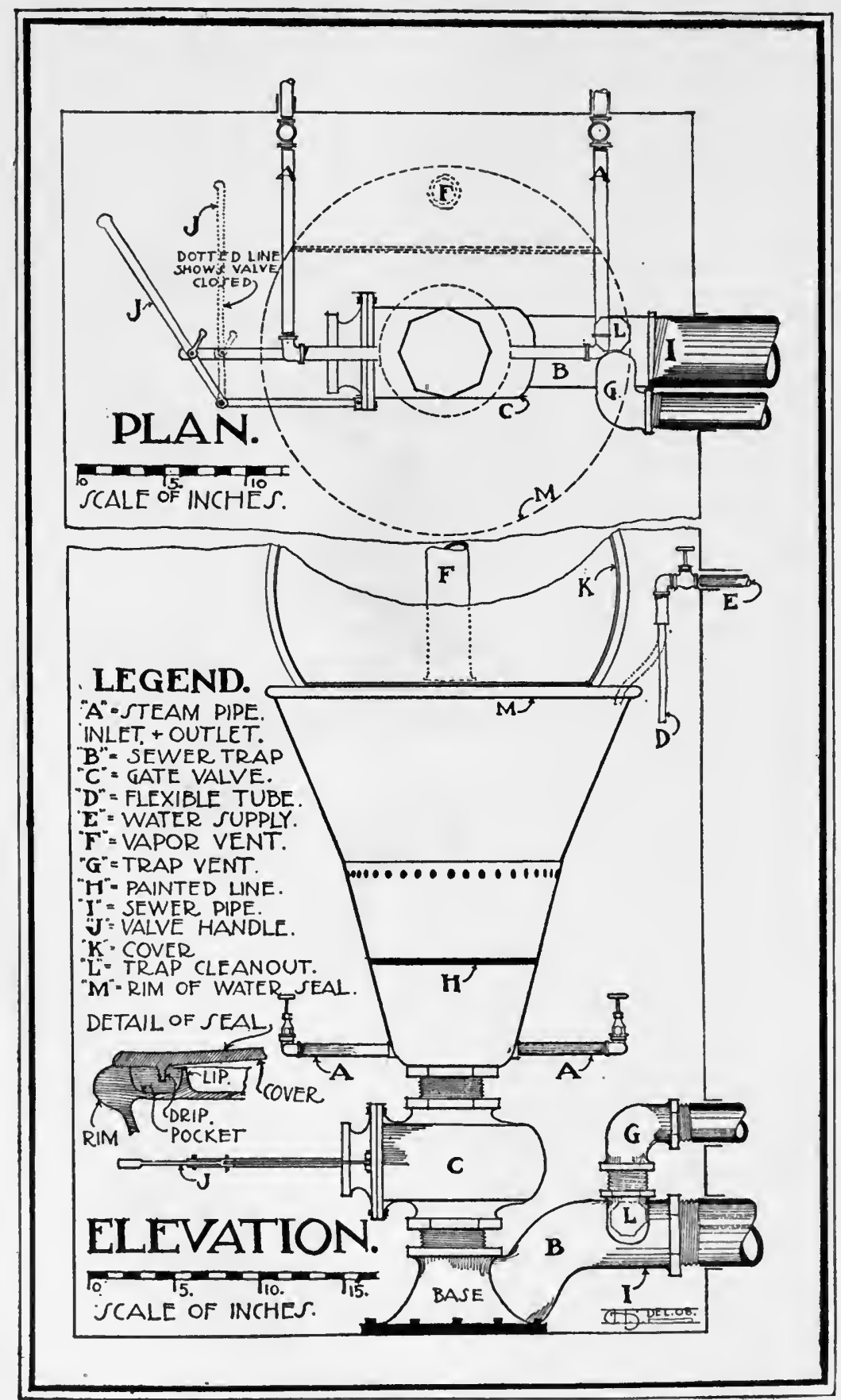

Sterilizing hopper used at Massachusetts General Hospital. 
the results were negative. In other experiments in which freezing was interrupted, no organisms were found after 6 and 7 days. But Wuknow ${ }^{1}$ kept them alive more than a month at $-32.5^{\circ} \mathrm{C}$., and Christian $^{2}$ has shown that under favorable conditions they can live longer than 4 months.

The typhoid organism, as is well known, may survive the action of cold for a long time. This was well shown in the experience of Plymouth, Pa., where, in 1885, a most devastating epidemic occurred after the thawing out of an accumulation of typhoid exereta situated near a brook which supplied the town with drinking-water, and at Ogdensburg, N. Y., where an outbreak was traced to ice that had been housed 9 months before.

The bacilli of diphtheria have been proved to be virulent after 6 months' continuous freezing, sometimes at $-25^{\circ} \mathrm{C}$., and those of plague have been found to be about equally resistant.

The exceedingly low temperature of liquid air, $-312^{\circ} \mathrm{F}$., appears to have no effect on organisms exposed to it for short or long periods. MacFadyen and Rowland ${ }^{3}$ subjected broth emulsions of B. typhosus, B. coli communis, B. diphtherice, B. proteus vulgaris, B. acidi lactici, Sp. cholerw Asiatica, Staphylococcus pyogenes aureus, B. anthracis (sporulating), B. phosphorescens, a sareina, a saccharomyees, and unsterilized milk, hermetically sealed in fine quills, to the refrigerating influence of liquid air for 7 days, and at the end of this time the quills were withdrawn and allowed to thaw. Culture experiments proved that the vitality of the varions micro-organisms was in no way impaired. Every speeies grew well, the photogenic bacteria grew and emitted light, and the milk became curdled. Later, Macfadyen ${ }^{4}$ exposed the organisms for 6 months, and in no case was there any appreciable effect upon their vitality.

\section{CHEMICAL AGENTS.}

The list of substances falling under the head of chemical disinfectants is very long, and includes a wide variety of organic and inorganic compounds, some of which are gases, some liquids, and others soluble salts. While it is very long-for almost any chemical substance possesses under one condition or another a certain degree of bactericiclal power-the number of agents which may be regarded as trustworthy in actual general practice is excecling small. Many substances which have a high reputation for efficiency are found to be actually worthless when subjected to modern methods of testing, and others which yield promising results in the laboratory are found often to fail when used under the conditions which obtain in practice.

The undeserved reputation of many preparations is based wholly upon the apparent influenee which they have exerted in limiting the spread of infectious diseases, and it has not been impared by mex-

1 Wratsch, 1893, No. 8.

${ }^{2}$ Archiv für IIygiene, I.X., 1909, No. 1.

3 The Lancet, $\dot{A}_{\text {pril }} 21,1900$.

- Proceedings of the Royal Society, LXX1., 1902, p. 76. 
plainable failure to acemplish the same result at other times. An outbreak of an infections disease occurs, for example, in a boarding-school, and during its continuance a number of bottles of some proprietary preparation are used; no further eases are reported, and the eredit is given to the disinfectant. Six months later, perhaps, another ontbreak oceurs, and, in spite of the use of the same agent, it spreads and the school is elosed; this result is not charged on the other side of the aceount, but to the inserutable ways of Providence, and the fame of the disinfectant is in no way injured. In many instances, strength and peculiarity of odor are the only qualities necessary for the building up of a reputation for efficiency, for man is wont to attribute potent properties to unusual things.

Many substances have undoubted germicidal power over eertain forms of baeteria, and are quite inert against others; some will kill every known form under some eonditions, and yet may wholly fail to affeet baeteria of slight resisting power protected by mueus or other matter, or may even be rendered inert almost immediately by chemical union with some other substance accidentally present.

Chemieal disinfeetants aet in various ways to bring about the destruction of bacteria. Some aet direetly upon the bacterial protoplasm and eanse its coagulation ; some bring about ehanges in reaction favorable to life and growth; some destroy nutritive material by ehemical change; some take up all the available oxygen, thus becoming themselves changed in character while depriving the bacteria of an essential element; and others bring in such an excess of this same element that the bacteria cannot withstand its action. Some even stimulate multiplication, and thus act only indirectly by promoting the formation of organie compounds which exert a destructive influence upon the organisms by which they have been produced. The disinfectant power of many of the metallic salts depends partly upon the nature of the solvent.

Different agents produce their best results in different degrees of concentration ; thus, while one may be efficient in 5 per cent. solution, another may aet equally well or better in 0.10 per cent. or even weaker solution. Some agents, as, for instance, alcohol, are most baetericidal at some one point of concentration, and above and below this the property progressively diminishes. In applying any agent whose best working strength is known, it should be borne in mind that it is not suffieient to use a small volume of solution of that particular strength, but that the substanee itself must be employed in suel an amount that it shall be present throughout the whole mass in the proportion required. Thus, an agent which is effeetive in 2 per eent. solution cannot be used in that strength to disinfect an equal bulk of infeetive material, sinee the mixture would then contain but 1 per cent.

\section{Non-metallic Elements and Their Compounds.}

Oxygen.-The disinfeetant property of pure air is due to its oxygen, which attacks organic matter under favorable conditions and 
converts it in great part to carbon dioxide and water. Prolonged aëration is rightly regarded as a valuable assistant in disinfection, hut it should not be overlooked that when infected objects are exposed to moving currents of outdoor air, they are subjected also to the powerful influence of the ehemical rays of sunlight and to the possibility of desiccation. Oxygen acts most powerfully in the nascent state, as when liberated from compounds whose decomposition results in the escape of the gas in the free condition. Among these compounds, ozone, the allotropic form of oxygen, containing in each molecule three atoms instead of two, and hydrogen peroxide, may be mentioned as conspieuous examples of oxidizing agents which part very readily with the loosely held element.

Ozone, in the minnte amounts in which it exists normally in air, can hardly be regarded as an important influence in practical disinfection. Produced artificially by means of the silent electric discharge, it is found to be possessed of marked bactericidal power, and has been recommended highly for speeial work, particularly in the sterilization of drinking-water. The researches of a number of investigators have demonstrated that dry bacteria are not much affected by dry ozone, but that in a moist condition they are quickly destroyed by small amounts.

Krukowitsch, quoted by Kowalkowsky, experimenting, in 1882, with putrefactive bacteria, fond that 3 milligrams of ozone per eubic meter of air killed fresh bacteria, exposed on paper, within an hour, and 8 milligrams per eubic meter sufficed to destroy the dried organisms. Later (1888), Lukaschewitsch, experimenting with B. subtilis, B. anthracis, Sp. cholerce Asiatica, and certain putrefactive bacteria, obtained results which were less favorable, but in agreement in so far as they demonstrated the relatively slower action exerted on dry bacteria. Spores of B. subtilis and B. anthrecis in a dry state were unaffected by 1.50 grams of ozone per eubie meter, and the comma bacillus, in a moist condition, was not affected until after 15 hours' exposure to the same atmosphere.

Ohlnïller ${ }^{2}$ employed a much greater strength, namely, 15 grams to the cubic meter, and enducted the air through distilled water, in which bacteria were suspended. Water containing anthrax spores was sterilized in 10 minutes by 89.9 milligrams of ozone; and containing millions of typhoid and cholera germs to the cubic centimeter, in 2 minutes by less than 20 milligrams. River-water and sewage were found to be much less affected, but with only moderate pollution it appeared probable that in ozone might be found a cheap and efficient means of purifying drinking-water. Later on, a number of processes were devised for this purpose and earried out on a large seale.

In the hope of arriving at some definite conclusion an to the availability of ozone as a roon disinfectant, Ransome and Fonlerton ${ }^{3}$ con-

1 Zeitschrift für Hygiene, IX., p. 89.

2 Arbeiten aus dem kaiserlichen Gesundheitsamte, VIII., 18?2, p. 229.

3 Public Health, July, 1901, p. 684. 
dueted a series of experiments in which large quantities were used, mixed with air or with pure oxygen. The organisms employed as tests ineluded B. tuberculosis, B. mallei, B. diphtherice, B. anthracis (sporing), B. typhosus, B.coli communis, B. pyocycineus, B. pneumonice (Friedlïnder), B. prodigiosus, Staph. pyogenes aureus, Strep. pyogenes, Micr. candicans, Saccharomyces albicans, Sarcina ventriculi, and an anaërobie, sporing, butyrie-acid-forming bacillus. The results demonstrated that dry ozone has no appreciable action on the vitality of these organisms; that prolonged exposure does not diminish the pathogenie virulence of $B$. tuberculosis in sputum, B. mallei or B. anthracis; that ozone passed through a fluid medium containing bacteria has germicidal power : "that any purifying action which ozone may have in the,economy of nature is due to the direet ehemical oxidation of putrescible matter; and that it does not in any way hinder the action of bacteria, which latter are, indeed, in their own way, working toward the same end as the ozone itself in resolving dead organic matter to simpler non-putrescible substances."

Hydrogen peroxide, $\mathrm{H}_{2} \mathrm{O}_{2}$, is quite stable in the presence of some substances, but gives up its loosely combined atom of oxygen very readily to others. It is a powerful, odorless oxidizing agent, prepared by the action of dilute sulphuric acid on barium peroxide. It is destructive of bacteria, but has no action on the enzymes of the digestive juices, and in dilute form is neither poisonous nor irritant in the human system.

Aceording to Altehöfer, ${ }^{2}$ in the proportion of 1 part in 1,000 of water containing the organisms of eholera and typhoid fever, it produces sterility within 24 hours. In 1 per cent. solution, aceording to Traugott, ${ }^{3}$ the bacilli of diphtheria and typhoid fever are killed in 5 minutes, the organisms of erysipelas and cholera in 2 minutes, Streptococcus pyogenes in 10 minutes, and Staphylococcus pyogenes aureus in from 15 to 30 minutes. With half this strength, the typhoid organism and Streptococcus pyogenes are destroyed with equal promptness, the cholera and erysipelas organisms in 5 minutes, the bacillus of diphtheria in 15, and Staphylococcus pyogenes aureus in an hour. It is believed by many that the bacterieidal effeet of sunlight on organisms in surface waters is due to the hydrogen peroxide produced through its influence, but the experiments of Thrill and $\mathrm{Wolf}^{3}$ indicate that this is not true, and that no peroxide is formed.

Chlorine, both in the free gaseous condition and in solution in water, has very powerful disinfeetant and deodorant properties. It decomposes the offensive gaseous products of putrefaction, such as ammonia and sulphuretted hydrogen, and in the presence of moisture unites with hydrogen, thus liberating oxygen in the naseent state, which is far more active than atmospheric oxygen against organie matter. In the dry state the action of ehlorine upon dry matter is slight and unreliable; its disinfectant action on dry matter is but slight and unreliable; but in

1 Centralblatt für Bakteriologie, VIII., p. 129.

2 Zeitschrift für Hygiene und Infectionskrankheiten, XIV., p. 427.

3 Archiv für Hygiene, LVII., p. 29. 
the presence of a moderate degree of atmospheric moisture, its effect is considerable, as is shown by its bleaching action on dyed fabries. The exhaustive research of Fischer and Proskauer ${ }^{1}$ demonstrated, however, that chlorine as a funigating agent is untrustworthy, and that its application is attended by serious disadvantages. The test-objects employed embraced a somewhat wide variety of pathogenic and non-pathogenic organisms, and were exposed under different conditions of moisture and dryness for varying periods and to different percentages of the gas. The results, as a whole, were highly unsatisfactory from $a$ practical standpoint, on account of the impossibility of properly regulating all the necessary conditions, the alsence of penetrating power, the destructive action of fabrics and other articles, and the uncertainty in achieving the object sought.

" Chloride of Lime," Bleaching Powder, Chlorinated Lime, which is a combination of calcium chloride and hypochlorite, the result of passing chlorine over dry slaked lime, was in use as a disinfectant and deodorant for a long time before the development of the science of bacteriology. In 1881, in the course of the first real investigation of the properties of what were commonly regarded as disinfectants, Koch obtained very unsatisfactory results from his tests with this agent, which thereupon to a great extent was discarded. In 1885, Sternberg, then chairman of the committee of the American Public Health Association, to which, in 1884, the subject of disinfectants had been referred, took very different ground regarding this and other hypochlorites, and asserted their efficiency in no uncertain terms. Since then the matter has been the subject of many investigations by competent observers, and while in some hands the results have failed to be uniformly favorable, the work, as a whole, has sustained the position taken by Sternberg as a result of his own experiments.

Woronzoff, Winogradoff, and Kolesnikoff ${ }^{2}$ demonstrated that anthrax spores were killed in 1 minute by a 5 per cent. solution, although in Koch's experiments they had been found still active at the expiration of 2 days. Jaeger, ${ }^{3}$ in 1889 , concluded, after a series of tests with a number of species of pathogenic bacteria, that it is a very efficient disinfectant, even in weak solutions. Nissen, ${ }^{4}$ in 1890, after a series of eareful experiments, reported that the organisms of cholera and typhoid fever were destroyed in 5 minutes when the material in which they were present eontained 0.12 per cent. of the agent, and in 10 minutes by half that amount. Anthrax baeilli were killed in 1 minute by 0.10 per cent. ; Stuphylococcus pyogenes uureus and Streptococcus erysipelutis in 5 minutes by 0.12 and 0.15 per cent., respectively, and in 1 minute by 0.20 . Anthrax spores of low resistance were destroyed in 15 minutes by 5 per cent. and in 70 minutes by 1 per eent. Very resistant spores, capable of surviving 4 hours' immersion in 0.10

1 Mittheilungen aus dem kaiserlichen Gesundheitsamte, II., p. 228.

${ }^{2}$ Centralblatt für Bakteriologie, 1887, p. 641.

3 Arbeiten aus dem kaiserlichen Gesundheitsamte, V., p. 247.

4 Zeitschrift für Hygiene, VIII., p. 62, 
per cent. corrosive sublimate and 10 minutes' exposure to streaming steam, were killed in 4.5 hours by 5 per cent.

Klein, ${ }^{1}$ experimenting with sodium hypochlorite in 10 per cent. solution (1.0 per cent. chlorine) on the eolon bacilhus, anthrax spores, Staphylococcus pyogenes aureus, B. enteritidis sporogenes, and the bacteria of typhoid fever, cholera, and swine fever, found that all were killed in 20 minutes, and the non-spore-bearers in 10 . In one-tenth as strong solution, all but the two kinds of spores were destroyed within 20 minutes. Duggan, ${ }^{2}$ working according to Sternberg's method, reported, in 1885, that his experiments had shown "that a solution eontaining 0.25 per cent. of ehlorine as hypochlorite is an effective germieide, even when allowed to aet for only $\mathrm{i}$ or 2 minutes, while 0.06 per cent. will kill spores of $B$. anthrecis and B. subtilis in 2 hours."

The composition of "chloride of lime," or, more properly, chlorinated lime, and its mode of action, are matters concerning which there is considerable disagreement. The substance is held varionsly to be: (1) a mixture of calcium chloride and hypochlorite; (2) calcium hypochlorite in which one $\mathrm{ClO}$ is replaced by $\mathrm{Cl}$, that is, $\mathrm{Ca}(\mathrm{ClO}) \mathrm{Cl}$, which, in contact with water, is broken up into calcium chloride and hypochlorite; (3) a compound of caleium hypochlorite and oxychloride with $4 \mathrm{H}_{2} \mathrm{O}$, formed according to the equation

$$
4 \mathrm{CaO}_{2} \mathrm{II}_{2}+2 \mathrm{Cl}_{2}=\mathrm{CaO}_{2} \mathrm{Cl}_{2} \cdot \mathrm{Ca}_{3} \mathrm{O}_{2} \mathrm{Cl}_{2} 4 \mathrm{H}_{2} \mathrm{O} \text {, }
$$

which is split up in water into calcium chloride, hrpochlorite, and hydroxide; and (4) a compound of calcium chloride with hydroxide, of which one $\mathrm{H}$ is replaced by $\mathrm{Cl}$. It is white or whitish in color, and occurs as a powder or as friable lumps; it should be dry or nearly so, and should have no more than a faint odor of chlorine, which element should be present in available form to the extent of not less than 35 per cent. to conform to the requirements of the U. S. P. (British standard $=33$ per cent., German standard $=25$ per cent.).

With keeping, under various conditions, chlorinated lime may undergo decomposition in a number of ways. A pasty condition or a strong odor of chlorine is evidence of partial decomposition. It is only partially soluble in water, and its aqueous preparations are made best by triturating the requisite amount with water to the consistency of cream, and then diluting to the desired volume. The addition of acids to the solution causes evolution of chlorine, but the carbon dioxide naturally present in the water or absorbed from the air decomposes the hypochlorite, yielding calcinm carbonate and hypochlorous acid, the latter of which breaks up into active oxygen and free hydrochlorie aeid. (See Hypochlorons Acid, p. 577.)

The solution known as the "American standard" contains 6 ounces of the powder to the gallon. It is used largely in the disinfection of discharges, and for scrubbing floors and other wook work. A weaker

1 The I ancet, Nov, 26,1896 , p. 509.

${ }^{2}$ Report of the Committee on Disinfectants of the American Public Health Association: Baltimore, 1885, p. 12. 
solution is employed for the treatment of infeeted bed-linen and washable clothing, but on account of its destructive action, these articles should, after a not too long immersion, be washed thoroughly in plenty of fresh water.

Sodium hypochlorite solution, otherwise known as chlorinated soda, Labarraque's solution, and liquor sode chloratre, is "an aqueous solution of several chlorine eompounds of sodium, ehiefly $\mathrm{NaClO}$ and $\mathrm{NaCl}$, and containing at least 2.6 per cent. by weight of available chlorine" (U.S. P.). It is used, but not so extensively, for the same purposes as chlorinated lime.

Hypochlorous Acid.-It being not improbable that ehlorine in solution in water exerts its disinfectant aetion as hypochlorous acid, Andrews and Orbon' 'tested the bacterieidal properties of preparations of the pure acid and found them to be of the most intense character, anthrax spores being very quiekly destroyed by the acid in extreme dilution, when they were suspended in pure water. The presence of organic matter, however, eauses the very unstable acid to deconipose very rapidly, so that whereas Staphylococcus pyogenes aureus in distilled water was killed immediately by $1: 100,000$, in veal broth it was killed only within 30 minutes by $1: 3000$. But it was found that the germicidal power of bleaching pöwder solution is increased by the addition of a weak acid (acetic or carbonic) to liberate free hypochlorous acid (a strong acid liberates free ehlorine). Thus, a saturated solution containing 5 per cent. of calcium hypochlorite required between 7 and 10 minutes to destroy dried anthrax spores, while the same solution diluted with two volumes of 1.25 per eent. acetic acid killed them in less than 1 minute.

Iodine has powerful disinfectant properties, but is more suited to the purposes of the operating room than to general disinfection. The experiments of Kinnamon ${ }^{2}$ indieate that in solutions of 0.2 to 1 per cent. it is far superior to corrosive sublimate-1:1000. The latter required 15 minutes for the destruction of streptoeocei, while iodine (2:1000) killed them in 2 minutes. Iodine possesses the advantage over eorrosive sublimate that it neither eoagulates albumin nor forms inert eompounds with the tissues, and in effective strength is non-toxic and non-irritating. Dannrenther ${ }^{3}$ eonsiders the tineture the best means of sterilizing a dirty wound, and an excellent agent for sterilizing the skin before incision and for limiting the extension of the erysipelatous rash.

Bromine.-While bromine has marked disinfectant properties, it is disagreeable and dangerous to handle, and, according to Kimnamon, ${ }^{4}$ is much inferior to iodine in all respects. Its use in the purification of water has not been markedly suecessful. (See chapter on Water.)

Sulphur dioxide casily outrunks all other disinfectants in point of

1 Centralblatt für Bakteriologie, etc., I. Abth., Originale, 1904, XXXV., p. 645.

2 Journal of the American Medical Association, Aug. 26 and Sept. 2, 1905.

3 Medical Record, January 25, 1908.

Journal of the American Merlical Association, February 1, 1908, p. 345. 
length of service, its use dating back to very ancient times. While it has undoubted baetericidal properties, it has been demonstrated by Koch, Wolffhïgel, and their associates, and many others, to be wholly untrustwortlyy for general use, and although still very extensively employed by public sanitary authorities, is rapidly being abandoned in favor of more efficient and reliable agents. It is purely a surface disinfectant under conditions most favorable to its aetion, and even then is effective against only a somewhat limited number of species of pathogenie bacteria.

Sulphur dioxide is a colorless irrespirable gas, produced by burning roll sulphur or "flowers" in an iron vessel, placed as a precaution against fire in a pan of water, or by burning sulphur candles or carbon disulphide, the latter in a lamp. The amount of sulphur employed varies, aceording to the custom of the operator, from 1 to 6 pounds per 1,000 eubie feet of air space; but the whole amount is never consumed, and, indeed, under ordinary eireumstances, combustion ceases before a half or even a third has been burned. In order to avoid the necessity of burning sulphur, the liquefied gas, contained in cylinders, is employed to some extent.

In the absence of moisture, the action of sulphur dioxide on even the least resistant bacteria is practically nil, and even when water is evaporated in the room beforehand or at the same time, and the gas is present in the lighest percentage possible, the exposed organisms, whether of low or high resistance, are likely to retain their vitality unimpaired. It is true that some experimenters have reported great suceess in the destruetion of pathogenie organisms by means of this agent, but the adverse reports are so numerous that it must be clear that much official disinfection by means of it is worse than an empty form and, by reason of causing a false sense of security, a positive danger. Even were it an efficient disinfeetant, the many disadvantages which attend its use would suffice to make it undesirable for general purposes, especially in view of the fact that the same disadvantages are wholly absent in other processes. In the presenee of moisture and air, it is to some extent oxidized to sulphurie acid, which corrodes fabries and other objeets; it reduces organie matters and destroys organic colors; it tarnishes brass and silver ware, gilt fiames, and other objeets; it leaves a disagreeable odor which persists for days and even weeks after thorough aëration; bedding and other articles become impregnated with a peenliar highly offensive odor whieh renders their use unpleasant and even impossible; and it has such little power of penetration that only such organisms as are exposed openly are likely to be affected.

Where sulphur dioxide is the official disinfectant, it is eommonly enjoined that the room shall be eleansed thoroughly and air freely admitted for some days after fumigation. The neessity of this supplementary process is in itself an admission of the inadequacy of the main operation, for if sulphur is an efficient disinfectant, the application of soft soap, carbolic aeid, hypochlorites, and other agents by means of 
the scrubbiug-brush and cloths, the removal and replacing of wallpapers, the process of white-washing, and other means of renovation recommended, are attacks against an imaginary evil. Granted that these processes are necessary, the claims of sulphur dioxide as a practical disinfectant must fall to the ground ; if not necessary, they should not be enjoined.

Although not an efficient disinfectant, sulphur dioxide is an exceedingly valuable agent for the destruction of mosquitoes in houses where malaria and yellow fever are rife (see chapter on The Rẻlation of Insects to Human Discases) and of rats in ships' holds (see chapter on Naval and Marine Hygiene).

\section{Sodium Carbonate.}

Sodium Carbonate, or "Washing Soda," used in every household as a cleaning agent, because it saponifies grease and dissolves albuminous substances, is a substance which possesses none of the disadvantages that belong, one or another, to almost all other chemical disinfectants. These are-1, disagreeable odor; 2 , poisonous properties; 3 , high cost ; 4, corrosive action. Simon, ${ }^{1}$ mindful of the fact that the hotter a disinfectant is applied the better the results, investigated the action of hot solutions of this substance upon some of the common pathogenic organisms, the maximum temperature employed being $140^{\circ} \mathrm{F}$, which marks the limit which the hands of a scrubwoman can endure. $\mathrm{He}$ employed the agent in solutions of $2,5,10$, and 20 per cent. in water at from $7 \cdot 2^{\circ}$ to $140^{\circ} \mathrm{F}$. against staphylococci, streptococci, $B$. diphtherice and $B$. tuberculosis in sputum, dried on threads, and on articles of furniture and other objects likely to be contaminated with infective matter.

Below $132^{\circ} \mathrm{F}$. none of the solutions exerted any immediate destructive action against $B$. diphtherio, but at that temperature the 2 per cent. solution killed it in 2 minutes, and the 5 per cent. solution in 1 minute, controls in distilled water kept at the same temperature being still capable of growth after 15 minutes. Staphylococci were resistant to all solutions up to $140^{\circ} \mathrm{F}$., at which temperature they were killed in 5 minutes. Streptococci were killed more quickly, and dried tuberculous sputum was sterilized by the 2 per cent. solution in 5 minutes and by the 10 per cent. solution in 1 minute. Kurpjuweit ${ }^{1}$ employed 2 and 5 per cent. solutions against colon, typhoid fever, and dysentery bacilli at $75^{\circ}, 95^{\circ}$, and $122^{\circ} \mathrm{F}$, with the following results : Typhoid fever bacilli were killed by the 2 per cent. solution in 1 minute at $122^{\circ} \mathrm{F}$. and in 5 minutes at $95^{\circ} \mathrm{F}$, and by the 5 per cent. solution in 15 minutes at $75^{\circ} \mathrm{F}$. The colon bacilli were more resistant, the 2 per cent. Golution requiring 5 minutes at $122^{\circ} \mathrm{F}$. and 1 hour at $95^{\circ} \mathrm{F}$. The dysentery organism was killed almost immediately by the 2 per cent. solution at $122^{\circ} \mathrm{F}$. and in 30 minutes at $95^{\circ} \mathrm{F}$.

The substance does not injure ordinary woodwork, furniture, or linoleum carpets.

1 Teitschrift für Hygiene und Infectionskrankheiten, XLIII., 1903, p. 348.

${ }^{2}$ Ibid., p. 367. 


\section{Lime.}

Lime, quicklime, or calcium oxide, has long been known as an agent possessing great power in destroying organie matter, and has been used extensively from very early times in eonneetion with disposal of the dead. Treated with half its weight of water, it is slaked to a dry powder, the hydrate, which, mixed with suffeient water, forms the well-known "white wash" commonly used for disinfecting, sweetening, and brightening the walls of cellars, rooms, barracks, barns, poultry-houses, and other outbuildings. Slaked lime, mixed with four volumes of water to the consistency of eream, forms what is eommonly known as "milk of lime," which is used extensively in the disinfeetion of exereta and privy vaults.

The scientific investigation of the disinfectant properties of lime by Liborius, ${ }^{1}$ undertaken at the instanee of Koch, demonstrated its value in the destruction of the bacteria of typhoid fever and cholera, the former of which were found to be destroyed in a few hours by limewater containing 0.0074 per eent., and the latter within the same time by 0.0246 per cent. Cholera bouillon eultures, eontaining numerons coagula of albumin, such as would be present in eholera discharges, thus offering unfavorable eonditions for the aetion of the disinfeetant, were eompletely disinfected within the course of a few hours by 0.40 per cent. of pure lime or by 2 per cent. of ordinary erude lime. $\mathrm{He}$ reeommended the employment of the pure dry powder or of milk of lime containing 20 per cent. thereof.

Favorable results were obtained also by Kitasato, ${ }^{2}$ who found that the same two speeies were destroyed by about 0.10 per eent. in from four to five hours. Pfuhl, ${ }^{3}$ carrying the experiments somewhat farther, recommended the use of milk of lime of 20 per eent. strength, freshly prepared from lime of good quality, for the disinfection of loose dejections, preseribing that it should be added in sufficient quantity, with thorough mixing, until the whole mass is strongly alkaline in every part, as shown by testing with red litmus-paper. With such treatment, he asserted that eomplete sterilization is acemplished within an hour. Extensive researehes by numerous other seientists, although differing somewhat in results in eertain unimportant particulars, have confirmed the eonclusions of these earlier investigators as to the great practical value of this agent. As to its value in comparison with chlorinated lime, there is disagreement, some authorities favoring the one and some the other, but praetically all unite in the opinion that, whichever is the more effieient, the difference is slight.

Of great practical importanee in the use of any disinfectant on a large seale is the item of expense. It happens, fortunately, that this valuable aid is exeeedingly eheap, and that its use with a liberal hand in excess of the reeommended amount may be urged without promoting lavish expenditure of money. In the disinfeetion of stools it is eom-

' 'eitschrift für Hygiene, II., p. 15.

2 Ibidem, II I., p. 404.

Ibidem, VI., p. 97. 
monly advised to add at least an equal volume of the milk, or even twice as much, and to allow the mixture to stand for two hours or longer before final disposal. In camp sanitation, it is much used with excellent results; but for their attainment, constant watchful supervision is neecssary.

It should be borne in mind that air-slaked lime should not be employed in the preparation of the milk, and that the latter on standing loses its homogeneous eharacter, which should be restored by stirring or shaking each time the material is used. The milk is most powerful when freshly prepared, and should not be used when older than a few days, unless most carefully protected from contact with air.

\section{Metallic Salts.}

Ferrous sulphate and other salts of iron have long been used extensively, both as germieides and deodorants. All scientific investigations of the disinfectant properties of ferrous sulphate by Koch, Sternberg, and others have demonstrated the utter worthlessness of this agent. Not only does it fail as a germicide, but, as has been pointed out by Foote, ${ }^{1}$ it has also no elaim to be considered as a deodorant. Its employment in this capacity not infrequently makes a bad odor worse, through ehemical action on organic compounds produced in the process of putrefaction.

Ferric sulphate has been shown by Riecke ${ }^{2}$ to have very marked action against the bacteria of typhoid fever and cholera in acid and alkaline excreta, when added in an equal volume of 5 per cent. solution. The disadvantages attending its use, however, more than outweigh any eonsiderations which may be urged in favor of its employment in place of other more efficient and, on all accounts, less objectionable agents.

Ferric chloride, also, has some claim to be regarded as a germicide, but it is inferior to the sulphate and is open to the same objections.

On the whole, therefore, the iron eompounds may safely be passed by in the practice of disinfection.

Zinc chloride, like ferrous sulphate, was, until subjected to the rigid test of bacteriologieal proof, regarded as a most efficient disinfectant, and to-day, althongh the original adverse findings of Koch, in 1881, have been eonfirmed by many careful experimenters, it is still very extensively employed, and in many places is preseribed officially by the loeal health anthorities. Under some conditions, it does suceed oceasionally in destroying some forms of bacterial life, but its place in the list of actual and supposed disinfeetants is well down toward the very bottom. It is, however, somewhat efficient as a deodorant. The sulphate and other salts are equally inefficient as disinfeetants.

Aluminum chloride is the ehief soluble eonstituent of a number of extremely popular proprietary disinfectants, preseribed by practising

1 American Journal of the Medieal Sciences, XCVIII., p. 329.

2 Zeitschrift für Iygiene und Infectionskrankheiten, XXIV., p. 303. 
physicians and bought with and without advice by the laity. Like other aluminum compounds, the sulphate and the alums, for example, it is powerfully astringent, even in dilute form. It is eheap, has no action on metallic substances, and does not stain nor otherwise injure fabries. Its disinfectant aetion is slight, and herein it agrees farther with other aluminum compounds. A number of proprietary preparations, in which it is present either as principal or auxiliary ingredient, examined by the author with Dr. R. M. Pearce, ${ }^{1}$ were found to be ineffieient. The test-objects included eultures of $B$. anthracis and $B$. typhosus, typhoid dejeeta, diphtheritic membranes, and tuberculous sputa. Each of five preparations, in the strength recommended, was subjected to 10 tests, and their proportions of successful disinfection varied from 20 to 70 per cent. Anthrax bacilli were destroyed by one; one culture of B. typhosus was killed by one, another by all, a third by two; one typhoid stool was unaffeeted by all, a second was sterilized by all, and a third by three; one specimen of diphtheritic membrane was sterilized by four, and another by only one; tuberculous sputum was affeeted by none.

Potassium permanganate, well known as a powerful oxidizing agent, is much used in surgical practice and in other lines of special work. In the process of sterilization of the hands, however, it is incapable, as the author has shown, ${ }^{2}$ of producing the results for which it is employed. In contact with organic matter and oxidizable mineral substances, it parts very readily with its available oxygen, and it is to this element that whatever disinfectant property it has, is due. It cannot be used in the treatment of excreta, because of the very large amount which would be required to produce complete sterility of even a single ounce of freces; nor can it be employed in the treatment of clothing, beeause of the permanent stains which it produces.

Copper sulphate in weak solutions destroys sporeless bacteria in great variety within a short time, but in practical work its use is rather limited. Although it appears to be of considerable value in the destruction of certain forms of algal growth in public water supplies, the assertions made concerning its germicidal value in the treatment of infected waters have not as yet been substantiated, and in the light of a number of recent investigations it would seem probable that they must fall to the ground. It bas been recommended strongly for the sterilization of fæces, but its cost and other disadvantages, not to mention its inferiority as a germicide to other cheaper and more available substances, make it improbable that its employment will ever become very extensive.

Mercuric chloride or corrosive sublimate is, beyond question, the most powerful of all the metallic salts as a disinfectant, but at the same time it enjoys a reputation for practical efficiency that is not wholly deserved. A number of the earlier experiments which gave it its standing led to conclusions which eould not be justified by later

1 Journal of the Boston Society of Medical Sciences, March, 1899.

2 Annals of Surgery, October, 1904. 
work conducted on lines of greater accuracy and with improved technic ; but while Koch and others saw fit to modify their original estimate of its general efficiency, it would appear that a large proportion of those who have occasion to employ germicides are influenced more by the original than by the later investigations. In testing its disinfection properties against anthrax spores and other highly resistant organisms, widely different results have been obtained and recorded by different observers, but these are explained by differences in nutrient media, in technic, and in virulence; and although it has been proved that the original findings were far too favorable, it also has been proved that as a germicide it stands far above all other metallic compounds. But it should be understood that, under conditions which obtain in practice, the same results as are obtained in laboratory experiments, made with broth eultures and spores dried on silk threads, are not always to be expected. In the treatment of tuberculous sputum, for example, the innermost bacilli are protected from contact with the disinfectant by the coagulum which forms on the surface of each separate mass. Again, in the treatment of other organic matter, the possibility of precipitation as albuminate or sulphide or other insoluble compound of mereury should be kept in mind.

Precipitation as albuminate may be prevented by the addition of about 5 parts of sulphuric, hydrochloric, or tartaric acid, or of 10 parts of common salt, for each part of sublimate in 1,000 , but conversion to sulphide cannot be prevented, if the conditions necessary for its formation are present. In the disinfection of feces, for which purpose corrosive sublimate is sometimes used, it is evident that, with the usual strength of solution employed, the whole of the salt must frequently be precipitated in one form or another very early in the process. In household disinfection, its corrosive action on plumbing must be considered as a serious drawback.

Its chief use in surgieal practice is as a sterilizing agent for the skin, ligatures, etc., the strength used being commonly 1 part in 1000 ; but weaker solutions, even 1 in 10,000, are also employed. Unfortunately the element of time seems not to be generally regarded in the practice of disinfection, and instantaneous germicidal action appears to be assumed as the result of contact of the agent with pathogenic bacteria. In order to determine the length of time required for solutions of different strengths to destroy some of the commoner pathogenie organisms, the author ${ }^{1}$ conducted, with Dr. Harold Walker, a series of experiments which led to the following conclusions :

(1) Different species of pathogenic bacteria, and different eultures of the same species, vary very greatly in their resistance to the action of corrosive sublimate. (2) With some species resistance is diminished in a remarkable degree ly a condition of dryness, so that even the $1: 10,000$ solution ean bring about sterility in a very short time. But some species are not materially affected in this respect by dryness. (3) Corrosive sublimate in as weak solution as 1:5000 is ineffective

${ }^{1}$ Boston Medical and Surgical Journal, April 2:3, 1903. 
against the eommon pathogenie bacteria, including the pus organisms when they are moist, excepting after prolonged contact. Since fifteen minutes' contact is not sufficient for the destruetion of B. coli communis, B. pyocyaneus, and Staph.pyogenes albus, in the moist state, or of Staph. pyogenes aurcus whether moist or dry, the use of this and of weaker preparations in surgical work and for irrigation and similar purposes should be abandoned. (4) The $1: 1000$ solution is very slow in its action on some of the commonest of the skin bacteria, and since under the most favorable eonditions more than ten minutes' contact may be necessary for it to kill Staphylococcus pyogenes albus, it should not be relied upon to any great extent to ensure sterility of the hands or of instruments. The mere dipping of the hands for a few seconds into solutions of this strength can serve no useful purpose, but, on the contrary, can lead to much harm by inducing a false sense of security. (5) Corrosive sublimate in any of the strengths commonly employed is a much overrated disinfectant, and, under the best of conditions, is so uncertain in its action that it would be of advantage to abandon its use altogether in surgery.

Mercuric cyanide, much praised by some, has been proved by the author ${ }^{1}$ to be far inferior to the chloride. In solution of $1: 1000$ it fails to kill Staphylococcus pyogenes aureus in 3 hours, but is far more effective against St. pyogenes albus, B. pyocyaneus, and B. coli. Tablets containing 2 parts by weight of borax to 1 part of the cyanide, recommended for use in the proportion of 1 tablet to a quart of water, were found to be ineffeetive against St. pyogenes aureus in 30 minutes, even when employed in 4 times the amount above stated.

Sublamin, or ethylenediamine-sulphate of mercury, possesses several advantages over corrosive sublimate in that it is non-irritating to the skin, even in 2 per cent. solution; forms no precipitate in the presence of allomminous material or soap solution, and, when used in the proportion $3: 1000$, acts with considerably greater rapidity against pyogenic organisms than sublimate-1:1000. In a series of experiments conducted by the author, ${ }^{2}$ while a $3: 1000$ solution failed to destroy Staphylococeus pyogenes aureus in 10 minutes, St. pyogenes albus, $\vec{B}$. pyocyaneus, and $B$. coli were killed in less than a minute and a half.

Silver Compounds. - $I_{n}$ addition to the familiar fluoride and nitrate a considerable number of organic compounds of silver have within recent years come into use in various special fields of medical practice, and for them are claimed great bactericidal efficiency. According to Marshall and Neave, ${ }^{3}$ those which are powerfully bactericidal include the nitrate, the fluoride, actol, itrol, argentamine, albargill, argonin, ichthargan, largin, novargan, and protargol ; nargol is much inferior; and argyrol and collargol are practically inert. With these findings, those of Derby ${ }^{4}$ are in substantial agreement. Argyrol

\footnotetext{
1 Boston Medical and Surgical Journal, January 14, 1904.

${ }^{2}$ Annals of Surgery, Uctober, 1904.

3 British Medical Journal, August 18, 1906, p. 362.

4'Transactions of the American Ophthalmological Society, 1906.
} 
and eollargol were found to be very weak in action; the nitrate in 0.5 to 2 per cent. solution killed Staphylococcus pyogenes aureus in 2 to 5 minutes ; protargol, 2 to 4 per cent., in 3 to 5 minutes; albargin, 10 to 20 per ceut., in 2 to 5 minutes ; ichthargan, 0.1 to 1 per cent., in 1 to 4 minutes ; largin, 10 to 20 per cent., in 2 to 5 minutes ; argonin, 5 per cent., in 3 to 6 minutes. The proportion of metallie silver in these compounds appears to bear no relation to the bactericidal efficiency.

Sodium Aurate.-Aceording to Verhoeff,', this compound of goll, reconmended for use in the treatment of gonorrheal ophthalmia, has remarkable germicidal properties. In his hands a solution representing 0.5 per cent. of chloride of gold destroyed Staphylococcus pyogenes aureus and various less resistent bacteria within 1 minute, and anthrax spores in less than 3 minutes.

\section{Mineral Acids.}

The nineral acids possess, in different degrees of dilution, varying disinfectant power against all species of bacteria. In any effective working strength, they corrode the common metals and destroy the tensile strength of all kinds of fabries.

The bactericidal effect of gastric juice on the bacteria of cholera, discovered by Koch, was ascribed by him to the contained hydrochloric acid ; and experimenting with bouillon cultures of this organism, Kitasato $^{2}$ showed that 0.132 per eent. of hyclrochloric or 0.049 of sulphuric acid produced sterility within a few hours. This result, so far as it coneerns sulphuric acid, was confirmed by Stutzer, ${ }^{3}$ who found that 0.05 per eent. killed in 15 minutes the organisms suspended in distilled water.

The experiments of Boer ${ }^{4}$ showed that the bacillus of typhoid fever in bouillon cultures was destroyed in 2 hours by 0.07 per eent. of hydrochloric acid, and in the same time by $0.1 \dot{2}$ per cent. of sulphurie acid. The cholera organism was killed by smaller amounts, 0.02 per cent. of each, within the same time; the bacilli of anthrix were but slightly more resistant than the cholera germ ; and those of diphtheria sueeumbed to the same amounts as were fital to those of typhoid fever. Ivanoff ${ }^{5}$ determined the amount of sulphurie acid necessaly to sterilize sewage. That of Potsdam, three times as foul as that of Berlin and slightly alkaline in raction, impregnated with cholera germs, was disinfected by 0.08 per cent. in 15 minutes. A proprietary preparation, containing 0.76 per cent. of sulphuric acid and nothing else, tested by the author, sterilized one of two bouillon cultures of typhoid bacilli and one of two typhoid dejecta in 2 homrs, but had no effect whatever on diphtheritic membrane and tuberculons sputum.

1 Journal of the American Medical Association, January 27, 1906, p. 270.

2 Zeitsehrift für Ilygiene, III., 1888, p. 404.

3 lbill., XIV., 1893, p. 9.

4 Ilid., IX., 1890, p. 479.

5 Ibid., XV., 1893 , p. 86. 


\section{Carbolic Acid and Cresol Preparations.}

Carbolic acid, phenol, phenic acid, obtained chiefly from coal, is a substance of varying degrees of purity and disinfectant power. The highest grade is praetically pure phenol, but the commoner qualities contain variable amounts of eresols, xylol, and other higher homologues, all of which have marked bactericidal properties, and tar oils which have none. In the opinion of many authorities, the crude aeid is superior to the highest grades in disinfecting power by reason of the presence of the eresols.

Prior to Koch's work on disinfectants in 1881, carbolic acid was believed generally to be one of the most powerful of germicides, a belief which was due doubtless, in part at least, to its peculiar and powerful odor. Koch's experiments with anthrax spores led him to the conelusion that, even in 5 per cent. solution, it was an inefficient agent against highly resistant organisms. Then followed a number of investigations by others, whose conclusions were by no means in agreement. It was found by some to be a very efficient general disinfectant, by others to be very unreliable, and by still others to be well suited to some lines of work and not to others. It was conceded very generally that in eertain respects its use has many advantages over that of corrosive sublimate and other metallic salts; that it is not destroyed or precipitated by eontact with albumin, aeids, salts, and other compounds ; and that, even in weak dilution, it destroys many of the common pathogenic organisms very quiekly.

Behring, Sternberg, and others found it effective against the bacilli of typhoid fever and cholera in 1 per cent. solution, but opposite conclusions have been reported as to its action against the former, which organism is said to flourish in mixed cultures in the presence of even as much as 5 per cent., the accompanying species being destroyed. For the disinfection of tubereulous sputum, Schill and Fischer ${ }^{1}$ found it to be reliable in 5 per cent. solution within 24 hours. An experiment by the author and Dr. R. M. Pearce, ${ }^{2}$ in which this material was treated with 17 different preparations, proprietary and otherwise, including a 5 per cent. solution of carbolic acid, was suecessful with this agent and 4 others after a 2 hours' exposure. With typhoid stools, diphtheritie membrane, and bouillon cultures of the typhoid organism, disinfection was not accomplished.

Against pus cocci and $B$. pyocyaneus, the $1: 20$ and $1: 40$ solutions act with considerable rapidity. In a series of experiments with different strains of Staphylococcus pyogenes aureus and albus, B. pyocyaneus, and $B$. coli, conducted by the author, ${ }^{3}$ the organism first mentioned, which is the most resistant of all the common pathogenic bacteria to most ehemical disinfectants, was killed uniformly within 2 minutes by the $1: 20$ solution and within 4 minutes by the weaker preparation. All of the other organisms suecumbed even more quickly. That the

1 Mittheilungen aus dem kaiserlichen Gesundheitsamke, II., 1884, p. 145.

2 Lisc. cit.

3 Annals of Surgery, October, 1904. 
typhoid bacillus, which is one of the least resistant of the common pathogenic bacteria to chemical agents, can withstand prolonged contact with 5 per cent. carbolic acid, indicates that certain species may possess exceptional resisting power against certain bactericidal agents, and emphasizes the importance of employing in experimental work the widest possible variety of bacterial species under like conditions before forming an opinion of the value of a given substance for general disinfectant purposes.

The presence of small amounts of mineral acids in solutions of carbolic acid is shown by Fränkel and Laplace to be very helpful, but it is to be borne in mind that the former, unassisted, are by no means without a very considerable degree of germicidal power. Both authorities, however, have proved that mixtures of carbolic and mineral acids are more bactericidal than either ingredient in the proportions used, and both, and Nocht as well, have demonstrated also the superiority of mixtures of the crude acid with mineral acids over combinations of the pure phenol with mineral acids in the same proportions. According to Epstein,"1 carbolic acid in alcoholic solution is more powerful in the same amount than in aqueous solution, which finding is endorsed by Minervini. ${ }^{2}$ On the other hand, in solution in oil, according to Koch, it loses its germicidal property completely. This is because, being more soluble in oils than in water, it does not leave the oil to penetrate the bacterial cell.

The experiments of Heller ${ }^{3}$ with mixtures of carbolic acid and the green soap of the German Pharmacopoeia, using cultures of B. typhosus as tests, indicate that the soap, which possesses but slight bactericidal power, increases that of phenol in a marked degree, especially when the two substances are present in equal parts. While the organisms were killed in 20 minutes by the carbolic acid in 5 per cent. solution, they were destroyed in the same time by a 4 per cent. solution of the two agents in equal parts; that is to say, by less than half the required amount of the acid alone. The reason for this increase in power may be that a new complex compound of greater bactericidal power is formed, or that the presence of the soap increases the rate of dissociation of the acid. The so-ealled carbolic powders are, as a rule, inert mixtures of mincral matter and waste products of coal-tar distillation. Their strong odor appeals to the imagination and promotes their sale.

Cresols (meta-cresol, ortho-cresol, and paril-cresol), which occur as impurities of carbolic acid, and, according to many authorities, are more powerful as germicides and less poisonous to higher organisms, are constituents of a large number of preparations which, within recent years, have come into extensive use. The cresols are closely related to phenol, from which they differ in that $\mathrm{CH}_{3}$ replaces one $\dot{\mathrm{H}}$ in the benzol ring, and according to the position of $\mathrm{CH}_{3}$, we have meta-cresol, ortho-cresol, or para-cresol. The latter may be made synthetically from pure para-toluidin. Cresols are practically insol-

1 Zeitschrift für Hygiene und Infectionskrankheiten, XXIV., 1897, p. 1.

3 Ibid., XXIX., 1898, p. $117 . \quad 3$ Archiv für Hygiene, XIVII., p. 213. 
uble in water, but solution is brought about by soaps and by cresol salts.

Laplace ${ }^{1}$ was the first to draw attention to the fact that crude carbolic acid and strong sulphuric acid, mixed together, form a compound soluble in water and of ligh disinfectant power. He reported that the mixture in 4 per cent. solution destroyed anthrax spores within 24 hours, while pure carbolic acid in 2 per cent. solution had no effect whatever. The first extensive study of the action of cresol was made by Frïnkel, ${ }^{2}$ who showed that the mixture of sulphuric acid and crude eresols is not of the nature of a new compound, but that each ingredient exists by itself and exerts its own action, and that the acid keeps the eresols in solution. Hammer ${ }^{3}$ investigated the properties of eresols dissolved in sodium meta-cresotinate; here, also, no double compound is formed, the salt acting merely as a solvent. Sodium salicylate acts equally well as a solvent. The various preparations containing cresols and solvents of the same are recommended highly as substitutes for phenol, on the ground of higher bactericidal power, lower toxicity, and of being less irritating in surgical work. They may be diluted at will with water, some forming milky enulsions, some clear solutions.

From a study of the comparative disinfectant action of the several cresols and of several other preparations, including tri-cresol (prepared synthetically from toluene) and phenol, Seybold ${ }^{4}$ concluded that of the three isomers, meta-cresol is the most powerful, and that the cresols are all superior to phenol. Tri-cresol, which is 40 per cent. meta-, 35 per cent. ortho-, and 25 per cent. para-cresol, proved to have double the bactericidal power of phenol against B. pyocyaneus, B. prodigiosus, and Staphylococcus pyogenes aureus. Another preparation of cresol, made by another manufacturer and examined by Schürmayer, ${ }^{5}$ also proved to be far superior to phenol and to a number of the more commonly known eresol compounds. Experiments with tri-cresol, conducted by the author, demonstrated considerably greater bactericidal efficiency than is possessed by phenol or any of the cresol preparations obtainable.

Among the more commonly used cresol preparations may be mentioned the following:

Liquor Cresolis Compositus (U. S. P.).-This is a liquid soap containing 50 per cent. of cresols. It is a thick, dark-brown liquid, miscible with water, and is made by adding 350 grams of linseed oil to 80 of caustic potash in 50 of water, mixing thoroughly, and then adding 500 of cresol, and finally enough water to make 1000 grams. The experiments of McBryde ${ }^{6}$ show that it is very considerably superior in

1 Deutsehe medicinisehe Wochensehrift, 1887, No. 40.

2 Teitsehrift für Hygiene, VI., 1889, p. 521.

3 Arehiv für Hygiene, XII., 1891, p. 359; XIV., 1892, p. 116.

4 'Keitschrift für Hygiene und Infeetionskrankheiten, XXIX., 1898, p. 377.

5 Archiv für Hygiene, XXV., 1896, p. 328.

'Bureau of Animal Industry, United States Department of Agrieultnre, Bulletin No. 100, May 31,1907 . 
the destruction of B. typhosus, Staphylococcus pyogenes aureus, B. pyocyaneus, and B. cholerce suis to carbolic acid enployed in the same dilution. Its germicidal efficiency is greater the ligher the boilingpoint of the cresol it contains, and hence is lowest when the preparation is made with ortho-cresol ; and even then it is nearly one and onehalf times greater than that of carbolic acid.

Creolin.-This is a dark-brown, thick, alkaline liquid, said to contain about 10 per cent. of cresols, held in solution by soap, and a small amount of phenol. According to Rideal, ${ }^{1}$ preparations bearing this name vary greatly in composition and properties, even when coming from the same manufacturer. Mixed with water, creolin forms a turbid, whitish emulsion. Specimens examined by Rideal varied greatly in germicidal efficiency, but were uniformly superior to carbolic acid in equal strength. That examined by Hünerman ${ }^{2}$ proved to be inferior to carbolic acid against anthrax bacilli and pus cocei; but Van Ermengem ${ }^{3}$ found it very effective in 5 per cent. solution against the latter and typhoid and cholera organisms; and Laser ${ }^{4}$ found that in the same strength it disinfects dejecta completely. The results obtained by various experimenters are, on the whole, very conflicting; but the product of different makers varies greatly in chemical composition, and hercin lies probably the cause. According to Rideal, ${ }^{5}$ its bactericidal efficiency does not depend upon its content of phenol and its homologues, and this appears to be most probable, since the favorable results reported for 5 per cent. solntions can hardly be due to the fraction of 1 per cent. of these substances present in this dilution.

On account of the variability in the composition and bactericidal properties, one manufacturing company has abandoned the name and adopted for its product the name CYLLIs, which substance is said by Klein ${ }^{6}$ to be more than twenty-seven times as efficient as phenol.

Lysol is a brown oily liquid containing about 50 per cent. of cresols with neutral potash soap, miscible with water in all proportions, forming a soapy, frothing liquid, and with alcohol and glycerin. Gruber ${ }^{7}$ found a 2 per cent. solution more effective against pus cocci than a 3 per cent. solution of phenol. Buttersack's ${ }^{s}$ experiments led to the same conclusion, and demonstrated also its suitability for the treatment of sputum. In the hands of the author, ${ }^{9}$ however, it acted less quickly against Staphylococcus pyogenes aureus and albus than carbolic acid and tricresol in the same dilutions-2.5 and 5 per cent. Vincent ${ }^{t 0}$ found it to be a valuable agent for the disinfection of freces and vanlt contents. In surgical practice, in which it is used exclusively, instances of poisoning through absorption, sometimes with fatal results, have

\footnotetext{
1 Public Health, December, 1903, p. 156.

2 Centralblatt für Bakteriologie, V., 1889, p. 650.

3 lbid., VII., 1890 , p. 75.

5 Journal of the Sanitary Institute, Nor, 1903, p. 425.

6 Public Health, Jnne, 1904, p. 566 .

7 Centralblatt für Bakterio ’ogie, XI., 1892, p. 117.

8 Arbeiten aus dem ka iserliehen Gesundheitsamte, VIII., 1892, p. 369.

Annals of Surgery, Octoler, 1904.

10 Annales de l'Institut Pasteur, $1 \mathrm{X} ., 1895$, p. 26.
} 
been numerously reported. Its use in Berlin, and elsewhere in Germany, for suicidal purposes lias become so widespread as to cause grave concern.

Bacillol is a product of the distillation of tar, and contains variable anounts of cresols according to source, but should contain not less than 50 per cent. It is very cheap and, as may be inferred from its content of eresols, is very efficient in 5 per cent. solution.

Saprol.-This is a liquid containing 20 per cent. of mineral oil and 80 per cent. of crude carbolie acid. It is lighter than water, and when thrown into it diffuses over the surface in a thin layer, which gradually yields its active ingredients to the strata below, which, in the course of a day, become impregnated to the extent of about 0.34 per cent. In this strength, according to Scheurlen, ${ }^{1}$ it destroys cholera bacteria in 1 hour. For the disinfection of privy vaults, Keiler ${ }^{2}$ determined that it must be added to the extent of 1 per cent. of the entire contents. In mixtures containing 5 per cent., the same observer showed that the typhoid fever bacillus is destroyed within a few minutes. Pfuhl ${ }^{3}$ found it to be much superior as a general disinfectant and deodorant to carbolic acid, but not suited to the treatment of vault contents. Laser, ${ }^{4}$ however, found that 1 per cent. will disinfect fæees and urine; and Scheurlen ${ }^{5}$ reported that for the disinfection of vault contents but two other agents are comparable with it, namely, milk of lime and crude carbolic acid.

Solveol is a concentrated aqueous solution of cresols with sodium cresotinate, containing more than 25 per cent. of cresols. It is highly recommended for use in surgical practice, being unirritating and much less toxic than carbolic acid. According to Hammer, ${ }^{6}$ it is more powerful in 2 per cent. solution than creolin, lysol, and carbolic acid in 2.5 per cent. strength. Hammerl ${ }^{7}$ also found it superior to carbolic acid and the other cresol preparations. A specimen tested by the author, however, was found to be markedly inferior to carbolic acid, tricresol, lysol, and bacillol in the same dilution, requiring 15 minutes' contact to kill pus cocci, whereas none of the others failed to do so in the 5 per cent. solution in less than 5 minutes.

Sulfonaphtol.- This is a coal-tar product of variable composition, widely employed in surgical practice and in general disinfection. One specimen tested by the author ${ }^{8}$ failed, in 5 per cent. dilution, to sterilize 2 typhoid stools and 2 typhoid cultures in 2 hours; and another ${ }^{8}$ in the same dilution required between 30 and 45 minutes to destroy Staphylococcus pyogenes aurcus.

${ }^{1}$ Archiv für Hygiene, XVIII., 1893, p. 35.

2 Ibid. XVIII., 1893, p. 57.

3 Zeitschrift für IIygiene und Infectionskrankheiten, XV., 1893, p. 192.

${ }^{4}$ Centralblatt für Bakteriologie, XII., 1892, p. 234.

s Archiv für Hygiene, XIX., 1893, p. 347.

Blbid., XII., 1891, p. 359.

${ }^{7}$ Ibid., XXI., 1894, p. 198.

8 Journal of the Boston Society of Mcdical Sciences, March, 1899.

Annals of Surgery, October, 1904. 


\section{Alcohol.}

Ordinary alcohol has long been used as a preservative of organic materials and as a disinfectant in surgical practice. Its disinfectant properties were studied first by Koch and his associates; and in his elaborate report he speaks incidentally of absolute aleohol and sterilized water as in the same class ("indifferent liquids"). His experiments showed that anthrax spores were not affected by nearly 4 months' exposure to absolute alcohol, and to 50 and 33 per cent. alcohol. Some years after Fürbringer recommended the use of alcohol for the removal of fatty matters from the skin in preparing the hands for surgical work. Reinicke ${ }^{1}$ announced that it was useful, not only in this direction, but as a germicide; and Petruschky ${ }^{2}$ reported that in his studies of infection of the skin by pyogenic cocei he had found it easy to produce sterility by means of ether and alcohol. Krönig, ${ }^{3}$ in the same year, failing to destroy dried Staphylococcus pyogenes aureus with 96 per cent. of alcohol in 5 minutes, although suceessful in less time with moist organisms, attributed the difference in action to the astringent influence of absolute alcohol in abstracting the moisture of the skin and locking up the bacteria in the shrunken particles. The first important investigation of alcohol as a germicide was conducted by Epstein, ${ }^{4}$ who, working with B. pyocyaneus, B. prodigiosus, and Staphylococcus pyogenes aureus, dried for a long time on silk threads, and then exposed to six different concentrations of alcohol for periods of 3,5 , and 10 minutes, was led to the eonelusion that absolute alcohol is devoid of germieidal properties, and that considerably stronger and weaker solutions than 50 per cent. are less powerfully germicidal than aleohol of that percentage dilution. He noted, however, that a preliminary wetting of the threads with water was essential to favorable results, which, however, were by no means constant. This had already been reported by Ahlfeld and Vahle, ${ }^{5}$ who found that, although they failed to destroy Strphylococcus pyogenes aureus with strong alcohol in 5 minutes, when the threads were given a preliminary wetting in water, the organisms were killed in 2 minutes. Minervini ${ }^{6}$ found that at ordinary temperatures alcohol and its aqueous dilutions are powerless against sporebearer's, even with long exposure, and that against others the action is variable, according to the amount of water present. The best results were obtained using 50 to 70 per cent. alcohol. Bertarelli, ${ }^{7}$ employing $25,50,70,80$, and 99 per ecnt. alcohol against $B$. prodigiosus, $B$. pyocyaneus, Staphylococcus pyogenes aureus, Sp. cholere, B. pestis, $B$. typhosus, and anthrax spores, all dried on silk threats, concluded that the most effective strength is 50 per cent.; and Salzmedel and

${ }^{1}$ Centralblatt für Gynäkologie, 1894, No. 47.'

2 Zeitschrift für IIygiene und Infectionskrankheiten, XVII., 1891, p. 59.

${ }^{3}$ Centralblatt für Gynäkologie, 1894.

4 Zeitschrift für Hygiene und Infeetionskrankheiten, XXIV., 1897, p. 1.

5 Deutsche medizinisehe Wochensehrift, 1896, No. 6 .

${ }^{6}$ Zeitschrift für Iygiene und Infeetionskrankheiten, XXIX., 1S98, p. 117.

7 Il Policlinico, October 1, 1900, p. 488. 
Elsner ${ }^{1}$ placed it at 55 per cent. Von Brunn ${ }^{2}$ found that, while the vapors of 51 and 7.4 per cent. alcohol at $167^{\circ} \mathrm{F}$. were very effeetive against sporulating agar eultures of anthrax within a few minutes, those of 95 per cent. aleohol produced no result at the end of an hour ; and he coneluded that the water present must play an important part. Frank, ${ }^{3}$ too, found that the vapors of 90 to 99 per eent. alcohol and of dilutions below 40 per cent. to be ineffeetive. The experiments of Weigl, in which bouillon cultures of cholera bacteria and pus eocei were mixed directly with different amounts of absolute alcolol. and threads impregnated with Staphylococeus pyogenes aureus or pus were treated, yielded conflieting results, unfavorable to the use of alcohol in surgical work.

The discrepant results of the above-mentioned experimenters and others whose work has not been eited are evidently due to differences in conditions, both of the agent and the test-objects, and this faet led the author and Walker ${ }^{5}$ to test the resistance of $B$. coli communis, $B$. pyocyancus, Staphylococcus pyogenes albus, Staphylococcus pyogenes aureus, B. typhosus, and B. diphtheric, in both dry and moist conditions, to 14 different strengths from 15 per cent. to absolute aleohol, the periods of contact ranging from 1 minute to 24 hour's $(1,2,3,4,5,10$, 15,30 , and 45 minutes, $1,2,7$, and 24 hours). The results of these experiments led to the following conclusions:

Against dry bacteria, absolute aleohol and ordinary commercial aleohol are wholly devoid of bactericidal power, even with 24 hours' direct contact, and other preparations of alcohol containing more than 70 per cent. by volume, are weak in this regard, aceording to their content of alcohol-the stronger in alcohol, the weaker in action. Against the commoner, non-sporing, pathogenic baeteria in a moist eondition, any strength of alcohol above 40 per cent. by volume is effeetive within five minntes, and certain preparations within 1 minute. Alcohol of less than 40 per cent. strength is too slow in action or too uncertain in results against pathogenie bacteria, whether moist or dry. The most effective dilutions of alcohol against the strongly resistant (non-sporing) bacteria, such as the pus organisms, in the dry state, are those containing from 60 to 70 per cent. by volume, which strengths are equally efficient against the same organisms in a moist condition. Unless the bacterial envelope contains a certain amonnt of moisture, it is impervious to strong alcohol; but dried baeteria, when brought into contact with dilnte alcohol eontaining from 30 to 60 per cent. of water by volume, will absorb the necessary amount of water therefrom very quiekly, and then the alcohol itself ean reach the cell protoplasm and destroy it. The stronger preparations of alcohol possess no advantage over 60 to 70 per cent. preparations, even when the bacteria are moist; therefore, and since they are inert against dry bacteria, they should not be em-

1 Berliner klinische Wochenschrift, 1900, No. 23, p. 496.

${ }^{2}$ Centralblatt für Bakteriologie, etc., XXVIII., 1900, p. 309.

3 Münchener medizinische Wochenschrift, 1901, No. 4, p. 134.

4 Archiv für Iygiene, XIIIV., 1902, p. 273.

${ }^{5}$ Boston Medical and Surgical Journal, May 21, 1903. 
ployed at all as a means of securing an aseptic condition of the skin. Provided the skin bacteria in the deeper parts can be brought into contact with disinfectants, alcohol of 60 to 70 per cent. strength may be depended upon usually, but not always, to destroy them within 5 minutes.

With regard to mixtures of alcohol and other disinfectants, the evidence is somewhat conflicting. Minervini found that 3 per eent. of carbolic acid in strong alcohol acted with undiminished energy, but that corrosive sublimate, nitrate of silver, and other agents acted with greater power the less the amount of aleohol present. According to Epstein, not only carbolic acid, but also corrosive sublimate, lysol, and thymol are more powerful in 50 per cent. alcohol, but other agents are weaker. Lenti ${ }^{1}$ reported that while 0.4 per eent. of corrosive sublimate in absolute alcohol had no effect on anthrax spores in 48 hours, 0.1 per cent. in 98 per cent. alcohol destroyed them in half the time. Similar results were obtained with 10 per cent. of earbolic acid; in absolute alcohol it was powerless, but in 30 per cent. alcohol it kilied them in 48 hours.

Endeavoring to find a preparation which would kill pus organisms not in minutes but in seconds, the author ${ }^{2}$ found that a mixture of $640 \mathrm{cc}$. of commercial alcohol, $60 \mathrm{cc}$. of hydrochloric acid, 0.8 gram of corrosive sublimate, and 300 cc. of water would kill Staphylococcus pyogenes aureus, albus, and citreus, and $B$. pyocyaneus within 10 seconds, and stcrilized pus from a carbuncle in 30 to 60 seconds, and 2 other specimens of pus in less than 30 seconds. Not one of these active agents alone in the same percentage strength is capable of producing these results with such rapidity, a stronger preparation of corrosive sublimate requiring not less than 15 minutes to destroy the most resistant of the pus cocci, and alcohol in its most effective working strength requiring from 1 to 5 minutes. Attempts to reduce the proportion of any one of the active ingredients of the mixture and retain the same rapidity of action were unsuccessful, but reports from many who have employed the mixture as a skin disinfectant agree that, in spite of the amount of free acid present, it is not likely to cause irritation.

\section{Essential Oils.}

The volatile oils have long been known to possess a certain degree of antiseptic power, but bacteriological experimentation has failed to demonstrate that they are very active as germicides. Those highest in favor are the oils of peppermint, encalyptus, and thyme, which contain, respectively, menthol, eucalyptol, and thymol. The latter wats in somewhat extensive use in surgical practice prior to 1870 . It is only slightly soluble in aleohol, ether, chloroform, and fixed and volatile oils. By many it has been regarded ats superior to phenol. Spencer Wells much preferred it in his extensive experience

1 Annali dell'istituto d'Igiene sperimentale della reale Unirersita di Roma, III., 1893, p. 515 .

2 Annals of Surgery, October, 1904. 
in ovariotomy. Accorling to Behring, however, it is only about a fourth as powerful, and Sauter ${ }^{2}$ ranks it even below salicylic acid. Eucalyptol is practically insoluble in water, but soluble in alcohol and other solvents. Concerning this agent, too, there is much diversity of opinion, some regarding it as vastly superior to phenol, others as much inferior. Lister praised it highly. Behring found it to be about equal to thymol. Menthol is sparingly soluble in water, but freely in alcohol and other solvents. It has been highly praised as a surgical antiseptic, and as freely criticised. Oneltschenko ${ }^{3}$ ranks the oil of peppermint above that of encalyptus, but below that of thyme. All three are placed by him below the oils of cinnamon and cloves.

Aside from the conflicting evidence as to the power of the various volatile oils, their cost alone would be sufficient to restrict their general use as disinfectants. They are employed considerably in various combinations in mouth washes and in a number of decidedly expensive proprietary disinfectants, one at least of which, tested by the author, was found to be efficient in the sterilization of tuberculous sputum, one of the few uses for which its manufacturers made no claims.

\section{Soaps.}

The evidence concerning the bactericidal influence of soaps is exceedingly conflicting. It was investigated first by Koch, who asserted that potash soap in the proportion of 1 to 5000 has a distinct inhibitory effect upon the growth of anthrax bacilli, and in five times that strength prevented it altogether. In 1885, Knisl, ${ }^{4}$ while admitting that this is true, asserted that against other bacteria, $B$. typhosus, for example, it is inert. In 1890, Behring, ${ }^{5}$ experimenting with 40 different soaps, announced that their disinfectant power was found to be considerable, and concluded that it is dependent upon their alkalinity ; but Serafini ${ }^{6}$ has pointed out that the free alkali present, even in concentrated soap solutions, is too small to exert any disinfectant action whatever. $\mathrm{He}$ believed that neither the alkali nor the fatty acid, but the combination of the two, is the effective agent; but it must be remembered that even a neutral soap is decomposed in contact with ordinary water containing lime and magnesium salts, with consequent setting free of the alkali with which the fatty acid was combined. Konrádi ${ }^{7}$ believed that the majority of soaps possess a fairly strong bactericidal power, quite independent of free alkali or fatty acid; but dependent alone upon the added perfunies. He tested a soap in the various stages of manufacture and found that the bactericidal power did not show itself until the perfume had been added. In a later communication ${ }^{8}$ he asserted

\footnotetext{
1 Zeitschrift für Hygiene, IX., 1890, p. 395.

2 Centralblatt für gesammte Therapie, VI., p. 376.

${ }^{3}$ Centralblatt für Bakteriologie, IX., 1891, p. 813.

- Inaugural Thesis, Munich, 1885 .

5 Zeitschrift für Hygiene, IX., 1890, p. 395.

- Arehiv für Hygiene, XXXIIII., 1899, p. 369.

${ }^{7}$ Ibid., XLIV., 1902 , p. 101.

8 Centralblatt für Bakteriologie, etc., XXXVII., Orig., April 27, 1904.
} 
that a 10 per cent. solution of a certain perfumed soap proved to possess a germicidal power equal to a $1: 1000$ solution of corrosive sublimate. Rodet, ${ }^{1}$ experimenting with 1 and 5 per cent. solutions of hard Marseilles soap containing no free alkali whatever, with staphylococci and typhoid bacilli as test-objects, obtained very positive bacterial results, a 1 per cent. solution killing the typhoid bacilli within a few minutes, although against staphylocoeci the action was very slow.

Nijland, ${ }^{2}$ experimenting with a potash soap containing 47.2 per cent. of water and a hard soap containing 14.5 per cent., found that the former in 0.24 per cent. solution killed cholera bacteria in 10 minutes, and the latter in the same strength was not wholly effective in 15 , but in 0.30 per cent. solution destroyed them within 1 minute. The cholera organism was used by Jolles ${ }^{3}$ in testing five soaps, all of which proved to be inefficient. By 10 per cent. solutions, the bacteria were destroyed within 1 minute; by 4 per cent., in 10 minutes; by 2 per cent., and in three instances by 1 per cent., in 30 minutes.

In a later series of tests with typhoid fever bacilli, Jolles ${ }^{4}$ tried an almost neutral soap, containing but 0.041 per cent. of free alkali, and with 1 per cent., sterilized a bouillon eulture within 12 hours, with 3 per cent. within 2 hours, and with 6 per ecnt. in 15 minutes. $\mathrm{He}$ showed that the action was much influenced by temperature. The above results were brought about at teniperatures between $4^{\circ}$ and $8^{\circ}$ C., but at $18^{\circ} \mathrm{C}$., the time which elapsed before complete sterilization was accomplished was about double. This result is not in accordance with the general rule that disinfeetants are more active with inereased temperature. He obtained practically the same results witl other varietics of bacteria, and reported that, because of its action on the most common pathogenic forms, soap is especially valuable and adaptable for precisely the kind of work in which it is the most natural agent; that is, in washing dirty and infected clothing.

Serafini, ${ }^{5}$ however, is of the opinion that, in the ordinary washing of clothes, soaps exert but little disinfection, because of the many influences, hardness of the water, for example, which cause a diminution of their power. He reeommends the avoidance of soft soaps, on account of the presence of all of the impurities of the fats and alkali from which they are made, and advises one to distrust the ordinary colored soaps, which are likely to contain rosin. If soap is the sole reliance, he recommends using it in strong solution at $30^{\circ}$ to $40^{\circ} \mathrm{C}$. $\left(86^{\circ}\right.$ to $104^{\circ} \mathrm{F}$ ), and immersing therein for a number of hour's the articles to be treated. Even with long soaking, Beyer ${ }^{6}$ reports unvarying failure of soap against pus cocei and the bacilii of cbolera and typhoid fever on clothing in hospital practice.

Reithoffer, ${ }^{7}$ experimenting with eommon soft soal containing traces

1 Revue d'IIygiène, A pril 20, 1905.

${ }^{2}$ Archiv für Hygiene, XVIII., 1893, p. 335.

3 Zeitschrift für Hygiene und Infectionskrankheiten, XV., 1893, p. 460.

"Ibid., XIX., 1895, p. 130.

${ }^{6}$ Fortschritte der Medicin, 1897, No. 1.

7 Archiv für Hygiene, XXVII., 1896, p. 350. 
of free alliali and 2.55 per cent. of potassium carbonate, a white almond-oil soap perfumed with nitrobeuzol and containing 0.062 per cent. of free alkali, and a patented potash soap coutaining 0.031 per cent. of free alkali, found that all three, even in 1 per cent. solution, were highly efficient against cholera germs within very few minutes, and, therefore, recommends soap as a pratical disinfectant for elothing, furniture, ete, during epidemies of that disease. For washing bodyand bed-linen, furniture, wood-work, floors, ete., he recommends a 4 to 5 per cent. soap solution as probably effieient under all eonditions after from 5 to 10 minutes' contact, but suggests care in avoiding the common commereial soft soaps, which are frequently of poor quality. Experimenting with B. typhosus and B. coli, he proved that here again the soaps possessed a high degree of power, though mnch larger amounts were necessary than in the case of $B$. cholerce. He demonstrated that a 10 per cent. solution was necessary for the destruction of the typhoid germs within 1 minute, and that a 5 per cent. solution required from 3 to 10 minutes according to the kind of soap, the soft soap being slowest in action, as was true also against the cholera germs. Against the colon bacillus, the action was still slower : 5 per cent. of the almond soap required 15 minutes, and the same strength of potash soap failed to accomplish complete sterilization in 20 minutes. The superiority of the almond soap suggrested the possibility that its increased power might be due to the nitrobenzol with which it was perfumed, and experiment showed this to be true. Against pus eocei, all three agents fitiled completely ; Staphylococcus pyogenes aureus was unaffected by 20 per cent. solutions at the expiration of more than an hour. For the disinfection of the hands, 5 per cent. solutions were found to be almost immediately effective against cholera germs, but longer and more thorough washing is recommended in typhoid infection.

According to Mikuliez, ${ }^{1}$ tincture of green soap, the German officinal Spivitus saponatus, containing 10.2 parts of potash soap, 0.8 of olive oil, 1 of glycerin, 43 of alcohol, and 45 of water, is admirable in undiluted form for sterilizing the hands in surgical work. They should be scrubbed for 5 minutes with the preparation in its full strength. In his experiments, Staphylococcus pyogenes aureus was killed in a half mimute and S. p. albus in a minute.

From all the evidence, eonflicting though it be in eertain respects, it must be evident that in soap we have an agent which, with all its limitations, is entitled to very serious consideration, at least as an auxiliary in complete disinfection.

Medicated Soaps.-In order to increase the disinfectant properties of ordinary soaps, varions agents, including mercury compounds, carbolic acid, and the cresol preparations, are incorporated in them. Compared with ordinary soaps, these preparations appear to be of doubtful utility, although in the hands of some experimenters they have yielded

${ }^{1}$ Deutsche medicinishe Wochenschrift, June 15, 1899. 
good results. From an extensive investigation of these soaps, Symes ${ }^{1}$ concluded that, for all practical purposes, most of them possess no adcled value, but that the mercury soaps are useful in disinfection of the hands. A 1 per eent. solution of the biniodicle soap killed pus eocei in 1 minute, while the other soaps failed to do so in 3 hours. Nijland $^{2}$ found that the addition of disinfectants to soalus increases their action in some eases and diminishes it in others, the latter espeeially when the added substance combines with the ordinary constituents. Accorling to his experiments, the most powerful of all is the corrosive sublimate soap, which, however, has less power than the corresponding amount of sublimate alone. In 0.003 per eent. solution it killed cholera bacilli in water within 10 minutes. Rideal ${ }^{3}$ asserts that the double iodide of potassium and mereury has stronger germicidal powers than corrosive sublimate, and is easily incorporated in the soalp stock. He recommends the admixture of $i$ to 3 parts esch of mercuric and potassic iodide in 100 of soap. "Potassio-mereuric iodide has the advantage of being compatible with strong alkalics. . . . Moreover, it does not precipitate albumin, and is not easily reduced." MeClintock ${ }^{4}$ tried to make an antiseptic soap in which the mereury salt should exist unchanged and active, and found the double iodide to be the most available agent in the proportion of 0.5 to 2.0 per cent. A solution containing 1 per eent. of the soap was found to be fatal to pus eocci and cholera, diphtheria, and typhoid fever bacilli in 1 minute. 'The soap attacked neither nickel, silver, aluminum, nor steel instruments, nor lead-pipes, and did not coagulate albumin.

Concerning carbolic acid and cresol soaps, the weight of evidence is elearly in support of the assertion that they are in no way superior to common soaps. Many contain no more than sufficient to make them powerful in odor, which is not sufficient to eonfer any marked bacterieidal power. Nocht ${ }^{5}$ ealls attention to the solvent property of soap on carbolic acid, showing that at $60^{\circ}$ C. a 3 per cent. solution of soalp will dissolve 6 per cent., and double that strength will dissolve 12 pel cent. of carbolic acid. He found that a cold solution of soap containing 1.5 per cent. of carbolic acid was fatal to pus cocei and non-sporing bacteria in half an hour, but recommends the employment of 3 per cent. solution of a 5 per cent. soaly for the treatment of clothing, leather articles, and other objects. Reithoffer ${ }^{6}$ found that earloslic acid is weakened by the presence of soap, and that a soft soap containing 40 per cent. of lysol was no more effective against pus cocei, $B$. coli and B. typhosus, than ordinary soaps, and was much weaker than a solution of lysol alone in the same lysol strength. 'Tonzig ${ }^{7}$ fount that various creolin soaps were ineffective, like other soaps containing eorrosive sublimates and other disinfectants, because new compounds are

${ }^{1}$ Bristol Medico-Chirurgical Journal, Sept., 1899.

2 Loc. cit.

${ }^{3}$ Disinfection and Disinfectants, London, 1898, p. 485.

4 Medical News, April 17, 1897,.p. 485.

5 Zeitschrift für Hygiene, V'II., 1889, 1). 521.

${ }^{7}$ Gazetta degli ospedali e delle cliniclse, 1900, No. 6. 
formed with the ordinary constituents of the soap, and the natural disinfectant properties of the same are thereby diminished.

Lysoform is a liquid perfumed soap, containing about 8 per cent. of formaldehyde, miscible with water and alcohol, and somewhat expensive. While it has a marked deodorant action, by virtue of its formaldehyde content, its bactericidal effect is decidedly slow. Symanski : found that a 2 per cent. solution required 5 hours' contact to destroy staphylococci in pus; but Seydewitz, ${ }^{2}$ working with pure cultures of staphylococci, streptococci, B.typhosus, B. coli, B. diphtherice, and other bacteria, found that a 3 per cent. solntion killed them in less than 3 minutes, and a 4 per cent. solution required but 1 minute. Anthrax spores were killed by a 5 per cent. solution in 4 hours. On the other hand, Galli-Valerio ${ }^{3}$ found that a 5 per cent. solution required 4 hours' contact to destroy Staphylococeus pyogenes aureus, and a 3 per cent. solution was ineffective against $B$. coli in less than 45 minutes. It is asserted and denied that it is non-irritant to the skin and mucous membranes. Weyl ${ }^{4}$ asserts that it is poisonous, even in small doses, and that to the gastric mucous membrane it is corrosive.

Paralysol is a solid cresol soap, said by Nieter ${ }^{5}$ to be able to destroy, in 3 per cent. solution, staphylococci in less than 1 minute, and in 1 per cent. solution, streptococci and $B$. typhosus in less than 2 minutes, and $B$. pyocyaneus, B. diphtherice, and Sp. cholerce Asiatice within 3 minutes.

Metakaline, a compound of hard soap and potassium metacresolate, is said by Wesenberg ${ }^{6}$ to possess such germicidal power that a 0.5 per cent. solution will destroy the common pathogenic bacteria within a few minutes.

In the disinfection of hands by means of medicated soaps it should be borne in mind that the added disinfectant is commonly present in insufficient amounts, and that, as used, the soaps form a very weak solution, which, in the time ordinarily given, can have but little, if any, effect.

\section{Formaldehyde.}

The germicidal properties of formaldehyde, otherwise known as methyl aldehyde and oxymethylen, the simplest known compound of carbon, hydrogen, and oxygen, were not recognized until 1886, and were not put to practical use until 1891. Formaldehyde is a gaseous product of oxidation of wood alcohol, made most simply by passing a current of the alcohol vapor over platinum sponge previously heated; as the vapor comes in contact with the incandescent platinum, it is oxidized to aldehyde and water $\left(\mathrm{CH}_{3} \mathrm{OH}+\mathrm{O}=\mathrm{CH}_{2} \mathrm{O}+\mathrm{H}_{2} \mathrm{O}\right)$. The continuous current maintains the incandescence. On a large scale, it is produced by treating the alcohol in copper tubes containing incandescent coke.

\footnotetext{
' Teitschrift für Hygiene und Infectionskrankheiten, XXXVII., 1901, p. 393.

${ }^{2}$ Centralblatı für Bakteriologie, ete., I Abt., XXXII., 1902, Orig., No. 3, p. 222.

3 Therapeutische Monatshefte, XVII., 1903, p. 452.

"Münchener medizinische Wochenschrift, 1905, No. 27.

5 Hygienische Rundschau, April 15, 1907, p. 451.

- Centralblatt für Bakteriologie, Abt. I., XXXVIII., No. 5, p. 612.
} 
Formaldehyde is soluble in water up to 40 per cent., and gives a neutral solution, but the commercial preparations are usually slightly acid in reaction from traces of formic acid. Its solution cannot be stronger than 40 per cent., and attempts to concentrate it or to condense the vapor cause it to polymerize to a white indistinctly crystalline solid, trioxymethylen or paraformaldehyde $\left(\mathrm{C}_{3} \mathrm{H}_{6} \mathrm{O}_{3}\right)$, which is almost insolnble in water, melts at $171^{\circ} \mathrm{C}$., when ignited, burns with a blue flame, but when gently heated in an open dish, is converted again to the gaseous formaldehyde. When the solution is heated in a closed vessel under pressure, polymerization is prevented by the presence of borax or of neutral salts, as chloride of calcium.

Formaldehyde vapor is exceedingly pungent and very irritating to the eyes and nose. It has a strong affinity for many organic substances, and combines with nearly all foul-smelling products of decomposition, forming odorless compounds, thus acting as a deodorant. It transforms gelatin in solution to a tough transparent substance insoluble in boiling water, causes blood serum to lose its coagulability by heat, combines with the protoplasm of bacteria, and converts egg albumin into a substance insoluble in water and indigestible. With ammonia, it forms an inert compound, hexamethylentetrmmin, which has the odor of neither substance $\left(4 \mathrm{NH}_{3}+6 \mathrm{CH}_{2} \mathrm{O}=\left(\mathrm{CH}_{2}\right)_{6} \mathrm{~N}_{4}+6 \mathrm{H}_{2} \mathrm{O}\right)$. It has no action on copper, brass, zinc, nickel, silver, iron, steel, or other metallic substances, causes no diminution in the tensile strength of fabrics, and has no bleaching or other effect on colors, excepting to intensify the effect of certain of the coal-tar dyes (fuchsin, saffranin, and perhaps others). It may, however, fix blood, pus, and freal stains on elothing. It has no injurious action on elothing and other woven fabries, fur's, articles of rubber, leather, and paper, photographs, paintings, woodwork, and furniture.

The antiseptic properties of formaldehyde were noted first in 1886 by Loew and Fischer, ${ }^{1}$ but its value as a practieal disinfectant was made known first by 'Trillat ${ }^{2}$ in a communieation to the Freneh Academy of Science in 1892, and since that time it has been the subject of very extensive investigation, which has demonstrated conclusively that formaldehyde is by far the most powerful and practical ehemical disinfectant known. In general, it is used in the form of gas generated in different ways from methyl alcohol or from the aqueous to per eent. solution, commonly known by the commereial name Formalin, or from the solid polymer trioxymethylen, otherwise known as paraformaldehyde and by the trade name Paraform. In some processers of disinfection and deodorization, it is applied directly in the form of aqueons solution.

Methods of Use, and Apparatus.-At first the gas was generated directly from methyl alcohol by means of lamps specially constructed for the purpose. The first of these was devised by Trillat, who was followed by Gambier, Barthel, Diendonné, Krell, Tollens, Robinson,

'Journal für praktische Chemie, XXXIII., p. 221.

${ }^{2}$ Comptes rendus, CXIV., p. 1278. 
and others, who presented various modifications and improvements, but all of the lamps thus far devised are open to several objections, among which may be mentioned the fact that a large, if not the greater, part of the alcohol is converted to carbon monoxide and dioxide, and the possibility of fire.

Trillat, recognizing the defects of his own and other lamps, and being convinced of the futility of attempting to disengage the gas by evaporating the aqueous solution from open vessels, whereby polymerization is caused, attempted to devise an apparatus in which the aqueous solution could be employed without the occurrence of this undesirable phenomenon. The outcome of his study was the autoclave which bears his name.

FIG. 97.

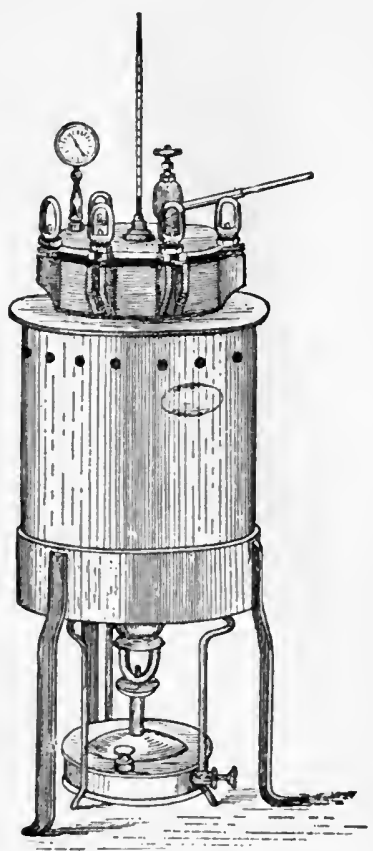

Trillat's autoelare.
Frg. 98.

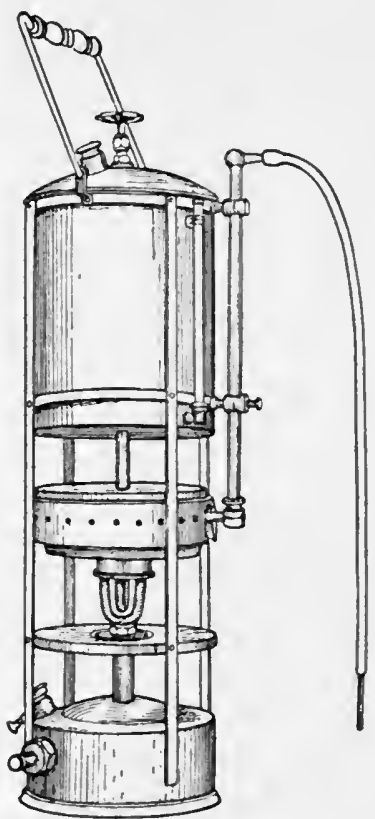

Sanitary Coustruction Company's regenerator.

Trillat's autoclave, shown in Fig. 97, consists of a cylindrical silverlined pot of heavy copper, of about a gallon capacity, with a cover resting on a rubber gasket and secured by means of turn-buckles. The cover carries a pressure gauge, a thermometer, and an outlet controlled by a valve and terminating in a narrow brass tube. The pot is supported on a tripod, and beneath it is a Swedish lamp, the flame of which is fed by vapors from kerosene oil forced out by compressed air. In the pot is placed not more than three-fourths nor less than onefourth of its capacity of a mixture of the 40 per cent. solution of 
formaldehyde and chloride of calcium, the latter for the purpose of preventing polymerization under pressure. This mixture, which contains 150 grams of the chloride to the liter, is known as Formochlorol. The formaldehyde solution used should be practically free from methyl alcohol, which, while of no practical interest under ordinary circumstances, is an objectionable impurity when the solution is heated under pressure, since then it unites with a eorresponding amount of formaldehyde to form inert methylal. The cover is firmly fixed by the turnbuekles, and then the lamp is put in operation. When the gange shows a pressure of three atmospheres, the outlet tube is introrluced into the keyhole of the door of the room to be disinfected, and the valve is opened gradually so as to release the vapor. The disengagement of the gas is

Fic. 99.

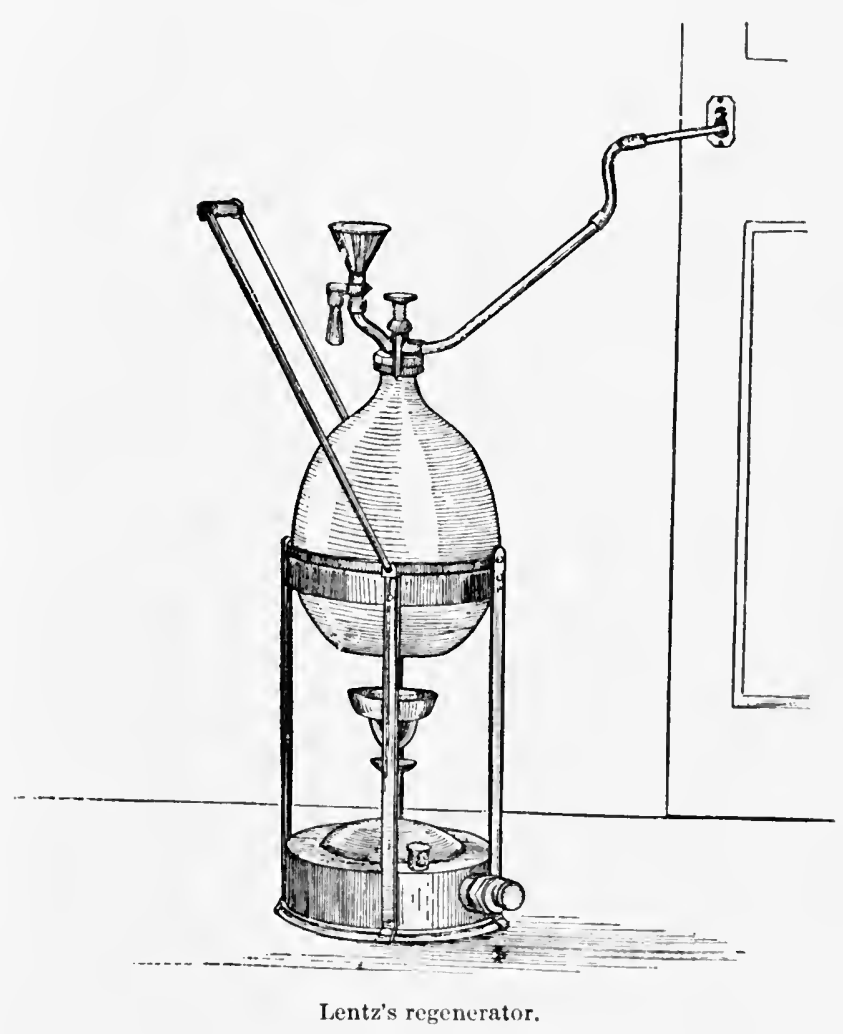

continued until a sufficient amount of the liquid, based upon the amount of air space treated, is consumed. Aceording to Trilkat, in the case of a room of ordinary size, say 18 feet square and 10 from floor to eciling, the operation should require about an hour. The objections urged against this form of apparatus are its cost, the want of uniformity in the anount of gas delivered within a given time, and the danger of 
explosion from the possibility of the non-working of the valve, or from obstruetion by one cause or another of the outlet tube.

A number of other apparatises for the same purpose have been devised, and to several of them these objections no not apply. One of these is the regenerator made by the Sanitary Construction Company, and used extensively by public authorities. (See Fig. 98.) It consists of a copper reservoir, holding about 3 quarts, from the bottom of which leads a quarter-ineh eopper tube, which forms a eoil 2 inches below, and then turns upward and extends above the top of the apparatus, where it is fitted with a rubber tube earrying a fine copper nozzle, through which the gas is delivered. Beneath the eoil is a Swedish lamp similar to that used with the Trillat autoclave. The formaldehyde solution is admitted to the heated coil through a valve, and is transformed to vapor, which escapes through the nozzle. Neither pressure nor the presence of calcium chloride is necessary, and the rapidity of action and amount of solution used can be determined by observing the height of the liquid in the glass gange on the side of the rescrvoir. The apparatus is very much cheaper than the Trillat and similar autoclaves.

Another regenerator which meets with favor is that of Lentz (see Fig. 99), in which the formaldehyde solution is heated in a retort by

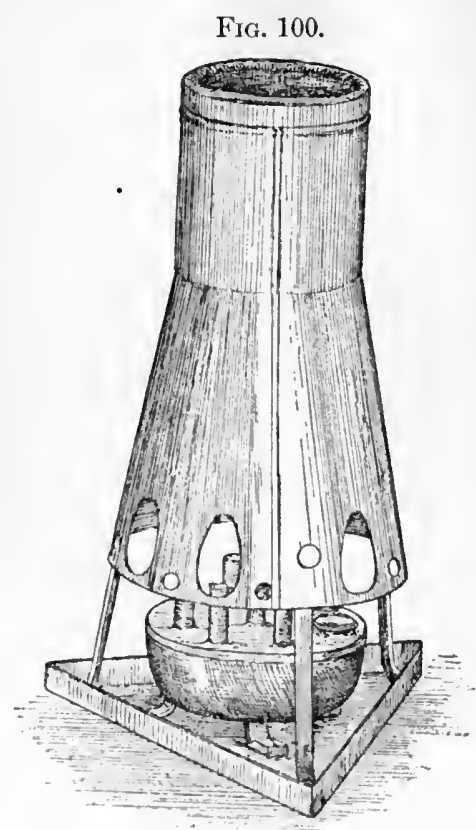

Schering paraform lamp. means of a Swedish lamp, the gas emerging through the metallic delivery tube connected by rubber tubing with the nozzle, which is inserted through a keyhole.

In order to avoid the use of the liquid preparation, and to employ in its place the solid polymer trioxymethylen, or paraform, the Seliering lamp was devised, and in 1897 was brought into notice by Aronson, ${ }^{1}$ after he had made a series of tests which yielded good results. This very simple and inexpensive apparatus, shown in Fig. 100, consists essentially of a metallic shell, not unlike an open piece of stove-pipe, supported on legs, and carrying in its upper part a basket made of sheetiron and wire gauze, and an alcohol lamp carrying 6 or more wicks. For convenience, the paraform is supplied in pastilles weighing a gram each, and these are placed in the basket to the number of 2 for every 35 cubic feet of air space to be disinfected. The lamp is supplicd with aleohol to the extent of 2 ee. for each pas-

' Zeitschrift für IIygiene und Infectionskrankheiten, XXV., 1897, p. 186. 
tille. The wicks should project not more than about a twelfth of an inch, which is sufficient to give a flame which will heat the basket and its contents sufficiently to cause volatilization of the agent, with absolutely no danger of its taking fire and thus yielding no formaldehyde gas. By the time the alcohol is consumed, the pastilles will have been volatilized completely or nearly so. If the space to be treated be of

FIG. 101 .

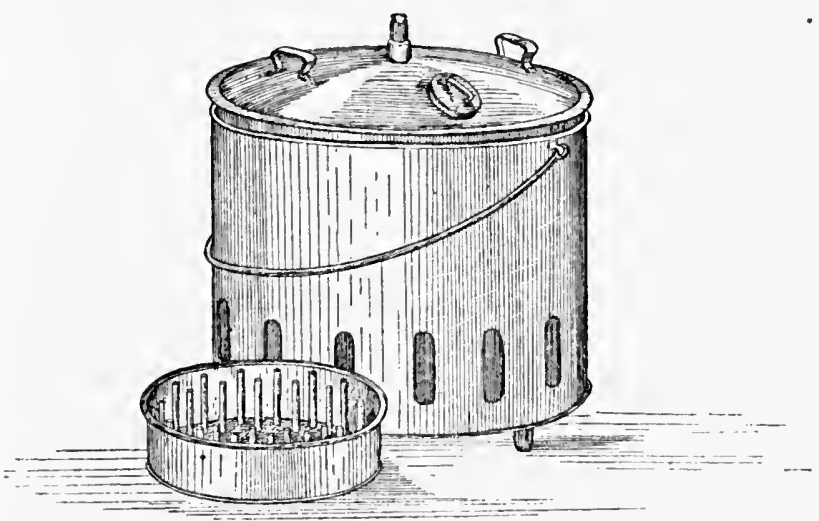

Breslau regenerator and lamp.

such size that the requisite number of pastilles cannot be placed in the basket, more than one apparatus should be used. This process hats the advantage of simplieity and econony of time, for when the apparatus is placed in position with its lamp burning, it requires no further attention on the part of the operator, who then, with other lamps, is enabled to start the process elsewhere, and thus accomplish much more than

FIG. 102.

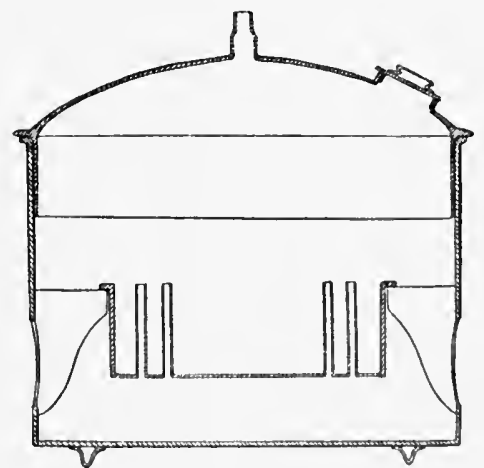

Vertical section of Breslau regenerator. (Iamp in position.)

another who, operating an autoclave, or similar apparatus, is obliged to give it constant attention as long ats the gas in being generated.

Still another apparatus is that used in what is known as the "Bres- 
lau method," in which the gas is disengaged in company with an abundance of steam, by boiling dilute formaldehyde solution. The apparatus shown in Figs. 101 and 102, taken from the description of the method by von Brumn, ${ }^{1}$ consists of a copper boiler about 14 inches in diameter and 3 in depth at the periphery, with an immovable cover slightly domed, in the eentre of which is an outlet tube, to which a stout rubber tube can be attaehed. The eover is provided also with two handles and an orifice elosed by a serew eap. A flange around the upper border of the boiler keeps the latter in place when it is put on its support, which is a cylinder of enameled sheet iron about 14 inches in height, provided in its lower half with slits for the free entrance of air, and on its inner side with three supports for an alcohol lamp. The lamp is an open dish, through the bottom of which, in two eoneentric rings, 20 tubes projeet upward as high as the sides of the vessel. With this apparatus, 3.5 liters (nearly 4 quarts) of fluid can be brought to boil in 10 minutes, and nearly the whole ean be evaporated in an hour. The amount of alcohol placed in the lamp should be about one-fourth of the volume of the solution in the boiler, and this will be consumed before the boiler is empty. Like the Schering lamp, the apparatus may be left in the room or it may be used outside with a delivery tube passing through the keyhole. In order to achieve the best results, a dilution of 1 part of the 40 per eent. solution of formaldehyde with 4 of water is reeommended. With this dilution, one avoids the polymerization observed when the undiluted solution is heated, which is due to the fact that the water is driven off faster than the formaldehyde.

A somewhat similar apparatus has been devised for the generation of steam in conneetion with the use of the Sehering lamp. It eonsists essentially of a circular copper boiler, surrounding the Schering lamp and heated by a cireular open alcohol lamp which is really a sort of gutter into which a measured amount of aleohol is poured.

Various methods have been devised for spraying the solution of formaldehyde itself, but they have had their day and have fallen into disnse.

In many municipalities the publie health authorities suspend, in the space to be disinfected, sheets wet with the requisite amount of formalin, whieh is thus allowed to evaporate into the atmosphere.

A method of generating the gas which does away with speeial apparatus and also the need of a flame is that of Evans and Russell, ${ }^{2}$ which depends upon the fact that when formalin and potassium permanganate are brought together, a violent reaction occurs, with the evolution of much heat and rapid liberation of the gas, and also vaporization of the water. Numerous experiments demonstrated that, for the attainment of the best results, 6.5 ounces of the permanganate in the form of powder or very small erystals should be employed with each pint of formalin. In any given ease, the necessary amount of each having been determined, the permanganate is placed in a suitable

1 Zeitschrift für Hygiene und Infeetionskrankheiten, XXX., p. 201.

2 Thirteenth Report of the State Board of Health of Maine, 1904, p. 234. 
vessel and the formalin is poured upon it. The evolution of the gas being very rapid, it is necessary for the operator to leave the room as quickly as possible. On account of the frothing which oceurs in consequence of the violence of the reaction very tall vessels are required. Experience has shown that these are best made of tin and with flaring tops. It is recommended that they have a diameter of 10 inches at the bottom and a height of 17 inches, the sides having a perpendicular height of 8 inches and then flaring at an angle of about 50 degrees.

Quantitative determinations proved that the yield of gas averages 81 per cent. of the amount present in the solution, and that about four-fifths of this are set free within 5 minutes, the remainder being given off in rapidly diminishing amount during the next 12 hours.

To avoid the violent ebullition, foaming and spattering, and to retard the evolution of the gas, Houghton and Clark ${ }^{1}$ propose mixing the crystals of permanganate with 15 per cent. of Portland cement and enough water to permit the making of small blocks, each containing 80 grains of the crystals. They recommend the use of 3 of such blocks to about a pint of formalin. The formalin is placed in a pail of about 3 gallons' eapacity, and the blocks are then dropped into it. The reaction is slower and less violent than that which occurs in the original process.

Another, somewhat similar, method is that proposed by Eichengrün, ${ }^{2}$ in which a mixture of paraformaldehyde and metallic peroxides (barium and strontium), called AUTAN, is employed. This preparation, which is presented in the form of powder and in tablets, on being thrown into water, gives off formaldehyle gas with a rapidity which varies according to the relative proportions of the ingredients. Equal weights of the peroxides and paraformaldehyde mixed with twice their volume of water cause a violent explosion, but the preparation in the proportions presented gives off the gas very quickly without explosion. Selter ${ }^{3}$ reported that the action is so rapid and the room is filled with the gas so quickly that the usual precautions of sealing minor apertures are unnecessary. Using as test-objects anthrax spores, staphylococei, and fresh tuberculous sputum, he reported favorable results, as did Wesenberg, ${ }^{4}$ who used the same and additional test-objects. But Nieter ${ }^{5}$ disagrees with Selter as to the necessity of sealing the room, and while conceding the advantages of simplicity, freedom from danger of fire, and the possibility of a number of disinfections simultaneously under control of a single individual, points out a very material disadvantage in the high price of the compound. Unfavorable results are reported by Ingelfinger, ${ }^{6}$ Bock, ${ }^{7}$ Kirehgaesser and Hilgemann, ${ }^{8}$ Proskauer and Sehneider," and also by Christian ${ }^{10}$ and Hammerl."

1 Therapeutic Gazette, July, 1907.

2 Zeitschrift für angewandte Chemie, XIX., 1906, No. 33, p. 1412.

3 Münchener medizinische Wochenschrift, 1906, p. 2425.

4 Itygienische Ruudschau, November 15, 1906, p. 1241.

5 Ibid., February 1, 1907. p. 151.

- Klinisches Jahrbuch, XVIII., 1907, No. 1.

7 lbid. 8 Ibid.

10 Uygienische Rundsehau, May 15, 1907, p. 571.

${ }^{9}$ Ibid.

11 Münchener medizinische Wochenschrift, 1907, No. 23 . 
Diendonné advocates the evaporation of diluted formalin with the aid of heated bricks, the liquid being poured over them, or of redhot steel bolts, weighing about 7 pounds, held in a sheet-iron pocket in the vessel in which the liquid is contained. $\Lambda$ perforated cover is employed to minimize the amonnt of loss of liquid by spurting.

Another simple method of generating the gas and steam at the same time is that of Schering, ${ }^{2}$ in which pastilles of paraform and unslaked lime are employed. These are wet with warm water, and the heat which is produced in the process of slaking the lime is sufficiently intense to cause the volatilization of formaldehyde from the paraform and the formation of steam at the same time. One may use also unslaked lime and diluted formalin, dropping the former into the latter. This process has the disadvantage that part of the formaldehyde released is decomposed. To avoid this the addition of oxalic acid or of sulphuric acid is proposed, but the process is patented.

Another method of generating the gas consists in the application of formalin to unslaked lime, the heat produced thereby liberating the gas with considerable rapidity. An improvement upon this method is offered by Huber and Bickel, ${ }^{3}$ who report very satisfactory results with a mixture of about 2 quarts of formalin, 4 pounds of quicklime, and about 6 quarts of boiling water for each 1000 cubic feet of air space. The lime is placed in a large wash-tub, the water is poured over it, and then the formalin is added. The gas and gencrous volumes of stean are given off very rapidly, and the space to be disinfected is soon filled with the vapors.

The method of Elb, with "carboformal Glühblocks," yields results which do not warrant commendation.

Germicidal Properties.-The first to note the antiseptic effect of formaldehyde were Loew and Fischer in 1886, but although Loew continued his observations for some months, and Buchner and Segall made a study of its antiseptic action in 1889 , 'Trillat, in 1892, was the first to draw attention to the importance of the agent as a disinfectant. Almost at the same time came a publication by Aronson, ${ }^{4}$ and since then the germicidal properties of this substance have been the subject of more numerous investigations than have been made of those of all other disinfectants combined. So many have been the favorable reports and so well has been established its claim to first place as a gaseous disinfectant that it is hardly necessary to present the evidence in detail. It is sufficient to state that, provided the gas can reach them in sufficient concentration under favorable conditions of temperature and moisture and with a reasonable period of contact, no pathogenic organisms can withstand its influenec.

Although certain experimenters have elaimed for formaldehyde a much greater penetrating power than can be explained by any law of

${ }^{1}$ Die ärztliche Praxis, 1901, No. 2.

2 Hygienische Rundschau, 1900, p. 708.

3 Münchener medizinische Wochenschrift, September 3, 1907.

4 Berliner klinische Wochenschrift, 1892, No. 30. 
physics, it is very generally agreed that in the gaseous form it is merely a surface disinfectant, unless the object exposed is casily permeable by any gas or mixture of gases, such as air. While it eanuot penetrate to the interior of a closely rolled bundle of clothing, for example, it can reach all parts of a loosely rumpled mass of eheese-cloth ; and, although it may be able to sterilize test-objects placed inside a pillow or mattress the covering of which is laid open, it cannot ordinarily be depended upon to do so, if the eovering is intact, any more than it can be counted upon to disinfect the pages of a tightly closed book. For superficial disinfection of walls, furniture, clothing, and fabries freely spread out and exposed, it is effieient in the highest degree. Long ago, Pfull ${ }^{1}$ warned against expecting too much in performance, saying that it will always be merely a surface disinfectant, not to be relicd upon to influence bacteria only slightly eovered or on dust which lies in measurable thickness, and in cracks of floors and walls.

It is important to bear in mind the lack of penetrating power of formaldehyde gas, sinee a disregard of this faet will cause much supposed disinfection to be a positive danger, beeause of orereonfidence in the results actually achieved. Therefore, in practice, all obstacles to thorough dissemination must be removed as far as is posible.

Conditions Favoring Action.-Coneerning the influenee of moisture on the efficiency of formaldehyde gas there was at one time a decided difference of opinion, but it is generally agreed that unless the air of the space acted upon has a relative humidity of at least 65 , the results are likely to be unsatisfactory. But if the objects exposed are actually wet, so that the gas is taken up virtually in solution, it has been shown by the author ${ }^{2}$ that penetration of a loose mass of fabrie is prevented, and by Rubner and Peerenboom ${ }^{3}$ that the concentration of the formaldehyde solution, formed by absorption, is too weak to be effective. With regard to temperature, it is agreed that the greater the degree of heat, the surer the action, and that below $60^{\circ} \mathrm{F}$. favorable results cannot be expected.

Toxicity.- It has been asserted by a number of experimenters, including A ronson, Trillat, Kobert, Pfubl, ${ }^{4}$ and others, that the gas is non-toxic to animals, but the experiments of Pottevin ${ }^{5}$ with grineapigs, of the author ${ }^{6}$ with rabbits, and the experienee of Brough ${ }^{7}$ and others engaged in the work of public disinfection, demonstrate that this is untrue. Dogs and eats, aceidentally overlooked in rooms undergoing disinfection, have repeatedly been found dead by public disinfectors, as well as flies and other insects, inchuling roaelies and bedbugs. Against mosquitoes, Rosenau ${ }^{8}$ finds formaldehyde to be far inferior to sulphur dioxide.

\footnotetext{
1 Zeitschrift für Hygiene und Infectionskrankheiten, XXIV., 1897, p. 289.

2 American Journal of the Medical Sciences, Jannary, 1898.

3 Hygienische Rundschan, 1899, p. 205.

${ }^{4}$ Berliner klinische Wochenschrift, 1892. No. 30, and Zeitschirft für IIygiene und Zeitschrift für Hygiene und Infectionskrankheiten, XXV., 1897, p. 68.

5 Annales de d'Institut Pasteur, November 25, 1894.

6 Loc. cit. 7 Transictions of the Massachusetts Mcdical Society, 1898.

8 Bulletin No. 6, of the Hygienie Laboratory, Washington, September, 1901.
} 
The solution, taken internally through nistake or with suicidal intent, has caused many deaths. The most rapidly fatal case known is that reported by Levison. ${ }^{1}$ The amount taken was estimated at 2 or 3 ounces, and death occurred in 20 minutes, after intense suffering.

Amount Necessary for Room Disinfection.-The amount of formaldehyde neeessary to disinfect any given air space depends very much upon the thoroughness with which the escape of the gas is prevented during the time given for action. Under ordinary conditions and with the observance of all reasonable precautions, it is generally agreed that for each 1,000 enbic feet, a pint of formalin, or about 60 pastilles of paraform, ought to suffice. Strüver ${ }^{2}$ would use 45 pastilles per 1,000 cubic fect against sporeless bacteria, but in practical disinfection one cannot always discriminate. Flügge ${ }^{3}$ advises that, in small rooms containing the usual amount of furniture, the number of pastilles be increased from 2 to 2.5 per cubic meter, or to 72 per 1,000 cubic feet.

With the Breslau method, it is claimed that less than half a pint of formalin (190 cc.) will suffice for 1,000 cubic feet with 7 hours' exposure. Novy ${ }^{4}$ also is of the opinion that in the presence of sufficient moisture, even less will be found adequate; namely, 150. Provided the gas is prevented from escaping, there can be no doubt that the smaller amounts are effective within much less time than that usually given in practical work. In a series of experiments in a practically air-tight glass cabinet, using as test-objects smears of anthrax spores, Staphylococcus pyogenes aureus, a highly resistent non-pathogenic sporebearer, and the bacilli of diphtheria and typhoid fever, the author found everything sterile after two and a half hours' exposure to an atmosphere containing the equivalent of 110 ec. formalin in 1,000 cubie feet. Using it to the extent of about a pint to the 1,000 cubic feet, the same result was attained in less than a half hour.

Disadvantages.-The principal disadvantage observed in disinfection by formaldehyde, aside fron its cost, which is considerable, is the odor, which is sometimes very persistent, especially when much moisture is present, and which, except under very unusual conditions, is plainly perceptible outside the room in which the gas is disengaged. Usually, however, this is a transient trouble, and is met by thorough aëration. If deemed advisable on the score of saving time, and when the gas has been absorbed by the condensed moisture on the walls and furniture, it may be neutralized by means of ammonia water, which may be exposed in the room in shallow dishes or vaporized from a flask or other apparatus and conducted into the room by means of an outlet tube through the keyhole of the door. Flïgge recommends the latter method, and advises the use of about $120 \mathrm{cc}$. of the 25 per cent. solution to each $100 \mathrm{cc}$ of formalin, and $320 \mathrm{ce}$. to each 100 pastilles of paraform used.

1 Journal of the American Medical Association, June 4, 1904.

2 Loc, cit.

3 'Zeitschrift für Hygiene und Infeetionskrankheiten, XXIX., 1898, p. 276.

Medical News, 1898, p. 641. 
Articles of elothing, stuffed furniture, and the like must otherwise require sometimes several days of airing.

Technic of Room Disinfection.-See under Practical Disinfection, page 612 .

Other Applications of Formaldehyde.-Besides its use in the gaseous state for house disinfection, formaldehyde in the form of its aqueous solution is well arlapted to the sterilization of urine, freces, sputum, and other waste produets, furniture, wood-work, toilet articles, and other objeets, and it is also valuable as a deodorant. In the disinfection of urine, the addition of one-twenticth of its volume of formalin will be found to produce sterility within an hour. Tubereulous sputum and diphtheritic membranes, covered by a suffieient volume of a mixture of about two and a half tablespoonfuls of formalin in a quart of water, are sterilized within 2 hours. Liquid stools plus and equal volume of the same mixture are disinfeeted eompletely within the same period.

A mixture of 1 part of formalin and 20 of water is very efficient as a wash for furniture, wood-work, and other objects, for spraying earpets and woollen clothing, ete., and for soaking bed-linen and other washable fabries. A tablespoonful to a quart of water will remove all odor from the hands after autopsies, and will deodorize other parts of the body to which it may be applied.

\section{Prevention of Dissemination of Infectious Material; Practical Disinfection.}

Even with the best disinfeetants available, and with the exercise of the greatest eare in their application, practical disinfection is by no means always effective in preventing the transmission of infective material to new fertile ground. Hence it is advisable and necessary to keep the infected area as small as possible and to prevent the aecumullation of infective material by destroying it continuously and as quickly as possible after it is thrown off by the body. With the exereise of due care, the waste produets which act as vehieles for the infective agents of our common and oceasional scourges may be so effectively dealt with from hour to hour and from day to day as to make the aftertreatment of the room and its contents somewhat of a mere form, earried out as a matter of rontine practice, or in order to make assurance doubly sure.

According to the nature of the disease, these agents reside in diseharges fiom the mouth, nose, and throat (diphtheria and pertussis), in sputum (pulmonary tubereulosis, influenzal, and pnemonia), in discharges from the bowels (typhoid fever, cholera, dysentery, and tuberculosis), in the urine (typhoid fever), and in matters thrown off by the skin (acute exanthemata). Therefore, the course to be pursued during the continuance of a sickness or eonvalescence varies according to the nature of the disease.

The linitation of the infeeted area and of the amount of material which may require disinfection on the termination of the disease should 
be a matter for immediate aetion on the discovery of the existence of the disease. The patient, especially in the case of the acute exanthemata, should be placed in a room which, if possible, may be isolated from the rest of the house, and from which all unnecessary furniture, especially of the upholstered kind, hangings, carpets, and rugs have been removed. Disinfectants for the prompt treatment of infective matter should be kept near at hand, together with a sufficient number of appropriate vessels and utensils.

In order to prevent or restriet the earriage of living organisms from the room, ingress should be denied to all whose presence is unnecessary; the wearing of other than cotton and linen dresses, that is, smooth-surfaced and washable, by the attendants should be interdicted; no food remainder should be taken away to be consumed by others; no used bed-linen or body-linen removed until after immersion in disinfeetant solutions, and no discharges finally disposed of until after appropriate treatment. If it be necessary to use the broom, the dust should be kept down by the use of wet sawdust or tea leaves, which, with the gathered dirt and dust, should be treated with disinfectant and burned.

Under no circumstances should the process known as "dusting," which is merely the seattering of dust through the air from surfaces where it was at rest and upon which and elsewhere it will again be deposited, be allowed, but such surfaces should be wiped with eloths moistened with or wrung out in disinfectant solution and afterward soaked and boiled. According to season, the windows should be provided with wire sereens to kcep out flies, which not only are an annoyance, but, through their habit of visiting all manner of excreta and other filth, act as carriers of infection.

Disinfection of Fæces. - The discharges from the bowels in typhoid fever, dysentery, eholera, and intestinal tuberenlosis, should be rceived in vessels eontaining an amount of disinfectant solution equal to, or, better, larger than, the probable volume of the discharges. Whatever the agent used, it should be brought into inmediate contact with the entire mass of the discharge by thorough mixing, and the whole should stand under cover for about an hour before final disposition. Milk of lime, although efficient, leaves a bulky residue which cannot be conveniently disposed of through the usual chamnels. Chlorinated lime is also efficient, but is disagreeable in odor. Corrosive sublimate is unsuitable for reasons elsewhere stated. Phenol, in 5 per cent. solntion, with or without the addition of mineral acids or common salt, and the varions eresol disinfectants, may be employed, but their odor is not always tolerable to the patient. Dilute formalin presents no objections, and is very efficient and rapid in aetion.

Urine.-In typhoid fever and tuberenlosis of the urinary tract, the urine should be sterilized by the addition of an equal volume of a 5 per cent. solution of chlorinated lime, carbolic acid, or one of the eresol compounds, but better by the addition of about a twentieth of its volume of formaliu. 
Sputum.-In pneumonia and pulmonary tuberculosis, the sputum should be received in spit-cups partly filled with disinfectant solution, and kept covered when not in actual use. It nay be treated with 5 per cent. carbolic acid, or about 5 per cent. of any of the cresol compounds, or with 4 per cent. of formalin. Milk of lime and chlorinated lime are also efficieut. Corrosive sublimate is very uncertain. By reason of its consistency and adhesive properties, sputum is one of the most difficult materials to sterilize. It is especially daugerous, as it may contain large numbers of entangled bacteria, which, on drying, may be disseminated by air currents.

Discharges from Mouth, etc.-In diphtheria and pertussis, all discharges from the mouth and throat should be received on pieces of rag, which should be burned. The diphtheria organism retains its vitality a long time in the dry state, and so may exist in the air of the room, if particles of false membrane which happen to be thrown out in coughing or sneezing are allowed to dry on walls, furniture, and elsewhere.

Eating Utensils, etc.-All cating utensils used by patients with pneumonia, diphtheria, pertussis, the exanthemata, and tubereulosis should be well sealded. All napkins should be treated in the same manner as infected bed-linen. All remains of meals should be destroyed.

Bed-linen and Clothing.- In any ease of sickness in which isolation is advisable or in which the norbifie agent is known to exist in the bowel discharges, all used body-linen, bed-linen, towels, napkins, wash-cloths, handkerchiefs, etc., even if not obviously soiled, should be inmersed for an hour in disinfectant solutions, and then conveyed under cover to the laundry or other suitable place, and boiled for an hour. Should the organism survive the first treatment, which event with proper eare is unlikely, it will perish in the second. Should there be no frecal or other stains, the boiling may be carried ont without the preliminary soaking; but in no case should the articles in a dry state be removel from the room except under cover or wrapped in a sheet wetted with an efficicnt disinfectant.

In scarlet fever, for example, the morbifie agent, whatever it may be, is exceedingly tenacious of life, and resides in the fine particles of epidermis which are continnally east off by the skin, and it is easily conceivable that an armful of linen from a ease of this discase might shed, in its journey to the laundry, a number of dust particles capable of much mischief: Neither lime nor chlorinated line may be nsed on clothing, on account of probable injury. Corrosive sublinate $1: 1,000$, phenols and eresols in 5 per cent. solution, and formalin in 4 or 5 per cent. solution, may be advised. Colorel goods alre sometimes affected by some of the cresol compounds, but to no greater extent than may be caused by ordinary laundry soap.

Hands.- In the nursing of cases of infertious disease, the soiling and infection of the hands are frequently unardable. After every use of the bed-pan, every wiping away of discharges, every handling 
of the patient's body, and, in short, after every act by which the hands may become infected, they should be washed inmediately and thoroughly, although not necessarily with that thoroughness which is so essential in surgical practice. Ordinary soap-and-water treatment should be supplemented by the application of some more powerful disinfectant. Carbolic aeid and the cresols may serve, but they leave a disagreeable smell, and have sometimes an unpleasant effect on the skin. Formaldehyde in 3 per cent. solution is effieient, but when applied frequently, causes a hardening of the epidermis which is far from agreeable. Corrosive sublimate $1: 1000$ is not so efficient, and its use is often followed by dermatitis. Schenk and Zaufal ${ }^{1}$ recommend the use of sand soap followed by immersion in corrosive sublimate $1: 1000$, as hot as the hands can bear.

Air.-All attempts to disinfect the air of the sick-room in the presence of the patient are futile, for the presence of sufficient of any chemieal disinfectant to have any effect on the bacteria present would cause the air to be irrespirable. It is a common practice to place about the room dishes containing earbolic acid, permanganate solution, chlorinated lime, iodine, and other agents, and to suspend sheets wrung out in all kinds of active and inert solutions, in the vain hope that thereby the air is made better for the patient and incapable of transferring infection to others. Whether the agent used is a true disinfectant in any strength whatever, and whether the sheet is continuously or only intermittently wet, do not appear to enter in any way into the question of efficiency. Ordinarily, anything sold in the shops at a high price and under a label alleging not infrequently the impossible, will be aceepted withont question. But it may safely be asserted that no disinfectant known ean be of the slightest service when used in this way, and if this is true of the disinfectant, it must be of the sheet.

Inch can be done to remove the well-known disagreeable sick-room smell, due to the excreta and to matters eliminated by the lungs and skin, but all hope of producing sterility of the air should be abandoned. If pathogenic organisms are present in the air, a much easier and more reasonable method of dealing with them is that of thorough aëration, and this is one of the most important parts of treatment in general. The germicidal properties of sunlight should also not be overlooked when it is possible to make use of this important aid. If good ventilation is not sufficient to keep the air sweet, the old-fashioned pastilles, containing benzoin, may be employed as occasion demands, or one or two paraform pastilles may be volatilized slowly in a small lamp for the purpose. In very small amounts in the air, the gas is in no way disagrecable or irritating, and acts very powerfully as a deodorant, not by supplanting the smell, but by destroying it by chemical union.

Room Disinfection.-Net until the termination of the disease or the removal of the patient should the disinfection of the sick-room and its contents be attemptcd. This is not such an easy matter as is com-

${ }^{1}$ Münchener medicinische Wochenschrift, April 10, 1900. 
monly believed, and much supposed disinfection is, by reason of a lack of thoroughness, no better than none at all, or, indeed, worse, becanse of undeserved eonfidence and unfounded sense of safety. Even with the utmost care, one can hardly expect absolute perfeetion of results, althougk in ideal disinfeetion every miero-organism present should be destroyed. Flügge, ${ }^{1}$ who has devoted much time and study to the question of house disinfeetion, avers that with any process by which 90 per cent. of the pathogenie bacteria present are destroyed, one should be eontent, and that no process practicable will kill all of them.

The processes employed up to within very recent years are notoriously inadequate, and the far superior proeesses in use to-day may yet be made more perfeet. House disinfeetion is often most insuffieient, even when what has been done has been earried out with every eare and under most favorable eonditions, since it is the usual practice to disinfeet only the partieular room which the patient has oeeupied during his sickness, without regard to the fact that all the connecting rooms, hallways, and distant parts of the house may have beeome infected.

The open doorway opposes no inseen obstaele to the passage of minute dried particles of false membrane or epidermal scales floating in the air, nor are these attraeted to and retained by the interposed sheet like particles of iron by a magnet. Even when the door is closed, there are air eurrents, now one way, now the other, nnder it and above the threshold. Infective material may be earried in one way and another by members of the family, visitors, attendants, and even by the patient himself, to various parts of the house, and the room in which he has lain ill may, by reason of proper attention, be the least infected one in the honse, but yet in ordinary practice it is the only one treated. Probably oftener than not, much more than one room, and iv not a small proportion of eases, the whole house, should receive attention.

The existing methods of room disinfection comprise mechanical treatment, direet applieation of disinfeetant solutions as spray or washes, liberation of gaseous agents, and combinations of all three. The bread process, devised by Esmarch, ${ }^{2}$ eonsists in rubling the walls with pieces of bread, to which bacteria adhere with great tenaeity. This is not applicable to rough walls, and when thoronghly and properly done, involves such an amount of labor and material as to be exceedingly expensive. The bread pieces, together with all crumbs which break off and fall to the floor, are carrefully removed and destroyed by fire. For the rest of the room and its contents, other processes are necessary, including serubbing with soft soalp and water, wiping with disinfectants, and transportation of ecrtain articles of clothing, furniture, bedling, ete., to the public disinferting station to be treated by steam.

The method of treating walls, floors, furniture, and elothing by

1 Zeitsehrift für Hygiene und Infectionskrankheiten, XXIX., 1898, p. 276.

2 'Zeitschrift für Hygiene, II., 1887, p. 491. 
spraying with solutions of mereuric cliloride and other agents eommends itself in some quarters and not in others. According to Rideal, 35,000 houses in Paris were disinfected by means of sublimate spray, $1: 1000$, in 1893 , and a still larger number in 1894 with satisfactory results and with no bad effects from the poison. It appears, however, according to later evidence, ${ }^{1}$ that a number of the employes of the disinfecting squad have shown symptoms of mercurial poisoning, and Rideal mentions cases of salivation in India attributed to corrosive sublimate wash for floors. The spraying process, whether satisfactory or not, and whether dangerous to health or not, is not quick, and requires other treatment which consumes time and adds to the expense.

The ideal disinfectant would be a gas with no destructive or harmful action on anything but micro-organisms, capable of penetrating materials by which they are hidden, and acting with great quickness. Such an agent, it is safe to say, will never be discovered, for, even though the other requirements may be met, it is improbable that the physical law governing diffusion will ever be modified by any gas as yet undiscovered. Gaseous disinfection must ever be superficial or nearly so, and should be assisted by other methods to bring about the best results. Gaseous disinfeetants which exert any injurious influence on the objects treated eannot be tolerated, and it happens that this class, which includes chlorine and sulphur dioxide, has been found wanting in efficiency.

Formaldehyde gas approaches more nearly the requirements of the ideal disinfectant than any thus far tried, and has supplanted all others. In its application, no matter how it is generated, whether from formalin or paraform, it is essential that every obstacle possible shall be interposed against its escape from the space under treatment, and that all objects within that space shall be so disposed as to present as much of their surface as possible to its action; and even then, absolute perfection of results cannot be attained. Flïgge ${ }^{2}$ relates that twice he prepared a small room, containing but little furniture, by plaeing pathogenie organisms on marked locations, and had the local disinfecting squad perform their office under careful supervision, and in both instances found that a fair percentage of the bacteria eseaped destruction. He suggests, with good reason, that, in routine practice, the results must ordinarily be far less fidvorable.

For the attainment of the best results, the various articles of furniture should be moved away from the walls, all articles of clothing, blankets, and other textiles should be suspended freely on lines or clothes-horses, the poekets of elothing turned inside out, and all eracks and other outlets carefully stopped with wet cotton, putty, adhesive paper, or other suitable material.

Particular attention should be paid to the complete closure of all inlet and ontlet legisters; those in the walls should be pasted over with stout paper, and. those in the floor should be so treated or eovered with thick eloth wrung out in sublimate solution or diluted formalin.

1 Journal of State Medicine, IV., 1896, p. 146.

${ }^{2}$ Loc. cit. 
Loosely fitting window-sashes may be made tight by means of wooden wedges, and the cracks around them properly stuffed. If there is a stove in the room, its doors and openings for drafts should be securely sealed. Open fireplaces and Franklin stoves require complete elosure of their flue-outlets. The doors of all closets and cupboards and the drawers of all bureaus and cabinets should be left open. All soiled places on the walls, floor, and furniture, possibly due to infective material, should be wetted with formalin or sublimate solution.

When the room has been properly prepared, the generation of the gas may be begun. If paraform lamps or the Breslau apparatuses are employed, the operator leaves the room and stops the erack under the door with wet cotton and closes the keyhole with a gummed label or with putty. If an autoelave or other similar apparatus is employed, the stopping of the keyhole of the door is necessarily deferred until the generation of the gas is completed. The room is then left unopened over night or, if the process is begun in the morning, through the day. On the expiration of the required time, ammonia in the necessary amount is vaporized through the keyhole, or the room is entered at once, the windows thrown open, and free aëration established. In the latter case, the operator's eyes should be protected by elosely fitting goggles, and he should hold his breath, if possible, until his object is accomplished. If ammonia is employed to neutralize the gas, the room will be sooner inhabitable than otherwise, especially if steam has been generated simultaneonsly with the gas, as advoeated by Flügge, for aëration may require many hours, and, in some eases, days, to rid the room of the odor. This is a matter of extreme importance with people of small means living in limited spaces, who eamnot afford even the temporary inconvenienee and expense of finding outside accommodations.

Mattresses which have been polluted ly soakinge of urine and excreta, thiek elothing, and other articles which do not lend themselves to superficial gaseous disinfection, require treatment by stean in the special apparatuses described on a preceding page. Straw, corn-husk, and "excelsior" mattresses should be differently treated. Their contents should be removerl and burned, and the ticking soaked in disinfeetants and boiled. Stuffed furniture covered with woven fibries should be taken out of doors and be well beaten and loft exposed to the air and direct sunlight. If upholstered in leather, it should be well wiped in all the erevices with cloths wrung out in sublimate solution or diluted formalin.

Heavy elothing and other fabrics sometimes are sent to be treated by the benzene process, in the belief that, by this means, not only are grease spots removed, but that sterilization is effeeted. Rüpl, however, has pointed ont that, in the ordinary benzene process, pus encei and the bacilli of typhoid fever, anthrax, diphtheria, and tubereulosis are not destroyed.

${ }^{1}$ Correspondenzblatt für Schweizerische Lerzte, 1s97, No. 19. 
Disinfection of Books.-Books are extremely difficult to sterilize with certainty, on account of the protection that is given to bacteria by the juxtaposed pages. Unbound books may be subjected to treatment by steam, but this process is not suited to bound volumes, because of its effect on the glue. For bound books, the only available disinfectant is formaldehyde, but even this agent is not efficient, unless the leaves are so disposed that the gas can have access to every page. Books of value will require very thorough and repeated treatment; but those of small value, known to have been probably or possibly infeeted, are best destroyed by fire. If formaldehyde treatment is deemed advisable, they should be placed on edge, with the leaves opened as much and as freely as possible, and subjected repeatedly to the action of the gas in a tight closet or box.

Disinfection of Water-closets. - Water-closet bowls may be treated with dilute formalin or 5 per cent. solution of the cresol preparations. The wood-work around and near them may be washed with the same agents. Sublimate solution should not be used in plumbing fixtures, on account of its action on lead. 


\section{CHAPTER IX.}

\section{MILITARY HYGIENE.}

Since the most important factor in the efficiency of an army is its health, it follows that everything which may influence this in any way for the better or worse should be looked after with the utmost eare. The men who compose an army are drawn from eivil life, in whieh each individual has, to a smonter or lesser extent, independent control of his time, ehoice of occupation, selection of food and dwelling-place, and general sanitary care. After enlistment, soldiers lose most of this independence; they are housed, clothed, fed, and exercised under regulations which it is beyond their power to amend; they are moved from one point to another, differing perhaps very widely in climatic and other conditions, under orders which they may not presume to question ; their hours for sleep, meals, work, and recreation are fixed for them without consultation with them, and without regard to individual or communal preference.

Since the government necessarily deprives the soldier of his independence of action, it is bound by every principle of fairness to him to look after his health and comfort, to promote contentment, and to ward off ennui by all reasonable and proper means. Thus, the care of troops is a double obligation; the men have every right to expect it, and the effieieney of the army is dependent upon it. But no matter how carrful the sanitary administration, it is a matter of common knowledge that in all wars, exeepting the Franeo-Prussian, and in that only with regard to the Germans, the mortality from disease has been far in excess of that from casualties, and in all armies, more discharges are due to sickness than to injuries.

The responsibility for the care of troops and health of eamps is placed upon the medical officers, who have no power to command and are hampered by being subordinate to laymen having often no adequate appreciation of matters purely medical. They have only advisory functions, and must be most careful in reconmending changes to the very conservative military mind, which finds in long continuance of a condition the strongest argument for its longer retention, and is prone to look upon recommendations for sweeping changes as evidence of whimsical disposition and defieient training in sanitary science. Nevertheless, the medieal officer hats a very heavy responsibility placed upon him, and must advise his lay superiors and explain the importance of the prineiples underlying sanitary practice. He must make proper recommendations for the protection of health of the troops in war and in peace, in camps and in garrison. 
Since the effieiency of a military body is so largely dependent upon the health of the units of which it is composed, the result of a campaign may be largely influenced by the adoption or rejection by the commanding offieer of the recommendations of his medieal adviser. Unfortunately, if, by reason of physical unfitness of the troops, a movement fuils or an epidemic of disease occurs, the public at once places the blame upon the medical department, and especially upon the head thereof, the Surgeon-General, and demands a reorganization, a sifting out of incompetent material, and especially, a change in the head, quite regardless of the possible fact that the ehoice of an unsanitary camping place may have been made against the judgment and advice of the medical branch, that the commissary department may have been largely to blame, or that other influences quite beyond the control of the medical corps may have been at fault.

The medical officer, both at lonie and in most countries abroad, has much with which to eontend. The eorps is, as a rule, not sufficiently large for the body for which it is to eare, but is expected to perform an amount of work and assume a responsibility which would fairly tax the capacity of one of double size. In an emergency requiring large additional levies and consequent employment of eivilian physicians untrained in military life, the responsibility becomes proportionately greater.

The recent experiences of this country and of England, when the outbreak of war necessitated the assembling and transportation of large armies, serve very well as illustrations. With us, on the breaking out of war with Spain, a standing army of 25,000 was suddenly increased by enlargement of the regular service and enrollment of volunteers to ten times that size, but the small body of trained military surgeons, too small before, conld hardly have been expected to be equal to the demands of the new army, even with the assistance of the physicians from eivil life, who, although doubtless lighly efficient in eivil practice, were for the most part inexperienced in camp hygiene. The difficulties of sanitary administration were very largely increased by the recklessness and ignorance of the volunteers in personal hygiene and general sanitation. The results were what night be expected, and are too well known to need further mention. The blame for all the disastrous experience was placed at once upon the medical department, which had but little to say in the eloice of camps, and nothing whatever to do with the inadequate means of transportation and other faetors in the production of a large mortality from disease. The experience of the English in the war in South Africa was essentially the same, and was due to the same causes.

In the large standing armies on the Continent, a different order of things obtains. The officers of the line are more inclined to defer to the opinious and advice of the medical staff in matters requiring expert sanitary knowledge, and the authorities demonstrate a much higher appreciation of the value of an adequate medical service. As an 
illustration of the difference in the ordering of such matters in Germany and England, the following is cited :

The British first infantry division and first cavalry brigade, with two batteries of field artillery, a company of engineers, telegraph corps, railway company, ammunition corps, and hospital corps, ordered to South Africa in the autumn of 1899 , and the German expeditionary corps, consisting of two brigades of infantry, three squadrons of cavalry, four batteries of light artillery, a batallion of pioneers, with a telcgraph corps, railway company, sanitary company, animunition corps, and hospital eorps, organized in the summer of 1900 for service in China, were about equal in number of men. For the care of these troops, the Euglish authoritics detailed 49 regular medical officers and 13 civilian surgeons, a total of 62 ; the Germans detailed 91 regular army surgeons, or nearly 50 per cent. more. The English hospital ship had 3 surgeons; the German had 10. The English sent 4 field hospitals with 16 surgeons; the Germans sent an equal number with 24. The English general hospital had 18 surgeons, of whom 11 were civilians; the German had 19, all of whom were regular's.

The superior medical equipment of the Germans is not dictated by extravagance, but by a greater appreciation of the necessity of furnishing adequate medical service.

In a standing army such as is maintained in this eountry, it would be far better to err on the side of extravagance than of undue economy in the size of the medical eorps. There should be systematic instruetion in general hygiene, which should not be limited to the medieal offiecrs alone, for the line officers also should be required to acquaint themselves with the principles of the seience, and esprecially with the sanitation of camps. Then, when the medical officers point out methods of conserving the health of troops, those in actual command would be in a better position to apply their anthority with a larger appreciation of the advice given.

Military hygiene has to deal with the selection and examination of men offering themselves as recruits, their habitations, elothing, exereise, food, diseases, and medical care; with camp sanitation, including water supply and sewerage, disposal of waste, and general police; and, in general, with all matters having any bearing on the health and, impliedly, the efficiency of troops.

\section{THE RECRUIT.}

Not every adult man aceustomed to hard work can be transformed into a good soldier, for there are many points of disqualification for military serviee, and an unsound man ran never he depended upon when his scrvices are needed. The ideal recruit is one who, in the first place, is well built and of superior muscular force, eapalble of resisting influences tending to depress the nervous and physical powers. Aceording to the great Napoleon, "The fir's quality of a soldier is the power to endure fatigue and privation ; courage is only second." This 
primary qualification is very commonly thought to be an attribute more of the country-bred than of the eity-bred lad.

Dr. Woodhull, 'Lt.-Colonel, Med. Dep't U. S. A., however, says on this point: "In raising new troops, when it is possible to select, for sharp and immediate active service take town-bred men. If a year or two can be added in which to train them, take country-bred men. Open-air military life is physical promotion to city men accustomed to irregular hours, unwholesome meals, and poorly ventilated rooms. To country lads the irregular and sometimes scanty meals, broken rest, necessity for prompt and exact action, and above all the certainty of acquiring such diseases as measles, whooping-cough, and mumps, which town boys always have in childhood, are very exhausting. After a year's training, country youths are more valuable."

"Applicants for first enlistment must be between the ages of cighteen and thirty-five years, of good character and temperate habits, able-bodied, free from disease, and must be able to speak, read, and write the English language.

"No person under eighteen years of age will be enlisted, reënlisted, or accepted with a view to enlistment, and minors betwcen the ages of eighteen and twenty-one years must not be enlisted, or accepted with a view to enlistment, without the written consent of the father, only surviving parent, or legally appointed guardian, to the minor's enlistment.

"Original enlistments will be confined to persons who are citizens of the United States, or of Porto Rico, or who have made legal declaration of their intention to become citizens of the United States. Applicants for original enlistment who claim to have been naturalized or to have declared their intention to become citizens of the United States will not be accepted for enlistment or cnlisted unless they exhibit to the recruiting officer documentary evidence, under the seal of a court of competent jurisdiction, of their naturalization or their declaration of intention to become citizens. . . .

"Married men will be enlisted only upon the approval of a regimental commander, or other proper commanding officer if for other than a regimental organization.

"Applicants will be required to satisfy the recruiting officer regarding age and character, and should be prepared to furnish the necessary evidence. $^{2}$

"For infantry, coast artillery, and engineers the height must be not less than five feet four inches, and weight not more than one hundred and ninety (190) pounds.

"For cavalry the height must be not less than five feet four inches, and not more than five feet ten inches, and weight not to exceed one hundred and sixty-five (165) pounds.

"For field artillery the height must be not less than five feet four inches and not more than six feet, and weight not more than one hun-

${ }^{1}$ Notes on Military Hygiene for Officers of the Line, New York, 1898, p. 18.

2 Circular No. 69, War Department, Oct. 25, 1910. 
dred and ninety (190) pounds. For the mountain batteries the height must be not less than five feet eight inches.

"A variation not exceeding a fraction of an inch above the maximum height given for eavalry and field artillery is permissible if the applicant is in good health and is in other respects desirable as a recruit.

"The minimum weight for all arms of the service is one hundred and twenty-eight (128) pounds, subjeet to variations below that standard as explained herein; but in no case will an applicant whose weight falls below one hundred and twenty (120) pounds be acepted without special authority from the Adjutant General of the Army.

Table of Physical Propontions for Height, Weight, and Cinest Measunemext.

\begin{tabular}{|c|c|c|c|c|}
\hline \multicolumn{2}{|c|}{ Height. } & \multirow{2}{*}{$\begin{array}{l}\text { Weight. } \\
\text { Pounds. }\end{array}$} & \multicolumn{2}{|c|}{ Chest measurement. } \\
\hline Feet. & Inehes. & & $\begin{array}{l}\text { At expiration: } \\
\text { Inehes. }\end{array}$ & $\begin{array}{l}\text { Mobility: } \\
\text { Inehes. }\end{array}$ \\
\hline 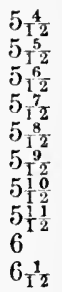 & $\begin{array}{l}64 \\
65 \\
66 \\
67 \\
68 \\
69 \\
70 \\
71 \\
72 \\
73\end{array}$ & $\begin{array}{l}128 \\
130 \\
132 \\
134 \\
141 \\
148 \\
155 \\
162 \\
169 \\
176\end{array}$ & $\begin{array}{l}32 \\
32 \\
32 \frac{1}{2} \\
33 \\
331 \\
33 \frac{1}{2} \\
34 \\
34 \frac{1}{4} \\
34_{4}^{3} \\
354\end{array}$ & $\begin{array}{l}2 \\
2 \\
2 \\
2 \\
2 \frac{1}{2} \\
2 \frac{1}{2} \\
2 \frac{1}{2} \\
2 \frac{1}{2} \\
3 \\
3\end{array}$ \\
\hline
\end{tabular}

"In calculating the proportional weight and chest measurements of an applieant for enlistment any fractional part of an inch in height equal to or greater than a half inch will be counted as a full inch; any fractional part of an inch in height less than a half inch will be disregarded. It is not neeessary that the applicant should conform exactly to the figures indieated in the foregoing table. The following variations below the standard given in the table are permissible when the applicant is active, has firm muscles, and is evidently vigorous and healthy.

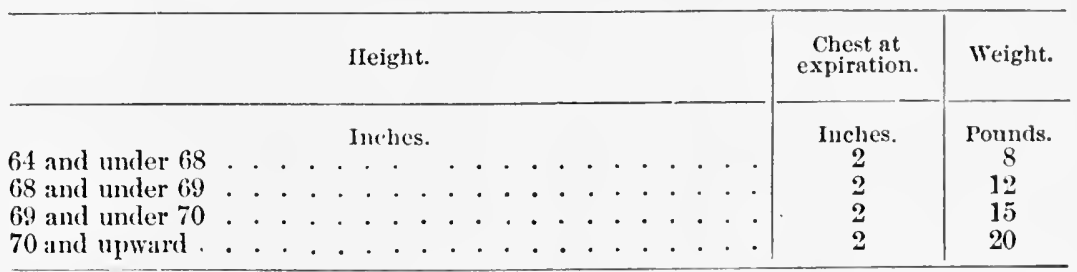

"Marked disproportion of weight over height is not a cause for rejection unless the applieant be positively obese."

Enlisted men of good character and faithful service, who, at the expiration of their terms, are undergoing treatment for injuries incurred or disease contracted in the line of duty, may reenlist, and if the disability prove to be permanent, they will be subsequently discharged. 
An enlisted man, not under treatment, but with infirmities contraeted in the line of duty not such as to prevent his performing the duties of a soldier, may be reënlisted by authority of the War Department, on application made through the surgeon and proper military channel, since it is recognized that what he may lack in sone minor particulars in soundness may be counterbalanced by experienee and habits of discipline.

Those whose enlistment is prohibited inelude former soldiers having bad reeord, deserters, drunkards, insane persons, minors below 16 years of age (nusicians), persons who have been convicted of felony or who have been imprisoned under sentenee of a court; and for first enlistments in time of peace, non-citizens, except those who have legally declared their intentions to become citizens, those who cannot speak, read, and write English, and those over 35 years of age.

It is almost the universal opinion that recruits ought not to be accepted below 20, or, better, 22. At 18 years, the recruit is immature ; the bones are not fully formed, nor have they reached their final hardness; the epiphyses have not become incorporated with the shafts of the long bones; the joints are not fully developed; the museles are soft and not wholly developed; the chest has by no means attained its full eapacity; and the organs of the body, in general, are immature. So it happens that, at' this age, it is useless to expect them to be in good condition after long-continued exertion or to undergo privations which are as nothing to the man of mature years and strength. At this period of life, he is still in the growing stage and needs all the energy of his body to bring the organism to completion, and the influenees which mature soldiers eontend against with varying degrees of success, namely, vicissitudes of weather, long marches, hard work in trenches, possible overerowding in barracks and camps, poor ventilation, and poor and insuffieient food, send him very quickly to the hospital.

It is beyond reason to expect the same work and endurance of a youth of 18 to 20 as of a fully mature man. During the Civil War, most of the boys who enlisted under 18 , and many of those above that age and under 20 , had to be discharged within the first few months.

It has been demonstrated repeatedly that the least efficient armies are those containing the greatest proportion of men below the age of 22. The first Napoleon objected to boys, saying on one occasion, "I demand a levy of 300,000 men. But I must have grown men ; boys serve only to fill the hospitals and eneumber the roadsides." A remarkable example of the importanee of maturity in soldiers is related by 'Tardien.' In the eampaign of 1805 , in which the army marched 400 leagues to reach Austerlitz, hardly any sick or stragglers were left on the way. In this army the youngest were 22 years of age and had had two years' training. In the eampaign of 1809 , on the other hand, the army, which lad but a short distance to march on its way to Vienna, filled all the hospitals on the way with its sick. More than

I Dictionnaire d'Ilygiène, III., p. 2. 
half the soldiers of this army were under 20 ycars of age and inexperienced. In the eelebrated march of Lord Roberts from Kabul to Kandahar, the young soldiers gave out from day to day and fell behind, while the old campaigners appeared to gain in vigor with each day's march.

Not only are young recruits less able to undergo the usual work and the hardships than seasoned men, but they are much more susceptible to disease. Aitken ${ }^{1}$ relates that, during the Crimean War, when the Commander-in-Chief, Lord Raglan, was informed that 2,000 recruits were ready to be sent to him, he replied: "Those last sent were so young and unformed that they fell vietims to disease and were swept away like flies." He preferred to wait rather than have such young lads sent to him as soldiers. Other commanders in the Crimea testified that young recruits were of very inferior value.

The greater susceptibility of young soldiers to typhoid fever was demonstrated by Dr. Farr, the British Registrar-General, and by Dr. Balfour, who showed that, in 1883, the army in India contained 41 per cent. of soldiers under 25 ycars of age, and that among this contingent the death-rate from this disease was $4.3+$ per thousand, while that of the men of 25 to 29 years was but 1.50 per thousand. In newly-arrived regiments, nearly half of the total death-rate was from this disease. Aitken gives a number of instanees of the influence of youth and short residence on the prevalenee of this fever. At one station, for example, out of 44 cases, 35 occurred in one regiment eomposed principally of young soldiers, and 33 among men of less than one year's residence in India.

In 1883 , in India, 36.55 per cent. of those invalided home were under 25 years of age, and in 1884, 38.70 , the prineipal diseases neessitating invaliding being anæmia, debility, phthisis, hepatitis, and diseases of the heart and arteries. Thronghont the Peninsular War, from 1805 to 1814 , it was observed that the "corps which arrived for service were always ineffective and siekly in proportion as they were marle up of men who had recently joined the ranks," and it wais calculated that 300 men having five years' experience were worth more thin 1,000 newly-arrived, inchuling the usual proportion of young recruits.

Surgeon-General Sternberg, of the U. S. Army, in his amual report for 1885 , shows that the greater proportion of sickness oecurred among soldiers under 31 years of age, and that up to the age of 25 , the rate was so mueh above the average for the whole army, that he questions whether their serviees had been a fair return for the eost of their maintenance. In 1899, the British Medical Aswoeiation passed a resolution requesting the Council to eonmunieate to the 11 al Otriee the opinion of the Section of Medieine, that no soldier ought to serve in the tropics carlier than 22 years of age.

In favor of the roung reeruit, Woothmll saly that young men are more easily trained and monkled than older men, ejoceially for the eavahy, and when well led, fight as well, as fir as mere courage goes.

1 On the Growth of the Reeruit and Young Soldier, 2d Edition, London, 1887, p. 58. 
But as we cannot keep young soldiers several years in training, and as large bodies of troops can only be raised for sudden war, men not absolutely mature must be rejeeted. Lord Wolseley prefers young men, and says:" "Give me young men: they do what they are bid, and they go where they are told; they become more amenable to discipline, and thongh when you cateh them first they may have some difficnlty in carrying their knapsacks, once they get beyond that they are in a fit condition to take the field."

If young men are enlisted, the work sbould be suited to their strength, and it should be kept in mind that they are still in the growing and developing stage, and should have no greater amount of physical exercise than is suited to their condition. In other words, their work should be proportioned to their growth, and in two years they will, perhaps, have developed into valuable soldiers. 'Taken between the ages of 18 and 20, and drilled and trained with due regard to his immaturity and limit of enduranee, the recruit often shows great progress in general development within the first half-year, particularly if, before enlistment, he was poorly fed, elothed, and housed, and engaged in an indoor oceupation. His work should be moderate in the beginning and only gradually increased, since changes for the better in the human body cannot be brought about suddenly like those for the worse, induced by attempting to do too much at the outset. Since his lungs, heart, and blood-vessels are not yet fully developed, he can neither go through the manual nor cover ground like the seasoned soldier. The heart is called upon by the new and unaccustomed exereise to contract at a greater rate than had been its habit, and he soon beeomes "winded." When this stage is reached, and he begins to feel or show distress, he should be allowed and encouraged to rest until the throbbing of the heart and the swelling of the blood-vessels subside and permit his lungs to resume easy breathing; otherwise, he is more than likely to break down sooner or later. With properly regulated exercise and good food, he ought soon to show gain and not loss in weight. Should progressive loss be observed, it is a question whether he is likely to become an efficient soldier, and he should forthwith be referred for medical examination. Under the regulations of the British army, all recruits are kept under medical observation during the first three months of service, during which time, in addition to the ordinary drill, they have an hour of gymnastic exereise daily, under the supervision of a medical man ; and if, during this period, a man shows unfarorable indications, he is examined by a medical board. Shonld this body conelude that he will not ultimately develop into an effieient soldier, he is at once discharged on that ground.

Military organizations composed exclusively of very tall men of imposing appearance are intended for display, and not for the usual work of the soldier, and, indeed, have often proved to be lacking in the essentials of good soldiers, unless they are unusually well proportioned. The superiority of additional height is commonly found to lie

${ }^{1}$ Quoted by Aitken. Loc. cit. 
in the leg and neck, and when 6 feet 3 inches is exceederl, the individual, as a rule, is not proportionately developed in the ehest and muscular system. Such men are said to be more prone to diseases in general, and more especially to pulmonary complaints, than men of medium height, and they become fatigued more early on the march and under all circunstances where endurance is of the first necessity. Their muscles are longer, possess less fasciculi, and work longer levers than those of the short men. They also offer a better target for the enemy. On the other hand, very short men are quite as objectionable as their over-tall comrades. During the Civil War, the smallest men enlisted broke down, as a rule, after but a few weeks' service in the field. There are, of course, exceptionally short men who are unusually muscular, but, as a class, they are wanting in strength.

Examination of the Recruit.-The first step in the examination of a recruit is thorough washing with soap and water. "It is not believed to be good policy to enlist men who, though able-borlied and intelligent, appear at recruiting stations in ragged or filthy dress, as the ehances are such men are tramps and vagabonds and will not make good soldiers. Men who, though attired in clean and respeetable clothing, are found to be filthy in their persons, shonld be promptly rejected for like reason." He is then presented to the examining offieer without clothing, in a well-lighted room large enough for exereise in walking, running, and jumping. Here, he is subjected to a searehing physical examination, and each deviation from the normal standard is noted. In addition, his family and personal history are obtained of the alpplicant, whose replies to the prescribed questions are recorded with such other information as bears on his fitness for the duties of a soldier. This inquiry is made before the physical examination is begun.

The examination is very thorough, and inchudes the mental condition, the senses, the principal organs of the body, the general formation, the chest capaeity, the condition of the teeth, skin, joints, and fect, and the presence or absence of hernia, varicocele, and other disqualifications.

The leading eharacteristics of a good constitution, as emumerated by Dr. C. S. Tripler, U.S. A., are as follows: "A tolerably just proportion between the different parts of the trunk and members, a wollshaped heat, thick hair, a countenance expressive of health, with a lively eye, skin not too white, lips red, teeth white and in goond condition, voice strong, skin firm, chest woll formed, belly lank, palrts of generation well developed, limbs museular, feet areherl and of moderate length, hands large. 'The gait should be sprightly and springy, speech prompt and clear, and manner cheerfinl. All latik, slight, pmuy men, with eontracted figures, whose development is, as it were, arrested, should be set aside. 'The reverse of the characteristics of a good eonstitution will indieate intirm health or a weakly latbit of body : loose, flabby, white skin; long, eylindrieal neck; long, flat feet; very fair complexion ; fine hair ; wam, sallow eountenance."

On being accepted, the reeruit must be vaccinated immediately, unless

1 Manual for the Medical Department, Washington, 1898, p. 65. 
there is unmistakable evidence of suecessful vaceination within a reasonable period.

Chest Capacity.-The determination of chest capacity is of great value and importance, since it furnishes an index of the vigor of the candidate. The factors employed are the chest measurements and extent of mobility. The chest girth is measured by means of a tapemeasure passed round on a line including the lower portions of the seapula and on a level with or just below the nipples. It is taken at forcel inspiration and forced expiration, and the difference in the two measurements represents the ehest mobility, which is one of the best indications of capacity for endurance, and is of much greater value than the actual maximum and minimum circumferenees, sinee a very large chest may have less mobility than one considerably smaller. For men under 5 feet 7 inches, the mobility should be not less than 2 inches; between that height and 6 feet, not less than 2.5 inches; 6 feet and above, not less than 3 inches.

Chest girth, weight, and height are very closely correlated in the growth and development of a healthy man, and these proportions should be carefully observed. (See table of physical proportions, taken from the Manual for the Medical Department, on page 621.)

Grounds for Rejection.-The most frequent single cause for rejection is defective development; during 1898, more than a fourth of the rejections of eandidates for the regular army were made on this ground. Second in order was defective vision; third, diseases of the eirculation. Such is the order which commonly obtains also in the British army. Other causes, in order, were diseases of the genito-urinary organs, diseases of the digestive apparatus, bad character, general unfitness, deafness, and illiteracy. Men of defective development, if admitted, are noted for the time which they spend in the hospital and in the guard-house. During the early part of the Civil War, thousands of physically inefficient men were allowed to enter the army, only to be discharged after a few weeks' service, most of which was passed in the hospitals. Another element which it is most important to exclude is the habitually intemperate. As Dr. Tripler has said, "First in a mutiny and last in a battle, the intemperate soldier is at once an example of insubordination and a nuisanee to his comrades."

Inasmuch as the ability to mareh is one of the prime qualifications of a soldier, particular attention is paid to the condition of the legs, ankles, and feet. The existence of eniarged veins of the ankle or thigh or back of the knee is sufficient cause for rejection. Large or recent bunions, and eorns on the scle, flaifoot, and "hammer-toe" are disqualifications. Fotid perspiration of the feet is an intolerable mnisanee to others in close association, and is sufficient ground for exclusion.

The loss of many teeth or a condition of general decay indicates, as a rule, a lack of stamina. Moreover, the soldier in the field needs good teeth to ehew his hard bisenit and not always tender meat. An insufficient number of opposed molars to insure proper mastication is suf- 
ficient ground for rejection. In 1898, in England, of 66,501 recruits for regular service, 1,767 , or nearly 1 in 38 , were rejected on account of bad teeth alone; but this figure gives no indication of the proportion of eandidates who might have been rejected on that ground, since many were summarily rejected on other grounds without examination of the teeth.

Defective hearing, that is, inability to distinguish ordinary convursation with either ear at 50 feet, is a disqualification, since orders may be either not heard at all or misunderstood.

\section{THE HYGIENE OF THE SOLDIER.}

Personal cleanliness is of great importance in the maintenance of health and efficiency, and should be the subject of much attention on the part of inspecting officers. General bathing can hardly be expected in a large camp in the winter months, or at any time when water is scaree; but whatever the season, a small amount of water, a quart or so, applied with a wash-rag or sponge, and with soap, should be sufficient for a decent degree of clcanliness. In the warmer months, where water is plenty, full baths and swimming should be eneouraged. During prolonged eampaigns with limited opportunities for keeping the person and elothing elean, many men are disabled by chafing and ulcerations, following irritation of the skin by perspiration, dust and dirt, and contact with unwashed, hardened underelothes. Body lice always make their appearance, and add much to the discomfort, which is only temporarily relieved, but eventually augmented, by scratching with the nails. Infested, dirty men convey the evil by contignity to their cleaner associates, who then saffer not only in body but in mind, filled with disgust and loathing, and longing to return to civil life.

Contentment and cheerfulness are very essential to the well-being of an army ; discontent and ennui undermine health and discipline and, consequently, efficiency. In the continental armies, ennui, leading to homesickness, is believed to be a prime cause of the large number of suicides and cases of insanity. This is more marked with the infantry, which branch requires less time devoted to work. In all armies, it is recognized as leading to exeessive use of tobaceo and liquor, and to all manner of bad habits. On the march and in time of general activity, the mind is stimulated and needs no special diversion; but after a camp has been permanently established, and the men have settled down to the routine of camp life, they begin to fret, and soon seek solace in tobaceo, alcohol, and gambling, and not infrequently in perversions of the generative function. Gambling is not only an unhealthy exeitement, but engenders serious quarrels, bitterness and disappointment, and is commonly carried on in crowded quarters and foul air.

The ability to keep troops in camps contented is regarded as one of the strongest evidences of capaeity for command and administration. To keep men oceupied is not sufficient; the oecupation should not be wholly routine drilling and marehing, but interesting and pleasant work 
of other kinds, and entertainments largely of an amusing nature. Extra drills, known to the men to be umnecessary, and carried out only to keep them busy, do not relieve the situation, but add to the difficulty. The establishment of reading-rooms and opjortunities for following mechanical trades are of much service. All men of experience testify to the great value of athletic sports, competitive target shooting, gardening for pleasure and profit, vocal and instrumental concerts, vaudeville and minstrel shows, theatricals, and, in fact, anything which will offer a change from the hum-drum of life. Very little things suffice to break the monotony of life in camps, just as in the country and at summer hotels, where the arrival of the train or stage, or the passing of a strange carriage, is an event calling forth the deepest interest, ancl a new arrival a genuine excitement.

\section{Clothing of the Soldier.}

Since the primary object of elothing is the conserving of body heat in eold weather and protection from the direet heat of the sun, it is essential that that worn in any one kind of elimate should be adapted to the neeessities of that particular elimate. It is obvious that the same uniform cannot be used in the Northwest and in the West Indies and the Philippine Islands, where the blue uniform, ordinarily used in our army, has been universally condemned on account of its weight. Therefore, the material should vary according to the nature and place of service. In choosing material for uniforms, the chief points to be borne in mind are the properties of heat conduction and heat absorption, permeability, and durability.

Wool is a poor conductor, and is not easily penetrated by cold winds; therefore, it is very suitable for eold elimates, but is likely to be oppressive in the tropies. It absorbs water freely, being very hygroscopie, and thus it absorbs the perspiration and prevents it from evaporating direetly from the surface of the skin and causing thereby loss of heat. 'The chief disadvantage of wool is the diffieulty with which it is properly washerl. When improperly washed, the fiber shrinks rapidly, and the fabrie becomes smaller and much less soft and absorbent. During washing, woollen materials should never be rubbed or wrung. They should be placed in water containing a proper amount of soap in solution, and moved about freely, well rinsed in water eontaining no soap, and hung up to dry without wringing. The soap used should be of good quality, as free as possible from excess of alkali, which injures the woollen by acting upon the natural fat of the wool, which is largely cholesterin.

Cotton and Linen.-Both these artieles are good heat eonductors, but are non-absorbent of moisture. Both soak up moisture from the skin, and evaporation of this requires so much heat as sometimes to cause chilling of the body. Both are durable, and neither, particularly cotton, need be very expensive. For underelothing, both are much inferior to wool, which, being a poor heat conductor and a good absorb- 
ent of moisture, prevents rapid cooling of the body when it is in a condition of active perspiration after physical exercise. It is far more permeable, also, to air, which it holds in the spaces between the fibers, and which adds to its property of non-conduction.

Light woollen underelothing, therefore, is preferable to either cotton or linen. A very good material is what is commonly known as merino, a mixture of woollen and cotton, in which the cotton constitutes about a third. This combines, in a way, the advantages of both materials, and is a much more washable fabric than pure woollen.

Shoddy is a very inferior material, made of the fiber of old, used woollen goods, mixed with fresh wool, with which it is woven. The manufacturers do not introduce any more fresh wool than is absolutely necessaly.

Color.-The color of elothing has an important bearing, both physiologically and from a military point of view. Color influenees the absorption of heat more than the nature of the material itself. White materials absorb least and black the most heat. The difference in absorptive power of different colors is shown in a marked degree by the fact that white cotton over a black surfice will reduce the temperature in the sun more than 10 degrees F. Gray stands next to white, and blue next to black.

From a military point of view, color is important, since different colors vary in their conspicuousness, and, therefore, strategically, the one which stands forth the least in the landscape is the best. The most conspicuous color is red, next white, then black and other dark shades, light blue and light brown and gray ; but, naturally, much de-' pends on the background : thus, green would be inconspicuous against grass and other green vegetation, but would show very distinetly against bare soil, whereas the light brown of the ordinary khaki is the least conspicuous in the latter position. Color also influences the absorption of odors by materials in practically the same order in which it influences the absorption of heat; that is, black and the dark shades are most absorbent, and white the least.

Military dress coats are usually closely fitting, warm and oppressive, and interfere with proper expansion of the chest, through tightness. In active service in the field, they are not worn. Undress coats are usually loose, and are far more comfortable and adapted to muscular effort. 'The khaki suits, worn by our troops in the tropies, are stiff and heavy at first, but become softer and more pliable with repeated washing. They are sufficiently loose for all purposes of comfort.

Trousers are made sufficiently roomy in the seat, and reasonably tight about the waist, with an inner belt, as no suspenders are worn. The bottoms are ent narrow ruther than with a "spring."

Gaiters and leggings are used for protecting the ankles and legs from dust and mud. They are made of brown cotton duck with lacings, and commonly are not well-fitting. When lined, as they sometimes are, with thin leather, they are likely to be uncomfortably hot. The puttee is made of a soft kind of cloth, in a strip $t$ inches wide and 
6 or 7 feet long. To one end, about 2 feet of strong tape are fastened. In applying the puttee, it is rolled up with the tape in the center of the roll. Two turns are wound over the top part of the ankle-boot and it is then wound spirally up the leg to a point belorw the knee, and the tape at the end is then continued spirally over the whole and fastened at the end. It is found to be more comfortable and more pliable than leggings, and does not blister the heels, which leggings sometimes do.

Head Covering.- The head covering is a very important article in the dress of a soldier. It should protect against cold, heat, rain, and the burning sun. It should be light, durable, and comfortable, not too closely fitting nor pressing unduly anywhere. Leather helmets, worn in some armies abroad, and felt helmets formerly used in ours, are hot, heavy, and oppressive. The ordinary white helmet is conspicuous, but comfortable in the sun. The ordinary forage cap is flexible and serviceable, but is not sufficiently ventilated for hot-weather use. The campaign hat of drab felt with broad brim and high crown has been found to fill most of the requirements in the field. In Cuba and in our new possessions, it was found at first to be too heavy, but experience, especially during the rainy season, has shown that it has advantages not possessed by any other form of head covering.

In foreign armies, unnecessarily heavy helmets and other head coverings are used largely for purposes of display, but to a certain extent also as a protection against mechanical injury. In the matter of display, there can be no question that many of them fulfil their object admirably; but as a means of defence, helmets of heavy leather and metal, weighing from three to four pounds and more, would hardly seem to secure such an amount of protection as to compensate for the great discomfort and the waste of energy which their use entails. In hot climates, helmets of bamboo, provided with puggeries, are very largely used, being light and affording good protection from the sun.

Stockings.-Concerning stockings, a great divergence of opinion exists. Woollen stockings frequently cause the feet to perspire, even in eold weather; but they are much warmer, and hence more eonducive to comfort than cotton at that time. Cotton is naturally more comfortable in summer, and, to many people, also in winter. In our army, both kinds are issued. Many regard thick woollen stockings as the best for walking, in all climates, and as a protection against foot-soreness; yet it is probable that many cases of sore feet are brought about by the excessive perspiration induced by them. Perhaps a happy mean is a thin woollen stocking or one of fine merino. It is important that the stocking should fit the foot properly, for an ill-fitting stocking, particularly one too long in the foot or too broad, gives rise to folds which cause excoriations and blisters.

Boots.-The value of well-fitting comfortable boots, permitting unobstrueted action of the muscles and joints and free circulation of blood when walking for pleasure and exereise, is too well known to need extensive discussion. To the soldier, the importance of good 
boots is still greater, since, as has been said, an efficient army is one that ean march well; and soldiers eannot march with erippled feet. Moreover, it happens frequently in time of war that in an emergency which makes a man dependent upon his walking power for his own life and liberty or for the proper earrying out of his order, a good boot is his best friend.

The sole should be thick and generously broad, so as to project all round beyond the upper, but should not be too heavy. The heel should be broad, low, and flat. The boot should be square at the toe or slightly rounded on the outer side in accordance with the natural outline of the foot, so as to allow the toes full play in walking. When placed side by side, the inner margins of each should nearly touch throughout the whole length from the end of the toe to the ball of the foot. The inside should nowhere have rough inner seams or projections, which may cause chafing and blistering.

According to Reno, ${ }^{1}$ soldiers' feet are badly deformed, and this deformity restricts, to a marked degree, the marching radius. In 521 enlisted men rarely a normal foot was seen ; " 73.9 per cent. were wearing ill-fitting shoes, and corns, callosities, fissures, bunions, ingrowing nails, hammer toes, over-riding toes, crowded toes, jammed toes, and shapeless toes were present in great profusion. In 60 per cent. of the men a very serious defect was observed, that is to say, the crowding of the first toe out of its natural aligument-i. e., hallux valgus. This latter defect reduces the marehing radius in direct proportion to the deviation." In Reno's opinion army shoes resemble too much those of eivilians. They must be made to conform more nearly to the natural foot.

If treated to a liberal amount of oil or grease at frequent intervals, the leather will be made more supple and at the same time more inpervious to water. A preparation, recommended by the late Professor Parkes, consists of a mixture of a half pound of shoemaker's dubbing in a half pint each of linseed oil and of a solution of India-rubber. Solution is effected by gentle heat, which should not be applied by naked flame, since the India-rubber solution, containing naplitha or ether, is exceedingly inflammable. This preparation is well rubbed into the leather and renewed at intervals of three months. This is said to be the best water-proofing material for leather.

Cavalry boots with long legs are not suited to walking, as they are likely to produce chafing. On aceount of the disadvantages attending their use on dismonnted duty they have, since 1902, been given up in all branches of the United States army.

Underclothing.-Undershirts should be of woollen or, better, of merino, since pure woollen is unbearable by many and because of the rapid deterioration which follows improper washing. The woollen undershirts issued at first to the troops in Cuba and the Philippines were eomplained of as eansing much irritation of the skin from prickly heat. In the tropies, a light-weight, woollen undershirt is of the high-

1 Military Surgeon, September, 1910. 
est importance in the prevention of body chilling from evaporation of perspiration. Half cotton and half woollen or two-thirds cotton and one-third woollen are highly reeommended as advantageous combinations.

The ordinary shirt of the soldier is made of flamnel, with a collar and breast pockets. It is made fairly full and is very comfortable. Woodhull recommends the earrying of an extra shirt for wearing next the body, the two being worn alternately. "At the elose of the day's work the worn shirt should be taken off, dried, stretehed, well-beaten, and hung in the wind and sun. This shonld be done even when there is no elange." Drawers, stockings, and trousers should be treated in the same manner. Drawers are necessary for cleanliness and warmtll. They are made of the same material as undershirts. In many of the foreign armies, drawers are not issued, and men who desire them are obliged to furnish them at their owu expense.

Abdominal Bands.-Abdominal protectors, either in the form of the well-known abdominal band or of small flamel aprons to be worn next the skin over the bowels, are regarded as very essential in preventing bowel troubles, which so commonly appear after abrupt changes in temperature; proteetors are especially valuable in the tropies, where diarrhœal diseases should be prevented as much as possible, on account of their possible serious and fatal results. The abdominal band, commonly called also "cholera belt," encircles the whiole of the lower part of the body. The flannel apron protects only the anterior part, and is fastened with a tape around the waist.

The "kummerbund" is much preferred by many. This is a common article of dress among the natives of hot Eastern countries. It is a broad fold of eloth, wound tightly five or six times about the waist, for the protection of the lower part of the spine from the sun's rays, and to aet as a support to the back and loins. It is made of silk or eotton, or a mixture of the two, in lengths of ten to fifteen feet and about twelve to eighteen inches in width. To put it on, one needs the assistance of a companion. It is folded onee lengthwise, so that its breadth is reduced a half and its thickness doubled, and then, while stretehed taut, one end is placed in position and held there, and the person turns the body round rapidly until the full length is wound off, when the end is carefully fastened, so that it may not work loose.

These protectives of the abdomen prevent the evaporation of perspiration and chilling of the abdomen; without them, diarrhoa is likely to be induced by slight causes.

Water-proof blankets of rubber or other material are very important as a protection against rain or soil moisture. When obliged to ie on damp ground, they are a great protection. In the tropies, at eertain seasons, the rainfall is exceedingly heavy and makes the use of some form of water-proof overeoat necessary ; but since these are very hot, it is important to obtain them of as light a material as possible without saerificing lightness to durability. India-rubber 
itself cannot be worn habitually or for a long time, because of its eausing great diseomfort through retention of heat and perspiration. It is of much more value in the form of a blanket to spread on the ground than as an artiele of elothing. Cloth may be made waterproof by alternate dipping into solutions of aluminum sulphate and soap, or by thorough soaking in raw linseed oil and exposing to the sun until thoroughly dry.

Other articles issued during very cold weather for extra warmth include hoods, gloves, overshoes, and overeoats. The overeoats are unlined.

\section{The Soldier's Exercise and Work.}

Marching.-Since the most efficient army is that which has the greatest eapaeity to endure hardship, it follows that such an army can do the longest and best marehing. While the eivilian may regard daily walks of ten, fifteen, twenty, and more miles as no great strain on the system, the first-mentioned figure is aceounted good average travelling for soldiers on a long mareh, and the second for short movements; lout either of these figures may represent exceedingly good work by the best of men in some elimates and seasons and over some roads, or by raw reeruits in their first marches over the best of roads. 'This is not for a moment to be looked upon as evidence of the eivilian's superiority over the soldier as a walker, for the two perform the exereise under very different conditions.

The civilian, in the first place, walks alone or with a eompanion or two, at his own gait and aceording to his own will. He may vary his step and may rest at his pleasure; he carries no greater burden than a walking stiek, and may suit himself in the matter of dress and in the manner of wearing it. The soldier, on the contrary, is one of a large body proceeding somewhat stiffly at a pace set by one in command and not alterable at will. He carries his arms, aceontrements, and all his belongings, and, perhaps, his rations for a number of days, and is hampered by strapss and elothing which interfere with free eirenlation. He rests when ordered, may be halted, without resting, with annoying frequeney, and may "march at ease" only when, in the judgment of the commanding officers, this is practicable. At one time, he is moving with exasperating slowness on aceount of obstacles ahead, and again, is hurrying to eatch up with those gone before. Moreover, his marching ground is ehosen for him, and his miles are either through dust or mud, for a soil so damp as to give off no dust is speerlily converted to mud by the impress of many feet. Therefore it is, that the soldier's 10 miles represents much more physical exertion than the civilian's 20, and his 15 miles much more, all things considered, than 50 per eent. increase over his 10 . Foreed marehes of 25 miles and longer are very exhausting, and cannot be kept up for more than a very short time.

One of the most notable instances of long distanee marehing in a few 
hours in recent times is that of the city of London Imperial Volunteers who, in South Africa, in August, 1900, covered 30 miles in 10 hours hoping, according to a despateh of Lord Roberts, to prevent General DeWet from erossing the Krugersdorp-Potchefstroom railway. The celebrated march of Lord Roberts from Kabul to Kandahar, in 1880 , over very rough country, was performed in 23 days. The longest day's marches were 20 and 21 miles, and the average distance covered was nearly 17 miles.

Among the best known long marches are several by United States troops, who hold the record for long distance continuous marching. In 1859, for example, a regiment of infantry marched from Fort Leavenworth, Kansas, to a point in California, a distance of 1,800 miles in 190 days, 28 of which were given up to resting, so that in 162 days of actual marching, an average distance of a little more than 11 miles was traversed. In 1860, a portion of another regiment went from Camp Floyd, Utah, to Fort Buchanan, New Mexico, a distance of 1,000 miles in 140 days.

In the Franco-Prussian War of 1870, a company of French chasseurs marched, in very inclement weather, over an exceedingly difficult road, for 41 hours, with one rest of an hour, another of two and a half hours, and halts of 8 minutes in each of the marching hours. The exact distance marched is not known, but the instance is cited as one of exceptional endurance and hardship.

In our army, ordinary and quick marching call respectively for 90 and 120 steps of 30 inches each per minute, or slightly over 2.5 and 3.4 miles per hour. Double time, which is quickly exhausting, calls for 180 steps of 35 inches each per minute, the equivalent of nearly 6 miles per hour; it can be sustained for not longer than 2 miles by more than average good troops. With the weight carried, 30 inches per step is quite sufficient. In the French army, 2.5 miles per hour are considered good average marching, beginning with 120 steps per minute, increasing gradually to 125 and 135, and returning during the second half hour to the original rate. The Euglish quick-step is the same as ours; the "double quick" is less than ours in length and frequency-33 inches, 175 to the minute. The German step is between 31 and 32 inches, and 114 to the minute; the Austrian and Italian, 29 inches, 120 to the minute; the Russian, 28 inches, 120 to the minute. From the above, it will be observed that in none of the great armies of the world is the marching rate equal to that of the active civilian when out for an exercise walk.

Every soldier is obliged to earry, besides his arms and accoutrements, certain necessary articles, the aggregate weight of which is variable, but always considerable. In the carrying of this weight, great eare is necessary so to dispose it that it shall not be over-burdensome or detract from his effieiency. In all services, the reduction to a minimum of the weight to be carried is a matter of great importance, but the disposition of the weight is, perhaps, of greater importance, for 
considerable harm may be induced by interference with respiration and circulation by pressure from the necessary straps across the chest and under the arm-pits. Under favorable circumstances, his impedimenta, with the execption of arms and cantecn, may be transported for him, the result being not only greater covering of ground with less strain, but great conscrvation of efficiency. In adjusting weight, eare should be taken to avoid compression of the chest as much as possible and to equalize the distribution so as to avoid fatiguing any one set of inuscles unduly.

The German infantry soldier is more heavily equipped than the British or Ameriean, the total load execeding 70 pounds, of which his clothing, exclusive of the heavy polished leather hemlet, accounts for nearly 24 pounds, and his arms and equipments, filled water-bottle, and entrenching tools nearly 43 pounds, the remainder being rations and sundries. His kit is carried in a leather knapsack, around which his rolled overcoat is fastened, and to the back of which his camp ketthe is strapped. The Russian soldier also carries more than 70.pounds; the Italian, abont the same; the French, between 65 and 70 , and the Austrian, about 60 pounds.

The blanket bag, which was substituted for the knapsack in our army in 1882 and abandoned after twenty years' use, is more oppressive than the blanket roll; but the blanket roll is also oppressive, since, being carried across the body from one shoulder, with the ends tied together, it impedes the movements of the chest. Morever, its use involves a eertain degree of inconvenience, since when the blanket itself ${ }^{\circ}$ is in use, the articles contained must be cared for in some other way. Other devices to take the place of blanket rolls and knapsacks are in use, and meet with different degrees of approval. The one most highly commended neither impedes respiration or circulation, nor involves contact with the back and consequent shutting out access of air. The weight is supported chiefly by the hips.

With new levies, the first marehes should not exced a very few niles, the distance being increased gradually day by day, until they become well seasoned, with occasional days, not including Sundays, set apart for rest and reereation. When thoroughly seasoned, there is less friction, and with greater experienec, comes inereased efficiency. It takes but a short time for new soldier's to learn not to attempt to carry unnecessary articles, which, at first, they are invariably prone to look upon as essential to comfort and pleasure.

Cavalry and infantry should march separately if possible, and in as open order as practicable, in order to avoid erowd-poisoning, which is a consequence not alone of indoor overerowding, but also of elose aggregation of men in the open air.

If possible, marehing by night and in the hottest part of the day should be avoided, for in hot weather the men are easily exhansted by exercise in the blazing sun, and since they ean get no sleep during the day, they need the night hours for their proper rest. The early morning hours are the best for marehing, as for other forms of work, the 
men being then at their best; but unless absolutely necessary, their sleep shonld not be broken before the usual time, since what is thereby gained in distance is more than lost through the interruption of necessary sleep. Before starting, a light breakfast, including hot eoffee, should be taken.

During the first hour, the pace should be fairly slow, and when two miles have been covered, there should be a halt of at least a quarter of an hour, during which the men should attend to calls of nature and throw off their loads and rest at full lengtll. When the mareh is resumed, the distance to be covered may be lengthened by a half mile, and when this distance has been traversed, there should be another halt of about the same length as the first. After this, the rate may be increased to three miles per hour with a halt of ten minutes in each hour, and this rate is sufficiently fast, exeept for foreed marches. The halt in the middle of the day for dinner should be of several hours' duration, so that the men may have a good rest, avoid heavy work direetly after a hearty meal, and look after the condition of their feet. As it is unsafe to eat heartily or drink copiously while greatly fatigned or overheated, a reasonable interval should be allowed before dinner.

Halts due to aceidental ciremustances are very trying to patience and strength, and when their probable duration can be determined, this should be communieated down the column, in order that, if the interval is to be of sufficiently long duration, the men may have the advantage of resting, rather than stand with their arms, losing patience and temper. Since, also, irregular rate of movement is fatiguing and annoying, minor obstacles, such as mud and water, should not be allowed to interfere with regular progress. Music of all kinds is very invigorating to marching men; band musie, fife and drum, the drum alone, and singing. In the continental armies, singing is much encouraged, as it keeps up the spirits and gives a rhythm and swing to the mareh.

If the weather is hot, men should be allowed to promote evaporation of perspiration by opening their coats or blouses; otherwise, water is lost from the body without performing its function of redueing the body-heat. To avoid excessive thirst, a full drink of water should be taken before starting. The eanteens should be filled with water or cold tea for use during the day ; but free drinking on the march is not to be advised, since it tends to beget constant thirst. The mouth should be kept elosed as mueh as possible during the march, and the sensation of thirst ean be eontrolled by holding a smooth pebble in the mouth or elrewing a green leaf. Simple occasional moistening of the mouth is better than free and frequent drinking.

In case of exhaustion by excessive loss of fluid by perspiration, drinking on the march is necessary ; lut under the usual conditions, the canteen should be used only at meals and near or at the end of the day's mareh. Another reason for abstaining as much as possible from drinking is the uncertainty of supply, for no dependence can be placed on 
the probability of refilling the canteen during the day's march. Hence, each man should conserve his supply as though he were certain that no more is to be had before the day's destination is reached. The amount carried may be kept fairly cool by wrapping the canteen in a wet cloth, the evaporation from which causes pereeptible lowering of temperature. A little vinegar or lime juice, if obtainable, added to the water, gives it a relish and helps to allay thirst.

"In many parts of the West, water is so searce that judicious management is required to forward troops over the route. Some camping-stations having only enough for one or two companies, the command, if larger, must pass in detachments. Or it may happen that the distance between the nearest water-supplied sites is too great to be marched without rest, in which case a dry camp must be formed at some intervening point. The passage of the Gila Bend Desert, 35 or 40 miles from water to water, is usually effeeted by making a night march of 25 miles, when the troops go into camp to rest for a few hours before resuming their journey, and to have coffee issued from a water-supply carried in the wagons." (Smart. ${ }^{1}$ ) On arriving at a camping-place, the water supply should be immediately guarded to prevent pollution and trampling of the margin. If the supply is small, the guard should be doubly efficient. If the supply presented is a small and shallow stream, it may be well to make small reservoirs by means of temporary dams, one for drinking-water for the men, another below for the horses, and another for bathing and laundry purposes.

Straggling should be prevented as much as possible, since it is a very serious evil to the morale and efficiency of the body as a whole. If straggling becomes considerable, the column should be halted until the straggless can overtike it, else they will get no rest, sinee the hourly intervals for rest must be utilized by them in coming up, and the column is, perhaps, already in motion again. Those claiming to be sick or unable to march should be examined by the medical officers, who will separate the really unfit from the malingerers; the former are given careful transportation ; the latter, disposed of according to their deserts.

At the end of a day's marehing, the men should be dismissed as soon as possible, and they should be careful to guard against becoming chilled through reckless removal of elothing, and should again look after the condition of their feet and persons.

On long marches, an oceasional day should be taken for complete rest and reenperation, otherwise an incvitable diminution in efficieney will be oceasioned. Woodhull eites an interesting instance of overmarching in the Franeo-Prussian War. The German Garde-Corps, consisting of 30,000 infintry, left the Rhine on August Bd, lost lesis than 9,000 in action, and on September $2 \mathrm{~d}$, the day after Sedan, numbered 13,000 for duty. On September 19th, they reached Paris with but 9,000 men,

1 Buck's Hygiene and Public Health, New York, 1879, Vol. II., p. 119. 
more than 11,000 having been broken down by exertion, little actual siekness having oecurred.

Care of the Feet on the March.-If good marchers make the best soldiers, it follows that the possession of the best soldiers is largely dependent upon the condition of the feet, and, therefore, it is ineumbent on the line officers and medieal corps to see that the individual men are properly instrueted in their care, and that they are faithful in performance. The footsore man, so far as efficieney is eoneerned, is a sick man and becomes the equivalent of baggage. He cannot mareh, and suffers pain when at rest. Nearly all new men not aceustomed to marehing are likely to suffer from excoriations across the toes, on the insteps and malleoli, and on the back and sides of the heels. This is due to friction, and, if attended to at once, may be prevented from becoming serious.

The application of strips of adhesive plaster of generous size to the affected parts will afford the same protection as is given by a leather glove to the hand engaged in any frictional work. Blisters shonld not be opened, except by a minute puneture at the edge; after the fluid has oozed away, the spot should be protected with adhesive plaster. The extensive opening of a blister permits aecess of air to the sore area beneath, and the stimulation therefrom is very active and painful. Men should be instructed to trim their toenails square across and not too elose.

Before marehing is begun, all men with any soreness of the feet should report themselves and be examined, and at the end of the day, if not before, they should be regularly inspected. Men unused to marehing will often find greasing or soaping the feet and stoekings an excellent prophylactic against soreness. A neutral grease like muttontallow is preferable to soap, since sometimes it happens that the latter assists the perspiration in macerating the cuticle. If the boots are made supple with grease, they tend less to cause soreness, and, in addition, are rendered waterproof. An excellent plan for officers and others who can afford them, is to wear silk stockings under the ordinary socks, especially when the feet are naturally tender. The feet may be toughened by being soaked in warm strong solutions of alum or common salt. Zine ointment, containing 5 per cent. of tannin, is also very useful. Salicylated tale (tale 87 , stareh 10 , salieylie acid 3 parts by weight) is used in the German army both on the mareh and in garrison. It is sifted from a dredging-box into the shoes and over the feet.

If the soreness is due to the stockings and not to the shoe, it is often advantageous to ehange them from one foot to the other, or to put them on inside out. Some of the continental armies use bandages in place of stockings, and some use neither, substituting therefor a liberal coating of grease. Soreness is due often to neglected bunions, corns, both hard and soft, and infleshed nails. These troubles need speeial treatment. In the British army, the authorities have caused a number of the non-commissioned offieers to be instructed in chiropody, and the 
suecess of the experiment has made it probable that a permanent corps of trained chiropodists will be established for the infantry.

During the long halt at midday, each man should remove his shoes and stockings, and, if water is to be had in abundance, he should remove the acria perspiration and dirt from his feet by thorough washing, paying particular attention to the surfaces between the toes, where excoriations and soft corns are prone to appear. Dusting-powder or zine ointment on absorbent cotton may be applied, if advisable, between the toes. The feet should be made quite dry before the stockings are again drawn on. If water cannot be obtained in sufficient amount, wiping with a dry or moist cloth will be found to add materially to comfort, and is much to be preferred to long soaking, which, by softening the cutiele, assists the formation of blisters. At the end of the day, the feet should be washed and the stockings changed; those removed should be washed as soon as practicable and dried during the night.

Care of Other Parts.-Not uneommonly, soldiers, especially raw recruits, are much inconvenieneed and annoyed by chafing at various points, particularly on the inside of the thighs and between the nates. This is promoted by perspiration and restrained by dusting-powder, zine ointment, vaseline, and eleanliness. Woodhull advises against washing the face and neck in the morning while on the march, because the removal of the natural secretion makes the skin more susceptible to the influence of heat and dust. He recommends washing the eyes and mouth, and merely wiping the face and neck with a damp eloth. At night, the face, neek, and whole body should be washed, if possible; but, foremost of all, the head, armpits, feet, and genitals and adjacent parts.

Care should be taken that the bowels are not neglected while on the march, any more than while in garrison. If purgatives are required, those given should be mild in charaeter, and not such as may require repeated operations at short intervals.

\section{The Soldier's Food; "Rations."}

The word "ration" is understood commonly to mean the amount of food issued to each soldier for a single meal. This, however, is far from being the truth. Under the regulations, "a ration is the allowance for sustenance of one person for one day, and consists of the meat, the bread, the regetables, the coffee and sugar, the seasoning, and the soap and candle components." Enlisted men and hospital matrons, and, when the circumstances of their service make it necessary, civilians employed by the army, each draw one ration each day. The ration is not necessarily the diet, since parts of it may be exchanged for other things or for the cash equivalent with which to buy them. It is fixed by law, and can be changed only by legislative enaetment.

The different artieles composing the ration for troops in garrison or in permanent eamps, excepting in Alaska, and their amounts, are as follows : 
Garrison Ration. ${ }^{1}$

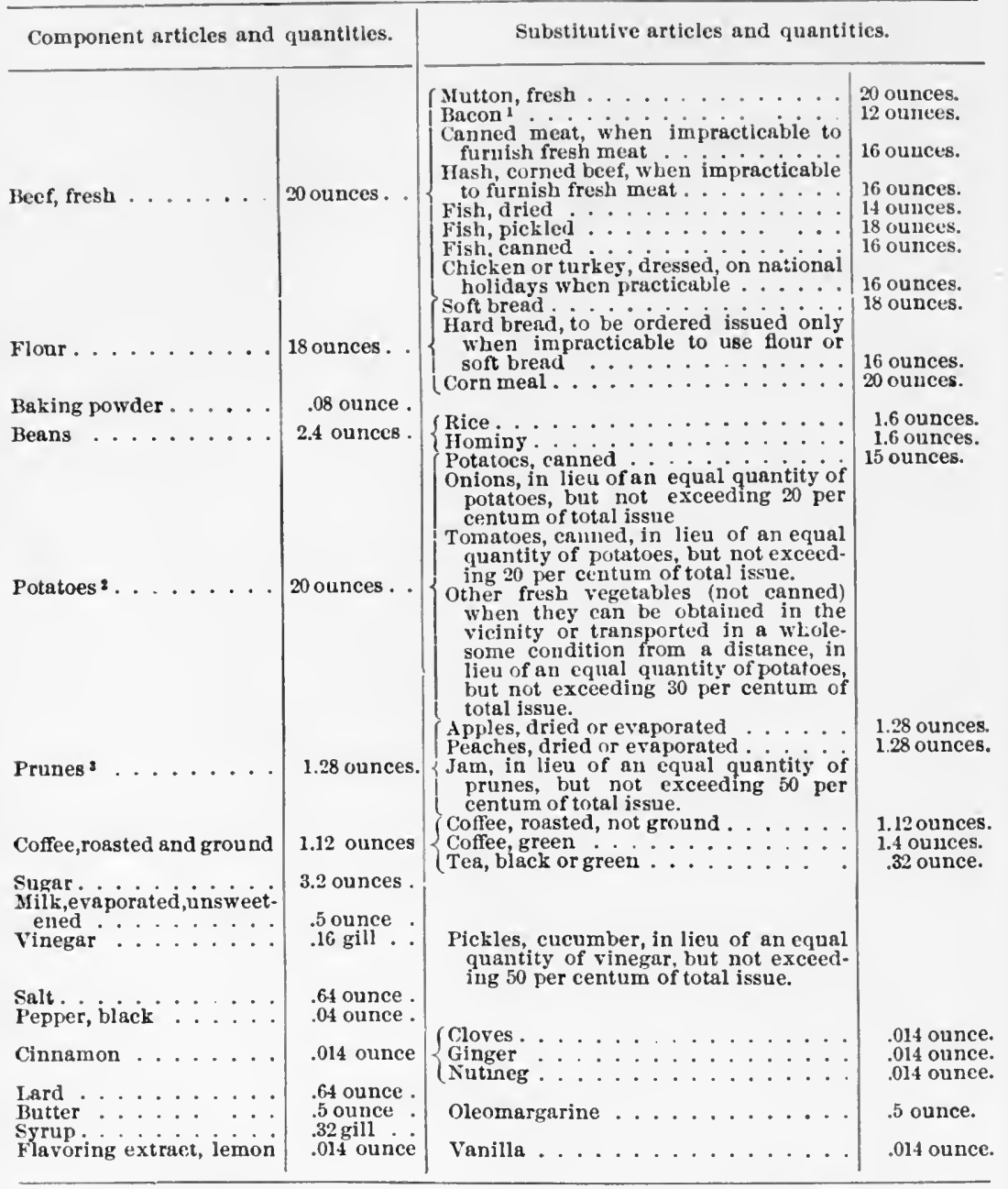

1 In Alaska 16 ounces baeon or, when desired, 16 ounces salt pork, or 22 ounces salt beef.

2 In Alaska the allowance of fresh vegetables will be 24 ounces instead of 20 ounces, or canned potatoes, 18 ounces instead of 15 ounces.

At least 30 per centum of the issue to be prunes when practicable.

NoTE.-Food for troops traveling on U.S. Army transports will be prenared from the articles of subsistence stores which compose the ration for troops in garrison, varied by the substitution of other articles of authorized subsistence stores, the total cost of the food consumed not to exceed 24 cents per man per day.

The ration issued to troops in the field in active campaign is the same in amount, but is somewhat less elastic. 'Thus, the various forms of fish are eliminated, as also are peas and hominy, and when potatoes are not procurable locally the desiecated form is served. The fruit component consists of eanned jam (1 $\frac{2}{5}$ ounces).

${ }^{1}$ General Orders No. 47, War Department, Washington, April 3, 1908, Paragraph 
Field RAtion.

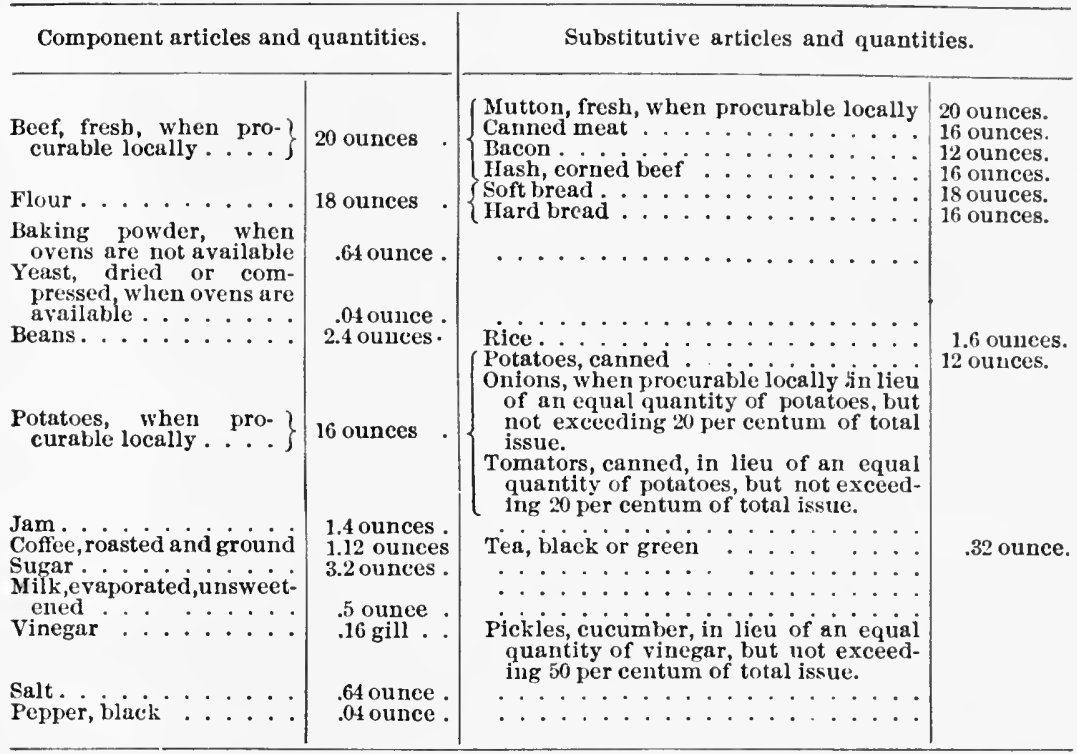

What is known as the "travel ration" is issued in place of the ordinary ration "when troops travel otherwise than by marching, or when for short periods they are separated from cooking facilities and do not carry cooked rations." It consists of the following articles and is issued in the amounts stated, per hundred rations :

Travel Ration.

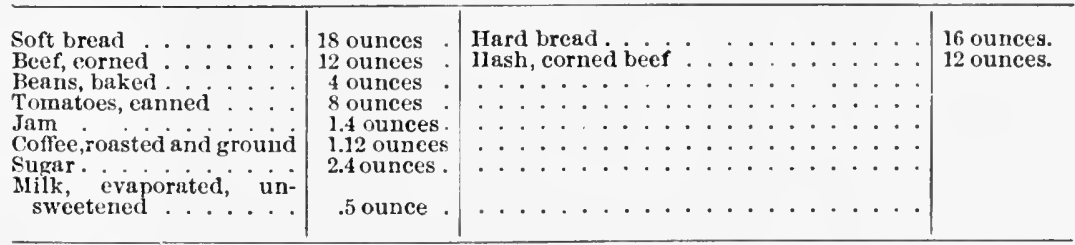

On arrival at their destination the ordinary ration is resumed. The haversack ration is as follows :

Haversack Ration.

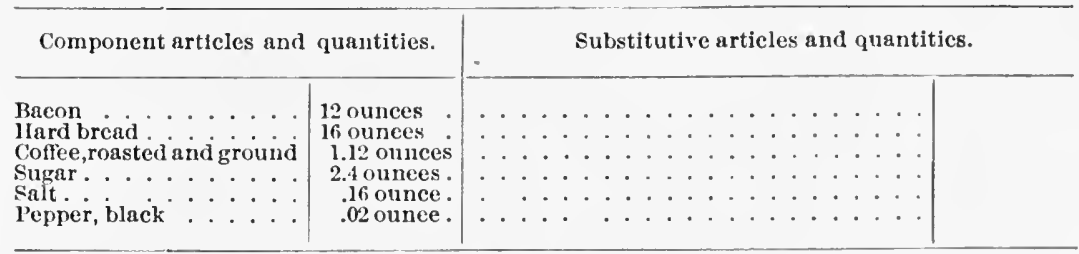

When travelling unaccompanied by an officer, each man may be allowed a cash sum per day for the purchase of liquid coffee in place of the coffee and sugar portion of the travel ration, 
An "emergeney ration," now being tested by the War Department, but not yet definitely adopted, owing to the fact that a suffieient time has not elapsed since its preparation to determine its keeping qualities under all conditions of serviee, is composed of the following :

$\begin{array}{rll}45.45 & \text { per cent. } & \text { clocolate liquor, } \\ 7.27 & \text { " } & \text { nucleo-casein, } \\ 7.27 & \text { malted milk, } \\ 14.55 & \text { " } & \text { egg-albumen, } \\ 21.82 & \text { " } & \text { powdered cane-sugar, } \\ 3.64 & \text { cocoa butter. }\end{array}$

Percentage of moisture not to exceed 3 per cent.

"Each ration weighs 8 ounces net and is put up in three eakes of equal size, each eake wrapped in tin-foil, and all three inclosed in a hermetically sealed, round-cornered tin, with key-opening attachment." 1

Abroad, the well-known pea sausage, consisting of pea flour and fat pork, is mueh used in the emergency ration. This, mixed with hot water, makes a very good soup, but soon proves to be eloying. Meat biscuits and dried meats also are much used.

It will be observed that the ordinary ration is fairly flexible as it stands, but it may be made more so by exchanging articles not wanted. It is established by law, but is not necessarily the daily dietary. Thus, the various articles (excepting the fresh vegetables, bread, and bakingpowder) not needed for eonsumption may be purchased by the commissary as savings at the invoice prices. "Savings and sales of fresh beef (exeept of that issued for the sick in hospital, the detachment of the hospital eorps, and the hospital matron serving therein) are prohibited," ${ }^{2}$ but the fresh meat allowance may be reduced in amount and its money value drawn in other things. For each ration of flour turned in, the eompany is entitled to one ration of bread or the price of one flour ration.

In many permanent eamps, gardens may be cultivated and a supply of fresh vegetables thus obtained both for immediate and future use. Commutation for these is allowed at the prices of potatoes and onions in the vicinity or in the market from which supplies are derived, in the proportion of 80 per cent. of potatoes and 20 per eent. of onions. The amounts of money from all sources form the company fund, which is disbursed by the eompany commander solely for the benefit of his own men.

Fruits and vegetables are very essential in the dietary, on aceount of their antiscorbutic properties. The most valuable of the antiseorbuties is held commonly to be lime juice; the juice from the fresh limes is superior to the bottled article. Lemons are of about the same value as limes. Among vegetables, potatoes, onions, and cabbage take high rank. The legumes are devoid of antiseorbutic properties. Aceording to Woodhull, the best antiseorbutic is the 1911.

${ }^{1}$ Personal communication from Henry G. Sharpe, Commissary General, Jan. 10,

${ }^{2}$ Army Regulations, p. 180. 
agave. "To prepare it, cut off the leaves close to the root, cook tuem well in hot ashes, express the juice, and drink, raw or sweetened, 1-4 wineglassfuls three times a day. The white interior of the leaves may be eaten.". The dried vegetables and fruit are less valuable than the fresh, and should be allowed to supersede the latter only when these cannot be obtained, but they are far superior to compressed vegetables, which, in the process of compression, lose much of their salts and a portion of their proteids. Dried vegetables should be soaked well in water before use, else they may cause digestive disturbance and diarrhœa.

Alcohol in the Ration.-The question of the advisability of including a spirit allowance in the ration has been the subject of much careful consideration in all countries, and has been answered with practical unanimity in the negative. But there are times when a single issue of spirits, or repeated issues according to circumstances, may be useful and even necessary. Thus, on a forced march, when exhaustion is great, a stimulant may be of very great necessity, although it is said that hot tea, if time admits of its preparation, may be equally or still more serviceable. When given at all, spirits should be taken well diluted, and never in concentrated form.

During the Civil War, a daily issue of a gill of whiskey to each officer and man of the Army of the Potomac was ordered, half to be given out in the morning and half in the evening. This was brought about by the fact that for several weeks the men had been subjected to unusual hardships and extra duty, and were breaking down under the strain. The issue, which was to continue "until further orders," was grected with enthusiastic appreciation of the farsightedness of the authorities responsible for it. "Until further orders" proved to be exactly one month, and hot coffee was substituted for the whiskey, the issue of which was ordered to be "immediately discontinued." During the month, the general condition of health of the troops was not only in no way improved, but became markedly worse, while drunkenness, with its attendant evils, became much more common.

Concerning the use of beer and light wines, a very different opinion is held by many of those best qualified to judge by results observed. In several of the great armies of Europe, an allowance of light wine is customary, and it seems reasonable to suppose that where the importance of a large standing army is so great, alcohol in this form would not be issued, were it not upon the belief, based on long experience, that, directly or indirectly, it is a benefit, and not an evil. A little light wine at the close of a day of hard work, but not before or during its performance, appears to be recuperative and restful, either in the usual strength or diluted with water. In this country, the so-called canteen system is believed to have been productive of a distinct gain for temperance among the soldiers; and by temperance is not meant total abstinence.

The canteen is a place at a military post where small wares, little 
luxuries, tobacco, and the lighter alcoholic drinks may be purehased under close supervision, so that abuses cannot occur. There is no inducement held out for the men to buy drink, and what is sold must be consumed on the premises. What small profit is derived goes to the post exchange, which, besides the canteen, comprises a general store, a linch counter, recreation rooms supplied with reading matter, and a gymnasinnı.

It is believed that the eanteen system, before its abolishment, had worked out the solution of much of the problem concerning drunkenness in our army. The soldier acenstomed in eivil life to the use of beer was enabled to obtain it in a decent way and only to a reasonable extent, and hence had no temptation to seek alcolol in, perhaps, stronger forms elsewhere and not under supervision. He was more likely to remain habitually sober, instead of being occasionally helplessly drunk and eommonly in difficulties. It is said that the order of things that obtained on pay day under the old system had been very largely abolished. Then, pay day was a source of satisfaction to nobody but the saloon-keepers, who sold bad liquor at high rates; men were absent days at a time without leave; courts-martial were busy, and there was much guard-house service. Those who have studied the matter, regard the canteen as the friend of decency and discipline, and the enemy of every saloon near a garrison. Naturally, the saloonkeepers and that elass of reformers who believe in the possibility of bringing about radical ehanges in human nature by legislation, beeame violently opposed to the continuance of the system; and, indeed, the latter were so suecessful in their agitation against it that, in spite of the practical unanimity of the officers of the army of all grades in its favor, it was abolished by Aet of Congress in January, 1901.

Preparation of Food.-The art of eooking is a very valuable accomplishment of a soldier, especially when on active serviee. In eamps, cooking is done by persons enlisted for that purpose, one cook being allowed by law for each company, troop, or battery. On application, he must first pass the regular examination of a reernit, and then one in which he must demonstrate his knowledge of methods and skill in caring for, preparing, and serving food. Kitchens are placed under the immediate charge of non-commissioned officers, who are held responsible for their condition and for the proper use of rations. Only those employed or those on duty are allowed to visit or remain in the kitchens. The general supervision of the cooking and messing devolves upon the company commanders, who are charged to exereise personal care and judgment to prevent waste and nuisance, and to see "that suitable men in sufficient numbers are fully instrueted in managing and cooking the ration of the field," since when the conveniences for cooking on a large scale are not at hand, it becomes necessary for men to divide into small squads and prepare their own meals.

The baking of bread is carried on in post bakeries, under the charge of enlisted men detailed as ehief and assistant bakers. Baking by companies at posts is expressly prohibited, but is the rule in temporary 
camps and with marching columns, portable ovens of various kinds and barrel ovens being employed. The barrel oven is best made with a barrel with iron hoops, which is placed on its side, covered eompletely with elay or stiff mud, except at its open end, and then with a thick layer of dry earth, leaving, however, a small (3-inch) opening at the top of the inner end to serve as a flue. A fire is made in the barrel and kept up until all the wood is burned, leaving an oven of clay, for which the hoops act as a support.

In the field, on account of transportation, it is necessary that cooking appliances should be as simple and economical of space as possible. The greater the amount of baggage, the greater the number of wagons necessary; the greater the number of wagons, the greater the number of animals and the greater the amount of necessary forage.

Comparison of the United States ration with that of European countries demonstrates that ours is, in most respects, the most liberal ration in the world. In only one instance is there a conspicuous superiority in the amount of an important constituent; namely, the very generous allowance of potatoes in the German ration. Not only is the U. S. ration the most abundant, but it admits of greater variety than any other. But even at that, it is held by many to be insufficient in amount for the proper performance of the work a soldier may be called upon to perform. Experts in the making of dietaries have proposed increasing the flour and soft bread allowance by about a fourth, and adding about 5 ounces of flour to the alternative allowance of hard bread and 20 per cent. to the alternative allowance of corn meal, with a reduction of 40 per cent. in the allowance of potatoes, and the alternative of money value in milk or cheese in place of the allowance of peas or beans.

In the consideration of the question of quality and variety, it should be borne in mind that, while it is necessiry to have a standard of food value fixed by law, it is not neeessary to consume precisely the articles named. Nor is it possible to fix a money value to the ration, and give out the eash equivalent in place of actual food, for the soldier is not always near a market, and, moreover, if he were, it is most evident that the same amount of money in different places would yield very different amounts of nutriment, since in one, the food supply is abundant and cheap, and, in another, scanty and expensive. What the soldier eats, depends upon eireumstances, and largely upon the diseretion of company commander's guided by the advice of the medical officer's, but, as said before, the aetual food vilue is fixed by Congress, and is based on the experience and study of many years.

Is the United States Ration Suited to the Tropics? - The question of the suitability of our ration to the tropies is one which las assumed great importance since the necessity arose for maintaining latge armies in our new possessions, and its diseussion has been marked by a much more temperate tone, and has, therefore, yielded better results. The beginning of the discussion may be said to have arisen from the fict that it beeame generally understood that bacon was a neessary 
constituent of the daily food, both in camp and in active operations, instead of an alternative, as may be gatherod from the wording of the statute-fresh beef, or fresh mutton, etc., or pork, or bacon, or salt beef, or dried fish, or pickled fish, or fresh fish. Bacon has its advantages at certain times, but is not eagerly sought after by those not in good health, nor is it acceptable in very hot elimates as a regular diet any more than any other fatty food. Fats are much needed in cold climates for the production of heat; in hot climates, the necessity for their use is but slight in comparison. But when fresh meat eannot be obtained either on the hoof or from cold storage, and when the appetite is cloyed by canned meats (and this is soon brought about), bacon is acceptable as an oceasioual substitute.

To those at a distance and unaequainted with local conditions, the ideal supply of fresh meat is eattle on the hoof. But the cattle of the tropics are not the same as those which we know, nor are they always to be had in even small numbers. Sending live cattle from home, to be driven along on the march to be killed as needed, is not always practicable, for even if landed in good condition, they eannot be kept on the march, and, unless the country traversed is good grazing land, they lose weight and die off rapidly. Canned meats are much inferior to fresh meats, and cannot long be eaten with relish. The canned socalled roast beef is commonly the residue of meat after the extractives have been boiled out of it for the manufacture of meat extract, and it is, therefore, lacking in flavor, although not materially diminished in nutritive properties. It is often as tasteless and almost as difficult to chew as towelling, and is far from inviting in appearance, especially when the cans are opened at ordinary hot summer temperature.

According to many experienced minds, the consumption of meat in any form should be much limited in the tropies. Roquemaure ${ }^{\mathrm{i}}$ advises the European in the tropics to take nothing into his stomach, except articles easily digested; mutton, beef, and pork only in moderation, and not too thoroughly cooked, and not regularly or too often; birds, eggs, and fish are more to be commended; especially to be relied upon are rice, dried vegetables, fresh vegetables, starchy foods, and ripe fruits in good condition. Kollbrügge ${ }^{2}$ places above all other influences in the deterioration of Europeans in the tropies the too extensive use of animal fats, which, he claims, are responsible for much of the diarrhœal troubles of the tropies. He recommends the regetable oils for supplying what fats are needed by the body.

The observations of Dr. L. I. Seaman, ${ }^{3}$ in Porto Rico, lead, in part, to the same conclusion. He relates that, within a week after landing in the summer of 1898 , in spite of the strictest sanitary precautions and personal hygiene, the entire foree with which he was connected suffered from some form of intestinal catarrh from one cause and another, and that medication was of no avail, since the diet of bacon,

1 Hygiène alimentaire aux pays ehands, Bordeaux, 1895.

2 Die Acclimatisation der Europüer in den Tropen: Deutsche medicinische WochenEehrift, 1898, Nos. $_{2} 7$ and 28.

${ }^{3}$ New York Medical Journal, March 18 and 25, 1899. 
salted beef, canned beans and pork, and hardtack proved to be a continual irritant, by which the troubles were aggravated and the power of resistance much reduced. Under such eonditions, malaria and typhoid fever gained a foothold in the system with much ease; first eame the malarial fevers of the various types, and, in the early part of September, on the introduction of the germs from Tampa and Chickamauga, typhoid fever broke out, and, spread by flies, continued with varying severity until embarkation for home in November. The value of a milk-diet was emphatically demonstrated.

Koerfer's ' recommendation to Europeans, to leave their pork fat, meats, and alcohol at home with their heating stoves and furs, when they go to reside in the tropies, is quoted in eonfirmation.

While the use of green vegetables is universally recommended in the tropies, it is not always easy, and, in faet, it is often extremely difficult or impossible, to obtain them, since the natives of the tropies are commonly content to live on rice, dried beans, and fruit, with an oceasional taste of fish or meat. Canned vegetables, while gritteful to the system, are not wholly to be recommended, on aceount of transportation. A can of string beans, for example, contains a maximum of water and a minimum of nutriment, and for its real service in the dietary may be said to be hardly worth its eost of earriage. Dried vegetables and fruits are more economical, but should be well soaked before use.

The Court of Inquiry, appointed to investigate the food supply of the army during the war with Spain, reported among other eonclusions the following: "As to the effects of the food supply, having regard to sufficieney and quality, it seems to be clearly established that the army ration as supplied, without modification, to the troops serving in the West Indies was by no means well adapted for use in a tropical climate. If this be true, the unfitness of the ration should have manifested itself by its failure to keep the troops, who subsisted upon it, in the best possible condition for service in hot elimates. This, in the opinion of the eourt, is fully established in evidence." Seaman advocates a reduction in the meat components, the use of salted meats not oftener than twice per week, and an inerease in the allowance of vegetable and farinaceous foods and dried fruits.

Dr. Elward L. Munson, U. S. A., has studied the suljeet of tropical diet from the standpoints of physiologieal seience, availability, and practicability, and concludes that the articles of the ration are correct as they stand, being admirably seleeted and of good valriety, but need some rearrangement in their respective amounts. He proposes certain modifications, and offers four dietaries, the average of which is not widely variant from a proposed nutritive standard for soldiers in the tropies, as follows: Protein, 100 grammes; carbohyclrates, 650 ; fats, 65. (Nitrogen, 16 ; total carbon, 392 ; fuel value, :3, 491 ealories.)

1 Deutsche medicinische Wochenschrift, July, 1898.

2 The Ideal Ration for an Army in the Tropies. (Prize essay.) Boston Merlical and Surgical Journal, May 3, 10, 17, and 24, 1900 . 
Dietary I. contains the greatest amount of food material which may be drawn by the soldier :

TROPICAL DIETARY I.

\begin{tabular}{|c|c|c|c|c|c|c|}
\hline Articles. & $\begin{array}{l}\text { Quantity, } \\
\text { ounces. }\end{array}$ & $\begin{array}{l}\text { Fats, } \\
\text { grams. }\end{array}$ & $\begin{array}{c}\text { Carboby- } \\
\text { drates, } \\
\text { gramus. }\end{array}$ & $\begin{array}{l}\text { Protein, } \\
\text { grams. }\end{array}$ & $\begin{array}{l}\text { Nitrogen, } \\
\text { grams. }\end{array}$ & $\begin{array}{c}\text { Fuel } \\
\text { value, } \\
\text { calories }\end{array}$ \\
\hline 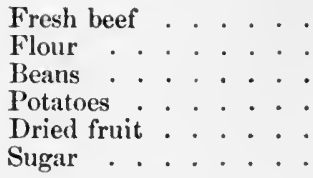 & $\begin{array}{l}10 \\
18 \\
2.4 \\
16 \\
3 \\
3.5\end{array}$ & $\begin{array}{r}44.75 \\
5.60 \\
1.22 \\
0.45 \\
1.53 \\
. \quad .\end{array}$ & $\begin{array}{r}380.46 \\
40.18 \\
81.70 \\
33.80 \\
94.25\end{array}$ & $\begin{array}{r}41.68 \\
55.08 \\
15.16 \\
9.50 \\
1.77 \\
. \quad .\end{array}$ & $\begin{array}{l}6.67 \\
7.90 \\
2.42 \\
1.52 \\
0.27 \\
. \quad .\end{array}$ & $\begin{array}{r}590 \\
1,850 \\
240 \\
380 \\
220 \\
397\end{array}$ \\
\hline Total ..... & 52.9 & 53.55 & 630.39 & 123.19 & 18.78 & 3,677 \\
\hline
\end{tabular}

Total carbon, 395.14 grams; nitrogen to carbon, 1 : 19.6.

Dietary II. is especially applicable to field service; in this, the fatty constituents attain their maximum and the potential energy is high:

TROPICAL DIETARY II.

\begin{tabular}{|c|c|c|c|c|c|c|}
\hline Articles. & $\begin{array}{l}\text { Quantity, } \\
\text { ounces. }\end{array}$ & $\begin{array}{l}\text { Fats, } \\
\text { grams. }\end{array}$ & $\begin{array}{l}\text { Carbohy- } \\
\text { drates, } \\
\text { grams. }\end{array}$ & $\begin{array}{l}\text { Protein, } \\
\text { grams. }\end{array}$ & $\begin{array}{c}\text { Nitrogen, } \\
\text { grams. }\end{array}$ & $\begin{array}{c}\text { Fuel } \\
\text { valne, } \\
\text { calories }\end{array}$ \\
\hline Bacon & 6 & 105.06 & & 15.64 & 2.49 & 1,042 \\
\hline Hard bread & 18 & 6.63 & 371.81 & 73.12 & 11.74 & 1,926 \\
\hline Beans . . & 2.4 & 1.22 & 40.18 & 15.16 & 2.42 & 240 \\
\hline Dried fruit . & 3 & 1.53 & 50.70 & 1.77 & 0.27 & 220 \\
\hline Sugar ..... & 3.5 & & 94.25 & . . & - & 397 \\
\hline Total . . . . . & 32.9 & 114.44 & 556.94 & 105.69 & 16.92 & 3,825 \\
\hline
\end{tabular}

Total carbon, 328.76 grams; nitrogen to carbon, $1: 23$.

Dietary III. is proposed for garrison duty :

TROPICAL DIETARY III.

\begin{tabular}{|c|c|c|c|c|c|c|}
\hline Articles. & $\begin{array}{l}\text { Quantity, } \\
\text { ounces. }\end{array}$ & $\begin{array}{l}\text { Fats, } \\
\text { grams. }\end{array}$ & $\begin{array}{l}\text { Carbohy- } \\
\text { đrates, } \\
\text { grans. }\end{array}$ & $\begin{array}{l}\text { Protein, } \\
\text { grams. }\end{array}$ & $\begin{array}{c}\text { Nitrogen, } \\
\text { grams. }\end{array}$ & $\begin{array}{c}\text { Fuel } \\
\text { value, } \\
\text { calories }\end{array}$ \\
\hline $\begin{array}{l}\text { Fresh beef } \\
\text { Soft bread } \\
\text { Potatoes and onions } \\
\text { Dried frnit } \\
\text { Sugar }\end{array}$ & $\begin{array}{c}10 \\
20 \\
16 \\
3 \\
3.5\end{array}$ & $\begin{array}{r}44.75 \\
6.80 \\
0.72 \\
1.53 \\
\cdot .\end{array}$ & $\begin{array}{r}299.20 \\
73.09 \\
50.70 \\
94.25\end{array}$ & $\begin{array}{r}41.68 \\
53.83 \\
8.60 \\
1.77 \\
.\end{array}$ & $\begin{array}{l}6.67 \\
8.61 \\
1.40 \\
0.27 \\
.\end{array}$ & $\begin{array}{r}590 \\
1,506 \\
340 \\
220 \\
397\end{array}$ \\
\hline Total . . . . . . & 52.5 & 53.80 & 517.24 & 105.88 & 16.95 & 3,053 \\
\hline
\end{tabular}

Total carbon, 328.76 grams; nitrogen to carbon, $1: 18$.

Dietary IV. is a combination of the several articles of the ration most closely approaching in eharacter the food materials used by the natives of the tropies, proportioned according to the proposed standard: 
TROPICAL DIETARY IV.

\begin{tabular}{|c|c|c|c|c|c|c|}
\hline Articles. & $\begin{array}{l}\text { Quantity, } \\
\text { ounces. }\end{array}$ & $\begin{array}{l}\text { Fats, } \\
\text { graus. }\end{array}$ & $\begin{array}{l}\text { Carbohy- } \\
\text { drates, } \\
\text { grams. }\end{array}$ & $\begin{array}{c}\text { Protein. } \\
\text { grans. }\end{array}$ & $\begin{array}{c}\text { Nitrogen, } \\
\text { grams. }\end{array}$ & $\begin{array}{c}\text { Fuel } \\
\text { value, } \\
\text { calories. }\end{array}$ \\
\hline 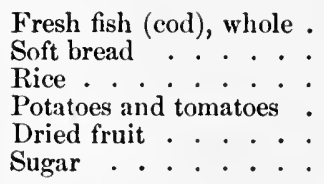 & $\begin{array}{c}14 \\
20 \\
4 \\
16 \\
3 \\
3.5\end{array}$ & $\begin{array}{l}0.79 \\
6.80 \\
0.45 \\
0.54 \\
1.53 \\
. \quad-\end{array}$ & $\begin{array}{r}299.20 \\
88.87 \\
65.80 \\
50.70 \\
94.25\end{array}$ & $\begin{array}{l}31.73 \\
53.83 \\
8.75 \\
8.17 \\
1.77 \\
. \quad \cdot\end{array}$ & $\begin{array}{l}5.07 \\
8.61 \\
1.40 \\
1.36 \\
0.27 \\
\cdot .\end{array}$ & $\begin{array}{r}120 \\
1,506 \\
407 \\
297 \\
220 \\
341\end{array}$ \\
\hline Total $^{1}$ & 64.5 & 10.11 & 598.82 & 104.25 & 16.71 & 2,947 \\
\hline
\end{tabular}

Total earbon, 327.50 grams; nitrogen to carbon, 1 : 19.6 .

The following table shows the mean nutrient composition of the four dietaries, and admits of ready eomparison of one with another :

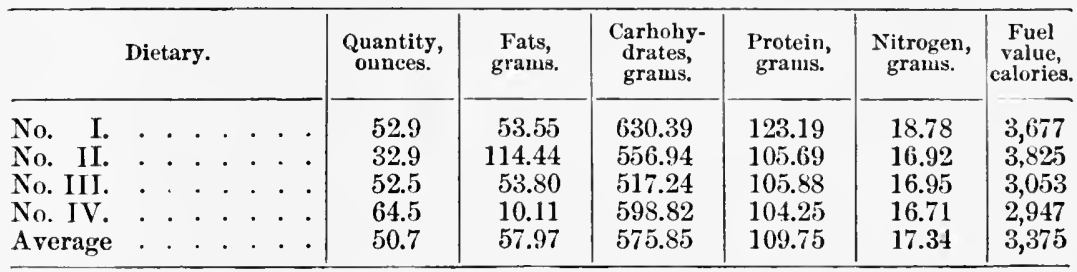

Total earbon, 350 grams; nitrogen to carbon, $1: 20$.

The so-called "Filipino Ration" is as follows : ${ }^{2}$

Filipino Ration.

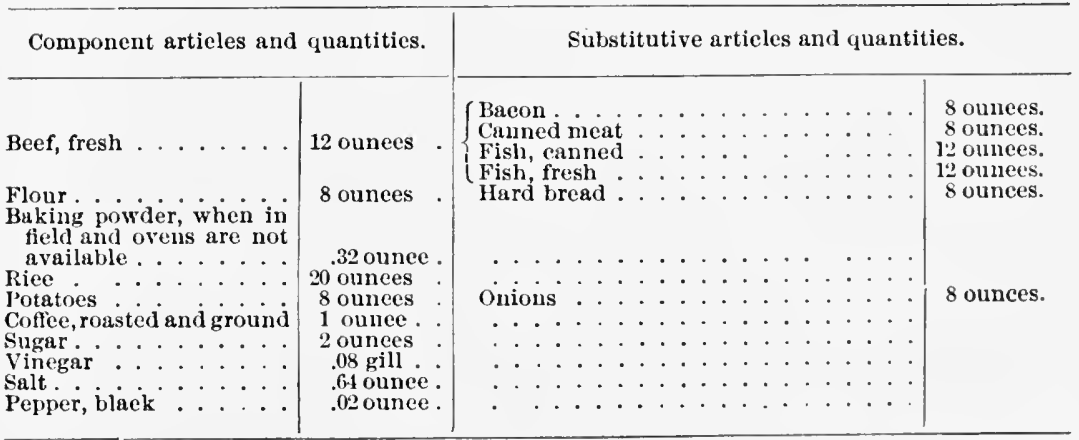

\section{Posts and Camps.}

Posts are permanent camps or those of position, and camps, in the usual sense, are temporary or incidental. At posts, the troops are housed in barracks, while at temporary camps they oceupy tents and

1 It will be noticed that the first and sixtl columns do not add up accorling to the totals expressed. 'The latter, however, being used in the table below, are retained unchanged.

${ }^{2}$ General Orders No. 47, War Department, Washington, April 3, 1908. 
huts. The same sanitary considerations apply equally well to both, but choice of location of temporary camps in time of war is determined commonly by immediate and strategical considerations. Both should be laid out in such a manner as to insure proper air supply, cleanliness,

FIG. 103.

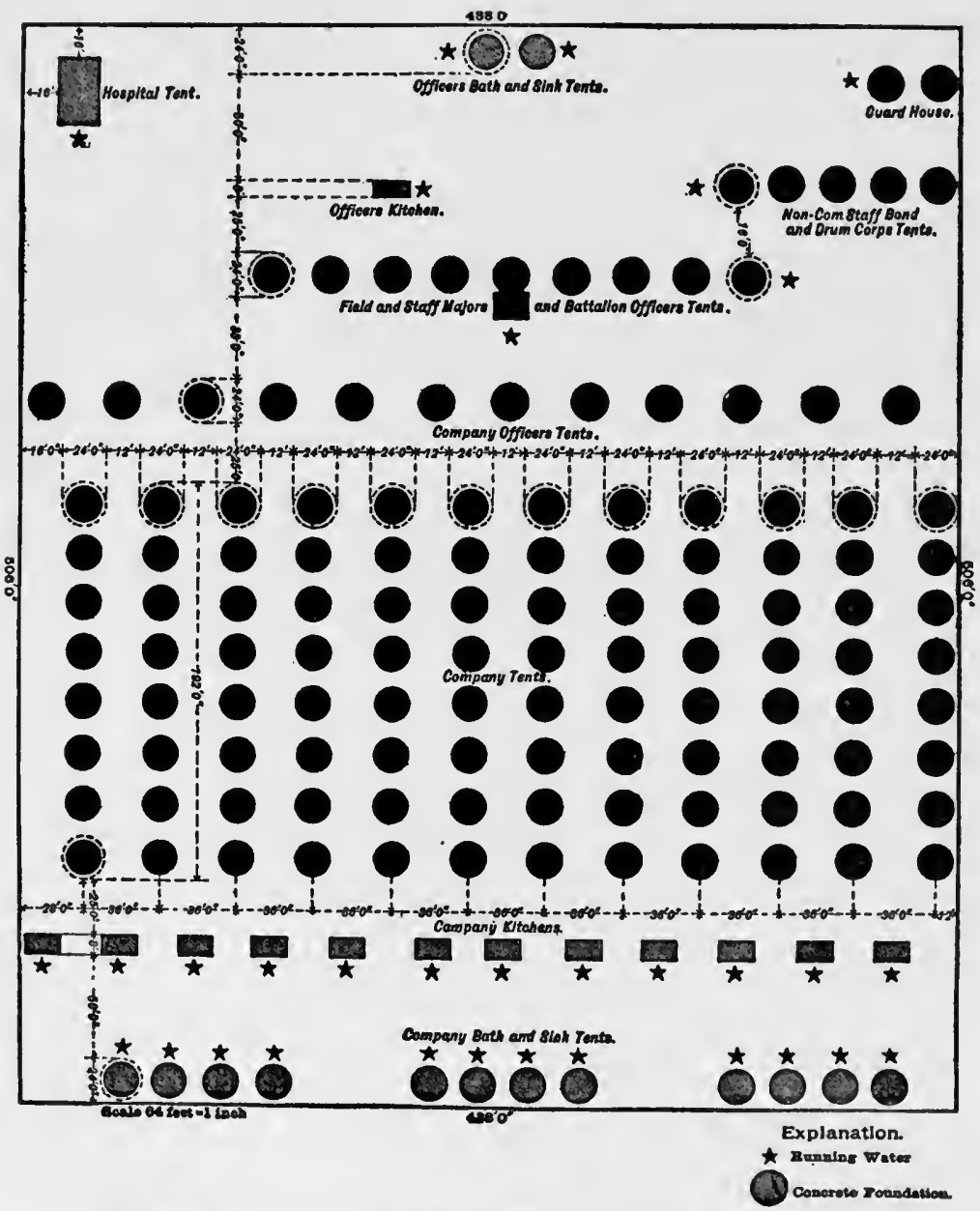

Plan of camp (reduced so that scale of 64 feet to the inch no longer applies).

and general salubrity, and should be as compact as is consistent with the principles of hygiene, for a compact camp is more easily cared for and defended, while one unnecessarily extended involves increased labor, slower delivery of orders and supplies, and greater difficulties in sanitary policing. With the tactical and strategical requirements and general plan, which is a matter of regulation, the hygienist has nothing to do, and his interest lies only in the distances between different bodies 
of men, the size of eompany areas, the cubic space per man, the proper location of sinks, latrines, and urinals, the measures adopted for surface drainage, disposal of sewage, garbage and stable manure, the watersupply, and other matters having a bearing on the health of the troops.

The general plan of a camp is shown in Fig. 103, taken from the Infantry Drill Regulation, and amended in the matter of distances and intervals by Dr. P. C. Harris, U. S. A., ${ }^{1}$ since no distances and intervals are given in the regulation, for they must vary according to the nature of the ground and the strength of the command. 'The plan is made "on a basis of 3 men to a common tent or 10 to a conical wall tent; the maximum allowance of tentage is 6 men to a common tent and 20 to a conical wall."

Sites.-One of the most important matters connected with military hygiene is the sclection of a proper site for camps. Everything bearing on the health of those who are to occupy the camp should be considered important, and every effort should be made to insure, so far as it is possible, that there is no point of least resistance in the barriers against disease. If an unhealthy site is chosen, no amount of care can ward off, though it may cheek the extent of, evil consequences. In active warfare, choice of sites is not always a wide one, and convenience and necessity play a greater part than sanitary consideration. When practicable, they should be placed on high, well-drained ground.

Proximity to water is always necessary, and this may involve exposure to malarial infection; but, other things being equal, the driest site should be selected. Where the choice is restricted, advantage should be taken, in cold weather, of any available protection from winds, and, in hot climates, from the burning sun. The general slope of the ground should be considered, so that surface drainage may be best provided for.

The soil should be dry and porous; elay and other soils of low permeability to air and moisture, but with ligh retentive power for the latter, should, if possible, be avoided. If the ground-water level is high, it should be lowered by tile draining or ditching, in ease the eamp is to be one of permanence. A clay soil or a soil underlaid at a short distance by a clay soil is regarded eommonly as the worst possible site for a camp, since it is retentive of water and is cold, and causes the atmosphere immediately above to be damp. Old river bottoms, deep alluvium, and marshy ground should be avoided. Grass land may- commonly be accepted as good camping ground, but ground covered with rank vegetation, as in the tropies, is not aceptable, because sueh is generally rich in decaying organie matter, and the presence of rank vegetation is in itself evidence either of a very humid atmosphere or of an undesirable degree of soil moisture. Lands subject to periodical flooding, especially by salt water, should be avoided as unhealthy.

Above all, it should be a rule to avoid old camp grounds, for these usually are left in a filthy condition by the previous oceupants, and the soil is always contaminated extensively and, perhaps, infeeted. If an

1 Camps of Instruction, Reprint, Buffalo, Dec. 14, 1898. 
old camp site is particularly desirable on account of the accessibility of wood, water, and grass (the three essentials demanded by the line officer), a position to windward and as near as is consistent with hygienic considerations may be selected.

Dryness of the site and vicinity is of prime importance in its bearing on the health of troops, but too great dryness with much dust is hurtful to the eyes. A position on the side of a hill is warmer than one at the top and drier than one at the bottom, and is favorably situated as regards that most essential provision in camp sanitation, drainage.

Barracks.-Barracks are permanent structures for the lodgment of soldiers, and are built commonly of one or two stories, but not more. Each building of a group should be completely independent of the others and placed with reference to prevailing winds and exposure to the sun. It is essential that the site be dry; the foundation walls solidly laid ; the walls, of whatever material constructed, dry and protected against capillary moisture; the floors, of hard wood, tightly laid ; and the ventilation efficient. Barrack rooms, which are the soldiers' living rooms as well as sleeping quarters, are generally made long and narrow, and each occupant has floor space and air space according to the regulations obtaining in the country which he serves. In this country, 600 cubic feet of air space per man are reckoned adequate, and this, in a room 12 fect from floor to ceiling, gives a floor space of 50 square feet. Cavalry and artillerymen are given somewhat more, on account of the odors which cling to them from eontact with horses. A less amount is allowed when troops are quartered in ordinary dwellings. At Southern posts, 800 cubic feet of air space and 70 square feet of floor space are allowed. In England, the allowanes are the same as with us for infantrymen in the North; in India, they are from 1500 cubic feet and 75 square feet to double those limits. In France, the cubic space allowed is 420 cubic feet for infantry and 500 for cavalry. In Germany, it is 500 cubic feet.

The wash-rooms, urinals, and latrines should be placed with due regard to convenience and to general hygienic considerations.

Ventilation should be planned with a view to the greatest possible reduction of the natural impurities due to occupancy, but with the present cubic space allowanee, whatever the system employed, ideal results cannot be attained. Barrack life is necessarily one of overerowding, but the conditions which now obtain are far superior to those which formerly prevailed. The evils of overerowding of soldiers were first brought to light by an investigation of the health of British soldiers in 1858. It was shown that, whereas the mortality rate of the population of England and Wales of the same age as the army was 9.2 for town and country and 7.7 for country alone, and 12.4 for the most unliealthy town (Manchester), that of the different arms of the service ranged from 11 for the honsehold cavalry to 20.4 for the footguards. According to age periods, the mortality was distributed as follows : 


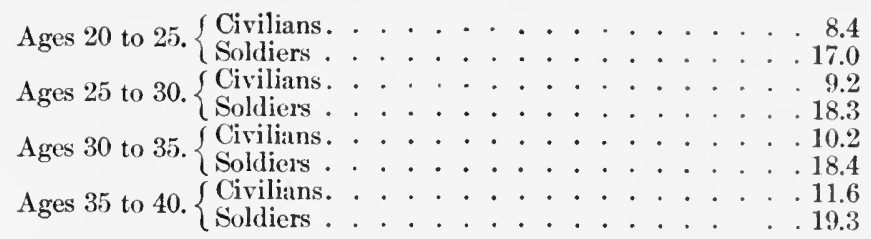

Since the soldiers were picked men, all applieants with any evidence of weakness or tendency to discase being rejected, these data indicated a serious condition of affairs. Comparison wats made with the rates obtaining among the class of agricultural laborers, their work, like that of the soldiers, being mainly out of doors. It would be expected that the latter, being well elothed, housed, and fed, and given free nedical care, would present the better showing, but such proved not to be the case, for the mortality of the laborer being expressed ats 1 , that of the houschold cavalry was 1.8 , dragoons 2.2 , infantry of the line 2.9 , and footguards 3.3. Comparison with men in other ocenpations showed that the soldiers presented the most unfavoruble statistics.

Inquiry as to the cause revealed that, whereas among eivilians at the soldiers' ages the deaths from diseases of the lungs were 6.3 per 1000 , they were $7.3,10.2$, and 13.8 respectively for the cavalry, infantry of the line, and guards; and, furthermore, that of the entire number of deaths from all eanses in the army, the proportion due to lung diseases amounted to $53.9,57.3$, and 67.7 per cent. respectively in the arms above mentioned. Finally, by exclusion, the cause of this great mortality was attributed to overerowding and lack of ventilation. Comparison of the mortality of the army at home with that of the troops quartered before Sebastopol in 1856 was mueh in favor of the latter. The rates, reckoned per anmum, were as follows: Before Sebastopol, including death by violence and atceident, 12.5; at home, 17.9 (infantry), and 20.4 (guards).

Increase in space allowance was soon followed by a marked decrease in phthisis mortality.

Tents.-In the United States Army, four kinds of tents are used: 1. The eonieal, or modified Sibley, tent. This is 16 feet 5 inches in diameter at the base; wall, 3 feet high ; apex, 10 foet from the floor; the area of the floor equals 212 square fect; the air space, 1450 cubic feet; allowanee, 20 infantry or 17 cavalry. The original Sibley tent had a diameter of 18 feet at the base and was 13 feet high. The apex was cut off; thus giving place to a cirenlar aperture which, being left open in fair weather, promoted ventilation. In foul weather, it was eovered. The allowance was the same. 2. Common tent, "I" or modified "A." Wall, 2 feet light ; base, 8 foet + inches by 6 feet 10 inches; ridge, 6 feet 10 inches from the ground ; floor space, 57 sinare feet; air space, 250 culic feet; allowance, 4 mounterl or 6 infintry. 3. Wall tent. Wall, 3 feet 9 inches; floor, 9 square feet; ridge, 8 feet 6 inches above the aromind floor spatce, 81 squilre feet ; air space, 500 cubie fect; covered by fly or filke roof. 4. Shelter tent. 'These are issned to troops in the field, and are not regarderl as tent allowance, 
but are provided in order that men and officers in bivonac while on active eampaign or on the mareh with deficient means of transportation may be sheltered. One forms a shelter for 2 men, each of whom carries his half, which weighs about $2 \frac{1}{2}$ pounds. The pieces are joined together by buttons and put over a ridge pole, which is supported by uprights about 4 feet high. The corners are fastened to pegs driven into the ground, and the uprights are steadied by gny lines. Hospital tents are wall tents of a larger size; they may be elosed or open at the ends, and several may be joined together so as to make a continuous whole. They are $14 \times 15$ with a $4 \frac{1}{2}$-foot wall; ridge, 12 feet from the ground.

The English army uses the eireular, or bell, tent. Diameter at base, 12 feet 6 inches; walls, 1 foot; apex, 10 feet; floor spaee, 123 square feet; air space, 492 cubic feet ; allowance, 12 to $16 \mathrm{men}$, and in war 18 to 20 . Formerly, the ventilation was practically nil, but now it has been somewhat improved. The French army uses a similar tent, ventilated at the top. The air space is 1059 cubic feet; allowance, 16 men. The Germans use a conical tent like the English bell tent. Diameter, under 15 feet; apex, 12 feet from the ground; floor space, 180 square feet; air space, 1050 eubie feet; allowanee, 15 men. They use also small bivouac tents designed to shelter 2 or more men. The different parts are distributed among and carried by the men who are to use them.

It will be observed that, of the four armies mentioned, ours is the most liberal in point of air space, the minimum allowance in the larger tents being $72 \frac{1}{2}$ eubic feet, against a maximum of 41 in the English service, 66 in the French, and 70 in the German serviee.

The material of which tents are made is cotton duek, which has proved to be much better for shedding water than linen. Comparatively little ventilation occurs through this material under the best of eircumstances, and none at all when it is wet by rain, for then it is impervious to air. Ventilation of tents is always defective, and eommonly the atmosphere becomes exceedingly foul. Since there is so little ventilation, it is neessary that the sides should be kept raised during the day, in order that thorongh airing, and, if possible, sunning, may oecur; and at night, when praeticable, the sides to leeward should be open, and the others, too, if advisable.

Dr. Edward L. Munson, U. S. A., ${ }^{1}$ has suggested improvements in the regular tentage, and espeeially in the hospital tents, for service in our tropical possessions, sinee the several forms in use, althongh well adapted to our elimatic conditions, are intensely hot and close in the high temperatures and humid atmosphere that there obtain. $\mathrm{He}$ proposes enlarging the tent fly of the hospital tent 2 feet in length and 4 in width, and that it be raised upon a light false ridge, 4 feet longer than the true ridge and projecting 2 feet to the front and rear. Further, he proposes that the canvas forming the top of the

1 Tentage for Tropical Service, Boston Medical and Surgical Journal, Nov. 16, 1899, p. 487. 
tent be cut out for a space 2 feet wide on each side of the ridge and ruuning the entire length of the tent, except 1 foot, front and rear, the canvas thus removed being replaced by heavy rope netting with a 2 -inch mesh. In order better to reflect the heat rays, the fly should be made of white canvas, the tent itself being of dark canvas, with a view to subduing the light in the interior. An experimental tent, made under orders of the Surgeon-General, was pitehed within a few feet of a regular hospital tent and a regular conieal wall tent, for purposes of comparison. Thermometric observations showed an average difference of 7 degrees in favor of the improved tent, which was never less than 4.5 degrees cooler, twice was 8.5 degrees, and once 10.5 degrees cooler than the regular hospital tent. Compared with the conical wall tent, the temperatture ranged 9.5 to 18.5 degrees lower in the improved tent, which difference "means in the tropies all the difference between comfort and distress for the well and such relief from great and depressing heat as would do much to bring about recovery in the sick." The experimental tent demonstrates that no tent should be issued for use in the tropies without the protection afforded by a fly. The U.S. A. Board of Equipment promptly adopted the improved hospital tent.

Dr. Myles Standish, M. V. M., first called attention to the intense white glare to which the occupant of the hospital tent is subjected from the covering above his head, and which must be a source of actual injury to eyes already in a pathological condition. Reasoning from general laws, he recommends a pale blue or an olive green as the safest color.

In India, the British use a tent with a double fly, having an air space of 2373 eubie feet and accommodating 16 healthy or 8 siek men, which gives a far greater allowance of space than in the service elsewhere. For field service, tents of 686 cubic feet capacity, aceommodating 16 British. or 20 native soldiers, and smaller ones of 392 cubic feet eapacity, aceommodating 8 British or 10 native soldiers, are in use.

Tents are arranged best in short single lines, the individual tents being distant from each other at least once and a half the tent's diameter; the intervals are not fixed by regulation. If possible, the tent should face the east, so that when the day is advanced, the southern wall may be lifted so as to admit the sun's rays to the whole of the interior. Each tent should be ditehed as soon as it is placed in position.

The tent ditch should be 6 inches wide and 4 rleep, and shonld connect with the company ditehes, and these in turn with each other, forming a complete system of surface drainage. All surface drainage from higher ground should be prevented by being intereepted and turned aside.

The floor of the tent should never be lowered by excavating, for

1 Color the Canvas of Hospital Tents. Reprint, Transactions of the Association of Military Surgeons of the United States, 1896. 
men should sleep above the level of the ground, and never below it. If the soil is not quite clean and firm, it should be dug out to the depth of about a foot and replaced by cletu gravel or sand, if such is obtainable, and then covered with boards. Elevated platforms are eminently desirable, and tents not so provided should be moved every week to the open spaces between, so that the sun may exert its purifying influence and, together with fresh air, may put the vacated sites again in a condition for oceupancy. The floors of the tents should, when possible, be covered with loose boards, if these are obtainable; and occasionally the surfuce of the soil should be scraped and replaced with clean gravel or sand. In malarial and yellow fever districts, nettings to exclude mosquitoes, especially at night, and individual netting on light frame-work for the protection of the head, the other parts of the body being protected by clothing, will be found to have great influence in checking infection.

Huts.-During cold weather, wooden huts are much better adapted for occupation than tents, and have come into extensive nse in the German, French, and English armies, both in war and in time of peace. The use of $\log$ cabins is advocated by Colonel Charles Smart, M.D., U. S. A., to house 4 men apiece. The inside dimensions given are $13 \times 7$ feet; walls, 6 feet; ridge, 10 feet from the floor; the door to open in the middle of one side; the chimney opposite the door outside the wall; the roof consists of canvas $14 \times 12$ feet, with a larger fly. This is regarded as the best size and allowance, but the present tactics require squads of 8 , for whom, according to Woodhull, "there should be two huts $8 \times 11$ feet end to end, 6 feet apart, with one continuous roof and door in the adjacent ends, but not midway. The chimney should be in the middle of one long end. Two platforms each $6 \frac{1}{2} \times 4 \frac{1}{2}$ feet, one lengthwise and one across the end, would accommodate 2 men, sleeping with their heids adjacent. The covered porch between the huts would be $6 \times 9$ feet in the elear, the sleeping platform be open beneath, and under no pretence should two-storied bunks be allowed." On damp sites, the walls should be raised a foot from the surface; but on dry soil, they may be built directly on the ground level, the soil well pounded down, eovered with sand and gravel, and concreted.

The floor of the lints raised from the ground is made best of split or dressed logs. The canvas roof and fly are attached in such a way that they may readily be removed when it is desired to admit the sun to the interior. Portable huts may be furnished, having frames of wood or iron. The German huts are made with wooden or iron frames covered with felt and lined with canvas. They are easily ventilated and warmed. The French huts are made circular in shape; the walls are of boards with glass windows. They are easily ventilated and heated. The huts should be at least $10^{\circ}$ feet apart at the ends, and the interspaces should be carefully protected from pollution.

Water Supply.-It goes without saying, that one of the first considerations in the establishment of a pernanent camp is an adequate sup- 
ply of potable water, which subject is presented elsewhere. It is customary to allow at least 5 gallons per capita per dien for all purposes, and as much more as is practicable. Water-closets and baths require, naturally, a very generous allowance. Hospitals require much more per capita than barracks. For horses, from 5 to 10 gallons per diem are required. In general, it may be said that the more generous the supply, the greater the general cleanliness and efficiency.

In temporary camps, the supply, both as to quality and quantity, is determined by natural conditions, and must be taken as it is found. If purification of that intended for drinking appears to be necessary, the methods mentioned in the consideration of the subject of water supplies may be adopted according to availability. The simplest are boiling and the application of alum, with subsequent filtration, if possible, through sand held in suitable receptacles such as half barrels with perforations through their bottoms. The so-called "mechanical filters," so much used in the purification of public water supplies, are more efficient and convenient. Experience has shown that, no matter how urgent the necessity for care in the avoidance of pollution of water, it is always difficult to prevent some of the men from reeklessness in drinking. The operation of purification should be in the inmediate charge of a non-commissioned officer, properly instructed and witl a suitable detail.

Sewerage.-The introduction of an abundant water supply in a camp is, of course, followed by more or less lavish use of water for all general purposes, and this necessitates a system of sewerage for carrying off liquid waste and human excreta. Camp sewers should be constructed in a proper manner of bricks or drain-pipe, and never of wood. The methor of final disposal of the sewage at the outfall will depend upon individual circumstances. All permanent camps should be properly sewered.

In case of outbreaks of typhoid fever, cholera, or other diseases of the same general class, the excreta shonld be disinfeeted before being otherwise disposed of. In army practice, ehloride of lime 4 per cent. and carbolic acid 5 per cent. are commonly used, with weaker solution of carbolic acid and corrosive sublimate $1: 1000$ for washing floors and artieles of furniture or for soaking soiled clothes. Milk of lime is highly to be recommended for exeretal, as is also formaldehyde solution, if it can be obtained. The Manual for the Meclical Department says on this point: "Sulphate of iron and other cheap antisepties and deodorants may be used when neessary. But the necessity for their use is a reproach upon the sanitary police of a post, and should only be required under exeeptional eircumstances, The alvine discharges of healthy persons do not require disinfection. and when properly disposed of, do not require treatment with any eliemical agent whatever. If water-elosets or earth-elocets are offensive, this is due to faulty construction, to insufficient supply of water or dry earth, or to neglect of ordinary cleanlines.s. The attempt to renedy such defects by the systematic use of antiseptics is expensive 
and unsatisfactory in its results. The same is true of foul drains, bad smelling urinals, accumulations of garbage, etc. The proper remedy for such conditions is cleanliness and strict sanitary police."

When there is reason to believe that infectious diseases are present in camps, the latrines and cesspools should be disinfeeted with milk of lime to the extent of one-twentieth of their contents, to which should be added every day an amonnt equal to at least a tenth of the daily addition of excrement. Hospital sewage is dangerous enough to warrant treatment on the spot with disinfectants.

In the absence of a regular system of sewerage, Sternberg recommended eylindrical galvanized iron vessels 18 inches in depth and diameter, with a trough around the upper end 3 inches deep, filled with disinfectant. Into this, the cover fits, and thus serves as a valve and prevents the escape of foul odors and the entrance of flies. A second cover with a hole serves as a seat. The receptacle is to be partly filled with carbolic solution or the contents are to be treated with caustic lime, or ashes, or dry earth. These vessels should be removed at regular times, and clean ones should be substituted while they are removed, emptied, and cleaned.

Sinks and Latrines.-A sink, in military parlance, is a cesspool or privy vault in a temporary camp; usually, a trench from twelve to fifteen feet in length, about two feet in width and eight in depth, with the earth, which has been thrown up, piled along one side. The requisite number should be dug before a camp is occupied or as quickly thereafter as possible. They should be placed to leeward, or in such position that the prevailing winds shall not convey the odor therefrom over the company areas, and they should never be placed near existing wells. They should not be placed any farther away from the men's quarters than is absolutely necessary. For convenience of use, a strong pole is laid horizontally on upright forks at the proper height and on the side opposite the excavated earth. The latter, kept as dry as possible, is thrown back each day over the deposited excreta, often with caustic lime, chlorinated lime, or ashes.

Behring ${ }^{1}$ recommends, in case of necessity, from 5 to 7.5 liters of milk of lime for each 250 men; Pfuhl ${ }^{2}$ advises 400 ce. per man. The addition of chlorinated lime possesses a double advantage, since it not only acts as a disinfectant, but also serves to drive way flies, which otherwise collect and may become active agents in the spread of infectious disease.

Small sinks for each company are regarded as much better on several accounts than one or more large ones for each regiment. 'They afford greater privacy when enclosed with brushwood, and are generally better looked after, since the responsibility for their care is more definitely fixed. When filled to within two feet of the surface, the remaining earth should be thrown in and rounded over, the site marked, and, at the same time, new trenches prepared. On breaking camp, all sinks, however little used, should be filled up and marked.
1 Zeitschrift für IIygiene, IX., p. 395.
${ }^{2}$ Ibid., IV., p. 97. 
When the probable stay is to be more than of a few days' duration, the horizontal poles are commonly replaced by box seats, open at the back. In winter, the trenches should be completely covered by box seats with covers; hinging of the top or rear side will be necessary for the proper throwing in of the excavated earth.

The word latrine is commonly used as synonymons with sink. It is properly defined as "a privy or water-closet, especially in trough form accommodating several at the same time." 1 A further description of a latrine is elsewhere given (see page 364). Latrines are more commonly installed in barracks or permanent camps. They require frequent flushing, if connected with a system of sewerage, and frequent emptying and cleansing, if not so connected. The scats and floors should be kept thoroughly clean by periodical washing; twice daily is strongly recommended.

Urinals apart from sinks and latrines are installed in both permanent and temporary camps, and in both it is essential that they be of easy access, and their use compelled on account of the nuisance arising from indiscriminate voiding of urine on the ground and of the possibility of the dissemination of typhoid fever by the urine of ambulatory cases of that disease and of convalescents therefrom. In inclement weather and at night, all parts of a camp, and especially the company areas, are liable to urinary contamination, which should be prevented as far as possible by stringent rules and constant vigilance.

Inspections.-Under the Army Regulations, an annual inspection of the buildings at every post is made by the commanding officer and quartermaster on the first day of March, and immediately afterward a report is submitted giving a description and showing the condition and capacity of each building, and the character and extent of any additions, alterations, and repairs. Sanitary inspections are more frequent and more searching in character. The surgeon is required to examine, at least onee a month, and to note, in the medical history of the post, the sanitary condition of all public buildings, the drainage, scwerage, amount and quality of water supply, clothing and the habits of the men, and character and cooking of the food, and immediately alfer such examination to report thereon in writing to the commanding officer, with such recommendations as he may deen proper. Sunerficial inspection is not enough, for everything may look clean externally and yet the general condition may be bad.

The condition of the air is of much more importance during the sleeping hours than during the day ; therefore, ventilation should be investigated at night. Walls and floors should be carefully examined, especially if they are made of porons material. Walls found to be contaminated with organie filth should be seraped and then thoronghly whitewashed. 'The floors, whether of barracks, tents, or huts, should be serupulously clean and dry ; the bedding should be free firom dampness; the spare clothing and the men themselves and their elothing in use should be clean. The site and immediate surroundings of every

1 Standard Dictionary. 
permanent or temporary strueture should be examined with particular reference to the drainage and general condition of the soil.

Sanitary Police.-Exceedingly strict sanitary polieing is necessary to keep a camp in a healthy condition. The responsibility for condition rests with the commanding officer, but is shared in by the company officers, who must look after their quarters and men. Under the title of "officer of the day," company commanders serve in turn, each for" a day, in charge of general sanitation, and each is responsible to his commanding officer for the order and eleanliness of the eamp on the day of his service.

It has been demonstrated repeatedly that untrained or inexperienced soldiers eannot be depended upon for thorough eleaning or keeping things elean, for they do not know how to take eare of themselves, because at home they are looked after by others; and unless sanitary police be very striet, a clean and everyway good natural site may quickly be contaminated and made unhealthy. Until discipline is well established, the enforcement of proper sanitary regulations is extremely difficult, for while they may be most carefully formulated, the necessary orders are diffienlt of enforecment. Even with the utmost care and vigilanee, contamination of the site is only a question of time, but the more efficient the system, the longer is that time deferred. A camp in which no attention is paid to cleanliness of the company streets and to habits of personal cleanliness is sure to be an unhealthy one, and men who will permit such conditions to obtain are commonly bad soldiers in every sense of the word, with no esprit de corps, slovenly in all their habits, conspicnously attentive to sick eall, and with no respect for themselves or their superiors.

In such a camp, the development of epidemies of infectious diseases, particularly typhoid fever, is only a question of time, sinee it needs only the introduction of the specifie germ and favorable opportunities for its dissemination. Since this disease is endemic in all parts of the country, it is not strange that among large numbers of men brought in from different quarters there should be one or more carrier's of the infection. In any camp of whatever degree of efficiency in sanitary police, unless such cases are recognized at once and their exereta completely disinfected or otherwise disposed of, so that no danger shall be possible therefrom, the site is likely to become polluted and the bacilli to be distributed through the usual ageneies.

One of the first essentials of maintaining cleanliness in eamp is good surface drainage. If the soil is damp, the site soon beeomes an expanse of mud, owing to the constant impress of hundreds of feet. Mud assists in the conservation of refuse and filth which it envelops and masks, and henee arises the necessity for efficient and thorough ditehing, and for filling up depressions likely to retain surface water. 'The usual pathways and sidewalks should be made as dry as possible by the application of gravel, and by such other methods as are applicable to each individual case.

All refuse of whatsoever kind should be prevented from aceumulating 
within the lines; everything should be promptly removed and disposed of, if possible, by burning. Kitchen refuse shonld be deposited in covered receptacles, which should be carried away twice daily. On no aecount should it be left exposed on the ground or elsewhere, since not only does it speedily develop the well-known nauseous odor of swill, and thus become a nuisance, but it is an attraction for flies, which, by their investigation of all sorts of filth, including the ficeal discharges in the sinks, and then of the soldiers' food both in the kitchen and at mess, have again and again proved themselves to be largely responsible for the spread of epidemic diseases, as will be explained more in detail on a later page.

The final disposition of kitchen refuse is often a problem fraught with serious diffieulties. When possible, it should be burned in one of the numerous forms of ineinerators devised for the purpose; but on no account should it be spread out in the vicinity of the apparatus to dry. If it be advisable to bury any part of it, at whatever distance below the surface it is deposited, it shonld be well covered with clean earth. The deeper it is buried, the longer will it resist eomplete decomposition.

Stable manure should be removed every day and deposited at a suffieient distance and in such a location as to insure that it shatl not be a nuisance or a source of danger to the water supply. Incombustible harmless refuse should be removed ont of sight, and not be allowed to aceumulate, for anything promoting untidiness of appearance invites additional untidiness by its example.

Considering the many details of eamp police and the neessity for coopperation on the part of every man, it is not strange that, in om war with Spain, the hasty gathering together of large bodies of undiseiplined troops from all parts of the country into large improvised eamps, largely under the control of inexperienced officers both of the line and medical service, was followed very quiekly by the outbreak of epidemic diseases, which earried off large numbers of men who, to at certain degree, were victims of their own carelessness. It is relater, for example, that a certain regiment of volunteers, encamping nearly side by side with one of regulars, was invaded to an extraordinary degree by typhoid fever, while the regulars were practically free from disease. One of the medical officers informed the aththor that most of these men were so dirty, lazy, ignorant, intemperate, and immoral, that nothing short of an extensive epidemie among them could have been expected, and was expected from the start. They salw some active service, and were eonspicuous for general inefficiency and lack of discipline. Their ranks were redued very largely by disease, and the casualties were practically nothing. The survivors returned to civil life and were weleomed as heroes; those who perished in consequence of their own and their eomrades' revolting habits of lite are enrolled with those who sacrificed their lives in defence of their country's houror.

The neessity of eonstant supervision and of enforcement of disci- 
pline has been well set forth by Joln S. Wise," who says : "To appreciate fully the truth that men are but children of a larger growth, one must have eommanded soldiers. Without constant guidance and government and punishment, they become careless about elothes, food, ammunition, clemliness, and even personal safety. They will at once eat or throw away the rations furnished for several days, never considering the morrow. They will east aside or give away their clothing because today is warm, never calenlating that tomorrow they may be suffering for the lack of it. They will open their cartridge boxes and dump their eartridges on the roadside to lighten their load, although a few hours later their lives may depend upon having a full supply. When they draw their pay, their first object is to find some way to get rid of it as quickly as possible. An officer, to be really efficient, must add to the qualities of courage and firmness, those of nurse, monitor, and purveyor for grown-up children, in whom the bumps of improvidence and destructiveness are abnormally developed."

A striking and interesting object-lesson in eamp sanitation is given by Colonel Charles R. Greenleaf, M. D., Medical Inspector, U. S. A. ${ }^{2}$ Two camps located very near together, nearly equal in the number of men contained (about 12,000), and with the same conditions of climate, soil, water supply, and food, showed very different records of morbidity and mortality. In one, "the men were scourged with sickness and death, and large numbers of them were permanently invalided; local epidemics became general, and soon the entire camp was so thoroughly infected that it was of necessity abandoned." In the other, "but little sickness (the percentage never exceeding five and a half of the aggregate strength), few deaths, and a few cases permanently invalided; local epidemies of contagious disease, due to importation," were quickly controlled, and never extended beyond the respective commands which brought them, nor did a single case of infectious disease originate in the camp.

The difference in the health conditions of the two camps was due to the fact that in one, "the advice of sanitarians was seldon asked, and when asked was not followed, and nearly every law of health was either ignored or violated," while in the other, "the advice of sanitarians was freely sought, aceepted, and carried out, no pains being spared to secure, as far as possible, compliance with the laws of health." The benefits of sanitation were recognized by both officers and men, and the advice of its teachers was carried out by all to the fullest extent.

The following sanitary regulations, published for the governing of certain model camps established in the Presidio Reservation, one for five regiments of volunteers returning from the Philippine Islands, one for four regiments of out-going volunteers, or about $5200 \mathrm{men}$, and one for about 2000 recruits for the regular regiments already in

1 The End of an Era, Boston, 1900, p. 347.

2 An Object Lesson in Military Sanitation, Boston Medical and Surgical Journal, Nov. 16,1899 ; p. 485 . 
the Philippines, are eommunicated by Dr. Greenleaf. ("In planning these camps the primary objects were to remove the kitchens as far as possible from the latrines, to provide a safe method for the disposal of exereta, garbage, etc., to seeure means for the personal cleanliness of the men, to heat their quarters, and to supply them with an abundance of good food and water.")

"The commanding officer of the troops occupying the camps will detail from his command two sanitary inspectors; one fiom the line, preferably a major of the regiment, and the other a regimental medical officer, whose daily duty it shall be to jointly inspect the regiment, inqurnng into the general police of the company quarters and streets, the kitehens, the food, its preparation, quality and method of serving, the latrines, urinals and sewers, and making to the regmental eommander a brief report of any unsanitary conditions they may diseover, this report to be forwarded the same day to the medieal inspector of the army at department headquarters.

"One medical officer and one hospital steward from each regiment will be required to be present for duty with the regiment at all times of the day and night.

"A daily sick call will be held, and slight cases of illness treated in quarters or in the regimental hospita!s provided for that purpose, but all men who are likely to remain siek more than three days will be promptly sent to the General Hospital at the I'residio of San Franciseo.

"If any ease of infectious disease occurs, the fact will be promptly reported to the camp surgeon, who is authorized to make proper disposition for its isolation and eare.

"An ambulance fully equipped with a team will be assigned to the camp by the commanding officer of the Presidio. This ambulance will report daily to the eamp surgeon at sick call, remaining in the camp during the day, subject to his orders. Under no circumstances will this ambulanee be used for any other purpose than the transportation of the sick, or medieal supplies. 'The commanding officer of the Presidio will also cause another ambulance to be sent to the eamp for service at night time. This ambulance will remain on duty from retreat to reveille for night emergency service. When the night ambulance reports for duty, the day ambulance will be relieved and returned to the post."

"Company commanders will cantion their men against exposure to the fogs and high winds that prevail here, especinlly in the carly morning and evening, at which time overcoats will be worn. Riding on the 'dummy' of the street cars, especially at night, is patrticularly hazardous to men reently returned from service in the tropics. Guard duty and other military functions required at these homs will be held in overeoats, and at breakfast and supper the stoves in the dining-rooms will be provided with fires. 'The sile, by eivilians, of food or drink within the limits of the eamp will be forlidden.

"At retreat, urine tubs, two to cach company, will be placed in each 
company street, and men desiring to urinate at any time during the night will be required to use then. The tubs will be removed from the company street at reveille to a place convenient for the scavengers, who will remove, clean and place lime in them for use the next night.

"The quartermaster's department will be required to provide an ample force of scavengers to clean the latrines and urinal troughs at least once daily, and to refill the troughs with milk of lime; they will also remove all kitchen garbage, and either cremate it or dispose of it in such place as the quartermaster shall direct. Particular care will be enjoined on company cooks to keep grease traps clean, and to deposit all solid garbage in cans prepared for that purpose in time for its removal by the scavengers.

"The quartermaster's department will furnish to each regiment an ample supply of necessary policing implements, to enable the men to thoroughly and effectively police the camp daily."

These regulations, Dr. Greenleaf reports, were promptly carried out by officers and men, and, in spite of the fact that nearly every body of men brought some form of infectious disease, including typhoid fever, tropical dysentery, diphtheria, smallpox, measles, and mumps, not a single case of any infectious disease originated in the camps, all of the imported cases being promptly segregated from the command, all infected material disinfected or destroyed, and all men who had been exposed isolated and quarantined.

In all these camps, the latrines and bath-houses were placed on the flanks and rear; the kitchens and mess halls, in the central lines. In the rear of each mess hall, a zinc-lined wash trough, supplied with a dozen bib cocks, was placed to be used as a lavatory ; near the door of each kitchen was a grease trap connected with the sewer, and galvanized cans for garbage and ashes were placed on the porch. Large caldrons for heating water for lanndry and other purposes were set up in convenient places. Two galvanized wash-tubs were furnished to each company, and "night soil tubs were placed in every company street at 'tattoo' for the use of the men during the night, a sentinel being posted in the street to see that the orders regarding their use were carried out." The construction of latrines and disposal of excretis were carried out according to the recommendations of a board of medical officers, consisting of Major Reed, U. S. A., and Majors Vaughan and Shakespeare, U. S. V., as follows:

"A trough made of No. 22 galvanized iron, fourtcen feet long, twenty-two inches wide at the top, parabolic in eross section, and with a maximum depth of eighteen inches, if set in a light wooden framework, which serves as a protective crate in transportation, gives support to the trough while in position, and serves for the attachment of a lid in two sections, furnished with seven seat holes. These holes are shaped so as to render soiling of the seat dificult, and a slanting board one foot wide, permanently fixed at a proper angle above the seat, prevents the men from getting up on it with their feet. When in position, 
one end of the trough is raised four inches higher than the other. The trough is placed in an ordinary frame privy house. At the upper end of the trough there is placed a galvanized iron gutter of proper height and inclination leading into the trough to serve as a urinal.

"The rear side of the gutter or that attached to the wall of the building is higher than the front side, to prevent soiling the building. The trough is prepared for the reception of frecal matter by filling it with water until a certain level, indieated by a line on the inside of the trough, is reached. A measure for the purpose, and holding one-sixth of a barrel, is now filled with quicklime and empticel into the water; some dry lime should also be placed in the urinal. The lime in the trough is thoroughly stirred with a wooden paddle. This stirring is repeated three times every day. The wooden paddle when not in use stands in a pail filled with milk of lime. Toilet paper is provided for the men's use in the latrines, because large pices of newspaper will float on the water holding masses of frecal matter above the surface, thus exposing it to the flies and other insects.

"Once a day the contents of these troughs are pumped out into an odorless excavator, carted away and properly disposed of. The milk of lime destroys the typhoid bacillus, and the contents of the trough, if properly cared for, will be quite innocuous. Not only is the milk of lime and fæcal matter innocuous, but its value as a fertilizer is considerable."

It may be stated, howerer, that these excellent results in sanitary police were not brought about without outsille assistanee, for it was found advisable to employ a corps of eivilian scavengers consisting of 2 overseers, 22 night seavengers, 54 day scavengers, and 17 teamsters, with 5 odorless excavating carts, 6 sanitary cars, and 12 dust earts. By means of this outside force, the eamp was kept thoroughly elean, and the excreta were promptly removed and disposed of. The latrine troughs were emptied twice in twenty-four hours, and garbage and all manner of waste material were removed twice daily. The tent floors, kitchens, mess halls, and company streets were swept daily by the soldiers themselves, and one man from each company did iluty each day in the company latrine to keep it elean and stir the lime solution frequently.

During the past few vears great improvements have been made in methods of disposing of garbage and human excrenent throngh the nise of portable ineinerators of different types, two of which have been tried out, with a large measure of snecess, by the United States War Department.

\section{The Diseases of the Soldier.}

While there are no discases peculiar to the soldicr, there are many to which the circunstances and conditions incident to camp life render him eonspicuously susceptible. These are mainly of the preventable class, and may be largely checked by proper regard to the principles of camp sanitation, by avoidance of jolluted water, improper eooking, 
overcrowding, and overwork, and, in some degree, by the inculcation of the principles of moral living.

It is difficult or impossible to determine how soldiers compare with civilians in the amount of sickness which they suffer, since we have no statistics of general morbidity, especially of corresponding age periods, of the civil population; and even were such available, it would be necessiry to bear in mind that the soldier is often on the sick list with ailments which, in civil life, would neither deter him from attending to his daily work nor cause him to go to the added expense of medical advice. The soldier has absolutely free medical attendance and care, and of this he freely avails himself, excepting, with many, in case of venereal troubles.

Concerning the constitution of the medical corps, the hospital accommodations, and general administration, all of which are fixed by law and regulation, no description or discussion is necessary; and a brief consideration of the prevalence and predisposing causes of the chief diseases of armies is all that lies within the scope of this work.

It is a well-known fact that in both war and peace the greatest mortality among soldiers is from disease, and not from violence, the single exception which history records being afforded by the German army in the war of 1870 with France. In our war with Mexico, according to Woodhull, 935 of the regular force were killed or died of wounds, and 4714 died of disease in the field. In the Civil War, 99,183 whites and 3417 negroes were killed or died of wounds, and 171,806 whites and 29,963 negroes died of disease. In our war with Spain and troubles in the Philippines, during the year from May 1, 1898, to April 30, 1899, aceording to the report of the Surgeon-General, 968 men were killed or died of wounds, injuries, and accidents, and 5438 died of disease. Typhoid fever was responsible for more than half the deaths from disease; next in order came malaria, followed by pueumonia, yellow fever, and smallpox.

Tuberculosis. - In the large standing armies of the world, tuberculosis has long played a leading part, due largely, as has been pointed out, to overerowding and deficient ventilation, and to the enlistment of men in whom the disease is latent before entrance and developed by changes in habits of life, climate, etc. Yet, according to Colin, ${ }^{1}$ Inspector-General of Hygiene in the French Army, many persons with latent tuberculosis not only withstand the hardships of military service well, but even become stronger and generally healthier. According to a statement by Surgeon-General Schjerning at the Tuberculosis Congress in Berlin (1899), a decided decrease in tuberculosis has been observed in the German army, while in other armies an increase from year to year in loss of men from this cause may be looked for as a certainty, especially when large increases in enlistment necessitate the inclusion of many not fit for service. Colin's statistics of losses to the French army are corroborative of Schjerning's statement, especially those for the year 1895, when a large increase of the army, 1 Journal d'Hygiène, March 1, 1900. 
necessitating a reduction in the quality demanded, was followed ly a more marked increase in yearly loss. The figures follow :

\begin{tabular}{c|c|c|c}
\hline Year. & $\begin{array}{c}\text { Discharges per 1000 } \\
\text { army strength. }\end{array}$ & $\begin{array}{c}\text { Deaths per 1000 arms } \\
\text { strength. }\end{array}$ & $\begin{array}{c}\text { Total ioss per 1000 army } \\
\text { streugth. }\end{array}$ \\
\hline 1888 & 4.30 & 1.18 & 5.48 \\
1889 & 4.94 & 1.05 & 5.99 \\
1890 & 5.70 & 1.08 & 6.78 \\
1891 & 6.10 & 1.33 & 7.43 \\
1892 & 6.55 & 1.04 & 7.59 \\
1893 & 6.33 & 0.94 & 7.27 \\
1894 & 6.55 & 1.01 & 7.56 \\
1895 & 8.34 & 1.14 & 9.48 \\
1896 & 7.34 & 0.94 & 8.28 \\
\hline
\end{tabular}

In the English service, phthisis is the chief cause of mortality and invaliding, the annual loss averaging somewhat below 5 per 1000 army strength. In the French service, the disease stands second to typhoid fever.

In armies, as in general life, tubereulosis finds the greater number of its vietims among those who are most confined, and is more frequent in the garrisons of large towns than among troops in the less thickly settled parts. The most eareful prophylaxis is demanded to prevent its spread, and the ideal measures would include the discharge of all persons eapable of acting as foci of the discase.

Typhoid Fever.-Typhoid fever is very prominent as a scourge, especially in time of war, when large bodies of raw and undisciplined troops are brought together in camps of instruction. Among lauge bodies of men drawn from different parts of a country in which the disease is very generally distributed, it is almost incritable that there will be some who will introduce the specifie germ. The individual soldier, owing to age and the abrupt changes in the nature of his surroundings and general habits of life, is very susceptible to infections in general. Statisties demonstrate that the seasoned regular suffers much less from discasc, in proportion to numbers, than the mudiseiplined volunteer and law reeruit. This is due to the filct that he has become accustomed to the mode of life, and, through training, has learned better how to take eare of himself in all departments of personal hygiene. Great eare is neecsiary to isolate cases as soon as recognized, and to treat exereta so that their final disposal shall not be a menace to the safety of others.

Of the highest importance is the prevention of aceess of flies to the discharges, for, as has been stated elsewhere, these pests have been responsible for the spread of this and other discases by contaminating the food supply after visiting the sinks. Also of the highest importance is the avoidanee of a polluted water supply; boiling of water eonecrning which nothing is known should always be tone as a natter of routine precaution, and the attention of the inen should be drawn to the danger which they incur in the incliseriminate drinking of 
water which has not been thus treated or shown by competent anthority not to require it. In general, it may be stated that, without efficient sanitary police, typhoid fever among troops is always to be expected.

The origin and spread of typhoid fever in our army during the Spanish War (1898) were investigated by a board consisting of Dr. Walter Reed, U. S. A., and Drs. V. C. Vaughan and E. O. Shakespeare, U. S. V., who reported that more than 90 per cent. of the volunteer regiments developed the disease within eight weeks of going into camp. In certain regiments of regulars, the disease developed within three to five weeks. Among the whole body of troops there were no less than 20,000 eases between May and September. The eauses included polluted water and dissemination of feeal matter by flies. In some cases, eamps were set up despite the protests of the medieal officers against the unfitness of the sites selected.

Preventive inoculation against this disease, although in its infancy, has given sufficiently eneouraging results to warrant trial on a large scale. (See section on "Immunity.")

Dysentery.-In the South and in our new tropical possessions, dysentery is one of the most important eamp diseases; in fact, it is said that, within the tropies, dysentery annually claims far more victims than Asiatic cholera. Once introduced, like typhoid fever, it is likely to become epidemic.

Shiga, ${ }^{1}$ in an effort to secure protection against the disease, inoculated 10,000 people in Japan with a mixture of dead bacilli and specific serum. 'The incidence of the disease was not much affected, but the mortality was reduced from 20 to 30 per eent. to practically nothing. (See also section on "Immunity.")

Malaria.-The various forms of malarial diseases are always a curse to armies, especially those operating in hot climates. Though the death-roll from malaria may not be great, sickncss and consequent invaliding are commonly enormous in amount, and an army stricken with malaria is an army unfit for field operations. The infection weakens the natural power of resistance to other infections, and is said to predispose the victim especially to infection by typhoid fever, and to exert a particularly pernicious influence on those who have already acquired or subsequently acquire venereal diseases.

The great value of measures directed against the presence of mosquitoes is well shown in a report by Dunbar. ${ }^{2}$ A naval board, appointed to consider anti-malarial prophylactic measures at the naval station, Olongapo, Philippine Islands, recommended, first, filling in the swampy land on the range and further clearing of the ground, so that there should be no shelter for the mosquito within at least 200 yards from the range; and, second, the erection of thoroughly sereened quarters for officers and men. The result of these measures was very striking; for whereas during the first quarter of last year there were 105 admissions to the hospital ship, giving 2214 sick days, during the

1 Osler's Modern Medicine.

2 Philippine Journal of Science, Aug., 1910. 
elapsed part, over one-half of the first quarter of this year, there had been but 8 admissions to the hospital ship for malaria, giving 120 sick days.

Since the confirmation of the discovery of the important part played by mosquitoes in the dissemination of the malarial poison, the necessity of the use of netting against these pests has been very clearly demonstrated. 'The preventive measures against malaria eonsist in the avoidance, if possible, of sites near which the eonditions are favorable to the puddle-breedingr mosquitoes, the avoidance of unnecessary going about during the hours when mosquitoes are most active, prevention of access of mosquitoes to the sleeping quarters, and the systematic use of prophylactic doses of quinine morning and night. Whiskey is not needed as an adjuvant, and is more likely to be an injury than an aid. Hot tea and coffee are more highly regarded.

Measles.-In all new levies of troops, measles is a serious imperliment to efficieney, for, once introdueed, the disease spreads raprilly through the eamp, especially if the troops are largely from the conntry, where they have eseaped the discases of ehildhood which mage the population of eities and large towns. The importance of the disease appears, according to recent evidence, to be likely to be underrated by commanding officers.

Diarrhœal Diseases in General._Because of the lesser resistance to specific infeetions, which appears to accompany even mild eonditions of diarrhea, it is essential to take such measures and preeations as are possible to prevent them. Among the prominent eauses may be mentioned the use of improperly eooked, indigestible foud, and ehilling of the body, particularly at night while sleeping on the ground, even althongl separated from immediate contact therewith by rubber blankets. The prevention of the first cause needs harlly to be pointed out; for the prevention of the second, the habitual use of light flannel garments or abdominal bands is recommended.

Sunstroke.-This consequence of extreme heat or over-exertion in high temperatures is very likely to be induced by imprudence in the matter of water supply, and by continuous work without periods for rest and receation. Aceording to Dr. Smart, U. S. A.," "If the allowance of water is seanty, it must, nevertheless, bo userl at regular intervals, but economically, lest it give ont. There is manifestly less danger of a fulminant stroke with a stinted but steady supply than with full allowance for a given time followed by a period of cuforeed abstinence. On the other hand, if the supply is liberal, it may be indulged in freely and with alvantage when the skin is acting well." He relates that, during a service of four years in the hot climate of Arizona, with commands of varying size, making long malches, often on seant allowance of water, he saw sunstroke on but one oceasion, and in this instance, the rule to nse the antern in the early part of the march with caution, as if no more conld be had until arlival in camp,

1 Philadelphia Medical Journal, Jamuary 19, 1901, p. 158. 
was not followed. It was the rule, when a supply presented itself on the line of march, to use it freely, and then, on proceeding, to use the refilled canteens with the same caution as before. A canteen of tea, not necessarily strong, containing a little lemon juice, lime juice, or vinegar, is more desirable when obtainable than plain water.

Venereal Diseases.-These are responsible for a very large amount of siekness in all armies, and their prevention has been the subject of much consideration by military authorities everywhere; but the remedies against the prevailing high figures of morbidity, namely, scientific and practical control of prostitution, find always and everywhere active opposition on the part of the public. 


\section{CHAPTER X.}

\section{NAVAL AND MARINE HYGIENE.}

The eonditions of life at sea in relation to health are very different in many respeets from those which obtain ashore. The seafuring man, wherever he goes, travels in his habitation, in which, necessarily, his share of cubic space is far less in amount than that which the prineiples of general hygiene stipulate as a permissible minimum for those ashore. His air-supply while at work on and above the deck is of the greatest known purity, and while below in his slepping quarters it is likely to be at times unutterably foul, and under usual conditions, even with the best of care and appliances, is usually not in conformity with the generally aceepted standard. His work exposes him to the hardships of the most inclement weather, to extremes of heat in the stokeholds of vessels propelled by steam, to long-sustained muscular effort at eritical periods; and involves short hours for sleep, and these not in one consecutive whole, but divided by intervening periods of duty. His food supply for the entire period from port to port must be transported with him, must necessarily possess keeping qualities, and hence consists largely of preserved instead of fresh meats, and dried and canned vegetables instead of those fresh from the fields.

In the matter of kitehens, cooking appliances, and fuel, he is circumstanced more fortunately than the soldier, since wherever he goes they acempany him, and he is independent of the frequently troublesome question of transportation of supplies and applianees in time of need. Thus it was that, during the battle of Manila Bay, all hands could be piped to breakfast, whereas at the fierce onslanghit by the land forees at San Juan, no such comfortable relief conld be afforded.

His water-supply must be carried in proper storage or be oltained by distillation from the salt water in his path. But he has not to cope with the difficulties which beset the soldier in the matter of eamp sanitation, for his sewer is the boundless ocean, and the question of disposal of garbage requires no thought.

\section{NAVAL RECRUITS.}

The United States Regulation forbids the culistment as a landsman of any man over 25 years of age unless he has learned some mochanical trade, and in this instance he may not be enlisted, without special authority, if over 35 years of age. $\dot{A}$ landsman is one who never before has gone to sea, or, having been alreadly at sea, does not posses the skill required of an ordinary seaman. In ordinary seamam must already have had two years' experience. An able seaman is one who has laid at least four years' experience and understands the navigation of ships. 
Apprentice seamen are enlisted from 17 to 25 years of age, are sent to training stations and given such instructions as tends to make them eligible for promotion to the higher ratings in the seaman branch of the service.

"The minimum weight for acceptance of a man 21 years old is 128 pounds. A variation of 10 pounds, not to fall below 128 pounds in weight, or 2 inches in chest measurement below the standard given in the table for adults, is admissible when the applieant for enlistment is active, has firm muscles, and is evidently vigorous and healthy, except for enlistment in the rate of coal passer, for which rate full standard measurements will be required.

"Chest expansion of less than 2 inches in a minor or of less than $2 \frac{1}{2}$ inches in an adult is a sufficient cause for rejection of an applicant. Marked disproportion of weight over height is not a cause for rejection unless the applicant is positively obese.

"Any one of the following conditions will be sufficient to cause the rejection of the applicant :

"1. Feeble constitution, general poor physique, or impaired general health.

"2. Any disease or deformity, either congenital or acquired, that would impair efficiency, such as: Weak or deranged intellect, cutaneous disease not of a mild type, parasites of the skin or its appendages, deformity of the skull, abnormal eurvature of the spine, torticollis, inequality of upper or lower extremities, inefficieney of joints or limbs, deformity of joints or bones either congenital or the result of disease or injury, fiat feet, evidence of epilepsy or other convulsions, defective vision (minimum ${ }_{2}^{15} \mathrm{~S}$ S. in either eye), disease of the eye, color-blindness, impaired hearing or disease of the ear, chronic nasal catarrh, ozæna, polypi, great enlargement of tonsils, impediment of speech, disease of heart or lungs or predisposition to such disease, enlarged abrlominal organs or evidence of cirrhosis, tumors, hernia, undescended testicle, large varieocele, sarcocele, hydrocele, stricture, fistula, hemorrhoids, large varicose veins, disease of the genito-urinary organs, chronic uleers, ingrowing nails, bad corns, large bunions, deformity of toes, loss of many teeth or teeth generally unsound (teetl properly filled not to be considered unsound). Every recruit must have at least twenty sound teeth, and of these not less than four opposed incisors and four opposed molars.

"3. Any acute disease." ${ }_{1}$

\section{THE NAVAL RATION.2}

The naval ration is always different from that of the soldier for reasons already given. The rations for the United States navy, as prescribed in 1907 , consists of the following daily allowance of provisions to each person: Furthermore, it will be noted that "any article com-

' Cireular relating to the Eulistment of Men for The U. S. Nary.

${ }^{2}$ General Order No. 44, Nary Departmęnt, April 16, 1907. 
prised in the navy ration may be issued in excess of the authorized quantity provided there be an under-issue of the same value in some other article or articles."

TABLe of Ration Components.

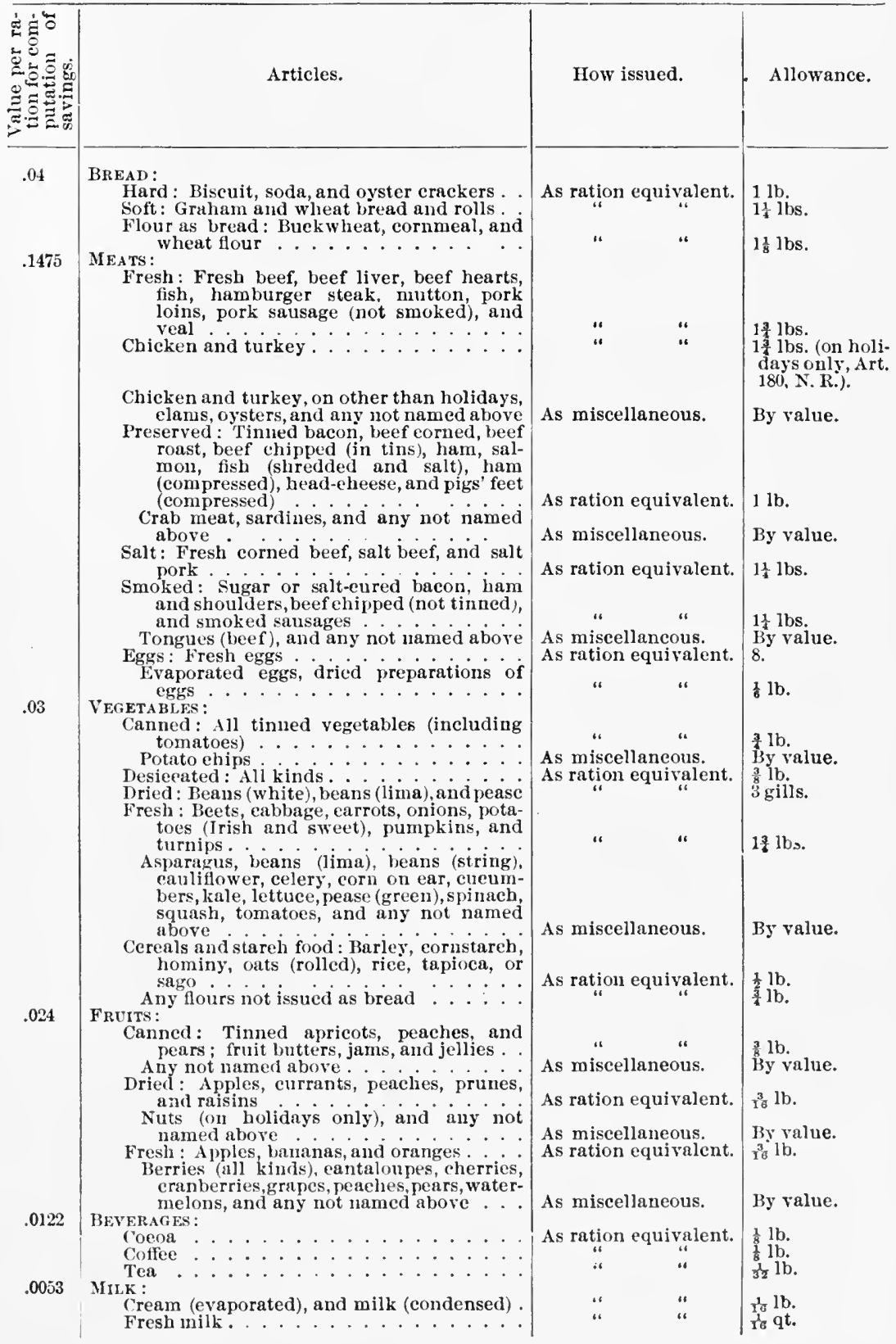


'Tamle of Ration Components-Continued.

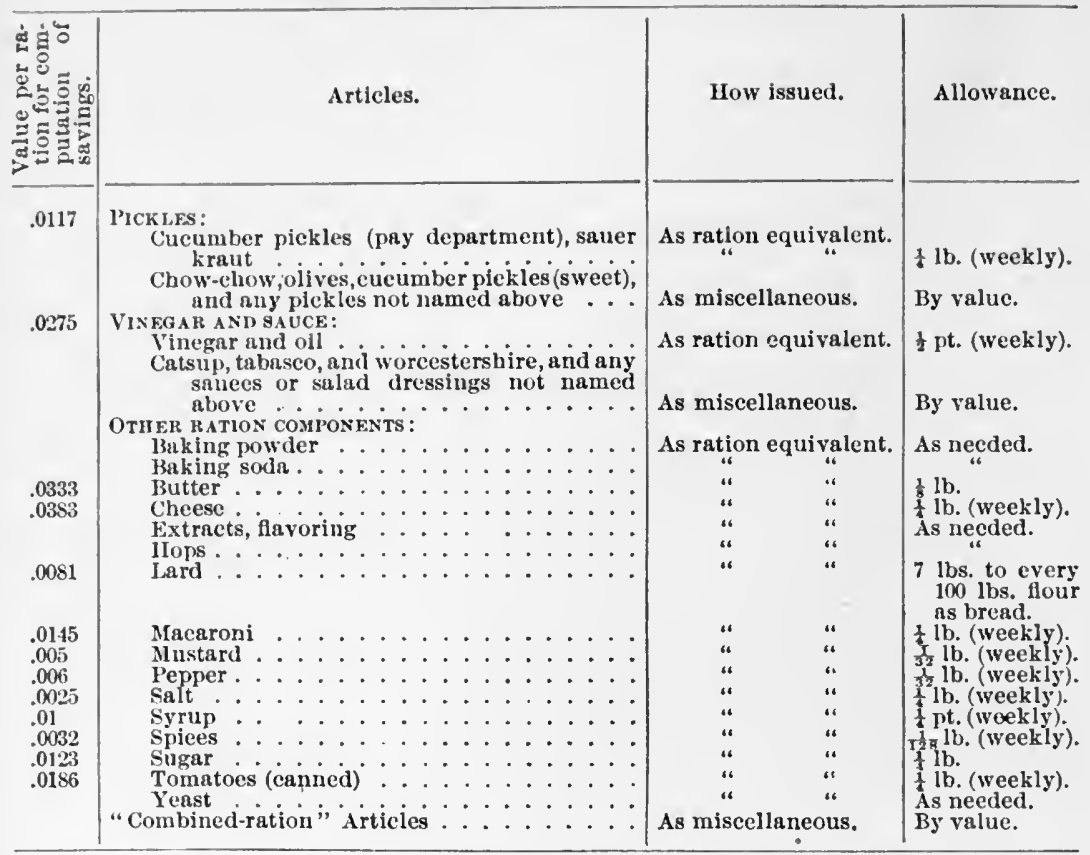

Preserved meats, in the meaning of the law, comprise canned beef, mutton, corned beef, bacon, ham, sausages, salted fish, and any other smoked or salted meats. Flour comprises wheat, rye, oatmeal, cornmeal, and hominy. Dried fruits include apples, peaches, prunes, raisins, dates, figs, and others suseeptible of preservation by drying.

From the above, it will be noted that our naval ration is very elastic and generous, and, indeed, is said to be superior in amount and variety to that of any forcign navy, just as our army ration surpasses in these respects those of other armies.

In spite of the elasticity and abundance of the ration, considerable improvement and much greater satisfaction appear to be attained by the system of the consolidated mess, instituted originally, in 1889, by Lieutenant Delehanty, of the U. S. S. Independence. Not the least of its advantages is the improvement in the preparation and serving of the food. In the ordinary method of messing, the ship's company is divided into a number of messes of about twenty men, and each has its own cook and mess attendants. The preparation of the food for all is in charge of the chief cook and a number of assistants, and the serving out and the care of the mess gear are attended to by the mess attendants or berth-deck cooks. According to Lieutenant B. C. Decker, of the U. S. S. Indiann, "the present system of messes with incompetent and often broken-down landsmen as cooks, ... and with general waste and mismanagement, is a failure."

1 The Consolidated Mess of the Crew of the U. S. S. Indiana, Proceedings of the U. S. Naval Institute, XXIII., 1897, p. 463, 
In the eonsolidated mess of the Indiana, as described by Deeker, the erew of 380 men have a eommon interest, and are attended to by seven cooks, one of the first class, two of the second, and four of the third class, a commissary yeoman, and a storeroom keeper. Funds for provisioning the mess are derived from the commuted rations and the canteen. (Here may be stated that, in the diseussion of the paper noted, the cantecn system, as it existed in the Navy, was the subject of severe critieism by offieers of the line. It is now abolished.)

The system saves much trouble, requires fewer eooks, and by making possible the purchase of a still wider variety of food materials, insures greater satisfaction throughout at a diminished eost.

The principal defects of all dietaries for seafaring men comprise monotony, deficiency in vegetable components, and excess of preserved meats. In order to guard against the results of an insufficient supply of antiscorbutic vegetables, the Revised Statutes require that all vessels of more than 75 tons bound across the Atlantic or Paeifie or around Cape Horn or Cape of Good Hope, or engaged in whaling or sealing, shall carry a sufficient supply of lemon juice or lime juice, and vinegar, which shall be served out within ten days after salt provisions have been served out, the lemon juiee or lime juice at the rate of one-half ounce daily, and the vinegar at the rate of one-lalf pint weekly, per man.

\section{WATER SUPPLY.}

The satisfactory storage of water aboard ships is a matter of some difficulty. Small vessels, as ordinary merehant ships and similar craft, not provided with distilling apparatus, must neeessarily earry a suffieiency of water for the passage between ports, reekoned at three quarts daily per man plus an amount sufficient for cooking. Water is stored in wooden easks and metallie tanks. Storage in easks is far from satisfactory, on aceount of the deterioration which oceurs in the quality of the water. This is due to the action of the water in extracting matters from the wood, and to decomposition of these matters induced and earried on by the usual ageneies. Casks should not be made of soft wood, and the interior should be very thoroughly charred, in order to diminish as much as possible the extration of soluble constituents and to guard against decay. Tanks are eommonly made of galvinized iron, lined sometimes with eement. They should be placed in easily accessible loeations which admit of ready inspection and cleansing.

No water should be taken on board unless its souree is known and its quality is such as to preelude the danger of introdncing waterborne discases. Large vessels and steamships provided with distilling apparatus do not, of eourse, need to provide for the storage of large volumes of water. The water yielded by a distilling apparatus is, on the whole, far superior in quality to that which, however good originally, has been stored for any considerable time. For full considerattion of the subjeet of water and its storage, the reader is referred to the chapter devoted to that subject. 


\section{THE SAILOR'S SLEEPING QUARTERS.}

The sailor is berthed commonly either in deck houses, forecastles, or between decks. Deck houses are by far to be preferred, since they are well lighted and can be well aired. They are placed about midships, and are most aceessible and convenient. There are two kinds of forecastles; one, known as the top-gallant forecastle, has side lights and is entered through a doorway; the other, commonly found on merchant vessels and small craft in general, is entered from above through a hatchway, and is not lighted. This is the least desirable lodging place, and is exceedingly difficult to keep in a cleanly condition. In fact, on merchant vessels, it is commonly infested with bedbugs and other vermin, and is the storehouse for wet, dirty clothes and all manner of rubbish. Forecastles are likely to be damper than other parts, on aceount of the greater amount of water shipped over the forepart of the vessel when under way.

Cubic space per capita depends upon the facilities for the convenient hanging of hammoeks; it ean never be generous : it is always far less in amount than is regarded ashore as essential for the maintenance of a fair degree of health. In fact, sailors are almost always overcrowded: they have nothing like the allowance which obtains in barracks, but rather that of the tent in the field. The fact that the sailor's rest is broken in upon, so that at no time dloes he get more than four hours of consecutive sleep, may perhaps be a benefit to him in that, in the intervals, he breathes the pure ontside air, and may thus, in some measure, counteract the evil results of breathing the necessarily impure air below. The English statute requires that a seaman in the merchant marine shall have not less than 72 cubic feet of air space and 12 square feet of floor space, exclusive of that occupied by the necessary articles of furniture and dunnage.

In the matter of cubic space, the crews of merchant vessels are, as a rule, better off than those of men-of-war, since, on ressels of the latter class, the eomplement of men required for all the various duties is so large that overerowding is to be looked upon as a matter of course. The sleeping quarters of most of the erew are located below the water line on the berth deck. Some are quartered on the gun deck, which is above the water line, and consequently is circumstanced better as to light and air.

The sailor sleeps in either a hammock or a bunk. The hammock is a hanging bed, made of heavy canvas, about six feet long and half as wide. At each end, brass or eopper eyelets are worked in, throngh which the nettles of the clews pass and are fastened. The clews end in an iron ring, to which the lashing for each end is attached. In the hammock are placed a mattress and the necessary coverings, and on this lie gets his modicum of rest in a constrained, unnatural position, bent into a curve, no matter low he may dispose himself. Bunks are far more rational and comfortable, since they permit of a horizontal attitude. They are made of iron framework, wound with canvas or other non-conducting matcrial, or of wood. They possess the addi- 
tional advantages of occupying less space and of being more easily kept in clean condition. Commonly, they are placed in two tiers and suffieiently far apart to permit of easy passage on either side. The lower tier should be not less than nine inches from the deck.

Quarters for officers and passengers are, as may naturally be supposed, more favorably located and more commodious than those assigned to the crew.

\section{THE DISEASES OF SAILORS.}

The chief diseases to which persons on shipboard are subject include diseases of the respiratory organs (particularly tuberculosis), rheumatism, diseases of the digestive apparatus, venereal diseases, and seasickness. Of nervous troubles, nostalgia, melancholia, and hypochondriasis are common. Skin discases of various kinds are also common. Cholera and yellow fever and other important infectious diseases appear to be closely connected with ships, by which, as elsewhere noted, the contagion is frequently carried from one country to another. Formerly, scurvy was associated especially with life on shipboard, but since the discovery and introduction of the proper prophylactic remedy, the disease has been practically eliminated from the list. In addition, troubles of minor importance, arising from special duties, are of common occurrence, but not lasting in charaeter; such, for instance, as eyestrain and other disturbances of vision, disturbances of hearing, and trauma.

In spite of improved hygiene, diseases of the lungs, particularly tuberculosis, appear generally to be on the increase among seafaring men, instead of on the decline. It is said that in the British Navy, between 1883 and 1890, diseases of the lungs increased 60 per cent. It had been supposed that the doing away with masts, sails, and rigging, with the consequent lessened exposure of the men to cold and wet, would have a contrary effect; but its influence, if any it had, has been more than counterbalanced by the change in conditions below, the men living now in a very crowded condition in hot steel ships.

Firemen and stokers are very prone to phthisis, and not infrequently the exhausting nature of their work causes them to become debilitated, morbid, and inclined to suicide. Among this class, vertigo, stupor, and convulsions are common.

Hospitals for the treatment of the sick at sea should not be located, as they usually are, on the berth deck forward, but should be about amidships, where they may receive a sufficient amount of light and air. The furniture should be of iron, thus permitting easy cleansing.

\section{VENTILATION OF VESSELS.}

The air of a ship below the deck is commonly fir from meeting the requirements generally accepted, and is often extremely foul, and hence wholly unfit for respiration. The contributing canses of this condition are an excess of aqueous vapor from respiration and from water 
used in swabbing decks or shipped over the sides while under way; an excess of carbon dioxide from respiration, combustion of illuminants, and decomposition of organic matters; eftuvia from the bilge-water, from oil, tar, paint, and other necessary supplies, from the components of the cargo, and from other sources. The crew's sleeping quarters, even though protected by all practicable means from contaminated air from the hold, bilges, and fore-peak, are commonly reached through some channel by the effluvia, which, mingling with those natural to the place, serve to make a very bad condition much worse.

The problem of efficient ventilation of vessels is exceedingly complex, and is quite different from that of ventilating dwellings and other buildings, since the fundamental conditions are so little in agreement; and it becomes more complicated with increase in the size of the ship. The principles are the same as in house ventilation, but the application of methods is surrounded by greater difficulties, due to peculiarities of construction and to external conditions. Natural ventilation may be effected under favoring conditions through the medium of hatchways, port holes, and other openings; canvas tubes or funnels with a side opening at the top, stayed to face the wind or the ship's course, known as windsails; fixed ventilating tubes acting in the same manner, hollow masts, and other appliances.

Hatchways are commonly the only openings for ventilating the lower forecastles, and in foul weather they are kept closed. Sometimes an outlet, capped by a cowl, is provided, but it is usually kept closed, on account of the discomfort of drafts. Deckhouses and topgallant forecastles are much more efficiently ventilated through the side openings and because of their greater exposure to the external air. Holds and spaces between decks are ventilated through hatehways, fixed tubes, and windsails, hollow masts which act as ventilating flues, funnel casings which act like jacketed stoves, and other means.

Vessels of large size cannot depend upon any system of natural ventilation, but must have recourse to mechanical methods of propulsion and extraction, and even then only an imperfect result can be hoped for. As in the mechanical ventilation of buildings, propulsion is likely to prove far more effective than extraction, and its efficiency is very greatly dependent upon the intelligent planning of the system of the channelways and valves. Valves are required not only for the purpose of shutting off the air current where it is not at the moment required, but also, on men-of-war and other large vessels, for the protection of water-tight bulkheads in case of accident, and of different compartments in case of fire.

The ventilation of vessels engaged in earrying passengers is provided for in part by legislation. The U. S. Revised Statutes require that vessels carrying a hundred or more passengers shall have for each apartment two ventilators, one forward and one aft, of a capacity proportionate to the size of the apartments, a tube 12 inches in diameter being regarded as the proper size for an apartment for 200 persons. If other means of attaining the same measure of ventilation are pro- 
vided, they may be used in place of those stipulated. Under the English law, the provisions for lighting and ventilating must receive the approval of the Emigration Officer at the port of elearance, and if there are as many as a hundred passengers on board, the vessel nuust be provided with "an adequate and proper ventilating apparatus to be approved by such officer and fitted to his satisfaction."

When artificial heating is required, use is made of stoves and steam leating. In the forecastle of sailing vessels, small square stoves of east iron with a movable eover are employed. They are dirty, inconvenient, and generally unsatisfactory.

\section{GENERAL HYGIENE OF SHIPS.}

Of the very first importance in the lyygiene of ships is general cleanliness of ship and personnel. Cleanliness of the ship requires constant watchfulness and unremitting attention, and daily inspection is necessary to insure that cleanliness is not wholly superficial, since it often happens that, whereas the decks and all visible portions are clean, parts which are out of sight are not in a wholesome condition. Naval vessels of all countries are, as a class, much more carefully looked after in this respect than those of the merchant marine.

In securing cleanliness, it is a mistake to use water too frequently and in too great abundance, and great care should be taken that all superfluous water is removed as quickly as possible from all parts below deeks, since one of the cardinal directions is to keep dry, for damp ships are notoriously unhealthy. The dampness that eondenses from the moist air upon the surface of metal plates and overhead beams is a souree of great annoyance from its constant dripping, and keeps up a continual dampness. This can be remedied only by sheathing or coverings of non-conducting material, such as granulated cork or asbestos fiber.

The most difficult parts to keep in even fairly sweet condition are the bilges, in which colleets that most disagreeable and offensive liquid known as bilge-water, the internal drainage of the ship, mneh of which, in wooden ships, leaks from without inward, through the seams. The disgusting odor of bilge-water is due to the decomposition of the organic matters present, and to the reduetion of sulphates of the salt water to sulphides. The bilges require periodical pumping, and are connected for this reason with pumps, known as bilge-pumps. The bilge-water removed is discharged into the sea, and after removal, the bilges are flushed with clean sea-water and again pumped out; sometimes they are regularly deodorized and disinfeeted.

Next in importance, on account of their eommonly unwholesome condition and the difficulty with which they are made clean and kept so, are the peaks. In small vessels, the fore-peak very commonly causes fouling of the air of the erew's quarters in the forecastle.

From a hygienic standpoint, the stoke holds of steamers are of great importance, for here, in a very restricted space, exposed to excessive 
heat from the furnaces, the stokers perform their exhausting office. The air of the stoke holds is commonly not only excessively hot, but exceedingly foul, and these conditions can be abated only by proper ventilation, which may be secured either by means of mechanical appliances or windsails.

Water-elosets and latrines should be of as simple a type as possible and capable of effective flushing. The soil-pipes may discharge above or below the water line. Where closets must be located below the water line, special pumping arrangements are provided for their emptying and flushing. Their placing differs aceording to the size and character of the ships. Latrines for the erew are placed forward and completely disconneeted from the foreeastle. They are supplied at the rate of not less than three for every hundred men. Urinals are commonly a source of great nuisance, and hence require extra care.

On passenger ships, three elosets should be provided for every hundred persons carried, and they should be so located with reference to sleeping quarters that they may not give rise to nuisance.

Whenever weather and other circumstances permit, all bedding should be thoroughly aired, each article being brought up from below and exposed separately, fastened to the rigging or upon the girt lines. Hammocks should be thoroughly cleaned and dried about once in every fortnight. Blankets should be washed with soap at least every six months; hammocks and all articles of bedding should be, when practicable, exposed for part of each day to the direct action of the sunlight.

For methods of disinfection and general cleansing, the reader is referred to the chapter on Quarantine.

Personal eleanliness of the men is of even greater importance than cleanliness of their surroundings, and, indeed, the two go hand in hand, for men of cleanly habits will not permit their surroundings to be otherwise than wholesome, and those who are not naturally so inclined should be required to keep themselves clean. Each man should be allowed a sufficient supply of fresh water daily, and the necessary appliances for washing should be provided. In navies, the washing of the person is commonly made a part of the routine. Special provision for the care of the person is required for those who have the dirtiest work to perform, namely, the firemen and stokers, since their ocenpation precludes the use of much wearing apparel, and the air of the place where the work is laden with coal dust and so hot that their borlies are eonstantly bathed in perspiration. Short bath-tubs of galvanized iron, a sufficient number of wash-basins, and a reasonable allowance of water and soap, should be provided. Given the conveniences and encouragement to make use of them, the chances are that they will be appreciated and freely used.

As in the case with soldiers, it is of very great importance that sailors should be kept busy and, at the same time, should have sufficient time for relaxation, which they should be encouraged to spend in such pursuits as will conduce best to the promotion of cheerfulness and the prevention of ennui. 


\section{CHAPTER XI.}

\section{TROPICAL, HYGIENE.}

\section{THE SOLDIER AND THE CIVILIAN IN THE TROPICS.}

The following pages, dealing with hygiene in the tropies, have greater general applieability to the life of eivilians, who have a wide choice in their mode of life and distribution of their time, but the main principles are equally applieable to the life of the soldier, even although his liberty of action in the following of his own inclinations is very greatly restricted.

It is a very common mistake among persons reared in temperate elimates to suppose that the change to a tropical elimate means chiefly a sudden access of heat, and that it is simply this increased heat which one has to consider; but it is not, as a rule, the actual temperature which affects the individual, for in the North we may have for days at a time a higher temperature than obtains customarily in some parts of the tropies, without suffering in the same way. The principal difference lies in the excessive tropical humidity, but tropical elimates are not equally humid, some being exceedingly moist, and some exceptionally dry.

In some parts of Australia, for example, the elimate is exceedingly dry and the temperature is very high, and yet there is mueh less liability to sunstroke and heat apoplexy than in some parts of India, where the temperature is less high, but the atmosphere exceedingly humid. Since all hot climates are not alike, the mode of life also varies; and in any case it is neessary to take into consideration the special local eharacteristies of elimate and the methods of life followed by the natives, and if one takes eare to adapt his clothing, his diet, and personal habits to the eonditions which surround him, life in the tropies may be bearable, even if not thoroughly enjoyable. On this point, Dr. S. O. L. Potter, U. S. V., ${ }^{1}$ writing on the spot, says: "If people can take reasonable care of themselves, and do not give way to excesses in any form, drink, eating, or working, they will live as healthily in Manila as in New Orleans or St. I conis or New York." But they cannot withstand the effects of any tropieal elimate for long withont an oceasional visit to the temperate zone, for prolonged residence brings about an undoubted deterioration of the system in spite of all possible care.

According to Freeman, ${ }^{2}$ Europeans, after some years' continuous residence in a hot country, degenerate, losing energy, initiative, and memory, which, from a military point of view, is not compensated for

I Notes on the Philippines, Philadelphia Medieal Joumal, April 7, 1900 p. 803.

2 The Sanitation of British Troops in India, London, 1899. 
by diminished liability to disease. Henee the neessity of furloughs at stated intervals. Potter says, "Many of our older officers have undergone a process of rapid aging here without any definite ailment to account for their condition. They simply grow thinner and thinner day by day, running down gradually in physical strength as emaciation goes on, until finally the General takes pity and sends them home."

According to a number of observers, the body temperature of new arrivals in hot climates is appreciably elevated (0.4-0.9 degree F.) above the normal, and under some conditions of high temperature, since the body cannot radiate heat to hotter surrounding air, the body temperature may run as high as $102^{\circ}$ in health. The body is then dependent chiefly upon evaporation from the surface for the keeping down of the temperature as nearly as possible to normal. But when bigh temperature is conjoined with high humidity, the difficulty and discomfort are much increased. Continued moist heat, through its influence on metabolism and the varions functions of the body, causes great nervous exhaustion and general deterioration. The respiration is depressed, the force and rate of the pulse.lowered, the mind becones dulled; the sweat is doubled in amount, and thirst increased in proportion ; the digestive fuuction is weakened, and appetite for even the lessened necessity for food is diminished and requires constant stimulation. The body loses in weight, and both body and mind in energy.

Dr. Federico Montaldo, of the Spanish Navy, in a practical handbook $^{1}$ written for the use of Europeans intending to visit the Spanish colonies, published just prior to the outbreak of our war with Spain, urges upon those who are not sure of the soundness of their health the necessity of submitting themselves for thorough physical examination, since a trivial ailment, easily corrected at home, may develop in the tropics into a trouble not easily managed. Potter, ${ }^{2}$ also, on this latter point, remarks : "It is all very nice as long as one is well, but those who get sick don't easily recover here. Convaleseence is very slow and very difficult." And again, "the general elimate of these islands is not pernicious for those who are able to avoid exposure, but when broken down by hardship or incidental disease, complete recovery is doubtful and convalescence is very slowly established." Burot and Legrand, ${ }^{3}$ also, lay stress on the necessity of selection of healthy individuals for service in the tropies, saying that if the soldier is too young or if his constitution is not strong, he will be an easy prey to disease, while if, on the contrary, he has been carefully selected in the light of the peculiar eonditions and the demands upon his strength, he will be better able to resist morbid influences.

Dr. Lueca, ${ }^{4}$ speaking from an experience of a number of years as a military surgeon in Borneo, urges the exereise of great eare to insure the health of troops on transports, so that they may not be landed

' Guia Practica Higiénica y Médiea del Europeo en los Países Törridos (Filipinas, Cuha, Puerto Rico, Fernando I'óo, ete.), Madrid, 1898, p. 19.

${ }^{2}$ Loco citato.

3 Hygiène du Soldat sous les Tropiques, Paris, 1898.

'Einige Bemerkungen über Acclimatisation und Leben in den Tropen, Munich, 1898. 
already sick and weak and ready for shipment home. Raseh ${ }^{1}$ advises all who are prone to nervous disorder, those already suffering, and, above all, epileptics, to keep away from the tropics; and Macleod ${ }^{2}$ offers the same adviee to anyone whose heart and blood-vessels are not wholly normal.

It is also well to choose, if possible, the best time of year for landing. There are, it is true, only two seasons in the tropies, the dry and the rainy ; but there are, nevertheless, transition periods of greater or lesser duration.

Residence.-If one has a choice in the matter of residence, it is well to be cautious in its excreise, and to begin on high land and away from the coast. The English have long recognized the necessity of sending their soldiers inland and to the hills, when military requirements are not opposed. After getting somewhat aceustomed to new conditions, the lower parts and the coast may gradually be ventured upon.

In some parts of the tropics, it is customary to leave sleeping apartments open during the day and closed at night; but in others, the contrary is the rule, the doors and windows being closed by day. The best form of bed is that made of not too heavy iron, with a frame or other device to support a mosquito bar. The bed should be placed away from the walls and out of draughts. The legs should stand in small vessels filled with water, in order to keep away small crawling insects. If in the eountry and neither bed nor hammock is to be had, and one is obliged to sleep on the floor or ground, a rubber or other waterproof sheet or a dressed hicke should be spread, and the body shonld be well protected against condensing moisture and troublesome insects.

Habits of Life.-All authorities agree in at least one particular, and that is, in urging moderation in all things - diet, drink, work, exercise, dress. The diet should be chosen with care, and iced drinks taken in great moderation, if at all. The elothing should be chosen with judgment, both as to protection from the heat of the sun and against chilling of the body.

Work should not be excessive, nor should it be performed in the sun during the hottest part of the day. Montaldo ${ }^{3}$ advises one to rise with the sun and take a quick cool bath, and then, after a light breakfast of coffee, tea, or chocolate, with a little bread, to attend to whatever duties one has to perform, until about 10.30 A. M., when luncheon may be had. This should not be heavy as to food or drink. The latter may consist of a little water with claret or lemon juice, or tea or coffee. If one's work is out of doors, it should not be resumed before 3 in the afternoon, and in the meantime one should rest indoors. After 6.30, a substantial, but not too hearty, dinner should be taken, observing the same moderation in the matter of drinking. One should never go out with an empty stomach nor do work immediately after a

'Allgemeine Zeitschrift für Psychiatrie, 1897, p. 745.

${ }^{2}$ Journal of Tropical Medicine, Tol. I., No. 1.

${ }^{3}$ Loco citato. 
meal. After dinner, a walk or some form of recreation until 10.30 or thereabouts, which is the proper time for retiring.

One is advised strongly not to expose one's self to the eool external night air ; to avoid eold bathing and eold drinks while perspiring; and especially to avoid standing for a long time in the shade in garments wet with perspiration. If one is eompelled to be exposed to the sun for long, the protection afforded by umbrellas and colored spectaeles against heat and grlare should be sought. The consequences of exposure may be execerlingly severe or even fatal. There are various forms of what are commonly known as sunstroke and heat apoplexy. A very common form is one of syneope, brought on by overexertion in the direct sunlight or even within doors by one already in a depressed eondition. The skin is moist and clammy, the pulse very feeble and almost imperceptible, the muscular power almost eompletely lost. Death may oceur by eardiae failure, but recovery under appropriate treatment is the general rule. Another form, due to direct action of the sun's rays on the brain and eord, is in the nature of a very sudden severe shock affecting the respiratory and eardiae eenters, and commonly quickly fatal. Complete recovery is rare. A third form, eommonly known as heat apoplexy, is due to exposure to constantly high temperature not necessarily involving direet exposure to the sun, and, in faet, may oecur in eloudy weather and at night. The whole body becomes overheated and the temperature may exeed $110^{\circ} \mathrm{F}$. The skin is generally dry, althongh sometimes moist; the pulse full and regular or small and irregular; respiration labored. There is intense restlessness, and epileptiform convulsions may supervene. These cases are frequently fatal, and if recovery occurs, it is not eomplete. In India, aceording to Freeman, ${ }^{1}$ heat apoplexy and sunstroke oceur usually toward the end of hot weather, although the nidday sun is strong enough in most places to eause severe headache, if not sunstroke, the year ronnd.

For the avoidance of sunstroke, in addition to having proper head eovering and umbrella, the neek and spine should be properly proteeted from the sun's rays. The double pleat in the baek of the Norfolk jacket is intended as a protection to the spine. A few green leaves in the hat are sometimes conducive to comfort.

The eonmonly given adviee to follow the customs and habits of the natives in respect to diet and physical exereise ean be accepted only in part, for the native of the tropies is, as a rule, a lazy individual who merely exists; the wear and tear of his system require but little in the way of repair, and his food is of the simplest kind; he has no ambition and no desire to hoard up a fortune which he eannot nse; but between his indolence and our high-pressure life, there is a happy mean, especially in the tropies.

Diet.-The question of diet in the tropies is a very serious one, for error's may be followed by disastrons results. Since prolonged heat exerts an unfavorable influence on digestion, this fimetion should not

${ }^{1}$ Journal of Tropical Medicine, Vol. I., No. 1. 
be made to bear too heavy a burden, and it becomes necessary to restrict the diet in several particulars. No more food should be taken than can comfortably be digested, for both dysentery and diarrhoea are favored by the irritation eaused in the intestines by food partially digested or undergoing fermentative processes. But the change from the accustomed diet should not be made with too great abruptness.

The natives depend chiefly upon a vegetable diet, in which rice and beans and fruits of all kinds play prominent parts. Meat, if eaten at all, is taken usually in very small quantities. As a rule, in hot elimates, it is not tender, for it cannot be hung days and weeks, as with us, to ripen, but must be cooked and eaten within a very few hours after slaughtering. Fish should not be used unless very fiesh, and shell-fish of all kinds should be avoided. Fresh milk is ordinarily not to be had or, at least, is difficult to obtain. It speedily sours and beeomes unfit to drink. Condensed milk of good quality is more to be depended upon. Vegetables should be thoroughly cooked, or they will seriously tax the digestive organs. Fruits should be perfectly ripe and sound; over-ripeness is quite as objectionable as greenness. Overindulgenee in fruit, even of the best quality, and especially in the sour fruits, is particularly to be avoided.

Tea, coffee, and chocolate are advised in moderation. Lime juice with water or cold tea makes a most refreshing drink. Tamarinds in water are also most grateful.

If aleohol in any form is desired, the light wines dilnted with water are recommended more highly than beer. Spirits are generally eondemned, but there appear's to be no valid reason why, when very liargely diluted with water or soda water, they should exert a more pernicious influence than wine only moderately extended. In any event, alcohol should be taken only with food.

The Use of Alcohol in the Tropics.-Writers on tropieal lygiene are almost unanimons in the opinion that, whatever may be said for and against the use of alcoholic drinks in other climates, their use in the tropies constitutes a distinet danger, and that mueh of disease commonly attributed to elimate is due actually to alcohol. Especially is this true of the various renal and hepatic tronbles. Aceording to Treille, ${ }^{1}$ the abuse of aleohol is the ehief cause of the frequency of diseases of the liver, not alone among visiting Europeans, but among natives as well.

Dr. Chr. Raseh, ${ }^{2}$ speaking of the futility of talk about Europeans getting aceustomed to continued high temperature with high humidity, and deseribing the various steps in physical and mental deterioration, to comteract which, one turns to alcohol and other stimulants, says that these, together with insomnia and enforeed lack of exereise, bring about a general atonic condition, or, in other words, a lowered physiologieal resistance to diseases in general. Dr. Breitenstem, ${ }^{3}$ who for

1 Principes d'IIygiène coloniale, Paris, 1899, p. 272.

${ }^{2}$ Allgemeine Zeitschrift für Psychiatrie, 1897, 1). 745.

${ }^{3}$ Hygiene in den Tropen, Monatsschrift für Gesundheitspflege, 1898, Nos. 7 and 8. 
twenty years served as an army surgeon in the Malay Archipelago, gives it as his opinion, based on long observation, that total abstinence from alcohol is far preferable to even the most moderate indulgence.

A writer in Manila has pointedly remarked concerning the health of the American troops, "It is not so much the climate as the glass bottle which injures people out here," which statement is corroborated by another who had seen actual service as a member of a company, nany of whose members were total abstainers and the rest made up of moderate drinkers and those prone to excesses, the latter constituting 20 to 25 per cent. of the whole. Of the latter elass, only two returned home in approximately the same condition of health which they enjoyed at the time of enlistment. Of the moderate drinkers who confined themselves to malt liquors, a large majority suffered more or less impairment of general health. But the total abstainers returned almost to a man in excellent health, having endured the same hardships of an active campaign. 'The same correspondent, speaking of the far greater harm induced by the stronger alcoholic drinks, relates that he had repeatedly seen Amcrican soldiers, after spending several hours under shelter, drinking round after round without perceptible harm, fall over with all the symptoms of sunstroke as soon as they stepped into the glaring rays of the hot sun.

On the other hand, in opposition to the general opinion adverse to even the moderate use of alcohol in the tropics, Dr. C. E. Woodruff, U.S. A., after a careful survey of the conditions obtaining in the Philippines, declares that he would change the statement in the general order from headquarters of the army, July 2, 1898, "The history of other armies has demonstrated that in a hot climate abstinence from the use of intoxicating drink is essential to continued health and efficiency," to "Experience has demonstrated that in a hot climate the moderate use of intoxicating drink is essential to continued health and efficiency." He asserts that the almost universal drinking must mean a natural defensive craving occasioned by the terrible nervous exhaustion, a true neurasthenia, due to long-continued exposure to great heat and atmospheric humidity, indicating that waste is greater than repair. He asserts that men who want no alcohol at home have this defensive craving for it in the Plilippines, and cites Spanish authority that a daily ration of wine has been found necessary. Whiskey, when sufficiently diluted, is the equivalent of wine, and the Scotch variety is regarded by him as superior for the purpose to Anerican, which soon occasions nausea. Beer, by reason of being conducive to colic, diarrhœa, headache, loss of appetite, and general distress, he regards as distinctly harmful. While advocating the moderate use of alcohol, he believes that the results of abuse are far more serious than at home.

Concerning beer in the tropies, there is much divergence of opinion, some regarding it as a valuable safeguard against abuse of stronger

1 Philadelphia Medical Journal, April 7, 1900, p. 76̣, 
alcoholics, others agreeing with Woodruff that it is harmful. It is said that the drinking of much beer followed by heavy sleeping predisposes to sunstroke and heat a poplexy.

Clothing.-One is advised to take plenty of light cotton, linen, and merino underwear, a generous assortment of trousers and coats of white duck or flannel, and light merino stockings. High boots, well oiled and with hob-nails, laced boots, leggings of cloth and leather, and light footwear for indoor and city use should be included. Light waterproof onter garments with cape and hood are recommended, and for protection against the sun, white umbrellas lined with blue or green material, and spectacles with green or blue colored glasses.

The head-covering should be selected with the double consideration of comfort and protection for the head and neck. The material of which it is made should be chosen with regard to local climatic conditions. In a particularly dry hot climate, for instance, pith is the most suitable material, being lighter than either cork or felt; but a hat made of this material is absolutely worthless in a wet elimate, since on being exposed to rain it absorbs water, becomes exceedingly heavy therefrom, and is reduced to a worthless, shapeless pulp. Hats should be properly ventilated in the crown, and there should be a generous space for the free passage of air between the head-band and the inner side of the hat; that is to say, the head-band should be fastened to the crown of the hat at only a limited number of points and with intervening small pieces of wood or other material, so that the band shall keep its proper shape. All head-covering of whatever form should afford proper protection for the sides of the head and the ears, as well as for the front and back. A puggery affords additional protection.

The brim of the head-covering should be lined with some material of a bluish or green color, as a relief to the eyes. The outside should be light in color. The head-band is made of leather, and is ensily saturated with perspiration, and then hardens on drying; while it is wet, it is exccedingly uncomfortable. If covered with fine flannel, it will be found to be much more comfortable.

Jackets and other onter garments should afford perfect freedom of action in both riding and walking. The Norfolk jacket is a favorite form, and may be made of duck, khaki, or similar material. It is well to leave a few inches of the arm-scyes unstitched for the sake of ventilation. For shirts, a mixture of silk and wool, known as kashmir, is regarded as the best material, being very light in texture and perfectly absorbent. Gauze undershirts with short slecves, or with no sleeves at all, should be worn beneath the shirt. Elastic cotton and jean are the best materials, so far as comfort and durability are concerned, for drawers.

If one is to do much riding, it is advised that as much eare be expended in the selection of a saddle as in seleeting boots, since comfort in horselback riding in the tropics is very largely dependent upon the fit of the saddle. 
Care of the Person. - The irritating effeet of hot winds, whieh frequently carry fine partieles of sand and dust, and the glare of the sun, whieh eonduees to troubles with the eyes, should be guarded against. Not infrequently the ears, too, are affeeted injuriously by hot winds, but they are easily proteeted by external coverings or by cotton-wool plugs.s. The nose and lips are subject to eracking and uncomfortable dryness, which may be helped by cold eream or some similar application. The nails should be kept elosely pared, since they beeome brittle and erack off.

The skin, having a very important funetion to fulfil, should be kept thoroughly clean, if on no other aceount; but bathing in too cold water or for too long a time should be avoided. Parasites abound in tropical elimates, and should be looked for on the person and removed with all care. Among these may be mentioned the chigœ, or jigger, an exeeedingly troublesome small flea (Sarcopsylla penetrans) which burrows beneath the skin, particularly of the feet, and beneath the nails. At first, it causes only itching, but if not then removed, sharp pain and inflammation ensue. A half teaspoonful of flowers of sulphur inside the shoe is said to be an efficient preventive. Another parasite of far greater importance, especially to the troops in the Philippines, is that which oceasions the dhobie itch, whieh ean be avoided only by very great attention to personal cleanliness and frequent ehanging of underclothes. It first attacks the perineum and axillæ, and when the acute stage passes by and the inflammation somewhat subsides, the seales become rubbed off and reach the feet, where the trouble spreads rapidly, causing intense itehing with consequent scratehing and the evil consequences thereof.

Diarrhøa and eonstipation are alike to be avoided. The former should be ehecked at onee, and should on no account be allowed to eontinue without treatment. It is easily brought on by improper or ill-cooked foods, impure water, green and over-ripe fruit, sudden changes in the weather, and intemperance. Constipation should be avoided by the aequirement of a regular habit. Sometimes, a eup of tea or coffee on rising will aet beneficially, and oatmeal and coarse bread, figs and prunes may be found to assist, but purgatives and enemata should be a voided, if possible to get along without them.

Tropical Diseases.- It is beyond the scope of this work to enter upon the field of tropical medicine, but it may be said, in general, that the discases of hot climates are exceedingly varied. Some of them are peculiar to certain distriets; some are exaggerated forms of what we in the temperate zone regard as simple maladies. In general, it may be said that in the tropies one meets nearly all the diseases of the temperate zone plus a great variety of others, but some of our most common diseases may be very rare in certain places. Thus, scarlet fever and diphtheria are rare in the tropics as a whole, tuberenlosis is rare in parts of India and common and quiekly fatal in other parts of the tropics. Rabies is more common in India than in Eugland, and the victims are almost always Europeans. Leprosy, beri-beri, and 
elephantiasis are common among the natives, but very rare among Europeans.

Throughout the tropies, dysentery kills many more people annually than cholera, and works greater havoe in armies than the contending forces. Typhoid fever always appears sooner or later in camps of soldiers from temperate elimates, and the new arrivals are commonly observed to be the most susceptible. This disease and eholera, according to Freeman, rarely occur in India during the hottest months, when the burning rays of the sun act as a germicide; but when the rains come and sweep the accumulated surface dirt into the water courses, they quickly appear.

For a most interesting description of the diseases observed in the tropies, the reader is referred to Castellani and Chalmers' Manual of Tropical Medicine, 1910. 


\section{CHAPTER XII.}

\section{THE RELATION OF INSECTS TO HUMAN DISEASES.}

Althougir a supposed relationship between insects and the spread of diseases has been considered in greater or lesser detail by writers of all times, it is only within the most recent years that the possible connection las been regarded as entitled to most serious consideration. It is not strange that the bare statements of ancient writers concerning the influence of flies and other insects as disseminators of plague and other diseases were not received with any degree of credence, for until recent advances in the fields of bacteriology and zoölogy made demonstration of the connection possible, there was no more reason for accepting them than for accepting similar unsupported assertions concerning the action of clouds and things supernatural. But as our knowledge of the exciting causes of diseases grew with bacteriological and zoölogical research, so, also, came an appreciation of the fact that these same causes might be disseminated by insects and other lower forms of animal life.

Disregarding the not infrequent reports of sickness and death attributed to insect-bites, which, so far as one may know, may have become secondarily infected, it may be said that serious attention was not drawn to insects as bearers of infection until the early 90's. And although Nott, in 1848, had suggested the mosquito as a cause of malaria and yellow fever, and Finlay, in 1881, had asserted that the latter disease was transmitted from infected to non-infected man by these insects, it was not until the closing years of the century that these theories were demonstrated as correct.

The insects which have been most extensively studied are, naturally, those which have the greatest opportunity for contact with human beings, namely, flies, fleas, bedbugs, and mosquitoes; but others have been the subject of more or less extensive investigation which has demonstrated their capacity for conveying, externally or within their bodics, virulent bacteria of many kinds. That insects, coming in contact with material containing pathogenic bacteria, may convey the same directly to wounds or food-stuffs upon which they may alight, needs hardly to be demonstrated, whether the organisms are adherent to the body, limbs, or proboscis; but how long the bacteria may retain their virulence during carriage, and whether, if taken into the insect's alimentary canal, they can survive the process of digestion and be discharged in the freces, can be determined only by direct experiment; and it was with such problems that the first researches on the agency of insects in the transmission of discase were engaged. It has been 
found that certain species of bacteria are digested by certain insects; but it must be borne in mind in practice that this should not be accepted as the inevitable or even usual result, for although flics, for example, will digest certain bacteria, they cannot always be depended upon to do so, and may excrete them with other undigested food.

Besides transmitting specific bacteria, the insect world is responsible for the spread of parasitic organisms belonging to the animal kingdom, now recognized as the causes of malaria, filariasis, and yellow fever, as will be shown.

\section{FLIES.}

Although the possibility of the spread of such diseases as cholera, dysentery, and typhoid fever was demonstrated as early as 1892, the matter did not receive particular attention until the unusual prevalence of typhoid fever in the great military camps in the South in 1898 was made the subject of a careful inquiry, which led to the conclusion that the great swarms of flies which infested the camps were largely responsible. A series of interesting experiments on the subject of infection through the agency of flies was conducted by Sawtchenko ${ }^{1}$ with pure cultures of cholera bacilli. The bacilli, fed to two kinds of flies, were found in the excreta and bowels as late as four days after ingestion ; removed on the third day and inoculated into guineapigs, they were found to be as active as the pure cultures themselves. Similar results were obtained when, instead of pure cultures, the discharges of cholera patients were employed as feeding material. Some of the experiments indicated that the bacilli probably multiply within the fly, which thus acts as a breeder and distributing agent at the same time. A fly, caught in the autopsy room at Hamburg during the great cholera epidemic of 1892, was examined by Simmonds, ${ }^{2}$ and yielded numerous bacilli. This suggested an inquiry into the length of time the poison could retain its activity when adherent to flying insects, and experiment showed that it remained virulent for at least an hour and a half after drying. Surgeon-General Sir William Moore ${ }^{3}$ drew attention, in 1893, to the fact that, in India, flies abound most extensively during the time and season of greatest prevalence of cholera; he suggested that they might act as carriers of typhoid fever, phthisis, and ophthalmia. He instanced an epidemic of anthrax spread by flies which had covered the carcass of a dog thrown into a ditch. It appears that the specific bacteria of this disease resist the digestive process, and may, therefore, be deposited from the external surface or in the frecs. According to Nuttall, ${ }^{4}$ who was the first to present from the exceedingly scattered literature a general view of the part played by insects and other low forms in the transmission of human and other diseases, flies do not convey anthrax by biting, but may become crushed upon the skin, and thus convey the organism to the wound. From a

1 Centralblatt für Bakteriologie und Parasitenkunde, XII., p. 983.

${ }^{2}$ Deutsche medicinisehe Woehensehrift, 1892, No. 41.

3 Medical Magazine, July, 1893.

4 Johns Hopkins Hospital Reports, VIII. (1899), Nos. 1 and 2, p. 1. 
study of the eases cited, it appears likely that in many instances the specifie organism may have been present on the skin prior to the advent of the fly or other insect.

An instance of strong presumptive evidence of an outbreak of cholera through the agency of tlies is furnished by Buchanan, ${ }^{1}$ who relates that in June, 1896, 9 cases of the disease oceurred in Burdwan jail, where, prior to and after the attack, there was exceptional freedom from bowel complaints. The water supply was above suspicion and was the same for all the inmates, who numbered 190, and were divided into two groups, the ordinary prisoners and the "infirm gang." The latter worked, slept, and assoeiated generally with the former, but their food was cooked specially, and they were fed in a separate place in the hospital eompound. The ordinary prisoners-and it was among these that

FIt. 104.

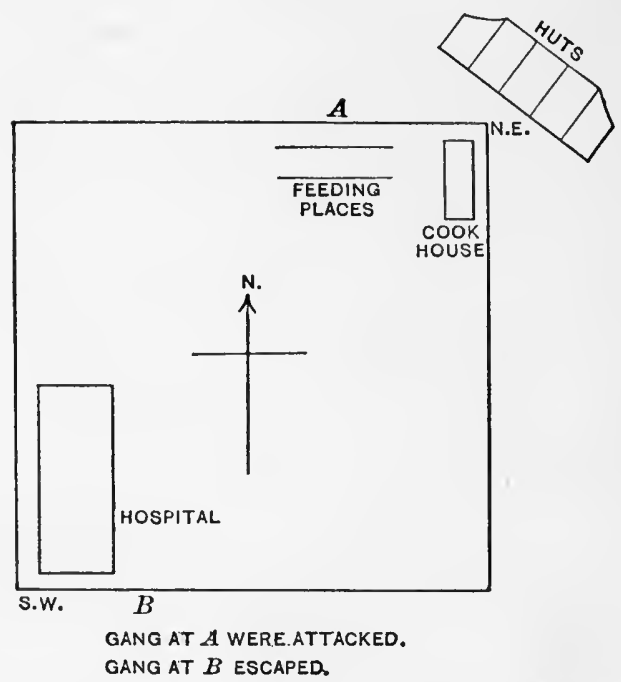

Plan of grounds of Burdwan jail, where cholera is supposed to have been carried by flies.

all the cases oceurred-had their food prepared and were fed at the extreme opposite corner, diagonally from the hospital. Over the wall at their corner were a deserted eompound, and a row of dirty huts where cholera had existed during the preceding year. At the time, the city was more than usually infested with swarms of flies, and just before the ontbreak, a storm had occurred, during which a strong E.N.E. wind blew across the jail yard from the locality mentioned. All who were seized were among those who were known to have had their evening meal in the corner during the storm, and it was believed that swarms of flies were blown from the huts, and on reaching the trees and eorner of the high jail wall, obtained shelter from the storm and settled upon the food exposed in the plates before the gang. The aceompanying figure shows the relative positions of the two gangs at

${ }^{2}$ Indian Medieal Gazette, March, 1897. 
their meal, and of the compound and huts from which the flies were supposed to have come. The evidenee here is purely cireumstantial, but it is to be noted that all of the sick belonged to the same gang; that all had been more than a month in jail, excepting 2 , who had been there seven and twelve days respectively; that there had been no prevalence of diarrhœa before, during, or after the outbreak; that the water and milk supply were the same for all, and that the outbreak was very limited in extent.

The ability of flies to infect food was well demonstrated in 1892 by Uffelmann,' who allowed a cholera-infected fly to drink from a glass of sterile milk, and then shook the latter and kept it at $70^{\circ} \mathrm{F}$. for sixteen hours, at the end of which time each drop contained about a hundred organisms.

The prevalence of typhoid fever among Europeans in India has been attributed by Surgeon-Major Battersby ${ }^{2}$ to the agency of flies, sinee, year by year, ontbreaks oceur which are most difficult or impossible to trace to a water-borne cause, the water supply being in many instances above snspicion, and even of exceptional purity. During our war with Spain, investigation of the great prevalence of typhoid fever in the large camps in the South showed the abundant opportunity which exists for infection by flies, and demonstrated the necessity of thorough camp sanitation, and of exeluding them from contact with both excreta and foods. Visiting the "sinks" at one time and the mess-tables at another, they have the widest opportunity for spreading infection.

The presence of plague bacilli in the intestines of flies has been demonstrated repeatedly within recent years, first by Yersin in 1894, who, noting the large number of dead flies where the victims were being autopsied, crushed one fly and inoculated it into a guinea-pig, which died of the disease in forty-eight hours. Further investigation showed the bacilli present in the intestines of the living fly, and led to the conclusion that they actually multiply therein. Nittall ${ }^{3}$ proved that flies may earry the disease, and that they themselves die of it. It is interesting to note that the statements of early writers to this effect were, therefore, correct. Most of these were vague, and gave no intimation of how the eontagion was earried; but a Venetian, Mereurialis, in 1577, wrote (De Pestilentia) that flies go to infeeted houses, alight upon the sick, and then convey the contagion to other houses and deposit it on bread and other foods.

That flies may play a part in the spread of tuberenlosis, too, seems probable, for the speeific bacilli have repeatedly been found in virulent condition both in their intestines and in their exerements.

Dr. Frederick T. Lord ${ }^{4}$ came to the following conclusions :

" 1 . Flies nay ingest tubereular sputum and excrete tuberele bacilli, the virulence of which may last for at least fifteen days.

1 Berliner klinische Wochenschrift, 1892, p. 1213.

2 British Medical Journal, August 10, 1895. No. 15 .

3 Centralblatt für Bakteriologie, etc., XXII. (1897), No. 4, and XXIII. (1898),

${ }^{4}$ Boston Medical and Surgical Journal, Dec. 15, 1904. 
“2. The danger of human infection from tubercular fly-specks is by the ingestion of the specks on food. Spontincous liberation of tubercle bacilli from fly-speeks is unlikely. If mechanically disturbed, infection of the surrounding air may occur.

"As a corollary to these conclusions, it is suggested that-

“3. Tubercular material (sputum, pus from discharging sinuses, fecal matter from patients with intestinal tuberculosis, etc.) should be carefully protected from flies, lest they act as disseminators of the tubercle bacilli.

" 4. During the fly season greater attention should be paid to the sereening of rooms and hospital wards containing patients with tuberenlosis and laboratories where tubercular material is examined.

" 5. As these precautions would not eliminate fly infection by patients at large, foodstuff's should be protected from flies which may already have ingested tubercular material." They are believed, also, to carry leprosy and various conjunctival diseases.

According to Castellani and Chalmers ${ }^{1}$ flies are capable of carrying the bacilli of dysentery and are, therefore, probably a prolific sonree of infection in tropical countries.

The larvæ of the common house-fly are sometimes found in the alimentary tract. Thus, Cohen ${ }^{2}$ reports finding them in the dejections of a nursing infant, the ova having probably been deposited in its mouth ; and Bachmann ${ }^{3}$ found them in the vomitus of a hard drinker, and later, after the administration of an infusion of pyrethrum, in large numbers in his fæces.

Flies may also transport the eggs of Tonia solium, Trichuris trichiura, Ascaris lumbricoides, and other parasites, and deposit them on foods.

Other flies mentioned by Castellani and Chalmers are Stomoxys calcitrans, the common stable fly found in houses, stables, and in the open near cattle. It bites all classes of mammals and is suspected of spreading trypanosomes, especially $T$. evansi.

Glossina palpalis (tse-tse-fly). The bite of this fly has long been known to be dangerous to animals, but Bruce first showed that it was responsible for the spread of Trypanosoma brucei and the cause of the disease nagana in horses. Furthermore, Bruce and Narbarro showed, in 1903, that Glossina palpalis is the means of transferring T. gambiense, the eause of sleeping sickness. That T. gambiense undergoes a cycle of development in Glossina palpalis has been shown through experiments recently by Kleine.

\section{FLEAS.}

In 1898, Simonds ${ }^{4}$ advanced the idea that fleas from rats sick with plague might spread the disease to other rats, and even to man. $\mathrm{He}$ found the specific bacilli in such fleas, as did also Ogata. ${ }^{5}$

1 Manual of Tropical Medicine, 1910, p. 992.

2 Deutsche medicinische Wochenschrift, March 24, 1898.

4 Annales de l'Institut Pasteur, XII., p. 625.

5 Centralblatt für Bakteriologie, etc., XXI., p. 769. 
The question was thoroughly investigated by the Indian Plague Commission in 1905, and the findings of this Commission are summarized by Blue ${ }^{1}$ as follows: "That fleas (and bugs) taken from plaguesick rats contain $B$. pestis, and that some of them remain alive in the bodies of the insects from five to sixteen days; that plague is conveyed by the bites of fleas which have previously fed on the blood of animals suffering with the disease; that rat fleas bite man ; that under experimental conditions the infection is not transferred from rat to rat in the absence of fleas." 'The fleas most commonly responsible for this transfer are Ceratophyllus fasciatus, the common rat flea of Europe and the United States, and Lomopsylla cheopis, the common rat flea in tropical and sub-tropical countries. The natural inference would be that the infection is transferred at the time of biting; but this seems not to be the case. According to Fox," "repeated examinations, both by dissecting out the salivary glands and by serial scetions of the entire flea, plague bacilli have never been demonstrated in these glands or anywhere outside of the alimentary tract. ... The most plausible explanation that has been advanced has been based on an observation that blood-sucking insects at the time of biting frequently eject a drop of blood from the rectum. We know that the rectum may contain numerous plague bacilli, and it is supposed that this blood ejected in the vicinity of the bite is either brought in contact with the slight wound by the feet or mandibles of the fiea itself or is rubbed in as a result of scratching."

Nuttall $^{3}$ speaks of the possibility of transmission of Trenia cucumerina through fleas. The adult worm is found in dogs, occasionally in eats, and rarely in man. The larval stage is found in dog fleas and lice, and even in the flea that infests man ( $P$. irritans); but the dog flea is the usual host, and may carry as many as 50 larvæ. Dogs infest themsclves by devouring their fleas and lice, and children may become infested by playing with and kissing dogs, the vermin being unconsciously swallowed. The larvæ are liberated in the intestine through digestion of the body of the insect, and they then exvaginate and take on their definite form as tapeworms.

According to Castellani and Chalmers, ${ }^{4}$ fleas may also carry blood parasites, as, for example, Trypanosoma lewisi.

\section{BEDBUGS.}

But fow cases of transmission of disease by bedbugs are known. Nuttall quotes Dewèvre's ${ }^{5}$ report of a case of transmission of tuberculosis after disinfection of a room in which a young man had died of the disease. After the process was completed, the room and bed were occupied by a brother of the deceased, and he, too, died. Investigation showed his body to be much bitten by bedbugs, and the bed to be swarming with the vermin. At this time the floor was soilcd with

1 The Rat and Its Relation to the Public IIealth, 1910, p. $146 . \quad{ }^{2}$ Ibid., p. 132.

3 Johns Hopkins Hospital Reports, VIII., Nos. 1 and 2.

4 Manual of Tropical Medicine, p. 577.

5 Revue de Médecine, XII., 1892, p. 291. 
sputum, and had not been cleaned for many weeks. The contents of 30 bugs were inoculated into 3 guinea-pigs with positive results : all died of tuberculosis. Virulent bacilli were obtained from 60 per cent. of the bugs examined.

According to Castellani and Chalmers, ${ }^{1}$ the Spirocheta recurrentis, the organism of relapsing fever, can live in the bedbug, Cimex lectularius, for some days, and Nuttall succeeded in transmitting it from mouse to mouse by the bites of the same bug. Goodhue, furthermore, is said to have demonstrated the bacilli of leprosy in the bedbug.

\section{ARACHNIDS.}

Ticks.-Although for some years it has been known that ticks were concerned in the spread of certain diseases in animals, it is only recently that they have been found to play any rôle in the etiology of disease in man.

Especially through the work of Ricketts, it has been demonstrated that spotted fever, or Rocky Mountain fever, is transferred by the tick Dermacentor occidentalis. The question as to the cause of this disease is still in dispute; but, according to Castellani and Chalmers ${ }^{2}$, the virus can be acquired and transmitted by the larva, the nymph, and the male and female adults of D. occidentalis, and in a few instances can pass through the eggs into a second generation of ticks.

Body Louse.-The epidemiological facts of tabardillo, or Mexican typhus, in the opinion of Anderson, ${ }^{3}$ point unmistakably to an insect intermediary, and he believes that observations made by him and Goldberger point strongly to the body louse (Pediculus vestimenti) as this insect.

\section{MOSQUITOES.}

Certain genera of mosquitoes have been definitely proved to be the intermediate cause of several of the most disastrous human scourges, and their connection with others has been suggested, and may at any time become demonstrated. The diseases which have been definitely connected with these pests are malaria, yellow fever, and filariasis.

Mosquitoes appear to be ubiquitous; they are found not alone in the torrid and temperate zones, but in the arctic regions, where, according to good authority, they are, in their season, even more of a pest than in warmer latitudes. In Siberia, they hibernate under the moss; and in all inhabited places they hibernate in cellars, outhouses, and other retreats. The larvæ, also, may hibernate, being frozen in the ice on the approach of winter, and able, when thawed out, to resume growth. Gorman found living larvæ in water beneath ice at Providence, R. I., in December; and Wright ${ }^{5}$ found Anopheles larvæ beneath ice in Aberdeenshire. Nuttall has known larve to live from seven to eight months. The adult mosquito may be found in the open,

1 Manual of Tropical Medicine, p. 305.

3 Public Health Reports, Vol. XXV., No. 8, p. 185.

2 Ibid., p. 714.

- Journal of the Boston Society of the Medical Sciences, V., p. 330.

- British Medical Journal, April 13, 1901, p. 882. 
even when the weather is wintry. Thus, Sterling ${ }^{1}$ saw mosquitoes at Mackinaw in March, 1844, when snow covered the ground to a depth of two to four feet. But it is only in warm weather that mosquitoes appear to have any part in the transmission of disease, for temperature has very great influence on the life and development of the parasites which they spread, and upon their own activity and inclination to bite. The parasite of the tropical æstivo-autumnal type of malaria, for example, will fail to thrive in a temperature not too low for that of the tertian; and the latter will not live at $65^{\circ} \mathrm{F}$., which temperature is not too low for that of the quartan type. Malaria rarely develops below $59^{\circ} \mathrm{F}$., and is completely eheeked at $32^{\circ}$, at which temperature mosquitoes are very shiggish and do not bite.

We have in this eountry, according to Dr. L. O. Howard, ${ }^{2} 9$ genera of mosquitoes, represented by about 24 speeies, the larger number of which belong to the genus Culex, and are quite harmless. We have 3 of the 8 or more species of malaria-bearing Anopheles, and Stegonyia calopus (formerly known as Culex fasciatus), the carrier of yellow fever.

Mosquitoes and Malaria.-The indigenous malarial species are as follows :

1. Anopheles maculipennis (A. quadrimaculatus, A. claviger) (Figs.

Frg. 105.

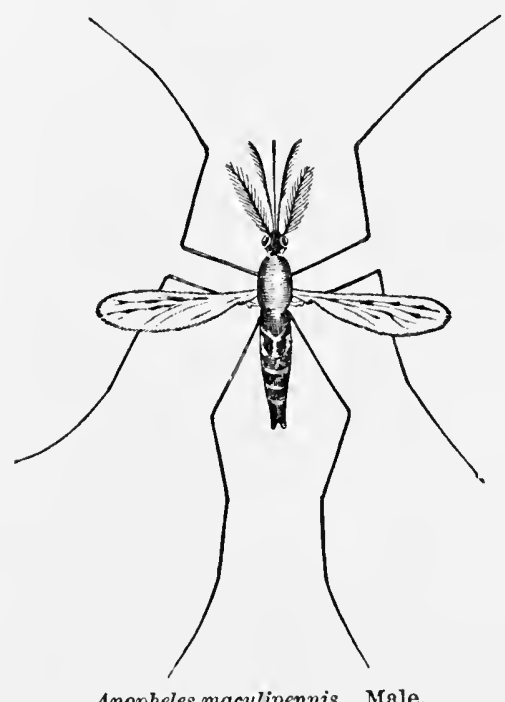

Anopheles maculipennis. Male.
Fig. 106.

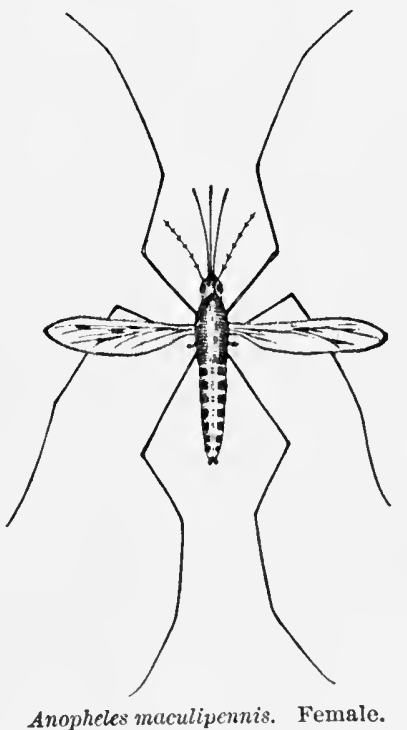

105) and 106) has the "dappled wings" described by Ross. The palpi are black.

2. Anopheles punctipennis has a yellowish-white spot extending about three-fourths of the length of the front margin of the wing. (Figs. 107 and 108.)

3. Auopheles crucians.- The seales of the last wing-rein are white,

1 Insect Life, III., p. 403.

2 Mosquitoes, New York, 1901, p. 230. 
marked with three black spots. The palpi are marked with white at the bases of the last four joints. (Figs. 109 and 110.)

A. maculipennis and $A$. punctipennis are distributed very widely, being found in greater or lesser abundance throughout the country. The former is the most common Anopheles in the malarial districts of Africa and Southern Europe, and is found in Great Britain, Germany, France, and elsewhere.

Fra. 107.

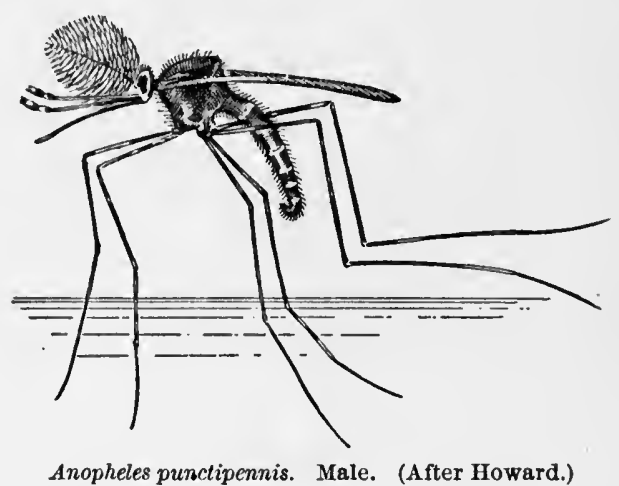

A. crucians is a Southern form, believed to be the carrier of the pernicious, tropical, æstivo-autumnal fever, but not the only one, for in St. Lueia, for example, where the great majority of cases of malaria are of the pernicious type, the common mosquito is $A$. albipes.

Fra. 108.

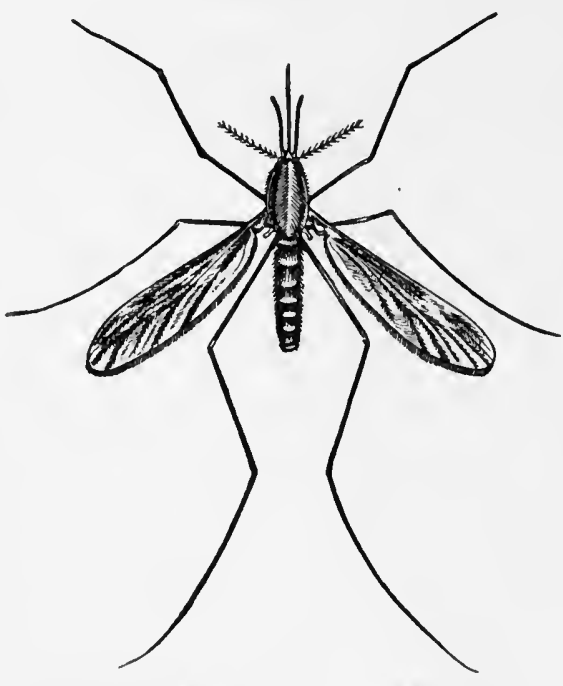

Anopheles punctipennis. Female. (After Iloward.)

Unlike Culiees and Stegomyia, the Anopheles do not breed in rainwater barrels, troughs, cisterns, tin cans, pitcher plants, and other 
small receptacles, but in pools, puddles, ditches, canals, and other bodies of stagnant or but very slowly moving water. The larvæ thrive in clean or foul water, but not in that which is so foul as to stink; they cannot live in salt- or very brackish water, nor where there is rapid movement.

Fı. 109.

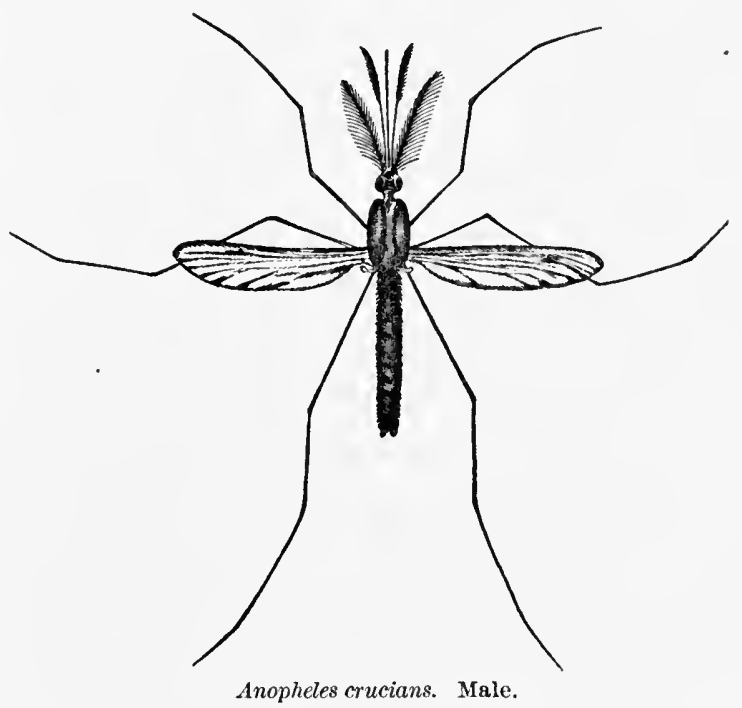

It is only the female imago that sucks human blood, and she is active only at night. She enters dwellings about sundown or later,

Fig. 110.

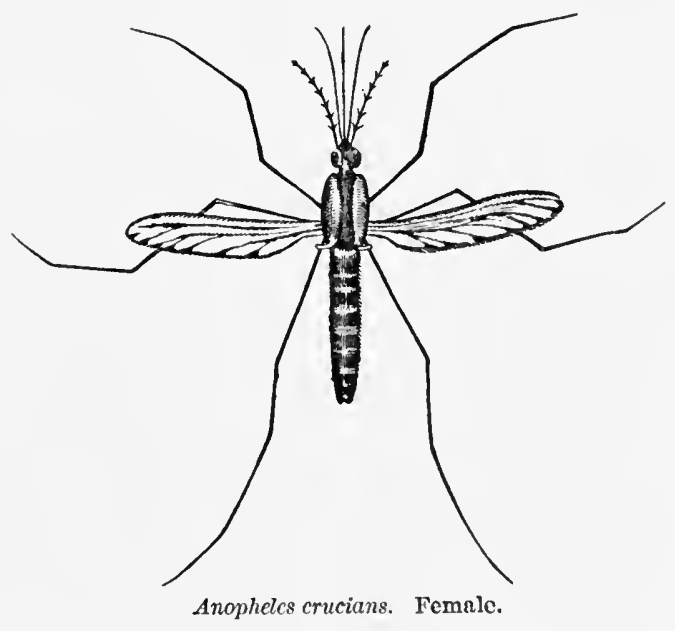

and, unless leaving before morning, seeks out the darkest corner in which to pass the day. 
According to Nuttall, ${ }^{1}$ Anopheles are attracted variously by different colors, navy blue being the most attractive, followed by dark red, reddish brown, searlet, black, and slate gray. Yellow, orange, white, and ochre proved to attraet the least. Joly is quoted as stating that mosquitoes in Madagascar are attracted more to brown than to red soil or white sand; that wearers of black shoes and stoekings are bitten more than those who wear white; that blacks are bitten more than whites, and black dogs than yellow. Nuttall noted in his experiments that, while the imagines frequently flew up and settled on persons entering the room elad in dark elothes, they never did when the dress was white. He suggests the employment of boxes colored dark inside, in which the pests may be caught and destroyed. The influence of color is noted also by Osborne Brown, ${ }^{2}$ who holds that walls, furniture, etc., should be of light color, and advises, among other measures, the putting away of all dark elothes. Anopheles appear to be attracted also by odors, according to the testimony of Stephens and Christophers, ${ }^{3}$ who found that when native Africans slept in a tent previously occupied by Europeans, the insects congregated there more numerously. During European occupancy, 2 Anopheles were usually found in the morning; but after the first night of African occupancy, 19 were caught, and after the second night, no less than 62 were found.

The Malarial Parasite.-The malarial parasite was discovered in 1880 , by Laveran, a French military surgeon stationed in Algeria, but until some years later its method of development was not demonstrated, and only recently has anything been known definitely as to the manner of its entrance into the human body. Before proceeding to an account of the researches by which this was determined, it may be well to describe the development of the parasite within the human subject and within the mosquito.

The several malarial parasites belong to the lowest order of the animal kingdom, the protozoa, suborder Homosporidia. The different forms corresponding to the clinical varieties of the disease were differentiated in 1886 by Golgi, one of the most prominent of the Italian biologists, who, between 1885 and 1890 , were the first to pay especial attention to Laveran's discovery, and study the life cyele of the parasite in the red blood-corpuscle. In this it appears as an amobula, which grows, digesting the red coloring matter, until it occupies nearly the whole volume of the corpuscle and shows spots of pigment in its interior. Then the nueleus divides and forms spores, which, when the cell wall bursts, are liberated into the blood plasma. This point marks the beginning of the malarial chill. The spores enter into other corpuscles, develop into mature organisms, segment, and produce new spores, which on being liberated proced to infect other corpuscles, and so the process continues. In the tertian form of fever, this process of sporulation oceurs at intervals of forty-eight hours; in the quartan form, which is comparatively rare, the intervals are seventy-two hours;

1 British Medical Journal, September 14, 1901, p. 668.

2 Journal of Tropical Medicine, October 1, 1901.

3 Quoted by Nuttall, Journal of Hygiene, January, 1901, p. 7. 
in the pernicious restivo-autumnal form, the intervals are very irregular, and the successive processes of sporulation may occur so rapidly that the fever becomes continuous.

After a number of generations of these asexual forms, male and female parasites appear, which are ineapable of further reproduction within the human subject, but require external eonditions whieh they find within the body of Anopheles mosquitoes. The female parasites are known as macrogametes, homologous with ova; the male organisms are known as microgametocytes. They give off flagella or microgametes, homologous with spermatozoa. In the next cycle, diseovered by Ross, these adult sexual forms, when sucked up in the blood by the mosquito, coalesce in its stomach. The fertilized organisms attach themselves to the walls and penetrate to the outer museular wall, where they increase in size and become mature zygotes (sporocysts), upon the surface of which, clear spaces, centromeres, begin to appear. In a short time, these become surrounded by minute spindle-shaped cells, sporoblasts, which divide into minute rods, sporozoites, which soon fill the whole cyst, which bursts and liberates them through the outer wall into the abdominal cavity. They then rapidly penetrate the tissues to the salivary duct, and thence into the proboscis, from which they are discharged with the salivary secretion into the blood of the next person bitten. From the time of entrance of the sexual forms into the mosquito to the completion of the proeess, about ten days elapse, and since the period of incubation in man is the same, it follows that, under favoring conditions of temperature (for in cool weather the process within the mosquito is slower), abont twenty days must elapse between the appearanec of a first ease and that of another connceted therewith. The inoculated sporozoites give rise to the successive asexual generations above deseribed.

The tertian parasite invades the whole corpuscle; the quartan, nearly the whole; the astivo-autumnal, from a fifth to a fourth of its volume. The pigment granules in the tertian form are fine; in the quartan, coarse; in the xstivo-autumnal, very fine.

Not alone man, but many of the lower animals, as eattle, sheep, monkeys, dogs, various species of birds, frogs, snakes, turtles, lizards, ete., are subject to malaria; but the parasites are peculiar to each species, and are not transferable from one to another.

Some years after Golgi and others of the Italian school had differentiated the several malarial parasites and traced their life eycle within the human subject, Manson, who had done much work in the investigation of mosquitoes as a cansative agent of filariasis, announced, in 1894 , his belief that malaria was caused by drinking water infected by mosquitoes or dust from the dried mud left on evaporation of the water in whieh they had bred. He believed that the female, already infested with the protozoon, laid her eggs and then clied in the water, and was later devoured by the larve. Bignami opposed this, and asserted that the infection was conveyed directly by inoculation in the process of sucking blood.

In 1895, Ross diseovered the malarial crescents in the stomachs of 
mosquitoes that had bitten a malarial subject, and followed them in their development into spheres and flagellated bodies, but was unable to find them in the body eavity or observe any metamorphosis there. For two yeurs, $\operatorname{Ross}^{1}$ endeavored to cultivate the parasite in mosquitoes, but without suceess, and he then ceased experimenting with the "brown and gray" speeies (Culex), and began anew with a few specimens of a larger kind having four black spots on the wings (Anopheles). After these had fed on malarial blood, he observed, on examination of one of them, certain pigmented cells, "the pigment absolutely identical in appearance with the well-known characteristic pigment of the malarial parasite." In a second mosquito, killed a day later, the cells were observed to be larger. The supply of Anopheles having become exhausted, he worked with other kinds, but with no results; but later ${ }^{2}$ he announced that he had found the pigmented cells in a third "dapplewinged" mosquito fed on crescent-containing blood. In the meantime, MacCallum, of Johns Hopkins, ${ }^{3}$ announced his discovery that with halteridum, a parasite of birds strictly analogous to the malarial parasite of man, the function of the flagellum is that of true spermatozoa. Ross then took up the study of bird parasites (Halteridium and Proteosoma), especially of the proteosoma of sparrows, larks, and crows, and was successful in growing the parasites in mosquitoes that had bitten sick sparrows, and in reproducing the disease in other birds bitten by them. He observed the liberation of the sporozoites from the zygotes, their passage into the body cavity of the insects, and their presence in the salivary glands. His belief that Anopheles acts as a carrier of the malarial parasites was proved by Grassi, Bastianelli, and Bignami, who allowed different kinds of mosquitoes, including $A$. maculipennis, to bite persons afflicted with the rstivo-autumnal type of fever, and found only in the species mentioned the developmental changes described by him. Later, Bignami ${ }^{4}$ reported that he, Grassi, and Bastianelli had caught a number of specimens of this mosquito in a malarious district twenty-two miles from Rome, and had released them at the Santo Spirito Hospital in a room occupied for some years by a man who had been under constant observation and had had no kind of fever whatever. The experiment yielded positive results, for the volunteer subject acquired the fever and yielded parasites in his blood. The demonstration of the agency of these pests was thus complete, and the connection has been proved repeatedly on a much larger scale. Thus, Ross ${ }^{5}$ reports that of 21 persons in a camp near Caleutta, 17 who slept without the protection of mosquitonetting were seized with malaria, while the others who slept under nets escaped. Grassi's experience is equally convineing, although without a control. For eight consecutive days, accompanied by a family of seven, he left Rome each day at 5.30 in the afternoon and went to a

1 British Medical Journal, December 18, 1897, p. 1786.

2 Ibidem, February 26, 1898, p. 550.

: Jonrnal of Experimental Medicine, January 7, 1898.

- Bulletino della R. Accad. Med. di Roma, XXV., 1898-1899.

${ }^{5}$ British Medical Journal, July 22, 1899. 
cottage in a notoriously malarious district between Rome and Civitavecchia, where they passed the nights in a cottage, the windows of which, screened with perforated zinc, were left open all the time. Not one of the party was in the least affected.

The longer experiment of Sambon and Low in an equally malarious district is even more convincing. They spent several months, including the summer of 1900 , with malaria raging all about them, but were themselves not affected. They took no drugs by" way of prophylaxis, and went about freely by day, but kept indoors between sunset and sunrise, protected by nettings and screens.

In 1901, an interesting experiment was tried by the Japanese government with two battalions of soldiers stationed together in Formosa. One battalion was completely protected from mosquitoes for 161 days during the malarial season, and not a man had the disease. In the other battalion, which was not protected, 259 cases were observed.

Another interesting experiment was that conducted by Fermi and Cano-Brusco, ${ }^{1}$ who took 16 persons, ranging from eighteen to thirty years of age, wino had had no malaria within a year, to a malarious place in Sardinia and kept them there eight days. Half were proteeted from mosquitoes at night, and the others not. Of the nonprotected, 5 were seized; of the 8 protected, not one.

The most convincing proof of the agency of mosquitoes may be said to be the occurrence of the discase in a non-malarious country through inoculation by mosquitoes imported from another where malaria abounds. Such an instance is reported by Manson, ${ }^{2}$ whose son was bitten in London on three different days by infected mosquitoes brought from Italy. Within a few days of the third inoculation, the characteristic symptoms of tertian malarial fever appeared and the parasites were found in the blood.

For the spread of malaria, two factors are thus evidently essential : the parasite in human blood and the Anopheles mosquito. Either alone is impotent. There are many places where Anopheles are common and malaria unknown. Indeed, if the Anopheles alone could cause the discase, no place would be safe, for although they are not strong fliers, they may be transported through hundreds and even thousands of miles by the vehicles of ordinary travel. Thus Grassi relates that, during a drive lasting two hours, he caught 200 specimens inside the coach; and others have noted their presence in railroad cars and passenger ships. Whether they would be able to breed aboard ship is doubtful, although instances of brecding of other mosquitoes in this manner are known. Thus, Dr. Cumming, of the Marine-Hospital Service, reported on Angust 2, 1901, to the Supervising Surgeon-General, the case of the Spanish barque Maria Blemquer, which was free from mosquitoes until the twenty-second day out from Rio de Janeiro, when some were noticed in the water tank when it was opened, after which the crew were attacked so persistently by

${ }^{1}$ Centralblatt für Bakteriologie, etc., XXIX., p. 985.

2 British Medical Journal, September 29, 1900. 
them that they were obliged to cover themselves to get any sleep. After fumigation of the forecastle, the dead mosquitoes could be seooped up in the hand. Howard relates that mosquitoes were introduced into the Hawaiian Islands by sailing ressels from the United States, and deems it probable that they bred more or less continuously in the water barrels during the voyage.

Mosquitoes may be blown along by the wind through long distances, but ordinarily they take shelter on the leeward side of any object as soon as the wind begins to be strong. Howard cites an instance of mosquitoes crossing a strip of water a mile wide, aided by gentle and continuous wind, and another in which a migratory cloud of the insects, extending three miles in width, traversed 60 miles; and Dr. Kallock, of the Gulf Quarantine Station, reports (August 2, 1901) that the captain of the ship America stated that mosquitoes came aboard the ressel when she was at least 10 miles from land. But Anopheles are not likely to fly far from their birtliplaces. They are not such strong fliers as Culices. Stephens and Christophers ${ }^{1}$ believe that Anopheles in Sierra Leone may fly a quarter of a mile or farther, but in Freetown they found them scarce at a distance of 200 yards from their breeding-places.

As stated above, there are many places in this country and elsewhere where Anopheles are common and malaria unknown, although formerly the disease may have raged most extensively. In England, for example, where malaria was once one of the great national scourges and is now seen only rarely, Nuttall ${ }^{2}$ and his associates found, in 1900, specimens either of the imago or of the larvæ in no less than 173 different places. In some of these places, malaria, so far as known, has never existed ; in others, it once had raged extensively. In France, Sergent $^{3}$ has found $A$. maculipennis and $A$. bifurcatus in great abundance where malaria was formerly common, but now is, and for twenty years has been, unknown ; and in Germany, $\mathrm{Pfeiffer}^{4}$ has found them in great numbers in formerly malarious distriets, but none of them showed the presence of the parasite. In Italy, too, where Grassi has held that the geographical distribution of Anopheles is identical with that of malaria, Celli ${ }^{5}$ has found the insects in situations where malaria has never been known.

To what the disappearance of malaria in England, Seotland, parts of the United States, France, Germany, and other countries, is due, is not easily explained. To a very large extent, it is doubtless due to drainage of the land and general sanitary improvement, the drying of the soil diminishing the opportunity for puddle-breeding mosquitoes to multiply. But this explanation will not apply generally, for in many places now free from malaria the same conditions of soil, wetness, and mosquitoes are found to-day as existed when the disease was endemic. It is interesting to note that, in England, the Anopheles, although fairly

${ }^{1}$ Ioco citato.

${ }^{2}$ Journal of Hygiene, January, 1901, p. 4.

${ }^{3}$ Annales de l'Institut Pasteur, XV., Oct. 25, 1901.

- Correspondenzblatt des allgemeinen ïrtlichen Vereins von Thüringen, 1901, No. 7.

${ }^{5}$ Centralblatt für Bakteriologie, ete., XXVIII., p. 534. 
common, does not bite; at least Nuttall states that neither he nor any of his associates was bitten while collecting, and that Mr. Theobald, of the British Museum, wrote that he had never known them to bite in England. (It is to be remembered that mosquitoes are naturally vegetarians.)

Nuttall suggests as a second reason for the disappearance of malaria from England the reduction of the population of the infected districts by emigration at about the time of the disappearance. This would, of course, reduce the number of infected individuals and lessen the chance of the Anopheles becoming infected. Koch and many others are strongly of the opinion that the use of quinine has had more to do with the disappearance of malaria than anything else, but it is probable that there is some other as yet unrecognized cause, and that all the influences mentioned have contributed in different degrees. That there is some such undiscovered local condition, must be very evident when we consider the following facts published by Celli and Gasperini : ${ }^{1}$ Certain localities in Tuscany, which less than thirty years ago were very malarious, are to-day, so far as can be ascertained, in precisely the same general condition as obtained before malaria disappeared therefrom. The stagnant marsh-water swarms with Anopheles larvæ, and the air above with myriads of the imagines. There is no lack of the malarial parasite for infection of the mosquitoes, for the people go to other districts and return with malaria ; and yet, in spite of the presence of the essential factors for an extensive epidemic, no outbreak oceurs. The children are robust and healthy, the adult population shows no effeets of malaria, and many who have lived there all their lives have never had the slightest attack of the fever. This freedom is not due to acquired immunity, for the inhabitants take the disease when they go to malarious districts for work. The mosquitoes are not insusceptible to infection, for specimens captured there are readily infected by malarial blood in Rome. Quinine cannot be credited with being the cause of the exemption, for it is not used more extensively than elsewhere. In India, too, there are districts which were formerly malarious, but are now comparatively healthy in spite of apparently unchanged conditions.

But although Anopheles may exist where malaria is unknown, the converse is not true, for where malaria is, there, also, are mosquitoes. The assertion that in Java there are places where malaria abounds without mosquitoes, has been investigated by Koeh, who found that mosquitoes were everywhere present where malaria prevailed. He found also a place in East Africa with all the eonditions favorable to malaria excepting mosquitoes, but with no evidence of the discase. In many of the islands of Polynesia, where marshes are very extensive and all malarial conditions are present at their maximum, with the exception of mosquitoes, no malaria is known.

It scems reasonable to assume that, given the necessary species of mosquitoes, the introduction of infected persons into a district would probably be followed by the appearance of other cases; but there are,

1 Centralblatt für Bakteriologie, etc., Oct. 23, 1901, p. 523. 
fortunately, a number of conditions which must be fulfilled in order to bring this about. First, the Anopheles must be blood-drinkers; second, they must bite the infected individuals; third, they must then develop the parasite within themselves; and, fourth, they must live to bite another person when the sporozoites are still present in the salivary duct. In addition, certain favoring conditions of temperature are required, both for the activity of the mosquito and for the development of the parasite. Should cold weather come on shortly after the malarial subject is bitten, no harm might follow, for about ten days are required before the mosquito becomes fully infective, and in a cold atmosphere she is sluggish and will not bite.

Preventive Measures.-In order to prevent multiplication of Anopheles, measures should be taken to diminish the number of breedingplaces by drainage and other means, and the larvæ should be destroyed where it is not possible to accomplish removal of the water. The natural enemies of the larvæ may be introduced at very slight expense and with a minimum of trouble. Among these, Howard mentions as most efficacious, sunfish, sticklebacks, and top-minnows. Where fish cannot be introduced, the application of the cheapest kerosene at regular intervals will not only kill all larvæ, but will prevent the impregnated female from laying her eggs. Kerosene spreads easily and does not evaporate too quickly, and a barrel will suffice for an area larger than two acres. A single application by means of mops or watering-potsabout an ounce to fifteen square feet, enough to give a very thin film-will remain for at least a wcek, and generally a fortnight; and since a week must elapse for eggs to develop into pupæ, a second application need not be made until about seventeen days have elapsed.

The sick should be protected by mosquito-netting, and the same means should be employed to prevent access to the houses of the well, and for the protection of those who may be obliged to sleep in the open. Local applications to the skin (oil of pennyroyal, oil of eucalyptus, etc.) are not of much value.

Fermi and Tonsini ${ }^{1}$ have reported a noteworthy instance of diminution in the emount of malaria after systematic destruction of the larva of mosquitoes. The Island of Asinara, inhabited solely by convicts and their guards, has often been ravaged by malaria. The larve of different species of mosquitoes were found in many wells and horseponds, and were treated with kerosene a number of times. Screens were placerl in the windows and doors of the dormitories. The results were most satisfactory, only 9 cases of malaria occurring during the year, against 99 in the year preceding.

If Anopheles gain access to houses, they may be destroyed by fumigation with sulphur dioxide, employing 1 pound of sulphur for each 1000 cubic feet of air space.

For prophylaxis by means of quinine sulphate, the daily ingestion of 2.5 to 5 grains is advised. However efficacious this may be, it will have to be admitted that it is an expensive measure, for the mini-

1 Zeitschrift für Hygiene und Infectionskrankheiten, XXX., p. 534. 
mum dose advised would require the annual use of no less than 65 tons per million population.

Mosquitoes and Yellow Fever.-Since 1693, when yellow fever made its first appearance in this country, there have been no less than 95 epidemies of greater or lesser magnitude within the United States. According to Reed and Carroll, ${ }^{1}$ since 1793 the disease has been the cause of no less than 100,000 deaths, 41,348 of which have occurred in New Orleans, 10,038 in Philadelphia, and 7759 in Memphis (1855, '73, '78, '79). Between 1851 and 1883, it cansed 23,338 deaths at Rio de Janeiro, where, according to Gouvéa, ${ }^{2}$ previous to 1849 it was unknown, being introduced in that year by the Brazil from New Orleans and Havana, and by the Navarre from Bahia. From Rio it spread to all the towns in the bay. Between 1853 and 1900 , it caused 35,952 deaths at Havana, where it had flourished continuously for more than a century, and where, after a practical application of the knowledge concerning the method of its dissemination-the outcome of brilliant work on the part of Reed and his associates, of the United States Army-it was demonstrated that it conld be completely eradicated, and that even though outbreaks should occur on ships arriving from infected ports, removal of the victims to the fever hospital need give rise to no new cases.

Inability to control the spread of the disease has hitherto been due to the fact that the manner of its dissemination was not known, and that all efforts to control it were exerted in the wrong direction, in the belief, now shown to have been unfounded, that fomites, filth, and soil conditions were the distributing agencies.

It was in 1848 that Dr. Josiah Nott, of Mobile, suggested that mosquitoes might be responsible for or comnected with the spread of yellow fever, but the idlea appears to have been received with indifference. In 1881, Dr. Finlay, of Havana, announced his theory of mosquito transference, and began his experiments, but it remained for Reed and his associates to demonstrate conclusively that mosquitoes are the principal, if not the sole, carriers of the exciting cause, and that fomites and filth have absolutely no influence whatever.

The experiments proving both statements are exceedingly interesting. In October, 1900, Reed ${ }^{3}$ reported positive results of experiments condneted by himself and Drs. Carroll, Agramonte, and Jazoar with mosquitoes, Stegomyia calopus, furnished by Dr. Finlay. Caroll was bitten by one that had bitten fonr yellow fever patient; alternately severe and mild cases, respectively, twelve, six, foul, and two days previonsly. Four days afterward he took to lis bel, and on the fifth day his disease was diagnosed as vellow fever. Another sulbject was bitten by the same mosquito, and by three others that had previously bitten patients with the disease, and in seven days he also hat the fever. Dr. Lazear was bitten withont result by an infected mosquito

${ }^{1}$ Medical Record, Oetober 26, 1901, p. 641.

2 Bullet in médical, October 1:2, 1901, p. 861.

${ }^{3}$ Philadelphia Medical Journal, October 27, 1900. 
on August 16th, and by another, an accidental stranger, on September 13th. In five days, he had a chill; on the day following, the diagnosis of yellow fever was made, and in a week, the case terminated fatally. Between Angust 17th and October 13th (fifty-seven days), these three were the only cases which occurred among 1400 non-immune Americans at Quemados.

On November 20, 1900, an experiment station, Camp Lazear, was established at Columbia Barracks, Cuba, under the direction of Reed, who, with his former associates, continued the work with gratifying results. A very strict quarantine was established, and no non-immune was subjected to mosquito inoculation (with one exception) who had not passed the full period of incubation of yellow fever under close observation, nor was any non-immune who left the camp permitted to return under any circumstances. Twenty-one subjects presented themselves, mostly immigrant Spaniards sceking immunity, and the result in each case was positive.

Experiments with fomites ${ }^{1}$ were equally convineing in results. Three large boxes of sheets, pillow-slips, blankets, etc., contaminated with the discharges of yellow fever patients, many of them purposely soiled with black vomit, urine, and fæces, were placed in a building of 2800 cubic feet capacity, tightly ceiled and battened, with small windows to prevent thorough circulation of air and wooden shutters to prevent the disinfectant action of sunlight. The windows were screened with wire ganze, and the entrance with a screen door. The articles were unpacked by Dr. Cooke and two privates, and they were shaken so that the specific agent might be disseminated throughout the room, if it were present. They were then used on the three beds provided, and some were hung about the room and near the beds. For twenty consecutive nights, the three slept in the uninviting beds, and every morning they packed the filthy articles back into the boxes, and every evening unpacked and distributed them again. They passed their days in tents in quarantine. During their tour of service, other bedding, soiled with the bloody stools of a fatal case, was received in a most offensive stiuking condition, and used with the rest. Then other non-immunes repeated the experiment for twenty-one nights, sleeping in the very garments which had been used by patients. Then these subjeets were followed by others, who, for fourteen nights ont of twenty, slept with pillows covered with towels that had been thoroughly soiled with blood drawn from a case of well-marked yellow fever on the first day of the discase. The result of the exposure of these nonimmunes in relays for nine weeks was wholly negative, for not one had the first symptom of yellow fever. Not so, however, in the case of a man who was exposed in a building of similar size, thoroughly ventilated, and containing only disinfected articles plus infected mosquitoes. On December 15, 1900, 15 of the insects were set free, and he was soon bitten several times. Later, he was bitten again, and also on the following day. He contracted the disease; but 2 men who

${ }^{1}$ Reported in Medical Record, Octoberr 26, 1901, and in other American journals. 
slept for eighteen nights in a half of the room which was screened from the other and from the mosquitoes by netting, had no symptoms.

Whatever the nature of the parasite, its life cycle would appear not to need the passage of the parasite through the intermediate host, for Reed $^{1}$ and his associates succeeded in producing the disease by injection of blood drawn from the general circulation. Although the specific causa morbi has not yet been discovered, it appears to be definitely settled that it is not Sanarelli's B. icteroides.

The conclusions arrived at by Reed, Carroll, and Agramonte, and reported to the American Medical Association, are, in brief, as follows: The intermediate bost is the Stegomyia calopus, which is capable of transmitting the disease after an interval of about twelve days or longer after becoming contaminated by biting a person already sick. The discase can be caused by subcutaneous injection of blood from the general circulation during the first or second day of sickness. Immunity is not conferred by the bite of a mosquito at an earlier period after contamination; but when the disease is produced through the agency of a mosquito, the subject is immune against infection by subcutaneous injection of blood. The period of incubation in cases of induced fever varied from forty-one hours to five days and seventeen hours. The disease is not conveyed by fomites, and hence disinfection of a house, except as to mosquitoes, is unnecessily. The spread of the disease can be controlled most effectually by measures directed to the destruction of mosquitoes and to protection of the sick against them.

That not less than twelve days are required for the contaminated mosquito to acquire the power to transmit the disease, is borne out by the observations of Pr. H. R. Carter, ${ }^{2}$ who found that, in sixteen houses in which 95 sceondary cases of yellow fever occurred, the interval between the first and second cases ranged between twelve and twentythree days.

The Yellow Fever Mosquito, Stegomyia calopus (Figs. 111 and 112), formerly known as Culex fasciatus, is, in this country, confined principally to the tropical and subtropical regions along the Atlantic Ocean and Gulf of Mexico, but may be transferred from one region to another by the usual vehicles of travel. It is found in all the principal eities and some of the smaller towns of Cuba ; in Jamaica, Isle of Pines, and Nicaragua ; in Louisiana, especially in New Orleans; in 'Eastern Texas; in various places in other Southern States; in a number of towns and cities in Brazil, and in certain other hot comntries. It is not essentially an Ameriean species, for Mr. Theobald, of the British Museum, states that he has received specimens from Italy, Greece, Spain, Portugal, and Malta. Its presence in Spain may explain the occurrence, in 1800 , of a very extensive epidemic of yellow fever in the province of Andalusia, and, in 1821, of another at Barcelona. Wherever it is found, it appears to prefer the larger, populous centres, and to be but little common in rural districts.

1 Philadelphia Medical Journal, July 6, 1901.

2 Medical Record, Jume 15, 1901, p. 933. 
The Stegomyia breeds, like Culices, in small collections of water. Reed and Carroll found the larve in rain-water barrels, sagging gutters containing rain-water, cesspools, tin cans used for romoving excreta, tin cans placed abont table legs to prevent inroads of red ants, horse-troughs, leaves of the Agave Americana, and generally in any collection of still water. 'The New Orleans Mosquito Commission' found the larvæ in 128 of 210 cisterns examined by them. According to this authority, the life cycle of Stegomyia is somewhat different from that of other genera, and these differences may necessitate more stringent measures than will suffice for the suppression of Culices and Anopheles, for the eggs hatch earlier (ten to twenty-four hours), and the larval (six and one-half to eight days) and pupal stages (two days) are much shorter, so that full development requires from two to four days less than for Culex pungens, and two weeks less than for any species of Anopheles. According to Rced and Carroll, the eggs begin

FIG. 111.

Fra. 112.

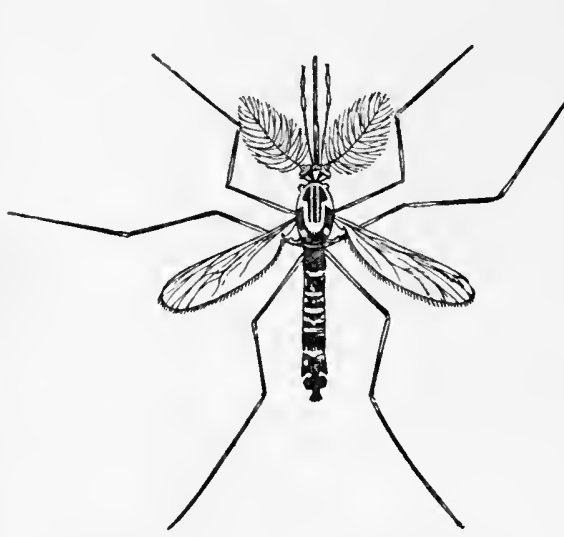

Stegomyia fasciata. Male. (After Howard.)

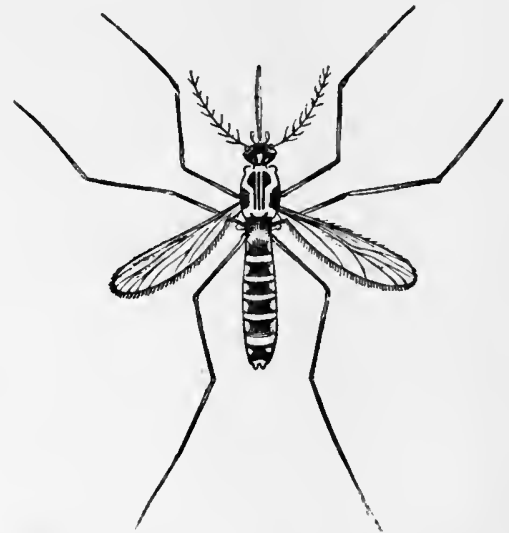

Stegomyia fasciata. Female. (After Howard.)

to hatch, as a rule, on the third day, and the process may last about a week; the larval stage lasts seven or eight days and the pupal stage two days; the shortest time for complete development observed by them was nine and one-half days. At an average temperature of $75^{\circ} \mathrm{F}$. or higher, the species multiplies abundantly, but exposure to a lower temperature for even a short time daily causes much retardation, and eggs kept at $68^{\circ} \mathrm{F}$. do not hatch. They found that newly hatched larvæ kept at $68^{\circ} \mathrm{F}$. develop slowly, and require twenty days to reach the pupal stage; kept at $50^{\circ} \mathrm{F}$, they fail to reach the pupal stage.

Although low temperatures are destructive of the larvæ, it is otherwise with the eggs, which Reed and Carroll found to be very resistant to the influcnce of dryncss and cold. They observed that eggs which had been dried on filter-paper and kept ninety days hatched promptly

${ }^{1}$ New Orleans Medical and Surgical Journal, January, 1902. 
on being placed in water. Dried eggs, brought from Havana to Washington in February, were easily hatehed in May, and furnished about 60 per cent. of the usual number of larvæ hatched from fresh eggs. Eggs frozen for an hour, thawed out at room temperature, and placed in an incubator at $95^{\circ} \mathrm{F}$., began to hatch on the sixth day, and furnished active larra on the eightl ; while others, frozen for a half hour on two successive days, began to hatch under the same conditions on the third day. Thus it would appear that eggs may survive the Havana winter, and that the presence of hibernating females is not necessary.

The female imago, when impregnated, is generally ready to bite on the second or third day. In New Orleans, according to the Mosquito Commission, the mosquitoes are active during the day, and particularly in the afternoon. In Cuba, Reed and Carroll found them to be especially active from 4 P. M. until midnight, although in captivity the hungry impregnated female will bite at any hour. When freed in a room, she does not appear to bite a second time within five to seven days.

Having bitten a yellow fever patient, it appears that the mosquito is incapable of inducing the disease before twelve days have passed. Those which failed to infect on the eleventh day were successful on the seventeenth. How long the ability to infect continues, was not determined, but suceessful inoculation was brought about as late as fiftyseven days after contamination.

How long the infected mosquito will live, is not known. The specimen which eonveyed the disease on the fifty-seventh day lived seventyone days, others have been known to live five months, but the majority die in captivity within five weeks. In a state of freedom their length of life depends largely upon access to water.

At temperatures below $62^{\circ} \mathrm{F}$., Stegomyia will not bite, and thus Reed accounts for the decline in epidemies of yellow fever at New Orleans in November, when the mean temperature is $61.8^{\circ} \mathrm{F}$, and their cessation in December, when it falls to $55.3^{\circ}$.

Preventive Measures.-CTo avoid epidemics of yellow fever, Reed advocates the prevention of inportation of cases of the disease from infected localities, and, when cases do appear, the application of measures to protect the sick from attacks of mosquitoes. Screens should be used for this purpose, and even the dead should be thus protected, for Stegomyia will bite even these. All mosquitoes in a house where a case occurs should be eaught, and search should be made for them in all the houses in the immediate vieinity. They may be destroyed by fumigation with sulphur dioxide (1 pound of sulphur for each 1000 cubie feet of air-space), which Rosenan ${ }^{1}$ finds far superior for this purpose to formaldehyde, for very small amounts of the dry gas will kill them, even when they are protected by four lavers of towelling, while formaldehyde acts feebly and with uncertainty. "Pyrethrum (Dalmatian) powder may be burned in the same proportion, and will either kill or stupefy them, so that in three hours they may be swept up and burned.

${ }^{1}$ Bulletin No. 6, Hygiene Laboratory of the U. S. M.-H. S., September, 1901. 
Non-immunes entering infeeted houses are advised to rub all exposed surfaces, including the ankles, with spirits of eamphor, oil of penuyroyal, or 5 per cent. menthol ointment; but these agents exert only a temporary protective influence against being bitten.

Of very great importance is the destruetion of larve and of breeding-places. The results of systematic work in this direction and of other preventive measures are manifest in the immense improvement in the sanitary condition of Havana. Under the direction of Dr. W. C. Gorgas, U. S. A., the "Stegomyia Brigade" began its work of inspection in March, 1901, when, in 16,000 houses examined, larvæ were found "at the rate of 100 per cent. This does not mean that every house examined had larva; many houses were found that had several receptacles which contained larvæ." During December, 1901, 16,121 houses were inspected, and in but 1.5 per cent. were the larva found. From May 7 to July 1 (fifty-four days), no case of the disease occured; then it was introduced from Santiago de las Vegas, and later from other places, and yet, during July, there were but 4 cases, and in August, but 8. During the whole year (1901), there were but 18 deaths from yellow fever, and 12 of these oceurred in January and February, before the work of prevention was begun. During the preceding forty-five years, the average number of deaths therefrom was 751.44 , the minimum, 51, occurring in 1866.

Mosquitoes and Filarial Disease.-In 1872, Dr. Timothy Lewis, of Calcutta, discovered that human blood is the normal habitat of the embryo nematode discovered, in 1863 , by Demarquay, in the milky fluid from chylous dropsy of the tunica vaginalis, and named it Filaria sanguinis hominis. Later, Manson, in consequence of the discovery of other filariæ in the blood, renamed this parasite Filaria nocturna, and named the others $F$.diurna, $F$. perstans, $F$. demarquaii, and $F$. ozzardi. The most important of these is $F$. nocturna, which is the embryo of $F$. bancrofti, diseovered in 1876 by Bancroft, of Australia, in patients with lymph-scrotum, and named in his honor by Cobbold. The parental form is a hair-like nematode, from 3 to 4 inches long, which infests small eyst-like dilatations of the distal lymphaties, lymphatic varices, the larger lymphatic trunks between the glands, the lymphatic glands, and the thoracic duct. The embryos, which are about an eightieth of an inch in length, and about as broad as the diameter of a red blood-corpuscle, are found in the blood of persons afflicted with filariasis from just before the approach of night until about 8 , or 9 , or 10 o'elock in the morning. They enter the general circulation as night approaches, and increase gradually in number until abont midnight, after which they gradually decrease until the time above mentioned, when they disappear from the peripheral eireulation. According to Manson, it is not unusual to find at midnight as many as 300 to 600 in a single drop of blood, from which he concludes that, at that hour, as many as 40 or 50 millions of them may be circulating simultaneously

1 Public Health Reports, February 14, 1902, p. 363. 
in the blood-vessels. During the day, they may be found in the larger arteries and in the lungs.

The parasite is found indigenous in almost all tropical and subtropical countries, and in this country as far north as Charleston, S. C. In many places, a half, and even more, of the population are found to be infested.

Aceording to Manson, the following diseases are known to be produeed by this parasite: abscess; lymphangitis; varicose groin and axillary glands ; lymph-scrotum; cutaneous and deep lymphatie varix ; orchitis; chyluria; elephantiasis of the leg, serotum, vulva, arm, mammæ, and elsewhere; chylous dropsy of the tunica vaginalis; chylous ascites; ehylous diarrhoa; and probably other diseases due to obstruction or varieosity of the lymphatics or to the death of the parent worm.

In 1878, Manson, having conceived the idea that mosquitoes might be instrumental in spreading the disease by acting as an intermediate host, observed the development of filariæe in a species of Culex (C. ciliaris, vel pipiens), which was allowed to bite an infected person. Within a few hours, the blood plasma in the mosquito's stomach beeomes thickened, but not eoagulated, and some of the embryos manage to escape from their sheaths and then move freely in the blood, and finally escape from the stomach and enter the thoraeic muscles, where they remain a number of days and undergo a proeess of metamorphosis, which results in the formation of a mouth, an alimentary canal, a peculiar trilobed tail, and great increase in size.

It was Manson's idea that the infested mosquito repaired to some body of water, laid her eggs, and died; and that the parasites freed themselves from the dead body, lived in the water, and, being received into the stomach of man through drinking, bored their way through the tissues and entered the lymphatie trunks, where, attaining sexual maturity, fecundation oceurred, resulting in due course of time in new generations of embryos to be poured into the lymph, then through the glands or by the lymphaties into the general circulation. Bancroft, however, suggested that the parasite is transmitted back to man not through drinking-water, but by the bite of the mosquito; and in 1900, G. C. Low diseovered that the metamorphosed worm makes its way to the insect's head, and finally into the root of the proboscis, in which it lies until the mosquito bites another person, when, stimulated into activity by the warmth of the encompassing tissues, it moves from its position in the proboscis and enters the wound. The worms thus introduced undergo farther derelopment in their new position in the skin and beeome adults, and proceed to breed embryos, which enter the lymph spaces or vessels.

According to Manson, in most cases of infection the parasite exercises no manifest injurious influence whatever, and in those cases in which injury is eaused, the trouble is due in the main to obstruction of the lymphaties by the parent worms. 
At first it was believed that the intermediate host was Culex ciliaris (vel pipiens) alone, but a number of other mosquitoes are now known to act, including species of Culex and Anopheles. These include, according to James, A. Rossii, C. albopunctatis, and C. microannulatus; and, according to Low, ${ }^{1} C$. fatigans; and to Vineent, ${ }^{2}$ A. albimamus. Low reports that, in Barbadoes, neither malaria nor any species of Anopheles is known, but that there are much filarial disease and an extraordinary abundance of $C$. fatigans. In 600 blood examinations of persons taken at random, 12.66 per eent. yielded Filaria noctuma. In Trinidad, Vincent found in 500 cases taken at random, 5 per cent. infested with filaria and 6.6 per cent. with elephantoid disease. In Culex fatigans, it was observed that the final stage of metamorphosis was reached between the sixteenth and nineteenth days, but with $A$. albimanus, since none of the specimens lived in captivity beyond the twelfth day, it was not possible to determine definitely when the final stage is reached. In the case of $C$. ciliaris, Bancroft prolonged the life of the insect and followed the development of the parasite to the last stage of its metamorphosis, which occurred, under favorable conditions of temperature, at about the sixteenth or seventeenth day after feeding.

Filaria diurna is a form which is detected in the blood only by day, and it has been supposed to be a distinct species, although nothing is known about its life history or pathological significance. According to the findings of the Nigeria Malaria Expedition, ${ }^{3}$ however, there are so many points of resemblance between the two forms that it is possible that they may be identical. It is pointed out that the geographical distribution of the two forms is in elose agreement, although in many places where $F$. nocturna is known to exist, $F$. diurna has not been noted; but the latter is not known to exist where the former is absent. Furthermore, in some of the Pacific islands where elephantiasis is exceedingly common and $F$. nocturna is found, there is none of the characteristic noeturnal periodicity. Where both were found, the members of the expedition were unable to distinguish in any way the one form from the other. In some cases, embryos were found during both day and night. It is known that when persons infested with $F$. nocturna change ther habits, so that they sleep by day and keep abont by night, the filarix are found in the peripheral circulation only during the day.

Filaria demarquaii resembles $F$. diurna and $F$. nocturna in shape, but not in size, being abont half as large. It is present in the blood both by day and by night in the peripheral eireulation. Low ${ }^{4}$ has attempted, without success, to determine the intermediate host necessary for the development of the embryos to the point where they are capable of farther growth in man, but is of the opinion that the intermediate host is a blood-sucking insect.

Mosquitoes and Dengue.-Concerning the etiology of this disease

${ }^{1}$ Intitish Medical Journal, September 14, 1901, p. 687. 2 2 Ibidem, January 25, 1902.

${ }^{3}$ Menoir, IV., p. $89 . \quad$ "British Medical Journal, January 25, 1902. 
of tropical climates, nothing has ever been known, although many hypotheses, differing widely, have been advanced. Recently, however, an investigation conducted by Dr. Harris Graham, ${ }^{1}$ in the vicinity of Beyrouth, in Syria, implicates the mosquito as an important factor in its spread. At the place mentioned, the disease is very prevalent, and mosquitoes of the genus Culex are a serious pest. Graham observed that the disease occurred in persons under observation only when they were bitten by infected mosquitoes, and that, when they were bitten, the disease invariably followed. For example: he applied mosquitoes to a person suffering from it, and, after they had bitten, carried them in a paper box to a village, high up on a mountain, where there was no case of the disease. There they were allowed to bite two apparently healthy persons, in whom, in four and six days, respectively, typieal attacks occurred. In a large number of cases, he made examinations of the blood, and in every instanee he found in the red corpuseles an amœboid parasite which bore considerable resemblance to the malarial organism, but required a much longer time for its cyclic development and showed no pigment at any stage. The organisms were found at times also in the blood plasma. Flagellated forms were observed also in some eases when the blood had stood for some time.

Further observation and study are obviously desirable and necessary.

1 Medical Record, February 8, 1902. 


\section{CH A P'T R XIII.}

\section{HYGIENE OF OCCUPATION.}

The influence of oceupation on health and length of life has been the subject of much investigation since attention was first called to its importance by Professor Bernardino Ramazzini, of Padua, in 1700, but more particularly during the last half century. Although his work was translated anonymously into English as early as 1705, the subject appears to have been one that did not appeal with any special foree to English social scientists and medical men, for the first English work of any importance was that by Mr. C. Turner Thackrah, a practitioner of Leeds, on The Effects of the Principal Arts, Trades and Professions, and of Civic States and Habits of Living, on Heatth and Longevity, published in 1831. A French translation of the work of Ramazzini appeared in 1777, and formed the groundwork of P. Patissier's Traité des Maladies des Artisans et de celles qui Résultent des Diverses Professions, d'après Ramazzini, which was published at Paris in 1822. It was translated early also into German; but the first work of any importance on the subject by a German writer was that of Halfort, Entstehung, Terlauf, und Behandlung der Krankheiten der Künstler und Gewerbetreibenden, published at Berlin in 1845 .

Since the awakening of interest in the subject in England, France, Germany, and other European countries, and the United States, it has been extensively and minutely studied in all its aspects, and to-day its bibliography includes thousands of titles, mostly, however, as would naturally be supposed, of monographs and memoranda pertaining to individual callings. From this vast amount of material from all sources, numerous tables have been eonstructed, showing, it is generally supposed, how the various oceupations stand relatively in the amount of influence which they exert on the longevity of those engaged in them. From these tables it appears, for example, that those who follow some particular ealling are more prone to eontract eertain diseases than those engaged in another ; that in each hundred individuals of some one class, a greater number of deaths will oceur in a year than in each hundred of another; that the average age at death of those engraged in one employment is lower or higher than that of those in another, and so on.

As in all findings based upon groups of units with, perhaps, but one eommon bond, each unit being subject to a variety of outside influences, the conclusions drawn from this vast mass of material are influenced largely by fallacy, and inelude wheat and ehaff, fact and fancy. In 
many cases, general statements are based upon such a slight foundation as to indicate that their authors are possessed of that degree of genius which has been defined as the ability to generalize from a single instance. In many others, they are based upon facts and conditions which no longer exist, the methods followed in the manufacture of the particular article concerned having undergone a complete change. For example, a process, formerly carried on by men in small establishments run by water-power in the country, may have been concentrated in large mills run by steam and situated in erowded cities; the machinery is different and more perfect, and requires nothing more than feeding, and this may be done by a boy or girl, instead of an adult man. Here, the older facts may no longer apply in any way, and for present purposes should be abandoned as belonging to an extinet occupation.

It is often difficult or impossible in the study of the effects of occupation to eliminate outside influences which may affect the health of the worker as much as or more than the circumstances of his trade. A hundred men, for example, from different strata of society-some marricd, others single; some living in comfortable houses, others in cheerless, unsanitary tenements; some spending their evenings in wholesome recreation amid wholesome surroundings, others doing evening work in places of public entertaimment and elsewhere, or spending their time and wages in the paths of vice; some naturally robust, and others inclined to disease-engage in the same oceupation at the same time. During the year, there is considerable sickness among them, and some of them die; perhaps these include mainly young men. Shall it be sairl without a eareful analysis of all the cireumstances of their lives and of the immediate causes of their deaths, that their calling is necessarily inimical to health and longevity? This one died of smallpox; this one of consumption; this one of a blow on the head while drunk; this one was drowned; two were rictims of typhoid fever and two of pnenmonia; eight in all-truly a large percentage, but shall the trade be blamed?

It must, of course, be self-evident that certain oceupations are intrinsically dangerous to health, because of the nature of the substances with which the workers are brought in contact; and these are properly classed as dangerous trades. Many others are so elassed, not because of any intrinsic danger, but on account of the peculiar conditions nuder which they are ordinarily carried on, these tending to reduce the physiological resistance to disease. Still others are classed as dangerous to health which are merely dangerous to life, the individual being subject to mechanical violenee while in the enjoyment of perfeet hicalth. These also are properly to be included among the dangerous trades. But the great majority of callings are neither intrinsically dangerous nor carried on under peculiar conditions favoring a low state of health, yet many of these figure in statistical tables in such a way as to lead to the conclusion that those engaged in them may have little hope of green old age, while others in occupations of practi- 
cally the same character, but under different names, give promise of a full period of usefulness.

Statistical tables of longevity of groups of individuals engaged in the various callings should be used with much eireumspeetion and with a due regard to the various cireumstanees which determine the choice of trade, the age of the individual at the time of engaging upon it, the length of time which one may serve before engaging in another, the peculiar conditions under which the ealling is pursued, and the probable character of the influences which affect the well-being of the individual while he is not immediately engaged; that is to say, his home surroundings, his personal habits, the nature of his relaxations, the quality of his food, and other faetors. Tables based on foreign statisties should, furthermore, be not too freely accepted as applicable to home conditions, owing to differences in racial peeuliarities and of conditions under which those engaged work and live, for one ean hardly suppose that any one elass works and lives under the same conditions in all countries.

The conditions which govern the choice of an occupation are of very great importance. Many callings demand men of robust build and good health, and manifestly are unsuited to the weakling, who naturally is attracted to other occupations of a lighter character. On this seore alone, statisties may be grossly fallacious. For example, in certain tables it will be observed that the class designated as clerks have a low average age at death, and from this it may be inferred that the calling is one which is intrinsically incompatible with long life. But is it fraught with danger? Is it eonducted under peculiar eonditions which tend to bring its unfortunate followers to an early grave? Or is it not rather the fact that it is the refuge of a great number of those whose physical powers are such that they are unsuited to employments which call for greater robustness, and who, inevitably marked for an early death, regardless of their calling, reduce the average age at death of the entire class.

On the other hand, eertain oceupations involving much severe muscular effort appear to be eonducive to long life, in spite of the conditions under which they are pursued. Here must be borne in mind that in these, the weaker individuals and those whose powers begin to fail are forced into other occupations, and that those who remain until the end show an average age at death which is eloquent of the benign influence of the calling. It is undoubtedly true that muscular effort, earried to excess, will undermine the health; but not forced beyond reasonable limits, and particularly if carried on under good hygienie surroundings, instead of being in itself prejudicial to health, is promotive of it. Those who are forced into lighter occupations may find the change advantageous; or, on the other hand, entering upon them already broken in health, may help to reduce the average age at death of all those engaged therein.

Another influence having a bearing on the choice of oecupation is the high wage offered to attract workmen to trades which are properly 
conceded to be dangerous to health. These are naturally unattractive to men of sound body and mind, to whom health and life are sweet, and hence they find their reeruits among the broken-down and vieious, to whom the rate of pay offers, in the one case, immediate much-needed and otherwise unattainable financial relief, and, in the other, opportunity for a short period of unrestrained license.

Statisties concerning occupations entered upon at an early age and followed for but a limited number of years as a preliminary training for other callings, and those which from their very nature demand men of wide experienee, hence well matured, ean be of little or no value unless the occupations are in some way of intrinsic danger. We find, for example, in certain statistical tables dealing only with individuals above the age of 20 years, that the average age at death of students is about 23 years, while that of professors exceeds 50 . The manifest absurdity of attempting comparisons of the healthfulness of these two occupations is brought out still farther by reversing the case, and supposing the professors to die off at 23 and the students at 50. Since even advanced students in the professional schools pass, as a rule, ont of the student class and into their chosen fields of usefulness long before their thirtieth year, it cannot cause surprise that those who die before their training is completed do not show a high average age at death; and, on the other hand, since men of learning are not ordinarily called upon to assume the duties of professors until they have passed through the lower grades which lead to that rank, it is to be expected that their average age at death will be fairly high. To compare lientenants and major-generals, shipping-clerks and retired merchants, apprentices and master carpenters, would be no more absurd. The average age at death of any one calling must be largely influenced by the relative number of individuals of the different age periods engaged therein, just as is the case with the population in general.

Another fact that affects the age at which work is undertaken is a very low wage offered even in times of prosperity, so low as to be no inducement to heads of families, but sufficiently high to cause them to help out their financial condition by making use of their offspring.

Before proceeding to a classification of occupations according to the sircumstances which determine their hcalthfulness, it is desirable to consider the significance of the somewhat loosely applied term, occupation diseases. Every form of oecupation and every form of life of leisure has some attendant cireumstances which may at some time, in one way or another, bring about a predisposition to some form of disease ; and to regard every disease of an artisan, tradesman, or professional man as attributable to his particular calling, is to fall into a common inexcusable error, for workers and drones have most diseases in common. It is beyond dispute that certain pathological conditions are caused and others promoted by certain oceupations, and it is equally true that most diseases already acquired may be influenced for better or worse by one or another calling. 
The true oceupation disease is that which in all probability would not have been acciuired had the individual not engaged in his particular calling or some other in which the conditions are essentially similar. As an instance, may be cited the lead paralysis of the house painter, potter, compositor, and file-cutter. Certain diseases of common occurrence in the population at large are promoted by the conditions under which various callings are earried on, but these eannot properly be called oceupation diseases, since the exciting eause is in no way a part of the business, and under better hygienic management, combined with more farorable outside influences, might be avoided. As a conspieuous instance of this elass, may be eited the tuberculosis of dressmakers, entlery grinders, and operatives in the eotton and flax industries, promoted by overerowding and inhalation of dust while at work, and by all extraneous conditions tending to lower vitality. The plying of the needle is in itself in no way inimical to the integrity of the lungs; the grinding of the steel implement on the wheel and the rumning of the loom send forth none of the specific bacilli; but the overerowding in the one ease, and the unavoidable inhalation of irritating dust in the others, bring about the conditions which offer fertile soil to the germ of the disease.

Certain conditions are influenced for better or worse by different occupations, as has been stated. Among these may be mentioned anæmia, which not uneommonly is classed among the diseases of oecupation. Under the conditions of many indoor callings, this state is easily brought about, or, if already existing, inereased; but, on the other hand, under those of outdoor occupation, it is not likely to be induced, and, if already existing, may be made to disappear. Many occupations, for easily explainable reasons, draw thcir workers largely from that portion of the population which is, if not already diseased, predisposed by heredity, habit, and home surroundings to anæmia, tuberculosis, and other disorders, the onset of which may be hastened or delayed, according to circumstanees. In these, and in occupations in general, it is not an easy matter to determine eorrectly the amount of influence properly chargcable to the calling when disease appears, since the conditions under which a trade is earried on may be widely variable, and their influence for good or evil exceedingly complex. Among these conditions may be mentioned indoor confinement, nature of materials, geographical location, and wages paid.

Whether an occupation is carried on indoors or outdoors, is of much importance, for, other things being equal, outdoor employment is far more conducive to health than is confinement, even in well-ventilated factories, in which, with the best of systems, the air cannot be maintained in the condition of purity which obtains outside. Even those callings which subject their followers to great vicissitudes of weather appear to be morc eonducive to robustness than those carried on indoors, particularly if the nature of the work is such as to call for freedom of movement and great bodily activity. The sailor, the letter-carrier, or the farm hand, for example, working in the open 
air, in heat and cold and in all kinds of weather, is better circumstanced in many ways than the loom-tender, the entry clerk, and the salesman at the ribbon counter. He works, perhaps, in a broiling sun, rather than in an overheated room filled with impure air; the air he inhales contains some dust, perhaps much, but it is a less harmful dust, less abundant, and not continuous. The air of the factory and workshop may be almost as pure as that out of doors, or it may be laden with fumes, gases, foul odors, or dust of a speeial nature, aecording to the materials used. The outdoor worker is also much less oppressed by the monotony which is so eonspieuously a concomitant of indoor work. He ean, at least, see some part of his world in everchanging conditions, while the mill operative tends his machine, of which he is perhaps only a minor part, day in and day out, seeing it do the same thing with mechanical exactness so many times per minute or per hour, with no more sense of responsibility than might reside in an automaton.

Geographical location of the place of employment has an important sanitary bearing on the condition of the workers, since it determines very largely the outside influenees to which they are subjected. Location in country districts is likely to insure better and cheaper homes than ean be found in erowded eities, with, perhaps, a patch of garden which may be worked for pleasure, profit, and variety in the diet. It is, furthermore, farther removed from the influence of the tippling-shop and other unhealthy influences of the eity.

The wages paid affect the health of the working elasses in several ways. A small wage means necessarily a small expenditure for rent, clothing, and food; it means overerowded tenements, lack of ventilation, insufficient protection of the body by elothing of inferior quality, inadequate food-usually improperly prepared and hastily boltedpersonal and general uncleanliness and other eonditions which lower the mental, moral, and physical well-being of the workers and all who are dependent upon them. It means more beside : it means the utilization of child-labor and the breaking-down of women, who perform the double duty of looking after the home and assisting in its maintenance. All these eireumstances promote the morbidity- and mortalityrates, and the partieular occupations, perhaps intrinsically wholesome, a.e then said to be inimical to healtb, when it is not the nature of the eallings, but the attendant cireumstanees, that are at fault. Thus, it often happens that the conditions leading to the most serious evils may be traced to sone cireumstance or combmation of eireumstances which are wholly external.

Classification of Occupations.-In a general way, we may, from a sanitary standpoint, classify oeeupations as follows: 1 . Those which are intrinsically dangerous to health by reason of the nature of the materials involved. 2. Those which are earried on under conditions, avoidable or unavoidable, which promote suseeptibility to disease. 3 . Those which, involving exposure to mechanieal violenee, are dangerous to life and limb rather thian to health. 4. Those neither intrinsically 
dangerous to health or life nor earried on necessarily under peculiar avoidable or unavoidable cireumstances.

The first and seeond of these classes are of especial interest to the sanitarian, whose efforts are direeted toward the removal of all unsanitary influences of whatsoever kind attending any and all oceupations. The third class includes oceupations which involve the possibility of injury due to eircumstances bearing no relation to hygiene. Thus, no effort of the hygienist can prevent a brakeman from falling beneath the wheels of a train or the operatives in a dynamite industry from being blown into eternity by the force of an explosion due to earelessness. The fourth elass-and this includes a great variety of perfectly colorless callings-presents nothing of especial hygienie interest, since the plysical condition of the individual would be essentially the same whether he were engaged in one or another of the different fields, and only those which are carried on under peeuliar conditions can be studied to advantage. Therefore, only the first two elasses will be considered lere, and since the dividing line between the two is often difficult to define, and since some occupations may be said to belong to both, the two may be merged into one for the sake of convenience, and then subdivided as below :

The occupations which are of particular hygienie interest embrace those which involve exposure to-

1. Air vitiated by respiration.

2. Irritating and poisonous gases and fumes.

3. Irritating and poisonous dusts.

4. Infective matter in dust.

5. Offensive gases and vapors.

6. Extremes of heat.

7. Dampness.

8. Abnormal atmospheric pressure.

Of distinct, but minor, importance are those which involve-

9. Constrained attitude.

10. Over-exercise of parts of the body.

11. Sedentary life.

Some occupations are conducted under such conditions that they may very properly be regarded as belonging to a number of these groups. Mining, for example, may be considered under groups 2, 3, $6,7,9$, and 10, and eigar-making under groups 1, 2, 3, 9, and 11 .

To attempt to describe the conditions which surround each individual industry, and to give the details of the countless processes involved, would be beyond the scope of a work of this nature, and quite unnecessary for a general understanding of the relation of oceupation to health. Therefore, in the following pages, only the most conspicuonsly characteristic examples will be eited by way of illustration of the dangers to which workers are exposed. 


\section{Occupations Involving Exposure to Air Vitiated by Respiration.}

This class may be made to include any indoor calling carried on in overerowded, ill-ventilated rooms, in which the air is vitiated only by the processes of the body, and not by adventitious gases or dust. These oceupations, therefore, are not in themselves dangerous, but are made so by a preventable cause.

As examples, may be eited the callings of tailoring and dressmaking, which, only too commonly, are conducted in rooms in which fresh air and enbic space per capita are at a minimum. The workers are packed into quarters no larger than absolutely necessary for the performance of their daily task, impossible of proper ventilation without an expensive mechanical system, so great is the overcrowding, and, as is naturally to be supposed, overheated. Here, the unfortunates spend a fairly long day, leaving at night to go to homes perhaps no less unsanitary. If not already so when they begin, they become, after a time, anæmic, dyspeptic, and depressed, these conditions, as in many other callings, being promoted by lack of exercise, by ill-chosen and badly cooked food, and by absence of healthful recreations. They become greatly susceptible to cold, and hence opposed to the admission of fresh air from without. Breathing excremental air by day and night, denying themselves proper food, their minds depressed, it is not to be wondered at that their condition invites disease, more particularly the one which stands forth conspicuonsly as a consequence of overcrowding; namely, pulmonary consumption. The onset is insidious. Beginning with a cold that resists being "thrown off," the cough becomes chronic; they continue to lose weight and strength, and the end can be foreseen. It is not to be understood that these callings are always or even usually associated with these conditions; but when they are, the result is generally the same.

\section{Occupations Involving Exposure to Irritating and Poisonous Gases and Fumes.}

This class includes a great variety of callings which may or may not be intrinsically dangerous, according to individual circumstances. In many eases, the danger may be much lessened by due regard to personal hygiene and by the use of respirators. These are simple pieces of apparatus designed to remove noxious matters from the air, on its way to the respiratory passages. It is the rule, however, that workmen refise to wear them after the first days, even though well aware of the possible consequences of laying them aside. One reason for this is that not one of the several forms invented can be worn with any degree of comfort. They demand faster respiration, soon get wet with expired moisture, and canse excessive perspiration. Furthermore, they eannot be made to fit tightly, and so, even when conscientionsly worn, they only partially perform their office. The 
majority of them are designed to filter out dust, but all are made on essentially the same principle, those intended for noxions fumes containing spongy or other absorbent material, wet with agents which exert a neutralizing influence.

One form consists of a muzale of fine wire gauze, single or double, on a metallic frame. If made with a single layer, it is lined with cotton-wool, kept in place by a very loosely woven fabric stitched to the wire meshes; if made double, the intervening space is occupied by a piece of thin flannel. Another form is made of woven or knitted stuff, instead of wire. This is said to be even hotter than the first mentioned, particularly in summer, and both are extremely uncomfortable. A third form, made of pieces of flat sponge large enough to cover the nose and month, interferes very much with free respiration. Another, consisting of a large bag of fine cambric, is said to be less objectionable, but is difficult to fasten tightly.

Aside from the discomfort caused by respirators of whatever form, the operatives have another, a senseless, objection to their use, women complaining that they are made to "look ridiculous," and men being moved to discard them by the gibes of their more reckless fellows.

(a) Irritating Gases and Fumes.-As examples of irritating gases or fumes, may be cited ammonia, chlorine, sulphur dioxide, hydrochloric acid, and nitrous fumes. In small amounts, they causc, perhaps, no more disturbance than a slight tickling cough, but in large amounts, they bring about great discomfort and acute and chronic catarhal conditions.

Chlorine, which is used or given off very extensively in a number of industries, is unimportant when it is present in the air in very small traces; but when in large amounts, it is said to cause minor catarrhal troubles and diminution or even.loss of the sense of smell. It is said by Pettenkofer that from 1 to 5 parts of chlorine in 100,000 of air are sufficient to affect the lungs; that 40 to 60 parts in 100,000 will produce alarming symptoms; and that more than 60 parts will cause death. It is giren off in the processes of making and using bleaching powder, in the operation of glazing bricks, and in various other processes. Among the workmen who make use of bleaching powder, the ocenrrence of bronchitis, asthma, and caries of the teeth, is neticeably frequent.

Hydrochloric acid fumes are given off in various industries, ard especially from alkali works, the immediate neighborhood of which is likely to be barren of vegetation in consequence thereof. They are given off also in the process of galvanizing iron, the first part of the work consisting in "pickling" the iron in the acid to clean it and to prevent the presence of oxide on the surface when it is dipped into the molten zinc. These fumes act much less energetically on the respiratory passages than chlorine. Pettenkofer states that as much as 1 part in 1,000 of air can be borne withont diffieulty by men who are aceustomed to it, but that this amount eannot be exceeded. In the galvaniring process, the workmen are exposed also to the dense fumes arising 
from the sal ammoniae which is, from time to time, thrown upon the surface of the molten zine. These are more insupportable than the acid fumes.

Sulphur dioxide is evolved in the smelting of various ores, in preparing hops, in the manufacture of sulphuric acid and of ordinary matches, and is used extensively as a bleaching agent. In small amounts, it causes cough, and, by those unacenstomed to it, cannot be tolerated. Those who are exposed to it in their daily work establish a gradual tolerance and take no notice whatever of an atmosphere in which it is present to such an extent that persons unaceustomed to it cannot breathe it. The weight of evidence concerning the relation of this gas to health indieates that its effects are neither serious nor lasting, and are exerted more on the digestive than on the respiratory function. In some individuals, a small amount in the atmosphere canses epigastrie pain and heartburn very quiekly.

Bromine is exceedingly irritating to the respiratory passages and to other mucous membranes with which it may come in eontact. In small amounts, it eauses cough, dizziness, and a feeling of general malaise; in large amounts, spasm of the glottis and asphyxia. Bronchial asthma is commonly observed among those constantly exposed. The fumes of iodine act practically in the same way, although to a much less marked extent. In occupations in which these two substances are used, men with a tendency to pulmonary troubles should not be permitted to work.

There is no evidence that ammonia in small amounts produces anything more than temporary irritation of the air-passages', but it is a general belief that it is conducive to emplysema.

Nitrous fumes, given off in a number of processes involving contact of metals with nitrie aeid, are also of no very great importance in small amounts, but it is said that those who are exposed are especially subject to phthisis, in the causation of which it is conceded that the constrained attitude and lack of ventilation have a large influence. It is noted that the tendency is greatest in those exposed to the largest amounts.

(b) Poisonous Gases and Fumes.-This class includes a very large number of occupations, since poisonous gases are an incident of proeesses without number.

Carbon monoxide is one of the most important of the poisonous gases, and this is given off in many mannfacturing operations, usually in eompany with other gases, and it is, therefore, not always an ensy matter to determine what proportion of the effects noticed are due to any one constituent of the mixture. The constant inlialation of even very small amounts of carbon monoxide causes disturbances of the digestive function, general weakening of the system, and diminished mental power. The one elass in whieh one would naturally expeet to find the greatest evidence of injury, namely, laborers in gats plants, yields very little.

Carbon disulphide is mueh used as a solvent for fats, but its ehief 
use is as a solvent and vulcanizing agent for India-rubber. The very peculiar effeets produced upon the operatives in rubber factories, especially when the work is carried on in imperfectly ventilated rooms, have been attributed generally to the use of this agent. There is at first a dull hearlache, which inereases much in severity toward the close of day ; sight becomes somewhat confused ; vertigo and epileptiform convulsions, pains in the extremities, and formication are common. In the early stages, an unrestrainable inclination to talk is almost invariably observed, and, coineidently, a stimulation of sexual desire. Soon, the victim becomes moody, irritable, and subject to violent outbreaks of anger; vision becomes further impaired; the sense of smell is much diminished. During this stage, obstinate insomnia is the rule. Next oceurs a stage of depression, in which the loquacity and increased sexual desire give way to impaired memory, feebleness of mind, taciturnity, and diminution of sexual desire and power even to complete abolishment, with intense headache, either somnolence or wakefulness, and local areas of anæsthesia. Sometimes cough, dyspnœa, and paraplegia are observed. As a rule, however, no permanent injury is caused, since, from the very nature of the symptoms, the victims are unable to continue to work; and removal from the cause, with appropriate medication, in which phosphorus is highly regarded, usually brings about a perfect cure. This train of symptoms seems to be peculiar to workers in rubber factories; and since the evidence at hand shows that those who make carbon disulphide do not suffer in the same way, it seems reasonable to suppose that other agents than this one are to be considered in the etiology. It happens that, in this same industry, naphtha is very much used as a solvent. The vapors of this substance cause embarrassment of respiration, and also dizziness and mental confusion. In France, the employment of women under eighteen in rubber factories, and in any work which exposes them to the combined fumes of naphtha and carbon disulphide, is prohibited. Santesson ' has reported 9 cases of naphtha-poisoning, 4 of which were fatal. They occurred in a rubber factory where a solution of rubber in naphtha was used. The symptoms were headache, dizziness, vomiting, palpitation, and hemorrhages. In those cases which recovered, the symptoms lasted several weeks. All the victims were young women. In 1 fatal case, the autopsy showed fatty degeneration of the heart, liver, kidneys, and other parts. Naphtha is used very extensively also in cleansing woollen and other unwashable elothing, and young women employed in establishments devoted to this kind of work suffer from dizziness, nausea and romiting, headache, insomnia, and hysteria. They find it necessary to go frequently into the open air in order to avoid hysterical outbreaks.

Another much more poisonous substance is nitrobenzol, which is very insidious in its effects. It is used in making aniline, like which it is a narcotic poison, and in the manufacture of roburite and other

${ }^{1}$ Gazette hebdomadaire de Médecine et de Chirurgie, August 26, 1897. 
of the newer explosives. Long exposure to small amounts produces a train of symptoms which include headache, dyspnœa, drowsiness, dizziness, nausea and vomiting, and loss of muscular strength, and which terminate in stupor and not infrequently in death. Death sometimes occurs within a few hours of the onset. Aniline vapor itself is dangerous to health when present in the air to the extent of 0.1 per cent.

The most prominent of all the poisonous vapors in manufacturing proeesses are those of mercury and phosphorus. It is hardly necessary here to enumerate the effects of exposure to these poisons, since they are so universally well known; but it is not so commonly recognized that operatives in industries in which metallie mercury is used extensively appear to be very subject to phthisis, and that, among the women, misearriage is very common. It is said that the offspring show the effects of the poison, and that two-thirds or more of those born at term die without eompleting a year of life; but it is well to consider that among the classes from whieh the operatives for this and similar occupations are drawn, ehild life, at best, labors under great disadvantages.

Mercury is commonly supposed to be used chiefly in the manufaeture of mirrors, and in gilding and silvering. This, however, is far from being the ease. In fact, the processes of making mirrors and of gilding have been so revolutionized that, in these industries, mercurial affections have been practically eliminated. At present, one of the most common sources of mercurial poisoning is the industry of felting, in which it has been discovered that the coney and other hairs used make better felt, if they have a preliminary treatment in a bath of mercuric nitrate. In a later process, the raw product is heated to a temperature sufficient to volatilize the mercury. Other occupations in which mercury is used extensively include the manufacture of thermometers, barometers, and eertain forms of electric batteries, and the bronzing of plaster easts with an amalgam containing tin, bismuth, and mercury.

Phosphorus is a substance of mueh more importance to the public health than mercury. The only industry of any magnitude in which phosphorus is used extensively is that of match-making, in which industry the operatives suffer from the well-known lesions which phosphorus produces. This is a danger which has received much legislative attention in England and other European comtries, and much has been done to avert it by more strict attention to lygiene and the introduetion of machinery to take the place of luman beings. In Switzerland, indeed, even the use of any matches other than those made with amorphous phosphorus is absolutely forbidden.

Common phosphorus gives off poisonous fumes at ordinary temperatures, provided the air eontains moisture. Amorphous, or red, phosphorus is not poisonous, and gives off no fumes under usual conditions. It cannot be used in the same way as common phosphorus, and is employed only in the manufacture of matehes that strike only on the box or on a specially prepared surface; this is obviously a 
disadvantage, since a match that will strike anywhere is much more eonvenient. It is said that, in England alone, no less than 60 tons of white phosphorus are consumed annually, against 4 tons of the red variety.

It is a very common notion that most of the workmen suffer extensively from the effeets of the poisonous fumes, and that necrosis of the jaw is exceedingly common. It appears, however, that, while this elass of workmen are in general anæmic and badly nourished, the extensive lesions that formerly were noticed have been of late years much less common. In 1897-8, in the United Kingdom, more than 1,500 persons were engaged, but in the four years, 1894-8, only 36 cases of neerosis of the jaw were recorded, 21 of which occurred in 1890 ; but possibly more may have occurred. This reduction is due to precautions taken to earry off the fumes by thorough ventilation, and to prevent their production as far as possible by the use of substances like turpentine, and by drying the matehes as quickly as possible after they have been dipped, sinee the fumes are given off only in the presence of moisture. Again, much of the work of dipping is done in closed hoods. It is said that the most difficult part of prevention lies in the handling of the work-people themselves, since they are of a class that can rarely be made to understand the importanee of cleanliness and of attention to the condition of the teeth. Persons with decayed teeth should be excluded from the business, since earies is known to increase enormously the risk of poisoning. They eannot, for reasons already explained, be persuaded to use respirators.

In the industry of brass-founding, fumes are given off which cause what is eommonly known as "brass-founders' ague," which is a disorder occurring sooner or later-usually, within a very short time-to all engaged. The trouble begins with a feeling of malaise, headache, stiffness, great muscular pain, and soreness of the chest. A chill eomes on, which lasts generally about a quarter of an hour, after which the patient falls into a profuse perspiration. The symptoms then begin to abate and within a day or two disappear. Although this train of symptoms does not commonly recur, a more or less marked chronic poisoning is common, in which the most prominent symptoms are anæmia, cough, tachycardia, headache, neuralgia, disordered digestion, progressive emaciation, and annoying eruptions of the skin. The acute and ehronic poisoning suffered by this class of workmen are supposed by some to be due to zinc, by some to eopper, by some to both together, and by others to arsenie, which is an important constituent of some kinds of brass and an impurity of others. Some incline to the belief that brass-founder's' ague is a true infection, for which the poisoned air prepares the ground and paves the way.

Fumes of arsenic are given off' in various smelting operations, but the chief danger from this substance is met with in oceupations to be considered later, in which it is given off in the form of dust. A peculiar source of poisoning by arseniuretted hydrogen has been brought to public notice by Maljean, ${ }^{1}$ who observed a number of cases of ieterus

${ }^{1}$ Archives de Mrédecine militaire, February, 1900, p. 12. 
among the balloonists of a regiment of engineers. The cause was traced by him to the hydrogen gas used in filling the balloons, which was made by the action of ordinary commercial sulphuric acid on commercial zinc, both of which contain arsenic in variable amounts, in consequence of which the product contained arseniuretted hydrogen. The impure gas was liberated through the valve of the balloon, but the maiu source of danger was the habit of smelling at the stopeock during filling, to ascertain when the air in the pipes had been expelled by the gas. In the cases observed, the onset was marked by great malaise, headache, nausea, stiffness of the joints, jaundice, and hæmoglobinuria. The symptoms subsided in a few days, leaving the patients in a condition of anæmia and pronounced malnutrition.

The vapors of wood alcohol have within recent years attracted considerable attention by reason of their disastrous effects upon vision. Since 1899 , many cases of blindness have been reported in the journals devoted to ophthalmology as due to the vapors and to the internal use of preparations such as essences of ginger, peppermint, etc., which are very commonly made with wood alcohol, and extensively consumed in places where the sale of liquor is prohibited. When wood alcohol as such is consumed, as it often is, with fatal results, it will be noted that the victims are generally quite blind before death approaches. Wuirdemann ${ }^{1}$ has reported a case of wood-alcohol blindness due to the inhalation of fumes from varnish. The subject was a moderate user of tobaceo and stimulants, whose sight had always been good. After working six days, he was obliged to quit work on account of nausea, dizziness, and severe frontal headache. On the following day, he had dimness of sight, and then became totally blind for twenty-four days, when his sight began to improve. In another case reported by Patillo, ${ }^{2}$ and quoted by Würdemann, the material worked with was the same, and total blindness occurred on the sixth day. This lasted a week, then sight improved, but in two weeks it began again to fail. Inhalation of the vapor is believed to cause retrobulbar neuritis, producing partial atrophy of the optic nerve, especially of the central fibers.

\section{Occupations Involving Exposure to Poisonous and Irritating Dusts.}

Dust is of very great importance in its influence on health. Its production is a prominent feature of many ocenpations, in some of which so much is caused as to be of the highest possible importance. It may be divided into poisonous and irritating, and the latter may be subdivided into mineral, metallic, vegetable, and animal.

(a) Poisonous Dusts.- The most important of the poisonous dusts are arsenic and lead.

One of the most dangerous of arsenical trades is the grinding of the well-known green pigments, Scheele's green (arsenite of copper) and

1 American Medicine, December 21, 1901, p. 995.

${ }^{2}$ Ophthalnic Record, December, 1899, p. 599. 
Schweinfurt green (aceto-arsenite of copper). These and many other arsenical colors are used in printing wall-papers, cretonnes, and other decorations, and in the manuficture of artificial flowers. The latter is an especially dangerous occupation, since after the leaves have been cut to the proper shape, they are smeared with gum, the green pigment is then dusted on from a dredging-box and much of the substance beeomes suspended in the air. Much of the green glazed paper used for covering boxes is made with these pigments, and other papers and articles of paper in green and other colors (playing cards, etc.), are made with arsenical pigments. Arsenite of sodium is a very common mordant, and white arsenic is much used in taxidermy. In fact, the list of processes in which arsenic is used is almost endless. The symptoms produced may be acute, but ordinarily are chronic in character. Workmen of this class frequently suffer from eczematous sores and obstinate ulcers. The symptoms of chronic poisoning are too well known to need description.

Lead is infinitely more disastrous in its effects upon health, and is by far the most important of all industrial poisons, because of the great diversity of its use. Among the many occupations in which it figures may be mentioned all the processes involved in obtaining lead in its commercially pure state from ores, the making of white and red lead, the glazing of many kinds of papers ; type-founding and setting, glasscutting and polishing, file-cutting; enamelling, dyeing and printing, working in weighted silk; plumbing, painting, leather varnishing; making artificial flowers, leaves, and jewels ; and several of the processes used in the making of earthenware and china. In many of these, the lead gains access to the system through inhalation, and in some it is carried into the mouth by the soiled fingers. The latter method of introduction is very commonly the case with compositors, plumbers, workers in lace and silk weighted with lead acetate, and others.

In Paris alone, it is said, there are more than 30,000 of the working classes following eallings which expose them to this very deleterious substance. In England, the great importance of the subject of industrial lead-poisoning has led to extensive investigations, resulting in stringent legislation; and in the year 1895, it was required that all cases of lead-poisoning should be reported to the authorities. During the year 1897, the number reported was 1,124 , and in $1898,1,278$. The largest number of eases are reported from the china and earthenware trades. It appears to be a fact, wherever the matter is investigated, that women suffer less than men. This is explainable in two ways : first, that women are naturally more cleanly in their habits; and second, that women are more likely to give up their work after the oceurrence of the first symptoms and before the affection becomes chronic. Men appear to be able to work longer without showing evidenee of injury.

Particular attention has been given of late years in England, France, and elsewhere to the pottery industry, in which lead is used in the 
glazes, the flux being made of litharge, clay, and flint. Much attention has been given to the possibility of finding a glaze which shall be free from lead. In the manufaeture of ordinary white porcelain, no lead glaze is required, and the danger of lead-poisoning arises almost wholly in the work of decoration, the powder which is dusted on and off the transfer paper, containing lead eompounds. According to a report of a committee of the master potters of Staffordshire, it is not possible to substitute a leadless glaze for ordinary china and earthenware, but this is said to be only partly true.

In Limoges, where 16,000 people, of whom 2,500 are children, are employed in sixteen pottery establishments, the workers are much less subject to lead-poisoning than those in Staffordshire, and in one of the establishments where the ware produeed is of the same kind as made in Staffordshire, the glaze contains only 8 per cent. of lead carbonate against 13 to 24 in that used in Staffordshire. It has been pointed out that where lead glazes are neeessary, the danger can be very much diminished, if the lead is used in the form of a double fritted silicate. In the Limoges factories, the lead is used in this condition, and to this fact, part of the difference in the amount of poisoning is probably due. In English potteries, the tendency is toward the abandonment of the old methods and the adoption of fritted lead.

Lead is, however, not the only danger to health with whieh workmen in potteries have to contend. In certain of the operations, large amounts of mineral dust are given off, and in consequence they suffer from the effeets of not only poisonous, but irritating, dust; in fact, the occupation is regarded from a sanitary standpoint as one of the least desirable. The flint-grinders, who belong to this class, are, according to Hirt, quite low down in the seale of longevity. It is said that the dust whieh is given off in the operation of grinding kaolin is unusually irritating to the lungs-worse, even, than steel dust. The most eommon discases among potters are bronchitis, phthisis, rheumatism, and lead-poisoning.

As another example of an industry in whieh the workmen suffer largely from lead-poisoning may be eited that of file-making, in which, as in pottery-making, the operative is subjected to the aetion of dust both poisonous and irritating. The best files are those eut by hand, no machinery having yet been invented to produce so satisfactory an article as the hand-made. While being ent, the file is held upon a leaden bed, ealled the "stiddy," which offers sufficient resistance to the blow, without at the same time being so unyielding as to cause a recoil. As fast as it is cut, it is brushed off', and the air becomes eharged with a combination of steel, lead, chalk, and ehareoal, and granite from the block, or "stock," upon which the "stiddy" is secured. The danger of lead-poisoning is thus always present, and its necurrence is hastened by the carcless habits of the workman, who, in handling the leaden bed, constantly wets the thumb and forefinger of his left hand with his tongue. Donbtless, if more attention were paid to personal hygiene, a smaller proportion would suffer from eolie and 
paralysis of the extensor muscles of the wrist and thumb. It is said that a robust file-cutter is rarely seen; as a class, they are sallow, anæmic, and dull, and the majority show the blue line of chronic leadpoisoning.

A more modern industrial danger is that involved in making and charging storage batteries of a certain kind. Dr. Talamon' relates that, during a single year of hospital service, he saw 30 eases of leadpoisoning among workmen so engaged. The work eonsists largely in spreading red lead and litharge over lead plates with the bare hands, and the results on the system are doubtless due in greatest part to absorption throngh the alimentary tract, the lead being conveyed to the mouth by the hands. The symptoms come on much more rapidly and are much more acute than with painters, type-setters, and others. Many of the men fall victims within three or four weeks from the beginning of their service.

(b) Irritating Dusts.-The irritating dusts act with variable intensity, according to their nature. It is generally thought that that of vegetable origin is the most irritating of all ; then, in order, metallic, animal, and mineral. The disease which is conspicuously common among dust-workers-more common than among any other large class-is phthisis, a predisposition to which is favored by constant irritation by the dust, assisted by poor ventilation, constrained attitude, and other unsanitary circumstances. In general, the first effects of an abnormal amount of dust in the air are cough and increased secretion of mucus. Then the cough becomes chronic, and when the soil has been properly prepared, the specific bacillus finds a lodgement and soon produces its results. Many of the dust-workers' disorders are traceable not to a single kind of dust, but to a mixture. Thus, the condition formerly known as "grinders' asthma" is superinduced by a mixture of metallic particles from the implement ground and mineral matter from the stone, and to which, if either, of the two kinds the prepondering influence belongs, cannot be stated.

The relative frequency with which diseases of the lungs occur in the different classes of dust-workers and in those whose occupation creates no unusual amount of dust was determined by Hirt ${ }^{2}$ from a large mass of material, in which, of course, the value of the primary factors can hardly be determined; nor that of collateral eircumstances, such as habits, heredity, and loeality. But his facts, which, to say the least, are coincidences of occupation and disease, show that the different classes of dust-workers suffer from pneumonia and phthisis in varying degrees, and much more frequently than those not exposed to dust, and that in the frequency of diseases of the digestive system, on the other hand, there is practically no difference. In the following table, compiled from his figures, the relative frequeney of these diseases per 100 workmen is shown :

${ }^{1}$ La Médecine moderne, Feb. 7, 1900.

${ }^{2}$ Die Krankheiten der Arbeiter, Breslau, 1871. 


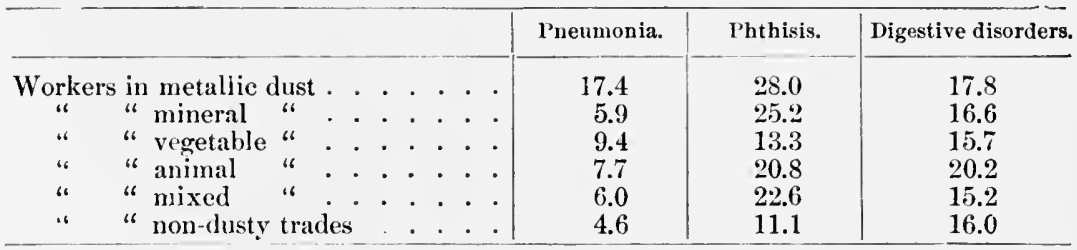

With regard to the influenee of the different kinds of dust oecupations, one must not lose sight of the fact that quantity as well as quality should be considered, and that local conditions of ventilation have a very deeided bearing.

Among the oceupations in which metallie dust is given off in notable amounts, that which stands forth most conspienously as dangerous is steel-grinding. In this work, the danger varies inversely with the size of the object ground; that is to say, the smaller the oljeet, the greater the danger. This is because large objects can be ground in the wet way, but very small ones, as needles, must be ground dry and require constrained attitude and close inspeetion, and thus the grinder constantly inhales the very fine, sharp particles of steel that are thrown off in the process. These, by constant irritation of the mucous membranes of the air-passages, prepare them for the reception of the speeifie organisms of pneumonia and phthisis. At first, the cough is diry, but in a short time is aceompanied by expectoration. Among those individuals who have followed the work for a year or longer under the usual conditions, a sound man is rare. Their average age at death is stated variously between twenty-five and forty years. The danger may be much reduced by the use of respirators, and by the employment of a blast of air to carry the dust away from the grinder into an appropriate exit.

Not all motallie dust is as irritating as that given off in cutlerygrinding, and in some oeeupations in which it is given off even more abundantly, there is no noticeable tendeney to phthisis, although, perhaps, the subject has not been investigated with suffieient thoroughness. In the operation of bronzing in the manufacture of show eards, Christmas carrls, and the like, the bronze powder, which, under the microseope shows sharp angles, is applied to the pattern, printed in sizing, by means of a soft pad worked largely by hand. The dust adheres tenaciously to the skin and eauses much loeal irritation, and is inhaled and eauses eatarrh of the upper air-passages. In addition, the workers suffer from headache, bad taste in the mouth, anorexia, nausea, voniting, and diarrhea, from absorption and local action in the alimentary canal. When the operations of dusting on and off are done by machinery, the evolution of dust is very much lessened.

The dusts of many of the metallic salts produce more or less serious local effects, aside from the results due to absorption into the system. In the manufacture and use of potassium dichromate, for example, great irritation of the nasal mucous membrane is eaused, followed by ulceration, which in most instances ends in perforation of the septum. 
Uleers are produced wherever the skin is abraded, and espeeially on the scalp, where action is promoted by the scratching which the irritation calls forth. No local effects appear to be caused in the lungs.

As an example of a calling in which mineral dust is given off in abundance, that of glass-grinding may be mentioned. This is much like eutlery-grinding, in a general way, and the dust produced is nearly, if not quite, as sharp and irritating. In addition, the workmen are often subjeet to lead-poisoning, due to the use of putty powder containing 70 per cent. of lead oxide. It is as rare to find sound men among this class, as among needle-grinders. Gem polishers and potters belong in this same category. Stonecutters and quarrymen are exposed to coarser kinds of mineral dust, but their work being conducted in the open air or in open sheds, they are by no means so prone to diseases of the lungs. Some stone is much dustier than others, and hence may cause more marked effects. Mica dust is exceedingly irritating, and, like the sharp particles of glass and steel, prepares indoor workers for the reception of the bacillus of tuberculosis. In the wall-paper industry, it is applied to obtain the effect of "frosting," and assists or is assisted in its action on the operatives by another very fine dust made of finely chopped or ground lambs' wool, which is applied to the pattern printed in size in much the same manner as obtains in bronzing cards. The workers are very prone to phthisis.

Vegetable dust is of very many varieties, which affeet the system with varying degrees of intensity. Ordinary wood dust appears to be quite innocent of injurious action on the lungs of carpenters, whose employment is very largely out of doors, and of cabinet-makers, who, on the other hand, work in confinement. Grain threshers, millers, and many others exposed to vegetable dust present no great evidence that their callings are markedly inimical to health. Certain others, however, offer important and interesting facts, indicating that, either alone or as one of a group of influences, some of the vegetable dusts are as disastrous in their effects as some of the most irritant of those of metallie nature. Among the most unhealthy classes of workpeople are those engaged in cotton and linen factories. Cotton dust, or "flue," is very irritant to the upper air-passages, and causes dryness of the throat, followed by cough and expectoration. In some operations, a sized eotton thread eontaining kaolin is used, and then the air is laden also with this very irritating substance. Flax dust, or " ponce," is even more irritating than cotton.

In the linen faetories of Belfast, which, according to G. H. Ferris, ${ }^{1}$ employ 30,000 persons, five-sixths of whom are women, the deaths from phthisis and other respiratory diseases have been shown to outnumber those from all other diseases by about two to one. Among the women below thirty years of age, the death-rate from phthisis is three or four times as high as among women of the same ages engaged in other employments. In 1892 , the phthisis death-rate reached the

1 Journal of State Medicine, March, 1895. 
enormous height of 41.1 per 10,000 , against 14.6 for the whole of England and Wales, and 21.6 for all Ireland. Apart from the intrinsic danger of the occupation, however, it must be noted that the eity itself, from the nature of the soil and elimate, eannot be a healthy place, but, on the other hand, it must be said that overerowding, which is so great a factor in the causation of the disease, cannot, in this instance, be eharged with an unusual amount of influence, since in no other eity in Great Britain and Ireland are there so many houses in proportion to the population.

Workers in tobaceo are exposed not alone to irritating and poisonous dust, but to fumes as well. They are much subject to nasal and bronehial eatarrhs and disorders of the digestive apparatus and nervous system. The women engaged are said to abort very commonly, on account of the death of the foetus. Many assert that the occupation in itself is not an unhealthy one, and that it possesses eertain advantages in that it renders the individual less susceptible to infective agents. As evidence of this, it is said that, during the great eholera epidemic at Hamburg, in 1892 , there were but 8 cases of the disease, with 4 deaths, among the 5,000 cigarmakers there resident.

Animal dust is given off in the numerous industries in which wool, silk, feathers, fur, bristles, hair, horn, bone, shell, ivory, and other substances of animal origin are used. These substances are irritating to different extents, as wonld naturally be supposed from their very diverse character, some, as wool, feathers, and silk, resembling in action cotton and flax, and others, as shell, bone, and ivory, acting more like the mineral dusts. The operatives in woollen mills, appear, on the whole, to be rather less subject to phthisis than those engaged in the cotton and flax industries. Among the others of this class, those making brushes and buttons, especially pearl buttons, are regarded as taking greater risks than the rest. Most statisties of these industries are faulty and inconelusive.

\section{Occupations Involving Exposure to Infective Matter in Dust.}

This class includes those having to do with rags, wool, horsehair, hides, and other materials likely to be infected. The importance of rags as a vehiele for infeetion has been much overrated, but the danger is, nevertheless, a real one, as the experience of paper-makers has often demonstrated. The only method of insuring freedom from infection through the handling of rags is thorough disinfection, a proeess involving an expense, it is asserted, much disproportionate to the results achicved.

The most eommon disease connected with infected raw material is anthrax, or "wool-sorters' disease," the spread of which is often traced to horsehair, wool, and hides. Nichols ${ }^{1}$ reported 26 cases of this disease as oceurring in one curled hair factory in three years. Ravenel ${ }^{2}$

' Second Annual Report of the State Board of Health of Massachusetts, p. 86.

${ }^{2}$ Report and Papers of the American Public Health Association, Vol. 24, p. 302. 
collected 12 cases occurring in men and 60 in cattle in three localities in Pennsylvania, during the summer and autumn of 1897. All of the men worked in tamneries, and all of the eattle were pastured in meadows watered by streams which received waste products from tanyards. The skins at fiult came from China.

Aceording to Dr. S. Leduc, ${ }^{1}$ imported horschair is the most dangerous material brought into France. The French market is supplied by South Ameriea, whenec it is shipped in bales compressed by hydraulic pressure. Unpacking the bales and sorting the contents according to color are alike regarded as dangerous. After being sorted, the hair is beaten, and in this process much dust is caused. It is then carded and spun into ropes. The precautions to be taken include removal of dust by special blower apparatus, perfect eleanliness, and great watehfulness. Disinfection of the hair without impairing its commercial value or unduly increasing its cost is said to be impracticable.

Naturally, the danger of infection by the spores of anthrax on hides, hair, and the many kinds of wools coming from countries where the disease is common eannot in any individual case be foreseen. From ordinary sheep's wool, the danger is slight, and from native wools is practically non-existent. When, for any reason, danger is apprehended, workmen with sores, euts, or abrasions on their hands, arms, faces, or necks, should not be employed, ventilation should be thorough, and all precautions should be taken to prevent dissemination of the dust.

\section{Occupations Involving the Inhalation of Offensive Gases and Vapors.}

This class of occupations includes a great variety of what are known as "offensive trades," having to do with organic matter largely of animal origin, such as tanning and currying, soap-making, glue-making, fertilizer-making, fat-rendering, bone-boiling, keeping animals, etc. While there can be no doubt that these offensive trades are a frequent source of misance to the community at large, evidence of injurious influence on the health of those actively engaged and of the population in the immediate vieinity of the works is decidedly slender. There can be no doubt of the disadvantage of having such establishments located in the midst of thickly settled communities, and hence their supervision constitutes a most important part of the duty of public anthorities. The workmen are likely at first to suffer from nausea, romiting, loss of appetite, and headache, but these evidenees of disturbance disappear within a short time, and do not reeur.

Contrary to general opinion, these occupations not only do not appear to shorten life, but from such facts as are presented by the mortality statisties of occupations, it may be inferred that they conduce to longevity, for, as a elass, their average age at death is quite

1 Public Health Reports, May 25, 1900, p. 1306. 
high. It is hardly necessary to go into the details of the processes involved in the different callings.

\section{Occupations Involving Exposure to Extremes of Heat.}

Exposure to extreme heat is a concomitant of a number of other unsanitary influenees which affeet the health of the worker in a variety of occupations, which include those of engineers, stokers, cooks, bakers, miners, foundrymen, weavers, employees in rolling mills, wire mills, sugar refineries, glass factories, and others. The effeets of great heat alone are exhaustion and thermic fever, and when to these are added those of vitiated air, dust, irritating fumes, and dampness, the consequences may be very grave. Sudden chilling of the body and prolonged exposure withont intervals of rest are especially to be guarded against. The workmen of this class are commonly affected with eatarrhal and rheumatic troubles, diseases of the kidneys, and skin eruptions.

\section{Occupations Involving Exposure to Dampness.}

Exposure to indoor dampness is nisually only one of a number of debilitating influences, the effects of any one of which are not suseeptible of eorrect measurement. Ontdoor dampness is probably far less influential for evil ; but continned exposure, coexistent with exhansting labor, is eonducive to rheumatism and bronchial troubles. With ordinary eare, however, those exposed to vicissitudes of weather and to wetness from other canses-drivers, boatmen, fishermen, and trench diggers, for example-enjoy good health and are, as a class, long lived.

\section{Occupations Involving Exposure to Abnormal Atmospheric Pressure.}

The prineipal ealling of this gromp is that of caisson workers, who suffer from what is known as the caisson disease, the pathology of which is by no means clear. A eaisson may be defined as a large inverted water-tight box in which work is performed below the water-level, as in the laving of foundations for the piers of bridges. It is, in fact, a diving bell on a large seale. It is provided at the top with a shaft for ingress and egress, eommunicating with which and with the interior is a chamber with two sets of doors, known as an air-lock. Placed in position and heavily weighted with masonry, it sinks into the nud beneath. The air in its interior is compressed by the action of the surrounding water, and the thereby diminished air space is restored by downward displacement of water through the ageney of powerful ail pumps. The deeper the eaisson sinks, the greater, of course, the atmospheric pressure within. As the work of excavation progresses, the apparatus sinks deeper and deeper, being assisted in its downward 
movement by the weight of the superimposed masonry; and when the proper geologieal formation is reached, the interior is filled with conerete, which thus forms the solid foundation, and the box is left there. In entering the caisson, the workman goes first into the air-lock and closes the door. The pressure in this compartment is then gradually equalized with that of the caisson chamber by means of an inlet pipe controlled by a valve, after which he opens the inner door and, entering the ehamber, eloses it again. In emerging, the process is reversed: the pressure in the air-lock being raised, he enters and closes the door; by means of another valve, the pressure is lowered gradually to normal, and then the outer door is opened. The operations of locking in and out must be conducted gradually. In locking out, the rule is to allow at least one minute for each 6 pounds of pressure within the chamber. Attention must be paid also to the lowering of temperature which accompanies the expansion of the air within the lock.

The symptoms of the peculiar disturbance do not, as a rule, appear until the pressure equals 20 pounds, and some time, measured in minutes or even hours, after emerging. In some cases in which cerebral and spinal symptoms are severe from the beginning, death oceurs within a short time. The symptoms include headache, pain in the ears, rapid pulse, sweating, severe pains in the legs, back, and epigastrium, and, later, paralysis of the motor nerves, generally of the legs, sometimes of the arms, and not infrequently of the bladder and rectum. The motor nerves are in some instances involved before the sensory disturbances appear. The epigastrie pain is aceompanied sometimes by romiting, more or less severe in character. Mild cases of the discase last from a few hours to a week or longer; but, whether mild or severe, complete recovery is the rule. Where electric lighting is not employed, irritation of the bronchial mucous membrane, cough and expectoration, due to soot, are not uncommon.

The cause of the main symptoms has been the subject of eonsiderable speculation, and whether it is an exeess of oxygen in the tissues, whieh seems improbable, or congestion of the central nervous system, or some other condition, appears to be incapable of elncidation. The use of intoxicants appears to be a predisposing influence; hence, drinking-men should not be employed. Thin men are much less susceptible than the stout and full-blooded. Work should never be performed on an empty stomach, and periods of absolute rest should be frequent when the pressure is unusually high.

Submarine divers are subject in a lesser degree to the same train of symptoms.

\section{Ocoupations Involving Constrained Attitude.}

These include a wide variety of trades leading to varions deformities, the most important of which is constriction of the chest. Vitiated air is a common coexistent condition, and phthisis is a frequent canse of reath. 


\section{Occupations Involving Overexercise of Parts of the Body.}

The occupations of this class bring about a variety of deformities and of fatigue neuroses characterized by disturbance of the functional activity of groups of muscles trained by practice in highly specialized coördinated movements. These include such conditions as the cramps of writers, telegraphers, pianists, violinists, engravers, seamstresses, and others, and localized paralyses and tremors. The pathology of these conditions is very obscure; but in certain of the caseses, especially those in which the larynx is overexercised, the element of hysteria enters to a considerable extent. These abnormal conditions are of far less hygienic importance than any that have been considered, and are of interest chiefly to the specialist.

\section{Occupations Involving Sedentary Life.}

Certain callings are commonly set down as sedentary occupations; but, strictly speaking, this class is closely interwoven with several of those already mentioned. For instanee, a very large number of indoor occupations, carried on, perhaps, under conditions peculiar to themselves, are at the same time sedentary in their nature.

The abnormal conditions brought about by sedentary life are those induced by a lack of general exercise of the body. This brings about a general sluggishness of the functions, which is ordinarily most marked in those of the abdominal organs and heart. The consequences of too close confinement and lack of exercise are too well known to need detailed mention. Ordinarily, they can be expressed by the term "general debility." There is no particular reason why sedentary occupations should injure health, and it will be found in almost all instances of impaired function that the sedentary habit is not peculiar to the individual while at work, but during both work and leisure hours. The sedentary worker has the matter of prophylaxis in his own hands, and should take a reasonable amount of exercise daily, preferably in the open air. It is common to inelude brain-workers in this class, and to attribute to the sedentary side of their lives the consequences of overexertion of the mind. It must be remembered that activity of the mind has no shortening influence on life; but abuse of the inental powers, and especially mental worry, conduce to headache, insomnia, and general breaking down of the nervous system and of the general health.

\section{PROPHYLAXIS IN GENERAL.}

In what has gone before, it will be notieed that the disastrous effects attributed to oceupations are in very large part due to non-observance of the principles of general hygiene, and ehiefly to inattention to that most important sanitary measure, perfect ventilation. It will have been noted that in Groups 1, 2, 3, 4, 5, and 6, the conditions which bring about impairment of health may be reduced very largely by a constant supply of fresh air. With proper attention to this matter and 
improvement in the lome and home influences, greater attention to the character and preparation of food, and a more general observance of the beneficial influence of active ontdoor exercise, no very great differences would be noted in the health of the various classes of workpeople, and the expression occupation diseases would lose whatever significance it now has.

\section{Employment of Women and Children.}

In view of the dangers and conditions incident to a great variety of oecupations directly or indircetly inimical to health, it is of the utmost importance to protect the health of women and children by restricting them in the daily number of hours which they may give, and prohibiting their employment in distinctly dangerous surroundings, for women and children are more delicately organized and less resistant to weakening influences. Particularly should women be protected during the child-bearing age, so that they may be insured, so far as is possible, a healthy progeny. It hardly needs to be said that children should be protected most carefully during the period of their full development, in order that they may come to maturity in a fit condition to take on the responsibilities of the family.

Inattention to the very great importanee of conserving the health of women and children is bound sooner or later to result in degeneration, and this fact has received the attention of the law-making bodies of all, or nearly all, civilized countries. In this country, it is constitutionally a matter for legislation by individual States, in many of which not only is their physical welfare protected, but the moral aspects of trades as well receive due attention.

As an example of such protective legislation may be given the following rules, made by the State Board of Health of Massachusetts, to conserve the health of minors within the State. By reason of a law passed by the Legislature of 1910, the State Board of Health was given power to declare, from time to time, whether or not any particular trade, process of manufacture, or occupation, or any particular method of carrying on such trade, process of manufacture, or occupation, is sufficiently injurious to the health of minors under 18 years of age employed therein to justify their exclusion therefrom. The processes named are given herewith :

I. Processes Involving Exposure to Poisonous Dusts or Substances :

1. Processes in the manufacture of white, red, orange, or yellow lead.

2. Processes in the manufacture of lead pipe, solder, and plumbers' supplies.

3. Cutting metal articles with a mixture of lead and tin, or lead alone.

4. Processes involving exposure to lead and the dust of plumbago in electrotyping. 
5. Processes involving the handling of white lead or lead monoxide (litharge) in rubber factories.

6. Lead paint griuding.

7. Lead working in the manufacture of storage batteries.

8. File cutting by hand.

9. Typesetting, cleaning or handling type in printing offices.

10. Glazing in pottery establishments.

II. Processes Involving Exposure to Irritating Dusts :

1. Processes involving exposure to the dust of graphite in the manufacture of stove polish.

2. The operation of bronzing in the lithographic business, and the consequent exposure to bronze powder.

3. Cutlery grinding, and grinding or polishing in the manufacture of machinery, machine parts, and metal supplies; and grinding, glazing, or polishing on emery or buffing wheels.

4. Cutting, boring, turning, planing, grinding, doming, facing, or polishing pearl shell.

5. Tale dusting in rubber works.

6. Sorting, dusting, cutting, or grinding rags.

III. Processes Involving Exposure to Poisonous Gases and Fumes:

1. Spreading rubber on cloth and the consequent exposure to naphtha in the manufacture of rubber goods.

2. The use of naphtha in cement work in rooms in shoe and rubber factories which are not provided with mechanical means of ventilation where the mixture containing naphtha is allowed to remain in uncovered receptacles.

3. Processes involving exposure to naphtha in the manufucture of japanned or patent leather.

4. Exposure to escape of fumes or gases from lead processes.

IV. Processes Involving Exposure to Irritating Gases and Fumes:

1. Gassing in textile factories.

2. Singeing in print works, bleaching, and dyeing works.

3. Dipping metal in acid solutions.

V. Processes Involving Exposure to Extremes of Heat and other

Conditions which Promote Susceptibility to Disease :

1. Melting or annealing glass.

By legal enactment, the employment of women in certain kinds of work is prohibited absolutely, and in many others is restricted as to number of hours, according to the nature of the work. The very great value of most of the legislation regulating labor by children and women is too clear to need demonstration. 


\section{CHAPTER XIV.}

\section{VITAL S'TATIS'TICS.}

THE seienee of vital statisties comprises the analysis and synthesis of facts eoncerning the life-history of populations. It points out where and to what extent disease and death are on the inerease, and suggests, therefore, the inauguration of combative sanitary effort, the efficiency of which it enables us to measure. It furnishes the basis for the study of all the various social problems which affeet inerease and diminution in numbers.

It is axiomatic that the faets employed must be numerous and accurately stated and classified, in order that the information supplied therefrom shall be trustworthy and of value. These facts comprise those which are yielded by the census, as numbers, age, sex, color, oceupation, and conjugal relations, and those reported to and recorded by local and central authorities concerning infectious discases, marriages, births, and deaths.

The study of these facts and their correet interpretation are by no means simple. In census years, it is not diffieult to obtain praetically accurate information of the size of the population, and the ratios of births, marriages, and deaths, and at all times to know the degree of prevalence of notifiable disease; but the intelligent interpretation of these faets is often, if not usually, a most complex problem. In the hands of those who understand the fallacies, the numerous sourees of error, the correetions to be applied, and the eomparative values, statisties can be made to yield knowledge of immense value to sanitary science; but in the hands of the unskilled or unscrupulous, they may be more productive of harm than absolute ignorance, for it is better not to know at all than to be misinformed.

It is well known that it is often possible apparently to prove two direct opposites with the same statisties, the fallaeies being unobserved, and to this fact is due the low estimate in which all statistical studies are held by those incapable of distinguishing the filse from the true. Statisties may be made to lie while they appear to tell the truth, and they have been raised to superlative rank, therefore, among falsifiers of all degrees.

As has been said, the interpretation of statisties is no simple matter. It requires, in faet, a mind not only naturally logical, but trained in drawing scientifie inferences, in the recognition and avoidance of the influenee of fallacy, and in the correct estimation of the value of different faetors and disturbing influences. But even with several such minds working on the same mass of material, decided differenees may 
be found in their respective conclusions, some apparently small fact being overlooked by one or being eredited with undue importance by another. Therefore, in publishing facts and inferences, it is well to give as much as possible of details, and to bring out clearly the thread of the reasoning leading to the final conclusions, for then, other analysts may, by pointing out debatable issues, assist in deducing the absolute truth.

The Census.-The very foundation of vital statisties is a knowledge of the size of the population and of the ages of the units of which it is composed. In census years this may be regarded as substantially accurate; but in the intervening years it is necessary to make estimates based on past and present indications, which may lead to wide variations from the truth, not susceptible of correction until the next enumeration. The census is taken in all civilized countries at stated intervals, usually of five or ten years. In France and in Germany, it is taken every five years; in this country and in Great Britain, every ten years. In this country, many of the individual States have an independent enumeration in the middle of the intercensal period, so that the census is virtually quinquennial. The census gives the population of each community, and also important facts as to age distribution, sex distribution, race, occupations, and civil state.

From the very nature of the work, dealing in a very short time with vast numbers of individual sources of information, no census can be absolutely accurate, but under present methods the results obtained may be regarded as being as nearly accurate as possible. It is probable that, in a large degree, the errors counterbalance one another, but how far, can be only a matter of conjecture.

The sources of error in census-taking are intentional frauds and negligence on the part of the enumerators, ignorance and wilful misstatement on the part of those interrogated, absence of residents when called upon, and inclusion of transient visitors. In 1890, it is well known, in certain cities gross frauds were practised in "padding" the returns so as to increase the fees due the individual enumerators concerned. In one ease, a hotel register, running back seven years, is known to have served as an aid in the manufacture of population returned. During the same census, many complaints were made that whole streets and districts were omitted, the inference being that the enumerators either did not regard the work as sufficiently remunerative, or made up their reports regardless of the facts, and without the disagreeable necessity of going from house to house for information only slowly obtained.

Ignorance on the part of the person questioned is doubtless a more fruitful source of error than intentional misstatement. Many persons do not know their age, and give, therefore, only a guess, which is most commonly expressed in multiples of five and ten, more especially the latter. This tendency appears, in general, only after the twenty-fifth year, and is shown graphically by means of the aceompanying diagram (Fig. 108) by Mr. R. H. Hooker, taken from Newsholme's Vital Statisties. Again, many data concerning the oceupants of a house are 
given by persons not qualified to know ; thus, the returns for a whole fimily may be based upon the statement of a servant not long in the place.

Intentional misstatement is most common with regard to age and occupation, many wishing to appear younger, others older, than they really are, and many being reluctant to state correctly the occupations of themselves and of members of their households, preferring, perhaps, to record others more " genteel" or important. Other wilful misstatements are due very commonly to that over-development of the sense of humor that disposes its unfortunate possessor to regard extravagant lying as the acme of wit.

The intentional misstatement of age is more commonly a fault of women than of men. Women are prone to understate their age after

Fra. 113.

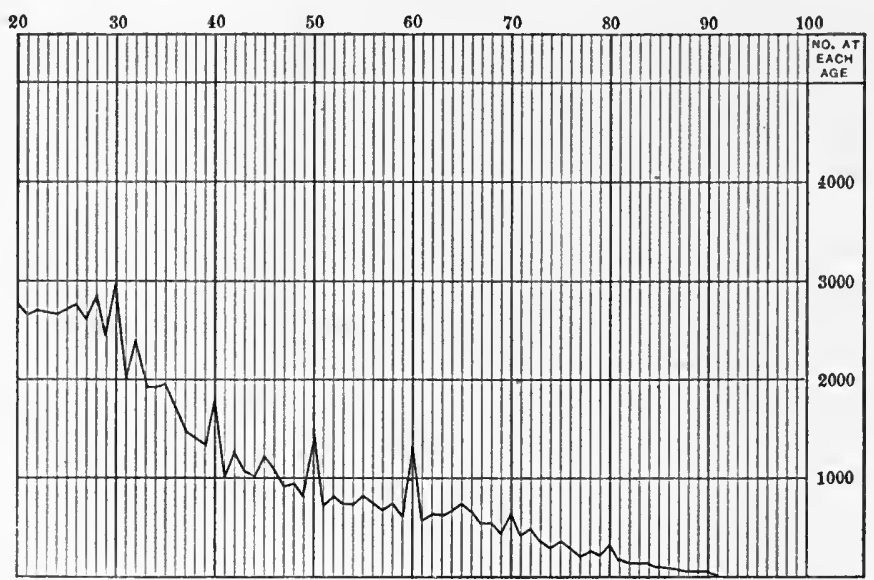

Number of persons in Tasmania living at each year of age, according to the census schedule: showing the tendency to cluster at round decennial periods.

passing twenty-five; with men, the tendency is to add rather than subtract. After twenty-five, many women become sensitive, and give their ages as under that age, and do not progress for several years. This is shown statistically by the British census returns, from which it appears that the girls of 10 to 15 years of one census, who become women of 20 to 25 years of the next census, reach these latter age periods without suffering any loss in number through death and emigration ; but, on the contrary, with an augmentation, while the women of 20 to 25 years, who become 30 to 35 years old at the next census, show a very ureat diminution in number.

Thus, als shown by Dr. Farr, the Registrar-General, in 1841, the number of girls of 10 to 15 years was $1,003,119$, and in 1851, the number of women of 20 to 25 years was $1,030,456$, or 27,337 more, while the women of 20 to 25 years in 1841 numbered 973,696 and yielded in 1851 only 768,711 -a loss of 204,985 . It is inconceivable 
that the losses among the younger group, due to death and emigration, should have been more than offset by immigration to the extent of 27,337 , and that the same influence should have failed to the extent of 204,985 to do the same thing for those of the later age periods. This diserepaney is said to be eapable of demonstration by comparison of the returns of any two consecutive subsequent enumerations. Children's ages are very commonly overstated in the earliest years; then, as the limit of age for free transportation in public conveyances is passed, they are understated as long as possible. Finally, when the statutory minimum of age is the only bar to the utilization of children in the various trades, the years held back are restored with some additions.

Estimated Population.-In intercensal years, it is necessary to estimate as nearly as possible the growth or decline of a population, making use of such factors as can be obtained by eomparison of the two preceding enumerations and from other observed influences. This is done very commonly by dividing the difference between the figures of the two by the number of years of the interval, thus obtaining the yearly increase or diminution, and redueing it to a percentage which is assumed to be the rule obtaining until the next census. 'This, of course, is merely a guess which may be near or very wide of the truth, since very many influences may be in operation to bring about conditions actually very different. But one must work with the best data available and eliminate as much of error as possible; hence the ratio of increase or diminution is assumed to hold until the next censis, and in the meantime errors must be diminished as much as possible.

One of the first errors into which one falls is in assuming a fixed ratio, based upon the above-mentioned method of ealculation. Let it be assumed, for example, that the annual increase in the population of a eity of 100,000 inhabitants, determined by a comparison of the two preceding enumerations, is 2 per cent.; if we reckon that in 5 years' time the population will have inereased 5 times 2 per cent., that is to say, from 100,000 to 110,000 , we fall at once into error, for the increase proeecds not by simple but by eompound interest, since in reekoning by simple interest no allowance is made for the augmentation of capital, so to speak, due to the annual increase in the number of persons arriving at the nubile period.

The method gencrally adopted is, therefore, based on the assumption that population inereases in geometrical rather than arithmetical progression, and the formula employed is $P^{\prime}=P(1+r)^{n}$, in which $P^{\prime}$ represents the estimated population, $P$ the population aceording to the last census, $r$ the annual rate of inerease per unit of population, aseertained by comparison of two successive enumerations, and $n$ the number of the intercensal year in question. On the basis of a 2 per cent. annual increase, the population at the end of the first year would be 102,000 ; at the end of the second, it would be 102,000 plus 2 per cent., or 104,040 ; at the end of the third, 106,121; at the end of the 
fourth 108,243; and at the end of the fifth, 110,408, or an increase of 408 over the original estimate.

As an illustration of the manner of applying this formula in the estimation of the population at the expiration of the fifth intercensal year, in this instance of an original population of 100,000 increasing at the rate of 2 per cent., the following may serve: The formula is $P^{\prime}=100,000 \times(1+0.02)^{5} ;(1+0.02)^{5}=1.10408 .100,000 \times$ $1.10408=110,408=P^{\prime}$ as given above. Much time is saved in the calculation by recourse to logarithms. For a proper estimation of the population at any particular period in the year on this basis, due allowance should be nade for the fraction of the uncompleted year.

Population is sometimes estimated by using as a factor the average number of persons per habitation according to the preceding census returns, and multiplying this by the number of houses found to be occupied at the time. Sometimes, also, the number of registered voters is user as a basis of calculation, and again the birth-rate, and again the number of ehildren in attendance at the several schools. These methods, however, are very faulty, and often even quite valueless.

Whatever the method adopted, and notwithstanding the calculations of the amount of infuence exerted by emigration, immigration, unusual prevalence of or freedom from infective diseases and other factors, estimation of population is very frequently wide of the truth. Within recent years, for example, the most careful estimate of the population of London by the Registrar-General was found by the eensus returns to be no less than a quarter of a million in excess of the truth. With errors in estimation come necessarily errors in all the ratios of births, marriages, and deaths, and these must, therefore, undergo correction at the proper time.

Increase of Population.-The growth in population due to excess of births over deaths is known as the natural increase. That which is due to excess of births plus immigration orer deaths plus emigration, is known as the actual increase. Fluctuations in natural increase are eaused by ehanges in mortality- and birth-rates; thus, a decline may be due to a diminution in the number of births, or to an increase in the number of deaths, or, more markedly, to both. Fluctuations in actual increase are caused by the same influences plus those of immigration and emigration. Growth may, therefore, be slow or fast, and steady or varied and spasmodic, according to ever-possible changing conditions, governed largely by commercial prosperity or depression. Decline in population may be due to excess of deaths over births, but is commonly the consequence of emigration.

Population Constitution.- What is known as the constitution of a population shows the relative proportions of males and females and of persons of different age periods. These facts are obtained only from the census returns, and are commonly accepted as holding good until the next census gives different figures. In cities and large towns, the proportion of females is generally considerably higher than that of males; while in country districts the reverse is true or the excess is 
slight. This is explained in several ways: In the first place, women are, in general, longer lived than men; in the second, men are more prone than women to return, when advanced in years, to country districts from which they originally sprang; and again, under the conditions obtaining in erowded communities, men wear out more rapidly than women. In the population at large, males are more numerous than females.

Age distribution has a very important bearing on the death-rate, since, as is well known, the highest death-rates, so far as age is conecrned, oceur always in the earlier age periods. Therefore, the preponderance of individuals of one and another age period has a very great influence in demonstrating apparent differences in salubrity of different localities, when the actual sanitary conditions are identieal. With such agreement in sanitary conditions, a community which includes a much larger proportion of young ehildren will show a larger death-rate and a smaller marriage-rate than another in which the population is made up more largely of young adults. In eonsequence, it is necessary, in instituting comparisons between two localities, to take into account (and make corrections therefor) the differences in age distribution, and to reduce the respective populations to a common standard.

Registrars' Returns.--Returns concerning births, marriages, deaths and causes thereof, and cases of infective diseases, are made to local authorities, such as boards of health, and eity or town elerks or registrars. In conjunction with census returns or estimates of population, they reveal the sanitary and sociological eonditions obtaining from week to week, month to month, and year to year, in any community in which they are made. Through them we are enabled to wateh the death-rate from all causes and from any one eanse, the amount of preventable disease, the probable fluctuations in populations, and other facts of interest concerning communities and groups thereof. They convey information as to sanitary conditions, and suggest wherein improvement in various direetions is possible.

'The individual facts must, of course, be aceurately observed and stated. This is particularly true of eauses of death and distribution of infective diseases. The importance of proper groupings is well shown by the worthlessness of the lax returns not infrequently observed. For example, it is not unusual, espeeially in the older tables, to find "dropsy" standing side by side with "heart disease," "kidney discase," Bright's discase, and other general or vague terms.

The value of the aggregate facts depends very largely upon the length of time during which they have been gathered, since only with the lapese of time can comparisons be instituted and the influence of temporary conditions eliminated or minimized. They must be suffieiently numerous to yicld correct averages, for the laiger the number of facts, the smaller the fluetuations caused by inclividual units; and, conversely, the smaller the number, the greater the influence of single units, and the greater the chance of error; or, more definitely stated, accuracy increases as the square root of the number of units. Thus, 
400 units will yield but half the error of 100 , and 900 will yield but a third. In no way, perhaps, can the great influence of individual components of a small aggregate and the small influence of the unit when the aggregate progressively increases be better illustrated than by the daily fluctuations in the comparative standing of a number of athletic organizations, such as ball clubs and bowling clubs, in competition among themselves for a prize or championship. In the beginning, single events may cause entire rearrangement, and the fluctuations are wide and the curves most irregular; then, as the number of events increases, the fluctuations are less abrupt and the changes in the curves are gradnal.

In order that statisties may be useful, they must admit of comparison with similar figures obtained in other years and also at other places. But correct deductions can be drawn only when the conditions are at least apparently the same or when there is but one essential difference. One may not, for example, compare the death-rate of New York for the winter of 1898 with that of Detroit for the summer of 1875 , and expect to obtain thereby information of value. In order to measure the full influence of any one important condition, the other conditions must be in agrecment, or it must be possible to make correct allowance for any degree of divergence.

Again one must not ignore the effect of temporary local conditions, such, for example, as an accident in a small community whereby a number of persons are killed at once and others die later from the effeets of their injuries. The death-rate of that town for that year would be abnormally high, and the sanitary condition of the place might be made by figures to appear much inferior to that of an adjoining one where sickness and death from preventable diseases are much higher all the time.

Marriage-rates.-Statistics as to marriage vary considerably from year to year, according to various circumstances, and especially with changing conditions in the prosperity of the general population. The rate is commonly greater in cities and towns than in country districts, not that conntry-bred people are less inclined to marry, but because large numbers of them are attracted to populons centers after arriving at the wage-earning age, and there they marry.

The marriage-rate is usually expressed as so many per 1,000 of popnlation; but this is commonly open to objection, in that it may convey false impressions concerning inclination or disinclination to assume the new responsibilities, and also concerning the communal prosperity. Here, the importance of the population constitution as to age periods and sex is very clear, for in a conmmnity made "p largely of old persons, young children, and domestic servants from without, the number of marriages occurring among the marriageable element might be very considerable, and yet the rate per 1,000 of population would be low. Therefore, a more instructive method of expression would be a statement of the rate obtaining among those of marriageable age. Again, the number per 1,000 of population does not admit of proper compari- 
son of different communities in this particular, unless their population constitution is substantially the same.

Fluctuations in marriage-rates are due to other causes than commercial prosperity and depression. It has been observed, for example, that a condition of war diminishes the rate by withdrawing from the marriageable ranks of wage-earners large numbers of able-bodied active men. With return of peace and its attendant release of the troops to civil life, the rate is augmented. Thus, during 1870, when France and Germany were at war, the marriage-rates sank respectively to 12.1 and 14.8 ; two years later (1872) they advanced to 19.5 and 20.7. Age constitution, too, has necessarily an important influence in eausing. fluctuations. Thus, in a community largely made up of youths and maidens, the time comes when an unusual amount of marriageable material becomes available, and the rate at once advances.

A period of unusual increase in the rate, from whatever cause, is commonly followed by a corresponding decline, just as business prosperity and depression are marked by regular waves; but the general trend is unmistakably toward a diminution. For nearly thirty years, a very gradual decline has obtained in nearly all highly eivilized countries.

That more women marry than men, sounds paradoxical, but it is, nevertheless, true; for men are more prone than women to seeond and third marriages, and statistics show that the tendeney of widowers to marry spinsters is much more marked than that of bachelors to marry widows.

The age at which marriage occurs has a very important bearing on the natural increase of population, since whether a woman marries early or late in the elild-bearing period, determines, other conditions being the same, the extent of fruitfilness and, more particularly, the interval between successive generations. Statistics indicate that, among the native-born of this country, particularly in those parts longest settled, and in Great Britain and other eountries in whieh the highest degree of civilization has been reached, the average age at marriage is steadily inereasing. This has been attributed to an intelligent selfishness, cending to defer the assumption of responsibility for the maintenance of others, thus insuring an unrestrieted enjoyment of the fruits of labor ; and to the wider opportunities for profitable employment of women, with consequent lessened dependence upon marriage as a means of support.

Birth-rates.-Statisties as to births are expressed in the same manner as those conecrning marriage ; namely, as so many per 1000 of population. This ratio is known as the crude birth-rate, and conveys no information coneerning the proportion of women of the ehild-bearing age who have added to the population. Here, again, a more aceurate and instructive method of expression might be based upon a eomparison of the number of legitimate births with the number of married women below forty-five years of age, and of the number of illegitimate births with the number of single women of the same limit of age. Under 
any system, still-births are not included in either the births or deaths, although they are certified.

Birth-rates naturally vary very greatly in different communities, the same as marriage-rates, and for the same reasons. Ordinarily, they are higher in eities than in the comtry, and during and immediately following periods of prosperity than during times of depression. A higher rate is to be expected of a manufacturing and commercial center than of a purely residential town, where a large number of unmarried domesties, employed by the well-to-do and rich, swell the population and lower the rates of both marriages and births in the manner already mentioned. In the latter ease, the married inhabitants may be unusually prolific, and the birth-rate, expressed per 1000 of married women below forty-five, would be very high; yet, the crude birth-rate would be low. So, in comparing two communities in respect to birtlis, accuracy demands that they shall be reduced to a common basis.

The higher birth-rate in cities and large towns is due to the greater proportion of women of child-bearing age, the higher marriage-rate, and the earlier marriage age that there obtain among people of the lower classes.

Since the proportion of deaths in the earliest years of childhood is very high, it follows that a high birth-rate is always associated with a high death-rate; but at the same time, a high birth-rate implies a large proportion of married persons in the full vigor of life at that age period which is associated with a low rate of mortality, and thus the inflnence on the death-rate is more or less corrected. A continued high birthrate necessarily implies a large proportion of growing children who, year by year, swell the ranks of the reproductive.

A low birth-rate, by causing a relative increase in the proportion of persons of the age periods of low mortality, may bring about a low death-rate; but if it continues long enough to bring the population to a high average age, it will be snceeded by a rapid increase in the death-rate due to diseases of advancing years.

The birth-rates of many countries, like the marriage-rates, have for some years shown a steady decline. This is due somewhat to the inereasing average age at marriage, which reduces the period of reproduction, but largely to artificial restrictions and economic considerations. The great decline in the birth-rate of France has attracted widespread attention, and has become the subject of grave concern to the authorities and other thinking people of that country. A hundred years ago, 'nore than a quarter of the population of what are known as the Great Pc wers was French; to-day, notwithstanding the marked disinclination of that people to emigrate and seek new homes, the proportion has fallen to about one-eighth. In 1891, according to census returns, of every hundred families, 22 had but 2 children, and 24, but 1 ehild, apiece. The decline in births is not due to poverty, for it is among the poorest there, as elsewhere, that the largest families are raised. The same influences appear to have been in operation for some years in England and Wales, where, since 1876, when the birth-rate was 36.3, 
it fell progressively in twenty years to 29.7 , and showed in the last years of the century a more striking decrease than in any other eountry of Europe.

In our own eountry, among the descendants of the original colonists and earlier immigrants, the same decline is most evident. Whereas in colonial times and in the earlier years of national independenee, families of a dozen, fifteen, and more were exceedingly common; nowadays, one of six or eight beeomes a subject for comment, surprise, and even ridicule. The large families of to-day are mainly those of the more recently arrived immigrants and of their first generation. In Massachusetts, the statistics for 1908 show that the greatest proportion of the number of births belongs to the foreign-born, the children of native parentage on both sides representing 31.08, those of mixed parentage, 18.25 , and those of foreign-born parentage, 50.51 per cent. of the total births. The erude birth-rate was 27.77.

Death-rates.-Death-rates are ealeulated in the same way and expressed in the same terms as birth- and marriage-rates, that is, by multiplying the number reported by 1000 and dividing the produet by the population, or by dividing the reported number by the number of thousands of population, the result in either case being the rate per 1000 of population. This is known as the general, gross, or crude death-rate, and is affeeted by so many factors that, without eareful study and due allowance for disturbing influences, it may prove to be a very faulty index of the health of the people and of the sanitary condition of the place. When used as a basis for eomparison of different places, the death-rates must first be eorrected by making careful allowances for differences in age, sex, and race distribution, and for abnormal influenees.

Influence of Sex.-Sex exerts a deeided influence, since, in general, females live longer than males and their mortality is lower at all age periods, exeepting from the tenth to the twentieth year. So, of two places equal in sanitary and all other conditions exeepting sex eonstitution, the one with the greater proportion of females will have the lower death-rate. Exeept in newly settled places, there is; as a rule, a preponderance of females over males, although everywhere the births of males execed in number those of females, the preponderance being the result of the higher mortality that obtains among males, exeept at the age periods above mentioned.

Influence of Age.-The influence of age distribution is far greater thin that of sex, since, for example, the mortality per 1000 of ehildren under 5 years of age is more than ten times that of persons between 5 and 25 , and more than six times that of adults between 25 and 4.5 . Thus it may be seen that the greater the proportion of population belonging to the earliest and latest periods of life, the higher will be the death-rate. One would expeet, for example, a higher mortality in a community made up largely of elderly people or young children than in one unusually rich in young adults, or, to reduce the 
matter to its simplest terms, in a foundling asylum or retreat for the aged than in a college for young men.

Influence of Race.-To a certain extent, racial peculiarities have an influence on vitality, and especially on susceptibility to certain diseases. Thus, the negro is far less prone to some and far more susceptible to other morbid influences than the white. As between different peoples of the same race, the differenees are not so wide. In those parts of this country where the negro population is considerable or preponderant, this influence can never be disregarded, and, indeed, it is commonly the practice to calculate separate rates for the whites and for the blacks. According to Hoffman, ${ }^{1}$ the mortality of whites and blacks in ten southern cities, including Baltimore, Washington, Richmond, Memphis, Louisville, Atlanta, Savannah, Charleston, Mobile, and New Orleans, during the years 1890-94, was expressed as 20.1 and 32.6, respectively. This divergence, it is pointed out, would be still greater, if correction were made for age distribution.

The excess of negro mortality obtaining at all age periods is especially noticeable in the earlier ones. Thus, in 1890, in Washington and Baltimore, the death-rates of negro children under 5 and between 5 and 15 years of age were more than double those of white children of the same age periods; in the age periods from the fifteenth to the forty-fifth year, the rates for both races naturally diminish very much, but the ratio is nearly the same. After the forty-fifth year, the difference begins to be much less, but the excess is always with the negro.

As instances of the differences in white and black death-rates, the following are presented:

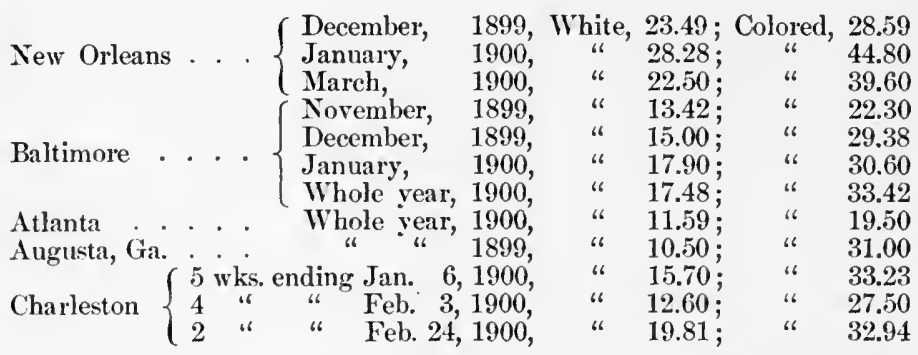

The difference between white and black mortality is believed to be due more largely to race degeneration than to sanitary conditions. In the North, the negro shows an excess of deaths over births, and holds his own only by influx of recruits from the South.

Aceording to Dr. Seale Harris, ${ }^{2}$ before the Civil War the negro death-rate in the South was less than that of the whites. For example, in Charleston, S. C., from 1822 to the beginning of the war the

${ }^{1}$ Race Traits and Tendencies of the American Negro. Publications of the American Economic $\Lambda$ ssociation, New York, 1896.

2 The Future of the Negro from the Staulpoint of the Southem Physician, American Medicine, Sept. 7, 1901. 
average death-rate of the whites was 25.98 , and of the blacks 24.05 ; but from 1865 to 1894 , although the rate was but slightly higher in the ease of the whites (26.77), it had nearly doubled (43.29) with the blacks.

From what has been said, it must be evident that erude death-rates cannot be relied upon as a basis of mortality comparison of two places, unless the respective populations are in substantial agreement in age, race, and sex constitution, nor for comparison of the conditions obtaining at the same place in different years, unless these factors are practically unchanged.

Other Influences.-Crude death-rates are influenced by errors in estimated population, by the presence of various kinds of public institutions, such as hospitals, state almshouses, and asylums for foundlings and the aged; by migratory movements ; by density of population, and, as has been stated, by the birth-rate. An important source of error lies in the return of persons afflieted with incurable diseases to their old homes, where they die; their deaths are registered there, instead of at the places where the causes thereof had their origin or where the sanitary conditions were such as to favor susceptibility.

Influence of Density.-Death-rates, especially those of the very young, are much higher in crowded localities than where the population has plenty of room ; and it is commonly accepted that, other things being equal, increased density means inereased mortality. To a certain extent this is undoubtedly true, particularly where inereased density means overcrowding; but it is not necessarily true of a large population spread out over a territory capable of acconmodating twice as many people very comfortably. 'Thus, in Massachusetts, for example, where, in 1855, the population averaged 136 to the square mile, the general death-rate was about the same as obtained forty years later, when the average population per square mile had more than doubled, the slight difference being in favor of the later period. During the decennium just prior to the outbreak of the Civil War, the average rate was 18.25 ; during the period 1887-1897, it was abont 19.50; and in 1908 the rate was 16.51, which figure was surpassed, however, by that of 1904 , which was 16.36 .

In densely populated, orercrowded localities, such as the slums of large eities, we find all the conditions which favor a high mortality; namely, poverty, immorality, ignorance, intemperance, unsanitary habitations, high birth-rate, carelessness, filth, and improper and insufficient food. In fact, the slums are, in very great measure, the canse of the differences observed in the death-rates of small and large communities. In country distriets, small towns, large towns, and eities situated within the same district, where climatic and other natural conditions are essentially the same, it is commonly observed that the higher average rates obtain in the larger communities, and the lower in the smaller places, where slums are unknown; while the very highest oecur in manufacturing centers, where the main population consists of mill operatives, who work by day under unsanitary conditions and pass their nights in crowded tenements. So, also, higher rates obtain in old manufacturing 
crowded tenements. So, slso, higher rates obtain in old manufacturing places, in which a larger proportion of population of a weak and degenerated type is to be found, than in others more recently established.

Weekly Death-rates, etc.- The death-rate for any particular week is obtained by multiplying the number of deaths oecurring during that period by 52.14 (the number of weeks in 365 days) and dividing the product by the number of thousands of population as estimated for the middle of the year.' 'The same method of reckoning may be employed for determining the rates for other fractions of a year, and for rates of birth, marriage, zymotic disease, and other matters of statistical interest. These weekly and other periodical rates are highly unreliable data upon which to base comparisons with those of other places and of other parts of a year, since seasonal influenees and temporary conditions must not be ignored; their principal value is in comparing the rates obtaining at the same place at corresponding periods of different year's.

In the same way, the weekly death-rate from any given cause, or the weekly number of cases of any particular notifiable disease, such as diphtheria, scarlet fever, or measles, may be determined.

Zymotic Death-rate.-The zymotic death-rate is the death-rate due to the seven principal so-called zymotic diseases; namely, smallpox, scarlet fever, measles, diphtheria, whooping-cough, typhoid fever, and diarrhoeal diseases. It is expressed in terms per 1000 of population, like the gross death-rate. The rate for any disease may be similarly obtained and expressed.

Infantile Death-rate.-The infantile mortality is not expressed in terms per 1000 of the whole population, but as the number of deaths of children under one year of age to each 1000 births registered during the year. It is assumed that the efflux of living children whose births have been registered with the loeal authorities is counterbalanced by the influx of others whose births are registered elsewhere.

Infantile mortality is always high, owing to a variety of eauses, and it is particularly high in slums and in manufacturing towns where women are largely employed in factories, and so are unable, even though so inclined, to give that personal attention to their offspring as is bestowed by mothers whose lives are purely domestic. In Massachusetts, for example, the infantile death-rate averaged, in the decade 1881-1890, 174.9 in the cities and 129.5 in the country, and the extremes for the eities were 239.7, at Fall River, preëminently a " mill town," with all that the term implies, and 111.9 at Newton, where manufacturing is at a minimum and overcrowding practically unknown. Lowell and Lawrence, also "mill towns," showed respectively 222.5 and 213.9, while Boston, commercial, manufacturing, and residential, showed 188.2.

1 Many statisticians employ the factor 52.17747 , the number of weeks in the solar year of 365 days, 5 hours, 48 minutes, and 46 seconds. This exaggeration of exactness in small things seems all the more absurd when we consider that the estimation of population at the middle of the year is nothing more than a fairly reasonable guess, and often proves to be wide of the truth. 
In the three cities with the highest rates, Fall River, Lowell, and Lawrence, the population is largely French-Canadian operatives of cotton and woollen mills, housed in erowded tenements. The so-called "shoe towns," Haverhill, Marlboro, Brockton, and Lynn, have a very different kind of population, much better paid and not inclined to a tenement-house life, and show respeetively $157.1,154.6,146.9$, and 140.7 , all of which rates are below that of the State at large, 160.4. ${ }^{1}$ Similarly, in England and Wales, where in 1894 the rate was 137, and in $1896,147.5$, Preston, which ean elaim one of the blackest reeords in all respects among mill towns, showed, in the former year, 229, and in the latter, 262, while in London the rate was but 159 .

The chief factors in the causation of high infant mortality are premature births, heredity, intemperance, early marriages, neglect, carelessness, ignorance, improper food, unsanitary surroundings, industrial conditions, illegitimacy, and, perhaps, infant life insurance. The immediate causes are chiefly inanition, diarrhœal diseases, measles, whooping-cough, and other infeetive diseases, and violence. The influence of premature birth, heredity, negleet, earelessness, ignorance, and unsanitary surroundings needs no elueidation. Industrial eonditions figure largely in the negleet of infants, since mothers in employment return as soon as possible after confinement to their work, and entrust their offispring to the eare of older children and others, by whom they are improperly fed and looked after. During pregnancy, also, the woman remains at work up to the last possible moment, so that her absence is limited to that period during which she is absolutely ineapacitated.

The age of the parents has mueh influence on the vitality of infants, those of mothers under 20 dying off appreciably faster than those of others between 20 and 30 . Between 30 and 35, the vitality of the offspring is still greater; but after this age period it begins to decline. The first ehildren of very young fathers also are, as a general rule, weaker than those begotten later. 'To this influence of the parents' age, eonjoined with that of ignorance and inexperience, may be attributed the excessive mortality which obtains among the first-born.

Illegitimacy has a very great influence on the ehanee of survival to even the early period of ehildhood, for the infant is in an unfavorable position as regards eare and home surroundings from the beginning. Abandoned by the mother to the eare of whomsoever may be willing to aecept the charge, or "furmed out" among persons whose interest in its welfare is wholly financial and subject to inmediate decline on the eessation or tardiness of payments, it has even less ehanee, perhaps, than when kept at home, an unweleome addition both to the family cirele and to the expense aceount.

Infint insurance is generally believed to be an influence in diminishing the amount of eare and solieitude for the health of the very young,

1 These fignres are taken from a commmication from Dr. S. W. Abbott, Secretary of the State Board of Health of Massachusetts, on "Infant Mortality in Massachusetts." Journal of the Massachusetts Association of Boards of IIealth, December, 1898, p. 134. 
and, therefore, has been the subject of considerable legislation, by which the maximum amount of the poliey is kept at a low figure, as, for instanee, the actual expense of burial. Whether insurance has more than an insignificant bearing, camnot be determined by trustworthy statisties.

Beyond doubt, the most fruitful single cause of high infant mortality is improper feeding, due partly to the neessity of supplying an artificial substitute for breast milk and partly to ignorance. The breastfed infant, carelessly looked after, has a far better ehance than the bottle-fed more earefully tended. 'The former reecives its natural fool at a uniform temperature and practically sterile; the latter is fed upon another kind of milk, differently eonstituted and of a different degree of digestibility, which, under the best of cireumstances, is comparatively rich in ordinary bacteria, and is administered at different temperatures, sometimes very hot, sometimes eold. With lack of care, the danger is inereased, for the milk may be stale and dirty, and act as the vehicle for the exeiting cause of cholera infantum, which is responsible to a greater extent than any other morbid eondition for the deaths in mill towns of infants whose mothers are employed in the various industries. Besides dirty and stale eows' milk, a variety of cereal and sugar substitutes are provided, which may or may not be digestible and nutritious.

Ignoranee of what is proper for introduetion into an infant's stomach is responsible for mueh infantile mortality, even when breast-feeding is followed. Who has not seen fond, but ignorant, mothers, in publie conveyanees, keeping their infants quiet with bananas, seed cakes, cookies, and other food materials unsuited to a digestive system which ean have diffieulty enough with milk alone? It seems unlikely that such practices are restrieted to the time spent in travel, when eonsideration for the comfort of strangers suggests the avoidance of fretting and erying.

Death-rates of children under five years of age are expressed in the same terms as infantile mortality, that is to say, as the proportion of deaths per 1000 children of that age period.

High and Low Death-rates.-In the absenee of any unusual general unsanitary eondition or of unusual prevalenee of epidemie diseases, an abrupt rise in, or a very high, death-rate is not infrequently only apparent, being based upon an underestimated population. A very low death-rate is always open to suspicion, although sometimes, as in newly settled eommunities with a very high proportion of young male adults, for a limited term of years, it is perfeetly possible and natural. A rate of 15 per 1000 , for example, in large eities, is so low as to suggest that the population has been very much overestimated. Within recent years, the authorities of a rapidly growing Western eity noted with great pride the gigantie strides in the estimated population, and were naturally mueh elated to find that the death-rate based thereon entitled the eity to a position in the first rank of the cities, large and small, of the whole world. The eensus of 1900 dispelled the illusion, 
for the population had been grossly exaggerated, and the actual deathrate was comparatively high.

Death-rates as low as 10 and 12 are sometimes noted. A continued rate of 10 in a stationary population would mean that the inhabitants would average 100 years of age at death; one of 12 would mean an average age of over 83 ; one of 15 wonld mean an average of nearly 37.

As examples of high and low death-rates, the following for the same quarter of the same year (1897) may be cited:

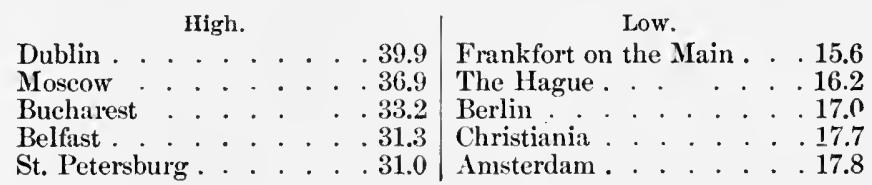

The influence of improved sanitation in the lowering of the mortality of any given place cannot be disputed, but in attributing the whole or even the greater part of the difference in the rates of any two places or of the same place in different years, one should be careful not to ignore factors, already mentioned, that exert influences beyond the eontrol of sanitary authorities. Permanent decline in mortality-rate is a matter of slow growth, and is the combined result of sanitary effort and mitigation of the occupational and social conditions tending to lower vitality. In Elizabethan times, the death-rate of London was about 40 ; at the beginning of the reign of Victoria, it was 24 , and at the end of the century, about 19.

Correction of Death-rates.-The impossibility of making a fair comparison of the death-rates at different places without taking into consideration the constitution of the respective populations as to age, sex, and race, has been sufficiently pointed out ; and since two places absolutely alike with regard to occupational influences, wealth, density of population, climate, soil, water-supply, sanitary administration, and general sanitary condition, but discrepant as regards the distribution of the scxes, age periods, and race, may show very different deathrates, perhaps masnifying the salubrity of the one and exaggerating the unhealthiness of the other, it becomes necessary to have some method of bringing them to a common basis. In the matter of race influence, the best plan is to separate the statistics absolutely, having one set for the white and another for the colored population, and to compare white with white and negro with negro.

The method commonly recommended for correcting according to sex and age is the one in use in the office of the Registrar-General for England and Wales; this may bricfly be described as follows:

The mean annual death-rite of the country for each sex at each of the eleven age periods, namely, below 5, 5-10, 10-15, 15-20, 20-25, $25-35,35-45,45-55,55-65,65-75$, and 75 and upward, during the last preceding ten year's, is obtained and multiplied by the number of those of each sex at each corresponding age period in the territory under consideration, according to the returns of the last preceding 
census. Each product thus obtained, divided by 1,000, gives the caleulated number of deaths for the respective sex and age periods. These 22 results, added together, represent the calculated number of deaths for the place in question in one year. The total calculated number of deaths, divided by the number of thousands of population or multiplied by 1,000 and divided by the population, gives the standard death-rate.

The next step is to obtain a factor for correction, by determining the ratio which the standard death-rate of the place bears to the death-rate of the whole country. This is obtained by the rule of simple proportion, the second mean being unity. The recorded death-rate for the year, multiplied by this factor, gives the corrected death-rate, which will, therefore, be above or below the recorded rate, aceording as the factor is above or below unity. By dividing the corrected death-rate by the death-rate of the whole country, and multiplying the quotient by 1,000 , the comparative mortality figure is obtained; that is to say, the number of deaths which will oceur in the same number of the local population as, in the general population, will yield 1,000 deaths.

Classification of Causes of Death.-In the registration of causes of death, a certinin amount of error is inevitable, for several reasons. In the first place, even the most eompetent practitioners are not infallible in diagnosis, and it is not always possible, when one pathological state is complieated by the advent of another, to determine which was the actual cause of the fatal termination. Next, the nomenclature of diseases is still faulty, although many of the sources of confusion have been removed by the adoption of the international classification ${ }^{1}$ of the causes of death, through which it is hoped to secure uniform and comparable statisties of the causes of death for the whole world. Again, the true cause of death frequently is misrepresented intentionally for private or family reasons; thus, apoplexy, instead of suicide, and peritonitis, when the actual cause of the peritonitis is criminal interference.

Lastly, it is sometimes the case that no cause whatever is assignable, even after eareful autopsy, and, obviously, such eannot be classified. With the existence of an indeterminate amount of error, it follows that caution should be exercised in comparing results representing a series of years, and allowances should be kept in mind with changes in nomenelature, when drawing deductions from what has been described as the classification of the more or less reliable guesses of a large uumber of more or less skilled observers.

Registration of Sickness, if it were possible, would afford a far more efficient index of the sanitary condition of the population than the registration of deaths, which gives us simply the number of cases of sickness which ended fatally, but no idea of the duration thercof or of the number of persons temporarily incapacitated. A disease ordinarily regarded as fairly dangerous may prevail very extensively in a mild form, and be attended by a very low death-rate, and, again, may exist

1 This classification can be obtained by applying to the Bureau of the Census, Washington, D. C. 
to a lesser extent, but in an unusually severe form, with a high proportion of fatalities. Many diseases, again, are temporarily disabling and often widely prevalent, but play a small part in mortality returns. Tonsillitis, for example, is responsible for much discomfort and lost time: its prevalence has some meaning, but its death roll is exceedingly small. Rheumatism is much more widespread than mortality returns would inply ; chickenpox is relatively unimportant, but in some places its notifieation is required as a safeguard against the spread of smallpox incorrectly diagnosed as varicella; gonorrhœa, without being fatal, does more harm than commonly is supposed; and syphilis, also not immediately and directly fatal, sends its victims into the mortality returns through various avenues. But however desirable such registration may be, the obstacles in the way of its accomplishment are too numerous to admit even of hope, and, excepting in the case of infective diseases, which law requires shall be reported, there is no satisfactory method of obtaining an accurate idea of the health of a community.

Duration of Life.-Several expressions and methods are employed to denote and measure the duration of life, a problem with which the science of vital statistics is largely engaged. One of the most fallacions indications of longevity and sanitary condition is the Mean age at Death or Mean Liffetime, which is the sum of the ages at death divided by the number of deaths. This is unreliable, because it fluctuates very widely, according to age distribution; for in a community containing a large proportion of children and in which the birth-rate and, consequently, the infantile mortality are high, the average age at death will be lower than in another, equally healthy, in which these conditions do not obtain. Henee, it can only be employed with any degree of safety where the population constitution is uniform in all respects, and when the observations are carried along over a long period. The mean age at death, not of a few hundreds or thousands of individuals, but of an entire generation of population, is necessary to show accurately the mean duration of life, and this is determined only by means of life tables.

Probable Duration of Life signifies the age at which half of any number of children born will have died, so that they have equal chances of dying before and after that age. It is also called the vie probable and the equation of Life; but all of these terms are ill-chosen, for every possible duration of life has a certain probability, which may be determined by life tables.

Mean Duration of Life is another ill-chosen term with which the lastmentioned is often confounded, but which has an entirely different meaning. It is meant to express the probable duration of life from the date of birth. In an ordinary popnlation, subjected to the usual disturbing influences of migration, it means present age plus the probable length of life after passing a given point, and is called conmonly the expectation of life or mean after-lifetime. It is a term, which, by reason of its indefiniteness and looseness of application, it would be well to eliminate altogether. 
Expectation of Life, or Mean After-lifetime, is the average number of years which an individual at any given age will continue to live, as shown by a life table. As applied to whole communities, it is the mean duration of life of a generation of individuals from birth to death, and is regarded as the only true measure of the health of entire populations. Like others which have gone before, it is an unfortunate expression tending to eonfusion. "The term does not imply that an individual may reasonably expect to live a given number of years. The exeess of those who die late is distributed among those who die early, "those who live longer enjoying as much more in proportion to their number as those who fall short enjoy less of life.' Thus the expeetation of life has no relation whatever to the most probable lifetime of any given individual." (Newsholme.)

"Expectation of life is an incorrect term : the time which it is expected a person will live is the time which it is an even ehance he will live; it is the vie probable of the French, and is correctly expressed by 'probable lifetime.' 'The after-lifetime can only be the same as the probable lifetime on Demoivre's hypothesis-that the surviving form an arithmetical progression. The term ' expeciation of life,' first used by Demoivre, is correct, on that supposition, whieh is, however, in itself quite erroneous. The idea intended to be expressed by 'expectation of life' is the mean time which a number of persons at any instant of age will live after that instant: it is the French vie moyenne; and this teehnical idea is strictly and shortly expressed by after-lifetime, a pure English word, formed on the same analogy as after-life, aftertimes, after-age, after-hours. The after-lifetime of men at the age of 30 is 33 years by the English Life Table: 33 years is not the precise time probably that anyone of that age will live, but the average time that a number of men of that age will live, taken one with another. Age + after-lifetime $=$ Lifetime. At 30 this is $30+33=63$, the average age which men now aged 30 will attain. At birth this is $0+40=40$; when lifetime and after-lifetime are the same thing.

"The lifetime simply, without the addition at a given age, will serve to express in one word what is improperly called the expectation of life at birth; thus the lifetime of males in England is 40 years, the lifetime of males in Manchester is 24 years. Those who, from habit, prefer 'expectation of life,' can always substitute it for after-lifetime; from the use of which, in this paper, no ambiguity can arise." (Dr. William Farr, Eighth Annual Report of the Registrar-General, p. 279.)

Life Tables. - A life table, according to Dr. Farr, is an instrument of precision. "It may be called a biometer, for it gives the exact measure of the duration of life under given eireumstances. . . . A life table represents a generation of men passing through time; and time under this aspect, dating from birth, is called age. In the first column of a life table, age is expressed in years, commeneing at 0 (birth), and proceeding to 100 or 110 years, the extreme limit of observed lifetime." 
In order to construet a life table, it is essential to have, as material, a knowledge of the size of the population and its age and sex distribution, and the returns of death for a year, or a series of years, arranged according to age at death and sex; and for tools, certain abstruse mathematical formulie which it is hardly necessary to consider here. The principle upon which the tables are based is that if a large number of persons, 100,000 , for instance, born at the same time, were followed from birth to the grave, and their deaths recorded in the usual manner, the average age lived could be obtained by dividing the sum of their ages at death by their original number, and the number of deaths and of survivors at each period would be known. Another lot of the same size, observed elsewhere and living under different conditions, would give different results, and thus the influence of the discrepant conditions could be measured.

To insure as great accuracy as possible in constructing life tables, it is best to take the death returns for the entire intercensal period of five or ten years, and the mean population, for the experience of a single year may be exceptional. Tables can be constructed comprising each year of life or according to quinquennial periods, and are made for each sex. From them may be determined the probable proportion of a given number that will arrive at different ages, the probability of living a given time at each year or period of age, the mean after-lifetime at the end of any given year or period, and the aggregate future lifetime of the survivors at the end of each year or age period, or what is known as the life capital of the entire community.

The probability of living a given time for each year of life or age period equals the number of survivors at the beginning, into the number at the end of the year or period. The probable number of survivors at each year or period is obtainable directly. The mean afterlifetime at the end of any given year or period is obtained by adding together the years lived by the whole life-table population beyond the year or period, and dividing the sum by the number of survivors at that particular time. The life capital of a community, divided by the population, gives the average future lifetime; and intri a hundred times the population, gives the percentage of annual expenditure of life capital, since the mean population equals years of life expended in a year.

For further information concerning this branch of vital statistics, and for further consideration of statistical methods, values, and errors, the reader is referred to the many standard works dealing with the subject. 


\section{CHA PTER X V.}

\section{PERSONAL HYGIENE.}

Is addition to the barriers which public hygiene interposes for the protection of the health of communities by protecting water supplies, disposing of sewage and other wastes, excluding exotic diseases by. means of quarantine, providing for isolation of communicable diseases, destroying infectious matter by disinfection, regulating the conduct of dangerous occupations, providing for the inspection of foods, and throwing out other safeguards, the individual owes it to himself and to the community, of which he constitutes a more or less valuable unit, to erect such other barriers for his own protection as he can, by due regard to such habits of life as conduce to a healthy existence. It is his duty to maintain habits of personal cleanliness, to regulate his diet, avoiding all excesses in eating and drinking; to protect his body by suitable clothing; to take sufficient exercise in the open air ; to keep his system in perfect working order throughout; to devote a sufficient part of each twenty-four hours to needful rest of mind and body ; and to keep his immediate surroundings in as cleanly a state as his own person. This is the domain of personal hygiene.

\section{Section 1. CARE OF THE PERSON.}

It is hardly necessary to impress upon intelligent people the importance of personal cleanliness, for with such it is a matter almost of instinct. In the case of the naturally dirty, the attempt to educate in this particular is, as a rule, a hopeless task, and with such, the maintenance of cleanliness of body and surroundings ean be obtained only by compulsion. There is in every civilized community an all-too-large proportion of persons who never bathe, and, indeed, regard a bath as a positive danger to health, as every physician who has had experience as a hospital interne or in practice among the ignorant poor can abundantly testify.

Bathing is of importance to health, both for its action in removing dirt and infectious matter of external origin, and for its influence in keeping the skin free from waste products of the system and in a condition for the proper exercise of its natural functions; for the skin is one of the most important natural defences.

Baths.-By an arbitrary division of temperatures, cold baths are those in which the water has a temperature below $65^{\circ} \mathrm{F}$.; cool, between $65^{\circ}$ and $80^{\circ}$; tepid, betwcen $80^{\circ}$ and $90^{\circ}$; warm, between $90^{\circ}$ 
and the normal temperature of the body; and hot, above this limit as high as the system can bear. Cold bathing is essentially stimulant: the cutaneous vessels contract at once, and send the superficial blood supply inward ; the respiration is momentarily gasping in character, and then slowed and inereased in depth. The whole nervous system and all of the mental faculties receive an immediate powerful stimulus. The pulse is somewhat slowed. On emerging from the cold water, the respiration and pulse return to their normal rates, the cutaneous vessels relax and dilate, and the return of the blood in inereased volume to the surface gives a sensation of warmth, which is inereased by the process of "rubbing down." This is known as the "normal reaction."

The eold bath is taken best in a tub in which the whole body may be immersed; but in default of the neeessary means, a sponge, saturated with water, applied repeatedly to the various parts and squeezed out, forms a desirable substitute. A shower bath is better still, especially one admitting of regulation of the temperature.

The proper time for cold bathing is on rising in the morning; never on retiring for the night. Cold baths should not be taken by those advaneed in years, in whom the arteries are atheromatous, nor by those with abnormal circulation, who do not quickly react.

Not the least in importance of the effects of cold bathing is the immunity which its devotees appear to enjoy against taking cold. Many of those who practise eold bathing the year round have no experience whatever with colds, and can withstand exposure which, to others, is produetive of mueh illness.

In sea bathing, the element of enjoyment has a most important influence. The salts are commonly supposed to be the chief source of benefit, and, in consequence of this belief, many persons are in the habit of dissolving in their daily bath in the household a quantity of more or less dirty material, sold at a price which insures at least a fair peeuniary retum, and known as sea salt. The influenee of the salts contained in sea water is nil, and the ? enefits of sea bathing are the result of the physiological aetion of co: !, the attendant exercise of swinming, the pure air, the absence of domestie and business eares (if on vacation), and the sense of enjoyment.

Warm and hot bathing cause dilatation of the entaneous vessels and more or less profuse perspiration. Respiration and pulse are inereased in frequency, and a general soothing effect is produced. Hot bathing is a most grateful means of reducing soreness of the museles after violent exercise and a valuable assistant in the treatment of insomnia. For purposes of personal eleanliness, warm and hot baths are more suited than eold, sinee they can be borne longer with eomfort, and the relaxation of the skin which they induce is more favorable to eomplete removal of the adherent matters.

If means for eomplete bathing are not at hand, the individual should in any event give daily attention to eareful cleansing of the axille, groins, genitals, and feet, as well as of the hands and face. 


\section{Section 2. REGULATION OF THE DIET.}

It is obvionsly impossible to formulate any system of rules, applicable to all classes, for the selection of diet and the regulation of hours with reference to the daily duties of life, but general rules concerning some aspects of the question may be laid down. The suggestion of light breakfasts, somewhat more substantial luncheons, and hearty dinners at elose of day, with periods of mental and physical rest after each meal, is easy to make; but the busy lives whieh the great majority of the population lead, and the widely different eonditions of life and occupation, make its general acceptance and adoption quite beyond the bounds of possibility. It is a common habit of writers on personal hygiene to compose menus for the several daily meals, to suggest the amount of time which should be devoted to the consumption of each, and to recommend the avoidance of physical or mental labor for varying periods before and after each meal, in order that the digestive apparatus may proceed with its work under the most favorable conditions for its uninterrupted completion.

The adoption of most of such recommendations, however, presupposes a curious state of the conditions of life, including an absence of any marked preferences in the matter of articles of diet, a complete mastery of one's time without reference to the demands of occupation, and pecuniary independence.

General rules may be offered to the effect that the diet should consist of wholesome articles of food; that these should be consumed in sufficient, but not excessive, amounts; that they should not be hurriedly bolted; and that as much time as is consistent with the needs of one's occupation should be allowed after each meal, before proceeding to a continuance of work. Obviously, in these particulars each person must be a law unto himself, and the greater the observance of general hygicnic principles, the better the physical and mental wellbeing.

\section{Section 3. REST AND RECREATION.}

For the repair of the daily wear and tear of a busy life, a reasonable period of rest of body and mind is indispensable. Nervous and mental breakdown result from overwork and absence of reereation, but it is impossible to make any rule as to what may be regarded as a safe limit of the amount of work which may be performed. Monotony of life is, perhaps, as potent a factor in mental breakdown as overwork, as is evidenced by statisties showing the high percentage of insanity among farmers and farmers' wives in sparsely settled districts. Mental worry, also, is far more potent than mere mental activity in causing physical and mental degeneration. Recreation is a most important remedy, therefore, for the prevention of monotony and worry.

It is impossible to lay down any rule, governing the amount of sleep, that can apply to all persons indifferently, since active minds may need much less than what commonly is regarded as a ninimum general 
requirement, and persons of conspicuously low mental capacity may require much more. It is generally accepted, however, that for the repair of waste, the average man needs to pass at least one-third of his time, namely, eight hours a day, in sleep.

\section{Section 4. PHYSICAL EXERCISE.}

It is essential to the maintenance of a completely healthy condition that a well-nourished borly shall be exereised properly in ald its parts. The muscular effort involved in what we designate as physical exercise and in the pursuit of certain callings which necessitate bodily activity affects not alone the general musculature, but all the organs of the body as well; the heart, the lungs, the digestive apparatus, the skin, the kidneys, the brain, and, in short, every part. The heart and lungs being stimulated to increased action, an increased supply of oxygenated blood is sent to every part, bringing with it the essentials to fill nutrition and eonveying to the eliminative channels the ultimate products of metamorphosis. The special stimuli of the various organs are excited, and thus the several functions are maintained in a normal state of activity.

In order to gain a full appreciation of the benefits of physical exercise, one needs but to compare the rugged condition of the well-nourished laborer in the fields or of the student or man of business, who, in the intervals away from his daily work, seeks recreation in ontdoor exereise or indoor gymmasties, with that of the pent-up, sedentary operative ol the indolent seeker after pleasures involving inaction. Whether the work of the individual be that of the hands or brain, it is sustained better, if the system is kept active in all its functions and parts.

\section{Effects of Active Exercise.}

Circulation and Respiration.-Muscular effort canses the heart to beat more rapidly and with greater force, so that more blood is sent through the lungs and all parts of the borly, including the substance of the heart itself. Unless the exereise is excessive in duration or violence, the increased action is regular and equal, and cessation of the exercise is followed by gradual slowing, until the rate is below the normal; and then by return to the natural rate. With exeess of muscular effort, the pulse becomes quick, small, and, often, more or less irregular, and even during the fall in rate in the interval of rest, it may be intermittent. Excessive rapidity, irregularity in pulsation, and inequality of volume are indicative of the necessity of rest and of danger from eontinuanee.

The increase in the pulmonary cireulation is aceompanied by inerease in respiratory action, so that a larger volume of blood is forced through the lungs and comes in contact with an increased air supply, from which it receives the necessary increase in oxvgen for conveyance to the tissnes, and to which it gives up its carbon dioxide, aqueous vapor, and other waste products, for removal from the body. According to 
the researches of Pettenkofer and Voit, the oxygen absorbed during an ordinary working day, with the usual interval for rest, is about onethird greater in amount than during a day of inaction, and the carbon dioxide produced and eliminated is inereased about two-fifths. During exertion, the action of the chest should be impeded as little as possible by tightly fitting clothing and other restrictions.

Excessive excrcise eauses labored breathing and sighing, which are indications that the lungs are too much eongested, and that rest is required.

Continued excessive exercise may bring about palpitation, dilatation, hypertrophy, and even valvular lesions of the heart, and congestion of the lungs, accompanied, sometimes, by hæmoptysis. Sudden unusual effort may cause rupture or other injury of the blood-vessels, and, rarely, even rupture of the heart.

Deficient exercise favors weakening of the heart's action, dilatation, and fatty degeneration; and in those with inherited predisposition, the preparation of suitable soil for the reception and development of the organism of tuberculosis.

Skin.-In consequence of the increased blood supply sent through the cutaneous vessels, the latter dilate and the skin becomes reddened. Heat is brought from the interior of the body and radiated from the surface, and a farther cooling effect is caused by the evaporation of the sweat which is poured out by the sweat glands. Thus the excess of heat produced in the system through excreise of its various parts is eliminated and the body temperature kept in a state of equilibrium. The amount of water given off by the lungs and skin during a day of average work was shown by Pettenkofer and Voit to be nearly twice and a half that eliminated during the same period of rest.

With the water of the sweat, the body loses salts, especially sodium chloride, and fatty acids and other organic substances.

During exercise, while the skin is active, there is little danger of chill, even though the skin be lightly covered or even exposed; but as soon as the body rests, the temperature falls, and sweating and evaporation continue, so that it is important to protect the body against sudden cheeking of the skin's action and chilling of the surface. This is done best by means of clothing of low heat conductivity, preferably woollen.

With normal action of the skin, the body temperature remains fairly constant, the heat of the blood, even during most violent exercise, rarely rising much more than a degree Fahrenheit above the normal. During work, a clecided rise in temperature indicates lessened evaporation from the skin and points to possible danger from heat apoplexy.

Nervous System.- It is a common belief that exereise has no effect in increasing the powers of the mind, this belief being based on the supposition that the greater expenditure of nervous energy called for in the exercise of the muscles is opposed to intellectual development or aceomplishment. In support of the idea that great muscular power and exertion are incompatible with marked mental attainments, the 
fact is often cited that trained athletes, as pugilists and wrestlers, are conspicuously stupid. But admitting that this is true, it may also be said that these persons are stupid in spite of rather than because of their physical development and training; and the fact may be pointed out that in our sehools and eolleges the chosen athletic representatives rank, as a class, even higher than the average of their non-athletic brethren. Intellectual ability is incompatible with the embracing of pugilism as a calling, but is quite consistent with a high degree of physical perfection and bodily exercise. Furthermore, a-reasonable degree of activity appears to be necessary to the performance of mental labor, for without proper nutrition and exereise of the system, the nerves and nerve centers must suffer with other parts, even as they must share in the benefits of healthy and vigorous living.

One part of the general system eannot monopolize the benefits of training: the muscles, for example, cannot be trained without the participation of the nervous system in the good results, nor, on the other hand, can they be abused without injury to other parts as well, for motor activity is the result of nervous energy, and all fatigue is nervous fatigue. As evidence of the beneficial influence of exercise on the nerves may be eited the greater readiness with which trained muscles respond to volition.

Deficient exereise is a common cause of morbid excitability, manifested by irritability of temper, sensitiveness, and that form of nervous unrest commonly known as fidgets.

Digestive Apparatus.-The great increase in the excretion of car bon dioxide and in general cellular activity causes a demand for food, and the appetite is increased, especially for proteid matter and fats. Digestion is assisted, and absorption is hastened. The volume of the exereta is lessened by reason of a diminished content of water, due to increased elimination through the skin and lungs. Lack of exereise, on the other hand, tends to diminish appetite and the powers of digestion.

Kidneys. - The amount of urine is lessened by reason of increased loss of water through the skin and lungs. 'The inorganie salts are commonly increased, both relatively and absolutely. Urea is not increased, and may even be diminished, as shown by Pettenkofer and Voit, in which ease, a more than compensatory inerease oceurs during the interval of rest.

Effect of Exercise on Weight.-The effect of systematic regular exercise on weight is by no means constant, but is influenced by the eondition of the body in the beginning, and by the amount and variety of the food ingested. Many persons shortly after beginning a course of training for the reduction of weight or, more correctly, of size, find that a reduction in girth is aecompanied by an inerease rather than a diminution in weight. This means simply that the system has drawn upon its stored firt for fuel, this fat being most eonspicuously placed in the vicinity of the waist line, and has built up tissues elsewhere for the increased work of moving the varions levers of the body. This inerease has its limitations, and when the maximum has been reached, 
the fall in weight, due to utilization of surplus fat, may continue until a point is reached when the curve of weight approximates a horizontal line, and the person may be said to be in perfect physical condition. The marked losses in weight which occur during violent exercise are soon counterbalaneed by ingestion and absorption of food and drink.

Amount of Exercise Required.- Since, in the ordinary routine of life, a considerable and varying amount of physical work is performed, it is impossible to fix any rule concerning the exact daily amount of exercise which a healthy normal adult should take. With the vast majority of persons, all the exercise needed is taken as an inseparable element of their regular occupation, and any additional work is performed as a means of recreation. On no other ground can be explained, for example, the evening bicycle ride of the letter-carrier after the monotony of his daily rounds on foot, or the game of ball begun at the close of the day's work by the hands from the mill or foundry.

A fair day's work for an adult may be said to be equivalent to about 300 foot-tons, a hard day's work to 400 , and a very hard day's work to 500 foot-tons. The latter is about the amount of work performed by a soldier of average weight marching at ease with his kit twenty miles over a level surface at the rate of three miles an hour.

It has been reckoned by Haughton that, in walking on the flat, one performs an amount of work equivalent to raising a certain proportion of his weight through the distance travelled, the proportion varying according to speed. The work performed is reckoned by the following formula :

$$
\begin{aligned}
\left(\frac{\left.W+W^{\prime}\right) \times D}{2240} \times C\right. & =\text { number of foot-tons. } \\
W & =\text { weight of the person. } \\
W^{\prime} & =\text { weight carried. } \\
D & =\text { distance in feet. } \\
2240 & =\text { number of pounds in a long ton. } \\
C & =\text { coefficient of traction. }
\end{aligned}
$$

The coefficients of traction, as determined by Haughton for different rates of speed, are as follows:

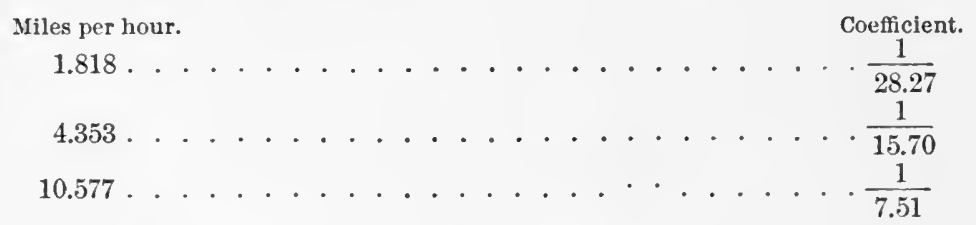

From these, the coefficients for any rate may be determined. For two, three, four, and five miles per hour, they are approximately $\frac{1}{26}, \frac{1}{20}, \frac{1}{16}$, and $\frac{1}{14}$, respectively. Thus, a man weighing 175 pounds walking 10 miles at the rate of 4 miles per hour and carrying 25 pounds, would, according to the formula, do nearly 300 foot-tons of work-

$$
\frac{(175+25) \times 52,800}{2240} \times \frac{1}{16}=295.25
$$


In ascending a height, a man lifts his entire weight through the vertical distance travelled. Thus, the same man, carrying the same weight, climbing six flights in an ordinary office building, would do about 8 foot-tons of work, reckoning the distance climbed as 90 feet.

For those who do no regular, ordinary physical labor, it has been estimated by different authorities that excreise equivalent to from 100 to 150 foot-tons is sufficient for the maintenance of a fair state of health. But this should not be pushed to the extent of being exhausting or irksome. When, in the course of exereise, the body begins to be fatigned or the heart and respiration to be embarrassed, rest is required; for excessive exercise confers no benefit. Severe prolonged exereise may canse dilatation of the heart, aneurysm, and respiratory disorders.

Kinds of Exercise.-Exereise as a hygienic measure may be divided into outdoor work, including walking, riding, and athletic sports, and indoor work, or systematic gymnastic exereises. The former, preferred by all English-speaking people, are carried on under far more healthy conditions and bring with them a much greater measure of enjoyment than the latter, which are preferred on the Continent, more especially by Swedes and Germans. Indoor work in the gymnasium is, as a rule, purely work, without the element of pleasure either in anticipation or during its continuance, and is performed as a serious duty. It is carried out from day to day for a longer period, if done in company with others, as in a class; in which case, emulation may stand in the place of actual enjoyment. But ordinary indoor exercise with Indian clubs, dumb-bells, ehest-weights, and similar appliances, carried on alone in one's room, is usually most unsatisfactory in its results.

There are some, donbtless, who regularly take a certain amount of this class of exereise, enjoy it, and profit by it; but, commonly, the enthusiasm which attends the purchase of the appliances declines in a marked degree by the end of the third or fourth day of use, and has disappeared in a week. Soon the excreise, simply a duty, develops into a bore, for the monotony of this kind of work, into which no sense of achievement enters, exeept that from the aceomplishment of a wearisome round of strokes measured by hundreds, prodnces a distaste; and soon the work becomes spasmodie, the intervals growing longer and longer, and finally is abandoned completely.

Golf.-This exeedingly popular game appears to be an ideal form of exereise for all ages above early childhood, and particularly for those whose lives are essentially sedentary or whose age precludes them from following the more violent games. The amonnt of work performed in going once over a course is very considerable, but it is done in such a way and under such surroundings, with ever-changing scene, that, at the time, it is lardly appreciated. The mind is pleasantly engaged in speculation as to the possibility of achieving certain results, and is filled witl pleasurable emotions when the effort is crowned with success; the body is gently exercised in all its parts by a form of work performed because it is so essentially a means of enjoyment. It cannot 
be abused as are so many other sports, and there is no necessity for quick and violent action, as in tennis and football.

Wheeling.-Wheeling involves very largely the entire muscular system, and brings into play groups of muscles, the existence of which has not before been appreciated by the beginner. With the wheel, one may take any desired amount of gentle, moderate, or violent exercise. It gives a constant change of scene and the pleasurable sense of motion, both of which are of value to the tired mind. It is not the particular form of muscular exertion that is the incentive to long exercise on the wheel, but the pleasure which it gives; for no more monotonous exercise can be devised than riding a stationary bicycle in a gymnasium, while, on the other hand, many who would regard an errand, involving a walk of a mile, as a hardship, will, without demur, wheel five times that distance for the same end.

Tennis, etc.-Tennis, football, baseball, and other outdoor sports are comparatively violent for the majority of people. They bring the whole body into action and are valuable, if not pushed too far. They do not admit of varying the pace according to the fatigue of individual players, in which respcet golf and wheeling possess an advantage.

Rowing is also a very healthful form of exercise, but the violent exertion required in the sustained effort of racing is not always a benefit.

\section{Section 5. CLOTHING.}

The objects of elothing are, aside from motives of decency, to protect the body from the sun's rays in hot weather, from the chilling influence of winds in all weathers, from rain and other forms of wet, and from mechanical and other external injuries and discomforts; to conserve the body temperature and prevent interference with the natural functions of the skin; and, finally, to adorn the person. The proper fulfilment of these various objects is dependent upon the nature of the material, the looseness of its texture, its color, its hygroscopicity and heat conductivity, and its special adaptability to some particular purpose.

Color.-The heat of the sun's rays is absorbed to the greatest extent by black materials, and least by white. Next to black come the dark shades of blue, and then, in order, grcen, red, and yellow. Heat is reflected most by white, and then, in order, the light shades of yellow, red, green, and blue. The color of undergarments (not exposed to the rays of the sun) cxercises no influence whatever.

Texture.-The looser the texture, the greater the amount of air in the interstices; and air being a very poor heat conductor, other things being equal, a loosely woven fabric prevents loss of body heat in a still air more than one of eloser texture. Thus it is that a thin, loosely woven garment of woollen is warmer to the body in a still, cold atmosphere than an equal amount of closely woven material of the same or other kinds. The same result is attained by wearing a number of garments, one over another, so that, having layers of con- 
fined air between, they act in the same way as double windows on a bouse. The value of furs as conservators of heat is largely due to the amount of air retained between the individual hairs.

Impermeable materials, being absolutely wind-proof, and hence permitting no natural ventilation through their substance, are very warm, but have serious disadvantages, the most important of which is the retention of the transpired moisture of the body, which collects on the surface and is absorbed only in part by the clothing next thereto. Against rain and cold winds, impermeable materials afford very great protection. Winds aet in two ways to chill the body : by constant removal of the air in contact with the body and warmed by reason of contact, and by hastening evaporation of the moisture within the substance of the clothing.

Heat Conductivity.-Materials vary widely in their power of heat conduction. Among the textiles, linen and cotton are by far the best conductors, and wool the poorest; but since the conductivity of a garment is governed mainly by the looseness of texture, it follows that the same amount of a good conductor, loosely woven, may be warmer than wool woven very closely. But the fabries made of the best conductors are commonly. very closely woven, and of wool are of varying degrees of looseness.

Hygroscopicity.-Fabrics hold moisture in two ways: first, by retaining it in the interstices between the fibers; and, secondly, by absorption directly into the substance of the fibers. The moisture held in the interstices gives the sensation of dampness or wetness, and may be largely removed by pressure, as in wringing; that absorbed into the fiber may be very large in amount without giving any sensation of dampress, and it cannot be expelled by pressure. The latter is known as hygroscopic moisture.

Materials of animal origin are more hygroseopic than those from the vegetable world, and while they absorb water readily, they part with it more slowly by evaporation. Thus it happens that a person, sweating to the same extent and under the same general eonditions, feels less sensation of chill on resting from his exercise or work when clothed in woollen, than when his dress is linen or cotton. In the latter instance, the moisture is held more largely in the interstices, and the garment may be distinetly wet, and then adheres to the skin, which, as evaporation proceeds, becomes chilled through rapid abstraction of the heat required in the process; whereas, in the former, the evaporation is gradual and the chilling mueh less perceptible or unnoticcable. But here, again, a hygroscopic material, very closely woven, may be incapable of holding as much moisture without imparting the sensation of distinct wetness, as one of a loosely woven substance of low hygroscopicity.

\section{Materials.}

The materials employed in the making of clothing come mainly from the animal and vegetable worlds; from the former are derived the 
wools of various kinds, silk, furs, feathers and down, and leather; from the latter, the principal derivatives are cotton and flax (linen), and, of lesser importance, straw, hemp, jute, and rubber.

Wool.-Wool of various kinds is yielded by a number of different genera of animals. That in commonest use and to which the name is very generally restrieted is derived from the sheep. Other kinds include mohair from the Angora goat; kashmir, or cashmere, from the 'Thibet goat; camel's hair and alpaca, from Auchenia pacos, a cameloid ruminant of South America. But the terms mohair, cashmere, and alpaea commonly refer to cotton and sheep's wool imitations containing no trace of either of these more expensive wools.

Under the mieroscope, the fibers of wool are seen to be cylindrical and translucent, and covered with small imbricated scales which, like those of a fish or the feathers of a bird, run all in the same direction.

Fig. 114.

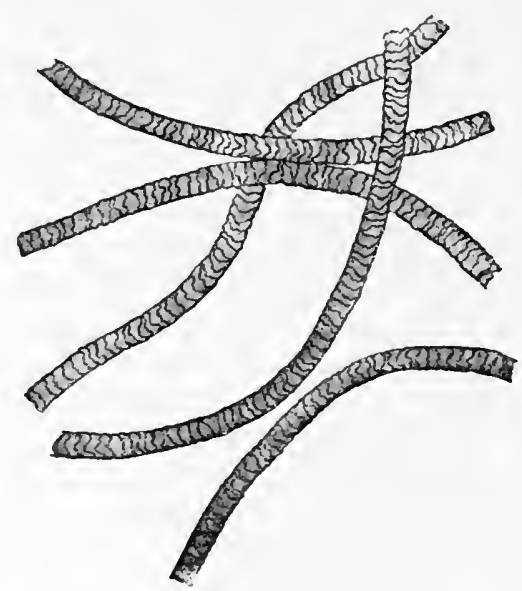

Woollen fibers.

They are sharpest and smallest, and hence most numerous, in the finest sorts; as many as 2800 and as few as 500 to the inch have been counted respectively in the best and very inferior kinds. They give to the fibers the tenacity with which they eling together when woven, and the readiness with which, when wet and subjected to pressure, as rubbing or wringing, they mat together and cause shrinking of the fabric. They are shown in Fig. 114, which is drawn from a specimen of fine Saxony crewel.

Woollen goods, being poor conductors and containing much enmeshed air, are the most valuable of all textiles for gencral purposes in all climates, and particularly in those in which abrupt wide changes in temperature occur. In very hot climates, they are inferior as outer garments to cotton and linen, which, being better conductors and reflectors, assist more in keeping the body comfortably cool. But for undergarments, wool is much better as a protection against chilling after 
active exercise, on account of its hygroscopic properties; the vapor from the body is condensed and absorbed, and the heat, which becomes latent when the moisture is vaporized, is set free, and the evaporation from the fabric to the external air proceeds slowly and without the chilling effect observed when one sits in clinging wet cotton or linen, which fecls cold in proportion to the rapidity with which it dries.

Woollen fabries are much subject to adulteration with cotton and other cheaper materials. What are known as flannelettes are very commonly made wholly of cotton or with a very small percentage of wool, althongh the name is intended to convey the idea that wool is the sole or chief material used. What some are pleased to designate "sanitary flannel" is often largely or wholly cotton. Shorldy is a fabric made with varying proportions of old ravelled woollen and other cloths with a minimum of new wool. It has, as may be supposed, a much inferior tensile strength and less uniformity of texture than woollen of good quality.

Silk.-Silk is the spun fiber produced by a number of species of insects, especially the larvæ of the bombycid moths, called silkworms,

Fig. 115.

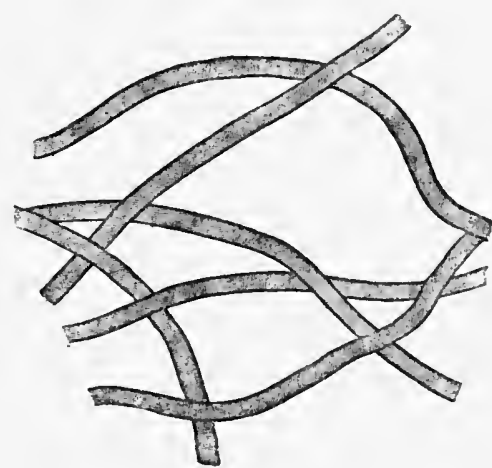

Silk fibers.

to form cocoons or protective coverings when about to assume the chrysalis stage. 'The cocoon in which the chrysalis is killed yields an exceedingly fine thread, consisting of two agglutinated filaments. This thread, when unwound, measures more than two miles in length, and when spun, yields in the neighborhood of 500 yards of silk thread. The outer part of the cocoon is of inferior quality, and is known as floss.

Silk is very hygroscopic. It is a poor heat conductor and a perfect non-conductor of electricity. It has great affinity for anilin and other dyes.

Under the microscope, the fibers appear as structureless tubes, and show no scales or surface markings, such as are seen on wool. They are represented in Fig. 115. Before being woven into fabrics, silk is commonly weighted with salts of tin and iron, with which it forms 
stable chemical compounds. Weighted silk, subjected to the action of a Bunsen flame, parts with its organic constituents, but retains its structural appearance.

Silk is very subject to adulteration with other fibers and to complete substitution by artifieial preparations. One form of artificial silk, invented, in 1884, by a Frenchman, Count Chardonnet, is made from prepared cotton or wood fiber. It possesses a very silky luster, and was at first very inflammable and even explosive, being pratically nitrocellulose; but later, the produet was subjected to further chemical process and made harmless. Another form, invented by Fremery and Urban, is made from cotton waste, and is produced much more cheaply. Still another form, invented by Professor Hummel, of Leeds, is made from gelatin at an expense of about $\$ 1.15$ per pound. It has a low tensile strength, but may be employed in a mixture with genuine silk or fine linen or cotton thread to make a durable fabric.

Silk is used ehiefly in the manufacture of silks, satins, velvets, crape, and plush.

Cotton.-Cotton is the soft woolly fibers appendant to the seeds of the cotton plant (Gossypium), consisting of cellulose, and varying in

Fig. 116.

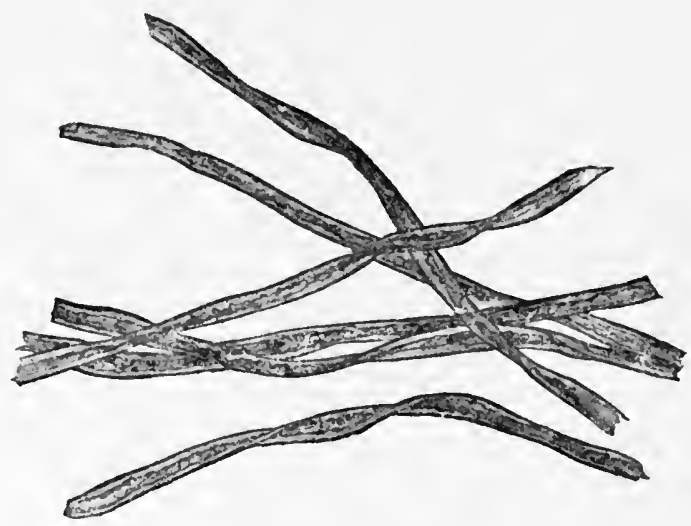

Cotton fibers.

length from a half to two inehes. It is contained with the seeds within the boll, which, when ripe, bursts and allows the fibers partially to escape. Microseopically, the fibers appear flattened and twisted; they have somewhat thickened borders, and some show a central canal. They are shown in Fig. 116. They are freed from the seeds by the cotton-gin, then cleaned and spun into thread, and woven into fabrics of various kinds, including what is known commony as "cotton eloth," sheeting, towelling, jean, drill, and others. For the purpose of giving weight, stiffness, and improved appearance, starch and other materials are commonly employed in finishing. Cotton is employed also with wool and 
other materials as an adulterant or to combine the useful properties of each, as, for example, in merino, which is much used in the manufacture of underclothing and stockings. Cotton is very durable and hard, has low hygroscopicity and high heat conductivity, does not shrink in washing, and is particularly adapted as a material for outer garments for hot weather.

Linen.-Linen is a fabric woven from the soft silky fiber obtained from the outer covering of the stalks of the flax plant (Linurn usitutissimum), which are allowed to rot until the proper stage of decomposition is attained, when they are beaten and carded. They yield about a sixteenth of their weight of fiber. Microscopically, the fibers appear as cylinders marked at regular intervals by striæ indicating cell divisions. (See Fig. 117.) Twisted into thread, they are used in weaving various fabrics known as linen, canbric, damask, diaper, lawn, and huckaback. Linen goods are smooth and lustrous, heavier than cotton, durable and hard, of low hygroscopicity and high heat conductivity. They are

FIG. 117.

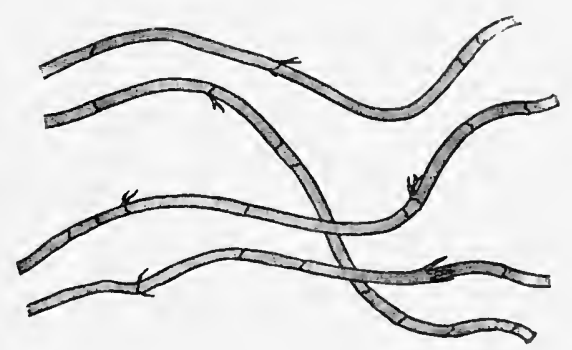

Linen fibers.

especially suited for shirtings, sheetings, and outer garments for hot climates.

Rubber.-India rubber is a prodnct derived from the milky juice of varions tropical plants. It is soluble in ether, naphtha, chloroform, and carbon disulphide. Its elasticity is impaired and destroyed by long exposure to the air and by extremes of atmospherie temperature, but is made lasting by the addition of a small amount of sulphur in the process known as vulcenizing, discovered by Goodyear in 1844 . This process, in addition, insures increased durability, flexibility, and impermeability to air and moisture. To the latter quality, rubber owes its extensive employment in articles of dress, including galoshes and other foot coverings, and outer garments made of rubber-sheeting or waterproof cloth, known as mackintosh. The latter is made by applying a solution of rubber in successive layers to cotton or other fabric, so that it shall be made impermeable to water.

Rubber garments are a very useful protection against wind and rain, but are objectionable on the score of being hot and confining the watery vapor given off by the skin, thus bringing about a condition of great 
discomfort. They should, therefore, be ventilated as much as is practicable, especially if worn in moderate or warm temperatures.

Clothing cau be male waterproof and, at the same time, permeable to air, by a number of processes, and such material has an obvious advantage over ordinary mackintosh and other impermeable fabrics.

Leather.-Leather is the skins of animals, eliefly the ox, calf, horse, sheep, and goat, prepared by tanning and tawing. In tanning, the skin is soaked in vats containing an infusion of oak bark rich in tannic acid, which causes the formation of tough, insoluble tannates of the gelatinous and albuminous constituents of the skin. In tawing, mineral astringents are used instead of oak bark; the end is attained more quickly, but the product is of inferior quality. After the process of tanning or tawing is completed, the skin, now tough and stiff, is subjected to a series of processes, collectively known as currying, whereby it is made soft, smooth, pliable, and ready for use.

Leather, being hygroscopic, takes up perspiration from the foot and gives it off to the outer air; but if it is made impermeable, as in the case of the so-called "patent leather," the latter office cannot be performed. That the perspiration of the foot is given off through the boot, is sufficiently proved by the dampness and dull appearance of the leather of a well-polished boot after half a day's confinement in a rubber overshoe. Although permeable to this extent, leather is sufficiently waterproof for ordinary use, and may be made more so by the external application of grease.

Fur.-Fur as an article of clothing presents the great advantage of impermeability to wind with that of very low heat conductivity, due in greatest part to the large volume of air retained between the hairs. No other kind of material is comparable as a protection against wind and cold.

Felt.-Felts are made from the hairs of various animals, but the best, such as are used for hats, both soft and stiff (the Derby, for example), are made from the hairs of the cony. They are made without weaving, the hairs being blown against a revolving, perforated, metallic cone of large size, connected with an exhaust blower. When a thin coating has formed, a jet of steam is directed against the cone, and then the felt in its first stage is stripped off in a coherent mass, held together by the minute imbrications on the individual hairs. By means of further processes of steaming and steeping, the mass is reduced in size and increased in wall thickness through shrinkage.

\section{Adulteration of Clothing.}

Fabrics are much subject to adulteration by admixture of fibers of lower value, as of entton or shoddy to wool, and by starch and mineral matters to give weight. Many of the eheapest of cotton fabries are so heavily sized that a single washing will convert a stiff, apparently close-woven piece of goods into a worthless, coarse, flimsy material fit only for sieves. 
Chemical analysis of fabries is not always to be relied upon, although fibers of vegetable origin behave very differently from those from the animal world; and any attempt on the part of an inexperienced person to determine the percentage of different kinds of fiber in a mixture is sure to lead him to two conclusions, namely, that he has wasted his time, and that much of what has been written eoncerning the behavior of different fibers when treated with strong chemicals is remarkable only for its small measure of truth.

Microscopical examination is a far simpler and mueli more satisfactory method of determining the composition of a fibric. A few threads, teased apart and examined with a moderately high power, will reveal the nature of the fibers and yield approximately aceurste quantitative results. Shoddy commonly shows fibers of wool of different shades of color, but this finding is by no means to be aecepted as conclusive evidence that a specimen of fabric under examination is shoddy, since only plain goods of a solid color yicld fibers all of one shade. But if the fibers show abrupt ehanges in diameter and partial obliteration of the imbrications, it may be safely concluded that the specimen is shoddy, since fresh wool is fairly regular in diameter and shows sharply marked imbrications.

Poisonous Dyes.-In the dyeing of textiles and other artieles of elothing, a great variety of substances of vegetable and mineral origin are used, and many of them lave been known to produce serious results. Among them may be mentioned potassium dichromate, zinc chloride, compounds of arsenic and antimony, and certain of the anilins. An outbreak of 34 cases of acute dermatitis, ocenrring amonir a number of workmen who had just donned new overenats, is reported by Taunton.' On the first wet day, when the coats were worn, the wrists, where they came in eontact with the elges of the wet slecres, became inflamed. In 1 case, the legs were similarly afficeted, the trousers being wet and rubbed against by the skirt. In 3 cases, the arms were affected. On soaking the eloth in water, it ricklenl free zinc ehloride.

According to U. S. Consul Hughes, of Coburg, in a communication to the Department of State, under date of $A$ pril $23,1901,1$ )r. Adolph Jolles has demonstrated before the Tienna Medieal Socioty the harmful effects of wearing pearl-gray silk stockings, colored hy repeated baths in a solution of zine chloride. It was shown that a large amomnt of the salt was present in the finished goods whon parked for the market, and that the danger therefrom hy alsorption wat very great.

A serious ease of poisoning by anilin black is quoted by Cartatz, from a report of Landonzy and Bronardel to the A sudeny of Madicine of Paris. A ehild of seventeen months hec:me suldenly monecious and apparently asphyxiated, and, although restored, remianod very ill for forty-eight hours. Then the brother of the child and at number of other children were seizel in the same way. All of the virtims wore shoes which gave off' a peculiar penetrating oder, and wore found to

${ }^{1}$ Lancet, December 6, 1898.

${ }^{2}$ La Nilure, Angust t, 1900. 
have been dyed with anilin black. Animal experimentation proved that absorption of this by the skin is favored by heat and moisture, which conditions are present in a tightly laced shoe, and may bring about alteration of the blood corpuscles and asphyxia.

Another case is reported by Besson, ${ }^{1}$ of a child of six years, who, after wearing a pair of new shoes during the forenoon while at play, becime cold and cyanosed in the afternoon, but was relieved by lieat and stimulants within twenty-four hours. The shoes had been polished with a preparation which had a distinctly nauseating odor, and contained 91 per cent. of anilin.

Laurent and Guillemin ${ }^{2}$ report still another, in which six children, all of one family, were seized, after wearing new shoes upon which the anilin polish had not completely dried, with sudden symptoms of poisoning, which included pallor of the face, bluish discoloration of the lips and vails, dilated pupils, headache, vertigo, albuminuria, great muscular weakness, slow pulse, slight convulsive movements, and unconscionsness. Recovery occurred in from one to three days.

It is commonly believed that arsenic in dyed and printed textiles is present as an accidental inpurity of various anilins, but this is far from being the truth, since white arsenic itself is used in several processes for the purpose of adding brilliancy to the colors. Thus, in the so-called arsenite of aluminum process, the dye, dissolved in acetic acid or water, is mixed with acetate of aluminum and white arsenic in glycerin, and the mixture is employed in printing the pattern; next, the printed fabric is subjected to moist heat, and the anilin, in combination with the arsenite of aluminum formed, is fixed in the fibers in an insoluble form.

\section{Selection of Clothing.}

The properties of the various materials used in the manufacture of textiles have already been given in some detail, and further consideration of underclothing and outer garments, beyond a word of caution against unnecessary weight of clothing and undue constriction of any part of the body is, therefore, unnecessary. In the matter of constriction, no part of the human body is so abused as the foot, especially that of woman. Boots, shoes, and stockings should fit the foot, and there should be no such thing as the agony which many people expect as a matter of course in the process of "breaking in." The toe should be neither pointed nor cut square, and the whole sole should follow the natural outline of the foot. The sole should project a reasonable distance from the upper, in order to give firmer support and increased protection to the soft parts from contact with loose stones and other objects. The heels should be low and broad High heels are worn, not for comfort in walking, but to increase the height of the body and diminish the apparent length of the foot. For purposes of suecessful deception, they take about equal rank

${ }^{1}$ Journal des Sciences médicales de Lille, 1901, No. 10.

2 Journal des Pracieiens, March 2, 1901. 
with hair dyes and artificial complexions. Their use conduces to weakness of the arch, atrophy of the muscles of the leg, and a variety of other abnormalities. The heel of the foot should fit snugly in its place within the shoe, but the toes should have sufficient room for freedom of movement, yet not enongh to cause chafing and excoriations. The upper should fit snugly, but not too tightly, about the ankle and over the instep; otherwise, the foot will drive forward and cramp the toes. 


\section{CHAPTER XVI.}

\section{INFECTION, SUSCEPTIBILITY, IMMUNITY.}

Exciting Causes of Disease.-The exciting causes of infeetious diseases are parasites belonging to both the animal and the regetable kingdoms. They gain access to the system, and if the individual be receptive or "susceptible," proced to bring about disturbance of function, some by mechanical obstruction, some by destroying the blood corpuscles which they invade, some by methods still unknown; but mostly through highly toxic substances which they produce and which act locally or generally, as the case may be. Most of those which have been discovered belong to the vegetable kingdom (bacteria); some are animal organisms (protozoa). Of many of the common diseases, notably the exanthemata, the still undiscovered causes belong probably to the latter class, if we may reason by analogy from the discoveries relative to smallpox by Councilman and concerning the cause of scarlet fever by Mallory.

Disease germs are endowed with life; and for its continuance and for multiplication within the tissues, certain favoring conditions are neeessary; invasion of a system offering hostile conditions begets no disease. Introduced in sufficient numbers, and finding their environment favorable, they multiply, as a rule, and eventually make their presenee manifest through the symptoms produced by their toxic produets or because of their power to obstruet or destroy. They differ essentially from poisons in the ordinary sense; for poisons, although causing disturbance of function, resulting likewise even in death, do not reproduce themselves within the tissues. An injection of aconitine, or of morphine, or of tetanus toxin, or of snake-venom does not grow in the system, and hence, if not sufficiently powerful to cause disturbance of function, it will not beeome so with lapse of time; but the introduction of a few streptocoeci, for example, may be followed by rapid multiplication in geometrical progression and result eventually in a fatal septicæmia.

Channels of Infection.-Of the various channels of infection, the most important are the respiratory and alimentary tracts (tuberenlosis, influenza, diphtheria, typhoid fever, cholera, dysentery, etc.); but some of the most devastating of human scourges are spread through inoculation into the skin (malaria, yellow fever, etc.). Invasion of the tissues by disease germs may be followed by localized infection with general disturbance of the system due to their toxic products (as in diphtheria and tetanus), or by general infection and disturbance (as in the septicæmias). 
Infection and Contagion.-The terms infectious and contagious have given rise to much confusion. Properly speaking, the one includes the other, for all contagious diseases, that is to say, those communicated by direct contact with the patient or with fomites (as scarlet fever and smallpox), are infectious; but many infectious diseases that are spread through the agency of contaminated water or food (as typhoid fever and cholerii), or by the bites of insects (as yellow fever and malaria), are not contagious, but are communieated from man to man indirectly.

Susceptibility.-When the exciting cause of an infectious disease either directly or indirectly communicable is introduced into a community, not all of those whose systems are invaded become stricken with the disease, even though they may receive the same dose of the organisms. Of a dozen children exposed at the same time and for a like period to a pre-existing case of scarlet fever, perhaps one, or three, or six, or none at all may be seized; of a hundred consumers of typhoid-infected milk, perlaps a dozen may be infected; in an entire community of a hundred thousand persons, all drinking water from a eommon supply, a few hundreds or thousands may be stricken with cholera in the event of extensive specific pollution of the supply, the rest of the population escaping with no symptoms whatever. The reason for this lies largely in differing susceptibility: one person may be very susceptible and others wholly resistant, regardless of the extent of exposure or of the number of exposures; some may resist a few exposures and later succumb. Some may be exposed without any resulting invasion. Whether or not a given individual will be attacked may depend also upon the number of organisms which enter his system ; for while a few disease germs may be overcome and destroyed, a larger dose may secure a foothold and cause injury. On the other hand, what might be an overwhelming dose to one may be doubled and trebled, and yet be ineffective against another.

Susceptibility is influenced by a number of conditions, including age, race, family predisposition, cold, fatigue, etc. A person who to-day is insusceptible may, a few days hence, acquire susceptibility through any one of a number of causes which bring about a depressed condition of the system, such as lack of proper food, exposure to cold or extreme heat, exhaustion from overexertion, mental disturbance, loss of sleep, abuse of alcohol, overerowding, mechanical injury, and constitutional discase. A person may carry virulent pneumococei in the respiratory tract and not be affected, because of the natural defensive properties of his cells; he may for the same reason escape an attack of Asiatic cholera, although large numbers of the specific organisms have gained access to his intestinal tract; and yet, in the former case, a bad cold, and in the latter, a derangement of digestion, may overeome his defence and he falls a victim.

An individual who is insusceptible to the influence of a particular pathogenic organism is said to be immune, or to enjoy inmunity. Immunity may be either natural or acquired, and acquired immunity may be active or passive. Natural immunity is the inherent ability to resist 
infection when the system is invaded by disease germs: for example, the insusceptibility of man to hog cholera and rinderpest; of carnivora to tuberculosis ; of rats, dogs, and birds to anthrax ; of horses and cattle to typhoid fever and cholera. In these and in many other instances that might be given, the respective organisms, on being introdueed, find themselves opposed by conditions which are inimical to their existence and multiplication, and they soon succumb to the hostile influenees. This form of immunity is, however, not always absolute: it can be overcome in various ways. Thus, while birds are naturally immune to anthrax, it has been shown that certain species may be rendered susceptible by starvation or cold; and rats lose their immunity to the same disease when they are fed wholly on a vegetable diet.

Acquired immunity is, as stated, of two kinds : active and passive. Active acquired immunity follows recovery from an attack of a disease which, except in rare instances, occurs but once in the same person (as yellow fever, scarlet fever, smallpox and ehicken pox); or from a disease of an allied nature (as immunity to smallpox after cow pox); or it can be induced artificially by the injection of increasing doses of bacterial toxins or of bacteria which have been killed by heat or diminished in virulence. It can be acquired not only against diseases, but against certain proteid vegetable poisons (ricin and abrin) and snake venoms (rattlesnake); but it cannot be acquired against the numerous alkaloidal poisons. In but few diseases does one attack confer a lasting immunity ; and even in these, second and even third attacks may sometimes occur, but their severity is, as a rule, much diminished; thus, smallpox and measles. With some diseases a single attack confers a temporary immunity (e.g., pneumonia, la grippe, and diphtheria), but subsequent attacks may be of equal or greater severity. With other diseases, notably malaria, immunity may be acquired with such extreme slowness that increased susceptibility may appear to become established.

Passive acquired immunity' is that which is brought about by the injection of serum obtained from the blood of an animal that has acquired an active immunity, the serum containing specific anti-bodies; and it may be acquired also through the milk of an immune mother, the anti-bodies being seereted therein. Passive immunity is acquired rapidly and with practically no danger or discomfort, but the protection conferred is only transient. On the other hand, active immunity is a matter of much less rapid appearance, but its protective influence is much more lasting.

The tolerance which the system develops toward a specific poison becomes established as a result of certain processes concerning which we have practically no actual knowledge. While we know that certain means employed produce eertain results, the various changes which oecur within the system during the process are matters coneerning which thus far we can only theorize. We are met at the ontset by the faet that protoplasm is a substance of extraordinarily complex composition, which defies exact analysis, and the products which it elaborates are, so far as we know, of equally complex nature. It combines with and 
is acted upon by varions materials, which, according to their nature, promote or disturb metabolism; $e . g$., nutritive matters and toxins. It is with the latter that problems of immunity have to deal, for although under some conditions protoplasm is by them destroyed or disturbed in its functions, under others it is able not only to withstand their influence, but to develop antagonistic products, which overcome them completely and thus prevent discase or promote recovery.

All our knowledge of what occurs in the establishment of immunity and all the therapeutical applications based upon this knowledgre we owe to animal experimentation of an excedingly ingenious and interesting nature, which has given rise to several theories. Of thesc, the "retention theory" of Chauveau and the "exhaustion theory" of Pastcur have long since been disproved and possess now merely an historical interest; and the only ones which have withstood the test of time and investigation are the "humoral theory" of Ehrlich and the "cellular theory" of Metschnikoff, both of which will be considered below.

\section{EHRLICH'S THEORY.}

Ehrlich's humoral or side-chain theory, which had its inception in 1897, explains first the action of the soluble bacterial toxins and their antitoxins, then deals with immunity against these poisons and the bacteria which secrete them, and finally embraces the far more complicated question of immunity against those pathogenic organisms which liberate no soluble toxins, but bring about results which in some way are dependent upon the actual presence of the bacterial cell. The analogy between bacteriolysis and hæmolysis has made the experimental work much less laborious, since the latter can be employed to solve the problems of the former.

Toxins and Antitoxins.-In their interference with metabolism, different spccies of pathogenic bacteria act in very different ways; they produce different kinds of poisons whose actual nature is as yet but little known, and these interfere with the cell functions, each in its own manner. They appear to possess certain definite chemical affinities, like the far simpler inorganic compounds; they are precipitated by certain agents and redissolved by others; they combine with other complex compounds and form more or less stable inert substances. Whether the bacteria are within the tissues claborating the poisons and sending them to distant parts of the body, or are grown in artificial culture media outside, the poisons which a given species produces appear to possess the same properties, so far as they can be studicd.

Bacterial diseases may be divided into two classes: (1) those in which the infective agents are localized and produce their effects through soluble poisons which they secrete and send through the system in the blood stream; and (2) those in which, whether localized or not, the infective agents act not through soluble poisons, but in some manner dependent upon their actual presence in the tissues and yet not explainable in all. cases by mere mechanical presence. These bacteria, however, contain 
poisons united with their protoplasm-intracellular toxins, some of whieh have been separated and subjected to careful chemical analysis; and it may be that they become effective on liberation from the baeterial cells when these die and are disintegrated. Indeed, we know that, in the autolysis of cultures of B. typhosus, a toxin is liberated into the eulture medium; and Vaughan and Wheeler ' have obtained, in soluble form, highly poisonous material from the cell substance of eolon, typhoid, and anthrax bacilli. That the last-named organism produces an intracellular poison was shown first by J. W. Vaughan, ${ }^{2}$ all prior investigation having given negative results. Intracellular poisons have been demonstrated also by Detweiler ${ }^{3}$ (B. prodigiosus, B. violaceus, Sarcina lutea, and Sarcina aurantica) and by Gelston. ${ }^{4}$

As examples of the first elass may be eited diphtheria and tetanus; and of the second, the true septicæmias, in which the bacteria are distributed generally, and typhoid fever and pneumonia, in which the bacteria have a selective affinity for special organs. It is likely that in the establishment of immunity to both elasses of disease, the general principles of the process are the same, although the details may differ.

In the diseases of the first class (diphtheria and tetanus), aequired immunity depends upon the formation, within the system, of substances termed Antitoxins, which, while having no power to destroy the causative bacteria themselves, neutralize their toxie products (toxins). In the immunizing process a very small part of what, under ordinary circumstances, would be a fatal dose of the specific toxin, or a small dose of a weakened toxin, is given subcutaneously to an animal, and this is repeated at intervals of a few days. After a time, the dose is increased, and eventually the animal is capable of receiving without injury a normally fatal dose, and is then possessed of an active acquired immunity. If now the animal be bled and its serum be injected into another, it will be found that the latter ean resist infection by the organism which produces the toxin, or that if infeeted before treatment, the injection will exert a curative influence. In 1890 Behring made this discovery as to diphtheria, after he and Kitasato had found it to be true of tetanus. In 1891, Ehrlich, working with abrin and ricin, found that these toxins treated in vitro with the serum of animals immunized therewith became neutralized and ineapable of eausing injury.

The protection transferred from the actively immune animal to the other is passive acquired immunity. The serum of the immunized animal differs from that of the normal in that it eontains the specific antitoxin, which is a substance believed, with good reason, to unite in a definitely chemical manner with the specific toxin to form an inert compound.

How the antitoxin is formed in the system is an interesting question, which Ehrlich explains in the following manner: The bacterial toxins have special affinities for special cells, and if they are introduced in

${ }^{1}$ Journal of the Amcrican Mredical Association, September 3, 1904.

${ }^{2}$ Transactions of the Association of American Physicians, 1902.

s Ibidem. 4 Ibidẹm. 
sufficient amounts those cells are destroyed; but if not, they are merely damaged by the mion of the toxin with certain atom-groups of the cell for which it possesses the special affinity. The atom-group with which the toxin unites is called a Receptor or Side-chain. The cell, being damaged by the loss of this portion of its substance, proceeds to repair itself by replacing this receptor ; but, following Weigert's law of supereompensation, it produces an excess of receptors, which, not being needed, are cast ont into the blood stream, where they are free to unite with any fresh portions of toxin with which they may come in contact. These free receptors are the antitoxin.

The union of the toxin with the receptor of the cell or with the free receptor (antitoxin) is effected by an atom-gronp called the Haptophore. When the toxin becomes fixed to the cell by this group, it may proceed to destroy the cell by its poison molecule or Toxophore; but when it unites with the free receptor and thus satisfies its only attaching group,

FIG. 118.

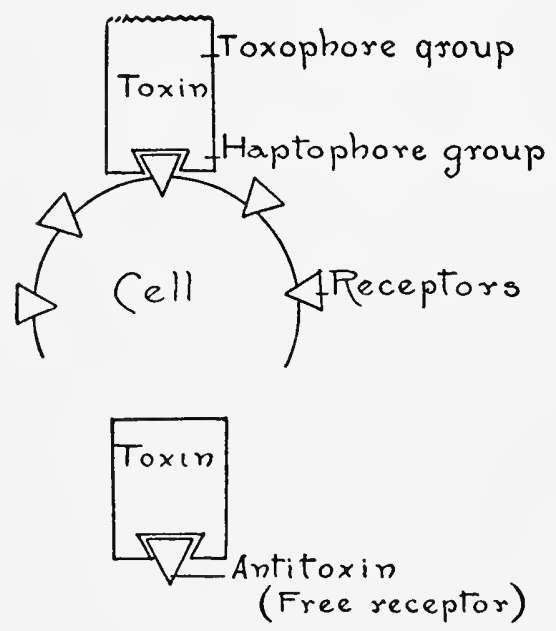

its poison molecule has no cell upon which to work, and is consequently unable to produce harm. The receptor thus acts in two ways: it may attract the toxin to the cell, which thus may suffer, or it nay protect the cell when it is no longer an integral part thereof. (See Fig. 118.) ${ }^{1}$

It has been shown by Ehrlich and others that a specific proteid toxin differs in one very important respect from alkaloidal and other common poisons, namely, that the latter are possessed of no haptophore groups with which they ean form chemical eombinations with the body cells or with substances derived therefrom. A dose of morphine, for example, no matter how frequently it is repeated, is incapable of eansing the

'Figure 113 and the sueceeding figures in this chapter are purely diagrammatie; and in order that no erroneous conception may be formed concerning the various substances which they represent, shapes have been adopted which are not likely to suggest actual cellular or molecular forms. 
formation of a substance with which it can unite to form an inert body, although it can establish a tolerance for larger doses; in other words, no morphine antitoxin can be produced. If one should attempt to immunize an animal against morphine, the serum of that animal when mixed with a fatal dose of morphine would not deprive the latter of its power to poison another, as will an antitoxic serum mixed in proper proportion with a lethal dose of its corresponding toxin. Ehrlich says that the term toxin should be applied only to those toxic products of metabolism with which, by animal experimentation, one can obtain a specific antitoxin. As examples of true toxins may be cited those of diphtheria and tetanus, snake-venoms, abrin (from the jequirity bean) and ricin (from the castor bean). In the case of any one of these, a reaction occurs in the body, whereby the toxin becomes bound firmly to the cell, instead of entering into loose combinations which are easily broken up, as in the case of alkaloids.

It must not be supposed that the so-called receptors or side-chains are concerned merely with toxins and antitoxin formation. The cell protoplasm is an exceedingly complex substance and the cell is something more than a mere molecule: it is made up of many very complex molecules. It is unfortunate that attempts to explain immunity with the aid of diagrams lead many to conceive that the words cell and molecule are in a sense synonymous. The smallest possible drop of water consists of many molecules, all of the same character ; but a cell is an aggregation of complex molecules of diverse natures and functions. The cell possesses certain atom-groups (receptors, side-chains) with affinities for nutritive materials which come within the range of their chemism, and through them it fixes within itself that which it needs for the carrying on of its functions. It possesses affinities also for the proteid toxins, which are believed to be similar to, though less complex in composition than, the nutritive materials. Doubtless, it possesses many other atom-complexes with other functions; and doubtless, also, the number of each kind is such that the destruction of a few does not necessarily mean the death of the cell, which under favoring conditions may proceed to make good its loss by processes of repair. The sidechains which are concerned in the fixation of toxins and which are cast off into the blood stream as antitoxin are denominated by Ehrlich Uniceptors or Receptors of the first order, being of the simplest kind and possessing a single bond of attachment, the haptophore group. Other more complicated receptors than these will be considered presently.

That the union of toxin with antitoxin is a purely chemical process, is believed by Ehrlich and most other investigators, and as proof are cited a number of facts. Thus, when a toxin is mixed with its corresponding antitoxin in proper proportions in a test tube, it becomes neutralized and is then incapable of acting injuriously any longer. Like acids and alkalies, the two can be titrated against each other. Again, as with most chemical reactions, the union of the two is hastened by warmth, and occurs more readily when concentrated solutions are employed. It appears, however, that with tetanus toxin, at least, 
the union with antitoxin is at first a somewhat loose association, which can be disrupted; and that, as time goes on, the combination becomes fixed. This has been shown in an interesting experiment by A. Wassermann, who, having found that a mixture of tetanus toxin and guineapig-brain emulsion possessed no toxic action for guinea-pigs, while mixtures with emulsions of other organs of the same animal retained their power, coneluded that the toxin has a special affinity for the cells of the central nervous system, and that these contain normally the antitoxic side-chains, which are the same as those existing in the serum of an immunized animal. It is known that the tetanus toxin reaches the cells of the central nervous system through the motor axones, and that the antitoxin reaches them through the circulation. Wassermann injected some neutralized toxin into the hind-foot of a guinea-pig and saw no result. Next he injected some adrenalin into the hind-foot of another guinea-pig, and after this agent had caused the capillaries to contract he injected some of the same neutralized toxin, and the animal became tetanized. The eirculation being stopped, the antitoxin could not reach the central nervous system, but the channel of absorption of the toxin was open, and the conclusion must be that the toxin broke away from its combination and was absorbed. On the other hand, when the mixture of toxin and antitoxin was allowed to stand some hours and was then injected into an animal after adrenalin treatment, no symptoms were produced, since firm union had become established between the two substances, and the toxin could no longer free itself.

Toxins are decidedly unstable, their strength diminishing with age. Ehrlich found that a single antitoxic unit saturated very variable amounts of different toxins, and that a neutralized mixture of one antitoxic unit and diphtheria toxin often required the addition of many minimum lethal doses (the amount necessary to kill a 250-gramme guinea-pig in 48 hours) of the toxin, in order to produce a fatal result. The combining power of the toxin was found to be unimpaired, but its toxic property had diminished, and from this fact Ehrlich concluded that the toxin molecule possesses two independent groups of atoms, one of which, the toxophore, is prone to undergo alteration of structure, while the other, the haptophore, remains unimpaired. To this degenerated toxin molecule Ehrlich applied the term Toxoid. By reason of the fact that the haptophores of the toxoids are unimpaired, an animal treated with toxoids can elaborate antitoxic substances, the toxoids attaching themselves to the cells in the same way as the toxins. Studying the degenerated toxins further, Ehrlich found in addition to Toxones, which are original produets feebly toxic to the nervous system, a number of modifications possessing weaker affinities for antitoxin and for cells than those of toxins, but capable of combining with antitoxin and of producing slow poisonous effects, as, for example, paralysis. To these intermediate products he gave the name Fipitoxoids. He found also other modifications which possess greater affinity for antitoxin than has toxin, and to these he gave the name Prototoxoids. 
To still others possessing the same degree of affinity that toxin has for antitoxin he gave the name Syntoxoids. Further researeh by Madsen and Dreyer and Ehrlich has demonstrated the existence of Toxonoids, poisonous for one species but not for another, and of Prototoxin, Deuterotoxin, and Tritotoxin, possessing different affinities for antitoxin, and also alpha and beta modifications of each.

Through the fact that toxoids are unimpaired as to their haptophores, so that they can link themselves to the cells and yet cause no ill effects, Wassermann and Bruck were enabled to prove experimentally the increased production of receptors. They found that, using an old wholly non-poisonous tetanus toxin on a rabbit, they could get no antitoxin production, and this indicated either that the material injected could produce no physiological action, or that if it caused the proliferation of recptors they were not cast off by the cells into the blood. But they demonstrated that the toxoid did act, for the animal could withstand a normally fatal dose of the toxin, the toxoid having united with the cells to which the toxin would have linked itself. On waiting several days until the receptors began to be produced in overabundance, thus increasing the number of points of attachment, they found that the animal not only could not withstand a minimum lethal dose, but was killed by a smaller dose than is required to kill a normal animal. This showed that the receptors were produced, but not cast off; and being retained by the cells they gave the toxin an extra number of points of attachment throngh which to poison the cells, whereas had they been cast off they would have linked themselves to the toxin in the blood-stream and thus neutralized it. It appears, therefore, that, when the receptors are overproduced they require for their liberation some stimulus which the haptophore itself is incapable of supplying, and that, under ordinary conditions of immunizing with toxins instead of with wholly non-poisonous toxoids, this stimulation comes from the toxophore group.

A true antitoxic serum is obtainable only by injecting soluble toxins, and it happens that the only pathogenic bacteria that produce them to any considerable extent are those of diphtheria and tetanus, the others retaining their poisons in some form of combination with their protoplasm. The production of immune serums for the bacteria of the latter class requires the injection of the bacterial cells themselves, either living or killed, the latter being most often employed for the first injections. There is this very important difference between the serums obtained through the injection of toxins and those caused by the injection of the bacterial cells themselves: the former are antitoxicthey neutralize the specific poison ; the latter are not antitoxic, but they act against the baeteria themselves. While the experimental work along the line of production of bactericidal serums has been enormous, and while our understanding of the processes which go on in the body is constantly growing, no such measure of success has yet been achieved as in the case of the diphtheria antitoxin.

Bacteriolysis.-In 1888, Nuttall discovered that normal serum and 
various body fluids have the power to kill and dissolve various species of bacteria, and that this property disappears when the same are heated to $55^{\circ} \mathrm{C} .\left(131^{\circ} \mathrm{F}\right.$.) or allowed to stand for a week or more. This property was ascribed by Buchner, in 1892, to the influence of substances which he called Alexins (now known as Complements). The living animal has the same power when the organisms are injected in not excessive numbers. Thus, one can inject small doses of cholera organisms into a guinea-pig without causing any injury, and if the dose be gradually increased the animal becomes so resistant that it ean withstand a single dose of many times the amount that, in an untreated animal, would inevitably cause death. In other words, the animal becomes immune to cholera; its system has undergone changes which enable it to destroy the specific organism in ordinarily overwhelming doses. If its serum is injected in very small amounts into other guineapigs, the latter also acquire the same immunity. It was shown by Pfeiffer, in 1894, that animals thus artificially immunized could receive without harm into their peritoneal cavities doses of cholera germs, which within 20 minutes would be dissolved by the peritoneal exudate; and he asserted that the result was due to a substance different from Buchner's alexins and produced in the body during the process of immunization. He showed also that a non-immunized guinea-pig, which would be killed by the intraperitoneal injection of a certain dose of cholera germs, could withstand the same if some heated immune serum (thus deprived of its complement) were introduced at the same time ; and he conchuded therefrom that the immunizing material, although it had been exposed to heat, had not lost its bactericidal property, and that it had influenced the organization in some way so that it could destroy the bacteria. Later, it was discovered by Bordet that the bactericidal power ean be restored by the addition to the heated serum of a small amount of normal serum from a non-immunized guinea-pig, thus showing that, for the solution of the bacteria, two substances are required, one of which (complement) is a normal constituent of the blood, and the other (immune body) a substance called forth by the immunizing process. While the perfectly fresh immune serum, like fresh normal serum, has power to dissolve cholera organisms in vitro, so, too, on keeping, it loses it; but the addition of some fresh normal serum or of some peritoneal exudate restores the property ; that is, it reactivates the inactive serum. This was shown by Metschnikoff and by Bordet (in 1896) prior to the beginning of experimental work in hæmolysis. It is thus evident that, with both normal and immune serum, two substances are involved in the process of bacteriolysis: one, the complement, is thermolabile (destroyed at $55^{\circ} \mathrm{C}$.) ; the other, the immune body, capable of conferring immunity, is thermostable (resistant to heat).

Hæmolysis. - The abandonment of transfusion of blood was eaused so long ago as 1869 by the fact that marked destruction of the red cells was found to occur, as was shown by the hamoglobinuria which followed the operation ; but transfusion can be practised without injury between animals of the same species and between certain animals elosely 
related, as, for example, between the $\operatorname{dog}$ and the wolf; but not between unrelated species, as the dog and rabbit, or the dog and horse. Rabbit serum will dissolve the red corpuseles of the horse, ox, pig, monkey, and man, but not those of the hare; guinea-pig serum acts against the corpuscles of rats and mice, but not against those of rabbits; human corpuscles are dissolved by the serum of the horse, monkey, ox, sheep, etc. Although transfusion was abandoned at the time and for the reason stated, the hrmolytic action of blood serum attracted but little attention until 1898, when it was shown by Belfanti and Carbone that the blood serum of horses which had bcen treated with injections of rabbit blood was poisonons to rabbits, while that of horses not so treated had no such property. Later, Bordet announced that guinea-pigs, after a similar course of treatment with rabbit blood, yield a serum which will dissolve the red corpuscles of a rabbit with great rapidity. The same solvent action was found to be exerted by the serum of other animals treated similarly with alien blood, and it was shown that it is a specific action ; that is, that it is exerted (with certain few exceptions) only against the red corpuscles of the particular species whose blood is used for injection. In other words, if species A is injected with the blood of species $B, A$ 's serum will acquire the property of dissolving B's corpuseles, but not those of species C or D. This destruction of blood cells is known as Homolysis, and the agents which bring it about are termed Homolysins. The nature of the hamolytic substance has been the subject of much investigation, which has proved that the solution is effected not by one single constituent of the serum acting alone, but by two acting together, each being powerless in the absence of the other. 'Ten years previously, in 1888, Nuttall had pointed out that many normal serums possess the property of destroying bacteria, and that this ceases on exposure of the serum to a temperature of $55^{\circ} \mathrm{C} .\left(131^{\circ} \mathrm{F}\right.$.). Investigating hæmolysis, Bordet found that in this process, too, the property disappears at this temperature, but can be restored by the addition of a very small amount of serum of another animal of the same species, that has not been subjected to treatment; that is to say, of a normal animal. Later, it was discovered that an inactivated normal or immune serum can be reactivated, not only by normal serum from the same species, but also by that of other animals not necessarily nearly related. Thus, goat serum, which is hæmolytic for guinea-pig and rabbit blood, loses this property on bcing heated to $55^{\circ} \mathrm{C}$., but gains it again on the addition of horse serum, which itself has no action whatever on rabbit blood.

It was clear, then, that at least two substances are required in hremolysis; one unable to resist exposure to $55^{\circ} \mathrm{C}$., but existing in both normal and immunized animals, and the other, resistant to $55^{\circ}$ and even $65^{\circ}$ and $70^{\circ} \mathrm{C}$., and existing only in the serum of those immunized. To the former, common to both kinds of serum, Bordet applied the term Alexin, invented in 1892 by Buchner for the bactericidal substances which Nuttall had shown to exist in normal blood; to the other, found only in the serum of the immunized animal, he applied 
the term Substance sensibilisatrice. These terms and many others that have been coined as substitutes have been superseded respectively by Complement (Ehrlich) and Immune body (Pfeitfer) or Amboceptor (Ehrlich). The actual solvent substance is the complement, but it cannot act unless the immune body (amboceptor) prepares the red corpuscles through some means of its own, fixing itself, according to Ehrlich and Morgenroth, in the red cells themselves. The complement is not only less resistant to heat than the immune body, but is less persistent on storage of the serum. Investigation by Ehrlich and Morgenroth of the power of normal blood serum to dissolve alien corpuscles demonstrated that this, too, does not depend upon a single substance, as was maintained by some, but upon two substances acting together, as had been proved to be the case with immune serum. 'The second substance analogous to the immune body is now known as the Interbody, Go-between, or Zwischenkörper. Ehrlich and Morgenroth proved also that a normal serum which will destroy the red cells of more than one animal species possesses an interbody for each species, and different complements as well.

A hæmolytic serum is intensely poisonous to the animal species whose blood has been employed in its production, injections of a few cubic centimetres causing destruction of the blood cells in corpore. It acts like a toxin, and similarly an artificial immunity to its action can be produced, an antihæmolysin being formed instead of an antitoxin.

In attempting to discover the relationship of the active constituents of hæmolytic serum to the blood-cells which it dissolves, and to determine upon what its specific action depends, Ehrlich and Morgenroth had recourse to a most ingenious experiment, by which they proved that the immune body combines with the corpuscles, and that the combination is of a chemical nature and resists attempts to break it apart. 'The specificity of the union was shown by the fact that the combination does not occur when blood is used other than that for which the serum is hemolytic. They proved also that a similar combination between the blood corpuscles and complement does not occur, and that the immune body possesses two affinities; one, very strong, for the corpuscle, and one, less strong, for the complement. Since the latter, as proved, has no combining affinity for the red corpuscle, its action must be dependent upon the interposition of some agent which has; and this is the immune body, with its two combining groups. Therefore, it is plain that the function of the immune body is to enahle

1 They destroyed the complement of a goat serum that was hxmolytic for sheep blood by heating it for a half-hour at $55^{\circ} \mathrm{C}$., then added 4 volumes of a 5 per cent. mixture of sheep blood in 0.75 per cent. salt solution, and after letting the mixture stand for 15 minutes at $40^{\circ} \mathrm{C}$. they caused all the corpuseles to separate as a sediment by centrifugation. That none of the immune body was present in the supernatant fluid they proved by adding to the latter some more sheep blood and normal serum (containing complement) and finding that the corpuseles were not dissolved, as they would have been in the presence of the immune body. The sediment of corpuscles which had combined with the immune body was mixed with normal (complement-containing) serum, and after a time the corpuseles were dissolved. 
the complement to attack and dissolve the corpuscle, and this it docs by acting as a coupling-link between the two. Its roble is the same in bacteriolysis, binding the complement to the bacterial cell in the same way. Diagrammatically, it may be shown as in Figure 119. It will be seen that the same relations exist between the immune body and the blood corpuscle or bacterial cell as between a toxin and its antitoxin. Both the immune body and the antitoxin possess haptophores, which fit respectively the receptors of the blood corpuscle and the haptophore of the toxin. They are analogous products-free side-chains.

Fig. 119.

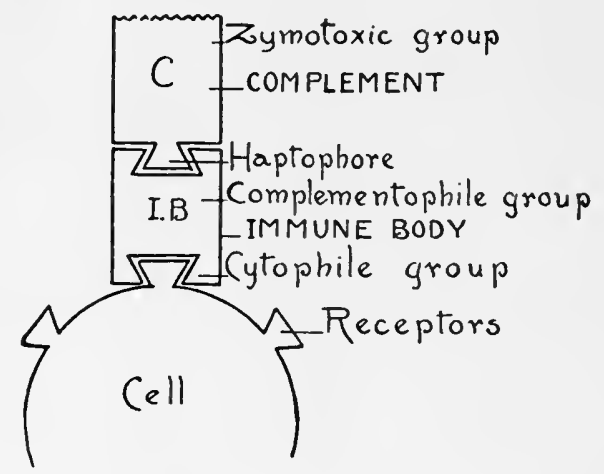

The importance of the study of the phenomena of hæmolysis lies in the fact that analogons, if not identical, processes occur in bacteriolysis; and it happens, too, that experiments with blood cells are more simple and convenient in several respects, among which is the fact that they can be carried out in vitro, and they are also better adapted to accuracy. Although the study of bacteriolysis antedates that of hæmolysis by ten years, it is to the latter that our knowledge of immunity is especially dne.

The side-chain theory, which originally applied to the production of specific antitoxins and was then extended to the formation of specific bacteriolysins and hæmolysins, was finally broadened so as to apply as well to the production of all other antibodies of whatever nature caused by the introduction of any substance which can combine with receptors in the body and bring about the overproliferation and setting free of the same. It is not to be supposed that the body cells are of such simple structure that they have affinities for only nutritive materials, toxins, alien bloods, and pathogenic bacteria. As bas been pointed out, the living cells are enormously complex aggregations of exceedingly complex molecules, and Ehrlich holds that the atom-complexes have a great diversity of functions and combine with whatever substances, and only those, for which they have receptors ; and these substances naturally must possess atom groups (haptophores) which can link themselves to the cell receptors. The haptophores of the immunizing substances are quite distinct from the atom complexes which 
have functional peculiarities; for example, the toxophore groups of toxins, and the zymophore groups of ferments.

Illustrative of the complex nature of body cells and of the multiplicity of atom groups which they possess, may be cited the production of various other cytotoxins. ${ }^{1}$ Thus, the injection of alien spermatozoa causes the production, in the serum of the animals injected, of specific substances termed Spermotoxins, which have the power to immobilize, if they do not dissolve, the spermatozoa of the species from which they are derived, and also to hæmolyze its red corpuscles. Again, in the same way, a serum can be obtained by injection of ciliated epithelium from the trachea of the ox which will have a similar action on this form of cells, and this serum also is hæmolytic (Trichotoxins). By injecting material from the central nervous system, from the liver, from the kidneys, from the mesenteric glands, and from bone marrow, specific serums have been obtained which are poisonous respectively to the nerve cells (Neurotoxins), liver substance (Hepatotoxins), kidney substance (Nephrotoxins), and leucocytes (Leucotoxins). Each of all these possesses a thermolable complement (destroyed by exposure to $55^{\circ} \mathrm{C}$.) and a thermostable immune body. But this is not all. The study of the production of antibodies has gone much farther, and it has been proved that, proceeding in the same way as in immunizing animals against toxins, a variety of antibodies can be produced. Thus, by beginning with very small doses of specific hæmolysin and gradually increasing the amount of the injection, an antihæmolytic serum can be produced, which, when added to the hæmolytic serum, will inhibit the latter's action. Investigation has demonstrated the existence in antibæmolytic serums of anticomplement and anti-immune bodies, both of which are specific. In the same way can be produced antispermotoxins, antileucotoxins, and even antibodies to these antibodies. An enormous amount of research work of a most complicated and ingenious nature is going on constantly, having for its object the solution of the many problems of immunity, and these few facts are given merely as examples, for a general survey of the subject in all its branches is beyond the scope of a work of this nature, particularly until a wider practical application can be made of the numerous discoveries.

Complements.-The elements of blood serum, which, through the intermediation of the immune body, bring about the destruction of alien blood cells or bacteria, are not produced as a result of an immunizing process, but are normal constituents of the blood. As stated elscwhere, Ehrlich has demonstrated that the blood contains not one, but a multiplicity of complements, and that they may differ in their resistance to heat. Thus, the serum of a goat immunized with sheep blood lost, on being heated to $55^{\circ} \mathrm{C}$., the power which it possesses normally to dissolve rabbit corpuscles, but was bæmolytic for sheep

1 "Cytotoxin is used for any substance in serum, venom, or bacterial cultures, or of plant origin, which destroys cellular elements, either animal or vegetable. The hæmolysins and other toxic substances which kill but do not dissolre cellular elements are included under Cytotoxins, also the bacteriolysins (bactericidal substance, alexin)." Nuttall, Blood Immunity and Relationship, p. 14. 
blood until it was heated to $65^{\circ} \mathrm{C}$. Most complements, however, are destroyed at the former temperature. The multiplicity of complements is, however, a matter of disagreement between Ehrlich and Morgenroth and others, on the one hand, and Gruber, Bordet and their followers, on the other; but the weight of experimental evidence appears to be with the former, who maintain that a different complement is required to link itself to immune bodies that are specifically hæmolytic for different kinds of blood corpuscles.

Complements are believed to excrt a sort of digestive fermentative action upon the cells (blood or bacteria) to which they are linked by the immune body. They lose this property, as a rule, when they are heated to $55^{\circ} \mathrm{C}$. They are believed to contain two important atom complexes : one, the haptophore, with an affinity for a similar group in the immune body ; the other, the zymotoxic group, is the functional (digestive) part. It is the latter that is affected by exposure to $55^{\circ} \mathrm{C}$., the former still possessing the power of combining with the immune body and of stimulating the production of anticomplement when the heated normal serum is injected. Complements that have been deprived of their zymotoxic groups are analogous to toxoids, and are known as complementoids.

An immune serum, while it acquires a large amount of immune body, does not, as a rule, gain any additional amount of complement; and inasmuch as the two work together, it cannot exert its full power in test-tube experiments without the addition of a sufficiency of complement, which can be supplied in such experiments by the addition of normal serum. In the practical therapeutical application, however, of a bactericidal serum, the necessary complement may exist already in the blood of the patient; and inasmuch as such a serum may contain many thousand times as much immune body as complement, it follows that a relatively small dose will be sufficient to furnish an enormous number of linking bodies to enable the complement of the blood to perform its office; but, as will appear, there may be an insufficient supply of complement for the attainment of the desired result, and in practice the deficiency cannot easily be made up. Moreover, an excess of immune body, as also will appear, may act to the disadvantage of the subject. (See page 803.)

As to the source of the complements, there is considerable disagreement. By some they are believed to be secretory products of the leucocytes and of other kinds of cells, many of which have been shown to have phagocytic properties; Metschnikoff believes that they are not secretory, but decomposition, products of the leucocytes; Pfeiffer and others believe that the leucocytes are in no way concerned in their production, and Wassermann asserts that these are practically their only source.

While the process of immunization appears to have no influence in increasing the amount of complement, it is donbtless the case that their amount in normal serum is subject to more or less fluctuation in the same individual from day to day under varying conditions of health 
and disturbance of the body functions. Thus, Ehrlich and Morgenroth have proved the disappearance of complement in poisoning by phosphorus, and Metschnikoff its diminntion following suppuration. It is possible that reduced resistance to infection may depend upon the reduction of complement by the spontaneous production of anticomplement in the system. Although this spontaneous production has not yet been demonstrated, it has been proved by Wassermann that the injection of anticomplements increases susceptibility to infection. Anticomplement can be produced (Bordet) by injection of " complement (normal serum of another species), thus eausing the production of a serum which is antagonistic to hæmolysis and bacteriolysis, since the anticomplement possesses a haptophore group, which links itself to the corresponding group of the complement and thus prevents a similar union of the complement and immune body. This action is shown diagrammatically in Figure 120 .

Except in those cases in which the complements of the two species possess identical combining groups, the anticomplements are specific bodies; that is, they combine only with their specific complements. The union of complement and anticomplement is very firm, as has been shown by Bordet, who found that it cannot be broken up by heat.

Immune Bodies.-The immune bodies, believed by the Ehrlich school to originate throngh the saturation of some particular atom complexes (side-chains) of some particular cells, are specific bodies; for example, that which links complement to one

FIG. 120.
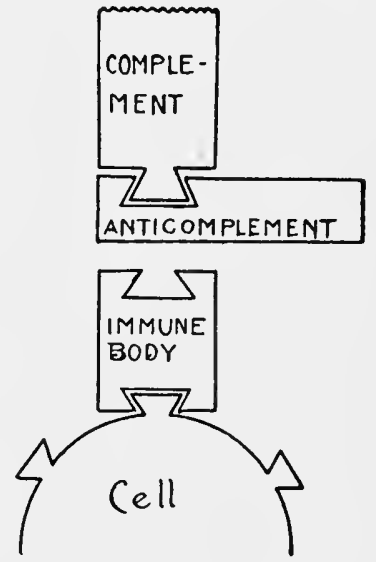

kind of blood cell will not act for that of another species; that which makes possible the destruction of a cholera germ will exert no action against the bacillus of typhoid fever. That they exist in one form and another in the system under normal conditions is generally admitted, for in the normal metabolism of the cells it is assumed that various substances-nutritive substances, for example-stimulate the overproduction and liberation of side-chains, among which may be some that are identical with those which originate in consequence of the introduction of alien bloods, bacteria, and other foreign substances.

Whether each immune body is a single definite substance or a combination of substances having special affinities for different materials is a matter in dispute, the former view being held by Bordet and Metschnikoff and the latter by Ehrlich and Morgenroth, who bring forward certain experimental proof of the correctness of their view.

It has been shown that different kinds of blood cells possess some similar receptors, and that each cell appears to have these atom complexes in great variety, so that a given cell may be able to link itself to the receptor of this or that immune body and not to that of some other; 
and Ehrlich and Morgenroth regard the immune body of a serum as the sum total of its affinities for different cells, cach corresponding to one partial immune body. A particular kind of blood cell or species of bacteria introduced into an animal's system may or may not find corresponding receptors for each of its many different combining atom complexes or haptophores. If it should not find them, then only a part of the possible number of partial immune bodies will be produced by the animal. In another species of animal, other receptors may be, and are, present; and in consequence the immune bodies produced by the two must differ to some extent in their composition, each containing certain atom groups or partial immune bodies that the other lacks, and each differing in similar respects from those produced by other species of animals subjected to the same and to different stimuli. If Ehrlich and Morgenroth are correct-and the weight of experimental evidence appears to indicate that they are-the employment of bacteriolytic serums made by combining a number of serums derived from different species of animals ought to give better therapeutical results than one derived from one species, and hence containing a smaller assortment of possible combining groups. The greater the variety of these groups, the greater the possibility for the human system to bring its complements into action; and these cannot exercise their functions unless they find the necessary intermediary agents-the immune or partial immune bodies. Indeed, it appears certain that in many experiments with lysins a number of different immune bodies or partial immune bodies are concerned. Inasmuch as the atom complexes or combining groups of the molecules that make up the bacterial cell may not be absolutely alike in different races of the same bacterial species, it is reasonable to believe that an immune serum produced through the employment of one particular culture will not affect all different cultures of that organism equally. In fact, that is what often is seen in actual practice : a bactericidal serum is active in a certain number of cases and of no value in others. Hence, as pointed out by Wassermann, ${ }^{1}$ the way out of the difficulty is to employ, not a single culture, but a number of different cultures of the same bacterium in the preparation of a scrum, in this way securing a very large number and variety of partial groups. Such a serum Wassermann would call multipartial.

In the same way that anticomplement can be produced by the injection of normal serum, so, also, can one bring about the formation of antiimmune body by injecting an immune serum into an animal in small and gradually increasing doses, after the method followed in immunization. The resulting serum will contain both anti-immune body and anticomplement.

Agglutinins.-It was observed so long ago as 1869 by Creite, and in 1875 by Landois, that the blood serum of an animal when mixed with the red corpuscles of many other species causes them to come together in clumps. In his experiments in hæmolysis, Bordet observed that in a hæmolytic serum this property is increased; that the agglutination

${ }^{1}$ New York Medical Journal and Philadelphia Medical Journal, October 15, 1904. 
precedes the solution of the cells ; and that the inerease in agghtinating property is specific-that is to say, it is increased with respect to the kind of blood corpuseles that have been employed in the process of producing the hrmolytic serum, and also to some extent for that of closely related speeies. The substance which brings about this phenomenon is called an Agglutinin. It is not destroyed by exposure to $55^{\circ} \mathrm{C}$., and it may resist even $70^{\circ} \mathrm{C}$.; and so a hæmolytic serum which has been heated to that temperature, while it loses its hæmolytie property, is still capable of causing agglutination. The exciting cause of its genesis is supposed to reside in the stroma of the injected corpuscles. According to Stewart, ${ }^{1}$ the injection of the stroma of an alien blood stimulates the produetion of agglutinins, while the cell contents stimulate more especially the production of hæmolysins.

The same agglutinating power is possessed by some normal serums for bacteria, and similarly it is specifically increased in bacteriolytic serums. The agghtination with which we are most familiar is that which is employed as a means of diagnosis in suspected typhoid fever - the Gruber-Widal reaction. The serum of a person ill with that disease, diluted with bouillon and mixed with a eulture of typhoid germs will cause the latter to elump together. This happens whether the bacilli are living or dead. The agglutinin may persist in the system for many months or years after an attack of typhoid fever, suggesting a persistence also of the specifie bacilli, which we know to be often the case, since they may be discharged in the urine continuously for many months after recovery.

The bacterial agghntinins were studied first by Gruber who concluded that in some way they affect the bacteria, so that they can be killed and dissolved; but experimental evidence tends to show that they are not necessarily injured, and that, on the contrary, they can even continue to multiply, even though agglutinated. It has been shown by Bordet and Malkoff that the bacterial agglntinins and the hæmagglutinins combine with the bacterial cells or blood cells in the same way as the go-hetweens ("Wwischenkörper) of normal serum.

The agglutinins are complex substances possessed of haptophores, which combine with haptophores in the blood cells and bacteria, and other atom groups which cause the clumping. The cells upon which they act (blood eorpuseles and baeteria) contain what is called "agglutinable substance," which also is made up of at least two atom complexes, one of which is a haptophore, as mentioned above, and the other is sensitive to the atom group which canses the clumping. Thus, the phenomenon of agglutination is analogous to the ehenism of hæmolysis and bacteriolysis; but the one is apparently not dependent upon the other, for hæmolysis and bacteriolysis may oceur without agghutination, and agghutination may oceur without subscquent solution. Thus, dog serum will agglutinate but not destroy anthrax bacilli, and rat serum will destroy but not agglutinate them.

${ }^{3}$ American Journal of Physiology, XI., No 3., June, 1904, p. 250. 
Ehrlich regards the agglutinins as special products in an immune serum, analogous to the bacteriolysins and hæmolysins.

The atom complex that causes agglutination is very susceptible to the action of acids and other substances, and when it is deprived of its functional power, the result is the same as with toxins that have lost their toxophore groups: the agglutinin retaining its haptophore group is converted to an agglutinoid, just as a toxin becomes a toxoid; it still can combine, but it cannot agglutinate.

Precipitins.-If the serum of one species of animal be injected into an animal of another not closely related species, the serum of the latter will acquire the property of precipitating part of the proteid material of that of the former when the two are mixed together. For example, if we mix normal rabbit serum and horse serum, we observe no reaction; but if we inject a rabbit with horse serum at proper intervals, after a time its serum will acquire the property of causing a precipitate when it is mixed with horse serum. The substance which is developed in this process of immunization and which brings about the reaction is known as a Precipitin. Precipitius are not wholly specific in their action. A serum obtained by immunizing with the serum of species $\mathbf{A}$ may precipitate the latter and also that of some other closely related species. 'This was pointed out first by Nuttall, ${ }^{1}$ whose extraordinarily extensive researches, conducted with hundreds of different kinds of blood and involving the making of many thousands of tests, have been very rich in results valuable alike to students of zoology, physiology, and immunity, and also to those who have to do with medico-legal investigation of suspected blood stains.

The use of these facts concerning precipitins in the detection of animal flesh of various kinds has already been referred to on page 34 of Chapter I., where a method for the detection of horse-meat has been described. This method has, however, its limitations. For instance, it is said to be difficult, if not impossible, to distinguish by this test between the flesh of sheep and that of goats.

Precipitins have been found in certain normal serums. Thus, ox serum will precipitate that of man and also that of a number of other species, and the same is true of the serum of dogs, goats, and other animals. They have been found also in the serum of animals immunized with bacterial cultures; these are known as bacterio-precipitins, and are specific for the culture filtrates of the germs employed and for solutions of the material within the bacterial cell.

Precipitins, like agglutinins, are far more resistant to heat than the other immune substances, their functional property being not completely destroyed under $70^{\circ} \mathrm{C}$. They combine in a definite chemical way with the substances precipitated, but the reaction is prevented by acetic acid. They are believed to contain two essential atom groups: one, unstable and functional; the other, a stable combining (haptophore) group. Precipitoids analogous to agglutinoids are known.

There is another form of precipitin, called Coagulin, which is de-

${ }^{1}$ Blood Immunity and Blood Relationship, Cambridge, 1904. 
veloped in the process of immunizing animals with other albuminous substances. Thus, by employing milk, there is developed an immune body that will coagulate milk of the same kind as used. These lactoserums are, in some substances, also specifically hæmolytic and spermotoxic.

The agglutinins and the precipitins are more complex than the toxins and less so than the hæmolysins and bacteriolysins. Ehrlich conceives of the individuals of this group of immune substances as possessed of two atom-complexes, one of which, the haptophore, holds the substance acted upon, and the other, the zymophore, exerts a fermentative action which brings about the change. (See Fig. 121.) They are called by Ehrlich Receptors of the second order. The receptors of the first and second orders are known also as Uniceptors.

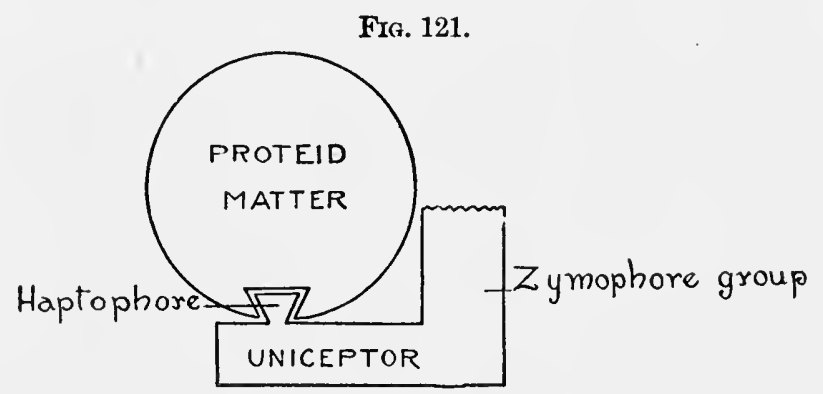

The immune bodies concerned in hæmolysis, bacteriolysis, and other lyses are more complicated than the antitoxins (receptors of the first order) and the precipitins and agglutinins (receptors of the second order). In this third kind, one haptophore group fixes the bacterium, blood cell, epithelium cell, food material or other substance concerned by the corresponding group in the latter, while another haptophore, represented usually as another arm, links to itself the complement

Fro. 122.

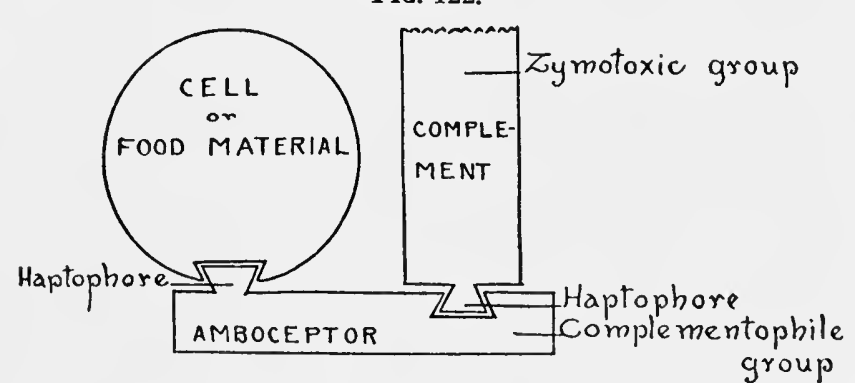

through the mutual attraction of the complementophile (haptophore) group of the immune body and the haptophore group of the complement. Both are held separately by the same kind of affinities, and the complement can proceed to exercise its digestive function upon its companion 
in captivity. This is shown diagrammatically by Figure 122, in the use of which and of the others presented in the chapter, it must be borne in mind that the action is not mechanical, but purely ehemical, and that the figures are mere diagrams and represent bodies which never have been seen. Figure 122 is but another way of expressing the same idea as Figure 117.

The inmune bodies of this class are known as Receptors of the third order. When they are formed and thrust out like the antitoxins into the blood stream in consequence of some immunizing process, they are known as Amboceptors; and those which are not so caused, but exist normally in the serum, are termed Intermediary bodies, Zwischenkörper, and Go-betweens.

From the fact that all receptors of whatever order possess haptophore groups, Ehrlich calls all free receptors Haptins. There are doubtless many more varieties of haptins than have yet been conceived of, and an infinite number of sub-varieties of cach kind.

\section{Wassermann's Reaction for Syphilis.}

As a result of the studies above detailed, concerning various phases of immunity, a test was devised by Wassermann ${ }^{1}$ for the diagnosis of syphilis. This test depends upon two factors: first, the hæmolysis of red corpuscles when sensitized with appropriate sera and treated with complements; and, second, to the fact that complements become anchored to antigens which have been treated previously with their specifie amboceptors or intermediate bodies.

In this special instance we have two systems of agents, the interaction of which must be observed in order to deternine whether or not the serum of an individual gives a syphilitic reaction. The first series consists of $(a)$ the red corpuscles of some animal, such as the sheep; (b) the serum of some other animal, such as the rabbit, which has been injected with sheep's red corpuscles, and which has been inactivated by heat; and $(c)$ fresh, normal serum to act as complement. The second series consists simply of syphilitic antigen, most commonly syphilitic liver of a newborn infant, together with the suspected serum (also inactivated).

In carrying out this test the syphilitic antigen is added in proper proportions to the serum which is nnder suspicion. If this serum comes from a syphilitic individual, the syphilitic amboceptor in that serum becomes anchored to the antigen. If, now, we add complement to this combination, this complement in turn becomes fixed to the antigen-serum combination. We next mix, in proper proportions, the red blood-cells of the sheep and the inactivated serum of the rabbit, previously inoculated with the red cells of the sheep. In this instance, also, there occurs a combination between the red cells and the specific amboceptor in the goat serum. Hæmolysis does not take place, how-

1 Berlin klin. Woch., 1907, Nos. 50 and 51. 
ever, because of the absence of complement. The two series are now mixed together, and the final result of the test depends upon whether, in this combination, hrmolysis takes place.

If the suspected serum is syphilitic, and the combination of antigen serum and complement has taken place, there will be no hæmolysis, because the complement present is so fixed in its combination that it cannot act upon the sensitized sheep's corpuscles. On the other hand, if the suspected serum be not syphilitic, the consplement in series No. 1 will be free, will act on the sensitized sheep's corpuscles, and hæmolysis will take piace.

\section{Metschnikoff's Theory.}

Metschnikoff's theory of Phagocytosis, which dates back to 1884, holds that bacterial invasion of the system is followed by either attraction or repulsion of the leneocytes and other phagocytic ectls by the bacteria, which in the former case become absorbed and destroyed. In case the phagocytes are repelled, or if the attraction is only partial, so that some bacteria escape, multiplication of the invaders occurs, with consequent lesions. The property of being attracted or repelled is known as Chemiotaxis, which is respectively positive or negative. In case of natural immunity, the chemiotaxis is positive and the cells move toward the bacteria and englobe them; in susceptibility, it is negative or only partially positive, or the phagocytes may not possess the requisite phagocytic power. In the acquirement of immunity, the negative chemiotaxis is converted to the positive form by the introduction of very small numbers of the specific bacteria or of weakencd cultures, which bring about a tolerance on the part of the phagocytes, which eventually are enabled to attack and destroy the organisms in numbers which ordinarily would cause death. The phagocytes include the mononuclear and polymorphonuclear lencocytes, certain cells in the serous cavities, connective-tissue spaces, lymph nodes, neuroglia, splenic pulp, and in the lining of small bloodvessels, and elsewhere; but those chiefly engaged are the lencocytes.

The destruction of bacteria by the phagocytes is attributed to the presence of digestive ferments, which Metschnikoff calls Cytases, and which in their function correspond to the complements of Ehrlich.

Metschnikoff believes that what the Ehrlich school calls immune bodies and eomplements are produced within the phagocytic cell, and that, in natural immunity, they are retained within the cell; while in the artificial form the immune body, but not the complement, is liberated into the plasma. He explains the presence of the two substances in an immune serum as a consequence of disintegration of phagocytes (Phagolysis) ; but Wassermann has demonstrated that complement exists naturally in the free state in the blood. He believes that under ordinary conditions the bacterium is englobed by the cell, which produces both substances necessary for the process of destruction. In what is 
known as "Pfeiffer's phenomenon" (see page 789), Metschnikoff asserts that the phagocytes are broken up in consequence of the operation on the animal, and thus the cytase (complement) is liberated; but this alleged phagolysis is denied and disproved.

The Metschnikoff school asserts that not only the process of bacteriolysis, but also that of hæmolysis, is carried on by the leucocytes; that they also absorb and destroy the soluble toxins; that anticomplements do not neutralize complements, but merely paralyze the leucocytes; and that the circulating blood has no bactericidal power.

\section{Opsonins.}

In the last few years, especially under the leadership of Sir A. E. Wright in England, a great amount of work has been done upon the study of those substances in the blood which have to do with the important functions of phagocytosis. These immune substances are present to a certain extent in all normal sera, but are developed much more extensively and specifically through the result of natural infection or throngh the agency of artificial immunization. Although it is held by some that phagocytosis is due to the fact that these specific immune substances stimulate the leucocytes to increased activity through the action of so-called stimulins, it is much more probable that they in some manner act upon the infecting bacteria themselves, so that they are more easily ingested by the white cells of the blood. The fact that the amount of these opsonins in the blood varied very much in health and disease, and seemed in fact to correspond to the amount of immunity possessed by the individual, led Wright to assert that in the opsonic index, so-called, we had a measure of the resistance of the infected individual. While it is true that, carried out under proper conditions and with proper precautions, this index is of much scientific interest and value, it cannot be said to have justified Wright's claim for its common use in medical practice. Together with the work of Wright and his pupils on the opsonic index has developed a tremendous amount of literature concerning artificial immunization with bacterial vaccines, and although results have not been so remarkable as at first claimed, they are important and give large hope for the future, not only for the prevention of general and local infections, but also for the cure for those infections when once the human body has been invaded.

\section{Practical Applications of the Results of Studies in Immunity.}

While it is true that, in spite of the vast amount of experimentation on the subject, the practical application of what has been thus far discovered to the prevention and cure of disease has made comparatively little progress, it must be borne in mind that the problems of biochemistry are exceedingly complex; that the work of solving them is of quite recent origin; that the pursuit of methods for their solution has neces- 
sitated the investigation of many points of apparently indirect relation to the main question; and that one is obliged to reason largely from phenomena which are the outcome of processes which do not occur in nature. It may be said that the whole subject is still in its infancy, and that only a small part of the foundation of the final structure has yet been laid. Thus fur the only really brilliant results achieved in the practical application of the discoveries in immunity are limited to one disease-Diphtheria-the toxie material of which, being soluble and extracellular, makes easily possible the production of an immune serum which can be used either as a prophylactic or as a eurative agent. The pathogenic organisms other than those of diphtheria and tetanus retain their toxins within their cell substance, and the immune serums produced by their introduction into living animals are not antitoxic, but bacteriolytic, and exert only temporary protection and but slight curative action.

The lack of success in the treatment of diseases eansed by this class of bacteria is due probably to the disparity in the amount of amboceptor and complement in the immune serum. As has been pointed out, a bacteriolytic immune serum contains an enormous increase in the amount of specific amboeeptor (sometimes 100,000 times as much), but no increase in complement. Inasmuch as the conjoint action of both is necessary for the destruction of the bacterial cells, it follows that, unless the patient can furnish the necessary amount of complement, the treatment must tail. To supply the needed additional complement is not an easy matter, even if normal serum be injected, on account of the multiplicity of complements; for, according to Ehrlich and Morgenroth, each kind of amboceptor requires a different specific complement; and hence they recommend the immunization of different species of animals with the same kind of bacteria and the utilization of a mixture of the several serums, thus bringing into action amboceptors and complements which, althongh differing according to the species in which they are produced, are, nevertheless, specific against the same organism, and some of them, at least, may satisfy the needs of the human system. Not only does a deficiency of complement in itself present an insuperable obstacle to successful treatment, but the excess of amboceptor may also work injuriously by preventing the available complement from exereising its function, as has been shown by Neisser and Wechsberg, who proved that it may unite directly with the complement, which has a greater affinity for free amboceptor than for that which has linked itself to the bacteria; whereas, in the absence of an excess, the complement will unite with that which already has engaged the bacteria. Thus it happens that successful treatment depends upon the very difficult problem of bringing together in the diseased system the proper amounts of amboceptor and complement to eope with the specific bacteria. An excess of eomplement is not to be thought of, but a material excess, either of amboceptor on the one hand or of specific bacteria on the other, is fatal to success. 


\section{DIPHTHERIA.}

As has been stated, the disease in which the most brilliant results have been achicved in the application of an immune serum is Diphtheria, against which the agent may be employed either as a means of cure or as a prophylactic. Its introduction as a curative agent, in 1894 , met at first with much adverse criticism, but its value was soon firmly established, and statistics of cases to the number of hundreds of thousands testify that the mortality has been reduced from about 40 per cent. to about 15 per cent. or lower. The statisties of the Boston City Hospital show that of 3067 cases treated during the period 18881894,43 per cent. resulted fatally ; while with antitoxic treatment the death-rate of 14,910 received during the period 1895-1904 was but 11.84 per cent. During the year ending December 31, 1904, the death-rate was 9.57 per cent., and if those eases which ended fatally within twenty-four hours of admission are eliminated, this figure is reduced to 6.95 per cent. Preventive treatment has been practised extensively in schools, hospitals, and other institutions for children, but the immunity thus conferred is but transient. In a children's hospital in which an outbreak of diphtheria occurred, Lohr ${ }^{1}$ immunized 460 inmates and the outbreak was checked, no cases occurring within three weeks of the operation. Later, a few cases occurred, which illustrated the temporary nature of the immunity. Of 99 patients with measles, treated because of the special danger of diphtherial supervention, not one was attacked. Similar outbreaks in children's institutions have repeatedly been checked, but since the protection conferred is so transient, reappearance of cases is likely to occur, as in the instance cited ; and to guard against this, it is advisable to remove the inmates long enough to give the premises a thorough disinfection.

According to Netter, ${ }^{2}$ immunity begins after 24 hours and wears off within 3 or 4 weeks. He recommends that, when a case of the disease occurs in a school, hospital, or other institution for children, the other inmates be treated. The treatment is advised also in measles and scarlet fever wards as a preventive of possible diphtherial complication. An instance is given in which the disease was a frequent complication in a measles ward, 2 to 4 cases occurring during each of 4 months, and 19 in the next succeeding 6 weeks, after which period each child was treated on entrance and no further cases occurred. The employment of the immunizing treatment as a routine practice is advocated by Caillé ${ }^{3}$ for young schoolchildren, for the purpose of preventing primary infection and diphtherial complication of scarlet fever and measles. $\mathrm{He}$ recommends two treatments during the school year.

Fig. 123, published by Park, shows the extraordinary influence of diphtheria antitoxin upon deaths from diphtheria in nineteen large cities of the world, from 1878 to 1905 . It will be noted that the

1 Jahrbuch für Kinderheilkunde und physische Erziehung, September, 1896.

${ }^{2}$ Bulletin de l'Académie de Médecine, March 18, 1902.

3 Archives of Pædiatrics, October, 1903. 
FIG. 123.

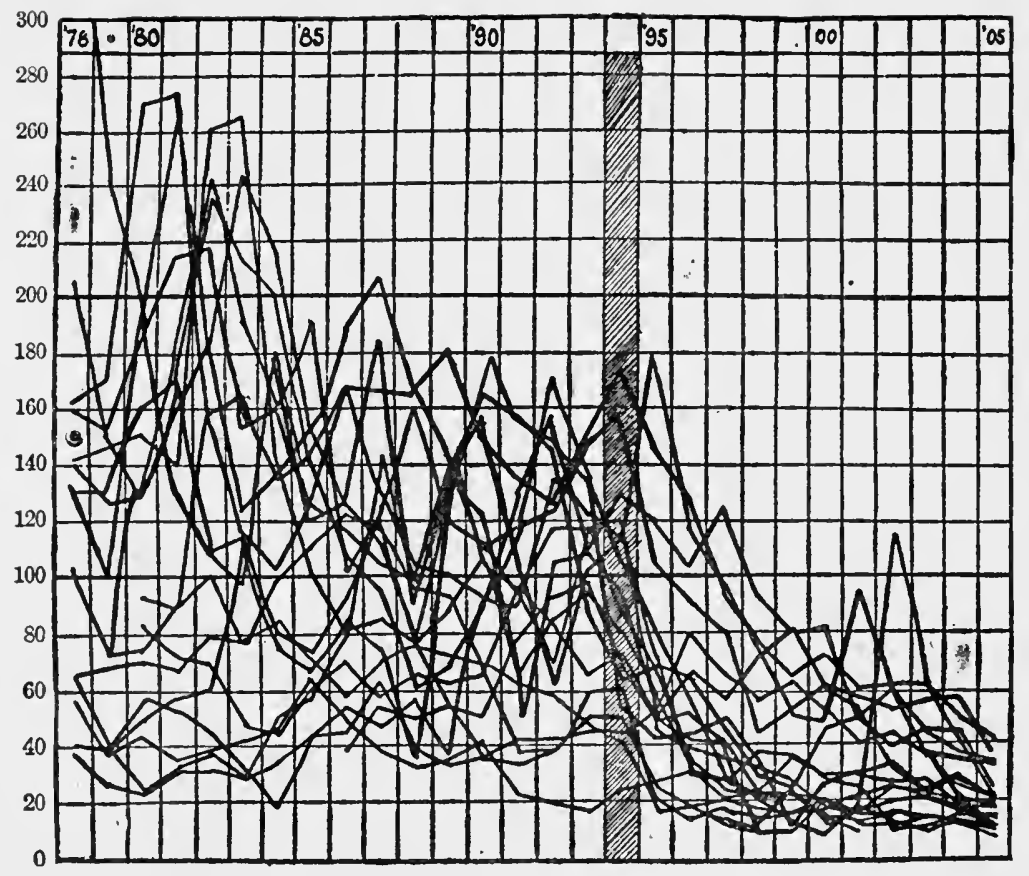

Deaths per 100,000 from croup and diphtheria in nineteeu large cities (1878-1905). (Park.)

year 1894, which is shaded, was the year in which diphtheria antitoxin was first introduced.

\section{TETANUS.}

Like diphtheria, tetanus is due to extraccllular toxins which are produced by the localized bacilli. They are conveyed in the blood stream to the cells of the central nervous systen, for which, as has been shown, they have a selective affinity, and with which they form a very elose union. Although it is possible to produce an antitoxic serum which, in test-tube experiments, acts equally well with the diphtheria antitoxin in nentralizing the specific toxins, the antitoxic treatment of the discase has failed signally in fulfilling expectations. This is because before the diagnosis can be established, the injury to the cells has been effected beyond the possibility of repair. 'The antitoxin is, however, valuable in aborting possible attack, and its injection has become a routine practice in cases of gunshot wounds and sinilar accidents, especially after the annual observance of Independence Day.

\section{HAY FEVER.}

In hay fever we have a true intoxication, but the toxin is not of bacterial origin. The discovery of the cause of this exceedingly annoying condition is due to the investigations of Professor. William 
Dunbar, of Hamburg, who proved that the disease is due not to bacteria, but to the poison contained in the pollen grains of varions grasses. In his first communication ${ }^{1}$ he showed the difference in the way susceptible and non-susceptible persons react to the dissolved toxin; 9 of the former subjected to its influence developed typical symptoms, and 20 of the latter were in no way affected. In a later paper $^{2}$ he showed that the autumnal catarrh, which is peculiar to this continent, is caused by the pollen of goldenrod, ragweed and other weeds not indigenous to Europe. In the same way that diphtheria antitoxin is produced, Dunbar obtains a horse scrum which neutralizes the pollen toxin completely. This toxin is so powerful that one-fortythousandth part of a milligram (corresponding to 2 or 3 pollen grains) is sufficient, when placed in the conjunctival sac of a susceptible person, to cause an attack lasting several hours, but it will yicld readily to the antitoxin. Although the toxin of the grass pollens differs from those of the pollens of goldenrod, ragweed, etc., the grass-pollen antitoxin neutralizes them all. Statistics collected by various writers abroad and in this country show most favorable results of treatment. Unlike diphtheria antitoxin, Dunbar's preparations (liquid and powdered forms) cannot be employed subcutaneously, but are applied locally. The serum, evaporated to dryness and converted to a fine powder with sugar of milk, is administered as a snuff in very small doses. It does not confer lasting immunity, and must be resorted to during the season at intervals of a day or two, or, if the outdoor air be unusually rich in pollen, at intervals of a few hours. For application to the eyes, the serum itself is preferred. It is said that in the majority of unsuccessful cases either the antitoxin is not used sufficiently often or is taken in excessive amounts, which aggravate the difficulty. In some cases the mucous membranes are in such swollen condition as not to permit absorption.

\section{DYSENTERY.}

Specific therapy has made a great deal of progress in this disease. Considerable confusion has arisen because of the varying types of bacillus found in different epidemics. The Shiga-Kruse variety has been found to be more virulent than the Flexner type and more efficient in the production of an anti-serum. A polyvalent serum produced by inoculation with both types of bacilli has been suggested, and would seem to have the best outlook. The serum is both bactericidal and antitoxic. Good results cannot be expected unless the patient is injected with serum corresponding to the serum infecting organism. Bacteriological diagnosis is, therefore, very important, unless a polyvalent serum be available.

As to the efficacy of the serum, reports from Japan, Austria, France, Russia, and England agree in according it marked power. Shiga ${ }^{3}$

1 Deutsche medicinische Wochenschrift, February 26, 1903.

${ }^{2}$ Berliner klinische Wochenschrift, June 15, 22, and 29, 1903.

3 Osler, Modern Medicine. 
treated 298 cases, with a death-rate of 9 to 12 per cent. The length of the disease in those who recovered was twenty-five days; in those who died, sixteen days. In 212 cases treated with drugs the mortality was 22 to 26 per cent. Those who recovered were sick forty days; those who died eleven days. In Russia Rosenthal gave serum treatment to 157 cases, with only 8 deaths- 5.1 per cent.

Shiga inoculated 10,000 peopie in Japan with a mixture of dead bacilli and specific serum. The incidence of the disease was not much affected, but the mortality was reduced from 20 to 30 per cent. to practically nothing. 'Treatment of the original disease with specific vaccines has been tried in a few cases with success.

\section{TYPHOID FEVER.}

The use of bacterial vaccines in the prevention of typhoid fever, especially in large bodies of military men, has, in the last few years, become quite common, and represents a very important development of the practical uses of artificial immunization. According to Russell, ${ }^{1}$ "sinee 1904, 60,000 men have been vaccinated in India, over 7000 in Sonthwest Africa, and over 14,000 in the United States, and in no case has any harm followed its administration. . . . Among the 14,000 persons vaccinated in the United States Army there have been reported, to date, 6 eases of typhoid with 1 death, while among the remainder of the army, during the same length of time, there have been 418 cases with 32 deaths. The rate per thousand among the vaccinated is 0.4 , while among the unvaccinated it is 6 , or 15 times as high. Only onesixth of the force has been immunized; had the entire army been vaccinated the same rate of incidence would have given only 36 cases rather than 418. . . The time has come when its use should be extended not merely in the military services, but also among the civil population."

In this connection the experience of the writer (M. W. R.) and Spooner may be quoted. In an investigation looking to the prevention of typhoid fever among nurses attendant upon typhoid cases in general hospitals, the writers gave 1588 inoculations to 405 individuals. "As yet there have been no untoward results, and we believe that the inoculated individuals have acquired an increased resistance to typhoid infection which will last them for several years at least. We have strong faith that the procedure will, within a short time, find increasing favor with the general public, which, exposed as it is to many sources of infection, is in great need of specific protection." 2

In the serum treatment of typhoid fever no one has approached, in experience or success, Chantemesse ${ }^{3}$ in Paris. With his colleagues he has treated 1000 cases, with a death-rate of 4.3 per cent. Of 5621 cases who were given routine treatment during the same period, 17 per cent. died. Of patients who were given serum treatment before the seventh day Chantemesse lost not a single one. The nature of Chan-

${ }^{1}$ Boston Medical and Surgical Journal, Jan. 5, 1911.

2 Ibid.

${ }^{3}$ Hygiene gén. et appliqué, Paris, 1907, 577. 
temesse's sermm is difficult to understand. He speaks of it as antitoxic and as produeed by inoenlation of horses with a true typhoid toxin. It does not, however, act directly upon the toxin, as does the diphtheria antitoxin, but in some way indirectly. It stimulates the spleen, bonemarrow, and other lymphatic apparatus to increased opsonin production. The sicker the individual the smaller must be the rlose, lest too many bacilli be destroyed at once. There would seem to be, therefore, a strong bactericidal element in the serum. The scrum treatment is combined with the eold bath treatment, and ealcium chloride is given as a routine measure to prevent hemorrhage. Cliantemesse's results have been confirmed to a certain extent by the Germans, and von Leyden ${ }^{1}$ reports 3 cases treated with antitoxic serum prepared by Meyer and Bergell.2 These eases were all remarkably short, having normal temperatures on the sixteenth, seventeenth, and nineteenth days. The serum is said to be of only moderate strength and to be both bacteriolytic and antitoxic. In this connection it is important to bear in mind, as suggested by von Stenitzer, that an antitoxin, although weak, as in dysentery, may be of great service in tiding over critical cases.

Personally, I have treated 132 eases of typhoid fever with specific typhoid products, ${ }^{3}$ serum, bouillon, filtrates, and the non-toxic residue of the typhoid bacillus as prepared by Professor Vaughan, of Ann Harbor. The results were largely negative, with one exception. By continued inoculation during convaleseence of the non-toxie residue the oceurrence of relapses was cut down apparently from 22 to 5 per cent.

\section{ASIATIC CHOLERA.}

Preventive inoculation against Asiatic cholera actually antedates the antitoxic treatment of diphtheria, since it was in 1890 that Haffkine, inspired by Pasteur's discovery in 1880 that chickens could be rendered immune to chicken cholera by preventive inoculation, discovered that the same was true of human beings in respect to Asiatic cholera. First he experimented upon himself, and then made 70,000 injections of living cholera germs into 40,000 people in India within a period of two years. By inoculating only a part of any given population where cholera was raging, he was sure of a control by which he could judge of the value of his work. The rate of attack among those inoculated fell to about one-twentieth, and the mortality in about the same proportion.

Experimental work by Kolle led to the conclusion that sterilized cultures possess the same immunizing power, and on his recommendation that such be used in place of the living organisms, Murata adopted this means of conferring immunity and employed it most extensively. Of every 10,000 persons so inoculated, 6 contracted the disease, against 13 of the same number not treated. This difference in the number of

1 Med. Klin., August 4, 1907.

3 Boston Med. and Surg. Jour., October 3, 1907.

2 Berl. klin. Woch., May 6, 1907.

4 Centralblatt für Bakteriologie, etc., 1904, XXXV., No. 5. 
seizures is, however, hardly large enough to be regarded as having much probative force, but it is worthy of note that the mortality among the inoculated was considerably lower and the severity of the attack was less marked.

Salambeni ${ }^{1}$ used serum treatment for cholera cases in St. Petersburg. The serum was supposed to be an antitoxic serum, and was produced by injecting horses with a soluble cholera toxin ; 42 cases were treated, 19 of these being very severe, 10 severe, 7 moderately serious, and 6 slight. The number of deaths was 10 , giving a percentage mortality of 23.8 . The official returns of the total cholera deaths during the same period showed a mortality of 45.6 per cent. In some instances anti-endotoxic sera have been nsed, and have been thought to be of greater potency than the antitoxic variety.

\section{BUBONIC PLAGUE.}

It is to Haffkine also that the prophylactic treatment for bubonic plague is due. He discovered that immunity could be attained by injecting sterilized cultures of the specific bacilli (treated at $70^{\circ} \mathrm{C}$. for an hour or longer). The injection causes slight fever, with enlargement of the nearest lymphatic glands, but all evidence of reaction disappears in from 2 to 3 days. While the treatment confers some degree of immunity, the duration thereof is very uncertain : it may be two days or several months. Haffkine asserts that it lasts from 4 to 6 months and sometimes for as long as 2 years, but the weight of evidence tends to indicate that it is not safe to count upon a more lasting immunity than 3 months, and hence that reinoculation every 3 months is advisable. Calmette has called attention to the fact that inoculation of persons in whom the infection is already present in the incubative stage will hasten the appearance of the disease and conduce to a fatal result. Pcrsonal investigation, in India, of the results obtained led B. R. Slaughter ${ }^{2}$ to conclude that the treatment acts within 24 hours and renders the subject immune for 3 months; that when applied during the stage of incubation, it frequently aborts the disease; that it has no effect on other diseases excepting eczema, which appears to derive benefit therefrom ; and that the chances of recovery are greatly increased in case of attack in spite of the inoculation.

According to a report of the Plague Commissioners in India, of 4,296 persons inoculated once, only 45 contracted the disease, and of 3,387 inoculated twice, 2 were seized. Fifteen of the former and 1 of the latter died. At the same time, among the non-inoculated persons, no less than 657 per thousand died in a single week (the third week of September, 1899). At Kirkee (India) the plague broke out in a small camp; 671 persons were inoculated and 859 were left unprotected. Thirty-two cases occurred among the inoculated and 143 among the minoculated. The mortality among the inoculated was 2.05 , and among the uninoculated, 11.40, per cent. In another camp,

1 Ann. de l'Inst. Pasteur, Jan. 25, 1910.

2 Bulletin of the Johns Hopkins Hospital, November, 1903. 
324 persons were inoculated and 300 left unprotected. Fourteen eases oeeurred among the uninoculated and none among those proteeted.

From further statisties which demonstrate the value of the treatment, the following may be quoted: In the Bombay Presideney, in one community, among 365 persons who were inoculated there were 13 eases with 3 deaths, while among 413 not inoculated, there were 48 eases with 36 deaths. In another eommunity there were 7 deaths among 5,184 inoeulated, and 177 among 8,146 not inoculated. At Lanowli, among 323 who were inoeulated, there were 14 eases with 7 deaths, and among 377 not inoeulated, 78 cases with 58 deaths.

Immunity appears to be prolonged by a second inoeulation within ten days of the first, as is shown by the following figures : At Shawar, among 5,614 persons not inoculated, there were 957 eases with 756 deaths; among 5,712 who were inoculated but onee, there were 69 cases with 31 deaths; but among 3,349 who were inoculated twice, there were only 9 cases with 5 deaths.

Prior to the discovery of the Haff kine prophylactie, Yersin's antipest serum, which is the only known remedy for the eure of the disease, was empioyed as an immunizing agent, but the duration of immunity was found rarely to exceed two weeks, and henee the treatment must be repeated every fourteen days in order to insure protection. It is claimed by Calmette that the serum eonfers an immunity, certain and effective, almost immediately after the injection; that the injection is not painful and is never harmful; and that the serum, properly prepared, retains its power almost indefinitely. On the other hand, the disadvantages are the short duration of immunity, the great cost of production, the diffieulty of obtaining a supply sufficient for the repeated treatment of entire populations, and the difficulty of inducing the natives to submit even onee to the operation. It takes from seven months to a year to immunize a horse to the point that his serum aequires preventive and curative properties, and many of the horses die before the process of immunization is eompleted. Aceording to Assistant Surgeon-General Greenleaf, protective inoeulation by means of the Yersin serum is not praetical for the following reasons: The enormous plant necessary for the production of the material; the large working foree neeessary for eonducting the inoeulations; the opposition of the people to the treatment; and the short duration of the benefit conferred.

Cairns, ${ }^{1}$ who used the serum with some success in the treatment of eases at Glasgow, concludes that it is both antitoxic and bactericidal, and that it produces its best effeets when the injection is made early and both subcutaneously and intravenously, the total initial dose ranging from 150 to $300 \mathrm{cc}$, according to the eircumstances of the case.

Both the Yersin serum and the Haffkine prophylactic are very unpopular with the natives of India. The Hindoos suspect that the materials are of animal origin, and the injection of such matters into the body constitutes an offence against their religion.

1 Therapeutische Monatshefte, May, 1904. 


\section{ANTISTREPTOCOCCUS SERUMS.}

Antistreptococcus serums of various kinds have been employed in the treatment of Erysipelas, Puerperal Sepsis, Malignant Endocarditis and other streptococcic infections and Scarlet Fever, but thus far they have not given results that indicate that they are of much value. They have been prepared by inoculating with living cultures of streptococci and with the intracellular substance of killed cultures, and, on account of the asserted differences in the organisms according to the nature of the pathologic processes in which they are a factor, with cultures obtained from a number of subjects with different diseases, and also with cultures taken directly from a number of individuals with the same disease, as is the method followed by Moser in the preparation of his polyvalent serum for scarlet fever. They have been prepared also by inoculating with organisms rendered unusually virulent by being passed through a series of animals.

How these various serums produce such results as have been observed is a matter of some disagreement. It is believed by some that they are bactericidal, but this is denied by others, who believe that they act as stimuli to the phagocytic cells. Howerer they may act, the hopedfor results have not been attained, and immunity to streptococcic invasion is evidently a very complex problem.

The use of streptococcus vaccines in the prevention of scarlet fever has been practised very extensively in Russia, following lines laid down especially by Gabritschewsky and other Russians.

They point out that the streptococcus is present in many scarlet fever throats; that streptococcus vaccines cause scarlatiniform eruptions; that complement deviation shows streptococcus amboceptors in scarlet fever blood; that the mortality in scarlet fever has bcen markedly reduced by the use of a serum produced by inoculation of a scarlet fever streptococcus (Moser); and, finally, that by inoculation of streptococcus vaccines efficient prophylaxis against scarlet fever has been secured.

This whole subject was reviewed by Smith, ${ }^{1}$ who concluded that from the published accounts it would scem that-

1. The streptococcus vaccines, used as advocated by Gabritschewsky, have some influence in controlling epidemics of scarlet fever.

2. Their use, with proper care, is attended by no harmful results.

3. They should be given a wider application in this country to prove or disprove the contentions of the Russian physicians.

\section{TUBERCULOSIS.}

Through ignorance of its dangers, specific therapy in tuberculosis received in its infancy a setback which it has taken years for it to recover from. Gradually, however, its laws and limitations have become better known and its great value is now recognized the world over. The favorable opinion refers now especially to active immunization produced by direct inoculation of the tubercle bacillus or its products.

${ }^{1}$ Boston Med. and Surg. Jour., Feb. 24, 1910. 
It makes little difference apparently what variety of tuberculin is used. More depends upon the method and skill of the physician. Inasmuch as, in animal experimentation, inoculation with the living bacillus produces the strongest immunity, we should, theoretically at least, aim to approach, as nearly as possible, these conditions in human treatment. This would be secured approximately by a combination of living filtrate (Tuberculin B. F. of Denys) with bacillary emulsion (Tuberculin B. E. of Koch). Corresponding tuberculins of the bovine type are much used by Spengler, who claims that there is a mutual antagonism between the two varieties of bacilli and their pathological processes. Thus, he says, pumonary tuberculosis is the result of infection with the human types of bacillus and must be treated with bovine tuberculin, whereas, tuberculosis of bones, joints, and glands, being due to bovine bacilli, is best treated with human tuberculin. Be that as it may, bovine tuberculins may be tried in those cases which do not improve on the human varieties.

The whole question of tuberculin treatment has been much clarified through the work of Denys and Trudeau, and has been well summed up by Ringer in the dicta that "time and tolerance" are the essential things, and that the word "haste" has no place in treatment with tuberculins. Although in the past a careful selection of cases for tuberculin treatment has been deemed essential, the opinion seems to grow that practically any case can be inoculated if sufficient care be exercised.

Allen has recommended in tuberculosis a vaccine made from tuberculous sputum. Such a vaccine has a number of theoretical advantages. It is a mixed vaccine, contains primary and secondary invaders, the bacteria concerned are autogenous, and their fighting powers have not been diminished by artificial cultivation.

Specific antisera have been used, especially in Europe. The best known are those of Marmorek and Maragliano. Opinions of these in their own countries have been, on the whole, favorable, but as tried in this country, at the Phipps Institute and at Saranac, the results have shown them to be of doubtful value.

\section{CEREBROSPINAL MENINGITIS.}

In no disease has serum treatment made more advance in recent years than in cerebrospinal meningitis. Most important in this advance has been the work of Flexner ${ }^{1}$ and his associates.' Briefly, the serum is produced in horses by subcutaneous inoculation of dead cultures, living cultures, and autolysates of dead cultures. Many different strains of the meningococcus are used. After a year of immunization the serum of such a horse has been used intradurally after lnmbar puncture in 130 cases, with 35 deaths, a mortality of 27 per cent. The dose is 20 to 30 cc., and may be repeated daily for four to five days if necessary. When cases are treated within the first twenty-four hours the results are most brilliant. ${ }^{2}$ The serum seems to act by stimulating phagocytosis, which destroys cocci and renders harmless their endotoxins.

1 Flexner and Jobling, Jour. Exper. Med., 1908, No. 1.

2 Dunn, Boston Med. and Surg. Jour., March 19, 1908. 
Quite similar results have been seen in Germany. For instance, Levy, ${ }^{1}$ using a serum prepared by Wassermann, had a death-rate of only 11.76 per cent. in 17 cases in which the serum was given intradurally. In 14 untreated cases the mortality was 78 per cent. Very interesting is a case of cerebrospinal meningitis described by Peabody. ${ }^{2}$ The infecting organism was, in this case, the streptococcus. Six intradural inoculations of streptococcus serum in doses of $10 \mathrm{cc}$. each were given in eight days. After the second inoculation the spinal fluid became sterile and remained so. Clinically, the patient improved rapidly and recovered.

This success with a streptococcic meningitis suggests immediately, of course, the treatment of other bacterial invasions of the meninges (pnemococcus or typhoid bacillus) with correspoding antisera. It is more than probable that such sera, although of doubtful value when given subcutaneously, might show valuable properties if applied in concentrated form at the very seat of infection.

Bacterial vaccines have been used in cerebrospinal meningitis with success by McKenzie ${ }^{3}$ and by Rundle and Mottram, ${ }^{4}$ but in the presence of such encouraging serum therapy their use does not seem likely to be extensive. Unique is the experience of Radman, ${ }^{5}$ who inoculated two patients subcutaneously with $8 \mathrm{ec}$. of their own cerobrospinal exudate. No harm was done, and Radman thinks this form of specific therapy has a hopeful future.

1 Deut. med. Woch., January 23, 1908.

3 Brit. Med. Jour., June 15, 1907.

5 Münch. med. Woch., July 4, 1907.

2 Med. Record, March 14, 1908.

4 'The Lancet, July $27,1907$. 


\section{CHAPTER X VII.}

\section{VACCINATION AND SMALLPOX.}

Prior to the discovery of vaccination by Jenner, toward the close of the eighteenth century, smallpox was one of the principal scourges of the world. It killed, on an average, nearly half a million people in Europe alone, and about once in three years was more than ordinarily severe. In England, Germany, France, Sweden, and other countries of Europe, the yearly mortality from smallpox was about two thousand per million inhabitants. More than half the cases of blindness throughout Europe were attributed to the disease, and about a third of the population showed in their faces evidences of having had it.

It was well known that those who recovered enjoyed protection from recurrence of the disease, and consequently it had long been the practice to produce immunity by causing the disease intentionally by inoculation when it prevailed in a modified form, favorable to recovery. For more than a thousand years, the Chinese and other Eastern peoples had produced the disease by blowing dried smallpox matter in powdered form into the nostrils. The discovery that the inoculation of material from a smallpox pustule was more certain and quick in its results led to the widespread practice of inoculation. This was begun in England in 1721, and toward the end of the century was enployed very extensively ; and even after the discovery of the beneficent results of vaccination, was practised to a certain extcut, until, in 1840, it was prohibited by law.

The first successful vaccination was performed by Benjamin Jesty, a Dorsetshire farmer, who inoculated his wife and two sons from the teats of cows afflicted with cowpox. The inoculation was successful in all three cases, although the wife had a badly inflamed arm. Fifteen years later, the two sons were inoculated with smallpox, but nothing resulted. It is said that $\mathrm{Heim}^{1}$ had noted as early as 1763 that the accidental inoculation of cowpox was followed by smallpox immunity. The practice of vaccination is, however, due to the work of Jenner, who, on May 14, 1796, performed his first successful operation. After some very strong opposition, intelligent people began to adopt the practice, and the uneducated classes began to fall gradually into line. The practice was adopted in America, France, Germany, and, in fact, the entire civilized world, and everywhere proved to be of the greatest benefit. In 1802, the English Parliament awarded Jenner

${ }^{1}$ Nothnagel's Specielle Pathologie und Therapie, IV., H. 2. 
4,000 pounds sterling, and later, a still larger grant was made. But the pioneer, Jesty, was not lost sight of, and in 1805 he was the honored guest of the Jennerian Society.

The practice was introduced into this country by Dr. Benjamin Waterhouse, Professor of Physick in Harvard University, who, on July 8, 1800, vaccinated his seven children, with six positive results. About the same time it was introduced into Philadelphia by John Redman Coxe, who vaccinated his eldest child and then exposed him to smallpox without result. In Boston, in August, 1802, 19 boys were vaccinated successfully at a temporary hospital on Noddle Island (now East Boston), and in November, these and one other, who had bcen vaceinated two years previously, were inoculated with smallpox, but in no ease was the disease produced. Two unvaceinated boys were inoculated at the same time, and both developed the disease. In 1806, Thomas Jefferson, who was the first to introduce the practice in the South, wrote to Jenner: "You have erased from the calendar of human afflictions one of its greatest. Yours is the comfortable reflection that mankind can never forget that you have lived. Future nations will know by history alone that the loathsome smallpox has existed, and by you has been extirpated."

The beneficent results of the introduction of vacination into this country are well shown by a comparison of the conditions obtaining in the early part of the eighteenth century and in the corresponding period of the nineteenth in Boston. In 1721, Boston, with a population of about 11,000 , had 5,989 eases of smallpox with 850 deaths. In 1730, in a population of about 15,000 , there were about 4,000 eases with 509 deaths; but between 1811 and 1830, in a very much larger population, there were but 14 cases of the disease.

In London, during the third quarter of the seventeenth century, the average annual mortality from smallpox per million was 4,000. A hundred years later, between 1770 and 1780 , it was more than 5,000; in the first years of vaecination, it was more than 2,000 ; by the middle of the nineteenth century it fell to abont 500, and in the last decade of the century, to less than 75 . In the whole of England, during the peroid of optional vaceination, the mortality-rate fell from about 2,000 to 417 , and after the practice was made compulsory in 1850 , it fell to 53. In Augnst, 1898, the "conscientiously believes" clause was enacted in rleference to the anti-raceinationists, and by December 31, $2: 30,1+7$ persons were exempted. The result of this modification of the law has recently been shown in extensive epidemics in London and elsewhere.

In Sweden, where very accurate records have been kept since 1774, the average mortality per million of population, between 1774 and 1801, was 2,045. During the years of optional vaccination, 1802-1816, it fell to 480 . In 1817, when vacination was made obligatory, the rate began to fall still lower, and up to 1893 the average mortality was 15.5. During the last nine years of this period, under more stringent regulations, it was never more than 5 , and in one year it was as low as 0.2. 
In Prussia, during the period of optional vaccination, the mortality rate fell from more than 2,000 to about 300. During the FrancoPrussian War, there were among the million well-vaccinated German troops but 459 deaths, while in the smaller, imperfectly vaccinated French army there were no less than 23,400. Between 1874, when vaccination was made obligatory, and 1896 , there was but one death from smallpox in the whole German army. In 1899, the total deaths in 285 German cities and towns, with a population of nearly $16,000,000$, amounted to only 4 . In the same year, in France, where vaccination is not universal, there were 600 deaths in 116 communities with a population of $8,500,000$.

In Austria, Hungary, and Belgium, where the practice is not required, the death-rates were, in 1886 , respectively 81,687 , and 48 times that which obtained in Germany. In Spain, where, also, the practice is optional, the death-rate in six provinces, in 1889 , was 12,050 per million against one of 4 per million in Germany.

In Denmark, where vaccination was made obligatory in 1816 , not a single case was known up to 1826 .

In Porto Rico, before the Spanish War, the annual mortality from snallpox was about 600 ; but since the wholesale vaccination by the United States authorities, the disease has virtually disappeared.

In all countries where vaccination has, at different periods, been optional and then required, a remarkable drop has occurred both in morbidity-and mortality-rates, and those countries in which, to-day, vaccination is not compulsory, suffer periodical visitations of the disease and lose thousands of lives. In 1889, for instance, the deathrate from smallpox in Spain was nearly as great as obtained a century before in the principal countries of Europe, while in the same year, in Germany, the disease was practically non-existent. In France, in the twenty-five years from 1870 to 1895 , more than 20,000 people died from smallpox in Paris alone, the epidemics of 1871 and 1872 being exceptionally severe and fatal. No epidemic has occurred in Germany since 1871, when the disease was brought in by French prisoners, although a few scattered cases have appeared occasionally.

The Director of Health of the Philippines, in his annual report for the fiscal year 1907 , states : ${ }^{1}$ " During the year there has been unquestionably less smallpox in the Philippines than has been the case for a great many years previous. In the provinces of Cavite, Batangas, Cebu, Bataan, La Union, Rizal, and La Laguna, where heretofore there have been more than 6000 deaths annually from this one cause alone, it is most satisfactory to report that since the completion of the vaccination in the aforesaid provinces, more than a year ago, not a single death from smallpox bas been reported. So thoroughly are the Philippines saturated with the contagion of smallpox that probably 25 per cent. of the residents would soon succumb to this disease if it were not for the ability to protect the inhabitants against it by vaccination." 1910.

1 Quoted by Trask, American Journal of Public Hygiene, Vol. XX., No. 1, Feb., 
In spite of the remarkable testimony concerning the value of vaccination in making a rarity of what was once one of the prineipal seourges, there are in this country and in others where laws compelling vaccination have been enaeted, numerous misguided individuals who band themselves together into anti-vaccination leagues and attempt to create a popular antagonism to the practice and to effect repeal of existing laws. In England, as has been noted, they have been partially sucecssful in eompelling the passage of a law which exempts parents who have "conscientious scruples" against having their ehildren vaceinated. In progressive Japan, where the government has decided to compel vaceination before the age of ten months, and revaccination at the age of six and again at twelve, the anti-vaceinationist is unknown.

The following table shows the smallpox mortality of the several countries named, in which vaceination is either not compulsory or imperfecily performed, as compared with that of Germany, which in each year is represented by 1 :

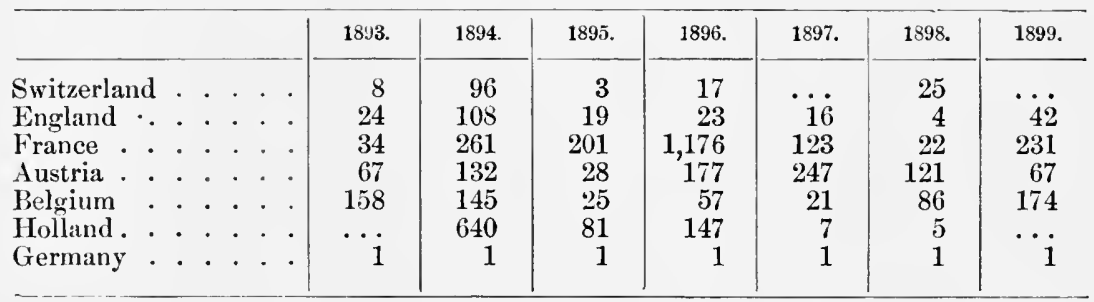

It cannot be elaimed that vacination confers absolute immunity against smallpox, but it is true that those who have been vaceinated and then acquire the disease have it in a much milder form and are more likely to recover than those who have not been vaceinated. Investigation of 11,036 eases of smallpox in England showed that, for unvaceinated and vaceinated eases, the rates of mortality were respectively 36.6 and 5.2 per cent., and that for all cases in children under ten, the rates were respectively 36.2 and 2.7 per cent. Among those stricken during the epidemie at Warrington, England, in 1891-92, 21.8 per cent. of the eases in vaceinated persons were eonfluent, while among the unvaecinated eases, the percentage was 70.6. In the Sheffield epidemic of $1887-88,1.55$ per cent. of raceinated and 9.7 of unvaccinated persons were attacked. Among the former, the death-rate was 0.7 , and among the latter, 48 per thousand. Among children under ten, the rate of attack was 5 and 101 per thousand, respectively, for vaceinated and unvaceinated, and the death-rate was 0.09 and 44 .

The protection conferred by vaccination is greatest during the year sneceeding the operation, and appears to diminish gradually during the suceeeding five or six years; but the modifying power does not diminish equally fast. The protective influence can be reëstablished by a repetition of the operation, and during epidemies, or when about to visit comntries where vaccination is not pratetised and smallpox is 
endemic, revaccination is always advisable. If the operation is negative in its results, the individual is regarded as immune or partially protected; but in the case of a first vaccination, it is customary to repeat the operation until success is attained. In most civilized countries, vaccination is not postponed until an outbreak of sniallpox occurs, but is attended to in the first few months of life.

Successful primary vaccination within three days after exposure to existing cases of smallpox will prevent the development of the disease, and as late as the fifth or sixth day will either prevent or modify an attack. This fuct has been utilized in many cases where smallpox has broken out among unprotected people with a prospect of unlimited spread, and has been the means of ending epidemics with some suddenness. 'Thus, for eximple, at Gloncester, England, in 1895, after eight years of practical abandonment of compulsory vaccination, that is to say, of neglect on the part of the authoritics to enforce the law, an epidemic of smallpox occurred in what was practically an unvaccinated community. The eases increased at such a rate that great alarm was felt and extensive measures were taken for general vaccination. In the closing weeks of 1895, 31 cases occurred. In January, 28 more were reported. In February, the number increased suddenly to 146 , and during March, to 644 . Toward the last of that month, the authorities gave directions for enforcement of the law, and work was begun; but during the following month, no less than 744 cases oceurred. During the last days of April, a committee undertook general vaccination of the city, and within a very few days, every house had been visited; by the end of June, the city had been converted from a practically unvaccinated city to the best vaccinated in the country. Nearly 36,000 persons were operated upon; the epidemic began at once to decline, and before Angust had disappeared. Nearly 450 persons, however, had died, and 1,600 others who survived, bore the usual lasting evidence of the disease in their faces.

As showing the influence of revaccination, the following figures from a study of the statistics of the Sheffield epidemic are presented:

Rates of attack per 1,000 persons.

Persons not vaccinated . . . . . . . . . . . . . 94

Persons once vaccinated .. . . . . . . . . . . . . . . 19

Persons twice vaccinated . . . . . . . . . . . . . 3

Death-rates per 1,000 persons.

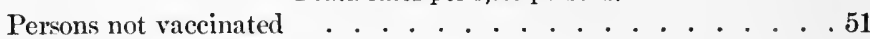

Persons once vaccinated . . . . . . . . . . . . . 1

Persons twice vaccinated . . . . . . . . . . . . 0.08

Similar facts are yielded by investigation of all epidemics where there is a large class of vaccinated and another of unvaccinated persons, and yet anti-vaccinationists still agitate and find sympathetic listeners to their arguments. One of their favorite charges is that vaccination not only has had nothing to do with the decline in the amount of smallpox, but, on the contrary, gives rise to other diseases. It is, indeed, true that syphilis has been conveyed from one to another 
through the practice of vaceination, but at the present time the danger is practically nil, since arm-to-arm vaceination has fallen into disuse; but while the arm-to-arm practice was continued, there were oecasional instances of grave injury. Thus, some years since, it happened that a company of French infantry, prior to being sent to Algiers, was vaccinated by the arm-to-arm method, and very many of the men were thereby inoculated with syphilis.

Parents are prone to ascribe to vaccination every disturbance which a child may suffer, particularly if there be any entaneous eruption. Sometimes a vesicular or pustular rash may occur and spread from the vaceinated arm to other parts of the borly; sometimes, erysipelas and other infeetions oceur at the point of vaccination; but these are no more likely to occur as a result of vaccination than of any other interference with the integrity of the skin. Persons of dirty habits, living in unclean surroundings, are more likely than others to suffer from ulceration of the vesicle and from other loeal disturbances not due to the influence of the virus itself.

With regard to the assertion that the three weeks following vaccination are a period of unusual danger from the various zymotic diseases, the results of extensive study by Dr. Voight, Director of Vaccination at Hamburg, are of interest. According to his records, the reverse of this assertion is true, for the process appears to exert a restraining influence upon the development of practically all of the infectious diseases. According to Dr. J. M. Mackenzie, ${ }^{1}$ scarlet fever, whooping cough, influenza, and syphilis are favorably influenced, tuberculosis and enteritis may be unfavorably influenced, and latent eczema and impetigo may be excited.

In revaccination, if the individual has become again wholly susceptible, the local manifestations occur earlier than in the primary vaceination, and the general symptoms are usually much more marked.

${ }^{1}$ British Medical Journal, August 15, 1903. 


\section{CHAPTER XVIII.}

\section{QUARANTINE.}

Quarastine is a term of wide signification. Derived from the French quarante, forty, its original meaning had reference to the number of days' detention to which vessels and their personnel, arriving from places infeeted or suspeeted of being infeeted with the plague, were subjeeted in plaees set apart for the purpose, to insure against the introduetion of the disease into the eountry or port of arrival.

The usual definitions of the term which, in a composite form, may be given as, "The enforeed detention of ressels, their personnel, and cargoes, arriving from infected ports, or having, or being supposed to have, cases of certain infeetious diseases on board, and interdiction for a fixed period of time of all communication therewith," are wholly inadequate under present eonditions. Far more aecurate and eomprehensive is that given by Dr. Walter Wyman, U. S. P. H. and M.-H. S. : "The adoption of restrietive measures to prevent the introduction of diseases from one country or locality into another," for the original meaning is now quite lost. To-day, we speak of port quarantine, land, interstate, railroad, municipal, house, and room quarantine. Restrietive measures are not adopted solely against human diseases, but also against those of the lower animals (cattle quarantine), and even of certain fruits and other inportant erops.

The necessity of restrictive measures in certain cases has long been recognized; in fact, in the case of leprosy, from earliest times. The first enaetment providing for the detention and isolation of travellers from infeeted places dates back to the fifteenth year of the Emperor Justinian (A. D. 542), but quarantine in the modern sense had its origin in the fourteenth eentury in Italy, where, on aceount of the ravages of the plague, local authorities at different times adopted preventive measures. Thus, Florence and Venice, in 1348 ; Lombardy, 1374 ; Milan, 1399.

The first maritime quarantine was instituted, in 1403, at Venice. A lazaret, the house of St. Lazarus, was founded on a small island, and all persons from the Levant were there detained for forty days before admission to the eity. The restrictive measures enforced at Mediterranean ports and elsewhere, were for many years, and at some places now are, unreasonable, harsh, useless, and a great injury to trade. Mast of the leading comntries have, for a long time, been strongly opposed to the oppressive, arbitrary, and irrational quarantine measures, and have now adopted rules and regulations, which, while effective as far as can be hoped for or expected, impose the least 
possible restrictions upon personal liberty and trade. The danger is estimated according to the condition of health of the port of departure, and this, with the sanitary history of the vessel, up to the time of arrival, determines what measures, if any, are to be taken.

The periods of detention are fixed with reference to the probable incubative period of the disease in question, and questions of necessity of disinfection, and of methods to be followed in carrying out the same, are determined by the circumstances of each individual case. Quarantines administered with reason do invaluable work in sifting ont infection and protecting the public health from exotic diseases, which, in the absence of precautionary measures, might easily gain aceess. At the same time, they act in restraint of trade to the slightest possible extent, since uninfected vesscls are not unnecessarily detained.

Unfortunately, not all quarantines are administered with reason, and it often happens that great injustice and unnecessary expense are carised by absurdly tenacious adherence to exploded theories and routine practice. As an example, may be eited the case of the Helene, a German vessel, which, arriving in an English port in August, 1893, with two cases of cholera, was disinfected and given free pratique; nine months later, she was refused pratique at a South American port, because in England she had not been held for a definite period at quarantine. As an example of quarantine absurdity of a minor character, but indicative of what might be imposed in ease opportunity presented itself, may be cited an experience with the municipal authorities at a Southern port, who required thorough disinfection of a barrel of carbolic acid before it was allowed to be landed.

Far more and almost ineredibly absurd is the following instance: On November 3, 1893, the steamship Cabo Machichaco, laden in part with dynamite, blew up at her dock at Santander, Spain, after having been on fire for some hours. The buming cargo was thrown about in all direetions and started a general conflagration. It happened that the entire fire department was, at the time of the explosion, engaged in attempting to overcome the fire raging in the ship's hold, and in the explosion was eompletely wrecked. Word was sent to Bilbao, and aid was urgently requested. 'Two steamships were sent with fire engines, firemen, surgeons, nurses, laborers, and others, and arrived in six hours. The provisional governor refused to permit the vessels to doek and discharge the much-needed apparatus and other aid, because quarantine had not been observed, and he insisted that they should comply with the regulations, which would involve several days' detention outside the harbor. It was several hours before a way was found to overeome the strict interpretation of the rules.

The first action taken by any official organization in this country looking to the establishment of a uniform system of quarantine regulations was at a conference of boards of health at Philadelphia in 1857, called on account of the exeitement caused by the breaking out of yellow fever at Bay Ridge in the previous year ; but in spite of this and other attempts, the various quarantines of the eountry were administered 
with no uniformity until after the passige of the Act of February 15, 1893, entitled "An Act granting additional quarantine powers and imposing additional duties upon the Marine Hospital Service." This act established a national system of quarantine, but in no way limited State and municipal authorities in their right to prescribe and enforee additional measures; and, indeed, it is beyond the power of Congress to interfere with local anthorities so long as the minimum requirements of the national law are complied with.

\section{Quarantine Law of 1893.}

Seetion 1 makes it unlawful for a ressel from a foreign port to enter any port of the United States, except in accordance with the provisions of the act and with such rules and regulations of State or municipal health anthorities nade in pursuance of or consistent therewith, under penalty of not exceeding $\$ 5,000$.

Section 2 provides that a vessel at a foreign port, clearing for any port in the United States, shall obtain from the consular or medical offieer of the United States at that place a bill of liealth in duplicate, in the form prescribed by the Seeretary of the Treasnry, setting forth its sanitary history and condition, and that it has complied with the rules and regulations prescribed for seeuring the best sanitary condition of the vessel and its eargo, passengers, and crew. Penalty for clearing and sailing without such bill of health and entering any port of the United States, not exceeding $\$ 5,000$. By an amendment approved August 18, 1894, it is provided that the provisions of this section shall not apply to vessels plying between foreign ports on or near the frontiers of the United States and ports of the United States adjacent thereto. But the Seeretary of the Treasury is authorized, when, in his diseretion, it is expedient for the preservation of the public health, to establish regulations governing such vessels.

Section 3 directs the Supervising Surgeon-General of the U. S. Public Health and Marine-Hospital Service to eoöperate with and aid State and munieipal boards of health in the execution and enforcement of the rules and regulations of such boards and of those made by the Secretary of the Treasury to prevent the introduction of contagious or infections diseases into the United States and into one State, Territory, or the District of Columbia from another.

It provides that all rules and regulations made by the Secretary of the Treasury shall operate uniformly and in no manner discriminate against port or place. Where no State or municipal quarantine regulations exist, and in the opinion of the Secretary of the Treasury are necessary to prevent the introduetion of such diseases, and where existing regulations are in his opinion insufficient, he shall make such additional rules and regulations as he may deem necessary, and they shall be enforced by the respective sanitary authorities; failing which, the President shall execute and enforee the same and adopt such measures as in his judgment are necessary, and may detail or appoint 
officers for that purpose. The Secretary of the Treasury shall make such rules and regulations as are necessary to be observed by vessels at the port of departure and on the voyage, to secure the best sanitary condition of themselves, their cargoes, passengers, and erews.

Section 4 makes it incumbent on the Supervising Surgeon-General to perform all the duties in respeet to quarantine and quarantine regulations, and to obtain information through consular officers of the sanitary condition of foreign ports and places from which contagious and infectious diseases are or may be imported into the United States. The Secretary of the Treasury is required to obtain through all available sourees, including State and municipal sanitary authorities throughout the United States, weekly reports of the sanitary condition of ports and places within the United States, to transmit to collectors of customs and to State and municipal health officers and other sanitarians weekly abstracts of the consular sanitary reports and other pertinent information received by him, to procure, through all available sources, public or private, information relating to climatic and other conditions affecting the public health, and to make an annual report to Congress, with such recommendations as he may deem important to the public interests.

Section 5 provides for the issuance from time to time to the United States consular and medical officers at the various foreign ports, of the rules and regulations made by the Secretary of the Treasury to be used and complied with by vessels in foreign ports for securing the best sanitary conditions before departure for the United States, and in course of the voyage, and of all other rules and regulations as shall be observed in inspection on arrival at any quarantine station and for disinfection and isolation, and treatment of eargo and persons on board, so as to prevent the introduction of cholera, yellow fever, and other contagious or infectious diseases. No vessel shall enter a port or discharge its cargo or land its passengers exeept upon a eertificate of the health officer at such quarantine station that the rules and regulations have in all respeets been observed and eomplied with both by him and by the master in respect to the vessel and its eargo, passengers, and erew. The master is required to deliver to the eollector with the other papers of the ressel, the bills of health obtained at the port of departure and the certificate above mentioned.

Section 6 provides that on the arrival of an infected ressel at any port not provided with proper facilities for treatment, the vessel shall be remanded at its own expense to the nearest national or other quarantine station where aceommodations and appliances are provided for the necessary disinfection and treatment of vessel, passengers, and eargo. After treatment of such vessel and after certification by the United States quarantine officer that ressel, cargo, and passengers are free from infectious discase or danger of carrying the same, the vessel shall be admitted to entry at any port of the United States named in the certifieate. But at ports where suffieient quarantine provision has 
been made by State or local authorities, the Secretary of the Treasury may direet the undergoing of quarantine at said station.

Section 7 provides that whenever the President is satisfied that by reason of the existence of cholera or other infectious diseases in a foreign country there is serious danger of the introduction of the same into the United States, and that notwithstanding the quarantine defence this danger is so increased by the introduction of persons or property from such country that a suspension of the right to introduce the same is demanded in the interest of the public health, he shall have power to prohibit, in whole or in part, the introduction of persons and property from such countries or places as he may designate, and for such period of time as he may deem necessary.

Sections 8 and 9 are of no sanitary interest.

In accordance with the provisions of this act, certain rules and regulations to be observed at foreign ports and at sea and at ports and on the frontiers of the United States have been adopted and amended and added to as occasion has made it neccssary or advisable. These rules are subject to very material modifications or additions, based on a wider knowledge of the causes of disease, modes of infection, etc., and thus what may be law todlay may be superseded tomorrow. Thus the very strongest regulations with regard to yellow fever, which were made before the method of its dissemination was known, and with the idea that infection could be conveyed by fomites, merchandise, baggage, etc., will undoubtedly be changed completely in consequence of the discovery, by Reed and his associates, that infection cannot thus be conveyed. It is only reasonable, in view of their work, that quarantine restrictions upon passengers and cargoes from non-infected ports should be very greatly modified, and that, in each instance of vessels from infected ports, the incubative period of the diséase, the possibility of the presence of infected mosquitoes on board, and the length of time a mosquito requires for the acquirement of dangerous propertics, should be kept in mind. Reed believes that a vessel at an infected port can be loaded in midstream by lighters, and ean then become infected only by persons who have been exposed on shore, since the probability of mosquitoes reaching the ship by flying or by lighters is very slight. If, then, a vessel thus loaded arrives at its destination free from discase, the non-immumes aboard should be quarantined not longer than five days, and the time consumed by the voyage should be included in this period. The cargo may be allowed to be discharged withont treatment or delay. But if the discase should occur while between ports, the sick should be removed, the sleeping quarters disinfected with sulphur dioxide in order to destroy all mosquitoes, and then the vessel should be allowed to dock. Under some eireumstances, it may be necessary to fumigate the hold, for mosquitoes may be there in an active condition; although, unless they have access to moisture, they will not live longer than five or six days. Rosenau has kept them alive in trunks for ten days and longer, but moisture was provided.

If mosquitoes are found on board a ressel from an infected port, the 
non-immumes should be detained, unless more than twenty days have already elapsed since clearing. This period will be sufficient to demonstrate the presence of infection in the mosquitoes, by the occurrence of cases during the voyage. If more than twenty days have elapsed, there can be no danger, and neither passengers nor cargo should be detained.

Since the publication of Reed's results and views, many cases have been cited in the medical press in opposition to the view that the disease cannot be spread by. baggage, fomites, and cargoes, but in no instance which has thus far fallen under the author's observation can the mosquito be ignored. Indeed, in many of the cases, the disease has broken out, after an uneventful voyage and the formalities of quarantine, in places where the specific yellow fever mosquito is known to be indigenous. In some cases, mention is made of the fact that, in spite of the very numerous mosquitoes present where a case of the disease has been brought, no extension of the fever has been produced; but it is not stated that the mosquitoes were Stegomyia fasciata, which is a vital point in the argument.

In view of the probable extensive changes in the rules, it is deemed best not to reproduce here existing rules in extenso, but advise one to apply, as occasion arises, to the Treasury Department for a printed copy thereof.

As they stand at present, the regulations prescribe forms for bills of health, methods of inspection of passengers, crew, baggage, cargo, food and water supplies, and of the vessel itself; requirements as to eleanliness of vessels, and as to ventilation; methods of disposal of bedding; location and arrangement of the "sick bay"; what may not be taken on board at ports infected with certain diseases; what must be disinfected, and how; what persons may not be shipped, and periods of detention according to the nature of the disease to which they have been exposed; and general and particular rules to apply in certain cases. The regulations prescribe, also, requirements as to cleanliness and ventilation at sea; isolation of the sick; disinfection and disposal of the dead; and give in detail the methods to be followed in disinfection of all parts of a ship, of various kinds of cargocs, and of personal effects.

The regulations to be observed at ports and on the frontiers of the United States provide for the establishment of quarantine stations at or convenient to the principal ports of the country, and prescribe methods of inspection according to the circumstances of each case, as, for instance, for vessels from healthy or infected ports, and for vessels snspected of being infected with plagne or yellow fever. Quarantinable diseases are named as follows: cholera and cholerine, yellow fever, smallpox, typhus, leprosy, and plague; and rules are laid down for the government of vessels on which any of these diseases have occurred during the voyage, and for the treatment and detention of passengers, crew, baggage, and cargo.

Following the passage of the quarantine law of 1893 and the promulgation of the rcgulations made in accordance therewith, at 
many ports the quarantine service was surrendered voluntarily to the national government, and at others it was taken over by the same authority, because of non-compliance with the regulations. At others, the regulations have been adopted and effieiently enforced by the local authorities, but these and all others are inspected regularly by the Public Health and Marine-Hospital Service, to insure efficieney of administration and eorrection of faults in methods and defects. in appliances.

In 1900 , there were in the United States no less than 120 quarantine and inspection stations, of which number, 81 were on the Atlantic eoast, 17 on the Pacific coast, and 22 on the Gulf of Mexico. They vary, naturally, very widely in importance and equipment, the most important one being that of New York, the chief gate of entrance of immigrants and of foreign eommerce, and the least important being several with practically no arrivals of vessels from foreign ports. Only a small proportion are equipped with extensive disinfeeting appliances, and but 8 are provided with quarters for the detention of persous held for observation.

\section{Interstate Quarantine.}

To prevent the introduetion of eontagious diseases from one State to another, Congress, on March 27, 1890, passed an Act providing that whenever the President is satisfied that eholera, yellow fever, smallpox, or plague exists in any part of the United States, and that there is danger of the spread thereof into other States, Territories, or the Distriet of Columbia, he is authorized to cause the Seeretary of the Treasury to promulgate such preventive rules and regulations as he may deem neeessary, and to employ such inspectors and other persons as may be necessary to enforee them.

These rules and regulations shall be prepared by the Supervising Surgeon-General of the Publie Health and Marine-Hospital Service, under the direetion of the Secretary of the Treasury, and any violation thereof entails a fine of not exceeding $\$ 500$, or imprisonment for not more than two years, or both, in the diseretion of the Court. In the ease of any officer or other person employed to prevent the spread of said diseases, wilful violation of any of the quarantine laws of the United States or of any of the rules and regulations made and promulgated as above, or of any lawful order of his superior officer or officers, the penalty is a fine not exceeding $\$ 300$ or imprisonment for not exceeding one year, or both, in the discretion of the Court. Any common earrier or servant thereof who shall wilfully violate any of the same, shall be liable to a fine of not exceeding $\$ 500$, or imprisonment for not exeeeding two years, or both, in the discretion of the Court.

\section{State Quarantine.}

The national quarantine law and the rules and regulations made thereunder are, as has been said, intended only as minimum require- 
ments, to which State or municipal authority may make such additions as may be deemed necessary for the preservation of the health of the people within its jurisdietion. Such additional requirements may be established for specific periods or without limit of time, and to meet general conditions or a special class of eases. As an example of special regulations made for a limited period, the following, adopted by the State Board of Health of Louisiana, with reference to vessels engaged in the tropical fruit trade during the season of 1899 , may be cited.

"All vessels engaged in the tropical fruit trade between Central American, South Ameriean, and West Indian ports and New Orleans will be allowed to pass the Mississippi River Quarantine Station without detention longer than is necessary for a thorough inspection by day by the quarantine officers, so long as a properly accredited medical agent of this board certifies that such ports and places are free from contagious or infectious disease, and provided said vessels shall strictly conform to the following conditions :

" 1 . They shall not be allowed to bring to this port bedding or household effeets of any kind.

"2. After leaving New Orleans, said vessels may take on board passengers during any part of their trip, and bring passengers to this port as herein provided.

"Cabin passengers only will be allowed at the discretion of the medical officer. This officer must satisfy himself that the applicant has not been in any infeeted locality in the past thirty days, and that none of his effects have been exposed to infection, and further such effeets shall have been fumigated or disinfeeted before going on board.

"Passengers may be taken on board from one healthy port to another, each of said ports having a medieal officer representing this board; under the same restrictions said passengers may be brought to New Orleans. Personal effeets of passengers are restrieted to personal wearing apparel, and should as much as possible eonsist only of elean, recently laundered clothing, and such effects, together with passengers' trunks, bags, valises or baskets, must be fumigated before being brought on board.

"The medical officer will refuse to permit the bringing of any unusual or unnecessary amount of baggage, it being the purpose of the board of health to facilitate the affairs of commeree by permitting passenger communication whereby business may be transacted in a safe manner, holding highest the health of the community ; and it is insisted that material capable of carrying any possible infection should be limited to the least possible amount. Woollen bags or carpet sacks will be prohibited. Trunks should be of metal, wood, or paper; valises of leather or paper.

"The medieal officer will make a personal inspection of all passengers and of every member of the crew just prior to the departure of the vessel, and give a certifieate to the master of the vessel of the condition of such persons examined, marking opposite the name of each 
person on the list furnished him by the officers of the vessel of every person on board such observations as may seem to him to be advisable coneerning the condition of said person's present or previous state of health.

"Medical officers will invariably assist masters of vessels in treatment of members of erew or passengers taken sick on board vessels and should make notes of such treatment in writing to be sent to the quarantine officer at home ports.

"3. Vessels shall not tonch at any infected port or have any communication with any vessel during their voyage except in case of distress.

"4. They shall not touch at such ports or stations as are not mentioned in their schedule, which latter shall be communicated to the board of health.

" 5 . They shall be required to make a full diselosure when arriving at quarantine station of all ports and places they have visited on their voyage.

" 6 . They may take on board a crew of laborers after inspection by the medical officer and disinfection of clothing of such crew for such healthy point where they permanently reside and remain, the crew being as nearly as possible eomposed of the same men. The captain or other officer may go ashore only for the purpose of entering or clearing vessels. Any further communication with shore or natives will be considered a violation of regulations, and vessels in default will be treated accordingly.

" 7 . These vessels shall be cleansed, and, when necessary, disinfeeted in the city of New Orleans after discharge of cargo."

\section{Sanitary Cordon.}

What is known as a sanitary cordon (" cordon sanitaire") consists of an extended line of guards thrown about a district to prevent access thereto or egress therefrom of any person or thing which may act as the carrier of infection. The object is, in other words, to protect the distriet from infection from the surrounding country or to protect the latter from infection from the distriet. Sometimes a double line is established, the territory intervening being, perhaps, only suspected of being infected. Cordons are not uncommonly established in the South against yellow fever, but are praetically unknown in the North. In California, in 1900, a cordon was maintained, for a short time only, against a district in which cases of bubonic plague were believed to be concealed.

\section{Municipal Quarantine.}

Municipal quarantine comprehends measures for isolating those sick with certain of the infectious diseases, such as scarlet fever, diphtheria, and smallpox, keeping others under observation, and disinfecting rooms and houses and objects contained therein which may be capable of harboring infection. It is beyond dispute that public safety requires that certain sick should be shut off from free communication with the outside world. This isolation is most complete and entails less hardship 
when it can be carried out at a special hospital for contagious diseases, but generally it is enforced, if at all, at the patient's home. Room and house quarantines are commonly difficult or impossible of enforcement, especially in tenement districts among the very poor, for it is among this elass that danger of infection is least understood and mutual help and neighborly visiting most extensively practised, and thus the foci of infection may become inereased indefinitely. In hospitals, on the other hand, where indiseriminate egress and ingress are under control and faeilities for the disinfection of discharges are at hand, the danger of spread is reduced to a minimum.

Especially diffieult and productive of hardship is the isolation not only of the patient, but also of the other members of his family. This is commonly practised in the case of smallpox, but is unnecessary if the other members have undergone recent successful vaceination, and their clothing and other effects are disinfeeted and they are then separated from all possible contact and communication with the patient. But even then, they should be kept under surveillanee for a time equal to the period of incubation. In times of epidemies of yellow fever in the South, house quarantine of entire families has proved to be the cause of much hardship and anything but an unqualified success. It causes great popular dissatisfaction, leads to concealment of cases, and tends, therefore, to spread rather than restrict the disease. Treatment of the sick in isolation hospitals and removal of those who have been exposed to infection to camps of detention for five full days have been found to give far better results.

In some ontbreaks of infectious diseases, it is necessary or advisable to conduct a house-to-house inspection for the discovery and isolation of unreported cases. When such a eourse is undertaken, the visits should be repeated at intervals equal to the period of ineubation.

The making of regulations for municipal quarantine and inspection is subject to no general rule, each local anthority being a law unto itself. In some cities, the rules governing notification, isolation, and disinfection are exceedingly thorough and strietly enforced; in others, they are inadequate in varying degrees and enforced with laxity.

Camps of Detention.-Camps of detention are places set apart for the reception and observation of persons who have been exposed or who are under suspicion of having been exposed to the eontagion of smallpox or other quarantinable disease. They should be under strict surveillance and governed by inflexible rules. Every person should be examined before admission, and such effects as he may be permitted to bring in shonld be disinfected thoroughly, for above all things, it is necessary to guard against the introduction of infection. The entire personnel should be mustered in quarters and examined at least twice daily, and such as are beginning to show symptoms must be promptly isolated. Indiseriminate ingress and egress must be strictly prevented. At the expiration of the proper period, in each ease the clothing and other personal effeets should be thoroughly disinfected before discharge. 


\section{CHAPTER XIX.}

\section{DISPOSAI, OF THE DEAD.}

The public health requires that the bodies of the dead shall be disposed of in such a way as not to be a menace to the living, and as soon as possible, with due consideration of the feelings of those bereaverl. In the case of those dead of infectious diseases, disposal should not be delayed by sentimental considerations, but should be accomplished with as little delay as possible, on account of the risk to which the living may be subjected by the retention of the body in the home.

Concerning methods of disposal, consideration may be limited to the two in use by most civilized peoples and by most others as well; namely, earth-burial and cremation.

Earth-burial.-Interment of the dead has ever been the principal mode of disposal among Christians, Jews, and Mussulmans. Within comparatively recent years, the results of overcrowding of ancient churchyards and cemeteries, and the necessity of dedicating great areas of valuable land to be held in perpetuity for the accommodation of the dead, have bronght about an economic sentiment against the practice, and to it has been added a feeling of danger to the public health from the decomposing tissues, particularly of those who have died of infections diseases.

Buried in soil of suitable character, a body gives off for a number of months_six to nine may be regarded as reasonable limits-foul gases of decomposition which are not evolved in the later stages. The rate of decomposition is influenced not alone by the nature of the soil, its pore volume, and its degrce of moisture, but also by the character of the coffin, the depth of interment, and the processes to which the body has been subjected before burial. After some years, the period varying within very wide limits according to circumstances, decomposition is complete and but little remains besides bones, more or less crumbly in character.

It is charged against earth-burial, that the places used for the purpose are offensive; that the air becomes poisoned; that the soil becomes laden with disease germs of all descriptions, which are preserved indefinitcly, and that water supplies are converted to dilute poisons of great potency; that is to say, cemeteries predispose to and act as direct causes of disease. As proof, numerous cases which will not bear close scrutiny are eited, but the whole mass of what is 
regarded as evidenee of the connection of cemeteries with the outbreak of disease has but little real weight and is uneonvincing. It has been said, for example, that typhus and other fevers were prevalent in the immediate neighborhood of old, overcrowded ehurchyards in London when it was enstomary to keep disturbing the soil for new interments, regardless of the number and eondition of those already buried. Even though the supposed connection were anything more than mere eoineidence, it may be said that nothing of the sort has been noticed within recent years, and never anywhere except in densely populated neighborhoods, in which densely crowded eemeteries happen to be located.

Cases of cholera, yellow fever, searlet fever, and other diseases have been attributed to the opening of old graves. In one ease, often quoted in all seriousness, a number of persons were seized with searlet fever supposedly from digging up the surface of a burial ground where, no less than thirty years before, a number of victims of that disease had been buried. Sir Henry Thompson has said: "The poisons of searlet fever, enterie fever, smallpox, diphtheria, malignant eholera, are undoubtedly transmissible through earth from the buried body by more than one mode. And thus by the act of interment we literally sow broadcast throughout the land innumerable seeds of pestilenee; germs which long retain their vitality, ete., many of them destined at some futmre time to fructify in premature death or ruined health to thousands."

Such broad statements are easy to make, but exceedingly difficult or, indced, impossible to substantiate. If true, it would appear that the earth, instead of being the great natural resolvent and disinfectant of all forms of dead organie matter deposited below the surface, is a mine of septie matter, in spite of which, the world at large continues to increase in health and the average length of life to extend little by little with every decade.

It is said also that the spores of all known species of pathogenic bacteria are very resistant and retain their virulence indefinitely. But even if this were true, and it is not true, it is not shown that the sporebearer's in the body form spores after death oceurs. As a matter of fact, the basis of the bacterial seare concerning the dangers of earth-burial rests on no more solid foundation than the instance, quoted in the chapter on Soils, of anthrax spores supposed to have been brought to the surfaee by earthworms that had aequired them from a cow buried two meters below, which instance has no value as evidence for reasons already explained.

Coming to a consideration of the aetual dangers arising from earth-burial and from the proximity of cemeteries, it must be adnitted at the outset that merely stinking gases are incapable of transmitting disease, and are, moreover, absorbed and deodorized by the soil itself. The same class of foul odors are borne without injury by those engaged in the numerous offensive trades. There is no ground for supposing that the emanations from graveyard soil are 
dangerous to health, for if they were, their effects should be most marked among grave-diggers, a class, who, like the workmen in sewer's, are obstinately healthy in spite of all a priori reasoning to the contrary.

Whether the soil becomes seriously polluted, is a question which bears on the possible contamination of the ground-water. This possibility may exist, but it is as nothing in comparison with the pollution of the soil and its contained water by leaching cesspools, into which man casts yearly several times his weight of liquid and solid excreta from his own body, and there is recorded no single well-authenticated case of outbreak of discase due to water contaminated by the drainage of a graveyard.

On general principles, the drainage of a cemetery should not be allowed to run into streams used as water supplies, and wells should not be located in close proximity to the boundaries of land used for interments.

While burial too near the surface should be avoided on account of the possibility that the body may be exhumed by dogs and other animals, it is to be borne in mind that the nearer the body is to the surface, the more rapid will decomposition occur. In order to shorten as much as possible the time required for complete resolution, the coffin, which should not be of too permanent material, should be placed in immediate contact with the earth, and not in a bricked enclosure or vault. The use of wicker coffins is urged, since they offer less obstacles to the natural processes of resolution than any other. Metallic coffins which retain the products of decomposition indefinitely should be prohibited. The top of the grave should be a mound of earth capable of supporting a fairly luxuriant growth of vegetation, which assists in draining the soil and makes use of the products of decay.

Sites for Cemeteries.-In the selection of a site for a cemetery, particular attention should be given to the nature of the soil. This should be dry and permeable to air; the ground-water level shonld normally be well below the bottom of the deepest grave; the surface should be of rich loam, which acts as a powerful deodorant and provides for an abundant growth of vegetation. Clay soils are objectionable on account of dampness and impermeability, which prevent rapid decomposition of the bodies. Rocky soils are objectionable on account of their drainage and the obstacles to the digging of graves.

Much has been written concerning the danger of pollution of water supplies by the drainage of cemeteries, and this danger should be kept in mind, but it is unlikely that, with proper locations well away from habitations, serious pollution will occur. Where land is abundant and cheap, the immediate neighborhood of cemeteries for purposes of residence is generally avoided, but it is always well to pay attention to the proper drainage of lands devoted to burial purposes, and to consider the possibility of the fouling of any wells already present or likely to be sunk in the surrounding soil.

Cremation.-Disposal of the dead by burning was practised in very 
early times as a mark of respect by some, or of dishonor by others, or from motives of expediency after great slaughter in warfare; but the practice of incineration, based on economic and sanitary eonsiderations, is of quite reeent origin among Christian peoples. The arguments urged in its favor from an economic standpoint are indisputable, for not only can the dead be thus disposed of much more cheaply, but the neeessity of devoting large tracts of valuable land for purposes of burial is done away with.

From a sanitary standpoint, the arguments are not so strong and, in fact, are easy of refutation. It is urged that earth-burial is a menace to public health, and a number of supposedly convincing instances are cited as proof of this statement; but these cannot withstand the test of careful examination and weighing of evidence, and it must be admitted, even by the strongest advocates of cremation, that there is no definite statistical evidence that the general death-rate or any special death-rate has ever been influenced by earth-burial.

It is urged also that earth-burial is repulsive in idea and horrible in practice, and while, in the minds of many, this statement is true, it is to be said, on the other hand, that in the minds of far more, the argument applies with greater force to the practice of incineration. From the time of the early Christians, who practised interment by stealth, earth-burial has ever been the one method of disposal, and the sentiment in its favor, fostered through nineteen centuries of practice, is a powerful obstacle to the general adoption of cremation, and can only slowly be overcome. A strong feeling that cremation is opposed to Christian doctrine concerning the resurrection of the body can only be overturned by the influence of the clergy, many of whom, including Protestants and Roman Catholics of eminence, have already done much in advocacy of the practice as a rational, economic, and sanitary means of disposal.

Aside from religions feeling, the strongest argument urged against cremation is the destruction thereby of evidence of poisoning in cases in which, after disposal of the body, suspicion of foul play may arise; but when one considers the very great infrequency of exhumations on this ground, and the still greater infrequency of positive results therefrom, this objection can hardly be regarded as entitled to much weight. In the case of the metallic poisons, the evidence would still be present in most cases in the ashes; in the ease of the organic compounds, it must be borne in mind that, under most favorable conditions, beginning the analysis before the onset of putrefaction, their detection in the sinall amounts commonly employed is by no means easy, and afterward is extremely diffieult and more often impossible.

Furthermore, it must be borne in mind that, unless suspicion arises before or immediately after death, chemical analysis is commonly vitiated by the universal practice of embalming the body with strong solutions containing the very substances sought. In every case of doubt as to the cause of death, the borly should be suljected at once to proper examination. In some States, legal provision has been made, forbid- 
ding embalming in case of death by violenee, until the body has been "viewed" by the proper anthority, and providing for proper certification before incineration.

History of Modern Cremation.-According to Japanese authorities, cremation, as at present practised among civilized nations, had its origin in their country many years ago. Until 1871, however, no special crematories were installed, the body in its coffin being placed on stones surrounded by wood or other inflammable material. In that year, crematories were erected; and since then, the practice of incineration has increased to suclı an extent that, in 1897, in Tokio, of 34,000 persons who died, 15,000, or 44 per cent., were cremated. In 1898, the percentage was abont the same.

In this country, the first movement in favor of cremation oceurred in New York, in 1873, but the first crematory was not erected until

FIG. 124.

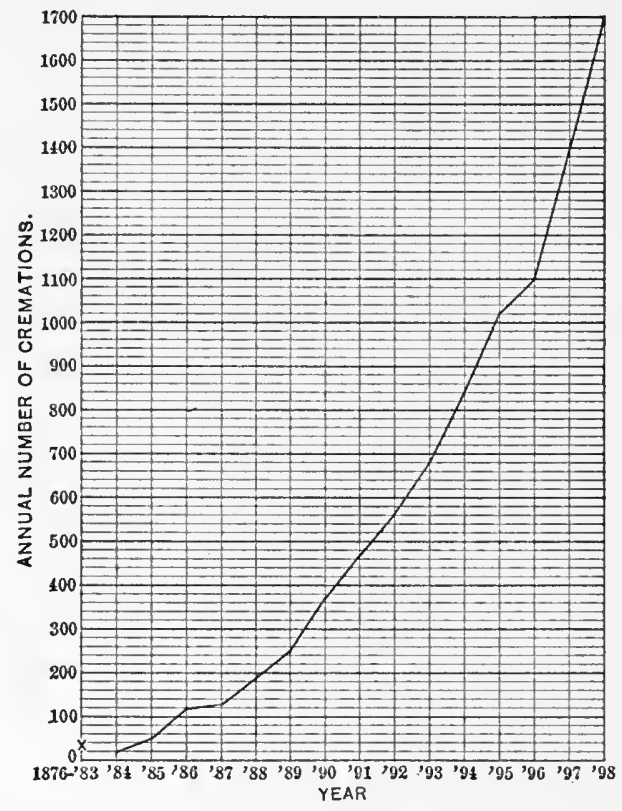

Curve showing number of cremations in the United States. (After ABвotr.)

1876. This was built at Washington, Pa., by Dr. J. T. LeMoyne, for the disposal of his own body, and was the only one in the country until 1884, when another was established at Lancaster, Pa. During this interval of eight years, the use of his crematory was allowed by Dr. LeMoyne for others, and 25 incinerations were performed. Between 1884 and 1900 , the number of crematories increased to 26, which growth indieates a steady increase in public sentiment in favor of the process. The number of cremations performed in the United States from 1884 to 1899 is shown in Figure 124 from the monograph 


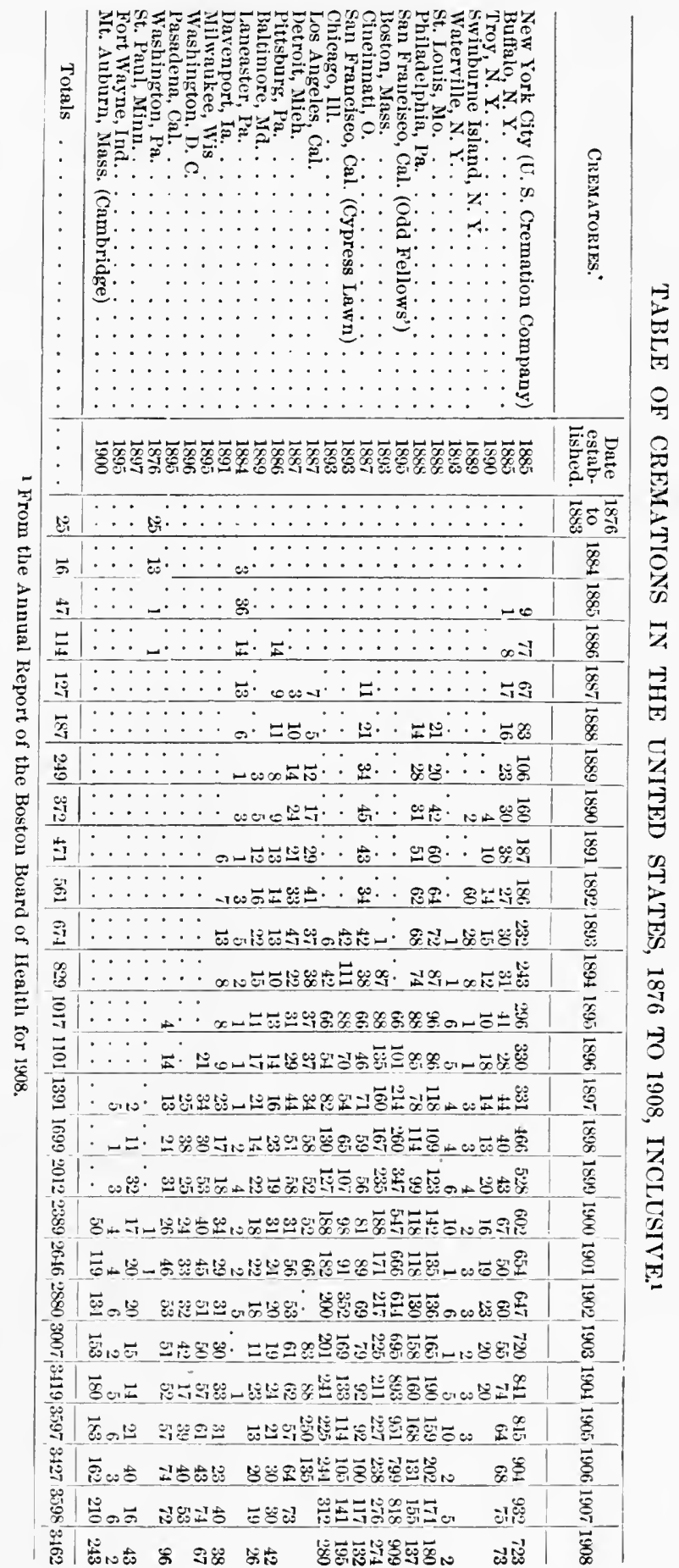


架

芴|

된

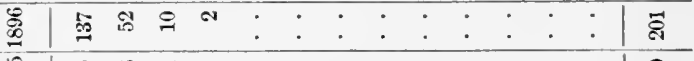

露|

畮|

焉|

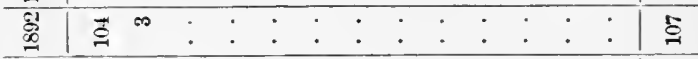

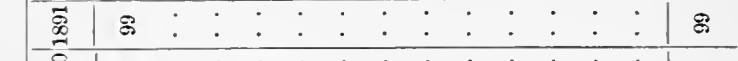

急

泾

落

:

突

曾

总

蛋

$\underset{\mathbb{X}}{\infty} \mid$

$\stackrel{\infty}{\Im}$

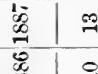

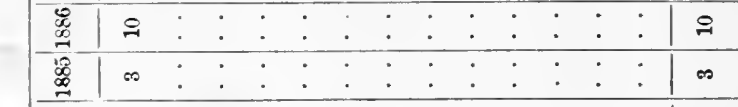


by Dr. Samuel W. Abbott, ${ }^{1}$ contributed by the Commonwealth of Massachusetts to the United States Social Economy Exhibit at the Paris Exposition. During this period 8885 cremations occurred.

The table on page 835 shows the further progress of the movement in the United States. The growth of the movement in Great Britain up to 1910 is shown on page $836 .^{2}$

A movement toward cremation began in Italy in 1857 ; but nothing was accomplished until 1897, three years after legal sanction was obtained. In 1901 there were in Italy 22 creamatories in operation. Germany had, in 1901, 7 establishments, the first of which was installed at Dresden in 1874; Great Britain had 7, the first of which was established in London in 1885; France had 2, Switzerland had 3, Sweden had 2, and Denmark had 1.

According to Sir Henry Thompson, ${ }^{3}$ there were in the United States during 1901, no less than 2,605 incinerations; in Germany, 693 ; in England, 445 ; in Paris, 297 ; in Italy, at 12 of the 22 institutions, 243 ; in Switzerland, at 2 of the 3 institutions, 144.

In the destruction of the body, the apparatus is so constructed that, while reduction to ashes is complete within three hours, no offensive fumes are given off. Commonly, the body, inclosed in a simple wooden coffin, is placed in the retort, which is then intensely heated by an oil flame, with whieh air under pressure is mixed by a blower.

1 The Past and Present Condition of Public Hygiene and State Medicine in the United States, Boston, 1900.

2 British Medical Journal, Mar. 5, 1910, p. 579.

3 The Lancet, July $5,1902$. 



\section{INDEX.}

A.

Abdominal bands, 632

Abyssinian wells, 387

Acetylene gas in illumination, 500

Acid, boric, 258

effect of, on digestion, 260

in milk, 118

detection of, 160

carbolic, 586

hypochlorous, as disinfectant, 577

oxalic, 24 standard solution, 304

phenic, as disinfectant, 586

salicylic, 261

detection of, in beer, 233

in wines, 240

in milk, 120

detection of, 160

Acids, mineral, as disinf cetants, 585 organic, 24

Actinomycosis, milk affected by, 128

Age in vital statistics, 751 statement of, 744

Agglutinins in scrum, 796

Air, 269

disinfection of, 612

examination of, 297

bacteriological, 314

filtration of, 493

humidity of, relative determination of, 299

infection carried by, 290

pollution of, through lighting, 501

saturation of, 279

in soil, 329

vitiated, effects of, 286 oceupations cxposing to, 723

in water, 371

water capacity of, 299

Albuminoid ammonia in water, 375

Albuminoids, 23 detection of, 445

Albumins, 20

Alcohol as disinfectant, 591

in becr, percentage of, 223

in ration, 643

in tropical hygiene, 685

in wines, 236

Alcoholic beverages, distilled, 241

$$
\text { fermented, } 217
$$

Aldehydc catalase, 105

Algæ, destruction of, in water, 412

Alkaline potassium permanganate, 445 soils, 318
Alkalinity indicator, 304

Alkaloids in beverages, 210

Allspice, 251

Almonds, 194

Aluminum chloride as disinfectant, 581 kitchenware, 268

in soil, 318

American wells, 387

Ammonia in air, 275 permanent standards of, 449

in soil, 319

in water, 373 determination of, 445

Ammonia-free water, 446

Ammonium chloride, standard solutions, 445

Anylase, 104

Anilin orange, 160

Ankylostomum duodenale in water, 442

Annatto, 158

Anthrax, milk affected by, 128 soil relation to, 349

Antistreptococcus serum, 811

Antitoxins, 783

Apples, 201

Apricots, 202

Aqueous vapor in air, 276 determination of, 298

Arachnids, relation of, to diseases, 696

Argand burners, 498

Argon in air, 272

Arrowroot, 193

Artesian wells, 389

Artichokes, 199

Ascaris lumbricoides in water, 441

Aspirating cowls, 480

Aspiration in ventilation, 479

Attitudes in hygiene, 738

Aurate of sodium as disinfectant, 585

B.

BABCOCK asbestos test, 151

centrifugal test, 150

Bacillol as disinfectant, 590

Bacon, smoked, 30

Bacteria in air, 288

in milk, 105 conditions affeeting, 110 number of, 107 source of, 110

of soil, 340

in water, 379

Bacterial action in purification of water, 397 
Bacterial diseases in animals, 45 poisoning of foods, 65 toxins, 783

Bacteriological examination of air, 314 of soil, 362 of water, 462

Bacteriolysis, 788

Baicr's test, 164

Baker's chemicals, 246

l3aking powders, 251

Bananas, 204

Bands, abdominal, 632

Barium hydrate solution, 303

Barley, 186 malt, substitutes for, in beer, 220

Barracks, 652

Bathing, 752

Bath-tubs, 532

Beans, 191

Bed-bugs, relation of, to diseases, 695

Bed linen, disinfection of, 611

Beef, composition of, 29

good, characteristies of, 27

poisoning by, 84

poisonous, characteristics of, 71

Beer, 217 acidity of, 233

adulteration of, 222

alcohol in, determination of, 223

barley malt in, substitutes for, 220

composition of, 222 ash, 234

extract of, determination of, 232

hops in, substitutes for, 221

manufacture of, 219

methyl alcohol in, determination of, 229

physical properties of, 222

preservatives in, 233

Beets, 199

specific gravity of, 224,232

Bernstein's test, 163

Berries, 204

Beverages, 210

alcoholic, distilled, 241

fermented, 217

Bicarbonate of sodium, 264

Bichloride of mereury as disinfectant, 582

Bilharzia hæmatobia in water, 442

Biological agencies affecting soils, 328

Birth-rates, 749

Biscuits, 183

Bisulphate of sodium in purifieation of water, 403

Blackberries, 204

Blackboards, school, 473

Blankets, waterproof, 632

Bleaching powder as disinfectant, 575

Body louse, relation of, to disease, 696 measurements of, 621

Boiling meat, 26

in purification of water, 404

water as disinfectant, 568

Books, disinfection of, 616

Boots, 630

Borax. See Boric acid.
Bored wells, 388

Boric acid, 258

$$
\begin{aligned}
& \text { effect of, on digestion, } 260 \\
& \text { in milk, } 118 \\
& \text { detection of, } 160
\end{aligned}
$$

Bovine tubcrculosis, human tuberculosis and, 50

Brand's test, 233

Brandy, 242

Bread, 180 pulled, 183

Broiling meat, 26

Bromine as disinfectant, 577

in purification of water, 401

Bubonic plague, air as earrier of, 295 immunization in, 809

Buckwheat, 189 soil relation to, 846

Burial of dead, 830

Butter, 164

Butyric ferments, 107

Butyro-refractometer, 171

C.

Caffeine, 210

Calcium, 24 chloride, standard solution of, 453 oxide as disinfectant, 580

Cameron tank, 554

Camps of detention, 829 military, 649

Cane sugar, 205

Canned fish, 38 meats, 30

Canning, preservation of food by, 254

Canteen, army, 644

Capillarity of soil, determination of, 359

Caramel, 159

Carbohydrates, 22

Carbolic acid, 586

Carbon dioxide in air, 272 determination of, 303

in soil-air, determination of, 360

in water, 372

monoxide in air, 280 determination of, 311

Carbonate of sodium, 120

Carbonates in soil, 218

Carbonic acid. See Carbon dioxide.

Care of person, 762

Carrots, 199

Cassia, 251

Catalase, 105

Cayenne pepper, 251

Celery, typhoid fever transmitted by, 64

Cellulose, 23

Cemeteries, 832

Census, 743

Cereals, 178

Chafing, care of and prevention of, 639

Chairs, school, 472

Cheerfulness, 627

Cheese, 173

Chemical agencies affecting soils, 328 agents as disinfectants, $\mathbf{5 7 1}$ 
Chemical precipitation of sewage, 542 purification of water, 398

Chemicals, bakers', 246 preservation of food by, 256 of milk by, 118

Cherries, 202

Chest eapacity, examination of, 626 measurements, 621

Chestnuts, 194

Chicory, 214

Children, death-rates of, 756 employment of, 740

Chloride of lime as disinfectant, 575

Chlorides, 24

Chlorinated lime as disinfectant, 575

Chlorine as disinfectant, 574 in purification of water, 401 in soil, 318

in water, 377 determination of, 452

Chocolate, 217

Cholera, air as carrier of, 296 food as bearer of, 58 immunization in, 808 infantum, milk as bearer of, 144 milk as bearer of, 137 soil relation to, 346 water relation to, 436

Chromates, 122 detection of, in milk, 162

Cider, 240 vinegar, 247

Cinnamon, 251

Circulation in active exercise, 765

Clays, 316

Cleanliness, personal, 627

Closets, 520 disinfection of, 616

Clothing, 770 adulteration of, 776 disinfection of, 611,615 selection of, 778 of soldier, 628 in tropies, 687 under, 631

Clouds, 279

Cloves, 250

Coagulated proteins, 21

Coal-gas in illumination, 499

Coal-tar colors in wine, detection of, 239

Cocoa, 215

Cocoanuts, 194

Coffee, 213

Cold as disinfectant, 569 preservation of food by, 254 of milk by, 114

Color in clothing, 629,770

Colostrum, 102

Complements in serum, 793

Condensed milk, 124

Condiments, 246

Confectionery, 209

Constitution of population, 746

Constrained attitudes, occupations involving, 738

Contact filtration of sewage, 550
Contagion, 781

Contentment, 627

Convection in ventilating, 486

Cooking meats, 26

Copper, food contaminated by, 264 sulphate as disinfectant, 582

Cordon, sanitary, 828

Corn, 187

Corned beef, 30

Corrosive sublimate as disinfectant, 582

Cotton, 774 clothing, 628

Cotton-seed oil, 196

Cowls for ventilation, 479

Crackers, 183

Cranberries, 204

Crawfish, typhoid fever transmitted by, 64

Cream, 124 gelatin in, detection of, 163 sucrate of lime in, detection of, 164

Cremation, 832 apparatus for, 837

history of, 833 statistics of, 834

Creolin as disinfectant, 589

Cresol preparations as disinfectants, 587

Cucumbers, 201

Currants, 204

Cyanide of mercury as disinfectant, 584

Cysticercus in meat, 39

\section{D.}

Dampness, oceupations exposing to, 737

Dead, disposal of, 830

Death, causes of, 758

Death-rates, 751, 754, 756 weekly, 754

Dececo eloset, 527

Dengue, relations of mosquitos to, 714

Density of population, 753

Desks, school, 472

Deterition camps, 829

Dew-point, 301

Dextrose, 23, 206

Diarrhœea, epidemic, soil relation to, 354 infantile, air as carrier of, 296

Diarrhoeal diseases in army, 669

Diastase, 104

Diet, regulation of, 764 in tropies, 684

Diffusion in ventilation, 476

Digestibility, comparative, of meats,

Digestion, effect of exercise on, 767

Dioxide of sulphur as disinfectant, 577

Diphtheria, air as carrier of, 295 immunization in, 804 milk as bearer of, 136 soil relation to, 347

Discharges, disinfection of, 611

Disease, air as carrier of, 290.

butter as carrier of, 167

dissemination of, 609 occupations exposing to, 735 exciting causes of, 780 
Disease, food as bearcr of, 44

insect relation to, 690

soil dampness and, 342 relations to, 312

susccptibility to, 781

water relations to, 420

Diseases of sailors, 677

of soldicrs, 665

tropical, 688

Disinfectants, 560,571

alcohol as, 791

carbolic acid as, 586

chemical, 571

cresol preparations as, 587

essential oil as, 593

formaldehyde as, 598

iodine as, 577

metallic salts as, 581

mineral acids as, 585

non-metal, 572

physical, 560

soap as, 594

Disinfeetion, 609

by formaldehyde, 599

special, 610

Disposal of dead, 830

Dissemination of infectious material, 609

Distillation in purifieation of water, 404

Distilled alcoholic beverages, 241

Distilling apparatus, 446

Distomatosis, 43

Domestic filters, 404

Dracuneulus medinensis in water, 441

Drainage areas, 391

Drains, 504

Dress coats, 629

Driven wells, 387

Drying, preservation of food by, 254

Duration of life, 759

Dust in air, 278, 288 determination of, 313

poisonous, 729 oceupations exposing to, 740

Dwellings, 470

Dyes, poisonous, 777

Dysentery in army, 668

immunization in, 806

E.

Earth-burial, 830

Eating utensils, disinfection of, 611

Egg-plant, 201

Eggs, 91

Ehrlich's theory, 783

Electric lighting, 502

Emergeney ration, 642

Enameller-kitchenware, 268

Endocarditis, immunization in, 811

Enteritis, specific, milk affeeted by, 128

Epirlemic poisoning by food, signs of, 68

Erysipelas, air as earrier of, 295

immunization in, 811

Essential oils as disinfectants, 593

Evaporation from oil, 335

Examination of recruit, 625
Exercise, 765

amount required, 768

kinds of, 769

over-, of parts, 739

of soldier, 633

Expectation of life, 760

F.

FABRICs, chemical analysis of, 777 microscopical examination of, 777

Facees, disinfection of, 610

Farinaceous preparations, 193 seeds, 178

Fats, 22

in butter, determination of, 169

in milk, 97

determination of, 148

vegetable, 195

Fatty seeds, 193

Feces, disinfection of, 610

Feet, care of, 638

Fehling's test, 152

Felt in clothing, 776

Fermented alcoholic beverages, 217

Ferments, butyric, 107

lactie, 106

of milk, 103

peptonizing, 107

salol-splitting, 105

Ferric ehloride as disinfectant, 581 test, 161

sulphate as disinfectant, 581

Ferrous sulphate as disinfectant, 581

Field ration, 641

Figs, 204

Filaria sanguinis hominis in water, 442

Filarial disease, relation of mosquitos to, 712

Filipino ration, 649

Filter galleries, 393

Filters, 404, 412

Filtration of air, 493

contact, 550

of public water supplies, 406

in purification of water, 404

in sewage disposal, 548

Fish, 35

composition of, 38

disease transmitted by, 44

parasitic, transmitted by, 38

poisoning, 64

preserved, 38

Fitz's test, 310

Flame, luminosity of, 497

Fleas, relation of, to disease, 694

Flies, relation of, to disease, 691

Flour, adulteration of, 184

bleaching of, 185

wheat, 179 preparations of, 180

Fluke in animals, 43

life history of, 43

Fluoride of sodium, 264

Fluorides, detection of, in beer, 233

Fog, 279 
Fog, effects of, 297

Foods, amount necessary, 18 animal, 24 calorimetric value of, 18 composition of, 19 contamination of, by metals, 264 nutritive value of, 17 preparation of, 644 preservation of, 253 chemical 256

rations of, for soldier, 639 vegetable, 177

Foot-and-mouth disease, milk affected by, 127

Formaldehyde, 262

as disinfectant, 598

disinfection by fumigation, 599 by solution, 609

germicidal properties of, 606

in milk, 118 detection of, 160

toxicity of, 607

in wines, detection of, 240

Fruit products, 201

Fruits, 201

Frying meat, 27

Fuchsine test, 161

Fumes, irritating, 724 occupations exposing to, 741 poisonous, occupations exposing to, 723,741

Fungi, edible, 205

Fur in clothing, 776

Furnaces, 489

\section{G.}

Gaiters, 629

Galactase, 104

Galactose, 23

Garbage disposal, 556 reduction in, 559

Garget, milk affected by, 128

Garrison ration, 640

Gas burners, 498

fixtures, 502

pipes, 501

Gases, illuminating, 499

irritating, 724 occupations exposing to, 741 poisonous, occupations exposing to, 723,741

Gasolene gas in illumination, 501

Gelatin, detection of, 163

Gin, 245

Ginger, 251

Globulins, 20

Glucose, 23, 207 vinegar, 248

Glutelins, 20

Glycoproteins, 21

Goitre, soil relation to, 353

Golf, 769

Gooseberries, 204

Grape sugar, 206

Grapes, 203
Gravelly soils, 318

Gravity in ventilation, 476

Grease-traps, 514

Ground-waters, 365 as water supply, 385

Guaiacol test, 162

Guinea worms in water, 441

H.

Habitations, 470

Habits of life in tropical hygiene, 683

Hamoglobins, 21

Hæmolysis, 789

Ham, smoked, 30

Hampton tank, 554

Hands, disinfection of, 611

Hardness of water, determination of, 453 effects of, 413

removal of, 413

Haversack ration, 641

Hay fever, immunization in, 805

Head covering, 630

Heart, beef, 30 veal, 31

Heat conductivity in clothing materials, 771

as disinfectant, 563

occupations exposing to, 737,741

Heating, 487

necessity for moisture in, 491

regulation of, 490

in relation to ventilation, 485

Hefelmann's test, 233

Height and weight, 621

Herbaceous articles, 200

Herrings, poisoning by, 73

Histones, 20

Honey, 208

adulteration of, 209

Hopper closets, 525

Hops, substitutes for, in beer, 221

Horse meat, 27, 32 detection of, in chopped meats, 34

poisoning by, 86

Hot-water heating, 489

Housekeeping, 471

House-maids' sinks, 535

House-service tanks, 535

Huckleberries, 204

Humidifiers, 492

Humidity, relative determination of, 299

Humus soils, 317

Huts, military, 656

Hydrogen in air, 272

peroxide, 263

in air, 275

as disinfectant, 574

Hydroquinone test, 163

Hygiene, military, 617

naval and marine, 671

of occupation, 716

personal, 762

of ships, 679

tropical, 681 
Hygrophant, 302

Hygroscopicity of clothing fabrics, 771

Hypochlorites in purification of water, 401 Hypochlorous acid as disinfectant, 577

\section{I.}

ICE, 443

Illuminating gases, 499

Imhoff tank, 554

Immune bodies in sera, 795

Immunity, 780 application of theories of, 802

Immunization, 802

Increase of population, 746

Infantile death-rate, 754

Infection, 780

air as carriers of, 290

Infectious material, dissemination of, 609

Inosite, 23 occupations exposing to, 735

Insects, relation of, to discase, 690

Inspections, military, 659

Interstate quarantine, 826

Iodine as disinfectant, 577

Iron, 24

action of water on, 418

content of yolk of egg, variability of, 93

in purification of water, 402

removal of, from water, 414

in soil, 318

in water, determination of, 459

Irrigation with sewage, 544

Irritating dusts, 732

occupations exposing to, 741

gases and fumes, 724

occupations exposing to, 741

J.

JAMS, 210

Jellies, 210

K.

KEFiR, 101

Kid meat, poisoning by, 89

Kidney, beef, 30

mutton, 31

pork, 30

veal, 31

Kidneys, effect of exercise on, 767

Kitchen utensils, food contaminated by, 267

Koumiss, 101

\section{L.}

LACTIC ferments, 106

Lactose, 23, 98

Lxvulose, 23

Lamb, characteristics of gond, 27 composition of, 31

Lard, 94
Latrines, military, 658

Laundry tubs, 535

Law, quarantine, 822

Lawrence tank, 554

Lead, action of water on, 414 food contaminated by, 266 in water, determination of, 456

Leather in clothing, 776

Lecitho-proteins, 21

Leggings, 629

Legumes, 190

Lemon-juice, 249

Lentils, 192

Life, duration of, 759 expectation of, 760 tables, 760

Light as disinfectant, 560 rays in purification of water, 403

Lighting, artificial, 497 electric, 502

impurities given off by, 501

natural, 495

ribbed glass in, 496

Lime as disinfectant, 580

juice, 249

in soil, 318

Limestone, 318

Linen, 775 clothing, 628

disinfection of, 611

Lipase, 104

Liqueurs, 245

Liquor cresolis comp. as disinfectant, 588

Liver, beef, 30

chicken, 32

goose, 32

mutton, 31

pork, 30

veal, 31

Liver-rot, 43

Loams, 317

Louse, relation of, to disease, 696

Luebert's test, 162

Luminosity of flame, 497

Lungs, beef, 30

Lysoform as disinfectant, 598

Lysol as disinfectant, 589

M.

Macaroni, 183

Mace, 251

Magnesia in soil, 318

Magnesium, 24

Malaria in army, 668 prevention of, 706

relation of mosquitoes to, 697 of soil to, 348

Malarial parasite, 700

Malic acid, 24

Malignant endocarditis, immunization in, 811

cedema, soil relation to, 348

Malt vinegar, 247

Maltose, 23

Mammitis, milk affected by, 128 
Manganese in soil, 318

Maple sugar, 206

Marching, 633

Marine hygiene, 671

Marls, 317

Marriage-rates, 748

Marrow, beef, 30

Mastitis, milk affected by, 128

Mattresses, disinfection of, 615

Mean after-life time, 760 duration of life, 759

Measles in army, 669

Measurements of body, 621

Meats, 25 characteristics of, which causc poisoning, 70

composition of, 28

cooking of, effect of, 26

digestibility of, comparative, 25

disease transmitted by, 44

extracts, 33

good, characteristics of, 27

inspection of, 89 tuberculosis and, 48

parasitic disease transmitted by, 38 poisoning, 64 from diseases of animals, 46

powder, 33

texture of, 26

Mechanical filters, 412 ventilation, 485

Medicated soaps as disinfectants, 596

Melons, 203

Meningitis, epidemic, air as carrier of, 295

$$
\text { immunization in, } 812
$$

Mercuric chloride as disinfectant, 582 cyanide as disinfectant, 584

Metakaline as disinfectant, 598

Metals, foods contaminated by, 264

Metaproteins, 21

Metchnikoff's theory, 801

Methyl alcohol, determination of, in beer, 229

Micro-organisms in air, 278, 283, 288 in soil, 319

Military hygiene, 617

Milk, 95

adulteration of, 122

analysis of, 146

bacteria in, 105

conditions affecting, 110

source of, 110

bactericidal properties of, 103

biological properties of, 103

condensed, 124

constituents of, 97

cooked, detection of, 162

detection of added water in, 154

of coloring matter in, 158

of prescrvatives in, 160

detcrmination of ash in, 153

of constituents of, 151

of fats in, 148

of specific gravity of, 147

diseases transmitted by, 125

ferments of, 103
Milk from diseased cows, 127

infections, acute, transmitted by, 136

physical properties of, 99

poisonous, 125

preservation of, 114

chemical, 118

products, 101

reaction of, 99

sterilization of, 114

Mineral acids as disinfectants, 585

matters, disease and, 421

Mist, 279 in water, 378 .

Moisture, determination of, by weighing, 298

needed in heating, 491

of soil, determination of, 359

Molasses, 207

vinegar, 248

Mosquitoes, relation of, to disease, 696

Moulds in air, 288

Muck soil, 318

Mulberries, 204

Municipal quarantine, 828

Mushrooms, 205

Mussels, poisoning by, 72

Mustard, 250

Mutton, composition of, 31

good, characteristics of, 27

N.

NAPHTHoL, $a$-, test, 163

Naphthylamine solution, 450

Naval hygiene, 671

Nervous system, exercise and, effect of, 766

Nesslerizing tubes, 447

Nessler's reagent, 445

Nickel, food contamination by, 267 kitchenware, 268

Nitrates in soil, 319

in water, 375 determination of, 450,451

Nitrifying organisms in purification of water, 409

Nitrite, permanent standards, 451

Nitrogen in air, 271

compounds in air, 275

in soil, 318

Norton's tube wells, 387

Nucleoproteins, 21

Nutmeg, 251

Nuts, 193

\section{0 .}

OAtmeal, 187

Oats, 186

Occupations, classification of, 721 hygiene of, 716 of women and children, 740

Oil, cotton-seed, 196 essential, as disinfectant, 593 olive, 195

Olein, 22 
Oleomargarine, 166

Olive oil, U. S. Standard for, 195

Open closets, 525

fires, 487

Opsonins in serum, 802

Oranges, 202

Organic matters in air, 286

in soil, detcction of, 360

in water, 372

pollutions of water, relation of, to disease, 423

Overcrowding, 286

Overexercise of parts, 739

Oxalic acid, 24

standard solution of, 304,454

Oxidation in purification of water, 396

in soil, 319

Oxydases, 105

Oxygen in air, 269

as disinfectant, 572

required for decomposition of organic matters in water, determination of, 454

Oxyuris vermicularis in water, 441

Oyster plant, 199

Oysters, infection transmitted by, 58 poisoning by, 75

Ozone in air, 274

determination of, 312

in purification of water, 402

P.

PaIl system of sewage disposal, 541

Palmitin, 22

Pan closet, 523

Paper coil extraction test, 148

Paralysol as disinfectant, 598

Parasitic disease, fish and, 38 meat and, 38

water and, 441

Parsnips, 199

Pasteurization of milk, 114

Peaches, 202

Peanuts, 194

Pears, 202

Peas, 191

Peat soil, 317

Pectin, 23

Pectose, 23

Pepper, 250

Cayenne, 251

Pepsin, 104

Peptides, 22

Peptones, 22

Peptonizing ferments, 107

Perflation in ventilation, 479

Permanganate of potassium as disinfectant, 582

Permeability of soils, 320 conditions affecting, 323 determination of, 356

Peroxide of hydrogen, 120, 263 in air, 275 as disinfectant, 574

Peroxydase, 105
Perry, 241

Person, care of, 762 in tropies, 688

Personal cleanliness, 627 of sailors, 680

hygiene, 762

Phaseomannite, 23

Phenic acid as disinfectant, 586

Phenol as disinfectant, 586

Phenoldisulphonic acid solution, 451

Phenolphthalein solution, 304

Phloroglucin test, 161

Phosphates, 24

in soil, 318

Phosphoproteins, 21

Pike, poisoning by, 75

Pimento, 251

Pin worms in water, 441

Plague, air as carrier of, 295 immunization in, 809 soil relation to, 346

Plumbing, 502 testing of, 537

Plums, 202

Plunger closets, 524

Pneumonia, air as carrier of, 295

Poisoning by beef, 84

by carbon monoxide, 281

by cheese, 177

by fish, 64

by herrings, 73

by horse meat, 86

by kid meat, 89

by meat, 64 diagnosis of, 69 postmortem appearance in, 69 symptoms of, 68

by milk, 126

by mussels, 72

by oysters, 75

by pike, 75

by pork, 78

by potatoes, 198

by salmon, 74

by sausages, 87

by veal, 76

Poisonous bacterial products in foods, 65 beef, 71

cheese, 176

dusts, 729 occupations exposing to, 740

dyes, 777

fumes, occupations exposing to, 723 , 741

gases, occupations exposing to, 723, 741

milk, 125

sausage, 71

spccies, 64

veal, 70

Polariscopic tests, 153

Police, sanitary, 660

Pollution of air by lighting, 501

of soil, 338

of water, discase and, 423

of wells, 391 
Population, estimation of, 745

Pore-volume of soils, 319 determination of, 355

Pork, composition of, 30 good characteristies of, 27 poisoning by, 78 salt, 30

Posts, military, 649

Potassium chromate solution, 452 nitrate standard solution, 451 permanganate as disinfectant, 582 solution, 454 sulphate test, 162

Potatoes, 196 sweet, 199

Poultry, composition of, 32

Precipitation in sewage disposal, 542

Precipitins in serum, 798

Preparation of food, 644

Preservation of food, 253 chemical, 256

of milk, 114 chemical, 118

Preserved fish, 38

Pressure, high, oceupations exposing to, 737

Prevention of dissemination of infectious matter, 609

of malaria, 706

of yellow fever, 711

Probable duration of life, 759

Proportion of body measurements, 621

Protamines, 21

Proteids, 19, 99

in soil, 319

Proteins, 20

Proteoses, 21

Psychrometer, 299

Puerperal sepsis, immunization in, 811

Pulled bread, 183

Pumpkins, 201

Purification of water, 396, 404 alga in, destruction of, 412 limitations of, 401

Pyrocatechin test, 163

\section{Q.}

Quarantine, 820

detention camps, 829

interstate, 826

municipal, 828

State, 826

Quicklime as disinfectant, 580

\section{R.}

RABıES, milk affected by, 128

Race in vital statistics, 752

Radiation in ventilating, 486

Radishes, 199

Rain, 279

Rain-water, 363 stored, 382

Raspberries, 204

Rations, naval, 672 of soldier, various, 639
Rations, tropical, 645

Recreation, 764

Recruit, 619

naval, 671

Red meats, 28

Reductases, 105

Reduction in garbage disposal, 559

Registrar's returns, 747

Regulating ternperature, 490

Residence in tropies, 683

Respiration in active exerčise, 765

Rest, 764

Ribbed glass in lighting, 496

Rice, 189

Rinderpest, milk affected by, 127

Roasting meat, 26

Room disinfection, 612

Roots, 196, 199

Rot in sheep, 43

Rotary cowls, 479

Round worms in water, 441

Rowing, 770

Rubber in clothing, 775

Rum, 245

Rusks, 183

Rye, 185

S.

Saccharine preparations, 205

Sago, 193

Salicylic acid, 261

in beer, detection of, 233

in milk, 120 detection of, 160

in wines, detection of, 240

Salmon, poisoning by, 74

Salol-splitting ferment, 105

Salt, 249

inorganic, 24, 99

pork, 30

soils, 318

Salting, preservation of food by, 254

Sand in purification of water, 407

Sandy soils, 316

Sanitary cordon, 828 police, 660

Sanitas closet, 527

Saprol as disinfectant, 590

Saturation of air, 279

Sausages, 33

coloring in, 35

poisoning by, 87

poisonous, characteristics of, 71

Scarlet fever, immunization in, 811 milk as bearer of, 138

School furniture, 472

School-houses, 471

Sea, discharge of sewage in, 541

Seal of traps, 511,516

Seat worms in water, 441

Sedentary life, 739

Sedimentation in sewage disposal, 542

Seeds, farinaceous, 178 fatty, 193

Sepsis, puerperal, immunization in, 811

Septic tanks, 554 
Serum, antistreptococcus, 811

Serviee-pipes, 536 -tanks, house, 535

Scwage disposal, 538 filtration, 548 infection of shellfish, 61 irrigation, 544

Sewer gas, 282

Sewerage, military, 657

Sex in vital statisties, 751

Shellfish, composition of, 38 infection of, by sewage, 61 varieties of, 38

Ships, hygiene of, 679

Shoddy, 629

Shoes, 778

Siliea in soil, 318

Silk in clothing, 773

Silver compounds as disinfectants, 584 nitrate standard solution, 452

Sinks, 534 military, 658

Siphon closets, 526

Skin in aetive exercise, 766

Slaughtering, 91

Sleep, 764

Sleeping quarters, sailors', 676

Slop-sinks, 535

Smallpox, 814

Smoke in air, 297

Smoked ham, 30

Smoking, preservation of food by, 254

Soap as disinfectant, 594 medicated, 596 standard solution of, 453

Sodium aurate as disinfectant, 585 bicarbonate, 264

carbonate as disinfectant, 579 solution, 445

fluoride, 264

hypochlorite solution as disinfectant, 577

nitrite solutions, 450

Soil, agencies effecting change in, 328

bacteria of, 340

bacteriological examination of, 362

constituents of, 318

dampness of, disease and, 342

detection of organic matter in, 360 of volatile matter in, 360

effect of vegetation on, 337

evaporation from, 335

examination of, 354

moisture of, determination of, 359

physieal properties of, 319 determination of, 355

pollution of, 338

relation of, to disease, 342

study of, 316

temperature of, 326

varieties of, 316

water-retaining capacity of, 325

water-transmitting eapacity of, 324

Soil-air, 329

determination of carbon dioxide in, 360
Soil-pipes, 504

Soil-water, 332 sources of, 335

Soldier, hygiene of, 627

Solvcol as disinfectant, 590

Spaghetti, 183

Spices, 246

Spirit, vinegar, 248

Springs as water supplies, 385

Sputum, disinfection of, 611

Squash, 201

Starches, 22

State quarantine, 826

Statistics, vital, 742

Steam as disinfectant, 565

Steam-pipe heating, 489

Stearin, 22

Sterilization of milk, 114

Stewing meat, 27

Stimulant beverages, 210

Stockings, 630

Storch's test, 163

Stoves, 487

Strawberries, 204

Streptococcus infection, air as carrier of, 295

immunization in, 811

Strongyloides intestinalis in water, 442

Sublamin as disinfectant, 584

Sucrate of lime, detection of, 164

Sucrose, 23

Suet, beef, 30

Sugar, 236 cane, U. S. standard, 205

determination of, in wine, 238

grape, 206

maple, 206

milk, 23, 98 determination of, 152

varieties of, 23

vinegar, 247

Sulfonaphthol as disinfectant, 590

Sulphanilic acid solution, 450

Sulphates, 24 in purification of water, 403 in soil, 318

Sulphites, 262 detection of, in wines, 240

Sulphur dioxide as disinfectant, 577

Sulphuric acid test, 161

Sunstroke in army, 669

Superoxydase, 105

Surface-water, 364 as water supply, 384

Susceptibility to disease, 781

Sweet potatoes, 199

Syphilis, Wassermann reaction in, 800

Syrup, maple, 206

T.

TANks, house-service, 535

Tapeworm, varieties of, in meat and fish, 38

Tapioca, 193

Tea, 210 
Tea, adulteration of, 212 composition of, 211

Temperature, regulation of, 490 of soil, 326

Tennis, 770

Tents, military, 653

Tetanus, immunization in, 805 relation of soil to, 348

Texture of clothing, 770

Theine, 210

Theobromine, 210

Thermometer in determination of humidity, 299

Ticks, relation of, to diseases, 696

Tin, action of water on, 419 food contaminated by, 267 in water, detection of, 459

Toast, 183

Tomatoes, 201

Tongue, beef, 30

Toxins, 783

Traps for grease, 514 plumbing, 507, 510 seal of, 511,516 ventilation of, 516

Travel ration, 641

Trichina spiralis, 39

Trichinosis, 41 diagnosis of, 42

Trichocephalus dispar in water, 442

Tripe, beef, 30

Tropical dietary, 648

diseases, 688

hygiene, 681

rations, 645

Trousers, 629

Truffles, 205

Trypsin, 104

Tuberculin tests of cattle, 47 therapy, 812

Tuberculosis, air as carrier of, 293 animal experimentation in, 50 in animals, 46 in army, 666 danger from carcasses affected with, 49

immunization in, 811

milk affected by, 130

relation between human and bovine, 50

Tubers, 196 of soil to, 343

Tubs, laundry, 535

Turnips, 199

Typhoid fever, air as carrier of, 294 in army, 667 celery as bearer of, 64 crawfish as carrier of, 64 food as bearer of, 58 immunization in, 807 milk as bearer of, 139 relation of soil to, 343 water-cress as bearer of, 64 supplies infected with, 425 rates, influence of water supplies on,
U.

ULTRA-VIOLET rays in purifieation of water, 403

Uncinaria duodenalis in water, 442

Uncinariasis, relation of soil to, 350

Underclothing, 631

Urinals, 530

Urine, disinfection of, 610

Utensils, disinfection of, 611

kitchen, food contaminated by, 267

\section{$\nabla$.}

VAccination against smallpox, 814

Vanes, 480

Vapor, aqueous, in air, 276

determination of, 298

tensions, 301

Veal, composition of, 31

good, 27

poisonous, 70,76

Vegetable fats, 195

foods, classification of, 177

marrow, 201

Vegetables, disease transmitted by, 44 fruit products as, 201

Vegetation, effect of, on soil, 336, 337 on water, 397

Venereal disease in army, 670

Ventilating cowls, 479 pipes in plumbing, 508, 516

Ventilation, 473

aspiration in, 479

diffusion in, 476

filtration in, 493

gravity in, 476

heat conduction in, 486

inlets, 482

mechanical, 485

natural, 481

outlets, 482

perflation in, 479 ..

radiation in -486

rates, 475,482 determination of, 493

space required, 475

of traps, 516

of vessels, 677

with heating, 485

Vermicelli, 183

Vessels, ventilation of, 677

Vinegar, adulteration of, 248

examination of, 248

Vinegars, 246

Vital statistics, 742

Vitiated air, effects of, 286 occupation exposing to, 723

\section{W.}

WALNUTS, 194

Waring system of irrigation, 547

Wash basins, 530

Washing soda as disinfectant, 579

Wash-out closets, 525 
Wassermann reaction, 800

Waste pipes, 509

Water, 363 aetion of, on metals, 414

bacteria in, 379

diseases related to, 420

cxamination of, 444

bacteriologic, 462, 467

chemical 444,467

inferences from, 459

gases in, 371

hardness of, 378 determination of, 453 removal of, 413

mineral contents of, disease and, 421 matters in, 377

organic matters in, 372

parasites in, 441

physical characters of, 367 determination of, 455

purification of, 396

by boiling, 404

chemical, 398

destruction of algæ in, 412

by distillation, 404

by filtration, 404

by light rays, 403

limitations of, 401

removal of iron in, 414

reaction of, 369

determination of, 455

residue in, determination of, 453

sanitary classification of, 394

in soil, 332

sources of, 335

substances normally found in, 371

supplies, 382

filtration of, 406

military, 656

naval, 675

typhoid infection of, 425

vapor in air, 276

determination of, 276

Water-closets, 520

connections of, 529

disinfection of, 616

flushing apparatus for, 528

in ships, 680

Water-gas in illumination, 499
Water-proof blankets, 632

Weight, effect of exercise on, 767 height and, 621

Wells, 386 deep, pollution of, 393 drainage area of, 391 pollution of, 391

Welsbach burners, 498

Werner-Schmidt test, 149

Wheat, 178 composition of, 179

flour, 179

adulteration of, 184

bleaching of, 185 preparations of, 180

Wheeling, 770

Whip worms in water, 442

Whiskey, 243 factitious, 244

White meats, 28

Wind, action of, 330

Wine vinegar, 247

Wines, 234 acidity of, 238 adulterations of, 396 analysis of, 238 classification of, 235 coal-tar colors in, 237 deteetion of, 239

composition of, 236

preservatives in, 237 detection of, 240

Wolpert's test, 309

Women, employment of, 740

Wool clothing, 628, 772

Work. 633

\section{$\mathbf{Y}$.}

YELLOW fever, prevention of, 711 relations of mosquitoes to, 707 of soil to, 348

Z.

ZINC, action of water on, 418

chloride as disinfectant, 581

food contaminated by, 267

in water, detection of, 458

Zymotic diseases, 754 
$\checkmark$ 



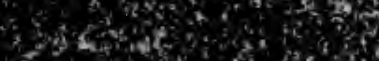

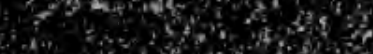
s.

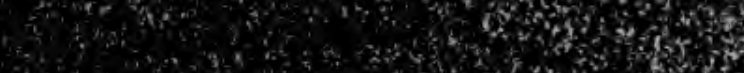

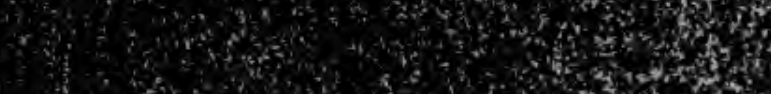

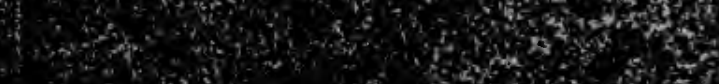


University of California

SOUTHERN REGIONAL LIBRARY FACILITY

405 Hilgard Avenue, Los Angeles, CA 90024-1388

Return this material to the llbrary from which it was borrowed. 


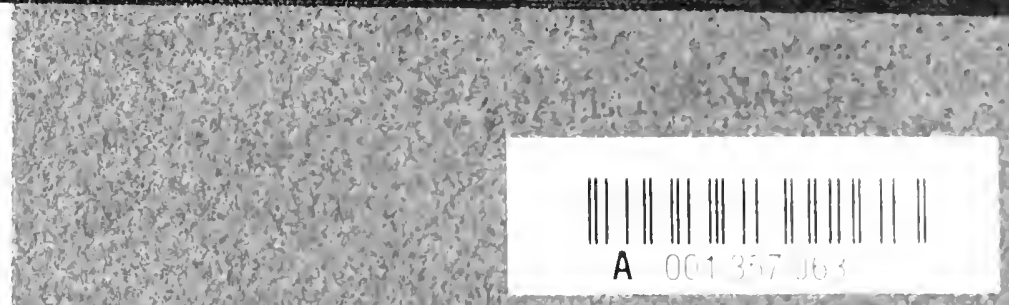

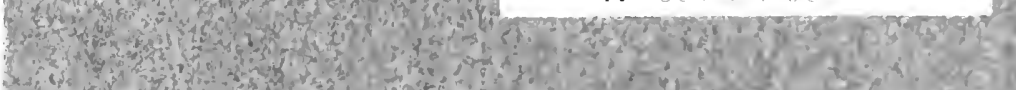

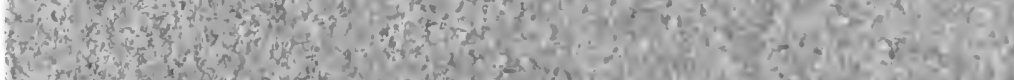

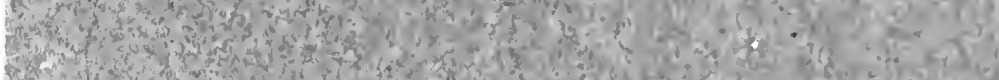

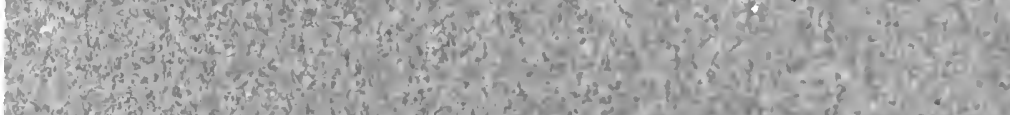
G. -

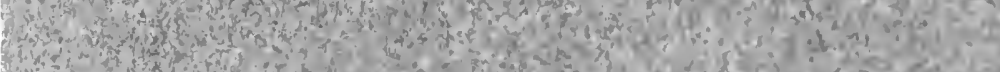

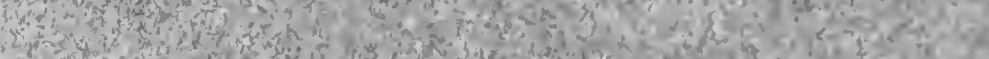

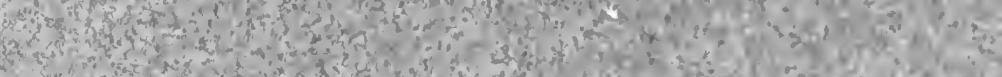

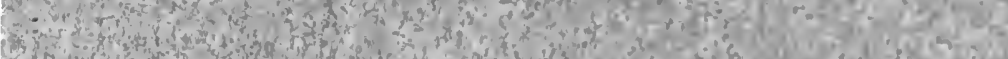
2.

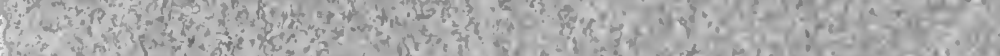

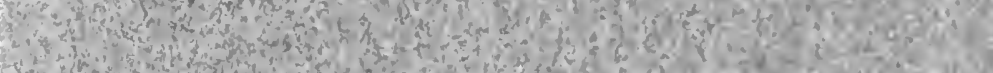

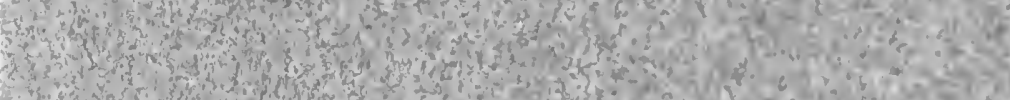

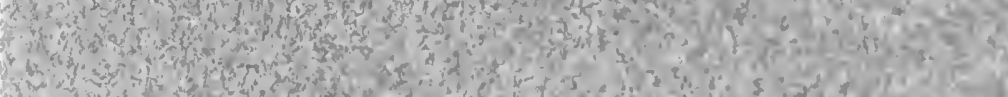

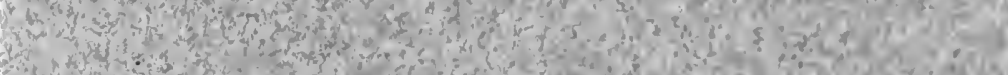

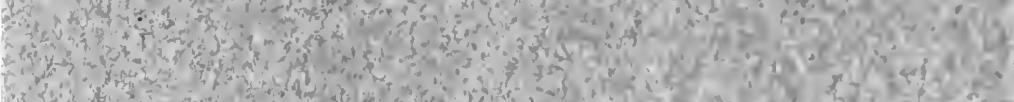
2. 3 and

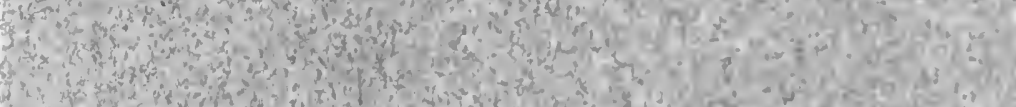

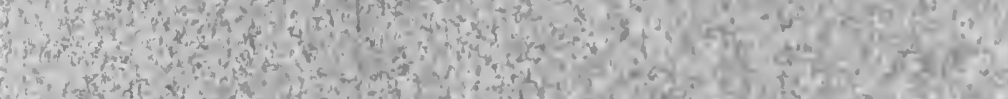

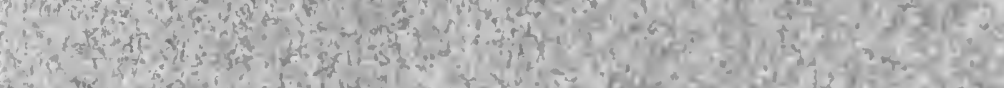

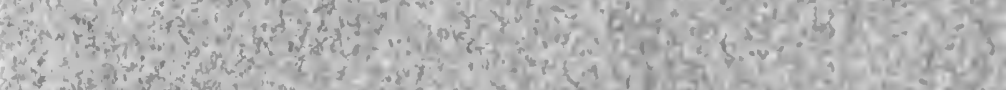

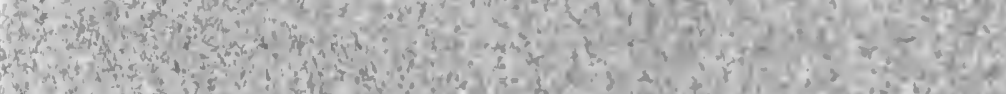

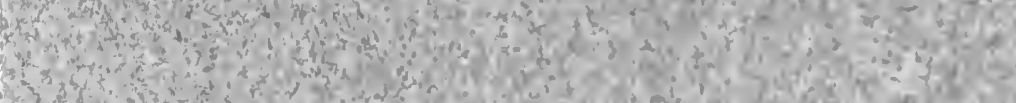
(1)

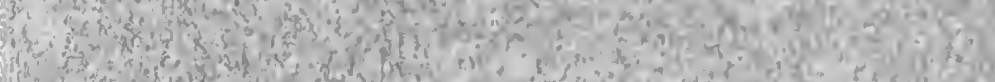
o.

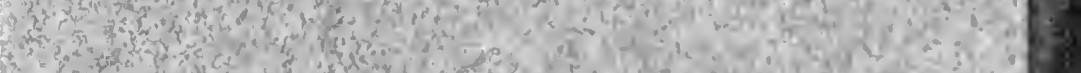

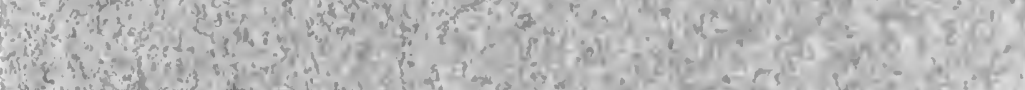
W. 


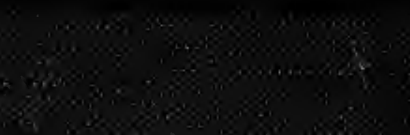

